\title{
Global Nuclear Energy Partnership Programmatic Environmental Impact Statement
}

DOE/EIS-0396

\section{October 2008}

U.S. Department of Energy, Office of Nuclear Energy 



\title{
COVER SHEET
}

RESPONSIBLE AGENCY: United States Department of Energy (DOE)

TITLE: Draft Global Nuclear Energy Partnership Programmatic Environmental Impact Statement (GNEP PEIS; DOE/EIS-0396)

\section{CONTACT:}

For further information on this PEIS, write or call:

For general information on the DOE National

Environmental Policy Act (NEPA) process, write or call:

Mr. Francis Schwartz

GNEP PEIS Document Manager

Carol Borgstrom, Director

Office of Nuclear Energy, NE-5

U.S. Department of Energy

1000 Independence Avenue, SW

Washington, DC 20585

(866) 645-7803

Office of NEPA Policy and Compliance, GC-20

U.S. Department of Energy

1000 Independence Avenue, SW

Washington, DC 20585

(202) 586-4600

or leave a message at 1-800-472-2756

\begin{abstract}
The proposed Global Nuclear Energy Partnership (GNEP) Program, which is part of the President's Advanced Energy Initiative, is intended to support a safe, secure, and sustainable expansion of nuclear energy, both domestically and internationally. Domestically, the GNEP Program would promote technologies that support economic, sustained production of nuclear-generated electricity, while reducing the impacts associated with spent nuclear fuel disposal and reducing proliferation risks. The Department of Energy (DOE) proposed action envisions changing the United States nuclear energy fuel cycle from an open (or once-through) fuel cycle-in which nuclear fuel is used in a power plant one time and the resulting spent nuclear fuel is stored for eventual disposal in a geologic repository - to a closed fuel cycle in which spent nuclear fuel would be recycled to recover energy-bearing components for use in new nuclear fuel. At this time, DOE has no specific proposed actions for the international component of the GNEP Program. Rather, the United States, through the GNEP Program, is considering various initiatives to work cooperatively with other nations. Such initiatives include the development of grid-appropriate reactors and the development of reliable fuel services (to provide an assured supply of fresh nuclear fuel and assist with the management of the used fuel) for nations who agree to employ nuclear energy only for peaceful purposes, such as electricity generation.
\end{abstract}

DOE's Office of Nuclear Energy is preparing this programmatic environmental impact statement (PEIS) to assess the potential environmental impacts of expanding nuclear power in the United States using either the existing fuel cycle or various alternative closed and open fuel cycles. Six programmatic alternatives are assessed: No Action Alternative; Fast Reactor Recycle Alternative; Thermal/Fast Reactor Recycle Alternative; Thermal Reactor Recycle Alternative; Thorium Alternative; and Heavy Water Reactor/High Temperature Gas-Cooled Reactor Alternative. DOE has not selected a specific preferred alternative in this Draft PEIS, but DOE's preference is to close the fuel cycle.

Public Comments: A 60-day comment period on this document begins with the publication of the Environmental Protection Agency's Notice of Availability in the Federal Register. DOE will consider comments received after the 60-day period to the extent practicable. DOE will hold public hearings to receive comments on this document at the times and locations announced in local media and the DOE Notice of Availability. Comments may also be submitted to Mr. Francis Schwartz by mail at the above address or electronically at http://www.regulations.gov/. This document and related information are available on the Internet at www.gnep.energy.gov. 

DOE/EIS-0396

Draft

Global Nuclear Energy Partnership Programmatic Environmental Impact Statement

October 2008

Prepared by:

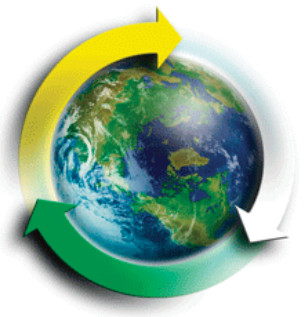





\section{Table of Contents}

Cover Sheet

Table of Contents i

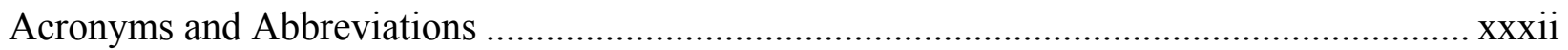

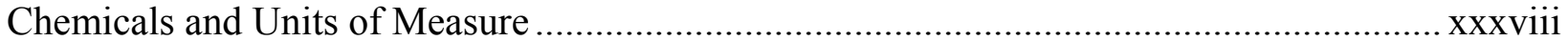

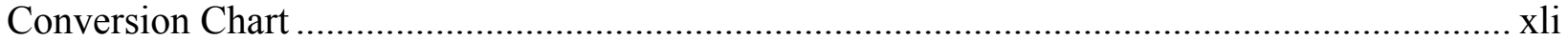

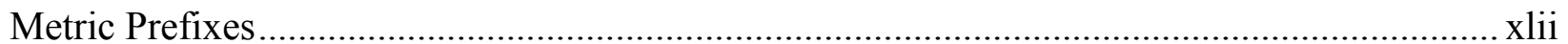

Chapter 1 Introduction ANd PuRPose ANd NeEd fOr Agency ACTION................ 1-1

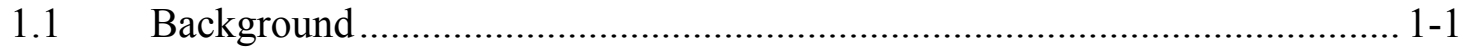

1.1.1 Global Nuclear Energy Partnership Program ............................. 1-1

1.1.2 Brief History of Spent Nuclear Fuel Reprocessing in the United States ....................................................................... 1-3

$1.2 \quad$ Purpose and Need for Agency Action ............................................... 1-5

1.2.1 Energy/Electricity ................................................................. 1-5

1.2.2 Reduction of Spent Nuclear Fuel and/or Waste Requiring Geologic Disposal...................................................................... 1-6

1.2.3 Proliferation Risk Reduction................................................... 1-7

1.2.4 Decisions to be Made................................................................ 1-8

1.3 Relevant National Environmental Policy Act Documents ........................... 1-9

1.3.1 Liquid Metal Breeder Reactor Environmental Statements ............. 1-9

1.3.2 DOE Programmatic Spent Nuclear Fuel Management (SNF Management PEIS) and Idaho National Engineering Laboratory Environmental Restoration and Waste Management Programs Environmental Impact Statement (DOE/EIS-0203) ......................................................... 1-10

1.3.3 Environmental Impact Statement for a Geologic Repository for the Disposal of Spent Nuclear Fuel and High-Level Radioactive Waste at Yucca Mountain, Nye County, Nevada (DOE/EIS-0250) (hereafter, Yucca Mountain FEIS) ............................................................... 1-10

1.3.4 Supplemental Environmental Impact Statement for a Geologic Repository for the Disposal of Spent Nuclear Fuel and High-Level Radioactive Waste at Yucca Mountain, Nye County, Nevada (hereafter, Yucca Mountain Final Supplemental EIS) (DOE/EIS-0250F-S1) .......... 1-10

1.3.5 Environmental Impact Statement for a Rail Alignment for the Construction and Operation of a Railroad in Nevada to a Geologic Repository at Yucca Mountain, Nye County, Nevada (hereafter, Rail Alignment Final EIS) (DOE/EIS-0369) $1-11$

1.3.6 Surplus Plutonium Disposition Final Environmental Impact Statement (DOE/EIS-0283), Supplement Analysis (DOE/EIS-0283-SA1), and Surplus Plutonium 


\begin{tabular}{|c|c|c|}
\hline & & $\begin{array}{l}\text { Disposition Supplemental Environmental Impact } \\
\text { Statement (DOE/EIS-0283-S2) }\end{array}$ \\
\hline & 3.7 & Disposal of Greater-than-Class-C Low-Level Radioactive \\
\hline & & Waste Environmental Impact Stateme \\
\hline & 1.3 .8 & Generic Environmental Impact Stat \\
\hline & & Leach Uranium Milling Facilities (NUR \\
\hline & 1.3 .9 & lel Cycle Nat \\
\hline & Publi & - \\
\hline & 1.4.1 & Advance Notice of Intent Public Comments .................... \\
\hline & 1.4 .2 & 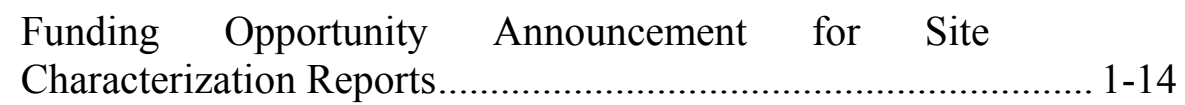 \\
\hline & 4.3 & Request for Expressions of Interest. \\
\hline & 1.4.4 & Funding Opportunity \\
\hline & & Engagement............ \\
\hline & 4.5 & coping Co \\
\hline & 1.4 .6 & $\begin{array}{l}\text { Global Nuclear Energy Partnership-Related Reports from } \\
\text { External Organizations. }\end{array}$ \\
\hline .5 & Orgar & 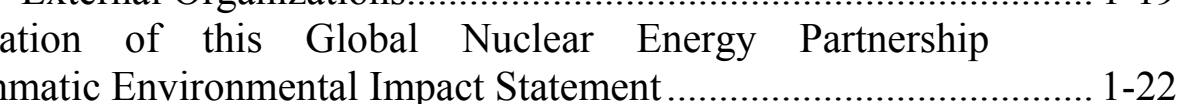 \\
\hline & & 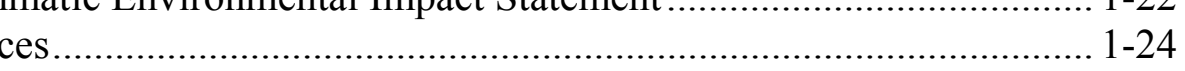 \\
\hline
\end{tabular}

Chapter 2 Domestic Programatic Alternatives ...................................................... 2-1

$2.1 \quad$ Development of Reasonable Alternatives .................................................. 2-1

2.2 No Action Alternative-Once-Through Uranium Fuel Cycle....................... 2-4

$2.3 \quad$ Fast Reactor Recycle Alternative............................................................. 2-8

$2.4 \quad$ Thermal/Fast Reactor Recycle Alternative ........................................... 2-11

2.5 Thermal Reactor Recycle Alternative......................................................... 2-13

2.5.1 Thermal Reactor Recycle Alternative (Option 1Thermal Recycle In Light Water Reactors) .................................. 2-13

2.5.2 Thermal Reactor Recycle Alternative (Option 2Thermal Recycle In Heavy Water Reactors) ................................ 2-15

2.5.3 Thermal Reactor Recycle Alternative (Option 3Thermal Recycle in High Temperature Gas-Cooled

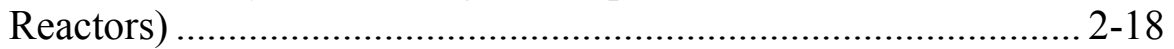

2.6 Thorium Alternative........................................................................ 2-20

2.7 Heavy Water Reactor/High Temperature Gas-Cooled Reactor Once-Through Fuel Cycle Alternative (HWR/HTGR Alternative)............. 2-21

2.7.1 HWR/HTGR Alternative (Option 1-Heavy Water Reactor) ..................................................................... 2-22

2.7.2 HWR/HTGR Alternative (Option 2-High Temperature Gas-Cooled Reactor) ................................................................... 2-23

2.8 Alternatives Considered but Eliminated from Detailed Study .................... 2-24

2.9 Global Nuclear Energy Partnership Programmatic Environmental Impact Statement Analysis Assumptions.................................................... 2-32 
2.9.1 Global Nuclear Energy Partnership Programmatic

Environmental Impact Statement Planning

Assumptions/Considerations/Basis for Analysis

2.9.2 Planning Assumptions-Future Electricity Growth,

Generation, and Nuclear Share .............................................. 2-38

2.10 Implementation Scenarios for the Global Nuclear Energy

Partnership Programmatic Environmental Impact Statement

Domestic Programmatic Alternatives

2.10.1 1.3 Percent Growth Scenario (200 Gigawatts Electric by

Approximately 2060-2070) .................................................. 2-40

2.10.2 2.5 Percent Growth Scenario (400 Gigawatts Electric by

Approximately 2060-2070) .................................................... 2-42

2.10.3 0.7 Percent Growth Scenario (150 Gigawatts Electric by Approximately 2060-2070).................................................. 2-44

2.10.4 Zero Growth Scenario (100 Gigawatts Electric by

Approximately 2060-2070) ...................................................... 2-46

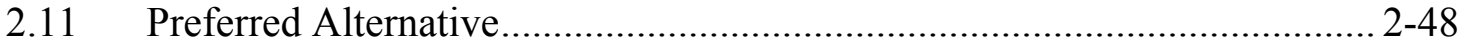

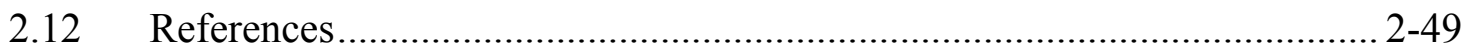

Chapter 3 Affected Environment For Domestic Programmatic

ALTERNATIVES ..................................................................................... 3-1

3.1 Nuclear Power Plants and Infrastructure .................................................. 3-1

3.2 Baseline Environmental Conditions of the Nuclear Power Industry ............. 3-2

3.2.1 Air Quality ...................................................................... 3-2

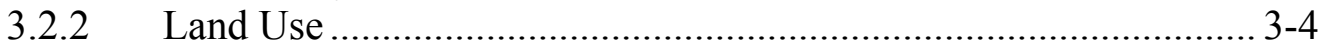

3.2.3 Water Resources .............................................................. 3-6

3.2.4 Socioeconomics ................................................................. 3-8

3.2.4.1 Historical Population Growth .................................. 3-8

3.2.4.2 The United States Labor Force ................................ 3-11

3.2.4.3 Economic Census Data for United States Industry .............................................................. 3-11

3.2.4.4 National Employment for the Electric Power Industry ......................................................... 3-12

3.2.4.5 National Employment for the Uranium Mining Industry .................................................................. 3-12

3.2.4.6 Projected Growth in Population and Energy Demand ................................................................ 3-12

3.2.4.7 Heavy Industrial Construction Industry .................... 3-12

3.2.4.8 Major Construction Materials ................................... 3-13

3.2.5 Radiological Waste Management and Transportation .................. 3-13

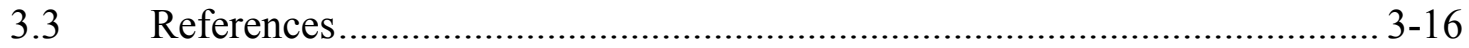

Chapter 4 EnVironmental Impacts OF Domestic Programmatic

ALTERNATIVES .............................................................................................4 4-1

4.1 Impacts Common to All Alternatives ................................................ 4-2

4.1.1 Uranium Mining and Milling .................................................. 4-2 
4.1.1.1 Current Uranium Mining and Milling

Capabilities in the United States

4.1.1.2 Environmental Impacts of Uranium Mining and Milling............................................................. 4-6

4.1.2 Uranium Enrichment........................................................... 4-11

4.1.2.1 Current Enrichment Capabilities in the United States .................................................................. 4-12

4.1.2.2 Environmental Impacts of Enrichment

Activities ......................................................... 4-13

4.1.3 Uranium Fuel Fabrication ................................................... 4-16

4.1.3.1 Current Fuel Fabrication Capabilities in the United States ....................................................... 4-16

4.1.3.2 Environmental Impacts of Fuel Fabrication Activities ............................................................ 4-16

4.1.4 Impacts of Disposing of Spent Nuclear Fuel and HighLevel Waste in Yucca Mountain

4.1.5 Impacts of Establishing a Geologic Repository for Future Spent Nuclear Fuel and High-Level Waste

4.1.6 Impacts of Establishing and Operating Disposal Capacity for Future Low-Level Waste.

4.1.6.1 Current Low-Level Waste Disposal Capabilities in the United States.

4.1.6.2 Environmental Impacts of Low-Level Waste

Disposal............................................................ 4-23

4.1.7 Impacts of the Advanced Fuel Cycle Initiative

4.1.7.1 Current Advanced Fuel Cycle Initiative

Capabilities

4.1.7.2 Environmental Impacts of the Advanced Fuel

Cycle Initiative at DOE Sites.

4.1.7.3 Environmental Impacts of the Advanced Fuel

Cycle Initiative at Non-DOE Sites

4.1.8 Greenhouse Gas Emissions Associated with Electricity

Generation

4.2 No Action Alternative-Existing Once-Through Uranium Fuel

Cycle

4.2.1 Spent Nuclear Fuel Generated Beyond the Yucca

Mountain Statutory Limit

4.2.1.1 Interim Spent Nuclear Fuel Storage

4.2.1.2 Transporting Future Spent Nuclear Fuel to a

Geologic Repository

4.2.2 Construction and Operation of New Nuclear Electricity

Capacity from 2010 to Approximately 2060-2070.

4.3 Fast Reactor Recycle Fuel Cycle Alternative (Fast Reactor Recycle Alternative) .....

4.3.1 Construction and Operation of Fast Reactor Recycle Alternative Facilities $4-48$ 
4.3.2 Sensitivity Analysis of the Fast Reactor Conversion Ratio .......... 4-57

4.3.3 Transuranic Storage and Cesium and Strontium Storage at the Recycling Center............................................................... 4-58

4.3.4 Analysis of Separations Process Options and Target

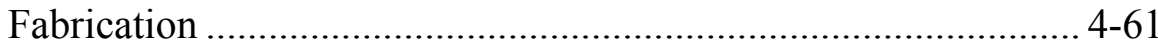

4.4 Thermal/Fast Reactor Recycle Fuel Cycle Alternative

(Thermal/Fast Reactor Recycle Alternative) ............................................. 4-64

4.5 Thermal Reactor Recycle Fuel Cycle Alternative (Thermal

Recycle Alternative)

4.5.1 Construction and Operation of Thermal Recycle

Facilities-Option 1

4.5.2 Construction and Operation of Thermal Recycle Facilities-Option 2.

4.5.3 Construction and Operation of Thermal Recycle

Facilities-Option 3

4.6 Once-Through Fuel Cycle Alternative Using Thorium (Thorium

Alternative)

4.7 Once-Through Fuel Cycle Alternative Using Heavy Water Reactors or High Temperature Gas-Cooled Reactors (Heavy Water Reactor/High Temperature Gas-Cooled Reactor Alternative)

4.7.1 All-Heavy Water Reactors (Option 1) ....................................... 4-103

4.7.2 All-High Temperature Gas-Cooled Reactors (Option 2)............ 4-109

4.8 Comparative Summary of Domestic Programmatic Alternatives ............. 4-116

4.8.1 Research and Development Needs for the Alternatives ............. 4-116

4.8.2 Transition and Implementation.............................................. 4-119

4.8.3 Facility and Resource Requirements ...................................... 4-121

4.8.4 Spent Nuclear Fuel and Radioactive Wastes ............................. 4-123

4.8.5 Human Health ....................................................................... 4-140

4.8.5.1 Impacts to Workers .................................................. 4-140

4.8.5.2 Impacts to the Public............................................... 4-141

4.8.6 Facility Accident Impacts ................................................... 4-142

4.8.7 Transportation Impacts .......................................................... 4-147

4.8.8 Potential Impacts on Design or Operation of a Future

Geologic Repository .............................................................. 4-153

4.8.9 Major Differences in Impacts for Other Growth Scenarios........ 4-156

4.9 Decontamination and Decommissioning Impacts ................................... 4-157

4.9.1 Decontamination and Decommissioning of the Maine

Yankee Reactor Plant................................................................... 4-157

4.9.2 Decontamination and Decommissioning Impacts Related to the Programmatic Environmental Impact Statement

Alternatives

4.10 Unavoidable Adverse Impacts .............................................................. 4-161

4.11 Relationship Between Short-Term Uses of the Environment and the Maintenance and Enhancement of Long-Term Productivity ............... 4-161

4.12 Irreversible and Irretrievable Resource Commitments ............................... 4-162

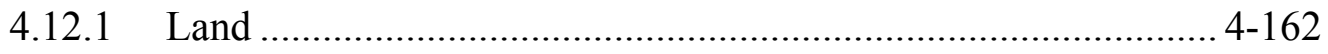




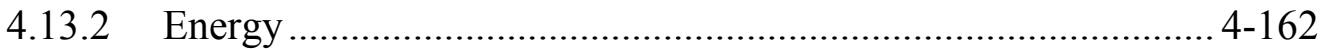

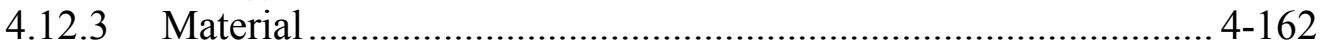

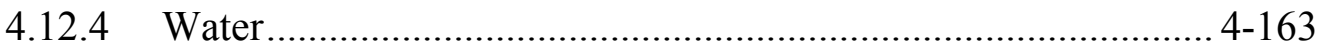

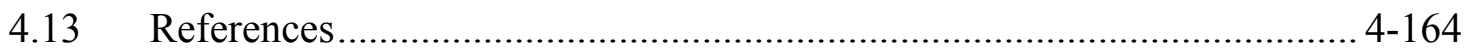

Chapter 5 Cumulative Environmental Impacts of the Domestic

PROGRAMMATIC ALTERNATIVES ...............................................................5-1

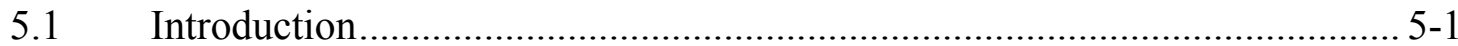

5.1.1 Methodology for Assessing Cumulative Impacts .......................... 5-2

5.1.2 Reasonably Foreseeable Future Actions ........................................ 5-2

5.1.3 Population Growth .................................................................... 5-3

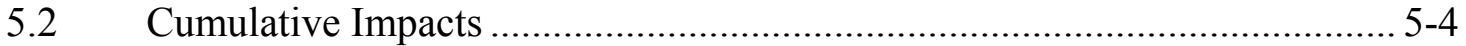

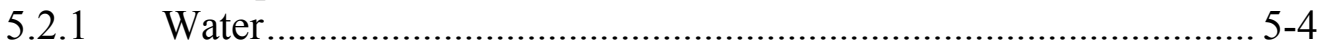

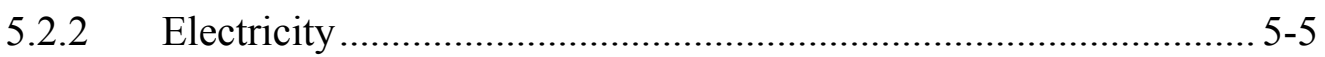

5.2.3 Spent Nuclear Fuel and Radioactive Waste................................. 5-6

5.2.4 Transportation .................................................................... 5-8

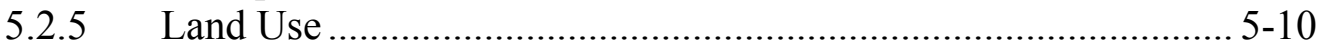

5.2.6 Air Quality and Greenhouse Gases............................................ 5-11

5.2.7 Construction Materials.............................................................. 5-12

5.2.8 Impacts Beyond 50 Years ……………………....................... 5-12

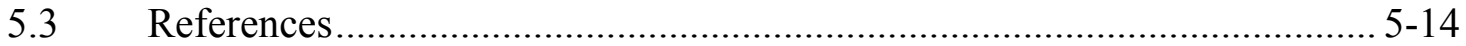

Chapter 6 Complance, Regulatory Requirements, And Permits For DoMestic Programmatic ALternatiVes ........................................ 6-1

6.1 Introduction ................................................................................... 6-1

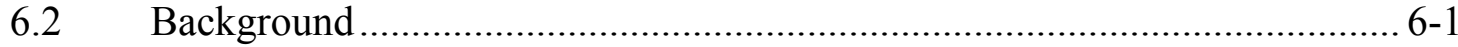

6.3 Environmental Statutes, Orders, and Agreements ........................................ 6-1

6.3.1 Federal Environmental Statutes and Regulations ........................... 6-3

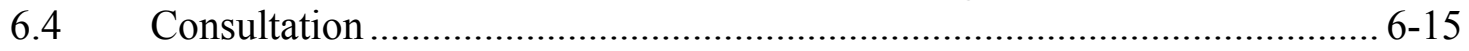

6.5 Waste Classification........................................................................ 6-15

\section{Chapter 7 International Initiatives and Impacts Of the Programmatic}

ALTERNATIVES ............................................................................................ 7-1

7.1 Introduction and Background ………................................................. 7-1

7.1.1 International Energy Demand ...................................................... 7-3

7.1.2 Grid-Appropriate Reactors.................................................... 7-4

7.1.3 Reliable Fuel Services............................................................. 7-5

7.1.3.1 Spent Nuclear Fuel Disposition ................................. 7-6

7.1.3.2 Wastes from Spent Nuclear Fuel Recycling and

Disposition .............................................................. 7-6

7.2 Potential Environmental Impacts in the United States and Global Commons from International Actions ……………................................. 7-7

7.2.1 Fast Reactor Recycle Alternative................................................... 7-7

7.2.1.1 Transportation of Reactor Fuel to and from Foreign Reactors ……............................................... 7-9

7.2.1.2 Ground Transportation of Reactor Fuel Assemblies .. 7-11 


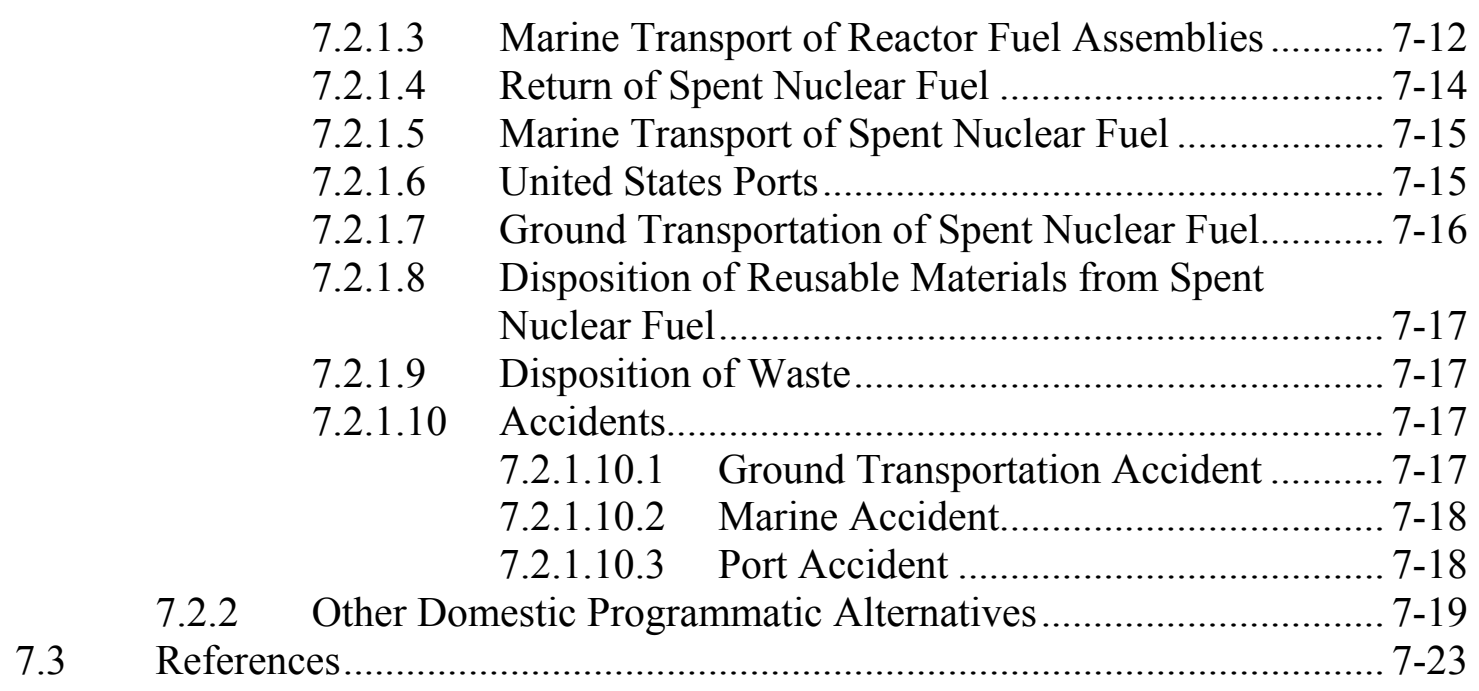

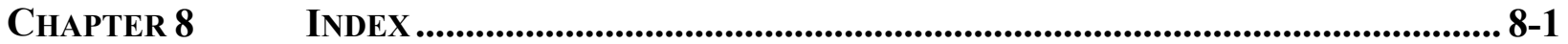

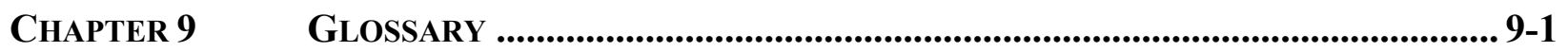

ChAPTER $10 \quad$ LIST OF PREPARERS .................................................................................... 10-1

CHAPTER 11 DISTRIBUTION LIST ................................................................................11

\section{Appendices}

APPENDiX A BaCKGround InFormation ON NuCleAR Fuel CyCle Technologies And The Advanced Fuel CyCle Initiative ................ A-1

A.1 Nuclear Fuel Cycle ............................................................................. A-1

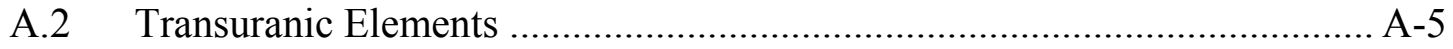

A.3 Mining, Enrichment, and Fuel Fabrication ...................................... A-5

A.3.1 Uranium ............................................................................. A-5

A.3.1.1 Uranium Mining................................................... A-6

A.3.1.2 Uranium Milling and Extraction.............................. A-6

A.3.1.3 Uranium Enrichment............................................. A-6

A.3.1.4 Uranium Fuel Fabrication ....................................... A-7

A.3.2 Thorium............................................................................... A-9

A.3.2.1 Thorium Mining.................................................. A-10

A.3.2.2 Thorium Use in a Nuclear Reactor .......................... A-10

A.3.3 Characterization of Commercial Nuclear Fuel

Fabrication Facilities.................................................... A-12

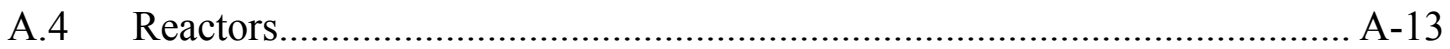

A.4.1 Thermal Reactors ................................................................. A-14

A.4.1.1 Uranium-Oxide Fueled Light Water

Reactors.......................................................... A-15

A.4.1.2 Mixed Oxide Fueled Light Water Reactors ............... A-16 
A.4.1.3 Heavy Water Reactors ………………………........ A-18

A.4.1.4 High Temperature Gas-Cooled Reactors (HTGRs)... A-21

A.4.1.5 Thorium-Fueled Light Water Reactors..................... A-24

A.4.2 Fast Reactors ................................................................... A-26

A.4.2.1 Sodium-Cooled Fast Reactor .................................... A-26

A.4.2.2 Plant Description................................................... A-27

A.4.2.3 Reactor Fuel ........................................................ A-28

A.5 Reprocessing Technologies ........................................................... A-29

A.5.1 Aqueous Processing .......................................................... A-29

A.5.2 Electrochemical Separations........................................................ A-35

A.5.3 Oxidation and Reduction of Oxide Fuel (OREOX)

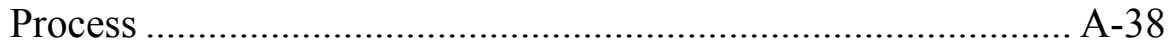

A.6 Nuclear Fuel Recycling Centers …………………................................ A-41

A.6.1 Light Water Reactor Spent Nuclear Fuel Recycling

Facility …….............................................................................. A-41

A.6.1.1 Separations Process Description............................... A-41

A.6.1.2 Facility Requirements .......................................... A-42

A.6.1.3 Operational Materials and Waste.............................. A-43

A.6.2 Transmutation Fuel Fabrication Facility ...................................... A-46

A.6.2.1 Process Description............................................... A-46

A.6.2.2 Facility Requirements ........................................... A-47

A.6.2.3 Operational Materials and Waste.............................. A-48

A.6.3 Fast Reactor Spent Nuclear Fuel Recycling Facility .................. A-48

A.6.3.1 Process Description................................................. A-48

A.6.3.2 Facility Requirements .......................................... A-49

A.6.3.3 Operational Materials and Waste............................... A-50

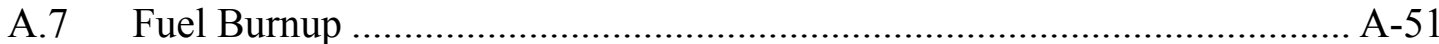

A.7.1 Thermal Spectrum Burnup Trends............................................. A-52

A.7.2 Fast Spectrum Burnup Trends ………………..................... A-54

A.8 Existing Reactor Replacements ………………….............................. A-55

A.9 Advanced Fuel Cycle Initiative—Sites and Facilities ............................... A-57

A.9.1 Argonne National Laboratory ………….................................. A-58

A.9.1.1 Sodium Test Loop.............................................. A-58

A.9.2 Hanford Site ................................................................... A-59

A.9.2.1 300 Area ........................................................ A-59

A.9.2.2 Applied Process Engineering Laboratory ………...... A-62

A.9.3 Idaho National Laboratory ...................................................... A-63

A.9.3.1 Materials and Fuels Complex ……………………... A-64

A.9.3.2 Reactor Technology Complex …………………..... A-66

A.9.4 Los Alamos National Laboratory................................................ A-68

A.9.4.1 Chemistry and Metallurgy Research

Building............................................................... A-68

A.9.4.2 Los Alamos Neutron Science Center......................... A-71

A.9.4.3 Technical Area - 35............................................... A-74

A.9.4.4 Technical Area - 55............................................... A-75

A.9.5 Oak Ridge National Laboratory ............................................... A-78 
A.9.5.1 Irradiated Fuel Examination Laboratory ................... A-78

A.9.5.2 Radiochemical Engineering Development

Center....

A-79

A.9.6 Sandia National Laboratories/New Mexico.............................. A-81

A.9.6.1 Brayton Cycle Demonstration.................................. A-81

A.9.7 Savannah River National Laboratory..................................... A-82

A.9.7.1 Building 773-A ................................................. A-83

A.9.7.2 Aiken County Technology Laboratory ................... A-84

A.10 References ............................................................................... A-8

APPENDIX B INTENTIONAL DESTRUCTIVE ACTS............................................................

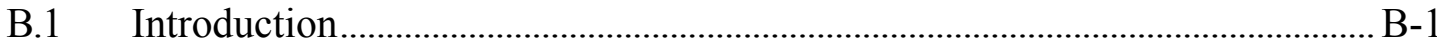

B.2 Domestic Programmatic Alternatives.......................................................... B-2

B.2.1 No Action Alternative...........................................................

B.2.1.1 Low Enriched Uranium Fueled Light Water

Reactor................................................................................. B-2

B.2.1.2 Low Enriched Uranium Fueled Advanced

Light Water Reactor ........................................................ B-3

B.2.2 Fast Reactor Recycle Alternative..............................................

B.2.2.1 Nuclear Fuel Recycling Center ........................................ B-4

B.2.2.2 Advanced Recycling Reactors......................................... B-5

B.2.3 Thermal/Fast Reactor Recycle Alternative ......................................6-6

B.2.3.1 Mixed Oxide-Uranium-Plutonium Fueled

Light Water Reactor ...................................................... B-6

$\begin{array}{ll}\text { B.2.3.2 } & \text { Mixed Oxide-Uranium-Plutonium Fueled } \\ \text { Advanced Light Water Reactor......................................... B-7 }\end{array}$

B.2.4 Thermal Reactor Recycle Alternative..........................................

B.2.4.1 Recycle in Light Water Reactors (Option 1).................. B-8

B.2.4.2 Recycle in Heavy Water Reactors (Option 2)................ B-8

B.2.4.3 Recycle in High Temperature Gas-Cooled

Reactors (Option 3)....................................................... B-8

B.2.5 Thorium Alternative..............................................................

B.2.6 Heavy Water Reactor/High Temperature Gas-Cooled

Reactor Alternative ...................................................................

B.2.6.1 Heavy Water Reactors (Option 1) ..................................... B-9

B.2.6.2 High Temperature Gas-Cooled Reactors

(Option 2) .................................................................

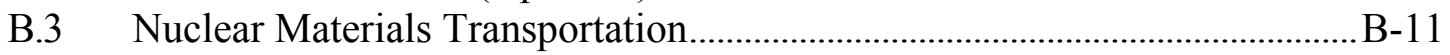

B.3.1 Methodology ..................................................................

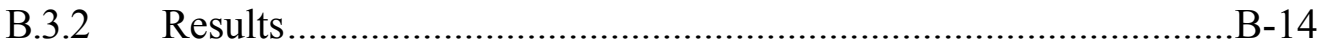

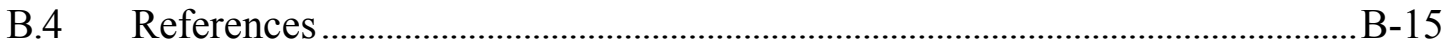

APPENdiX C Human Health AND Worker SAFETY ....................................................... C-1

C.1 Radiological Impacts on Human Health .............................................................

C.1.1 Radiation and Radioactivity .................................................

C.1.1.1 What Is Ionizing Radiation? ............................................ C-1 
C.1.1.2 What Are the Units of Radioactivity?............................... C-2

C.1.1.3 How Does Radiation Affect the Human Body?............. C-3

C.1.1.4 What Are Some Types of Radiation Dose

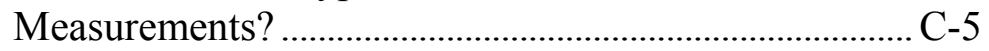

C.1.1.5 What Are Some Sources of Radiation? ........................... C-6

C.1.2 How Is Radiation Exposure Regulated? ......................................

C.2 Risk Characterization and Interpretation of Radiological Data ......................... C-8

C.3 Risk Estimates and Health Effects for Radiation Exposures to Workers ...... C-9

C.4 Risk Estimates and Health Effects for Radiation Exposures to

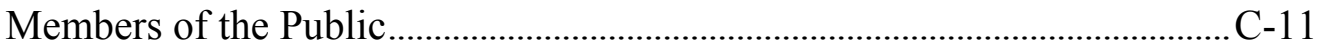

C.5 Hazardous Chemical Impacts to Human Health ...............................................

C.5.1 Chemicals and Human Health .................................................... -13

C.5.1.1 How Do Chemicals Affect the Body? ............................. -13

C.5.1.2 Chemical Noncarcinogens................................................. -14

C.5.1.3 Chemical Carcinogens ..................................................... -15

C.5.2 How Is Chemical Exposure Regulated? ..................................... -15

C.5.2.1 Environmental Protection Standards................................ C-15

C.5.2.2 Regulated Occupational Exposure Limits...................... -16

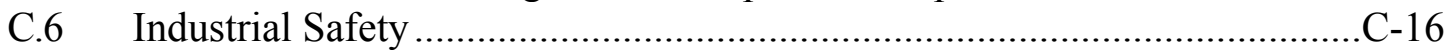

C.6.1 Regulation of Worker Safety ..................................................

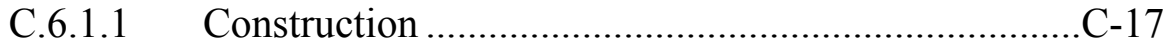

C.6.1.2 Operations ............................................................. 18

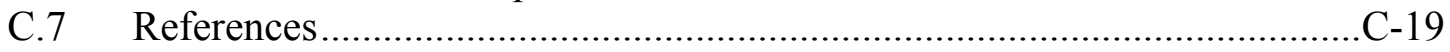

APPENDIX D $\quad$ FACILITY ACCIDENT SCENARIOS.................................................................... D-1

D.1 Approach to the Analysis of Potential Accidents ................................. D-1

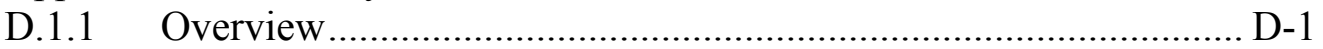

D.1.2 Accident Selection Methodology........................................... D-4

D.1.2.1 Assembly of Available Information.......................... D-5

D.1.2.2 Identification of Candidate Scenarios ......................... D-6

D.1.2.3 Selection of Accidents for Analysis.......................... D-6

D.1.3 Accident Frequencies .................................................... D-6

D.1.4 Source Term ...................................................................... D-7

D.1.5 Consequence Analysis .................................................... D-9

D.1.5.1 Radioactive Material Releases .................................. D-9

D.1.5.2 Hazardous Chemical Releases ................................ D-14

D.1.6 Sites Selected for Analysis................................................. D-15

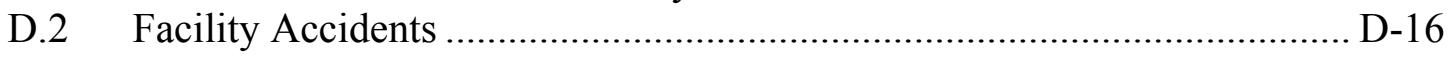

D.2.1 No Action Alternative....................................................... D-17

D.2.1.1 Low Enriched Uranium Fueled Light

D.2.1.2 Low Enriched Uranium Fueled Advanced

Light Water Reactor.............................................. D-24

D.2.2 Fast Reactor Recycle Alternative.......................................... D-31

D.2.2.1 Nuclear Fuel Recycling Center ............................... D-31

D.2.2.1.1 Accident Selection Process .................. D-33 

D.2.2.1.2 Accidents Selected for
Analysis.
D-35
D.2.2.1.3 Results
D-43
D.2.2.1.4
Involved Worker Impacts
D-47
D.2.2.2 Advanced Recycling Reactor...................................... D-48
D.2.2.2.1 Accident Selection Process ................... D-48
D.2.2.2.2 Accidents Selected for
Analysis.
D-52
D.2.2.2.3 Results
D-64

D.2.3 Thermal/Fast Reactor Recycle Alternative ................................. D-69

D.2.3.1 Mixed Oxide-Uranium-Plutonium Fueled

Light Water Reactor................................................... D-69

D.2.3.2 Mixed Oxide-Uranium-Plutonium Fueled

Advanced Light Water Reactor ................................ D-77

D.2.3.3 Nuclear Fuel Recycling Center ................................. D-78

D.2.4 Thermal Reactor Recycle Alternative........................................ D-78

D.2.4.1 Thermal Recycle in Light Water Reactors

(Option 1)...

D-78

D.2.4.1.1 Mixed Oxide-Uranium-

Plutonium Fueled Light

Water Reactor

D-79

D.2.4.1.2 Mixed Oxide-Uranium-

Plutonium Fueled Advanced

Light Water Reactor.

D.2.4.1.3 Nuclear Fuel Recycling

Center.

D-79

D.2.4.2 Thermal Recycle in Heavy Water Reactors

(Option 2) .............................................................. D-79

D.2.4.2.1 Heavy Water Reactor............................. D-79

D.2.4.2.2 Nuclear Fuel Recycling

Center......

D-80

D.2.4.3 Thermal Recycle in High Temperature

Gas-Cooled Reactors (Option 3)................................ D-80

D.2.4.3.1 High Temperature Gas-

Cooled Reactors ..................................... D-80

D.2.4.3.2 Nuclear Fuel Recycling

Center...................................................... D-81

D.2.5 Thorium Alternative.............................................................. D-81

D.2.6 Heavy Water Reactor/High Temperature Gas-Cooled

Alternative

D-82

D.2.6.1 Heavy Water Reactor (Option 1) .............................. D-82

D.2.6.2 High Temperature Gas-Cooled Reactor

(Option 2)

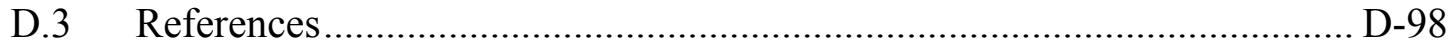


APPENDIX E TRANSPORTATION .........................................................................................

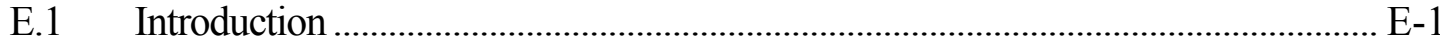

E.1.1 Transportation Regulations ........................................................E-1

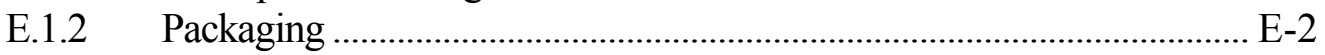

E.1.3 Emergency Management ……………………………………………..... E-3

E.1.4 Safeguards and Security Regulatory Environment............................. E-5

E.1.5 Transportation Routes.......................................................................... E-6

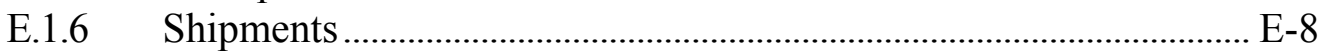

E.1.7 Loading Operations ............................................................................ E-8

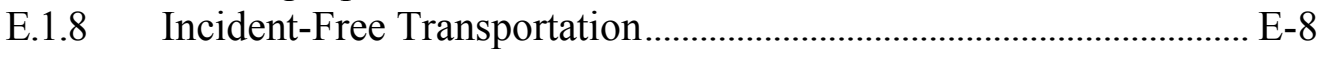

E.1.8.1 Worker and General Populations ………………………..... E-9

E.1.8.2 Incident-Free Exposure to Escorts....................................... E-10

E.1.8.3 Nonradiological Vehicle Emissions ......................................E-11

E.1.9 Transportation Accidents ..........................................................................E-11

E.1.9.1 Transportation Accident Rates .............................................. E-12

E.1.9.2 Conditional Probabilities and Release Fractions .................. E-12

E.1.9.3 Severe Transportation Accidents .......................................... E-13

E.2 Transportation Analysis of the Domestic Programmatic Alternatives................... E-15

E.2.1 Routing Analysis for Domestic Programmatic Alternatives ................ E-15

E.2.2 Shipment Data for Domestic Programmatic Alternatives...................... E-17

E.2.2.1 Fresh and Spent Nuclear Fuel Shipments ...........................E-18

E.2.2.2 Separation Process Material and Waste Shipments ............ E-23

E.2.3 Loading Operations - Domestic Programmatic Alternatives................ E-29

E.2.4 Incident-Free Transportation Impacts-Domestic

Programmatic Alternatives ..................................................................E-30

E.2.5 Accident Analysis—Domestic Programmatic Alternative.................... E-39

E.3 International Transportation Analysis ................................................................ E-49

E.3.1 Routing Analysis for International Shipments ...................................... E-49

E.3.2 International Program Shipments......................................................... E-50

E.3.3 Loading and Inspection Impacts and Incident-Free Impacts of

International Shipments............................................................................ E-50

E.4 Summary of Assumptions Used in Transportation Analyses ..................................E-51

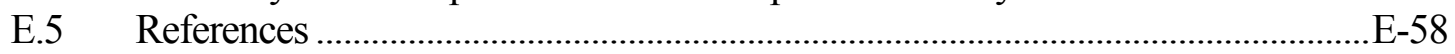

APPENDIX F ENVIRONMENTAL IMPACT Methodology …….............................................F-1

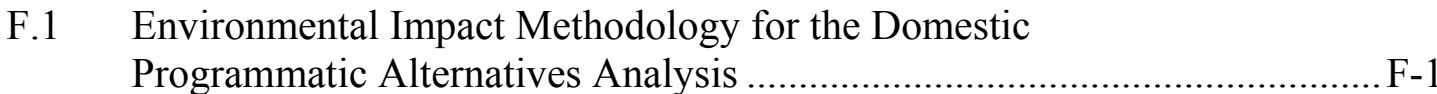

F.1.1 Electricity Projections, Nuclear Share of the Electricity

Market, and Planning Period ..........................................................F-1

F.1.2 Facilities and Capacities Needed to Meet the Demand and

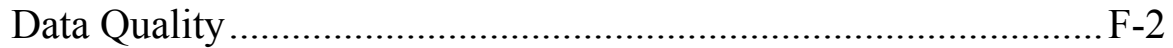

F.1.3 Facility Locations...................................................................

F.1.4 Resource Analyses ...................................................................

F.1.5 Impacts of Transportation ...........................................................F-6

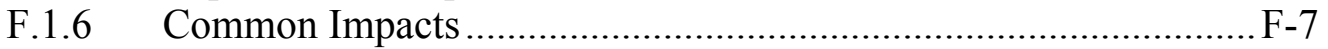

F.1.7 Cumulative Impacts .............................................................. 
F.2 Environmental Impact Methodology for the International Activities

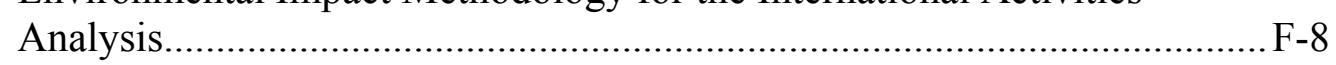

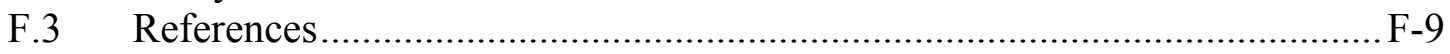

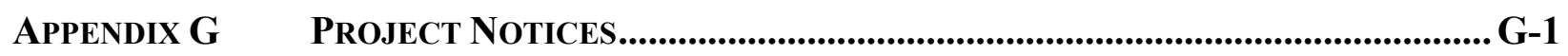

APPENDIX H SUMMARY OF SCOPING COMMENTS ......................................................... H-1

H.1 Advance Notice of Intent Scoping Summary ......................................... H-1

H.1.1 Advance Notice of Intent Major Scoping Comments.................... H-1

H.2 Notice of Intent Scoping Summary...................................................... H-3

H.2.1 Major Scoping Comments .................................................. H-4

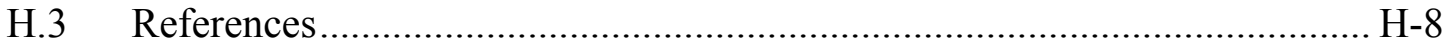

APPENDix I NEPA Disclosure Statement for PREPARATION OF THE GLobaL

NUCLEAR ENERGY PARTNERSHIP PRogRAMMATIC ENVIRONMENTAL IMPACT

STATEMENT ..........................................................................................I-1

APPENDIX J $\quad$ FUNDING OPPORTUNITY ANNOUNCEMENT SITE SUMMARIES.................. J.1-1

J.1 Introduction.................................................................................

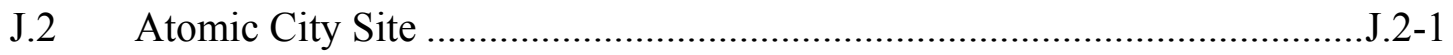

J.2.1 Land Use .............................................................................2-1

J.2.2 Visual Resources......................................................................

J.2.3 Site Infrastructure.............................................................. $2-1$

J.2.4 Air Quality and Noise .......................................................... 2-1

J.2.5 Water Resources ................................................................ 2-2

J.2.6 Geology and Soils ................................................................. $2-2$

J.2.7 Biological Resources .............................................................. 2-3

J.2.8 Cultural and Paleontological Resources ..................................... . 2-4

J.2.9 Socioeconomics ................................................................ $2-4$

J.2.10 Environmental Justice ............................................................. 2-4

J.2.11 Public and Worker Health and Safety...................................... 2-5

J.2.12 Transportation .................................................................... $2-5$

J.2.13 Waste Management................................................................ 2-5

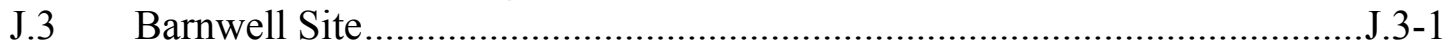

J.3.1 Land Use .................................................................. $3-1$

J.3.2 Visual Resources...............................................................3-1

J.3.3 Site Infrastructure.................................................................... $3-1$

J.3.4 Air Quality and Noise ..................................................... 3-1

J.3.5 Water Resources ............................................................... 3-2

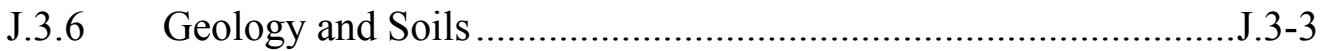

J.3.7 Biological Resources ..............................................................

J.3.8 Cultural and Paleontological Resources .................................... 3-4

J.3.9 Socioeconomics .................................................................... $3-4$

J.3.10 Environmental Justice ..........................................................3-4

J.3.11 Public and Worker Health and Safety....................................... 3-5

J.3.12 Transportation ...................................................................... 
J.3.13 Waste Management .....................................................................

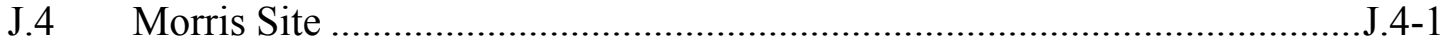

J.4.1 Land Use ............................................................................

J.4.2 Visual Resources.....................................................................

J.4.3 Site Infrastructure.......................................................................

J.4.4 Air Quality and Noise ................................................................

J.4.5 Water Resources ....................................................................

J.4.6 Geology and Soils .....................................................................

J.4.7 Biological Resources ................................................................ $4-4$

J.4.8 Cultural and Paleontological Resources .......................................... 4.4

J.4.9 Socioeconomics .........................................................................

J.4.10 Environmental Justice ................................................................4-4

J.4.11 Public and Worker Health and Safety............................................. $4-5$

J.4.12 Transportation ............................................................................ $4-5$

J.4.13 Waste Management.....................................................................

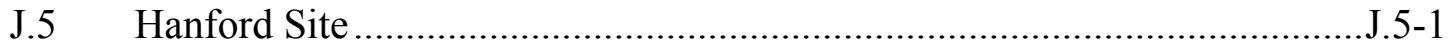

J.5.1 Land Use .............................................................................

J.5.2 Visual Resources...................................................................

J.5.3 Site Infrastructure.............................................................................

J.5.4 Air Quality and Noise .................................................................. $5-2$

J.5.5 Water Resources ……………………......................................

J.5.6 Geology and Soils ....................................................................

J.5.7 Biological Resources .................................................................

J.5.8 Cultural and Paleontological Resources .........................................5-6

J.5.9 Socioeconomics .........................................................................

J.5.10 Environmental Justice ................................................................ $5-7$

J.5.11 Public and Worker Health and Safety............................................5-7

J.5.12 Transportation ..........................................................................

J.5.13 Waste Management.......................................................................5-8

J.6 Idaho National Laboratory ......................................................................

J.6.1 Land Use .............................................................................

J.6.2 Visual Resources.......................................................................

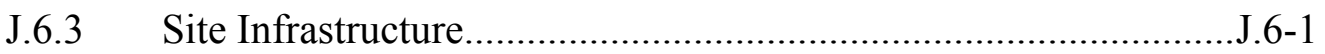

J.6.4 Air Quality and Noise .................................................................6-2

J.6.5 Water Resources .......................................................................6-2

J.6.6 Geology and Soils .....................................................................

J.6.7 Biological Resources ...................................................................

J.6.8 Cultural and Paleontological Resources .......................................... 6-5

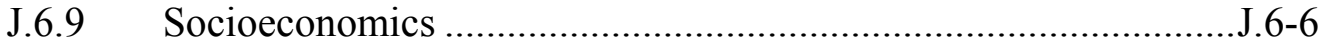

J.6.10 Environmental Justice .................................................................6-6

J.6.11 Public and Worker Health and Safety..............................................6-7

J.6.12 Transportation ...........................................................................

J.6.13 Waste Management.....................................................................6-8

J.7 Lea County Site.....................................................................................

J.7.1 Land Use …….....................................................................

J.7.2 Visual Resources.................................................................. 
J.7.3 Site Infrastructure...................................................................

J.7.4 Air Quality and Noise ..............................................................

J.7.5 Water Resources ....................................................................

J.7.6 Geology and Soils .....................................................................

J.7.7 Biological Resources ..................................................................

J.7.8 Cultural and Paleontological Resources ……….............................

J.7.9 Socioeconomics ……..........................................................

J.7.10 Environmental Justice................................................................

J.7.11 Public and Worker Health and Safety............................................ .

J.7.12 Transportation.......................................................................

J.7.13 Waste Management....................................................................

J.8 Oak Ridge Reservation …………………….......................................

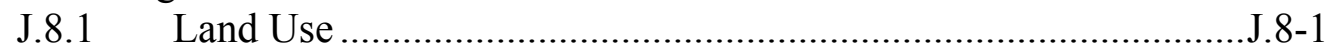

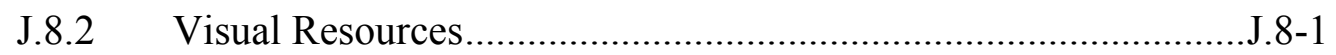

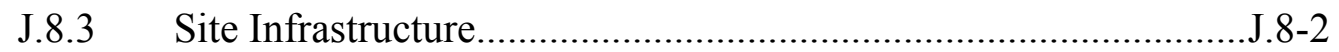

J.8.4 Air Quality and Noise ..............................................................

J.8.5 Water Resources ..................................................................

J.8.6 Geology and Soils .....................................................................

J.8.7 Biological Resources .................................................................

J.8.8 Cultural and Paleontological Resources ......................................... $8-6$

J.8.9 Socioeconomics ……………...............................................

J.8.10 Environmental Justice...............................................................

J.8.11 Public and Worker Health and Safety............................................. $8-8$

J.8.12 Transportation......................................................................... $8-8$

J.8.13 Waste Management.................................................................

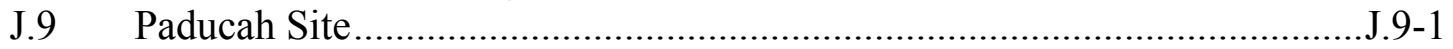

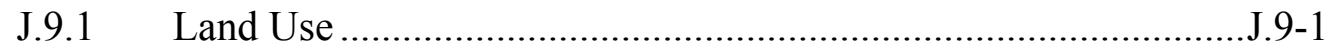

J.9.2 Visual Resources.....................................................................

J.9.3 Site Infrastructure.....................................................................

J.9.4 Air Quality and Noise ................................................................. $9-2$

J.9.5 Water Resources ................................................................... $9-2$

J.9.6 Geology and Soils ........................................................................9-3

J.9.7 Biological Resources ................................................................9-3

J.9.8 Cultural and Paleontological Resources .........................................9-4

J.9.9 Socioeconomics ……............................................................

J.9.10 Environmental Justice................................................................9-4

J.9.11 Public and Worker Health and Safety.............................................9-5

J.9.12 Transportation........................................................................

J.9.13 Waste Management....................................................................

J.10 Portsmouth Site.....................................................................................

J.10.1 Land Use ...............................................................................

J.10.2 Visual Resources..................................................................10-1

J.10.3 Site Infrastructure.......................................................................

J.10.4 Air Quality and Noise .............................................................. 10-2

J.10.5 Water Resources …………….................................................10-2

J.10.6 Geology and Soils ......................................................................10-3 
J.10.7 Biological Resources ................................................................10-4

J.10.8 Cultural and Paleontological Resources ……….............................10-5

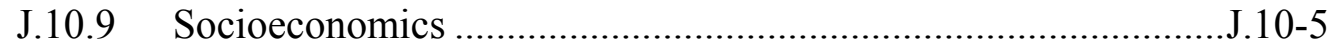

J.10.10 Environmental Justice ..............................................................10-5

J.10.11 Public and Worker Health and Safety...........................................10-6

J.10.12 Transportation ......................................................................10-6

J.10.13 Waste Management...................................................................10-7

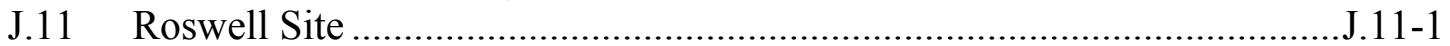

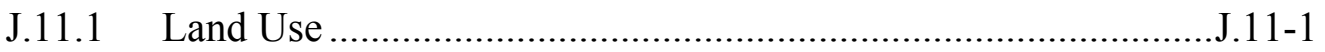

J.11.2 Visual Resources......................................................................11-1

J.11.3 Site Infrastructure....................................................................11-1

J.11.4 Air Quality and Noise ................................................................11-1

J.11.5 Water Resources ......................................................................

J.11.6 Geology and Soils .....................................................................11-2

J.11.7 Biological Resources .................................................................11-3

J.11.8 Cultural and Paleontological Resources ........................................11-3

J.11.9 Socioeconomics .......................................................................

J.11.10 Environmental Justice ...............................................................11-4

J.11.11 Public and Worker Health and Safety............................................ 11-4

J.11.12 Transportation .........................................................................11-4

J.11.13 Waste Management.....................................................................

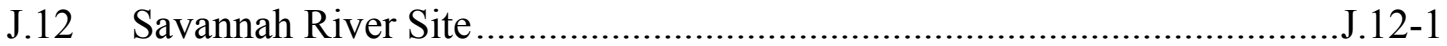

J.12.1 Land Use ...............................................................................

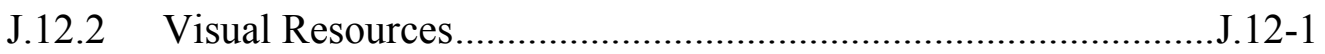

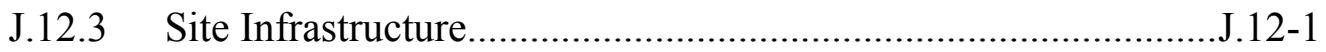

J.12.4 Air Quality and Noise ...........................................................12-2

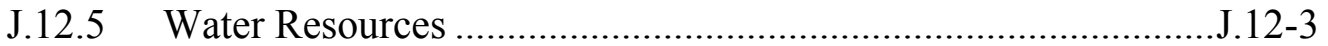

J.12.6 Geology and Soils .....................................................................

J.12.7 Biological Resources ................................................................12-5

J.12.8 Cultural and Paleontological Resources ......................................12-6

J.12.9 Socioeconomics ..................................................................12-6

J.12.10 Environmental Justice ...............................................................12-7

J.12.11 Public and Worker Health and Safety.........................................12-7

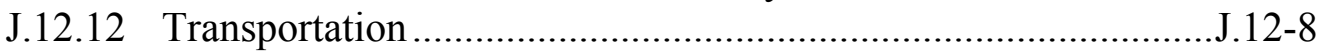

J.12.13 Waste Management................................................................12-9

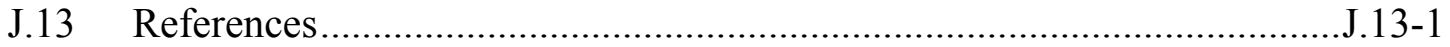

\section{List of Figures}

FIGURE 1.4.5-1

FIGURE 2.1-1

FigURE 2.2-1

FIGURE 2.3-1

FigURE 2.4-1
Global Nuclear Energy Partnership Public Scoping Meetings $1-17$ Global Nuclear Energy Partnership Programmatic Environmental Impact Statement Scope and Alternatives....................... 2-3 No Action Alternative Once-Through Uranium Fuel Cycle ................... 2-5 Fast Reactor Recycle Alternative.......................................................... 2-9 Thermal/Fast Reactor Recycle Alternative ……….............................. 2-12 
FIGURE 2.5.1-1

FIGURE 2.5.2-1

FIGURE 2.5.3-1

FigURE 2.6-1

FIGURE 2.7.1-1

FIGURE 2.7.2-1

FigURE 2.8-1

FIGURE 3.2.1-1

FiguRE 3.2.2-1

FigURE 3.2.3-1

FIGURE 3.2.4.1-1

FIGURE 3.2.4.1-2

FIGURE 3.2.4.1-3

FIGURE 3.2.5-1

FigURE 4.1-1

FIGURE 4.1.1.2-1

Figure 4.2-1

FIGURE 4.3-1

FigURE 4.3-2

FigURE 4.6-1

Figure 4.8-1

FigURE 4.8-2

Figure 4.8-3

FIGURE 4.8-4

FigURE 4.8-5

FigURE 4.9-1

FigURE 4.9-2

FIGURE 7.1.1-1

FIGURE 7.1.3-1
Thermal Reactor Recycle Alternative: Option 1 (Mixed Oxide

Uranium Plutonium Recycle) ........................................................... 2-14

Thermal Reactor Recycle Alternative: Option 2 (DUPIC Fuel

Cycle)

Thermal Reactor Recycle Alternative: Option 3 (Thermal

Recycle in High Temperature Gas-Cooled Reactors)........................... 2-19

Thorium Alternative..................................................................... 2-21

Heavy Water Reactor Open Fuel Cycle.............................................. 2-23

High Temperature Gas-Cooled Open Fuel Cycle .................................. 2-24

Historical Fuel Burnup Levels for United States Commercial

Boiling Water Reactors and Pressurized Water Reactors...................... 2-27

Nonattainment Areas of the United States............................................. 3-4

Land Cover and Use by Major River Basin for 2003 ............................. 3-5

United States Water Consumption by Use Category ................................ 3-7

United States Population Trend from 1900 to 2000 (Millions) ................ 3-9

Population Growth by Region Between 1900 and 2000....................... 3-10

Population Density of the United States for 2000 ................................. 3-10

Sites that Currently Store Spent Nuclear Fuel and High-Level

Radioactive Waste Destined for Geologic Disposal ............................... 3-15

In Situ Leaching Process to Mine Uranium............................................. 4-5

Typical Open Pit Uranium Mine........................................................... 4-7

Dry Spent Nuclear Fuel Storage Modules on a Concrete Pad ............... 4-33

Equilibrium Fraction of Fast Reactors in the United States .................. 4-58

Annual Worker Dose for Cesium/Strontium Storage over 300

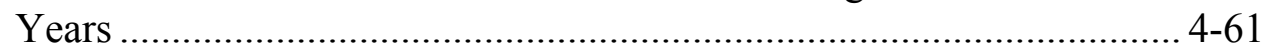

Radiotoxicity of Uranium Ore versus Thorium Ore .............................. 4-95

Cumulative Spent Nuclear Fuel Quantities Requiring Geologic

Disposal for the 200 Gigawatts Electric Scenario (2010 to

2060-2070).

Cumulative Quantities of High-Level Waste Requiring

Geologic Disposal for the 200 Gigawatts Electric Scenario

(Based on Recycling Spent Nuclear Fuel Generated Between

2010 and 2060-2070)

Cumulative Quantities of Greater-Than-Class-C Low-Level

Radioactive Waste Generated for the 200 Gigawatts Electric

Scenario (Based on Recycling Spent Nuclear Fuel Generated

Between 2010 and 2060-2070).

Cumulative Quantities of Low-Level Waste Generated for the

200 Gigawatts Electric Scenario (Based on Recycling Spent

Nuclear Fuel Generated Between 2010 and 2060-2070)....

Radiotoxicity of Spent Nuclear Fuel and/or High-Level Waste

Over Time

Maine Yankee Before Decontamination and Decommissioning......... 4-159

Maine Yankee After Decontamination and Decommissioning ............ 4-159

World Electric Power Generation .......................................................... 7-3

One International Reliable Fuel Services Program Concept .................... 7-6 
FiguRE 7.2.1.1-1

FigURE 7.2.1.1-2

FiguRE A.1-1

Figure A.1-2

FiguRE A.1-3

FiguRE A.1-4

FiguRE A.3.1.4-1

Figure A.3.2.2-1

FigURE A.4-1

FiguRE A.4.1.2-1

FigURE A.4.1.2-2

FIGURE A.4.1.4-1

FIGURE A.4.1.4-5

FiguRE A.4.2.2-1

FIGURE A.5.1-1

FIGURE A.5.1-2

FIGURE A.5.1-3

FIGURE A.5.2-1

FiguRE A.5.2-2

FIGURE A.5.3-1

FIGURE A.5.3-2

FiguRE A.9.1.1-1

FiguRE A.9.2.1-1

FIGURE A.9.2.1-2

FiguRE A.9.3.1-1

FIGURE A.9.3.2-1

FigURE A.9.4.1-1

FiguRE A.9.4.2-1

FIGURE A.9.4.4-1

FiguRE A.9.5.1-1
The Atlantic Ocean 7-10

The Pacific Ocean 7-10

SNF Assemblies Being Loaded Into a Typical SNF Pool ..................... A-2

Typical Dry Cask Storage .................................................................... A-2

Constituents of Light Water Reactor Spent Nuclear Fuel .................... A-3

Open and Closed Nuclear Fuel Cycle ................................................. A-4

Typical Nuclear Reactor Uranium Dioxide Fuel Fabrication Facility.... A-7

Thorium Open Fuel Cycle ................................................................ A-12

Electricity Production in a Typical Commercial Nuclear Plant........... A-14

Pin Loading Pattern of Mixed Oxide-Uranium-Plutonium

Assembly

A-17

Multi-Recycling of Plutonium in Light Water Reactors.

A-18

TRISO Fuel Concept Showing the Fuel Particles, Fuel

Compacts, and Fuel Assembly Blocks

Seed-Blanket Unit and Whole Assembly Seed and Blanket

Fuel Assembly Design ....

A-24

Schematic of a Sodium-Cooled Fast Reactor (Pool-type)...

A-28

Plutonium Uranium Reduction and Extraction Flow

Diagram.

A-31

Rokkasho Flow Diagram ....

A-31

Uranium Reduction and Extraction Process Aqueous Reprocessing

Technology Flow Diagram

A-34

Simplified Schematic Block Flow Diagram of Electrochemical

Separations A-36

Diagram of Electrorefiner Used to Treat Experimental Breeder

Reactor-II Fuel at INL

Direct Use of Spent Pressurized Water Reactor Fuel in Canada

Deuterium Uranium Fuel Fabrication Process Using Oxidation and

Reduction of Oxide Fuel....

Direct Use of Spent Pressurized Water Reactors Fuel in Canada

Deuterium Uranium Fuel Fabrication Process................................... A-40

Sodium Test Loop Schematic ......................................................... A-59

Hanford Site 300 Area (Looking South to North) .............................. A-61

Radiochemical Processing Laboratory ........................................... A-62

Materials and Fuels Complex at INL (Looking West to

East) ..................................................................................... A-65

Reactor Technology Complex at INL (Looking South to

North)

Operation of Hot Cell Equipment within the Chemistry and

Metallurgy Research Building....

A-70

The Los Alamos Neutron Science Center (Looking East to

West)......

Technical Area - 55 at LANL (Looking West to East)...................... A-76

Exterior of the Irradiated Fuel Examination Laboratory .....

A-79 
FIGURE A.9.6.1-1 Engineering Layout Drawing of Spent Nuclear Fuel Closed

Brayton Loop and Picture of Brayton Loop with Full

Insulation.

A-82

FIGURE A.9.7.1-1

The Savannah River National Laboratory

FIGURE A.9.7.1-2

The Shielded Cells Facility at the Savannah River National

Laboratory.

FIGURE D.1.5.1-1

Release and Exposure Pathways

D-11

FIGURE H.2-1

Location of Global Nuclear Energy Partnership

Programmatic Environmental Impact Statement Scoping

Meetings

\section{List of Tables}

TABLE 2.10.1-1 Capacity/Facility Information for Programmatic Alternatives

(200 Gigawatt Electric)................................................................ 2-41

TABLE 2.10.2-1 Capacity/Facility Information for Programmatic Alternatives

(400 Gigawatt Electric)................................................................ 2-43

TABLE 2.10.3-1 Capacity/Facility Information for Programmatic Alternatives

(150 Gigawatt Electric) ............................................................... 2-45

TABLE 2.10.4-1 Capacity/Facility Information for Programmatic Alternatives

(100 Gigawatt Electric) ..................................................................... 2-47

TABLE 3.2.3-1

TABLE 3.2.4.3-1

Average Water Demand for a Nuclear Power Generation Plant ............. 3-8

TABLE 3.2.4.7-1

TABLE 3.2.4.8-1

TABLE 4.1-1

TABLE 4.1-2

TABLE 4.1-3

TABLE 4.1-4

Employment by Industrial Sector for 2002.

Employment Data for Heavy Industrial and Civil Construction

Activities

United States and World Consumption of Steel and Cement ............... 3-13

Uranium Production from Mines (tons) ............................................... 4-3

United States Light Water Reactor Fuel Fabrication Capacity............. 4-16

Waste Generation at Westinghouse Fuel Fabrication Facility.............. 4-19

Annual Carbon Dioxide Emissions Displaced by 1,000

Megawatts Electric Nuclear Plant Operating at 90 Percent

Capacity Factor

TABLE 4.2-1

Cumulative Radiological Impacts for Storing 158,000 Metric

TABLE 4.2-2

Tons Heavy Metal of Spent Nuclear Fuel....

Implementation, No Action Alternative

Alternative (Truck Transit)-200 Gigawatts Electric

Alternative (Truck and Rail Transit) - 200 Gigawatts Electric....

TABLE 4.2-5

In-Transit Transportation Impacts for 50 Years of

Implementation, No Action Alternative (Truck Transit)—200

Gigawatts Electric.

TABLE 4.2-6

In-Transit Transportation Impacts for 50 Years of

Implementation, No Action Alternative (Truck and Rail

Transit)-200 Gigawatts Electric 
TABLE 4.2-7

TABLE 4.2-8

TABLE 4.3-1

TABLE 4.3-2

TABLE 4.3-3

TABLE 4.3-4

TABLE 4.3-5

TABLE 4.3-6

TABLE 4.3-7

TABLE 4.3.4-1

TABLE 4.4-1

TABLE 4.4-2

TABLE 4.4-3

TABLE 4.4-4

TABLE 4.4-5

TABLE 4.4-6

TABLE 4.5-1
Normal Operation Radiological Impacts to the Public from the No Action Alternative at Six Hypothetical Sites in the United

States 4-43

Total Spent Nuclear Fuel and Wastes Generated by the No

Action Alternative (50 Years of Implementation)... $4-46$

Normal Operation Radiological Impacts to the Public from Fast

Reactor Recycle Alternative Facilities at Six Hypothetical Locations in the United States

Total Spent Nuclear Fuel and Wastes Generated by the Fast

Reactor Recycle Alternative (50 Years of Implementation)................. 4-54

Total Number of Radiological Shipments for 50 Years of

Implementation, Fast Reactor Recycle Alternative

Handling Impacts for 50 Years of Implementation, Fast

Reactor Recycle Alternative (Truck Transit) - 200 Gigawatts

Electric

Handling Impacts for 50 Years of Implementation, Fast

Reactor Recycle Alternative (Truck and Rail Transit) - 200

Gigawatts Electric

In-Transit Transportation Impacts for 50 Years of

Implementation, Fast Reactor Recycle Alternative (Truck

Transit) - 200 Gigawatts Electric

In-Transit Transportation Impacts for 50 Years of

Implementation, Fast Reactor Recycle Alternative (Truck and

Rail Transit) - 200 Gigawatts Electric

Aqueous Separation Processes.

Total Spent Nuclear Fuel and Wastes Generated by the

Thermal/Fast Reactor Recycle Alternative (50 Years of

Implementation)

Total Number of Radiological Shipments for 50 Years of

Operation, Thermal/Fast Reactor Recycle Alternative

Handling Impacts for 50 Years of Operation, Thermal/Fast

Reactor Recycle Alternative (Truck Transit) - 200 Gigawatts

Electric

Handling Impacts for 50 Years of Operation, Thermal/Fast

Reactor Recycle Alternative (Truck and Rail Transit) - 200

Gigawatts Electric

In-Transit Transportation Impacts for 50 Years of Operation, Thermal/Fast Reactor Recycle Alternative (Truck Transit) -

200 Gigawatts Electric.....

In-Transit Transportation Impacts for 50 Years of Operation,

Thermal/Fast Reactor Recycle Alternative (Rail Transit) - 200

Gigawatts Electric

Total Spent Nuclear Fuel and Wastes Generated by the Thermal Reactor Recycle Alternative (Option 1) (50 Years of Implementation) 
TABLE 4.5-2

TABLE 4.5-3

TABLE 4.5-4

TABLE 4.5-5

TABLE 4.5-6

TABLE 4.5-7

TABLE 4.5-8

TABLE 4.5-9

TABLE 4.5-10

TABLE 4.5-11

TABLE 4.5-12

TABLE 4.6-1

TABLE 4.6-2

TABLE 4.6-3

TABLE 4.6-4

TABLE 4.6-5

TABLE 4.6-6
Total Number of Radiological Shipments for 50 Years of Implementation, Thermal Reactor Alternative, Option 1 .... 4-81 Handling Impacts for 50 Years of Implementation, Thermal Reactor Alternative, Option 1 (Truck Transit)-200 Gigawatts Electric

Handling Impacts for 50 Years of Implementation, Thermal Reactor Alternative, Option 1 (Truck and Rail Transit) - 200 Gigawatts Electric

In-Transit Transportation Impacts for 50 Years of Implementation, Thermal Reactor Alternative, Option 1 (Truck Transit)-200 Gigawatts Electric

In-Transit Transportation Impacts for 50 Years of Implementation, Thermal Reactor Alternative, Option 1 (Truck and Rail Transit)—200 Gigawatts Electric....

Total Spent Nuclear Fuel and Wastes Generated by the Thermal Reactor Recycle Alternative (Option 2) (50 Years of Implementation)

Total Number of Radiological Shipments for 50 Years of Implementation, Thermal Reactor Alternative, Option 2

Handling Impacts for 50 Years of Implementation, Thermal Reactor Alternative, Option 2 (Truck Transit) - 200 Gigawatts Electric

Handling Impacts for 50 Years of Implementation, Thermal Reactor Alternative, Option 2 (Truck and Rail Transit) - 200 Gigawatts Electric

In-Transit Transportation Impacts for 50 Years of Implementation, Thermal Reactor Alternative, Option 2 (Truck Transit) - 200 Gigawatts Electric

In-Transit Transportation Impacts for 50 Years of Implementation, Thermal Reactor Alternative, Option 2 (Truck and Rail Transit) - 200 Gigawatts Electric....

Total Spent Nuclear Fuel and Wastes Generated by the Thorium Alternative (50 Years of Implementation)

Plutonium Produced in Uranium-Fueled Light Water Reactor Versus Thorium-Fueled

Total Number of Radiological Shipments for 50 Years of Operation, Thorium Alternative.

Handling Impacts for 50 Years of Implementation, Thorium 4-101 Alternative (Truck Transit)_-200 Gigawatts Electric Alternative (Truck and Rail Transit) - 200 Gigawatts Electric In-Transit Transportation Impacts for 50 Years of Implementation, Thorium Alternative (Truck Transit)—200 Gigawatts Electric 
TABLE 4.6-7

TABLE 4.7-1

TABLE 4.7-2

TABLE 4.7-3

TABLE 4.7-4

TABLE 4.7-5

TABLE 4.7-6

TABLE 4.7-7

TABLE 4.7-8

TABLE 4.7-9

TABLE 4.7-10

TABLE 4.7-11

TABLE 4.7-12

TABLE 4.7-13

TABLE 4.8-1

TABLE 4.8-2

TABLE 4.8-3
In-Transit Transportation Impacts for 50 Years of Implementation, Thorium Alternative (Truck and Rail Transit) - 200 Gigawatts Electric

Normal Operation Radiological Impacts to the Public from Tritium Releases for a Typical Heavy Water Reactor at Six Hypothetical Sites in the United States.

Total Spent Nuclear Fuel and Wastes Generated by the AllHeavy Water Reactors Option (50 Years of Implementation).

Total Number of Radiological Shipments for 50 Years of Implementation, All-Heavy Water Reactors Option

Handling Impacts for 50 Years of Implementation, All-Heavy Water Reactors Option (Truck Transit)-200 Gigawatts Electric

Handling Impacts for 50 Years of Implementation, All-Heavy Water Reactors Option (Truck and Rail Transit)-200 Gigawatts Electric.....

In-Transit Transportation Impacts for 50 Years of Implementation, All-Heavy Water Reactors Option (Truck Transit)-200 Gigawatts Electric

In-Transit Transportation Impacts for 50 Years of Implementation, All-Heavy Water Reactors Option (Truck and Rail Transit) - 200 Gigawatts Electric.

Total Spent Nuclear Fuel and Wastes Generated by the AllHigh Temperature Gas-Cooled Reactors Option (50 years of Implementation).

Total Number of Radiological Shipments for 50 Years of Implementation, All-High Temperature Gas-Cooled Reactors Option

Handling Impacts for 50 Years of Implementation, All-High Temperature Gas-Cooled Reactors Option (Truck Transit) 200 Gigawatts of Electric.

Handling Impacts for 50 Years of Implementation, All-High Temperature Gas-Cooled Reactors Option (Truck and Rail Transit)_-200 Gigawatts Electric

In-Transit Transportation Impacts for 50 Years of Implementation, All-High Temperature Gas-Cooled Reactors Option (Truck Transit) - 200 Gigawatts Electric

In-Transit Transportation Impacts for 50 Years of Implementation, All-High Temperature Gas-Cooled Reactors Option (Truck and Rail Transit) -200 Gigawatts Electric.

Comparative Summary of Programmatic Alternatives - SteadyState 200 Gigawatts Electric Scenario.

Comparative Summary of Programmatic Alternatives - Steady-

State 400 Gigawatts Electric Scenario

Comparative Summary of Programmatic Alternatives-Steady-

State 150 Gigawatts Electric Scenario. 4-134 
TABLE 4.8-4

TABLE 4.8-5

TABLE 4.8-6

TABLE 4.8-7

TABLE $4.8-8$

TABLE 4.8-8a

TABLE 4.8-9

TABLE 4.8-10

TABLE 4.8-11

TABLE 4.8-12

TABLE 4.8-13

TABLE 4.8-14

TABLE 5.1.2-1

TABLE 5.1.3-1

TABLE 5.2.3-1

TABLE 5.2.4-1

TABLE 6.3.1-1

TABLE 6.3.1-2

TABLE 7.2.1.2-1

TABLE 7.2.1.3-1

TABLE 7.2.1.3-2

TABLE 7.2.1.5-1

TABLE 7.2.1.6-1
Comparative Summary of Programmatic Alternatives-Steady-

State 100 Gigawatts Electric Scenario

Comparison of Domestic Programmatic Alternatives for 200

GWe (Annual Impacts at Steady-State Endpoint)

Comparison of Programmatic Alternatives for $200 \mathrm{GWe}$

(Cumulative Impacts, 50 Years of Implementation).

Annual Impacts to Workers for Domestic Programmatic

Alternatives

Highest Internally Initiated Accident Consequences and Risks

for Facilities Assessed (Site 6).....

Summary of Bounding Intentional Destructive Acts Scenarios .......... 4-146

Total Number of Shipments (50 years of Implementation),

Truck Transit (200 Gigawatts Electric)

Total Number of Shipments (50 years of Implementation),

Truck and Rail Transport (200 Gigawatts Electric).

Summary of Handling Impacts for 50 Years of Implementation, All Programmatic Domestic Alternatives (Truck Transit) - 200 Gigawatts Electric

Summary of Handling Impacts for 50 Years of Implementation, All Programmatic Domestic Alternatives (Truck and Rail Transit)—200 Gigawatts Electric

Summary of In-Transit Transportation Impacts for 50 Years of Implementation, All Programmatic Domestic Alternatives (Truck Transit) - 200 Gigawatts Electric

Summary of In-Transit Transportation Impacts for 50 Years of Implementation, All Programmatic Domestic Alternatives (Truck and Rail Transit)-200 Gigawatts Electric. $4-152$

Reasonably Foreseeable Future Actions in the United States .................. 5-3

Projected Future United States Population ............................................... 5-4

Cumulative Impacts of Radioactive Waste Generation ........................... 5-8

Potential Cumulative Transportation Impacts ...................................... 5-10

Major Federal Requirements and Executive Orders with

Respect to Environmental Control Remediation and Worker

Safety Arranged by Topic.

Selected Department of Energy Directives. 6-14

Impacts of Shipping Fresh Fuel Assemblies from Manufacturer to a Port by Truck.

Impacts During Loading and Inspection at the Ports for 24

MTHM of Fresh Fuel.

Impacts During Voyage Between the Ports for 24 MTHM

of Fresh Fuel-31-Day Voyage.

Impacts of Transporting Spent Nuclear Fuel Casks from

Foreign Nation Back to a United States Port-31-Day

Voyage

Impacts During Loading and Inspection at a United States

Port for 22 MTHM of Spent Nuclear Fuel. 7-16 
TABLE 7.2.1.7-1 Impacts of Shipping Spent Nuclear Fuel Casks from a United States Port of Entry to a Recycling Center by Truck,

Rail, or Barge. $7-16$

TABLE 7.2.1.10.2-1 Consequences Resulting from the Loss at Sea of a Rail Transportation Cask Containing Spent Nuclear Fuel ......................... 7-18

TABLE 7.2.2-1

Potential Differences Among the Domestic Programmatic

Alternatives Related to Disposition of Foreign Reactor

TABLE A.3.2-1

Spent Nuclear Fuel.

World Thorium Reserves ........................................................... A-10

TABLE A.3.2.2-1

TABLE A.5.1-1

Summary of Commercial Fuel Fabrication Facilities

Uranium Reduction and Extraction Separations Processes . A-33

TABLE A.6.1.1-1

Maximum Number of Spent Nuclear Fuel Assemblies

Processed Annually.....

TABLE A.6.1.2-1

TABLE A.6.1.3-1

Light Water Reactor Spent Nuclear Fuel Recycling Facility

Building Footprint Based on Representative Technology.

Estimates of Fuel Processing Materials and Wastes from

Light Water Reactor Spent Nuclear Fuel Recycling Facility

Operations 100 Metric Tons Heavy Metal/Year Facility ...

TABLE A.6.1.3-2

Estimates of Fuel Processing Materials and Wastes from

Light Water Reactor Spent Nuclear Fuel Recycling Facility

Operations 800 Metric Tons Heavy Metal/Year Facility

TABLE A.6.1.3-3

Estimates of Wastes from Light Water Reactor Spent

Nuclear Fuel Recycling Facility Operations.

TABLE A.6.1.3-4

Summary of Light Water Reactor Spent Nuclear Fuel

Recycling Facility Operations Data Based on

Representative Technology....

A-45

TABLE A.6.2-1

United States Light Water Reactor Fuel Fabrication

Capacity

TABLE A.6.2.2-1

Transmutation Fuel Fabrication Facility Building Size

Details

TABLE A.6.2.3-1

Estimates of Fuel Processing Materials and Wastes from

Transmutation Fuel Fabrication Operations 100 Metric

Tons Heavy Metal/Year Facility.

TABLE A.6.2.3-2

Estimates of Wastes from Transmutation Fuel Fabrication

Operations.....

TABLE A.6.3.1-1 Fast Reactor Spent Nuclear Fuel Recycling Facility

Inventory of Nuclear Materials for Defining the Operations

Basis

TABLE A.6.3.2-1

Fast Reactor Spent Nuclear Fuel Recycling Facility

Building Size Details....

TABLE A.6.3.3-1 Estimates of Fuel Processing Materials and Wastes from

Fast Reactor Spent Nuclear Fuel Separations Operations

(100 Metric Tons Heavy Metal/Year Facility)

TABLE A.6.3.3-2 Estimates of Wastes from Fast Reactor Spent Nuclear Fuel

Separations Operations 
TABLE A.7-1

TABLE A.8-1

TABLE A.9.7.2-1

TABLE B.2.1.1-1

TABLE B.2.1.2-1

TABLE B.2.2.1-1

TABLE B. 2.2.2-1

TABLE B.2.3.1-1

TABLE B.2.6.1-1

TABLE B. 2.6.2-1

TABLE B.3.1-1

TABLE B.3.1-2

TABLE B.3.2-1

TABLE C.6.1.1-1

TABLE C.6.1.2-1

TABLE D.1.1-1

TABLE D.1.3-1

TABLE D.1.4-1

TABLE D.1.5.1-1

TABLE D.1.6-1

TABLE D.2.1.1-1

TABLE D.2.1.1-2

TABLE D.2.1.1-3

TABLE D.2.1.1-4
Programmatic Environmental Impact Statement

Alternatives Indicating Assumed Reactor Mixes and Fuel

Burnup Levels A-52

Operating Licenses of United States Light Water Reactors ................ A-55

Fiscal Year 2008 Forecasted Volume of Radioactive Waste............... A-85

Potential Consequences - Intentional Destructive Acts for a Low

Enriched Uranium Fueled Light Water Reactor

Potential Consequences - Intentional Destructive Acts for a Low

Enriched Uranium Fueled Advanced Light Water Reactor.

Potential Consequences - Intentional Destructive Acts at a Nuclear

Fuel Recycling Center......

Potential Consequences - Intentional Destructive Acts at an

Advanced Recycling Reactor.

Potential Consequences -Intentional Destructive Acts for a Mixed

Oxide-Uranium-Plutonium Light Water Reactor

Potential Consequences - Intentional Destructive Acts at a Heavy

Water Reactor

Potential Consequences - Intentional Destructive Acts at a High

Temperature Gas-Cooled Reactor.

Radionuclide Inventories for Commercial Spent Nuclear Fuel

Shipped in Rail Casks

B-13

Release Fractions for Transportation Sabotage Event

B-14

Consequences of a Radiological Transportation Sabotage Event..........B-14

Annual Worker Injury and Lost Work Day Incidences for

Construction Activities-All Domestic Programmatic

Alternatives

Annual Calculated Nonfatal Total Recordable Cases and Lost

Workdays for Operations_-All Domestic Programmatic

Alternatives

Power Level of Reactors Evaluated ............................................... D-2

Accident Frequency Categories ................................................... D-7

Release Parameters for Reactor Beyond Design Basis

Earthquakes and Aircraft Crashes.................................................... D-9

General MACCS2 Analysis Assumptions ....................................... D-12

Characteristics of Generic Sites Selected for Accident Analysis ......... D-16

Ratio of Accident Impacts for Mixed Oxide-Uranium-

Plutonium Fueled and Low Enriched Uranium Fueled Light

Water Reactors (Mixed Oxide-Uranium-Plutonium

Impacts/Low Enriched Uranium Impacts)...................................... D-18

Low Enriched Uranium Fueled Light Water Reactor Accident

Risks to the Offsite Population (All Sites).

D-19

Low Enriched Uranium Fueled Light Water Reactor Accident

Risks to the Maximally Exposed Individual

(All Sites)....

Low Enriched Uranium Fueled Light Water Reactor Accident

Risks to the Noninvolved Worker (All Sites). D-21 
TABLE D.2.1.1-5

TABLE D.2.1.1-6

TABLE D.2.1.1-7

TABLE D.2.1.2-1

TABLE D.2.1.2-2

TABLE D.2.1.2-3

TABLE D.2.1.2-4

TABLE D.2.1.2-5

TABLE D.2.1.2-6

TABLE D.2.1.2-7

TABLE D.2.2.1.2-1

TABLE D.2.2.1.2-2

TABLE D.2.2.1.2-3

TABLE D.2.2.1.2-4

TABLE D.2.2.1.2-5

TABLE D.2.2.1.2-6

TABLE D.2.2.1.3-1
Low Enriched Uranium Fueled Light Water Reactor Accident Health Consequences (Dose in Person-Rem/Increased Number of Latent Cancer Fatalities) to the Offsite Population (All Sites) Low Enriched Uranium Fueled Light Water Reactor Accident Health Consequences (Dose in Rem/Increased Likelihood of a Latent Cancer Fatality) to the Maximally Exposed Individual (All Sites).

Low Enriched Uranium Fueled Light Water Reactor Accident Health Consequences (Dose in Rem/Increased Likelihood of a Latent Cancer Fatality) to the Noninvolved Worker (All Sites)........... D-24 Low Enriched Uranium Fueled Advanced Light Water Reactor Accident Release Parameters for Accidents

Low Enriched Uranium Fueled Advanced Light Water Reactor Accident Risks to the Offsite Population (All Sites)

Low Enriched Uranium Fueled Advanced Light Water Reactor

Accident Risks to the Maximally Exposed Individual (All Sites)

Low Enriched Uranium Fueled Advanced Light Water Reactor

Accident Risks to the Noninvolved Worker

(All Sites).

Low Enriched Uranium Fueled Advanced Light Water Reactor

Accident Health Consequences (Dose in Person-Rem/Increased

Number of Latent Cancer Fatalities) to the Offsite Population

(All Sites).

Low Enriched Uranium Fueled Advanced Light Water Reactor

Accident Health Consequences (Dose in Rem/Increased

Likelihood of a Latent Cancer Fatality) to the Maximally

Exposed Individual (All Sites).

Low Enriched Uranium Fueled Advanced Light Water Reactor

Accident Health Consequences (Dose in Rem/Increased

Likelihood of a Latent Cancer Fatality) to the Noninvolved

Worker (All Sites)......

Nuclear Fuel Recycling Center Accidents Selected for Analysis........ D-36

Nuclear Fuel Recycling Center Release Parameters for the Fuel

Handling Accident

Nuclear Fuel Recycling Center Release Parameters for the

Aqueous Separations Explosion and Fire Accident.

Nuclear Fuel Recycling Center Release Parameters for the

Beyond Design Basis Earthquake Accident

Nuclear Fuel Recycling Center Release Parameters for the

Nuclear Criticality Accident

Nuclear Fuel Recycling Center Release Parameters for the

Aircraft Crash Accident ....

Nuclear Fuel Recycling Center Accident Risks to the Offsite

Population (All Sites). D-43 
TABLE D.2.2.1.3-2 Nuclear Fuel Recycling Center Accident Risks to the

Maximally Exposed Individual (All Sites)

D-44

TABLE D.2.2.1.3-3 Nuclear Fuel Recycling Center Accident Risks to the

Noninvolved Worker (All Sites)

TABLE D.2.2.1.3-4 Nuclear Fuel Recycling Center Accident Health Consequences

(Dose in Person-Rem/Increased Number of Latent Cancer

Fatalities) to the Offsite Population (All Sites).

TABLE D.2.2.1.3-5 Nuclear Fuel Recycling Center Accident Health Consequences

(Dose in Rem/Increased Likelihood of a Latent Cancer

Fatality) to the Maximally Exposed Individual (All Sites)....

TABLE D.2.2.1.3-6

Nuclear Fuel Recycling Center Accident Health Consequences

(Dose in Rem/Increased Likelihood of a Latent Cancer

Fatality) to the Noninvolved Worker (All Sites)

TABLE D.2.2.1.3-7

Nuclear Fuel Recycling Center Nitric Acid Spill Impacts.

TABLE D.2.2.2.1-1

Fast Reactors - United States and Foreign

TABLE D.2.2.2.1-2

Documents Reviewed for Accident Related Information for

Fast Reactors.

D-52

TABLE D.2.2.2.2-1

Advanced Recycling Reactor Accidents Selected for Analysis

D-53

TABLE D.2.2.2.2-2

Advanced Recycling Reactor Release Parameters for the

Turbine Trip Event

D-55

TABLE D.2.2.2.2-3

Advanced Recycling Reactor Release Parameters for the Spent

Fuel Cladding Failure in the Ex-Vessel Transfer Machine

Event (FH-2)

TABLE D.2.2.2.2-4

Advanced Recycling Reactor Release Parameters for the Cover

Gas Released During Refueling Event (RF-2)....

TABLE D.2.2.2.2-5 Advanced Recycling Reactor Release Parameters for the

Failure of Ex-Containment Primary Sodium Tank (SP-2)

D-58

TABLE D.2.2.2.2-6

Advanced Recycling Reactor Release Parameters for the

Failure of Ex-Vessel Shortage Tank Sodium Cooling System

During Operation (SE-1).

TABLE D.2.2.2.2-7 Advanced Recycling Reactor Release Parameters Intermediate Heat Transport System Piping Leak (SI-1).

TABLE D.2.2.2.2-8 Advanced Recycling Reactor Release Parameters for the

Rupture of the Radioactive Argon Processing System Cold Box (CG-1)

TABLE D.2.2.2.2-9 Advanced Recycling Reactor Release Parameters for the Beyond Design Basis Earthquake

TABLE D.2.2.2.2-10 Advanced Recycling Reactor Release Parameters for the

Beyond Design Basis Aircraft Crash

TABLE D.2.2.2.3-1 Advanced Recycling Reactor Accident Risks to the Offsite

Population (All Sites)... D-64

TABLE D.2.2.2.3-2 Advanced Recycling Reactor Accident Risks to the Maximally Exposed Individual (All Sites).

TABLE D.2.2.2.3-3

Advanced Recycling Reactor Accident Risks to the

Noninvolved Worker (All Sites) D-66 
TABLE D.2.2.2.3-4 Advanced Recycling Reactor Accident Health Consequences (Dose in Person-Rem/Increased Number of Latent Cancer Fatalities) to the Offsite Population (All Sites).

TABLE D.2.2.2.3-5 Advanced Recycling Reactor Accident Health Consequences

(Dose in Rem/Increased Likelihood of a Latent Cancer

Fatality) to the Maximally Exposed Individual (All Sites)

TABLE D.2.2.2.3-6 Advanced Recycling Reactor Accident Health Consequences

(Dose in Rem/Increased Likelihood of a Latent Cancer

Fatality) to the Noninvolved Worker (All Sites)

TABLE D.2.3.1-1 Release Parameters for Mixed Oxide-Uranium-Plutonium

Fueled Light Water Reactor Accidents

TABLE D.2.3.1-2 Mixed Oxide-Uranium-Plutonium Fueled Light Water Reactor Accident Risks to the Offsite Population (All Sites)

TABLE D.2.3.1-3 Mixed Oxide-Uranium-Plutonium Fueled Light Water Reactor

Accident Risks to the Maximally Exposed Individual (All

Sites)

TABLE D.2.3.1-4 Mixed Oxide-Uranium-Plutonium Fueled Light Water Reactor

Accident Risks to the Noninvolved Worker

(All Sites).

TABLE D.2.3.1-5 Mixed Oxide-Uranium-Plutonium Fueled Light Water Reactor

Accident Health Consequences (Dose in Person-Rem /

Increased Number of Latent Cancer Fatalities) to the Offsite Population (All Sites)

TABLE D.2.3.1-6 Mixed Oxide-Uranium-Plutonium Fueled Light Water Reactor

Accident Health Consequences (Dose in Rem/Increased

Likelihood of a Latent Cancer Fatality) to the Maximally

Exposed Individual (All Sites)

TABLE D.2.3.1-7 Mixed Oxide-Uranium-Plutonium Fueled Light Water Reactor

Accident Health Consequences (Dose in Rem/Increased

Likelihood of a Latent Cancer Fatality) to the Noninvolved

Worker (All Sites)

D-77

TABLE D.2.6.1-1

Release Parameters for Heavy Water Reactor Accidents

TABLE D.2.6.1-2

Heavy Water Reactor Accident Risks to the Offsite Population

(All Sites)

TABLE D.2.6.1-3 Heavy Water Reactor Accident Risks to the Maximally

Exposed Individual (All Sites)...

TABLE D.2.6.1-4

Heavy Water Reactor Accident Risks to the Noninvolved

Worker (All Sites)

TABLE D.2.6.1-5 Heavy Water Reactor Accident Health Consequences (Dose in

Person-Rem/Increased Number of Latent Cancer Fatalities) to the Offsite Population (All Sites)

TABLE D.2.6.1-6

Heavy Water Reactor Accident Health Consequences (Dose in

Rem/Increased Likelihood of a Latent Cancer Fatality) to the

Maximally Exposed Individual (All Sites) 
TABLE D.2.6.1-7

TABLE D.2.6.2-1

TABLE D.2.6.2-2

TABLE D.2.6.2-3

TABLE D.2.6.2-4

TABLE D.2.6.2-5

TABLE D.2.6.2-6

TABLE D.2.6.2-7

TABLE E.1.8-1

TABLE E.1.9.3-1

TABLE E.2.1-1

TABLE E.2.2.1-1

TABLE E.2.2.2-1

TABLE E.2.2.2-2

TABLE E.2.2.2-3

TABLE E.2.3-1

TABLE E.2.4-1

TABLE E.2.4-2

TABLE E.2.4-3

TABLE E.2.4-4
Heavy Water Reactor Accident Health Consequences

(Dose in Rem/Increased Likelihood of a Latent Cancer

Fatality) to the Noninvolved Worker (All Sites) ...

D-90

Accidents

Offsite Population (All Sites).

Maximally Exposed Individual (All Sites) .

Noninvolved Worker (All Sites).

High Temperature Gas-Cooled Reactor Accident Health

Consequences (Dose in Person-Rem / Increased Number of

Latent Cancer Fatalities) to the Offsite Population (All Sites).....

High Temperature Gas-Cooled Reactor Accident Health

Consequences (Dose in Rem/Increased Likelihood of a Latent

Cancer Fatality) to the Maximally Exposed Individual (All

Sites)

High Temperature Gas-Cooled Reactor Accident Health

Consequences (Dose in Rem/Increased Likelihood of a Latent

Cancer Fatality) to the Noninvolved Worker (All Sites)....

RADTRAN Suggested Vehicle Speeds

Population Density in Urban Areas E-14

Summary of Routing Inputs for Generic Domestic

Programmatic Alternatives Analysis

Nuclide Inventories of the Programmatic Alternative Nuclear

Fuels

Transportation Containers for Analyzed Shipments by Material

Type

Number of Shipments per Material Type-All-Truck

Scenario-200 Gigawatts Electric

Number of Shipments per Material Type-All-Rail Scenario-

200 Gigawatts Electric.

Per-Shipment Loading Parameters for Domestic Programmatic

Alternatives .

Per-Shipment Radiological Exposure Handling Impacts and Impacts at Stops - Domestic Programmatic Alternative Scenarios-Spent Nuclear Fuel-All-Truck Option....

Per-Shipment In-Transit Incident-Free Impacts-Domestic

Programmatic Alternative Scenarios-Spent Nuclear Fuel-

All-Truck Option

Per-Shipment Loading Impacts Associated with Thermal/Fast

Reactor Recycle Alternative-All-Truck Option

Per-Shipment Incident-Free In-Transit Impacts-Thermal/Fast

Reactor Recycle Alternative-All-Truck Option 
TABLE E.2.4-5

TABLE E.2.4-6

TABLE E.2.4-7

TABLE E.2.4-8

TABLE E.2.4-9

TABLE E.2.4-10

TABLE E.2.4-11

TABLE E.2.5-1

TABLE E.2.5-2

TABLE E.2.5-3

TABLE E.2.5-4

TABLE E.2.5-5

TABLE E.2.5-6

TABLE E.2.5-7

TABLE E.2.5-8

TABLE E.2.5-9

TABLE E.2.5-10

TABLE E.2.5-11
Per-Shipment Radiological Exposure Handling Impacts and Impacts at Stops - Domestic Programmatic Alternative Scenarios-Spent Nuclear Fuel-All-Rail Option

Per-Shipment Incident-Free In-Transit Impacts_-Domestic

Programmatic Alternative Scenarios-Spent Nuclear Fuel-

All-Rail Option

Per-Shipment Loading Impacts Associated with Thermal/Fast

Reactor Recycle Alternative-All-Rail Option

Per-Shipment Incident-Free In-Transit Impacts-Thermal/Fast

Reactor Recycle Alternative-All-Rail Option

Per-Shipment Incident-Free Radiation Doses to Escorts-Spent

Nuclear Fuel Shipments of Spent Nuclear Fuel and Fresh

Transmutation Fuel—Domestic Programmatic Alternatives....

Per-Shipment Incident-Free Radiation Doses to Escorts-Fresh

MOX Fuel Shipments-Domestic Programmatic Alternatives

Per-Shipment Nonradiological Impacts to General Population

due to Escort Vehicle Traffic_-Fresh and Spent Nuclear Fuel

Shipments - Domestic Programmatic Alternatives .

Conditional Probabilities and Release Fractions for Light

Water Reactor, Mixed-Oxide, and Thorium Cycle Spent

Nuclear Fuel Shipments-Truck Cask

Conditional Probabilities and Release Fractions for Heavy

Water Reactor Spent Nuclear Fuel Shipments-Truck Cask

Conditional Probabilities and Release Fractions for High

Temperature Gas-Cooled Reactor Spent Nuclear Fuel

Shipments-Truck Cask

Conditional Probabilities and Release Fractions for Light

Water Reactor Spent Nuclear Fuel, Mixed-Oxide Spent

Nuclear Fuel, and Thorium Cycle Spent Nuclear Fuel

Shipments-Rail Cask

Conditional Probabilities and Release Fractions for Heavy

Water Reactor Spent Nuclear Fuel Shipments-Rail Cask.

Conditional Probabilities and Release Fractions for High

Temperature Gas-Cooled Reactor Spent Nuclear Fuel

Shipments-Rail Cask....

Conditional Probabilities and Release Fractions for High-Level

Radioactive Waste Canister Shipments .

Conditional Probabilities and Release Fractions for 9975

Container Shipments

Conditional Probabilities and Release Fractions for Class B

Cask for Fresh MOX Fuel.

Per-Shipment Accident Impacts-Domestic Programmatic

Alternative Scenarios-All-Truck Option.

Per-Shipment Accident Impacts-Domestic Programmatic

Alternative Scenarios-All-Rail Option. 
TABLE E.2.5-12 Maximum Reasonably Foreseeable Accident Impacts-

Domestic Programmatic Alternatives …………………………….......

TABLE E.4-1 Summary of Transportation Analysis Assumptions ...............................

TABLE H.2-1 Scoping Comment Categories.................................................................. H-4 


\section{ACRONYMS AND ABBREVIATIONS}

AEI

AFCF

AFCI

AGR

AHWR

ALARA

ALWR

ANL

ANOI

ARF

ARR

ATR

BWR

CANDU

CERCLA

CEQ

CFR

CMR

COEX

$\mathrm{CR}$

CRBR

CRBRP

CWA

D\&D

$\mathrm{dBA}$

DOD

DOE

DOT

DU
Advanced Energy Initiative

Advanced Fuel Cycle Facility

Advanced Fuel Cycle Initiative

Advanced Gas-Cooled Reactor

Advanced Heavy Water Reactor

As Low As Reasonably Achievable

Advanced Light Water Reactor

Argonne National Laboratory

Advance Notice of Intent

Airborne Release Fractions

Advanced Recycling Reactor

Advanced Test Reactor

Boiling Water Reactor

Canada Deuterium Uranium

Comprehensive Environmental Response, Compensation, and Liability Act

Council on Environmental Quality

Code of Federal Regulations

Chemistry and Metallurgical Research

Coextraction

Conversion Ratio

Clinch River Breeder Reactor

Clinch River Breeder Reactor Plant

Clean Water Act

Decontamination and Decommissioning

A Weighted Decibels

U.S. Department of Defense

U.S. Department of Energy

U.S. Department of Transportation

Depleted Uranium 


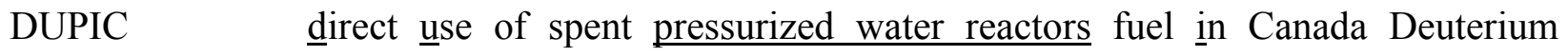
Uranium

EA Environmental Assessment

EAS Engineering Alternative Studies

EBR Experimental Breeder Reactor

EDE $\quad$ Effective Dose Equivalent

EIS Environmental Impact Statement

EOI Expression of Interest

EPA U.S. Environmental Protection Agency

ERDA Energy Research and Development Administration

ERPG Emergency Response Planning Guideline

ETTP East Tennessee Technology Park

FBTR Fast Breeder Test Reactor

FEMA Federal Emergency Management Agency

FFTF Fast Flux Test Facility

FMEF Fuels and Materials Examination Facility

FMF Fuel Manufacturing Facility

FOA Funding Opportunity Announcement

FONSI Finding of No Significant Impact

FPR Fuel Processing Restoration

FR Federal Register

FY Fiscal Year

GE General Electric

GNEP Global Nuclear Energy Partnership

GTCC Greater-than-Class-C

GWe gigawatt-electric

HEPA High-Efficiency Particulate Air (Filter)

HEU High Enriched Uranium

HF Hydrofluoric Acid

HLW High-Level Radioactive Waste

HP Health Physics Technician 
HTGR

HTTR

HVAC

HWR

IAEA

INEEL

INL

INTEC

KAERI

LANL

LANSCE

LCF

LTAs

LEU

LLNL

LLW

LMFBR

LWR

LOC

MCL

MEI

MFC

MHTGR

MLLW

MMI

MOX

MOX-TRU

MOX-U-Pu

MSBR
High Temperature Gas-Cooled Reactor

High Temperature Engineering Test Reactor

Heating, Ventilating and Air Conditioning

Heavy Water Reactor

International Atomic Energy Agency

Idaho National Engineering and Environmental Laboratory

Idaho National Laboratory (Formerly Idaho National Engineering and Environmental Laboratory)

Idaho Nuclear Technology and Engineering Center

Korea Atomic Energy Research Institute

Los Alamos National Laboratory

Los Alamos Neutron Science Center

Latent Cancer Fatality

Lead Test Assemblies

Low Enriched Uranium

Lawrence Livermore National Laboratory

Low-Level Waste

Liquid Metal Cooled Fast Breeder Reactor

Light Water Reactor

Level-of-Concern

Maximum Contaminant Level

Maximally Exposed Individual

Materials and Fuels Complex

Module High Temperature Gas Reactor

Mixed Low Level Waste

Modified Mercalli Intensity

Mixed-oxide

Mixed-oxide fuel made up of uranium and transuranics

Mixed-oxide fuel in which pure plutonium is not separated out from the uranium

Molten Salt Breeder Reactor 
MSR

MTHM

NAAQS

NE

NEPA

NERI

NESHAPs

NFS

NGNP

NHPA

NMED

NNSA

NOAA

NOI

NP-2010

NPDES

$\mathrm{NPH}$

NPIA

NRC

NRHP

NTS

NWPA

OREOX

ORNL

ORR

OSHA

PEIS

PHWR

PIDAS

$\mathrm{PM}_{10}$
Molten Salt Reactor

Metric Tons Heavy Metal

National Ambient Air Quality Standards

Office of Nuclear Energy

National Environmental Policy Act

Nuclear Energy Research Initiative

National Emission Standards for Hazardous Air Pollutants

Nuclear Fuel Services, Inc.

Next Generation Nuclear Plant

National Historic Preservation Act

New Mexico Environmental Department

National Nuclear Security Administration

National Oceanic and Atmospheric Administration

Notice of Intent

Nuclear Power - 2010

National Pollutant Discharge Elimination System

Natural-Phenomena Hazards

Nonproliferation Impact Assessment

U.S. Nuclear Regulatory Commission

National Register of Historic Places

Nevada Test Site

Nuclear Waste Policy Act

Oxidation and Reduction of Oxide Fuel

Oak Ridge National Laboratory

Oak Ridge Reservation

Occupational Safety and Health Administration

Programmatic Environmental Impact Statement

Pressurized Heavy Water Reactor

Perimeter Intrusion, Detection, and Assessment System

Particulate Matter Less Than or Equal To 10 Microns in Aerodynamic Diameter 


\begin{tabular}{|c|c|}
\hline PNNL & Pacific Northwest National Laboratory \\
\hline ppm & Parts Per Million \\
\hline PSD & Prevention of Significant Deterioration \\
\hline PSDF & Process Support and Development Facility \\
\hline PUREX & Plutonium and Uranium Recovery by Extraction \\
\hline PWR & Pressurized Water Reactor \\
\hline $\operatorname{Rad}$ & Radiation Absorbed Dose \\
\hline RCRA & Resource Conservation and Recovery Act \\
\hline PS\&D & Process Support \& Development \\
\hline REDC & Radiochemical Engineering Development Center \\
\hline Rem & Roentgen Equivalent Man \\
\hline RESRAD & RESidual RADioactivity \\
\hline $\mathrm{RF}$ & Respirable Fractions \\
\hline ROD & Record of Decision \\
\hline ROI & Region of Influence \\
\hline RTC & Reactor Technology Complex \\
\hline SEIS & Supplemental Environmental Impact Statement \\
\hline SHPO & State Historic Preservation Officer \\
\hline SNF & Spent Nuclear Fuel \\
\hline SNF EIS & Spent Nuclear Fuel Environmental Impact Statement \\
\hline SNL & Sandia National Laboratories \\
\hline SNM & Special Nuclear Materials \\
\hline SRS & Savannah River Site \\
\hline $\mathrm{SST} / \mathrm{SGT}$ & Safe, Secure Trailer/Safeguards Transports \\
\hline SWEIS & Site Wide Environmental Impact Statement \\
\hline TA & Technical Area \\
\hline TAD & Transportation, aging, and disposal canister \\
\hline TALSPEAK & $\begin{array}{l}\text { Trivalent Actinide Lanthanide Separations by Phosphorousreagent Extraction } \\
\text { from Aqueous Complexes }\end{array}$ \\
\hline TEDE & Total Effective Dose Equivalent \\
\hline $\mathrm{ThO}_{2}$ & Thorium Oxide \\
\hline
\end{tabular}


THOREX Thorium based fuel

TRAGIS Transportation Routing Analysis Geographic Information System

TRANSCOM Transportation Tracking and Communications System

TRU Transuranic

TRUEX Transuranic Extraction

TSCA Toxic substance Control Act

TVA Tennessee Valley Authority

U-233 Uranium-233

U-235 Uranium-235

UMTRCA Uranium Mill Tailings Radiation Control Act

UOX Uranium Oxide

UREX Uranium Extraction

USACE U.S. Army Corps of Engineers

U.S.C. United States Code

USEC United States Enrichment Corporation

USFWS U.S. Fish and Wildlife Service

USGS U.S. Geological Survey

VHTR Very High Temperature Reactor

VOC Volitile Organic Compound

WIPP Waste Isolation Pilot Plant

Y-12 Y-12 Plant 


\section{CHEMICALS AND UNITS OF MEASURE}

\begin{tabular}{|c|c|}
\hline Am & Americium \\
\hline $\mathrm{Ba}$ & Barium \\
\hline Btu & British Thermal Unit \\
\hline${ }^{\circ} \mathrm{C}$ & Celsius \\
\hline $\mathrm{C}$ & Carbon \\
\hline $\mathrm{Ci}$ & Curie \\
\hline $\mathrm{Cm}$ & Curium \\
\hline $\mathrm{cm}$ & centimeters \\
\hline $\mathrm{CFC}$ & Chlorofluorocarbons \\
\hline $\mathrm{Co}$ & Cobalt \\
\hline $\mathrm{CO}$ & carbon monoxide \\
\hline $\mathrm{CO}_{2}$ & carbon dioxide \\
\hline Cs & Cesium \\
\hline $\mathrm{dB}$ & Decibel \\
\hline $\mathrm{dBa}$ & Decibel A-Weighted \\
\hline DCE & 1, 2-Dichloroethylene \\
\hline DNA & Deoxyribonucleic Acid \\
\hline${ }^{\circ} \mathrm{F}$ & Fahrenheit \\
\hline $\mathrm{ft}$ & feet \\
\hline $\mathrm{ft}^{2}$ & square feet \\
\hline $\mathrm{ft}^{3}$ & cubic feet \\
\hline $\mathrm{ft}^{3} / \mathrm{s}$ & cubic feet per second \\
\hline $\mathrm{g}$ & grams \\
\hline gal & gallons \\
\hline gpm & gallons per minute \\
\hline GWe & gigawatt electric \\
\hline GWh & gigawatt hour \\
\hline $\mathrm{H}_{3}$ & Tritium \\
\hline ha & hectares \\
\hline $\mathrm{He}$ & Helium \\
\hline $\mathrm{hr}$ & hour \\
\hline I & Iodine \\
\hline in & inches \\
\hline $\mathrm{kg}$ & kilograms \\
\hline $\mathrm{km}$ & kilometers \\
\hline $\mathrm{km}^{2}$ & square kilometers \\
\hline
\end{tabular}




\begin{tabular}{|c|c|}
\hline $\mathrm{kPa}$ & kilopascals \\
\hline $\mathrm{kph}$ & kilometers per hour \\
\hline $\mathrm{kV}$ & kilovolts \\
\hline $\mathrm{kVA}$ & kilovoltampere \\
\hline $\mathrm{kW}$ & kilowatts \\
\hline $\mathrm{kWh}$ & kilowatt hours \\
\hline $\mathrm{L}$ & liter \\
\hline $\mathrm{lb}$ & pounds \\
\hline $\mathrm{Ln}$ & Lanthanide \\
\hline $\mathrm{m}$ & meters \\
\hline $\mathrm{m}^{2}$ & square meters \\
\hline $\mathrm{m}^{3}$ & cubic meters \\
\hline $\mathrm{m} / \mathrm{s}$ & meters per second \\
\hline $\mathrm{mg}$ & milligram (one-thousandth of a gram) \\
\hline $\mathrm{mg} / \mathrm{L}$ & milligrams per liter \\
\hline $\operatorname{mgd}$ & million gallons per day \\
\hline mgy & million gallons per year \\
\hline $\mathrm{mi}$ & miles \\
\hline $\mathrm{mi}^{2}$ & square miles \\
\hline $\mathrm{mph}$ & miles per hour \\
\hline mrem & millirem (one-thousandth of a rem) \\
\hline MT & metric ton \\
\hline MTHM & metric ton heavy metal \\
\hline mtpy & metric ton per year \\
\hline MVA & megavolt-ampere or million volt amps \\
\hline MWe & megawatt electric \\
\hline MWh & megawatt hour \\
\hline MWth & megawatt thermal \\
\hline $\mathrm{Nb}$ & Niobium \\
\hline $\mathrm{nCi}$ & nanocurie \\
\hline $\mathrm{Ni}$ & nickel \\
\hline $\mathrm{NO}_{2}$ & nitrogen dioxide \\
\hline $\mathrm{NO}_{\mathrm{x}}$ & nitrogen oxides \\
\hline $\mathrm{Np}$ & neptunium \\
\hline $\mathrm{O}_{3}$ & ozone \\
\hline $\mathrm{Pa}$ & Protactinium \\
\hline $\mathrm{Pb}$ & lead \\
\hline PCB & polychlorinated biphenyl \\
\hline
\end{tabular}




\begin{tabular}{|c|c|}
\hline $\mathrm{pCi}$ & picocurie (one-trillionth of a curie) \\
\hline $\mathrm{pCi} / \mathrm{L}$ & picocuries per liter \\
\hline PEG & polyethylene glycol \\
\hline $\mathrm{PM}_{10}$ & particulate matter (less than 10 microns in diameter) \\
\hline $\mathrm{PM}_{2.5}$ & particulate matter (less than 2.5 microns in diameter) \\
\hline $\mathrm{ppb}$ & parts per billion \\
\hline ppm & parts per million \\
\hline psi & pounds per square inch \\
\hline $\mathrm{Pu}$ & Plutonium \\
\hline $\mathrm{Rb}$ & Rubidium \\
\hline rem & roentgen equivalent man \\
\hline $\mathrm{Ru}$ & Ruthenium \\
\hline $\mathrm{s}$ & seconds \\
\hline $\operatorname{scf}$ & standard cubic feet \\
\hline $\mathrm{SO}_{2}$ & sulfur dioxide \\
\hline $\mathrm{Sr}$ & strontium \\
\hline $\mathrm{T}$ & short ton \\
\hline $\mathrm{Tc}$ & Technetium \\
\hline Th & Thorium \\
\hline TCA & 1,1,1-Trichloroethane \\
\hline TCE & Trichloroethylene \\
\hline tpy & tons per year \\
\hline $\mathrm{U}$ & Uranium \\
\hline $\mathrm{UO}_{3}$ & Uranium Trioxide \\
\hline $\mathrm{yd}^{3}$ & cubic yards \\
\hline $\mathrm{yr}$ & year \\
\hline $\mathrm{ZnO}$ & zinc oxide \\
\hline $\mathrm{Zr}$ & Zirconium or Zircaloy (When an Alloy) \\
\hline$\mu \mathrm{Ci}$ & microcurie (one-millionth of a curie) \\
\hline$\mu \mathrm{Ci} / \mathrm{g}$ & microcuries per gram \\
\hline$\mu \mathrm{g}$ & microgram (one-millionth of a gram) \\
\hline$\mu \mathrm{g} / \mathrm{kg}$ & micrograms per kilogram \\
\hline$\mu \mathrm{g} / \mathrm{L}$ & micrograms per liter \\
\hline$\mu \mathrm{g} / \mathrm{m}^{3}$ & micrograms per cubic meter \\
\hline
\end{tabular}




\section{CONVERSION CHART}

\begin{tabular}{|c|c|c|c|c|c|}
\hline \multicolumn{3}{|c|}{ To Convert Into Metric } & \multicolumn{3}{|c|}{ To Convert Into English } \\
\hline If You Know & Multiply By & To Get & If You Know & Multiply By & To Get \\
\hline \multicolumn{6}{|l|}{ Length } \\
\hline Inch & 2.54 & Centimeter & Centimeter & 0.3937 & Inch \\
\hline Feet & 30.48 & Centimeter & Centimeter & 0.0328 & Feet \\
\hline Feet & 0.3048 & Meter & Meter & 3.281 & Feet \\
\hline Yard & 0.9144 & Meter & Meter & 1.0936 & Yard \\
\hline Mile & 1.60934 & Kilometer & Kilometer & 0.62414 & Mile \\
\hline \multicolumn{6}{|l|}{ Area } \\
\hline Square Inch & 6.4516 & Square Centimeter & Square Centimeter & 0.155 & Square Inch \\
\hline Square Feet & 0.092903 & Square Meter & Square Meter & 10.7639 & Square Feet \\
\hline Square Yard & 0.8361 & Square Meter & Square Meter & 1.196 & Square Yard \\
\hline Acre & 0.40469 & Hectare & Hectare & 2.471 & Acre \\
\hline Square Mile & 2.58999 & Square Kilometer & Square Kilometer & 0.3861 & Square Mile \\
\hline \multicolumn{6}{|l|}{ Volume } \\
\hline Fluid Ounce & 29.574 & Milliliter & Milliliter & 0.0338 & Fluid Ounce \\
\hline Gallon & 3.7854 & Liter & Liter & 0.26417 & Gallon \\
\hline Cubic Feet & 0.028317 & Cubic Meter & Cubic Meter & 35.315 & Cubic Feet \\
\hline Cubic Yard & 0.76455 & Cubic Meter & Cubic Meter & 1.308 & Cubic Yard \\
\hline \multicolumn{6}{|l|}{ Weight } \\
\hline Ounce & 28.3495 & Gram & Gram & 0.03527 & Ounce \\
\hline Pound & 0.45360 & Kilogram & Kilogram & 2.2046 & Pound \\
\hline Short Ton & 0.90718 & Metric Ton & Metric Ton & 1.1023 & Short Ton \\
\hline \multicolumn{6}{|l|}{ Force } \\
\hline Dyne & 0.00001 & Newton & Newton & 100,000 & Dyne \\
\hline \multicolumn{6}{|l|}{ Temperature } \\
\hline Fahrenheit & $\begin{array}{l}\text { Subtract } 32 \\
\text { Then } \\
\text { Multiply By } \\
\text { 5/9ths }\end{array}$ & Celsius & Celsius & $\begin{array}{l}\text { Multiply By } \\
\text { 9/5ths, Then } \\
\text { Add } 32\end{array}$ & Fahrenheit \\
\hline
\end{tabular}




\section{METRIC PREFIXES}

\begin{tabular}{llll}
\hline \multicolumn{1}{c}{ Prefix } & Symbol & \multicolumn{1}{c}{ Multiplication Factor } \\
\hline exa- & $\mathrm{E}$ & 1000000000000000000 & $=10^{18}$ \\
peta- & $\mathrm{P}$ & 1000000000000000 & $=10^{15}$ \\
tera- & $\mathrm{T}$ & 1000000000000 & $=10^{12}$ \\
giga- & $\mathrm{G}$ & 1000000000 & $=10^{9}$ \\
mega- & $\mathrm{M}$ & 1000000 & $=10^{6}$ \\
kilo- & $\mathrm{k}$ & 1000 & $=10^{3}$ \\
hecto- & $\mathrm{h}$ & 100 & $=10^{2}$ \\
deka- & $\mathrm{da}$ & 10 & $=10^{1}$ \\
deci- & $\mathrm{d}$ & 0.1 & $=10^{-1}$ \\
centi- & $\mathrm{c}$ & 0.01 & $=10^{-2}$ \\
milli- & $\mathrm{m}$ & 0.001 & $=10^{-3}$ \\
micro- & $\mu$ & 0.000001 & $=10^{-6}$ \\
nano- & $\mathrm{n}$ & 0.000000001 & $=10^{-9}$ \\
pico- & $\mathrm{p}$ & 0.000000000001 & $=10^{-12}$ \\
femto- & $\mathrm{f}$ & 0.000000000000001 & $=10^{-15}$ \\
atto- & $\mathrm{a}$ & 0.000000000000000001 & $=18$ \\
\hline
\end{tabular}




\title{
CHAPTER 1
}

\author{
INTRODUCTION \\ AND PURPOSE AND NEED \\ FOR AGENCY ACTION
}





\section{CHAPTER 1 \\ INTRODUCTION AND PURPOSE AND NEED FOR AGENCY ACTION}

Chapter 1 presents an overview of this Global Nuclear Energy Partnership (GNEP) Programmatic Environmental Impact Statement (PEIS). This chapter discusses the background and the need for agency action, and explains the relationship of GNEP to other programs. The chapter concludes with an overview of the public involvement process and the organization of this PEIS.

This Programmatic Environmental Impact Statement (PEIS) provides an analysis of the potential environmental impacts of the proposed Global Nuclear Energy Partnership (GNEP) program, which is a United States (U.S.) Department of Energy (DOE) program intended to support a safe, secure, and sustainable expansion of nuclear energy, both domestically and internationally. Domestically, the GNEP Program would promote technologies that support economic, sustained production of nuclear-generated electricity, while reducing the impacts associated with spent nuclear fuel ${ }^{1}$ (SNF) disposal and reducing proliferation risks. DOE envisions changing the U.S. nuclear energy fuel cycle from an open (or oncethrough) fuel cycle-in which nuclear fuel is used in a power plant one time and the resulting SNF is stored for eventual disposal in a geologic repository - to a closed fuel cycle in which SNF would be recycled ${ }^{2}$ to recover energy-bearing components for use in new nuclear fuel. Recycling would be accomplished by separating SNF into usable components and waste. The usable components would be available for use as new nuclear

Spent Nuclear Fuel

Spent nuclear fuel consists of nuclear fuel that has been withdrawn from a nuclear reactor following irradiation. Typically, no more than five percent of the fuel has been used before the nuclear fuel is considered used, or "spent," and must be replaced with fresh fuel.

\section{Nuclear Energy Fuel Cycle}

A nuclear energy fuel cycle is the series of steps from mining to waste disposal involved in the production of electricity from nuclear fuel. fuel to produce electricity and the waste components would be put into stable waste forms for storage and disposal. Internationally, the GNEP Program framework would help to ensure that nuclear power electricity generation can be expanded with reduced nuclear proliferation risk. ${ }^{3}$

\section{1}

1.1.1

\section{BACKGROUND}

\section{Global Nuclear Energy Partnership Program}

Electricity use in the U.S. is expected to continue to grow. In its most recent Energy Outlook Report, issued in June 2008, the Energy Information Administration (EIA), an independent organization within DOE, estimates that

\section{Note to Readers}

This PEIS involves a technically complex subject matter with unique concepts and terminology. To aid the readers' understanding of this PEIS, a background discussion of nuclear power concepts, technologies, and terminology is provided in Appendix A.

\footnotetext{
${ }^{1}$ Text boxes provide additional information on words that are bold-faced.

${ }^{2}$ In this PEIS, the term "recycled" is used to describe the process of reuse of portions of SNF as new reactor fuel. The process, in most cases, involves "reprocessing" SNF and recovering and using the portions of the SNF that can be used in new nuclear fuel.

${ }^{3}$ Proliferation risk relates to the potential use of the nuclear materials and technologies from the civil nuclear fuel cycle to make a nuclear weapon.
} 
demand for electricity will increase by approximately 1.1 percent annually through 2030 (EIA 2008a). An early release of that report, issued in December 2007, estimated U.S. electricity growth at 1.3 percent annually through 2030 (EIA 2007a). This Draft PEIS utilizes the higher 1.3 percent growth rate; however, in the Final PEIS, DOE will consider whether any changes to the document are warranted to account for the 1.1 percent growth rate or other relevant information that becomes available. Based on an annual growth rate of 1.3 percent, electricity use could increase by approximately 40 percent by 2030, and if that annual rate were to continue, electricity use could double (relative to use in 2004) by approximately 2060 . World electricity demand is projected to grow by 2.4 percent per year from 2000 to 2030 , nearly doubling total electricity consumption compared to $2004^{4}$ (EIA 2007e, EIA 2008b).

Nuclear energy is part of the diverse portfolio of power-generating systems that meet national and international energy demand. The use and availability of nuclear power generating systems domestically and internationally is projected to increase, causing an increase in nuclear material use, the amount of SNF, and potential proliferation risks.

As part of the President's Advanced Energy Initiative (AEI) ${ }^{5}$, the United States would work with other nations through the GNEP Program to develop and deploy advanced nuclear recycling and reactor technologies. The Initiative would help provide reliable, emission-free energy with less of the waste impact of older technologies and without making available separated plutonium that could be used by rogue states or terrorists for nuclear weapons. These new technologies would make possible a dramatic expansion of safe, clean nuclear energy to help meet the growing global energy demand (Bush 2006).

The National Environmental Policy Act (NEPA) requires that an Environmental Impact Statement be prepared in order to inform the public and the decision makers of the potential environmental impacts of proposed major Federal actions and the reasonable alternatives prior to making decisions on any such proposals. For a broad program such as GNEP, which could involve many actions with far-reaching consequences over a long period of time, a program-level EIS (referred to as a PEIS), is the appropriate document because it is relevant to policy-level decisions and is timed to coincide with meaningful points in agency planning and decision making (40 Code of Federal Regulations [CFR] Section 1502.4(b)).

While a change to a closed fuel cycle represents DOE's preferred approach, this PEIS analyzes several alternatives for accomplishing the GNEP objectives, including open fuel cycle alternatives. DOE will not make any decision regarding which alternative(s) to pursue before completing this PEIS. These alternatives, which are described below and in Chapter 2, are the result of the evolution of the programmatic analysis of the GNEP program, including public comment as part of the NEPA process. As discussed in Section 1.4, DOE initially proposed facilities to demonstrate three elements of a closed fuel cycle. DOE later revised the proposal to include both a programmatic analysis of the broad implementation of alternative nuclear fuel cycles and a project-specific analysis to construct and operate three particular facilities - a

\footnotetext{
${ }^{4}$ Both the early release 2008 International Energy Outlook (EIA 2007e), published in December 2007 and the 2008 International Energy Outlook (EIA 2008b), published in June 2008, project world electricity demand to grow by 2.4 percent per year until 2030.

${ }^{5}$ The AEI includes, in part, a combination of initiatives intended to accelerate research and development in three areas of power generation:

1) National and international nuclear energy activities, such as the GNEP Program; 2) Coal-based clean power and carbon sequestration; and

3) Renewable resources such as solar, wind and geothermal power.
} 
nuclear fuel recycling center, an advanced recycling reactor, and a DOE-owned advanced fuel cycle research facility. The GNEP Program has since further evolved so that this PEIS only addresses programmatic alternatives for broad implementation of alternative nuclear fuel cycles. This GNEP PEIS does not analyze any project-specific proposals. DOE may make projectspecific proposals following completion of this PEIS and would prepare appropriate NEPA analysis for any such proposal.

This GNEP Program also has an international component (referred to as international initiatives) pursuant to which the U.S. would cooperate with other fuel cycle nations (i.e., those already recycling SNF) to develop and deploy advanced nuclear recycling and reactor technologies in those countries in order to move away from producing separated pure plutonium. Further, GNEP would work to put in place a framework for nuclear fuel services in order to remove the need for a country to develop its own enrichment or reprocessing facilities. This PEIS identifies two international initiatives and discusses how these initiatives could produce environmental impacts within the U.S. and the global commons (defined as the environment outside the jurisdiction of

Enrichment. The process of increasing the proportion (or ratio) of uranium-235 atoms to uranium-238 atoms to make the mixture more usable as nuclear fuel.

Reprocessing. The process of separating the usable and unusable constituents of spent nuclear fuel. any nation, such as the oceans or Antarctica).

\subsubsection{Brief History of Spent Nuclear Fuel Reprocessing in the United States}

Essential to recycling SNF is separating fissionable material from the SNF in order to make new nuclear reactor fuel. This separations process is commonly referred to as reprocessing. Nuclear fuel reprocessing technology was developed during the Manhattan Project while working to build the first atomic bomb. The first large-scale reprocessing plants in the United States were located at nuclear weapons production sites in Washington (Hanford, built in the 1940s) and South Carolina (Savannah River Site, built in the 1950s).

As commercial nuclear power evolved in the mid-1950s, reprocessing was considered necessary because of the belief at the time that uranium was a very scarce material. In 1956, the Atomic Energy Commission (AEC), predecessor agency of DOE and the Nuclear Regulatory Commission (NRC), announced a program to encourage private industry to begin reprocessing SNF, and by 1959 the Davison Chemical Company (later called Nuclear Fuel Services) began extensive discussions with AEC on commercial reprocessing. In 1963, the AEC-sponsored Experimental Breeder Reactor (EBR-II) began operations in Idaho, and included a reprocessing facility using "melt-refining." In 1964, Congress gave the AEC the authority to authorize private companies holding appropriate AEC licenses to own special nuclear material.

In 1966, the AEC granted an operating permit for commercial reprocessing to Nuclear Fuel Services at its West Valley plant near Buffalo, NY. The plant operated from 1966 to 1972, reprocessing approximately 705 tons (640 metric tons [MT]) of SNF from commercial nuclear power plants and DOE sites. This reprocessing generated approximately 600,000 gallons 
(2.3 million liters) of liquid high-level radioactive waste (HLW) ${ }^{6}$. Nuclear Fuel Services stopped operations initially to increase the plant's capacity and make other improvements. However, Nuclear Fuel Services determined in 1976 not to restart the plant because of the cost of the improvements plus the cost to address changes to regulatory requirements (DOE 2004f). Under the 1980 West Valley Demonstration Project Act, DOE has completed vitrification of the liquid HLW in preparation for disposal in a geologic repository.

In 1967, the AEC authorized the General Electric Company to construct a commercial SNF reprocessing facility in Morris, Illinois. In 1970, Allied-General Nuclear Services began construction of a large commercial nuclear reprocessing facility near Barnwell, South Carolina. The Morris plant never reprocessed spent fuel, and the Barnwell plant was never completed. Plans for both these facilities were affected by U.S. policy changes that halted commercial recycling (described below) and by economic factors.

In 1974, India conducted a nuclear test (which it stated was a peaceful nuclear explosion). This test used plutonium separated from SNF from the CIRUS $^{7}$ civil research reactor. On October 28, 1976, President Ford announced his decision that reprocessing should not proceed unless the associated proliferation risks could be overcome. On April 7, 1977, President Carter announced that the United States would defer commercial reprocessing indefinitely. Although President Reagan lifted the indefinite ban on commercial reprocessing in the United States on October 8, 1981, the U.S. commercial nuclear power industry has continued to operate using a "oncethrough" open fuel cycle. This has been, in large part, because of the availability of uranium, which has kept the price of new fuel relatively low, and the capital cost associated with constructing a reprocessing plant. As a result, commercial power plants in the United States have been generating SNF and storing it on-site until it can be disposed of in a geologic repository. ${ }^{8}$

President Carter's 1977 announcement also established the policy to discourage civilian reprocessing internationally. The Nuclear Nonproliferation Act of 1978 established export licensing criteria, including a requirement for prior U.S. consent before any recipient country could reprocess SNF produced through the use of nuclear material exported by the U.S. (Public Law 95-242). That Act also required renegotiation of existing U.S. Agreements for Peaceful Nuclear Cooperation to incorporate this and other new requirements. However, the European Atomic Energy Community (Euratom) and Japan had already committed to civil reprocessing programs. The United States eventually decided not to oppose these established programs and to grant consent, first on a case-by-case basis and later on a long-term programmatic basis for reprocessing in these countries of SNF over which the U.S. exercises fuel consent rights.

Past reprocessing in the United States - at the West Valley plant in New York and at DOE facilities in Idaho, South Carolina, and Washington - generated millions of gallons of highly radioactive liquid waste. In South Carolina and Washington, spills from storage tanks have

\footnotetext{
${ }^{6} \mathrm{HLW}$ is defined as: 1) the highly radioactive material resulting from the reprocessing of SNF, including liquid waste produced directly in reprocessing and any solid material derived from such liquid waste that contains fission products in sufficient concentrations; and 2) other highly radioactive material that the $\mathrm{NRC}$, consistent with existing law, determines by rule requires permanent isolation.

${ }^{7}$ CIRUS, which stands for Canada India Research U.S., is a research reactor at the Bhabha Atomic Research Center near Mumbai, India. CIRUS was supplied by Canada in 1954, but used heavy water supplied by the United States.

${ }^{8}$ Although this section presents a brief history of SNF reprocessing in the United States, it is worth noting that France, Russia, Japan and the United Kingdom have been reprocessing SNF for many years.
} 
resulted in localized soil contamination. Preparing these liquid wastes for disposal will cost tens of billions of dollars. Some alternatives analyzed in this GNEP PEIS would produce similar liquid radioactive wastes. To avoid repeating problems associated with past reprocessing operations, DOE would support prompt conversion of such liquid HLW to solid forms, and would not support any long-term storage of such waste.

\subsection{PuRPOSE AND NEED FOR AgENCY ACTION}

DOE's underlying purpose and need is to support expansion of domestic and international nuclear energy production, while reducing the risks of nuclear proliferation and reducing the impacts associated with the disposal of future spent nuclear fuel (e.g., by reducing the volume, thermal output, or radiotoxicity of waste requiring geologic disposal). To meet its nonproliferation goals with regard to spent nuclear fuel recycling, DOE will assess, as reasonable alternatives, only those technologies that do not separate or use pure plutonium.

\subsubsection{Energy/Electricity}

Since 1950, electricity use in the United States has grown from 300 billion kilowatts to 3,800 billion kilowatts (EIA 2007b). This equates to an annual compounded growth rate of approximately 5 percent. Electricity use in the United States is expected to continue to grow, driven primarily by population increases and economic growth. The EIA has developed projections for U.S. electricity generation through 2030 to meet future demands (EIA 2007a, EIA 2008a). According to the most recent estimate, electricity use could increase by approximately 1.1 percent annually (EIA 2008a). An early release of that report, issued in December 2007, estimated U.S. electricity growth at 1.3 percent annually through 2030 (EIA 2007a). As discussed above, this Draft PEIS utilizes the higher 1.3 percent growth rate. Based on an annual growth rate of 1.3 percent, electricity use could increase by approximately 40 percent by 2030 , and if that annual rate were to continue, electricity use could double (relative to use in 2004) by approximately 2060. The EIA has also developed projections for nuclear electricity generation through 2030. For nuclear electricity generation, which currently supplies approximately 19 percent of the United States' electricity needs, the EIA currently projects an increase of approximately 0.6 percent annually (EIA 2008a). When compared to either a 1.1 percent or a 1.3 percent growth in the overall electricity generation market, nuclear production would lose market share over the period of 2005 through 2030.

Consistent with the President's 2006 Advanced Energy Initiative DOE seeks to develop ways to support the expanded use of nuclear energy to meet growing electricity demand. DOE policies and actions resulting from decisions in response to this PEIS could affect subsequent decisions made by the U.S. commercial utility industry, which ultimately would determine how to meet the future increased demands for electricity. 


\subsubsection{Reduction of Spent Nuclear Fuel and/or Waste Requiring Geologic Disposal}

The Nuclear Waste Policy Act of 1982, as amended (NWPA), provides for the disposal of commercial SNF and DOE SNF and HLW in the Nation's first proposed geologic repository to be located at Yucca Mountain, Nevada. Yucca Mountain is located in a remote desert on Federal land on and adjacent to the secure boundaries of the Nevada Test Site in Nye County, Nevada (DOE 2008f). ${ }^{9}$ Pursuant to the NWPA and by contract, the Federal government has responsibility for the disposal of commercial SNF currently being stored onsite at commercial reactor facilities. DOE filed a license application with the Nuclear Regulatory Commission for the repository at Yucca Mountain on June 3, 2008 (73 FR 34348, June 17, 2008).

\section{Metric Tons of Heavy Metal}

Quantities of spent fuel are traditionally expressed in terms of metric tons of heavy metal (typically uranium), without the inclusion of other materials such as cladding (the tubes containing the fuel) and structural materials. One metric ton of heavy metal disposed of as spent nuclear fuel would fill a space approximately the size of the refrigerated storage area in a typical household refrigerator.

Under the NWPA, the statutory capacity limit for the Yucca Mountain repository is $70,000^{10}$ metric tons of heavy metal (MTHM) of SNF and HLW. DOE estimates that the limit for the Yucca Mountain repository will be reached by approximately 2010. Regardless of any DOE decision related to the GNEP PEIS, the Nation requires a permanent geologic repository for the disposal of SNF and HLW. The GNEP Program has been proposed in addition to the Yucca Mountain repository mandated by the NWPA, and does not change the planning for the Yucca Mountain repository. Any decisions pursuant to the GNEP PEIS would not, in any way, diminish the need for the nuclear waste disposal program at a permanent geologic repository, and under all alternatives SNF and/or HLW would continue to be produced and require disposal. ${ }^{11}$

The GNEP PEIS assesses alternatives that would reduce the volume, thermal output, and/or radiotoxicity of SNF and wastes requiring geologic disposal for quantities in excess of the 70,000 MTHM that DOE has proposed for disposal in the repository at Yucca Mountain. Reducing the volume, thermal output, and/or radiotoxicity could expand the number of

\footnotetext{
${ }^{9}$ The potential environmental impacts of the construction, operation, and closure of the Yucca Mountain repository are addressed in the Environmental Impact Statement for a Geologic Repository for the Disposal of Spent Nuclear Fuel and High-Level Radioactive Waste at Yucca Mountain, Nye County, Nevada (DOE/EIS-0250, February 2002) (DOE 2002i) and the Final Supplemental Environmental Impact Statement for a Geologic Repository for the Disposal of Spent Nuclear Fuel and High-Level Radioactive Waste at Yucca Mountain, Nye County, Nevada (DOE/EIS-0250F-S1) (Yucca Mountain SEIS) (DOE 2008f).

${ }^{10}$ The NWPA limits the initial capacity of Yucca Mountain, the first proposed geologic repository, to 70,000 MTHM of SNF and HLW (DOE has allocated this capacity between 63,000 MTHM of commercial SNF and 7,000 MTHM of DOE SNF and HLW) until such time as a second repository is in operation. In its cumulative impacts analysis, the Yucca Mountain SEIS, issued in June 2008, evaluated the disposal of up to approximately 130,000 MTHM of SNF, equivalent to the amount projected from all existing commercial power reactors during all of their projected lifetimes. Disposal of more than 70,000 MTHM of SNF and HLW at the Yucca Mountain site prior to completion of a second repository would require a legislative change. DOE believes that if the statutory capacity limit is eliminated, then the Yucca Mountain geologic repository would have sufficient capacity to receive at least all of the SNF that has been or will be generated by the current fleet of nuclear power reactors.

Also, the current 70,000 MTHM statutory limit as defined in the NWPA pertains to the heavy metal content of the original fuel. As a result, from the standpoint of the Yucca Mountain geologic repository statutory capacity limit, it does not matter if SNF is emplaced as the original spent fuel rods or SNF is reprocessed and only the resulting HLW is emplaced. While recycling SNF could significantly reduce the volume, radiotoxicity, and/or heat load in a future repository, recycling would have no impact on the initial Yucca Mountain repository capacity, because under current law its statutory capacity limit is based on initial MTHM (not volume, radiotoxicity, or heat load).

${ }^{11}$ All reprocessing technologies under consideration as part of the GNEP initiative would produce wastes requiring disposal in a repository and moreover, deployment of reprocessing technologies would have little, if any, effect on the quantity of DOE SNF and HLW.
} 
acceptable sites for future geologic repositories, and could reduce both the cost and difficulty of siting and operating a geologic repository. ${ }^{12}$

\subsubsection{Proliferation Risk Reduction}

It is a long-standing U.S. national security policy objective to reduce proliferation risks throughout the nuclear fuel cycle via systematic and comprehensive efforts to prevent the spread of nuclear weapons materials and sensitive technologies. The United States has also long been concerned about the spread of enrichment and reprocessing technologies. In recent times, proliferation concerns about the nuclear fuel cycle have focused on the spread of centrifuge enrichment technology, first to Pakistan and then to Libya, Iran, and North Korea. On February 11, 2004, President Bush announced an initiative to prevent the further spread of both enrichment and reprocessing (Bush 2004). A key aspect of that initiative is to create a safe, orderly system to support civilian nuclear power without adding to the danger of weapons proliferation. This is one of the main purposes that the GNEP Program is intended to address.

Specific statutes and provisions in the CFR provide requirements for safeguards, security, and export controls, as do international treaties and arrangements to which the United States is party. ${ }^{13}$ In order for the United States to support nuclear energy in an expanded role in the global energy market, the risk of proliferation needs to be addressed. Proliferation risk begins with the ability to acquire the necessary nuclear materials for making nuclear weapons. Key measures for reducing proliferation risks are international safeguards, which seek to detect and thereby help prevent proliferation by other states, physical protection, which aims to protect nuclear materials and technologies against threats from non-state actors, including terrorists, and export control, which seeks to control or limit access to the materials, equipment and technology necessary to produce weapons-usable material. Safeguards are a basic building block of the international nuclear nonproliferation regime. They include inspections and other measures to verify compliance with international agreements and obligations regarding the peaceful use of nuclear energy, and rely on accounting for nuclear materials, monitoring nuclear facilities, and measures to detect clandestine nuclear activity. Physical protection includes measures to detect and defeat efforts to obtain unauthorized access to materials or facilities. Export control includes measures to limit access to materials, facilities, equipment, and technology that could be used for nuclear weapons production.

The GNEP PEIS assesses alternatives that aim to reduce the proliferation potential associated with the weapons-usable materials inherent in the nuclear fuel cycle. As a significant proliferation risk reduction activity, the GNEP Program is exploring a Reliable Fuel Services Program (ISAB 2008) to enable other nations to acquire nuclear energy economically while limiting the spread of sensitive fuel cycle technologies, particularly enrichment and reprocessing.

\footnotetext{
${ }^{12}$ The health and safety effects from a repository on members of the public currently are evaluated by projecting the reasonably expected radiation doses to the maximally exposed individual that lives in the vicinity of the repository. These projections are made through probabilistic performance assessments that take into account a number of factors, including the waste form, engineered barriers, physical barriers and lifestyles, some of which might be affected by reductions in volume, thermal output, and/or radiotoxicity.

${ }^{13}$ These statutes include the Atomic Energy Act, of 1954 (42 U.S.C. 2011 et seq.) the Nuclear Non-Proliferation Act, of 1978 (Public Law 95-242) and the Arms Control Act (22 U.S.C. 2778). Regulations implementing safeguards, security and export controls are published in the Code of Federal Regulations and are issued by the Departments of Commerce, Energy, State as well as the Nuclear Regulatory Commission. Article III of the Treaty on the Non-Proliferation of Nuclear Weapons (DOS 1970) (the U.S. is a signatory to this Treaty) addresses export control of nuclear material and equipment. Many international arrangements entered into by the U.S. address these issues including U.S. membership in the Nuclear Suppliers Group under the International Atomic Energy Agency (ECO 2008).
} 
In this program, existing holders of these sensitive technologies would make those fuel cycle services available to other countries that refrain from developing such capabilities on their own. By participating in this program, nations could pursue nuclear power while both minimizing proliferation concerns and minimizing the need for expensive fuel cycle infrastructure investments.

As another significant proliferation risk reduction activity, the GNEP Program is exploring an expanded program to design and deploy nuclear reactors with less proliferation potential that are both cost effective and well suited to infrastructure conditions in developing nations. Under the GNEP Program, the United States would seek agreement on key safety, security, nonproliferation, and safeguards standards for such reactors. The GNEP Program is also exploring the development of a grid-appropriate reactor ${ }^{14}$ that has enhanced nonproliferation characteristics, such as one that can keep the same nuclear fuel for the lifetime of the reactor, eliminating the need for refueling.

Separate from the GNEP PEIS, the National Nuclear Security Administration (NNSA), a separately organized agency within DOE, is preparing a Nonproliferation Impact Assessment (NPIA) that will analyze the nonproliferation aspects of the programmatic alternatives evaluated in this GNEP PEIS. The assessment framework is based on a qualitative evaluation of U.S. government policy factors and on internationally-accepted Proliferation Resistance and Physical Protection methodology (GIF 2006). This framework addresses: 1) the ability of the alternative nuclear fuel cycles to support established nuclear nonproliferation policy objectives, and 2) a technical evaluation of the nonproliferation features of the alternative processes and technologies. NNSA intends to make a draft of the NPIA publicly available in the same time frame as this Draft GNEP PEIS. The final NPIA will be publicly available prior to the Record of Decision (ROD) for this GNEP PEIS, and will be considered by DOE in decisions regarding the GNEP Program.

\subsubsection{Decisions to Be Made}

Following completion of this PEIS, DOE could make decisions related to the domestic programmatic alternatives (described in Chapter 2), including the alternative of continuing the status quo (i.e., the No Action Alternative). This PEIS also discusses international aspects of the GNEP Program (Chapter 7), but does not evaluate any proposed actions or alternatives. Consequently, DOE would not make any decisions related to international activities based on this PEIS.

This PEIS evaluates six domestic programmatic alternatives, which represent different nuclear fuel cycles. DOE could decide to support the demonstration and deployment of any of these alternatives or combinations thereof:

- Current uranium-based light water reactor (LWR) fuel cycle activities described under the No Action Alternative

\footnotetext{
${ }^{14}$ See Chapter 7 for a discussion of grid-appropriate reactors. Grid-appropriate reactors, which would be well suited to the capabilities and needs of developing countries, would be designed to achieve high standards of safety and security and would be sized to suit those countries' smaller and less developed power grids.
} 
- Advanced SNF separations and fast reactor transmutation technologies

- SNF separation with potential for both thermal and fast reactor transmutation

- Recycle of SNF through a dry thermal/mechanical separation process in which spent LWR fuel is used in a heavy water reactor (HWR)

- Thorium open fuel cycle

- Uranium-based once-through high temperature gas-cooled reactor (HTGR) or HWR fuel cycles

At this time, DOE is not proposing project-specific or site-specific actions to support the demonstration and deployment of any of these alternative fuel cycles. If DOE does make such proposals after completion of this PEIS, DOE will determine the appropriate steps to comply with NEPA and other applicable requirements. For example, additional NEPA review(s) would be conducted for the siting, construction, operation, and decommissioning of individual facilities that would be required to support demonstration or deployment of a different open fuel cycle or any of the closed fuel cycle options outlined above. Also, NRC, as part of its licensing process for a nuclear facility, would be responsible for complying with NEPA.

\section{3}

Relevant National EnVIronmental Policy act Documents

DOE and other Federal agencies have prepared, or are currently preparing, other NEPA documents that are related to the scope of this GNEP PEIS. These documents, and their relationship to the GNEP PEIS, are discussed below.

\subsubsection{Liquid Metal Breeder Reactor Environmental Statements}

In the 1970s, the Energy Research and Development Administration (ERDA), a predecessor agency of DOE, proposed the Liquid Metal Fast Breeder Reactor Program. As part of this program, the Clinch River Breeder Reactor Plant was a proposed liquid-sodium cooled fast breeder reactor to be constructed and operated in East Tennessee. The reactor would have produced up to about 439 megawatts electric (MWe) and used, for its initial core, a uranium and plutonium Mixed Oxide Fuel (MOX), similar to the fast reactors described in this PEIS.

An Environmental Statement was prepared by the NRC in connection with its licensing process (NUREG-0139, February 1977; Supplemented October 1982) (NRC 1977a, NRC 1982). ERDA also prepared a PEIS on the Liquid Metal Fast Breeder Reactor Program (ERDA-1535, 1975), DOE prepared a supplement to that document (the Liquid Metal Fast Breeder Reactor Program EIS [DOE/EIS-0085-FS, May 1982]), and ERDA prepared an EIS on Expansion of the U.S. Breeder Reactor Program (ERDA-1541, June 1976) (DOE 1975, DOE 1976, and DOE 1982). 
DOE Programmatic Spent Nuclear Fuel Management (SNF Management PEIS) and Idaho National Engineering Laboratory Environmental Restoration and Waste Management Programs Environmental Impact Statement (DOE/EIS-0203) (DOE 1995e)

In 1995, this EIS analyzed, at a programmatic level, the potential environmental consequences over a 40-year period of alternatives related to the transportation, receipt, processing, and storage of SNF under the responsibility of DOE. It also addressed the site-wide actions anticipated to occur at Idaho National Laboratory (INL) for waste and SNF management over a 10-year period. Many of the issues addressed in this EIS are similar to the issues addressed in the GNEP PEIS including SNF management, technologies for SNF management, and transportation of SNF and other nuclear materials, including nuclear waste.

1.3.3 Environmental Impact Statement for a Geologic Repository for the Disposal of Spent Nuclear Fuel and High-Level Radioactive Waste at Yucca Mountain, Nye County, Nevada (DOE/EIS-0250) (hereafter, Yucca Mountain FEIS) (DOE 2002i)

The NWPA requires that a final EIS accompany any Secretarial recommendation to approve the Yucca Mountain site to the President. The Yucca Mountain FEIS assesses the potential environmental impacts from construction, operation, and closure of a NRC-licensed geologic repository for disposal of 70,000 MTHM of SNF and HLW. The FEIS was completed in February 2002.

1.3.4 Supplemental Environmental Impact Statement for a Geologic Repository for the Disposal of Spent Nuclear Fuel and High-Level Radioactive Waste at Yucca Mountain, Nye County, Nevada (DOE/EIS-0250F-S1) (hereafter, Yucca Mountain Final Supplemental EIS) (DOE 2008f)

Since publication of the Yucca Mountain FEIS, DOE has continued to develop the repository design and associated plans. As now planned, the proposed surface and subsurface facilities would allow DOE to operate the repository following a primarily canistered approach in which most commercial SNF would be packaged at the commercial sites in transportation, aging and disposal canisters, and all DOE materials would be packaged in disposable canisters at DOE sites. Waste packages would be arrayed in the repository underground. Most SNF and HLW would arrive at the repository by rail. The Yucca Mountain Final Supplemental EIS updates the analysis of the environmental effects associated with the proposed action to construct, operate, monitor, and eventually close a geologic repository for the disposal of 70,000 MTHM of SNF and HLW at Yucca Mountain, including the impacts associated with transportation of the SNF and HLW from the generator sites to the repository.

The Final Supplemental EIS, issued in June 2008, recognizes that the GNEP initiative has been proposed and that a GNEP PEIS is being prepared. The Final Supplemental EIS states that the proposed action $^{15}$ of constructing and operating a repository for 70,000 MTHM will not change

${ }^{15}$ The proposed action is disposal of the 70,000 MTHM permitted under existing law. This 70,000 MTHM consists of 63,000 MTHM of commercial spent nuclear fuel and 7,000 MTHM of DOE spent nuclear fuel and high-level radioactive waste. 
because of the GNEP Program. Under all nuclear fuel cycles, the United States requires a permanent geologic repository to dispose of SNF and/or HLW. All of the programmatic alternatives included in the GNEP PEIS, including the No Action Alternative, would produce materials and wastes that would need to be isolated in a geologic repository as a means of final disposition. In addition, none of the programmatic alternatives would affect the current statutory mandate and need to develop a repository for the disposal of existing inventories of SNF and/or HLW.

Given the current uncertainties associated with the timelines, potential capacities, technological developments, and other matters related to the GNEP programmatic alternatives, the Final Supplemental EIS did not supplement the analysis of the proposed action to take into account the potential recycling of commercial SNF. The Final Supplemental EIS did, however, supplement the analysis of the cumulative impacts associated with commercial SNF generated by existing power plants after 2010 (that is, the commercial SNF from existing power plants in excess of the 63,000 MTHM included in the Proposed Action) to evaluate the potential effects of the GNEP Program on the impacts of the repository. Specifically, the Final Supplemental EIS evaluated two disposal cases (A and B). Case A assumed the Department would dispose of the estimated 130,000 MTHM of existing and future commercial spent nuclear fuel from existing power plants as spent nuclear fuel. Case B assumed the Department would dispose of 63,000 MTHM of commercial spent nuclear fuel as spent nuclear fuel, while recycling the remaining estimated 67,000 MTHM and then transporting the resultant commercial HLW to Yucca Mountain for disposal.

1.3.5 Environmental Impact Statement for a Rail Alignment for the Construction and Operation of a Railroad in Nevada to a Geologic Repository at Yucca Mountain, Nye County, Nevada (DOE/EIS-0369) (hereafter, Rail Alignment Final EIS) (DOE 2008g)

The Rail Alignment Final EIS assesses the construction and operation of a rail line to connect the repository site at Yucca Mountain to an existing rail line in the State of Nevada for the shipment of SNF and HLW, in the event that the NRC authorizes construction of the repository and receipt and possession of these materials at Yucca Mountain. The Rail Alignment Final EIS analyzes the potential impacts of constructing and operating a railroad to connect the Yucca Mountain repository site to an existing rail line near Wabuska, Nevada (in the Mina rail corridor). The Rail Alignment Final EIS also analyzes the potential impacts of constructing and operating support facilities.

The Rail Alignment Final EIS, issued in June 2008, recognizes that the GNEP initiative has been proposed and that a GNEP PEIS is being prepared. GNEP does not eliminate the need for Yucca Mountain, and it is necessary for DOE to proceed with the repository and rail facilities as planned. The Rail Alignment Final EIS focuses on the initial 70,000 MTHM of SNF and HLW that would require transportation to a geologic repository, while the GNEP PEIS focuses on future SNF and HLW that would require transportation to a geologic repository. 


\subsubsection{Surplus Plutonium Disposition Final Environmental Impact Statement (DOE/EIS-0283) (DOE 1999d), Supplement Analysis (DOE/EIS-0283-SA1) (DOE 2003g), and Surplus Plutonium Disposition Supplemental Environmental Impact Statement (DOE/EIS-0283-S2) (See 72 FR 14543)}

In 1999, DOE proposed in this EIS a dual strategy for disposing of surplus weapons grade plutonium by using some of the plutonium to fabricate MOX fuel and irradiating it in commercial power reactors, and immobilizing the rest of the plutonium. A supplement analysis was prepared in 2003 that supported the decision to proceed only with the MOX alternative. DOE is constructing a MOX plant at DOE's Savannah River Site (SRS) which is expected to become operational in 2017. This facility will dispose of 34 MT of surplus weapons-grade plutonium by converting it to MOX fuel to be irradiated in commercial reactors. LWRs can use MOX fuels in lieu of enriched uranium fuels and some of the plutonium in the MOX fuel will be consumed in the process in a manner similar to the consumption of transuranic elements in the thermal recycle reactors described in this PEIS. DOE is currently preparing a Surplus Plutonium Disposition Supplemental EIS, which, among other things, analyzes the potential environmental impacts of dispositioning additional surplus weapons-grade plutonium as MOX fuel.

\subsubsection{Disposal of Greater-than-Class-C Low-Level Radioactive Waste Environmental Impact Statement (DOE/EIS-0375) (See 72 FR 40135)}

Through legislation enacted in 1985 (the Low-Level Radioactive Waste Policy Amendments Act of 1985, Public Law 99-240 [42 U.S.C. 2021b et seq.]), DOE is responsible for the disposal of Greater-than-Class-C (GTCC) low-level waste (LLW) that results from activities licensed by the NRC. GTCC LLW is defined in NRC regulations at 10 CFR 72.3 as LLW that exceeds the concentration limits or radionuclides established for Class C waste in 10 CFR Part 61. The 1985 legislation specified that GTCC LLW that results from activities licensed by the NRC is to be disposed of in a facility licensed by the NRC. Currently, no facilities are licensed by NRC for disposal of GTCC LLW.

DOE will evaluate a range of reasonable alternatives for disposal of GTCC LLW in the GTCC EIS. The GTCC EIS will also include DOE owned or generated LLW and transuranic waste having characteristics similar to GTCC LLW and which may not have an identified path to disposal. The scoping period for the GTCC EIS ended in late September 2007, and DOE is currently preparing a draft EIS. DOE plans to issue the draft EIS in 2009. The GTCC EIS will evaluate potential impacts from the construction and operation of a new facility or facilities, or the use of existing facilities, for the disposal of this waste at potential DOE sites or at generic commercial locations. The disposal methods to be analyzed include enhanced near surface disposal, intermediate depth borehole disposal, and disposal in a geologic repository. The DOE sites under consideration in the GTCC EIS are Hanford, INL, Los Alamos National Laboratory (LANL), Nevada Test Site, Oak Ridge Reservation (ORR), SRS, the Waste Isolation Pilot Plant and vicinity, and the proposed Yucca Mountain Repository (72 FR 40135). Alternatives analyzed in this GNEP PEIS would generate GTCC LLW. Disposal of that waste will be evaluated qualitatively among cumulative impacts in the GTCC EIS. 


\subsubsection{Generic Environmental Impact Statement for In-Situ Leach Uranium Milling Facilities (NUREG-1910, Draft) (NRC 2008f)}

The NRC issued this draft generic EIS in July 2008 that addresses the potential environmental impacts associated with the construction, operation, aquifer restoration, and decommissioning of in-situ leach uranium recovery facilities for four uranium milling regions in the western United States. Two of the four regions are in Wyoming (the Wyoming West and Wyoming East Uranium Milling Regions), one covers parts of northeastern Wyoming, southwestern South Dakota, and a small part of northwestern Nebraska (the South Dakota-Nebraska Uranium Milling Region), and the fourth is the New Mexico Uranium Milling Region, located in westerncentral New Mexico.

The NRC is the licensing authority for in-situ leach facilities and as such is preparing this generic EIS to use as a starting point for its future NEPA analyses for site-specific license applications for new in-situ leach facilities. These facilities are expected to be located within the four identified uranium milling regions as these are the areas with uranium deposits and past, existing, or expected future milling operations. Since the facilities analyzed in this PEIS would use new sources of uranium, these operations are related to the scope of this PEIS.

\subsubsection{Commercial Nuclear Fuel Cycle National Environmental Policy Act Documents}

All U.S. commercial nuclear fuel cycle facilities must be licensed by the NRC prior to operating. In support of these license applications and renewals, the NRC prepares a NEPA document (generally an EIS) to support its licensing decision. Accordingly, NEPA documents have been prepared for all U.S. commercial nuclear fuel cycle facilities, and information found in applicable documents has been used in the programmatic analysis conducted for this PEIS. Generally, these NEPA documents include an analysis of reactor operations, enrichment facilities, SNF management, and depending on the specific reactor facility, may or may not have included an analysis of modular dry storage facilities.

\subsection{Public Participation}

Regulations of the Council on Environmental Quality (CEQ) require "an early and open process for determining the scope of issues related to a proposed action" as part of NEPA compliance (40 CFR 1501.7). This activity is known as the public scoping process. The purpose of this scoping process is to inform the public about a proposed action and the alternatives being evaluated, and to solicit public comments on the range of reasonable alternatives and potential environmental impacts.

\subsubsection{Advance Notice of Intent Public Comments}

On March 22, 2006, DOE published an Advance Notice of Intent (ANOI) for the Global Nuclear Energy Partnership Technology Demonstration Program Environmental Impact Statement (GNEP TDP EIS) in the Federal Register (71 FR 14505). That ANOI explained the goals of GNEP, the three major elements of the then-proposed GNEP Technology Demonstration 
Program, the purpose and need for action, and presented a list of potential environmental issues for analysis. The ANOI also invited comments on the proposed scope, alternatives, and environmental issues to be analyzed in the GNEP TDP EIS. The comment period for the ANOI ended on May 8, 2006.

DOE received more than 800 comment documents related to the GNEP Technology Demonstration Program in response to the ANOI. More than 750 of these were part of a campaign letter template and contained similar substantive comments. The major issues identified focused on the following topics:

- DOE should prepare a programmatic EIS (PEIS) of the entire GNEP Program proposal, not just the GNEP Technology Demonstration Program

- The proposed technologies are not sufficiently advanced to proceed with engineeringscale demonstrations

- DOE should pursue alternatives to nuclear power and GNEP

- $\quad$ DOE is proceeding with Federal actions related to GNEP before conducting the required NEPA analyses

Appendix H, Section H.1 provides a summary of the comments received on the ANOI. As a result of the comments received on the ANOI and other considerations, DOE decided to prepare this PEIS.

\subsubsection{Funding Opportunity Announcement for Site Characterization Reports}

On August 3, 2006, DOE issued a Financial Assistance Funding Opportunity Announcement (FOA) of \$20 million for public or commercial entities interested in hosting GNEP Program facilities to conduct detailed siting studies (DOE 2006n). Applications for these financial assistance grants were received by DOE by September 7, 2006. DOE reviewed these applications and on January 30, 2007, issued financial assistance grants to 11 commercial and public consortia to conduct detailed siting studies for hosting an advanced nuclear fuel recycling center and/or an advanced recycling reactor (DOE 2007aa) at: Atomic City, ID; Idaho National Laboratory, ID; Morris, IL; Paducah, KY; Hobbs, NM; Roswell, NM; Portsmouth, OH; Barnwell, SC; Savannah River Site, SC; Oak Ridge Reservation, TN; and Hanford, WA. Recipients completed these siting studies and submitted Site Characterization Reports to DOE by May 1, 2007 (DOE 2007b). The results of these site studies were reviewed by DOE and are included in the Administrative Record for this PEIS, and certain information from those site studies is summarized in Appendix $\mathrm{J}$ of this PEIS. However, DOE no longer proposes to pursue construction of either an advanced nuclear fuel recycling center or an advanced recycling reactor at this time, and this PEIS does not analyze the construction and operation of either facility.

\subsubsection{Request for Expressions of Interest}

Also in August 2006, in addition to the FOA described in Section 1.4.2, DOE requested Expressions of Interest (EOI) from domestic and international industry in building a Consolidated Fuel Treatment Center (CFTC) and an advance burner reactor (ABR). In issuing the EOIs, DOE sought to define industry interest in demonstrating SNF recycling technologies. 
DOE explained in the EOIs that the responses to them would aid DOE in identifying the issues that industry, and potential host sites, consider key in making feasible the construction of sustainable, commercial-scale SNF recycling technologies. If DOE makes a programmatic decision based on this PEIS to pursue such SNF recycling technologies, DOE may use the information gained from EOIs to create Requests for Proposals (RFPs) for the two facilities. If so, DOE also would prepare appropriate NEPA analyses as part of the decision making process.

Two EOIs were issued: one for a CFTC that would contain facilities for SNF recycling and transmutation fuel fabrication, and one to construct an ABR (referred to in this PEIS as an advanced recycling reactor) to consume transuranic elements within the fuel and generate electricity. A total of 18 responses were received by DOE on the two EOIs. Most of the information submitted was identified by the submitters as proprietary or business sensitive, and DOE is required by law to protect this information from unauthorized disclosure. Thirteen of the 18 respondents granted DOE permission to identify them as a submitter. Those names and additional information related to these two EOIs are available at www.gnep.energy.gov/gnepParticipation.html.

\subsubsection{Funding Opportunity Announcement-Industry Engagement}

DOE has solicited input from the nuclear industry regarding approaches to achieve the GNEP Program goals as outlined in the GNEP Strategic Plan (DOE 20071). In May 2007, DOE issued an FOA to industry to investigate the business and technical parameters that would support the GNEP Program, and to share their recommendations for potential deployment of fuel cycle facilities as described above in Section 1.2. Information in the areas of business planning, technology development roadmaps, and a communications plan for disseminating scientific, technical and practical information relating to closing the fuel cycle was sought. The requested plans (business plan, technology development roadmap and communications plan) would be developed to address approaches to achieve GNEP goals and to inform the public and key stakeholders regarding proposed options for successful GNEP implementation.

In addition to the plans, DOE also requested conceptual design studies for potential GNEP Program facilities that are to focus on providing scope, cost and schedule information for an initial nuclear fuel recycling center and advanced recycling reactor. Three capabilities were specified: 1) separating LWR SNF into its reusable components and waste components; 2) reducing the volume, heat load, and radiotoxicity of waste requiring geologic repository disposal; and 3) generating electricity with an advanced reactor that consumes transuranic elements as part of its fuel.

In September 2007, DOE funded four cooperative agreements with the nuclear industry to provide the analysis, plans, and designs described above. The agreements reflect that the GNEP Program is in the "conceptual design phase" with multiple technical and programmatic approaches under consideration.

An important element of these cooperative agreements is that they provide an opportunity for nuclear industry participants to provide input and recommendations on how to effectively and efficiently implement the GNEP Program goals. The inputs from industry, in conjunction with 
other data, will be used to inform the Secretary of Energy's decision on the path forward for the GNEP Program and to educate and inform the public as to the potential approaches for implementation and achieving the overall long-term GNEP Program goals.

Final reports were provided by the four industry teams in the spring of 2008. These reports outlined approaches to separations and reactors with respect to business planning, technology development roadmaps, and conceptual design studies for fuel cycle facilities. The conceptual design studies for these facilities focused on providing scope, cost, and schedule information for an initial nuclear fuel recycling center and advanced recycling reactor, with capabilities of: 1) separating LWR SNF into its reusable components and waste components; 2) reducing the volume, heat load, and radiotoxicity of waste requiring geologic repository disposal; and 3) generating electricity with an advanced reactor that consumes transuranic elements as part of its fuel. The business plan and technology development roadmap address approaches to achieve the overall long-term GNEP goals. The releasable summaries of these reports are available at: www.gnep.energy.gov/gnepParticipation.html.

\subsubsection{Public Scoping Comments}

On January 4, 2007, DOE published a Notice of Intent (NOI) to prepare this GNEP PEIS in the Federal Register (72 FR 331) (see Appendix G). That NOI explained the scope of the revised GNEP Program, identified the alternatives that were then proposed for evaluation, described the purpose and need for action, identified potential sites that could host GNEP Program facilities, and listed potential environmental issues for analysis. The NOI also invited comments on the proposed scope, alternatives, and environmental issues to be analyzed in the GNEP PEIS, and announced the schedule for public scoping meetings.

Subsequent to the NOI, DOE held public scoping meetings at 13 locations (see Figure 1.4.5-1). A neutral facilitator conducted the meetings to direct and clarify discussions and comments. Court reporters were present to provide a verbatim transcript of oral comments. Based on sign-ins, approximately 2,450 persons attended the meetings. Attendance varied from a high of approximately 600 at the meeting in Idaho Falls, ID, to a low of approximately 50 at the meeting in Los Alamos, NM. Average attendance was approximately 200. Approximately 550 persons provided oral comments at the meetings (see Appendix H, Section H.2). 


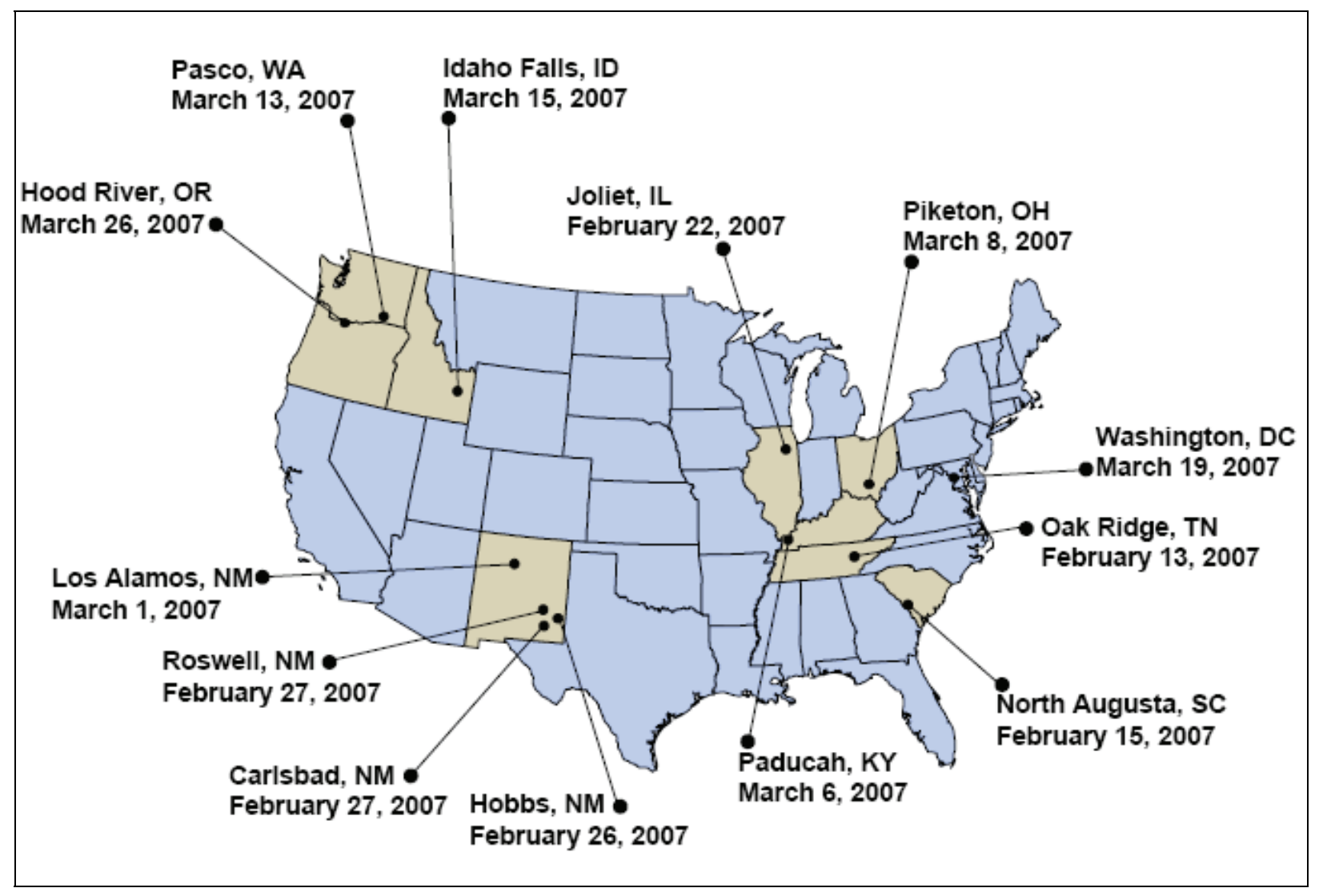

FIGURE 1.4.5-1—Global Nuclear Energy Partnership Public Scoping Meetings

The scoping comment period for the NOI was originally scheduled to end on April 4, 2007. In response to requests from the public, the scoping comment period was extended by 61 days, through June 4, 2007. A notice of this extension was published in the Federal Register (72 FR 15871).

In addition to the public scoping meetings, the public was encouraged to provide comments via mail, e-mail, phone, and fax. All comments received during the public scoping period, as well as late comments, were systematically reviewed by DOE in preparing this GNEP PEIS. Where possible, comments on similar or related topics were grouped under comment issue categories as a means of summarizing the comments. The comment issue categories were used to identify specific issues of public concern. After the issues were identified, they were considered in developing the scope of this GNEP PEIS.

During the public scoping process, DOE received more than 14,000 comment letters/e-mails and oral comments. Of the comment letters/e-mails, more than 12,400 were part of various campaign letters associated with one of 28 different form letters/e-mail campaigns.

In the NOI, DOE proposed to analyze in this PEIS the construction and operation of three facilities: an advanced nuclear fuel recycling center, an advanced recycling reactor, and the Advanced Fuel Cycle Facility (AFCF). Scoping comments addressed these facilities, including potential locations for them. DOE has since decided not to propose construction and operation of 
any of these facilities at this time. Because site selection will not be completed at this time, no determination has been made regarding the sites suggested through the FOA and public scoping processes as potential locations for any of these three facilities.

In response to public comments and as the programmatic analysis developed, DOE determined that to make project-specific or site-specific decisions regarding any of the three originally proposed facilities would be premature. The programmatic decisions to be made would influence the size and type of facilities required for implementing an alternative fuel cycle (the originally proposed nuclear fuel recycling center and advanced recycling reactor), as well as the facility needed to support the program with research, development, and deployment (an Advanced Fuel Cycle Facility). As a result, no project-specific or site-specific proposals are being made at this time. Based on the proposed programmatic decisions, DOE might make future proposals for particular actions. Any such proposals would be subject to appropriate NEPA review.

A summary of the additional major comments received during the public scoping process are provided below. (Italics indicate where the comments are addressed in this PEIS).

Commentors stated that the purpose and need is excessively narrow and leads to a unique answer to the issue at hand. Commentors stated that combining the programmatic analysis with projectspecific proposed actions prejudices the PEIS and presumes a certain programmatic outcome. Commentors identified a broad range of possible alternatives for evaluation in the PEIS. These included different reactor and fuel types (e.g., reactor technologies, coolants [gas, sodium], mixed-oxide $[\mathrm{MOX}]$ recycle in thermal reactors, and thorium fuel).

DOE has modified its statement of Purpose and Need to clarify that DOE did not intend to unduly limit the range of reasonable alternatives. DOE reviewed the scoping comments and other available information carefully and, as a result, added both closed and open fuel cycle technologies to the range of reasonable programmatic alternatives. Chapter 1 of the PEIS provides a discussion of the Purpose and Need. Chapter 2 provides a description of the additional programmatic alternatives that have been added for consideration.

Commentors recommended a demonstration program to ensure both that the fuel recycling technology is feasible and that it will not cause more waste than current technologies. Commentors stated that the PEIS should assess timing issues such as building fast reactors before a reprocessing plant and, conversely, assess impacts of reprocessing without fast reactors.

The GNEP PEIS identifies the major research and development $(R \& D)$ needs associated with each programmatic alternative (Chapter 4, Section 4.8.1) and discusses how these needs could affect implementation of the technologies analyzed and associated environmental impacts (Chapter 4, Section 4.8.2).

Commentors stated that the PEIS should analyze a wide range of potential environmental impacts associated with each alternative, and they provided specific comments regarding public and worker health and safety, accidents and intentional destructive acts, transportation, land use, cultural impacts, waste management issues, water quality/water availability issues, air quality, socioeconomics, environmental justice, and other potential impacts. 
The GNEP PEIS discusses each of these types of impacts based on the best available information. The potential environmental impacts of programmatic alternatives are discussed in Chapters 4 and 5.

Commentors stated that the PEIS should assess nonproliferation issues. Commentors stated that GNEP involves a major departure from U.S. policy on SNF and may affect agreements and treaties with other nations.

Separate from the GNEP PEIS, the National Nuclear Security Administration (NNSA), a separately organized agency within DOE, is preparing a Nonproliferation Impact Assessment (NPIA) that will analyze the nonproliferation aspects of the programmatic alternatives evaluated in this GNEP PEIS.

Commentors would like all technology information to be presented and include a history and evaluation of past performance of reactors and reprocessing facilities.

Chapter 2 and Appendix A include a discussion of reactor technologies being considered in the PEIS, and Chapter 1 includes a history of reprocessing.

Commentors stated that the PEIS should propose and assess specific international aspects of the GNEP Program and include reasonably foreseeable scales of global action.

Chapter 7 of the PEIS describes the international implications of the domestic programmatic alternatives, as well as the types of environmental impacts that could occur from international activities.

Commentors stated that GNEP is fundamentally inconsistent with DOE's objective of disposing of SNF deep underground where it would be as inaccessible as possible.

As explained in Chapter 4, Section 4.1.5, a geologic repository would be needed under any programmatic alternative. Each fuel cycle technology generates some quantity of SNF and/or $H L W$, although the forms and quantities differ among alternatives.

Appendix $\mathrm{H}$ of this PEIS contains a more detailed accounting of all comments received. Table H.2-1 lists the comment issue categories.

\subsubsection{Global Nuclear Energy Partnership-Related Reports from External Organizations}

In addition to public scoping comments and the other information sources referred to above, DOE reviewed several reports prepared by external organizations in the preparation of this Draft GNEP PEIS. Some of these reports provided useful, albeit critical, analysis regarding the proposed GNEP Program. These reports are briefly summarized below and many of the points raised are addressed at appropriate points throughout the PEIS. 
Global Nuclear Energy Partnership, DOE Should Reassess Its Approach to Designing and Building Spent Nuclear Fuel Recycling Facilities-The Government Accountability Office (GAO) criticized the GNEP Program for its lack of early industry participation, and for proposing to build reprocessing and reactor facilities at commercial scale (bypassing engineering scale) and for scheduling the completion of a reprocessing facility before completion of the R\&D facility needed to determine the former's design requirements. The report expressed concern as to DOE's readiness to select its preferred reprocessing technology prior to conducting additional R\&D at the dedicated facility, and criticized DOE's ability to manage large design and construction projects, particularly those that utilize new technologies. The report concluded that the GNEP Program should work closer with industry, start with engineering scale approaches to reprocessing, and conduct sufficient testing in an $\mathrm{R} \& \mathrm{D}$ facility and advanced reactor to assure the suitability of an eventual commercial-sized recycling plant to the selected recycling technology. The report also expressed skepticism that any of the claims or arguments advanced in support of developing MOX technology for fuel recycle in thermal reactors showed sufficient promise to warrant the necessary investment (GAO 2008a).

Review of DOE's Nuclear Energy Research and Development Program-The National Academy of Science's National Research Council devoted Chapter 4 of its 2008 Review of DOE's Nuclear Energy Research and Development Plan to the GNEP Program. The investigating committee took the view that the GNEP Program offered exclusively long-term benefits (i.e., it disputed GNEP claims of nearer-term benefits). Working from this premise, the committee's overriding conclusion was that the rationale for the GNEP Program, as expressed through the stated goals, objectives and criteria, was unpersuasive and unable to support an accelerated deployment strategy that would create significant technical and financial risks by prematurely narrowing (or, in some cases, predetermining) the technical options. Among the options that the committee believed warranted further exploration was electrochemical separation of SNF. They also questioned GNEP's selection of a sodium-cooled reactor as the reactor of choice, and challenged DOE's claim that the accelerated deployment would save nearly a decade of time and a substantial amount of money. The report stressed that all committee members agreed that the GNEP Program should not go forward as outlined in the GNEP Strategic Plan and that it should be replaced by a less aggressive research program. The report emphasized the high political risk of the program, which would need to survive successive administrations. All of these factors led the committee to conclude that the "safest, most effective, least risky course" by which to move forward would be an engineering-scale demonstration of the relevant technologies, and that "DOE should commit to the construction of a major demonstration or facility only when there is a clear economic, national security, or environmental policy reason for doing so" (NAS 2008).

Radioactive Wastes and the Global Nuclear Energy Partnership - The Institute of Policy Studies published a report stating that the GNEP Program is too costly, would take 150 years to accomplish, poses a health and safety risk to the public through the storage of dangerous materials, and lacks a credible plan for the safe management and disposal of radioactive wastes stemming from the GNEP Program (IPS 2007).

Risky Appropriations: Gambling on the Global Nuclear Energy Partnership-This report, written by David A. Schlissel, concluded that: 1) The GNEP Program lacks important details about technical viability, proliferation risks, waste streams, and ultimate life-cycle costs; 
2) The administration has presented no economic analysis of the costs and benefits of the GNEP Program and has not compared GNEP to other technically feasible and cost-effective alternatives, and such an economic justification should be provided before significant funds are appropriated for GNEP; 3) Full implementation of GNEP would represent a significant expansion and redirection of the nuclear industry; 4) The reference technologies and processes for GNEP have already been selected by the DOE, none of these technologies and processes currently exists in commercially viable applications, and few of them have even been shown to be viable in large, engineering-scale demonstration projects; 5) The contemplated schedule for deployment of GNEP is not feasible - the technologies that would be required to implement GNEP successfully would take decades to develop if, in fact, they can be made technically and commercially viable; 6) The plan for GNEP would lock the United States into decisions to deploy certain nuclear technologies and processes well before $\mathrm{R} \& \mathrm{D}$ is completed, demonstration projects are tested and operated, and the chosen technologies and processes are shown to be feasible and cost-effective; 7) Developing and deploying the facilities required for GNEP would likely be prohibitively expensive; 8) GNEP would be an unreasonably expensive and slow option for addressing global climate change; 9) GNEP would reverse the U.S. practice of not reprocessing reactor wastes; 10) It is unclear whether GNEP would eliminate the need for additional geologic waste repositories; 11) GNEP is unlikely to reduce the risk of proliferation of nuclear materials; 12) Deployment of the facilities that would be required in GNEP might entail significant risks to the public health and safety; and 13) Successful implementation of GNEP would require overcoming a number of significant political challenges. (Schlissel 2008).

Nuclear Power Joint Fact-Finding-The purpose of this report issued by the Keystone Center, was to develop a joint understanding of the facts regarding nuclear power and provide an objective interpretation of the most credible information in areas where uncertainty persists. With respect to GNEP specifically, the report concluded that, from a waste management perspective, there are many potential problems with the GNEP concept including cost, technology choice, and waste streams. While generally agreeing with the GNEP concept, the report stated that GNEP was not a strategy for resolving either the radioactive waste problem or the weapons proliferation problem. The report also concluded that critical elements of the GNEP Program are unlikely to succeed. These critical elements included the deployment of commercial-scale reprocessing plants and the reliance on unproven (particularly from an economic standpoint) fast reactors. Additionally, the GNEP Program could encourage activities which pose a grave proliferation risk (i.e., by encouraging the development of hot cells and reprocessing technology in non-weapons states). The report also challenged the cost-effectiveness of reprocessing technology (KC 2007).

Nuclear Fuel Recycling: More Trouble Than It's Worth-This report written by Dr. Frank von Hippel, concluded that SNF reprocessing was not a proper strategy for managing SNF. The author stated that reprocessing costs much more than the new fuel is worth, and that recycling plutonium reduces the waste problem only minimally, while significantly introducing proliferation risks if the separated plutonium gets into the wrong hands. The author also stated that sodium-cooled reactors proved to be much more costly to build and troublesome to operate than expected, and most countries abandoned their efforts to commercialize them. Additionally, the author stated that keeping older SNF produced by the once-through system in dry storage 
casks represents a negligible addition to the existing nuclear hazard to the surrounding population (von Hippel 2008).

Nuclear Power in a Warming World, Assessing the Risks, Addressing the Challenges-A Union of Concerned Scientists report assessed the nuclear power industry's key problems and offered recommendations to strengthen nuclear plant safety, better protect facilities against sabotage and attack, ensure the safe disposal of nuclear waste, and minimize the risk that nuclear power would help more nations and terrorists acquire nuclear weapons. With respect to GNEP specifically, the report stated that the GNEP Program offered no waste disposal benefits and would increase the risks of nuclear proliferation and terrorism. The report stated that GNEP would require a complex system of dangerous facilities that must be operated and repeatedly rebuilt for centuries. These facilities include those that potentially allow above-ground "decay storage" of short-lived fission products, and a host of added facilities needed to reprocess and fission highly radioactive actinides. In the view of the report, this system clearly would fail to meet fundamental criteria for responsible waste management. The report went on to state that the GNEP Program "should be dropped" (UCS 2007).

\section{Organization OF This Global Nuclear Energy Partnership Programmatic ENVIRonMental IMPACT STATEMENT}

This PEIS consists of a summary and the main body of the PEIS with appendices. The specific topics of each chapter are presented below.

Chapter 1-Introduction and Purpose and Need for Agency Action. An overview of the GNEP PEIS, the relationship of GNEP to other programs, and an overview of the public involvement process.

Chapter 2-Domestic Programmatic Alternatives. An explanation of the reasonable alternatives and description of facilities related to domestic programmatic alternatives.

Chapter 3-Affected Environment for Domestic Programmatic Alternatives. Presents information regarding the environments that might be affected by implementing the GNEP PEIS domestic programmatic alternatives.

Chapter 4-Environmental Impacts of Domestic Programmatic Alternatives. Analyses of the potential impacts on the environment from the domestic programmatic alternatives. Impacts are compared to the projected environmental conditions that would be expected if no action were taken. This includes an analysis of unavoidable adverse environmental impacts, the relationship between short-term uses of the environment and long-term productivity, and irreversible and irretrievable commitments of resources associated with the programmatic alternatives.

Chapter 5-Cumulative Environmental Impacts of the Domestic Programmatic Alternatives. Analyses of the cumulative impacts of the domestic programmatic alternatives in conjunction with other past, present, and reasonably foreseeable projects and activities. 
Chapter 6-Compliance, Regulatory Requirements, and Permits for Domestic Programmatic Alternatives. Environmental, safety, and health requirements that would apply for the PEIS alternatives and agencies consulted for their expertise.

Chapter 7-International Initiatives and Impacts of the Programmatic Alternatives. Describes the international initiatives, as well as the type of impacts that could occur from international activities.

Chapters 8-11. An index; glossary; list of preparers; and list of agencies, organizations, and persons to whom copies of this PEIS were sent.

In addition to Chapters 1 through 11, this volume contains 10 appendices of information that supports the environmental analyses presented in the main text. These appendices contain the following information: details of the SNF processing technologies, advanced fuel fabrication technologies, and reactor technologies; intentional destructive acts analysis; human health and worker safety; accidents; transportation; methodology; project studies and notices; scoping comment summaries and DOE responses; FOA site summaries; and contractor disclosure. 


\subsection{REFERENCES}

10 CFR Part 61

10 CFR 72.3

40 CFR 1501.7

71 FR 14505

72 FR 331

72 FR 15871

72 FR 14543

72 FR 40135
U.S. Nuclear Regulatory Commission (NRC), "Licensing Requirements for Land Disposal of Radioactive Waste," Code of Federal Regulations, Office of the Federal Register, National Archives and Records Administration, Washington, DC, Revised January 1, 2008.

NRC, "Definitions," Code of Federal Regulations, Office of the Federal Register, National Archives and Records Administration, Washington, DC, Revised January 1, 2008.

Council on Environmental Quality (CEQ), "Scoping," Code of Federal Regulations, Office of the Federal Register, National Archives and Records Administration, Washington, DC, Revised July 1, 2007.

U.S. Department of Energy (DOE), "Advance Notice of Intent to Prepare an Environmental Impact Statement for the Global Nuclear Energy Partnership Technology Demonstration Program," Office of the Federal Register, National Archives and Records Administration, Washington, DC, March 22, 2006.

DOE, "Notice of Intent to Prepare a Programmatic Environmental Impact Statement for the Global Nuclear Energy Partnership," Office of the Federal Register, National Archives and Records Administration, Washington, DC, January 4, 2007.

DOE, "Notice of Extension of Time to Submit Scoping Comments on the Programmatic Environmental Impact Statement for the Global Nuclear Energy Partnership," Office of the Federal Register, National Archives and Records Administration, Washington, DC, April 4, 2007.

DOE, "Notice of Intent To Prepare a Supplemental Environmental Impact Statement for Surplus Plutonium Disposition At the Savannah River Site," Office of the Federal Register, National Archives and Records Administration, Washington, DC, March 28, 2007.

DOE, "Notice of Intent to Prepare an Environmental Impact Statement for the Disposal of Greater-Than-Class-C Low-Level Radioactive Waste," Office of the Federal Register, National Archives and Records Administration, Washington, DC, July 23, 2007. 
73 FR 34348

22 U.S.C. 2278

42 U.S.C. 2011 et seq.

42 U.S.C. 2021 b et seq.

Public Law 95-242

Bush 2004

Bush 2006

DOE 1975

DOE 1976

DOE 1982

DOE 1995e
NRC, "Yucca Mountain; Notice of Receipt and Availability of Application," Office of the Federal Register, National Archives and Records Administration, Washington, DC, June 17, 2008.

"Arms Control Act of 1976, Sec. 38," United States Code, Washington, DC, January 2, 2006

"The Atomic Energy Act of 1954," United States Code, Washington, DC, January 2, 2006

"Low-Level Radioactive Waste Policy Amendments Act of 1985," LLRWPA, United States Code, Washington, DC, January 15, 1986.

Public Law 95-242, "Nuclear Non-Proliferation Act of 1978," NNPA, Washington, DC, 1978.

Bush, G.W., "Remarks by the President on Weapons of Mass Destruction Proliferation," White House, Washington, DC, February 2004. Accessed at http://www.whitehouse.gov/news/ releases/2004/02/20040211-4.html on September 22, 2008.

Bush, G.W., "State of the Union Address by the President," White House, Washington, DC, January 31, 2006. Accessed at www.whitehouse.gov/stateoftheunion/2006 on January 3, 2008.

DOE, "Final Environmental Statement, Liquid Metal Fast Breeder Reactor Program," ERDA-1535, U.S. Department of Energy, Washington, DC, 1975.

DOE, "Light Water Breeder Reactor Program, Final Environmental Statement," ERDA-1541, U.S. Department of Energy, Washington, DC, June 1, 1976.

DOE, "Final Environmental Impact Statement, Liquid Metal Fast Breeder Reactor Program-Supplement to ERDA 1535," DOE/EIS0085-FS, U.S. Department of Energy, Washington, DC, May 1982.

DOE, "DOE Programmatic Spent Nuclear Fuel Management and INEL Environmental Restoration and Waste Management Programs Final Environmental Impact Statement," DOE/EIS-0203, U.S. Department of Energy, Washington, DC, 1995. 
DOE 1999d

DOE 2002i

DOE 2003g

DOE 2004f

DOE 2006n

DOE 2007b

DOE 20071

DOE 2007aa

DOE $2008 f$
DOE, "Surplus Plutonium Disposition Final Environmental Impact Statement," DOE/EIS-0283, U.S. Department of Energy, Washington, DC, November 1999.

DOE, "Final Environmental Impact Statement for a Geologic Repository for the Disposal of Spent Nuclear Fuel and High-Level Radioactive Waste at Yucca Mountain, Nye County, Nevada," DOE/EIS-0250, U.S. Department of Energy, Washington, DC, February 1, 2002.

DOE, "Changes Needed To the Surplus Plutonium Disposition Program, Supplement Analysis and Amended Record of Decision," DOE/EIS-0283-SA1, U.S. Department of Energy, Washington, DC, April 2003.

DOE, "West Valley Demonstration Project Final Waste Management Environmental Impact Statement," DOE/EIS-0337, U.S. Department of Energy, West Valley Area Office, West Valley, NY, January 2004.

DOE, "Financial Assistance Funding Opportunity Announcement Global Nuclear Energy Partnership (GNEP) Siting Studies," Funding Opportunity Number: DE-PS07-06ID14760, U.S. Department of Energy, Washington, DC, 2006.

DOE, "GNEP Siting Studies Received," U.S. Department of Energy, Washington, DC, 2007. Accessed at www.gnep.energy. gov on May 30, 2007.

DOE, "Global Nuclear Energy Partnership Strategic Plan," GNEP167312, Rev. 0, Office of Nuclear Energy, Office of Fuel Cycle Management, U.S. Department of Energy, Washington, DC, January 2007.

DOE, "Waste Locations By State: Sites Storing Spent Nuclear Fuel, High-Level Radioactive Waste, or Surplus Plutonium Destined for Geologic Disposition," U.S. Department of Energy, Washington, DC, June 1, 2007. Accessed at http://www.ocrwm. doe.gov/info_library/newsroom/photos/photos_natlmap.shtml on January 5, 2008.

DOE, "Final Supplemental Environmental Impact Statement for a Geologic Repository for the Disposal of Spent Nuclear Fuel and High-Level Radioactive Waste at Yucca Mountain, Nye County, Nevada," DOE/EIS-0250F-S1, Office of Civilian Radioactive Waste Management, Las Vegas, NV, June 2008. 
DOE 2008g

DOS 1970

ECO 2008

EIA 2007a

EIA $2007 b$

EIA 2007e

EIA 2008a
DOE, "Final Supplemental Environmental Impact Statement for a Geologic Repository for the Disposal of Spent Nuclear Fuel and High-Level Radioactive Waste at Yucca Mountain, Nye County, Nevada - Nevada Rail Transportation Corridor DOE/EIS-0250FS2 and Final Environmental Impact Statement for a Rail Alignment for the Construction and Operation of a Railroad in Nevada to a Geologic Repository at Yucca Mountain, Nye County, Nevada, DOE/EIS-0369," U.S. Department of Energy, Office of Civilian Radioactive Waste Management, Las Vegas, NV, June 2008.

U.S. Department of State (DOS), "Treaty on the Non-Proliferation of Nuclear Weapons," U.S. Department of State, Washington, DC, Entered into force on March 5, 1970. Accessed at http://www.state.gov/www/global/arms/treaties/npt1.html on September 2008.

Export Control Organization (ECO), "Overview of U.S. Export Control System," Export Control Organization, U.K., 2008. Accessed at www.exportcontrol.org/index.php/pagetype/htmlpage/ $\mathrm{id} / 2081 . \mathrm{html}$ on September 22, 2008.

Energy Information Administration (EIA), "AEO 2008-Overview, Annual Energy Outlook 2008 (Early Release)," DOE/EIA-0383, Energy Information Administration, U.S. Department of Energy, Washington, DC, December 2007. Accessed at http://www.eia.doe. gov/oiaf/aeo/pdf/earlyrelease.pdf on January 22, 2008.

EIA, "Annual Energy Outlook 2007 With Projections to 2030," DOE/EIA-0383(2007), Energy Information Administration, U.S. Department of Energy, Washington, DC, 2007. Accessed at http://www.eia.doe.gov/oiaf/archive/aeo07/index.html on December 21, 2007.

EIA, “International Energy Outlook 2007,” DOE/EIA-0484(2007), Energy Information Administration, U.S. Department of Energy, Washington, DC, May 2007. Accessed at http://www.eia.doe. gov/oiaf/ieo/world.html on January 21, 2008.

EIA, "Annual Energy Outlook 2008 With Projections to 2030," DOE/EIA-0383 (2008), Energy Information Administration, U.S. Department of Energy, Washington, DC, June 2008. Accessed at http://www.eia.doe.gov/oiaf/aeo/pdf/0383(2008).pdf on July 3, 2008. 
EIA 2008b

GAO 2008a

GIF 2006

IPS 2007

ISAB 2008

KC 2007

NAS 2008

NRC 1977a
EIA, “International Energy Outlook 2008: Highlights," DOE/EIA0484(2008), Energy Information Administration, U.S. Department of Energy, Washington, DC, June 2008. Accessed at http://www.eia.doe.gov/oiaf/ieo/world.html on July 3, 2008.

United States Government Accountability Office (GAO), "Global Nuclear Energy Partnership, DOE Should Reassess Its Approach to Designing and Building Spent Nuclear Fuel Recycling Facilities," GAO-08-483, United States Government Accountability Office, Washington, DC, April 2008.

Generation IV International Forum (GIF), "Evaluation Methodology for Proliferation Resistance and Physical Protection of Generation IV Nuclear Energy Systems," Revision 5, The Proliferation Resistance and Physical Protection Evaluation Methodology Expert Group Of the Generation IV International Forum, November 30, 2006.

Institute for Policy Studies (IPS), "Radioactive Wastes and the Global Nuclear Energy Partnership," Institute for Policy Studies, April 16, 2007. Accessed at http://www.whistleblower.org/doc/ 2007/gnepFINAL.pdf on June 2, 2008.

International Security Advisory Board (ISAB), "Report on Proliferation Implications of the Global Expansion of Civil Nuclear Power," International Security Advisory Board Department of State, April 7, 2008.

The Keystone Center (KC), "Nuclear Power Joint Fact-Finding," The Keystone Center, June 2007. Accessed at http://www.keystone.org/spp/documents/FinalReport_NJFF6_12_2 007(1).pdf on June 23, 2008.

National Academy of Sciences (NAS), "Review of DOE's Nuclear Energy Research and Development Program," Board on Energy and Environmental Systems, Division on Engineering and Physical Sciences, The National Academies Press, Washington, DC, 2008.

NRC, "Environmental Statement Related to the Construction and Operation of Clinch River Breeder Reactor Plant," NUREG-0139, Docket No. 50-537, Office of Nuclear Reactor Regulation, U.S. Nuclear Regulatory Commission, Washington, DC, 1977. 
NRC 1982

NRC 2008f

Schlissel 2008

UCS 2007

von Hippel 2008
NRC, "Supplement to Final Environmental Statement Related to Construction and Operation of Clinch River Breeder Reactor Plant," NUREG-0139-Suppl.1-Vol.2, U.S. Nuclear Regulatory Commission, Washington, DC, October 1, 1982.

NRC, "Generic Environmental Impact Statement for In-Situ Leach Uranium Milling Facilities," NUREG-1910, Office of Federal and State Materials and Environmental Management Programs, U.S. Nuclear Regulatory Commission, Washington, DC, July 2008.

Schlissel, D.A., "Risky Appropriations: Gambling US Energy Policy on the Global Nuclear Energy Partnership," January 2008. Accessed at http://www.nirs.org/radwaste/reprocessing/ gnepmarch.pdf on June 23, 2008.

Union of Concerned Scientists (UCS), "Nuclear Power in a Warming World, Assessing the Risks, Addressing the Challenges," Lisbeth Gronlund, David Lochbaum, Edwin Lyman, Union of Concerned Scientists, December 2007. Accessed at http://www.ucs usa.org/global_warming/solutions/nuclearandclimate.html on June 23, 2008.

von Hippel, F.N., "Nuclear Fuel Recycling: More Trouble Than It's Worth," Scientific American Magazine, April 2008. 



\section{CHAPTER 2}

\section{DOMESTIC PROGRAMMATIC ALTERNATIVES}





\section{CHAPTER 2 DOMESTIC PROGRAMMATIC ALTERNATIVES}

Chapter 2 describes the domestic programmatic alternatives that are assessed in this Global Nuclear Energy Partnership (GNEP) Programmatic Environmental Impact Statement (PEIS). The majority of Chapter 2 is a description of each domestic programmatic alternative. Chapter 2 also discusses domestic programmatic alternatives that were considered and subsequently eliminated from detailed evaluation. The chapter concludes with a discussion of the major planning assumptions and implementation scenarios for the domestic programmatic alternatives.

This Global Nuclear Energy Partnership (GNEP) Programmatic Environmental Impact Statement (PEIS) assesses domestic fuel cycle alternatives that may support the expansion of nuclear electricity production by reducing the risks associated with nuclear proliferation and by reducing the volume, heat load, or radiotoxicity of spent nuclear fuel (SNF) or wastes requiring geologic disposal. This GNEP PEIS provides relevant environmental information to the Secretary of Energy on whether to pursue changes to the current domestic once-through uranium fuel cycle. Based on such a programmatic decision, the U.S. Department of Energy (DOE) might make future proposals for particular actions. Any such proposals would be subject to appropriate National Environmental Policy Act (NEPA) review.

Development of Reasonable Alternatives

Chapter 1 of this PEIS describes the background information and sequence of events that led to the development of this GNEP PEIS. In the Notice of Intent (NOI) to prepare this PEIS, DOE identified the following two programmatic alternatives for analysis:

- Programmatic Alternative 1, No Action Alternative: Continue to rely upon a "oncethrough" or open fuel cycle, in which commercial reactors generate and store SNF until DOE can dispose of the SNF in a geologic repository, while continuing DOE's ongoing nuclear fuel cycle research and development (R\&D) activities, including those activities associated with DOE's Advanced Fuel Cycle Initiative (AFCI).

- Programmatic Alternative 2, Proposed Action: Pursue the GNEP closed fuel cycle in a system that would process light water reactor (LWR) SNF in one or more nuclear fuel recycling centers and that would repeatedly recycle some of the recovered materials in one or more advanced recycling reactors.

During the scoping process, the public suggested that DOE evaluate additional alternatives. (See Chapter 1, Section 1.4 and Appendix H for a description of the scoping process, a summary of the comments received, and DOE's consideration of these comments.) In response to these suggestions, DOE added four domestic programmatic alternatives to those alternatives that it had identified in the NOI. Based on the purpose and need, DOE determined that the other suggested alternatives are not reasonable; these alternatives are briefly discussed in Section 2.8. 
To meet the purpose and need described in Chapter 1, DOE's proposed action is to close the nuclear fuel cycle. In a closed fuel cycle, SNF would be recycled, and some of the usable constituents would be made into new reactor fuel. This PEIS assesses the domestic programmatic alternatives that could achieve a closed fuel cycle. Additionally, this PEIS includes an assessment of domestic programmatic alternatives that would meet the purpose and need with an open fuel cycle. In an open fuel cycle (also known as a "once-through fuel cycle"), reactor fuel is used in a nuclear power plant only once. Under each of the domestic programmatic alternatives, DOE would continue its ongoing nuclear fuel cycle R\&D activities, including those activities associated with the AFCI.

As shown in the first three columns of Figure 2.1-1, this PEIS assesses the following six domestic programmatic actions/alternatives, which include both closed and open fuel cycles:

- No Action Alternative-Existing Once-Through Uranium Fuel Cycle (hereafter referred to as the "No Action Alternative"): The United States would continue to rely upon a once-through or "open" fuel cycle, in which commercial LWRs generate and store SNF until DOE could accept the SNF for disposal in a geologic repository. ${ }^{1}$

- Fast Reactor Recycle Fuel Cycle Alternative (formerly referred to as the "GNEP Closed Fuel Cycle;" hereafter referred to as the "Fast Reactor Recycle Alternative"): The United States would pursue a domestic closed fuel cycle in a system that processes LWR SNF in one or more nuclear fuel recycling centers and would recycle some of the recovered materials in one or more fast reactors. The SNF from the advanced recycling reactors would also be processed to recover materials for repeated recycle in advanced recycling reactors. High-level wastes (HLW) from separations would be disposed of in a geologic repository.

- Thermal/Fast Reactor Recycle Fuel Cycle Alternative (hereafter referred to as the "Thermal/Fast Reactor Recycle Alternative"): This alternative would be similar to the Fast Reactor Recycle Alternative, but it would recycle some of the recovered materials in a thermal reactor prior to recycling in advanced recycling reactors. HLW from separations would be disposed of in a geologic repository.

- Thermal Reactor Recycle Fuel Cycle Alternative (hereafter referred to as the "Thermal Reactor Recycle Alternative"): The United States would pursue a domestic fuel cycle that processes LWR SNF and recycles some of the recovered materials in thermal reactors. The following three options are assessed: Option 1-Recycle LWR SNF to produce a mixed oxide uranium plutonium (MOX-U-Pu) fuel for use in LWRs; Option 2-Recycle LWR SNF to produce fuel for use in heavy water reactors (HWR); and Option 3Recycle LWR SNF to produce a transuranic fuel for use in high temperature gas-cooled reactors (HTGR). Option 1 would be a closed fuel cycle, in which HLW would be disposed of in a geologic repository. Options 2 and 3, which include recycling of LWR SNF, would dispose of HLW and SNF in a geologic repository.

\footnotetext{
${ }^{1}$ As discussed in Section 2.9.1, future repository capacity could be either an expansion of the Yucca Mountain geologic repository or a separate geologic repository.
} 
5
0
2
5
5
5
0
0
0
0

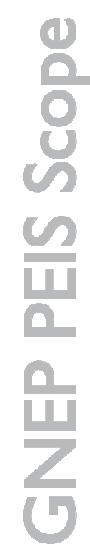

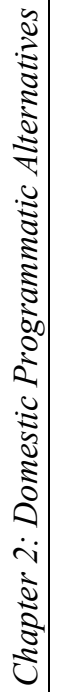

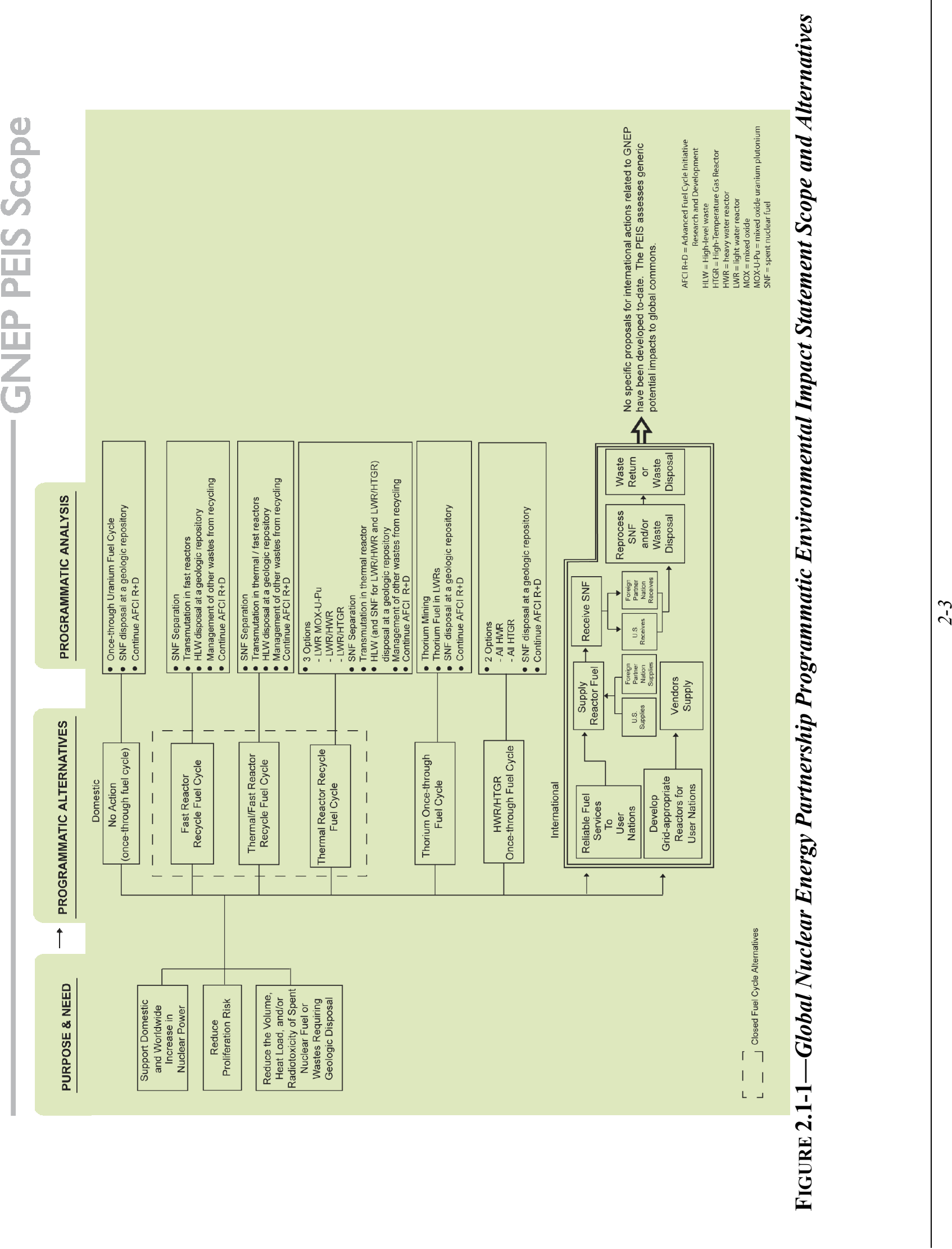


- Once-Through Fuel Cycle Alternative Using Thorium (hereafter referred to as the "Thorium Alternative"): The United States would pursue a thorium once-through fuel cycle, in which commercial reactors would be fueled with thorium/uranium-based fuels. Because thorium-based fuels would be compatible with existing LWRs, the Thorium Alternative could also be characterized as representing a "new fuel design." The SNF would be stored until DOE could accept it for disposal in a geologic repository.

- Once-Through Fuel Cycle Alternative using Heavy Water Reactors (HWRs) or High Temperature Gas-Cooled Reactors (HTGRs) (hereafter referred to as the "HWR/HTGR Alternative"): The United States would pursue a domestic once-through fuel cycle that uses either HWRs or HTGRs. For the HWR/HTGR Alternative, two options are assessed: Option 1-Use HWRs only; and Option 2-Use HTGRs only. In either case, the SNF would be stored until DOE could accept it for disposal in a geologic repository.

These domestic programmatic alternatives are not mutually exclusive. That is, DOE could decide to pursue implementation of one or more domestic programmatic alternatives. Market forces, coupled with government incentives and other factors, would determine which technologies are deployed, as well as the manner and degree of implementation.

Sections 2.2 through 2.7 describe the six domestic programmatic alternatives that are assessed in this PEIS. Section 2.2 discusses the No Action Alternative, an open fuel cycle. Sections 2.3 through 2.5 discuss the fuel cycle alternatives that would achieve a closed fuel cycle. Some alternatives would achieve a completely closed fuel cycle (recycling of all SNF), while others would only achieve a partially closed fuel cycle (some SNF recycled, and some SNF disposed of in a geologic repository). For example, Section 2.3 discusses the Fast Reactor Recycle Alternative, which would recycle the SNF from LWRs to produce fuel for advanced recycling reactors. Because this alternative would also recycle the SNF from the advanced recycling reactors, all of the SNF from this fuel cycle would be recycled. In contrast, Section 2.5.2 discusses the Thermal Reactor Recycle Alternative (Option 2), which would recycle the SNF from LWRs to produce fuel for HWRs. This alternative, however, would not recycle the SNF from the HWRs, and, thus, would only achieve a partially closed fuel cycle. Section 2.6 (Thorium Alternative) and Section 2.7 (HWR/HTGR Alternative) discuss open fuel cycle alternatives that would not recycle SNF, but that could reduce the volume, heat load, and/or radiotoxicity of the SNF requiring geologic disposal consistent with DOE's underlying purpose and need. Section 2.8 describes the alternatives not selected for detailed evaluation. Section 2.9 provides the assumptions used for analyzing the domestic programmatic alternatives. Section 2.10 discusses implementation of the domestic programmatic alternatives.

No ACtion Alternative-OnCe-Through Uranium Fuel CyCle

The No Action Alternative, which is required in an EIS, provides a baseline from which to compare the environmental impacts of the action alternatives. Under the No Action Alternative, DOE would continue to support a once-through fuel cycle (Figure 2.2-1) in which nuclear fuel would be used one time to generate electricity, and the resulting spent nuclear fuel would be stored for eventual disposal in a geologic repository. In this alternative, commercial LWRs 
would generate and store SNF until DOE could accept it for disposal in a geologic repository. DOE would also continue its ongoing nuclear fuel cycle R\&D activities, including those activities associated with the AFCI. This alternative assumes that future commercial reactors would be similar to the reactors currently licensed by the U.S. Nuclear Regulatory Commission (NRC) and those reactors under consideration for licensing by the NRC (i.e., LWR and Advanced LWR [ALWR] designs). In addition, this alternative assumes continued performance improvements in reactor operation (e.g., higher fuel burnup ${ }^{2}$ at discharge from the reactor). The environmental impacts of the No Action Alternative are presented in Chapter 4, Section 4.2.

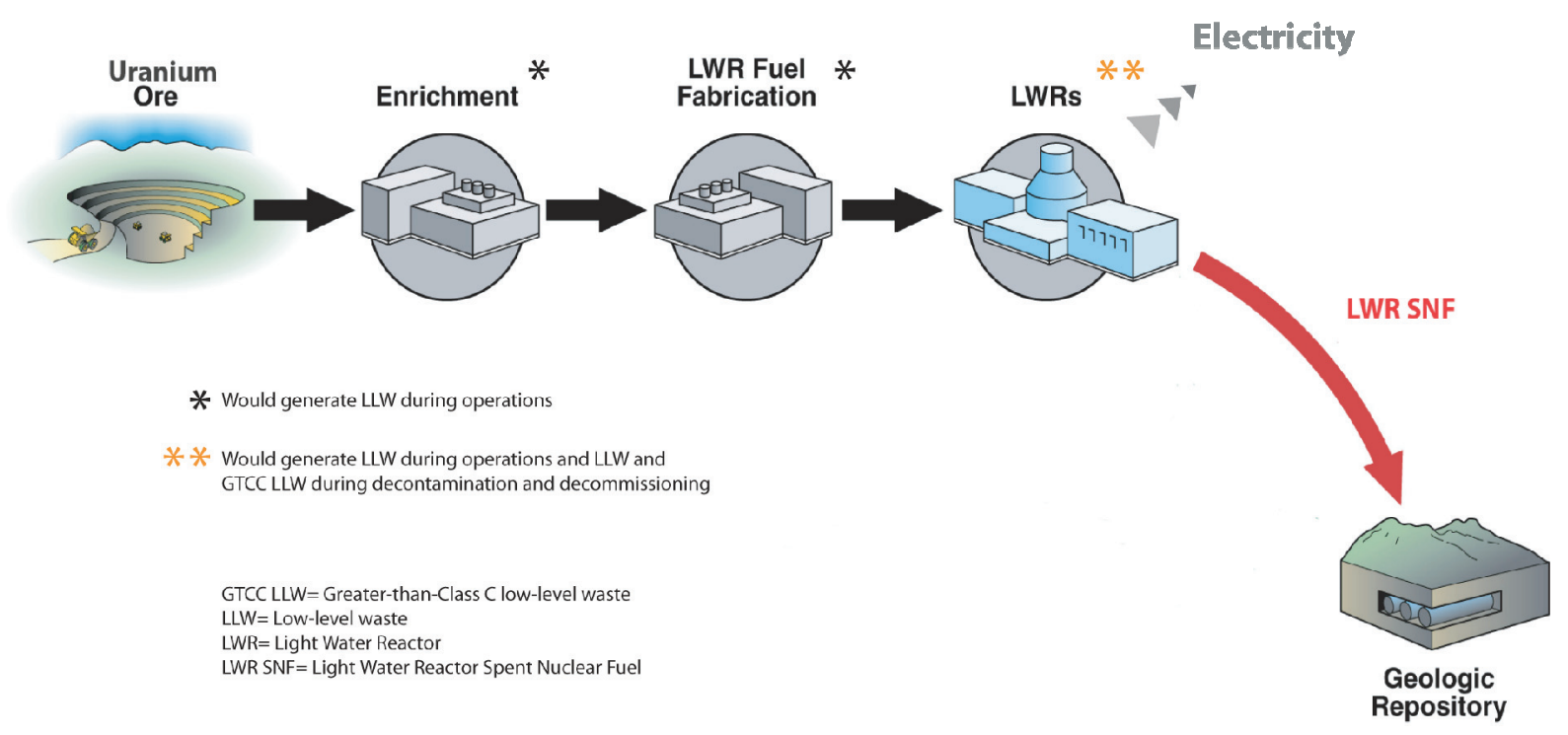

FIGURE 2.2-1-No Action Alternative Once-Through Uranium Fuel Cycle

The statutory capacity limit for the Yucca Mountain repository is $70,000^{3}$ metric tons of heavy metal (MTHM) of spent nuclear fuel and high-level radioactive waste. DOE estimates that this statutory capacity limit will be reached by approximately 2010. Quantities of SNF beyond the

\footnotetext{
${ }^{2}$ Burnup refers to the amount of energy generated per unit mass of fuel. Higher burn-up fuels can reduce the total amount of spent nuclear fuel generated by providing more energy per fuel assembly. Improved performance as a result of higher fuel burn-up would be pursued under all domestic programmatic alternatives. Burnup is normally quoted in either megawatt-days per kilogram $(\mathrm{MWd} / \mathrm{kg})$ or in gigawatt-days per metric ton of heavy metal (GWd/MTHM) (typically, uranium or its equivalent). Historical U.S. commercial reactor operations show a steady trend toward higher burnup. The average improvement over the last 20 years is about $1 \mathrm{GWd}$ /MTHM per year. The development work necessary to reach these higher burnup levels has been successfully handled primarily by the commercial sector. Due to a number of practical limits, this trend in increasing burnup is expected to slow down in the future. These include licensing and design limits on commercial enrichment plants, physical limits of fuel cladding, and operational cycle limits at the power plants to support preventative maintenance activities.

${ }^{3}$ The Nuclear Waste Policy Act of 1982 (NWPA) limits the initial capacity of Yucca Mountain, the first proposed geologic repository, to 70,000 MTHM of SNF and HLW (DOE has allocated this capacity between 63,000 MTHM of commercial SNF and 7,000 MTHM of DOE SNF and HLW) until such time as a second repository is in operation. In its cumulative impacts analysis, the Yucca Mountain SEIS, issued in June 2008, evaluated the disposal of up to approximately 130,000 MTHM of SNF, equivalent to the amount projected from all existing commercial power reactors during all of their projected lifetimes. Disposal of more than 70,000 MTHM of SNF and HLW at the Yucca Mountain site prior to completion of a second repository would require a legislative change. DOE believes that if the statutory capacity limit is eliminated, then the Yucca Mountain geologic repository would have sufficient capacity to receive at least all of the SNF that has been or will be generated by the current fleet of nuclear power reactors.

Also, the current 70,000 MTHM statutory limit as defined in the NWPA pertains to the heavy metal content of the original fuel. As a result, from the standpoint of the Yucca Mountain geologic repository statutory capacity limit, it does not matter if SNF is emplaced as the original spent fuel rods or SNF is reprocessed and only the resulting HLW is emplaced. While recycling SNF could significantly reduce the volume, radiotoxicity, and/or heat load in a future repository, recycling would have no impact on the initial Yucca Mountain repository capacity, because under current law its statutory capacity limit is based on initial MTHM (not volume, radiotoxicity, or heat load).
} 
Yucca Mountain statutory capacity limit would be stored at commercial LWR sites until they could be disposed of in one or more permanent geologic repositories. ${ }^{4}$

Under the No Action Alternative, and all of the action alternatives, DOE would continue the activities associated with the AFCI (described below) including programs that address safety, safeguards and security requirements for advanced fuel cycle technologies. Appendix A, Section A.8 includes a more detailed discussion of the AFCI, including a discussion of the major facilities associated with the AFCI.

\section{Advanced Fuel Cycle Initiative and Other Department of Energy Programs}

The objective of the AFCI is to develop the technologies needed to: reduce the environmental consequences associated with spent nuclear fuel management, reduce the proliferation risk from the use of nuclear power, and extend uranium resources. Key elements of the initiative include the following:

- An Integration task, which is focused on providing overall consistency for the program and on directing modeling and simulation and regulatory efforts for all tasks.

- A Systems Analysis task, which is focused on investigating the interactions between program elements, evaluating deployment scenarios for various technical options, and identifying criteria that technologies must meet to allow the overall system to function effectively.

- A Separations task, which develops and demonstrates advanced separations technologies for processing SNF, with an emphasis on LWR SNF. AFCI Separations research would continue at various radiological facilities and analytical laboratories, including the following: Argonne National Laboratory (ANL), Idaho National Laboratory (INL), Los Alamos National Laboratory (LANL), Oak Ridge National Laboratory (ORNL), Pacific Northwest National Laboratory (PNNL), Sandia National Laboratories (SNL), and Savannah River National Laboratory (SRNL).

- A Fuels task, which develops and demonstrates transmutation fuels (i.e., fuels containing recovered materials from processing SNF), including clad materials, that will be used to destroy transuranic elements. Essentially, this task is aimed at gathering empirical data and relies on fabrication facilities, irradiation facilities, and examination facilities. The following sites are involved in AFCI Fuels research: INL, LANL, and the French Phenix reactor. ${ }^{5}$

- A Waste Forms task, which verifies the long-term behavior of existing waste forms and develops new waste forms that would be appropriate for future use. The following sites are involved in AFCI Waste Forms research: ANL, INL, LANL, PNNL, SNL, and the SRNL.

- A Safeguards task, which develops and demonstrates new radiation detection technologies and integrates them into high-sensitivity nuclear protection systems. The

\footnotetext{
${ }^{4}$ The analysis of SNF disposition is generic and non-site-specific (i.e., this PEIS does not identify how a future repository could be designed or where it could be located). The PEIS analysis quantifies how much SNF would need to be stored, pending disposal. Transportation impacts to the hypothetical repository are calculated for several different distances to a hypothetical repository (see Appendix E).

${ }^{5}$ In the absence of appropriate irradiation facilities in the United States, fuels irradiations for fast reactor fuels are currently being performed in the French reactor, and there are plans to use Russian (BOR60, BN-600) and Japanese reactors (JOYO, MONJU) in the future.
} 
following facilities are involved in AFCI Safeguards research: ANL, INL, LANL, ORNL, and SRNL.

- A Grid Appropriate Reactor task, which develops small-to-medium-sized reactors that could be used in foreign countries with limited infrastructures. This task is an analytical activity that will eventually require the use of experimental facilities.

- A Reactor task, which develops and demonstrates sodium-cooled fast reactor technologies that could be used for transmutation ${ }^{6}$ of nuclear wastes. The following sites are involved in AFCI Sodium Fast Reactor research: ANL, INL, LANL, and SNL.

The AFCI would be expected to evolve as needed to support any programmatic decisions made as a result of this PEIS.

The No Action Alternative also includes the continuation of other ongoing programs associated with nuclear power deployment within DOE. These programs include the following: the Nuclear Power 2010 (NP-2010) program, the Next Generation Nuclear Plant (NGNP) project, and the Generation-IV Initiative. Similar to the AFCI, these ongoing programs would continue regardless of any decision made as a result of this PEIS.

The NP-2010 program is focused on reducing the technical, regulatory, and institutional barriers to deployment of new nuclear power plants, based on expert recommendations documented in A Roadmap to Deploy New Nuclear Power Plants in the United States by 2010 (DOE 2001b). The technology focus of NP-2010 is on Generation III+ ALWR, designs which offer advancements in safety and economics over current U.S. reactors and are now being deployed internationally. To enable the domestic deployment of new Generation III+ plants in the nearterm, it is essential to demonstrate the new NRC regulatory and licensing processes for the siting, construction, and operation of new nuclear plants. This includes the NRC's early site permit process and its combined construction and operating license (COL) process. As of April 2008, four early site permit applications have been filed, and the NRC has issued three permits (the other one is undergoing NRC review). Seven COL applications have been submitted to the NRC; through 2010, the NRC expects to receive another 15 COL applications (NRC 2008a). The NGNP project is part of the Generation IV Nuclear Energy Systems Initiative, which is focused on developing and demonstrating the next generation of nuclear plants. While the goals of the Generation IV Initiative are to continue advances in the safety, reliability, economics, and sustainability of nuclear power, the objectives of the NGNP project, in particular, include the demonstration of a reactor with operating temperatures higher than standard LWRs. This would significantly improve plant thermal efficiency for producing electricity, while also enabling a number of direct heat applications (such as the generation of hydrogen and other chemical manufacturing processes). The NGNP project proposes to demonstrate both the high temperature reactor and associated fuels, and the generation of both electricity and hydrogen using the high temperature steam. The demonstration facilities would be constructed in the next 10 to 15 years. This PEIS does not provide a NEPA analysis for the NGNP.

\footnotetext{
6 "Transmutation" is the conversion of one isotope to another by changing its structure. Changing one isotope to another changes its nuclear properties and, if the chemical element is changed, changes its chemical properties. Transmutation can be used to destroy long-term hazardous elements, such as transuranic elements, while creating energy.
} 


\section{CLOSED FUEL CYCLE ALTERNATIVES}

\section{3}

\section{Fast Reactor RecyCle Alternative}

Under this alternative, DOE would support a domestic closed fuel cycle in a system that would process LWR SNF in a nuclear fuel recycling center and would recycle some of the recovered materials in advanced recycling reactors, i.e., fast reactors. The SNF from the fast reactors also would be processed to recover materials for repeated recycle in advanced recycling reactors.

The Fast Reactor Recycle Alternative is shown in Figure 2.3-1. The uranium mining, uranium enrichment, LWR disposing of LWR SNF in a geologic repository, however, the LWR SNF would be recycled at a nuclear fuel recycling center. Recycling the LWR SNF would create an opportunity to reuse uranium in LWRs and advanced recycling reactors. Other recovered material (transuranic [TRU] elements-neptunium [Np], plutonium $[\mathrm{Pu}]$, americium $[\mathrm{Am}]$, and curium $[\mathrm{Cm}]$ ) would be fabricated into fuel, along with uranium, for advanced recycling reactors. SNF from advanced recycling reactors would also be recycled.

The processing of spent nuclear fuel would result in HLW requiring eventual disposal in a geologic repository. The advanced separations technology could include the capability to separate cesium and strontium, which could be stored for about 300 years until they have become less radioactive, and then potentially disposed of as low-level radioactive waste, depending upon the regulatory framework. Alternatively, cesium and strontium could be disposed of as high-level radioactive waste in a geologic repository. In addition, implementation of this alternative would result in the generation of Greater-than-Class-C low-level radioactive waste (GTCC LLW), and lowlevel radioactive waste (LLW), both of which would require disposal. The analysis of the environmental impacts of the Fast Reactor Recycle Alternative is presented in Chapter 4, Section 4.3.

\section{Fast Reactor}

A fast reactor is a reactor in which the chain reaction is sustained by fast neutrons. These higher energy neutrons can fission all types of uranium and transuranic elements, rather than only the fissile isotopes split in thermal reactors. This allows the fast reactor to transmute (consume) the transuranics. Thus, fast reactors can extract energy from both uranium and transuranic elements.
These are man-made elements that are heavier (i.e., have a higher atomic number) than uranium, and include, for example, neptunium, plutonium, americium, and curium.

Transuranic elements are created in nuclear power plants when uranium absorbs or captures neutrons. Transuranic elements are generally longlived and radiotoxic, and certain transuranic elements can be used in nuclear weapons.

\section{Greater-than-Class-C Low-Level Radioactive Waste}

As defined by the Nuclear Regulatory Commission in 10 CFR 72.3, low-level radioactive waste that exceeds the concentration limits of radionuclides established for Class $\mathrm{C}$ waste in $10 \mathrm{CFR}$ 61.55 . 


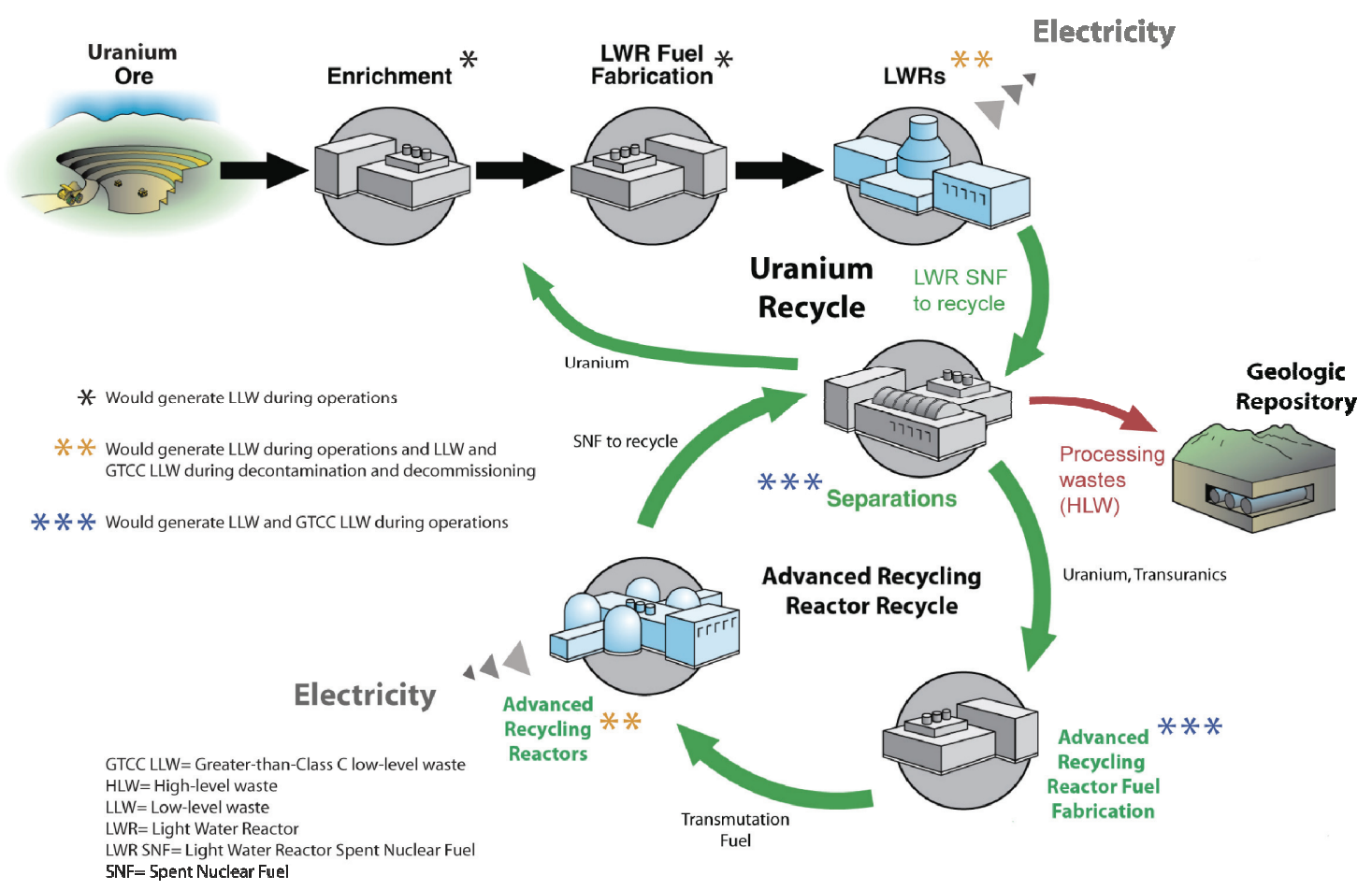

FIGURE 2.3-1-Fast Reactor Recycle Alternative

The Fast Reactor Recycle Alternative would require R\&D primarily in the following areas: fast reactor fuel fabrication and fuel performance; increasing fast reactor capacity to commercial scale; and scaling up fuel recycling (see Chapter 4, Section 4.8.1 for more details). Because transition to this fuel cycle would involve both new reactors and fuels, and the new fuels would require separations to provide feedstock, transition is expected to be more complex than most other fuel cycle alternatives (see Chapter 4, Section 4.8.2 for more details).

With the Fast Reactor Recycle Alternative, a balanced system could be achieved, in which the amount of transuranics produced in LWRs approximates the amount consumed in the advanced recycling reactors. Based on a transuranic conversion ratio $(\mathrm{CR})^{7}$ of 0.5 , a balance could be achieved when the domestic nuclear industry consists of approximately 60 percent LWRs and 40 percent fast reactors (Wigeland 2008a). Such a balanced system would avoid the accumulation of separated transuranics. It is important to note, however, that starting up a fast reactor takes considerably more transuranic material than does the yearly refueling. This fact means that during the transition to a "balanced system," there may be fewer than the equilibrium value of fast reactors, and it may take many decades before the fraction of fast reactors is close to the equilibrium value (which would only be reached in a steady-state system).

Although not shown on Figure 2.3-1, the processing of the SNF from the advanced recycling reactor and the fabrication of the fuel for the advanced recycling reactor would not have to be

\footnotetext{
${ }^{7}$ As used in this PEIS, the CR of a fast reactor is the ratio of the amount of transuranic elements produced to the amount that is consumed in the reactor during the time the fuel is in the reactor. The CR determines the number of fast reactors required to consume transuranics separated from the LWR SNF. At a CR of 0.5, approximately 20 percent of the transuranics would be destroyed per fast reactor recycle pass. The PEIS also includes a sensitivity analysis in Chapter 4 of changing the CR.
} 
done at the same location as the processing of the LWR SNF. The location(s) for all of these processes would be influenced by a number of considerations, including transportation.

Under the Fast Reactor Recycle Alternative, processing methods would be needed that meet the separations requirements for the system, for LWR SNF and for advanced recycling reactor SNF. Typically, processing goals include the recovery of one or more of the actinide elements, determined by which elements are desired for recycle (see Chapter 4, Section 4.3 for a discussion of the advanced separation options and an analysis of how environmental impacts would vary depending upon the separation technology employed). A number of advanced separations technologies have been developed as part of the DOE AFCI program and elsewhere, and they are discussed in Appendix A. In principle, one of these methods could be considered for implementation, or an alternative method that meets the separations requirements could be used. For nonproliferation reasons, DOE is not considering separations processes that produce a pure plutonium stream.

\section{Advanced Separations}

This PEIS considers the use of technologies that could separate spent nuclear fuel into usable and non-usable constituents. The objective of advanced separations is to allow options for management of particular elements in the spent fuel and reduce the wastes requiring geologic disposal.

Advanced separations technologies could provide the capability to selectively remove certain fission products (e.g., technetium, cesium, and strontium) and minor actinides (e.g., neptunium, americium and curium) from the high level waste stream. The minor actinides could be recycled in reactors, while the fission products could be managed and disposed appropriate to their hazard.

Variations to existing separations technologies that have been developed and could be implemented in the near term would target the co-extraction of uranium and plutonium (and possibly neptunium) but would leave the other minor actinides and fission products in the high level waste. Existing separations technology with variations could be deployed at commercial scale with confidence in its readiness. However, advanced separations technologies require research, development and demonstration prior to deploying at commercial scale.

Separating out minor actinides (and destroying them in a reactor) and select fission products would allow tailored management of the wastes streams and could significantly reduce the heat load and radiotoxicity of wastes requiring disposal in a geologic repository.

The advanced recycling reactor must be able to effectively recycle materials such as the TRU elements until they are transmuted and/or fissioned into less hazardous fission products. Although it may be possible in principle to use other reactor types, DOE studies have shown that the fast neutron reactor is most suitable for this role (DOE 2006t, DOE 2006u). This finding is discussed in more detail in Appendix A.

There are also options for how the recycled materials could be arranged in the fuel of the advanced recycling reactor. In one option, all of the fuel could contain the recycled materials, so that the contents of the reactor core would be essentially "homogeneous." Alternatively, one or more of the recycled materials could be placed in the fuel in either separate fuel pins or separate 
fuel assemblies, with the remainder of the core being composed of more traditional fuel. This approach is referred to as a "heterogeneous" reactor core. Depending on the attributes of the fuel and the performance needs, one or the other approach may be superior, but either could be used in principle. The essential aspect of the Fast Reactor Recycle Alternative is that all SNF would be processed, and only the HLW would require geologic disposal. In general, the content of the processing wastes would be mainly fission products and process loss amounts of the actinide elements (including the TRU), although it is possible to decide to not recover one or more of the TRU elements for recycling, in which case they would also be part of the waste contents.

\section{4}

\section{TherMal/FAST REACTOR RECYCle} Alternative

Under this alternative, DOE would support a domestic closed fuel cycle in a system that would process LWR SNF in a nuclear fuel recycling center, and would recycle some of the recovered materials in both thermal reactors, such as LWRs, and fast reactors. This alternative would be similar to the Fast Reactor Recycle Alternative described in Section 2.3, with the following difference: the LWR SNF would be separated into a uranium plus plutonium constituent that would be fabricated into a mixed oxide-uranium-plutonium fuel (referred to hereafter as MOX-U-Pu ${ }^{8}$ fuel) for use in a thermal reactor. Following use in a thermal reactor, the MOX-U-Pu SNF would be recycled, and the recovered materials would be fabricated into fuel for advanced recycling reactors (see Figure 2.4-1). Such an approach would lower the number of fast reactors required to balance the amount of TRU being generated in the LWRs. For example, based on a CR of 0.5 , a balance could be achieved when the domestic nuclear industry consists of approximately 70 percent LWRs (of these, approximately 90 percent would use a traditional uranium dioxide $\left(\mathrm{UO}_{2}\right)$ fuel and 10 percent would use a MOX-U-Pu fuel) and 30 percent fast reactors. (As discussed in Section 2.3, during the transition period, the fraction of fast reactors would be less than in the "balanced" system). Spent nuclear fuel would be processed to create new nuclear fuel, but the process would result in the same waste types (i.e., HLW, GTCC LLW, and LLW) as the Fast Reactor Recycle Alternative, but in different quantities and with different characteristics.

Under the Thermal/Fast Reactor Recycle Alternative, there are many variations that could be proposed, including which of the TRU elements would be recovered, which would be recycled in reactors as fuel or targets, and which would be sent to the waste stream.

\footnotetext{
${ }^{8}$ The use of a MOX-U-Pu fuel is analyzed as the baseline approach for this alternative. It would, however, be conceptually possible to use a MOX-TRU fuel, particularly for the stabilization of the total transuranics, rather than disposing of the minor actinides in a repository. Chapter 4 discusses the major differences between the use of MOX-U-Pu fuel and MOX-TRU fuel.
} 


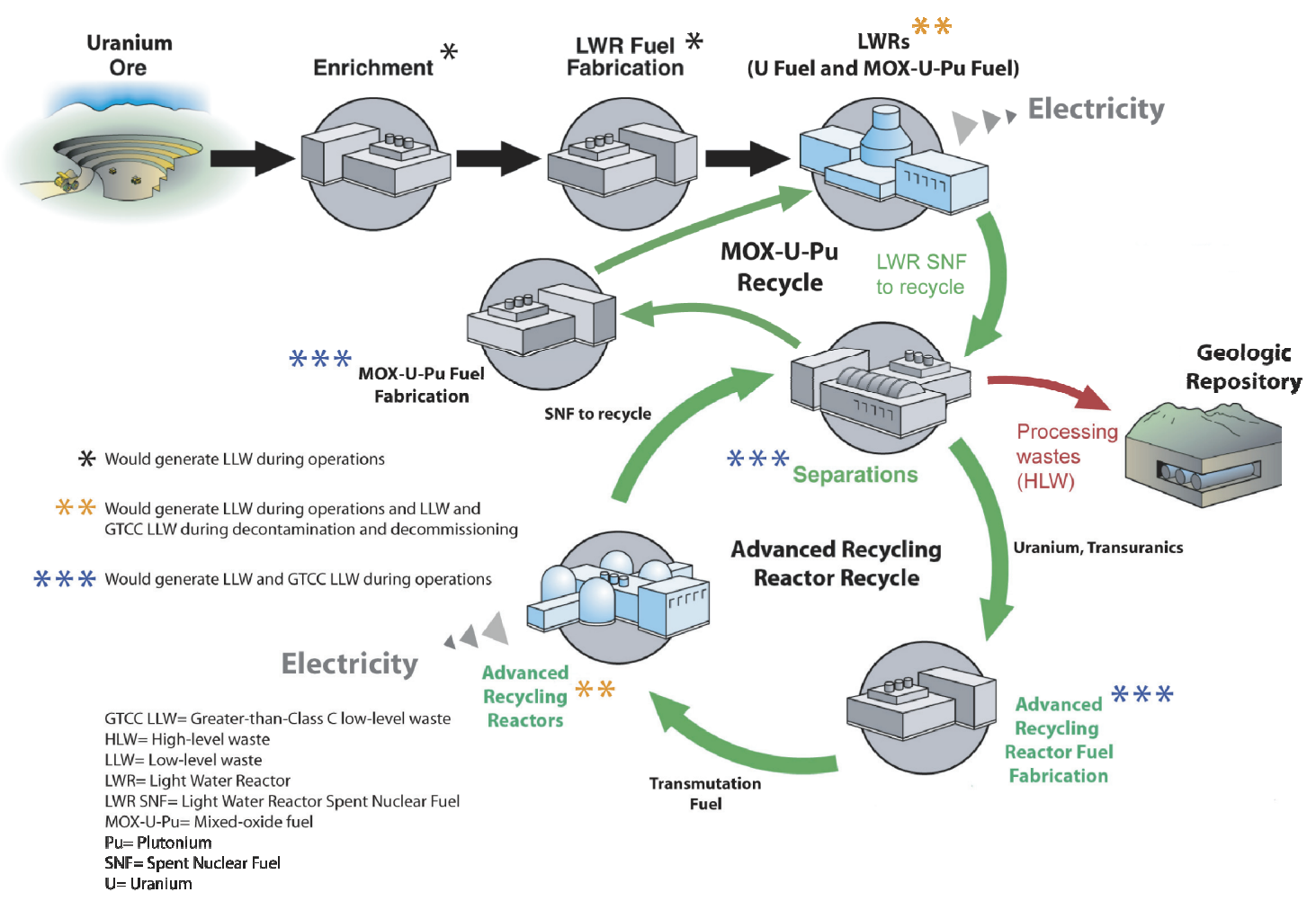

FIGURE 2.4-1-Thermal/Fast Reactor Recycle Alternative

The Thermal/Fast Reactor Recycle Alternative would require R\&D in the same areas as the Fast Reactor Recycle Alternative (see Chapter 4, Section 4.8.1). However, because the initial recycling would be performed in thermal reactors, near-term deployment of the Thermal/Fast Reactor Recycle Alternative is possible with variations to existing separations technologies, fuel, and reactor technologies. For example, for the initial recycle in thermal reactors, a MOX-U-Pu fuel has already been developed and is in use in Europe. From an implementation standpoint, because the Thermal/Fast Reactor Recycle Alternative would require limited development and licensing of a new fuel type and the development of facilities to provide feedstock for the fuel, this alternative could start transition relatively quickly, compared to some

Feedstock refers to the nuclear materials used to produce fuel for a reactor.

of the other action alternatives (see Chapter 4, Section 4.8.2). This alternative differs from the Fast Reactor Recycle Alternative in that the Thermal/Fast Reactor Recycle Alternative could be implemented more quickly by use of existing thermal reactors and variations to existing separations technologies as the first step in this fuel cycle. The Thermal/Fast Reactor Recycle Alternative differs from the Thermal Reactor Recycle Alternative because, in the longer term, this alternative would transition to advanced separations technologies and fast reactors resulting in a greater reduction in the radiotoxicity and heat load of remaining spent nuclear fuel. Both the Thermal/Fast Reactor Recycle Alternative and the Fast Reactor Recycle Alternative have the potential for much greater reductions in radiotoxicity and heat load for materials requiring geologic disposal than any other closed or open fuel cycles.

The analysis of the environmental impacts of the Thermal/Fast Reactor Recycle Alternative is presented in Chapter 4, Section 4.4. 
This alternative would recycle LWR SNF and use the recovered material to fuel thermal reactors. For this Alternative, the following three options are assessed:

- Option 1-Recycle LWR SNF to produce a MOX-U-Pu fuel for use in LWRs;

- Option 2-Recycle LWR SNF to produce fuel for use in HWRs; and

- Option 3-Recycle LWR SNF to produce a transuranic fuel for use in HTGRs.

Unlike the Fast Reactor Recycle Alternative, which would require comparably more R\&D (related to transmutation fuel development and fast reactor fuel separation), Option 1 could use existing thermal reactor technologies and fuel fabrication technologies. Consequently, this Option may be implemented more quickly (although it is acknowledged that the Thermal/Fast Reactor Recycle Alternative could be initiated in the same timeframe). In contrast to the Fast Reactor Recycle Alternative and the Thermal/Fast Reactor Recycle Alternative, however, only the partial consumption of the transuranics would occur, and the minor actinides in the SNF that are not recovered for recycle would have to be disposed of in a geologic repository.

For Option 1, only processing wastes (HLW containing the minor actinides, in addition to fission products) would be disposed of in a geologic repository. In contrast, for Options 2 and 3, both HLW and SNF would require disposal in a geologic repository. Consequently, Option 1 would achieve a completely closed fuel cycle, while Options 2 and 3 would only achieve a partially closed fuel cycle. All three options would include GTCC LLW and LLW as part of the wastes from reprocessing. Since these three options are significantly different from one another, in terms of the facilities required and performance, they are addressed separately below. The environmental impacts of the Thermal Reactor Recycle Alternative are presented in Chapter 4, Section 4.5.

\subsubsection{Thermal Reactor Recycle Alternative (Option 1-Thermal Recycle in Light Water Reactors)}

Under Option 1, DOE would support a domestic closed fuel cycle in a system that would process LWR SNF at a nuclear fuel recycling center and recycle some of the recovered materials as new fuel for use in LWRs. This option would involve the recycle of uranium and plutonium for reuse in LWRs using a fuel assembly concept that combines traditional $\mathrm{UO}_{2}$ and $\mathrm{MOX}-\mathrm{U}-\mathrm{Pu}$ fuels. This approach is shown in Figure 2.5.1-1. 


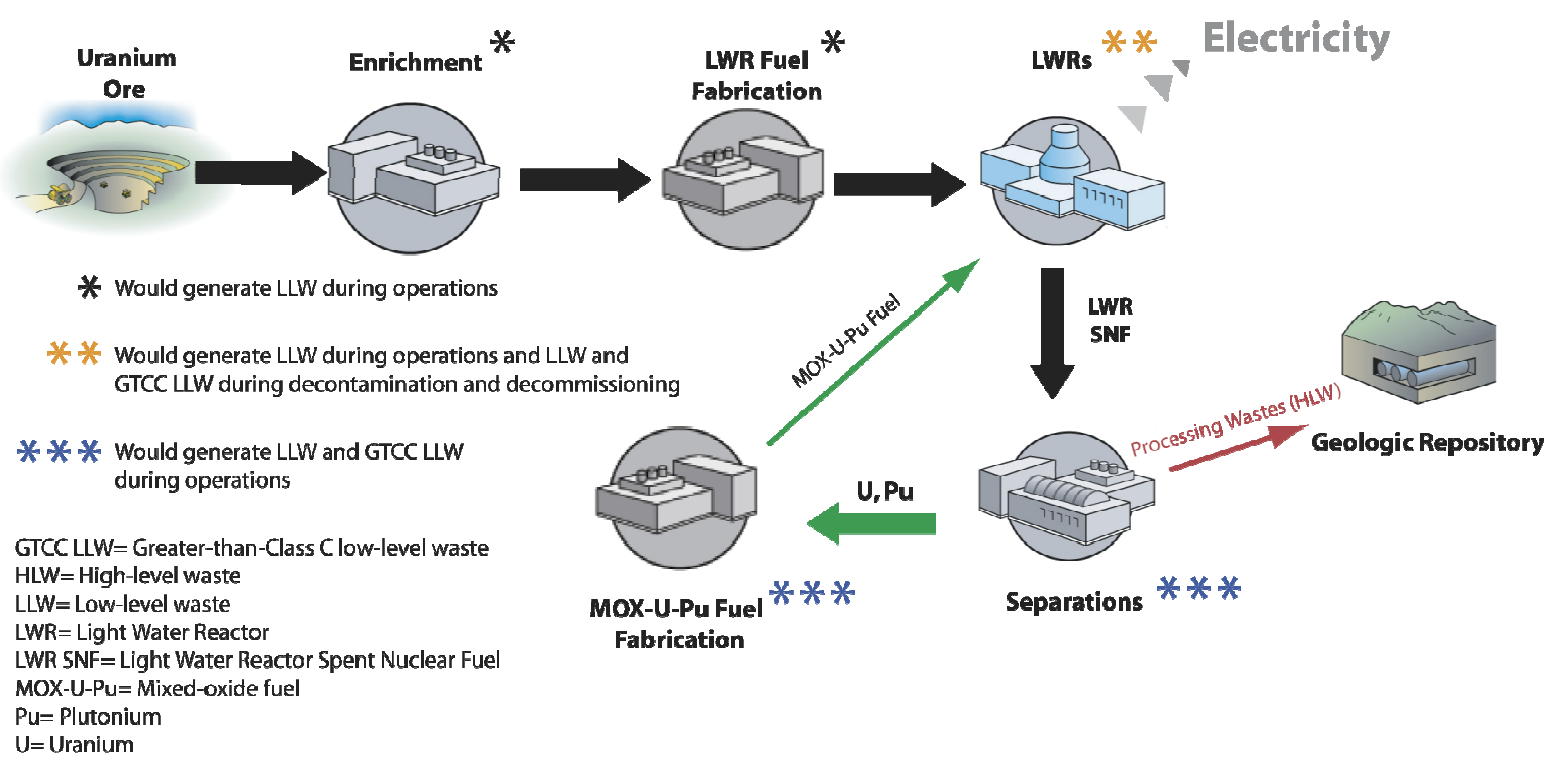

FIGURE 2.5.1-1-Thermal Reactor Recycle Alternative:

Option 1 (Mixed Oxide Uranium Plutonium Recycle)

Multiple recycle of the plutonium would make it possible to stabilize the total plutonium inventory. Stabilization of the plutonium inventory in the LWR fuel cycle implies no growth in the plutonium inventory in the quantities of SNF being generated and processed. Multiple recycle of plutonium in LWRs could, therefore, slow down the accumulation of plutonium in the waste destined for disposal in a geologic repository. Under this option, all of the MOX-U-Pu $\mathrm{SNF}$ would be recycled to recover the U-Pu in the assembly. During the separation, most U-Pu would be recycled, while all fission products and the minor actinides (Np, Am, Cm, and higher) would be separated during fuel reprocessing between recycle passes and sent to waste storage and eventual disposal in a repository. The reusable material would then be used for fabricating the fuel for the next stage of the multi-recycle operation (ANL 2002a).

This option would require facilities to recycle LWR SNF (using variations to existing separations technologies) and to fabricate MOX-U-Pu fuel. During SNF recycling, this option would generate the same waste types as the Fast Reactor Recycle Alternative, but in different quantities and with different characteristics.

The Thermal Reactor Recycle Alternative (Option 1) would require R\&D related to fuel development and fabrication, and large-scale recycling (see Chapter 4, Section 4.8.1). However, this alternative could start transition sooner, and proceed through transition more quickly, than many fuel cycle alternatives because it would only require development and licensing of a new fuel type and development of facilities to provide feedstock for the fuel (see Chapter 4, Section 4.8.2). 
The baseline approach analyzed in this PEIS for this option would be to use a MOX-U-Pu fuel. ${ }^{9}$ In theory, however, it would be possible to use a MOX-TRU fuel, particularly for the stabilization of the total transuranics, rather than disposing of the minor actinides in a repository. Analyses have shown that such complete TRU transmutation in LWRs is difficult in practice (Salvatores et al. 2003). With each successive recycle in the early recycle passes, the TRU content in the MOX-TRU pins would increase as more TRU is produced in the $\mathrm{UO}_{2}$ pins than is consumed in the MOX-TRU pins (although the rate of increase slows as the equilibrium state is approached). Multi-recycling of the TRU would lead to a significant increase in the higher actinide content of the fuel assembly, which would complicate fuel handling, as compared to standard $\mathrm{UO}_{2}$ or MOX assemblies, due to the much higher radiation from the transuranics in the transmutation fuel (ANL 2004).

Another heterogeneous approach (sometimes referred to as using "targets") could also be pursued. Previous studies performed in the AFCI program (Salvatores et al. 2003 and Collins et al. 2007) concluded that the recycle of Am and $\mathrm{Cm}$ in separate "target" pins was technically feasible from a nuclear physics viewpoint, and that such a recycle approach could result in effective fission and/or transmutation of transuranics. Practically, in LWRs using targets, the driver and target pins are located in the same assembly. This situation is due to the need to provide neutrons for the irradiation of the predominantly fertile target pins. The target pins are neutron absorbers and, consequently, their use requires an increase of the fissile content of the fuel (higher enrichment uranium fuel or higher plutonium-content MOX fuel) to meet specified cycle length and burnup requirements. In this regard, using target pins with MOX pins in an LWR core would require enriched uranium to support the fission process, if multiple recycle of the MOX pin is envisaged. Chapter 4, Section 4.3 discusses the use of targets in more detail and explains how the environmental impacts could change, compared to the baseline homogeneous approach.

\subsubsection{Thermal Reactor Recycle Alternative (Option 2-Thermal Recycle in Heavy Water Reactors)}

Under Option 2, DOE would support a domestic closed fuel cycle in a system in which light water reactor spent nuclear fuel would be used as a source of fissile material to fuel heavy water reactors (HWRs). Due to the fundamental characteristics of LWRs and HWRs, a synergistic fuel cycle could be developed to accomplish the objectives described in Chapter 1. This option would be possible because HWRs require no or low initial fuel enrichment, which can be provided by LWR SNF, which has a relatively high end-of-cycle fissile content (approximately

Heavy water reactors are thermal reactors that use deuterium oxide (heavy water) as a moderator and coolant for the reactor core. Natural (non-enriched) uranium typically is used as fuel, although other fuels consisting of slightly enriched uranium, mixed oxides of plutonium and uranium, or mixed oxides of plutonium and thorium, can be used.

0.9 percent $\mathrm{U}-235$ and 0.6 percent $\mathrm{Pu}-239$, depending on the initial LWR fuel enrichment and discharge burnup). For this PEIS, this fuel cycle will also be referred to as the "Direct $\underline{\text { Use of }}$

\footnotetext{
${ }^{9}$ MOX-U-Pu fuel could potentially include neptunium. The addition of minor actinides (such as neptunium) to the MOX fuel would reduce the quantity of transuranics in the HLW stream, thus also providing some further reduction in long-term radiotoxicity and thermal output (see Table 4.8.1). From the standpoint of potential impacts or difficulties in fuel fabrication and reactor operations, MOX-U-Pu fuel and MOX-U-Pu-Np fuel are expected to be similar.
} 
Spent $\underline{P W R}^{10}$ Fuel in $\underline{\mathrm{C} A N D U}{ }^{\prime 11}$ (or DUPIC) fuel cycle. The DUPIC fuel cycle is particularly attractive in Korea, which is the only country in the world that has HWR (CANDU) and PWR reactors. As such, much of the research involving DUPIC has involved South Korean and Canadian researchers.

The basic concept of the DUPIC fuel cycle is to fabricate the HWR nuclear fuel from PWR ${ }^{12}$ SNF, principally by use of dry thermal/mechanical processes. The advantages of using the DUPIC fuel cycle are as follows: 1) to eliminate the PWR SNF, which would be re-fabricated into HWR fuel; 2) to save natural uranium resources that would have been required to produce HWR fuel; and 3) to reduce SNF accumulation (Yang and Park 2006).

The DUPIC fuel cycle (Figure 2.5.2-1) would be relatively simple and would require the following: 1) one or more facilities to receive LWR SNF and then directly fabricate HWR fuel bundles by thermal and mechanical processes (hereafter, such a facility will be referred to as a DUPIC Fuel Fabrication Facility); and 2) a mix of LWRs and HWRs. By utilizing LWR SNF as an energy source for HWRs, approximately 50 percent more energy can be derived from the LWR fuel. A steady-state material balance for the DUPIC fuel cycle would require approximately 73 percent LWRs and 27 percent HWRs $^{13}$ (Yang and Park 2006). Recycling the LWR SNF would generate the same waste types as the other recycle alternatives but in different quantities and with different characteristics. This option would also generate HWR SNF that would require disposal in a geologic repository.

\footnotetext{
${ }^{10}$ A pressurized water reactor (PWR) is a type of LWR.

${ }^{11}$ The acronym "CANDU," a registered trademark of Atomic Energy of Canada Limited (AECL), stands for "CANada Deuterium Uranium." This is a reference to its deuterium-oxide (heavy water) moderator and its use of natural uranium fuel. All current power reactors in Canada are of the CANDU type.

${ }^{12}$ In principle, either PWR or boiling water reactor (BWR) SNF could be used, as long as the content of the SNF is appropriate for use in the HWR.

${ }^{13}$ In the Summary, this ratio is rounded to 75 percent LWRs and 25 percent HWRs.
} 

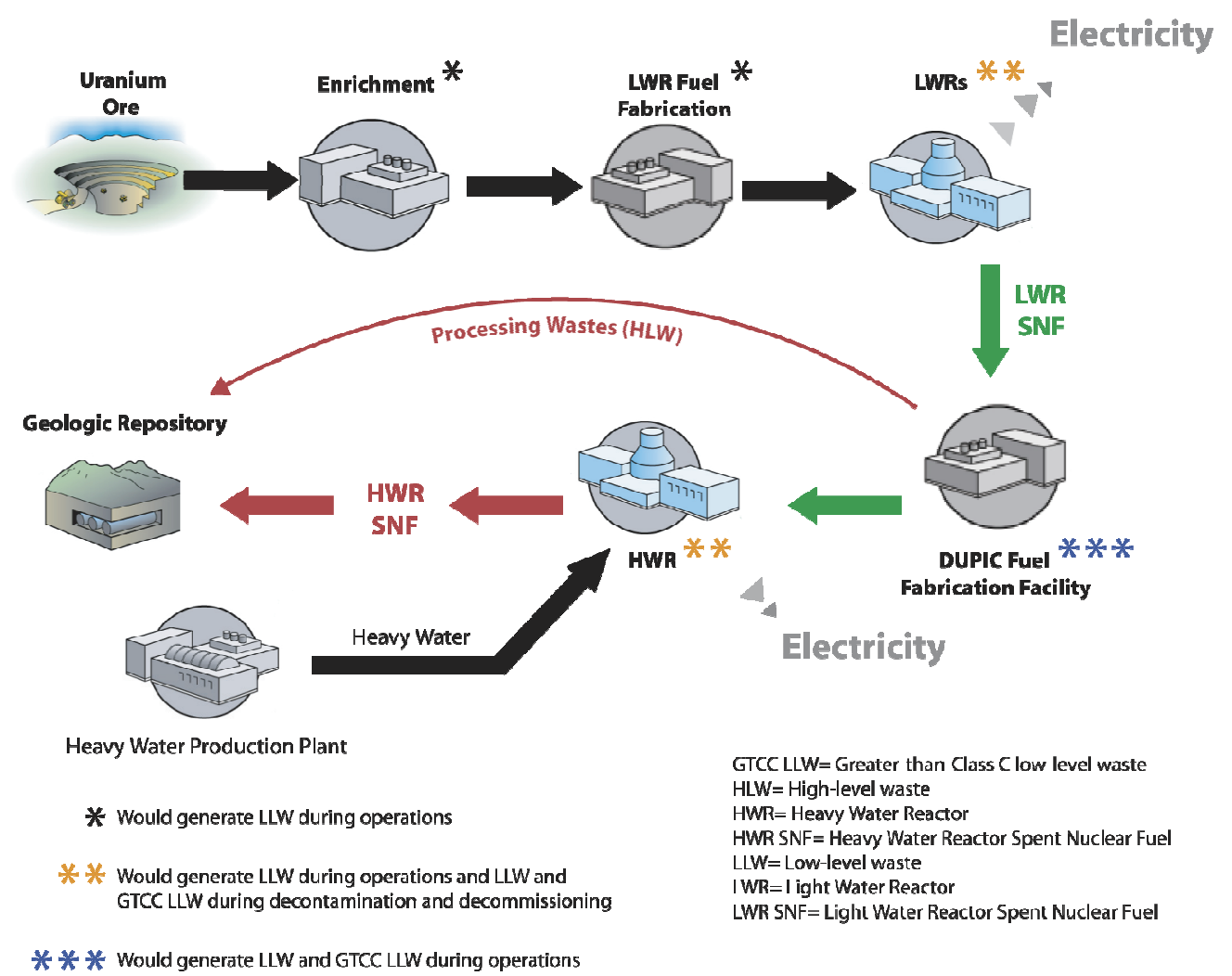

* * * Would generate LWW and GTCC uW during operations

\section{FIGURE 2.5.2-1-Thermal Reactor Recycle Alternative: Option 2 (DUPIC Fuel Cycle)}

The Thermal Reactor Recycle Alternative (Option 2) would require R\&D related to fuel development and fabrication, and large-scale recycling (see Chapter 4, Section 4.8.1). Because both LWRs and HWRs are widely used commercially, most transition issues would be related to spent fuel treatment to provide feedstock for the HWRs (see Chapter 4, Section 4.8.2). Additionally, the development and deployment of heavy water production facilities would be required.

Depending upon the process employed to produce fuel assemblies for a HWR, the DUPIC recycling process has the potential to be simpler than the separation processes assessed for the Fast Reactor Recycle Alternative and the Thermal Reactor Recycle Alternative (Option 1). In fact, the transfer from LWR to CANDU might be literally "direct," involving only the cutting of spent LWR fuel rods to CANDU length (approximately 50 centimeters), resealing (or doublesheathing), and reengineering into cylindrical bundles suitable for CANDU geometry (Yang et al. 2005). Alternatively, a dry recycling technology that could provide more optimal reactivity and, therefore, higher burnup for the CANDU core is being developed and demonstrated. This technology includes mechanical removal of the cladding, followed by a thermal process to reduce the spent LWR fuel to powder. The powder is then sintered and pressed into CANDU sized pellets. This fuel fabrication process has been termed the Oxidation and Reduction of Oxide Fuel (OREOX) process (Yang et al. 2005). In this PEIS, the OREOX 
process is assessed. ${ }^{14}$ Waste streams from the OREOX process would include HLW, GTCC LLW, and LLW.

The Korea Atomic Energy Research Institute (KAERI) has fabricated DUPIC fuel elements in a laboratory-scale remote fuel fabrication facility. KAERI has demonstrated the fuel performance in the research reactor, and it has confirmed the operational feasibility and safety of a CANDU reactor loaded with the DUPIC fuel using conventional design and analysis tools, which will be the foundation of the future practical and commercial uses of DUPIC fuel (Yang et al. 2005).

\subsection{3}

\section{Thermal Reactor Recycle Alternative (Option 3-Thermal Recycle in High Temperature Gas-Cooled Reactors)}

Under Option 3, DOE would support a domestic closed fuel cycle in a system that would recycle light water reactor spent nuclear fuel using advanced separations and use the recovered transuranic materials in high temperature gas-cooled reactors (HTGRs) to achieve deep-burn. A representative system of this alternative is the deep-burn modular helium reactor (DB-MHR) concept, which is being developed by General Atomics (Kim et al. 2006, Hong et al. 2007).

The essential feature of the concept is the use of HTGRcoated fuel particles that are considered strong and highly resistant to irradiation and, therefore, potentially

High temperature gas-cooled reactors are thermal reactors that use graphite as a moderator to slow down neutrons and gas (such as helium) to remove heat from the reactor core. Thorium, uranium or transuranic elements can be used as fuel.

Deep-burn refers to the relatively high amount of transuranics that would be consumed in the high temperature gas reactor. For transuranic consumption of 60 percent, the burn-up could be about 610 times greater than other reactor technologies.

a durable waste form for the permanent disposal of SNF. Recent evaluations have indicated that a TRU consumption level as high as approximately 60 percent is attainable in a single-pass in the DB-MHR system (Kim et al. 2006).

Thermal Recycle in HTGRs (Figure 2.5.3-1) would require one or more facilities to recycle LWR SNF (using the same advanced separation options as the Fast Reactor Recycle Alternative) and to fabricate HTGR fuel made up of transuranic elements. Recycling the light water reactor spent fuel would generate the same waste types as other recycle alternatives, but likely in different quantities and with different characteristics. ${ }^{15}$ This option would also generate HTGR SNF that would require disposal in a geologic repository. Based on a steady-state material balance for transuranic consumption, this alternative would require approximately 82 percent LWRs and 18 percent HTGRs ${ }^{16}$ (Goldner and Versluis 2006), although, as explained below, there are uncertainties with data related to the Thermal Reactor Recycle Alternative (Option 3 ).

The Thermal Reactor Recycle Alternative (Option 3) is the least developed domestic programmatic alternative, with only limited data available. Many key data (such as the amount of

\footnotetext{
${ }^{14}$ In 1992, AECL, the Korea Atomic Energy Research Institute (KAERI), and the U.S. Department of State completed Phase I of an assessment of the DUPIC cycle. All of the options were assessed against a set of selection criteria, which included: retrofitability to CANDU and to PWR, safeguardability, licensability, reactor physics, fuel performance, fuel handling, fuel fabrication, and waste management. It was concluded that OREOX is the most promising option, largely because of the homogeneity of the resultant powder and pellets.

${ }^{15}$ Because the Thermal Reactor Recycle Alternative (Option 3) is the least developed domestic programmatic alternative, with only limited data available, it is not possible to quantify the specific differences in quantities and characteristics.

${ }^{16}$ In the Summary, this ratio is rounded to 80 percent LWRs and 20 percent HTGRs.
} 
LWR SNF that would be processed, the amount of transuranics to be recovered, and the deepburn fuel composition) have not been determined. Much of that data that has been quantified has been from one of the principal HTGR vendors. Data from the vendor indicates that a 70 percent reduction in transuranic waste and a 2-3 time reduction in thermal heat load are possible (Goldner and Versluis 2006). The use of these data would indicate an improvement in meeting the purpose and need objectives compared to the No Action Alternative. While DOE has reviewed the information available, there is currently insufficient research available to verify that these data are correct. The available information for the deep burn alternative can best be characterized as initial estimates due to the approximations made and the requirements placed on the analyses, and only provides a rough estimate of the number of HTGRs that would be required to support the light water reactors. However, DOE believes that these data represent an initial estimate that can be used to reach some general conclusions that are not sensitive to the potential inaccuracies associated with such estimates. Consequently, any quantifications presented in this section for this option are only preliminary estimates, and do not have the same level of confidence as the data for other alternatives. DOE has recently funded additional research through the Generation IV program, which will result in information that will increase DOE's knowledge base regarding this alternative, but this research will not be available for use in this PEIS.

The Thermal Reactor Recycle Alternative (Option 3) would require significant R\&D related to: fuel development and fabrication; large scale high temperature gas-cooled reactors that utilize a non-uranium fuel; and large-scale recycling of light water reactor spent fuel (see Chapter 4, Section 4.8.1). This alternative would also require one or more reactor-grade graphite production plants, which currently do not exist in the United States. Transition to this alternative is considered complex (see Chapter 4, Section 4.8.2).

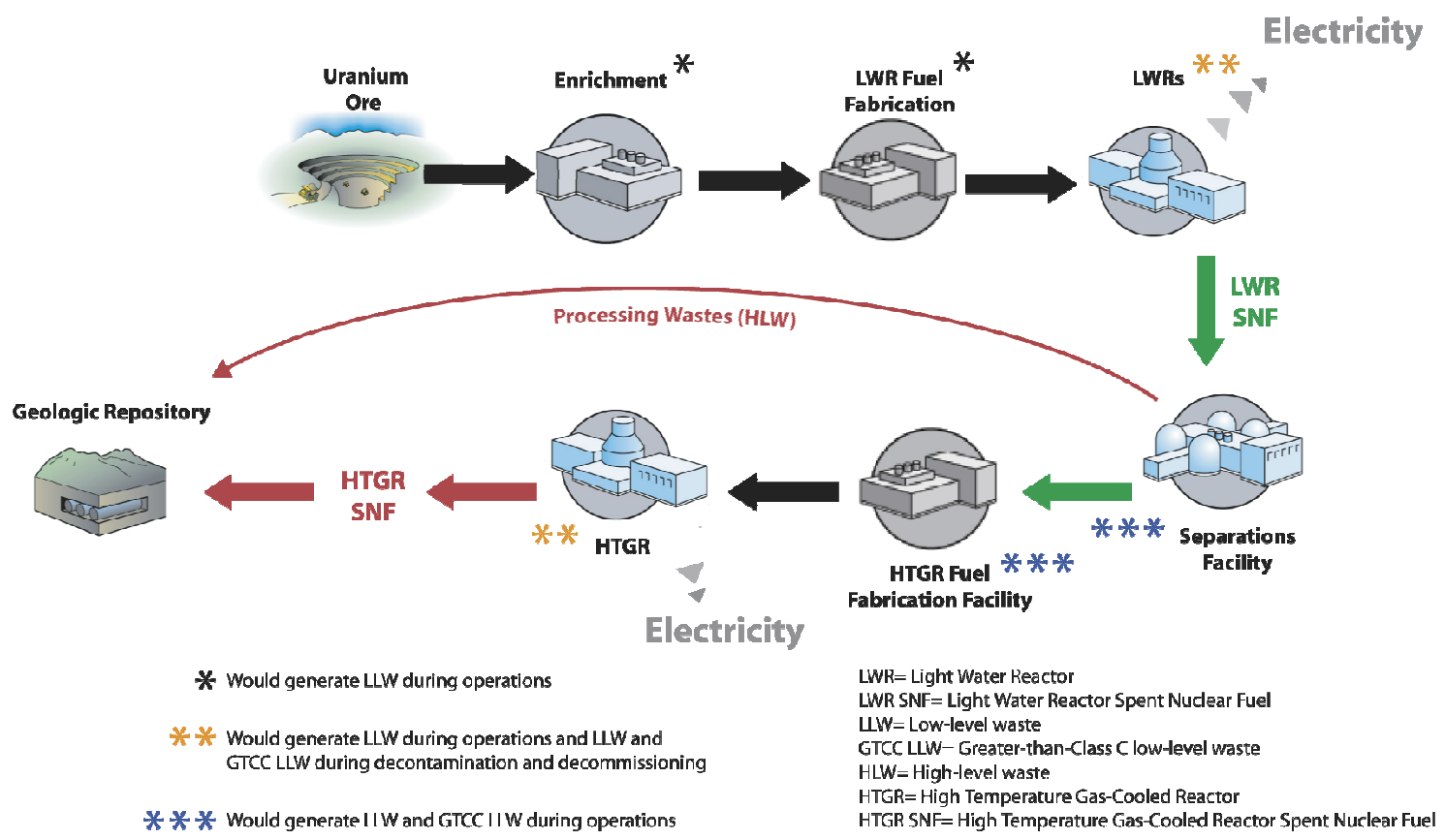

FIGURE 2.5.3-1—Thermal Reactor Recycle Alternative: Option 3 (Thermal Recycle in High Temperature Gas-Cooled Reactors) 


\section{OPEN FUEL CYCLE ALTERNATIVES}

\section{6}

\section{THORIUM Alternative}

The Thorium Alternative, a once-through fuel cycle, has the potential to reduce the volume and heat load of SNF requiring disposal in a geologic repository, which makes this fuel cycle a reasonable alternative for consideration in this PEIS. The environmental impacts of the Thorium Alternative are presented in Chapter 4, Section 4.6.

Currently, almost all reactors use uranium and/or plutonium derived from uranium as their fuel. Thorium, however, can also be used to breed uranium-233 (U-233) to fuel nuclear reactors. Thorium is about three times as abundant as uranium in nature, but it cannot, by itself, create or sustain the nuclear chain reaction ("criticality") needed to produce the heat in a nuclear reactor to generate electricity, as natural thorium occurs mainly as the fertile thorium-232 (Th-232) isotope. If, however, Th-232 absorbs a neutron, it can become fissile U-233. The U-233 created in the reactor is a more effective fuel than either U-235 or Pu-239 in a thermal neutron spectrum and, therefore, relatively small amounts of it can provide a significant contribution to sustaining a reactor's operation.

Thorium is a lighter element than either uranium or plutonium. As such, when thorium is used as a major component of reactor fuel, the production of transuranics $(\mathrm{Np}, \mathrm{Pu}, \mathrm{Am}$, and $\mathrm{Cm})$, which are the primary contributors to long-term waste radiotoxicity and heat load in geologic repositories, is reduced relative to conventional uranium-based fuels (IAEA 2002b). Although fewer transuranics are produced, they are replaced with shorter half-life uranium isotopes (such as U-232 and U-233). As these uranium isotopes decay, they produce isotopes with a radiotoxicity that is higher than with uranium-based fuels. (See Chapter 4, Figure 4.6-2, which shows that the radiotoxicity of thorium SNF would be higher than uranium SNF after approximately 50,000 years.)

Between the mid 1960s and the 1980s, several experimental and prototype power reactors were successfully operated using thorium fuels. In addition, the Indian Point-2 commercial PWR successfully used thorium-based fuel, and thorium-based fuel was also used in several commercial HTGRs. Despite the generally positive experience with these fuels, however, so far, thorium fuels have not been introduced commercially on a large scale, mainly because the estimated uranium resources have turned out to be sufficient to support the existing reactor fleets in a cost-effective manner.

Because it would be compatible with existing or future thermal reactors (e.g., LWRs, HWRs, and HTGRs), the Thorium Alternative (shown in Figure 2.6-1) can be characterized as a "new fuel design," rather than as a new reactor concept, though it is different in many respects from the existing uranium once-through fuel cycle. In fact, based on recent studies, albeit generally not involving detailed designs, the Thorium Alternative would be feasible for implementation in most existing commercial nuclear power plants without major modifications to the engineered systems (e.g., control rods and soluble boron control systems) (IAEA 2005a). 
For purposes of this PEIS, the Thorium Alternative as implemented in an LWR is assessed. While it is technically possible to recycle the SNF from a thorium-based fuel cycle to recover the actinides for reuse, this alternative is not assessed in this PEIS as a reasonable one, for the reasons explained in Section 2.8. Thorium SNF would be sent to a geologic repository.

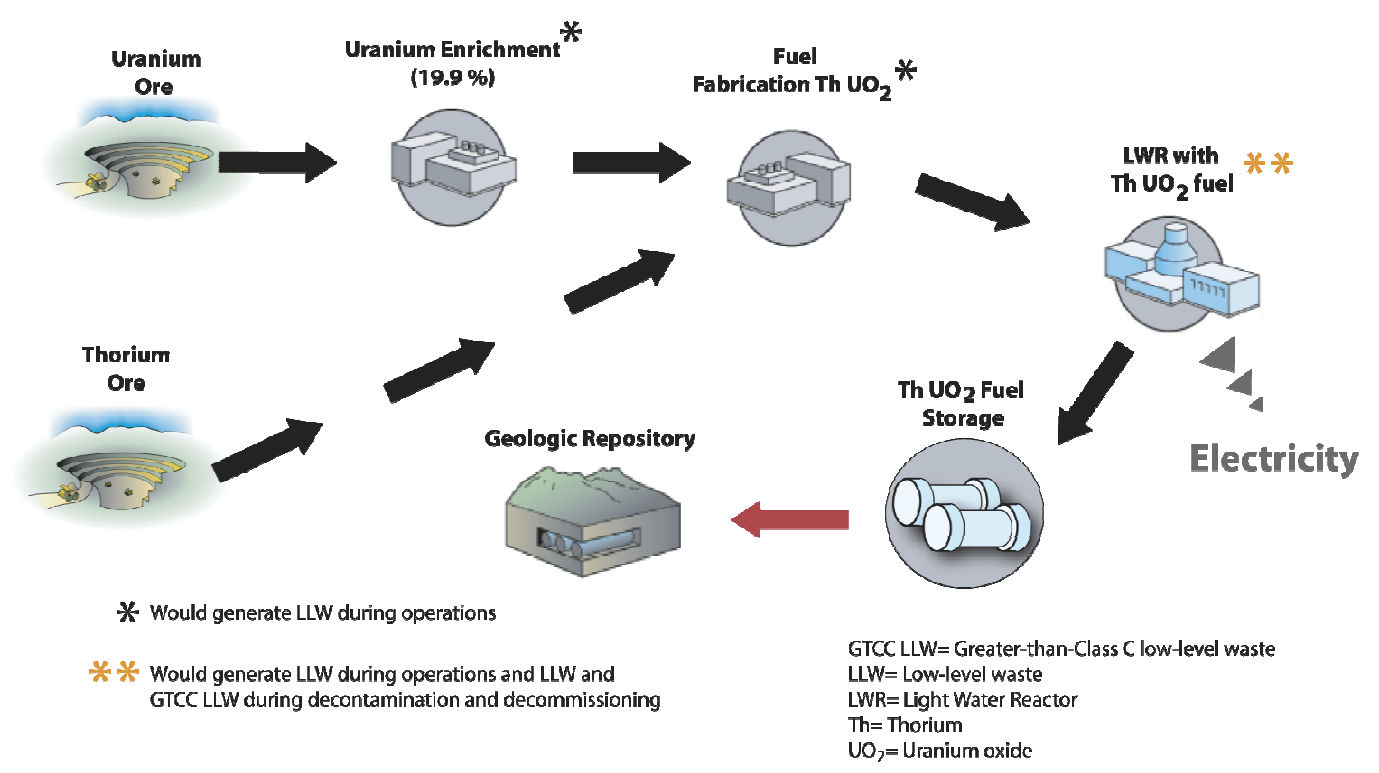

FIGURE 2.6-1-Thorium Alternative

The Thorium Alternative would require R\&D related to fuel development and fabrication, and increasing reactor capacity to commercial scale. Transition could proceed relatively quickly because development and licensing of a new fuel type would be less complex than issues related to many of the other fuel cycle alternatives.

\section{HeAVy WATER REACTOR/High TeMPERATURE GAS-COOLED REACTOR Once-Through Fuel CyCle Alternative (HWR/HTGR Alternative)}

This alternative would involve a once-through fuel cycle that uses either HWRs or HTGRs. Because the HWR/HTGR Alternative has the potential to reduce the volume, heat load, and/or radiotoxicity of SNF requiring disposal in a geologic repository, it is being assessed as a reasonable alternative in this PEIS. For the HWR/HTGR Alternative, the following two options are assessed: Option 1-Use HWRs only (Section 2.7.1); and Option 2-Use HTGRs only (Section 2.7.2). In either case, the SNF would be stored until DOE can accept the SNF for disposal in one or more permanent geologic repositories. This is the only domestic programmatic alternative that would completely phase-out LWRs in the United States. For this alternative, this PEIS assumes that full implementation would occur by approximately 2060-2070, meaning that all LWRs would be phased-out by that time. However, because it is possible that some LWRs could continue to operate past 2060-2070, the PEIS also discusses how impacts would change if that were to occur. The environmental impacts of the HWR/HTGR Alternative are presented in Chapter 4, Section 4.7. 


\subsubsection{HWR/HTGR Alternative (Option 1-Heavy Water Reactor)}

For their reactor cores, HWRs use deuterium oxide (heavy water) as a moderator and coolant. Deuterium is a stable but rare isotope of hydrogen containing one proton and one neutron in its nucleus. Common hydrogen has only one proton in its nucleus. Chemically, the additional neutron in heavy water changes its characteristics only slightly, but in nuclear terms, the difference is significant. The role of water as the moderator in a thermal reactor is to slow neutrons down to an energy level where they will cause fissions to occur in uranium atoms in the fuel. Since the natural water used in LWRs absorbs more neutrons than heavy water, LWR fuel must be enriched to increase the amount of fissionable U-235 content needed to maintain a nuclear reaction. With fewer neutrons absorbed by heavy water (600 times fewer), more neutrons are available to fission the uranium atoms in the fuel and, therefore, enrichment is not required. This enables even natural uranium rather than enriched uranium to be used for fuel in a HWR.

There has been a great deal of experience internationally with HWRs. Canada has been the principal developer of HWRs for commercial power production, and Canada has several in operation and under continued development. In the 1950s, Canada began development of the CANDU power reactor concept. CANDU is a pressurized heavy water reactor using natural uranium fuel. The selection of this concept built upon the Canadians' previous experience and allowed them to use indigenous uranium reserves. The use of natural uranium avoids the requirement for uranium enrichment capability and eliminates the creation of depleted uranium enrichment plant tails (Canada 2007, Whitlock 2000, Boczar et al. 2002).

While natural uranium fuel is used in Canada, a variety of enrichments and fissile loadings can be accommodated in existing CANDU designs. These include slightly enriched uranium (SEU), mixed oxides of plutonium/uranium or plutonium/thorium, and fuels containing no fertile material. Unlike PWRs and boiling water reactors (BWRs), the CANDU reactors can also be refueled while the reactor is operating at full power ("online"), a capability created by the subdivision of the core into hundreds of separate pressure tubes that contain fuel.

This alternative would require R\&D related to fuel development and fabrication (see Chapter 4, Section 4.8.1). Because HWRs are widely used commercially in other countries, transition issues would be less complex than for some other fuel cycle alternatives (see Chapter 4, Section 4.8.2). However, because HWRs are not used commercially in the United States and commercial scale heavy water production facilities do not exist domestically, the development and deployment of heavy water production facilities would be required.

Under this option, for analysis purposes, it is assumed that the U.S. nuclear fuel cycle would fully transition to an all-HWR once-through fuel cycle (Figure 2.7.1-1). It is acknowledged that such transition would take many decades to accomplish (as existing LWRs would continue operations until reaching end-of-life). 


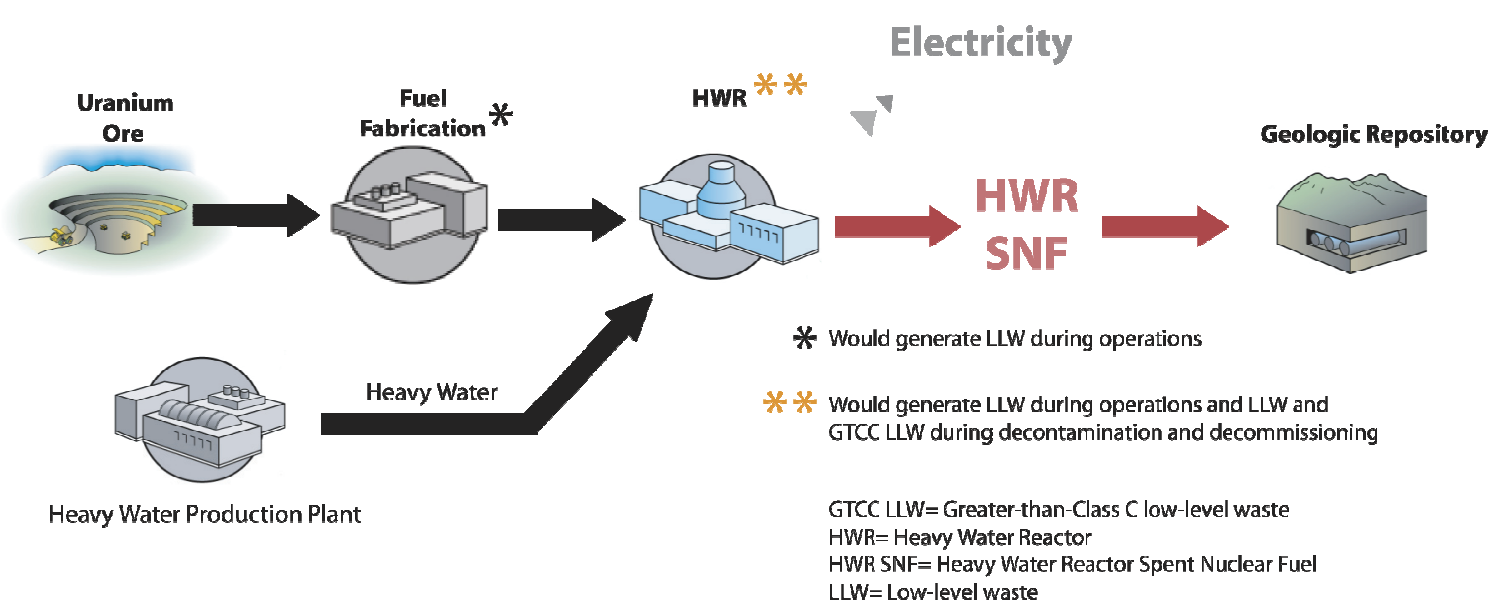

FigURE 2.7.1-1-Heavy Water Reactor Open Fuel Cycle

2.7.2

HWR/HTGR Alternative (Option 2-High Temperature Gas-Cooled Reactor)

HTGRs use graphite as a moderator to slow down neutrons and gas circulation to remove heat from the reactor core. While other gases had been used earlier, the development of helium-cooled gas reactors began in the 1960s, with prototype power plants constructed in the United States, Great Britain, and Germany. Helium coolant allowed the gas reactor to achieve higher operating temperatures and, therefore, higher efficiencies for producing electricity. The 13 MWe AVR in Germany operated successfully for 21 years, demonstrating the application of HTGR technology for electric power production (WNA 2008f). The 300 MWe Thorium High Temperature Reactor (THTR-300) was another plant built and operated in Germany, which helped demonstrate the HTGR concept. Both were pebble bed reactors that used U-235 and Th-232 fuel. Pebble bed reactors are fueled by spheres of graphite moderator with small particles of fuel dispersed throughout. These spheres are stacked in a close-packed lattice and cooled by helium. The heated helium may then be used to create steam for electricity or drive a turbine generator directly.

HTGRs can also be built using hexagonal (prismatic) graphite blocks. The fuel in a prismatic core is made of small particles pressed into graphite compacts that are placed into the graphite blocks. Fort St. Vrain (now shut down) had a hexagonal (prismatic), graphite block core with thorium and uranium fuel. Internationally, there are several active programs directed at developing the HTGR concept for commercial power production (e.g., the High Temperature Engineering Test Reactor (HTTR) in Japan; the HTGR (HTR-10) in China; and the Pebble Bed Modular Reactor (PBMR) being developed for commercial use by an international conglomerate that includes South African-based ESKOM). The hexagonal block and pebble bed approaches continue to be explored, along with alternate power production cycle options, as capabilities to generate electricity and, possibly, hydrogen, and various module power ratings.

Over the past decade, DOE has also focused substantial resources on the Generation IV Nuclear Energy Systems Initiative, wherein new reactor systems are being developed for deployment over the next 20 years. The NGNP, a part of the Generation IV Nuclear Energy Systems Initiative, is planned to be an advanced nuclear reactor design that can improve upon the current generation of operating commercial nuclear power plants. In addition to producing electricity 
safely and economically, the NGNP will focus on establishing the feasibility of producing electricity and hydrogen from a nuclear reactor. DOE is considering the very high temperature reactor (VHTR), which is an HTGR, as a potential technology for the NGNP.

The key building block of most HTGR concepts is a coated fuel particle that is less than approximately 1,000 microns in diameter, and that contains a central fuel "kernel" (e.g., $\mathrm{UO}_{2}, \mathrm{UCO}$, etc.) and layers of pyrolytic carbon and silicon carbide/zirconium carbide. These layers protect the central fuel kernel, serve as a barrier to fission product release, and provide the potential for achieving high burnups. The particles can be placed in fuel compacts which are then inserted into either prismatic graphite blocks or coated graphite pebbles (which are approximately 2 in $(6 \mathrm{~cm})$ in diameter).

This alternative would require $\mathrm{R} \& \mathrm{D}$ related to fuel development and fabrication, and increasing the capacity of HTGRs to commercial scale (see Chapter 4, Section 4.8.1). This alternative would also require one or more reactor-grade graphite production plants, which currently do not exist in the United States. Transition to this alternative could be deployed once a new reactor type is available (see Chapter 4, Section 4.8.2).

Under this option, for analysis purposes, it is assumed that the U.S. nuclear fuel cycle would transition to an all-HTGR once-through fuel cycle (Figure 2.7.2-1). It is acknowledged that such transition would take many decades to accomplish, as existing LWRs would continue operations until reaching end-of-life.

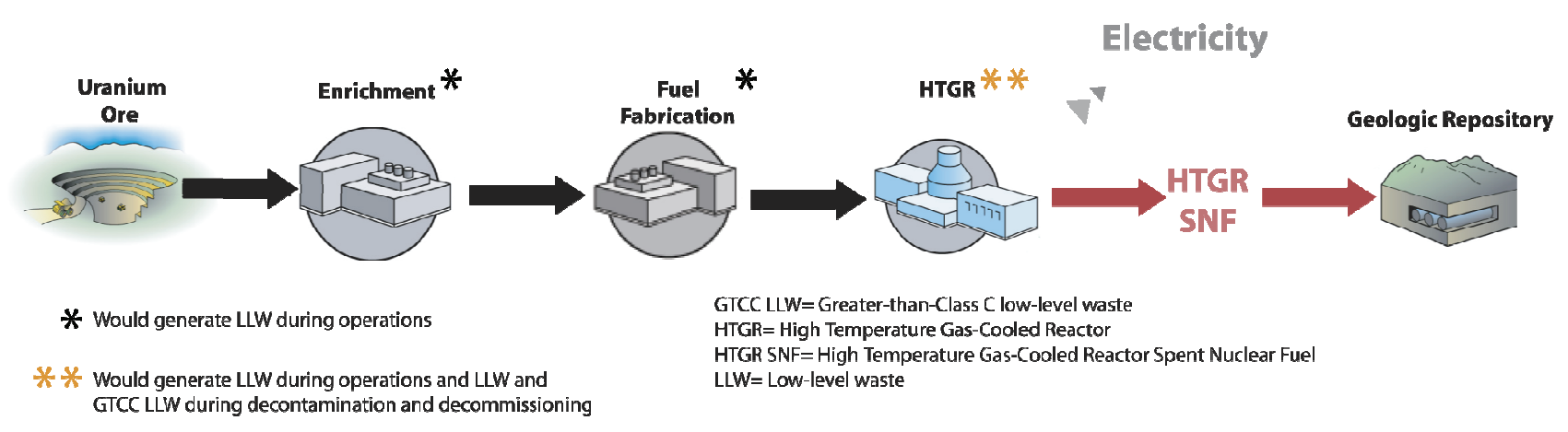

FiguRE 2.7.2-1—High Temperature Gas-Cooled Open Fuel Cycle

\subsection{ALternatives CONSIDERED bUt Eliminated From DetaILED STUdY}

In preparing this PEIS, DOE considered many alternatives for meeting the underlying purpose and need for agency action. Some of these alternatives were identified by DOE through internal discussion, while others were identified by the public during the public scoping process (see Appendix $\mathrm{H}$ ). The following alternatives were considered but eliminated from detailed study:
A. Institute Interim Storage of LWR SNF
B. Increase Burnup of Light Water Reactor Fuels
C. Terminate the Advanced Fuel Cycle Initiative
D. Recycle SNF Now Planned for the Yucca Mountain Repository 
E. Use the Plutonium and Uranium Recovery by Extraction (PUREX) SNF Separation Process

F. Use Fast Reactor Types Other than Sodium-Cooled Reactors for the Initial Fast Reactor

G. Assess Fuel Cycle Alternatives with Other Reactor Technologies:

1. Supercritical Water-Cooled Reactor; and

2. Molten Salt Reactors

H. Use Accelerators for Transmutation

I. Use Thorium Closed Fuel Cycle

J. Recycle Spent HTGR Fuel

K. Use MOX-U-Pu Open Fuel Cycle

L. Use Breeder Reactors

M. Switch to Non-Nuclear Electricity Production, Including Renewable Energy and Conservation

DOE reviewed each of these alternatives in light of their ability to meet the purpose and need to support the expansion of domestic and international nuclear energy production, while also reducing the risks of nuclear proliferation and reducing the impacts associated with disposal of future SNF (e.g., by reducing the volume, thermal output, or radiotoxicity of waste requiring geologic disposal).

A. Institute Interim Storage of Light Water Reactor Spent Nuclear Fuel. The concept of interim storage contemplates gathering the commercial SNF that now resides at each nuclear power plant and consolidating it for centralized storage at one or more sites until ultimate disposal in a geologic repository is available. ${ }^{17}$

Proponents of interim storage offer the advantages of this strategy described below. This strategy arguably might support growth in nuclear electricity production by providing some added assurance to the commercial nuclear industry that SNF would not continue to require on-site storage at the commercial sites. Removing SNF from reactor sites would relieve the SNF buildup at commercial reactor sites, reduce the amount of dry storage capability required at these sites, and support continued reactor operations. Interim storage without separation would leave the SNF in a form that would require significant processing to extract weapon-usable material; the volume, mass, and high level of radiation associated with SNF make it difficult to steal or divert to other purposes. Centralized storage could also make the fuel easier and more efficient to protect. $^{18}$

DOE does not have the authority under law to accept commercial spent nuclear fuel for interim storage at this time. Furthermore, consolidating spent fuel would not reduce its volume and would have a limited effect on the use of space in a geologic repository from the standpoint of thermal output since the longer-term thermal contribution is driven by the decay of the long-lived actinides, not the short-lived fission products that would decay more quickly during interim storage. Furthermore, this limited benefit can be achieved simply by continuing on-site storage at

\footnotetext{
${ }^{17}$ In this context, "interim storage" is distinguished from "process storage," which is the storage of a quantity of SNF as feedstock that is reasonably related to a facility's processing throughput (e.g., a nuclear fuel recycling facility).

${ }^{18}$ For example, centralized storage could use hardened storage technology that would provide better protection against terrorist attacks.
} 
commercial sites, without incurring the impacts associated with construction of an interim storage site and transportation of SNF to an interim storage site. Finally, interim storage does not address the long-term radiotoxicity of SNF (see Chapter 4, Figure 4.8-5).

In certain respects, interim storage would be analogous to the No Action Alternative but would defer a decision of what to do with spent nuclear fuel to the future. Further, even if current law were modified and interim storage was authorized and pursued, there would be additional costs and risks associated with handling and transport of the spent fuel from the utilities to the interim storage sites, and then again to a repository for disposal or to a recycling facility for processing and additional transport.

Interim storage facilities present significant problems and would fail to meet DOE's purpose and need here. In light of the forgoing, DOE has concluded that interim storage (even for periods of 100 to 300 years) does not satisfy DOE's purpose and need to reduce impacts associated with the disposal of SNF and, therefore, is not considered to be a reasonable alternative.

B. Increase Burnup of Light Water Reactor Fuels. DOE considered a scenario in which LWR operations would significantly increase the burnup of LWR fuels. Burnup refers to the amount of energy generated per unit mass of fuel. Because fuel assemblies are of approximately equal mass, higher burnup fuels can reduce the total amount of SNF generated by providing more energy per fuel assembly. Historical U.S. commercial reactor operations show a steady trend toward higher burnup (see Figure 2.8-1); this is considered part of the No Action Alternative. Scenarios were considered in which burnup would be doubled, which could cut the mass of future SNF in half for the same total energy generation.

However, any benefit from this volume reduction would be off-set by a larger quantity of fission products in the SNF, which would increase the radiotoxicity and thermal loading. In addition, higher burnup requires higher enrichment (i.e., more fissile material in the fresh fuel) and, therefore, more natural uranium. Thus, while more energy can be produced per unit of fuel, the natural uranium resources needed stay roughly constant per unit of energy. As a result, increased burnup of LWR fuels was not analyzed as a discrete alternative. 


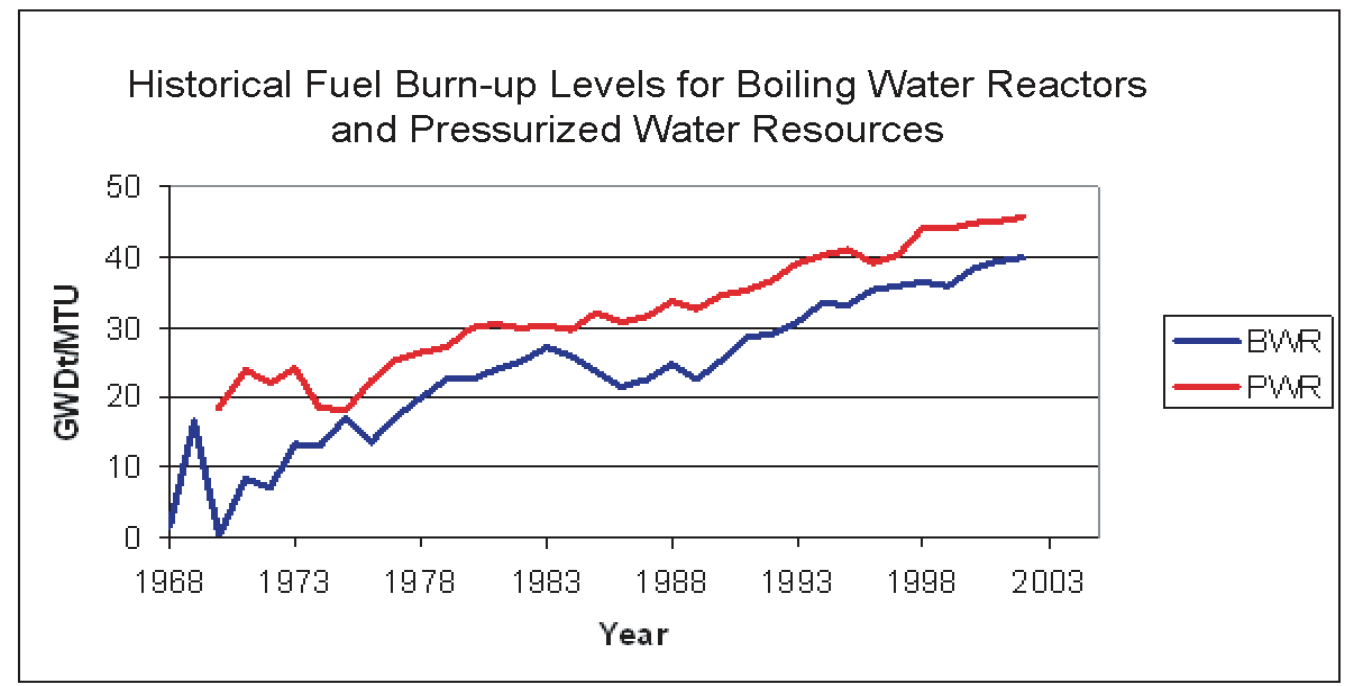

Source: Finck 2007b

FIGURE 2.8-1-Historical Fuel Burnup Levels for United States Commercial Boiling Water Reactors and Pressurized Water Reactors

C. Terminate the Advanced Fuel Cycle Initiative. One of the missions of DOE's Office of Nuclear Energy is to undertake R\&D activities in support of civilian nuclear energy programs. The objective of the AFCI is to provide technology options that would enable long-term growth of nuclear power, to improve environmental sustainability, and to improve energy security. AFCI technology development focuses on reducing the long-term environmental impacts of nuclear waste, improving proliferation resistance, and enhancing the use of nuclear fuel resources. During the scoping period, some commentors suggested that DOE consider terminating the ongoing AFCI program as an alternative. DOE has determined that this alternative is inappropriate; it would do nothing to advance the purpose and need and would inhibit the nation's ability to conduct research necessary for its energy future.

D. Recycle Spent Nuclear Fuel Now Planned for the Yucca Mountain Repository. During the scoping period, some commentors suggested that DOE should recycle the SNF that is now planned for disposal at the Yucca Mountain repository. Some commentors stated that recycling this SNF could eliminate the need for the Yucca Mountain repository. Under all nuclear fuel cycles, however, the United States will need a permanent geologic repository to dispose of SNF and/or HLW from the operation of commercial nuclear power plants and defense-related activities. All programmatic alternatives analyzed in this PEIS, including the No Action Alternative, would require at least one geologic repository, and the GNEP PEIS would have no effect on the ongoing planning for that initial repository. GNEP PEIS alternatives are at a stage of initial proposal, and DOE has not made any decisions to proceed with any specific alternative. Given the many uncertainties associated with the timing and the scope of the implementation of any action alternative that might be selected here, the present pressing need for disposal capacity that the Yucca Mountain repository is intended to address, and current statutory mandates, it is reasonable and necessary to go forward with the Yucca Mountain repository as planned. Consequently, the GNEP PEIS does not address the recycle of SNF currently planned for disposal at the Yucca Mountain geologic repository (i.e., up to the statutory capacity limit). On the other hand, to ensure comparability among all closed fuel cycle alternatives, the GNEP PEIS 
assumes that all commercial SNF generated in excess of the Yucca Mountain geologic repository statutory capacity limit would be recycled.

E. Use the Plutonium and Uranium Recovery by Extraction (PUREX) Spent Nuclear Fuel Separation Process. During the scoping period, some commentors suggested that DOE utilize the PUREX process to separate LWR SNF. PUREX is an aqueous separation process that is used to extract uranium and plutonium, independently of each other, from the fission products in SNF. This process was used during the Cold War at DOE's Hanford Site and Savannah River Site to separate weapons-grade plutonium for the U.S. nuclear weapons program and has been used since at the Savannah River Site for stabilization and disposition of nuclear materials. One element of the purpose and need is to reduce the risks associated with nuclear proliferation, and DOE will assess as reasonable alternatives only those technologies that do not separate or use pure plutonium. The PUREX process, which separates pure plutonium, fails to meet this criterion. As such, the PUREX process was eliminated from detailed study. Separate from the GNEP PEIS, the National Nuclear Security Administration (NNSA), a semiautonomous agency within DOE, is preparing a Nonproliferation Impact Assessment (NPIA) that will analyze the nonproliferation aspects of the programmatic alternatives evaluated in this GNEP PEIS. The NPIA will assess the programmatic alternatives and technologies against major U.S. nonproliferation policy objectives (see Chapter 1, Section 1.2.1.3).

F. Use Fast Reactor Types Other than Sodium-Cooled Fast Reactors for the Initial Fast Reactor. There are a number of potential fast reactor technologies that could eventually be used to generate electricity by consuming transuranic elements. The reactor technology being analyzed for the initial fast recycling reactor is a liquid metal (sodium)-cooled fast reactor, which is referred to as an advanced recycling reactor in this PEIS. DOE judged that the sodium-cooled fast reactor possesses the "most viable technical maturity" for achieving effective transmutation in the near-term ${ }^{19}$ (DOE 2006t). As such, the sodium-cooled fast reactor is the reference reactor technology considered in this PEIS for the Fast Reactor Recycle Alternative and the Thermal/Fast Reactor Recycle Alternative.

Additionally, because this PEIS is not supporting a specific reactor technology decision, the purpose of the reference reactor technology is to provide a reasonable basis for analyzing the environmental impacts of the Fast Reactor Recycle Alternative and the Therma1/Fast Reactor Recycle Alternative. A fast reactor is used to reflect the transuranic destruction that could be achieved to compare against the other alternatives. Design, construction, and operational information is available for this fast reactor type. Future proposals could involve other reactor types; any actual proposal to deploy a reactor would include a further NEPA analysis.

G. Assess Fuel Cycle Alternatives with Other Reactor Technologies. In addition to the HWR/HTGR Alternative, DOE considered fuel cycle alternatives that could use other reactor technologies, including supercritical water-cooled reactors and molten salt reactors. As discussed below, neither of these reactors was considered to be technically mature enough to consider as a

${ }^{19}$ DOE concluded that a demonstration reactor could be pursued today with sodium-cooled fast reactor technology, in roughly 5 to 10 years with a lead-cooled fast reactor, and in roughly 20 years with a gas-cooled fast reactor. DOE stated that "the challenges for sodium-cooled fast reactor technology are well understood" (The United States Generation IV Fast Reactor Strategy, December 2006 [DOE 2006t]). 
reasonable alternative in this PEIS. These other reactor types could be considered by DOE for further development through the AFCI or other R\&D program.

1. Supercritical Water-Cooled Reactor. Supercritical water-cooled reactors (SCWR) are promising advanced nuclear systems to generate electricity, both because of their high thermal efficiency (i.e., about 45 percent versus about 33 percent efficiency for current LWRs) and because of the considerable plant simplification. Basically, SCWRs are LWRs operating at higher pressure and temperatures, with a direct, once-through cycle. Operation above the critical pressure eliminates coolant boiling, so the coolant remains single-phase throughout the system. Thus, the need for recirculation and jet pumps, pressurizers, steam generators, and steam separators and dryers in current LWRs is eliminated.

The SCWR begins with a thermal neutron spectrum and once-through fuel cycle, but, ultimately, it may be able to achieve a fast-spectrum with recycle. It is built upon two proven technologies: LWRs, which are the most commonly deployed power-generating reactors in the world, and supercritical fossil-fired boilers, a large number of which are also in use around the world.

For any SCWR design, materials for reactor internals and fuel cladding would need to be evaluated and identified. Zirconium-based alloys, which are commonly used in conventional water-cooled reactors, would not be a viable material for most of the proposed SCWR core designs without a thermal and/or corrosion-resistant barrier. Based on the available data for other alloy classes, no alloy has received sufficient study to unequivocally ensure its viability in an SCWR. A variety of potential materials have been identified for both fuel cladding and core internal components (Finck 2007d).

2. Molten Salt Reactors. Molten salt reactors (MSR) are liquid-fueled reactors that can be used for production of electricity, burning of actinides, production of hydrogen, and production of fissile fuels. Fissile, fertile, and fission isotopes are dissolved in a high temperature molten fluoride salt with a very high boiling point $\left(2,552^{\circ} \mathrm{F}\left[1,400^{\circ} \mathrm{C}\right]\right)$, which is the reactor fuel and the coolant. The near-atmospheric-pressure molten fuel salt flows through the reactor core. Traditional MSR designs have a graphite core that would operate with thermal neutrons of slightly higher energy levels than those in many current thermal reactors. Alternative designs are now being explored with no reactor internals and a fast neutron spectrum. In the core, fission occurs within the flowing fuel salt that is heated to approximately $1,292^{\circ} \mathrm{F}\left(700^{\circ} \mathrm{C}\right)$, which then flows into a primary heat exchanger, where the heat is transferred to a secondary molten salt coolant. The fuel salt then flows back to the reactor core. The clean salt in the secondary heat transport system transfers the heat from the primary heat exchanger to a high temperature Brayton cycle that converts the heat to electricity. The Brayton cycle (with or without a steambottoming cycle) may use either nitrogen or helium as a working gas.

Development of an MSR involves multiple fuel cycle challenges. Specifically, because the system is a molten fluoride salt system, there are unique chemical issues not associated with other reactors. There is a need to develop a fluoride HLW form and an 
integrated fuel recycle strategy. The current regulatory structure was developed with the concept of solid-fuel reactors, but liquid fueled reactors use different approaches to reactor safety than do solid-fueled reactors. The comparable regulatory requirements for this system must be defined. Appropriate safety analysis is required, followed by appropriate research on the key safety issues.

The major challenges in materials R\&D are to identify and qualify materials with properties appropriate for MSR operating conditions, including corrosion resistance, mechanical performance, and radiation performance. The primary materials of interest are the moderator (graphite) and the reactor vessel/primary loop alloy (presently a nickelbased alloy). It is also necessary to develop corrosion control and coolant monitoring strategies for protecting the reactor vessel and primary piping alloys (Finck 2007d).

H. Use Accelerators for Transmutation. The use of accelerators to transmute the transuranic radionuclides in SNF was extensively studied via the Accelerator-based Transmutation of Waste (ATW) Program, which DOE initiated in 1999. The 1999 ATW Program focused primarily on one technology option (accelerator-driven fast neutron spectrum transmutation systems) and one implementation scenario (burn-down of the SNF from all past and existing U.S. power reactors) (Van Tuyle 2001). The research results from the ATW program and its successor, the Advanced Accelerator Applications Program, led to the conclusion that stand-alone accelerator-driven systems were not a viable solution to dealing with large amounts of SNF, because the mission time was long, and because the technical and economic challenges were formidable (DOE 2006u).

I. Use Thorium Closed Fuel Cycle. As described in Section 2.6, this PEIS assesses in detail a once-through Thorium Alternative. A closed cycle for thorium was also considered, and, while technically possible, it was eliminated from detailed study for the following reasons:

- Highly penetrating radioactive materials (thallium-208 and bismuth-212) are unavoidably created in thorium-based SNF. These are very high-energy gamma emitters, which complicate all handling operations (i.e., recycling, manufacture, transport, and disposal) and, thus, shielded and remote lines must be used.

- Thorium dioxide $\left(\mathrm{ThO}_{2}\right)$ fuel is relatively inert and, unlike uranium dioxide $\left(\mathrm{UO}_{2}\right)$, does not dissolve easily in concentrated nitric acid. Addition of small quantities of hydrogen fluoride (HF) in concentrated nitric acid $\left(\mathrm{HNO}_{3}\right)$ is needed to dissolve $\mathrm{ThO}_{2}$, which would cause corrosion of stainless steel equipment and piping in reprocessing plants. Perhaps more importantly, while the technology for reprocessing and recycling thoriumbased fuels (THOREX) is viable, it is significantly less developed at this stage than the technology for reprocessing and recycling other candidate fuel options, especially if separate streams of elements are desired (e.g., uranium and minor actinides).

- Though viable, the process of separating uranium and transuranics from spent $\mathrm{ThO}_{2}$ fuel is yet to be developed (IAEA 2002b).

J. Recycle Spent High Temperature Gas-Cooled Reactor Fuel. As described in Section 2.7.2, this PEIS assesses in detail a once-through HTGR Alternative. A closed cycle for HGTR fuel was also considered and, while technically possible, it was eliminated from detailed study. The 
nature of the fuel makes reprocessing more difficult due to the need to first separate the particles from the rest of the block or pebble, open the particles via mechanical processes (cracking/grinding/crushing), and then chemically dissolve the fuel. While an approach for reprocessing and recycling particle-based fuels exists in concept, substantial development and demonstration of a fuel cycle using these technologies would be required to bring this technology to the same level of maturity as other candidate fuel cycles.

K. Use MOX-U-Pu Open Fuel Cycle. This PEIS assesses the potential use of MOX-U-Pu fuel in closed fuel cycles (see Section 2.4, which would use MOX-U-Pu in LWRs prior to fast reactor recycle, and Section 2.5.1 for a description of continuous recycle using LWRs fueled with MOX$\mathrm{U}-\mathrm{Pu}$ ). DOE also considered an open fuel cycle that would use MOX-U-Pu fuel. For example, MOX-U-Pu fuel is being pursued for use in the Catawba and McGuire commercial power reactors as part of DOE's plutonium disposition program. There would be no reprocessing or subsequent reuse of this SNF. Once the cycle is completed, the spent MOX fuel would ultimately be disposed of in a geologic repository (NRC 2008b). The alternative to use MOX-U-Pu fuel in an open fuel cycle would produce SNF not amenable to substantially reducing the impacts of disposal; that is, it would not reduce volume, thermal output, or radiotoxicity.

L. Use Breeder Reactors. Breeder reactors are used to produce more fissile material than they consume, which could be needed if sufficient uranium resources are no longer available to support nuclear power based on uranium enrichment. The breeder reactor is a variation of the fast reactor evaluated in detail as part of the Fast Reactor Recycle Alternative and the Thermal/ Reactor Recycle Alternative. One objective addressed in this PEIS is to reduce quantities of plutonium and minor actinides, in order to reduce the environmental impacts and proliferation risks from SNF. Breeder reactors would be inconsistent with the nonproliferation goal to reduce quantities of plutonium and other potential weapons-usable materials from the civil fuel cycle. The long-term sustainability of nuclear energy may require breeders at some time in the future, if uranium and thorium resources become scarce or uneconomical to extract. The long-term sustainability of nuclear energy is, however, a mission of the Generation-IV Initiative, not the GNEP Program (DOE 2006t). While the fast reactor technology is capable of being designed and operated as a breeder reactor, this PEIS analyzes fast reactors that would be designed, built, and operated as net users of fissile material.

M. Switch to Non-Nuclear Electricity Production, Including Renewable Energy and Conservation. Some commentors suggested that the United States should meet future electricity demands through conservation and increased use of renewable energy sources, rather than through increased use of nuclear energy. While DOE agrees that conservation and increased use of renewable energy resources are desirable, it is clear that the United States needs significant power to sustain and advance its productivity. DOE does not consider the alternatives in this PEIS to be "either/or" alternatives, with respect to meeting future electricity demands by nonnuclear means or conservation. The alternatives in this PEIS are consistent with either conservation or the use of new and significant renewable energy resources. The alternatives in this PEIS relate to nuclear fuel cycles. Other DOE programs address other means of energy production, as well as conservation. Indeed, DOE is presently addressing new and novel means of producing energy through its basic and applied research, as well as the development funding of new technologies. 


\section{Global Nuclear Energy Partnership Programmatic EnVironmental IMPACT STATEMENT ANALYSIS ASSUMPTIONS}

In support of the programmatic analysis, DOE has identified a number of relevant issues (such as technologies, capacities, and timing) that should be factored into the assessment, in order to inform the decision maker of the environmental impacts of the programmatic alternatives.

\subsubsection{Global Nuclear Energy Partnership Programmatic Environmental Impact Statement Planning Assumptions/Considerations/Basis for Analysis}

This section discusses some of the more specific assumptions and considerations that form the basis of the analyses and impact assessments that are the subject of this PEIS. Section 2.9.2 explains the assumptions related to the issue of future electricity projections in detail.

Yucca Mountain Repository. Under all nuclear fuel cycles, the United States requires a permanent geologic repository to dispose of SNF and/or HLW. All of the GNEP programmatic alternatives, including the No Action Alternative, would produce materials that would need to be isolated in a deep geologic repository as a means of final disposition. In addition, none of the GNEP programmatic alternatives would affect the current statutory mandate and the need to develop a repository for the disposal of existing inventories of SNF and/or HLW. Therefore, the ongoing planning, engineering design, and licensing activities for the Yucca Mountain repository are proceeding.

In the Nuclear Waste Policy Act of 1982, as amended, 42 U.S.C. 10101 et seq. (NWPA), the U.S. Congress has recognized that "a national problem has been created by the accumulation of...spent nuclear fuel from nuclear reactors; and...radioactive waste from (i) reprocessing of spent nuclear fuel; (ii) activities related to medical research, diagnosis, and treatment; and (iii) other sources." The NWPA requires that DOE submit an application to the NRC for construction authorization for a geologic repository at Yucca Mountain. DOE has finished that application and submitted it to the NRC on June 3, 2008. Further, the NWPA requires DOE to submit to the President and Congress a report on the need for a second repository after January 1 , 2007, but no later than January 1, 2010, and prohibits DOE from engaging in site-specific activities with respect to a second repository without specific Congressional authorization and funding.

In addition to the existing legislative mandate, the purpose and need addressed by the GNEP Program is consistent with, and is not adversely affected by, the ongoing planning, engineering design, and licensing activities for the repository. The GNEP Program seeks to develop ways to support expanded use of nuclear energy to meet growing electricity needs. However, given the current uncertainties associated with the timeframes, potential capacities, and technological development needs of, and private industry support for, the facilities evaluated in the GNEP programmatic alternatives, it would not be reasonable or consistent with the GNEP Program 
goals to defer or delay current activities for the planning and development of the Yucca Mountain repository for the disposal of commercial SNF. ${ }^{20}$

Demonstrating that a repository can be licensed and operated for the disposal of SNF would allay concerns that SNF and HLW storage or processing sites would become permanent, and it would facilitate design of advanced fuel cycle facilities. It would also provide a basis for assurance that reactor sites will not be long-term waste repositories by default. On the other hand, delaying repository development to await the resolution of questions about the fate of commercial SNF could continue to add substantial costs to the taxpayer for the interim management of such fuel, including the costs of delayed closure of the facilities in which it is now stored. Using the figures in this PEIS as a basis for projection, there conceivably could be more than 200,000 MTHM of commercial SNF in storage by 2100 , if a repository were not operational by that time.

Since the Carter Administration, the policy of the United States has espoused the principle that the responsibility for the disposal of radioactive waste should be shouldered by the generation that created it, and that it not be passed on to future generations. This principle is consistent with the principle enumerated by the International Atomic Energy Agency (IAEA) that the "generations that produce the waste have to seek and apply safe, practicable and environmentally acceptable solutions for its long term management" (IAEA 2006b). Leaving HLW and SNF in storage while awaiting the potential development of new recycling technologies is inconsistent with these principles.

Future Repository Capacity. For the purposes of analysis, this PEIS assumes that any SNF or HLW exceeding the statutory capacity limit of the first repository could be ultimately disposed of in one or more permanent geologic repositories. Such future repository capacity could either be an expansion of the Yucca Mountain geologic repository, if the statutory capacity limit is amended, or a separate geologic repository at a site to be determined.

Capacities, Implementation Scenarios, and Timeframe Analyzed. The GNEP PEIS includes an evaluation of the domestic programmatic alternatives at four different capacity levels, based on the electricity demand scenarios and timeframes discussed in Section 2.9.2. The alternatives were evaluated for the following four assumed nuclear electricity capacities by approximately $2060-2070^{21}$ :

\footnotetext{
${ }^{20}$ The Yucca Mountain geologic repository is intended for the disposal of DOE SNF and HLW, as well as commercial SNF. DOE (and Navy) SNF contains a number of characteristics that would make it ill-suited for recycling. Furthermore, the commercial fuel cycle technologies considered in this PEIS are not intended to recycle HLW.

${ }^{21}$ The analysis of the domestic programmatic alternatives in this PEIS is broad and long-term. For each of the action alternatives, transition and full implementation could not be achieved for many decades. The term "approximately 2060-2070" is used to define a reasonable endpoint during which transition and full implementation could potentially be achieved. The endpoint is not meant to be definitive as to when full implementation could be achieved, and this date should not be construed as absolute. The term reflects the mathematical endpoint at which the growth rates of 0.7 percent, 1.3 percent, and 2.5 percent would reach the values of 150 gigawatts electric (GWe), $200 \mathrm{GWe}$, and $400 \mathrm{GWe}$, respectively, as projected from the year 2006. For example, the baseline scenario analyzed in greatest detail in this PEIS uses the early release electricity projections that estimate an average annual growth rate of 1.3 percent for the period from 2006 to 2030 (see Section 2.9.2) (EIA 2007a). Starting with 100 GWe in 2006, a 1.3 percent growth rate would result in 200 GWe of capacity by approximately $2060-2070$. (Note: $100 \mathrm{GWe}$ of capacity would grow to $200 \mathrm{GWe}$ in 54 years at a rate of 1.3 percent per year.) During this 54 -year timeframe, there will likely be periods of annual growth that are higher and lower than the 1.3 percent average. For example, over the next two decades or so (until 2030), EIA projects that nuclear production will only grow by approximately 0.7 percent annually. When compared to the 1.3 percent growth expected in the overall electricity generation market, nuclear production would lose market share over this period (EIA 2007a). Similarly this PEIS assumes that nuclear power is expected to remain constant (zero growth rate) until 2015, given the fact that no new nuclear plants are currently under construction. After 2015, new LWRs are expected to begin coming online, and the PEIS assumes a 1.3 percent growth rate until approximately 2020. After 2020, this PEIS assumes that a higher growth rate than average would occur in order to achieve $200 \mathrm{GWe}$ by approximately 2060-2070. Although many factors (e.g, economics, demand, national policies, etc.) would affect the year-to-year nuclear power
} 
- $\quad 100 \mathrm{GWe}$ (which represents the current nuclear electricity capacity)

- $\quad 150 \mathrm{GWe}$ (which is based on a 0.7 percent growth rate in nuclear electricity capacity)

- $\quad 200 \mathrm{GWe}$ (which is based on a 1.3 percent growth rate in nuclear electricity capacity)

- $\quad 400 \mathrm{GWe}$ (which is based on a 2.5 percent growth rate in nuclear electricity capacity)

It is not possible to predict with confidence when any of the action alternatives would be fully implemented. Many factors would affect the success of implementing any alternative, including market forces, public policy, and regulatory issues. Consequently, there could be considerable uncertainty as to when successful implementation would be considered to have been achieved. While it is recognized that there are other potential combinations, the scenarios analyzed are considered to provide a reasonably foreseeable range of future conditions. For the purposes of this PEIS, the analysis focuses on the overall environmental impacts of achieving and operating a fully operational system for each of the alternatives. By evaluating each alternative at the various electric generating capacities, a consistent comparison of environmental impacts (e.g., SNF, wastes, transportation, etc.) can be made among the alternatives. There could be differences in implementation of the alternatives compared to what is presented in this PEIS. To the extent possible, the PEIS discusses these issues and attempts to explain how these differences could affect the impacts presented.

Phase-out of Light Water Reactors. LWRs are the only reactor technology used for electricity production in the United States today. This PEIS assumes that current LWRs begin retirement in 2029 and are replaced at retirement by the same amount of nuclear generating capacity. By approximately 2060, all existing LWRs would have been retired/replaced. As discussed in Section 2.2, new LWRs are currently being pursued by the commercial nuclear power industry, independent of this PEIS, and could be constructed during the PEIS analysis timeframe. Consequently, this PEIS assumes that new LWRs would be constructed during the planning timeframe used in this PEIS and could be operated beyond 2060. (Assuming that new LWRs are constructed in approximately 2015 and are granted a 40-year operating license, these LWRs would be expected to operate until at least 2055. Because it is also reasonable to assume that some or all of these future LWRs could receive life-extensions for an additional 20 years of operation, these LWRs could operate beyond 2060). Except for the HWR/HTGR Alternative, each of the domestic programmatic alternatives would continue to need/utilize LWRs. For the HWR/HTGR Alternative, this PEIS assumes that full implementation would occur by approximately 2060-2070, but also discusses how impacts would change if this were not to occur.

Domestic Fuel Cycle Facility Ownership, Control, and Regulatory Status. For the programmatic alternatives analyzed in this PEIS, DOE is not proposing or deciding whether any nuclear reactors or nuclear fuel recycling centers to be demonstrated or deployed under the GNEP Program would be commercial or government owned or controlled facilities. For the purposes of this PEIS, DOE addresses the environmental impacts from such facilities regardless of such factors, and under the assumption that the facilities could be regulated either by the NRC or DOE. Further, for the purposes of this PEIS, DOE analyzes LLW as either Class A, B, or C

growth, the PEIS assumes that the growth rate after 2020 is constant. Overall, this would result in an average annual growth rate of 1.3 percent over the entire PEIS timeframe. This approach is consistent with current events, consistent with the Energy Information Administration's approach for projecting electricity growth, and provides a basis for analyzing the differences between the domestic programmatic alternatives. 
waste, or Greater-than-Class-C (GTCC) LLW, in accordance with NRC classification criteria, and without regard to whether the LLW is owned or controlled by DOE.

Facility Locations. This PEIS is not intended to support siting decisions for the programmatic alternatives. Instead, tiered, project-specific NEPA reviews would be required to make any such decisions. For example, if one of the closed fuel cycle alternatives were selected in a Record of Decision (ROD), a nuclear fuel recycling center could not be constructed without a projectspecific NEPA review. That review would include a consideration of reasonable site alternatives.

Future Reactors. For any of the fuel cycle alternatives, there could be a large number of reactor scenarios that could be employed to achieve a capacity of $200 \mathrm{GWe}$, including the following: 1) 200 reactors, each with a nominal capacity of $1,000 \mathrm{MWe}$; 2) 400 reactors, each with a nominal capacity of $500 \mathrm{MWe}$; and 3) 500 reactors, each with a nominal capacity of $400 \mathrm{MWe}$. Historically, when new types of reactors have been introduced, the initial reactors are small, and later reactors are much larger. For this PEIS, environmental impacts are based on electrical production, rather than on the number of reactors, because reactors vary considerably in size.

However, because of potential differences among the alternatives with respect to the number of new reactors that would be needed to implement each programmatic alternative, the PEIS includes such information. The information below is generally based on Energy Information Administration estimates of future reactor designs for each reactor type (EIA 2006d), as follows:

- LWR: Current LWRs in the United States vary in generating capacity from less than $500 \mathrm{MWe}$ to over $1.3 \mathrm{GWe}$. The capacity of future reactors may or may not fall within this range. This PEIS assumes that future LWRs would produce an average of approximately $1 \mathrm{GWe}$.

- HWR: Two models of the CANDU reactor have been marketed internationally: the CANDU-6, which has a capacity of approximately $700 \mathrm{MWe}$, and the CANDU-9, with a capacity of approximately 900 MWe. A larger CANDU design (approximately $1.2 \mathrm{GWe}$ ) has been proposed. The capacity of future reactors may or may not fall within this range. In estimating the number of future reactors, this PEIS assumes that future HWRs would produce an average of approximately $800 \mathrm{MWe}$.

- Fast Reactor: Advanced recycling reactors (i.e., fast reactors) are currently being studied across a large capacity range. Initial industry responses to a GNEP Program technology funding opportunity indicate that fast reactors in the range of $300 \mathrm{MWe}$ to more than $1 \mathrm{GWe}$ are being considered for future development. Initial fast reactors could be on the lower end of the range, while later reactors could be much larger. In estimating the number of future fast reactors for a particular system power level, this PEIS assumes that the future fast reactors would produce an average of approximately $800 \mathrm{MWe}^{22}$

\footnotetext{
${ }^{22}$ EIA 2006d only provides information related to the Toshiba 4S fast reactor concept, which is intended for use in remote locations. Other domestic and international fast reactor concepts and systems, however, range from about $300 \mathrm{MWe}$ (liquid metal reactor program modular type concept) to $1.5 \mathrm{GWe}$ (Japan Atomic Energy Agency Sodium-cooled Fast Reactor [JSFR]). More specifically, the Phenix and MONJU reactors (built and operated) are about $250 \mathrm{MWe}$ and $280 \mathrm{MWe}$, respectively, and the Clinch River Breeder Reactor design was about $350 \mathrm{MWe}$. India is constructing a prototype fast breeder reactor at about $500 \mathrm{MWe}$. Russia has also operated BN-600 (600 MWe) and is constructing the BN-800 (800 MWe). The French have built and operated Superphenix at approximately $1200 \mathrm{MWe}$, and the Japanese are pursuing the JSFR (at $1500 \mathrm{MWe}$ ). Thus, a capacity of $800 \mathrm{MWe}$ for future fast reactors is not unreasonable.
} 
- HTGR: According to the Energy Information Administration, HTGRs are currently being studied in the power range of $180 \mathrm{MWe}$ to $325 \mathrm{MWe}$ (EIA 2006d). Within DOE, HTGRs are being studied in the range of approximately 300 megawatts thermal (MWth) to 600 MWth. ${ }^{23}$ This PEIS assesses the HTGR at an average of 300 MWe output.

For all reactor technologies, it is likely that future siting decisions would consider the potential advantages that could be realized by co-locating more than one reactor facility at a given site. While relevant to all reactor technologies, this consideration is most important for the smaller capacity reactors. For example, it is likely to be more economical to site six modular HTGRs at one site than to locate six HTGRs at six sites. Thus, for the same total generating capacity, although the number of reactors may be increased with the use of smaller reactors, the number of power-generating stations may be comparable to that based on use of higher power reactor concepts (e.g., two 1 GWe LWRs at one site or six 300 GWe HTGRs at one site).

Future Spent Nuclear Fuel Separation Facilities. Each of the closed fuel cycle alternatives would require LWR SNF separation facilities. Additionally, the Fast Reactor Recycle Alternative and the Thermal/Fast Reactor Recycle Alternative would require fast reactor SNF separation facilities and associated fast reactor fuel fabrication facilities. For this PEIS, the following two SNF separation facilities are assessed:

- LWR SNF separation facility with a capacity of $800 \mathrm{MTHM} / \mathrm{yr}$

- Fast reactor SNF separation facility with a capacity of $100 \mathrm{MTHM} / \mathrm{yr}$. (It also is assumed that the facility for the fabrication of fuel for recycling (regardless of the nature of that fuel) will have a capacity of $100 \mathrm{MTHM} / \mathrm{yr}$.)

These facilities are described in Appendix A, Section A.3.

Construction and Operation. Both construction and operational impacts are considered. Construction impacts are generally short-term (e.g., would occur over the construction period). In contrast, operational impacts are expected to be long-term (e.g., would occur annually as long as the facility operates and could extend beyond operations, depending on the status of waste storage or other considerations).

Source of Spent Nuclear Fuel to be Recycled. For those alternatives that recycle SNF, this PEIS assesses the recycling of commercial LWR SNF that is generated above the statutory capacity limit discussed above with regard to the Yucca Mountain geologic repository.

Transportation of Spent Nuclear Fuel to be Recycled. This PEIS analyzes the impacts of transporting SNF from U.S. reactors to either a recycling facility or a geologic repository, as appropriate for each alternative. The PEIS assesses both truck and railway transport of SNF. Details regarding specific assumptions used for the transportation analysis are contained in Appendix E.

\footnotetext{
${ }^{23}$ One concept being considered by DOE-Office of Nuclear Energy (NE) for an NGNP is a 300 MWth-600 MWth HTGR (600 MWth being commercial size). The electrical output of the $600 \mathrm{MWth}$ unit operating at close to 50 percent thermal efficiency is approximately $300 \mathrm{MWe}$.
} 
Disposition of High-Level Waste from Recycling Spent Nuclear Fuel. Not all alternatives would produce HLW. Any facilities that produce HLW would, however, store HLW until there is a disposal path for this HLW. This PEIS assesses the impacts of the following: 1) storing HLW on-site at any recycling facility; and 2) transporting HLW to a geologic repository for ultimate disposal. The impacts from disposal of HLW at a geologic repository are not analyzed in this PEIS.

Disposition of Greater-than-Class-C Low-Level Waste. All of the alternatives would generate GTCC LLW, either during normal operations or during decontamination and decommissioning. The Low Level Radioactive Waste Policy Amendments Act of 1985 assigns the responsibility for the disposal of GTCC LLW to the Federal Government (DOE) (42 U.S.C. 2021b). This legislation specified that the GTCC LLW that results from NRC-licensed activities is to be disposed of in a facility licensed by the NRC. There are no facilities currently licensed by the NRC for disposal of GTCC LLW. DOE is preparing a separate EIS to evaluate a range of reasonable alternatives for disposal of GTCC LLW. That EIS is expected to evaluate potential impacts from the construction and operation of new facilities, or use of an existing facility, for the disposal of this waste at potential DOE sites or at generic commercial locations. The disposal methods to be analyzed include enhanced near-surface disposal, intermediate-depth borehole disposal, and disposal in a geologic repository. This PEIS assesses the impacts of transporting GTCC LLW to a hypothetical disposal site.

Disposition of Uranium from Recycling Spent Nuclear Fuel. Not all alternatives would require disposition of uranium from recycling SNF. As applicable to the alternatives, uranium from SNF recycling could either be considered LLW and disposed of, or considered a fuel source for reuse, dependent upon economic viability. This PEIS assesses both possibilities. This PEIS assesses disposal in accordance with current law, policies, and disposal practices. This PEIS also assesses the transportation of the uranium to an enrichment facility, such as the USEC, Inc. American Centrifuge Plant, or the Louisiana Energy Services National Enrichment Center (both under construction), or to Canada for use in a CANDU reactor.

Cesium and Strontium Storage from Recycling Spent Nuclear Fuel. If separated from LWR SNF, cesium (Cs) and strontium ( $\mathrm{Sr}$ ) could either be transported to a geologic repository or stored, possibly for extended timeframes up to approximately 10 "half-lives" 24 following recycle (approximately 300 years). If stored, institutional controls to safeguard this material would be required during this time period. No design presently exists for a $\mathrm{Cs} / \mathrm{Sr}$ storage facility. Additionally, the regulatory requirements are not defined for the storage design, waste form, packaging, and operation of a facility for $\mathrm{Cs} / \mathrm{Sr}$ storage. It is possible that a storage facility design could be adequate for up to 300 years of storage. In the event the $\mathrm{Cs} / \mathrm{Sr}$ storage facility design life is less than the needed storage period, new storage construction would be required during the storage period, and the material would be moved from the original storage facility to the new facility. Impacts from construction, material handling, and operation would be similar to those for the original facility.

\footnotetext{
${ }^{24}$ Radioactive materials decay over time. "Half-life" refers to the time required for the quantity of a radioactive material to decay to half of its initial value. After approximately 10 half-lives, there would be approximately a 99.9 percent reduction (or a factor of 1,000 reduction) in the amount of the isotope present.
} 
Gaseous Emissions. Process gas streams containing radiological and nonradiological constituents would be treated as necessary to meet state and Federal air emission standards. Any solid wastes resulting from these treatment processes would meet applicable waste acceptance criteria prior to leaving a facility.

Liquid Radiological Wastes. Liquid radioactive waste streams would be treated and solidified, as appropriate, as part of a facility process (i.e., a facility would not generate any liquid radioactive waste that requires long-term storage prior to ultimate disposition). Prior to leaving a facility, the solidified waste forms would meet applicable waste acceptance criteria. To address concerns prompted by historical releases from liquid radioactive waste tanks, DOE would not support any long-term storage of such liquid wastes.

Storage of Processing Products. Depending on the choices for recycled materials, or for issues associated with the timing of implementation for facilities, it may be necessary to plan for storage of one or more of the processing products, such as minor actinides. The environmental impact of such storage is considered in the analysis of the reasonable alternatives.

\subsection{2}

\section{Planning Assumptions-Future Electricity Growth, Generation,} and Nuclear Share

Assumptions have been made regarding future electricity demand/growth and the nuclear power share of the market. These assumptions would affect the potential quantities of SNF that would be generated and need to be managed. This is an important parameter, as it drives, among other factors, the amount of transportation, the potential demand for future SNF recycling facilities, and the requirements for future geologic repository capacity.

To assess the alternatives relative to projected growth in electricity generation, DOE developed a planning baseline related to future electricity demand/growth. Several approaches were considered by DOE in developing this baseline, including the use of projections from the Energy Information Administration. The Energy Information Administration is an autonomous statistical and analytical agency within DOE and is charged with providing objective, timely, and relevant data, analysis, and projections for the use of DOE, other government agencies, the U.S. Congress, and the public. Each year, the Energy Information Administration publishes the Annual Energy Outlook, which provides projections and analyses of domestic energy consumption, supply, prices, and carbon emissions. As the Energy Information Administration acknowledges, these projections are not meant to be exact predictions of the future but, instead, represent a likely future, assuming known trends in demographics and technology improvements and also assuming no change in current laws, regulations, and policies (EIA 2007b).

Electricity use in the United States is expected to continue to grow, driven primarily by population increases and economic growth. In its most recent Energy Outlook Report, issued in June 2008, the Energy Information Administration estimates that demand for electricity will increase by approximately 1.1 percent annually through 2030 (EIA 2008a). An early release of that report, issued in December 2007, estimated U.S. electricity growth at 1.3 percent annually through 2030 (EIA 2007a). For most detailed analyses, this Draft PEIS utilizes the higher 1.3 percent growth rate; however, in the Final PEIS, DOE will consider whether any changes to 
the document are warranted to account for the 1.1 percent growth rate or other relevant information that becomes available. Based on an annual growth rate of 1.3 percent, electricity use could increase by approximately 40 percent by 2030 , and if that annual rate were to continue, electricity use could double (relative to use in 2004) by approximately 2060.

With respect to the generation of electricity by nuclear power, which currently supplies approximately 19 percent of United States electricity needs, the Energy Information Administration estimated an annual growth of 0.6 percent in the June 2008 Energy Outlook Report and 0.7 percent in the December 2007 report (EIA 2008a, EIA 2007a). This Draft PEIS utilizes the higher 0.7 percent growth rate. When compared to the 1.3 percent annual growth in overall electricity use, nuclear energy's contribution to U.S. needs (its market share) would decline.

In addition to the 1.3 percent annual growth rate, this GNEP PEIS considers a range of electricity growth rates, including the following: a zero growth scenario, a 0.7 percent annual growth scenario, and a 2.5 percent annual growth scenario. Based on all of the growth rates considered, the domestic programmatic alternatives are evaluated for $100 \mathrm{GWe}, 150 \mathrm{GWe}, 200 \mathrm{GWe}$, and $400 \mathrm{GWe}$ by approximately $2060-2070$.

The PEIS uses the 1.3 percent growth rate as the reference basis, and the environmental impact analysis in Chapter 4 is based on this 1.3 percent growth scenario (which would equate to approximately $200 \mathrm{GWe}$ by approximately 2060-2070). At the program level, many of the environmental consequences associated with the alternatives vary linearly with the power capacity. For example, if the future power capacity at full implementation is $400 \mathrm{GWe}$, instead of $200 \mathrm{GWe}$, the number of reactors associated with any alternative would be approximately twice as much as for the corresponding $400 \mathrm{GWe}$ scenario. Many other factors (such as the annual amount of SNF generated, the annual quantities of wastes generated, and the annual radiological emissions from facilities) could be scaled in a similar manner. Where there are non-linear differences, they are discussed in Chapter 4, Section 4.8.8.

\subsection{IMPLEMENTATION SCENARIOS FOR THE GLOBAL NUCLEAR ENERGY PARTNership Programmatic EnVIronmental ImPaCt Statement Domestic Programmatic Alternatives}

In all likelihood, the deployment of any of the domestic programmatic alternatives would occur due to actions of private industry, and they would primarily be driven by future economics. Future policy and regulatory issues might also influence future deployment. In order to prepare this PEIS analysis, it is assumed that these factors would not be barriers to the widespread implementation of any reasonable domestic programmatic alternative. As such, this PEIS assumes that widespread implementation could occur for each of the alternatives. Assuming success, transition to any new fuel cycle would take many decades to complete. This section discusses the implementation of each domestic programmatic alternative.

For all programmatic alternatives, implementation actions use the following common simplified approach: 
- $\quad$ Existing U.S. nuclear electrical capacity is approximately $100 \mathrm{GWe}$.

- Nuclear electricity capacity grows to approximately $200 \mathrm{GWe}$ by approximately $2060-2070 .^{25}$

- $\quad$ The first new LWR would come on-line in approximately 2015.

- Conversion to new fuel types, if applicable, would begin in approximately 2020. New reactors are assumed to operate on the new fuel, while the 104 currently existing reactors continue to operate on standard uranium-dioxide fuel until their retirement.

- Retirement of current LWR reactors would begin in 2029 and current LWRs would be replaced at retirement by the same amount of nuclear generating capacity. By approximately 2060-2070, all existing LWRs would have been retired/replaced.

- New LWRs, which are being pursued by the commercial nuclear power industry independently of DOE, could be constructed during the PEIS analysis timeframe. Except for the HWR/HTGR Alternative, each of the domestic programmatic alternatives would continue to need and use LWRs. As such, for these alternatives, it is likely that any newly constructed LWRs would continue to operate in the 2060-2070 timeframe. For the HWR/HTGR Alternative, this PEIS assumes that full implementation would occur by approximately 2060-2070, meaning that all LWRs would be phased-out by that time. However, because it is possible that some LWRs could continue to operate past 2060-2070, for the HWR/HTGR Alternative, the PEIS also discusses how impacts would change if that were to occur.

- SNF totals are based on generation from approximately 2010 through approximately 2060-2070.

This section presents information for each of the domestic programmatic alternatives relative to achieving the four electrical generating capacities discussed in Section 2.9. Implementation of the programmatic action alternatives could begin slowly, and, initially, it might include the construction and operation of a "demonstration capacity." Long-term, this PEIS assesses the alternatives at capacities of $200 \mathrm{GWe}$ (Section 2.10.1), $400 \mathrm{GWe}$ (Section 2.10.2), $150 \mathrm{GWe}$ (Section 2.10.3), and $100 \mathrm{GWe}$ (Section 2.10.4). Chapter 4, Section 4.8.2 discusses the implementation issues associated with the domestic programmatic alternatives.

\subsection{Percent Growth Scenario (200 Gigawatts Electric by Approximately 2060-2070)}

For this scenario, under all alternatives, nuclear electricity capacity is assumed to increase from the current $100 \mathrm{GWe}$ to approximately $200 \mathrm{GWe}$. This would be equivalent to constructing approximately 100 new GWe of reactor capacity and replacing the existing $100 \mathrm{GWe}$ of LWR capacity when the existing LWRs reach their end-of-life. The types and numbers of facilities (i.e., reactors and recycling facilities) would vary depending on the particular domestic programmatic alternative (see Table 2.10.1-1).

\footnotetext{
${ }^{25}$ As previously discussed, the PEIS also assesses a zero growth scenario (100 GWe), a 0.7 percent growth scenario (150 GWe by approximately 2060-2070), and a 2.5 percent growth scenario (400 GWe by approximately 2060-2070).
} 
TABLE 2.10.1-1—Capacity/Facility Information for Programmatic Alternatives (200 Gigawatts Electric)

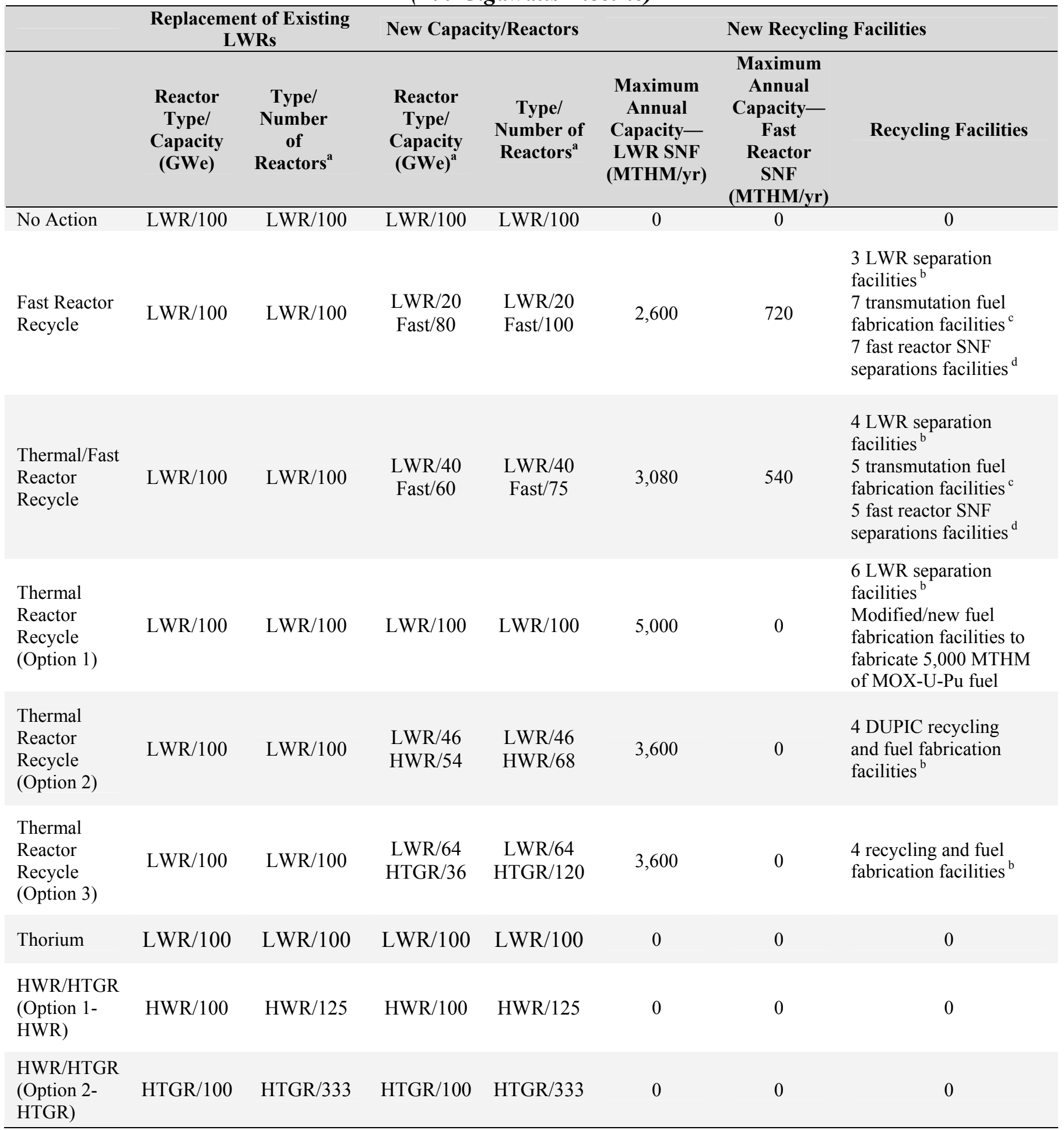

${ }^{a}$ Number of reactors based on following output: LWR: 1 GWe; HWR: 800 MWe; Fast Reactor: 800 MWe; HTGR: 300 MWe.

${ }^{\mathrm{b}}$ Each facility with a capacity to separate $800 \mathrm{MTHM} / \mathrm{yr}$ of LWR SNF.

${ }^{\mathrm{c}}$ Each facility with a capacity to fabricate $100 \mathrm{MTHM} / \mathrm{yr}$ of fuel.

${ }^{\mathrm{d}}$ Each facility with a capacity to separate $100 \mathrm{MTHM} / \mathrm{yr}$ of fast reactor SNF. 


\subsection{Percent Growth Scenario (400 Gigawatts Electric by Approximately 2060-2070)}

For this scenario, under all alternatives, nuclear electricity capacity is assumed to increase from the current $100 \mathrm{GWe}$ to approximately $400 \mathrm{GWe}$. This would be equivalent to constructing approximately 300 new GWe of reactor capacity, and replacing the existing $100 \mathrm{GWe}$ of LWR capacity when the existing LWRs reach their end-of-life. The types and numbers of facilities (i.e., reactors and recycling facilities) would vary depending on the particular domestic programmatic alternative (see Table 2.10.2-1). 
TABLE 2.10.2-1—Capacity/Facility Information for Programmatic Alternatives (400 Gigawatts Electric)

\begin{tabular}{|c|c|c|c|c|c|c|c|}
\hline & \multicolumn{2}{|c|}{$\begin{array}{l}\text { Replacement of Existing } \\
\text { LWRs }\end{array}$} & \multicolumn{2}{|c|}{ New Capacity/Reactors } & \multicolumn{3}{|c|}{ New Recycling Facilities } \\
\hline & $\begin{array}{l}\text { Reactor } \\
\text { Type/ } \\
\text { Capacity } \\
\text { (GWe) }\end{array}$ & $\begin{array}{c}\text { Type/ } \\
\text { Number } \\
\text { of } \\
\text { Reactors }^{\mathrm{a}}\end{array}$ & $\begin{array}{l}\text { Reactor } \\
\text { Type/ } \\
\text { Capacity } \\
(\text { GWe })^{\mathbf{a}}\end{array}$ & $\begin{array}{c}\text { Type/ } \\
\text { Number of } \\
\text { Reactors }^{\mathrm{a}}\end{array}$ & $\begin{array}{c}\text { Maximum } \\
\text { Annual } \\
\text { Capacity- } \\
\text { LWR SNF } \\
\text { (MTHM/yr) }\end{array}$ & $\begin{array}{c}\text { Maximum } \\
\text { Annual } \\
\text { Capacity- } \\
\text { Fast } \\
\text { Reactor } \\
\text { SNF } \\
\text { (MTHM/yr) }\end{array}$ & Recycling Facilities \\
\hline No Action & $\mathrm{LWR} / 100$ & LWR/100 & LWR/300 & $\mathrm{LWR} / 300$ & 0 & 0 & 0 \\
\hline $\begin{array}{l}\text { Fast Reactor } \\
\text { Recycle }\end{array}$ & LWR/100 & $\mathrm{LWR} / 100$ & $\begin{array}{l}\mathrm{LWR} / 140 \\
\text { Fast/160 }\end{array}$ & $\begin{array}{l}\mathrm{LWR} / 140 \\
\text { Fast/200 }\end{array}$ & 5,200 & 1,440 & $\begin{array}{l}6 \text { LWR separation } \\
\text { facilities }{ }^{\text {b }} \\
14 \text { transmutation fuel } \\
\text { fabrication facilities }^{c} \\
14 \text { fast reactor SNF } \\
\text { separations facilities }\end{array}$ \\
\hline $\begin{array}{l}\text { Thermal/Fast } \\
\text { Reactor } \\
\text { Recycle }\end{array}$ & LWR/100 & $\mathrm{LWR} / 100$ & $\begin{array}{l}\mathrm{LWR} / 180 \\
\text { Fast/120 }\end{array}$ & $\begin{array}{l}\mathrm{LWR} / 180 \\
\text { Fast/150 }\end{array}$ & 6,160 & 1,080 & $\begin{array}{l}4 \text { LWR separation } \\
\text { facilities }{ }^{b} \\
10 \text { transmutation fuel } \\
\text { fabrication facilities }^{c} \\
10 \text { fast reactor SNF } \\
\text { separations facilities }\end{array}$ \\
\hline $\begin{array}{l}\text { Thermal } \\
\text { Reactor } \\
\text { Recycle } \\
\text { (Option 1) }\end{array}$ & LWR/100 & $\mathrm{LWR} / 100$ & $\mathrm{LWR} / 300$ & $\mathrm{LWR} / 300$ & 10,000 & 0 & $\begin{array}{l}12 \text { LWR separation } \\
\text { facilities }{ }^{b} \\
\text { Modified/new fuel } \\
\text { fabrication facilities to } \\
\text { fabricate } 10,000 \text { MTHM } \\
\text { of MOX-U-Pu fuel }\end{array}$ \\
\hline $\begin{array}{l}\text { Thermal } \\
\text { Reactor } \\
\text { Recycle } \\
\text { (Option 2) }\end{array}$ & LWR/100 & $\mathrm{LWR} / 100$ & $\begin{array}{l}\text { LWR/192 } \\
\text { HWR/108 }\end{array}$ & $\begin{array}{l}\mathrm{LWR} / 192 \\
\mathrm{HWR} / 135\end{array}$ & 7,200 & 0 & $\begin{array}{l}9 \text { DUPIC recycling } \\
\text { and fuel fabrication } \\
\text { facilities }^{b}\end{array}$ \\
\hline $\begin{array}{l}\text { Thermal } \\
\text { Reactor } \\
\text { Recycle } \\
\text { (Option 3) }\end{array}$ & LWR/100 & $\mathrm{LWR} / 100$ & $\begin{array}{l}\mathrm{LWR} / 228 \\
\mathrm{HTGR} / 72\end{array}$ & $\begin{array}{c}\mathrm{LWR} / 228 \\
\mathrm{HTGR} / 240\end{array}$ & 7,200 & 0 & $\begin{array}{l}9 \text { recycling and fuel } \\
\text { fabrication facilities }\end{array}$ \\
\hline Thorium & LWR/100 & $\mathrm{LWR} / 100$ & $\mathrm{LWR} / 300$ & $\mathrm{LWR} / 300$ & 0 & 0 & 0 \\
\hline $\begin{array}{l}\text { HWR/HTGR } \\
\text { (Option 1- } \\
\text { HWR) }\end{array}$ & $\mathrm{HWR} / 100$ & HWR/125 & $\mathrm{HWR} / 300$ & $\mathrm{HWR} / 375$ & 0 & 0 & 0 \\
\hline $\begin{array}{l}\text { HWR/HTGR } \\
\text { (Option 2- } \\
\text { HTGR) }\end{array}$ & HTGR/100 & HTGR/333 & HTGR/300 & HTGR/1,000 & 0 & 0 & 0 \\
\hline
\end{tabular}




\subsection{Percent Growth Scenario (150 Gigawatts Electric by Approximately 2060-2070)}

For this scenario, under all alternatives, nuclear electricity capacity is assumed to increase from the current $100 \mathrm{GWe}$ to approximately $150 \mathrm{GWe}$. This would be equivalent to constructing approximately 50 new GWe of reactor capacity, and replacing the existing $100 \mathrm{GWe}$ of LWR capacity when the existing LWRs reach their end-of-life. The types and numbers of facilities (i.e., reactors and recycling facilities) would vary depending on the particular domestic programmatic alternative (see Table 2.10.3-1). 
TABLE 2.10.3-1—Capacity/Facility Information for Programmatic Alternatives (150 Gigawatts Electric)

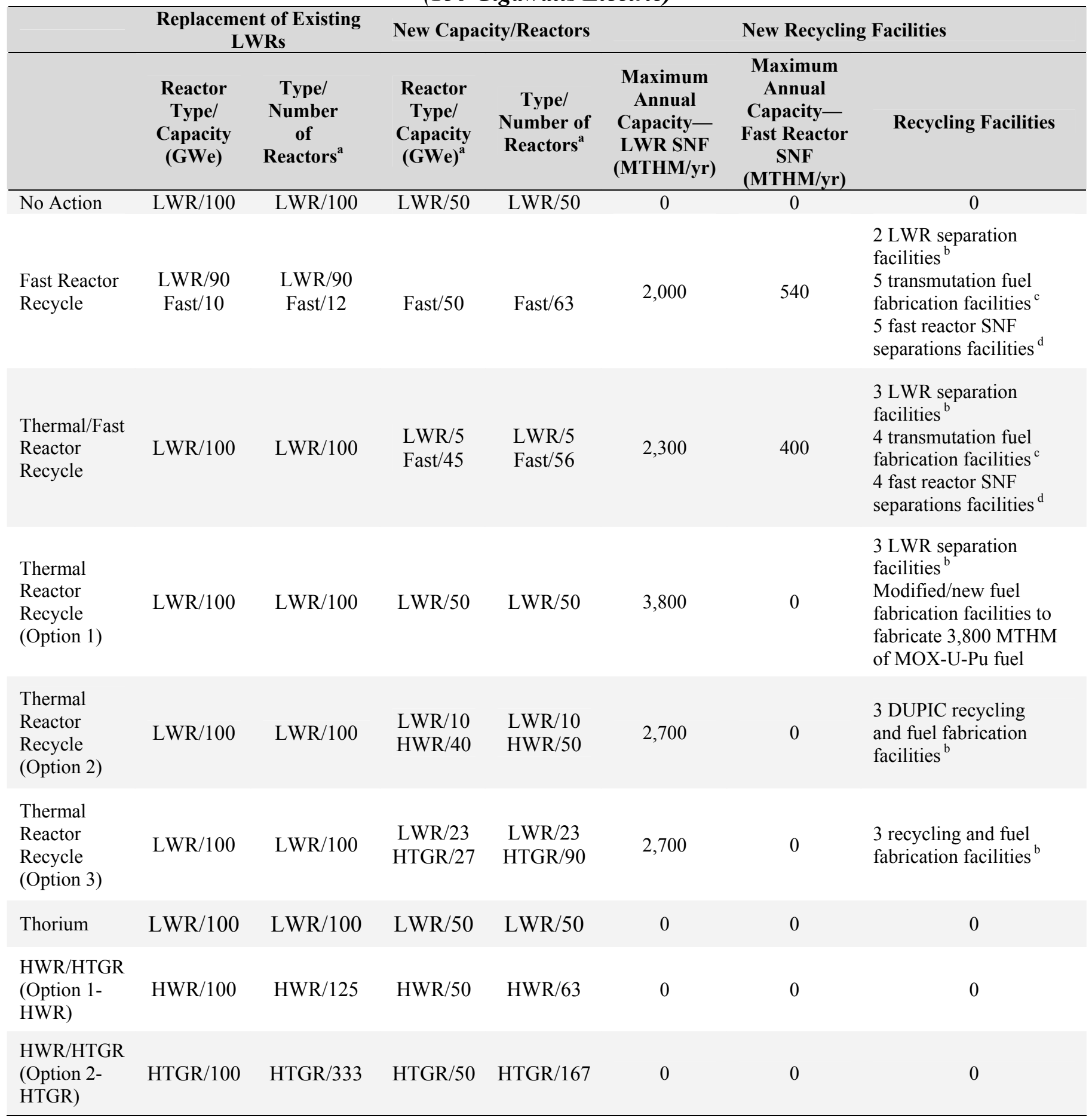

${ }^{a}$ Number of reactors based on following output: LWR: 1 GWe; HWR: 800 MWe; Fast Reactor: 800 MWe; HTGR: 300 MWe.

${ }^{\mathrm{b}}$ Each facility with a capacity to separate $800 \mathrm{MTHM} / \mathrm{yr}$ of LWR SNF.

${ }^{\mathrm{c}}$ Each facility with a capacity to fabricate $100 \mathrm{MTHM} / \mathrm{yr}$ of fuel.

${ }^{\mathrm{d}}$ Each facility with a capacity to separate $100 \mathrm{MTHM} / \mathrm{yr}$ of fast reactor SNF. 


\subsubsection{Zero Growth Scenario (100 Gigawatts Electric by Approximately 2060-2070)}

For this scenario, under all alternatives, nuclear electricity capacity is assumed to remain at the current $100 \mathrm{GWe}$. This is not meant to imply that the existing commercial fuel cycle would remain the same. In fact, the fuel cycle (and the associated facilities) could change, based on transitioning to, and implementing, each domestic programmatic alternative. To implement any of the programmatic alternatives, the existing $100 \mathrm{GWe}$ of LWR capacity would be replaced when the existing LWRs reach their end-of-life. The types and numbers of facilities (i.e., reactors, recycling facilities) would vary depending on the particular domestic programmatic alternative (see Table 2.10.4-1). 
TABLE 2.10.4-1—Capacity/Facility Information for Programmatic Alternative (100 Gigawatts Electric)

\begin{tabular}{|c|c|c|c|c|c|}
\hline & \multicolumn{2}{|c|}{$\begin{array}{c}\text { Replacement of Existing } \\
\text { LWRs } \\
\end{array}$} & \multicolumn{3}{|c|}{ New Recycling Facilities } \\
\hline & $\begin{array}{l}\text { Reactor } \\
\text { Type/ } \\
\text { Capacity } \\
\text { (GWe) }\end{array}$ & $\begin{array}{c}\text { Type/ } \\
\text { Number of } \\
\text { Reactors }^{\mathrm{a}}\end{array}$ & $\begin{array}{c}\text { Maximum } \\
\text { Annual } \\
\text { Capacity-LWR } \\
\text { SNF (MTHM/yr) }\end{array}$ & $\begin{array}{c}\text { Maximum } \\
\text { Annual } \\
\text { Capacity- } \\
\text { Fast Reactor } \\
\text { SNF } \\
\text { (MTHM/yr) }\end{array}$ & Recycling Facilities \\
\hline No Action & $\mathrm{LWR} / 100$ & $\mathrm{LWR} / 100$ & 0 & 0 & 0 \\
\hline $\begin{array}{l}\text { Fast Reactor } \\
\text { Recycle }\end{array}$ & $\begin{array}{l}\mathrm{LWR} / 60 \\
\text { Fast/40 }\end{array}$ & $\begin{array}{l}\mathrm{LWR} / 60 \\
\text { Fast/50 }\end{array}$ & 1,300 & 360 & $\begin{array}{l}2 \text { LWR separation facilities }{ }^{b} \\
4 \text { transmutation fuel fabrication }^{c} \\
\text { facilities }^{c} \\
4 \text { fast reactor SNF separations } \\
\text { facilities }^{\mathrm{d}}\end{array}$ \\
\hline $\begin{array}{l}\text { Thermal/Fast } \\
\text { Reactor } \\
\text { Recycle }\end{array}$ & $\begin{array}{l}\mathrm{LWR} / 70 \\
\text { Fast/30 }\end{array}$ & $\begin{array}{l}\mathrm{LWR} / 70 \\
\text { Fast/38 }\end{array}$ & 1,540 & 270 & $\begin{array}{l}2 \text { LWR separation facilities }{ }^{b} \\
3 \text { transmutation fuel fabrication } \\
\text { facilities }^{c} \\
3 \text { fast reactor SNF separations } \\
\text { facilities }^{d}\end{array}$ \\
\hline $\begin{array}{l}\text { Thermal } \\
\text { Reactor } \\
\text { Recycle } \\
\text { (Option 1) }\end{array}$ & LWR/100 & LWR/100 & 2,500 & 0 & $\begin{array}{l}3 \text { LWR separation facilities }{ }^{b} \\
\text { Modified/new fuel fabrication } \\
\text { facilities to fabricate } 2,500 \\
\text { MTHM of MOX-U-Pu fuel }\end{array}$ \\
\hline $\begin{array}{l}\text { Thermal } \\
\text { Reactor } \\
\text { Recycle } \\
\text { (Option 2) }\end{array}$ & $\begin{array}{l}\mathrm{LWR} / 73 \\
\mathrm{HWR} / 27\end{array}$ & $\begin{array}{l}\mathrm{LWR} / 73 \\
\mathrm{HWR} / 90\end{array}$ & 1,800 & 0 & $\begin{array}{l}2 \text { DUPIC recycling and fuel } \\
\text { fabrication facilities } b\end{array}$ \\
\hline $\begin{array}{l}\text { Thermal } \\
\text { Reactor } \\
\text { Recycle } \\
\text { (Option 3) }\end{array}$ & $\begin{array}{c}\mathrm{LWR} / 82 \\
\mathrm{HTGR} / 18\end{array}$ & $\begin{array}{c}\mathrm{LWR} / 82 \\
\mathrm{HTGR} / 60\end{array}$ & 1,800 & 0 & $\begin{array}{l}2 \text { recycling and fuel fabrication } \\
\text { facilities } b\end{array}$ \\
\hline Thorium & LWR/100 & LWR/100 & 0 & 0 & 0 \\
\hline $\begin{array}{l}\text { HWR/HTGR } \\
\text { (Option 1- } \\
\text { HWR) }\end{array}$ & HWR/100 & HWR/125 & 0 & 0 & 0 \\
\hline $\begin{array}{l}\text { HWR/HTGR } \\
\text { (Option 2- } \\
\text { HTGR) }\end{array}$ & HTGR/100 & HTGR/333 & 0 & 0 & 0 \\
\hline
\end{tabular}




\subsection{Preferred Alternative}

The Council on Environmental Quality regulations require an agency to identify its preferred alternative or alternatives, if one or more exists, in a draft EIS (40 CFR 1502.14(e)). For this Draft GNEP PEIS, DOE's preference is to close the fuel cycle, which would recycle SNF. DOE has not identified which of the specific closed fuel cycle alternatives is preferred. DOE will identify one or more preferred alternatives in the Final PEIS.

Recycling SNF could include the destruction and use of the transuranic materials in the SNF, thereby significantly reducing the thermal output and radiotoxicity of wastes requiring geologic disposal. The analysis shows that recycling SNF could reduce the time period required for the radiotoxicity of the wastes to fall to that of natural uranium ore from approximately 240,000 years (for the No Action Alternative) to 1,000 years or less (for the Fast Reactor Recycle and Thermal/Fast Reactor Recycle Alternatives) or to 55,000 years (for the Thermal Reactor Recycle Alternative-Option 1). Moreover, recycling has the potential to significantly reduce the thermal loading on any geologic repository (in the best case, up to a factor of 235 relative to the No Action Alternative). This could be a substantial reduction in heat load. Finally, the reprocessing of the spent fuel would be designed to meet nonproliferation objectives and would avoid separation of pure plutonium.

The closed fuel cycle offers the potential for near-term deployment with variations to existing separations, fuel, and reactor technologies. Commercial SNF reprocessing is presently being done in other countries, while the recovered material is recycled in mixed-oxide fuel for existing light water reactors. Consequently, the near-term deployment (by approximately 2020) could allow the recycle of SNF generated in amounts beyond the Yucca Mountain geologic repository statutory capacity limit, rather than storing it pending development of the additional geologic disposal capacity. Recycling SNF could also delay the need for, and decrease the magnitude of, additional geologic repository capacity compared to direct disposal of SNF. A longer-term strategy could include the use of advanced separations and reactor technologies. The potential to use variations to existing separations technology in the near-term could allow time, where necessary, to complete additional research, development, and demonstration on advanced separations and reactor technologies, if pursued. The closed fuel cycle also supports expansion of nuclear energy by making better use of uranium resources. 


\subsection{REFERENCES}

10 CFR 61.55

10 CFR 72.3

40 CFR 1502.14

42 U.S.C. 2021 b et seq.

42 U.S.C. 10101 et seq.

ANL 2002a

ANL 2004

Boczar et al. 2002

Canada 2007

Collins et al. 2007
U.S. Nuclear Regulatory Commission (NRC), "Waste Classification," Code of Federal Regulations, Office of the Federal Register, National Archives and Records Administration, Washington, DC, Revised January 1, 2008.

NRC, "Definitions," Code of Federal Regulations, Office of the Federal Register, National Archives and Records Administration, Washington, DC, Revised January 1, 2008.

Council on Environmental Quality (CEQ), "Alternatives Including the Proposed Action," Code of Federal Regulations, Office of the Federal Register, National Archives and Records Administration, Washington, DC, Revised July 1, 2007.

"Low-Level Radioactive Waste Policy Amendments Act of 1985," (LLRWPAA), United States Code, Washington, DC, January 15, 1986.

"Nuclear Waste Policy Act of 1982," (NWPA), United States Code, Washington, DC, January 7, 1983.

Argonne National Laboratory (ANL), "Feasibility Study of a Proliferation Resistant Fuel Cycle for LWR-Based Transmutation of Transuranics," T.A. Taiwo, T.K. Kim, M. Salvatores, ANLAAA-027, Argonne National Laboratory, 2002.

ANL, "Homogeneous Recycling Strategies in LWRs for Plutonium, Neptunium, and Americium Management," John A. Stillman, ANL-AFCI-124, Argonne National Laboratory, 2004.

Boczar, P.G., G. Dyck, H. Chow, J.D. Sullivan, D.S. Cox, W.W.R. Inch, and P.J. Fehrenba, "CANDU Advanced Fuels and Fuel Cycles," Atomic Energy of Canada Limited, Chalk River Laboratories, Chalk River, Ontario, Canada, 2002.

The Canadian Nuclear FAQ, "CANDU Nuclear Power Technology," The Canadian Nuclear FAQ, Section A, 2007. Accessed at www.nuclearfaq.ca/cnf_sectionA.htm on August 22, 2007.

Collins, E.D., G.D. DelCul, J.P. Renier, and B.B. Spencer, "Preliminary Multicycle Transuranic Actinide PartitioningTransmutation Studies," ORNL/TM-2007/24, Oak Ridge National Laboratory, February 1, 2007. 
DOE 2001b

DOE 2006t

DOE 2006u

EIA 2006d

EIA 2007a

EIA $2007 b$

EIA 2008a

Finck 2007b

Finck 2007d
U.S. Department of Energy (DOE), "A Roadmap to Deploy New Nuclear Power Plants in the United States by 2010," U.S. Department of Energy, Washington, DC, 2001. Accessed at http://www.ne.doe.gov/nerac/neracPDFs/ntdroadmapvolume1.pdf on May 15, 2008.

DOE, "The U.S. Generation IV Fast Reactor Strategy," DOE/NE0130, Office of Nuclear Energy, U.S. Department of Energy, Washington, DC, December 2006.

DOE, "Report to Congress: Spent Nuclear Fuel Recycling Program Plan," U.S. Department of Energy, Washington, DC, May 2006.

Energy Information Administration (EIA), "New Commercial Reactor Designs," Energy Information Administration, U.S. Department of Energy, Washington, DC, November 2006. Accessed at http://www.eia.doe.gov/cneaf/nuclear/page/analysis/ nucenviss2.html\#_ftn10 on April 29, 2008.

Energy Information Administration (EIA), "AEO 2008-Overview, Annual Energy Outlook 2008 (Early Release)," DOE/EIA-0383, Energy Information Administration, U.S. Department of Energy, Washington, DC, December 2007. Accessed at http://www.eia.doe.gov/oiaf/aeo/pdf/earlyrelease.pdf on January 22, 2008.

EIA, "Annual Energy Outlook 2007 With Projections to 2030," DOE/EIA-0383(2007), Energy Information Administration, U.S. Department of Energy, Washington, DC, 2007. Accessed at http://www.eia.doe.gov/oiaf/archive/aeo07/index.html on December 21, 2007.

EIA, "Annual Energy Outlook 2008 with Projections To 2030," DOE/EIA-0383(2008), Energy Information Administration, U.S. Department of Energy, Washington, DC, June 2008. Accessed at http://www.eia.doe.gov/oiaf/aeo/ on July 3, 2008.

E-mail from Phillip J. Finck, Idaho National Laboratory to Jay Rose, Tetra Tech and Francis Schwartz, U.S. Department of Energy, "High Burnup Write up," October 15, 2007.

E-mail from Phillip J. Finck, Idaho National Laboratory to Jay Rose, Tetra Tech, "Need Some Inputs- Attachments: SWCR (Supercritical Water-Cooled Reactors) \& MSR (Molten Salt Reactors)," October 23, 2007. 
Goldner and Versluis 2006

Hong et al. 2007

IAEA 2002b

IAEA 2005a

IAEA 2006b

Kim et al. 2006

NRC 2008a

NRC 2008b

Salvatores et al. 2003
Goldner, F. and R. Versluis, "Transmutation Capabilities of GENIV Reactors," Global Nuclear Energy Partnership Program, U.S. Department of Energy, Washington, DC, September 28, 2006.

Hong, G. S., Y. Kim, and F. Venneri, "Neutronic Characterization of Sodium-Cooled Fast Reactor in an MHR-SFR Synergy for TRU Transmutation," Proceedings of ICAPP 2007, Nice, France, May 13-18, 2007.

International Atomic Energy Agency (IAEA), "Thorium Fuel Utilization: Options and Trends," IAEA-TECDOC-1319, Proceedings of Three IAEA Meetings held in Vienna in 1997, 1998, and 1999, November 1, 2002.

IAEA, "Thorium Fuel Cycle_-Potential Benefits and Challenges," IAEA-TECDOC-1450, International Atomic Energy Agency, May 1, 2005.

IAEA, "Fundamental Safety Principles, Safety Fundamentals No. SF-1," International Atomic Energy Agency, 2006. Accessed at http://www-pub.iaea.org/MTCD/publications/PDF/

Pub1273_web.pdf on April 29, 2008.

Kim, T.K., T.A. Taiwo, W.S. Yang, R.N Hill, and F. Venneri, "Assessment of Deep Burnup Concept Based on Graphite Moderated Gas-Cooled Thermal Reactor," Proc. PHYSOR 2006Advances in Nuclear Analysis and Simulation, Vancouver, British Columbia, Canada, September 10-14, American Nuclear Society, La Grange Park, IL, 2006.

NRC, "Interactions of the U.S. Nuclear Regulatory Commission with Native American Tribal Governments," Remarks by Dr. Peter B. Lyons, U.S. Nuclear Regulatory Commission, Washington, DC, 2008. Accessed at http://www.nrc.gov/reading-rm/doccollections/commission/speeches/2008/s-08-010.html on April 4, 2008.

NRC, "Fact Sheet on Mixed Oxide Fuel," U.S. Nuclear Regulatory Commission, Washington, DC, 2008. Accessed at http://www.nrc.gov/reading-rm/doc-collections/factsheets/mox.htmlmox fuel on January 2008.

Salvatores, M., G. Youinou., R. N. Hill, T. Taiwo, and T.K. Kim, "Systematic Assessment of LWR Recycle Strategies," ANL-AFCI-100, Argonne National Laboratory, September 1, 2003. 
Van Tuyle 2001

Whitlock 2000

Wigeland 2008a

WNA 2008f

Yang and Park 2006

Yang et al. 2005
Van Tuyle, G.J., "Candidate Approaches for an Integrated Nuclear Waste Management Strategy-Scoping Evaluations," Report No. AAA-PDO-GEN-01-0051, LA-UR-01-5572, November 2001. Accessed at http://aaa.nevada.edu/pdffiles/Microsoft Word GregMultiTier.pdf on February 27, 2008.

Whitlock, J., "The Evolution of CANDU Fuel Cycles and Their Potential Contribution to World Peace," Presented at the International Youth Nuclear Congress 2000, Bratislava, Slovakia, April 9-14, 2000.

Wigeland, R.A., "Performance Summary of Advanced Nuclear Fuel Cycles," GNEP-TIO-AI-AI-RT-2008-000268 Revision 1, Idaho National Laboratory, Nuclear Science \& Technology, June 10, 2008.

World Nuclear Association (WNA), "Nuclear Power in Germany," World Nuclear Association, January 2008. Accessed at http://www.world-nuclear.org/info/inf43.html on June 5, 2008.

Yang, M.S., and J.H. Park, "Korean Assessment of the Proliferation Resistance on the Whole Fuel Cycle of DUPIC," Korean Atomic Energy Research Institute, 2006.

Yang, M.S., H. Choi, C.J. Jeong, K.C. Song, J.W. Lee, G.I. Park, H.D. Kim, W.I. Ko, J.J. Park, K.H. Kim, H.H. Lee and J.H. Park, "The Status and Prospect of DUPIC Fuel Technology," Korean Atomic Energy Research Institute, September 1, 2005. 


\section{CHAPTER 3}

\section{AFFECTED ENVIRONMENT FOR DOMESTIC PROGRAMMATIC ALTERNATIVES}





\section{CHAPTER 3 AFFECTED ENVIRONMENT FOR DOMESTIC PROGRAMMATIC ALTERNATIVES}

Chapter 3, the affected environment for the domestic programmatic alternatives, provides the context to understand the environmental impacts described in Chapter 4. The affected environment serves as a baseline from which environmental impacts caused by implementation of the domestic programmatic alternatives can be evaluated. The baseline conditions are the currently existing conditions.

This section describes the affected environment with respect to nuclear electric power generation, including nuclear power plants and related nuclear infrastructure and their effects on the resource areas of air quality, land use, water resources, socioeconomics, radiological waste management, and transportation. The region of interest is the entire United States because facilities associated with the programmatic alternatives could be deployed anywhere in the country. However, emphasis is placed on the contiguous 48 states because they represent the vast majority of population and land area and allow for more effective transportation of materials and wastes. There are no existing or proposed commercial nuclear power reactors in Alaska or Hawaii.

\section{1}

\section{NuClear Power Plants And Infrastructure}

Nuclear power facilities include both generation plants and the associated infrastructure necessary to provide fuel and dispose of wastes. The main structures at a nuclear power plant include the reactor facility, cooling systems, and waste storage facilities. The land where these structures are sited, as well as surrounding resources and communities, is considered part of the affected environment of the power plant. There are currently 104 commercial nuclear power reactors in operation at 65 sites in the United States (NRC 2007e).

Current U.S. nuclear infrastructure supports uranium mining and milling, uranium enrichment, fuel fabrication, and management of spent nuclear fuel (SNF). As with any commercial power plant, transmission line infrastructure for connection to the power grid is also required. These components of the nuclear infrastructure involve numerous sites and facilities, and like the generation plants, each has surrounding land, resources, and communities that constitute the affected environment. Brief descriptions of these components are provided below, and more details are found in Chapter 4, Section 4.1 (NRC 2007d).

Uranium is mined in the United States and numerous countries around the world, including Canada, Australia, and Kazakhstan (WNA 2008e). Three principal methods are used to mine uranium: surface (open pit), underground, and in-situ leaching (solution mining). The method of extraction is dependent on the grade, size, location, and geology of the deposit, and is generally selected to maximize ore recovery within economic constraints. A low-grade cutoff point is established on a site-specific basis and depends on recovery costs at the site, the market price of the ore, and feed requirements at the mill (IAEA 1998). According to the Energy Information Administration, there were 10 operating uranium mines in the United States in 2006 (5 underground mines and 5 in-situ leaching mines) (EIA 2007n). 
Uranium ore deposits in the United States are generally rich in radium and vanadium. Radium has some commercial use, mainly in the medical industry, and vanadium is used as a hardener in the steel production industry. The isotopic content of uranium metal, as found naturally in ore deposits, is mostly uranium-238. Uranium-235 (U-235) generally represents around 0.72 percent of natural uranium ore, by weight. This percentage is far less than the 3 to 5 percent U-235 required by current U.S. nuclear power plants as fuel for electricity generation. Therefore, uranium must be enriched so it can be used in commercial nuclear power plants. Enrichment is the process applied to increase the percentage of the fissile U-235 isotope and decrease the percentage of U-238 (NRC 2007b).

Fuel fabrication is the final step in the process used to produce uranium fuel for commercial light water nuclear power reactors (NRC 2007c). During fabrication, enriched uranium hexafluoride $\left(\mathrm{UF}_{6}\right)$ is converted to uranium dioxide $\left(\mathrm{UO}_{2}\right)$ powder that is then ground, pressed, sintered (i.e., fused together), and loaded into prefabricated zirconium alloy clad tubes. The tubes are then filled with an inert gas and welded shut. These tubes, or pins, are bundled together and made into a fuel assembly (NRC 2007c).

Use of uranium as fuel in a reactor produces SNF. Management of SNF is required for the operation of nuclear power plants. SNF is stored by the nuclear power plants until an approved disposal facility is made available. The disposal of commercial SNF and U.S. Department of Energy (DOE) SNF and high-level waste (HLW) is planned for a geologic repository at Yucca Mountain in Nevada (DOE 2008g). SNF could be transported to the repository by rail or truck, or both. On April 8, 2004, DOE issued a Notice of a Record of Decision in the Federal Register (69 FR 18557), stating the preference to transport HLW and SNF to Yucca Mountain mainly by rail with a smaller portion of the SNF transported by truck. Also on April 8, 2004, DOE issued a Notice of Intent to Prepare an EIS for the Alignment, Construction, and Operation of a Rail Line for Shipments of SNF, HLW, and Other Materials from a Site Near Caliente, Lincoln County, Nevada, to a Geologic Repository at Yucca Mountain, Nye County, Nevada (69 FR 18565).

\subsection{Baseline EnVironmental Conditions of the Nuclear Power Industry}

The subsections below describe the nuclear power industry with respect to air quality, land use, water resources, socioeconomics, radiological waste management, and transportation.

\subsubsection{Air Quality}

In administering the Clean Air Act, the U.S. Environmental Protection Agency (EPA) has identified seven air pollutants that have well-known adverse effects on human health and welfare. These seven pollutants are called criteria pollutants, and they include carbon monoxide $(\mathrm{CO})$, nitrogen dioxide $\left(\mathrm{NO}_{2}\right)$, sulfur dioxide $\left(\mathrm{SO}_{2}\right)$, ozone $\left(\mathrm{O}_{3}\right)$, lead $(\mathrm{Pb})$, particulate matter with a diameter of less than 10 micrometers $\left(\mathrm{PM}_{10}\right)$, and particulate matter with a diameter less than 2.5 micrometers $\left(\mathrm{PM}_{2.5}\right)$. The EPA has established National Ambient Air Quality Standards (NAAQS) that limit the concentration levels for these pollutants in the ambient air (40 Code of Federal Regulations [CFR] Part 50). Regulations also are established for other harmful pollutants, such as mercury, asbestos, radionuclides, and the 188 hazardous air pollutants (HAPs) listed at 40 CFR Part 61. However, the concentration levels in ambient air for these pollutants are 
generally not regulated; rather, these pollutants are regulated on the basis of emission rates. In addition, there are pollutants that are presently unregulated, such as certain greenhouse gases (e.g., carbon dioxide), that also may have harmful environmental effects.

Nitrogen and sulfur compounds can react with the air to form acid compounds. Precipitation such as rain or snow causes these compounds to fall to the earth (acid rain). Some pollutants react with the air and erode the ozone layer that blocks harmful radiation from the sun. Ozone layer reductions allow higher levels of B-type ultraviolet radiation (UVB) to reach the surface of the earth. Ozone reductions cause a variety of adverse conditions with respect to plant growth, marine ecosystems, and terrestrial and biogeochemical cycles, and have been linked to increased incidences of skin cancer in humans (EPA 2006e).

Regional air quality is primarily a function of pollutant emission levels in the area. For this reason, air quality is generally much lower in urban and highly industrialized areas where a large number of pollutant emission sources are present in a relatively small area. To a lesser extent, weather patterns, topography and vegetation cover, and state air quality standards can affect regional air quality. Regions of the United States that currently fail to satisfy the NAAQS (i.e., nonattainment regions) are illustrated in Figure 3.2.1-1 (EPA 2007b). A more detailed discussion of air quality concepts is provided in Chapter 9 .

Nuclear power plants have a relatively low impact on air quality because they do not involve the chemical combustion of fossil fuels. Auxiliary equipment and processes are the principal direct sources of nonradiological emissions from a nuclear power plant. Other nonradiological emissions are generated by trains and trucks that transport materials to and from the plant, and from plant worker vehicles.

Activities and processes that support the nuclear power industry also generate nonradiological and/or radiological emissions. For example, emissions are produced by equipment and activities at the uranium mines where raw uranium ore is extracted, by processes applied to convert uranium ore into enriched reactor grade fuel, and by transportation systems that transfer material between destinations.

Underground uranium mines produce exhaust which typically includes radon-222 (Rn-222) in measurable concentrations. Rn-222 is present in the exhaust because it emanates from the ore. The concentration of Rn-222 in mine exhaust varies and depends on the ventilation rate, mine volume, mine age, grade of exposed ore, size of active work areas, moisture content and porosity of the rock, barometric pressure, and mining practices. "A previous EPA study indicates that higher Rn-222 emission rates occur at older mines, probably because there are larger surface areas of exposed ore and sub-ore" (EPA 1983).

Small levels of radiological emissions may be released at a nuclear power plant from routine operations; however, these emissions are continuously monitored and are subject to strict Federal regulations under the aegis of the U.S. Nuclear Regulatory Commission (NRC). Radiation dose exposures are small relative to doses from natural radioactivity. 


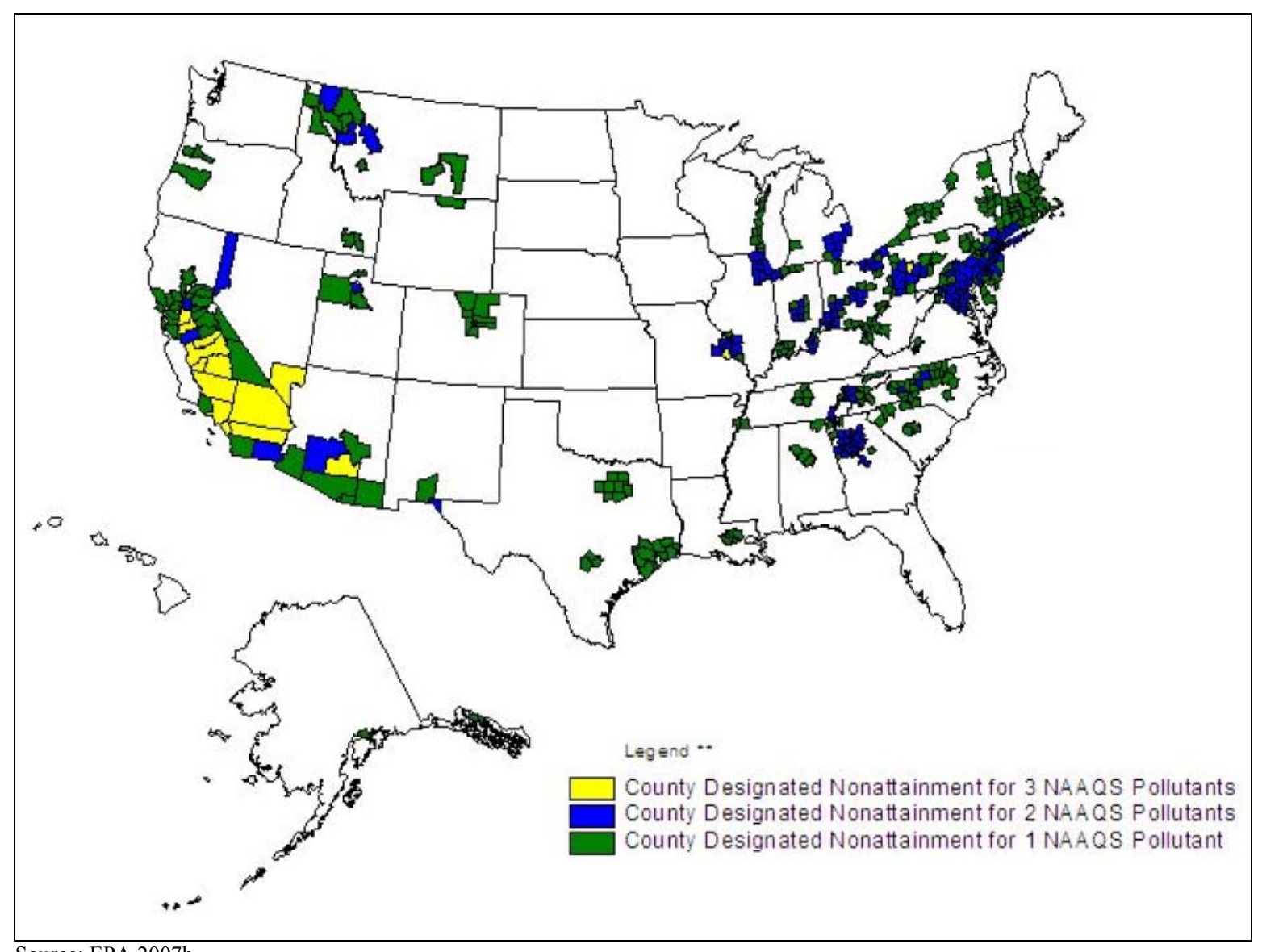

Source: EPA 2007b

FIGURE 3.2.1-1-Nonattainment Areas of the United States

\subsection{2}

Land Use

Land area of the continental United States covers about 1.94 billion acres (785 million hectares [ha]). Allocation of these lands (by major river basin) is illustrated in Figure 3.2.2-1. Cropland, pasture, open range, and forest land comprise the majority of U.S. land resources. The condition of these lands directly or indirectly influences the environment. The ability to meet national objectives for natural resources and environmental quality depends on how these lands are used and conserved (NRCS 2007). 
2
0
0
5
5
5
0
0
0
0

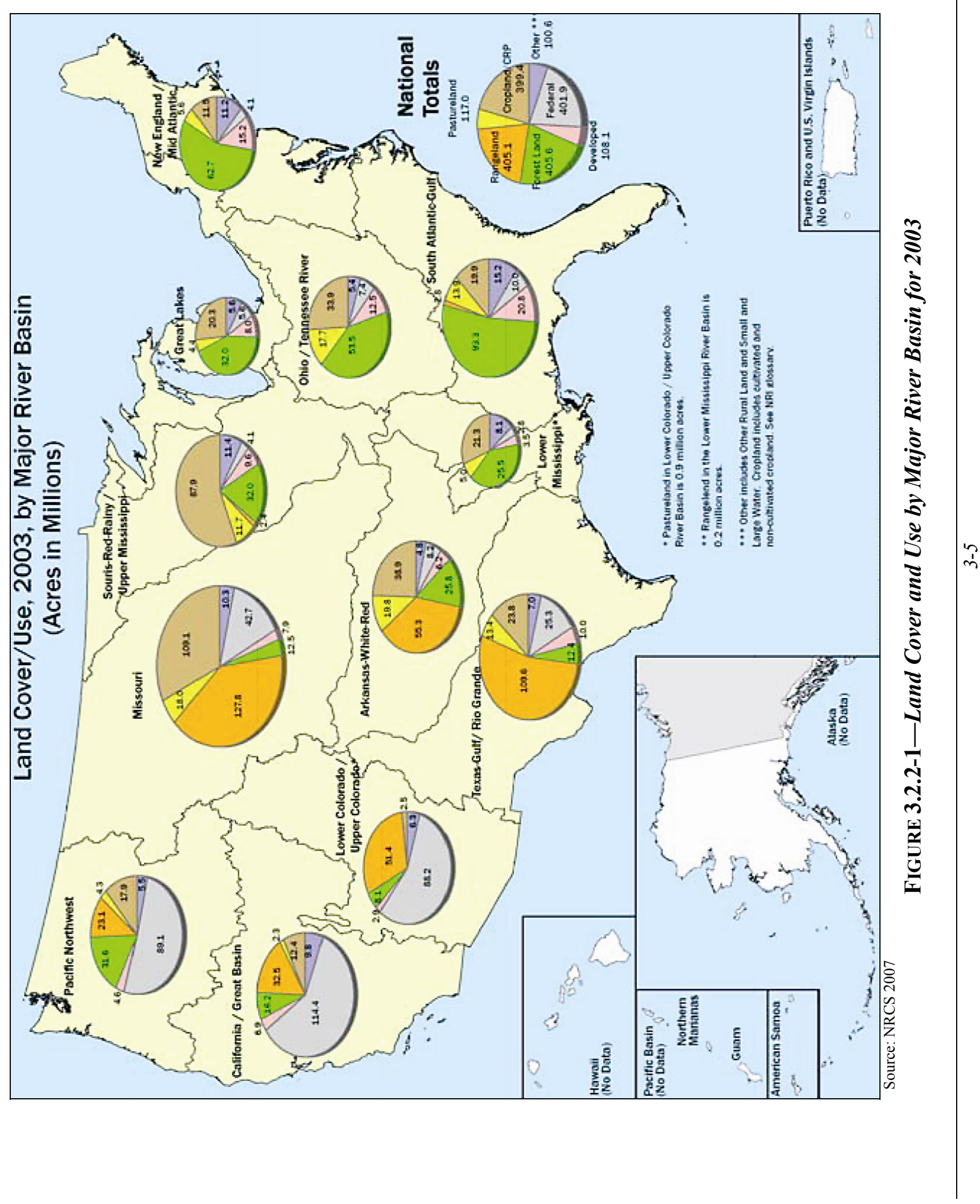


Land is required to accommodate the various aspects of a nuclear power plant, such as the reactor facility, cooling systems, waste storage facilities, and other support infrastructure. Additional land is required to mine uranium ore, process the ore into metallic uranium, enrich the uranium, and fabricate the fuel assemblies. Land is also required for disposal of low-level waste (LLW), HLW, hazardous waste, Greater-than-Class-C (GTCC) waste, transuranic waste, and SNF. There is currently no long-term repository available for HLW and SNF (DOE 2008g). In addition, there is currently no disposal capability for GTCC waste (72 FR 40135).

The land area controlled by individual commercial nuclear power plants in the United States ranges from 84 acres ( $34 \mathrm{ha}$ ) to 30,000 acres $(12,100 \mathrm{ha})$; however, the exclusion zones range from 58 acres (23 ha) to 3,192 acres (1,292 ha), with an average exclusion zone area of 742 acres (300 ha). This includes land and facilities to store SNF onsite (NRC 1996). Using the actual size of reactor sites identified in NUREG-1437, the average footprint of existing reactor sites is about 3,000 acres (1,214 ha) (NRC 1996). The land area required for a new reactor would be dependent on factors such as location, reactor design, and cooling water availability.

\subsubsection{Water Resources}

With respect to this discussion on water resources, there are two important terms to define. "Water withdrawal" is the amount of water collected for an activity or process. "Water consumption" is the amount of water that is somehow lost or consumed by the activity or process (e.g., evaporation or leakage), and is therefore not directly returned to the source where it was withdrawn (USGS 2004a). The terms "water use" and "water demand" are used generically to describe either water withdrawal or water consumption.

The U.S. Geological Survey (USGS) estimated that the average amount of water withdrawn daily for all uses in the United States for 2000 was about 405 billion gallons (gal) (1,532 billion liters [L]). Daily withdrawal sources included 83 billion gal (312 billion L) of fresh groundwater, 1.3 billion gal (4.9 billion L) of saline groundwater, 262 billion gal (992 billion L) of fresh surface water, and 58.7 billion gal (221 billion L) of saline surface water (USGS 2004a).

The U.S. Department of Agriculture (USDA) reports water use in the United States by major categories, such as thermoelectric power (i.e., electrical power generated by a thermal conversion process such as a coal-fired boiler or nuclear plant), irrigation, public supply, industrial, agriculture, domestic use, mining, and livestock. Figure 3.2.3-1 illustrates the relative percentage of each category for 2000. Thermoelectric power generation represented the largest share, followed by agriculture and public supply. All other categories represent about 8 percent of total water consumption (USGS 2004a).

Thermoelectric power generation accounted for roughly 192.9 billion gal/day ( 730 billion L/day), or 48 percent of all withdrawals in 2000. Large amounts of water are needed for cooling. For this reason, thermoelectric power plants are located near an abundant water supply. More than 99 percent of total thermoelectric power withdrawals were from surface waters (USGS 2004a); however, water consumption (evaporative loss to the atmosphere) was only about 2.2 percent of withdrawals. 
There are two principal methods of heat rejection at thermoelectric power plants-once through (open-loop) and recirculation (closed-loop). In an open-loop system, the steam is cooled by water that is pumped from an outside source through a condenser and then discharged; usually back into the water body from which it was withdrawn. In a closed-loop system, the steam is cooled in towers and the water that is not lost to evaporation is recycled through the plant with periodic discharges to reduce the concentration of minerals in the circulation water. Open-loop systems have a much higher withdrawal rate than closed-loop systems; however, closed-loop systems lose more water to evaporation, and thus have a higher overall rate of consumption (USGS 2004a).

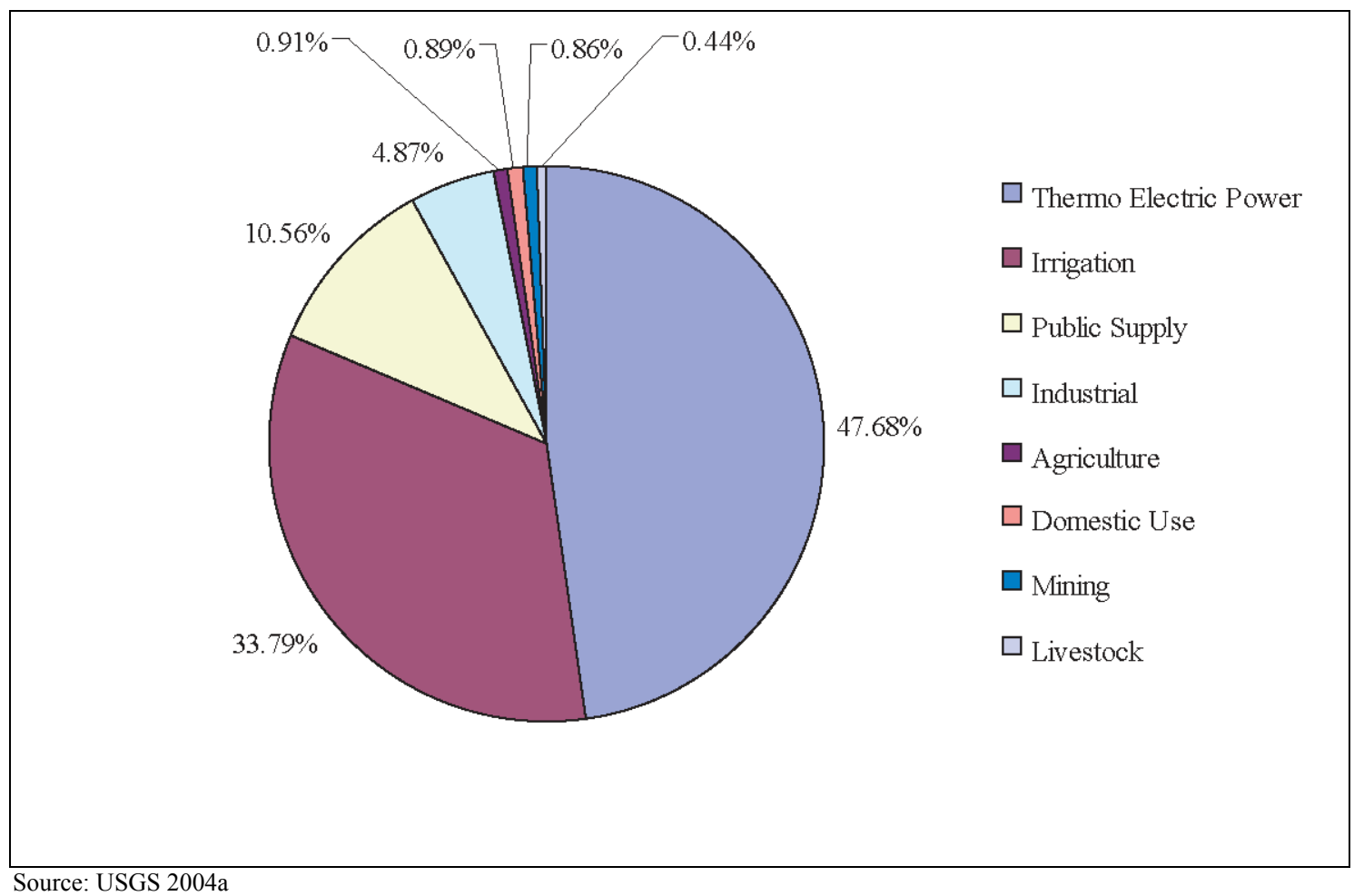

FIGURE 3.2.3-1—United States Water Consumption by Use Category

Although open-loop systems have a higher withdrawal rate than closed-loop systems, the USGS report shows that closed-loop power plants accounted for 91 percent of all thermoelectric power withdrawals, and open-loop power systems accounted for 9 percent of the withdrawals. Average water demand (withdrawal and consumption) for each method is listed in Table 3.2.3-1 based on a report from the National Energy Technology Laboratory (NETL). The rates of water withdrawal and consumption required to cool a nuclear power plant are typically higher than for a fossil-fired power plant, because nuclear power plants are designed to operate at lower temperatures and pressures. Operation at a lower temperature and pressure reduces the thermodynamic efficiencies and thus requires more water to reject the heat (NETL 2006b, USGS 2004a). 


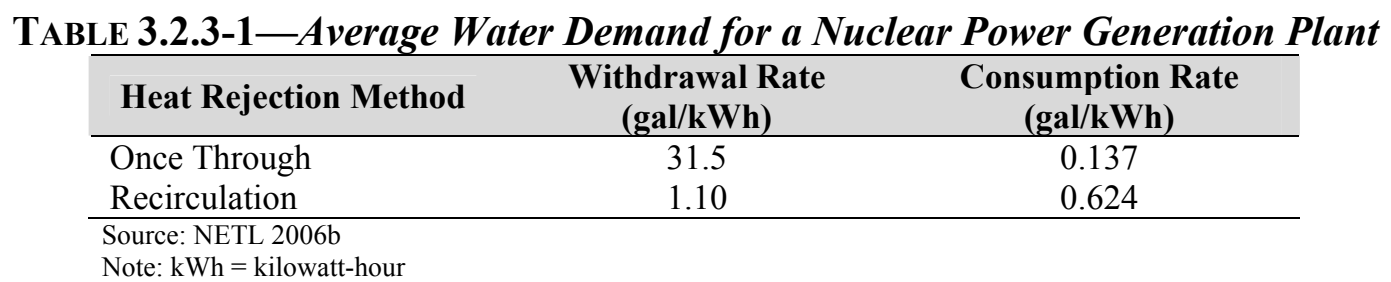

About 44 percent of nuclear power plants use a recirculation system for heat rejection. Daily water withdrawal for U.S. nuclear power generation is around 42.9 billion gal (182.4 billion L). Daily water consumption for uranium mine operations ranges from 0.07 to 0.26 billion gal (0.26 to 0.98 billion L) (NETL 2006b, POA 2006).

\subsubsection{Socioeconomics}

This section provides an overview of the affected environment for the domestic power generation industry with respect to socioeconomics. It includes a discussion of historical population trends and projected population growth; a description of major industrial activities and employment totals; a description of employment totals associated with power generation and distribution, and the mine activities needed to provide nuclear fuels; a discussion of projected demand growth in the power generation industry; nationwide employment data for the heavy construction industry; and an estimate of the major material requirements for nuclear power plants.

\subsubsection{Historical Population Growth}

The current U.S. population is around 303 million, which represents 4.58 percent of the world's population (USDOC 2007a). Between 1900 and 2000, the combined increase of 135 million people in the South and the West represented 66 percent of the U.S. population increase of 205 million people (Figure 3.2.4.1-1). Figure 3.2.4.1-2 shows the population growth by region (USDOC 2002a). Figure 3.2.4.1-3 shows the population density of the United States based on Census 2000 data (USCB 2000b). 


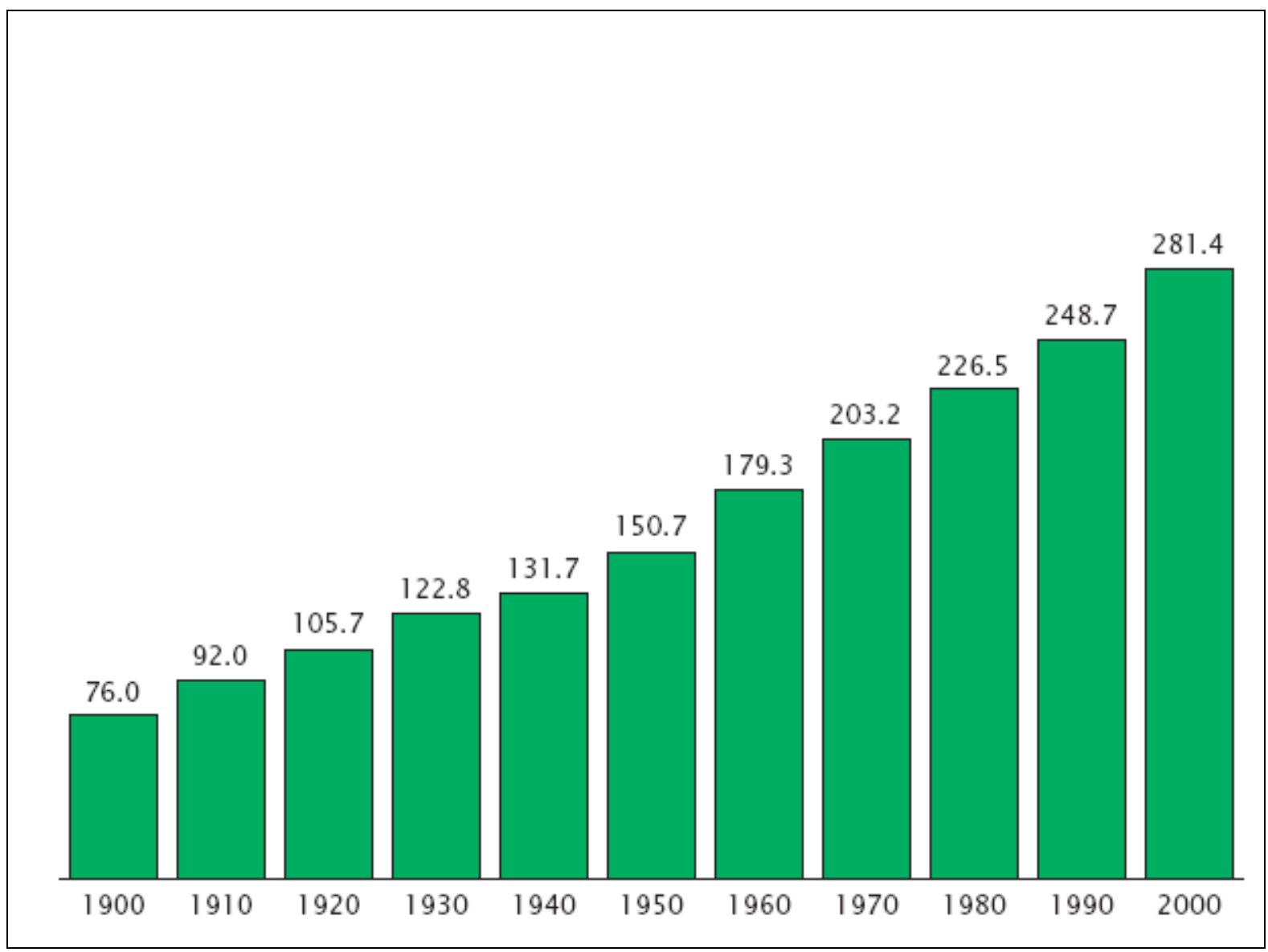

Source: USDOC 2002a

Figure 3.2.4.1-1—United States Population Trend from 1900 to 2000 (Millions) 


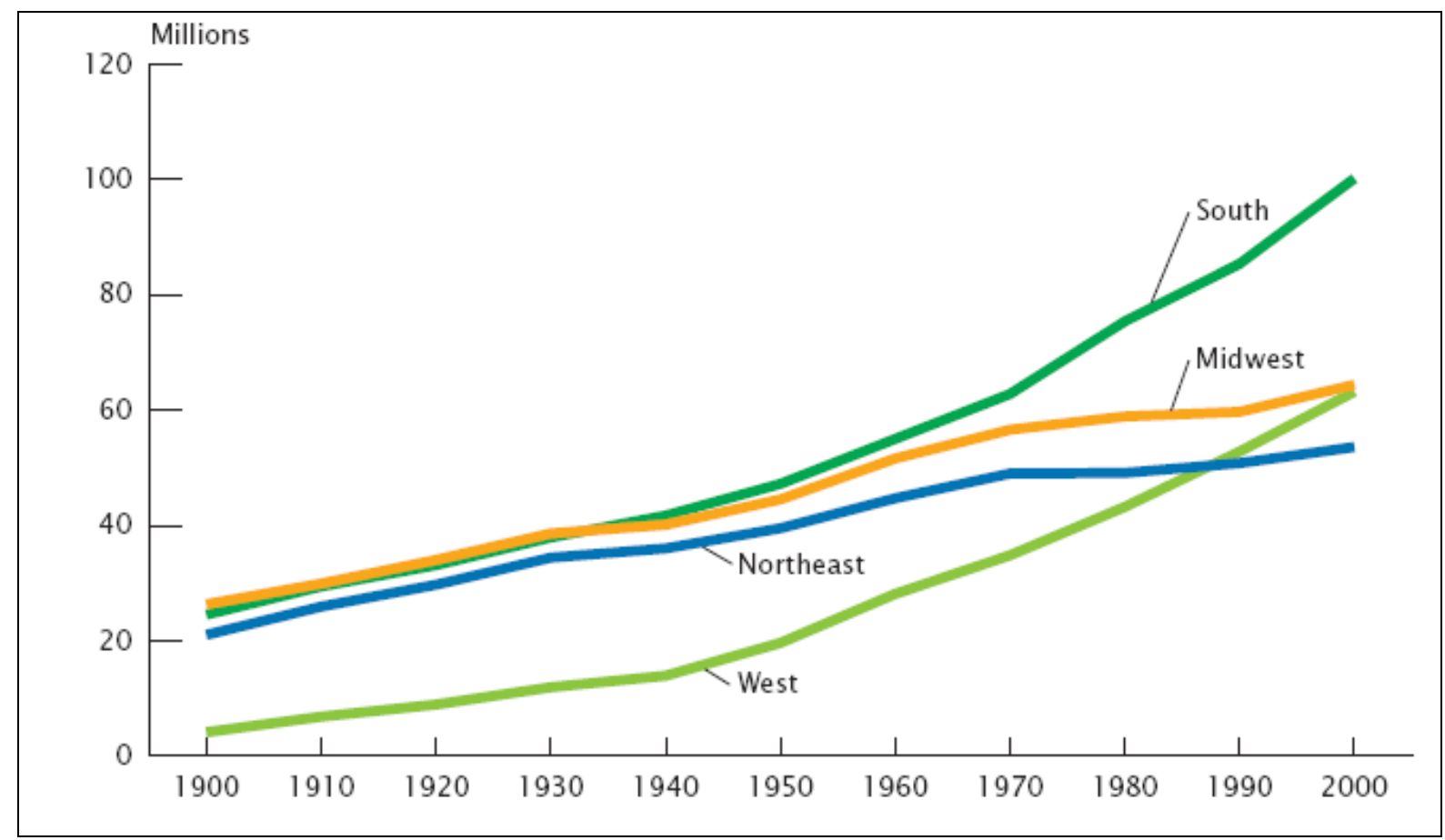

Source: USDOC 2002a

FIGURE 3.2.4.1-2-Population Growth by Region Between 1900 and 2000

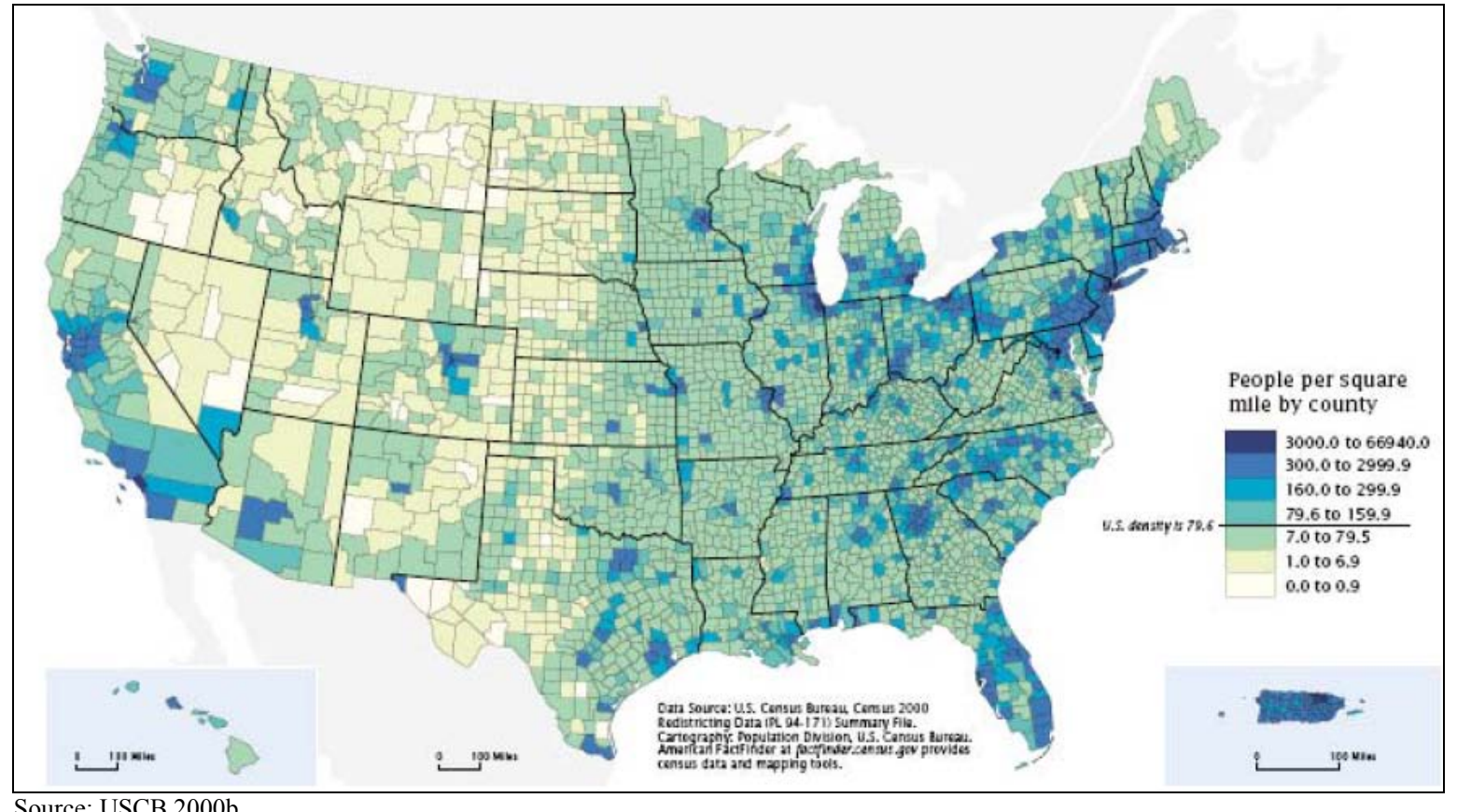

Source: USCB 2000b

FIGURE 3.2.4.1-3—Population Density of the United States for 2000 


\subsubsection{The United States Labor Force}

The Bureau of Labor Statistics (BLS) tracks labor economics and statistics for the Department of Labor. Since 1970, the unemployment rate in the United States has ranged from a low of 4.0 percent in 2000 to a high of 9.7 percent in 1982. The average rate was around 6.2 percent. The recent trend documents a steady decline each year from 6.0 percent in 2003 to 4.6 percent in 2007 (BLS 2008).

\subsubsection{Economic Census Data for United States Industry}

Every 5 years the U.S. Census Bureau provides a detailed portrait of the U.S. economy that categorizes economic activity based on the principal activity in which U.S. industry is engaged, consistent with the 2002 North American Industry Classification System (NAICS) that covers 1,179 industry categories (USDOC 2005a).

The most recently available U.S. Economic Census was completed in 2002 and covers 1,070 of the 1,179 industries listed in the 2002 NAICS. The industries included in the 2002 Economic Census are organized into 18 major industrial sectors (Table 3.2.4.3-1). Total employment for these sectors was nearly 109 million; however, this total excludes employment in government and other non-industrial sectors. The total labor force is the number of people age 16 or older who are employed or seek to be employed. The BLS reports that the total labor force in 2002 was about 145 million (BLS 2004).

TABLE 3.2.4.3-1—Employment by Industrial Sector for 2002

\begin{tabular}{lr}
\hline \multicolumn{1}{c}{ Industrial Sector } & Employment \\
\hline Educational services & 430,164 \\
Mining & 477,840 \\
Utilities & 663,044 \\
Arts, entertainment, \& recreation & $1,848,674$ \\
Real estate, rental \& leasing & $1,948,657$ \\
Management of companies \& enterprises & $2,605,292$ \\
Other services (except public administration) & $3,475,310$ \\
Transportation \& warehousing & $3,650,859$ \\
Information & $3,736,061$ \\
Wholesale trade & $5,878,405$ \\
Finance \& insurance & $6,578,817$ \\
Construction & $7,193,069$ \\
Professional, scientific, \& technical services & $7,243,505$ \\
Administrative \& support \& waste management \& remediation service & $8,741,854$ \\
Accommodation \& food services & $10,120,951$ \\
Retail trade & $14,647,675$ \\
Manufacturing & $14,699,536$ \\
Health care \& social assistance & $15,052,255$ \\
TOTAL & $\mathbf{1 0 8 , 9 9 1 , 9 6 8}$ \\
\hline Source: USDOC 2005b &
\end{tabular}

Source: USDOC 2005b 


\subsubsection{National Employment for the Electric Power Industry}

An estimated 535,675 people were employed in the electric power generation, transmission, and distribution industry in 2002. This included 122,875 employees for power generation and 412,890 for power transmission, control, and distribution. The number of employees associated with the nuclear power generation industry was around 31,400 based on 62 employees per million megawatt-hours (MWh) and an annual consumption of 507 million MWh (EIA 2007k, USDOC 2005c).

\subsubsection{National Employment for the Uranium Mining Industry}

In 2002, an estimated 3,264 people worked directly in the uranium/radium/vanadium mines that support the nuclear power generation industry. This estimate does not include employees who worked in central administrative offices, warehouses, or other establishments that served mining establishments within the same organization (USDOC 2005d).

\subsubsection{Projected Growth in Population and Energy Demand}

The U.S. population is projected to increase by 23.2 percent between 2005 and 2030 (USDOC 2004). Over that same time span, total electricity generation is projected to grow by 43.4 percent, and the per capita rate of energy generation is projected to increase by 13.5 percent, from 13.3 MWh per person in 2005 to 15.1 MWh per person in 2030 (EIA 2007a).

\subsubsection{Heavy Industrial Construction Industry}

Based on data from the 2002 Economic Census, the construction industry employed nearly 7.2 million workers. As shown in Table 3.2.4.7-1, a total of about 6.65 million workers were involved in heavy industrial and civil construction activities including specialty trade contractors (USDOC 2005e).

TABLE 3.2.4.7-1—Employment Data for Heavy Industrial and Civil Construction Activities

\begin{tabular}{lr}
\hline \multicolumn{1}{c}{ Description of Construction Activity } & Employment \\
\hline Nonresidential buildings & 791,186 \\
Utility system construction & 539,615 \\
Oil and gas pipeline construction & 94,323 \\
Power and communication system construction & 246,669 \\
Land subdivision & 52,607 \\
Highway, street, and bridge construction & 410,822 \\
Other heavy construction & 140,202 \\
Specialty trade contractors & $4,380,432$ \\
TOTAL & $\mathbf{6 , 6 5 5 , 8 5 6}$ \\
\hline Source: USDOC 2005e
\end{tabular}




\subsubsection{Major Construction Materials}

Principal construction materials for a nuclear power plant include steel and cement. Worldwide demand for these materials has increased rapidly over the past several years. Recent worldwide and domestic consumption data for these commodities are shown in Table 3.2.4.8-1.

\begin{tabular}{|c|c|c|}
\hline Commodity & World Consumption & U.S. Consumption \\
\hline $\begin{array}{l}\text { Steel } \\
\text { Cement }\end{array}$ & $\begin{array}{l}1.2 \text { billion } \mathrm{MT}^{\mathrm{a}} \\
2.45 \text { billion } \mathrm{MT}^{\mathrm{c}}\end{array}$ & $\begin{array}{l}120 \text { million } \mathrm{MT}^{\mathrm{b}} \\
120 \text { million } \mathrm{MT}^{\mathrm{d}}\end{array}$ \\
\hline $\begin{array}{l}{ }^{a} \text { Penton } 2007 \\
{ }^{b} \text { IISI } 2007 \\
{ }^{c} \text { OSC } 2006 \\
{ }^{d} \text { MSNBC } 2007\end{array}$ & & \\
\hline
\end{tabular}

Material requirements for a nuclear power generation plant vary by design and site location, but requirements for a typical 1-gigawatt electric (GWe) nuclear plant include 165,000 tons $(150,000$ metric tons [MT]) of steel and 937,000 tons $(850,000$ MT) of cement (CEEDATA 2006).

\subsubsection{Radiological Waste Management and Transportation}

The major sources of radioactive waste generation in the United States include the nuclear fuel cycle, DOE operations, industry, medical institutions, and research facilities. Nuclear fuel cycle operations and DOE operations represent the majority of radioactive waste generation each year.

As part of the nuclear fuel cycle, radioactive wastes are generated at the uranium mine, the conversion mill, the enrichment plant, the fuel fabrication plant, and the power plant. The bullets below provide a quantitative description of the nuclear fuel cycle material balance for a full year of operation $(8,760$ hours) for a nominal 1-gigawatt electric $(\mathrm{GWe})$ commercial nuclear power plant (WISE 2006).

- Uranium mine operations generate 542,000 tons (492,000 MT) of waste rock to produce 108,000 tons $(98,400 \mathrm{MT})$ of uranium ore that contains around 217 tons $(197 \mathrm{MT})$ of uranium metal (WISE 2006).

- Uranium mill operations generate slightly less than 108,000 tons (98,200 MT) of mill tailings to produce 245 tons (222 MT) of uranium oxide in the form of triuranium octaoxide $\left(\mathrm{U}_{3} \mathrm{O}_{8}\right)$ (WISE 2006).

- Conversion plant operations generate around 145 tons (131 MT) of solid waste and 47,500 cubic feet $\left(\mathrm{ft}^{3}\right)\left(1,340\right.$ cubic meters $\left.\left[\mathrm{m}^{3}\right]\right)$ of liquid waste to yield 306 tons (277 MT) of uranium hexafluoride (WISE 2006).

- Enrichment plant operations generate around 268 tons (243 MT) of depleted uranium hexafluoride to produce 38 tons (34.5 MT) of enriched uranium hexafluoride (WISE 2006). 
- Fuel fabrication operations generate around $372 \mathrm{ft}^{3}\left(10.6 \mathrm{~m}^{3}\right)$ of solid waste and $6,718 \mathrm{ft}^{3}$ $\left(190 \mathrm{~m}^{3}\right)$ of liquid waste to produce roughly 23.9 tons $(21.7 \mathrm{MT})$ of uranium oxide in the form of $\mathrm{UO}_{2}$. This quantity of $\mathrm{UO}_{2}$ contains around 21.1 tons (19.1 MT) of uranium metal (derived from WISE 2006).

- Nuclear power plant operations generate approximately 23.9 tons (21.7 MT) of SNF per GWe-year of production (Wigeland 2008a). Collectively, U.S. nuclear power plants currently generate approximately 2,390 tons (2,170 MT) of SNF each year (EPA 2006a). In addition, a typical LWR generates approximately 740 to $2,790 \mathrm{ft}^{3}\left(21\right.$ to $\left.79 \mathrm{~m}^{3}\right)$ of LLW annually (NEI 2007).

In addition to current waste generation volumes, there are significant quantities of legacy HLW that will ultimately require transport to a geologic repository. Figure 3.2.5-1 shows the location of U.S. sites that currently store SNF or HLW destined for geologic disposal (DOE 2008f).

The LLW generated at nuclear power plants is transferred to domestic, permitted, commercial treatment and/or disposal facilities. Treatment facilities process the LLW by various methods to reduce toxicity, reduce volume, and immobilize the waste prior to transferring the waste to a permitted disposal facility. Currently, the United States is served by three commercial disposal facilities which are located in South Carolina, Utah, and Washington (NRC 2007m). The volume and radioactivity of LLW processed varies from year to year based on the types and quantities of waste. In 2005 these facilities collectively disposed of 4 million $\mathrm{ft}^{3}\left(113,000 \mathrm{~m}^{3}\right)$ and 530,000 curies (Ci) of LLW (NRC 2007g). Disposal capacity of these facilities is established in licenses with the NRC. Depleted $\mathrm{UF}_{6}$ is the responsibility of DOE and is currently being stored for further processing at Portsmouth and Paducah Gaseous Diffusion Plants (DOE 2007gg). SNF is currently being stored pending the opening of a geologic repository at Yucca Mountain.

Between 1971 and 2000, more than 2,700 deliveries of SNF traveled over 1.7 million miles (2.7 million kilometers). SNF containers used to transport nuclear waste are the most robust in the transportation industry. Transport containers use several layers of protection and consist of nearly 4 tons (3.6 MT) of structural and shield material for every ton of SNF (DOE 2001g). 


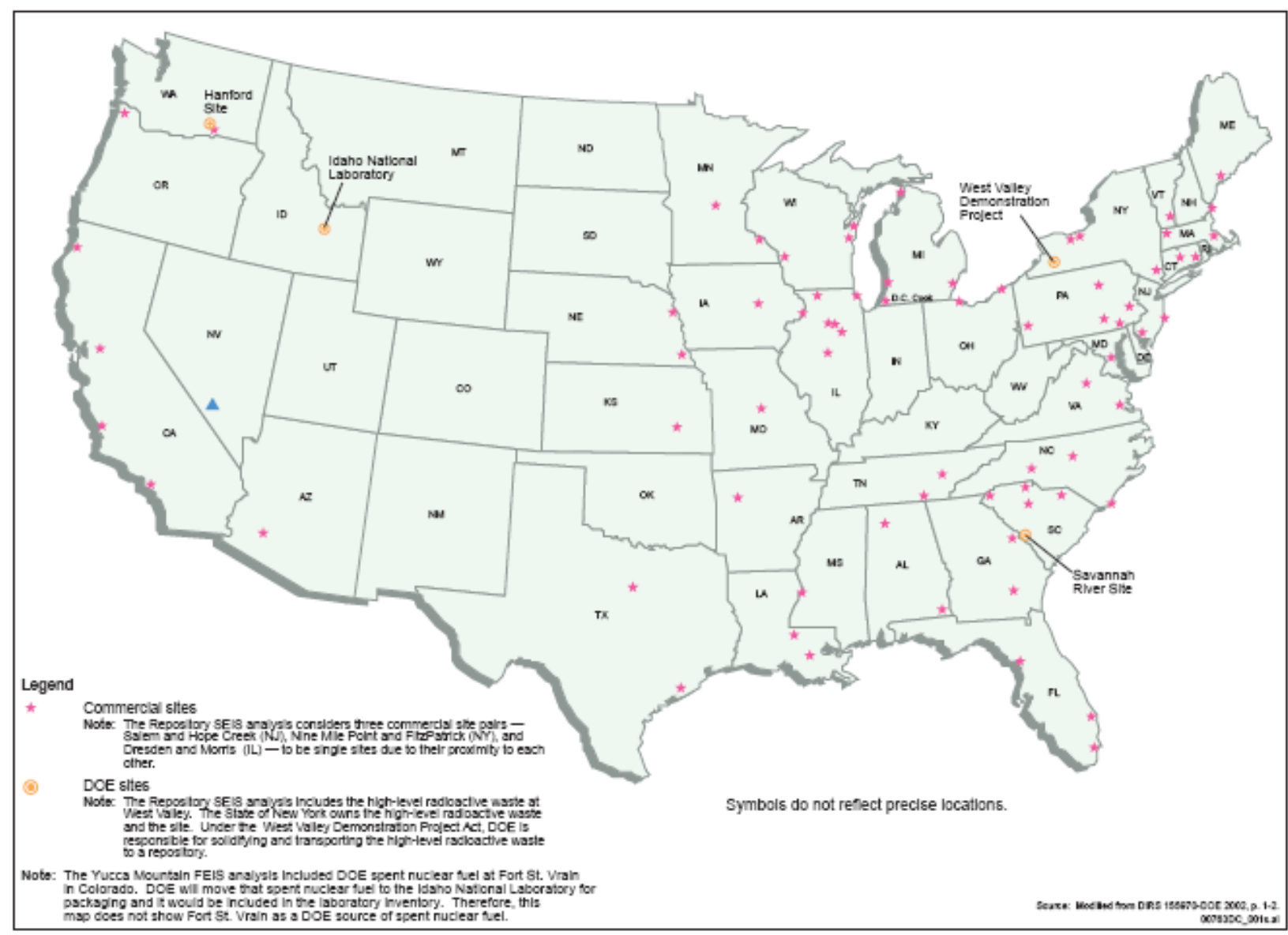

Source: DOE 2008f

FIGURE 3.2.5-1—Sites that Currently Store Spent Nuclear Fuel and High-Level Radioactive Waste Destined for Geologic Disposal

The environmental impacts associated with the transport and disposal of SNF and HLW in Yucca Mountain geologic repository have been assessed in the Yucca Mountain Supplemental EIS (DOE 2008f). 


\subsection{REFERENCES}

40 CFR Part 50

40 CFR Part 61

69 FR 18557

69 FR 18565

72 FR 40135

BLS 2004

BLS 2008
U.S. Environmental Protection Agency (EPA), "National Primary and Secondary Ambient Air Quality Standards," Code of Federal Regulations, Office of the Federal Register, National Archives and Records Administration, Washington, DC, Revised July 1, 2007.

EPA, "National Emission Standards for Hazardous Air Pollutants (NESHAPs)," Code of Federal Regulations, Office of the Federal Register, National Archives and Records Administration, Washington, DC, Revised July 1, 2007.

U.S. Department Of Energy (DOE), "Record of Decision on Mode of Transportation and Nevada Rail Corridor for the Disposal of Spent Nuclear Fuel and High-Level Radioactive Waste at Yucca Mountain, Nye County, NV," Office of the Federal Register, National Archives and Records Administration, Washington, DC, April 8, 2004.

DOE, "Notice of Intent to Prepare an EIS for the Alignment, Construction, and Operation of a Rail Line for Shipments of SNF, HLW, and Other Materials from a Site Near Caliente, Lincoln County, Nevada, to a Geologic Repository at Yucca Mountain, Nye County, Nevada," Office of the Federal Register, National Archives and Records Administration, Washington, DC, April 8, 2004.

DOE, "Notice of Intent to Prepare an Environmental Impact Statement for the Disposal of Greater-Than-Class-C Low-Level Radioactive Waste," Office of the Federal Register, National Archives and Records Administration, Washington, DC, July 23, 2007.

Bureau of Labor Statistics (BLS), "Labor Force," Occupational Outlook Quarterly, U.S. Bureau of Labor Statistics, Washington, DC, 2004.

BLS, "Household Data Annual Averages: Employment Status of the Civilian Noninstitutional Population 16 Years and Over by Sex, 1973 to Date," U.S. Bureau of Labor Statistics, Washington, DC, 2008. Accessed at http://www.bls.gov/cps/cpsaat2.pdf on April 17, 2008. 
CEEDATA 2006

DOE 2001g

DOE 2007gg

DOE 2008f

DOE $2008 \mathrm{~g}$

EIA 2007a

EIA $2007 \mathrm{k}$
CEEDATA Consulting, "Construction of a Nuclear Power Plant," CEEDATA Consulting, April 2006. Accessed at www.iop.org/activity/groups/professional/emg/Group_Events/file 6890.doc on November 14, 2007.

DOE, "Spent Nuclear Fuel Transportation," U.S. Department of Energy, Washington, DC, 2001. Accessed at http://www.ocrwm.doe.gov/transport/pdf/snf_trans.pdf on January 5, 2008.

DOE, "Depleted UF 6 Storage," $\mathrm{UF}_{6}$ Management and Uses, Argonne National Lab, Argonne, IL, 2007. Accessed at http://web.ead.anl.gov/uranium/mgmtuses/storage/index.cfm on March 21, 2008.

DOE, "Final Supplemental Environmental Impact Statement for a Geologic Repository for the Disposal of Spent Nuclear Fuel and High-Level Radioactive Waste at Yucca Mountain, Nye County, Nevada," DOE/EIS-0250F-S1, U.S. Department of Energy, Office of Civilian Radioactive Waste Management, Las Vegas, NV, June 2008.

DOE, "Final Supplemental Environmental Impact Statement for a Geologic Repository for the Disposal of Spent Nuclear Fuel and High-Level Radioactive Waste at Yucca Mountain, Nye County, Nevada - Nevada Rail Transportation Corridor DOE/EIS-0250FS2 and Final Environmental Impact Statement for a Rail Alignment for the Construction and Operation of a Railroad in Nevada to a Geologic Repository at Yucca Mountain, Nye County, Nevada," DOE/EIS-0369, U.S. Department of Energy, Office of Civilian Radioactive Waste Management, Las Vegas, NV, June 2008.

Energy Information Administration (EIA), "AEO2008, Annual Energy Outlook 2008 (Early Release)," DOE/EIA-0383, Energy Information Administration, U.S. Department of Energy, Washington, DC, December 2007. Accessed at http://www.eia.doe.gov/oiaf/aeo/pdf/earlyrelease.pdf on January 22, 2008.

EIA, "State Electricity Profiles 2005," DOE/EIA-0348(01)/2, Energy Information Administration, U.S. Department of Energy, Washington, DC, March 2007. Accessed at http://www.eia.doe.gov/cneaf/electricity/st_profiles/sep2004.pdf on January 15, 2008. 
EIA $2007 n$

EPA 1983

EPA 2006a

EPA 2006e

EPA 2007b

IAEA 1998

IISI 2007

MSNBC 2007

NEI 2007
EIA, "U.S. Uranium Mine Production and Number of Mines and Sources," Energy Information Administration, U.S. Department of Energy, Washington, DC, May 2007. Accessed at http://www.eia.doe.gov/cneaf/nuclear/dupr/umine.html on May 9, 2008.

EPA, "Report to Congress Of The United States - Potential Health and Environmental Hazards of Uranium Mine Wastes," EPA 520/1-6-83-007, U.S. Environmental Protection Agency, Washington, DC, June 1983.

EPA, "Solid Waste Generation," U.S. Environmental Protection Agency, Washington, DC, July 19, 2006. Accessed at http://www.epa.gov/cleanrgy/solidwaste_gen.htm on December 4, 2007.

EPA, "The Effects of Ozone Depletion," U.S. Environmental Protection Agency, Washington, DC, March 1, 2006. Accessed at http://www.epa.gov/ozone/science/effects.html on January 5, 2008.

EPA, "Counties Designated Nonattainment," Map of the United States, Greenbook, U.S. Environmental Protection Agency, Washington, DC, October 11, 2007. Accessed at http://www.epa.gov/air/oaqps/greenbk/mapnpoll.html on January 16, 2008.

International Atomic Energy Agency (IAEA), "Guidebook on Good Practice in the Management of Uranium Mining and Mill Operations and the Preparation for their Closure," IAEATECDOC-1059, International Atomic Energy Agency, 1998.

International Iron and Steel Institute (IISI), "World Steel in Figures 2007, Apparent Steel Use, 2000 to 2006," International Iron and Steel Institute, 2007. Accessed at http://www.worldsteel.org/ ?action=programs\&id=52 on April 21, 2008.

MSNBC, "Bridge Collapse May Spur Steel, Cement Demand," MSNBC, August 2007. Accessed at http://www.msnbc.msn.com/id/20114511/ on January 31, 2008.

Nuclear Energy Institute (NEI), "Nuclear Waste: Amounts and OnSite Storage," Nuclear Energy Institute, 2007. Accessed at http://nei.org/resourcesandstats/nuclear_statistics/nuclearwasteamo untsandonsitestorage/ on September 1, 2007. 
NETL 2006b

NRC 1996

NRC 2007b

NRC 2007c

NRC 2007d

NRC 2007e

NRC 2007g

NRC $2007 \mathrm{~m}$

NRCS 2007
National Energy Technology Laboratory (NETL), "Estimating Freshwater Needs to Meet Future Thermoelectric Generation Requirements," DOE/NETL-2006/1235, National Energy Technology Laboratory, August 2006. Accessed at http:/www.netl.doe.gov/technologies/coalpower/ewr/pubs/ WaterNeedsAnalysisPhaseI1006.pdf on January 31, 2008.

U.S. Nuclear Regulatory Commission (NRC), "License Renewal Generic Environmental Impact Statement," NUREG-1437, U.S. Nuclear Regulatory Commission, Washington, DC, June 1996. Accessed at http://www.nrc.gov/reading-rm/doc-collections/ nuregs/staff/sr1437/ on January 30, 2008.

NRC, "Uranium Enrichment," Nuclear Materials, Fuel Cycle Facilities, U.S. Nuclear Regulatory Commission, Washington, DC, September 2007. Accessed at www.nrc.gov/materials/fuel-cyclefac/ur-enrichment.html on February 10, 2008.

NRC, "Fuel Fabrication," Nuclear Materials, Fuel Cycle Facilities, U.S. Nuclear Regulatory Commission, Washington, DC, February 2007. Accessed at www.nrc.gov/materials/fuel-cycle-fac/fuelfab.html on February 10, 2008.

NRC, "Stages of the Nuclear Fuel Cycle," U.S. Nuclear Regulatory Commission, Washington, DC, July 2007.

NRC, "Information Digest," NUREG-1350, Volume 19, U.S Nuclear Regulatory Commission, Washington, DC, August 2007.

NRC, "Year 2005 Low-Level Waste Disposal Statistics," U.S. Nuclear Regulatory Commission, Washington, DC, March 21, 2007.

NRC, "Locations of Low Level Waste Disposal Facilities," Locations Map, U.S. Nuclear Regulatory Commission, Washington, DC, April 5, 2007. Accessed at http://www.nrc.gov/ waste/llw-disposal/locations.html on September 8, 2008.

Natural Resources Conservation Service (NRCS), "National Resources Inventory - 2003 Annual NRI," February 1, 2004. Accessed at http://www.nrcs.usda.gov/TECHNICAL/land/nri03/ nri03landuse-mrb.html on January 5, 2008. 
OSC 2006

Penton 2007

POA 2006

USCB 2000b

USDOC 2002a

USDOC 2004

USDOC 2005a

USDOC $2005 b$
Ocean Shipping Consultants (OSC) Limited, "CementConsumption Growth Ahead," April 2006. Accessed at http://osclimited.com/releases/cementto2020.pdf on January 31, 2008.

Penton Media Inc. Online, "Global Steel Demand Seen Rising 6.8\%," Penton Media Inc. Online, October 2007. Accessed at http://www.metalproducing.com/full story.php?WID $=16686$ on January 31, 2008.

Parliament of Australia (POA), "Water Requirements of Nuclear Power Stations," Department of Parliamentary Services, Parliament of Australia, December 4, 2006. Accessed at http://www.aph.gov.au/library/pubs/RN/2006-07/07rn12.pdf on January 5, 2008.

U.S. Census Bureau (USCB), "Population Density: 2000," U.S. Census Bureau, Washington, DC, 2000.

U.S. Department of Commerce (USDOC), "Demographic Trends in the 20th Century," CENSR-4, U.S. Census Bureau, Washington, DC, November 2002. Accessed at

www.census.gov/prod/2002pubs/censr-4.pdf on January 31, 2008.

USDOC, "Table 1a. Projected Population of the United States, by Race and Hispanic Origin: 2000 to 2050," U.S. Census, U.S. Department of Commerce, Washington, DC, March 18, 2004. Accessed at http://www.census.gov/population/www/projections/ usinterimproj/natprojtab01a.pdf on August 13, 2008.

USDOC, "Understanding the 2002 Economic Census," EPCD-05A02ECD, U.S. Census, U.S. Department of Commerce, Washington, DC, September 2005. Accessed at www.census.gov/econ/census02/guide/understandingEC02.pdf on January 31, 2008.

USDOC, "2002 Economic Census: Summary Statistics by 2002 NAICS United States," U.S. Census, U.S. Department of Commerce, Washington, DC, November 2002. Accessed at http://www.census.gov/econ/census02/data/us/US000.HTM on January 31, 2008. 
USDOC 2005c

USDOC 2005d

USDOC $2005 \mathrm{e}$

USDOC 2007a

USGS 2004a

Wigeland 2008a

WISE 2006

WNA 2008e
USDOC, "Utilities: Geographic Area Series: Summary Statistics: 2002," U.S. Census, U.S. Department of Commerce, Washington, DC, November 2005. Accessed at http://factfinder.census.gov/ servlet/IBQTable?_bm=y\&-geo_id=\&-ds_name=EC0222A1\&_lang=en on January 31, 2008.

USDOC, "2002 Economic Census-Mining," EC02-21SG-1, U.S. Census, U.S. Department of Commerce, Washington, DC, 2005. Accessed at http://www.census.gov/prod/ec02/ec0221sg1.pdf on January 31, 2008.

USDOC, "2002 Economic Census-Construction, United States," U.S. Census, U.S. Department of Commerce, Washington, DC, 2005. Accessed at http://www.census.gov/econ/census02/data/us/ US000_23.HTM on January 31, 2008.

USDOC, "U.S. Census Bureau Home Page," U.S. Department of Commerce, Washington, DC, 2007. Accessed at www.census.gov on October 14, 2007.

U.S. Geological Survey (USGS), "Estimated Use of Water in the United States in 2000," Susan S. Huston, Nancy L. Barber, Joan F. Kenny, Kristin S. Linsey, Deborah S. Lumia, and Molly A. Maupin, Survey Circular 1268, Released March 2004, Revised February 2005. Accessed at http://pubs.usgs.gov/circ/2004/ circ1268/ on January 23, 2008.

Wigeland, R.A., "Performance Summary of Advanced Nuclear Fuel Cycles," GNEP-TIO-AI-AI-RT-2008-000268 Rev 1, Idaho National Laboratory, Nuclear Science \& Technology, June 2008.

World Information Service on Energy (WISE), "Nuclear Fuel Production Chain for Light Water Reactors," World Information Service on Energy, March 21, 2006. Accessed at http://www.wiseuranium.org/nfp.html on May 15, 2008.

World Nuclear Association (WNA), "World Uranium Mining," World Nuclear Association, July 2008. Accessed at http://www.world-nuclear.org/info/inf23.html on July 30, 2008. 



\section{CHAPTER 4}

\section{ENVIRONMENTAL IMPACTS OF DOMESTIC PROGRAMMATIC ALTERNATIVES}





\section{CHAPTER 4 ENVIRONMENTAL IMPACTS OF DOMESTIC PROGRAMMATIC ALTERNATIVES}

Chapter 4 presents the environmental impacts of the domestic programmatic alternatives assessed in this Global Nuclear Energy Partnership (GNEP) Programmatic Environmental Impact Statement (PEIS). The potential impacts are presented for each alternative, assuming widespread implementation to achieve a capacity of approximately 200 gigawatts of electricity $(\mathrm{GWe})$. A comparative analysis of the alternatives is also presented for capacities of $100 \mathrm{GWe}, 150 \mathrm{GWe}$, and $400 \mathrm{GWe}$. This chapter also discusses unavoidable adverse impacts, the relationship between short-term uses of the environment and the maintenance and enhancement of long-term productivity, and irreversible and irretrievable commitment of resources.

This chapter presents the potential environmental impacts of the domestic programmatic alternatives described in Chapter 2. Because this Global Nuclear Energy Partnership (GNEP) Programmatic Environmental Impact Statement (PEIS) is intended to support policy decisions regarding the future course of the U.S. commercial nuclear fuel cycle, the analysis is necessarily broad and long-term, focusing on the impacts that would result from implementing each of the programmatic alternatives over many decades. For widespread implementation of the programmatic alternatives, the impacts are presented as follows:

- Section 4.1 presents the impacts that are common to all the alternatives (e.g., uranium mining). Differences in the magnitude of the impacts are discussed, as appropriate, for each alternative in Sections 4.2 through 4.7.

- Section 4.2 presents the impacts of the No Action Alternative-Existing Once-Through Uranium Fuel Cycle (No Action Alternative).

- $\quad$ Section 4.3 presents the impacts of the Fast Reactor Recycle Fuel Cycle Alternative (Fast Reactor Recycle Alternative).

- Section 4.4 presents the impacts of the Thermal/Fast Reactor Recycle Fuel Cycle Alternative (Thermal/Fast Reactor Recycle Alternative).

- Section 4.5 presents the impacts of the Thermal Reactor Recycle Fuel Cycle Alternative (Thermal Reactor Recycle Alternative) using Light Water Reactors (LWRs), Heavy Water Reactors (HWRs), or High Temperature Gas-Cooled Reactors (HTGRs).

- Section 4.6 presents the impacts of the Once-Through Fuel Cycle Alternative using Thorium (Thorium Alternative).

- Section 4.7 presents the impacts of the Once-Through Fuel Cycle using Heavy Water Reactors (HWR) or High Temperature Gas-Cooled Reactors (HTGR) (HWR/HTGR Alternative).

In addition to the analyses presented in Sections 4.1 through 4.7, a comparative summary of each fuel cycle alternative is presented in Section 4.8. The environmental impact analysis in this chapter is based on a 1.3 percent growth scenario (which would equate to approximately 200 gigawatts electric $\left(\mathrm{GWe}^{1}\right)$ in approximately 2060-2070).

\footnotetext{
${ }^{1}$ One GWe is equal to 1,000 megawatts electric
} 
At the programmatic level, many of the environmental consequences associated with the alternatives vary linearly with the power capacity. For example, if the future power capacity at full implementation is $400 \mathrm{GWe}$ instead of $200 \mathrm{GWe}$, the number of reactors associated with any alternative would be twice as many as in the $200 \mathrm{GWe}$ scenario (assuming the same size reactors in both scenarios). Many other factors (such as the annual amount of spent nuclear fuel [SNF] generated, the annual quantities of wastes generated, and the annual radiological emissions from facilities) could be scaled in a similar manner. However, some factors would not vary linearly, such as the cumulative amounts of SNF and wastes that would be generated (see Section 4.8.8).

\subsection{Impacts Common to All Alternatives}

This section presents impacts that would be common to each of the domestic programmatic alternatives, with a focus on the impacts from uranium mining, uranium enrichment, uranium fuel fabrication, disposing of SNF and high-level waste (HLW) in amounts up to the Yucca Mountain statutory limit (70,000 metric tons of heavy metal [MTHM]), disposing of low-level waste (LLW) and continuation of the Advanced Fuel Cycle Initiative (AFCI). Although these impacts would be common to all of the alternatives, this does not mean impacts would be the same for each alternative. For example, although each alternative would require uranium enrichment, both the quantities of uranium requiring enrichment and the percentage of enrichment could be different. Those differences, where notable, are discussed later in the chapter. This section also addresses greenhouse gas emissions associated with nuclear power capacity in comparison to electricity production from coal and natural gas. Those impacts would be the same for each alternative. Section 4.1 is organized as follows:

- $\quad$ Section 4.1.1-Uranium Mining and Milling

- Section 4.1.2-Uranium Enrichment

- $\quad$ Section 4.1.3-Uranium Fuel Fabrication

- $\quad$ Section 4.1.4 - Impacts of Disposing of SNF and HLW in Yucca Mountain

- Section 4.1.5-Impacts of Establishing a Geologic Repository Capacity for Future SNF and HLW

- $\quad$ Section 4.1.6 - Impacts of Establishing and Operating Disposal Capacity for Future LLW

- $\quad$ Section 4.1.7-Impacts of the AFCI

- Section 4.1.8 - Greenhouse Gas Emissions Associated with Electricity Generation

\subsubsection{Uranium Mining and Milling}

\subsubsection{Current Uranium Mining and Milling Capabilities in the United States}

Background: Although ore containing uranium was mined in the United States as early as the late 1800 s to obtain radium, and in the early 1900 s to obtain vanadium, mining to obtain large quantities of uranium did not begin in the United States until the 1940s. At that time, large quantities of uranium were needed for use in the nuclear weapons program and later for use as fuel for nuclear reactors. With the drop in market price of uranium, beginning in the 1980s, U.S. production fell and producers turned to in-situ leaching ${ }^{2}$ operations as a principal means of

\footnotetext{
${ }^{2}$ In-situ leaching involves injecting solutions directly into the ground that will dissolve the uranium from the ore and then pumping out the uranium-containing solution.
} 
extracting uranium from ore bodies. By the 1990s, uranium mining almost ceased in the United States as other countries increased production at a lower cost. By 2004, according to the U.S. Department of Energy's (DOE) Energy Information Administration (EIA), there were only six uranium mines operating in the United States, half of which were in-situ operations. A database compiled by the U.S. Environmental Protection Agency (EPA) includes 15,000 specific mine locations where uranium has been mined in 14 western states. Most of these locations are in Colorado, Utah, New Mexico, Arizona, and Wyoming, with about 75 percent on Federal and tribal lands. The majority of these sites were conventional (open pit and underground) mines (EPA 2008c).

Although the current United States production of uranium has been steadily increasing since 2003, Canada produces the largest share of uranium from mines (23 percent of world supply from mines), followed by Australia (21 percent) and Kazakhstan (16 percent) (Table 4.1-1). Australia has the world's largest uranium reserves with 40 percent of the Earth's known supply (WNA 2008e).

TABLE 4.1-1-Uranium Production from Mines (tons)

\begin{tabular}{lcccccc}
\hline \multicolumn{1}{c}{ Country } & $\mathbf{2 0 0 2}$ & $\mathbf{2 0 0 3}$ & $\mathbf{2 0 0 4}$ & $\mathbf{2 0 0 5}$ & $\mathbf{2 0 0 6}$ & $\mathbf{2 0 0 7}$ \\
\hline Canada & 11,604 & 10,457 & 11,597 & 11,628 & 9,862 & 9,476 \\
Australia & 6,854 & 7572 & 8,982 & 9,516 & 7,593 & 8,611 \\
Kazakhstan & 2,800 & 3,300 & 3,719 & 4,357 & 5,279 & 6,637 \\
Niger & 3,075 & 3,143 & 3,282 & 3,093 & 3,434 & 3,413 \\
Russia (est.) & 2,900 & 3,150 & 3,200 & 3,431 & 3,262 & 3,153 \\
Namibia & 2,333 & 2,036 & 3,038 & 3,147 & 3,067 & 2,879 \\
Uzbekistan & 1,860 & 1,598 & 2,016 & 2,300 & 2,260 & 2,320 \\
United States & 919 & 779 & 878 & 1,039 & 1,672 & 1,654 \\
Ukraine (est.) & 800 & 800 & 800 & 800 & 800 & 846 \\
China (est.) & 730 & 750 & 750 & 750 & 750 & 712 \\
South Africa & 824 & 758 & 755 & 674 & 534 & 539 \\
Czech Repub. & 465 & 452 & 412 & 408 & 359 & 306 \\
India (est.) & 230 & 230 & 230 & 230 & 177 & 299 \\
Brazil & 270 & 310 & 300 & 110 & 190 & 270 \\
Romania (est.) & 90 & 90 & 90 & 90 & 90 & 77 \\
Germany & 212 & 150 & 150 & 77 & 50 & 45 \\
Pakistan (est.) & 38 & 45 & 45 & 45 & 45 & 38 \\
France & 20 & 0 & 7 & 7 & 5 & 4 \\
Total world & $\mathbf{3 6 , 0 6 3}$ & $\mathbf{3 5 , 6 1 3}$ & $\mathbf{4 0 , 2 5 1}$ & $\mathbf{4 1 , 7 0 2}$ & $\mathbf{3 9 , 4 2 9}$ & $\mathbf{4 1 , 2 7 9}$ \\
\hline Source: WNA 2008e & & & & & &
\end{tabular}

Uranium is typically mined using one of three techniques: surface (open pit), underground, or insitu leaching (solution mining). The method of extraction is dependent on the grade, size, location, and geology of the deposit and is based on maximizing ore recovery within economic constraints. A low-grade cutoff point is established on a site-specific basis and depends on recovery costs at the site, the market price of the ore, and feed requirements at the mill (EPA 1995d).

Open Pit Mining: Open pit mining techniques are employed to exploit ore deposits relatively close to the surface of the earth. Topsoil is typically removed separately and stockpiled. Overburden, the material under the topsoil and overlying the deposit, is removed using scrapers, trucks and loaders, or mechanical shovels. Depending on the extent of consolidation, the 
overburden may be ripped with bulldozers or blasted prior to removal. Overburden may be stockpiled outside the pit or placed in mined-out portions of the pit once pit development has progressed to an acceptable point. Mining economics typically require that overburden haulage be minimized. Once the ore body is exposed, it is ripped, loaded into trucks, and trucked to an onsite stockpile. The ore can then be moved from the stockpile to the mill site as required (EPA 1995d).

Piles of so-called waste rock, which often contain elevated concentrations of radioisotopes, are produced during the open pit mining of uranium when overburden is removed. A determination of what is waste rock and what is ore is based on the technical and economic feasibility of removing the uranium from the rock. These piles of waste rock pose hazards to people and the environment once the mining activity has been discontinued at a site (EPA 1995d).

Underground Mining: A variety of techniques are employed in underground mining operations depending on the distribution and orientation of the ore deposit. In general, underground mining involves sinking a shaft near the ore body and extending levels from the main shaft at various depths to the ore. Entrances to the mine, shafts, drifts, and cross-cuts are developed to access and remove the ore body. Levels and adits often slope slightly upward away from the main shaft to encourage positive drainage of any water seeping into the mine. Ore and development rock (the non-ore bearing material generated during mining) may be removed either through shaft conveyances or chutes, and hoisted in elevators to the surface, or used to backfill mined out areas. Ore is placed in stockpiles while development rock brought to the surface is placed in waste rock piles (EPA 1995d).

As underground mining techniques are able to leave much of the non-ore bearing material in place, the ratio of waste (development) rock to ore is much lower than stripping ratios in open pit mines. Ratios of waste rock to ore range from 1:1.5 to 1:16 (EPA 1983). In shallow underground mines, ore and waste rock may be brought to the surface by train or conveyor belt. As with surface mining operations, ores and sub-grade ores may be stockpiled on the surface. These materials may be treated to make them more suitable for extracting ore (or "beneficiated") as market conditions allow or left with mine development rock in waste rock piles (EPA 1995d).

In Situ Leaching: In situ leaching, also known as solution mining, or in situ recovery in the United States, involves leaving the ore in place and recovering the minerals from it by dissolving them and pumping the solution to the surface where the minerals can be recovered (see Figure 4.1-1). There is little surface disturbance and no mill-tailings or waste rock generated; however, the ore body needs to be permeable to the liquids used, and located so that the liquids do not contaminate groundwater away from the ore body (AUA 2007b).

The design of in situ leaching wellfields varies greatly depending on the local geologic and hydraulic conditions such as permeability, sand thickness, deposit type, ore grade, and distribution. Whatever the type of pattern used, there is a mixture of injection wells, to introduce the leach solution to the ore body, and extraction wells with submersible pumps used to deliver solution to the processing plant. Wells are typical of normal water bores. Upon decommissioning, wells are sealed or capped, process facilities removed and any evaporation ponds revegetated so the land can revert to its previous uses (AUA 2007b). 


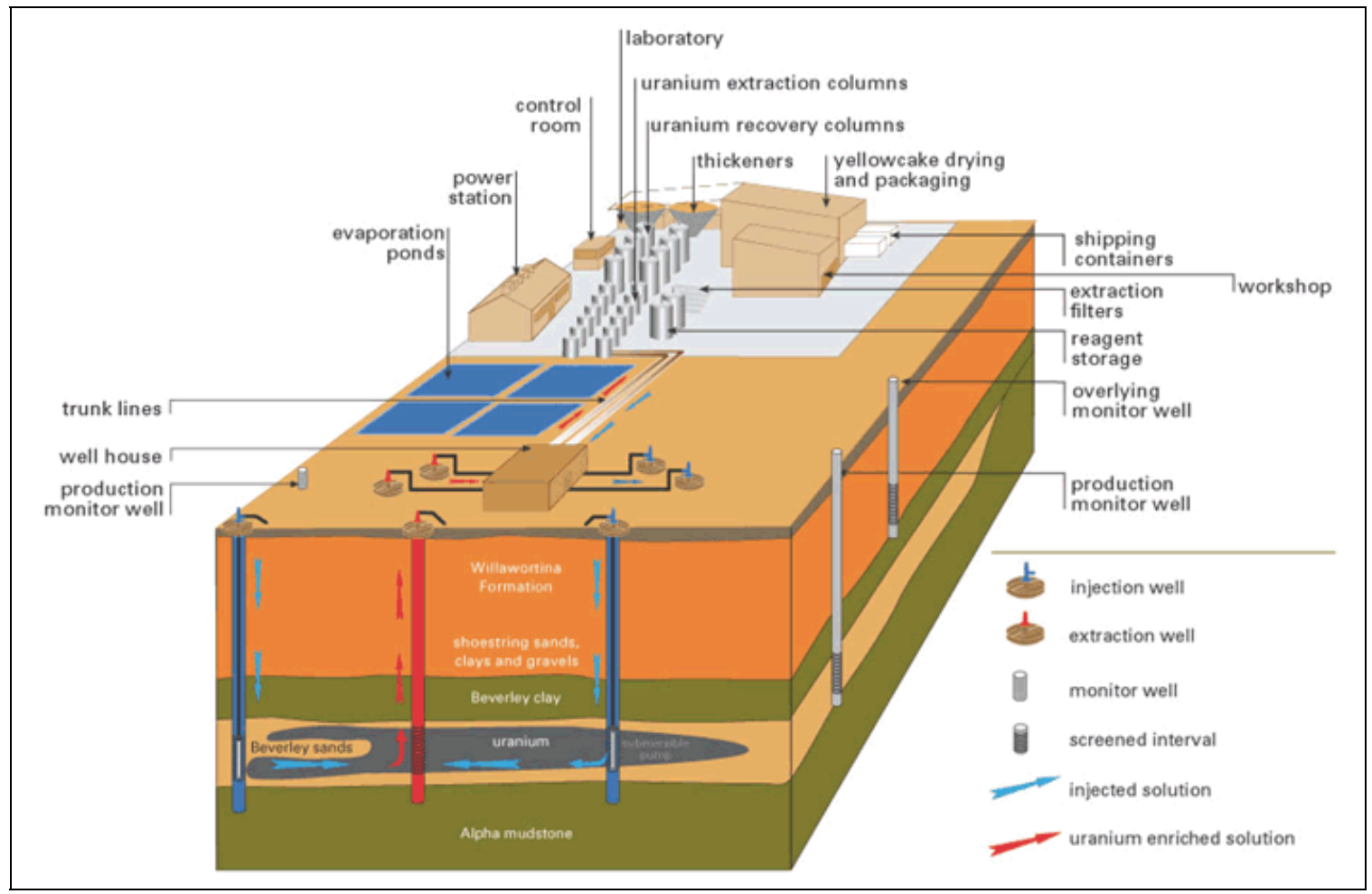

Source: AUA 2007b

FIGURE 4.1-1—In Situ Leaching Process to Mine Uranium

Uranium Milling: Once the uranium ore is removed from the ground, it is crushed and then ground to a fine grain size. Grinding and mixing with water produces a slurry of fine ore particles suspended in water. This slurry is leached with either an acid or an alkali, depending on the metallurgical characteristics of the ore. Leaching causes the uranium to dissolve in the solution. Most of the other minerals in the ore remain undissolved, and these solids, called "tailings," are then separated from the uranium-rich liquid, usually by allowing them to settle out. The uranium-rich liquid is filtered to remove any remaining solids and the uranium is then recovered by techniques using solvent extraction, ion exchange, or direct precipitation. The method used depends on the nature of the particular ore (AAMMPC 2007).

Uranium is finally recovered in a chemical precipitate that is filtered and dried to produce a yellow powder known as "yellowcake." The yellowcake is then heated to about $1292^{\circ} \mathrm{F}\left(700^{\circ} \mathrm{C}\right)$ to produce a dark grey-green uranium oxide powder containing more than 98 percent $\mathrm{U}_{3} \mathrm{O}_{8}$, and then packed in drums for shipment to an enrichment facility (AAMMPC 2007).

Due to technical and economic limitations, not all of the uranium present in the ore can be extracted. As a result, uranium-containing sludge or tailings remain at the end of this process and are dumped in special ponds or piles. Some of these mill tailing piles in the United States and Canada can contain up to 30 million tons of solid material at a single mine location. These piles contain many contaminants, most notably high concentrations of radium-226, which continuously decays to the radioactive gas radon-222, the decay products of which are known to cause lung cancer. Tailing piles are subject to erosion, which can carry the contamination to much wider areas. After a rainfall, erosion gullies can form; floods can destroy the whole 
deposit; plants and burrowing animals can penetrate into the deposit and disperse the material. When the surface of the pile dries out, the fine sands of the pulverized rock can be blown by the wind over vast areas (AAMMPC 2007).

\subsubsection{Environmental Impacts of Uranium Mining and Milling}

Open pit mining activities may create environmental effects typical of surface disturbances: increased runoff as well as increased erosion by wind and water. Dewatering operations conducted by surface and underground mines may create groundwater depressions that can persist long after the mining ceases. Potential environmental effects from in situ operations are primarily groundwater-related. Since surface disturbance is not extensive, the impacts of surface operations associated with in situ mining (e.g., drilling wastes and ponds) are not well documented (EPA 1995d).

Mill tailings, and particularly the radionuclides contained within, appear to be a major source of environmental impact to air, soil, surface water, and groundwater. Findings in the Report to Congress: Potential Health and Environmental Hazards of Uranium Mine Wastes indicate that the most serious threat to human health is the use of uranium mill tailings in offsite construction (EPA 1983). DOE, through Title I of the Uranium Mill Tailings Radiation Control Act (UMTRCA), has been conducting remedial activities on tailings generated by 24 uranium mills throughout the western United States (with one site in New Jersey). UMTRCA's Title II licenses place requirements on operations and closure at currently operating (and inactive) mills (EPA 1995d). The closing of uranium mines is regulated by Title II of UMTRCA. In other instances, the EPA and states use the Clean Air Act and Clean Water Act regulations to limit some mining activities (EPA 1995d). The general impacts associated with uranium mining and milling are presented below.

Land Resources: Uranium mines and mills are typically greater than 1,000 acres (405 hectares [ha]) in size. However, the size of a uranium mine is very dependent upon the site-specific ore deposits and the type of mining used.

Visual Resources: Visual impacts are highly dependent upon the mining method used. Deposits up to approximately 300 feet (ft) $(91$ meters [m]) below the surface are generally mined through open pit mining, which can create large crater-like pits (see Figure 4.1.1.2-1). Deeper reserves are normally accessed through underground mining or in-situ leaching, which have the potential to create less visual impacts. However, as shown in Figure 4.1-1, surface facilities (such as power stations, control rooms, and evaporation ponds) are generally needed. 


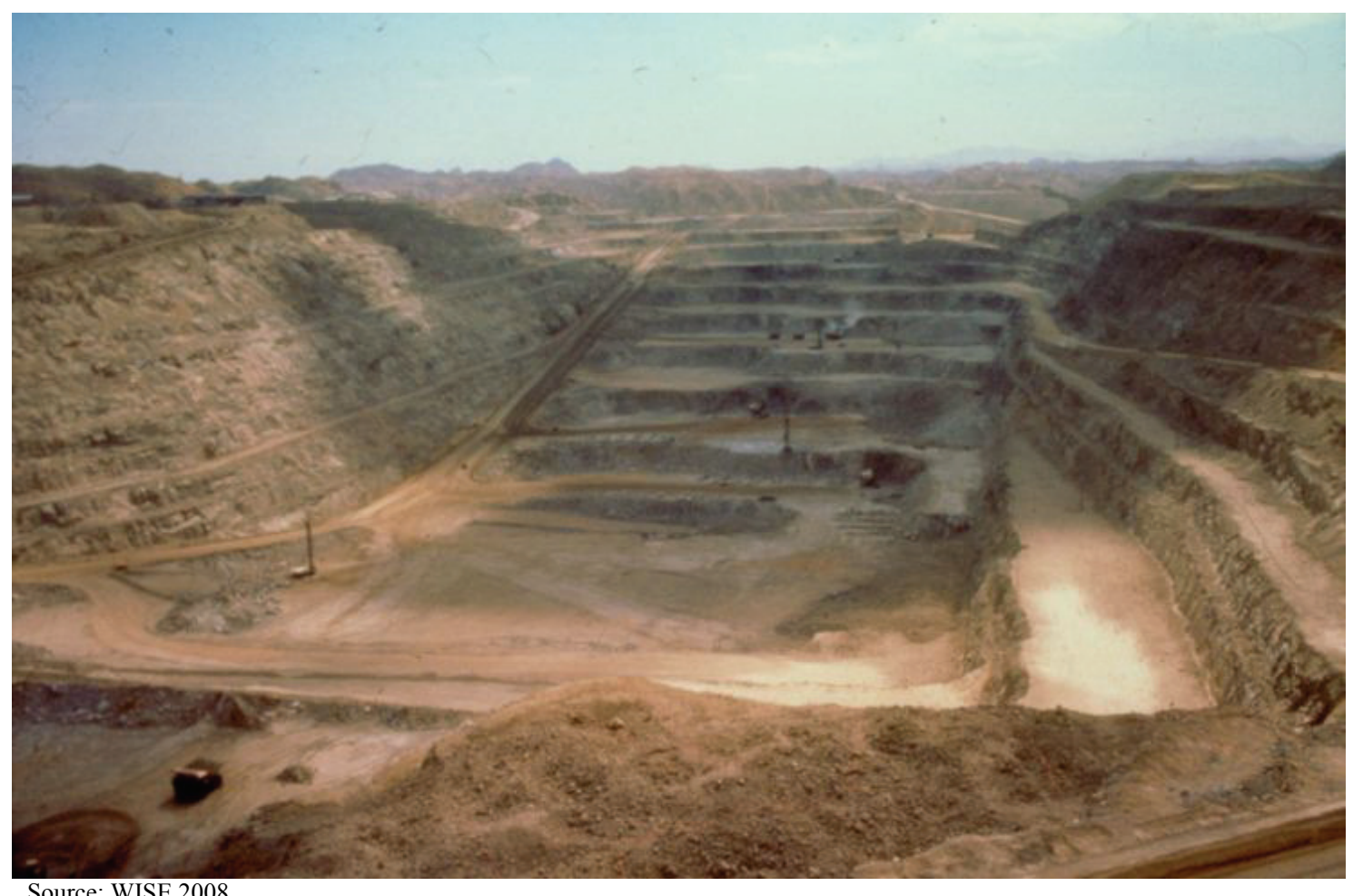

Source: WISE 2008

FIGURE 4.1.1.2-1-Typical Open Pit Uranium Mine

Air Resources: Underground uranium mines produce exhaust, which typically contains measurable concentrations of radon-222 from the ore. The concentration of radon-222 in mine exhaust varies depending on ventilation rate, mine volume, mine age, grade of exposed ore, size of active working areas, moisture content and porosity of rock, barometric pressure, and mining practices. A previous EPA study indicates that higher radon-222 emission rates occur at older mines, probably because there are larger surface areas of exposed ore. By properly capping the exhaust vents and sealing the shaft and mine entrances with bulkheads, radon emission rates from inactive or closed underground mines can be dramatically reduced (EPA 1995d).

Aboveground sources of radon-222 at both underground and surface extraction and beneficiation operations include emanation from ore, waste rock, overburden (at surface mines only), and tailings. The amount of radon emitted from these materials into the surrounding atmosphere can depend on, among other things: the exposed surface area of the units in which the materials are located; the grade of material; the control mechanisms used; and, in the case of tailings, the method of deposition (EPA 1995d). When the development drill penetrates the ore body, the ore and sub-ore formations in the drill hole become exposed to air. Consequently, the radon emanates from the ore into the drill hole and can escape into the atmosphere (EPA 1995d).

A primary source of air contamination at mine sites is fugitive dust emissions from mine pits and underground workings, overburden, mine rock dumps, ore, sub-ore, and haul roads. Tailings may also be a potential source of fugitive dust when particulates are transported by wind. Dust emissions vary depending on factors such as moisture content, number and types of equipment operating, and climate. The movement of heavy-haul haul trucks can be a source of dust at most uranium mines. To minimize fugitive dust, haul roads are frequently sprinkled with water during 
dry periods or dust suppressants are applied. During the active life of the mine, water may be applied to these piles to control dust and prevent entrainment. After mine closure, revegetation or other stabilizing methods may be used to control dust. Potential contaminants are heavy metals and other toxics (EPA 1995d).

\section{Water Resources:}

Surface Water: Surface, in situ, and underground mines are frequently dewatered to allow for the extraction of ore. Dewatering can be accomplished in two ways: 1) pumping from groundwater interceptor wells to lower the water table; and 2) pumping directly from the mine workings. At the end of a mine's active life, pumping typically is stopped and the pit or underground workings are allowed to fill with water. The mine water may be contaminated with radioactive constituents, metals, and suspended and dissolved solids (EPA 1995d).

When mine water is discharged to surface waters, it can change the quality of the surface water. Elevated concentrations of metals and radionuclides, constituents typical of mine waters, have been detected in surface waters near uranium mines (EPA 1983). In arid climates, like New Mexico, the discharge of mine water to a receiving stream can significantly change the hydrologic conditions of the receiving body. Typically, mine water is discharged to ephemeral streams in arid climates. The mine waters have, in some instances, transformed ephemeral streams to perennial streams (EPA 1995d).

These newly created perennial streams often lose flow to subsurface alluvial material which recharges shallow alluvial aquifers. Studies have documented that infiltration of uranium mine dewatering effluents have been accompanied by a gradual change in the overall chemistry of the groundwater, and the groundwater later bears a greater resemblance to the mine dewatering effluent (EPA 1995d).

Groundwater: Potential and documented effects on groundwater from uranium mining activities vary with the type of activity being conducted. Operation of open pit and underground mines potentially influence groundwater through dewatering operations and through approved discharges as discussed in the surface water section above. Tailings impoundments associated with conventional mills have the potential to leak; while some of the liquid constituents of the tailings are recycled or evaporated, unlined tailings ponds may allow liquids to seep into the ground, eventually reaching groundwater. This is also true for evaporation and radium settling ponds, although some states require liners in all wastewater ponds. In situ operations inject a specific liquid (frequently strong acids) into what is termed the production zone, normally a sandstone aquifer (EPA 1995d).

The potential impacts of these operations result from the increased solubility of the uranium ore and other compounds, which facilitates migration of these species into neighboring aquifers. As a result, complete restoration of mine aquifers is not necessarily a simple task. Dewatering operations at open pit and underground mines may impact local aquifers through drawdowns in the direct vicinity of the mine with (presumably) little lasting effect. However, depending on the transmissivity (the measure of how much groundwater can be transmitted horizontally) of the aquifer, the size of the dewatering operation, and the number of mines actively conducting 
dewatering, impacts to aquifers may be significant (EPA 1995d). The degree of migration is related to numerous factors, including: the chemistry of the tailings material; the permeability of the impoundment and liner (if present); the amount of precipitation; the nature of the underlying soils; and the proximity to both surface water and groundwater (EPA 1995d).

Socioeconomic Impacts: Uranium mining employment is highly dependent upon the size of the mine and the mining method used. Smaller mines can employ less than 100 workers. For example, a typical in situ leaching mine in the United States generally requires an operational labor force of 25 to 80 personnel (NRC 2008f). Large open pit uranium mines can employ hundreds. World-wide, there are more than 250,000 uranium miners (WISE 2008).

Human Health: Uranium mine workers are exposed to radiation in three ways: 1) inhalation of radon, accounting for 69 percent of total dose for underground miners, and 34 percent for open pit miners; 2) external radiation, accounting for 28 percent of total dose for underground miners, and 60 percent for open pit miners; and 3) inhalation of uranium ore dust, representing 3 percent of the total dose for underground miners and 6 percent for open pit miners (UNSCEAR 1993).

Typical individual doses vary within the range of 0.03 to 0.20 millirem per year (mrem/yr) (average: $0.05 \mathrm{mrem} / \mathrm{yr}$ ) for underground miners, and within the range of 0.01 to $0.05 \mathrm{mrem} / \mathrm{yr}$ (average: $0.02 \mathrm{mrem} / \mathrm{yr}$ ) for open pit miners (UNSCEAR 1993). As an example of dose to workers, the license renewal application for the Crow Butte in situ leaching facility in Dawes County, Nebraska contains the average individual dose for monitored employees for 1994-2006. The largest annual average dose during the time period was $700 \mathrm{mrem}$ in 1997. More recently, the maximum total effective dose equivalents were reported for 2005 and 2006 as $675 \mathrm{mrem}$ and 713 mrem, respectively. These doses represent 12 and 14 percent, respectively, of the annual dose limit for workers of 5 rem (NRC 2008f).

The collective dose for all underground uranium miners worldwide is estimated at 11.4 personrem per year, and for all 2,500 open pit uranium miners at 0.04 person-rem per year. This corresponds to 0.26 person-rem per 1,000 tons of uranium mined underground, and to 0.003 person-rem per 1,000 tons of uranium mined in open pits, with an average of 0.2 person-rem per 1,000 tons, for all uranium mined (UNSCEAR 1993). The expected number of fatal cancers in all uranium miners is 0.66 per year, or 0.005 per 1000 tons of uranium mined.

Uranium milling workers are exposed to radiation in three ways: 1) inhalation of radon, accounting for 37 percent of total dose, 2) inhalation of uranium concentrate dust, accounting for 47 percent of total dose, and 3) external radiation, accounting for 16 percent of total dose (UNSCEAR 2006). Typical individual doses for uranium mill workers vary within the range of 0.001 to $0.13 \mathrm{mrem} / \mathrm{yr}$ (average: $0.06 \mathrm{mrem} / \mathrm{yr}$ ). The collective dose for all 18,000 uranium mill workers worldwide is estimated at 1.2 person-rem per year; this corresponds to 0.02 person-rem per 1,000 tons of uranium extracted (UNSCEAR 1993). The expected number of increased fatal cancers in all uranium mill workers is 0.07 per year, or 0.0008 per 1,000 tons of uranium extracted.

Dose to miners are maintained as low as reasonably achievable (ALARA) through radiation safety precautions. Employees are monitored for alpha radiation contamination and personal 
dosimeters are worn to measure exposure to gamma radiation. Routine monitoring of air, dust and surface contamination is undertaken.

Uranium mining and milling activities have the potential to impact public health through 1) inhalation and ingestion of airborne radioactive particulates; 2) ingestion of contaminated foods (plant and animal) produced in areas contaminated by wind-blown tailings; 3 ) ingestion of surface water contaminated by tailings; 4) inhalation of radon and radon daughters; and 5) direct exposure to radiation emitted from the tailings. Potential impacts to the public would be highly site-specific and would depend upon many factors, including the amount of radionuclides released, site meteorology, population distribution and density relative to the radionuclides released, and the behavior of the population regarding ingestion of contaminated foods. Because of these many factors, it is not possible to predict with confidence the overall population risks from uranium mining and milling activities, including post-operational impacts from uranium tailings. One estimate of the lifetime risk of developing an excess cancer from radon and decay products for residents living at $1 \mathrm{~km}(0.6 \mathrm{mi})$ downwind from a typical 1970s uranium mine and mill in the Western United States is approximately 0.35 percent (or approximately 1 in 283). For this analysis, operations were assumed to occur for 12 years with an assumed annual production of 1,000 tons of uranium. The operations accounted for approximately 45 percent of the total risk, while the uranium tailings account for the remaining 55 percent (WISE 2008).

Transportation: There are no unique transportation impacts associated with uranium mining and milling. Any mining and milling operations would require localized transportation of workers and materials, and would include heavy machinery transport.

Waste Management: A variety of wastes and other materials are generated and managed by uranium mining and milling operations. Some, such as waste rock and tailings, are generally considered to be waste and are managed as such, in on-site management units. The definition of waste for mining operations, however, is not clear cut. Many mining "wastes" are not "solid wastes" as defined by the Resource Conservation and Recovery Act (RCRA) and therefore are not subject to regulation under RCRA (EPA 1995d). This would also include mine water or process wastewater that would be discharged pursuant to a National Pollutant Discharge Elimination System (NPDES) permit (EPA 1995d). Additionally, wastes and constituents of concern in those wastes are a site-specific and process-specific issue.

The greatest volume of waste generated by conventional uranium mining (open pit and underground) is waste rock, which is typically disposed of in waste rock piles (EPA 1995d). Waste rock is quite frequently used as fill, for road beds, and in construction. Conventional mining also generates substantial quantities of a waste called mill tailings which are typically disposed of in a slurry of water, acids and other chemicals in a pile. Radium-226, thorium 230, and radon-222 are the principal radioactive constituents of concern in uranium waste rock and mill tailings (EPA 1995d).

The greatest volume of waste generated by in-situ uranium mining is comprised of waste leaching solutions, which are typically disposed of in evaporation ponds, land applications, deep well disposal, or by shipment to U.S. Nuclear Regulatory Commission (NRC)-licensed waste disposal facilities (EPA 1995d). Waste constituents of concern include radionuclides (radium, 
radon, thorium, and to a lesser extent lead), arsenic, copper, selenium, vanadium, molybdenum, other heavy metals, and dissolved solids. Brines, spent ion exchange resins, acids, and other chemicals used in the mining process are also constituents of concern in waste leaching solutions (EPA 1995d).

Facility Accidents: Uranium miners face similar accident risks as other miners, including the risks associated with mine collapses, explosions, and other industrial hazards. Because specific statistics related to uranium mining accidents are not available, the information in this section is presented for the U.S. mining industry in general, which includes coal, metal, and non-metal mining. In the United States, mining deaths have decreased from about 0.20 fatalities per 200,000 hours worked by miners (or one death per million production hours) in 1970 to an average of 0.03 fatalities for the 2001-2005 period. The year 2004 was the safest year in modern mining history, with a total of 55 coal, metal, and non-metal mining fatalities in the United States. In 2007, there were 67 mining fatalities in the United States (DOL 2008).

\subsubsection{Uranium Enrichment}

Uranium ore contains approximately 0.711 weight percent uranium-235 (U-235), and most of the rest is U-238. This natural concentration is significantly less than the 3 to 5 percent U-235 required by current U.S. nuclear power plants as fuel for electricity generation. Therefore, uranium must be enriched (increasing the percentage of fissile U-235) so it can be used in commercial nuclear power plants. Facilities in the United States have produced enriched uranium from a few percent U-235 to much higher levels (greater than 20 percent). The separation line between low and highly enriched uranium is 20 percent, where low enriched uranium is less than 20 percent. Foreign sources currently provide approximately 84 percent of the natural uranium that is enriched for use in U.S. commercial nuclear reactors (EIA 2006a).

The two enrichment methods used on a large scale are gaseous diffusion and gas centrifuge. In gaseous diffusion, natural uranium in the form of uranium hexafluoride $\left(\mathrm{UF}_{6}\right)$ is heated and pressurized until it becomes a gas. The $\mathrm{UF}_{6}$ gas is then pumped through special filters (called "barriers" or "porous membranes"). The holes in the barriers are so small that there is barely enough room for the $\mathrm{UF}_{6}$ gas molecules to pass through. The lighter $\mathrm{UF}_{6}$ gas molecules (with the U-234 and U-235 atoms) pass through the barriers at a greater rate than the heavier $\mathrm{UF}_{6}$ gas molecules (which contain U-238), thereby slightly enriching the uranium at each barrier stage. However, it takes many hundreds of barriers, one after the other, before the $\mathrm{UF}_{6}$ gas contains enough U-235 to be used in reactors. At the end of this process, the enriched $\mathrm{UF}_{6}$ is condensed into a liquid and allowed to cool and solidify before it is transported to fuel fabrication facilities where it is turned into fuel assemblies for nuclear power reactors (NRC 2007b).

The gas centrifuge uranium enrichment process also relies on the slight mass difference between U-235 and U-238 to concentrate the former isotope. The process uses a large number of rotating cylinders in series and parallel formations. In this process, $\mathrm{UF}_{6}$ gas is placed in a cylinder and rotated at a high speed. This rotation creates a strong centrifugal force and the heavier gas molecules (containing U-238) move toward the outside of the cylinder and the lighter gas molecules (containing U-235) collect closer to the center. The lighter gas molecules are then fed into higher stages, which further separate the lighter and heavier gas molecules. At the end of 
this process, the enriched $\mathrm{UF}_{6}$ is condensed into a liquid and allowed to cool and solidify before it is transported to fuel fabrication facilities where it is turned into fuel assemblies for nuclear power reactors. Significantly more U-235 enrichment can be obtained from a single unit gas centrifuge than from a single unit gaseous diffusion stage. Currently, no gas centrifuge commercial production plants are operating in the United States, however, both the United States Enrichment Corporation (USEC) and Louisiana Energy Services (LES) have recently received licenses to construct and operate commercial enrichment facilities using centrifuge technology (see Section 4.1.2.1) (NRC 2007b).

Electricity requirements vary significantly between gaseous diffusion and gaseous centrifuge. Gas centrifuge enrichment requires only a fraction of the electricity that is required by gaseous diffusion. For example, at Paducah, the diffusion process consumes approximately 2200 kilowatt-hour $(\mathrm{kWh})$ per kilogram of a separative work unit (SWU) compared to approximately $40 \mathrm{kWh}$ per kilogram of SWU that is expected at the LES facility using centrifuge technology (NRC 2005b).

What is a SWU?
A SWU (separative work unit) is a
measure of enrichment in the
uranium enrichment industry; it
represents the level of effort or
energy required to raise the
concentration of U-235 to a
specified level, and is an indicator
of the amount of enriched uranium.
For example, if one begins with 220
lbs ( $100 \mathrm{~kg}$ ) of natural uranium, it
takes about 60 separative work units
to produce 22 lbs (10 kg) of
uranium enriched in U-235 content
to 4.5 percent.

\subsubsection{Current Enrichment Capabilities in the United States}

Historically there were three locations in the United States capable of uranium enrichment. These were the K-25 facility in Tennessee; the Portsmouth facility in Ohio; and the Paducah facility in Kentucky. The K-25 facility was shut down in 1985 and the Portsmouth facility was shut down in 2001 .

Paducah: Today, the Paducah facility is the only operating enrichment facility in the United States. Owned by the USEC, the Paducah facility is capable of uranium enrichment up to 5.5 percent U-235 (NRC 2007o), and has a uranium enrichment capacity of about 11 million separative work units (SWUs) per year (USEC 2008b). USEC plans to shut down the Paducah plant after it opens a new enrichment plant at Portsmouth that uses newer centrifuge enrichment technology (see American Centrifuge Plant below) (GAO 2008b).

American Centrifuge Plant: In April 2007, the NRC issued a Construction and Operating License for the American Centrifuge Plant that will be located in Portsmouth, OH. The license, which is valid for 30 years, includes authorization to enrich uranium up to an assay level of 10 percent U-235. USEC began construction on the American Centrifuge Plant in May 2007. USEC is working toward beginning commercial plant operations in late 2009 and having approximately 11,500 machines deployed in 2012, which would produce about 3.8 million SWUs annually (USEC 2008a).

Louisiana Energy Services Facility: In June 2006, the NRC issued a license for the LES Facility in Lea County, NM. The license, which is valid for 30 years, includes authorization to enrich uranium up to an assay level of 5 percent U-235 for a nominal production capacity of 
3 million SWUs per year (NRC 2006d). Construction on the LES Facility began in May 2007 and the facility is scheduled to be operational in approximately 2009 .

In order to provide the enriched uranium required to fuel a typical light water reactor (LWR) with a capacity of $1 \mathrm{GWe}$, it would take approximately 100,000 SWUs per year of enrichment services. As such, once the American Centrifuge Plant and the LES Facility become operational, the U.S. capacity will be 17.8 million SWUs per year, which will be enough capacity to support approximately 178 GWe. However, if the Paducah plant shuts down in 2012, the U.S. capacity would be 6.8 million SWUs, which would only be enough capacity to support approximately $68 \mathrm{GWe}$.

In addition to the facilities discussed above, two other entities have made public statements of interest regarding deployment of additional enrichment facilities in the United States. On May 6, 2008, AREVA announced its plans to license, site, and construct a gaseous centrifuge uranium enrichment facility in Bonneville County, Idaho, close to the Idaho National Laboratory (Reuters 2008). General Electric is also working on a laser process for enriching uranium at a test facility in North Carolina and has indicated its intent to apply for a full-scale project (Herald Tribune 2008).

\subsubsection{Environmental Impacts of Enrichment Activities}

The environmental impacts of enriching uranium are generally well known. A recent NRC EIS for the American Centrifuge Plant, Piketon, OH (NRC 2006b) analyzes the potential impacts associated with the annual production of up to 7 million SWUs of enriched uranium. ${ }^{3}$ The following summary is based on that EIS.

Land Resources: The facility would occupy approximately 60 acres (24.2 ha) of land.

Visual Resources: The facility would not change the existing industrial setting of the site. Moreover, the existing and new facilities would generally not be visible from off the DOE reservation, because views along the property line are limited by distance, rolling terrain, and heavy forests and vegetation. The operations would not create any new visual impacts (e.g., they would not result in the release of a visible plume to the air) and would not generate much new or different looking activity than already exists.

Air Resources: All modeled concentrations from site preparation and construction activities would be below the National Ambient Air Quality Standard (NAAQS) for each criteria pollutant with the exception of the annual average concentration of particulate matter with a mean diameter of 2.5 micrometers or less. The vast majority of the exceedance is the result of high background concentrations for particulate matter with a mean diameter of 2.5 micrometers or less in the area. To avoid nuisance conditions and particulate matter concerns, USEC intends to use dust suppression techniques (e.g., water sprays and speed limits on dirt roadways) to mitigate releases of dust during excavation under dry conditions.

\footnotetext{
${ }^{3}$ As presented in Section 4.1.2.1, the American Centrifuge Plant is expected to produce about 3.8 million SWUs annually. The EIS evaluates a bounding production of 7 million SWUs annually.
} 
During routine operation of the facility, principal non-radiological pollutants would come from the exhaust of stationary diesel generators used for emergency power if supplied power is lost. All air concentrations expected to result from the operation of the emergency diesel generators are well below the NAAQS for each criteria pollutant. The primary nonradiological air pollutant associated with the operation of the facility would be hydrogen fluoride (HF). When UF6 is released to the air, it reacts with atmospheric moisture to form particulate uranium (in the form of uranyl fluoride) and HF fumes. The maximum predicted HF concentration would be more than six orders of magnitude below the Occupational Safety and Health Administration Permissible Exposure Limit (as an 8-hour average) for HF.

Radiological emissions would include uranium-234, uranium-235, uranium-238, and technetium99 (technetium-99 is a fission product that has contaminated much of the fuel cycle as a result of past recycling of reprocessed uranium). Experience at the gaseous diffusion plant has shown that these three uranium isotopes account for more than 99 percent of the public dose due to uranium emissions. The NRC staff estimated that the projected maximum airborne concentration of total uranium due to proposed operations would be less than 1 percent of the applicable concentration limit in 10 CFR Part 20, Appendix B, Table 2. Radiological releases to air would be routinely monitored to ensure that releases are at or below the expected quantities.

Water Resources: The facility would require approximately 650,000 gallons (gal) of water (2.6 million liters [L]) per day for drinking, hygiene, and cooling tower makeup water (noncontact cooling water). The increase in consumption would be only 10 percent higher than current withdrawal rates and would represent only 31 percent of the total design capacity (and currently permitted rate) of the well field groundwater withdrawal system.

Any liquid discharges of radioactive materials would be controlled through plant design, operations, and monitoring. Based on historical operating experience at the Portsmouth reservation, USEC has established maximum effluent concentrations expected under normal operations of the facility. Any effluents potentially containing radioactive material would have to meet the NRC standards in 10 CFR Part 20 prior to being discharged. All effluents would be sampled prior to discharge to ensure concentrations are below standards.

Socioeconomic Impacts: Construction activities would generate 3,362 full-time jobs (direct and indirect). The employment expected to be generated by construction activities represents 3.5 percent of the total employment in the region of influence and 22.5 percent of Pike County employment at the year 2000 levels. Based on these figures, NRC concluded that the impacts to regional employment would be moderate.

During operations, the facility would create 600 full-time jobs and 900 indirect jobs in the region of influence. The employment expected to be generated by the operations represents 1.6 percent of the total employment in the region and 10 percent of Pike County employment. Given these results, the NRC concluded that the impacts to regional employment would be moderate. 
Human Health: The facility would result in small increases in the current number of occupational injuries and illnesses at the site, though still less than historical levels. ${ }^{4}$ Construction and process areas would be segregated, and personnel monitoring programs would be implemented to minimize worker exposures and to limit annual radiation doses below limits outlined in 10 CFR Part 20.

The maximum individual 50-year total effective dose equivalent rate at this location from air emissions is modeled to be $0.21 \mathrm{mrem} / \mathrm{yr}$. This estimated dose is well below the U.S. EPA National Emission Standards for Hazardous Air Pollutant limit of $10 \mathrm{mrem} / \mathrm{yr}$ and the NRC total effective dose equivalent limit of $100 \mathrm{mrem} / \mathrm{yr}$. Although NRC did not estimate the total dose to the 50-mile population, $\mathrm{NRC}$ concluded that all exposures are also expected to be significantly below the EPA limit of $25 \mathrm{mrem} / \mathrm{yr}$, as set in 40 CFR Part 190 for uranium fuel-cycle facilities.

With respect to doses for occupational workers, NRC estimated that the most significant contributor to occupational radiation exposure would be direct radiation from the $\mathrm{UF}_{6}$. The average dose to workers in 2003 at the enrichment facility that was previously operated at Portsmouth was $29 \mathrm{mrem}$. Based on this, NRC concluded that the impacts from occupational exposure at the proposed American Centrifuge Plant are expected to be small.

Transportation: The transportation of materials containing radionuclides would result in some increased risk of cancer to both the workers transporting and handling the material and to members of the public driving along the roads or living along the transportation routes. The transport of all materials is estimated to result in approximately 0.014 latent cancer fatalities (LCFs) per year of operation from exposure to direct radiation during "incident-free" transport (i.e., shipping that does not involve the breach of a shipping container and subsequent release of radioactive material), and an additional 0.008 LCF per year from accidents that result in the release of radioactive material into the environment. The total LCFs are estimated to be 0.02 per year of operation, or less than one cancer fatality over 30 years of operation.

Waste Management: The facility would generate approximately 41,000 cylinders of depleted $\mathrm{UF}_{6}$, containing approximately 500,000 metric tons (MT) of material. Enrichment of 1,000 tons of uranium in the form of $\mathrm{UF}_{6}$ leads to generation of around 850 tons of depleted uranium with a U-235 content of approximately 0.25 percent. This material may be potentially reused or disposed of as a waste.

Facility Accidents: NRC regulations and USEC's operating procedures for the proposed American Centrifuge Plant are designed to ensure that the high and intermediate accident scenarios would be highly unlikely. Based on the Safety Evaluation Report that NRC prepared, accidents at the proposed American Centrifuge Plant would result in small to moderate impacts to workers, the environment, and the public. ${ }^{5}$ The most significant accident consequences are those associated with the release of $\mathrm{UF}_{6}$ caused by a breach of an over-pressurized cylinder. The proposed American Centrifuge Plant design reduces the likelihood of this event by having automatic high temperature and high pressure trips.

\footnotetext{
${ }^{4}$ This information was based on a comparison of the American Centrifuge Plant to the enrichment facility that was previously operated at Portsmouth, $\mathrm{OH}$

${ }^{5}$ The NRC excluded any specific information related to accidents pursuant to 10 CFR 2.390. As such, no further information related to accidents from the American Centrifuge Plant can be released.
} 


\subsubsection{Uranium Fuel Fabrication}

Fuel fabrication is the final step in the process used to produce uranium fuel for commercial reactors. The feed material for the manufacture and fabrication of fuel is $\mathrm{UF}_{6}$ enriched to about 3 to 5 percent in uranium-235. The $\mathrm{UF}_{6}$ is converted to uranium dioxide powder $\left(\mathrm{UO}_{2}\right)$ and inserted into a die, where it is pressed into a pellet shape. Next the pellet is sintered in a furnace at 2,732 to $3,272{ }^{\circ} \mathrm{F}\left(1,500\right.$ to $\left.1,800{ }^{\circ} \mathrm{C}\right)$. This sintering is similar to the firing of other ceramic ware, and produces a dense ceramic pellet to achieve the desired density. These pellets are then ground to the required dimensions. Fuel pellets are loaded into tubes of zircaloy (a zirconium-tin alloy) or stainless steel, then filled with an inert gas, and welded at both ends to form a fuel rod. The fuel rods are spaced in fixed parallel arrays, and together with other necessary hardware, constitute a fuel assembly (IAEA 2002a).

\subsubsection{Current Fuel Fabrication Capabilities in the United States}

The United States currently has three NRC-licensed uranium fuel fabrication facilities capable of processing $\mathrm{UF}_{6}$ to $\mathrm{UO}_{2}$ powder and then fabricating $\mathrm{LWR}$ fuel assemblies from this $\mathrm{UO}_{2}$ powder. Three additional facilities, Nuclear Fuel Services, in Erwin, TN, BWX Technologies, in Lynchburg, VA, and AREVA NP, in Lynchburg, VA are NRC-licensed, but currently do not have the ability to process $\mathrm{UF}_{6}$ to $\mathrm{UO}_{2}$ powder. Table $4.1-2$ shows the capacity of the three facilities presently able to produce commercial LWR fuel assemblies. The current LWRs require approximately 2,000 MT of fresh fuel assemblies annually (Wigeland 2008a). For purposes of this PEIS, DOE has assumed that these fuel fabrication facilities would continue to operate to support the nuclear electricity generating sector.

TABLE 4.1-2—United States Light Water Reactor Fuel Fabrication Capacity

\begin{tabular}{lccc}
\multicolumn{1}{c}{ Facility } & Location & License Expiration & $\begin{array}{c}\text { Capacity } \\
\text { (Metric Tons) }\end{array}$ \\
\hline Global Nuclear Fuel-Americas, LLC & Wilmington, NC & $2007^{\mathrm{a}}$ & 1,200 \\
Westinghouse & Columbia, SC & $9 / 30 / 2027$ & 1,600 \\
Areva NP, Inc. & Richland, WA & $11 / 30 / 06^{\mathrm{a}}$ & 700 \\
TOTAL & & & 3,500 \\
\hline
\end{tabular}

Source: NRC 2007c

${ }^{a}$ Have applied for license extension; NRC allows operations to continue pending license extension resolution.

\subsubsection{Environmental Impacts of Fuel Fabrication Activities}

Operations at fuel fabrication facilities could impact the environment through the release of radiological and nonradiological material into the air, water, and soil. Workers and the public could be impacted by radiation exposure, including the inhalation and ingestion of released materials. A fuel fabrication facility would also create socioeconomic impacts by employing workers and would generate wastes. Additionally, accidents at a fuel fabrication facility could impact worker and public health. Fuel fabrication facilities operate a comprehensive environmental monitoring program that collects air, groundwater, surface water, sediment, soil, and vegetation samples and tests them for radiological content. This program is part of the NRC license requirements for the facility (NRC 2007p). 
The general impacts of fuel fabrication facilities are presented below. The analysis below includes specific information related to the impacts from the Westinghouse fuel fabrication facility near Columbia, SC, as that is the largest fuel fabrication facility in the United States and was recently granted a license extension for operations (NRC 2007p).

Land Resources: The typical land requirements for a fuel fabrication facility range from hundreds of acres to several thousand acres. For example, the Westinghouse fuel fabrication facility is located on approximately 1,160 acres (470 ha). Of this, approximately 1,100 acres (445 ha) of the site remain undeveloped. No licensed activities occur on this undeveloped property. Only 60 acres $(24$ ha) (about 5 percent) have been developed to accommodate the licensed activities associated with the fuel fabrication facilities, holding ponds, and landscaped areas (WEC 2006).

Visual Resources: Fuel fabrication facilities are large industrial facilities, with some portions that are multiple stories in height. Stacks for air emissions are generally the tallest structures. Visibility of a fuel fabrication facility would be highly dependent on the site and the surrounding area's physical characteristics, including topography, as well as the distance of the facility to a site boundary.

Air Resources: The radioactive and nonradioactive emissions of the fuel fabrication facilities represent only a small fraction (about 1 percent) of total emissions from the nuclear fuel cycle (IAEA 2002a). Nonradiological emissions are typically associated with heating and cooling systems and are generally small. For example, the nonradiological releases from the Westinghouse fuel fabrication facility produce concentrations in the air that are well below all NAAQS (NRC 2007p).

Gaseous effluents from the radioactive material operations are treated and sampled prior to release to the environment. High Efficiency Particulate Air (HEPA) filters and scrubbers are commonly used pollution control equipment employed to treat gaseous effluents for both radiological and nonradiological constituents. Emissions from stacks that could release radioactive material are continuously sampled and analyzed daily for uranium levels (NRC 2007p). The impacts of radiological effluents on worker and public health are discussed under "Human Health."

Water Resources: Fuel fabrication facilities use water for operations, including process cooling and domestic uses, such as drinking and sanitary uses. On a typical day, the Westinghouse fuel fabrication facility uses more than 100,000 gal (400,000 L) (NRC 2007p). Most of this water is not consumed, and is discharged back to the supply source. Effluents from facility operations may contain radiological and nonradiological contaminants. These effluents are monitored and treated as necessary to comply with regulatory requirements, including NPDES permits for nonradiological contaminants and 10 CFR Part 20 (Standards for Protection Against Radiation) for radiological contaminants (NRC 2007p).

Socioeconomic Impacts: Employment would be highly dependent on the capacity of the fuel fabrication facility, and the demand for fuel. Typical employment would be more than 500 up to more than 1,000. For example, approximately 1,200 people are employed at the Westinghouse fuel fabrication facility (NRC 2007p). 
Human Health: The continued handling of materials and conduct of operations at a fuel fabrication facility pose potential impacts to public and occupational health. For normal operations, the potential impacts are related to the release of low levels of toxic or radioactive materials to the environment over extended periods of time. This section discusses both worker and public doses.

At uranium fuel fabrication facilities, the concentration of uranium in the air and external dose rates are low compared to regulatory limits. This means that special hot cells ${ }^{6}$ for containment and shielding are not necessary. Workers are monitored for radiation exposure and generally receive relatively low occupational doses (IAEA 2002a). For example, for the 4-year period from 2001 to 2004, the average annual dose to a worker at the Westinghouse fuel fabrication facility ranged from $337 \mathrm{mrem}$ to $394 \mathrm{mrem}$ (NRC 2007p). These doses are less than 10 percent of the 5 rem annual occupational dose limit imposed by 10 CFR 20.1201. During that same time period, no individual radiation worker had an annual dose above this limit (NRC 2007p).

Workers are also subject to occupational health and safety risks, including industrial hazards. Industrial hazards for fuel fabrication facilities are typical for similar industrial facilities and include exposure to chemicals and accidents ranging from minor cuts to industrial machinery accidents. As a point of reference, no serious injuries or deaths have occurred at the Westinghouse fuel fabrication facility since operations began in 1969. For 2005, the Westinghouse fuel fabrication facility Occupational Safety and Health Administration (OSHA) Total Recordable Incident Rate was 1.167 (NRC 2007p). The incident rate accounts for both the number of OSHA recordable injuries and illnesses and the total number of man-hours worked. The incident rate is used for measuring and comparing work injuries, illnesses, and accidents within and between industries. The average incident rate for manufacturing facilities like the Westinghouse fuel fabrication facility is 6.5 (NRC 2007p).

Radiological exposures to the public from fuel fabrication facilities operations are primarily via air emissions results. In fact, over 99 percent of the offsite dose to the public originates from the airborne emissions (WEC 2006). Air emissions from fuel fabrication facilities are routinely monitored, the results are trended, and corrective actions are taken if necessary to ensure that emissions remain as low as reasonably achievable (NRC 2007p). At the Westinghouse fuel fabrication facility, typical cumulative stack emissions would result in a dose of less than $0.4 \mathrm{mrem}$ to a hypothetical exposed individual living at the site boundary (NRC 2007p). For the 6-year period from 2000 to 2005 , this annual dose ranged between $0.30 \mathrm{mrem}$ and $0.38 \mathrm{mrem}$ (NRC 2007p). This is approximately 4 percent of the $10 \mathrm{mrem}$ annual dose limit from air emissions imposed by 10 CFR 20.1101 .

Facility Accidents: NRC regulations require that a fuel fabrication facility licensee perform an Integrated Safety Analysis (ISA) (10 CFR Part 70, Subpart H). An ISA is "a systematic analysis to identify facility and external hazards and their potential for initiating accident sequences, the potential accident sequences, their likelihood and consequences, and the items relied on for safety" (10 CFR 70.4). Generally, an ISA is not available for public review because it contains information that is related to the security of the facility (NRC 2007p). In the development of the

${ }^{6} \mathrm{~A}$ hot cell is a heavily shielded room that is maintained at a negative pressure, supported by remote handling equipment and viewing systems (e.g., shielded windows or cameras) to work with radioactive material. These design features preclude exposing operating personnel to high levels of external or internal radiation. 
ISA for the Westinghouse fuel fabrication facility, only one accident sequence was identified as having potential consequences to cause significant impacts. The licensee identified safety control for this accident sequence such that the consequences are unlikely to occur. NRC determined that the items relied on for safety are adequate to control the likelihood of the accident sequence and that the Westinghouse fuel fabrication facility can be operated in compliance with the performance requirements of $10 \mathrm{CFR} 70.61$, which is adequate to control the environmental consequences of accidents to a level acceptable to the NRC (NRC 2007p). ${ }^{7}$

Waste Management: Fuel fabrication facilities generate solid LLW, hazardous waste, and nonhazardous waste. The LLW is either decontaminated for free release or reuse, incinerated onsite, or shipped offsite for disposal. From 1996 to 2003, the annual amount of LLW shipped offsite from the Westinghouse Columbia, SC fuel fabrication facility varied between 2,789 cubic feet $\left(\mathrm{ft}^{3}\right)\left(79\right.$ cubic meters $\left.\left[\mathrm{m}^{3}\right]\right)$ and $181,256 \mathrm{ft}^{3}\left(5,132 \mathrm{~m}^{3}\right)$ (NRC 2007p). Hazardous wastes such as degreasing solvents, lubricating and cutting oils, and spent plating solutions are typically disposed of offsite through permitted contractors. Nonhazardous waste is generated from routine office and industrial activities and is disposed of locally at an offsite state-permitted landfill. Typical waste generation rates for the Westinghouse fuel fabrication facility are shown in Table 4.1-3.

\begin{tabular}{lc}
$\begin{array}{c}\text { TABLE 4.1-3_Waste Generation at Westinghouse } \\
\text { Fuel Fabrication Facility }\end{array}$ \\
\hline \multicolumn{1}{c}{ Waste Type } & Generation Rate \\
\hline LLW & $15,600 \mathrm{ft}^{3} / \mathrm{yr}$ \\
Hazardous & $40,000 \mathrm{lbs} / \mathrm{yr}$ \\
Non-Hazardous & \\
Liquid & $12,000 \mathrm{lbs} / \mathrm{yr}$ \\
Solid & $600 \mathrm{tons} / \mathrm{yr}$ \\
\hline Source: NRC $2007 \mathrm{p}$ &
\end{tabular}

Transportation: With respect to transportation associated with fuel fabrication activities, the following types of radiological materials could be transported: enriched uranium feed material, LLW from operations, and fuel assemblies. These types of materials are unirradiated and do not generally require shielding. An analysis of the radiological impacts associated with transporting enriched uranium feed materials for fuel fabrication estimated a maximum of approximately 0.014 LCF per year of operation from exposure to direct radiation during incident-free transport, and an additional 0.008 LCF per year from accidents that result in the release of radioactive material into the environment (NRC 2006b). The total LCFs was estimated to be 0.02 per year of operation or less than one cancer fatality over 30 years of operation (NRC 2006b). Unirradiated uranium fuel assemblies are transported in licensed and regulated packages, and do not have the potential to cause significant impacts (NRC 2007p).

\footnotetext{
${ }^{7}$ The NRC excluded any specific information related to accidents pursuant to 10 CFR 2.390. As such, no further information related to accidents from the Westinghouse fuel fabrication facility can be released.
} 


\subsubsection{Impacts of Disposing of Spent Nuclear Fuel and High-Level Waste in Yucca Mountain}

The environmental impacts of transporting and disposing of SNF and HLW in Yucca Mountain have been assessed in a previous NEPA document (Final Environmental Impact Statement for a Geologic Repository for the Disposal of Spent Nuclear Fuel and High-Level Radioactive Waste at Yucca Mountain, Nye County, Nevada [hereafter Yucca Mountain FEIS] [DOE 2002i]) and is further assessed in final NEPA documents that were issued to the public in June 2008 (Supplemental Environmental Impact Statement for a Geologic Repository for the Disposal of Spent Nuclear Fuel and High-Level Radioactive Waste at Yucca Mountain, Nye County, Nevada [hereafter, Yucca Mountain SEIS] [DOE 2008f] and Environmental Impact Statement for the Alignment, Construction, and Operation of a Rail Line to a Geologic Repository at Yucca Mountain, Nye County, Nevada [DOE 2008g]). Because none of the alternatives in this PEIS would affect the construction and operation of the Yucca Mountain repository, this PEIS would not change the environmental impacts of transporting and disposing of SNF and HLW in Yucca Mountain. For information regarding Yucca Mountain, the reader is directed to the two most recent NEPA documents (DOE 2008f and DOE 2008g).

\subsubsection{Impacts of Establishing a Geologic Repository for Future Spent Nuclear Fuel and High-Level Waste}

All alternatives analyzed in this PEIS, including the No Action Alternative, would require the establishment, construction, and operation of new repository capacity (in addition to the planned capacity for the Yucca Mountain geologic repository) for disposal of SNF and/or HLW. This capacity could be at the Yucca Mountain site (if Congress were to amend the statutory limit on the capacity of Yucca Mountain) or at a new site. The environmental impacts of establishing a geologic repository to dispose of SNF and/or HLW would be highly dependent on the ultimate location selected; therefore, the environmental impacts for many resources cannot be estimated with precision without knowing where such a repository would be located. Consequently, this analysis is limited. Nonetheless, previous studies for the Yucca Mountain repository provide a reasonable basis for estimating the potential generic impacts associated with establishing, constructing, and operating a future geologic repository.

General Site Characteristics: Any repository site would be required to possess characteristics that would limit or restrict possible long-term impacts from the disposal of SNF or HLW. The Nuclear Waste Policy Act of 1982 provides for a multi-staged siting process including preliminary site screening, site characterization, DOE site recommendation to the President, and Presidential approval of a site for location of a nuclear waste repository (42 U.S.C. 10101 et seq.). DOE has published general guidelines for evaluating the suitability of sites at 10 CFR Part 960. These guidelines were based on and consistent with the repository licensing requirements promulgated by the NRC at 10 CFR Part 60 and applied the generally applicable standards for the protection of the general environment promulgated by the EPA at 
40 CFR Part $191 .^{8}$ Site suitability is evaluated on the basis of whether or not the site disposal system is likely to meet applicable radiation protection standards. Any potential future repository will first be screened in a way that "will consider large land masses that contain rock formations of suitable depth, thickness, and lateral extent and have structural, hydrologic, and tectonic features favorable for waste containment and isolation" (10 CFR 960.3-2-1).

Land Resources: Any future repository could occupy a relatively large area of land. For example, the Yucca Mountain repository consists of 230 square miles $\left(\mathrm{mi}^{2}\right.$ ) (596 square kilometers $\left[\mathrm{km}^{2}\right]$ ) of land currently under the control of government agencies. Surface repository facilities could occupy more than $2.3 \mathrm{mi}^{2}\left(5.6 \mathrm{~km}^{2}\right)$. The remainder of the site would be used to locate support facilities, and for continued performance confirmation and testing activities (e.g., wells) and to separate repository facilities from other human activities.

Visual Resources: With respect to visual characteristics, the visibility of the repository from publicly accessible locations would be dependent on the future site characteristics. DOE would provide lighting for operation areas at the repository that might be visible from public access points. The use of shielded or directional lighting at a repository would limit the amount of light that could be seen from outside the repository area. Closure activities, such as dismantling facilities and reclaiming the site, would restore the visual quality of the landscape, as viewed from the site itself.

Air Resources: During construction activities, principal nonradiological pollutants such as certain criteria pollutants (nitrogen dioxide, sulfur dioxide, carbon monoxide, and particulate matter with a diameter less than 10 micrometers $\left[\mathrm{PM}_{10}\right]$ ) and carbon dioxide could be emitted. Emission of the gases nitrogen dioxide, sulfur dioxide, carbon monoxide, and carbon dioxide would come primarily from fuel combustion by vehicles, construction equipment, generators, and boilers. $\mathrm{PM}_{10}$ would be released mainly as a component of fugitive dust from land and excavation activities, as well as in smaller quantities from fuel combustion.

Radiological air quality impacts (radiation doses) could occur from airborne releases of radionuclides caused by accidents and equipment failures during operations. Measures would be taken to prevent such accidents and to mitigate their consequences in the unlikely event they should occur (off-normal event planning). Releases of very small quantities of manmade radionuclides (krypton-85 and other noble gases) could occur only during the operations period, when a small percentage of SNF assemblies, with small failures in their cladding, could be removed from transportation casks in a waste handling facility.

Water Resources: Construction and operation and monitoring activities could disturb more than 1,000 acres (405 ha). The amount of newly disturbed land would vary depending on the operating mode used and the specific site selected. Disturbing the land surface probably would alter the rate at which water would infiltrate the surface. However, assuming a large enough area is withdrawn for the repository, DOE would expect relatively minor changes in the amount of

\footnotetext{
${ }^{8}$ In 1987 the Nuclear Waste Policy Act of 1982 was amended and Congress directed DOE to consider only one site-Yucca Mountain —and DOE and NRC subsequently adopted site-specific criteria for Yucca Mountain (DOE-10 CFR Part 963; NRC - 10 CFR Part 63). In 1992, the EPA was directed to provide public health and safety standards for protection of the public from releases from radioactive materials from Yucca Mountain and subsequently published those standards for Yucca Mountain (40 CFR Part 197). This set of guidelines and regulations establish requirements applicable only to Yucca Mountain and would not necessarily apply to a future repository.
} 
runoff actually reaching the drainage channels so long as repository activities disturb a relatively small amount of the natural drainage area. The eventual removal of structures and impermeable surfaces, with mitigation (soil reclamation) and rehabilitation of natural plants in disturbed areas, would decrease runoff from these areas.

Facilities at which DOE would manage radioactive materials should be able to withstand the probable maximum flood (the most severe flood that is reasonably foreseeable). The foundations should be built up as necessary so the facilities would be above the flood level. It is unlikely that naturally occurring wetlands would exist on any future repository site, so no impacts to such areas would be expected as a result of repository construction, operation and monitoring, or closure.

Socioeconomic Impacts: Impacts to the socioeconomic environment in communities in the vicinity of any future repository would occur. Employment, population, economic measures, housing, and public services could all be affected by construction and operation. Peak construction employment would likely be several thousand workers. Operational employment would be expected to be more than 1,000 .

Human Health: Occupational and public health and safety impacts would result from routine operations: 1) to workers from hazards that are common to similar industrial settings and excavation operations, such as falling or tripping (referred to as industrial hazards); 2) to workers and the public from naturally occurring nonradiological materials in the geologic media; 3) to workers as a result of radiation exposure during their work activities; and 4) to the public from airborne releases of radionuclides.

Workers would be subject to industrial hazards during construction and operation. Examples of the types of industrial hazards that could present themselves include tripping, being cut on equipment or material, dropping heavy objects, and catching clothing in moving machine parts. Most impacts would result from fuel handling during the operations period and industrial hazards resulting from any subsurface excavation. Workers and the public would also be subject to radiological impacts. A summary of the human health impacts estimated for the Yucca Mountain repository, which could be representative of the impacts for any future repository, are presented in the Yucca Mountain SEIS (DOE 2008f).

Facility Accidents: With respect to accidents, the maximum reasonably foreseeable accident (i.e., a credible accident scenario with the highest foreseeable consequences) impacts would be dependent on the specific site characteristics of any future repository. For the Yucca Mountain SEIS, DOE estimated that the maximum reasonably foreseeable accident scenarios would result in less than one additional LCF to the surrounding population and workers (DOE 2008f).

Waste Management: Repository construction, operations, monitoring, and closure would generate waste and entail the use of hazardous materials. The types include construction and demolition debris, industrial wastewater, LLW, sanitary sewage, sanitary and industrial waste, hazardous waste, and mixed waste. DOE could build onsite solid waste facilities to accommodate non-hazardous waste or dispose of such waste at offsite facilities. DOE would manage industrial wastewater with onsite evaporation ponds. DOE would dispose of 
construction and demolition debris and sanitary and industrial waste either at an onsite landfill or at offsite facilities. Hazardous waste and LLW would be disposed of in offsite facilities (DOE 2008f).

Transportation: SNF and HLW are packaged for transportation in specially designed containers to meet stringent NRC and U.S. Department of Transportation (DOT) standards. Appendix E presents information on these containers. The impacts of transporting future SNF and HLW to a geologic repository are included in Sections 4.2 through 4.7 for each of the domestic programmatic alternatives. (See also the Yucca Mountain SEIS [DOE 2008f] for more discussion of potential transportation impacts, including transportation for any expanded capacity.)

\subsubsection{Impacts of Establishing and Operating Disposal Capacity for Future Low- Level Waste}

\subsubsection{Current Low-Level Waste Disposal Capabilities in the United States}

All alternatives analyzed in this PEIS, including the No Action Alternative, would require additional LLW disposal capacity. This capacity could be at either existing LLW disposal facilities (if existing licenses and/or policies were to be revised) or at new facilities. Currently there are three sites in the United States licensed to dispose of commercial LLW.

- EnergySolutions Barnwell Operations, located in Barnwell, South Carolina Currently, EnergySolutions/Barnwell accepts waste only from generators in the Atlantic compact ${ }^{9}$ states (Connecticut, New Jersey, and South Carolina). The Barnwell disposal facility was closed to out-of-compact waste generators in July 2008.

- United States Ecology, located in Richland, Washington U.S. Ecology is licensed by the State of Washington to accept waste from the Northwest and Rocky Mountain Compacts.

- EnergySolutions Clive Operations, located in Clive, Utah EnergySolutions/Clive accepts waste from all regions of the United States. The disposal site has the capacity for more than 20 years of disposal under its current license.

\subsubsection{Environmental Impacts of Low-Level Waste Disposal}

The environmental impacts of establishing LLW disposal capacity would be highly dependent on the location; therefore, the environmental impacts for many resources cannot be estimated with precision without knowing where these facilities would be located. Consequently, this analysis is limited. Nonetheless, previous studies of the impacts of LLW disposal provide a reasonable basis for estimating the potential generic impacts associated with establishing, constructing, and operating future facilities for the disposal of LLW.

General Site Characteristics: The different types of near-surface disposal facilities that are being used to dispose LLW include: trench facilities, trench facilities with disposal vaults, and above-grade disposal vaults. In 1994, the NRC issued NUREG 1200, Standard Review Plan for a

${ }^{9}$ States may enter into "compacts" to provide for the establishment and operation of regional disposal facilities for LLW. 
review of a license application for a low-level radioactive waste disposal facility (NRC 1994b). The NRC regulations applicable to commercial LLW disposal facilities are in 10 CFR Part 61. The NRC regulations contain procedural requirements and performance objectives applicable to any method of land disposal. The regulations contain specific technical requirements for nearsurface disposal of radioactive waste, a subset of land disposal, which involves disposal in the uppermost portion of the earth, approximately $100 \mathrm{ft}(30 \mathrm{~m})$. Near-surface disposal includes disposal in engineered facilities which may be built totally or partially above-grade provided that such facilities have protective earthen covers. Near-surface disposal of radioactive waste takes place at a near-surface disposal facility, which includes all of the land and buildings necessary to carry out the disposal and consists of disposal units and a buffer zone. A disposal unit is a discrete portion of the disposal site into which waste is placed for disposal. For near-surface disposal, the disposal unit is usually a trench. A buffer zone is a portion of the disposal site that is controlled by the licensee and that lies under the site and between the boundary of the disposal site and any disposal unit. It provides controlled space to establish monitoring locations which are intended to provide an early warning of radionuclide movement, and to take mitigative measures if needed.

In choosing a disposal site, site characteristics should be considered in terms of the indefinite future and evaluated for at least a 500-year timeframe. The NRC regulations provide that disposal of radioactive waste in near-surface disposal facilities must have the following safety objectives: 1) protection of the general population from releases of radioactivity; 2) protection of individuals from inadvertent intrusion; and 3) protection of individuals during operations (10 CFR 61.7). A fourth objective is to ensure stability of the site after closure (10 CFR 61.7). A cornerstone of the system is stability - stability of the waste and the disposal site so that once emplaced and covered, the access of water to the waste can be minimized. Interstate Compacts established under the Low-Level Radioactive Waste Policy Amendments Act of 1985 may enact regulations for LLW disposal that are more stringent than those established by NRC, provided that those regulations are not incompatible with NRC regulations or inconsistent with Department of Transportation regulations (42 U.S.C. 2021d).

The EnergySolutions/Barnwell site disposes of LLW in concrete vaults located in trenches. The bottom of each trench is located a minimum of $5 \mathrm{ft}(1.5 \mathrm{~m})$ above the site's maximum historically measured water table elevation. When a vault is full, the space between the vaults is backfilled with clay. Engineered covers are constructed over the backfilled vaults as the trenches fill. The engineered cover consists of a minimum 1 -foot $(0.3-\mathrm{m})$ thick clay layer, a geosynthetic clay liner, a high density polyethylene liner, a sand drain layer, and a vegetated topsoil cover (SCDHEC 2007). The U.S. Ecology LLW disposal facility is also a trench design. The trenches are typically $45 \mathrm{ft}(14 \mathrm{~m})$ deep, $850 \mathrm{ft}(258 \mathrm{~m})$ long, and $150 \mathrm{ft}(45 \mathrm{~m})$ wide. An engineered cover is placed on the trenches as they are filled (WSDH 2008).

Land Resources: Construction and operation and monitoring activities could disturb hundreds of acres of land. The amount of land required would be linked to the amount of waste that would be disposed of as allowed under a license. The land would be disturbed in a phased approach with disposal capacity (e.g., trenches and vaults) constructed to match pace with waste receipt. For example, when full, the EnergySolutions/Barnwell site will cover over 200 acres ( 81 ha), the U.S. Ecology site approximately 100 acres (40 ha), and the EnergySolutions/Clive site 
approximately 500 acres (203 ha). Additional engineered barriers, in particular earthen covers, would be constructed to enhance the isolation of waste from the environment as disposal capacity is filled. Institutional control over the land would be needed until the facility meets the post-closure performance objectives established at 10 CFR Part 61 or an equivalent state regulation.

Visual Resources: With respect to visual characteristics, the visibility of a LLW disposal facility from publicly accessible locations would be dependent on the location of the site, site characteristics, and the design of the facility. During construction and operations, the aesthetics would be similar to those of a municipal solid waste landfill or an operating LLW disposal facility. Construction and waste emplacement activities would be ongoing and involve the use of heavy equipment and trucks to transport the LLW packages. Lighting for operation areas at the facility may all be visible from public access points. However, the use of shielded or directional lighting at a facility would limit the amount of light that could be seen from outside the facility area. Closure activities, in particular the construction of the final closure covers, would restore the visual quality of the landscape.

Air Resources: During construction activities, principal nonradiological pollutants such as certain criteria pollutants (nitrogen dioxide, sulfur dioxide, carbon monoxide, and particulate matter with a diameter less than 10 micrometers $\left[\mathrm{PM}_{10}\right]$ ) and carbon dioxide could be emitted. Emission of the gases nitrogen dioxide, sulfur dioxide, and carbon monoxide would come primarily from fuel combustion by vehicles and construction equipment. $\mathrm{PM}_{10}$ would be released mainly as a component of fugitive dust from trench excavation, waste disposal, vehicular traffic, and earthen cover construction. Sites located in arid climates with windy conditions could add to the generation of fugitive dust. Routine dust abatement measures (e.g., watering roads, covering loose soils, and re-vegetation) could help minimize impacts.

Airborne releases during normal operations are expected to be low. For example, data from regular airborne radioactivity monitoring at the U.S. Ecology LLW site shows that a maximally exposed person would receive less than $0.1 \mathrm{mrem} / \mathrm{yr}$, significantly lower than the $10 \mathrm{mrem} / \mathrm{yr}$ ambient air standard (WSDH 2004).

Radiological air quality impacts (radiation doses) could occur from airborne releases of radionuclides caused by accidents and equipment failures during operations. Measures would be taken to prevent such accidents and to mitigate their consequences in the unlikely event they should occur (off-normal event planning).

Water Resources: LLW disposal facilities are designed to use engineered barriers to isolate the LLW from water. Standard construction techniques would be applied during construction to minimize effects to water quality. The waste packages and any temporary barriers installed during the construction and operations phase would preclude radionuclide release. A leachate collection system would likely be included in the design of the facility to capture any radionuclides that would potentially be released during this period. Closure of the facility would include the installation of additional engineered barriers and an earthen cover. The cover further isolates the waste by diverting water off of the facility to minimize the amount of water that could infiltrate. The leaching of radionuclides and their subsequent release to the groundwater 
system is expected to be minimal, as the engineered barriers would not begin to degrade until hundreds of years after closure. The safety analysis submitted to the regulator would demonstrate that the facility would meet the post-closure performance objectives established at 10 CFR Part 61 or an equivalent state regulation.

Mitigation activities could be implemented such as directing runoff to a permanent infiltration pond where it would not leave the site as surface flow. Erosion and sedimentation impacts are expected to be minimal. Discharge of stormwater during construction and/or operations would also have to meet applicable water quality regulations.

In accordance with 10 CFR 61.50, LLW disposal facilities must be sited in locations that are generally well drained and must not be sited in a 100-year floodplain, a coastal high-hazard area, or a wetland. Upstream drainage must be minimized to decrease the amount of runoff that could erode or inundate disposal units.

Socioeconomic Impacts: Impacts to the socioeconomic environment in communities in the vicinity of any LLW disposal facility would occur. Employment, population, economic measures, housing, and public services could all be affected by construction and operation. Peak employment during the construction and operation phase would likely be several hundred workers. The specific impacts of workers would depend on the site-specific location of any LLW disposal facility.

Human Health: Occupational and public health and safety impacts would result from routine operations: 1) to workers from hazards that are common to similar industrial settings and excavation operations, such as falling or tripping (referred to as industrial hazards); 2) to workers as a result of radiation exposure during their work activities; and 3) to the public from airborne releases of radionuclides.

Workers would be subject to industrial hazards during construction and operation. Examples of the types of industrial hazards that could present themselves include tripping, being cut on equipment or material, dropping heavy objects, and catching clothing in moving machine parts. Most impacts would result from waste handling during the operations period and industrial hazards encountered during facility construction and closure. Based on previous experience, adverse occupational impacts are expected to be low (WSDH 2004).

Workers and the public would also be subject to radiological impacts. The general population must be protected from releases of radioactivity. Concentrations of any radioactive materials released from the facility into groundwater, surface water, air, soil, plants, or animals must not result in an annual dose exceeding the equivalent of $25 \mathrm{mrem}$ to the whole body, $75 \mathrm{mrem}$ to the thyroid, and 25 mrem to any other organ to any member of the public (10 CFR Part 61). Annual occupational dose limits are established as the more limiting of 5 rem total effective dose equivalent or the sum of deep dose equivalent and the committed dose equivalent to any individual organ or tissue other than the lens of the eye being equal of $50 \mathrm{rem}$. The annual limit to the lens of the eye is $15 \mathrm{rem}$ and to the skin is 50 rem (10 CFR 20.1201). Radiological doses are expected to remain well below these limits. For example, the U.S. Ecology LLW facility has historically been significantly below occupational dose limits (WSDH 2004). 
Facility Accidents: No significant impacts from accidents are expected from LLW disposal facilities. For example, for the U.S. Ecology LLW facility, many potential accidents were analyzed, including extreme weather, volcanic activity, earthquakes, fire, and human-caused accidents. In all scenarios, no significant impacts were expected (WSDH 2004).

Waste Management: LLW disposal facilities do not generate any significant quantities of wastes.

Transportation: LLW may be packaged for transportation in containers designed to meet NRC and DOT standards. Materials with very low radiation levels may be transported in what the regulations refer to as a "strong, tight container." An example of a strong, tight container is a plywood box secured with steel bands. Materials with higher radiation levels must be shipped in Type A or Type B containers. Type A containers, used to transport most LLW, are typically steel drums or steel boxes. Type B containers, used in transporting waste with high radiation levels, are heavy engineered metal casks (Fentiman et al. 2008). No injuries or deaths have ever been caused by a release from LLW in a transportation accident (NEI 2008). The impacts of transporting future LLW to a waste disposal site is included in Sections 4.2 through 4.7 for each of the domestic programmatic alternatives.

\subsubsection{Impacts of the Advanced Fuel Cycle Initiative}

The AFCI program evolved from DOE's Accelerator Transmutation of Waste (ATW) program, initiated in 1999, which outlined the use of high-powered accelerators for destruction of actinides from spent fuel and conducted research to explore transmutation technology. In 2001, the Advanced Accelerator Applications (AAA) Program was launched which combined ATW with the Accelerator Production of Tritium (APT) program to optimize use of resources. The AAA program was subsequently subsumed by the AFCI program which Congress appropriated funds for beginning in Fiscal Year 2003. Initial activities were directed at potential use of reactor based systems for transmutation, accelerator transmutation focused on a "burning" role to minimize toxicity, and support for Generation IV reactor system fuel cycle development. Section 953 of the Energy Policy Act of 2005 (42 U.S.C. 15801), entitled "Advanced Fuel Cycle Initiative," directed the Secretary of Energy to "conduct an advanced fuel recycling technology research, development, and demonstration program...to evaluate proliferation-resistant fuel recycling and transmutation technologies that minimize environmental and public health and safety impacts as an alternative to aqueous reprocessing technologies deployed as of the date of enactment of this Act in support of evaluation of alternative national strategies for spent nuclear fuel and the Generation IV advanced reactor concepts." With the announcement of the vision for the GNEP Program in February 2006, AFCI efforts were refocused on GNEP technology development needs, with early emphasis applied to advanced separations of LWR SNF and fast reactors for transmutation, followed by studies and research on additional technology options conducted by industry and national laboratories. The AFCI is now the main domestic component of the GNEP Program and includes early planning for the development of U.S. fuel cycle capabilities which may be pursued in support of the GNEP Program. AFCI activities are conducted as part of the existing R\&D mission of DOE's Office of Nuclear Energy and work is generally performed using existing infrastructure capabilities at multiple DOE sites. The program also includes 
international collaborations to support these R\&D efforts. Additional information on AFCI R\&D activities and sites and facilities is provided in Appendix A.

\subsubsection{Current Advanced Fuel Cycle Initiative Capabilities}

As discussed in Chapter 2, Section 2.2, the AFCI program performs research to provide technology options that would enable long-term growth of nuclear power, to improve environmental sustainability, and to improve energy security. Typical AFCI activities consist of data analysis, document preparation, bench scale research projects, and small-scale research and development projects. The initiative relies on a series of existing facilities, located mostly within U.S. national laboratories, including facilities at Argonne National Laboratory (ANL), Idaho National Laboratory (INL), Los Alamos National Laboratory (LANL), Oak Ridge National Laboratory (ORNL), Pacific Northwest National Laboratory (PNNL), Sandia National Laboratories (SNL), and Savannah River National Laboratory (SRNL). Appendix A, Section A.8 discusses the major facilities at these sites used for the AFCI. Laboratories, hot cells, and research reactors are all used in support of the AFCI.

See Appendix A for a more detailed discussion of current AFCI capabilities.

\subsubsection{Environmental Impacts of the Advanced Fuel Cycle Initiative at DOE Sites}

The environmental impacts of AFCI contribute to the environmental baseline for ANL, INL, LANL, ORNL, PNNL, SNL, and SRNL. In general, AFCI operations are relatively small in scale and their impacts do not appreciably add to overall impacts from normal DOE Site operations. AFCI operations use existing infrastructure, contribute to waste generation, and cause personnel exposures and human health impacts at all sites where these activities occur. The following is a summary of the compilation of environmental impacts at all of the AFCI facilities:

Land and Visual Resources: Because AFCI projects are hosted in existing facilities, AFCI activities do not impact land resources or change the visual landscape.

Air Resources: The majority of the multi-purpose facilities utilized by the AFCI program are large laboratory or nuclear materials production facilities which have controlled air ventilation systems. Radiological air quality impacts (radiation doses) could occur from airborne releases of radionuclides caused by normal operations and accidents. All of these facilities are monitored for air releases and regulated through permit systems. All multipurpose facilities hosting AFCI operations are in compliance with their regulatory emissions limits, which are reported to the public, on an annual basis, in the Annual Site Environmental Reports.

Water Resources: None of the activities conducted in support of the AFCI program are large users of water. For the most part, water use is limited to the personal consumption and sanitary needs of the workers. Since the number of workers is small in relation to other DOE programs, water consumption is small and not a factor in the total water consumption at the DOE facilities where AFCI projects are conducted. 
Socioeconomic Impacts: Because the number of workers involved in AFCI program is small, the socioeconomic impacts attributable to the operation of the AFCI program are small. AFCI employees account for a small percentage (less than 10 percent) of the total workers at each of the DOE sites. Employment, population, economic measures, housing, and public services are not adversely affected by the operation of the AFCI Program and it is not expected that continued operation would place unreasonable demands upon these resource areas.

Human Health: Occupational and public health and safety impacts result from routine operations in support of the AFCI Program: 1) to workers from hazards that are common to similar industrial settings, such as falling or tripping (referred to as industrial hazards); 2) to workers and the public from naturally occurring radiological materials; 3 ) to workers as a result of radiation exposure during their work activities; and 4) to the public from airborne releases of radionuclides.

Examples of the types of industrial hazards that could present themselves include tripping, being cut on equipment or material, dropping heavy objects, and catching clothing in moving machine parts. Workers and the public would also have the potential to be subject to radiological impacts. DOE has a strong health and safety program which has been successful in minimizing such accidents. DOE Orders require training, review procedures, assessments and a number of other requirements which have proven successful in giving DOE one of the better industrial safety records.

Estimated radiological doses to workers associated with AFCI activities are generally small, ranging from $0 \mathrm{mrem} / \mathrm{year}$ at ANL and SNL to less than $15 \mathrm{mrem} /$ year at Hanford, INL, LANL, ORNL, and SRNL. Radiological doses to AFCI workers at the specific DOE Sites may be found in Appendix A. Doses to the public from AFCI operations are also small and are included in the overall does to the public as reported in Annual Site Environmental Reports.

Transportation: Radiological materials (such as small fuel specimens) used in support of the AFCI Program are packaged for transportation in specially designed containers to meet stringent NRC and DOT standards. Appendix E presents information on these containers. Because DOE must comply with stringent transportation requirements and the limited quantities of material transported, the impacts of transporting these materials are small, and pose little threat to the public.

Waste Management: Waste generation from operation of the AFCI program is small. The estimated quantities of waste generated at each of the AFCI facilities in support of the AFCI Program are included in Appendix A. None of the AFCI activities at these multi-program facilities generate a significant amount of waste in relation to the total waste generated by the other activities at these DOE sites. The types of wastes which are generated are similar to the wastes generated by other DOE programs, in much greater quantities, and can readily be handled by existing waste management resources both at the DOE sites and at near-by commercial waste management facilities. 


\subsubsection{Environmental Impacts of the Advanced Fuel Cycle Initiative at Non-DOE Sites}

AFCI is also supported by a University Research Program. The University Research Alliance, located in Canyon, TX and sponsored by Texas A\&M University, manages a fellowship program of more than 40 students. Students and faculty at the University of Nevada-Las Vegas transmutation research program have been directly involved in collaborative research supporting the broader AFCI transmutation research effort for a number of years. During the 2004 to 2005 academic year, 23 faculty-supervised graduate student projects performed research in collaboration with the AFCI transmutation program utilizing 42 graduate students in 5 academic departments. The Idaho Accelerator Center at Idaho State University also provides research facilities for the AFCI program.

International collaborations are also an important component of the AFCI program and include joint research programs with facilities in Switzerland, Japan, and France. The United States no longer has an operating fast reactor. DOE is exploring options with Japan and France that would allow transmutation test fuels to be irradiated in fast reactors now operating in those countries.

In the future, AFCI plans include developing more types of fuels and irradiating these fuels in fast reactors, as well as test reactors at the national laboratories, and potentially in foreign reactors. Wastes generated from these activities would be of the same categories as those wastes DOE currently manages. Such wastes would continue to be managed by DOE in the same manner as its other wastes.

\subsubsection{Greenhouse Gas Emissions Associated with Electricity Generation}

This section presents the potential reductions in emissions of carbon dioxide $\left(\mathrm{CO}_{2}\right)$, which is a major greenhouse gas, which would be associated with displacing approximately $100 \mathrm{GWe}$ of non-nuclear electricity capacity with nuclear generating capacity. Because coal and natural gas plants account for approximately 70 percent of electricity production and are the largest emitters of greenhouse gases in the electricity production sector, the analysis focuses on displacing these two sources. ${ }^{10}$ Renewable energy sources, which do not emit significant quantities of greenhouse gases, are not assessed. Greenhouse gas reductions are presented for two cases: 1) displacing $100 \mathrm{GWe}$ from coal; and 2) displacing $100 \mathrm{GWe}$ from natural gas.

As shown in Table 4.1-4, the typical coal plant would emit approximately 2,000,000 MT of $\mathrm{CO}_{2}$ yearly to produce the same amount of electricity as a typical $1 \mathrm{GWe}$ nuclear plant, assuming no carbon sequestration (EIA 2001). Similarly, the typical natural gas plant would emit approximately $1,000,000 \mathrm{MT}$ of $\mathrm{CO}_{2}$ yearly to produce the same amount of electricity as a typical 1 GWe nuclear plant (EIA 2001).

\footnotetext{
${ }^{10}$ For non-nuclear market shares, coal is approximately 62 percent, natural gas is approximately 24 percent, renewable sources are approximately 10 percent, and other fuels are approximately 4 percent.
} 


\section{TABLE 4.1-4-Annual Carbon Dioxide Emissions Displaced by 1,000 Megawatts Electric Nuclear Plant Operating at 90 Percent Capacity Factor

\begin{tabular}{lc}
\hline Alternative Fuel & Carbon Dioxide Displaced (Metric Tons) \\
\hline Coal & $2,098,580$ \\
Natural Gas & $1,041,401$ \\
\hline Source: EIA 2001
\end{tabular}

U.S. carbon dioxide emissions in 2006 were approximately 5,935 million MT, which was 110 million MT below the 2005 level of 6,045 million MT. ${ }^{11}$ Carbon dioxide emissions in 2006 from power generation were approximately 2,344 million MT. Approximately 83 percent (1,938 million MT) was due to electricity generation from coal and 15 percent (340 million MT) was due to electricity generation from natural gas. By displacing approximately $100 \mathrm{GWe}$ of coal burning plants with nuclear, approximately 200 million MT of $\mathrm{CO}_{2}$ would not be emitted to the air. This would reduce $\mathrm{CO}_{2}$ emissions by 8.5 percent compared to the 2,344 million MT emitted by electric utilities in 2006. Compared to the total U.S. $\mathrm{CO}_{2}$ emissions from all sources (5,935 million MT in 2006), $\mathrm{CO}_{2}$ emissions would be reduced by approximately 3.4 percent (EIA 20071).

By displacing approximately $100 \mathrm{GWe}$ of natural gas burning plants with nuclear power plants, approximately 100 million MT of $\mathrm{CO}_{2}$ would not be emitted into the air. This would reduce $\mathrm{CO}_{2}$ emissions by 4.2 percent compared to the 2,344 million MT emitted by electric utilities in 2006. Compared to the total U.S. $\mathrm{CO}_{2}$ emissions from all sources (5,935 million MT in 2006), $\mathrm{CO}_{2}$ emissions would be reduced by approximately 1.7 percent (EIA 20071).

\subsection{No ACtion Alternative-EXisting ONCE-Through UraniUm Fuel CYCLE}

The No Action Alternative is described in Chapter 2, Section 2.2. Under the No Action Alternative, the United States would continue to rely on a once-through uranium fuel cycle. The Yucca Mountain repository would dispose of 63,000 MTHM of commercial SNF and 7,000 MTHM of DOE SNF and HLW. DOE estimates that the Yucca Mountain statutory capacity limit will be reached by approximately 2010. Quantities of commercial SNF generated beyond 63,000 MTHM would be stored at commercial LWR sites until they can be disposed of in a geologic repository. Based on the 1.3 percent growth rate assessed, nuclear electricity capacity would grow to approximately $200 \mathrm{GWe}$ under the No Action Alternative by about 2060-2070.

This PEIS presents the environmental impacts of the No Action Alternative as follows:

- SNF generated beyond the Yucca Mountain statutory limit: This PEIS assesses the impacts of interim SNF storage at commercial reactor sites, as well as the impacts of transporting the SNF to a geologic repository. These impacts are presented in Section 4.2.1.1 and Section 4.2.1.2, respectively.

- Nuclear electricity generation from 2010 to approximately 2060-2070: The environmental impacts of constructing and operating commercial LWRs with a capacity

\footnotetext{
${ }^{11}$ Total U.S. greenhouse gas emissions in 2006 were approximately 1.5 percent below the 2005 total — the first annual drop since 2001 and only the third since 1990. This decrease was attributed to favorable weather conditions; higher energy prices; a decline in the carbon intensity of electric power generation that resulted from increased use of natural gas and greater reliance on non-fossil energy sources (EIA 20071).
} 
of $200 \mathrm{GWe}$ is presented in Section 4.2.2. This analysis includes the replacement of approximately $100 \mathrm{GWe}$ in capacity from existing LWRs that reach end-of-life, and the construction and operation of approximately $100 \mathrm{GWe}$ of capacity in new advanced light water reactors (ALWRs).

\subsubsection{Spent Nuclear Fuel Generated Beyond the Yucca Mountain Statutory Limit}

Under the No Action Alternative, quantities of commercial SNF generated beyond 63,000 MTHM would be stored at commercial LWR sites until they can be disposed of in a geologic repository. Under the No Action Alternative, nuclear electricity capacity would increase from approximately $100 \mathrm{GWe}$ in 2010 to approximately $200 \mathrm{GWe}$ in 2060-2070. Over this time period, this would be equivalent to constructing approximately $100 \mathrm{GWe}$ of new capacity, as well as replacing the existing $100 \mathrm{GWe}$ of LWR capacity with new advanced LWRs. The amount of SNF generated by these plants, which would be a function of the amount of electricity produced and the burnup of the fuel (assumed to be approximately 51 gigawatt-days per metric ton of heavy metal (GWd/MTHM), would be approximately 158,000 MTHM. ${ }^{12}$ Interim storage of approximately 158,000 MTHM of SNF represents more than twice the storage that is currently required for SNF destined for Yucca Mountain. The PEIS assesses such interim storage and presents the impacts of transporting this SNF to a geologic repository.

\subsubsection{Interim Spent Nuclear Fuel Storage}

Most commercial reactor operators currently store their SNF in water-filled basins (fuel pools) at the reactor sites. Because of inadequate pool storage space, some commercial sites have built what are called independent spent fuel storage installations, in which they store dry SNF above ground in metal casks or in welded canisters inside reinforced concrete storage modules. The canisters use an inert gas, such as helium, to reduce corrosion rates and extend the lifetime of the canisters. Other commercial sites plan to build independent SNF storage installations so they can proceed with the decommissioning of their nuclear plants and termination of their operating licenses (e.g., the Rancho Seco plant in California and the Trojan plant in Oregon).

The No Action Alternative assumes that the commercial nuclear power industry would continue to manage SNF onsite. Dry storage is expected to be used for SNF at commercial sites for the following reasons:

- Dry storage is a safe, economical method of storage.

- $\quad$ Fuel rods in dry storage are likely to be environmentally secure for long periods.

- $\quad$ Dry storage generates minimal, if any, LLW.

- $\quad$ Dry storage units are simpler and easier to maintain (NRC 1996).

\footnotetext{
${ }^{12}$ Calculation of SNF generated assumes the first new LWR is added in 2015, and other LWRs are added over the 2015 to $2060-2070$ time period to achieve a capacity of $200 \mathrm{GWe}$. Existing LWRs are assumed to be replaced as they reach end-of-life (assuming approximately 60 years of operation for all LWRs, regardless of current license expiration date) between 2020 and 2060-2070. This PEIS assesses widespread implementation of the alternatives until approximately 2060-2070. The PEIS acknowledges that any decisions made based on this PEIS could result in actions/impacts beyond this time period. Because of the existing statutory limit for the Yucca Mountain repository (i.e., the repository has a statutory capacity of 70,000 MTHM of SNF and HLW), this PEIS focuses on SNF in excess of this amount.
} 
Accordingly, this PEIS assumes that all commercial SNF would be stored in dry configurations in concrete storage modules on a concrete pad at the ground surface (see Figure 4.2-1). The design of the canister and concrete storage modules would enable outside air to circulate and remove the heat of radioactive decay. For purposes of analysis, the PEIS analyzes the potential impacts of long-term storage with institutional controls followed by transportation to and emplacement in a geologic repository.

The combination of the dry storage canister and the concrete storage module would provide safe storage of SNF as long as the fuel and storage facilities were maintained properly. The reinforced concrete storage module would provide shielding against the radiation emitted by the SNF. In addition, the concrete storage module would provide protection from damage resulting from accidents such as aircraft crashes, from natural hazard phenomena such as earthquakes or tornadoes, and from malevolent acts (NRC 1996).

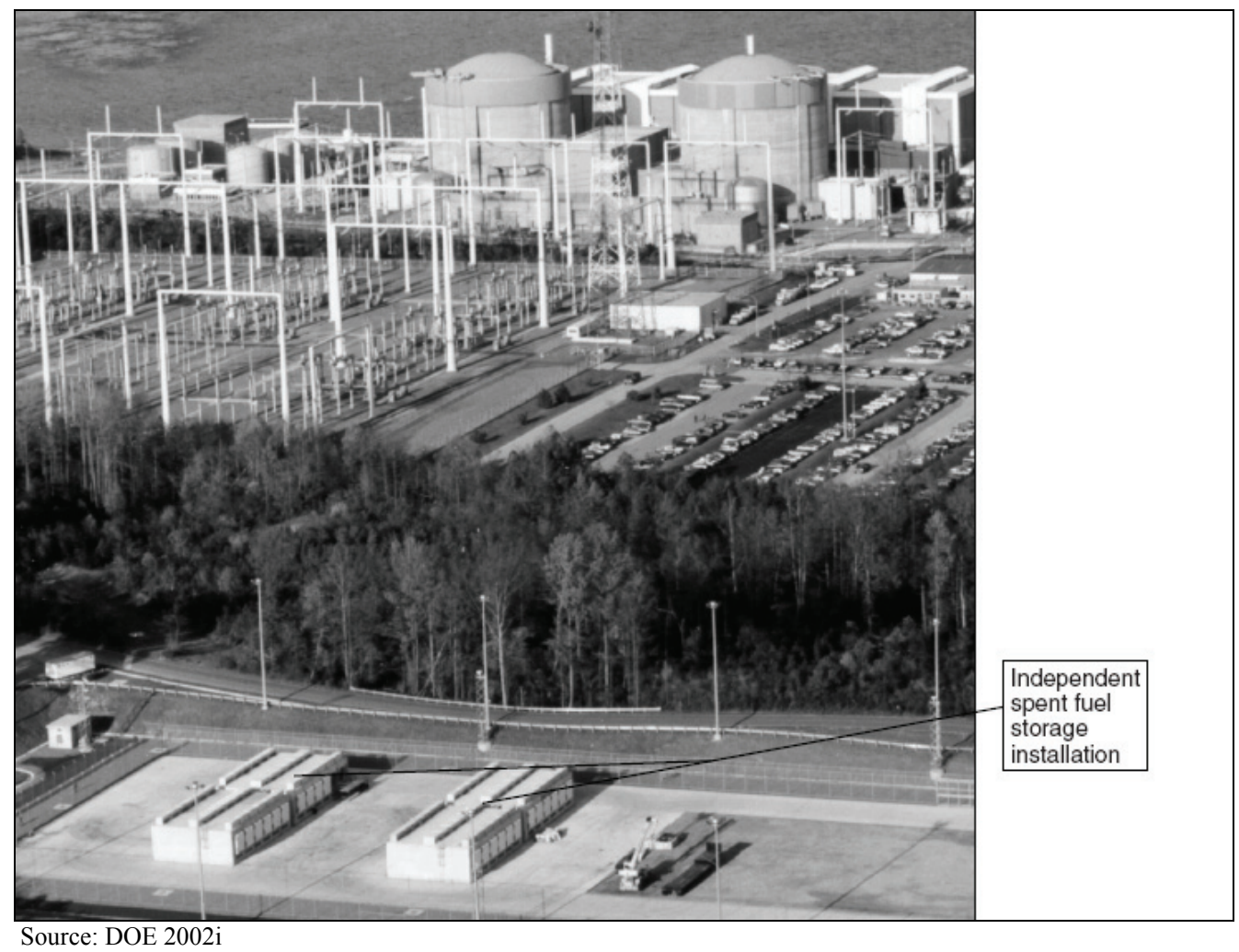

FIGURE 4.2-1-Dry Spent Nuclear Fuel Storage Modules on a Concrete Pad

Release of contaminants to the ground, air, or water would not be expected during routine operations of a spent nuclear fuel dry storage facility (NRC 1996). The results of the analysis described in this section are consistent with the NRC's findings in its Generic Environmental Impact Statement for License Renewal of Nuclear Plants (NRC 1996). The NRC stated:

The Commission's regulatory requirements and the experience with onsite storage of spent fuel in fuel pools and dry storage has been reviewed. Within the context of a license renewal review and determination, the Commission finds that there is ample basis to conclude that continued storage of existing spent fuel and 
storage of spent fuel generated during the license renewal period can be accomplished safely and without significant environmental impacts. Radiological impacts will be well within regulatory limits; thus radiological impacts of onsite storage meet the standard for a conclusion of small impact. The nonradiological environmental impacts have been shown to be not significant; thus they are classified as small. The overall conclusion for onsite storage of spent fuel during the term of a renewed license is that the environmental impacts will be small for each plant. The need for the consideration of mitigation alternatives within the context of renewal of a power reactor license has been considered, and the Commission concludes that its regulatory requirements already in place provide adequate mitigation incentives for onsite storage of spent fuel.

The land required for dry storage facilities is typically a few acres at each reactor site. These storage facilities would be on land currently owned by a utility and, therefore, would be unlikely to affect land ownership. SNF storage requirements for 158,000 MTHM would increase land usage associated with storage by about 200 percent over current storage requirements. Impacts to aesthetic or scenic resources from storage facilities would be unlikely. Further, as SNF begins to be disposed of in a geologic repository, additional storage space would become available.

Best management practices and effective monitoring procedures would ensure that contaminant releases to the air would be minimal and would not exceed current regulatory limits (40 CFR Part 61 for hazardous air pollutants emissions and Part 50 for air quality standards). Therefore, air quality would not be adversely affected during routine operations. Under long-term institutional control ${ }^{13}$, best management practices such as stormwater pollution prevention plans and stormwater holding ponds would ensure that, in the unlikely event of an inadvertent release, contaminants would not reach surface-water systems. Therefore, surface-water quality would not be adversely affected by routine operations.

Under long-term institutional control, impacts to biological resources or soils would be minimal. The facilities necessary to store SNF would be fenced to keep wildlife out. In addition, spills would be contained and cleaned up immediately, thus minimizing the area of soil affected and the likelihood of any groundwater contamination.

The size of the additional facilities and supporting infrastructure would be small enough to probably avoid known cultural resources. In addition, if previously unknown archaeological sites were uncovered during construction, the commercial utility would comply with Executive Orders and Federal and state regulations for the protection of cultural resources. Thus, construction and operations should not significantly affect cultural resources.

Routine repairs and maintenance of the facilities and storage containers, routine radiological surveys, and overpacking of failed containers would generate sanitary waste, industrial solid waste, and LLW. Because there would not be a large, dedicated workforce at the storage facilities, only small amounts of sanitary wastes, from the guard force and maintenance workers would be generated, except during periods of construction.

${ }^{13}$ In the context of a on-site SNF storage, long-term institutional control is generally considered to be 100 years. 
With respect to employees required to safely manage SNF, the total staff required at existing commercial sites and any new commercial sites would increase from about 700 for the existing inventory of SNF to approximately 2,100 for the storage of 158,000 MTHM (derived from DOE 2002i). ${ }^{14}$ This increase would be approximately equivalent to adding no more than six individuals at each of the existing sites, and staffing the new commercial sites with an equivalent complement of employees to manage their SNF. Additional storage requirements would be unlikely to have a significant effect on socioeconomic factors such as infrastructure and regional economy.

During the approximately 50 years of operation, about 105,000 full-time equivalent work years would be required to maintain the SNF storage facilities at the commercial reactor sites and new reactor sites (derived from DOE 2002i). Radiation exposures to offsite populations, involved workers, and noninvolved workers would increase because of the construction of additional facilities required to store the SNF. The analysis assumes that radiation exposures would increase proportionately by the increase in SNF stored. Table 4.2-1 presents the radiological human health impacts resulting from storing an accumulation of 158,000 MTHM over approximately 50 years. The analysis assumes that the LWR SNF would be stored among the different reactors sites rather than consolidated at a single storage site.

As shown in Table 4.2-1, the estimated dose to the hypothetical Maximally Exposed Individual (MEI) would be about $0.34 \mathrm{mrem} / \mathrm{yr}$. During the approximate 50 years of operation, this dose could result in an increase in the lifetime risk of contracting fatal cancer by 0.01 (statistically, there would be a 1 chance in 98 of an LCF). For the short-term impacts, the offsite exposed population would be likely to receive a total collective dose of 2,100 person-rem. This dose could result in $1.2 \mathrm{LCFs}$.

\section{Maximally Exposed Individual (MEI)}

A hypothetical member of the public at a fixed location who, over an entire year, receives the maximum effective dose equivalent (summed over all pathways) from a given source of radionuclide releases to air.

The analysis assumes the MEI in the involved worker populations would be a worker involved with construction and loading of replacement facilities. Assuming a maximum dose rate of $0.11 \mathrm{mrem} /$ hour and an average exposure time of 1,500 hours/yr, this worker would receive about $170 \mathrm{mrem} / \mathrm{yr}$. During the 50 years, this dose could result in an increase in the lifetime risk of contracting a fatal cancer by $2.0 \times 10^{-5}$, an increase of 0.09 percent over the natural fatal cancer incidence rate. ${ }^{15}$

In the involved worker populations (approximately 2,100 storage facility workers over 50 years), the collective dose over 50 years would be 7,050 person-rem, which would result in an estimated increase of approximately 4.2 LCFs. The non-involved workforces would receive a total dose of approximately 120,000 person-rem over 50 years of operation, which would result in an estimated increase of approximately 72 LCFs.

\footnotetext{
${ }^{14}$ Assumes increases in employment would be linear relative to increases in the mass of SNF to be stored.

${ }^{15}$ Analysis is presented for one worker over a 50-year exposure period. For two workers (one the first 25 years and a second the next 25 years), each worker's risk would be half the total risk; the total risk for the two workers would be the same as for a single worker over a 50-year exposure period.
} 
TABLE 4.2-1—Cumulative Radiological Impacts for Storing 158,000 Metric Tons Heavy Metal of Spent Nuclear Fuel

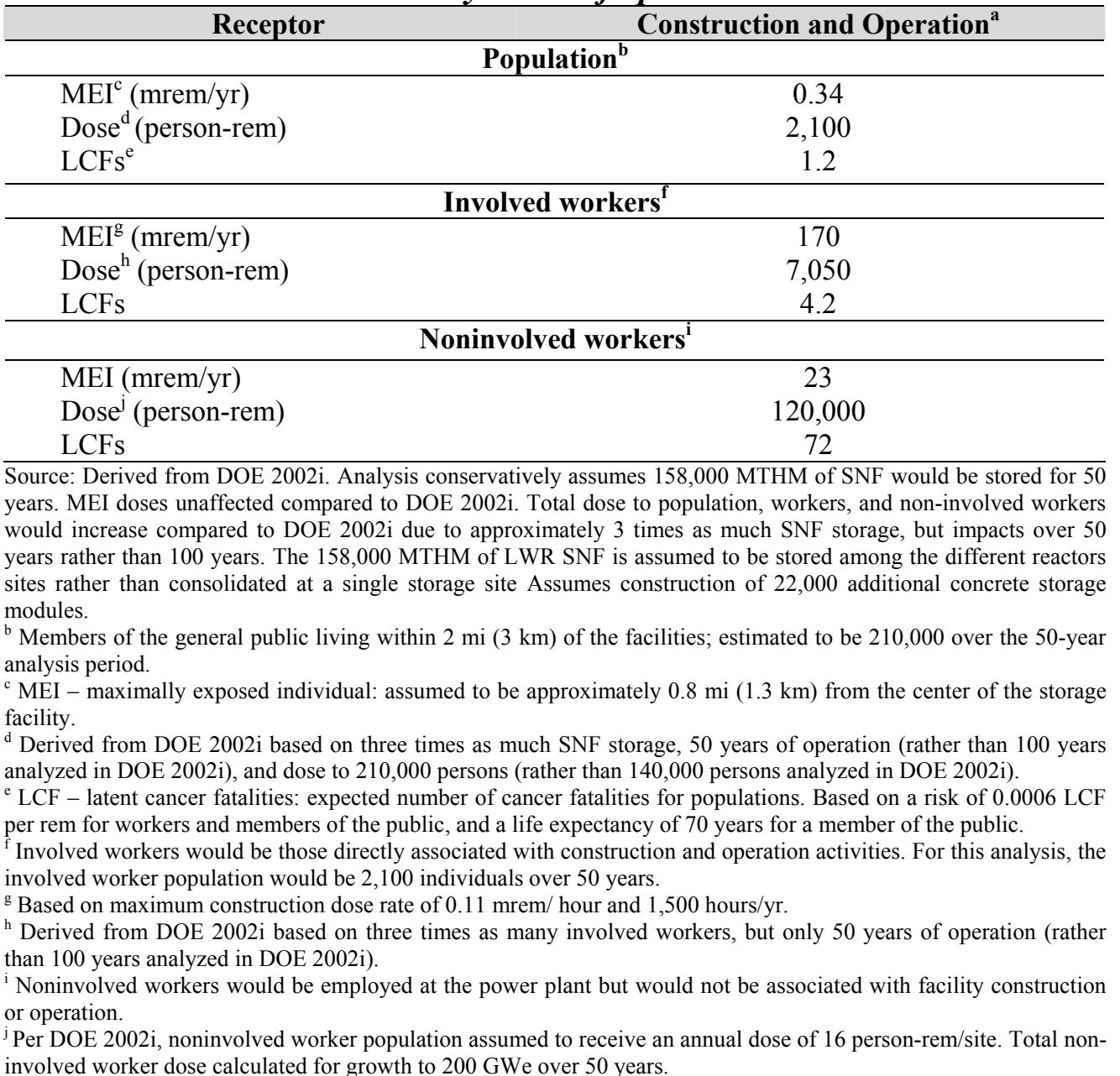

The accident scenarios consider drops and collisions involving shipping casks, bare fuel assemblies, low-level radioactive waste drums, and the waste package transporter. The maximum reasonably foreseeable accident (i.e., a credible accident scenario with the highest foreseeable consequences) was determined to be a beyond-design-basis seismic event. For this accident, using unfavorable weather conditions, the impacts to the MEI would be 38 mrem (NRC 1996).

With respect to externally initiated events, the National Academy of Sciences (NAS) released a report in April 2005 that found that "successful terrorist attacks on SNF pools, though difficult, are possible," and that "if an attack leads to a propagating zirconium cladding fire, it could result in the release of large amounts of radioactive material"(NAP 2005). NAS recommended that the hottest SNF be interspersed with cooler SNF to reduce the likelihood of fire, and that water-spray systems be installed to cool SNF if pool water were lost. The report also called for NRC to conduct more analysis of the issue and consider earlier movement of SNF from pools into dry storage (NAP 2005). The potential impacts of an airplane crash into a SNF storage pool were considered in the Yucca Mountain SEIS but eliminated from detailed study because the pool water would limit the potential for a fire to affect the fuel directly and would limit releases from damaged fuel assemblies (DOE 2008f). 
With respect to dry storage facilities, such analysis has been performed by the NRC in a supplemental environmental assessment that was prepared in 2007 for the Diablo Canyon spent fuel storage facility (NRC 2007q). That assessment concludes that the probability of a successful terrorist attack resulting in a significant radiation release is very low. This conclusion is based on the NRC's continual evaluation of the threat environment and coordination with other Federal, state and local agencies; protective measures currently in place that reduce the chances of any terrorist attack being successful; the robust design of dry cask storage systems, which provide substantial resistance to penetration; and NRC's security assessments of potential consequences of terrorist attacks at these facilities (NRC 2007q).

Although the NRC concludes the likelihood of a terrorist attack on the facility resulting in a substantial radiological release is very low, the supplement describes the potential impacts of such an event at Diablo Canyon. It concludes that any radiation dose to members of the public near the plant from a successful terrorist attack on the facility would likely be well below $5 \mathrm{rem}^{16}$, even in the most severe plausible threat scenarios. In many scenarios, the hypothetical dose could be substantially less than 5 rem, or none at all (NRC 2007q).

\subsubsection{Transporting Future Spent Nuclear Fuel to a Geologic Repository}

Once generated at a commercial reactor, SNF would eventually need to be transported to a geologic repository for disposal under the No Action Alternative. The environmental impacts of transporting future SNF from commercial sites to a geologic repository were estimated using the methodology described in Appendix E. Because it is unknown whether future SNF would be transported via rail or truck, the PEIS assesses both means of transport. Table 4.2-2 presents the number of radiological shipments (broken down by material to be transported) that would be required for the No Action Alternative for: 1) all truck and 2) a combination of truck and rail. Because all shipments of fresh nuclear fuel are assumed to occur via truck transport, there is no transportation scenario in which all transportation would occur via rail only. Consequently, the PEIS presents transportation impacts for a combined truck and rail scenario (in tables this scenario is designated as "truck/rail").

TABLE 4.2-2-Total Number of Radiological Shipments for 50 Years of Implementation, No Action Alternative

\begin{tabular}{lcc}
\hline Material/Waste & $\begin{array}{c}\text { Truck Transport } \\
\text { (Number of } \\
\text { Shipments) }\end{array}$ & $\begin{array}{c}\text { Truck/Rail } \\
\text { Transport (Number } \\
\text { of Shipments) }\end{array}$ \\
\hline Fresh LWR fuel & 26,300 & $26,300^{\mathrm{a}}$ \\
\hline LWR SNF & 79,000 & 6,300 \\
GTCC LLW & 3,200 & 630 \\
LLW & 19,000 & 3,800 \\
\hline
\end{tabular}

Source: Appendix E

${ }^{a}$ All shipment of fresh nuclear fuel is assumed to be via truck transport.

The results of the transportation analysis are presented in two sets of tables. The first set of tables (Tables 4.2-3 and 4.2-4) present the impacts associated with handling (loading and inspection) radiological material for the $200 \mathrm{GWe}$ scenario. Impacts are presented in terms of radiological

${ }^{16}$ Five rem is the maximum annual occupational dose limit for workers in the nuclear industry and the regulatory dose limit for persons outside the boundary of a spent fuel storage facility to receive from accidents (NRC 2007q). 
impacts (expressed in person-rem and converted to LCFs using a dose-to-risk conversion factor of $6 \times 10^{-4}$ LCF per person-rem). Table $4.2-3$ presents the handling impacts for truck transport and Table 4.2-4 presents the handling impacts for combined truck and rail transport. Handling operations (loadings and inspections) would not affect the public.

The impacts of handling radiological materials are independent of the distance that the material would be transported. As such, the handling impacts would be the same whether the material is transported, for example, $500 \mathrm{mi}(805 \mathrm{~km}), 2,100 \mathrm{mi}(3,380 \mathrm{~km})$, or any other distance. For this reason, these impacts are presented separately from the in-transit impacts (which are presented in the second set of tables).

TABLE 4.2-3-Handling Impacts for 50 Years of Implementation, No Action Alternative (Truck Transit)—200 Gigawatts Electric

\begin{tabular}{ccc|cc|cc}
\hline & \multicolumn{3}{c}{ Laading } & \multicolumn{2}{c}{ Inspection } & \multicolumn{2}{c}{ Total } \\
\cline { 2 - 7 } & person-rem & LCFs & person-rem & LCFs & person-rem & LCFs \\
\hline No Action & 36,700 & 22 & 6,430 & 4 & 43,200 & 26 \\
\hline
\end{tabular}

Source: Appendix E

Note: All LCFs rounded to nearest whole number.

TABLE 4.2-4-Handling Impacts for 50 Years of Implementation, No Action Alternative (Truck and Rail Transit)-200 Gigawatts Electric

\begin{tabular}{|c|c|c|c|c|c|c|}
\hline & \multicolumn{6}{|c|}{ Handling Impacts } \\
\hline & \multicolumn{2}{|c|}{ Loading } & \multicolumn{2}{|c|}{ Inspection } & \multicolumn{2}{|c|}{ Total } \\
\hline & person-rem & LCFs & person-rem & LCFs & person-rem & LCFs \\
\hline No Action & 22,800 & 14 & 647 & 0 & 23,400 & 14 \\
\hline
\end{tabular}

The in-transit impacts are shown in Tables 4.2-5 (truck transit) and 4.2-6 (truck and rail transit). These impact estimates would vary based on a variety of factors, including the distance that the radiological material would be transported, the specific routes that would be utilized, the population densities along those routes, and others. Of these factors, transport distance is the most significant. Because the locations of future reactors and future disposal facilities are unknown, DOE analyzed transportation impacts over five distances: $150 \mathrm{mi}(241 \mathrm{~km}), 500 \mathrm{mi}$ $(805 \mathrm{~km}), 1,500 \mathrm{mi}(2,414 \mathrm{~km}), 2,100 \mathrm{mi}(3,380 \mathrm{~km})$, and 3,000 $\mathrm{mi}(4,828 \mathrm{~km})$. In-transit impacts presented in Tables 4.2-5 and 4.2-6 are based on 2,100 mi (3,380 km) of transport. This distance was selected as a reference distance because it represents the average distance for all SNF shipments analyzed in the Yucca Mountain FEIS (DOE 2002i). Impacts associated with the other four distances are presented, on a per shipment basis, in Appendix E, which describes the transportation methodology and assumptions. Although the in-transit impacts are not exactly "linear" (i.e., twice the impacts for twice the distance transported), that is a close approximation. Consequently, if the radiological material were transported $500 \mathrm{mi}(805 \mathrm{~km})$, all of the in-transit impacts presented in Tables 4.2-5 and 4.2-6 could be estimated by multiplying the values in those tables by $0.24(500 / 2,100)$. 
TABLE 4.2-5-In-Transit Transportation Impacts for 50 Years of Implementation, No Action Alternative (Truck Transit) -200 Gigawatts Electric

\begin{tabular}{|c|c|c|c|c|c|c|c|c|}
\hline & \multicolumn{4}{|c|}{ In Transit Impacts } & \multirow{3}{*}{$\begin{array}{c}\text { Total } \\
\text { Incident- } \\
\text { Free } \\
\text { LCFs } \\
\end{array}$} & \multirow{2}{*}{\multicolumn{3}{|c|}{ Accident Impacts }} \\
\hline & \multicolumn{2}{|c|}{ Crew } & \multicolumn{2}{|c|}{ Public } & & & & \\
\hline & $\begin{array}{c}\text { person- } \\
\text { rem }\end{array}$ & LCFs & $\begin{array}{c}\text { person- } \\
\text { rem }\end{array}$ & LCFs & & $\begin{array}{l}\text { person- } \\
\text { rem }\end{array}$ & LCFs & $\begin{array}{l}\text { Collision } \\
\text { Fatalities }\end{array}$ \\
\hline $\begin{array}{l}\text { No } \\
\text { Action }\end{array}$ & 14,900 & 9 & 71,300 & 42 & 52 & 1.37 & 0 & 11 \\
\hline
\end{tabular}

Source: Appendix E

Note: All LCFs rounded to nearest whole number.

TABLE 4.2-6-In-Transit Transportation Impacts for 50 Years of Implementation, No Action Alternative (Truck and Rail Transit)-200 Gigawatts Electric

\begin{tabular}{|c|c|c|c|c|c|c|c|c|}
\hline & \multicolumn{4}{|c|}{ In Transit Impacts } & \multirow{3}{*}{$\begin{array}{c}\text { Total } \\
\text { Incident- } \\
\text { Free } \\
\text { LCFs }\end{array}$} & \multirow{2}{*}{\multicolumn{3}{|c|}{ Accident Impacts }} \\
\hline & \multicolumn{2}{|c|}{ Crew } & \multicolumn{2}{|c|}{ Public } & & & & \\
\hline & $\begin{array}{c}\text { person- } \\
\text { rem }\end{array}$ & LCFs & $\begin{array}{c}\text { person- } \\
\text { rem }\end{array}$ & LCFs & & $\begin{array}{c}\text { person- } \\
\text { rem }\end{array}$ & LCFs & $\begin{array}{c}\text { Collision } \\
\text { Fatalities }\end{array}$ \\
\hline $\begin{array}{l}\text { No } \\
\text { Action }\end{array}$ & 456 & 0 & 1,430 & 1 & 1 & 0.0828 & 0 & 3 \\
\hline
\end{tabular}

Source: Appendix E

Note: All LCFs rounded to nearest whole number.

There are potentially significant differences in impacts depending upon whether transportation occurs via truck or a combination of truck and rail. For all alternatives, truck and rail transport would result in smaller impacts than truck transport. This is due to the fact that there would be many fewer transportation shipments for truck and rail compared to truck only. This would directly affect the distance traveled and exposures to both crews and the public. Additionally, the number of accident fatalities (collisions) would be smaller for the truck and rail transport.

\subsubsection{Construction and Operation of New Nuclear Electricity Capacity from 2010 to Approximately 2060-2070}

This section discusses the environmental impacts of constructing and operating approximately 200 GWe of commercial LWR capacity, including the construction and operation of approximately $100 \mathrm{GWe}$ of new ALWR capacity and the replacement of approximately $100 \mathrm{GWe}$ of capacity once existing LWRs reach their end-of-life. ${ }^{17}$ Because the environmental impacts of constructing and operating $200 \mathrm{GWe}$ of reactor capacity cannot be estimated with precision, without knowing the location of these reactors, that analysis is limited. Nonetheless, at a national level, the impacts can be estimated.

Construction: Completing construction of up to $200 \mathrm{GWe}$ of new and replacement LWR capacity over a minimum 45 -year period ${ }^{18}$ would amount to completion of an average of approximately $4.5 \mathrm{GWe}$ of new LWR (or other reactor types that may be licensed by the NRC) capacity every year. While this would be a significant amount of new construction, on a national level, it would not be unprecedented. In comparable terms, all of the 104 existing commercial LWRs (which represent approximately $100 \mathrm{GWe}$ of capacity) began construction over

\footnotetext{
${ }^{17}$ Appendix A, Section A.8, provides more details regarding the replacement of existing LWRs that reach end-of-life.

${ }^{18}$ Although the period of analysis in this PEIS is generally 2010 to approximately 2060-2070, the construction period is based on an assumption that no new LWRs are expected to be completed prior to about 2015; hence, the minimum 45-year period of construction (2015-2060).
} 
approximately 12 years (1966-1977), and almost every one of these reactors began operations within a 20-year period (1970-1990). ${ }^{19}$ Consequently, constructing up to $200 \mathrm{GWe}$ of new and replacement LWR capacity over a 45 -year period would be similar in scope to the nuclear power construction that took place in the United States in the $20^{\text {th }}$ century.

The 104 existing commercial LWRs are located on 65 commercial sites in 31 states. Many sites contain multiple reactors. Most commercial reactor sites (whether supporting one or more LWRs) are approximately 3,000 acres (1200 ha) in size (NRC 1996). If $200 \mathrm{GWe}$ of new LWR capacity were constructed nationally, it is expected that not more than 600,000 acres ( $243,000 \mathrm{ha})$ of land would be disturbed. Indeed, it is likely that new LWRs would be colocated, to the extent economical and practical, with existing LWRs. Depending on the specific sites, construction activities would disturb land and have the potential to impact stormwater runoff, cause erosion, affect cultural resources, and disturb plant and animal habitats.

Construction impacts would be typical of major projects and would involve similar risks of any large industrial activity. During construction activities, principal nonradiological pollutants such as certain criteria pollutants (nitrogen dioxide, sulfur dioxide, carbon monoxide, and particulate matter) and carbon dioxide could be emitted. Emission of the gases nitrogen dioxide, sulfur dioxide, and carbon monoxide would come primarily from fuel combustion by vehicles, construction equipment, and boilers. Particulate matter would be released mainly as a component of fugitive dust from land and excavation activities, as well as in smaller quantities from fuel combustion.

Socioeconomic impacts would occur in communities in the vicinity of any future LWR. Employment, population, economic measures, housing, and public services could all be affected by construction. Peak construction employment would likely be several thousand workers, and construction duration for a typical LWR would likely span 5 to 10 years.

Workers would be subject to industrial hazards during construction. Examples of the types of industrial hazards that could present themselves include tripping, being cut on equipment or material, dropping heavy objects, and catching clothing in moving machine parts.

Operation: Operation of LWRs would require natural uranium, enriched uranium, fuel fabrication, and affect water resources, impact the visual environment, produce socioeconomic impacts, impact human health and safety, and produce wastes. These topics are addressed below.

Uranium Requirements: The quantity of natural uranium needed to support a capacity of $200 \mathrm{GWe}$, assuming an average enrichment of 4.4 percent, would be approximately $39,200 \mathrm{MT} / \mathrm{yr}$ (see Table 4.8-1). The 39,200 MT of natural uranium would represent approximately the amount of uranium that was mined in the world in 2006 and would be 24 times more than the quantities currently mined in the United States annually (see Table 4.1-1). From this 39,200 MT, approximately 4,340 MT of enriched uranium (assuming 4.4 percent enrichment) would be required annually. Approximately 26 million SWUs would be required annually to support a capacity of $200 \mathrm{GWe}$. The licensed capacity of the enrichment facility at Paducah, the American Centrifuge Plant, and the LES Facility is 17.8 million SWUs.

${ }^{19}$ See http://www.eia.doe.gov/cneaf/nuclear/page/nuc_reactors/operational.xls for more details (EIA 2007j). 
Consequently, enrichment facilities in the United States would need to be expanded by approximately 47 percent or larger quantities of enriched uranium would need to be imported. Additionally, if Paducah shuts down in 2012, the U.S. enrichment capacity would be reduced to approximately 6.8 million SWUs. To support a 200 GWe capacity, enrichment capacities in the United States would need to be expanded by approximately 300 percent or larger quantities of enriched uranium would need to be imported.

Fuel Fabrication Requirements: The United States currently has three operational LWR uranium fuel fabrication facilities with a capacity to produce approximately 3,500 MT of LWR fuel assemblies (Table 4.1-2). The current LWRs require approximately 2,000 MT of fresh LWR fuel assemblies annually. For $200 \mathrm{GWe}$, approximately 4,340 MT of fresh LWR fuel assemblies would need to be produced annually. Consequently, the fuel fabrication facilities in the United States would need to be expanded by approximately 25 percent or fresh LWR fuel assemblies would need to be imported.

Land Resources: Once operational, a total of approximately 600,000 acres (243,000 ha) of land could be occupied by facilities, paved areas, and buffer zones. Most of this area would not be disturbed but would serve as a buffer between the actual facility and the outer facility boundary. The total site area would be determined by accident analyses and regulatory requirements, including safeguards and security.

Visual Resources: With respect to visual characteristics, the visibility of any LWR from publicly accessible locations would be dependent on the future site characteristics. For sites that use "wet" cooling tower systems, the water vapor plume from cooling tower operations may be visible for many miles from the plant.

Air Resources: LWRs generate both nonradiological and radiological emissions. Nonradiological emissions, which are predominantly associated with vehicle emissions and emergency diesel generator testing and operations, are generally small. With respect to radiological emissions, all nuclear power plant operators are required to monitor radioactive airborne emissions from the plant and to file a report of these emissions annually with the NRC with a list of the radioactive isotopes released, the quantity released, and the radiation dose to the public. The concentrations of radionuclides released into the environment from a nuclear facility are generally too low to be measurable outside the plant's boundary (NRC 2008c). The potential impacts to human health are presented in the "Human Health" section below.

Water Resources: Every operating LWR would use significant quantities of water. A typical GWe of LWR capacity requires approximately 3 to 6 billion gal (11 to 23 billion L) of water yearly, mainly for heat dissipation ${ }^{20}$ (EPRI 2002). As a result, most LWRs are located near major sources of water, such as natural lakes, man-made lakes, rivers, or the ocean. Water can also be supplied from groundwater. In arid environments, "dry" cooling towers can be utilized to reduce water requirements. ${ }^{21}$ The heat dissipation system selected would be dependent on site

\footnotetext{
${ }^{20}$ A typical 1 GWe reactor would withdraw 3 to 6 billion gal/yr (11 to 23 billion L/yr) for cooling (using "wet cooling"). Water consumption would be less than 60 million gallons/yr (227 million L/yr).

${ }^{21}$ There are two main types of cooling technology, the air system ("dry cooling") and the wet system. An air-cooled system operates like a very large automobile radiator. These systems use a flow of air to cool water flowing inside finned tubes. It is essentially a closed-loop system where air is passed over large heat exchange surfaces. While air cooling is a reliable and proven technology, it has some technical and economic
} 
characteristics. Although LWRs withdraw large quantities of water from a source body, virtually all of that water is returned to its source at a quality similar to that removed, albeit a bit warmer and sometimes with a trace of residual chlorine. Only a small quantity (about 1 percent) is consumed via increased evaporation to the atmosphere from the warm discharge water plume (EPRI 2002).

Socioeconomic Impacts: Similar to construction, socioeconomic impacts would occur in communities in the vicinity of any future LWR. Although operations would generally employ fewer workers than peak construction, employment, population, economic measures, housing, and public services could all be affected. A typical LWR employs approximately 500 to 1,000 workers.

Human Health: In addition to nonradiological hazards, workers would be subject to radiological hazards, including radiation exposure. In 2006, approximately 116,000 individuals working in commercial nuclear plants in the United States were monitored, and approximately 59,000 received a measurable dose (hereafter, workers who received a measurable dose will be referred to as "radiation workers"). During 2006, these radiation workers incurred a collective dose of approximately 11,000 person-rem; this represents a 4 percent decrease from the 2005 value. The average dose to radiation workers was approximately 190 mrem (NRC 20071). Assuming these doses would be similar for LWRs in the future, the average LWR worker would have a $1.0 \times 10^{-5}$ risk of developing an LCF (a 1 in 9,000 chance of an LCF).

The public would also be subject to radiation exposure, primarily from airborne releases of radionuclides. To estimate radionuclide releases from normal operations, DOE obtained actual radiological emission data from the South Texas Project Electric Generating Station. This generating station operates two of the newest LWRs (operations began in 1988 for Unit 1 and 1989 for Unit 2). In terms of electrical output, these LWRs are also relatively large (more than 1,250 megawatts electric (MWe) each), which provides a measure of conservatism regarding radiological emissions. Because these reactors are relatively new and large, their radiological emissions are assumed to be representative of future LWRs.

DOE developed six hypothetical sites to assess the impacts of various scenarios (see Appendix D, Section D.1.6.1). These sites provide a range of values for two parameters: offsite (50-mi $[80-\mathrm{km}])$ population and meteorological conditions that would directly affect the offsite consequences of any release. The $50-\mathrm{mi}(80-\mathrm{km})$ population has a direct effect on the collective dose received in the area surrounding the site. The environmental concentrations which would result from a hypothetical release depend on the meteorological mechanisms of advection and dispersion that a release would experience as it is transported downwind. An additional parameter, the distance to the site boundary, was also considered as a site differentiator. This distance affects the dose to the MEI. In general, the greater the distance to the site boundary is, the smaller the dose to the MEI will be. There are no current regulatory minimum distances which apply to facility siting. In order to keep the number of permutations of analyzed site conditions reasonable and still represent a range of conditions, this distance was held constant for

drawbacks in comparison to a wet mechanical cooling system, which requires the use of significant amounts of water. The principal drawbacks of air cooling are increased noise levels, higher capital costs, and larger physical dimensions. There are currently no existing LWR facilities in the United States using the "dry cooling system." 
each generic site at $3,020 \mathrm{ft}(920 \mathrm{~m})$ based on the average distance to the site boundary at existing reactors.

Based on modeling results, the impacts from normal operations of future LWRs are shown in Table 4.2-7.

\begin{tabular}{|c|c|c|c|c|}
\hline \multicolumn{5}{|c|}{ LWR $(1,264 \mathrm{MWe})^{\mathrm{a}}$} \\
\hline & $\begin{array}{c}\text { Maximally } \\
\text { Exposed } \\
\text { Individual } \\
\text { (MEI) dose } \\
\text { (mrem/yr) }\end{array}$ & MEI LCFs & $\begin{array}{l}\text { 50-Mile } \\
\text { Population dose } \\
\text { (person-rem/yr) }\end{array}$ & $\begin{array}{l}\text { 50-Mile Population } \\
\text { LCFs }\end{array}$ \\
\hline Site 1 & 0.02 & $1.1 \times 10^{-5}$ & 0.05 & $3.0 \times 10^{-5}$ \\
\hline Site 2 & 0.02 & $1.1 \times 10^{-5}$ & 0.06 & $3.8 \times 10^{-5}$ \\
\hline Site 3 & 0.01 & $8.6 \times 10^{-6}$ & 0.46 & $2.7 \times 10^{-4}$ \\
\hline Site 4 & 0.04 & $2.4 \times 10^{-5}$ & 0.22 & $1.3 \times 10^{-4}$ \\
\hline Site 5 & 0.04 & $2.4 \times 10^{-5}$ & 0.27 & $1.6 \times 10^{-4}$ \\
\hline Site 6 & 0.03 & $2.0 \times 10^{-5}$ & 2.04 & 0.001 \\
\hline
\end{tabular}

As shown in Table 4.2-7, MEI doses for the LWR would be well below the $10 \mathrm{mrem} / \mathrm{yr}$ standard at each of the six hypothetical sites.

Facility Accidents: With respect to accidents, impacts would be dependent on many factors, including the type of accident, site characteristics, and the distribution of population in the surrounding environment; therefore, a traditional accident analysis is not meaningful. Any LWR would need to meet NRC regulatory licensing limits which would limit the dose to the MEI at the site boundary to 25 rem for extremely unlikely events (i.e., those with a frequency between $1 \times 10^{-4} / \mathrm{yr}$ to $1 \times 10^{-6} / \mathrm{yr}$ ) (see $10 \mathrm{CFR} 100.11$ ). It would be expected that any severe accidents may result in the deaths of some involved workers. As a point of reference, however, the accident at the Three Mile Island Unit 2 nuclear power plant near Middletown, PA, on March 28, 1979, was the most serious in U.S. commercial nuclear power plant operating history, ${ }^{22}$ even though it led to no deaths or injuries to plant workers or members of the nearby community (NRC 2007f).

Appendix D presents the impacts for a range of accidents, at a variety of sites, which are expected to be representative of the types of accidents that could occur in existing LWRs and future ALWRs. For the No Action Alternative, it is assumed that LWRs and ALWRs would be fueled with conventional low-enriched uranium (LEU). ${ }^{23}$ This section summarizes the accident impacts associated with LEU fueled LWRs and ALWRs.

\footnotetext{
${ }^{22}$ The catastrophic Chernobyl accident in the former Soviet Union, in 1986, is generally considered the most severe nuclear reactor accident to occur in any country. It is widely believed an accident of that type could not occur in U.S.-designed plants. The NRC evaluated the Chernobyl accident and "concluded that no immediate changes were needed in the NRC's regulations regarding the design or operation of U.S. commercial nuclear reactors as a result of lessons learned from Chernobyl. U.S. reactors have different plant designs, broader shutdown margins, robust containment structures, and operational controls to protect them against the combination of lapses that led to the accident at Chernobyl' (NRC 2007n).

${ }^{23}$ DOE acknowledges that a limited use of mixed-oxide (MOX) fuel, fabricated from surplus plutonium from the defense program, could be used in certain LWRs and ALWRs. Section 4.4 summarizes accident impacts associated with use of MOX-fueled LWRs and ALWRs.
} 
With respect to existing LEU fueled LWRs, the internally initiated accident with the highest consequence to the onsite and offsite populations would be the "Interfacing System Loss of Coolant Accident (Interfacing System LOCA)" scenario (see Appendix D, Section D.2.1 for more information on this accident and others analyzed for the No Action Alternative). Using the dose-to-risk conversion factor of $6 \times 10^{-4} \mathrm{LCF}$ per person-rem, the collective population doses are

\section{Internally, Externally, and Natural Phenomena Initiated Accidents}

This PEIS considers accidents that are internally, externally, and natural phenomena initiated. Internally initiated accidents are associated with a specific reactor design. These accidents could include events like failure of a reactor coolant pump, operator error, or loss of coolant. Externally initiated accidents are location-dependent and could be caused by an event such as an aircraft crash. Natural phenomena are typically location-dependent and include events such as earthquakes and tornadoes. Externally and natural phenomena initiated events are analyzed by the use of consistent release parameters regardless of the reactor design or generic location in order to provide a common basis for comparison.

Externally and natural phenomena initiated accidents, which are described and the results presented in Appendix $\mathrm{D}$, are generally the highest consequence accidents. Externally and natural phenomena accidents have the potential to mask any differences between reactor technologies and are most useful in providing a basis of comparison for core inventory (i.e., ultimate consequences).

estimated to result in 900 to 40,000 additional LCFs in the surrounding population. These consequences are consistent with the results of the NRC's Severe Accident Risks: An Assessment for Five U.S. Nuclear Power Plants, NUREG-1150 (NRC 1990) and the SPD EIS (DOE 1999d) when the high population and unfavorable meteorology are considered. The higher consequences for this accident are not the result of differences in the fuels relative to other reactors, but are instead the result of the use of high release parameters and an assumption that all containment and filter systems would fail. For the MEI, this scenario would result in an increased likelihood of an LCF of 1 . These noninvolved worker doses would likely result in prompt radiation health effects, up to death.

Consequences do not account for the probability (or frequency) of an accident, and thus represent the impacts that could result if an accident were to occur. Another useful metric to consider in an accident analysis is risk. Risk takes into account the probability of an accident and is determined by multiplying the consequences of an accident by the probability of occurrence.

For existing LEU fueled LWRs, the internally initiated accident with the highest risk to the onsite and offsite populations is the "Interfacing System LOCA" scenario (see Appendix D, Section D.2.1 for more information on this

Probability and Frequency

The probability of an accident occurring is expressed as a number between 0 (no chance of occurring) and 1 (certain to occur). Alternatively, instead of probability of occurrence, one can specify the frequency of occurrence (e.g., once in 200 years, which also can be expressed as 0.005 times per year) (DOE 2006p). accident and others analyzed for the No Action Alternative). The collective risk to the offsite population for this scenario would range from $6 \times 10^{-5}$ expected LCF per year of operation in the Site 1 offsite population to 0.002 expected LCF per year of operation in the Site 6 offsite population. For the MEI, the same scenario would result in an increased risk of an LCF of $6 \times 10^{-8}$ per year of operation at all sites. For the noninvolved worker, this scenario would result in an increased risk of an LCF of $7 \times 10^{-8}$ per year of operation. 
With respect to future LEU fueled ALWRs, the internally initiated event with the highest consequence to the onsite and offsite populations would be the "Low Pressure Core Melt with Loss of Long-Term Coolant Makeup and Containment Vessel" scenario, which has a frequency of $1.1 \times 10^{-8} / \mathrm{yr}$ (see Appendix D, Section D.2.1 for more information on this accident and others analyzed for the No Action Alternative). Using the dose-to-risk conversion factor of $6 \times 10^{-4} \mathrm{LCF}$ per person-rem, the collective population doses would result in 5 to 200 additional LCFs in the surrounding population. For the MEI, this scenario would result in an increased likelihood of LCF of 0.1 to 0.9 . The noninvolved worker doses would likely result in prompt radiation health effects, up to death.

Consequences do not account for the probability of an accident, and thus represent the impacts that could result if an accident were to occur. Another useful metric to consider in an accident analysis is risk. Risk takes into account the probability of an accident and is determined by multiplying the consequences of an accident by the probability of occurrence.

The internally initiated LEU fueled ALWR accident with the highest risk to the onsite and offsite populations is the "Failure of Small Primary Coolant Line Outside the Containment" scenario (see Appendix D, Section D.2.1 for more information on this accident and others analyzed for the No Action Alternative). The collective risk to the offsite population for this scenario would range from $2 \times 10^{-7}$ expected LCF per year of operation in the Site 1 offsite population to $6 \times 10^{-6}$ expected LCF per year of operation in the Site 6 offsite population. For the MEI, the internally initiated accident with the greatest risk is also the "Failure of Small Primary Coolant Line Outside Containment" scenario, which would result in an increased risk of an LCF of $2 \times 10^{-9}$ per year (at Sites 1-3) to $1 \times 10^{-8}$ per year of operation (at Sites 4-6). For the noninvolved worker, the "Failure of Small Primary Coolant Line Outside Containment" scenario would result in an increased risk of an LCF ranging from $2 \times 10^{-8}$ per year of operation (at Sites 1-3) to $1 \times 10^{-7}$ per year of operation (at Sites 4-6).

Spent Nuclear Fuel and Radioactive Wastes: Typical nuclear power plants generate SNF and LLW, including Greater-than-Class-C (GTCC) LLW. Interim SNF storage is addressed in Section 4.2.1.1. LLW consists of items that have come in contact with radioactive materials, such as gloves, personal protective clothing, tools, water purification filters and resins, plant hardware, and wastes from reactor cooling-water cleanup systems. It generally has levels of radioactivity that decay to background radioactivity levels in less than 500 years. About 95 percent of such radioactivity decays to background levels within 100 years or less. A typical LWR generates approximately 740 to $2,790 \mathrm{ft}^{3}\left(21\right.$ to $\left.79 \mathrm{~m}^{3}\right)$ of LLW annually (NEI 2007). The LLW generated at nuclear power plants is transferred to a domestic licensed commercial treatment and/or disposal facility. Over a 50-year implementation period ${ }^{24}$, the No Action Alternative would generate the SNF and radioactive wastes shown in Table 4.2-8.

${ }^{24}$ The 50-year implementation period is used to reflect the period of time from 2010 to approximately 2060-2070, during which any of the alternatives would be implemented to support the growth in nuclear electricity generating capacity from approximately $100 \mathrm{GWe}$ to $200 \mathrm{GWe}$. 
recycling reactors) that would utilize recycled constituents (uranium and transuranics) as fuel to produce electricity. At the programmatic level, this PEIS assesses the potential environmental impacts associated with broad implementation of the Reactor Recycle Alternative with a capacity of approximately $200 \mathrm{GWe}$, based on a 1.3 percent growth rate for nuclear power. The PEIS also provides information for a growth scenario of 2.5 percent, which would result in a capacity of approximately $400 \mathrm{GWe}$ (see Table 4.8-2), a 0.7 percent growth rate (see Table 4.8-3), and a zero growth scenario, which would result in a capacity of approximately $100 \mathrm{GWe}$ (see Table 4.8-4).

This PEIS presents the environmental impacts of the Fast Reactor Recycle Alternative as follows:

Construction and Operation of Fast Reactor Recycle Alternative Facilities: The impacts of establishing and implementing the Fast Reactor Recycle Alternative with a capacity of approximately $200 \mathrm{GWe}$ are presented. This analysis includes the construction of Fast Reactor Recycle Alternative facilities, transportation of LWR SNF from commercial reactors to SNF recycling facilities, operations to recycle SNF and produce fuel for advanced recycling reactors, transportation of fuel to/from advanced recycling reactors, and waste management impacts (which would include the impacts of establishing additional geologic repository capacity for HLW, and the transport of HLW to a geologic repository). The analysis includes the environmental impacts of operating up to $200 \mathrm{GWe}$ of capacity in LWRs and fast reactors, including the replacement of approximately 100 GWe of LWR capacity that reaches end-of life, and the construction and operation of approximately 100 GWe of new reactor capacity using both LWRs and fast reactors. These impacts are presented in Section 4.3.1.

The following assumptions are relevant to the analysis of the Fast Reactor Recycle Alternative.

Destruction of Transuranics in Advanced Recycling Reactor(s): The advanced recycling reactors in the PEIS alternatives provide for the net destruction of transuranic elements in transmutation fuel in each advanced recycling reactor cycle. The amount of transuranic destruction is usually expressed by the "conversion ratio" $(\mathrm{CR})^{26}$. The PEIS assumes a CR of 0.5 and discusses less efficient and more efficient transuranic destruction.

Percent of Electricity Generation from Advanced Recycling Reactors: In simple terms, a balance would be achieved when the mass of transuranics produced and recovered from LWR SNF during processing equals the mass of transuranics consumed in advanced recycling reactors per unit time. This balance would depend on a number of factors, including advanced recycling reactor size, transuranic destruction efficiency, and the number of operating LWRs (which, in turn is based on estimated future electricity growth and the nuclear power share of the electricity generation market). For this PEIS, a balance of 60 percent LWRs and 40 percent advanced recycling reactors is presented.

\footnotetext{
${ }^{26}$ As used in this PEIS, the "conversion ratio" (CR) of a fast reactor is the ratio of the amount of transuranic elements that are produced to the amounts that are consumed in the reactor during the time the fuel is in the reactor. The CR determines the number of fast reactors required to consume transuranics separated from the LWR SNF. At a CR of 0.5 , approximately 20 percent of the transuranics would be destroyed per fast reactor recycle pass. This PEIS also includes a sensitivity analysis of changing the CR in Section 4.3.2.
} 


\subsubsection{Construction and Operation of Fast Reactor Recycle Alternative Facilities}

Appendix A (Sections A.4.2 and A.6, respectively) describes an advanced recycling reactor and a nuclear fuel recycling center, which would be the two major types of facilities required to implement the Fast Reactor Recycle Alternative. This PEIS acknowledges that implementation of the Fast Reactor Recycle Alternative to achieve a capacity of $200 \mathrm{GWe}$ would be a long-term process carried out over many decades. Initially, implementation of the Fast Reactor Recycle Alternative could begin at demonstration capacity (on the order of a 100 MTHM per year SNF recycling center and a 250-megawatts thermal (MWth) advanced recycling reactor) before ramping-up to commercial capacities.

Construction: For the Fast Reactor Recycle Alternative with a capacity of $200 \mathrm{GWe}$, the following facilities could be built:

- $120 \mathrm{GWe}$ of LWR capacity (which would include the replacement of approximately $100 \mathrm{GWe}$ of LWR capacity when existing LWRs reach their end-of-life).

- $\quad 80 \mathrm{GWe}$ of fast reactor capacity.

- Three LWR separation facilities (each with a capacity of approximately $800 \mathrm{MTHM} / \mathrm{yr}){ }^{27}$

- Up to eight transmutation fuel fabrication facilities (each with a capacity to fabricate $100 \mathrm{MTHM} / \mathrm{yr}$ of transmutation fuel). ${ }^{28}$

- Up to eight fast reactor SNF separations facilities (each with a capacity to separate $100 \mathrm{MTHM} / \mathrm{yr}$ of fast reactor SNF). ${ }^{29}$

Although some facilities could be colocated, the construction of this much capacity would necessitate that many sites in the United States be utilized. For this analysis, it is assumed that none of the facilities would be colocated, which would necessitate transportation of material between the facilities during operations. If facilities were colocated, transportation impacts would decrease compared to the results presented. With respect to health and safety impacts, co-locating facilities would produce additive impacts comprised of the individual facility impacts. The impacts of accidents from each individual facility would not change due to colocation. That is, an accident in one facility would not cause an accident in another facility. Some external events, such as a large seismic event, could cause multiple accidents in colocated facilities. However, even in those cases, the total accident impacts would be comprised of the additive impacts from the individual facilities.

On a national level, constructing up to $200 \mathrm{GWe}$ of reactor capacity over approximately 45-years (assuming the first LWR comes on-line in approximately 2015, fast reactors begin coming on-line in approximately 2020, and construction continues at a relatively steady pace thereafter

\footnotetext{
${ }^{27}$ As shown in Table 2.10-1, the 200 GWe scenario would require approximately 2,600 MTHM/yr of LWR separations capacity. The PEIS analysis is based on a LWR separation facility sized at $800 \mathrm{MTHM} / \mathrm{yr}$. Therefore, three to four $800 \mathrm{MTHM} / \mathrm{yr}$ facilities would be required to treat this amount of SNF. For the purposes of this analysis, three facilities were assumed having a capacity to separate 2,400 MTHM/yr. Approximately $200 \mathrm{MTHM} / \mathrm{yr}$ would need to be stored (see Section 4.3.3) until additional capacity is made available.

${ }^{28}$ As shown in Table $2.10-1$, the $200 \mathrm{GWe}$ scenario would require approximately $720 \mathrm{MTHM} / \mathrm{yr}$ of transmutation fuel fabrication capacity. The PEIS analysis is based on a transmutation fuel fabrication facility sized at $100 \mathrm{MTHM} / \mathrm{yr}$. Because eight facilities would have a capacity to fabricate $800 \mathrm{MTHM} / \mathrm{yr}$, there would be an excess capacity of approximately $80 \mathrm{MTHM} / \mathrm{yr}$.

${ }^{29}$ As shown in Table 2.10-1, the 200 GWe scenario would require approximately $720 \mathrm{MTHM} / \mathrm{yr}$ of fast reactors SNF separation capacity. The PEIS analysis is based on a fast reactor SNF separation facility sized at $100 \mathrm{MTHM} / \mathrm{yr}$. Because eight facilities would have a capacity to separate $800 \mathrm{MTHM} / \mathrm{yr}$, there would be an excess capacity of approximately $80 \mathrm{MTHM} / \mathrm{yr}$.
} 
until 2060-2070) is assumed. Assuming an average of 3,000 acres (1,200 ha) per GWe of reactor capacity (see Chapter 3, Section 3.2.2), the amount of land disturbed by construction of the reactor facilities could be up to 600,000 acres $(243,000 \mathrm{ha}$ ) of land (assuming none of the reactors are colocated, which is a conservative assumption because it is likely that a reactor site would include multiple reactors, as is common in the commercial nuclear power industry).

Construction of 3 LWR separation facilities would require a total of approximately 1,500 acres (600 ha) (based on 500 acres [200 ha] per facility, see Appendix A, Section A.6.1.2). Construction of 8 fast reactor SNF separations facilities would require a total of approximately 2,000 acres (800 ha) (based on 250 acres [100 ha] per facility, see Appendix A, Section A.6.3.2). Construction of 8 transmutation fuel fabrication facilities would require a total of approximately 800 acres (320 ha) (based on 100 acres [40 ha] per facility, see Appendix A, Section A.6.2.2). The total land required for the Fast Reactor Recycle Alternative with a capacity of $200 \mathrm{GWe}$ would be approximately 604,000 acres $(244,000 \mathrm{ha})$.

Construction of any of these nuclear facilities could produce peak employments of several thousand workers. Because construction impacts would be highly localized and dependent on specific sites proposed for facilities, any further discussion of construction impacts would not provide meaningful information relative to the programmatic construction impacts.

Operation: Operation of the facilities would predominantly affect land resources, water resources, impact the visual environment, produce socioeconomic impacts, impact human health and safety, produce wastes, and require transportation of nuclear materials. These topics are addressed below.

Uranium Requirements: The quantity of natural uranium needed to support a capacity of $200 \mathrm{GWe}$, assuming an average enrichment of 4.4 percent, would be approximately 24,400 MT per year (see Table 4.8-1). The 24,400 MT of natural uranium would represent approximately 62 percent of uranium that was mined in the world in 2006 and would be 14 times more than the quantities currently mined in the United States annually (see Table 4.1-1). From this 24,400 MT, approximately 2,700 MT of enriched uranium (assuming 4.4 percent enrichment) would be required annually. Approximately 16 million SWUs would be required annually to support a capacity of $200 \mathrm{GWe}$. The licensed capacity of Paducah, the American Centrifuge Plant, and the LES Facility is 17.8 million SWUs. Consequently, enrichment facilities in the United States could meet this demand. However, if Paducah shuts down in 2012, the United States enrichment capacity would be reduced to approximately 6.8 million SWUs. To support a $200 \mathrm{GWe}$ capacity, enrichment capacities in the United States would need to be expanded by more than 100 percent or larger quantities of enriched uranium would need to be imported.

Fuel Fabrication Requirements: The United States currently has three operational LWR uranium fuel fabrication facilities with a capacity to produce approximately 3,500 MT of LWR fuel assemblies (Table 4.1-2). For the Fast Reactor Recycle Alternative, approximately 2,700 MT of fresh LWR fuel assemblies would need to be produced annually to support the $200 \mathrm{GWe}$ scenario. Consequently, the fuel fabrication facilities in the United States would be able to provide this capacity. The fast reactor fuel fabrication requirements would be met by 
constructing and operating the eight fast reactor SNF separations facilities with an associated transmutation fuel fabrication capability.

Land Resources: Once operational, a total of approximately 605,000 acres (245,000 ha) of land could be occupied by facilities, paved areas, and buffer zones. Most of this area would not be disturbed but would serve as a buffer between the actual facility and the outer facility boundary. The total site area would be determined by accident analyses and regulatory requirements, including safeguards and security.

Visual Resources: With respect to visual characteristics, the visibility of any facility from publicly accessible locations would be dependent on the future site characteristics. For sites that use "wet" cooling tower systems, the water vapor plume from cooling tower operations may be visible for many miles from the plant.

Air Resources: The facilities associated with the Fast Reactor Recycle Alternative would generate both nonradiological and radiological emissions. Nonradiological emissions, which are predominantly associated with vehicle emissions and emergency diesel generator testing and operations, would be small. With respect to radiological emissions, all facility operators would be required to monitor radioactive airborne emissions discharges and file a report of these discharges annually with the NRC with a list of the radioactive isotopes released, the quantity released, and the radiation dose to the public (NRC 2008c). The potential impacts to human health are presented in the "Human Health" section below.

Water Resources: Every operating reactor would use significant quantities of water. A typical GWe of reactor capacity requires approximately 3 to 6 billion gal (11 to 23 billion L) of water yearly, mainly for heat dissipation ${ }^{30}$ (EPRI 2002). As a result, most reactors are located near major sources of water, such as natural lakes, man-made lakes, rivers, or the ocean. Water can also be supplied from groundwater. In arid environments, "dry" cooling towers can be utilized to reduce water requirements. ${ }^{31}$ The heat dissipation system selected would be dependent on site characteristics. Although reactors withdraw large quantities of water from a source body, virtually all of that water is returned to its source at a quality similar to that removed, albeit a bit warmer and sometimes with a trace of residual chlorine. Only a small quantity (about 1 percent) is consumed via increased evaporation to the atmosphere from the warm discharge water plume (EPRI 2002).

A nuclear fuel recycling center would use significant quantities of water. Each LWR SNF separation facility would require approximately 330 million gal/yr $(1.3$ billion L/yr $)$ (WSRC 2008a). Three facilities would require approximately 1 billion gal/yr (3.8 billion L/yr). A fast reactor SNF separation facility with an associated transmutation fuel fabrication capability

\footnotetext{
${ }^{30}$ A typical 1 GWe reactor would withdraw 3 to 6 billion gal/yr (11 to 23 billion L/yr) for cooling (using "wet cooling"). Water consumption would be less than 60 million gal/yr ( 230 million $\mathrm{L} / \mathrm{yr})$.

${ }^{31}$ There are two main types of cooling technology, the air system ("dry cooling") and the wet system. An air-cooled system operates like a very large automobile radiator. These systems use a flow of air to cool water flowing inside finned tubes. It is essentially a closed-loop system where air is passed over large heat exchange surfaces. While air cooling is a reliable and proven technology, it has some technical and economic drawbacks in comparison to a wet mechanical cooling system, which requires the use of significant amounts of water. The principal drawbacks of air cooling are increased noise levels, higher capital costs, and larger physical dimensions. There are currently no existing LWR facilities in the United States using the "dry cooling system."
} 
would require approximately 125 million gal/yr (470 million L/yr) (WSRC 2008b, WSRC 2008c). Eight facilities would require approximately 1 billion gal/yr (3.8 billion L/yr).

Socioeconomic Impacts: Socioeconomic impacts would occur in communities in the vicinity of any future facility. For each GWe of capacity, an LWR and advanced recycling reactor would require approximately 500 to 1,000 workers. Employment estimates for the recycling facilities are: approximately 3,000 workers for each LWR SNF separation facility; approximately 2,000 workers associated with a fast reactor SNF separation facility; and approximately 1,000 workers associated with a transmutation fuel fabrication facility (WSRC 2008a, WSRC 2008b).

Human Health: In addition to nonradiological hazards, workers at each of the facilities would be subject to radiological hazards, including radiation exposure, as discussed below.

- The total annual dose to workers associated with the nuclear fuel recycling centers would be approximately 4,600 person-rem (LWR separation: 3 facilities $x$ 2,226 radiation workers/facility x $250 \mathrm{mrem} / \mathrm{yr}$ average dose [WSRC 2008a]; fast reactor SNF separation/fuel fabrication: 8 facilities x 1,456 radiation workers/facility x $250 \mathrm{mrem} / \mathrm{yr}$ average dose [WSRC 2008b, WSRC 2008c]).

- The total annual dose to workers at the advanced recycling reactors ( $80 \mathrm{GWe}$ of capacity) would be approximately 8,360 person-rem (assumes 550 radiation workers/GWe $\mathrm{x}$ $190 \mathrm{mrem} / \mathrm{yr}$ average dose $\left.{ }^{32}\right)$.

- At the LWRs (120 GWe of capacity), the total annual dose to workers would be approximately 12,500 person-rem (assumes 550 radiation workers/GWe x $190 \mathrm{mrem} / \mathrm{yr}$ average dose).

The total annual dose to workers associated with the 200 GWe Fast Reactor Recycle Alternative would be approximately 25,500 person-rem, which equates to an annual LCF risk of approximately 15 . Statistically, this means that 15 LCFs could occur for every year of operation of a Fast Reactor Recycle Alternative at the capacities assumed at the end of the implementation period (i.e., that separates 2,400 MTHM/yr of LWR SNF and $800 \mathrm{MTHM} / \mathrm{yr}$ of fast reactor SNF, produces $800 \mathrm{MTHM} / \mathrm{yr}$ of fast reactor transmutation fuel, and operates $200 \mathrm{GWe}$ of LWR and advanced recycling reactor capacity.

The public would also be subject to radiation exposure, primarily from airborne releases of radionuclides. As described in Appendix D, Section D.1.6, DOE developed six hypothetical sites to assess the impacts of potential radiological releases associated with normal operations of facilities. Potential doses from LWRs are shown in Table 4.2-6 for the six hypothetical sites. For the nuclear fuel recycling center and the advanced recycling reactor, public exposures would vary depending on many factors, but would predominantly be affected by prevailing weather patterns and the proximity of the facilities to local population centers. Based on modeling results, the impacts from normal operations of the nuclear fuel recycling center ${ }^{33}$ and the advanced

\footnotetext{
32550 radiation workers/GWe x $190 \mathrm{mrem} / \mathrm{yr}$ average dose is based on data for the actual average operating LWR. The "Advanced Burner Reactor" report (Briggs et al. 2007), estimated 385 workers with an average annual worker dose of 210 mrem per GWe of capacity. This would equate to a total dose of 6,468 person-rem for the $80 \mathrm{GWe}$ capacity. For purposes of this dose estimate, the PEIS uses the actual LWR data. These data represented the best available information and were used to facilitate the comparison of programmatic alternatives.

${ }^{33}$ For recycling facilities, radiological releases associated with the LWR SNF separation facility were modeled. This facility would have a much higher throughput than the fast reactor SNF separation facility and the transmutation fuel fabrication facility, and would be expected to have the highest releases and potential impacts.
} 
recycling reactor are shown in Table 4.3-1. As shown in that table, MEI doses for the nuclear fuel recycling center and the advanced recycling reactor would be below the $10 \mathrm{mrem} / \mathrm{yr}$ standard (40 CFR Part 61) for each of the six hypothetical sites. The results presented in Table 4.3-1 are based on releases from a single facility. If two nuclear fuel recycling centers (each with an 800 MTHM capacity) or two advanced recycling reactors were located at the same site, the MEI and 50-mi $(80-\mathrm{km})$ population doses would be expected to double.

TABLe 4.3-1-Normal Operation Radiological Impacts to the Public from Fast Reactor Recycle Alternative Facilities at Six Hypothetical Locations in the United States

\begin{tabular}{|c|c|c|c|c|}
\hline & \multicolumn{2}{|c|}{$\begin{array}{l}\text { Nuclear Fuel Recycling Center } \\
(800 \mathrm{MTHM} / \mathrm{yr})^{\mathrm{a}}\end{array}$} & \multicolumn{2}{|c|}{$\begin{array}{c}\text { Advanced Recycling Reactor } \\
\text { (per } 1 \text { GWth) }\end{array}$} \\
\hline & $\begin{array}{l}\text { MEI dose } \\
\text { (mrem/yr) }\end{array}$ & $\begin{array}{l}\text { 50-Mile } \\
\text { Population dose } \\
\text { (person-rem/yr) }\end{array}$ & $\begin{array}{l}\text { MEI dose } \\
\text { (mrem/yr) }\end{array}$ & $\begin{array}{l}\text { 50-Mile Population dose } \\
\text { (person-rem/yr) }\end{array}$ \\
\hline Site 1 & 3.5 & 6.0 & $7.4 \times 10^{-4}$ & $1.8 \times 10^{-3}$ \\
\hline Site 2 & 3.4 & 7.6 & $7.4 \times 10^{-4}$ & $2.9 \times 10^{-3}$ \\
\hline Site 3 & 2.6 & 53.3 & $6.1 \times 10^{-4}$ & 0.02 \\
\hline Site 4 & 7.2 & 21.6 & $1.6 \times 10^{-3}$ & $7.3 \times 10^{-3}$ \\
\hline Site 5 & 7.1 & 28 & $1.6 \times 10^{-3}$ & $9.8 \times 10^{-3}$ \\
\hline Site 6 & 6.0 & 194 & $1.4 \times 10^{-3}$ & 0.07 \\
\hline
\end{tabular}

Source: Annett 2008

${ }^{a}$ Data is presented for $800 \mathrm{MTHM} / \mathrm{yr}$ LWR SNF separations facility. If a smaller or larger facility were constructed and operated, results would be expected to scale linearly.

Facility Accidents: Appendix D presents the impacts for a range of accidents, at the six hypothetical sites, which are expected to be representative of the types of accidents that could occur in a future nuclear fuel recycling center, an advanced recycling reactor, and future LWRs and ALWRs. ${ }^{34}$

Nuclear Fuel Recycling Center Accidents: With respect to a future nuclear fuel recycling center, the internally initiated accident with the highest consequence to the onsite and offsite populations would be the "Explosion and Fire in Aqueous Separations" scenario for a facility throughput of $800 \mathrm{MTHM} / \mathrm{yr}$ (see Appendix D, Section D.2.2 for more information on this accident and others analyzed for the nuclear fuel recycling center). Using the dose-to-risk conversion factor of $6 \times 10^{-4} \mathrm{LCF}$ per person-rem the collective population dose is estimated to result in 0.02 to 0.9 additional LCFs. For the MEI, this scenario would result in a probability of $2 \times 10^{-4}$ (or approximately one chances in 5,000 ) to $8 \times 10^{-4}$ (approximately one chance in 1,200 ) of a LCF should this scenario occur. For the noninvolved worker, this scenario would result in an increased likelihood of an LCF of $2 \times 10^{-4}$ to $9 \times 10^{-5}$.

Consequences do not account for the probability of an accident, and thus represent the impacts that could result if an accident were to occur. Another useful metric to consider in an accident analysis is risk. Risk takes into account the probability of an accident and is determined by multiplying the consequences of an accident by the probability of occurrence.

The internally initiated accident with the highest risk to the onsite and offsite populations is also the "Explosion and Fire in Aqueous Separations" scenario (see Appendix D, Section D.2.2). The

\footnotetext{
${ }^{34}$ The accident impacts of future LWRs are presented in Section 4.2.2 and are not repeated in this section.
} 
risk to the offsite population for this scenario would range from $2 \times 10^{-5}$ expected LCF per year of operation in the Site 1 offsite population to $9 \times 10^{-4}$ expected LCF per year of operation in the Site 6 offsite population. For the MEI, the same scenario would result in an increased risk of an LCF of $2 \times 10^{-7}$ per year of operation (at Sites 1-3) to $8 \times 10^{-7}$ per year of operation (at Sites 4-6). For the onsite noninvolved worker, this scenario would result in an increased LCF risk of $9 \times 10^{-8}$ per year of operation (at Sites 4-6) to $2 \times 10^{-7}$ per year of operation (at Sites 1-3).

Advanced Recycling Reactor Accidents: The highest consequence, and highest risk, internally initiated accident involving advanced recycling reactors is based on the published Clinch River Breeder Reactor analysis and is a "Radioactive Argon Processing System Cold Box Rupture." The radioactive argon processing system extracts radioactive argon from the reactor cover gas and a rupture can release radioactive gases to the reactor building and the atmosphere if the airtight cell leaks and the automatic controls do not shut off the ventilation system (PMC 1982). The Clinch River Breeder Reactor information assigned this accident a probability of occurrence of about 1 in 1,000 per year $\left(1 \times 10^{-3} / \mathrm{yr}\right)$, and it would result in an estimated 0.004 additional latent cancer fatalities to the surrounding population. The collective risk to the offsite population is about $4 \times 10^{-6}$ latent cancer fatalities per year of operation. For the maximally exposed individual, this accident would result in an increased risk of contracting a fatal cancer of $8 \times 10^{-9}$ per year of reactor operation. Accident analysis without a reactor design and specific site location gives results that could be misleading. The use of these results should be interpreted as providing a general range of impacts. Any reactor that would be proposed would be required to meet current Nuclear Regulatory Commission licensing and safety requirements regardless of the technology proposed.

Spent Nuclear Fuel and Radioactive Wastes: The amount of SNF generated between 2010 and 2060-2070 would be approximately 132,000 MTHM (approximately 118,000 MTHM for the LWRs and 14,000 MTHM for the advanced recycling reactors) ${ }^{35}$. By 2060-2070, approximately 2,600 MTHM of SNF would be generated annually from commercial LWRs. This SNF would go to a recycling center or would be stored temporarily, depending upon available separations capacity. By approximately 2060-2070, the advanced recycling reactors would generate approximately an additional 720 MTHM of fast reactor SNF annually. This SNF would also be recycled or stored pending recycling.

Based on the assumption that the Fast Reactor Recycle Alternative would recycle all of the SNF generated by commercial LWRs and advanced recycling reactors, over approximately a 50-year implementation period, the Fast Reactor Recycle Alternative would generate the quantities of spent nuclear fuel and radioactive wastes shown in Table 4.3-2. HLW would be disposed of in a geologic repository (see Section 4.1.5). LLW would be disposed of in commercial disposal facilities (see Section 4.1.6). Disposal of GTCC LLW would occur pursuant to the Low-Level Radioactive Waste Policy Amendments Act of 1985, at facilities to be determined by the DOE. For the $200 \mathrm{GWe}$ capacity, annual LLW volumes could grow to 68,500 to $80,000 \mathrm{~m}^{3}$. By approximately 2060-2070, the annual quantity of LLW generated by the Fast Reactor Recycle Alternative would be 61 to 71 percent as much as the total LLW disposed of in 2005

\footnotetext{
35 Based on the following assumptions: the first new LWR is constructed in 2015; each LWR produces approximately 21.7 MTHM of $\mathrm{SNF} / \mathrm{GWe}-\mathrm{yr}$; in 2020, fast reactors begin to come on-line; from 2020 to 2060-2070, total nuclear generating capacity (LWRs + fast reactors) grows until $200 \mathrm{GWe}$ is achieved; and fast reactors produce approximately 9 MTHM of SNF/GWe-yr.
} 
$\left(113,000 \mathrm{~m}^{3}\right)$. Cesium $(\mathrm{Cs})$ and strontium $(\mathrm{Sr})$ could be stored at the recycling center for 300 years (see Section 4.3.3) or transported to a HLW storage or disposal facility. Because any recovered uranium could be reused, the quantities in Table 4.3-2 do not include recovered uranium.

TABLE 4.3-2_-Total Spent Nuclear Fuel and Wastes Generated by the Fast Reactor Recycle Alternative (50 Years of Implementation)

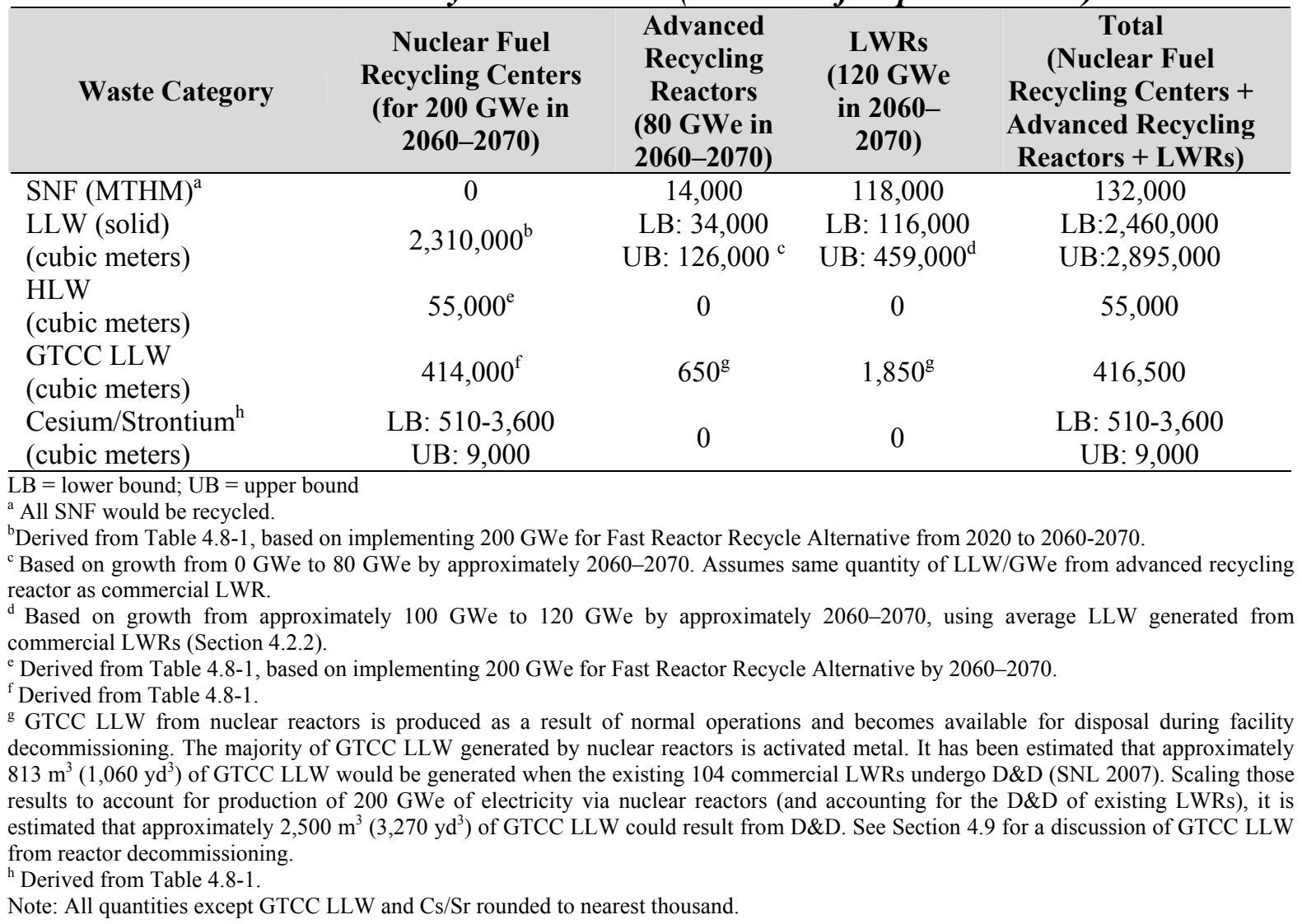

This PEIS assumes that wastes (i.e., HLW, GTCC LLW, and LLW) would be transported to disposal sites annually to prevent accumulation on-site. In the event these wastes are not transported off-site, on-site storage facilities would be needed. These storage facilities would be designed to address the required shielding, security, heat loading, inventory, storage duration, and other requirements. Although the capacity of these storage facilities would depend on many factors, the throughput of the recycling facilities would be most important. The more SNF that is recycled, the more wastes that would need to be managed. Potential storage capacities for HLW, GTCC LLW, and LLW have not been estimated for the programmatic alternatives. However, estimates for storing the HLW, GTCC $\mathrm{LLW}^{36}$, and cesium/strontium $(\mathrm{Cs} / \mathrm{Sr})$ wastes for the previously-proposed Advanced Fuel Cycle Facility (AFCF) have been made. Based on that analysis, approximately 230,000 square feet $\left(\mathrm{ft}^{2}\right)\left(21,400\right.$ square meters $\left.\left[\mathrm{m}^{2}\right]\right)$ of waste storage facilities would be required for a facility that separates a total of approximately 1,700 MTHM of SNF and performs limited fuel fabrication. Based on the amount of SNF that would be recycled over the implementation period for the Fast Reactor Recycle Alternative (132,000 MTHM total),

${ }^{36}$ GTCC LLW is referred to as "TRU waste" for the previously-proposed Advanced Fuel Cycle Facility. 
the on-site waste storage capacity requirements would be significant if wastes accumulate. For information related to storing transuranics and Cs/Sr wastes, see Section 4.3.3.

Transportation: A transportation analysis was prepared to determine the potential impacts associated with the Fast Reactor Recycle Alternative (see Appendix E for a discussion of the methodology and modeling results). The transportation analysis considered all radiological material that could be transported (i.e., LWR SNF, spent fast reactor fuel wastes from the recycling center, etc.). Table 4.3-3 presents the number of radiological shipments (broken down by material to be transported) that would be required for the Fast Reactor Recycle Alternative for: 1) all truck and 2) a combination of truck and rail. Because all shipments of fresh nuclear fuel are assumed to occur via truck transport, there is no transportation scenario in which all transportation would occur via rail only. Consequently, the PEIS presents transportation impacts for a combined truck and rail scenario (in tables this scenario is designated as "truck/rail"). As shown in that table, truck transport would require significantly more shipments than truck and rail.

\begin{tabular}{|c|c|c|}
\hline Material/Waste & $\begin{array}{c}\text { Truck Transport } \\
\text { (Number of } \\
\text { Shipments) } \\
\end{array}$ & $\begin{array}{c}\text { Truck/Rail } \\
\text { Transport (Number } \\
\text { of Shipments) }\end{array}$ \\
\hline Fresh LWR fuel & 19,700 & $19,700^{\mathrm{c}}$ \\
\hline Fresh Transmutation fuel & 35,000 & $35,000^{\mathrm{c}}$ \\
\hline LWR SNF & 59,000 & 4,720 \\
\hline Fast Reactor SNF & 35,000 & 7,000 \\
\hline Cs/Sr waste & 10,800 & 2,150 \\
\hline HLW & 53,600 & 10,700 \\
\hline GTCC LLW $^{\mathrm{a}}$ & 524,000 & 103,000 \\
\hline $\mathrm{LLW}^{\mathrm{b}}$ & 93,400 & 18,900 \\
\hline Recovered Uranium (Aqueous) & 16,400 & 3,200 \\
\hline Recovered Uranium (Metal) & 7,580 & 1,520 \\
\hline
\end{tabular}

The results of the transportation analysis are presented in two sets of tables. The first set of tables (Tables 4.3-4 and 4.3-5) present the impacts associated with handling (loading and inspection) radiological materials for the $200 \mathrm{GWe}$ scenario. Impacts are presented in terms of radiological impacts (expressed in person-rem and converted to LCFs using a dose-to-risk conversion factor of $6 \times 10^{-4}$ LCF per person-rem). Table 4.3-4 presents the handling impacts for truck transport and Table 4.3-5 presents the handling impacts for truck and rail transport. Handling operations (loadings and inspections) would not affect the public.

The impacts of handling radiological material are independent of the distance that the material would be transported. As such, the handling impacts would be the same whether the radiological material is transported, for example, $500 \mathrm{mi}(805 \mathrm{~km}), 2,100 \mathrm{mi}(3,380 \mathrm{~km})$, or any other distance. For this reason, these impacts are presented separately from the in-transit impacts (which are presented in the second set of tables). 
TABLE 4.3-4-Handling Impacts for 50 Years of Implementation, Fast Reactor Recycle Alternative (Truck Transit)_200 Gigawatts Electric

\begin{tabular}{lcc|cc|cc}
\hline & \multicolumn{6}{c}{ Handling Impacts } \\
\cline { 2 - 7 } & \multicolumn{2}{c}{ Loading } & \multicolumn{2}{c}{ Inspection } & Total \\
\cline { 2 - 7 } & person-rem & LCFs & Person-rem & LCFs & person-rem & LCFs \\
\hline Fast Reactor Recycle & 160,000 & 96 & 17,900 & 11 & 177,000 & 106 \\
\hline Source: Appendix E & & & & & \\
Note: All LCFs rounded to nearest whole number.
\end{tabular}

TABLE 4.3-5-Handling Impacts for 50 Years of Implementation, Fast Reactor Recycle Alternative (Truck and Rail Transit)_200 Gigawatts Electric

\begin{tabular}{ccc|cc|cc}
\hline & \multicolumn{6}{c}{ Handling Impacts } \\
\cline { 2 - 7 } & \multicolumn{2}{c}{ Loading } & \multicolumn{2}{c}{ Inspection } & \multicolumn{2}{c}{ Total } \\
\cline { 2 - 7 } & person-rem & LCFs & person-rem & LCFs & person-rem & LCFs \\
\hline Fast Reactor Recycle & 213,000 & 128 & 13,300 & 8 & 226,000 & 136 \\
\hline
\end{tabular}

Source: Appendix E

Note: All LCFs rounded to nearest whole number.

The in-transit impacts are shown in Tables 4.3-6 (truck transit) and 4.3-7 (truck and rail transit) for the Fast Reactor Recycle Alternative. These impact estimates would vary based on a variety of factors, including the distance that the radiological material would be transported, the specific routes that would be utilized, the population densities along those routes, and others. Of these factors, transport distance is the most significant. Because the locations of future reactors, nuclear fuel recycling facilities, and future disposal facilities are unknown, DOE analyzed transportation impacts over five distances: $150 \mathrm{mi}(241 \mathrm{~km}), 500 \mathrm{mi}(805 \mathrm{~km}), 1,500 \mathrm{mi}(2,414$ $\mathrm{km}), 2,100 \mathrm{mi}(3,380 \mathrm{~km})$, and 3,000 $\mathrm{mi}(4,828 \mathrm{~km})$. In-transit impacts presented in Tables 4.3-6 and 4.3-7 are based on $2,100 \mathrm{mi}(3,380 \mathrm{~km})$ of transport. This distance was selected as a reference distance because it represents the average distance for all SNF shipments analyzed in the Yucca Mountain FEIS (DOE 2002i). Impacts associated with the other four distances are presented, on a per shipment basis, in Appendix E, which describes the transportation methodology and assumptions. Although the in-transit impacts are not exactly "linear" (i.e., twice the impacts for twice the distance transported), that is a close approximation. Consequently, if the radiological material were transported $500 \mathrm{mi}(805 \mathrm{~km})$, all of the in-transit impacts presented in Tables 4.3-6 and 4.3-7 could be estimated by multiplying the values in those tables by $0.24(500 / 2,100)$.

TABLE 4.3-6-In-Transit Transportation Impacts for 50 Years of Implementation, Fast Reactor Recycle Alternative (Truck Transit)_200 Gigawatts Electric

\begin{tabular}{|c|c|c|c|c|c|c|c|c|}
\hline & \multicolumn{4}{|c|}{ In Transit Impacts } & \multirow{3}{*}{$\begin{array}{c}\text { Total } \\
\text { Incident-Free } \\
\text { LCFs }\end{array}$} & \multirow{2}{*}{\multicolumn{3}{|c|}{ Accident Impacts }} \\
\hline & \multicolumn{2}{|c|}{ Crew } & \multicolumn{2}{|c|}{ Public } & & & & \\
\hline & $\begin{array}{c}\text { person- } \\
\text { rem }\end{array}$ & LCFs & $\begin{array}{c}\text { person- } \\
\text { rem }\end{array}$ & LCFs & & $\begin{array}{c}\text { person- } \\
\text { rem }\end{array}$ & LCFs & $\begin{array}{l}\text { Collision } \\
\text { Fatalities }\end{array}$ \\
\hline Fast Reactor Recycle & 151,000 & 90 & 371,000 & 222 & 313 & 51.6 & 0 & 73 \\
\hline
\end{tabular}

Source: Appendix E

Note: All LCFs rounded to nearest whole number. 
TABLE 4.3-7-In-Transit Transportation Impacts for 50 Years of Implementation, Fast Reactor Recycle Alternative (Truck and Rail Transit)—200 Gigawatts Electric

\begin{tabular}{|c|c|c|c|c|c|c|c|c|}
\hline & \multicolumn{4}{|c|}{ In Transit Impacts (Note 1) } & \multirow{3}{*}{$\begin{array}{c}\text { Total } \\
\text { Incident- } \\
\text { Free LCFs }\end{array}$} & \multirow{2}{*}{\multicolumn{3}{|c|}{ Accident Impacts }} \\
\hline & \multicolumn{2}{|c|}{ Crew } & \multicolumn{2}{|c|}{ Public } & & & & \\
\hline & $\begin{array}{c}\text { person- } \\
\text { rem }\end{array}$ & LCFs & $\begin{array}{c}\text { person- } \\
\text { rem }\end{array}$ & LCFs & & $\begin{array}{c}\text { person- } \\
\text { rem }\end{array}$ & LCFs & $\begin{array}{c}\text { Collision } \\
\text { Fatalities }\end{array}$ \\
\hline Fast Reactor Recycle & 10,600 & 6 & 54,100 & 32 & 39 & 10.9 & 0 & 15 \\
\hline
\end{tabular}

Source: Appendix E

Note: All LCFs rounded to nearest whole number.

There are potentially significant differences in impacts depending upon whether transportation is by truck or a combination of truck and rail. For all alternatives, truck and rail transport would result in smaller impacts than truck transport. This is due to the fact that there would be many fewer transportation shipments by truck and rail than by truck only. This would directly affect the distance traveled and exposures to both crews and the public. Additionally, the number of accident fatalities (collisions) would be smaller for the truck and rail transport.

\subsubsection{Sensitivity Analysis of the Fast Reactor Conversion Ratio}

The number of fast reactors that would ultimately need to be deployed, to achieve a balanced system in which the amount of transuranics consumed (in fast reactors) equals the amount of transuranics produced (in LWRs), would be largely affected by the Conversion Ratio (CR) of the fast reactors. Because the $\mathrm{CR}$ is essentially a measure of the efficiency by which a fast reactor consumes transuranics, it could directly affect how many fast reactors would ultimately be deployed, how much transuranic material would be consumed, and how much SNF and HLW must ultimately be disposed of in a geologic repository. This PEIS analysis is based on a CR of 0.5 , which means that a fast reactor would consume approximately 20 percent of the transuranics per fast reactor recycle pass. The lower the $\mathrm{CR}$, the faster that transuranics can be consumed with fewer fast reactors required. In programmatic terms, a lower CR means this alternative would be less sensitive to fast reactor deployment. As shown on Figure 4.3-1, for a CR of 0.5, approximately 35 to 40 percent of the reactors in the United States would need to be fast reactors in order for the system to be in equilibrium (i.e., a balanced system in which the quantity of transuranics produced and recovered from LWR SNF equals the transuranics consumed in fast reactors). 


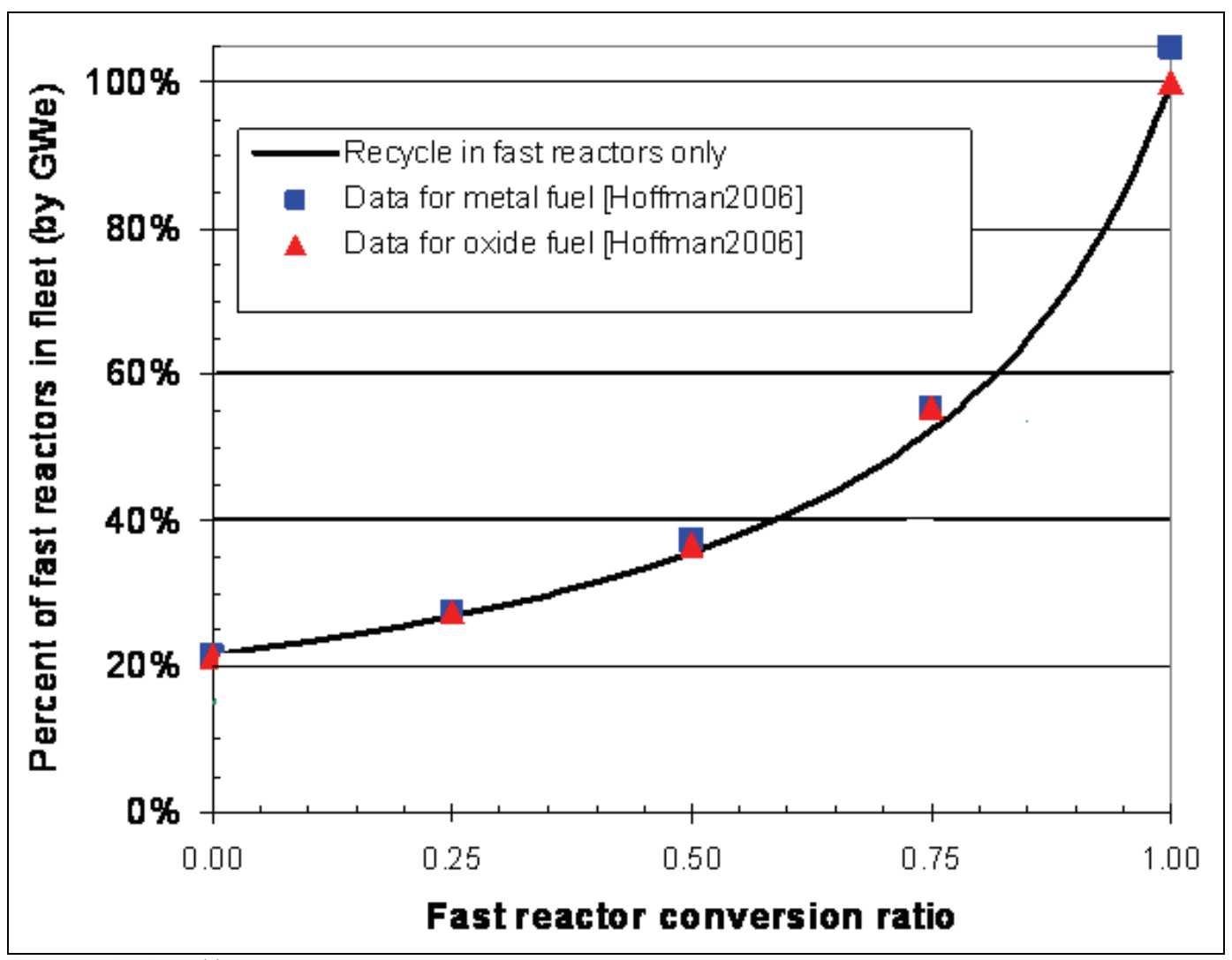

Source: DOE 2007dd

FIGURE 4.3-1-Equilibrium Fraction of Fast Reactors in the United States

At a CR of 0.25 (which means greater consumption of transuranics in each fast reactor), this percentage would drop to approximately 30 percent. Conversely, a CR of 0.75 (indicating less efficient transuranic consumption) would require that the percentage of fast reactors be increased to more than 50 percent. Assuming the same nuclear power growth rates as described in Chapter 2, the CR would affect the mix of thermal reactors to fast reactors. In terms of environmental impacts, at the programmatic level, the differences between building and operating fast reactors compared to thermal reactors would not be significant.

\subsubsection{Transuranic Storage and Cesium and Strontium Storage at the Recycling Center}

The recycling center might need to store a variety of radiological material pending ultimate disposition. For example, if fast reactors are delayed, it might be necessary to store the TRU that is separated from LWR SNF. As discussed below, the impacts of storing TRU would not be expected to be significantly different from the storage of LWR SNF (which is described in Section 4.2.1.1). ${ }^{37}$ Although TRU storage at the scale that might be needed is beyond current (or past) practice, experience with other radioactive material storage provides a useful basis for planning. The technical challenge includes simultaneously coping with heat output, radiation

\footnotetext{
${ }^{37}$ Although this section discusses TRU and cesium/strontium storage, the considerations in this section could also be applicable to mixed oxide (MOX) SNF that might be stored under the Thermal/Fast Recycle Alternative (see Section 4.4).
} 
emissions, criticality limits and security requirements. TRU would be managed with the following considerations:

- $\quad$ Quantities per package must be limited for criticality and decay heat limits. Limits are likely to be in the $\mathrm{kg} /$ package range.

- $\quad$ This material would require secure and monitored storage.

- $\quad$ The TRU product can be stored in a metal form, loose oxide, or pressed oxide.

- A custom storage facility would be needed, probably inside the separations plant or the fuel fabrication plant (Halsey 2007).

To support an $800 \mathrm{MTHM} / \mathrm{yr}$ separation process, approximately 94,000 lbs/yr (43,000 kg/yr) of TRU oxide would be generated. This material could be stored in approximately 3,000 cans (assuming approximately $37.5 \mathrm{lbs} / \mathrm{can}[14 \mathrm{~kg} / \mathrm{can}]$ ). To support 10 years of storage, a facility capacity of approximately $250,000 \mathrm{ft}^{2}\left(23,200 \mathrm{~m}^{2}\right)$ would be required (Bayer 2007).

Initial facilities could make use of past experience related to the storage of nuclear materials, including plutonium and other transuranics, and concentrated fission products (e.g., Cs and Sr). Existing packages, methods and protocols could be modified to cover these materials. Existing security methods would be reviewed to determine adequacy. Finally, to enable such storage as a commercial activity, a regulatory framework would need to be developed.

Cs-137 and Sr-90 are relatively short-lived fission product radionuclides contained in SNF that generate significant radioactive decay heat within 10 half-lives of their formation (approximately 300 years). The Fast Reactor Recycle Alternative may separate the Cs and Sr into a separate waste stream at the nuclear fuel recycling center. The $\mathrm{Cs} / \mathrm{Sr}$ stream would then be contained in sufficiently robust waste/storage forms and packaged in NRC-licensed transportation, storage, and/or disposal casks, as required by the chosen disposition path (see discussion below). Such an approach would lead to a range of potential disposition options for $\mathrm{Cs} / \mathrm{Sr}$. One approach assumes storage of the $\mathrm{Cs} / \mathrm{Sr}$ form for approximately 300 years in a surface or near-surface facility. The specific impacts of such a facility, including any design alternatives, would be assessed in a tiered NEPA document.

The storage facility would contain the necessary institutional controls to safeguard the material for approximately 300 years, after which time the original $\mathrm{Cs} / \mathrm{Sr}$ form might be disposed of as LLW. However, there is some uncertainty as to whether such a $\mathrm{Cs} / \mathrm{Sr}$ form would be classified as LLW after approximately 300 years under the current regulatory framework. This uncertainty leads to alternatives that could involve: 1) disposal of a $\mathrm{Cs} / \mathrm{Sr}$ waste form as HLW in a repository soon after generation; 2) disposal of a $\mathrm{Cs} / \mathrm{Sr}$ waste form as $\mathrm{HLW}$ in a repository after approximately 300 years of storage; and 3) disposal of a $\mathrm{Cs} / \mathrm{Sr}$ waste form in a LLW disposal facility after approximately 300 years of storage. Finally, alternative separations and processing that would not produce a separate $\mathrm{Cs} / \mathrm{Sr}$ stream must also be considered. The cost and benefit of separate $\mathrm{Cs} / \mathrm{Sr}$ management versus inclusion of $\mathrm{Cs} / \mathrm{Sr}$ with other waste streams requires further analysis. If $\mathrm{Cs} / \mathrm{Sr}$ is combined with other waste streams, another set of options for disposition (similar in many ways to 1 through 3 described above) could be envisioned. Further regulatory and technical analyses are required to narrow the range of options for $\mathrm{Cs} / \mathrm{Sr}$ management. 
If $\mathrm{Cs} / \mathrm{Sr}$ were stored at the nuclear fuel recycling center, the impacts of storing Cs and Sr fission products for approximately 300 years would be as follows. An 800-MTHM recycling facility would produce approximately 4.4 MT of Cs and Sr annually. ${ }^{38}$ Over a 40 -year operating life, the nuclear fuel recycling center would generate approximately 177 MT of Cs and Sr. These fission products could be solidified and stored in a ceramic waste form that would be contained in robust storage canisters until it has sufficiently decayed for disposal. These canisters would provide safe storage of the $\mathrm{Cs}$ and $\mathrm{Sr}$ and shielding against radiation as long as the storage facilities were maintained properly. Similar to the storage of SNF, release of contaminants to the ground, air, or water would not be expected during routine operations. Depending on waste form and package size, this 4.4 MT would likely require approximately 100 to 300 canisters (Geddes 2008). For 177 MT, approximately 4,000 to 12,000 canisters would be required. Cooling of these canisters would be accomplished using either a forced air-cooling system or a passive cooling system. For most scenarios, it is likely an engineering analysis would conclude that natural draft (passive) cooling is preferred. To store approximately 4,000 to 12,000 canisters, the building would have a footprint of about 80,000 to $240,000 \mathrm{ft}^{2}\left(7,400\right.$ to $22,300 \mathrm{~m}^{2}$ ) (Geddes 2008). A building of this size would likely require approximately 10 to 20 acres (4 to $8 \mathrm{ha}$ ) of land, depending upon the facility design.

Operations at the Cs and Sr storage facility would consist primarily of security and surveillance activities. Routine repairs and maintenance to the facilities and storage containers, and routine radiological surveys would generate sanitary and industrial solid waste and LLW. Approximately 100 staff would be required to support operations at the facility, with half of these workers considered to be "radiation workers." Typical doses to radiation workers would be approximately $100 \mathrm{mrem} / \mathrm{yr}$, and maximum individual exposure should not exceed $500 \mathrm{mrem}$ (Geddes 2008). Assuming that all radiation workers received a dose of $100 \mathrm{mrem}$, the total annual dose would be 5 person-rem. Statistically, an annual worker dose of 5 person-rem would result in an annual risk of $0.003 \mathrm{LCF}$. After the facility stops receiving additional $\mathrm{Cs}$ and $\mathrm{Sr}$, the doses to workers would be expected to decrease over time as the Cs and Sr decays. Assuming that radiation doses would decrease at the same rate as the $\mathrm{Cs}$ and $\mathrm{Sr}$ decays, doses to workers would decrease by half every 30 years. Consequently, after 30 years of operation, the total annual worker dose would decrease to 2.5 person-rem. After 60 years, this dose would decrease to 1.25 person-rem and would continue to decrease by half every 30 years. In the final 30 years of storage, the total annual worker dose would be 0.005 person-rem, which would statistically translate to an annual risk of $3.0 \times 10^{-6} \mathrm{LCF}$ (see Figure 4.3-2).

\footnotetext{
${ }^{38}$ Derived from Table 4.8-3. Approximately $12 \mathrm{MT}$ of Cs and Sr are generated for each 2,170 MTHM of LWR spent fuel recycled.
} 


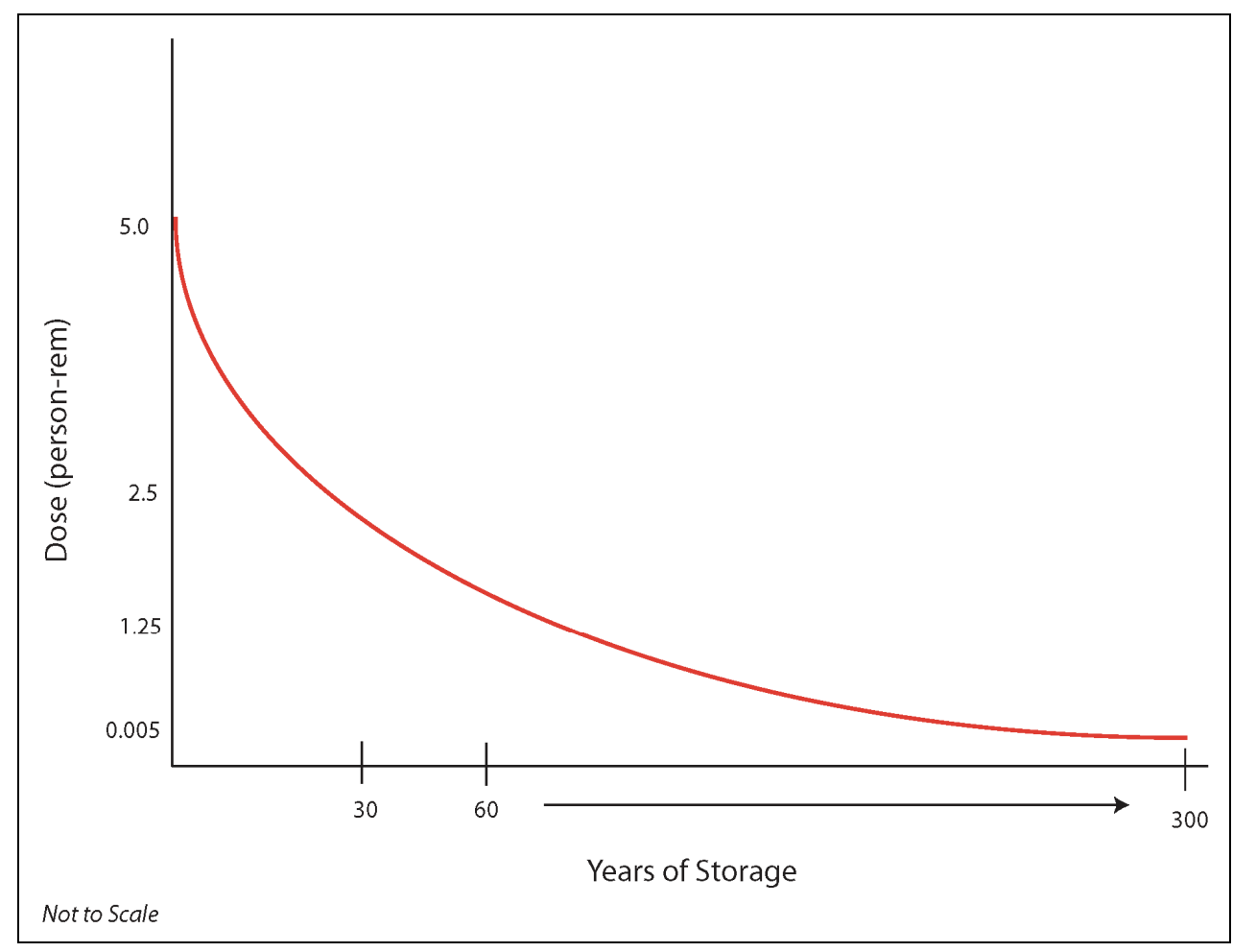

FIGURE 4.3-2 - Annual Worker Dose for Cesium/Strontium Storage over 300 Years

Accidents associated with $\mathrm{Cs}$ and $\mathrm{Sr}$ storage were considered, but determined to be bounded by other accidents associated with the nuclear fuel recycling center (see Appendix D, Section D.2.2.1). Consequently, the impacts from $\mathrm{Cs}$ and $\mathrm{Sr}$ storage accidents would not exceed the consequences and risks presented for other processes in the nuclear fuel recycling center. Additionally, after the facility stops receiving additional $\mathrm{Cs}$ and $\mathrm{Sr}$, any potential impacts from $\mathrm{Cs}$ and Sr storage accidents would decrease over time as the materials decay.

Some of the fission products (such as $\mathrm{Cs} / \mathrm{Sr}$ ) separated in a nuclear fuel recycling center could have beneficial uses, including direct production of energy in thermionic generators or for other uses such as gamma sterilization of medical equipment or food products. The consideration of beneficial uses of fission products is outside the scope of the proposed actions and their alternatives and accordingly the analysis in this PEIS is limited to storage onsite and/or disposal. If there are proposals to utilize these fission products in the future, appropriate NEPA review would be conducted at that time.

\subsubsection{Analysis of Separations Process Options and Target Fabrication}

There are several different separation technologies that could be used to recycle SNF. The current operating reprocessing facilities in the United Kingdom and France are using the PUREX process. PUREX is an acronym standing for Plutonium and Uranium Recovery by Extraction. The PUREX process is a proven technology that has been used by DOE and commercial industry since the 1950s. However, it does not meet the GNEP strategic goals of not producing a separated plutonium stream. 
Under the AFCI program, the United States has been developing alternative separation processes that would not separate out a pure plutonium stream. The United States research and development (R\&D) programs have primarily centered on the UREX+ suite of processes, or Uranium Recovery by Extraction. UREX+ variations also have the capability to separate other radionuclides from the SNF such as cesium, strontium, and technetium, as well as individual transuranics such as americium and curium. Plutonium would not be separated out as a separate stream. In addition to the UREX+ processes, the international nuclear community has also been developing alternatives to the PUREX process, such as COEX ${ }^{\circledR}$ which produces a U-Pu blended product and $\mathrm{NUEX}^{\circledR}$, a process yielding a U-Pu-Np blend. Additionally, non-aqueous processes (e.g., electrochemical-based approaches) have also been considered for the separations and recovery of various constituents of SNF. Additional details on the various separations processes including UREX+ and electrochemical are provided in Appendix A.

The data provided in Appendix A are based on the UREX+1a process, consistent with past U.S. policy, which would not result in a civilian nuclear fuel cycle involving separated plutonium. UREX+1a was chosen as the baseline for developing the data in this PEIS since it was assumed to be the most likely process for future deployment and to bound the environmental impacts among the most likely recycle options Table 4.3.4-1 provides a summary of various UREX+ processes. The waste products from UREX +1 a are technetium, cesium, and strontium, and the remainder of the fission products. Off-gases from the UREX+ separation processes include various volatile fission products such as iodine, tritium, and carbon. These volatile fission products would be produced regardless of the separation process used.

TABLE 4.3.4-1-Aqueous Separation Processes

\begin{tabular}{|c|c|c|c|c|c|c|c|}
\hline Process & Product 1 & Product 2 & Product 3 & Product 4 & Product 5 & Product 6 & Product 7 \\
\hline UREX+1 & $\bar{U}$ & Tc & $\mathrm{Cs} / \mathrm{Sr}$ & TRU+Ln & F.P. & & \\
\hline UREX+1a & U & Tc & $\mathrm{Cs} / \mathrm{Sr}$ & TRU & All F.P. & & \\
\hline UREX+2 & U & Tc & $\mathrm{Cs} / \mathrm{Sr}$ & $\mathrm{Pu}+\mathrm{Np}$ & $\mathrm{Am}+\mathrm{Cm}+\mathrm{Ln}$ & F.P. & \\
\hline UREX+3 & $\mathrm{U}$ & Tc & $\mathrm{Cs} / \mathrm{Sr}$ & $\mathrm{Pu}+\mathrm{Np}$ & $\mathrm{Am}+\mathrm{Cm}$ & All F.P. & \\
\hline UREX+4 & $\mathrm{U}$ & Tc & $\mathrm{Cs} / \mathrm{Sr}$ & $\mathrm{Pu}+\mathrm{Np}$ & $\mathrm{Am}$ & $\mathrm{Cm}$ & All F.P. \\
\hline
\end{tabular}

The differences in facility size, resources, and other environmental impacts for the various UREX+ processes are relatively minor (WSRC 2008d). The main differences would be in the waste and products produced. The separation of americium and curium from the TRU leads to increased impacts on waste volumes, worker exposure, transportation, and impacts on fuel fabrication. These impacts have only been evaluated qualitatively (WSRC 2008d).

The additional products (americium and curium) under UREX +3 and UREX +4 separation processes would be extremely radioactive and thermally hot. There is no mature technology to solidify, package, store, transport, or further process this material in significant quantities. Solidification, packaging, and storage would have to be developed. This would be a difficult and challenging task. A specially designed hot cell facility would be required. Due to the concentration and handling of these highly radioactive products, an increase in the dose to workers and those affected by transport of the products would be expected, although design features would be in place to maintain ALARA (WSRC 2008d). 
The separation of americium and curium from the major transuranics, as well as potentially from each other into separate product streams, would require more facilities and equipment and result in more containers to be stored and transported. Fabrication of qualified reactor targets would be a complex process. Fabricating americium and curium targets in addition to a uranium/plutonium fuel (or uranium/plutonium/neptunium fuel) would require a larger facility with larger environmental impacts than the homogeneous fuel of the UREX+1a approach (WSRC 2008d). The additional separations would be required for the UREX +3 or +4 approaches would make the americium and curium available for targets in a heterogeneous reactor concept. The amount of americium and curium recovered by the separation processes is relatively small when compared to the remaining uranium, plutonium and neptunium product. Fabrication of americium and curium targets would require the use of hot cells and remote equipment. By performing this additional separation, the complex remote process using hot cells and remote fabrication techniques would be confined to the small quantity of $\mathrm{Am} / \mathrm{Cm}$ targets. The bulk $\mathrm{Pu}-\mathrm{Np}$ fuel could be made more efficiently in gloveboxes. In addition, the targets could potentially be used in both fast reactors and LWRs. Targets used in LWRs would need to be left in the core over several fuel cycles to obtain the same amount of transmutation as in a fast reactor.

The other main aqueous separation technologies being considered are COEX ${ }^{\circledR}$ and NUEX ${ }^{\circledR}$. The French have developed the uranium-plutonium co-extraction process, COEX ${ }^{\circledR}$. The $\mathrm{COEX}^{\circledR}$ process, described in Appendix A, does not produce a separated plutonium stream anywhere in the process line. This process would meet the GNEP goal of not separating out pure plutonium. The front end (e.g., fuel receipt, storage, chopping, voloxidation, dissolving, hull disposal, etc.) of a COEX ${ }^{\circledR}$ plant would be similar to the front end of a UREX+ based facility. Based on the best information available, the overall plant size would be smaller than the UREX+1a baseline discussed in Appendix A. This would be due to fewer extraction processes and support systems, in addition to fewer product and waste solidification, packaging and storage operations. The uranium-plutonium product stream is suitable as feedstock for conventional MOX technology (WSRC 2008d).

NUEX $^{\circledR}$ is a proprietary co-extraction technology developed by the British, and licensed to Energy Solutions, Inc. NUEX ${ }^{\circledR}$ produces a plutonium-neptunium product stream and has no separated pure plutonium anywhere in the process line. Uranium can also be solidified with the $\mathrm{Pu}-\mathrm{Np}$ product to further dilute the plutonium. There are currently no facilities in operation using the NUEX ${ }^{\circledR}$ separations process. The separations chemistry uses relatively new complexants and process reagents (Energy Solutions 2007). Additional testing and development of the NUEX ${ }^{\circledR}$ process is required (Energy Solutions 2007).

All aqueous processes under consideration for future deployment would include design features to preclude separating pure plutonium in a surreptitious manner. While all aqueous processes under consideration could be modified to have this capability, physical changes in the highly radioactive process cells and process piping networks would be required and could not be accomplished surreptitiously.

A recycling facility using a non-aqueous electrochemical separations process would be slightly smaller than a UREX+ facility for any given throughput. Electrochemical separation does not require solvent systems and the multiple stages of separation like its aqueous counterparts. 
However, while the main process facility is likely to be slightly smaller in an electrochemical plant than an aqueous operation, most of the plant is identical (e.g., fuel receipt/storage, product and waste handling, utilities, support, etc.); therefore, only a very minor reduction in total facilities or resources would be expected. Electrochemical processing employs an electrorefiner, chloride salt, and liquid metals to separate SNF. Additional information on electrochemical processing is provided in Appendix A. Electrochemical processing is widely used in metal processing and refining, but application at the scale considered in this PEIS has not been attempted for nuclear processes. Additional $\mathrm{R} \& \mathrm{D}$ would be required to support potential deployment of this technology for commercial application.

The UREX +1 a baseline was used to provide the bounding risks and environmental impacts. The risk to workers and the public for a UREX +1 a separations operation is expected to be essentially the same as with any other aqueous process, including UREX+ variations, COEX ${ }^{\circledR}$, and NUEX ${ }^{\circledR}$. Risk is a function of source terms and accident scenarios, and all aqueous separations processes handle the same radionuclide inventories and have similar equipment and chemical inventories. Environmental impacts of the UREX +1 a baseline would bound the impacts of simpler processes like COEX ${ }^{\circledR}$ and NUEX ${ }^{\circledR}$, and be similar to those of the more complex UREX+ variations like UREX+3 and UREX+4.

In a 2006 comparison study (Chandler 2006), $\operatorname{COEX}^{\circledR}$ was chosen as the technology of choice if operating temperature, proliferation, or equal ranking of attributes was the guiding factor. If the guiding factor was more effluent streams, the choice was UREX+2 (Chandler 2006). The NUEX $^{\circledR}$ process was not one of the separation processes evaluated in the study. The attributes used in the study were number of steps, operating temperature, operating pressure, use of corrosive materials, maximum credible accident, explosiveness, secondary waste, separate plutonium stream, decontamination factor, and number of effluent streams. Another study concluded that the Attractiveness Level, which is analogous to proliferation resistance, for $\mathrm{UREX}+\mathrm{a}$ and $\mathrm{COEX}^{\circledR}$ are nominally the same (Bathke et al. 2008).

The data provided in Appendix A assumes that the transmutation fuel fabrication facility would produce a U/TRU ceramic oxide fuel. Due to the high radioactivity and thermal output of a mixed TRU fuel containing Am and $\mathrm{Cm}$, operations would take place in hot cells instead of gloveboxes typical for a Pu-based mixed-oxide (MOX) fuel fabrication facility. A fuel fabrication facility using $\mathrm{U} / \mathrm{Pu}$ or $\mathrm{U} / \mathrm{Pu} / \mathrm{Np}$ product from a COEX ${ }^{\circledR}$ or $\mathrm{NUEX}^{\circledR}$ separations process, would have similar processing steps to the fuel fabrication facility described in Appendix A, however; the operations generally could be conducted in gloveboxes. The fuel fabrication facility would be smaller and less costly due to the reduced shielding requirements and elimination of the remote operation and maintenance features required for U/TRU fuel fabrication (WSRC 2008d).

\subsection{Thermal/Fast Reactor Recycle Fuel CyCle Alternative (THERMaL/FAST REACTOR RECYCLE ALTERNATIVE)}

As described in Chapter 2, Section 2.4, for the Thermal/Fast Reactor Recycle Alternative, this PEIS considers recycling transuranics in MOX-U-Pu fuel in commercial LWRs (thermal recycle) prior to recycling in fast reactors. The use of thermal recycle prior to fast recycle has the 
potential to allow the United States to begin recycling SNF sooner. Additionally, thermal recycle could reduce the number of fast reactors that may need to be deployed. This section describes the major environmental impacts associated with initial thermal recycling followed by fast reactor recycle. Under the Thermal/Fast Reactor Recycle Alternative, DOE could decide to recycle the transuranics multiple times in LWRs (similar to the approach described in Chapter 2, Section 2.5.1). Eventually, however, fast reactor transmutation would ultimately be employed.

The use of thermal recycling could be affected by many factors, including nuclear power growth rates, conversion ratios, and the SNF separations capacity deployed. The use of thermal recycle would reduce the required number of fast reactors by approximately 25 percent (from a balanced system that includes 60 percent LWR capacity and 40 percent fast reactor capacity to one of 70 percent LWR capacity and 30 percent fast reactor capacity) (see Table 4.8-1 and contrast the Fast Reactor Recycle Alternative and the Thermal/Fast Reactor Recycle Alternative).

Construction: If a Thermal/Fast Reactor Recycle Alternative with a capacity of $200 \mathrm{GWe}$ is pursued, the following facilities could be built:

- $\quad 140 \mathrm{GWe}$ of LWR capacity, consisting of approximately $126 \mathrm{GWe}$ using a traditional uranium dioxide $\left(\mathrm{UO}_{2}\right)$ fuel and $14 \mathrm{GWe}$ using a MOX-U-Pu fuel (the $140 \mathrm{GWe}$ also includes the replacement of approximately $100 \mathrm{GWe}$ of LWR capacity when existing LWRs reach their end-of-life).

- 60 GWe of fast reactor capacity.

- Four LWR separation facilities (each with a capacity of approximately $800 \mathrm{MTHM} / \mathrm{yr}$, and the capability to separate both LEU fuel and MOX-U-Pu fuel). ${ }^{39}$

- Up to six transmutation fuel fabrication facilities (each with a capacity to fabricate $100 \mathrm{MTHM} / \mathrm{yr}$ of fuel). ${ }^{40}$

- Up to six fast reactor SNF separations facilities (each with a capacity to separate $100 \mathrm{MTHM} / \mathrm{yr}$ of SNF). ${ }^{41}$

- Internal modifications to LEU fuel fabrication capabilities, or a new fuel fabrication facility, to fabricate MOX-U-Pu fuel to support 14 GWe of LWR capacity.

Although some facilities could be colocated, the construction of this much capacity would necessitate that many sites in the United States be utilized. For this analysis, it is assumed that the nuclear fuel recycling center(s) and the reactors would not be colocated, which would necessitate transportation of material between the facilities during operations.

From a construction standpoint, the use of thermal recycling would have similar construction impacts compared to the Fast Reactor Recycle Alternative. For example, for a $200 \mathrm{GWe}$ capacity, the Thermal/Fast Reactor Recycle Alternative would still require the construction of

\footnotetext{
${ }^{39}$ As shown in Table 2.10-1, the 200 GWe scenario would require approximately 3,080 MTHM/yr of LWR separations capacity. The PEIS analysis is based on a LWR separation facility sized at $800 \mathrm{MTHM} / \mathrm{yr}$. Because four facilities would have a capacity to separate 3,200 MTHM/yr, there would be approximately $120 \mathrm{MTHM} / \mathrm{yr}$ of excess LWR separation capacity.

${ }^{40}$ As shown in Table 2.10-1, the 200 GWe scenario would require approximately $540 \mathrm{MTHM} / \mathrm{yr}$ of transmutation fuel fabrication capacity. The PEIS analysis is based on a transmutation fuel fabrication facility sized at $100 \mathrm{MTHM} / \mathrm{yr}$. Because six facilities would have a capacity to fabricate $600 \mathrm{MTHM} / \mathrm{yr}$, there would be an excess capacity of approximately $60 \mathrm{MTHM} / \mathrm{yr}$.

${ }^{41}$ As shown in Table 2.10-1, the 200 GWe scenario would require approximately $540 \mathrm{MTHM} / \mathrm{yr}$ of fast reactors SNF separation capacity. The PEIS analysis is based on a fast reactor SNF separation facility sized at $100 \mathrm{MTHM} / \mathrm{yr}$. Because six facilities would have a capacity to separate $600 \mathrm{MTHM} / \mathrm{yr}$, there would be an excess capacity of approximately $60 \mathrm{MTHM} / \mathrm{yr}$.
} 
multiple nuclear fuel recycling centers with a total capacity of approximately 3,080 MTHM/yr (see Table 2.10-1). Construction of 4 LWR separation facilities would require a total of approximately 2,000 acres ( 810 ha) (based on 500 acres [200 ha] per facility; see Appendix A, Section A.6.1.2). Construction of 6 fast reactor SNF separations facilities would require a total of approximately 1,500 acres (600 ha) (based on 250 acres [100 ha] per facility, see Appendix A, Section A.6.3.2). Construction of 6 transmutation fuel fabrication facilities would require a total of approximately 600 acres (240 ha) (based on 100 acres [40 ha] per facility, see Appendix A, Section A.6.2.2). The total land required for the Thermal/ Fast Reactor Recycle Alternative with a capacity of $200 \mathrm{GWe}$ would be approximately 604,000 acres $(244,000 \mathrm{ha})$.

If a new fuel fabrication facility to fabricate MOX-U-Pu fuel were constructed, it could add to the land required, but would be expected to be smaller than 350 acres. Alternatively, existing or future LEU fuel fabrication facilities could be modified to fabricate MOX-U-Pu fuel. As explained in Appendix A, Section A.3.1.4, because MOX-U-Pu fuel fabrication is similar to LEU fuel fabrication, these modifications are expected to be minor, and could include additional shielding within the facility. These modifications are expected to be accomplished within the footprint of existing facilities.

Relative to fast reactor construction impacts, thermal recycle could reduce the number of fast reactors ultimately constructed. However, because the total reactor capacity would be $200 \mathrm{GWe}$, the overall impacts $(600,000$ acres [243,000 ha] for reactors) would not change significantly compared to the Fast Reactor Recycle Alternative. The total land required for the Thermal/Fast Reactor Recycle Alternative with a capacity of $200 \mathrm{GWe}$ would be approximately 604,000 acres (244,000 ha).

No new construction would be needed to support the irradiation of MOX-U-Pu fuel, rather than LEU fuel, at commercial reactor sites. As a result, the following resource areas would be unaffected by MOX-U-Pu fuel use: land use; visual resources; cultural and paleontological resources; geology and soils; site infrastructure; air quality and noise; ecological resources; water resources; and socioeconomics.

Operation: The environmental impacts described in this section were largely developed from data in the Surplus Plutonium Disposition Final Environmental Impact Statement (hereafter SPD EIS) (DOE 1999d), which assessed the impacts of using a partial MOX-U-Pu core (i.e., up to 40 percent MOX-U-Pu fuel) instead of an LEU core in existing, commercial LWRs, for operations over approximately 15 years. The potential impacts had been analyzed for the following nuclear power plants: Catawba Nuclear Station near York, SC; the McGuire Nuclear Station near Huntersville, NC; and the North Anna Power Station near Mineral, VA. Under the thermal recycle approach, both MOX-U-Pu and LEU fuel assemblies would be loaded into the reactor. The MOX-U-Pu assemblies would remain in the core for two 18-month cycles and the LEU assemblies for either two or three 18-month cycles, in accordance with the plant's operating schedule. When the MOX-U-Pu fuel completes a normal cycle, it would be withdrawn from the reactor in accordance with the plant's standard refueling procedures and placed in the plant's SNF pool for cooling alongside other SNF. No changes are expected in the plant's SNF storage plans to accommodate the MOX-U-Pu SNF. Although the amount of fissile material would be higher in MOX-U-Pu SNF rods than in LEU SNF, rod numbers and spacing in the SNF pool and 
dry storage casks could be adjusted as necessary to maintain safety margins. When sufficiently cooled, the SNF would be shipped to the nuclear fuel recycling center for recycling.

Operationally, the use of thermal/fast recycle would result in similar impacts to those presented in Section 4.3.1 (Fast Reactor Recycle Alternative), along with the impacts associated with the use of MOX-U-Pu in LWRs.

Uranium Requirements: The quantity of natural uranium needed to support a capacity of $200 \mathrm{GWe}$, assuming an average enrichment of 4.4 percent, would be approximately $25,400 \mathrm{MT} / \mathrm{yr}$ (see Table 4.8-1). The 25,400 MT of natural uranium would represent approximately 64 percent of uranium that was mined in the world in 2006 and would be 15 times more than the quantities currently mined in the United States annually (see Table 4.1-1). From this 25,400 MT, approximately 2,800 MT of enriched uranium (assuming 4.4 percent enrichment) would be required. Approximately 17 million SWUs would be required annually to support a capacity of $200 \mathrm{GWe}$. The licensed capacity of Paducah, the American Centrifuge Plant, and the LES Facility is 17.8 million SWUs. Consequently, enrichment facilities in the United States could meet this demand. However, if Paducah shuts down in 2012, as planned, the United States enrichment capacity would be reduced to approximately 6.8 million SWUs. To support a $200 \mathrm{GWe}$ capacity, enrichment capacities in the United States would need to be expanded by more than 100 percent, or larger quantities of enriched uranium would need to be imported.

Fuel Fabrication Requirements: The United States currently has three operational LWR uranium fuel fabrication facilities with a capacity to produce approximately 3,500 MT of LWR fuel assemblies (Table 4.1-2). For the Thermal/Fast Recycle Alternative, approximately 2,800 MT of fresh fuel assemblies (90 percent would use a traditional $\mathrm{UO}_{2}$ fuel and 10 percent would use a MOX-U-Pu fuel) would need to be produced annually to support the $200 \mathrm{GWe}$ scenario. Consequently, the existing fuel fabrication facilities in the United States would be able to provide this capacity, although internal modifications could be required for MOX-U-Pu fuel fabrication. Fabrication of MOX-U-Pu ${ }^{42}$ fuel is described below. The fast reactor fuel fabrication requirements would be met by constructing and operating the six fast reactor SNF separations facilities with an associated transmutation fuel fabrication capability.

MOX-U-Pu Fuel Fabrication Requirements: Appendix A, Section A.3.1.4 contains a brief description of the MOX-U-Pu fuel fabrication process. Viewed from the outside, MOX-U-Pu fuel for PWRs or boiling water reactors (BWRs) would be identical to the enriched-uranium fuel it replaces - same assembly structure, spacing, rods, claddings, grids, and springs. The pellets enclosed in the claddings are of the same size - the only difference is their composition. A MOX-U-Pu assembly would be made in the same way as a standard assembly, except for the manufacture of the pellets, which are made from a mixture of uranium and plutonium oxide. In the core of a LWR, because of non-fissile plutonium isotopes, among other things, twice the amount of plutonium would be needed to obtain the energy equivalence of a fuel enriched in U-235. This would impose additional constraints on the fuel fabrication plant but would not result in major physical changes. Design features would be in place to maintain ALARA

\footnotetext{
${ }^{42}$ This section discusses MOX-U-Pu fuel, as that is the most extensively used MOX fuel. However, a MOX-TRU fuel could also be used. Section 4.5.1.1 discusses the issues associated with the use of MOX-TRU fuel.
} 
exposures. Public risk is unlikely to result in significant impacts (see, for example, NRC 2005c, which concluded that operations from a MOX fuel fabrication facility at the Savannah River Site, SC would result in an annual collective population dose of 0.073 person-rem/yr and the MEI would receive an estimated annual dose of $5.1 \times 10^{-4} \mathrm{mrem} / \mathrm{yr}$.)

Land Resources: Once operational, a total of approximately 604,000 acres (244,000 ha) of land could be occupied by facilities, paved areas, and buffer zones. Most of this area would not be disturbed but would be provided as a buffer between the actual facility and the outer facility boundary. The total site area would be determined by accident analysis and regulatory requirements, including safeguards and security.

Visual Resources: With respect to visual characteristics, the visibility of any reactor from publicly accessible locations would be dependent on the future site characteristics. For sites that use "wet" cooling tower systems, the water vapor plume from cooling tower operations may be visible for many miles from the plant.

Air Resources: The estimated air pollutants resulting from operation of the reactors would not be expected to increase due to the use of MOX-U-Pu fuel in reactors.

Water Resources: Impacts to water would be similar to the Fast Reactor Recycle Alternative presented in Section 4.3.

Socioeconomic Impacts: The reactor sites would not need to employ any additional workers to support the use of MOX-U-Pu fuel in the reactors. As such, the overall socioeconomic impacts would be similar to those presented for the Fast Reactor Recycle Alternative.

Human Health: There should be no change in the radiation dose to the public from normal operation of the reactors with a partial MOX-U-Pu fuel core versus a full LEU fuel core. The dose to workers at an LWR fueled with MOX-U-Pu would be the same as an LWR fueled with uranium (190 mrem/yr). Doses to workers at the recycling centers would be similar to those presented in Section 4.3.1. Overall, the total dose to workers for the Thermal/Fast Reactor Recycle Alternative would be as follows:

- The total annual dose to workers associated with the nuclear fuel recycling centers would be approximately 4,400 person-rem (LWR separation: 4 facilities x 2,226 radiation workers/facility x $250 \mathrm{mrem} / \mathrm{yr}$ average dose [WSRC 2008a]; fast reactor SNF separation/fuel fabrication: 6 facilities x 1,456 radiation workers/facility x $250 \mathrm{mrem} / \mathrm{yr}$ average dose [WSRC 2008b, WSRC 2008c]).

- The total annual dose to workers at the advanced recycling reactors ( $60 \mathrm{GWe}$ of capacity) would be approximately 6,270 person-rem (assumes 550 radiation workers/GWe x $190 \mathrm{mrem} / \mathrm{yr}$ average dose).

- At the LWRs (140 GWe of capacity), the total annual dose to workers would be approximately 14,600 person-rem (assumes 550 radiation workers/GWe x $190 \mathrm{mrem} / \mathrm{yr}$ average dose). 
The total annual dose to workers associated with the $200 \mathrm{GWe}$ Thermal/Fast Reactor Recycle Alternative would be approximately 25,300 person-rem, which equates to an annual LCF risk of approximately 15 . Statistically, this means that 15 LCFs could occur for every year of operation of a Thermal/Fast Reactor Recycle Alternative at the capacities assumed at the end of the implementation period (i.e., that separates 3,080 MTHM/yr of LWR SNF $\left(\mathrm{UO}_{2}\right.$ and MOX-U-Pu) and $540 \mathrm{MTHM} / \mathrm{yr}$ of fast reactor SNF, produces $540 \mathrm{MTHM} / \mathrm{yr}$ of fast reactor transmutation fuel, and operates $200 \mathrm{GWe}$ of LWR and advanced recycling reactor capacity).

Facility Accidents: The Thermal/Fast Reactor Recycle Alternative would utilize LWRs and ALWRs with uranium fuel, LWRs and ALWRs with MOX-U-Pu fuel, a nuclear fuel recycling center, and advanced recycling reactors. The potential accident impacts of LWRs with uranium fuel are presented in Section 4.2.2; the potential accident impacts at a nuclear fuel recycling center and an advanced recycling reactor are presented in Section 4.3.1. This section presents the potential accident impacts of an LWR and ALWR using a MOX-U-Pu fuel. ALWRs and LWRs using MOX-U-Pu fuel are part of other alternatives as well.

The impact of potential accidents at LWRs utilizing recycled MOX-U-Pu fuel was evaluated for the SPD EIS (DOE 1999d). The SPD EIS evaluated accidents at three existing LWR sites utilizing conventional LWR (LEU) cores, as well as cores consisting of 40 percent MOX-U-Pu fuel and 60 percent conventional LWR fuel. The SPD EIS considered both design basis and beyond design basis events, both of which are included here. In this PEIS, DOE has re-analyzed the consequences of the accident scenarios presented in the SPD EIS at the six generic sites described in Appendix D.

With respect to MOX-U-Pu fueled LWRs, the internally initiated accident with the highest consequence to the onsite and offsite populations would be the "Interfacing System LOCA." Using the dose-to-risk conversion factor of $6 \times 10^{-4} \mathrm{LCF}$ per person-rem, the collective population doses are estimated to result in 1,000 to 40,000 additional LCFs in the surrounding population. For the MEI, this scenario would result in prompt fatality. For the noninvolved worker this scenario would also result in a prompt fatality.

Consequences do not account for the probability of an accident, and thus represent the impacts that could result if an accident were to occur. Another useful metric to consider in an accident analysis is risk. Risk takes into account the probability of an accident and is determined by multiplying the consequences of an accident by the probability of occurrence.

With respect to MOX-U-Pu fueled LWRs, the accident with the highest risk to the onsite and offsite populations is also an "Interfacing System LOCA." The risk to the offsite population for this scenario would range from $7 \times 10^{-5}$ expected LCF per year of operation in the Site 1 offsite population to $3 \times 10^{-3}$ expected LCF per year of operation in the Site 6 offsite population. For the MEI, the same scenario would result in an increased risk of an LCF of $7 \times 10^{-8}$ per year of operation; that risk corresponds with the probability that the accident would occur. For the onsite noninvolved worker, this scenario would result in an increased LCF risk of $7 \times 10^{-8}$; that risk corresponds with the probability that the accident would occur. 
The LWR (both LEU fueled and MOX-U-Pu fueled) internally initiated accident population consequences are two or more orders of magnitude greater than the corresponding values for the other reactors. The higher consequence for the MOX-U-Pu case is not the result of differences in the fuels, but is instead the result of differences in the assumed designs of the reactors. The SPD EIS found that the MOX-U-Pu fuel increased risk an average of 5 percent with a maximum increase of 22 percent (DOE 1999d, pages 68 to 74). The ALWR design used as the basis for this PEIS includes advanced active safety features that are not present on the existing LWR design used as the basis for the MOX-U-Pu analysis. The internally initiated accident with the greatest consequence and risk for the LWR is an "Interfacing System LOCA," as shown in Appendix D, Section D.2.3. This scenario could result in a direct release of radioactive material from containment (see page K-62 of DOE 1999d). The internally initiated accident with the greatest consequence and risk for the ALWR is a "Low Pressure Core Melt with Loss of Long-Term Coolant Makeup and Containment Vessel" (DOE 1995b). This accident involves containment venting through a scrubber, which is expected to reduce particulate releases by roughly two orders of magnitude.

If the MOX-U-Pu analysis were based on use of an ALWR rather than an LWR, the internally initiated event results would have been approximately the same as those for the ALWR. As with the ALWR, the other advanced reactor designs considered in this PEIS include inherent passive and/or advanced active safety features that prevent releases. The conclusion, that the difference between the LWR internally initiated accident results and the results for the other reactors is due to differences in the assumed reactor designs, is supported by the results for the externally initiated and natural phenomena accidents. For these accidents (i.e., the "Beyond Design Basis Earthquake" and "Aircraft Crash"), the reactor designs were ignored and common release parameters were applied to the core inventories for all reactors. These results (see Appendix D) show the LWR and ALWR results are nearly identical. The difference in the assumed power levels for the other reactors, ranging from roughly 3,400 MWth for the largest MOX-U-Pu LWR (see Section K-7 of DOE 1999d) to 350 MWth for the HTGR (Bowman 1991) accounts for much of the differences between reactors for the externally initiated and natural phenomena events.

With respect to MOX-U-Pu fueled ALWRs, the bounding scenarios, consequences, and risks are expected to be the same as those for the LEU fueled ALWRs. This expectation is based on the SPD EIS (DOE 1999d), which concluded that use of MOX-U-Pu fuel in an LWR rather than LEU would result in an average of about a 5 percent increase in consequences. Therefore, the bounding scenarios, consequences, and risks for the MOX-U-Pu fueled ALWR would be approximately the same as the consequences and risks for the LEU fueled ALWR presented in Section 4.2.

Spent Nuclear Fuel and Radioactive Wastes: The amount of SNF generated over the period between 2010 and 2060-2070 would be approximately 143,000 MTHM (approximately 132,000 MTHM for the LWRs [of this, 126,000 MTHM would be from LEU fuel and 6,000 would be from MOX-U-Pu fuel] and 11,000 MTHM from the advanced recycling reactors). ${ }^{43}$ By

\footnotetext{
${ }^{43}$ Based on the following assumptions: the first new LWR is constructed in 2015; each LWR produces approximately 21.7 MTHM of SNF/GWeyr; in 2020, implementation begins and approximately 10 percent of LWRs transition to MOX-U-Pu fuel. Each LWR with MOX-U-Pu fuel produces approximately $22 \mathrm{MTHM}$ of SNF/GWe-yr. Fast reactors begin to come on-line; from 2020 to 2060-2070, total nuclear generating capacity (i.e., LWRs and fast reactors) grows until $200 \mathrm{GWe}$ is achieved. Fast reactors produce approximately $9 \mathrm{MTHM}$ of SNF/GWe-yr .
} 
2060-2070, approximately 3,000 MTHM of SNF would be generated annually from commercial LWRs. This SNF would go to a recycling center. The advanced recycling reactors would generate an additional 540 MTHM of fast reactor SNF annually. This SNF would also be recycled.

The Thermal/Fast Reactor Recycle Alternative would produce wastes similar to the Fast Reactor Recycle Alternative, with some minor changes. Table 4.4-1 presents the wastes associated with the Thermal/Fast Reactor Recycle Alternative. As shown in Table 4.4-1, the LLW, HLW, and GTCC LLW generated by the recycling centers for the Thermal/Fast Reactor Recycle Alternative would be approximately 10 percent lower than the wastes from the recycling centers for the Fast Reactor Recycle Alternative (Wigeland 2008a). Overall, however, the total quantities of wastes generated by the Thermal/Fast Reactor Recycle Alternative would be similar to the total quantities of wastes generated by the Fast Reactor Recycle Alternative (see Table 4.4-1 versus Table 4.3-2). The cesium and strontium wastes generated would be the same as the Fast Reactor Recycle Alternative and could be stored at the recycling center for 300 years (see Section 4.3.3), or transported to a HLW storage or disposal facility. Because any recovered uranium could be reused, the quantities in Table 4.4-1 do not include recovered uranium.

TABLE 4.4-1-Total Spent Nuclear Fuel and Wastes Generated by the Thermal/Fast Reactor Recycle Alternative (50 Years of Implementation)

\begin{tabular}{|c|c|c|c|c|}
\hline Waste Category & $\begin{array}{l}\text { Nuclear Fuel } \\
\text { Recycling } \\
\text { Centers (for } \\
200 \text { GWe in } \\
2060-2070)\end{array}$ & $\begin{array}{c}\text { Advanced } \\
\text { Recycling } \\
\text { Reactors } \\
\text { (60 GWe in } \\
2060-2070)\end{array}$ & $\begin{array}{c}\text { LWRs } \\
\text { (140 GWe in 2060-2070) }\end{array}$ & $\begin{array}{c}\text { Total } \\
\text { (Nuclear Fuel } \\
\text { Recycling Centers } \\
\text { + Advanced } \\
\text { Recycling Reactors } \\
\text { + LWRs) }\end{array}$ \\
\hline SNF (MTHM) ${ }^{a}$ & 0 & 11,000 & $\begin{array}{c}132,000 \\
(126,000 \text { of LEU SNF; } \\
6,000 \text { of MOX-U-Pu SNF) }\end{array}$ & 143,000 \\
\hline $\begin{array}{l}\text { LLW (solid) } \\
\text { (cubic meters) }\end{array}$ & $2,082,000^{b}$ & $\begin{array}{l}\text { LB: } 32,000 \\
\text { UB: } 119,000^{c}\end{array}$ & $\begin{array}{l}\text { LB: } 118,000 \\
\text { UB: } 466,000^{\mathrm{d}}\end{array}$ & $\begin{array}{l}\text { LB: } 2,232,000 \\
\text { UB: } 2,667,000\end{array}$ \\
\hline $\begin{array}{l}\text { HLW (cubic } \\
\text { meters) }\end{array}$ & $54,000^{\mathrm{e}}$ & 0 & 0 & 54,000 \\
\hline $\begin{array}{l}\text { GTCC LLW } \\
\text { (cubic meters ) }\end{array}$ & $398,000^{f}$ & $500^{\mathrm{g}}$ & $2,000^{\mathrm{g}}$ & 400,500 \\
\hline $\begin{array}{l}\text { Cesium/Strontium } \\
\text { (cubic meters) }\end{array}$ & $\begin{array}{l}\text { LB: } 510-3,600 \\
\text { UB: } 9,000\end{array}$ & 0 & 0 & $\begin{array}{l}\text { LB: } 510-3,600 \\
\text { UB: } 9,000\end{array}$ \\
\hline \multicolumn{5}{|c|}{ 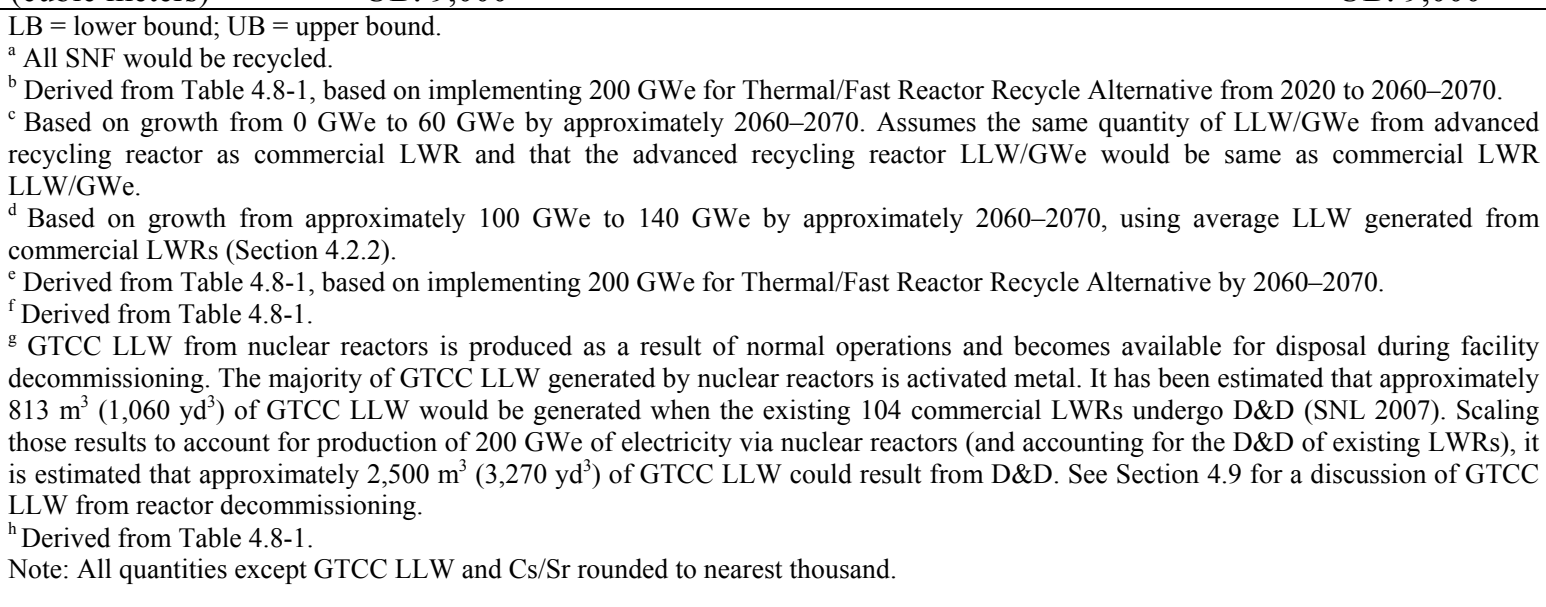 } \\
\hline
\end{tabular}


Transportation: A transportation analysis was prepared to determine the potential impacts associated with the Thermal/Fast Reactor Recycle Alternative (see Appendix E for a discussion of the methodology and modeling results). The transportation analysis considered all radiological material that could be transported (i.e., LWR SNF, MOX-U-Pu SNF, spent transmutation fuel from fast reactors, wastes from the recycling center, etc.). Table 4.4-2 presents the number of radiological shipments (broken down by material to be transported) that would be required for the Thermal/Fast Reactor Recycle Alternative for 1) all truck and 2) a combination of truck and rail. Because all shipments of fresh nuclear fuel are assumed to occur via truck transport, there is no transportation scenario in which all transportation would occur via rail only. Consequently, the PEIS presents transportation impacts for a combined truck and rail scenario (in tables this scenario is designated as "truck/rail"). As shown in that table, transport by truck would require significantly more shipments than by truck and rail.

TABLE 4.4-2_Total Number of Radiological Shipments for 50 Years of Operation, Thermal/Fast Reactor Recycle Alternative

\begin{tabular}{lcc}
\hline \multicolumn{1}{c}{ Material/Waste } & $\begin{array}{c}\text { Truck Transport } \\
\text { (Number of Shipments) }\end{array}$ & $\begin{array}{c}\text { Truck/Rail Transport (Number } \\
\text { of Shipments) }\end{array}$ \\
\hline Fresh LWR fuel $^{\text {Fresh Transmutation fuel }}$ & 21,000 & $21,000^{\mathrm{d}}$ \\
Fresh MOX fuel $^{\mathrm{a}}$ & 27,500 & $27,500^{\mathrm{d}}$ \\
LWR SNF & 4,380 & $4,380^{\mathrm{d}}$ \\
Spent Fast Reactor Fuel & 63,000 & 5,280 \\
Cs/Sr waste & 27,500 & 5,500 \\
HLW & 10,800 & 2,150 \\
GTCC LLW & 52,700 & 10,540 \\
LLW $^{\mathrm{c}}$ & 504,000 & 101,000 \\
Recovered Uranium (Aqueous) & 83,200 & 16,600 \\
Recovered Uranium (Metal) & 18,300 & 3,660 \\
MOX SNF & 5,960 & 1,190 \\
\hline S & 8,000 & 178 \\
\hline
\end{tabular}

Source: Appendix E

${ }^{a}$ The MOX spent fuel was assumed to be transported in DOE spent fuel canisters, with a capacity of 0.75 MTHM per container. Fresh MOX fuel was assumed to be transported in Class B containers as described in NRC 2005c. These containers have a capacity of 1.37 MTHM per shipment and are not appropriate for the shipment of spent fuel. Considering this, there would be approximately 83 percent more spent fuel shipments than fresh for the same amount of fuel.

${ }^{\mathrm{b}}$ Includes mixed GTCC LLW.

${ }^{\mathrm{c}}$ Includes mixed LLW.

${ }^{\mathrm{d}}$ All shipment of fresh nuclear fuel is assumed to be via truck transport.

The results of the transportation analysis are presented in two sets of tables. The first set of tables (Tables 4.4-3 and 4.4-4) present the impacts associated with handling (loading and inspection) radiological material for the $200 \mathrm{GWe}$ scenario. Impacts are presented in terms of radiological impacts (expressed in person-rem and converted to LCFs using a dose-to-risk conversion factor of $6 \times 10^{-4}$ LCF per person-rem). Table 4.4-3 presents the handling impacts for truck transport and Table 4.4-4 presents the handling impacts for truck and rail transport. Handling operations (loadings and inspections) would not affect the public.

The impacts of handling radiological material are independent of the distance that the material would be transported. As such, the handling impacts would be the same whether the radiological material is transported, for example, $500 \mathrm{mi}(805 \mathrm{~km}), 2,100 \mathrm{mi}(3,380 \mathrm{~km})$, or any other 
distance. For this reason, these impacts are presented separately from the in-transit impacts (which are presented in the second set of tables).

TABLE 4.4-3-Handling Impacts for 50 Years of Operation, Thermal/Fast Reactor Recycle Alternative (Truck Transit)—200 Gigawatts Electric

\begin{tabular}{lcc|cc|cc}
\hline & \multicolumn{5}{c}{ Handling Impacts } \\
\cline { 2 - 7 } & \multicolumn{2}{c}{ Loading } & Inspection & \multicolumn{2}{c}{ Total } \\
\cline { 2 - 7 } & person-rem & LCFs & person-rem & LCFs & person-rem & LCFs \\
\hline Thermal/Fast Reactor Recycle & 155,000 & 93 & 17,200 & 10 & 172,000 & 103 \\
\hline Source: Appendix E & & & & & \\
Note: All LCFs rounded to nearest whole number.
\end{tabular}

TABLE 4.4-4-Handling Impacts for 50 Years of Operation, Thermal/Fast Reactor Recycle Alternative (Truck and Rail Transit)-200 Gigawatts Electric

\begin{tabular}{ccc|cc|cc}
\hline & \multicolumn{5}{c}{ Handling Impacts } \\
\cline { 2 - 7 } & \multicolumn{2}{c|}{ Loading } & \multicolumn{2}{c}{ Inspection } & \multicolumn{2}{c}{ Total } \\
\cline { 2 - 7 } & person-rem & LCFs & person-rem & LCFs & person-rem & LCFs \\
\hline Thermal/Fast Reactor Recycle & 205,000 & 123 & 12,700 & 8 & 217,000 & 131 \\
\hline
\end{tabular}

Source: Appendix E

Note: All LCFs rounded to nearest whole number.

The in-transit impacts are shown in Tables 4.4-5 (truck transit) and 4.4-6 (truck and rail transit) for the Thermal/Fast Reactor Recycle Alternative. These impact estimates would vary based on a variety of factors, including the distance that the radiological material would be transported, the specific routes that would be utilized, the population densities along those routes, and others. Of these factors, transport distance is the most significant. Because the locations of future reactors, nuclear fuel recycling facilities, and future disposal facilities are unknown, DOE analyzed transportation impacts over five distances: $150 \mathrm{mi}(241 \mathrm{~km}), 500 \mathrm{mi}(805 \mathrm{~km}), 1,500 \mathrm{mi}$ $(2,414 \mathrm{~km}), 2,100 \mathrm{mi}(3,380 \mathrm{~km})$, and 3,000 $\mathrm{mi}(4,828 \mathrm{~km})$. In-transit impacts presented in Tables 4.4-5 and 4.4-6 are based on 2,100 mi (3,380 km) of transport. This distance was selected as a reference distance because it represents the average distance for all SNF shipments analyzed in the Yucca Mountain FEIS (DOE 2002i). Impacts associated with the other four distances are presented, on a per shipment basis, in Appendix E, which describes the transportation methodology and assumptions. Although the in-transit impacts are not exactly "linear" (i.e., twice the impacts for twice the distance transported), that is a close approximation. Consequently, if the radiological material were transported $500 \mathrm{mi}(805 \mathrm{~km})$, all of the in-transit impacts presented in Tables 4.4-5 and 4.4-6 could be estimated by multiplying the values in those tables by $0.24(500 / 2,100)$.

TABLE 4.4-5-In-Transit Transportation Impacts for 50 Years of Operation, Thermal/Fast Reactor Recycle Alternative (Truck Transit)-200 Gigawatts Electric

\begin{tabular}{|c|c|c|c|c|c|c|c|c|}
\hline & \multicolumn{4}{|c|}{ In Transit Impacts } & \multirow{3}{*}{$\begin{array}{c}\text { Total } \\
\text { Incident-Free } \\
\text { LCFs }\end{array}$} & \multirow{2}{*}{\multicolumn{3}{|c|}{ Accident Impacts }} \\
\hline & \multicolumn{2}{|c|}{ Crew } & \multicolumn{2}{|c|}{ Public } & & & & \\
\hline & $\begin{array}{l}\text { person- } \\
\text { rem }\end{array}$ & LCFs & $\begin{array}{l}\text { person- } \\
\text { rem }\end{array}$ & LCFs & & $\begin{array}{l}\text { person- } \\
\text { rem }\end{array}$ & LCFs & $\begin{array}{l}\text { Collision } \\
\text { Fatalities }\end{array}$ \\
\hline $\begin{array}{l}\text { Thermal/Fast } \\
\text { Reactor Recycle }\end{array}$ & 146,000 & 87 & 360,000 & 216 & 303 & 41.0 & 0 & 71 \\
\hline
\end{tabular}

Source: Appendix E

Note: All LCFs rounded to nearest whole number. 
TABLE 4.4-6-In-Transit Transportation Impacts for 50 Years of Operation, Thermal/Fast Reactor Recycle Alternative (Rail Transit)—200 Gigawatts Electric

\begin{tabular}{|c|c|c|c|c|c|c|c|c|}
\hline & \multicolumn{4}{|c|}{ In Transit Impacts } & \multirow{3}{*}{$\begin{array}{c}\text { Total } \\
\text { Incident-Free } \\
\text { LCFs }\end{array}$} & \multirow{2}{*}{\multicolumn{3}{|c|}{ Accident Impacts }} \\
\hline & \multicolumn{2}{|c|}{ Crew } & \multicolumn{2}{|c|}{ Public } & & & & \\
\hline & $\begin{array}{c}\text { person- } \\
\text { rem }\end{array}$ & LCFs & $\begin{array}{c}\text { person- } \\
\text { rem }\end{array}$ & LCFs & & $\begin{array}{c}\text { person- } \\
\text { rem }\end{array}$ & LCFs & $\begin{array}{l}\text { Collision } \\
\text { Fatalities }\end{array}$ \\
\hline $\begin{array}{l}\text { Thermal/Fast } \\
\text { Reactor Recycle }\end{array}$ & 9,250 & 6 & 42,300 & 25 & 34 & 8.64 & 0 & 15 \\
\hline
\end{tabular}

Source: Appendix E

Note: All LCFs rounded to nearest whole number.

There are potentially significant differences in impacts depending upon whether transportation occurs via truck or a combination of truck and rail. For all alternatives, rail transport would result in smaller impacts than truck transport. This is due to the fact that there would be many fewer transportation shipments for truck and rail compared to truck only. This would directly affect the distance traveled and exposures to both crews and the public. Additionally, the number of accident fatalities (collisions) would be smaller for the truck and rail transport.

\subsection{Thermal Reactor Recycle Fuel CyCle Alternative (Thermal REACTOR RECYCLE ALTERNATIVE)}

The Thermal Reactor Recycle Alternative is described in Chapter 2, Section 2.5. Under this alternative, the United States would pursue a domestic closed fuel cycle that recycles LWR SNF in one or more recycling facilities and uses the recycled fuel in thermal reactors. Unlike the Fast Reactor Recycle Alternative, which would require comparably more R\&D (related to transmutation fuel development and fast reactor fuel separation), existing thermal reactor technologies and fuel fabrication technologies could be utilized for this alternative. Consequently, this alternative may be implemented more quickly.

Three options are assessed for the Thermal Reactor Recycle Alternative: Option 1-recycle LWR SNF to produce a MOX-U-Pu fuel for use in LWRs; Option 2-recycle LWR SNF to produce fuel for use in HWRs; and Option 3-recycle LWR SNF to produce a transuranic fuel for use in HTGRs.

At the programmatic level, this PEIS assesses the potential environmental impacts associated with broad implementation of the Thermal Reactor Recycle Alternative to achieve a capacity of $200 \mathrm{GWe}$ based on a 1.3 percent growth rate for nuclear power. The analysis of this broad implementation assumes that the United States commercial reactors begin to recycle LWR SNF by approximately 2020. Thereafter, the recycled fuel would be utilized in LWRs (Option 1), in new HWRs (Option 2), or in new HTGRs (for Option 3). The PEIS also provides information for a growth scenario of 2.5 percent, which would result in a capacity of approximately $400 \mathrm{GWe}$ (see Table 4.8-2), a 0.7 percent growth rate, which would result in a capacity of approximately 150 GWe (see Table 4.8-3), and a zero growth scenario, which would result in a capacity of approximately $100 \mathrm{GWe}$ (see Table 4.8-4). 
This PEIS presents the environmental impacts of the Thermal Reactor Recycle Alternative as follows:

- Construction and Operation of Thermal Recycle Facilities: The impacts of establishing and implementing the Thermal Reactor Recycle Alternative for Options 1, 2, and 3 are presented. This analysis includes the construction of multiple SNF recycling centers, transportation of LWR SNF from commercial reactors to the recycling centers, operations to recycle SNF and produce MOX-U-Pu fuel (Option 1), or HWR fuel (Option 2), or HTGR fuel (Option 3), transportation of fuel to reactors, and waste management impacts (which would include the impacts of establishing additional geologic repository capacity for generated HLW and any SNF), and the transport and emplacement of HLW and SNF in a geologic repository. The impacts of Option 1 are presented in Section 4.5.1, Option 2 are presented in Section 4.5.2, and Option 3 are presented in Section 4.5.3.

- New nuclear electricity generation between 2010 and 2060-2070: For Option 1, the environmental impacts of constructing and operating approximately $200 \mathrm{GWe}$ in LWR capacity (including the replacement LWRs that reach end-of-life), would be the same as those presented in Section 4.2.2 and are not repeated. For options 2 and 3, the construction and operation of new LWRs and replacement LWRs is bounded by the analysis presented in Section 4.2.2. For new HWRs (Option 2), this PEIS includes an assessment of constructing and operating approximately 54 GWe in new HWR capacity in Section 4.5.2. The impacts of constructing and operating approximately $146 \mathrm{GWe}$ in LWR capacity (including the replacement LWRs that reach end-of-life) would be bounded by the analysis presented in Section 4.2.2 and are not repeated. For new HTGRs (Option 3), this PEIS includes an assessment of constructing and operating approximately 34 GWe in new HTGR capacity in Section 4.5.3. The impacts of constructing and operating approximately $166 \mathrm{GWe}$ in LWR capacity (including the replacement LWRs that reach end-of-life) would be bounded by the analysis presented in Section 4.2.2 and are not repeated.

\subsubsection{Construction and Operation of Thermal Recycle Facilities-Option 1}

The PEIS analysis in this section focuses on the $200 \mathrm{GWe}$ end-state (approximately $200 \mathrm{GWe}$ of LWR capacity, approximately 5,000 MTHM/yr of LWR SNF separation capacity, and fuel fabrication capacity to support the fabrication of MOX-U-Pu fuel for $200 \mathrm{GWe}$ of LWR capacity).

Construction: If a Thermal Reactor Recycle Alternative (Option 1) with a capacity of $200 \mathrm{GWe}$ is pursued, the following facilities could be built:

- 200 GWe of LWR capacity (which would include the replacement of approximately 100 GWe of LWR capacity when existing LWRs reach their end-of-life).

- Six nuclear fuel recycling centers (LWR separation facilities [based on a capacity of $800 \mathrm{MTHM} / \mathrm{yr}])$.

- Internal modifications to LEU fuel fabrication capabilities and/or new fuel fabrication facilities to fabricate MOX-U-Pu fuel to support 200 GWe of LWR capacity. 
Although some facilities could be colocated, the construction of this much capacity would necessitate that many sites in the United States be utilized. For this analysis, it is assumed that the nuclear fuel recycling center(s) and the reactors would not be colocated, which would necessitate transportation of material between the facilities during operations.

From a construction standpoint, the Thermal Reactor Recycle Alternative (Option 1) would have similar impacts to the overall construction impacts presented in Section 4.3 for the Fast Reactor Recycle Alternative. Construction of six LWR separation facilities would require a total of approximately 1,500 acres (600 ha) (based on 250 acres [100 ha] per facility, see Appendix A, Section A.6.3.2). Because the total reactor capacity would be $200 \mathrm{GWe}$, relative to reactor construction impacts, the overall reactor impacts to land would be approximately 602,000 acres (244,000 ha). Because LWRs would transition from LEU fuel to MOX-U-Pu fuel, modifications to LEU fuel fabrication facilities and/or new fuel fabrication facilities to fabricate MOX-U-Pu fuel could be required. As explained in Appendix A, Section A.3.1.4, because MOX-U-Pu fuel fabrication is similar to LEU fuel fabrication, any modifications are expected to be minor, and could include additional shielding within the facility. These modifications are expected to be accomplished within the footprint of existing facilities. If new fuel fabrication facilities to fabricate MOX-U-Pu fuel were constructed, it could add to the land required, but would be small relative to land requirements for reactor facilities.

Operation: Operation of the facilities associated with the Thermal Reactor Recycle Alternative (Option 1) would be similar to the Fast Reactor Recycling Alternative. This section discusses potential impacts related to uranium requirements, fuel fabrication, land, visual, water, socioeconomics, human health and safety, waste generation, and transportation of nuclear materials.

\section{Option to Use Mixed Oxide-Transuranic Fuel and/or Targets}

The Thermal Reactor Recycle Alternative (Option 1) could also use a MOX-TRU fuel, although there is no commercial experience with MOX-TRU fuel (ANL 2002a). Compared to a uraniumoxide fuel cycle, the same reactor cycle length could be maintained by adjusting the MOX-U-Pu (or MOX-TRU) and uranium enrichments. For MOX-TRU, a MOX-TRU pin loading of 7.48 percent TRU would be used in the first recycle. To meet the end-of-life burnup of $45 \mathrm{GWd} / \mathrm{MT}$, it would be necessary to increase the enrichment of the uranium-oxide pins in the interior of the fuel assembly to 4.85 percent U-235. With each successive recycle, the TRU content in the MOX-TRU pins would increase as more TRU is produced in the uranium-oxide pins than is consumed in the MOX-TRU pins (although the rate of increase slows as the equilibrium state is approached). By the seventh recycle, the MOX-TRU pin loading would reach 11.0 percent and the uranium-oxide fuel pin enrichment would need to be increased to slightly more than 5.0 percent to meet the cycle length requirements (ANL 2002a).

Multi-recycling of the TRU would lead to a significant increase in the higher actinide content of the fuel assembly, which would complicate fresh fuel handling compared to standard $\mathrm{UO}_{2}$ or MOX-U-Pu assemblies (ANL 2004). One estimate suggests that the radiation of MOX-TRU SNF could be approximately 1,000 to 6,000 times as great as typical LWR SNF, and the decay heat could be 1 to 6 times as great (Wigeland 2008a). If MOX-TRU fuel were pursued, potential 
modifications to existing fuel fabrication facilities could be major, and could include remote operations. Potential modifications to LWRs would primarily necessitate modifications to fuel loading processes (i.e., the use of a shielded cask). There are also mitigation measures that could reduce the neutron source. For example, if the SNF were stored for approximately 40 years prior to recycle in an LWR, curium would significantly decay and reduce the radiation and decay heat. However, this would require significant storage capabilities.

Consideration has also been given as to what transuranics should be in the target pins. In one option, both Pu and Np could be in the driver MOX fuel and Am could be in the target fuel. The presence of both $\mathrm{Am}$ and $\mathrm{Cm}$ in the target leads to the production of higher actinides that are intense producers of spontaneous fission neutrons (Finck 2007c).

The intermixing of driver and target pins in the same assembly, however, negates the potential benefit of heterogeneous recycle, which is the confinement of the higher radiotoxic and heating target to a fraction of the reactor core to reduce handling and other dose-related issues. Previous evaluations indicated that a large fraction of the assemblies in the reactor core might be required to contain target pins to successfully use the heterogeneous approach (as much as 30 percent to 100 percent). Stabilization of the minor actinide inventory would require a higher fraction (up to 100 percent) of the core to contain target pins, and higher burn-down would require a lower fraction of the core to contain target pins. There are also fuel performance issues pertaining to helium production in the target pins that would have to be addressed in detailed design and fuel development studies. Consequently, the perceived benefits of using targets would have to be properly quantified to justify their utilization (Finck 2007c). Further R\&D regarding the heterogeneous approach could be pursued if DOE announces a decision to pursue the Thermal Reactor Recycle Alternative in a future Record of Decision.

Uranium Requirements: The quantity of natural uranium needed to support a capacity of $200 \mathrm{GWe}$, assuming an average enrichment of 4.6 percent, would be approximately $33,000 \mathrm{MT} / \mathrm{yr}$ (see Table 4.8-1). The 33,000 MT of natural uranium would represent approximately 84 percent of uranium that was mined in the world in 2006 and would be 20 times more than the quantities currently mined in the United States annually (see Table 4.1-1). From this 33,000 MT, approximately 3,320 MT of enriched uranium (assuming 4.6 percent enrichment) would be required annually. Approximately 21 million SWUs would be required annually to support a capacity of 200 GWe. The licensed capacity of Paducah, the American Centrifuge Plant, and the LES Facility is 17.8 million SWUs. Consequently, enrichment facilities in the United States could not meet this demand. Additionally, if Paducah shuts down in 2012, as planned, the United States enrichment capacity would be reduced to approximately 6.8 million SWUs. To support a 200 GWe capacity, enrichment capacities in the United States would need to be expanded by approximately 200 percent, or larger quantities of enriched uranium would need to be imported.

Fuel Fabrication Requirements: The United States currently has three operational LWR uranium fuel fabrication facilities with a capacity to produce approximately 3,500 MT of LWR fuel assemblies (Table 4.1-2). For $200 \mathrm{GWe}$, approximately 5,000 MT of MOX-U-Pu fuel assemblies would need to be produced annually. Consequently, the existing fuel fabrication 
facilities in the United States would need to be expanded and modified for MOX-U-Pu fuel fabrication to be able to meet this demand.

Land Resources: Once operational, a total of approximately 603,000 acres (244,000 ha) of land could be occupied by facilities, paved areas, and buffer zones. Most of this area would not be disturbed but would serve as a buffer between the actual facility and the outer facility boundary. The total site area would be determined by accident analyses and regulatory requirements, including safeguards and security.

Visual Resources: With respect to visual characteristics, the visibility of any facility from publicly accessible locations would be dependent on the future site characteristics. For sites that use "wet" cooling tower systems, the water vapor plume from cooling tower operations may be visible for many miles from the plant.

Air Resources: Impacts to air resources would be similar to the Fast Reactor Recycle Alternative presented in Section 4.3.

Water Resources: Every operating reactor would use significant quantities of water. A typical GWe of reactor capacity requires approximately 3 to 6 billion gal (11 to 23 billion L) of water yearly, mainly for heat dissipation ${ }^{44}$ (EPRI 2002). A nuclear fuel recycling center would also use significant quantities of water. Each nuclear fuel recycling center would require approximately 330 million gal/yr (1.3 billion L/yr) (WSRC 2008a). Five facilities would require approximately 1.7 billion gal/yr (6.5 billion $\mathrm{L} / \mathrm{yr})$.

Socioeconomic Impacts: Socioeconomic impacts would occur in communities in the vicinity of any future facility. These impacts would be similar to those discussed for the Fast Reactor Recycle Alternative. For each GWe of capacity, an LWR would require approximately 500 to 1,000 workers. The employment estimate for each LWR SNF separations facility is approximately 3,000 workers.

Human Health: As the MOX-U-Pu is multi-recycled, there would be a gradual buildup of higher-mass transuranics in the discharged fuel, causing an increase in the radioactive properties (e.g., decay heat and radiotoxicity) of the SNF (ANL 2002b). These higher heat loads can have a negative impact on aqueous fuel processing efficiencies and the increased neutron source may require specific measures to maintain the safety of fuel-handling workers (ANL 2002b). This PEIS assumes that design features would be in place to maintain exposures at ALARA levels. For analysis purposes, it is expected that worker doses would be similar to those of the Fast Reactor Recycling Alternative.

In addition to nonradiological hazards, workers at each of the facilities would be subject to radiological hazards, including radiation exposure, as discussed below.

\footnotetext{
${ }^{44}$ A typical $1 \mathrm{GWe}$ reactor would withdraw 3 to 6 billion gal/yr (11 to 23 billion L/yr) for cooling (using "wet cooling"). Water consumption would be less than 60 million gal/yr (230 million L/yr).
} 
- The total annual dose to workers associated with the nuclear fuel recycling centers would be approximately 3,300 person-rem (LWR MOX-U-Pu separation: 6 facilities x 2,226 radiation workers/facility x $250 \mathrm{mrem} / \mathrm{yr}$ average dose [WSRC 2008a]).

- At the LWRs (200 GWe of capacity), the total annual dose to workers would be approximately 20,900 person-rem (assumes 550 radiation workers/GWe x $190 \mathrm{mrem} / \mathrm{yr}$ average dose).

The total annual dose to workers associated with the $200 \mathrm{GWe}$ Thermal Reactor Recycle Alternative (Option 1) would be approximately 24,200 person-rem, which equates to an annual LCF risk of approximately 14. Statistically, this means that 14 LCFs could occur for every year of operation of a Thermal Reactor Recycle Alternative (Option 1) at the capacities assumed at the end of the implementation period (i.e., that separates 5,000 MTHM/yr of LWR SNF and operates $200 \mathrm{GWe}$ of LWRs fueled with MOX-U-Pu).

The public would also be subject to radiation exposure, primarily from airborne releases of radionuclides. Potential doses from LWRs are expected to be similar to those shown in Table 4.2-7 for the six hypothetical sites. For the nuclear fuel recycling centers, public exposures would vary depending on many factors, but would predominantly be affected by prevailing weather patterns and the proximity of the facilities to local population centers. The impacts presented in Table 4.3-1 are representative of the impacts that could result.

Facility Accidents: The accidents analysis for LWRs using a MOX-U-Pu fuel is presented in Section 4.4 and is not repeated here.

Spent Nuclear Fuel and Radioactive Wastes: This PEIS assesses the wastes associated with recycling of all LWR SNF that would be generated over the period 2010 to 2060-2070. For Option 1, this would be approximately 168,000 $\mathrm{MTHM}^{45}$, of which 22,000 MTHM would be from LEU fuel and 146,000 MTHM would be from MOX-U-Pu fuel. In this situation, no SNF would require repository disposal, and only HLW from recycling (which would contain TRU from processing losses) would require repository disposal. With respect to the amount of HLW that would be generated, it is expected that 0.1 percent of the $\mathrm{Pu}$, plus all the minor actinides $(\mathrm{Np}, \mathrm{Am}$, and $\mathrm{Cm})$, and fission products, with the possible exception of cesium and strontium, would require disposal in a repository. Because any recovered uranium could be reused, the quantities in Table 4.5-1 do not include recovered uranium.

Over a 50-year operational period (2010 to 2060-2070), the Thermal Reactor Recycle Alternative (Option 1) would generate the radioactive wastes shown in Table 4.5-1. HLW would be disposed of in a geologic repository (Section 4.1.5). LLW would be disposed of in commercial disposal facilities (Section 4.1.6). Disposal of GTCC LLW would occur, pursuant to the Low-Level Radioactive Waste Policy Amendments Act of 1985, at facilities to be determined by the DOE. Cesium and strontium wastes could be stored at the recycling centers for 300 years (see Section 4.3.3) or transported to a HLW storage or disposal facility.

${ }^{45}$ Based on the following: first new LWR is constructed in 2015; each LWR produces approximately 21.7 MTHM of SNF/GWe-yr; in 2020, LWRs transition to MOX-U-Pu fuel and produce approximately 25 MTHM of SNF/GWe-yr; LWR capacity grows to 200 GWe by approximately 2060-2070. Existing LWRs are assumed to be replaced as they reach end-of-life between 2020 and 2060-2070. 


\begin{tabular}{|c|c|c|c|}
\hline Waste Category & $\begin{array}{c}\text { Nuclear Fuel } \\
\text { Recycling Centers } \\
\text { (for } 200 \text { GWe in } \\
2060-2070)\end{array}$ & $\begin{array}{c}\text { LWRs } \\
(200 \text { GWe in 2060-2070) }\end{array}$ & $\begin{array}{c}\text { Total } \\
\text { (Nuclear Fuel } \\
\text { Recycling Centers + } \\
\text { LWRs) } \\
\end{array}$ \\
\hline
\end{tabular}

\begin{tabular}{|c|c|c|c|}
\hline SNF (MTHM) ${ }^{\mathrm{a}}$ & 0 & $\begin{array}{c}168,000 \\
(22,000 \text { of LEU SNF; 146,000 } \\
\text { of MOX-U-Pu SNF) }\end{array}$ & 168,000 \\
\hline LLW (solid) & $1500000^{b}$ & LB: 150,000 & LB: $1,740,000$ \\
\hline (cubic meters) & $1,590,000$ & UB: $585,000^{\mathrm{c}}$ & JB: $2,175,000$ \\
\hline HLW (cubic meters) & $52,000^{\mathrm{d}}$ & 0 & 52,000 \\
\hline $\begin{array}{l}\text { GTCC LLW } \\
\text { (cubic meters) }\end{array}$ & $405,000^{\mathrm{e}}$ & $2,500^{f}$ & 407,500 \\
\hline $\begin{array}{l}\text { Cesium/Strontium }{ }^{\mathrm{g}} \\
\text { (cubic meters) }\end{array}$ & $\begin{array}{l}\text { LB: } 510-3,600 \\
\text { UB: } 10,800\end{array}$ & 0 & $\begin{array}{l}\text { LB: } 510-3,600 \\
\text { UB: } 10,800\end{array}$ \\
\hline \multicolumn{4}{|c|}{ 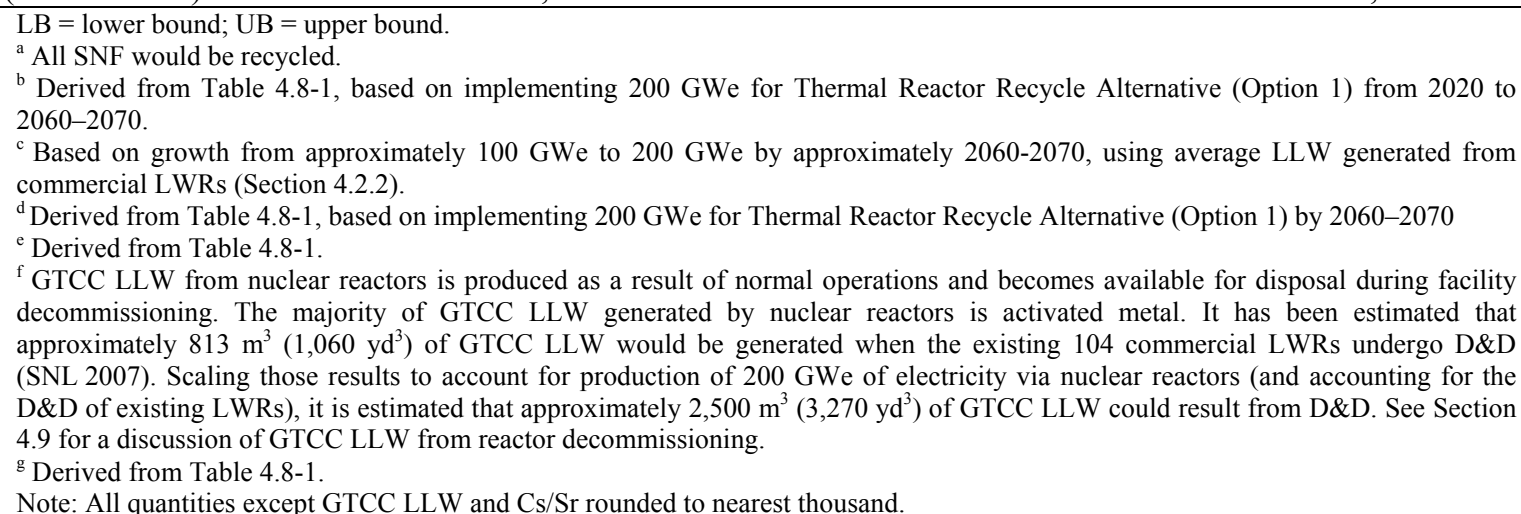 } \\
\hline
\end{tabular}

Transportation: A transportation analysis was prepared to determine the potential impacts associated with the Thermal Reactor Recycle Alternative (Option 1) (see Appendix E for a discussion of the methodology and modeling results). The transportation analysis considered all radiological material that could be transported (i.e., LWR SNF, spent MOX-U-Pu fuel, wastes from the recycling center, etc.). Table 4.5-2 presents the number of radiological shipments (broken down by material to be transported) that would be required for the Thermal Reactor Recycle Alternative (Option 1) for 1) all truck and 2) a combination of truck and rail. Because all shipments of fresh nuclear fuel are assumed to occur via truck transport, there is no transportation scenario in which all transportation would occur via rail only. Consequently, the PEIS presents transportation impacts for a combined truck and rail scenario (in tables this scenario is designated as "truck/rail"). As shown in that table, truck transport would require significantly more shipments than rail. 


\section{TABLE 4.5-2_Total Number of Radiological Shipments for 50 Years of Implementation, Thermal Reactor Alternative, Option 1}

\begin{tabular}{lcc}
\hline \multicolumn{1}{c}{ Material/Waste } & $\begin{array}{c}\text { Truck Transport } \\
\text { (Number of Shipments) }\end{array}$ & $\begin{array}{c}\text { Truck/Rail Transport } \\
\text { (Number of Shipments) }\end{array}$ \\
\hline Fresh LWR fuel & 3,670 & $3,670^{\mathrm{d}}$ \\
Fresh MOX fuel ${ }^{\mathrm{a}}$ & 107,000 & $107,000^{\mathrm{d}}$ \\
LWR SNF & 11,000 & 880 \\
Cs/Sr waste & 10,800 & 2,150 \\
HLW & 50,700 & 10,100 \\
GTCC LLW & 513,000 & 101,000 \\
LLW & 84,000 & 17,000 \\
Recovered Uranium (Aqueous) & 2,920 & 584 \\
MOX SNF & 195,000 & 4,330 \\
\hline Source: Appendix E & & \\
${ }^{\mathrm{a}}$ The MOX spent fuel was assumed to be transported in DOE spent fuel canisters, with a capacity of 0.75 MTHM per container. \\
Fresh MOX fuel was assumed to be transported in Class B containers as described in NRC 2005c. These containers have a capacity \\
of 1.37 MTHM per shipment and are not appropriate for the shipment of spent fuel. Considering this, there would be approximately \\
83 percent more spent fuel shipments than fresh for the same amount of fuel. \\
${ }^{b}$ Includes mixed GTCC LLW. \\
${ }^{c}$ Includes mixed LLW. \\
${ }^{\mathrm{d}}$ All shipment of fresh nuclear fuel is assumed to be via truck transport.
\end{tabular}

The results of the transportation analysis are presented in two sets of tables. The first set of tables (Tables 4.5-3 and 4.5-4) present the impacts associated with handling (loading and inspection) radiological material for the $200 \mathrm{GWe}$ scenario. Impacts are presented in terms of radiological impacts (expressed in person-rem and converted to LCFs using a dose-to-risk conversion factor of $6 \times 10^{-4}$ LCF per person-rem). Table 4.5-3 presents the handling impacts for truck transport and Table 4.5-4 presents the handling impacts for truck and rail transport. Handling operations (loadings and inspections) would not affect the public.

The impacts of handling radiological material are independent of the distance that the material would be transported. As such, the handling impacts would be the same whether the radiological material is transported, for example, $500 \mathrm{mi}(805 \mathrm{~km}), 2,100 \mathrm{mi}(3,380 \mathrm{~km})$, or any other distance. For this reason, these impacts are presented separately from the in-transit impacts (which are presented in the second set of tables).

TABLE 4.5-3-Handling Impacts for 50 Years of Implementation, Thermal Reactor Alternative, Option 1 (Truck Transit)_200 Gigawatts Electric

\begin{tabular}{ccc|cc|cc}
\hline & \multicolumn{4}{c}{ Handling Impacts } \\
\cline { 2 - 8 } & \multicolumn{2}{c|}{ Loading } & \multicolumn{2}{c}{ Inspection } & \multicolumn{2}{c}{ Total } \\
& person-rem & LCFs & person-rem & LCFs & person-rem & LCFs \\
\hline Thermal Reactor Recycle, Option 1 & 198,000 & 119 & 23,800 & 14 & 222,000 & 133 \\
\hline
\end{tabular}

Source: Appendix E

Note: All LCFs rounded to nearest whole number. 
TABLE 4.5-4-Handling Impacts for 50 Years of Implementation, Thermal Reactor Alternative, Option 1 (Truck and Rail Transit)-200 Gigawatts Electric

\begin{tabular}{lcc|cc|cc}
\hline & \multicolumn{3}{c}{ Handling Impacts } \\
\cline { 2 - 7 } & \multicolumn{2}{c}{$\begin{array}{c}\text { Loading } \\
\text { person-rem }\end{array}$} & LCFs & $\begin{array}{c}\text { Inspection } \\
\text { person-rem }\end{array}$ & LCFs & Total \\
person-rem & LCFs \\
\hline Thermal Reactor Recycle, Option 1 & 181,000 & 109 & 10,700 & 6 & 192,000 & 116 \\
\hline Source: Appendix E & & & & & \\
Note: All LCFs rounded to nearest whole number. & & &
\end{tabular}

The in-transit impacts are shown in Tables 4.5-5 (truck transit) and 4.5-6 (truck and rail transit) for the Thermal Reactor Recycle Alternative (Option 1). These impact estimates would vary based on a variety of factors, including the distance that the radiological material would be transported, the specific routes that would be utilized, the population densities along those routes, and others. Of these factors, transport distance is the most significant. Because the locations of future reactors, nuclear fuel recycling facilities, and future disposal facilities are unknown, DOE analyzed transportation impacts over five distances: $150 \mathrm{mi}(241 \mathrm{~km}), 500 \mathrm{mi}(805 \mathrm{~km})$, 1,500 $\mathrm{mi}(2,414 \mathrm{~km}), 2,100 \mathrm{mi}(3,380 \mathrm{~km})$, and 3,000 mi $(4,828 \mathrm{~km})$. In-transit impacts presented in Tables 4.5-5 and 4.5-6 are based on 2,100 $\mathrm{mi}(3,380 \mathrm{~km})$ of transport. This distance was selected as a reference distance because it represents the average distance for all SNF shipments analyzed in the Yucca Mountain FEIS (DOE 2002i). Impacts associated with the other four distances are presented, on a per shipment basis, in Appendix E, which describes the transportation methodology and assumptions. Although the in-transit impacts are not exactly "linear" (i.e., twice the impacts for twice the distance transported), that is a close approximation. Consequently, if the radiological material were transported $500 \mathrm{mi}(805 \mathrm{~km})$, all of the in-transit impacts presented in Tables 4.5-5 and 4.5-6 could be estimated by multiplying the values in those tables by $0.24(500 / 2,100)$.

TABLE 4.5-5-In-Transit Transportation Impacts for 50 Years of Implementation, Thermal Reactor Alternative, Option 1 (Truck Transit)-200 Gigawatts Electric

\begin{tabular}{|c|c|c|c|c|c|c|c|c|}
\hline & \multicolumn{4}{|c|}{ In Transit Impacts } & \multirow{3}{*}{$\begin{array}{l}\text { Total Incident- } \\
\text { Free LCFs }\end{array}$} & \multirow{2}{*}{\multicolumn{3}{|c|}{ Accident Impacts }} \\
\hline & \multicolumn{2}{|c|}{ Crew } & \multicolumn{2}{|c|}{ Public } & & & & \\
\hline & $\begin{array}{l}\text { person- } \\
\text { rem }\end{array}$ & LCFs & $\begin{array}{l}\text { person- } \\
\text { rem }\end{array}$ & LCFs & & $\begin{array}{c}\text { person- } \\
\text { rem }\end{array}$ & LCFs & $\begin{array}{l}\text { Collision } \\
\text { Fatalities }\end{array}$ \\
\hline $\begin{array}{l}\text { Thermal Reactor } \\
\text { Recycle, Option } 1\end{array}$ & 157,000 & 94 & 441,000 & 265 & 359 & 2.97 & 0 & 84 \\
\hline
\end{tabular}

Source: Appendix E

Note: All LCFs rounded to nearest whole number

TABLE 4.5-6-In-Transit Transportation Impacts for 50 Years of Implementation, Thermal Reactor Alternative, Option 1 (Truck and Rail Transit)-200 Gigawatts Electric

\begin{tabular}{|c|c|c|c|c|c|c|c|c|}
\hline & \multicolumn{4}{|c|}{ In Transit Impacts } & \multirow{3}{*}{$\begin{array}{l}\text { Total Incident- } \\
\text { Free LCFs }\end{array}$} & \multirow{2}{*}{\multicolumn{3}{|c|}{ Accident Impacts }} \\
\hline & \multicolumn{2}{|c|}{ Crew } & \multicolumn{2}{|c|}{ Public } & & & & \\
\hline & $\begin{array}{c}\text { person- } \\
\text { rem }\end{array}$ & LCFs & $\begin{array}{c}\text { person- } \\
\text { rem }\end{array}$ & LCFs & & $\begin{array}{c}\text { person- } \\
\text { rem }\end{array}$ & LCFs & $\begin{array}{l}\text { Collision } \\
\text { Fatalities }\end{array}$ \\
\hline $\begin{array}{l}\text { Thermal Reactor } \\
\text { Recycle, Option } 1\end{array}$ & 4,920 & 3 & 42,300 & 25 & 28 & 0.345 & 0 & 19 \\
\hline
\end{tabular}

Source: Appendix E

Note: All LCFs rounded to nearest whole number

There are potentially significant differences in impacts depending upon whether transportation occurs via truck or a combination of truck and rail. For all alternatives, truck and rail transport 
would result in smaller impacts than truck transport. This is due to the fact that there would be many fewer transportation shipments for truck and rail compared to truck only. This would directly affect the distance traveled and exposures to both crews and the public. Additionally, the number of accident fatalities (collisions) would be smaller for the truck and rail transport.

\subsubsection{Construction and Operation of Thermal Recycle Facilities-Option 2}

The PEIS analysis in this section focuses on the $200 \mathrm{GWe}$ end-state (approximately $200 \mathrm{GWe}$ of LWR and HWR capacity, approximately 3,200 MTHM/yr of LWR SNF separation capacity, and fuel fabrication capacity to support the fabrication of fuel for 54 GWe of HWR capacity).

Construction: If a Thermal Reactor Recycle Alternative (Option 2) with a capacity of $200 \mathrm{GWe}$ is pursued, the following facilities could be built:

- 4 DUPIC $^{46}$ recycling and fuel fabrication facilities (to recycle LWR SNF and produce HWR fresh fuel (based on a capacity of $800 \mathrm{MTHM} / \mathrm{yr}$ for each recycling center) with a total capacity to separate approximately 3,200 MTHM/yr of LWR SNF and to fabricate HWR fuel to support 54 GWe of HWR capacity.

- $\quad 146$ GWe of LWR capacity (which would include the replacement of approximately $100 \mathrm{GWe}$ of LWR capacity when existing LWRs reach their end-of-life).

- 54 GWe of HWR capacity.

Although some facilities could be colocated, the construction of this much capacity would necessitate that many sites in the United States be utilized. For this analysis, it is assumed that the nuclear fuel recycling center(s) and the reactors would not be colocated, which would necessitate transportation of material between the facilities during operations. From a construction standpoint, the Thermal Reactor Recycle Alternative (Option 2) would have similar impacts to the overall construction impacts presented in Section 4.3 for the Fast Reactor Recycle Alternative.

Operation: The DUPIC recycling and fuel fabrication facilities would operate differently than the recycling facilities described for the Fast Reactor Recycle Alternative. For example, the DUPIC facilities would not employ any chemical processes to extract fissile materials. Rather, the LWR SNF rods would be mechanically removed from the LWR fuel assembly, chopped into an appropriate size by a mechanical and/or laser cutting method, and the fuel material and cladding would be separated. This section discusses potential differences in the operation of facilities associated with the Thermal Reactor Recycle Alternative (Option 2) compared to the Fast Reactor Recycle Alternative.

Uranium Requirements: The quantity of natural uranium needed to support a capacity of $200 \mathrm{GWe}$, assuming an average enrichment of 3.5 percent would be approximately 25,600 MT/yr (see Table 4.8-1). The 25,600 MT of natural uranium would represent approximately 65 percent of uranium that was mined in the world in 2006 and would be 15 times more than the quantities currently mined in the United States annually (see Table 4.1-1). From this 25,600 MT, approximately 3,600 MT of enriched uranium (assuming 3.5 percent

${ }^{46}$ DUPIC $=\underline{\text { direct }} \underline{\text { use of spent }} \underline{\mathrm{P} W R}$ fuel $\underline{\text { in }} \underline{\mathrm{C}} \mathrm{ANDU}$. 
enrichment) would be required. Approximately 16 million SWUs would be required annually to support a capacity of 200 GWe. The licensed capacity of Paducah, the American Centrifuge Plant, and the LES Facility is 17.8 million SWUs. Consequently, enrichment facilities in the United States could meet this demand. However, if Paducah shuts down in 2012, as planned, the United States enrichment capacity would be reduced to approximately 6.8 million SWUs. To support a 200 GWe capacity, enrichment capacities in the United States would need to be expanded by more than 200 percent, or larger quantities of enriched uranium would need to be imported.

Fuel Fabrication Requirements: The United States currently has three operational LWR uranium fuel fabrication facilities with a capacity to produce approximately 3,500 MT of LWR fuel assemblies (Table 4.1-2). For 146 GWe of LWR capacity, approximately 3,600 MT of fresh LWR fuel assemblies would need to be produced annually. Consequently, the existing fuel fabrication facilities in the United States could likely meet this demand with minor changes. HWR fuel fabrication demands would be met by the construction and operation of the 4 DUPIC recycling and fuel fabrication facilities.

Land Resources: Assuming that a DUPIC recycling and fuel fabrication facility would be similar in size (approximately 500 acres [200 ha]) to a nuclear fuel recycling center discussed in Section 4.3.2, once operational, a total of approximately 602,000 acres (244,000 ha) of land could be occupied by facilities, paved areas, and buffer zones. Most of this area would not be disturbed but would serve as a buffer between the actual facility and the outer facility boundary. The total site area would be determined by accident analyses and regulatory requirements, including safeguards and security.

Visual Resources: With respect to visual characteristics, the visibility of any facility from publicly accessible locations would be dependent on the future site characteristics. For sites that use "wet" cooling tower systems, the water vapor plume from cooling tower operations may be visible for many miles from the plant.

Air Resources: Impacts to air resources would be similar to the Fast Reactor Recycle Alternative presented in Section 4.3.

Water Resources: Every operating reactor would use significant quantities of water. A typical GWe of reactor capacity requires approximately 3 to 6 billion gal (11 to 23 billion L) of water yearly, mainly for heat dissipation ${ }^{47}$ (EPRI 2002). Assuming that water use in a DUPIC recycling and fuel fabrication facility would be similar to a nuclear fuel recycling center discussed in Section 4.3.2, approximately 330 million gal/yr (1.3 billion L/yr) would be used annually. Four facilities would require approximately 1.3 billion gal/yr (5.2 billion L/yr).

Socioeconomic Impacts: Socioeconomic impacts would occur in communities in the vicinity of any future facility. These impacts are expected to be similar to those discussed for the Fast Reactor Recycle Alternative. For each GWe of capacity, an LWR and HWR would employ approximately 500 to 1,000 workers and each DUPIC recycling and fuel fabrication facility

\footnotetext{
${ }^{47}$ A typical 1 GWe reactor would withdraw 3 to 6 billion gal/yr (11 to 23 billion L/yr) for cooling (using "wet cooling"). Water consumption would be less than 60 million gal/yr (230 million L/yr).
} 
would employ approximately 4,000 workers (assuming approximately 3,000 workers for each LWR SNF separation facility and approximately 1,000 workers associated with fuel fabrication).

Human Health: In addition to nonradiological hazards, workers at a DUPIC recycling and fuel fabrication facility would be subject to radiological hazards, including radiation exposure. Because of the simplicity of operations compared to other SNF separation techniques, the total annual dose to workers at the DUPIC recycling and fuel fabrication facilities should be bounded by those at the nuclear fuel recycling center discussed in Section 4.3.1. ${ }^{48}$

Similar to the nuclear fuel recycling center discussed in Section 4.3.1, the public could also be subject to radiation exposure, primarily from airborne releases of radionuclides. Because the DUPIC recycling and fuel fabrication facilities would employ mechanical and thermal processes only, it is expected that airborne radionuclide emissions would be bounded by those for the nuclear fuel recycling center $^{49}$ (see Table 4.3-1). The fission gases released in this process would be sent to the off-gas treatment system and would be stored after going through the separation, treatment, and packaging processes before ultimate disposal in a repository. The cladding material would be cleaned and decontaminated for more than a 99 percent recovery of the fuel material and then transferred to the solid waste treatment area before ultimate disposal.

Facility Accidents: The DUPIC fuel cycle would utilize LWRs, HWRs, and DUPIC recycling and fuel fabrication facilities. Accidents associated with LWRs would be the same as presented in Section 4.2.2. The impacts of HWR accidents are presented in Section 4.7.1. The accident impacts of a DUPIC recycling and fuel fabrication facility would be expected to be bounded by those presented in Section 4.3.1 for the Fast Reactor Recycle Alternative recycling center, due to simpler operations and less material separations.

Spent Nuclear Fuel and Radioactive Wastes: By 2060-2070, the 146 GWe of LWR capacity would generate SNF that would be recycled in the DUPIC recycling and fuel fabrication facilities. A total of 212,000 MTHM of SNF (141,000 MTHM of LWR SNF and 71,000 MTHM of HWR SNF) would be generated. ${ }^{50}$ The LWR SNF would be recycled to provide fresh fuel for the HWRs. In 2060-2070, approximately 3,600 MTHM/yr of LWR SNF would be recycled to fuel approximately 54 GWe of HWR capacity. By 2060-2070, the DUPIC fuel cycle would

\footnotetext{
${ }^{48}$ Because the DUPIC fuel cycle is part of a South Korean program, in a research stage, only open literature publications are available. Consequently, there is less information available for this technology than many of the other technologies presented in this PEIS. In the OREOX process (Oxidation and Reduction of Oxide Fuel; OREOX is the name of the DUPIC separation and fuel fabrication process) the actinide and fission inventories coming from LWR SNF would be similar. Additionally, because the OREOX process only uses mechanical and thermal processes (which are similar to the front end step used in both the aqueous and electrochemical separation processes), it is expected that the environmental impacts (e.g., emissions, radiation dose to workers, and wastes) would be no greater than those other processes.

${ }^{49}$ Based on the literature reviewed (IAEA 2005b, Parent 2003), the emissions from the OREOX process are similar to the process used at the front end of the UREX and electrochemical separation processes, in that the volatile fission products are released. In the OREOX process, PWR cladding is removed and the fuel is subjected to a series of high-temperature oxidation and reduction reactions. During the chemical changes, volatile fission products including xenon, krypton, iodine, technetium, and some molybdenum and ruthenium are removed. The volatile fission products would be captured to comply with environmental regulations. The product is then fabricated into DUPIC fuel. If a pellet DUPIC fuel is used, it can be assumed that the radiological emissions for the fuel fabrication would be similar to the potential emission from U/TRU fuel fabrication since the fuel making process is the same (i.e., sintering). Overall, normal radiological emissions should be less than the values provided for a UREX+1a recycling plant and fast reactor fuel fabrication plant.

${ }_{50}$ Based on the following assumptions: the first new LWR is constructed in 2015 and LWR capacity grows to 146 GWe by approximately 2060-2070; existing LWRs are assumed to be replaced as they reach end-of-life between 2020 and 2060-2070; each LWR produces approximately 25 MTHM of SNF/GWe-yr (Note: normally, an LWR produces approximately 21.7 MTHM of SNF/GWe-yr; however, in the DUPIC fuel cycle, an LWR would produce $25 \mathrm{MTHM} / \mathrm{GWe}-\mathrm{yr}$. This is because the burnup of LWR SNF at discharge for the DUPIC fuel cycle is only $35 \mathrm{GWd} / \mathrm{MTHM}$ compared to $51 \mathrm{GWd} / \mathrm{MTHM}$ for the burnup assumed for other fuel cycles that utilize LWRs). HWR construction begins in 2020 and grows to 54 GWe by 2060-2070; and each HWR produces approximately 66 MTHM of SNF/GWe-yr.
} 
generate approximately 3,600 MTHM of HWR SNF annually that would need to be disposed of in a geologic repository. Although this alternative would generate a high volume and mass of SNF, the HWR SNF would have a lower radiotoxicity than LWR SNF (see Section 4.8 for a discussion of the radiotoxicity of HWR SNF relative to other SNF).

The LWR SNF would be treated by the OREOX process to form fuel powder that satisfies the powder characteristics requirements. The DUPIC fuel pellets would be produced from the LWR SNF powder through the pre-compaction, granulation, final compaction, sintering, and the grinding processes. The fuel pellets would be loaded into the cladding tube manufactured outside the hot cell and the end cap would be welded to form a fuel element. These fuel elements would then be bundled into fuel bundles and the fresh DUPIC fuel would be transported to a HWR reactor. The wastes from a DUPIC recycling and fuel fabrication facility are shown in Table 4.5-7.

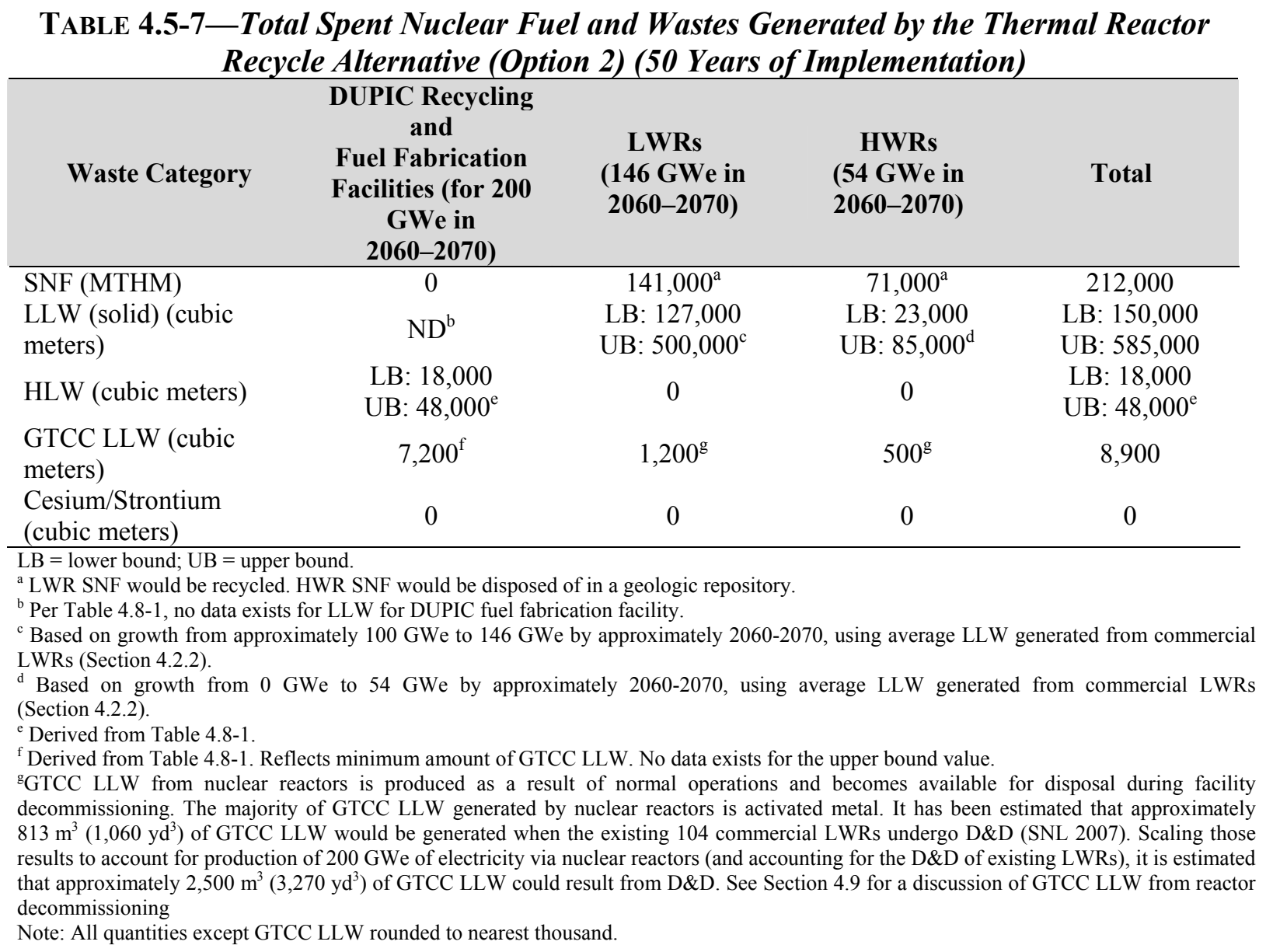

Transportation: A transportation analysis was prepared to determine the potential impacts associated with the Thermal Reactor Recycle Alternative (Option 2) (see Appendix E for a discussion of the methodology and modeling results). The transportation analysis considered all radiological material that could be transported (i.e., LWR SNF, HWR SNF, wastes from the recycling center, etc.). Table 4.5-8 presents the number of radiological shipments, broken down by material to be transported, that would be required for the Thermal Reactor Recycle 
Alternative (Option 2) for 1) all truck and 2) a combination of truck and rail. Because all shipments of fresh nuclear fuel are assumed to occur via truck transport, there is no transportation scenario in which all transportation would occur via rail only. Consequently, the PEIS presents transportation impacts for a combined truck and rail scenario (in tables this scenario is designated as "truck/rail"). As shown in that table, truck transport would require significantly more shipments than rail.

TABLE 4.5-8 - Total Number of Radiological Shipments for 50 Years of Implementation, Thermal Reactor Alternative, Option 2

\begin{tabular}{lcc}
\hline \multicolumn{1}{c}{ Material/Waste } & $\begin{array}{c}\text { Truck Transport } \\
\text { (Number of Shipments) }\end{array}$ & $\begin{array}{c}\text { Truck/Rail Transport } \\
\text { (Number of Shipments) }\end{array}$ \\
\hline Fresh LWR fuel & 23,500 & $23,500^{\mathrm{c}}$ \\
Fresh HWR fuel & 21,900 & $21,900^{\mathrm{c}}$ \\
LWR SNF & 70,500 & 5,640 \\
HWR SNF & 44,840 & 996 \\
HLW & 31,000 & 6,200 \\
GTCC LLW & 10,000 & 2,000 \\
LLW $^{\mathrm{b}}$ & 23,000 & 4,500 \\
Recovered Uranium (Aqueous) & 19,000 & 3,800 \\
\hline Source: Appendix E & \\
${ }^{\mathrm{a}}$ Includes mixed GTCC LLW. & \\
${ }^{\mathrm{b}}$ Includes mixed LLW. & \\
${ }^{\mathrm{C}}$ All shipment of fresh nuclear fuel is assumed to be via truck transport. &
\end{tabular}

The results of the transportation analysis are presented in two sets of tables. The first set of tables (Tables 4.5-9 and 4.5-10) present the impacts associated with handling (loading and inspection) radiological material for the $200 \mathrm{GWe}$ scenario. Impacts are presented in terms of radiological impacts (expressed in person-rem and converted to LCFs using a dose-to-risk conversion factor of $6 \times 10^{-4}$ LCF per person-rem). Table 4.5-9 presents the handling impacts for truck transport and Table 4.5-10 presents the handling impacts for rail transport. Handling operations (loadings and inspections) would not affect the public.

The impacts of handling radiological material are independent of the distance that the material would be transported. As such, the handling impacts would be the same whether the radiological material is transported, for example, $500 \mathrm{mi}(805 \mathrm{~km}), 2,100 \mathrm{mi}(3,380 \mathrm{~km})$, or any other distance. For this reason, these impacts are presented separately from the in-transit impacts (which are presented in the second set of tables).

TABLE 4.5-9—Handling Impacts for 50 Years of Implementation, Thermal Reactor Alternative, Option 2 (Truck Transit)-200 Gigawatts Electric

\begin{tabular}{|c|c|c|c|c|c|c|}
\hline & & & Handling II & ipacts & & \\
\hline & Loadin & & Inspecti & & Total & \\
\hline & person-rem & LCFs & person-rem & LCFs & person-rem & LCFs \\
\hline Thermal Reactor Recycle, Option 2 & 67,100 & 40 & 11,100 & 7 & 78,100 & 47 \\
\hline
\end{tabular}


TABLE 4.5-10—Handling Impacts for 50 Years of Implementation, Thermal Reactor Alternative, Option 2 (Truck and Rail Transit)_200 Gigawatts Electric

\begin{tabular}{|c|c|c|c|c|c|c|}
\hline & \multicolumn{6}{|c|}{ Handling Impacts } \\
\hline & \multicolumn{2}{|c|}{ Loading } & \multicolumn{2}{|c|}{ Inspection } & \multicolumn{2}{|c|}{ Total } \\
\hline & person-rem & LCFs & person-rem & LCFs & person-rem & LCFs \\
\hline Thermal Reactor Recycle, Option 2 & 37,900 & 23 & 2,950 & 2 & 40,900 & 25 \\
\hline
\end{tabular}

The in-transit impacts are shown in Tables 4.5-11 (truck transit) and 4.5-12 (truck and rail transit) for the Thermal Reactor Recycle Alternative (Option 2). These impact estimates would vary based on a variety of factors, including the distance that the radiological material would be transported, the specific routes that would be utilized, the population densities along those routes, and others. Of these factors, transport distance is the most significant. Because the locations of future reactors, nuclear fuel recycling facilities, and future disposal facilities are unknown, DOE analyzed transportation impacts over five distances: $150 \mathrm{mi}(241 \mathrm{~km}), 500 \mathrm{mi}(805 \mathrm{~km})$, 1,500 $\mathrm{mi}(2,414 \mathrm{~km}), 2,100 \mathrm{mi}(3,380 \mathrm{~km})$, and 3,000 mi $(4,828 \mathrm{~km})$. In-transit impacts presented in Tables 4.5-11 and 4.5-12 are based on 2,100 mi $(3,380 \mathrm{~km})$ of transport. This distance was selected as a reference distance because it represents the average distance for all SNF shipments analyzed in the Yucca Mountain FEIS (DOE 2002i). Impacts associated with the other four distances are presented, on a per shipment basis, in Appendix E, which describes the transportation methodology and assumptions. Although the in-transit impacts are not exactly "linear" (i.e., twice the impacts for twice the distance transported), that is a close approximation. Consequently, if the radiological material were transported $500 \mathrm{mi}(805 \mathrm{~km})$, all of the in-transit impacts presented in Tables 4.5-11 and 4.5-12 could be calculated by multiplying the values in those tables by $0.24(500 / 2,100)$.

TABLE 4.5-11-In-Transit Transportation Impacts for 50 Years of Implementation, Thermal Reactor Alternative, Option 2 (Truck Transit)-200 Gigawatts Electric

\begin{tabular}{|c|c|c|c|c|c|c|c|c|}
\hline & \multicolumn{4}{|c|}{ In Transit Impacts } & \multirow{3}{*}{$\begin{array}{l}\text { Total Incident- } \\
\text { Free LCFs }\end{array}$} & \multirow{2}{*}{\multicolumn{3}{|c|}{ Accident Impacts }} \\
\hline & \multicolumn{2}{|c|}{ Crew } & \multicolumn{2}{|c|}{ Public } & & & & \\
\hline & $\begin{array}{c}\text { person- } \\
\text { rem }\end{array}$ & LCFs & $\begin{array}{l}\text { person- } \\
\text { rem }\end{array}$ & LCFs & & $\begin{array}{c}\text { person- } \\
\text { rem }\end{array}$ & LCFs & $\begin{array}{l}\text { Collision } \\
\text { Fatalities }\end{array}$ \\
\hline $\begin{array}{l}\text { Thermal Reactor } \\
\text { Recycle, Option } 2\end{array}$ & 31,000 & 19 & 137,000 & 82 & 101 & 1.23 & 0 & 21 \\
\hline
\end{tabular}

Source: Appendix E

Note: All LCFs rounded to nearest whole number

TABLE 4.5-12-In-Transit Transportation Impacts for 50 Years of Implementation, Thermal Reactor Alternative, Option 2 (Truck and Rail Transit)-200 Gigawatts Electric

\begin{tabular}{|c|c|c|c|c|c|c|c|c|}
\hline & \multicolumn{4}{|c|}{ In Transit Impacts } & \multirow{3}{*}{$\begin{array}{c}\text { Total } \\
\text { Incident- } \\
\text { Free LCFs }\end{array}$} & \multirow{2}{*}{\multicolumn{3}{|c|}{ Accident Impacts }} \\
\hline & \multicolumn{2}{|c|}{ Crew } & \multicolumn{2}{|c|}{ Public } & & & & \\
\hline & $\begin{array}{c}\text { person- } \\
\text { rem }\end{array}$ & LCFs & $\begin{array}{c}\text { person- } \\
\text { rem }\end{array}$ & LCFs & & $\begin{array}{c}\text { person- } \\
\text { rem }\end{array}$ & LCFs & $\begin{array}{l}\text { Collision } \\
\text { Fatalities } \\
\end{array}$ \\
\hline $\begin{array}{l}\text { Thermal Reactor } \\
\text { Recycle, Option } 2\end{array}$ & 1,010 & 1 & 5,260 & 3 & 4 & 0 & 0 & 6 \\
\hline
\end{tabular}

There are potentially significant differences in impacts depending upon whether transportation occurs via truck or a combination of truck and rail. For all alternatives, truck and rail transport 
would result in smaller impacts than truck transport. This is due to the fact that there would be many fewer transportation shipments for truck and rail compared to truck only. This would directly affect the distance traveled and exposures to both crews and the public. Additionally, the number of accident fatalities (collisions) would be smaller for the truck and rail transport.

\subsubsection{Construction and Operation of Thermal Recycle Facilities-Option 3}

The Thermal Reactor Recycle Alternative (Option 3-Transuranic Consumption in HTGRs) is the least developed domestic programmatic alternative, with only limited data available. Any quantifications presented in this section are only preliminary estimates, and do not have the same level of accuracy as the data for other alternatives. The Generation IV sponsored work, which is ongoing, will result in information that will increase DOE's knowledge base of this concept, but this work will be long term and not available for use in this PEIS. In preparing the environmental analysis of this option, DOE utilized the best available information, including reports prepared under the AFCI, industry reports, and publicly-available documents. Based on this information, DOE has concluded that the environmental impacts of this option would be similar to other alternatives in the following respects: 1) construction and operation impacts for nuclear fuel recycling centers would be similar to other closed fuel cycle alternatives; 2) construction activities and impacts for HTGRs would be the same as the HWR/HTGR Alternative (all-HTGR option); and 3) operations of the deep-burn HTGRs would be similar to the HWR/HTGR Alternative (all-HTGR option), with minor differences related to increased fuel burnup and the use of transuranic fuel. These differences are discussed in this section.

The PEIS analysis in this section focuses on the $200 \mathrm{GWe}$ end-state (approximately $200 \mathrm{GWe}$ of LWR and HTGR capacity, approximately 3,200 MTHM/yr of LWR SNF separation capacity, and fuel fabrication capacity to support the fabrication of fuel for 36 GWe of HTGR capacity).

Construction: If a Thermal Reactor Recycle Alternative (Option 3) with a capacity of $200 \mathrm{GWe}$ is pursued, the following facilities could be built:

- $\quad 164$ GWe of LWR capacity (which would include the replacement of approximately 100 GWe of LWR capacity when existing LWRs reach their end-of-life).

- $\quad 36$ GWe of HTGR capacity.

- Four recycling and fuel fabrication facilities to recycle LWR SNF and produce HTGR transmutation fuel (based on a capacity of $800 \mathrm{MTHM} / \mathrm{yr}$ for each recycling center) with a total capacity to separate approximately 3,200 MTHM/yr of LWR SNF and fabricate HTGR fuel to support 36 GWe of HTGR capacity.

Although some facilities could be colocated, the construction of this much capacity would necessitate that many sites in the United States be utilized. For this analysis, it is assumed that the nuclear fuel recycling centers and the reactors would not be colocated, which would necessitate transportation of material between the facilities during operations.

Under Option 3, multiple recycling facilities would be constructed to recycle LWR SNF and fabricate HTGR fuel. These facilities would operate similarly to the recycling facilities described for the Fast Reactor Recycle Alternative, and would have similar impacts to those presented in 
Section 4.3.1. As such, the environmental impacts of this facility are not repeated. With respect to the reactor capacity that would be required for Option 3, for the $200 \mathrm{GWe}$ scenario, approximately 164 GWe in LWR capacity and 36 GWe in HTGR capacity would be required. The environmental impacts of constructing and operating approximately 164 GWe in LWR capacity (including the replacement LWRs that reach end-of-life) and 36 GWe of HTGR capacity would be similar to the impacts presented in Section 4.2.2 and are not repeated.

Operation: This section discusses potential differences in the operation of HTGRs with transuranic fuel compared to the HTGR discussed in Section 4.7.2. The discussion focuses on human health and safety, waste generation, and transportation of nuclear materials.

Uranium Requirements: The Thermal Reactor Recycle Alternative (Option 3) would utilize a combination of LWRs using enriched uranium fuel and HTGRs using a transuranic fuel with no uranium in the fuel, possibly using an inert matrix if needed. Preliminary estimates indicate that the reactor fleet would have about 82 percent of the power being generated by the LWRs, while the other 18 percent would be generated by the deep-burn HTGRs. (Schwartz 2008).

Fuel Fabrication Requirements: The transuranics recovered from processing all of the LWR SNF would be used for fabrication of the HTGR fuel. The amount of LWR SNF to be processed and the amount of transuranics that would be recovered is not known accurately at this time. Given that the recovered transuranics would be radioactive, the fuel fabrication would need to be done remotely, as in the other alternatives where spent LWR fuel is processed to recover the transuranics for recycle. At this time, it is expected that the same fuel fabrication technologies that have been developed for enriched uranium HTGR fuel would be applicable to the HTGR transuranic fuel, although modifications would be needed for remote fuel fabrication. However, since the deep-burn TRU fuel composition has not yet been determined, the amount of deep-burn fuel fabrication cannot be determined, and it is not known if additional modifications to the fuel fabrication technologies will be required, or if a new technology would be needed (Schwartz 2008).

Infrastructure Requirements: The Thermal Reactor Recycle Alternative (Option 3) would utilize large quantities of nuclear grade graphite in the HTGR reactor cores. Graphite production is a basic industrial operation and the capability to produce nuclear grade graphite would be driven by the demand. Although there is currently little demand for this today, it is expected that the commercial industry would readily respond to meet an identified need without significant issues.

Helium is the coolant of choice for HTGRs, due to its favorable neutronic and heat exchange properties, and also due to its chemical stability in the temperature range of interest. A typical HTGR requires an initial inventory of 5 to 10 tons of helium. The annual make-up, due to system losses, would be a small percent of that inventory. Natural gas contains trace amounts of helium which is extracted during natural gas refining. The United States is the largest producer of helium in the world, with an annual production exceeding 20,000 tons, and geological resources of more than 1 million tons (Finck 2007a). Consequently, there should be no adverse impacts associated with providing the required quantities of helium to support HTGRs. 
Land Resources: Impacts to land resources are expected to be similar to the Reactor Recycle Alternative presented in Section 4.3.

Visual Resources: Impacts to visual resources are expected to be similar to the Fast Reactor Recycle Alternative presented in Section 4.3.

Air Resources: Impacts to air resources are expected to be similar to the Fast Reactor Recycle Alternative presented in Section 4.3.

Water Resources: Impacts to water resources are expected to be similar to the Fast Reactor Recycle Alternative presented in Section 4.3.

Socioeconomic Impacts: Impacts to socioeconomic resources are expected to be similar to the Fast Reactor Recycle Alternative presented in Section 4.3.

Human Health: The public would be subject to radiation exposure, primarily from airborne releases of radionuclides from HTGRs. Based on similar design requirements that would need to be met for either HTGR transuranic fuel or uranium-fuel, the doses to the public should be similar. Although HTGR worker impacts should also be similar, the higher burnup associated with thermal recycle in an HTGR has the potential to produce SNF with higher radiation doses. Data does not exist to quantify these potential increased impacts. Operating procedures could likely be designed to mitigate any potential increased doses.

Facility Accidents: The thermal recycle in HTGRs fuel cycle would utilize LWRs, HTGRs, and nuclear fuel recycling centers. Accidents associated with LWRs would be the same as presented in Section 4.2.2. The impacts of HTGR accidents are presented in Section 4.7.2. The accident impacts of a nuclear fuel recycling center would be the same as those presented in Section 4.3.1 for the Fast Reactor Recycle Alternative recycling center.

The use of a TRU fuel instead of an enriched uranium fuel in the HTGR may have some impact on reactor response mainly due to differences in neutron characteristics with the transuranic fuel. However, for the spectrum of accidents typically considered for the HTGR, past experience with other reactor types has shown that these differences in neutron characteristics would not result in a significant difference in reactor response for accident conditions. Consequently, the use of a transuranic fuel instead of a uranium fuel should not significantly change the impacts of accidents (Schwartz 2008).

Spent Nuclear Fuel and Radioactive Wastes: By 2060-2070, the 164 GWe of LWR capacity would generate SNF that would be recycled. A total of 140,000 MTHM of LWR SNF and an unknown quantity of HTGR SNF would be generated. ${ }^{51}$ The higher burnup of HTGRs would result in a larger quantity of fission products in the HTGR SNF, which would increase the radiotoxicity and thermal loading relative to the HTGR SNF discussed in Section 4.7.2. Approximately 3,200 MTHM/yr of LWR SNF would be recycled, and the recycled fuel would

${ }^{51}$ Based on the following: first new LWR is constructed in 2015 and LWR capacity grows to 164 GWe by approximately 2060-2070. Existing LWRs are assumed to be replaced as they reach end-of-life between 2020 and 2060-2070. Each LWR produces approximately 21.7 MTHM of SNF/GWe-yr. HTGR construction begins in 2020 and grows to 36 GWe by 2060-2070. The amount of SNF generated by a deep-burn HTGR is not known, but is expected to be less than 7.7 MTHM of SNF/GWe-yr. These quantities represent values at system equilibrium. 
be used to fuel 36 GWe of HTGR capacity. The HTGR SNF would be disposed of in a geologic repository.

The wastes from this alternative would be from several sources. For the processing of the LWR SNF, HLW, GTCC LLW, and LLW would be generated, similar to that generated for the other recycle alternatives. Fabrication of the HTGR fuel would generate GTCC LLW and LLW, but there are no estimates for the amounts at this time given that there is no relevant remote fuel fabrication experience for this HTGR fuel. After irradiation, the deep-burn HTGR fuel would be sent for disposal in a geologic repository. Preliminary estimates indicate that the transuranic content of the HTGR SNF would be approximately 30 percent of that for the No Action Alternative. As a result, with such a large amount of transuranics being placed in a geologic repository, it is estimated that the reduction in decay heat load would be about a factor of 2 to 3 as compared to the No Action Alternative. There are no estimates for the change in radiotoxicity, but given that the transuranic content of the disposed SNF would be 30 of that for the No Action Alternative, there would be a corresponding reduction in radiotoxicity since radiotoxicity is primarily a result of the higher actinide content in the wastes. It is estimated that the HTGR SNF would drop to that of the natural uranium approximately in the time period of 50,000-100,000 years (Schwartz 2008).

The amount of HTGR SNF is not known at this time since the fuel composition is undetermined, but the amount would be affected by the ability to remove the fuel compacts from the graphite blocks as in the HWR/HTGR Alternative (all-HTGR option-see Section 2.7.2). While the amount of SNF compacts can be relatively smaller with the HTGR fuel, if the compacts are not removed from the graphite blocks, the volume of SNF can be substantial. The intact spent fuel compacts would be SNF, while if removed, the graphite blocks may be GTCC LLW (Schwartz 2008).

Transportation: Although the radionuclide inventories are different for the HTGR and deep burn HTGR SNF, the "per-shipment" incident-free transportation impacts of the deep-burn HTGR are expected to be similar to the incident-free HTGR handling impacts and in-transit impacts discussed in Section 4.7.2. This is due to the fact that the transportation analysis assumes that packages would have the regulatory maximum exposure rate of $10 \mathrm{mrem} / \mathrm{hour}$ at a distance of $6.6 \mathrm{ft}(2 \mathrm{~m})$ from the source. The number of SNF shipments for the deep-burn HTGR are unknown, therefore the incident-free transportation impacts of the deep-burn HTGR SNF cannot be further quantified. Due to the lack of a radionuclide inventory in the SNF, transportation accident impacts of the deep-burn HTGR SNF cannot be quantified.

The impacts associated with the transportation of 140,000 MTHM of LWR SNF would be similar to (approximately 90 percent as much as) the impacts presented in Section 4.2.1.2, which are based on transporting 158,000 MTHM of LWR SNF.

4.6

Once-Through Fuel CyCle Alternative Using Thorium (Thorium Alternative)

The Thorium Alternative, described in Chapter 2, Section 2.6, would represent a fundamental shift in the fuel used for U.S. commercial reactors. Rather than being fueled solely by enriched 
( 3 to 5 percent) uranium, U.S. commercial reactors would transition to a fuel composed of thorium and enriched uranium (less than 20 percent), but would continue to operate using a once-through fuel cycle to produce electricity. Of the possible implementation options, the most attractive approach is a heterogeneous, seed-blanket configuration along the lines of the seedblanket-unit or whole-assembly-seed-blanket concepts described in Chapter 2, Section 2.6. These concepts involve two distinct zones in a reactor: a seed region containing uranium oxide fuel with the uranium enriched up to approximately 19.9 percent enrichment, and a blanket region containing thorium oxide and uranium oxide, where the uranium enrichment could also range up to approximately 19.9 percent enrichment. These concepts therefore include characteristics of both conventional uranium fuels, albeit with a significantly higher enrichment than in current commercial reactors, and thorium based fuels.

At the programmatic level, this PEIS assesses the potential environmental impacts associated with broad implementation of the Thorium Alternative to achieve a capacity of approximately $200 \mathrm{GWe}$, based on a 1.3 percent growth rate for nuclear power. The analysis of this broad implementation assumes that the U.S. commercial reactors begin to shift to thorium-based fuel alternatives by approximately 2020, and that by approximately 2060-2070 all commercial reactors would operate using thorium-based fuels. The PEIS also provides information for a growth scenario of 2.5 percent, which would result in a capacity of approximately $400 \mathrm{GWe}$ (see Table 4.8-2), a 0.7 percent growth rate, which would result in a capacity of approximately $150 \mathrm{GWe}$ (see Table 4.8-3), and a zero growth scenario, which would result in a capacity of approximately $100 \mathrm{GWe}$ (see Table 4.8-4).

This PEIS presents the environmental impacts of the Thorium Alternative as follows:

- Thorium-Based Facility Operations: Existing facilities would operate differently using a thorium fuel cycle. At the front end of the fuel cycle, thorium would need to be mined and there would be a minor reduction in natural uranium requirements. With respect to uranium enrichment and fuel fabrication, a thorium fuel cycle would also operate differently than the uranium fuel cycle. The impacts of producing higher enriched uranium fuel (up to approximately 19.9 percent) are presented. Reactor operations using thorium-based fuel are also discussed, including the transport and emplacement of SNF in a geologic repository.

- New nuclear electricity generation between 2010 and 2060-2070: The environmental impacts of constructing and operating $200 \mathrm{GWe}$ of capacity in nuclear reactors, including the construction and operation of new LWRs and replacement LWRs, would be the same as those presented in Section 4.2.2 and are not repeated.

Widespread implementation of the Thorium Alternative would result in the following domestic impacts:

- Thorium-specific mining (as opposed to by-product mining) would be required.

- Natural uranium needs would be approximately the same as the uranium-based fuel cycle.

- $\quad$ Facilities capable of enriching uranium to 19.9 percent would be required, which could necessitate construction and operation of one or more dedicated enrichment facilities. 
- $\quad$ One or more dedicated thorium-uranium fuel fabrication facilities would be required.

- Some reactor-related facilities and operations may need to be modified to use thoriumbased fuel, which could necessitate construction and operation of additional SNF pools and SNF dry storage facilities with more shielding.

- Additional geologic repository capacity would be required for ultimate disposition of thorium SNF. This would also be required for all of the alternatives to accommodate the postulated growth in nuclear power.

Each of these impacts is discussed below. The seed-and-blanket concept is a mixture of uranium and thorium-based fuels and therefore exhibits the characteristics of both.

\section{Thorium Requirements:}

Thorium-specific mining: The Thorium Alternative would require both uranium mining (discussed in Section 4.1.1) and thorium mining (discussed in this section). In general, the impacts of thorium mining would be less than uranium mining. There would be less overburden, less radioactive waste produced, less radiological impact to miners, and simpler tailings management than in the case of uranium. However, because the uranium requirements would not be significantly reduced, the thorium-specific mining impacts would be additive. Thorium mining impacts would be site-dependent.

Thorium is relatively abundant and easily mined. Monazite, a mixed thorium rare earth uraniumphosphate, is the most popular source of thorium and is available in many countries (particularly Brazil [600,000 MT of thorium metal], Turkey [380,000 MT], and India [320,000 MT]) in beach or river sands along with heavy minerals - ilmenite, rutile, zircon, sillimenite and garnet. In the United States, there are an estimated 137,000 MT of thorium metal in reasonably assured reserves (IAEA 2005a).

The present production of thorium is almost entirely as a by-product of rare earth extraction from monazite sand. The mining and extraction of thorium from monazite is relatively easy and significantly different from that of obtaining uranium from its ores. For example, the overburden (the soil and rock above the deposit) during mining is much smaller than in the case of uranium and the total radioactive waste production in mining operation is about two orders of magnitude lower than that of uranium. The potential radiological impact to miners is also much smaller than in the uranium case due to the short lifetime of thoron (predominant radon in the thorium, $\mathrm{Rn}-220$ with a half-life of 56 seconds) as compared with the predominant radon in the uranium ore (Rn-222 with a half-life of 3.8 days), and therefore, needs much simpler tailings management than in the case of uranium to prevent long term public doses (see Figure 4.6-1). External gamma exposure is not a major concern because thorium emits only a small amount of gamma radiation. Consequently, thorium is generally a health hazard only if it is taken into the body. If inhaled, however, thorium can have approximately 8 times greater health risk than natural uranium. The main health concern for environmental exposures is generally bone cancer (IAEA 2005a). 


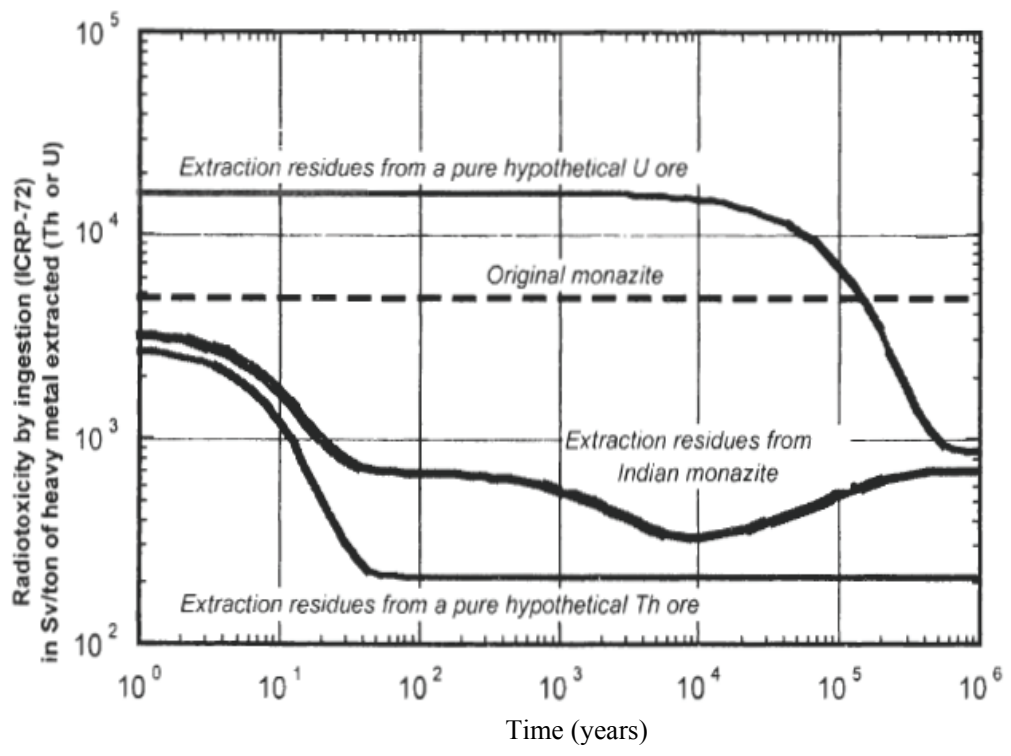

Source: Gruppelaar et al. 2000

FIGURE 4.6-1-Radiotoxicity of Uranium Ore versus Thorium Ore

Thorium Availability: A thorium fuel cycle producing $200 \mathrm{GWe}$ would require approximately 1,070 MT of thorium annually (see Table 4.8-1). With approximately 137,000 MT of thorium in United States reliable reserves, the United States could supply its thorium needs for more than 100 years without importing any thorium from foreign sources.

Uranium Requirements: Assuming that nuclear electricity generating capacity would grow to approximately $200 \mathrm{GWe}$ by approximately 2060-2070, the quantity of natural uranium needed to support $200 \mathrm{GWe}$ of capacity in a thorium fuel cycle would be approximately the same as for the uranium-based fuel cycle, approximately 39,200 MT/yr.

Enrichment and Fuel Fabrication Facilities for 12.2 and 19.9 Percent Uranium: The environmental impacts of enriching uranium to 12.2 percent and 19.9 percent and fabricating fuel for thorium-fueled reactors would be similar to the impacts described in Section 4.1. More details regarding uranium enrichment and thorium fuel fabrication are contained in Appendix A. The thorium fuel cycle would require uranium enrichments of approximately 12.2 percent and 19.9 percent versus the 3 to 5 percent for the uranium fuel cycle. ${ }^{52}$ Enrichment facilities to support a thorium fuel cycle would be large industrial facilities, similar in size to those discussed in Section 4.1.2, with the same types of environmental impacts (see NRC 2005b and NRC 2006b). In general, enriching uranium to higher than 5 percent does not produce different types of impacts, but requires more steps. Supporting a typical thorium-fueled LWR $(1 \mathrm{GWe})$ on an annual basis would require:

\footnotetext{
${ }^{52}$ In theory, U-233 or Pu-239 could be used instead of U-235 enriched to 19.9 percent for the fissile material in the seed fuel. However, there is no identified source for these isotopes for this purpose, so U-233 and Pu-239 are not analyzed.
} 
- Natural uranium requirements normalized to GWe-year would be 196 MT for the thorium-fueled reactor;

- $\quad$ Approximately 5 MT of low enriched uranium (19.9 percent enrichment and below) would be required annually; and

- Approximately 5.3 MT of thorium would be required annually (Todosow 2007b).

Currently, there is no capacity in the United States to enrich uranium to 12.2 percent and 19.9 percent. The American Centrifuge Plant, once operational, would be capable of enriching uranium up to 10 percent. While the technology exists and has been utilized in the past to produce uranium with enrichments of 19.9 percent (and higher), an existing enrichment facility would need to be retrofitted (with additional centrifuges connected in series or additional gaseous diffusion stages) or a new facility constructed. In the past, these facilities (such as the existing Paducah facility) required hundreds of acres, used significant quantities of electricity, and employed thousands of workers. Modern enrichment facilities would likely be more compact, and more efficient in terms of electricity and staffing. The size of an enrichment facility is generally a compromise among criticality concerns (which govern the size of components), and desired enrichment and throughput. For example, multiple passes through enrichment stages can be used to increase the enrichment, subject to criticality constraints. The option of obtaining these enrichments by down-blending surplus highly enriched uranium (HEU) from the weapons complex may be available to satisfy some of the requirement.

There are only two existing fuel fabrication facilities in the United States that are operational and have licenses to fabricate reactor fuels with uranium enrichments greater than 5 percent. These facilities produce fuels for the Naval Reactors Program, as well as research reactor fuels. Because the capacity of these fuel fabrication facilities would not be sufficient to produce all of the 12.2 percent and 19.9 percent enriched uranium fuel for the commercial industry, it is likely that one or more new fuel fabrication facilities would be constructed.

Thorium Fuel Fabrication Requirements: Thorium fuels have been made in the past (see Appendix A, Section A.3.2). Thorium fuels would likely be fabricated in a manner similar to uranium oxide and MOX fuels, which are formed from pellets in tubular cladding. A separate plant may be needed to avoid cross contamination (or dedicated lines in existing facilities may be adequate), and the optimum conditions could well be rather different, but no serious difficulties seem likely for once-through applications. If interest develops in nitride or other less familiar fuel forms, then commercialization of the fuel production would likely require an appropriate development program. No special problems are expected in the manufacturing technology for MOX thorium-uranium pelletized fuel (IAEA 2002b).

Fuels containing naturally occurring "fissile" U-235 in combination with "fertile" U-238 or Th-232, emitting only alpha particles of relatively low specific activity, can be manufactured by the so-called "contact operations" where the operator has direct contact with the fuel material. However, process operations that involve generation and handling of fine powders of U-235, U-238, or Th-232 bearing fuels are carried out in ventilated enclosures, such as gloveboxes, for minimizing radioactive aerosol (IAEA 2002b).

Thorium-specific hazards (such as greater risks from inhalation) would need to be accommodated in the design of the fuel fabrication facility. These would likely not be present in 
a facility designed for HEU fuels, and retrofitting would likely be undesirable due to cost and other considerations.

Reactor Facilities and Operations: Although there would be changes in reactor operations for the thorium fuel cycle, it is expected that the design would ensure that all safety and operational parameters of existing nuclear plants would be preserved with the seed-blanket options (IAEA 2002b). Reactor-specific designs and operating procedures could also be employed to ensure margins are maintained. For example, the seed material could be replaced more often and/or reshuffled more frequently, similar to conventionally-fueled uranium reactors. Issues associated with the increased reactivity due to continuing production of U-233 from the decay of protactinium-233 (Pa-233) following shutdown need to be taken into consideration but should not be a practical concern. However, the additional U-233 that would be produced as Pa-233 decays needs to be accounted for in satisfying potential nonproliferation concerns. In theory, longer refueling cycles and higher plant capacity factors could be achieved with thorium fuel because thorium fuel has a significantly higher thermal conductivity at LWR operating temperatures and a lower rate of fission gas release. Therefore, thorium fuel can be operated to higher burnup with less difficulty than uranium fuel (Todosow 2007b). This PEIS assumes that the thorium-fueled reactor would achieve higher burnups (149 GWd/MT for $\mathrm{UO}_{2}$ and $75 \mathrm{GWd} / \mathrm{MT}$ for the $\mathrm{ThO}_{2}$ ) (Todosow 2003).

In general, for a concept employing thorium-based fuel, the following plant parameters could change compared to conventionally-fueled uranium reactors; statements related to advantages due to the properties of thorium oxide, however, are only applicable to the blanket portion of seed-blanket configurations:

Land Resources: Overall land use would not change appreciably, with the possible exception of expanded pool storage, which might be required to accommodate the longer cooling times of thorium fuels. Because SNF storage pools are a relatively small portion of a nuclear power plant's total land area, this impact is not expected to be major. Once operational, a total of approximately 600,000 acres $(243,000 \mathrm{ha})$ of land could be occupied by facilities, paved areas, and buffer zones. Most of this area would not be disturbed but would serve as a buffer between the actual facility and the outer facility boundary. The total site area would be determined by accident analyses and regulatory requirements, including safeguards and security.

Visual Resources: With respect to visual characteristics, the visibility of any LWR (using thorium fuel) from publicly accessible locations would be dependent on the future site characteristics. For sites that use "wet" cooling tower systems, the water vapor plume from cooling tower operations may be visible for many miles from the plant.

Air Resources: Impacts to air resources would be similar to the No Action Alternative presented in Section 4.2.

Water Resources: Cooling water requirements are largely a function of reactor power and thus would not be affected by the thorium fuel cycle. Every operating reactor would use significant 
quantities of water. A typical GWe of reactor capacity requires approximately 3 to 6 billion gal (11 to 23 billion L) of water yearly, mainly for heat dissipation ${ }^{53}$ (EPRI 2002).

Socioeconomic Impacts: Socioeconomic impacts would occur in communities in the vicinity of any future facility. For each GWe of capacity, an LWR using thorium fuel would require approximately 500 to 1,000 workers.

Human Health: Irradiated thorium-based fuels contain a significant amount of U-232, which has a half-life of 73.6 years and is associated with strong gamma emitting daughter products. As a result, there is significant buildup of radiation dose with the storage of spent thorium-based fuels. Therefore, operational doses could be higher for storage workers for the thorium fuel cycle. However, it is expected that operational procedures and ALARA exposure principles could be employed such that impacts to workers at an LWR fueled with thorium would not be expected to differ significantly from the impacts presented in Section 4.2.2 for a uranium-fueled LWR.

With respect to potential doses to the public, because thorium-based fuels are expected to have superior thermo-physical properties, such as higher melting point and better thermal conductivity, they could be expected to release less fission gases as compared to uranium-based fuels. However, assuming no changes in the integrity of the fuel assembly cladding, radiation exposures to the public would be expected to be similar to those of uranium-fueled LWRs (see Section 4.2.2).

Facility Accidents: Accident analyses for two heterogeneous "seed-blanket" implementation schemes for thorium fueled LWRs have been performed by Brookhaven National Laboratory and the Massachusetts Institute of Technology (see Todosow and Kazimi 2004). The two concepts are the seed-blanket-unit where the seed and blanket occupy the same space as a conventional assembly, and the whole-assembly-seed-blanket where the seed and blanket rods are located in distinct assemblies. Several "bounding" accidents were evaluated, for each concept: 1) large break loss-of-coolant; 2) loss of primary flow; and 3) loss of offsite power. The results for safety-related parameters were comparable to those for a conventional uranium-fueled LWR, and were well below limits (Todosow and Kazimi 2004).

Spent Nuclear Fuel and Radioactive Wastes: As discussed in Section 4.2.2, typical nuclear power plants generate SNF and LLW, including GTCC LLW. SNF management is addressed below. Use of thorium fuel would not change the amount of LLW generated by a typical LWR. Because GTCC LLW from nuclear reactors is produced as a result of normal operations and becomes available for disposal during facility decommissioning, the use of thorium fuel would not change the amount of GTCC LLW generated by a typical LWR. Over a 50-year implementation period (2010 to 2060-2070), the Thorium Alternative would generate the radioactive wastes shown in Table 4.6-1.

\footnotetext{
${ }^{53}$ A typical 1 GWe reactor would withdraw 3 to 6 billion gal/yr (11 to 23 billion L/yr) for cooling (using "wet cooling"). Water consumption would be less than 60 million gal/yr (230 million L/yr).
} 


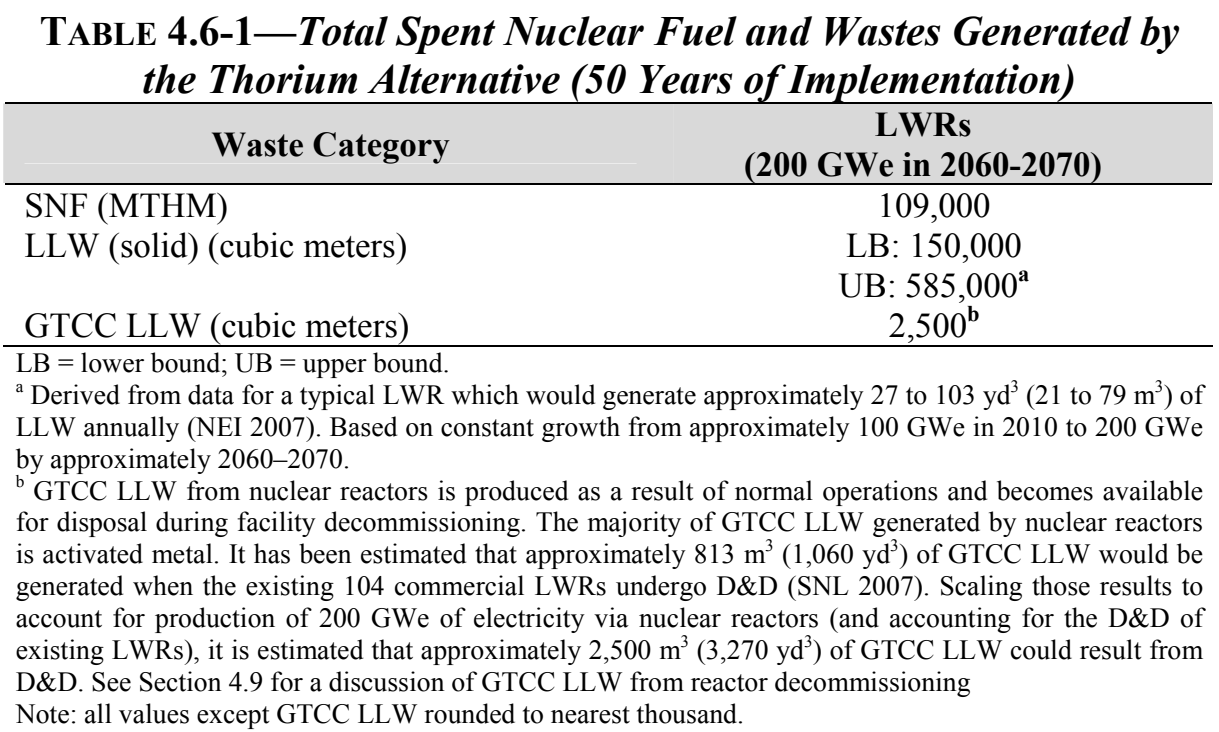

Spent Nuclear Fuel: The most noteworthy change associated with a thorium open fuel cycle would involve the management of SNF. Because both the discharged volume and mass of SNF would be reduced (by approximately 50 percent), there would be less SNF to be managed. For a nuclear electricity generating capacity of approximately 200 GWe in 2060-2070, the annual discharged SNF mass would be approximately 2,050 MTHM (see Table 4.8-1). Of this quantity, approximately 820 MTHM would be $\mathrm{UO}_{2}$ SNF and 1,230 MTHM would be $\mathrm{ThO}_{2}$ SNF (Schwartz 2008). Based on the assumption that all commercial reactors would transition to a thorium-based fuel cycle by approximately 2060-2070, the total amount of SNF generated by commercial LWRs by 2060-2070 would be approximately 109,000 MTHM. $^{54}$

The thorium fuel cycle offers several potential advantages relative to the conventional uranium fuel cycle, including: 1) reducing the quantity and quality of plutonium produced; 2) producing less transuranics, and 3) improving the long-term SNF waste characteristics (IAEA 2005a). These advantages are further explained below.

Plutonium Produced: Table 4.6-2 presents the characteristics of the plutonium produced by a thorium-fuel reactor (assuming $149 \mathrm{GWd} / \mathrm{MT}$ for $\mathrm{UO}_{2}$ and $75 \mathrm{GWd} / \mathrm{MT}$ for the $\mathrm{ThO}_{2}$ ) versus a typical uranium-fueled PWR $(51 \mathrm{GWd} / \mathrm{MT})$. As can be seen from that table:

- Total plutonium production is a factor of 3 to 4 less in thorium fuel than in uranium fuel due to the higher enrichment in the seed and the thorium in the blanket.

- $\quad \mathrm{Pu}-239$ production is a factor of 4.2 less in thorium fuel than in uranium fuel.

- $\quad$ The plutonium produced in the thorium fuel and in the seed is high in Pu-238, leading to a decay heat rate 3.7 times greater than that from plutonium derived from uranium fuel and 29 times greater than that from weapons grade plutonium.

\footnotetext{
${ }^{54}$ Based on the following: first new LWR is constructed in 2015 and LWR capacity grows to 200 GWe by approximately 2060-2070. Each LWR fueled with uranium-oxide produces approximately 21.7 MTHM of SNF/GWe-yr. Use of thorium-based fuel begins in 2020 and all new LWRs use a thorium-based fuel. Existing LWRs are assumed to be replaced as they reach end-of-life between 2020 and 2060-2070. When replaced, these LWRs begin to use thorium-based fuel. Each LWR fueled with thorium-based fuel produces approximately $10 \mathrm{MTHM}$ of SNF/GWe-yr.
} 
TABLE 4.6-2-Plutonium Produced in Uranium-Fueled Light Water Reactor Versus Thorium-Fueled

\begin{tabular}{|c|c|c|c|c|c|c|}
\hline \multirow[b]{2}{*}{$\begin{array}{c}\text { Plutonium } \\
\text { Isotope }\end{array}$} & \multicolumn{2}{|c|}{$\begin{array}{c}\text { Typical Present-Day } \\
\text { Uranium-Fueled LWR }\end{array}$} & \multicolumn{2}{|c|}{$\begin{array}{c}\text { Typical Thorium-Fueled } \\
\text { LWR } \\
\text { (SBU Seed + Blanket) } \\
\end{array}$} & \multicolumn{2}{|c|}{$\begin{array}{c}\text { Typical Thorium-Fueled } \\
\text { LWR } \\
\text { (WASB Seed + Blanket) }\end{array}$} \\
\hline & kg/GWe-yr & $\begin{array}{c}\text { Fraction of } \\
\text { Pu (\%) } \\
\end{array}$ & kg/GWe-yr & $\begin{array}{c}\text { Fraction of } \\
\text { Pu (\%) }\end{array}$ & kg/GWe-yr & $\begin{array}{c}\text { Fraction of } \\
\text { Pu (\%) }\end{array}$ \\
\hline 238 & 7.2 & 3 & 5 & 7 & 6 & 8 \\
\hline 239 & 148.8 & 55 & 38 & 47 & 42 & 49 \\
\hline 240 & 56.4 & 21 & 17 & 20.5 & 15 & 17 \\
\hline 241 & 40.8 & 15 & 12 & 15.5 & 14 & 17 \\
\hline 242 & 16.8 & 6 & 8 & 10 & 8 & 9 \\
\hline Total & 270 & 100 & 80 & 100 & 85 & 100 \\
\hline
\end{tabular}

Source: Todosow 2003

Note: SBU $=$ Seed blanket unit; WASB $=$ whole-assembly-seed-blanket

The higher burnups (149 GWd/MT for $\mathrm{UO}_{2}$ and $75 \mathrm{GWd} / \mathrm{MT}$ for the $\mathrm{ThO}_{2}$ ) of the Thorium Alternative would result in a reduction in the discharged SNF mass (about a 50 percent reduction) (IAEA 2002b, Todosow 2003).

Producing Fewer Transuranics: Being a lighter element than uranium, thorium fuels produce fewer transuranics. The level of radiotoxicity of spent thorium fuel is initially lower than that of spent uranium fuel for the first 1,000 years where the radiotoxicity is dominated by $\mathrm{Pu}-238$ and U-232. From 1,000 years to 50,000 years, the dominant isotopes are U-233, Am-241, and Th-229. At 50,000 years the dominant isotopes are Th-229 and Ra-225 and the radiotoxicity of spent thorium fuel is higher than that of spent uranium fuel (IAEA 2002b).

Improving Long-Term Spent Nuclear Fuel Waste Characteristics: $\mathrm{ThO}_{2}$ is the highest oxide of thorium and does not depart significantly from its stoichiometric composition when exposed to air or water at temperatures up to $3140^{\circ} \mathrm{F}\left(1,727^{\circ} \mathrm{C}\right)$. Thus, the stability of the oxide form of thorium may help retard the migration of actinides in a geologic repository in case of failure of the clad and other engineered barriers (IAEA 2005a). By contrast, in case of exposure to water, uranium-based SNF fragments react and disintegrate relatively rapidly (about 1 percent per year) (IAEA 2002b).

Transportation: Once generated at a commercial reactor, SNF from a thorium open fuel cycle would eventually need to be transported to a future geologic repository for disposal. The environmental impacts of transporting future SNF from commercial sites to a geologic repository were estimated using the methodology described in Appendix E. Table 4.6-3 presents the number of radiological shipments (broken down by material to be transported) that would be required for the Thorium Alternative for 1) all truck and 2) a combination of truck and rail. Because all shipments of fresh nuclear fuel are assumed to occur via truck transport, there is no transportation scenario in which all transportation would occur via rail only. Consequently, the PEIS presents transportation impacts for a combined truck and rail scenario (in tables this scenario is designated as "truck/rail"). As shown in that table, truck transport would require significantly more shipments than truck and rail. 


\begin{tabular}{|c|c|c|}
\hline \multicolumn{3}{|c|}{ Thorium Alternative } \\
\hline Material/Waste & $\begin{array}{c}\text { Truck Transport } \\
\text { (Number of } \\
\text { Shipments) } \\
\end{array}$ & $\begin{array}{c}\text { Truck/Rail Transport } \\
\text { (Number of } \\
\text { Shipments) }\end{array}$ \\
\hline Fresh LWR fuel & 22,800 & $22,800^{\mathrm{a}}$ \\
\hline Fresh Thorium fuel & 155,000 & $155,000^{\mathrm{a}}$ \\
\hline LWR SNF $\left[\mathrm{UO}_{2}\right]$ & 50,500 & 4,040 \\
\hline $\begin{array}{l}\text { LWR Thorium SNF } \\
{\left[\mathrm{ThO}_{2}\right]}\end{array}$ & 155,000 & 3,450 \\
\hline GTCC LLW & 3,200 & 630 \\
\hline LLW & 19,000 & 3,800 \\
\hline
\end{tabular}

The results of the transportation analysis are presented in two sets of tables. The first set of tables (Tables 4.6-4 and 4.6-5) present the impacts associated with handling (loading and inspection) radiological material for the $200 \mathrm{GWe}$ scenario. Impacts are presented in terms of radiological impacts (expressed in person-rem and converted to LCFs using a dose-to-risk conversion factor of $6 \times 10^{-4}$ LCF per person-rem). Table 4.6-4 presents the handling impacts for truck transport and Table 4.6-5 presents the handling impacts for truck and rail transport. Handling operations (loadings and inspections) would not affect the public.

The impacts of handling radiological material are independent of the distance that the material would be transported. As such, the handling impacts would be the same whether the radiological material is transported, for example, $500 \mathrm{mi}(805 \mathrm{~km}), 2,100 \mathrm{mi}(3,380 \mathrm{~km})$, or any other distance. For this reason, these impacts are presented separately from the in-transit impacts (which are presented in the second set of tables).

TABLE 4.6-4-Handling Impacts for 50 Years of Implementation, Thorium Alternative (Truck Transit)-200 Gigawatts Electric

\begin{tabular}{lcc|cc|cc}
\hline & \multicolumn{4}{c}{ Handling Impacts } & \multicolumn{2}{c}{ Total } \\
\cline { 2 - 8 } & \multicolumn{2}{c}{ Loading } & \multicolumn{2}{c}{ Inspection } & person-rem & LCFs \\
\cline { 2 - 8 } & person-rem & LCFs & person-rem & LCFs & 107,000 & 64 \\
\hline Thorium & 91,700 & 55 & 15,800 & 9 & \\
\hline
\end{tabular}

Source: Appendix E

Note: LCFs rounded to nearest whole number.

TABLE 4.6-5-Handling Impacts for 50 Years of Implementation, Thorium Alternative (Truck and Rail Transit)_-200 Gigawatts Electric

\begin{tabular}{lcc|cc|cc}
\hline & \multicolumn{6}{c}{ Handling Impacts } \\
\cline { 2 - 7 } & \multicolumn{2}{c}{ Loading } & \multicolumn{2}{c}{ Inspection } & \multicolumn{2}{c}{ Total } \\
\cline { 2 - 8 } & person-rem & LCFs & person-rem & LCFs & person-rem & LCFs \\
\hline Thorium & 27,000 & 16 & 784 & 0 & 27,700 & 17 \\
\hline
\end{tabular}

Source: Appendix E

Note: LCFs rounded to nearest whole number.

The in-transit impacts are shown in Tables 4.6-6 (truck transit) and 4.6-7 (truck and rail transit) for the Thorium Alternative. These impact estimates would vary based on a variety of factors, including the distance that the radiological material would be transported, the specific routes that 
would be utilized, the population densities along those routes, and others. Of these factors, transport distance is the most significant. Because the locations of future reactors and future disposal facilities are unknown, DOE analyzed transportation impacts over five distances: $150 \mathrm{mi}(241 \mathrm{~km}), 500 \mathrm{mi}(805 \mathrm{~km}), 1,500 \mathrm{mi}(2,414 \mathrm{~km}), 2,100 \mathrm{mi}(3,380 \mathrm{~km})$, and 3,000 $\mathrm{mi}$ $(4,828 \mathrm{~km})$. In-transit impacts presented in Tables 4.6-6 and 4.6-7 are based on 2,100 mi $(3,380 \mathrm{~km})$ of transport. This distance was selected as a reference distance because it represents the average distance for all SNF shipments analyzed in the Yucca Mountain FEIS (DOE 2002i). Impacts associated with the other four distances are presented, on a per shipment basis, in Appendix E, which describes the transportation methodology and assumptions. Although the intransit impacts are not exactly "linear" (i.e., twice the impacts for twice the distance transported), that is a close approximation. Consequently, if the radiological material were transported $500 \mathrm{mi}$ $(805 \mathrm{~km})$, all of the in-transit impacts presented in Tables 4.6-6 and 4.6-7 could be estimated by multiplying the values in those tables by $0.24(500 / 2,100)$.

TABLE 4.6-6-In-Transit Transportation Impacts for 50 Years of Implementation, Thorium Alternative (Truck Transit)—200 Gigawatts Electric

\begin{tabular}{|c|c|c|c|c|c|c|c|c|}
\hline & \multicolumn{4}{|c|}{ In Transit Impacts } & \multirow{3}{*}{$\begin{array}{c}\text { Total } \\
\text { Incident- } \\
\text { Free } \\
\text { LCFs }\end{array}$} & \multirow{2}{*}{\multicolumn{3}{|c|}{ Accident Impacts }} \\
\hline & \multicolumn{2}{|c|}{ Crew } & \multicolumn{2}{|c|}{ Public } & & & & \\
\hline & $\begin{array}{c}\text { person- } \\
\text { rem }\end{array}$ & LCFs & $\begin{array}{c}\text { person- } \\
\text { rem }\end{array}$ & LCFs & & $\begin{array}{c}\text { person- } \\
\text { rem }\end{array}$ & LCFs & $\begin{array}{c}\text { Collision } \\
\text { Fatalities }\end{array}$ \\
\hline Thorium & 36,300 & 22 & 179,000 & 107 & 129 & 0.881 & 0 & 23 \\
\hline
\end{tabular}

Source: Appendix E

Note: All LCFs rounded to nearest whole number

TABLE 4.6-7-In-Transit Transportation Impacts for 50 Years of Implementation, Thorium Alternative (Truck and Rail Transit) -200 Gigawatts Electric

\begin{tabular}{|c|c|c|c|c|c|c|c|c|}
\hline & \multicolumn{4}{|c|}{ In Transit Impacts } & \multirow{3}{*}{$\begin{array}{c}\text { Total } \\
\text { Incident- } \\
\text { Free } \\
\text { LCFs }\end{array}$} & \multirow{2}{*}{\multicolumn{3}{|c|}{ Accident Impacts }} \\
\hline & \multicolumn{2}{|c|}{ Crew } & \multicolumn{2}{|c|}{ Public } & & & & \\
\hline & $\begin{array}{c}\text { person- } \\
\text { rem }\end{array}$ & LCFs & $\begin{array}{c}\text { person- } \\
\text { rem }\end{array}$ & LCFs & & $\begin{array}{l}\text { person- } \\
\text { rem }\end{array}$ & LCFs & $\begin{array}{c}\text { Collision } \\
\text { Fatalities }\end{array}$ \\
\hline Thorium & 550 & 0 & 1,740 & 1 & 1 & 0.0561 & 0 & 4 \\
\hline
\end{tabular}

Source: Appendix E

Note: All LCFs rounded to nearest whole number

There are potentially significant differences in impacts depending upon whether transportation occurs via truck or a combination of truck and rail. For all alternatives, truck and rail transport would result in smaller impacts than truck transport. This is due to the fact that there would be many fewer transportation shipments for truck and rail compared to truck only. This would directly affect the distance traveled and exposures to both crews and the public. Additionally, the number of accident fatalities (collisions) would be smaller for the truck and rail transport.

4.7
Once-Through Fuel Cycle Alternative Using Heavy Water Reactors OR High TEMPERATURE GaS-COOLED REACTORS (HEAVY WATER REACTOR/High TEMPERATURE GaS-COOLED ReaCtOR Alternative)

At the programmatic level, this PEIS assesses the potential environmental impacts associated with broad implementation of the HWR/HTGR Alternative to achieve a capacity of $200 \mathrm{GWe}$, based on a 1.3 percent growth rate for nuclear power. The analysis of this broad implementation assumes that the United States commercial reactors begin to transition to either all-HWRs 
(Option 1) or all-HTGRs (Option 2) in approximately 2020, with full implementation accomplished by approximately 2060-2070. The analysis assesses the replacement of existing LWRs that reach end-of-life with either HWRs or HTGRs. The PEIS also provides information for a growth scenario of 2.5 percent, which would result in a capacity of approximately $400 \mathrm{GWe}$ (see Table 4.8-2), a 0.7 percent growth rate, which would result in a capacity of approximately 150 GWe (see Table 4.8-3), and a zero growth scenario, which would result in a capacity of approximately $100 \mathrm{GWe}$ (see Table 4.8-4).

\subsubsection{All-Heavy Water Reactors (Option 1)}

\section{Comparison of Light Water Reactor and Heavy Water Reactor Fuel Cycles}

The HWR has some significant differences from the commercial LWRs used extensively elsewhere in the world. Beginning at the front end of the fuel cycle, HWRs do not necessarily require enrichment of fuel, which could eliminate the environmental impacts discussed in Section 4.1.2. However, HWRs can also use slightly enriched uranium (SEU), which is enriched in U-235 to between approximately 0.9 and 1.2 percent. The benefits of using SEU fuel cycle in a HWR can be significant. With SEU, fuel cycle costs can be reduced by 20 to 30 percent relative to the natural uranium fuel cycle. This is due largely to the reduction in uranium feedstock requirements. SNF costs can potentially be reduced as well due to the higher burnups that can be achieved with SEU relative to natural uranium. This PEIS assesses the use of SEU in HWRs (see Table 4.8-1). At the back end of the HWR fuel cycle, the lower burnup of HWR fuel relative to LWR fuel translates to a lower heat load for a repository.

Canada has significant experience with SNF handling and short term (pool) and medium term (dry canister) storage of SNF from HWRs. They also have performed over two decades of R\&D on the permanent disposal of HWR SNF in a geologic repository. HWRs produce SNF that contains depleted uranium roughly equivalent to the depleted uranium tails from enrichment plants (approximately 0.2 percent). There is therefore no incentive to recycle uranium from HWR SNF. Plutonium produced in the HWR fuel cycle is also dilute - typically 2.6 grams of fissile plutonium per initial kilogram of uranium. LWR SNF has roughly twice that concentration. However, because the HWR fuel cycle would generate more than twice as much volume and mass of SNF, the quantities of SNF requiring geologic disposal would be significantly greater than for other fuel cycle alternatives.

\section{Implementation of All-Heavy Water Reactors (Option 1)}

Under this option, the U.S. nuclear fuel cycle would transition to an all-HWR once-through fuel cycle. It is acknowledged that such transition would take many decades to accomplish (as existing LWRs would continue operations until reaching end-of-life). This PEIS assesses transition to an all-HWR commercial fleet by approximately 2060-2070. This PEIS presents the environmental impacts of the all-HWR option of the HWR/HTGR Alternative as follows:

Construction: The PEIS analysis in this section focuses on the $200 \mathrm{GWe}$ end-state (approximately $200 \mathrm{GWe}$ of HWR capacity and supporting infrastructure). From a construction standpoint, the all-HWR option would have similar impacts to the overall construction impacts 
presented in Section 4.3 for the Fast Reactor Recycle Alternative, with the exception that no nuclear fuel recycling facilities would be required. Relative to reactor construction impacts, because the total reactor capacity would be $200 \mathrm{GWe}$, the overall impacts would be similar to the Fast Reactor Recycle Alternative.

Supporting Infrastructure: Transition to an all-HWR commercial fleet would require one or more heavy water production facilities. Any such facility would be a large industrial facility with a capacity of producing thousand of tons of heavy water annually. Because a typical HWR requires at least 450 tons of heavy water (Miller 2001), tens of thousands of tons of heavy water would need to be produced to support approximately $200 \mathrm{HWRs}$. Historically, the world's largest heavy water production plant had a capacity of 700 tons/yr and required 340,000 tons ( 85 million gal [322 million L] based on $8 \mathrm{lbs} / \mathrm{gal}$ ) of feed water to produce one ton of heavy water (FAS 1998). Consequently, any heavy water production plant would need to be sited in an area with significant water availability. A commercial fleet of $200 \mathrm{GWe}$ of HWRs would require approximately 150,000 tons of heavy water (approximately 37 million gal [142 million L]) over the time period analyzed. To produce this much heavy water, approximately 12.5 trillion gal (47.5 trillion L) of water would be needed as feed.

Operation: Most HWR operations would be similar to LWR operations previously discussed. Potential impacts are addressed below.

Uranium Requirements: The quantity of natural uranium needed to support a capacity of $200 \mathrm{GWe}$, assuming an average enrichment of 2.1 percent, would be approximately 42,800 MT/yr (see Table 4.8-1). The 42,800 MT of natural uranium would represent approximately 109 percent of the uranium that was mined in the world in 2006 and would be 25 times more than the quantities currently mined in the United States annually (see Table 4.1-1). From this 42,800 MT, approximately 10,600 MT of slightly enriched uranium (2.1 percent) would be required. Approximately 20 million SWUs would be required annually to support a capacity of $200 \mathrm{GWe}$. The licensed capacity of Paducah, the American Centrifuge Plant, and the LES Facility is 17.8 million SWUs. Consequently, enrichment facilities in the United States could not meet this demand. Additionally, if Paducah shuts down in 2012, as planned, the United States enrichment capacity would be reduced to approximately 6.8 million SWUs. To support a 200 GWe capacity, enrichment capacities in the United States would need to be expanded by approximately 200 percent, or larger quantities of enriched uranium would need to be imported.

Fuel Fabrication Requirements: The United States does not have any HWR fuel fabrication facilities. However, existing LWR fuel fabrication facilities could be modified to produce HWR fuel with minimal changes. For $200 \mathrm{GWe}$, approximately 10,600 MT of fresh HWR fuel assemblies would need to be produced annually. This would exceed the current LWR fuel fabrication capability (3,500 MT) by approximately 200 percent. Consequently, the fuel fabrication facilities in the United States would need to be expanded or fresh HWR fuel assemblies would need to be imported. 
Land Resources: Once operational, a total of approximately 600,000 acres (243,000 ha) of land could be occupied by facilities, paved areas, and buffer zones. Most of this area would not be disturbed but would serve as a buffer between the actual facility and the outer facility boundary.

The total site area would be determined by accident analyses and regulatory requirements, including safeguards and security.

Visual: With respect to visual characteristics, the visibility of any HWR from publicly accessible locations would be dependent on the future site characteristics. For sites that use "wet" cooling tower systems, the water vapor plume from cooling tower operations may be visible for many miles from the plant.

Air Resources: Impacts to air resources would be similar to the No Action Alternative presented in Section 4.2.

Water Resources: Every operating HWR would use significant quantities of water. A typical GWe of LWR capacity requires approximately 3 to 6 billion gal (11 to 23 billion L) of water yearly, mainly for heat dissipation ${ }^{55}$ (EPRI 2002). Because the amount of water required for heat dissipation is largely a function of the thermal output of a reactor, a typical GWe of HWR capacity would also require approximately 3 to 6 billion gal (11 to 23 billion L) of water yearly.

Socioeconomic Impacts: Similar to construction, socioeconomic impacts would occur in communities in the vicinity of any future HWR. Although operations would generally employ fewer workers than peak construction, employment, population, economic measures, housing, and public services could all be affected. For each GWe of capacity, an HWR would require approximately 500 to 1,000 workers.

Human Health: In addition to nonradiological hazards, workers would be subject to radiological hazards, including radiation exposure. These doses would not be expected to be significantly different than the doses workers receive from LWRs (see Section 4.2.2). ${ }^{56}$

The public would also be subject to radiation exposure, primarily from airborne releases of radionuclides. Because HWRs use heavy water as both the moderator and coolant, more tritium is produced in a HWR than a typical LWR (IAEA 2004b). Nuclear power plants routinely and safely release dilute concentrations of tritiated water. These authorized releases are closely monitored by the utility, reported to the NRC, and information on releases is made available to the public (see www.reirs.com/effluent/). Most of the tritium released from an HWR occurs via gaseous emissions (see IAEA 2004b, Table 23). Because of the higher potential for HWRs to produce and release tritium, this PEIS assesses these potential impacts to the public. Doses were modeled for gaseous tritium releases at the six hypothetical sites (see Appendix D, Section D.1.6) and the results are presented in Table 4.7-1.

\footnotetext{
${ }^{55}$ A typical $1 \mathrm{GWe}$ reactor would withdraw 3 to 6 billion gal/yr (11 to 23 billion L/yr) for cooling (using "wet cooling"). Water consumption would be less than 60 million gallons/yr (227 million gal/yr.

${ }^{56}$ According to a 2008 report from the Canadian Minister of Health, the average dose to the 18,922 workers/visitors monitored at Canadian nuclear power plants in 2007 was 114 mrem (Health Canada 2008). Annual doses for employees at power plants varied from 14 mrem for administrative personnel to 233-261 mrem for fuel handling and industrial radiographer personnel. The average dose to reactor operators used in this PEIS (190 mrem/year) falls within this range.
} 


\section{TABLe 4.7-1-Normal Operation Radiological Impacts to the Public from Tritium Releases for a Typical Heavy Water Reactor at Six Hypothetical Sites in the United States

\begin{tabular}{|c|c|c|c|c|}
\hline & \multicolumn{4}{|c|}{ HWR (600 MWe) ${ }^{a}$} \\
\hline & $\begin{array}{l}\text { MEI dose } \\
(\mathrm{mrem} / \mathrm{yr})\end{array}$ & $\begin{array}{l}\text { MEI } \\
\text { LCFs }\end{array}$ & $\begin{array}{c}\text { 50-Mile Population dose } \\
\text { (person-rem/yr) }\end{array}$ & $\begin{array}{c}\text { 50-Mile Population } \\
\text { LCFs }\end{array}$ \\
\hline Site 1 & 1.0 & $5.8 \times 10^{-7}$ & 3.3 & $2.0 \times 10^{-3}$ \\
\hline Site 2 & 0.3 & $1.9 \times 10^{-7}$ & 4.0 & $2.4 \times 10^{-3}$ \\
\hline Site 3 & 0.2 & $1.1 \times 10^{-7}$ & 29.2 & $1.8 \times 10^{-2}$ \\
\hline Site 4 & 1.7 & $1.0 \times 10^{-6}$ & 14.9 & $8.9 \times 10^{-3}$ \\
\hline Site 5 & 0.6 & $3.8 \times 10^{-7}$ & 17.3 & $1.0 \times 10^{-2}$ \\
\hline Site 6 & 0.5 & $2.7 \times 10^{-7}$ & 135 & $8.1 \times 10^{-2}$ \\
\hline
\end{tabular} \\ Source: IAEA 2004b \\ ${ }^{a}$ Based on average annual airborne tritium emissions $\left(7.24 \times 10^{3} \mathrm{Ci} / \mathrm{yr}\right)$ from a CANDU $600 \mathrm{MW}(\mathrm{e})$ reactor (Point Lepreau nuclear power plant, Canada, 1984 to 1994). Doses are presented for a 600-MWe HWR.}

With respect to all radionuclide releases, any new commercial HWR would need to comply with NRC regulations. Under 10 CFR Part 20, each licensee is required to conduct operations so that the total effective dose equivalent to individual members of the public from the licensed operations does not exceed $100 \mathrm{mrem} / \mathrm{yr}$. Furthermore, $10 \mathrm{CFR}$ Part 20 requires that power reactor licensees comply with EPA's environmental radiation standards contained in 40 CFR Part 190 (i.e., 25 mrem to the whole body, 75 mrem to the thyroid, and 25 mrem to any other organ of any member of the public from the uranium fuel cycle).

Facility Accidents: DOE has previously analyzed accidents associated with HWRs at a variety of locations (DOE 1995b). In this PEIS, DOE has re-analyzed the consequences of the accident scenarios presented in DOE 1995b (see Appendix D, Section D.2.5.1) at the six generic sites described in Appendix D, Section D.1.6.1.

The internally initiated accident with the highest consequence to the onsite and offsite populations would be the "Core Melt with Early Containment Spray System and Containment Failure" scenario (see Appendix D, Section D.2.5.1 for information on this accident and others analyzed for the HWR). Using the dose-to-risk conversion factor of $6 \times 10^{-4}$ per person-rem, these collective population doses would result in 5 to 100 additional LCFs in the surrounding population. For the MEI, this scenario would result in an increased likelihood of an LCF of 0.1 to 0.8. For the noninvolved worker this scenario would result in an increased likelihood of an LCF of 1 and would result in prompt radiation health effects, up to death.

Consequences do not account for the probability of an accident, and thus represent the impacts that could result if an accident were to occur. Another useful metric to consider in an accident analysis is risk. Risk takes into account the probability of an accident and is determined by multiplying the consequences of an accident by the probability of occurrence.

The internally initiated accident with the highest risk to the onsite and offsite populations is the "Core Melt with Containment Spray System and Containment Functioning" scenario. The collective risk to the offsite population for this scenario would range from $2 \times 10^{-6}$ in the Site 1 offsite population to $7 \times 10^{-5}$ expected in the Site 6 offsite population. For the MEI, that same scenario would result in an increased risk of an LCF of $2 \times 10^{-8}$ per year of operation to $3 \times 10^{-7}$ per year of operation. For the onsite noninvolved worker, this scenario would result in an increased risk of an LCF ranging from $5 \times 10^{-7}$ to $3 \times 10^{-6}$. 
Spent Nuclear Fuel and Radioactive Wastes: HWRs generate significantly more SNF (both volume and mass) than LWRs. If the United States transitions to an all-HWR commercial fleet, the amount of SNF generated by LWRs (prior to the replacement by HWRs) would be approximately 68,000 MTHM. ${ }^{57}$ The amount of SNF generated by HWRs by approximately 2060-2070 would be approximately 212,000 MTHM. $^{58}$ By 2060-2070, approximately 10,600 MTHM of SNF would be generated annually from HWRs, which would require disposal in a repository.

The only wastes generated for the HWR option would be associated with HWR operations. As discussed in Section 4.2.2, typical nuclear power plants generate SNF and LLW, including GTCC LLW. SNF management is addressed below. For this analysis, it is assumed that HWRs would generate the same types and quantities of wastes as typical LWRs. Over a 50-year implementation period, the HWR option would generate the radioactive wastes shown in Table 4.7-2.

\begin{tabular}{|c|c|c|c|}
\hline Waste Category & $\begin{array}{c}\text { LWRs } \\
\text { (prior to replacement) }\end{array}$ & $\begin{array}{c}\text { HWRs } \\
(200 \text { GWe in 2060-2070) }\end{array}$ & Total \\
\hline SNF (MTHM) & 68,000 & 212,000 & 00 \\
\hline & LB: 65,000 & LB: 85,000 & LB: 150,000 \\
\hline LLW (solid) (cubic meters) & UB: $150,000^{\mathrm{a}}$ & UB: $435,000^{\mathrm{a}}$ & UB: 585,000 \\
\hline GTCC LLW (cubic meters) & $800^{\mathrm{b}}$ & $1,700^{\mathrm{b}}$ & $2,500^{\mathrm{b}}$ \\
\hline \multicolumn{4}{|c|}{$\begin{array}{l}\mathrm{LB}=\text { lower bound, } \mathrm{UB}=\text { upper bound. } \\
\text { a Derived from data for a typical LWR which would generate approximately } 27 \text { to } 103 \mathrm{yd}^{3}\left(21 \text { to } 79 \mathrm{~m}^{3}\right) \text { of LLW annually (NEI 2007). } \\
\text { Based on constant growth from approximately } 100 \mathrm{GWe} \text { in } 2010 \text { to } 200 \mathrm{GWe} \text { by approximately } 2060-2070 \text {. } \\
\text { b GTCC LLW from nuclear reactors is produced as a result of normal operations and becomes available for disposal during facility } \\
\text { decommissioning. The majority of GTCC LLW generated by nuclear reactors is activated metal. It has been estimated that } \\
\text { approximately } 1,060 \mathrm{yd}^{3}\left(813 \mathrm{~m}^{3}\right) \text { of GTCC LLW would be generated when the existing } 104 \text { commercial LWRs undergo D\&D } \\
(\text { SNL 2007). Scaling those results to account for production of } 200 \mathrm{GWe} \text { of electricity via nuclear reactors (and the D\&D of existing } \\
\text { LWRs), it is estimated that approximately } 2,500 \mathrm{~m}^{3}\left(3,270 \mathrm{yd}^{3}\right) \text { of GTCC LLW could result from D\&D. See Section } 4.9 \text { for a } \\
\text { discussion of GTCC LLW from reactor decommissioning. } \\
\text { Note: All quantities except GTCC LLW rounded to nearest thousand. }\end{array}$} \\
\hline
\end{tabular}

Transportation: Once generated at a commercial reactor, SNF from the HWR open fuel cycle would eventually need to be transported to a geologic repository for disposal. Table 4.7-3 presents the number of radiological shipments (broken down by material to be transported) that would be required for the all-HWR option for 1) all truck and 2) a combination of truck and rail. Because all shipments of fresh nuclear fuel are assumed to occur via truck transport, there is no transportation scenario in which all transportation would occur via rail only. Consequently, the PEIS presents transportation impacts for a combined truck and rail scenario (in tables this

\footnotetext{
${ }^{57}$ Based on the following assumptions: New LWRs would be constructed at a growth rate of 1.3 percent from 2015 to 2020; beginning in 2020, all new reactors are HWRs and total reactor capacity grows to 200 GWe by approximately 2060-2070; each HWR capacity produces approximately 53 MTHM of SNF/GWe-yr (note: in the HWR fuel cycle, HWRs produce approximately 53 MTHM/GWe-yr, based on a burnup of $21 \mathrm{GWd} / \mathrm{MTHM}$ at discharge; this is higher than the $66 \mathrm{MTHM} / \mathrm{GWe}-\mathrm{yr}$ for the HWRs that would be used for the DUPIC fuel cycle, which is based on a burnup of $15 \mathrm{GWd} / \mathrm{MTHM}$ at discharge). LWRs are assumed to be replaced by HWRs as they reach end-of-life between 2020 and 2060-2070; and by approximately 2060-2070, all LWRs would be replaced by HWRs. The full implementation scenario (complete transition to all HWRs) is described in this analysis. However, any new LWRs constructed between 2015-2020 would likely operate a full 60 years (40-year initial life with a 20-year life extension). In this case, in the 2060-2070 timeframe, there could be approximately 7 GWe of LWR capacity. In this case, the total SNF quantities presented in this section would decrease slightly (less than 1 percent) due to the fact that LWRs produce less SNF than HWRs.

${ }^{58}$ Assumes all new reactors are HWRs, beginning in approximately 2020, and added at a rate to keep pace with the 1.3 percent growth in nuclear electricity production until approximately $200 \mathrm{GWe}$ is achieved. A total of $200 \mathrm{GWe}$ of HWRs are built and each GWe from an HWR results in approximately 53 MTHM of SNF.
} 
scenario is designated as "truck/rail"). As shown in that table, truck transport would require significantly more shipments than truck and rail.

TABLE 4.7-3-Total Number of Radiological Shipments for 50 Years of Implementation, All-Heavy Water Reactors Option

\begin{tabular}{lcc}
\hline \multicolumn{1}{c}{ Material/Waste } & $\begin{array}{c}\text { Truck Transport } \\
\text { (Number of Shipments) }\end{array}$ & $\begin{array}{c}\text { Truck/Rail Transport } \\
\text { (Number of Shipments) }\end{array}$ \\
\hline Fresh LWR fuel & 11,300 & $11,300^{\mathrm{a}}$ \\
Fresh HWR fuel & 55,600 & $55,600^{\mathrm{a}}$ \\
LWR SNF & 34,000 & 2,720 \\
HWR SNF & 110,000 & 2,500 \\
GTCC LLW & 3,200 & 630 \\
LLW & 19,000 & 3,800 \\
\hline Source: Appendix E &
\end{tabular}

The results of the transportation analysis are presented in two sets of tables. The first set of tables (Tables 4.7-4 and 4.7-5) present the impacts associated with handling (loading and inspection) radiological material for the $200 \mathrm{GWe}$ scenario. Impacts are presented in terms of radiological impacts (expressed in person-rem and converted to LCFs using a dose-to-risk conversion factor of $6 \times 10^{-4} \mathrm{LCF}$ per person-rem). Table 4.7-4 presents the handling impacts for truck transport and Table 4.7-5 presents the handling impacts for truck and rail transport. Handling operations (loadings and inspections) would not affect the public.

The impacts of handling radiological material are independent of the distance that the material would be transported. As such, the handling impacts would be the same whether the radiological material is transported, for example, $500 \mathrm{mi}(805 \mathrm{~km}), 2,100 \mathrm{mi}(3,380 \mathrm{~km})$, or any other distance. For this reason, these impacts are presented separately from the in-transit impacts (which are presented in the second set of tables).

TABLE 4.7-4-Handling Impacts for 50 Years of Implementation, All-Heavy Water Reactors Option (Truck Transit)-200 Gigawatts Electric

\begin{tabular}{lcc|cc|ccc}
\hline & \multicolumn{9}{c}{ Handling Impacts } \\
\cline { 2 - 8 } & \multicolumn{2}{c}{ Loading } & \multicolumn{2}{c}{ Inspection } & \multicolumn{2}{c}{ Total } \\
\cline { 2 - 9 } & person-rem & LCFs & person-rem & LCFs & person-rem & LCFs \\
\hline HWR & 67,500 & 40 & 11,700 & 7 & 79,100 & 47 \\
\hline
\end{tabular}

Source: Appendix E

Note: LCFs rounded to nearest whole number.

TABLE 4.7-5-Handling Impacts for 50 Years of Implementation, All-Heavy Water Reactors Option (Truck and Rail Transit)_200 Gigawatts Electric

\begin{tabular}{lcc|cc|cc}
\hline & \multicolumn{6}{c}{ Handling Impacts } \\
\cline { 2 - 7 } & \multicolumn{2}{c}{ Loading } & \multicolumn{2}{c}{ Inspection } & \multicolumn{2}{c}{ Total } \\
\cline { 2 - 7 } & person-rem & LCFs & person-rem & LCFs & person-rem & LCFs \\
\hline HWR & 20,000 & 12 & 722 & 0 & 20,700 & 12 \\
\hline
\end{tabular}

Source: Appendix E

Note: LCFs rounded to nearest whole number.

The in-transit impacts are shown in Tables 4.7-6 (truck transit) and 4.7-7 (truck and rail transit) for the HWR/HTGR Alternative (Option 1-HWR). These impact estimates would vary based 
on a variety of factors, including the distance that the radiological material would be transported, the specific routes that would be utilized, the population densities along those routes, and others. Of these factors, transport distance is the most significant. Because the locations of future reactors and future disposal facilities are unknown, DOE analyzed transportation impacts over five distances: $150 \mathrm{mi}(241 \mathrm{~km}), 500 \mathrm{mi}(805 \mathrm{~km}), 1,500 \mathrm{mi}(2,414 \mathrm{~km}), 2,100 \mathrm{mi}(3,380 \mathrm{~km})$, and 3,000 mi $(4,828 \mathrm{~km})$. In-transit impacts presented in Tables 4.7-6 and 4.7-7 are based on $2,100 \mathrm{mi}(3,380 \mathrm{~km})$ of transport. This distance was selected as a reference distance because it represents the average distance for all SNF shipments analyzed in the Yucca Mountain FEIS (DOE 2002i). Impacts associated with the other four distances are presented, on a per shipment basis, in Appendix E, which describes the transportation methodology and assumptions. Although the in-transit impacts are not exactly "linear" (i.e., twice the impacts for twice the distance transported), that is a close approximation. Consequently, if the radiological material were transported $500 \mathrm{mi}(805 \mathrm{~km})$, all of the in-transit impacts presented in Tables 4.7-6 and 4.7-7 could be estimated by multiplying the values in those tables by $0.24(500 / 2,100)$.

TABLE 4.7-6-In-Transit Transportation Impacts for 50 Years of Implementation, All-Heavy Water Reactors Option (Truck Transit)-200 Gigawatts Electric

\begin{tabular}{|c|c|c|c|c|c|c|c|c|}
\hline & \multicolumn{4}{|c|}{ In Transit Impacts } & \multirow{3}{*}{$\begin{array}{c}\text { Total } \\
\text { Incident- } \\
\text { Free } \\
\text { LCFs } \\
\end{array}$} & \multirow{2}{*}{\multicolumn{3}{|c|}{ Accident Impacts }} \\
\hline & \multicolumn{2}{|c|}{ Crew } & \multicolumn{2}{|c|}{ Public } & & & & \\
\hline & $\begin{array}{c}\text { person- } \\
\text { rem }\end{array}$ & LCFs & $\begin{array}{c}\text { person- } \\
\text { rem }\end{array}$ & LCFs & & $\begin{array}{c}\text { person- } \\
\text { rem }\end{array}$ & LCFs & $\begin{array}{l}\text { Collision } \\
\text { Fatalities }\end{array}$ \\
\hline HWR & 26,600 & 16 & 130,000 & 78 & 94 & 0.597 & 0 & 20 \\
\hline
\end{tabular}

Source: Appendix E

Note: All LCFs rounded to nearest whole number

TABLE 4.7-7-In-Transit Transportation Impacts for 50 Years of Implementation, All-Heavy Water Reactors Option (Truck and Rail Transit)_200 Gigawatts Electric

\begin{tabular}{|c|c|c|c|c|c|c|c|c|}
\hline & \multicolumn{4}{|c|}{ In Transit Impacts } & \multirow{3}{*}{$\begin{array}{c}\text { Total } \\
\text { Incident- } \\
\text { Free } \\
\text { LCFs }\end{array}$} & \multirow{2}{*}{\multicolumn{3}{|c|}{ Accident Impacts }} \\
\hline & \multicolumn{2}{|c|}{ Crew } & \multicolumn{2}{|c|}{ Public } & & & & \\
\hline & $\begin{array}{c}\text { person- } \\
\text { rem }\end{array}$ & LCFs & $\begin{array}{c}\text { person- } \\
\text { rem }\end{array}$ & LCFs & & $\begin{array}{c}\text { person- } \\
\text { rem }\end{array}$ & LCFs & $\begin{array}{l}\text { Collision } \\
\text { Fatalities }\end{array}$ \\
\hline HWR & 450 & 0 & 1,540 & 1 & 1 & 0.0407 & 0 & 6 \\
\hline
\end{tabular}

Source: Appendix E

Note: All LCFs rounded to nearest whole number

There are potentially significant differences in impacts depending upon whether transportation occurs via truck or a combination of truck and rail. For all alternatives, truck and rail transport would result in smaller impacts than truck transport. This is due to the fact that there would be many fewer transportation shipments for truck and rail compared to truck only. This would directly affect the distance traveled and exposures to both crews and the public. Additionally, the number of accident fatalities (collisions) would be smaller for the truck and rail transport.

\subsubsection{All-High Temperature Gas-Cooled Reactors (Option 2)}

\section{Comparison of Light Water Reactor and High Temperature Gas-Cooled Reactor Fuel Cycles}

Current HTGR technology with high fuel burnups (approximately $100 \mathrm{GWd} / \mathrm{MT}$ ) could produce SNF with substantially less transuranic waste than existing LWRs. In general, on an equivalent 
electricity production basis (see Table 4.8-1), the HTGR once-through fuel cycle and the existing LWR once-through fuel cycle compare as follows:

- $\quad$ HTGRs require approximately 14 percent greater quantities of natural uranium.

- $\quad$ HTGRs produce approximately one-half as much transuranics in SNF as LWRs.

- $\quad$ HTGRs produce SNF with approximately one-third the thermal load on a repository as an LWR.

- $\quad$ HTGRs generate approximately 35 percent as much SNF as LWRs in terms of heavy metal mass (Wigeland 2008a).

\section{Implementation of All-High Temperature Gas-Cooled Reactors (Option 2)}

Under this option, the United States would transition to an all-HTGR once-through fuel cycle. It is acknowledged that such transition would take many decades to accomplish (as existing LWRs would continue operations until reaching end-of-life). This PEIS assesses transition to an all-HTGR commercial fleet by approximately 2060-2070. This PEIS presents the environmental impacts of the all-HTGR option of the HWR/HTGR Alternative as follows:

Construction: The PEIS analysis in this section focuses on the $200 \mathrm{GWe}$ end-state (approximately $200 \mathrm{GWe}$ of HTGR capacity and supporting infrastructure). From a construction standpoint, the all-HTGR option would have similar impacts to the overall construction impacts presented in Section 4.3 for the Fast Reactor Recycle Alternative, with the exception that no nuclear fuel recycling facilities would be required. Relative to reactor construction impacts, because the total reactor capacity would be $200 \mathrm{GWe}$, the overall impacts would not change compared to the Fast Reactor Recycle Alternative.

Supporting Infrastructure: This alternative would utilize large quantities of nuclear grade graphite in the HTGR reactor cores. Graphite production is a basic industrial operation and the capability to produce nuclear grade graphite would be driven by the demand. Although there is currently little demand for this today, it is expected that the commercial industry would readily respond to meet an identified need without significant issues.

Helium is the coolant of choice for HTGRs, due to its favorable neutronic and heat exchange properties, and also due to its chemical stability in the temperature range of interest. A typical HTGR requires an initial inventory of 5 to 10 tons of helium. The annual make-up, due to system losses, would be a small percent of that inventory. Natural gas contains trace amounts of helium which is extracted during natural gas refining. The United States is the largest producer of helium in the world, with an annual production exceeding 20,000 tons, and geological resources of more than 1 million tons (Finck 2007a). Consequently, there should be no adverse impacts associated with providing the required quantities of helium to support HTGRs.

Operation: Most HTGR operations would be similar to LWR operations previously discussed. Potential impacts are addressed below.

Uranium Requirements: The quantity of natural uranium needed to support a capacity of $200 \mathrm{GWe}$, assuming an average enrichment of 14 percent would be approximately 45,600 MT/yr 
(see Table 4.8-1). The 45,600 MT of natural uranium would represent approximately 116 percent of uranium that was mined in the world in 2006 and would be 28 times more than the quantities currently mined in the United States annually (see Table 4.1-1). From this 45,600 MT, approximately 1,540 MT of enriched uranium (14 percent) would be required. Approximately 39 million SWUs would be required annually to support a capacity of $200 \mathrm{GWe}$. The licensed capacity of Paducah, the American Centrifuge Plant, and the LES Facility is 17.8 million SWUs. Consequently, enrichment facilities in the United States could not meet this demand. Additionally, if Paducah shuts down in 2012, as planned, the United States enrichment capacity would be reduced to approximately 6.8 million SWUs. To support a 200 GWe capacity, enrichment capacities in the United States would need to be expanded by more than 500 percent, or larger quantities of enriched uranium would need to be imported.

The HTGR fuel cycle would require uranium enrichments of approximately 14 percent versus the 3 to 5 percent for the LWR fuel cycle. Enrichment facilities to support an HTGR fuel cycle would be large industrial facilities, similar in size to those discussed in Section 4.1.2, with the same types of environmental impacts (see NRC 2005b and NRC 2006b). In general, enriching uranium to higher than 5 percent does not produce different types of impacts, but requires more steps.

Currently, there is no capacity in the United States to enrich uranium to 14 percent. The American Centrifuge Plant, once operational, would be capable of enriching uranium up to 10 percent. While the technology exists and has been utilized in the past to produce uranium with enrichments of 14 percent (and higher), an existing enrichment facility would need to be retrofitted (with additional centrifuges connected in series or additional gaseous diffusion stages) or a new facility constructed. In the past, these facilities (such as the existing Paducah facility) required hundreds of acres, used significant quantities of electricity, and employed thousands of workers. Modern enrichment facilities would likely be more compact, and more efficient in terms of electricity and staffing. The size of an enrichment facility is generally a compromise among criticality concerns (which govern the size of components), and desired enrichment and throughput. For example, multiple passes through enrichment stages can be used to increase the enrichment, subject to criticality constraints. The option of obtaining these enrichments by down-blending surplus HEU from the weapons complex may be available to satisfy some of the requirement.

Fuel Fabrication Requirements: The United States does not have any HTGR fuel fabrication facilities. There are only two existing fuel fabrication facilities in the United States that are operational and have licenses to fabricate reactor fuels with uranium enrichments greater than 5 percent. These facilities produce fuels for the Naval Reactors Program, as well as research reactor fuels. Because the capacity of these fuel fabrication facilities would not be sufficient to produce all of the 14 percent enriched uranium fuel for the commercial industry, it is likely that one or more new fuel fabrication facilities would be constructed. For $200 \mathrm{GWe}$, approximately 1,540 MT of fresh HTGR fuel assemblies would need to be produced annually.

Land Resources: Once operational, a total of approximately 600,000 acres (243,000 ha) of land could be occupied by facilities, paved areas, and buffer zones. Most of this area would not be disturbed but would serve as a buffer between the actual facility and the outer facility boundary. 
The total site area would be determined by accident analyses and regulatory requirements, including safeguards and security.

Visual Resources: With respect to visual characteristics, the visibility of any HTGR from publicly accessible locations would be dependent on the future site characteristics. For sites that use "wet" cooling tower systems, the water vapor plume from cooling tower operations may be visible for many miles from the plant.

Air Resources: Impacts would be similar to the No Action Alternative presented in Section 4.2.

Water Resources: Every operating HTGR would use significant quantities of water. A typical GWe of HTGR capacity would require approximately 3 to 6 billion gal (11 to 23 billion L) of water yearly, mainly for heat dissipation ${ }^{59}$ (EPRI 2002).

Socioeconomic Impacts: Similar to construction, socioeconomic impacts would occur in communities in the vicinity of any future HTGR. Although operations would generally employ fewer workers than peak construction, employment, population, economic measures, housing, and public services could all be affected. For each GWe of capacity, an HTGR would require approximately 500 to 1,000 workers.

Human Health: In addition to nonradiological hazards, workers would be subject to radiological hazards, including radiation exposure. These doses would not be expected to be significantly different than the doses workers receive from LWRs. The public would also be subject to radiation exposure, primarily from airborne releases of radionuclides. Any new commercial HTGR would need to comply with NRC regulations. Under 10 CFR Part 20, each licensee is required to conduct operations so that the total effective dose equivalent to individual members of the public from the licensed operations does not exceed 100 mrem in a year. Furthermore, 10 CFR Part 20 requires that power reactor licensees comply with EPA's environmental radiation standards contained in 40 CFR Part 190 (i.e., $25 \mathrm{mrem}$ to the whole body, $75 \mathrm{mrem}$ to the thyroid, and $25 \mathrm{mrem}$ to any other organ of any member of the public from the uranium fuel cycle).

Facility Accidents: DOE has previously analyzed accidents associated with HTGRs at a variety of locations (DOE 1995b). In this PEIS, DOE has re-analyzed the consequences of the accident scenarios presented in DOE 1995b at the six generic sites described in Appendix D, Section D.1.6. The internally initiated accidents with the highest consequence to the onsite and offsite populations would be the "Depressurized Conduction Cooldown with Reactor Cavity Cooling System Functioning" and the "Air Ingress" scenario (see Appendix D, Section D.2.5 for information on this accident and others analyzed for the HTGR). Using the dose-to-risk conversion factor of $6 \times 10^{-4}$ per person-rem, these collective population doses would result in 0.05 to 2 additional LCFs in the surrounding population. For the MEI, these scenarios would result in a probability of $5 \times 10^{-4}$ to 0.003 of an LCF. As described in Appendix D, Section D.1.6, the MEI would likely be further from the boundary than is assumed for this analysis and thus the

\footnotetext{
${ }^{59}$ A typical 1 GWe reactor would withdraw 3 to 6 billion gal/yr (11 to 23 billion L/yr) for cooling (using "wet cooling"). Water consumption would be less than 60 million gallons/yr (227 million gal/yr.
} 
consequences to the MEI likely would be less. For the noninvolved worker, these scenarios would result in a probability of 0.006 to 0.07 of an LCF.

Consequences do not account for the probability of an accident, and thus represent the impacts that could result if an accident were to occur. Another useful metric to consider in an accident analysis is risk. Risk takes into account the probability of an accident and is determined by multiplying the consequences of an accident by the probability of occurrence.

The internally initiated accident with the highest risk to the onsite and offsite populations is the "Depressurized Conduction Cooldown with Reactor Cavity Cooling System Functioning" scenario (see Appendix D, Section D.2.5). The collective risk to the offsite population for this scenario would range from $3 \times 10^{-7}$ expected LCF per year of operation in the Site 1 offsite population to $1 \times 10^{-5}$ expected LCF per year of operation in the Site 6 offsite population. For the MEI, this scenario would result in an increased risk of an LCF of $3 \times 10^{-9}$ to $2 \times 10^{-8}$ per year of operation. For the onsite noninvolved worker, this scenario would result in an increased risk of an LCF ranging from $4 \times 10^{-8}$ to $4 \times 10^{-7}$.

Spent Nuclear Fuel and Radioactive Wastes: Due to their higher burnups, HTGRs generate significantly less mass of SNF than LWRs (approximately 35 percent as much). By approximately 2060-2070, the amount of SNF generated by LWRs (prior to the conversion to HTGRs) would be approximately 68,000 MTHM. ${ }^{60}$ The amount of SNF generated by HTGRs by approximately 2060-2070 would be approximately 31,000 MTHM. $^{61}$ By 2060-2070, approximately 1,500 MTHM of SNF would be generated annually from HTGRs. However, compared to LWRs, HTGRs generate relatively high volumes of SNF. As shown in Table 4.8-1, for the same electrical production, HTGRs could generate up to 15 times more volume of SNF than LWRs, primarily due to the fuel compacts that are attached to the hexagonal prismatic blocks (Wigeland 2008a).

The only wastes generated for the all-HTGR option would be associated with HTGR operations. As discussed in Section 4.2.2, typical nuclear power plants generate SNF and LLW, including GTCC LLW. SNF management is addressed below. For this analysis, it is assumed that HTGRs would generate the same types and quantities of LLW (from annual operations) and GTCC LLW (from D\&D) as typical LWRs. Over a 50-year operational period, the HTGR option would generate the radioactive wastes shown in Table 4.7-8.

\footnotetext{
${ }^{60}$ Based on the following: new LWRs are constructed at a growth rate of 1.3 percent from 2015 to 2020; beginning in 2020, all new reactors are HTGRs and total reactor capacity grows to $200 \mathrm{GWe}$ by approximately 2060-2070; each HTGR produces approximately 7.7 MTHM of SNF/GWe-yr; LWRs are assumed to be replaced by HTGRs as they reach end-of-life; and by 2060-2070, this PEIS assumes that all LWRs would be replaced by HTGRs. The full implementation scenario (complete transition to all HWRs) is described in this analysis. However, any new LWRs constructed between 2015-2020 would likely operate a full 60 years (40-year initial life with a 20-year life extension). In this case, in the 2060-2070 timeframe, there could be approximately 7 GWe of LWR capacity. In this case, the total SNF quantities presented in this section would increase slightly (less than 1 percent) due to the fact that LWRs produce more SNF than HTGRs.

${ }^{61}$ Assumes all new reactors are HTGRs, beginning in approximately 2020, and added at a rate to keep pace with the 1.3 percent growth in nuclear electricity production until approximately $200 \mathrm{GWe}$ is achieved. A total of $200 \mathrm{GWe}$ of HTGRs are built and each GWe from an HTGR results in approximately 7.7 MTHM of SNF.
} 


\section{TABLE 4.7-8-Total Spent Nuclear Fuel and Wastes Generated by the All-High Temperature Gas-Cooled Reactors Option (50 Years of Implementation)

\begin{tabular}{lccc}
\hline Waste Category & $\begin{array}{c}\text { LWRs } \\
\text { (prior to } \\
\text { replacement) }\end{array}$ & $\begin{array}{c}\text { HTGRs } \\
(\mathbf{2 0 0} \text { GWe in } \\
\mathbf{2 0 6 0 - 2 0 7 0 )}\end{array}$ & Total \\
\hline SNF (MTHM) & 68,000 & 31,000 & 99,000 \\
LLW (solid) (cubic meters) & LB: 65,000 & LB: 85,000 & LB: 150,000 \\
GTCC LLW (cubic meters) & UB: $150,000^{\mathrm{a}}$ & UB: $435,000^{\mathrm{a}}$ & UB: 585,000 \\
\hline
\end{tabular}

$\mathrm{LB}=$ lower bound, $\mathrm{UB}=$ upper bound.

${ }^{a}$ Derived from data for a typical LWR which would generate approximately 27 to $103 \mathrm{yd}^{3}$ (21 to $79 \mathrm{~m}^{3}$ ) of LLW annually (NEI 2007). Based on constant growth from approximately $100 \mathrm{GWe}$ in 2010 to 200 GWe by approximately 2060-2070.

${ }^{\mathrm{b}}$ GTCC LLW from nuclear reactors is produced as a result of normal operations and becomes available for disposal during facility decommissioning. The majority of GTCC LLW generated by nuclear reactors is activated metal. It has been estimated that approximately $813 \mathrm{~m}^{3}\left(1,060 \mathrm{yd}^{3}\right)$ of GTCC LLW would be generated when the existing 104 commercial LWRs undergo D\&D (SNL 2007). Scaling those results to account for production of $200 \mathrm{GWe}$ of electricity via nuclear reactors (and accounting for the D\&D of existing LWRs), it is estimated that approximately $2,500 \mathrm{~m}^{3}\left(3,270 \mathrm{yd}^{3}\right)$ of GTCC LLW could result from D\&D. See Section 4.9 for a discussion of GTCC LLW from reactor decommissioning

Note: all values except GTCC LLW rounded to nearest thousand.

Transportation: Once generated at a commercial reactor, SNF from the HTGR open fuel cycle would eventually need to be transported to a future geologic repository for disposal. Table 4.7-9 presents the number of radiological shipments (broken down by material to be transported) that would be required for the all-HTGR option for 1) all truck and 2) a combination of truck and rail. Because all shipments of fresh nuclear fuel are assumed to occur via truck transport, there is no transportation scenario in which all transportation would occur via rail only. Consequently, the PEIS presents transportation impacts for a combined truck and rail scenario (in tables this scenario is designated as "truck/rail"). As shown in that table, truck transport would require significantly more shipments than truck and rail. The reason why the number of shipments for the all-HTGR option is so high relative to other fuel cycle alternatives is due to the large volume of SNF generated by the all-HTGR option (see Table 4.8-1).

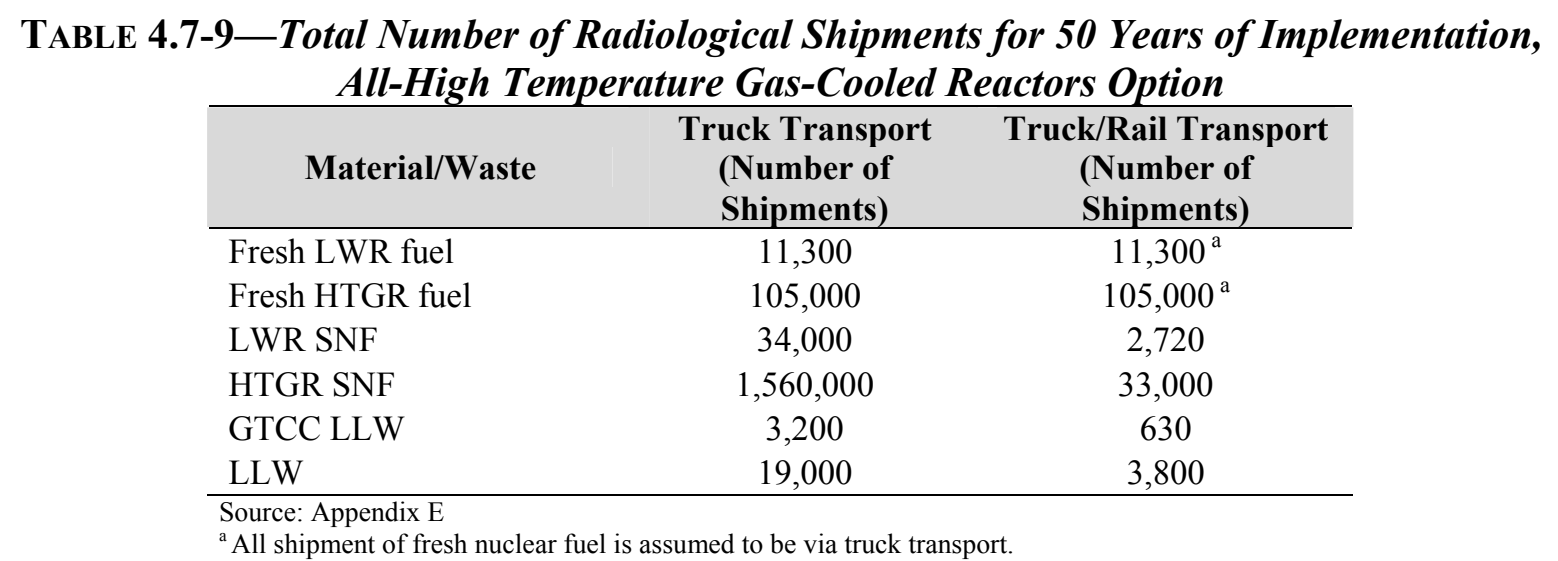

The results of the transportation analysis are presented in two sets of tables. The first set of tables (Tables 4.7-10 and 4.7-11) present the impacts associated with handling (loading and inspection) radiological material for the $200 \mathrm{GWe}$ scenario. Impacts are presented in terms of radiological impacts (expressed in person-rem and converted to LCFs using a dose-to-risk conversion factor of $6 \times 10^{-4}$ LCF per person-rem). Table 4.7-10 presents the handling impacts for truck transport and Table 4.7-11 presents the handling impacts for rail transport. Handling operations (loadings and inspections) would not affect the public. 
The impacts of handling radiological material are independent of the distance that the material would be transported. As such, the handling impacts would be the same whether the radiological material is transported, for example, $500 \mathrm{mi}(805 \mathrm{~km}), 2,100 \mathrm{mi}(3,380 \mathrm{~km})$, or any other distance. For this reason, these impacts are presented separately from the in-transit impacts (which are presented in the second set of tables).

Table 4.7-10-Handling Impacts for 50 Years of Implementation, All-High Temperature Gas-Cooled Reactors Option (Truck Transit)_200 Gigawatts Electric

\begin{tabular}{cccccccc}
\hline & \multicolumn{6}{c}{ Handling Impacts } \\
\cline { 2 - 8 } & \multicolumn{2}{c}{ Loading } & \multicolumn{2}{c}{ Inspection } & \multicolumn{2}{c}{ Total } \\
\cline { 2 - 8 } & person-rem & LCFs & person-rem & LCFs & person-rem & LCFs \\
\cline { 2 - 9 } HTGR & 693,000 & 416 & 119,000 & 71 & 812,000 & 487 \\
\hline
\end{tabular}

Source: Appendix E

Note: All LCFs rounded to nearest whole number.

Table 4.7-11-Handling Impacts for 50 Years of Implementation, All-High Temperature GasCooled Reactors Option (Truck and Rail Transit)-200 Gigawatts Electric

\begin{tabular}{ccccccc}
\hline & \multicolumn{6}{c}{ Handling Impacts } \\
\cline { 2 - 8 } & \multicolumn{2}{c}{ Loading } & \multicolumn{2}{c}{ Inspection } & \multicolumn{2}{c}{ Total } \\
\cline { 2 - 8 } & person-rem & LCFs & person-rem & LCFs & person-rem & LCFs \\
\hline HTGR & 122,000 & 73 & 3,160 & 2 & 126,000 & 75 \\
\hline
\end{tabular}

Source: Appendix E

Note: LCFs rounded to nearest whole number.

The in-transit impacts are shown in Tables 4.7-12 (truck transit) and 4.7-13 (truck and rail transit) for the HWR/HTGR Alternative (Option 2-HTGR). These impact estimates would vary based on a variety of factors, including the distance that the radiological material would be transported, the specific routes that would be utilized, the population densities along those routes, and others. Of these factors, transport distance is the most significant. Because the locations of future reactors and future disposal facilities are unknown, DOE analyzed transportation impacts over five distances: $150 \mathrm{mi}(241 \mathrm{~km}), 500 \mathrm{mi}(805 \mathrm{~km}), 1,500 \mathrm{mi}(2,414 \mathrm{~km}), 2,100 \mathrm{mi}$ $(3,380 \mathrm{~km})$, and 3,000 $\mathrm{mi}(4,828 \mathrm{~km})$. In-transit impacts presented in Tables 4.3-6 and 4.3-7 are based on $2,100 \mathrm{mi}(3,380 \mathrm{~km})$ of transport. This distance was selected as a reference distance because it represents the average distance for all SNF shipments analyzed in the Yucca Mountain FEIS (DOE 2002i). Impacts associated with the other four distances are presented, on a per shipment basis, in Appendix E, which describes the transportation methodology and assumptions. Although the in-transit impacts are not exactly "linear" (i.e., twice the impacts for twice the distance transported), that is a close approximation. Consequently, if the radiological material were transported $500 \mathrm{mi}(805 \mathrm{~km})$, all of the in-transit impacts presented in Tables 4.7-12 and 4.7-13 could be estimated by multiplying the values in those tables by 0.24 $(500 / 2,100)$. 
TABLE 4.7-12-In-Transit Transportation Impacts for 50 Years of Implementation, All-High Temperature Gas-Cooled Reactors Option (Truck Transit)-200 Gigawatts Electric

\begin{tabular}{|c|c|c|c|c|c|c|c|c|}
\hline & \multicolumn{4}{|c|}{ In Transit Impacts } & \multirow{3}{*}{$\begin{array}{c}\text { Total } \\
\text { Incident- } \\
\text { Free } \\
\text { LCFs } \\
\end{array}$} & \multirow{2}{*}{\multicolumn{3}{|c|}{ Accident Impacts }} \\
\hline & \multicolumn{2}{|c|}{ Crew } & \multicolumn{2}{|c|}{ Public } & & & & \\
\hline & $\begin{array}{c}\text { person- } \\
\text { rem }\end{array}$ & LCFs & $\begin{array}{c}\text { person- } \\
\text { rem }\end{array}$ & LCFs & & $\begin{array}{c}\text { person- } \\
\text { rem }\end{array}$ & LCFs & $\begin{array}{l}\text { Collision } \\
\text { Fatalities }\end{array}$ \\
\hline HTGR & 271,000 & 162 & $1,360,000$ & 816 & 979 & 0.592 & 0 & 149 \\
\hline
\end{tabular}

Note: All LCFs rounded to nearest whole number

TABLE 4.7-13-In-Transit Transportation Impacts for 50 Years of Implementation, All-High Temperature Gas-Cooled Reactors Option (Truck and Rail Transit)—200 Gigawatts Electric

\begin{tabular}{|c|c|c|c|c|c|c|c|c|}
\hline & \multicolumn{4}{|c|}{ In Transit Impacts } & \multirow{3}{*}{$\begin{array}{c}\text { Total } \\
\text { Incident- } \\
\text { Free } \\
\text { LCFs }\end{array}$} & \multirow{2}{*}{\multicolumn{3}{|c|}{ Accident Impacts }} \\
\hline & \multicolumn{2}{|c|}{ Crew } & \multicolumn{2}{|c|}{ Public } & & & & \\
\hline & $\begin{array}{l}\text { person- } \\
\text { rem }\end{array}$ & LCFs & $\begin{array}{c}\text { person- } \\
\text { rem }\end{array}$ & LCFs & & $\begin{array}{c}\text { person- } \\
\text { rem }\end{array}$ & LCFs & $\begin{array}{l}\text { Collision } \\
\text { Fatalities }\end{array}$ \\
\hline HTGR & 2,250 & 1 & 6,470 & 4 & 5 & 0.0361 & 0 & 13 \\
\hline
\end{tabular}

Source: Appendix E

Note: All LCFs rounded to nearest whole number

There are potentially significant differences in impacts depending upon whether transportation occurs via truck or a combination of truck and rail. For all alternatives, truck and rail transport would result in smaller impacts than truck transport. This is due to the fact that there would be many fewer transportation shipments for truck and rail compared to truck only. This would directly affect the distance traveled and exposures to both crews and the public. Additionally, the number of accident fatalities (collisions) would be smaller for the truck and rail transport.

\subsection{Comparative Sumary OF Domestic Programatic Alternatives}

This section presents a summary comparison of the domestic programmatic alternatives. The alternatives are compared and contrasted in the following areas: R\&D needs; issues associated with transition and implementation; facility and resource requirements; quantities of SNF and wastes generated; transportation impacts; potential impacts on the development of a future repository; and decontamination and decommissioning. Table 4.8-1 (200 GWe, 1.3 percent annual growth rate in nuclear electricity production), Table 4.8-2 (400 GWe, 2.5 percent annual growth rate), Table 4.8-3 (150 GWe, 0.7 percent annual growth rate), and Table 4.8-4 (100 GWe, zero growth rate) are presented to support discussions related to: facility and resource requirements; quantities of SNF and wastes generated; transportation impacts; and potential impacts on development of a future repository. Tables 4.8-5 and 4.8-6 present a comparative summary of the impacts of the domestic fuel cycle alternatives. Table 4.8-5 presents the annual impacts once implementation is achieved in approximately 2060-2070. Table S.4.8-6 presents the cumulative impacts over the entire implementation period (2010 to approximately 2060-2070).

\subsubsection{Research and Development Needs for the Alternatives}

Many of the alternatives require that additional $\mathrm{R} \& \mathrm{D}$ be completed before wide-scale deployment of the alternative could be accomplished. The R\&D needs vary significantly among alternatives. All alternatives, including the no-action alternative, would benefit from R\&D for 
improvements to waste form processing and fuel fabrication. For the action alternatives, the R\&D is necessary for successful demonstration of the fuel cycle selected. In the following discussion, the R\&D needs are grouped by technical area for comparison among the alternatives. In preparing this section, DOE considered issues that were raised in reports prepared by external organizations (see Chapter 1, Section 1.4.6).

- $\quad$ Fuel Development and Fabrication. The need for R\&D of fuel fabrication technologies is considered from two perspectives, first, whether a fabrication technology exists, and second, whether the existing technology has been developed sufficiently to allow an alternative to be implemented. Most of the alternatives have candidate processes for fabrication of fuel; however, all but the No Action Alternative and the HWR/HTGR Alternative (Option 1-all-HWR) would require additional R\&D to apply these technologies. The time frame to complete the necessary R\&D would be similar among the alternatives and is estimated to require about 5 to 10 years.

- $\quad$ Fuel Performance. R\&D would be required to develop and demonstrate fuel performance in the reactor and in storage after discharge from the reactor (whether destined for processing or not) for each of the alternatives, except for the No Action Alternative and the HWR/HTGR Alternative (Option 1-all-HWR), which utilize proven fuel technologies. For most alternatives, relevant fuel performance experience is available, although for some of the reactor types this experience may be limited to experimental or testing conditions only. Even for reactor types for which there may be prior commercial experience, it is likely that testing and verification of fuel performance would be required as one of the licensing conditions, regardless of the alternative, prior to widespread use (with the exceptions of LWRs and HWRs). In contrast, however, it is also likely that each reactor type, whether commercially available or not, could begin operations using nuclear fuel that is within the existing experience base, and then move toward the required fuel composition as new experience is gained.

Some of the alternatives would use reactor types that are not available in the United States, although either they have existed in the United States in the past as experimental or first-of-a-kind commercial plants, or they exist outside of the United States. For example, HWRs are used extensively in Canada, which would likely facilitate licensing in the United States. For alternatives involving fast reactors and HTGRs, no facility exists in the United States where fuel performance experience sufficient for licensing can be acquired. Even for those alternatives where LWRs would be used, it is likely that the licenses of existing LWRs would need to be amended to allow fuel performance tests, and this may not be possible. The time frame for achieving the required fuel performance information would depend on the availability of the appropriate irradiation facilities, but such development could be done as part of the ongoing operation of the facility.

- Reactor Technology. Each of the reactor technologies associated with the domestic programmatic alternatives have different operating experience, which could affect the amount of R\&D needed to implement that technology. For example, LWRs and HWRs are used throughout the world and would not necessarily require any new R\&D. Other 
reactor technologies (thorium-fueled reactors, ${ }^{62}$ fast reactors, and HTGRs) have been operated on much smaller scales than LWRs and HWRs, and therefore these reactor technologies would benefit the most from R\&D. The HTGR, in particular, would require the most R\&D, as the operating experience with this reactor technology at industry-scale (greater than 250 megawatts) has been limited.

- Spent Fuel Reprocessing. Only the closed fuel cycle alternatives require reprocessing of spent nuclear fuel. For these alternatives, reprocessing technologies have been developed and tested that would meet separations requirements. Some of the new technologies are evolutions of technologies operated at commercial scale, and for those, implementation would expedite the required scale-up. There are many subsidiary issues associated with each new technology that would require R\&D, especially with final treatment and consolidation of the wastes, and with ensuring that the new technologies are capable of limiting releases of radioactive materials from the reprocessing plant to allowable limits. The time frame for completing the required $\mathrm{R} \& \mathrm{D}$ is estimated to be 5 to 10 years for each of the closed fuel cycle alternatives.

- Spent Fuel and High-Level Radioactive Waste Disposal. All fuel cycle alternatives would require disposal of spent nuclear fuel and/or high-level radioactive waste in a geologic repository. DOE has already conducted significant R\&D related to such disposal at the proposed Yucca Mountain repository and has submitted a license application for construction authorization with the NRC. The need for R\&D related to geologic disposal in any future geologic repository would depend on the characteristics of the future geologic repository as determined by a site-specific assessment of repository performance (i.e., how well the repository would contain radionuclides). Such a performance assessment would consider: the form of the materials to be disposed of; barriers to release (e.g., waste packages and engineered repository systems); characteristics of the geologic environment (e.g., presence of water, chemistry of water, temperature, rock stability); and exposure pathways. DOE estimates that it would take 5 to 10 years or longer to complete such a R\&D review. Testing of the waste forms under accelerated repository-relevant conditions could be accomplished more quickly. However, experimenting with changes to the formulation of proposed waste forms to enhance performance, if deemed necessary for a particular repository concept, could add years to such an effort.

The No Action Alternative and the HWR/HTGR Alternative (Option 1-all-HWR) would require the least amount of $R \& D$. This conclusion is consistent with the fact that the technologies associated with these two alternatives are currently widely used around the world for electricity generation. The closed fuel cycle alternatives (particularly Fast Reactor Recycle and Thermal/Fast Reactor Recycle alternatives) would generally require the highest amount of R\&D, especially in the area of fuel development, fuel fabrication, and fuel performance associated with fast reactor operations.

\footnotetext{
${ }^{62}$ With respect to the use of thorium-fuel in LWRs, although the Thorium Alternative is characterized as a "new fuel design" rather than as a new reactor concept in this PEIS, the insertion of thorium fuel into an LWR may not be as simple as, for example, the substitution of MOX-U-Pu fuel assemblies for uranium fuel assemblies in an LWR.
} 


\subsubsection{Transition and Implementation}

All alternatives except the No Action Alternative would involve an evolution from the current system to one involving a new system. The environmental consequences during transition to the new system would be a mix of the No Action Alternative effects and the effects of the new system.

The alternatives can be grouped into three types for transition analysis:

- Alternatives that require new fuels with current reactor types - this includes the Thorium Fuel Cycle Alternative and the Thermal Reactor Recycle Alternative (Option 1).

- Alternatives that require transition from the current reactor type (LWRs) to a single new reactor type (homogeneous system) — this includes both the HWR option and the HTGR option for the HWR/HTGR Alternative.

- Alternatives that require transition to a system involving more than one reactor type in a balanced heterogeneous system - this includes the Fast Reactor Recycle Alternative, the Thermal/Fast Reactor Recycle Alternative, the Thermal Reactor Recycle Alternative (Option 2), and the Thermal Reactor Recycle Alternative (Option 3).

For purposes of consistency in analysis, it has been assumed for all alternatives that there would be a gradual transition period beginning around 2020 from the current LWR uranium oxide (UOX) once-through nuclear energy system to an alternative system that would be fully implemented in the 2060-2070 timeframe. This approach was used because the future is too uncertain to predict the actual transition time for any alternative and using the same transition schedule facilitates comparisons among the alternatives. This section provides qualitative information on the constraints which may impact actual transition timing.

Initially, only the current system would be in deployment while development and licensing is completed for the technologies and infrastructure necessary for a new system. Once the pre-transition activities are in place, the new system can be deployed. The minimum time to start the transition for each alternative depends on the amount of development required. The transition rate for each alternative would depend on a number of constraints, as discussed below. The impact during transition would depend on both the time to transition and the transition rate.

Transition for the first group of alternatives (the Thorium Alternative and the Thermal Reactor Recycle Alternative (Option 1)) would be less complex and could start sooner than other alternatives because it would primarily require development and licensing of a new fuel type and development of facilities to provide feedstock ${ }^{63}$ for the fuel. For the Thermal Reactor Recycle Alternative (Option 1), the MOX-U-Pu fuel has already been developed and is in use in Europe. Thorium fuel has been used in the past but larger scale use of thorium would require some reactor R\&D and new data for licensing. The Thermal Reactor Recycle Alternative (Option 1) would require separations of UOX SNF to provide feedstock material for the new fuel. The same separations technology (likely with different equipment) could then support the recycle of MOX-U-Pu SNF as it becomes available. Complete transition for the Thermal Reactor Recycle

\footnotetext{
${ }^{63}$ Feedstock refers to the materials used to fuel a reactor.
} 
Alternative (Option 1) would require adequate separations facilities in order to support the equilibrium level of recycling.

Thorium fuel would obtain its feedstock of uranium and thorium from mining and from stockpiles; adequate uranium mining exists and reliable reserves of thorium are available both in the United States and around the world. The level of enrichment of the uranium for the thorium fuel is also much higher, and would require new or modified enrichment facilities that are appropriately designed, for increased levels of enrichment, and licensed. Both alternatives would require construction or modification of fuel fabrication facilities.

All of the needed technologies and facilities are straightforward and transition from the current system could begin within approximately 10 to 15 years. During such a transition, the new fuel could be used as a replacement during refueling and any specific reactor could switch over to the new system during a period of 5 to 6 years. Equilibrium for the Thermal Reactor Recycle Alternative (Option 1) would also require recycle of the MOX-U-Pu SNF, which could begin roughly 5 years after it is discharged from the reactors. Thus, transition from the current LWR uranium oxide system to the new system could be completed in 20 to 25 years from a decision to proceed for both alternatives. Actual transition may occur at a much slower pace due to economics or other factors. The major constraint for the Thermal Reactor Recycle Alternative (Option 1) would be separations capacity, while the major constraint for the Thorium Alternative would be fresh fuel infrastructure, including facilities to enrich uranium to 19.9 percent.

The second group of alternatives (the HWR/HTGR Alternative (Options 1 and 2) could be deployed once these reactor types were developed and licensed by the NRC. HWRs are available commercially internationally and would only require U.S. licensing, while HTGRs would require development of both the reactor and the fuel, which could take 10 to 15 years or longer. Feedstock would not be a constraint, because both options would depend on the existing uranium fuel infrastructure. Complete transition would require early construction of production facilities, including heavy water production plants for HWRs and reactor-grade graphite production plants for HTGRs. The completion of transition would occur once all current (legacy) reactors were retired. Based on licensing and license extension considerations, DOE expects that reactors in the existing LWR fleet would be operated for 60 years, with retirements beginning in 2029 and completing in 2053. Construction of new LWRs now under consideration could extend the transition period.

Transition for the final group of alternatives (the Fast Reactor Recycle Alternative, the Thermal/Fast Reactor Recycle Alternative, the Thermal Reactor Recycle Alternative (Option 2), and the Thermal Reactor Recycle Alternative (Option 3)) would be more complex. The start of transition would involve both new reactors and fuels, and the new fuels would require separations to provide feedstock. Transition could begin in 15-20 years, but the rate of transition would be slower than the other groups of alternatives. This would be due to the feedstock required for startup of the new reactors - a full core of fuel would be needed to start each new reactor. The feedstock would initially come from LWR SNF separations, and therefore, would be tied to the separations capacity. While this would not affect deployment of HWRs associated with the Thermal Reactor Recycle Alternative (Option 2) ${ }^{64}$, it could significantly constrain the

\footnotetext{
${ }^{64}$ The HWR fresh fuel does not depend on dissolving and separating LWR spent fuel but only on dry thermal/mechanical processes.
} 
rate of fast reactor or HTGR deployment, each of which would require a significant quantity of transuranics in the transmutation fuel (more than $5 \mathrm{MT} / \mathrm{GWe}$, based on a thermal efficiency of approximately 40 percent). The amount of transuranics needed to start up a new fast reactor would also depend on whether the fast reactor spent nuclear fuel would be recycled on-site or at a central facility. Centralized recycling would require longer storage of the fast reactor spent nuclear fuel so it could cool prior to transport. This could result in greater delay before any of the residual transuranics from the fast reactor spent fuel could become available, so more transuranics would be required from separated uranium oxide before any would be available from the fast reactor spent fuel. The result would be that transition would not be completed for several decades. The Thermal/Fast Reactor Recycle Alternative could have an additional delay of 10 or more years because of the potential time required to accumulate feedstock for the fast reactor fuel from spent MOX-U-Pu fuel or spent LWR fuel. The MOX-U-Pu fuel would spend approximately 5 years in the reactor, then would have to cool for at least 5 years before it could be separated, and the transuranics extracted and made available for fast reactor fuel fabrication.

For the closed fuel cycle alternatives, the analysis in this PEIS assumes that implementation would be "highly successful" (e.g., no delays would be encountered in developing advanced fuels or new reactors; reactors would become operational "on-schedule"; and reactor capacities would be optimally matched to the availability of transuranic product from LWR SNF separations). This section addresses some of the potential implementation challenges.

For example, for the Fast Reactor Recycle Alternative, it is possible that the separation capacity of LWR SNF would not expand as needed to support the desired percentage of fast reactors (40 percent of production) compared to LWRs (60 percent of production). If not enough LWR separations capacity were constructed, only a limited number of "second tier" reactors could be constructed due to the limited availability of feed material (e.g., transuranic radionuclides) that would be needed. ${ }^{65}$ This would result in a high percentage of total reactors being LWRs. In such a situation, LWR separations capacity would be insufficient to keep up with LWR SNF discharges, and excess LWR SNF would require storage. These impacts would be similar to those presented for the No Action Alternative.

It is also possible that fast reactor capacity could be delayed. For example, the process of lead test assembly irradiation, post-irradiation examination, and fuel certification could take longer than expected. If this were to occur, there could be an excess of separations capacity. Until additional fast reactor capacity could be brought on-line, there would be an excess of transuranic radionuclides that would require storage (see Section 4.3.3) or disposal. Any stored transuranic radionuclides would be used when fast reactors were brought on-line.

\subsubsection{Facility and Resource Requirements}

This PEIS assumes that all reactor fuel cycles could be implemented to achieve a capacity of approximately $200 \mathrm{GWe}$. As shown on Table 4.8-1, the reactor types would be different for each of the programmatic alternatives. For example, the No Action Alternative would produce

\footnotetext{
${ }^{65}$ For example, the amount of fuel required to support $1 \mathrm{GWe}$ (based on a thermal efficiency of 40 percent) of fast reactor capacity is approximately $28 \mathrm{MT}$ of uranium and $5 \mathrm{MT}$ of transuranics (TRU) in start-up fuel and approximately 5.0 to $6.8 \mathrm{MT}$ of uranium and $1.9 \mathrm{MT}$ of TRU as make-up fuel over the 4- to 5-year cycle.
} 
electricity using LWRs in a once-through fuel cycle, while the Fast Reactor Recycle Alternative would produce electricity using a mix of LWRs and fast reactors in a closed fuel cycle in which the separated LWR SNF provides the transmutation fuel for the fast reactors.

The number of reactors that would ultimately be required to support any fuel cycle alternative would be a function of reactor size, thermal efficiency, and capacity factor. This PEIS assumes that approximately $1 \mathrm{GWe}$ of capacity would be located at any future site. ${ }^{66}$ Consequently, each fuel cycle alternative would require approximately 200 reactor sites. Based on an average size of approximately 3,000 acres (1200 ha) per site, the total land occupied by the 200 nuclear power plant sites would be about 600,000 acres $(243,000$ ha). Other potential support facilities (such as fuel fabrication facilities, nuclear fuel recycling centers, heavy water production facilities) would not significantly change this land requirement for any of the alternatives).

Although material requirements for nuclear power plants and recycling centers would vary by design and site location, the requirements for a major nuclear facility (i.e., a 1,000 MWe LWR) would include approximately 150,000 MT of steel and 850,000 MT of concrete (CEEDATA 2006). Constructing 200 major new nuclear facilities over approximately 50 years would result in an average of 4 new major nuclear facilities, annually. On an annual basis, these new nuclear facilities would use approximately 0.6 million MT of steel and 3.4 million MT of concrete.

All fuel cycle alternatives would require significant quantities of natural uranium feed. In all cases, the open fuel cycle alternatives (No Action Alternative, Thorium Alternative, HWR/HTGR Alternative) would require the highest quantities of natural uranium feed. At the upper end of the requirement, the HTGR Option (for the HWR/HTGR Alternative) would require the highest natural uranium feed (approximately 45,600 MT/yr), which would be 16 percent higher than the No Action Alternative. This amount of natural uranium feed is approximately four times higher than current domestic uranium feed requirements. The closed fuel cycle alternatives would require natural uranium feed quantities that could be approximately one-half as much as the open fuel cycle alternatives. This illustrates one of the benefits of recycling SNF- to recover usable materials. The closed fuel cycle alternatives would recover significant quantities of uranium (2,460 to 4,500 MT/yr) and transuranics (approximately 26 to $56 \mathrm{MT} / \mathrm{yr}$, depending upon the closed fuel cycle alternative) for potential future use. In terms of using the least amount of natural uranium feed, the Fast Reactor Recycle Alternative would be the most efficient fuel cycle, requiring approximately $24,400 \mathrm{MT} / \mathrm{yr}$ to produce $200 \mathrm{GWe}$.

All alternatives would require various types of new facilities, including fuel enrichment and fuel fabrication facilities to support a capacity of $200 \mathrm{GWe}$. In addition to increased uranium fuel fabrication capacity, the Thorium Alternative would also require a fuel fabrication facility for thorium. The closed fuel cycle alternatives (Fast Reactor Recycle Alternative, Thermal/Fast Reactor Recycle Alternative, and the Thermal Reactor Recycle Alternative [all options]) would require LWR separation facilities/fuel fabrication facilities. The Thermal Reactor Recycle Alternative (Option 2) and the HWR/HTGR Alternative (Option 1-all-HWR) would require

\footnotetext{
${ }^{66}$ This assumption is conservative, as the existing nuclear infrastructure in the United States consists of approximately 100 GWe of capacity at approximately 64 sites, or approximately $1.5 \mathrm{GWe} / \mathrm{site}$. If the PEIS assumed $1.5 \mathrm{GWe} / \mathrm{site}$, each fuel cycle alternative would require approximately 133 reactor sites. Based on an average size of approximately 3,000 acres per site, the total land occupied by the 133 nuclear power plant sites would be about 400,000 acres.
} 
one or more facilities to produce heavy water. Finally, the Thermal Reactor Recycle Alternative (Option 3) and the HWR/HTGR Alternative (Option 2-all-HTGR) would significantly affect the demand for graphite and helium.

During operations, the facilities could use significant quantities of water for domestic needs, process support, and to cool the reactor (primary and secondary cooling). Most of this water would not be consumed but would be used for cooling and then discharged. Each LWR separation facility with an approximate $800 \mathrm{MTHM} / \mathrm{yr}$ capacity would require approximately 330 million gal/yr (1.3 billion L/yr). Each GWe of reactor output could use approximately 3 to 6 billion gal/yr (11 to 23 billion L/yr), mainly for heat dissipation. In arid environments, "dry" cooling towers could be utilized to reduce water requirements to approximately 195 million gal/yr (740 million L/yr). The heat dissipation system selected would be dependent on site characteristics and regulatory requirements.

\subsubsection{Spent Nuclear Fuel and Radioactive Wastes}

All fuel cycle alternatives would generate SNF and/or HLW that would ultimately require disposal in a geologic repository. The most radiotoxic contents of SNF and HLW are generally the actinide elements (heavy metals, especially the transuranic elements) and to a lesser extent certain fission products. The amount of SNF and HLW created per year would vary from one alternative to another. In addition, all fuel cycle alternatives would generate LLW during operations and LLW and GTCC LLW during decontamination and decommissioning (D\&D) following plant shutdown. The Fast Reactor Recycle Alternative, Thermal/Fast Reactor Recycle Alternative, and Thermal Reactor Recycle Alternative (Options 1 and 3) would generate GTCC LLW during SNF recycling operations. Under the closed fuel cycle alternatives, it is also possible that cesium and strontium could be separated from other fission products, creating an additional waste stream.

The following SNF and waste streams do not have a clear path to disposal at this point:

- $\quad$ SNF quantities generated beyond the Yucca Mountain statutory limit

- $\quad$ HLW generated under any of the alternatives

- $\quad$ GTCC LLW generated under any of the alternatives

- $\quad$ LLW that exceeds disposal capacities

- $\quad$ Separated cesium and strontium (if applicable)

The impact on SNF and HLW management for each alternative is evaluated by assessing the mass/volume of SNF and/or HLW that would be sent to geologic disposal, the amount of fission product and transuranic elements requiring consolidation in waste forms that would be sent to geologic disposal, the radiotoxicity of the emplaced SNF and/or HLW, and the decay heat that would have to be accommodated by the repository design.

The relative importance of the waste management metrics (e.g., volume, radiotoxicity, and heat load) would be affected by the repository environment and the design of the engineered emplacement system. This has the potential to decrease the regulatory uncertainty involved in predicting the long-term performance of such a repository, or to increase the public acceptability 
of geologic disposal for these waste management measures, so that adequate disposal capacity can be found for future commercial nuclear waste inventories. Because no repository has yet been licensed for the disposal of either SNF or HLW, all of the metrics have been included in Table 4.8-1 for comparison of the alternatives.

Amount of Spent Nuclear Fuel Requiring Repository Disposal: All alternatives would require a geologic repository. Even if nuclear electricity generation continues throughout this century at a zero growth rate, the cumulative amount of SNF created between the years 2010 and approximately 2060-2070 (approximately 110,000 MTHM) would require a repository more than 1.5 times larger than the statutory capacity limit of the Yucca Mountain repository, which would have reached its statutory capacity limit. ${ }^{67}$ This increase would need to be met by physical expansion of the first repository or by siting an additional repository. For the 1.3 percent growth rate, the No Action Alternative would generate approximately 158,000 MTHM of SNF from 2010 to approximately 2060-2070, which would be approximately 2.2 times that of the Yucca Mountain statutory capacity limit.

Yucca Mountain Statutory Capacity Limit

Under Section 114(d) of the Nuclear Waste Policy Act of 1982, as amended, the Yucca Mountain repository can not accept more than 70,000 metric tons of heavy metal of spent nuclear fuel and high-level radioactive waste until such time as a second repository is in operation.

For alternatives other than the No Action Alternative, which also assume a nuclear energy growth rate of 1.3 percent for the $200 \mathrm{GWe}$ scenario, the cumulative amount of SNF generated between 2010 and approximately 2060-2070 requiring geologic disposal would be as shown on Figure 4.8-1. As shown on that figure, only the Fast Reactor Recycle Alternative, Thermal/Fast Reactor Recycle Alternative, and the Thermal Reactor Recycle Alternative (Option 1) would avoid this SNF accumulation; however, these alternatives would produce HLW as part of the recycling of SNF.

On an annual basis, at the state of full implementation (approximately 2060-2070), the HWR/HTGR Alternative (Option 1-all HWR) would generate the highest mass of SNF requiring geologic disposal $(10,600 \mathrm{MTHM} / \mathrm{yr}$ for $200 \mathrm{GWe})$, while the Fast Reactor Recycle Alternative, Thermal/Fast Reactor Recycle Alternative, and Thermal Reactor Recycle Alternative-Option 1 would generate no SNF requiring geologic disposal. For the once-through fuel cycles, the HWR/HTGR Alternative (Option 2-all HTGR) could generate the least mass of SNF requiring geologic disposal (1,540 MTHM/yr for $200 \mathrm{GWe})$. This reflects the higher burnup of HTGRs compared to the lower burnup of HWRs. However, while the mass of SNF can be relatively smaller with the HTGR fuel, if the compacts are not removed from the graphite blocks, the volume of SNF can be substantial. The Thorium Alternative would generate approximately 2,050 MTHM/yr of SNF. As a point of comparison, the No Action Alternative would generate approximately 4,340 MTHM/yr for $200 \mathrm{GWe}$. The total quantities generated between 2010 and approximately 2060-2070 for each alternative, as shown in Table 4.8-1, reflect the time-phased implementation of the alternative. For example, the all-HWR option would generate no HWR SNF until after the initial facilities begin operation in the early 2020s, and the annual HWR SNF generation then gradually increases up to $10,600 \mathrm{MTHM} / \mathrm{yr}$ when full implementation is reached (approximately 2060-2070).

${ }^{67}$ These numbers relate to the status quo - current types of fuel, current uranium enrichment, and current burnup. 


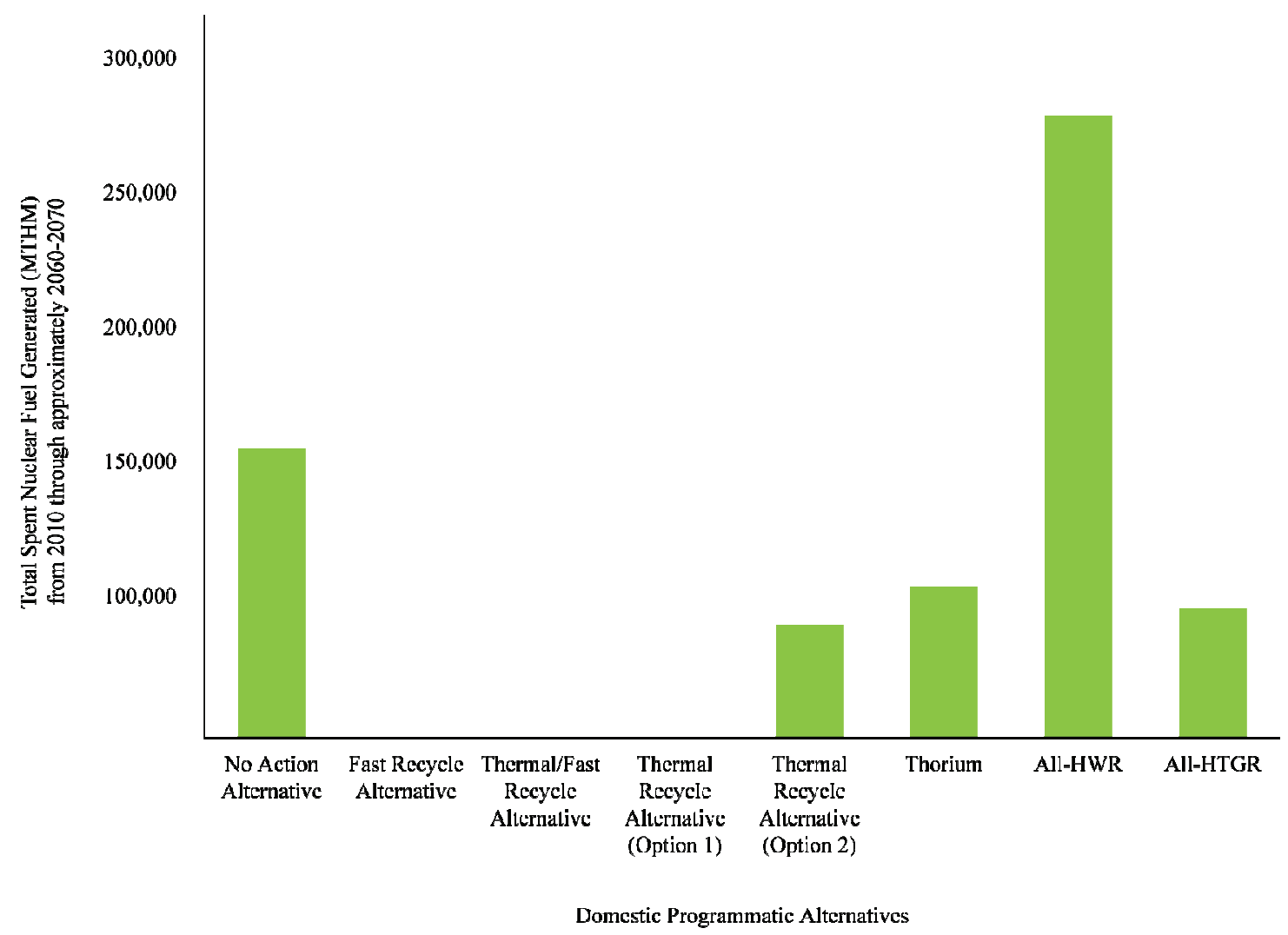

Source: Table 4.8-6

Note: Thermal Reactor Recycle Alternative (Option 3) not included due to unavailability of data

FIGURE 4.8-1-Cumulative Spent Nuclear Fuel Quantities Requiring Geologic Disposal for the 200 Gigawatts Electric Scenario (2010 to 2060-2070)

Amount of Processing Wastes Classified as High-Level Radioactive Waste Requiring Repository Disposal. The Fast Reactor Recycle Alternative, Thermal/Fast Reactor Recycle Alternative, and the Thermal Reactor Recycle Alternatives (all options) would be the only alternatives that generate processing wastes that would be classified as HLW. For a capacity of $200 \mathrm{GWe}$, the amount of HLW generated by these alternatives would be approximately 50 to $1,840 \mathrm{~m}^{3} / \mathrm{yr}$ (65 to $2400 \mathrm{yd}^{3} / \mathrm{yr}$ ). From the SNF generated from 2010 to approximately 2060-2070, these alternatives could generate more than $50,000 \mathrm{~m}^{3}\left(71,500 \mathrm{yd}^{3}\right)$ of HLW between 2010 and approximately 2060-2070 (Figure 4.8-2). There are several existing options for encapsulating these materials in waste forms suitable for geologic disposal, including borosilicate glass, as is planned for some DOE defense-related wastes.

The volume of the HLW would depend on the loading density of the waste form(s), with higher loading densities resulting in lower total volumes of waste. Whether this volume is relevant for geologic disposal would depend on the constraints that may exist for repository design, such as the space available within the repository and thermal limits, and the potential for mitigation of HLW volumes that are larger than desired by the repository design changes. Such considerations are beyond the scope of these comparisons and are not considered in this PEIS. The values listed 
in Table 4.8-1 are estimates based on existing technology and the best available information for encapsulating both transuranics and fission products for the purposes of comparison (Wigeland 2008a).

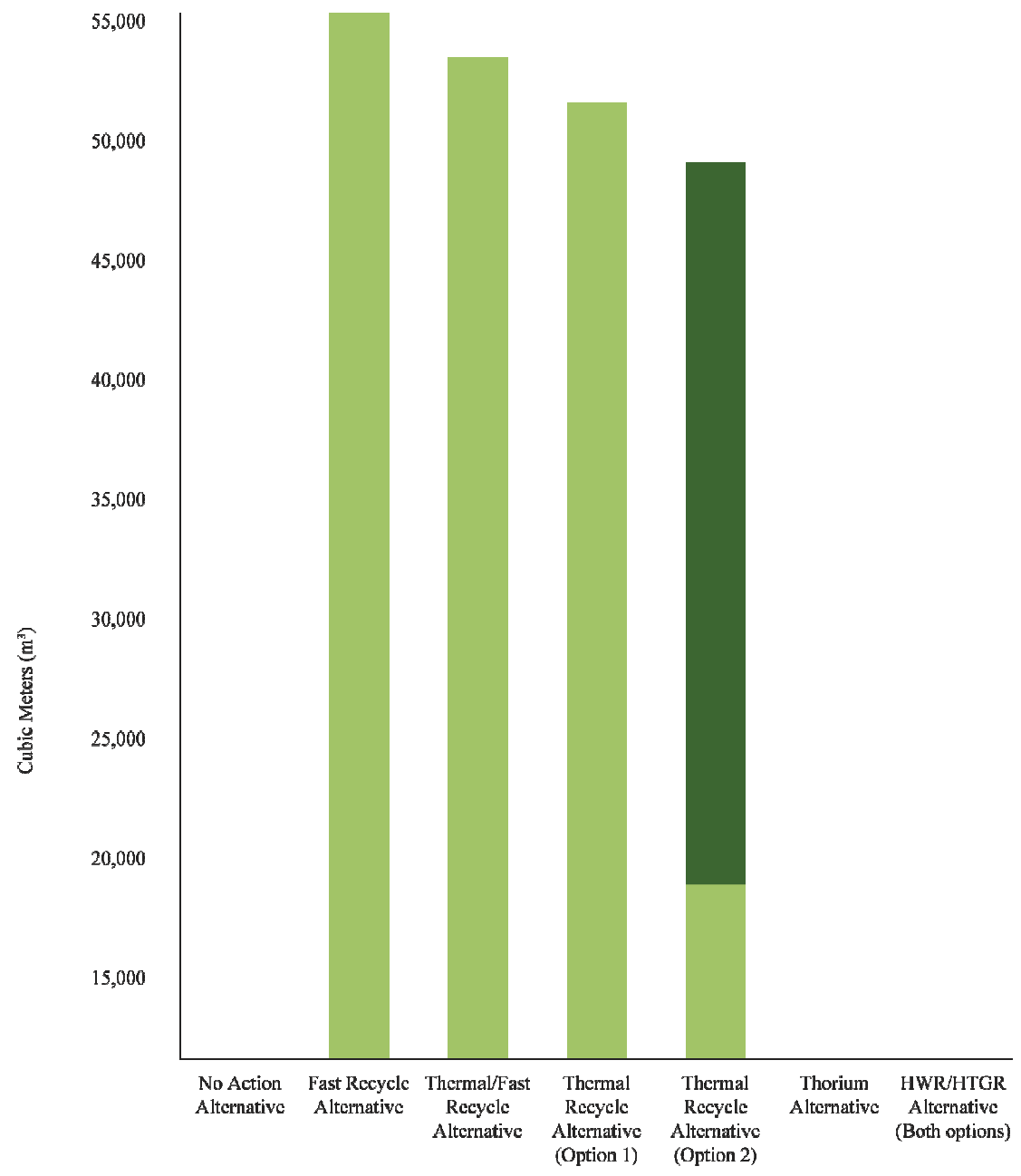

Source: Table 4.8-6

Notes: Thermal Reactor Recycle Alternative (Option 3) not included due to unavailability of data.

A range, represented by the dark green band, is presented for the Thermal Recycle Alternative (Option 2) due to the uncertainty related to the upper bound data for HLW associated with this alternative. This alternative is a South Korean program, in a research stage, with only open literature publications available.

FIGURE 4.8-2-Cumulative Quantities of High-Level Waste Requiring Geologic Disposal for the 200 Gigawatts Electric Scenario (Based on Recycling Spent Nuclear Fuel Generated Between 2010 and 2060-2070)

The amount of transuranic radionuclides in the HLW and SNF varies from one alternative to another. The mass of transuranic radionuclides in the HLW or SNF, or both, is a measure of the amount of the potentially hazardous material that would be accommodated in a repository, although not all isotopes of the transuranic radionuclides are equally hazardous (the hazard is expressed by the radiotoxicity, which is covered in Section 4.8.6). In general, the potential hazard from the repository grows as the amount of transuranic radionuclides grows. As shown on 
Table 4.8-1, for 200 GWe, the Fast Reactor Recycle Alternative and Thermal/Fast Reactor Recycle Alternative would generate the least amount of transuranic radionuclides which would have to be sent to a geologic repository $(0.2$ to $0.22 \mathrm{MT} / \mathrm{yr})$. These transuranic radionuclides would result from process losses during recycling, with the transuranic radionuclides contained in a waste form for processing wastes. The Thorium Alternative (15.6 MT/yr), Thermal Reactor Recycle Alternative (Option 1) (16.6 MT/yr), Thermal Reactor Recycle Alternative (Option 2) (30 MT/yr), and the HWR/HTGR Alternative (Option 2-all-HTGR) (32 MT/yr) are the next lowest generators of transuranic radionuclides (either in HLW and/or in SNF) that would have to be sent to a geologic repository The No Action Alternative and the HWR/HTGR Alternative (Option 1-all-HWR) produce relatively large quantities of transuranic radionuclides (56 and $76 \mathrm{MT} / \mathrm{yr}$, respectively) in spent fuel that would have to be sent to a geologic repository.

Other Wastes: Compared to the open fuel cycle alternatives, recycling SNF creates much higher quantities of other wastes that would require management. For example, as shown in Table 4.8-1, the closed fuel cycle alternatives would create separate wastes streams consisting of GTCC LLW and, potentially, cesium and strontium. If cesium and strontium wastes are stored for approximately 300 years, their radioactivity levels would have decayed sufficiently so that these wastes potentially could be disposed of as LLW. Another option would be to send these wastes to an off-site HLW storage or disposal facility after they are separated from the SNF. About 24 metric tons per year of cesium and strontium wastes could be generated for the Fast Reactor Recycle Alternative, Thermal/Fast Reactor Recycle Alternative, and Thermal Reactor Recycle Alternative (Options 1 and 3) in the peak year of operation for $200 \mathrm{GWe}$. The Fast Reactor Recycle Alternative, Thermal/Fast Reactor Recycle Alternative, and Thermal Reactor Recycle Alternative (Option 1) would generate (considering the upper bound estimates) relatively large quantities of GTCC LLW (more than 13,000 $\mathrm{m}^{3} / \mathrm{yr}$ of GTCC LLW in the peak year of operation) that would also need to be managed annually for the 200 GWe capacity. From reprocessing the SNF generated between 2010 and approximately 2060-2070, each of these alternatives would cumulatively generate more than approximately $400,000 \mathrm{~m}^{3}\left(520,000 \mathrm{yd}^{3}\right)$ of GTCC LLW (Figure 4.8-3). The cladding and assembly hardware recovered at the separations facility have been included in the estimated quantity of GTCC LLW. Non-radioactive wastes (e.g., hazardous, sanitary, and industrial) would also be generated, but should be similar for all programmatic domestic alternatives. 


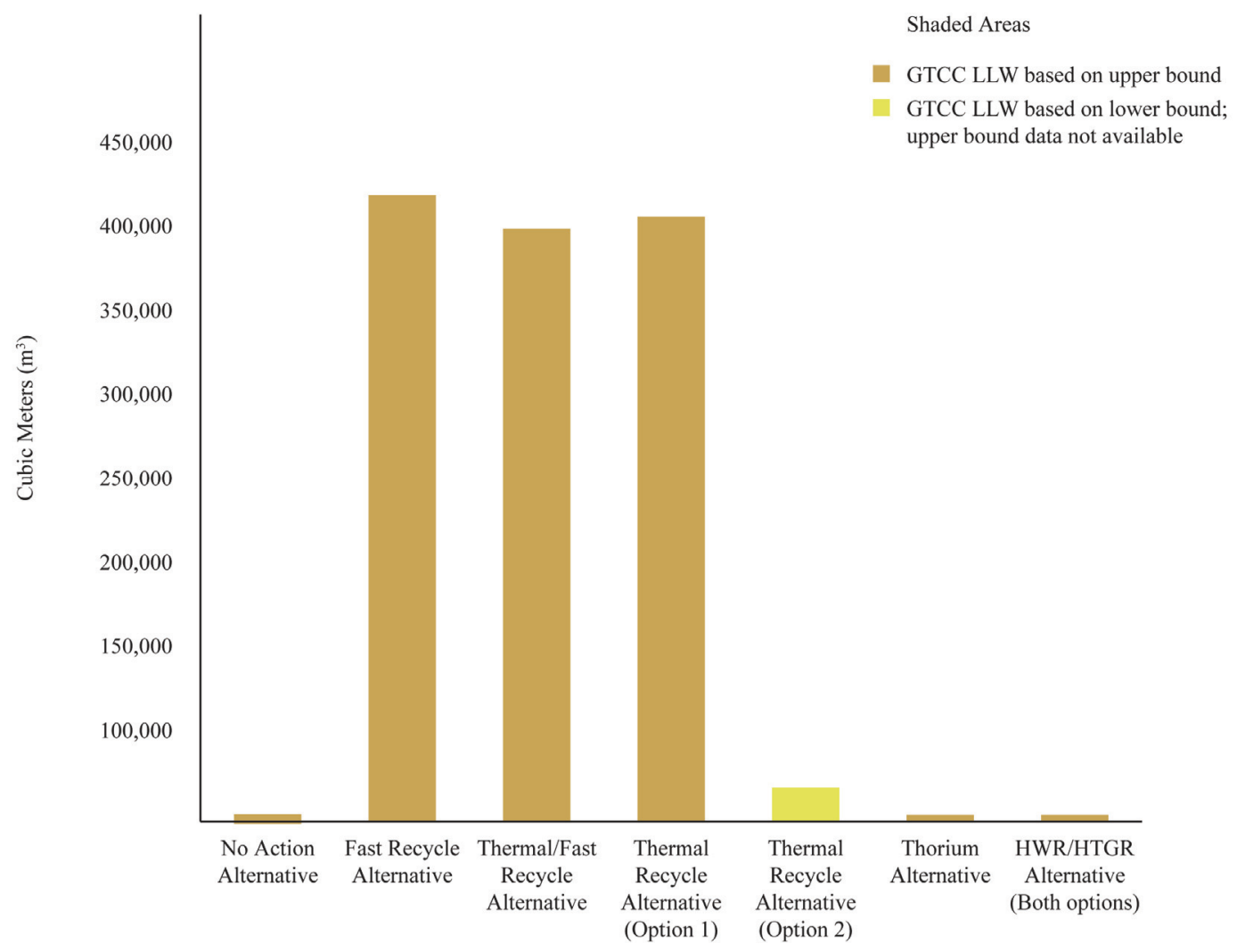

Source: Table 4.8-6

Note: Thermal Reactor Recycle Alternative (Option 3) not included due to unavailability of data.

FIGURE 4.8-3-Cumulative Quantities of Greater-Than-Class-C Low-Level Radioactive Waste Generated for the 200 Gigawatts Electric Scenario (Based on Recycling Spent Nuclear Fuel Generated Between 2010 and 2060-2070)

The Low-Level Radioactive Waste Policy Amendments Act of 1985 assigns the responsibility for the disposal of GTCC LLW from activities licensed by the NRC to the Federal government (DOE), and specifies that such GTCC LLW must be disposed of in a facility licensed by the NRC. There are no facilities currently licensed by the NRC for the disposal of GTCC LLW, and therefore this waste would remain in storage until a disposal facility can be developed. ${ }^{68}$

The programmatic alternatives that recycle SNF would also generate relatively large quantities of LLW compared to open fuel cycle alternatives. As shown on Figure 4.8-4, the Fast Reactor Recycle Alternative, Thermal/Fast Reactor Recycle Alternative, and Thermal Reactor Recycle Alternative (Option 1) would cumulatively generate approximately 1.7 million to 2.9 million $\mathrm{m}^{3}$ (2.2 to 3.8 million $\mathrm{yd}^{3}$ ) of LLW from 2010 to approximately 2060-2070.

\footnotetext{
${ }^{68} \mathrm{DOE}$ is currently preparing an Environmental Impact Statement to evaluate a range of reasonable alternatives for disposal of Greater-thanClass-C low-level radioactive waste (see Section 1.3.7).
} 


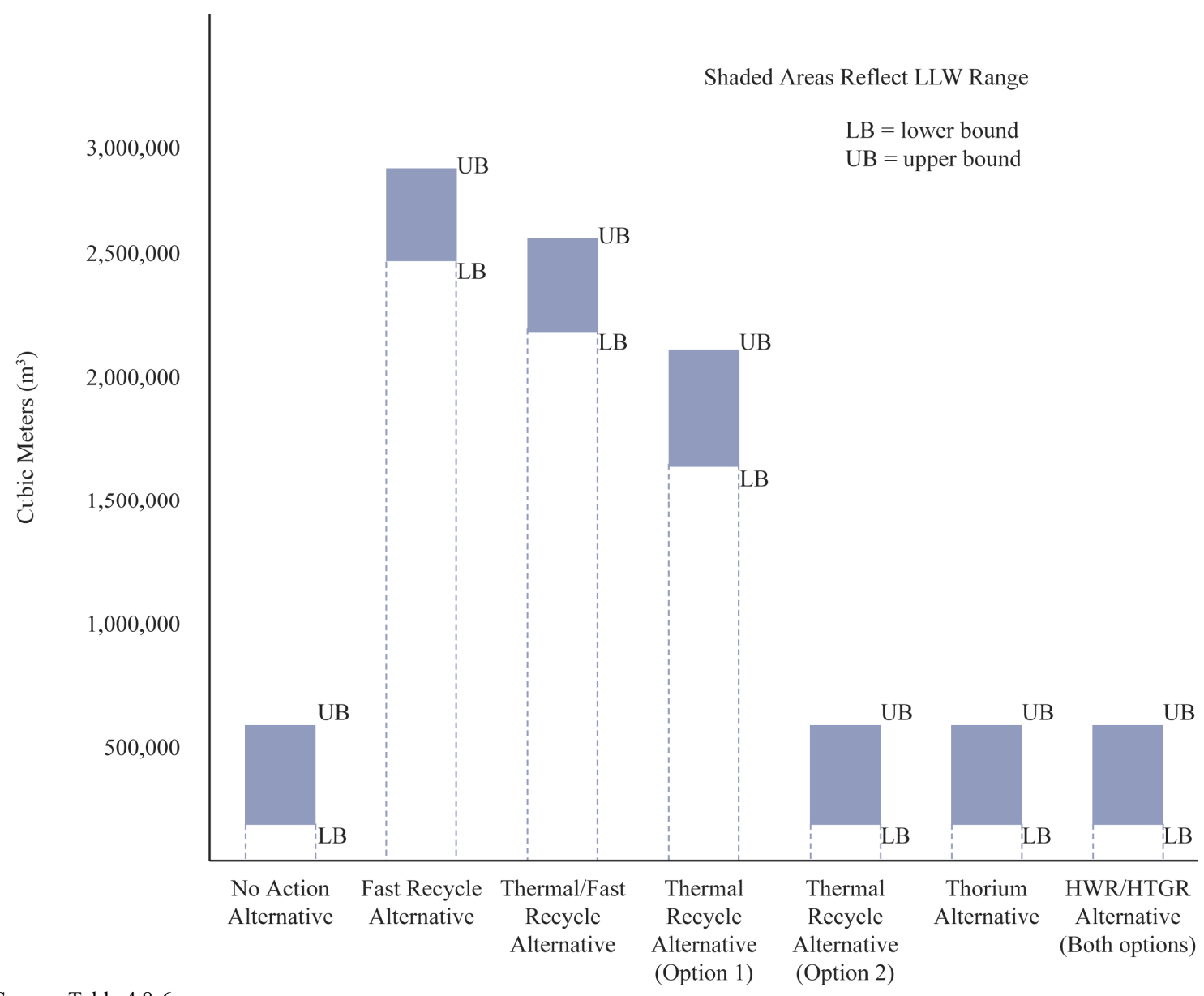

Source: Table 4.8-6

Note: Thermal Reactor Recycle Alternative (Option 3) not included due to unavailability of data

FIGURE 4.8-4-Cumulative Quantities of Low-Level Waste Generated for the 200 Gigawatts Electric Scenario (Based on Recycling Spent Nuclear Fuel Generated Between 2010 and 2060-2070) 


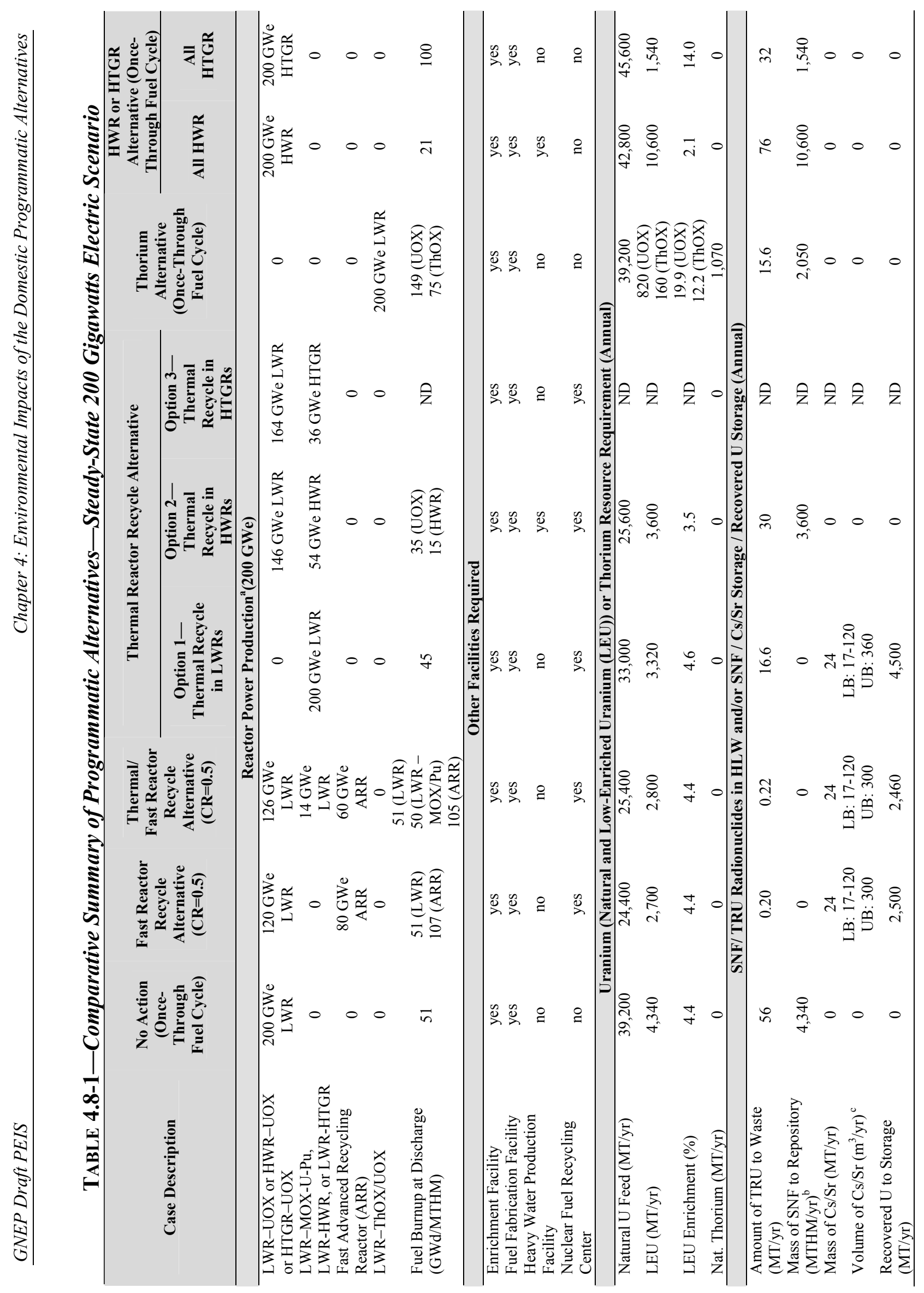




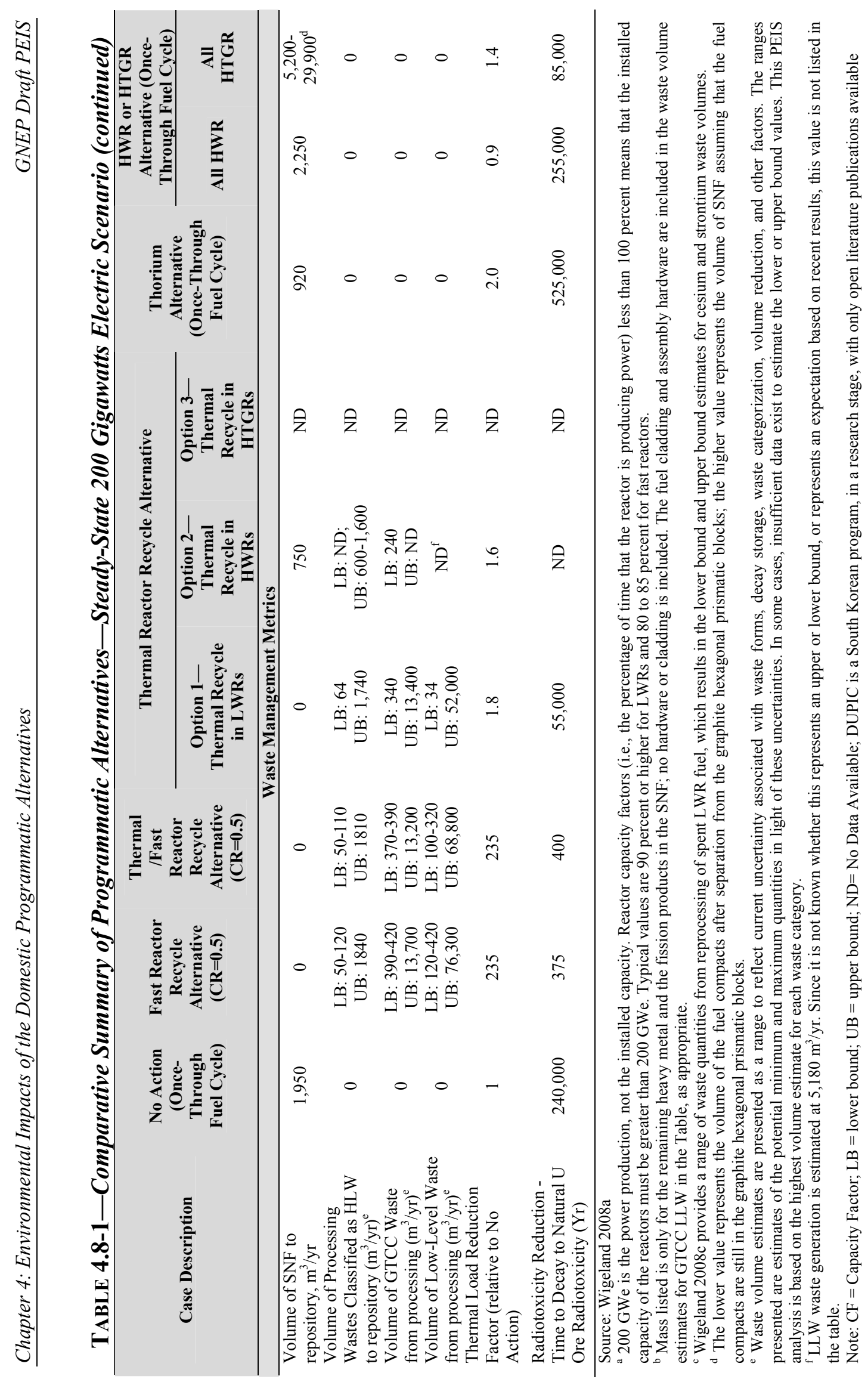




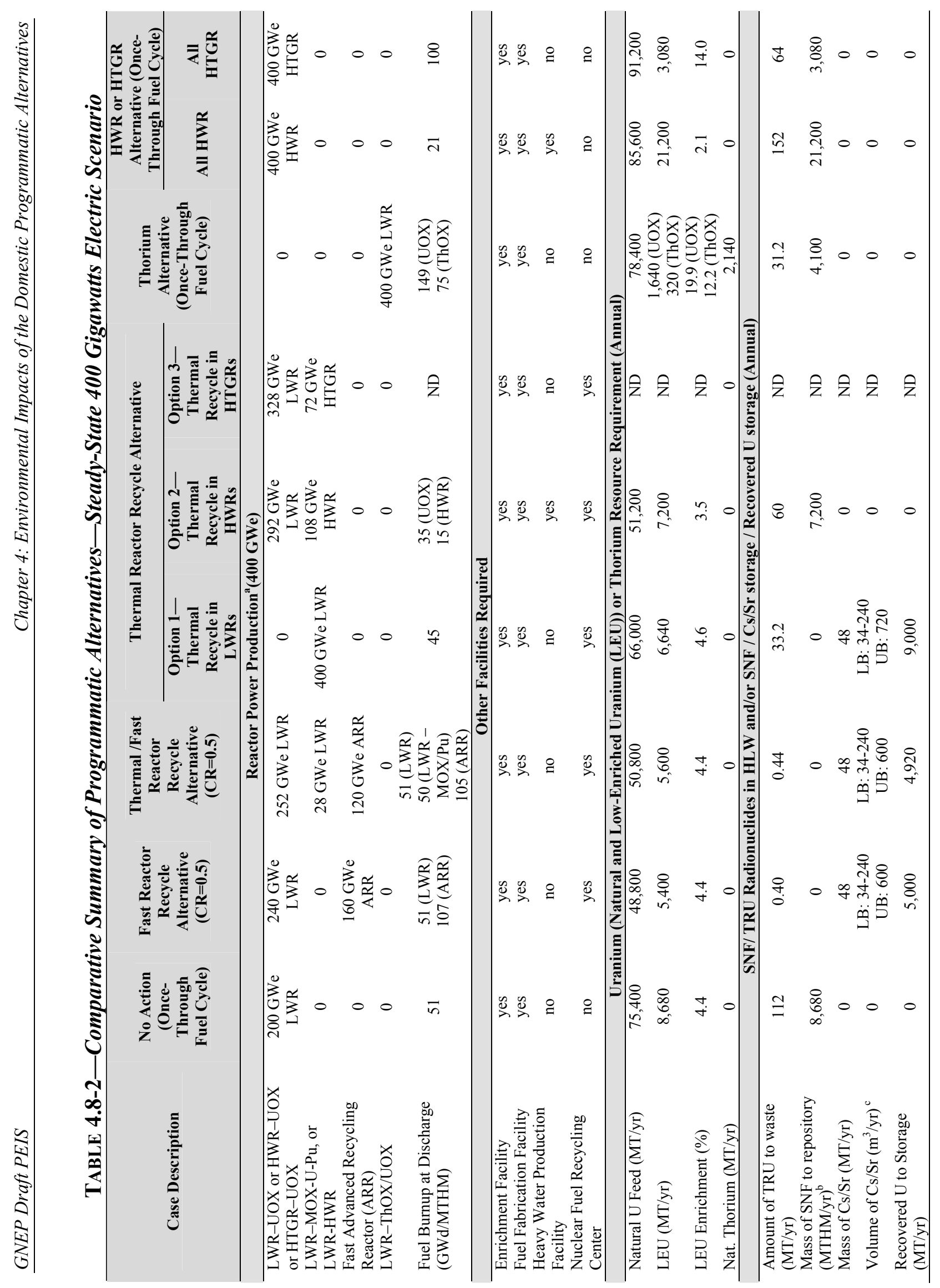




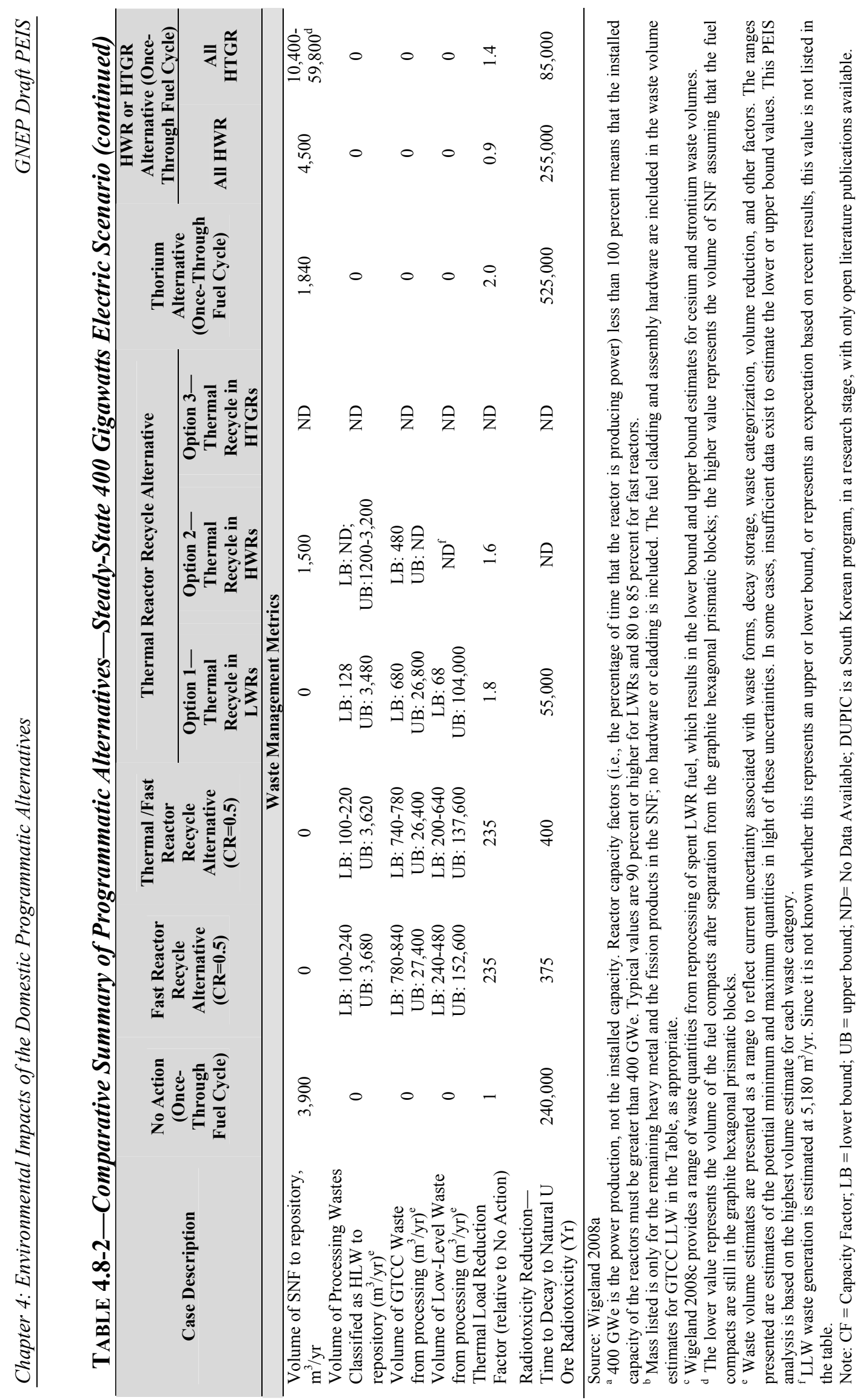




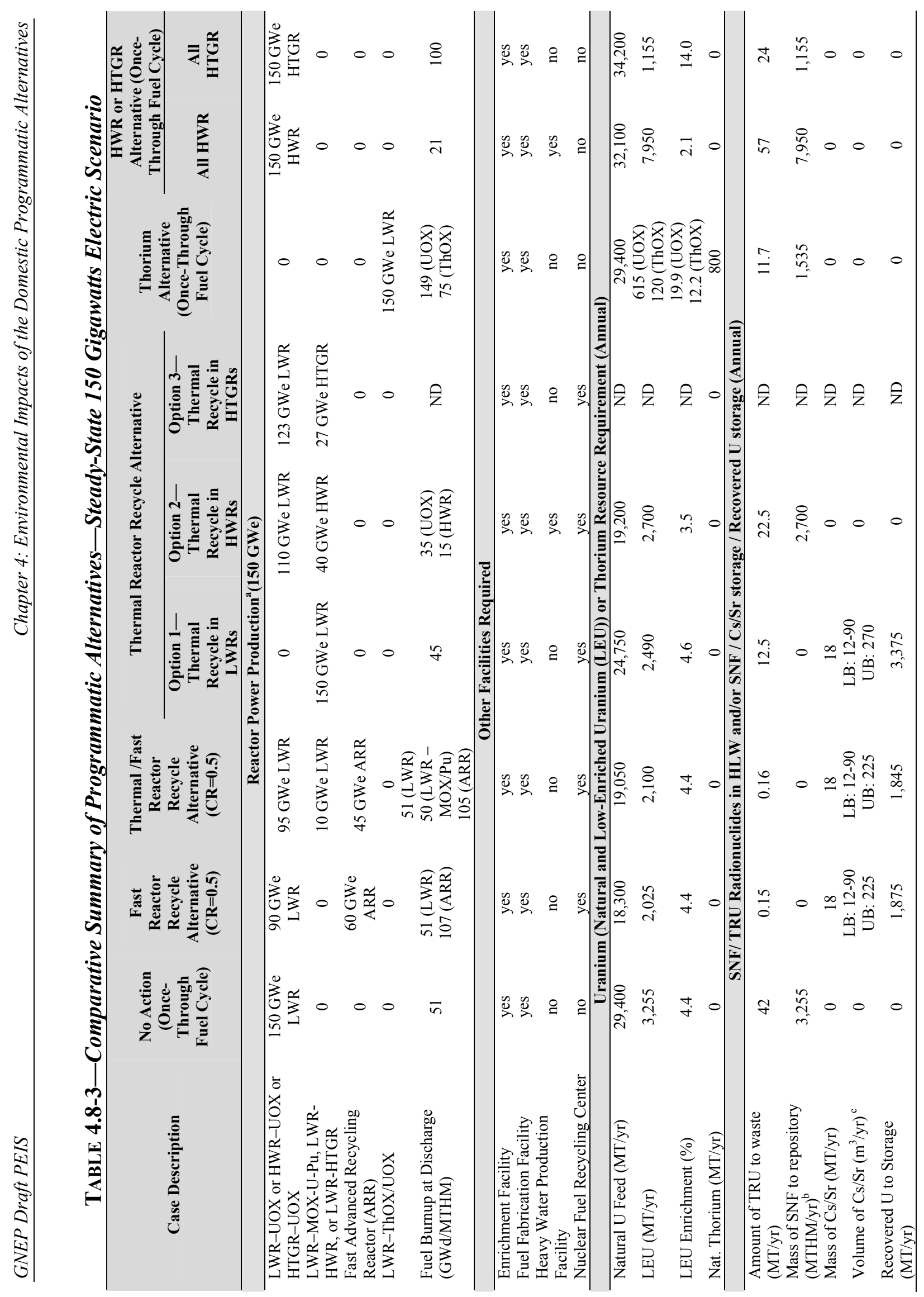




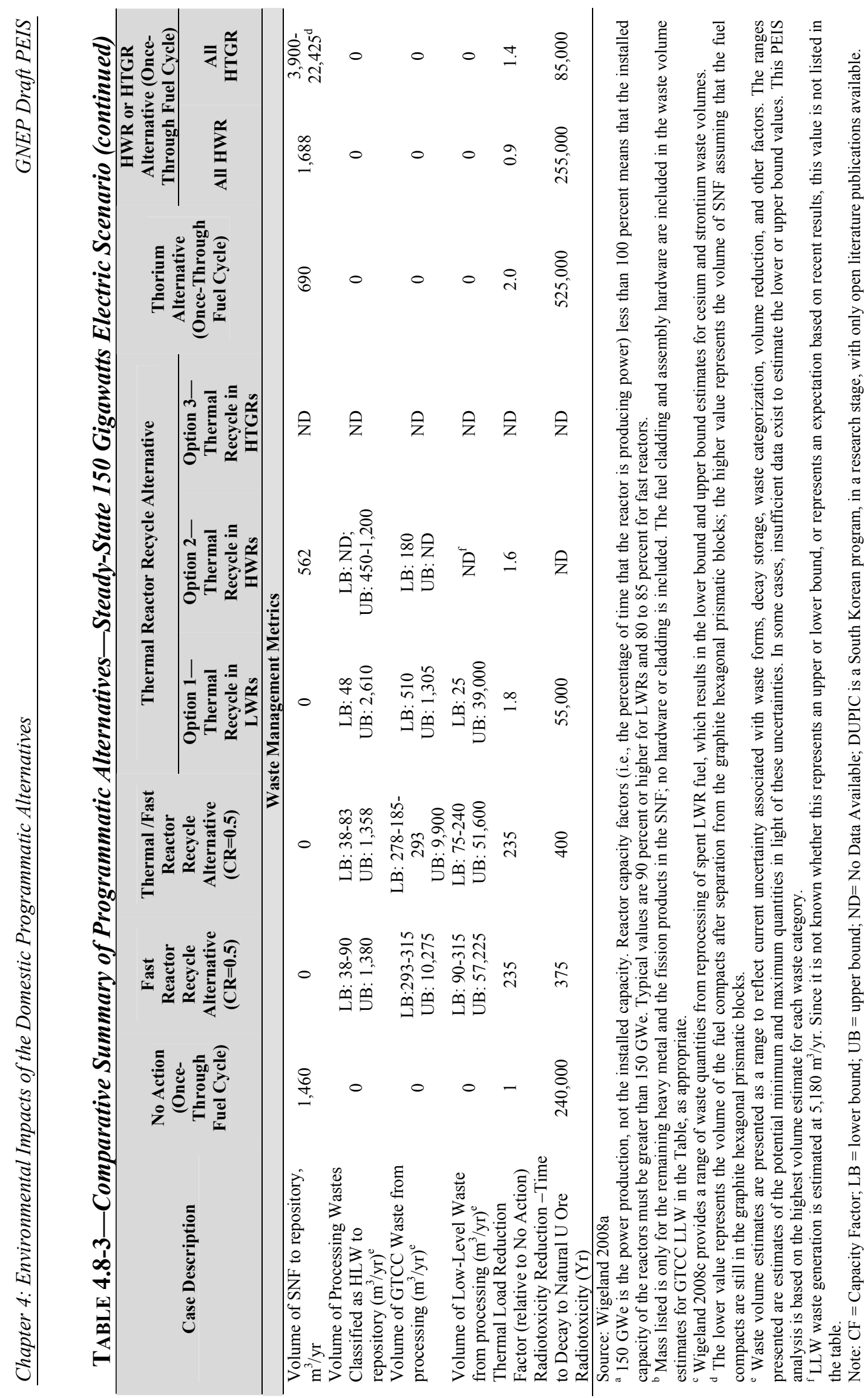




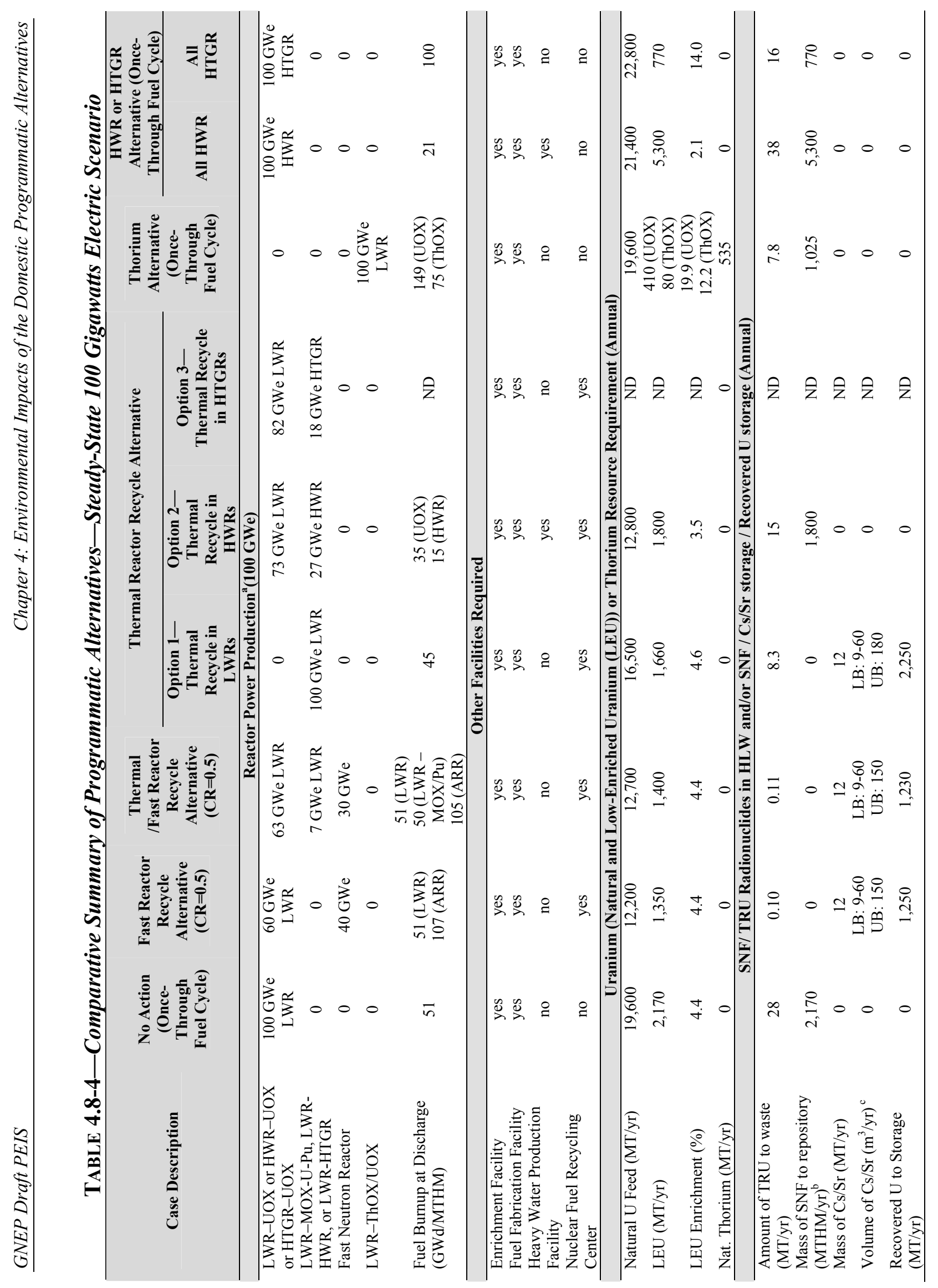




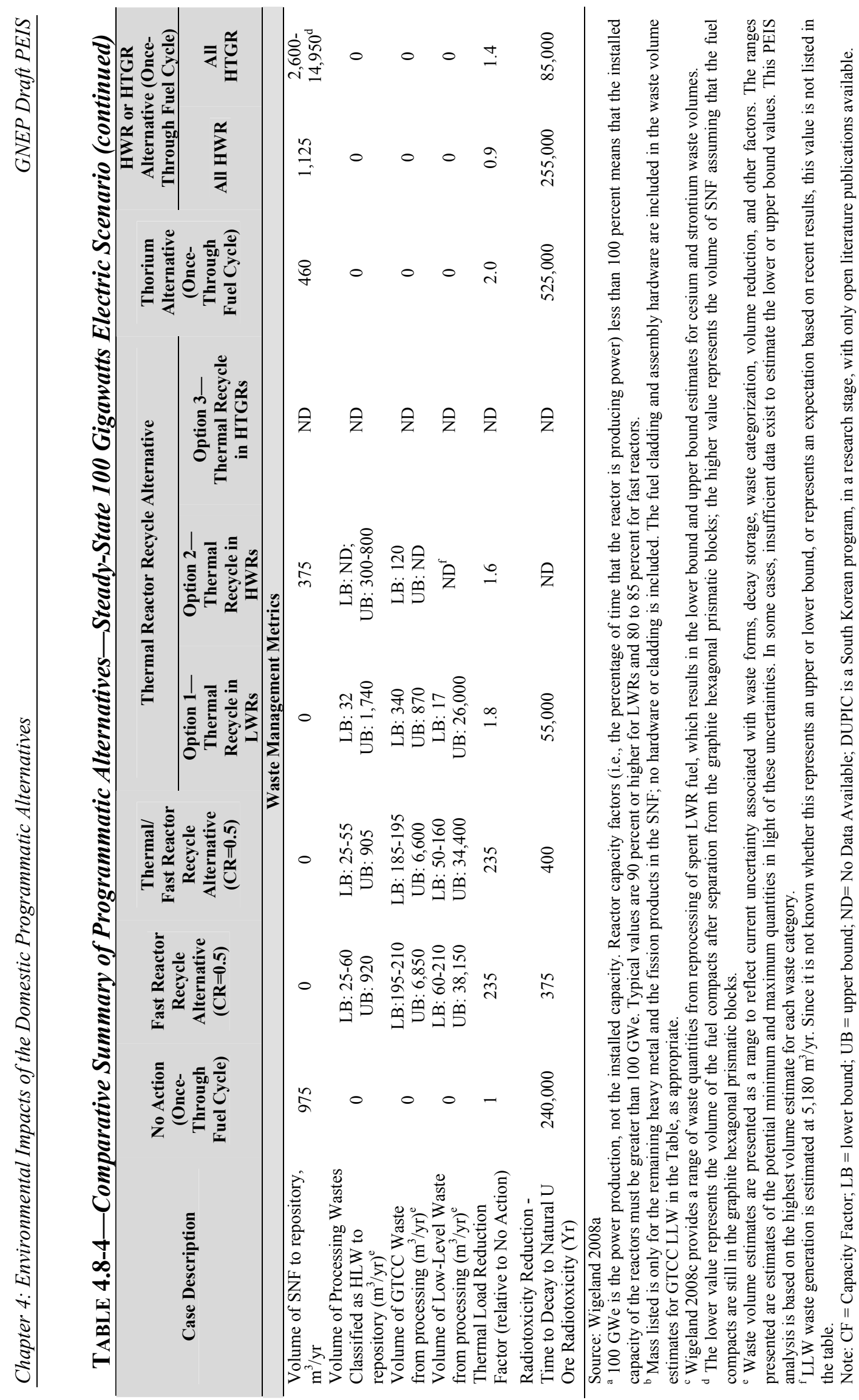




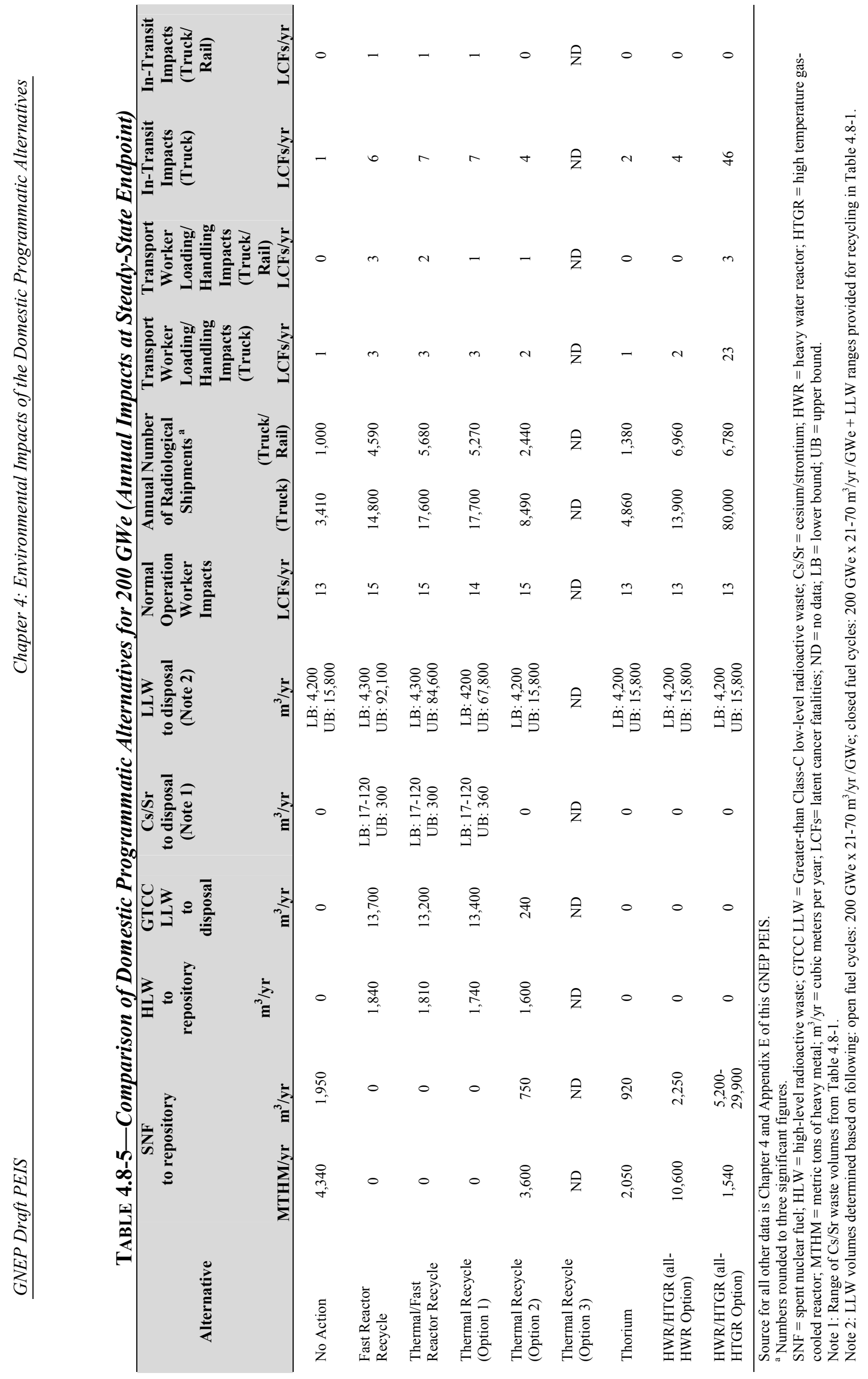




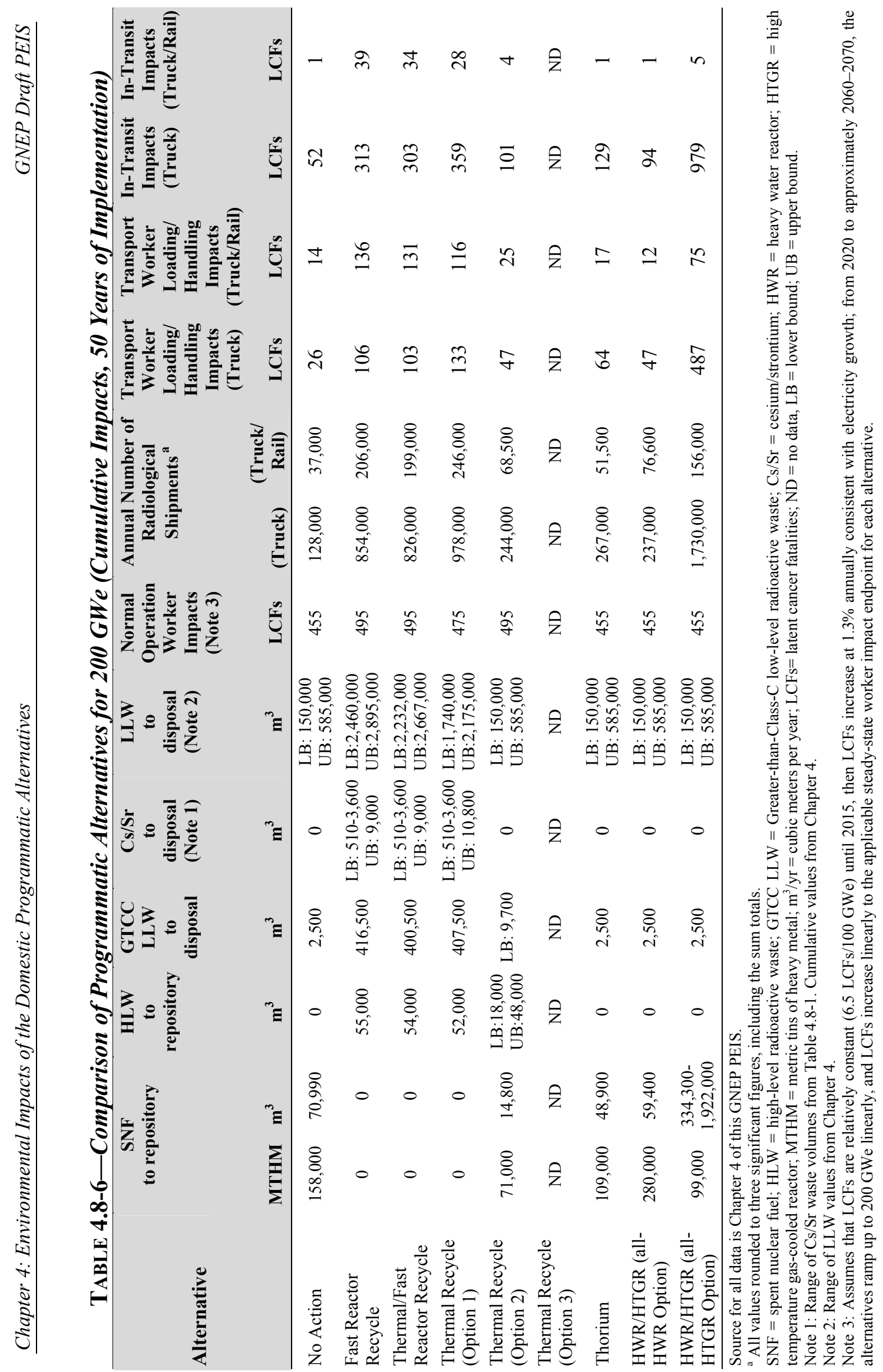




\subsubsection{Human Health}

In this PEIS, DOE estimates the health and safety impacts to workers and the public that could occur during construction and operation of facilities under each domestic alternative. These impacts include those that could occur: 1) to workers from hazards common to similar industrial settings and excavation operations, such as falling or tripping (referred to as industrial hazards); 2) to workers as a result of radiation exposure during their work activities; and 3) to the public from airborne releases of radionuclides. Based on previous experience, DOE concluded that adverse occupational impacts from industrial hazards would be expected to be low, do not offer a means to discriminate among the alternatives, and therefore are not discussed further in this section.

To estimate potential radiological impacts, DOE used actual information from commercial nuclear plants and preliminary design information for other reactors and SNF recycling facilities. Using this data, DOE was able to estimate the total dose to workers and calculate the potential health impacts (expressed in terms of LCFs). For public exposures, DOE used the CAP-88 computer program to model the radiological releases from the facilities and estimate impacts. Because the location of any new facility is unknown, DOE developed six hypothetical sites, based on existing commercial reactor facilities, that provide a range of values for two key parameters - offsite $(50-\mathrm{mi}[80-\mathrm{km}])$ population and meteorological conditions - that directly affect the offsite consequences of any release. The health effects identified in this PEIS analysis are for the operational period (2010 through approximately 2060-2070) only. By reducing the volume, thermal output, or radiotoxicity of SNF and HLW requiring geologic disposal, there is also a potential to reduce long-term health impacts from such disposal. The potential magnitude of the reduction in health impacts would be dependent upon site-specific factors and facility design.

\subsubsection{Impacts to Workers}

All domestic programmatic alternatives could affect worker health through direct radiation exposure. Table 4.8-7 presents annual impacts to the involved workers for each of the domestic programmatic alternatives. As shown in that table, reactor operation doses were assumed to not vary among reactor technologies. ${ }^{69}$ As shown, there would be slightly higher impacts to workers for the closed fuel cycle alternatives than the open fuel cycle alternatives. These higher impacts are due to the additional worker doses associated with recycling. Additionally, the closed fuel cycle alternatives that recycle the highest quantities of spent fuel would result in the highest worker doses.

There also would be impacts to workers due to the storage of spent fuel and/or radioactive wastes. For the No Action Alternative, doses from storing the cumulative quantity of spent fuel that would be generated during the implementation period (approximately 158,000 MTHM of spent fuel) for 50 years at the reactor sites prior to geologic disposal was estimated at 140 person-rem, or less than 3 person-rem per year. Doses from the other open fuel cycle

\footnotetext{
${ }^{69}$ In 2006, the average dose to a radiation worker at a Light Water Reactor in the United States was approximately 190 mrem (NRC 20071). This average dose to a radiation worker falls within the range of doses to radiation workers at Heavy Water Reactors in Canada (Health Canada 2008). This average dose represents the best estimate of the dose to a radiation worker for the other reactor technologies.
} 
alternatives would be expected to vary according to the quantity of spent fuel in storage, and to range from approximately 90 person-rem to 250 person-rem. For the closed fuel cycle alternatives, the doses from the recycling facilities would include storage of radioactive wastes. Doses from such storage were not estimated for the cumulative quantities of wastes that would be generated, but these impacts are expected to be less than or similar to the spent fuel storage impacts, as these wastes would generally produce smaller radiation doses. Therefore, worker doses due to storage are not expected to vary significantly among alternatives, and are expected to be much lower than doses due to reactor operations or recycling facility operations.

TABLE 4.8-7-Annual Impacts to Workers for Domestic Programmatic Alternatives

\begin{tabular}{lccc}
\hline \multicolumn{1}{c}{ Alternative } & $\begin{array}{c}\text { Annual Dose from Reactor } \\
\text { Operations (person-rem) }\end{array}$ & $\begin{array}{c}\text { Annual Dose from Recycling } \\
\text { Facility Operations } \\
\text { (person-rem) }\end{array}$ & $\begin{array}{c}\text { Annual Latent } \\
\text { Cancer Fatalities } \\
\text { from All Facility } \\
\text { Operations }\end{array}$ \\
\hline $\begin{array}{l}\text { No Action } \\
\text { Fast Reactor Recycle }\end{array}$ & 20,900 & 0 & 13 \\
$\begin{array}{l}\text { Thermal/Fast Reactor } \\
\text { Recycle }\end{array}$ & 20,900 & 4,600 & 15 \\
$\begin{array}{l}\text { Thermal Reactor Recycle } \\
\text { (Option 1) }\end{array}$ & 20,900 & 4,400 & 15 \\
$\begin{array}{l}\text { Thermal Reactor Recycle } \\
\text { (Option 2) }\end{array}$ & 20,900 & 3,300 & 14 \\
$\begin{array}{l}\text { Thermal Reactor Recycle } \\
\text { (Option 3) }\end{array}$ & 20,900 & 4,600 & 15 \\
$\begin{array}{l}\text { Thorium } \\
\text { All-Heavy Water }\end{array}$ & No Data & No Data & No Data \\
$\begin{array}{l}\text { Reactor Option } \\
\text { All-High Temperature }\end{array}$ & 20,900 & 0 & 13 \\
Gas-Cooled Reactor & 20,900 & 0 & 13 \\
Option & 20,900 & 0 & 13 \\
\hline${ }^{2}$ Doses from recycling facility operations differ because of worker differences among the closed fuel cycle alternatives. &
\end{tabular}

\subsubsection{Impacts to the Public}

All domestic programmatic alternatives could affect public health through the release of radiological materials to the environment. These radiological materials, which could be ingested through air, water, and food, could cause radiation exposures to the public. The PEIS analyzes the impacts to both the maximally exposed individual (MEI), as well as the 50-mile population surrounding a facility. The PEIS analysis indicates that all of the facilities associated with the programmatic alternatives would be expected to meet all regulatory dose requirements. The analysis indicates that the doses from nuclear fuel recycling facilities would generally cause the highest doses. As a result, the alternatives that involve SNF recycling would be expected to result in the highest doses to the public. However, the PEIS analysis indicates that all alternatives would result in less than 1 LCF per year to the population surrounding the six hypothetical sites. 


\subsubsection{Facility Accident Impacts}

Each of the domestic programmatic alternatives could impact public and worker health in the event of an accident. An accident can be initiated by external or internal events. External initiators originate outside a facility and affect the facility's ability to confine radioactive material. The PEIS presents the

Accident

An unplanned event or sequence of events that results in undesirable consequences. impacts for a range of accidents, at six hypothetical sites, which are expected to be representative of the types of accidents that could occur in future domestic fuel cycle facilities. Analyses of accidents associated with different reactor types (e.g., LWRs, advanced LWRs, advanced recycling reactors, HWRs and HTGRs), different fuel sources (e.g., uranium-oxide, MOX-U-Pu, and thorium-uranium-oxide), and at nuclear fuel recycling facilities are included. For each accident scenario, the PEIS includes the likelihood (frequency) of that accident occurring during each year of reactor or facility operation, the potential consequences to the population and a MEI if the accident were to occur (expressed as LCFs), and the increased risk (frequency multiplied by consequences) of those LCFs.

Table 4.8-8 presents a summary comparison of the estimated frequencies, consequences, and risks for internally initiated accidents for the various fuel cycle facilities. That table includes facility internally initiated accidents with both the highest consequences and the highest risks.

For existing LEU fueled LWRs, the internally initiated accident with the highest consequences to the onsite and offsite populations is the "Interfacing System LOCA" scenario, which is also the highest risk internally initiated accident.

For the MOX-U-Pu LWR, the highest consequence internally initiated accident is the "Interfacing System LOCA," which is also the highest risk internally initiated accident.

For the LEU or MOX-U-Pu fueled ALWR, the highest consequence internally initiated accident is the "Low Pressure Core Melt with Loss of Long-Term Coolant Makeup and Containment Vessel" and the highest risk internally initiated accident is the "Failure of Small Primary Coolant Line Outside Containment."

For the advanced recycling reactor, the highest consequence internally initiated accident is the "Radioactive Argon Processing System Cold Box Rupture," which is also the highest risk internally initiated accident.

For the HWR, the highest consequence internally initiated accident is the "Core Melt with Early Containment Spray System and Containment Failure." The internally initiated HWR accident with the highest risk is the "Core Melt with Containment Spray System and Containment Functioning."

For the HTGR, the highest consequence internally initiated accident is the "Depressurized Conduction Cooldown with Reactor Cavity Cooling System Functioning," which is also the highest risk accident. 
For the nuclear fuel recycling center, the highest consequence internally initiated accident is the "Explosion and Fire in Aqueous Separations," which is also the highest risk internally initiated accident.

Risk values shown in Table 4.8-8 are roughly comparable for most facilities evaluated. However, the off-site population risk for the LEU fueled and MOX-U-Pu fueled LWR facility is relatively high. This is because the risk-dominant event for an LWR facility (as compared to an advanced LWR) is an "Interfacing System LOCA" that has a high consequence because of the unmitigated release. DOE estimates that this accident, which has a probability of occurrence of about 7 in 100 million per year (i.e., frequency of about $7 \times 10^{-8} / \mathrm{yr}$ ), would result in an estimated 40,000 additional latent cancer fatalities to the surrounding population of 8.2 million. These consequences are consistent with the results of the NRC's Severe Accident Risks: An Assessment for Five U.S. Nuclear Power Plants, NUREG-1150 (NRC 1990) and the Surplus Plutonium Disposition Final Environmental Impact Statement, DOE/EIS-0283 (DOE 1999d) when the high population and least favorable meteorological conditions used in this analysis are considered. The higher consequences for this accident are not the result of differences in the fuels relative to other reactors, but are instead the result of the use of high release parameters and an assumption that all containment and filter systems would fail. Therefore, although the consequences of such an accident could be large, to put such an accident into perspective, the probability of the accident should be considered. When probability is taken into account, the collective risk to the offsite population from this accident is about $2 \times 10^{-3}$ to $3 \times 10^{-3}$ latent cancer fatalities per year of operation. For the maximally exposed individual, this accident would result in an increased risk of contracting a fatal cancer of about $7 \times 10^{-8}$ per year of reactor operation.

The highest consequence, internally-initiated accident involving advanced light water (MOX-U$\mathrm{Pu}$ or LEU fueled) reactors is a scenario in which a relief value is opened inadvertently, thereby allowing the reactor to depressurize and the nuclear fuel rods to melt causing a release of radionuclides to the environment. DOE estimated that this accident would result in approximately 200 additional latent cancer fatalities in a population of about 8.2 million. The probability that such an accident would occur is about 1 in 100 million per year (i.e., frequency of $1.1 \times 10^{-8} / \mathrm{yr}$ ). Another useful metric is risk, which takes into account the probability of an accident, and is determined by multiplying the consequences of an accident by the probability of occurrence. The internally-initiated advanced light water reactor accident with the highest risk to the public is a small loss of coolant that would occur outside of the containment structure and would be released into the reactor building. The collective risk to the offsite population for this accident is $6 \times 10^{-6}$ latent cancer fatalities per year of operation. For the maximally exposed individual, this accident would result in an increased risk of contracting a fatal cancer of $1 \times 10^{-8}$ per year of reactor operation.

The accident impacts for the thorium fueled LWR and ALWR are estimated to be the same as the low enriched uranium fueled LWR and ALWR, respectively.

This GNEP PEIS also includes an assessment of externally initiated events and natural phenomena events (see Appendix D). For these accidents, the reactor accident with the highest risk is always the "Unmitigated Beyond Design Basis Earthquake" and the events with the highest consequence are generally the "Unmitigated Beyond Design Basis Earthquake" and 
"Unmitigated Aircraft Crash", which have the same consequences. However, for the LWR, both LEU fueled and MOX-U-Pu fueled, the "Interfacing System Loss of Coolant Accident" consequences are greater than the "Unmitigated Beyond Design Basis Earthquake" or "Unmitigated Aircraft Crash" event consequences. Compared to internal events, risk values shown for external events are relatively high. This reflects the conservative analysis used for this type of event that posits large source terms with no credit for holdup by the containment. Appendix D contains details of the consequence and risk analysis performed for each facility. 


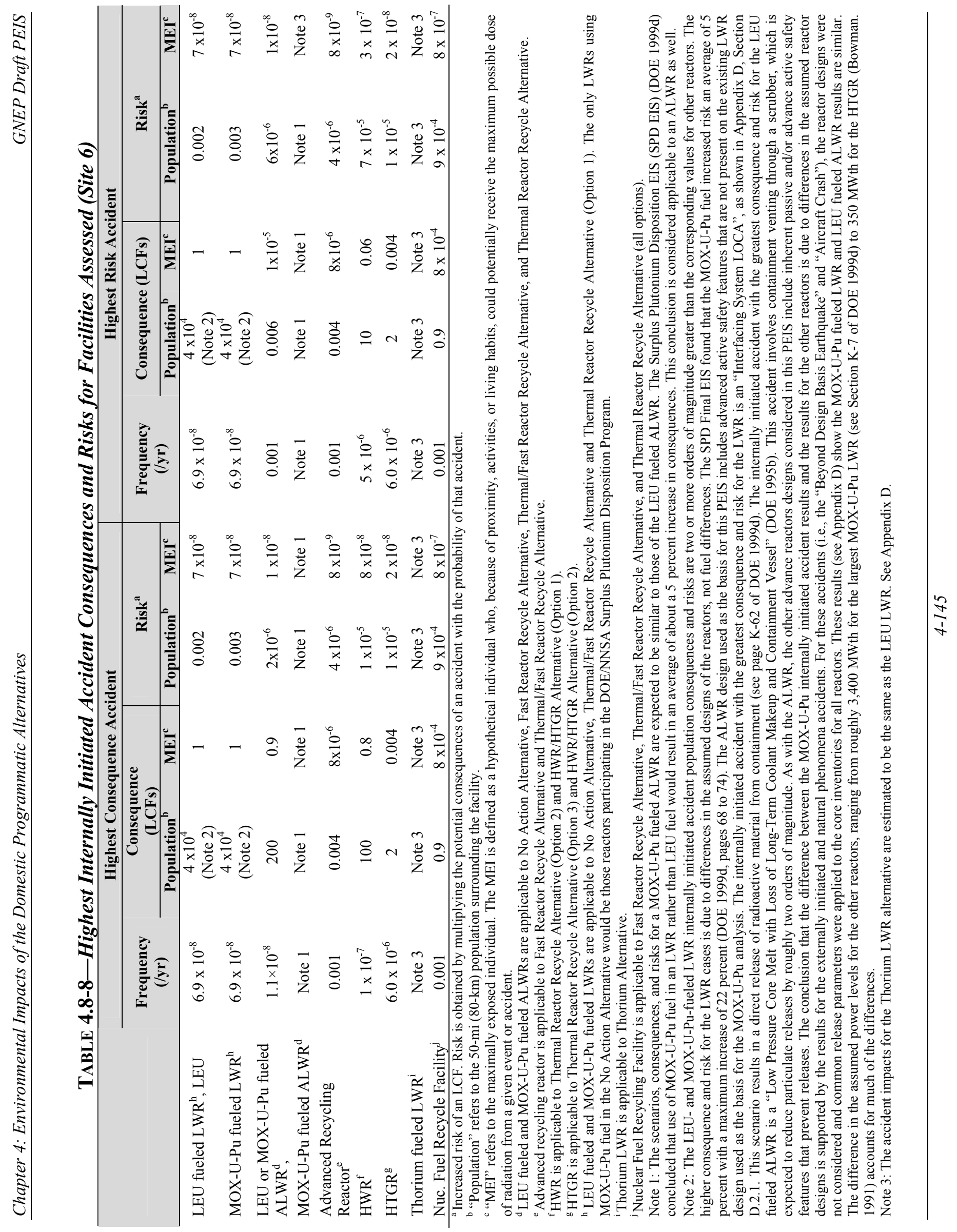




\section{Intentional Destructive Acts}

Whether acts of sabotage or terrorism would occur, and the exact nature and location of the events or the magnitude of the consequences of such acts if they were to occur, are inherently uncertain. Nevertheless, DOE estimated the consequences of intentional destructive acts, such as terrorism events. The analysis of intentional destructive acts differs from the accident analysis presented above in that this analysis is intended to provide an estimate of the consequences of such events, without attempting to determine a frequency associated with intentional destructive acts (DOE assumes an intentional destructive act would occur; i.e., with a probability of 1.0). Table 4.8-8a summarizes the results of the analysis.

Table 4.8-8a—Summary of Bounding Intentional Destructive Acts Scenarios

\begin{tabular}{|c|c|c|c|c|c|c|}
\hline \multirow[t]{2}{*}{ Facility } & \multicolumn{2}{|c|}{$\underline{\text { Offsite Population }}^{\mathrm{a}}$} & \multicolumn{2}{|c|}{$\underline{\text { MEI }^{\mathbf{b}}}$} & \multicolumn{2}{|c|}{$\frac{\text { Noninvolved }}{\text { Worker }^{b}}$} \\
\hline & $\begin{array}{c}\text { Dose } \\
\text { (person-rem) }\end{array}$ & $\begin{array}{l}\text { Latent } \\
\text { Cancer } \\
\text { Fatality }\end{array}$ & $\begin{array}{l}\text { Dose } \\
\text { (rem) }\end{array}$ & $\begin{array}{l}\text { Latent } \\
\text { Cancer } \\
\text { Fatality }\end{array}$ & $\begin{array}{l}\text { Dose } \\
\text { (rem) }\end{array}$ & $\begin{array}{l}\text { Latent } \\
\text { Cancer } \\
\text { Fatality }\end{array}$ \\
\hline $\begin{array}{l}\text { Light Water Reactor- Low Enriched } \\
\text { Uranium, MOX-U-Pu, thorium }\end{array}$ & $6 \times 10^{7}$ & $4 \times 10^{4}$ & $1 \times 10^{5}$ & 1 & $5 \times 10^{5}$ & 1 \\
\hline $\begin{array}{l}\text { Advanced Light Water Reactor- Low } \\
\text { Enriched Uranium or MOX-U-Pu, thorium }\end{array}$ & $8 \times 10^{6}$ & 5,000 & $2 \times 10^{4}$ & 1 & $2 \times 10^{5}$ & 1 \\
\hline Advanced Recycling Reactor & $2 \times 10^{7}$ & $1 \times 10^{4}$ & $5 \times 10^{4}$ & 1 & $4 \times 10^{5}$ & 1 \\
\hline Heavy Water Reactor & $3 \times 10^{6}$ & 2,000 & 7,000 & 1 & $6 \times 10^{4}$ & 1 \\
\hline High Temperature Gas-Cooled Reactor & $1 \times 10^{6}$ & 800 & 3,000 & 1 & $3 \times 10^{4}$ & 1 \\
\hline Nuclear Fuel Recycling Center & $2 \times 10^{5}$ & 100 & 70 & 0.09 & 500 & 0.6 \\
\hline
\end{tabular}

${ }^{\mathrm{a}}$ Increased number of Latent Cancer Fatalities.

${ }^{\mathrm{b}}$ Increased likelihood of a Latent Cancer Fatality.

Note: $\mathrm{MEI}=$ maximally exposed individual

The offsite population impacts in Table 4.8-8a differ among the various reactors due in part to the differences in the amount of electricity produced (power levels) by the reactors. For example, the power level of an LWR is nearly ten times greater than the power level of an HTGR. When power level is considered, offsite population impacts are consistent among the reactors, with the exception of the LWR.

Even after considering differences in power levels, the low enriched uranium and MOX-U-Pu fueled LWR offsite population impacts are still greater than the offsite population impacts for the other reactors. This is because the LWR results are based on an internally-initiated, intentional event in which coolant is lost, whereas the impacts for all other reactors are based on an aircraft crash event. The advanced LWR design includes safety features that make the probability of internal events, such as a catastrophic loss of coolant, remote, but the LWR analyzed does not include these safety features. As a result of the different events and higher release parameters, the LWR offsite population impacts are greater than the impacts for the ALWR. All future reactors are expected to have advanced designs that would make scenarios, such as the catastrophic loss of coolant, remote. 


\subsubsection{Transportation Impacts}

Transportation of SNF and/or HLW and other radiological materials would be required for all alternatives. Once generated at a commercial reactor, SNF would eventually need to be transported to a repository (for the open fuel cycle alternatives) or to a recycling facility (for the closed fuel cycle alternatives). Reusable materials from recycling would be fabricated into new reactor fuel for further use, and non-reusable materials would be transported for disposal as appropriate. Tables 4.8-9 and 4.8-10 identify the number of shipments associated with the programmatic domestic alternatives for 1) all truck and 2) a combination of truck and rail. Because all shipments of fresh nuclear fuel are assumed to occur via truck transport, there is no transportation scenario in which all transportation would occur via rail only. Consequently, the PEIS presents transportation impacts for a combined truck and rail scenario (in tables this scenario is designated as "truck/rail") for the $200 \mathrm{GWe}$ scenario. As shown on those tables, the number of shipments would vary significantly among the alternatives depending upon whether shipments are made via truck (highest number of shipments) or a combination of truck and rail (lowest number of shipments).

The results of the transportation analysis are presented in two sets of tables. The first set of tables (Tables 4.8-11 and 4.8-12) present the impacts associated with handling (loading and inspection) SNF and/or HLW and other radiological materials for the $200 \mathrm{GWe}$ scenario. Impacts are presented in terms of radiological impacts (expressed in person-rem and converted to LCFs using a dose-to-risk conversion factor of $6 \times 10^{-4} \mathrm{LCF}$ per person-rem). Table 4.8-11 presents the handling impacts for truck transport and Table 4.8-12 present the handling impacts for truck and rail transport. The impacts of handling radiological material are independent of the distance that the material would be transported. As such, the handling impacts would be the same whether the material is transported $500 \mathrm{mi}(805 \mathrm{~km}), 2,100 \mathrm{mi}(3,380 \mathrm{~km})$, or any other distance. For this reason, these impacts are presented separately from the in-transit impacts (which are presented in the second set of tables).

The handling of spent fuel and other radiological materials at the various facilities could result in health and safety impacts to workers. The estimated latent cancer fatalities from the handling of truck casks (under the open fuel cycle alternatives) would range from about 26 (No Action Alternative) to 487 (HWR/HTGR Alternative [Option 2-all HTGR]); under the closed fuel cycle alternatives from about 47 (Thermal Reactor Recycle [Option 2]) to about 133 (Thermal Reactor Recycle [Option 1]) (Table 4.8-11). The estimated LCFs from the handling of casks for the combination of truck and rail transport under the open fuel cycle alternatives would range from about 12 (HWR/HTGR Alternative [Option 1-all HWR]) to 75 (HWR/HTGR Alternative [Option 2-all HTGR]), and under the closed fuel cycle alternatives would range from about 25 (Thermal Reactor Recycle [Option 2]) to 136 (Fast Reactor Recycle Alternative) (Table 4.8-12). The estimated number of LCFs would occur in a worker population of several hundred thousand who would be involved in these operations every year. 
TABLE 4.8-9—Total Number of Shipments (50 Years of Implementation), Truck Transit (200 Gigawatts Electric)

\begin{tabular}{|c|c|c|c|c|c|c|c|c|}
\hline Material/Waste & $\begin{array}{c}\text { No } \\
\text { Action }\end{array}$ & $\begin{array}{c}\text { Fast } \\
\text { Reactor } \\
\text { Recycle }\end{array}$ & $\begin{array}{c}\text { Thermal/ } \\
\text { Fast } \\
\text { Reactor } \\
\text { Recycle }\end{array}$ & $\begin{array}{l}\text { Thermal } \\
\text { Reactor } \\
\text { Recycle } \\
\text { Option } 1\end{array}$ & $\begin{array}{l}\text { Thermal } \\
\text { Reactor } \\
\text { Recycle } \\
\text { Option } 2\end{array}$ & $\begin{array}{c}\text { Thorium } \\
\text { Cycle }\end{array}$ & $\begin{array}{c}\text { All- } \\
\text { HWR }\end{array}$ & All-HTGR \\
\hline LWR SNF & 79,000 & 59,000 & 63,000 & 11,000 & 70,500 & 50,500 & 34,000 & 34,000 \\
\hline Fast Reactor SNF & & 35,000 & 27,500 & & & & & \\
\hline $\mathrm{Cs} / \mathrm{Sr}$ waste & & 10,800 & 10,800 & 10,800 & & & & \\
\hline HLW & & 53,600 & 52,700 & 50,700 & 31,000 & & & \\
\hline GTCC LLW & 3,200 & 524,000 & 504,000 & 513,000 & 10,000 & 3,200 & 3,200 & 3,200 \\
\hline LLW & 19,000 & 93,400 & 83,200 & 84,000 & 23,000 & 19,000 & 19,000 & 19,000 \\
\hline $\begin{array}{l}\text { Recovered } \\
\text { Uranium } \\
\text { (Aqueous) }\end{array}$ & & 16,400 & 18,300 & 2,920 & 19,000 & & & \\
\hline $\begin{array}{l}\text { Recovered } \\
\text { Uranium (Metal) }\end{array}$ & & 7,580 & 5,960 & & & & & \\
\hline MOX SNF & & & 8,000 & 195,000 & & & & \\
\hline Thorium SNF & & & & & & 155,000 & & \\
\hline HWR SNF & & & & & 44,840 & & 114,000 & \\
\hline HTGR SNF & & & & & & & & $1,560,000$ \\
\hline Fresh LWR fuel & 26,300 & 19,700 & 21,000 & 3,670 & 23,500 & 16,800 & 11,300 & 11,300 \\
\hline $\begin{array}{l}\text { Transmutation } \\
\text { fuel }\end{array}$ & & 35,000 & 27,500 & & & & & \\
\hline Fresh MOX fuel ${ }^{\mathrm{a}}$ & & & 4,380 & 107,000 & & & & \\
\hline $\begin{array}{l}\text { Fresh Thorium } \\
\text { fuel }\end{array}$ & & & & & & 22,800 & & \\
\hline Fresh HWR fuel & & & & & 21,900 & & 55,600 & \\
\hline Fresh HTGR fuel & & & & & & & & 105,000 \\
\hline $\begin{array}{l}\text { Total Shipments } \\
\text { (Note 2) }\end{array}$ & 128,000 & 854,000 & 826,000 & 978,000 & 244,000 & 267,000 & 237,000 & $1,730,000$ \\
\hline
\end{tabular}

Source: Appendix E

${ }^{a}$ The MOX spent fuel was assumed to be transported in DOE spent fuel canisters, with a capacity of 0.75 MTHM per container. Fresh MOX fuel was assumed to be transported in Class B containers as described in NRC 2005c. These containers have a capacity of 1.37 MTHM per shipment and are not appropriate for the shipment of spent fuel. Considering this, there would be approximately 83 percent more spent fuel shipments than fresh for the same amount of fuel.

Note 1: Thermal Reactor Recycle Alternative (Option 3) not included due to unavailability of data.

Note 2: Total shipments rounded to nearest thousand. 
TABLE 4.8-10-Total Number of Shipments (50 Years of Implementation), Truck and Rail Transport ${ }^{a}$ (200 Gigawatts Electric)

\begin{tabular}{|c|c|c|c|c|c|c|c|c|}
\hline Material/Waste & $\begin{array}{c}\text { No } \\
\text { Action }\end{array}$ & $\begin{array}{c}\text { Fast } \\
\text { Reactor } \\
\text { Recycle }\end{array}$ & $\begin{array}{c}\text { Thermal/F } \\
\text { ast } \\
\text { Reactor } \\
\text { Recycle } \\
\end{array}$ & $\begin{array}{l}\text { Thermal } \\
\text { Reactor } \\
\text { Recycle } \\
\text { Option } 1 \\
\end{array}$ & $\begin{array}{l}\text { Thermal } \\
\text { Reactor } \\
\text { Recycle } \\
\text { Option } 2 \\
\end{array}$ & $\begin{array}{c}\text { Thorium } \\
\text { Cycle }\end{array}$ & $\begin{array}{l}\text { All- } \\
\text { HWR }\end{array}$ & $\begin{array}{c}\text { All- } \\
\text { HTGR }\end{array}$ \\
\hline LWR SNF & 6,320 & 4,720 & 5,280 & 880 & 5,640 & 4,040 & 2,720 & 2,720 \\
\hline Fast Reactor SNF & & 7,000 & 5,500 & & & & & \\
\hline $\mathrm{Cs} / \mathrm{Sr}$ waste & & 2,150 & 2,150 & 2,150 & & & & \\
\hline HLW & & 10,700 & 10,540 & 10,100 & 6,200 & & & \\
\hline GTCC LLW & 630 & 103,000 & 101,000 & 101,000 & 2,000 & 630 & 630 & 630 \\
\hline LLW & 3,800 & 18,900 & 16,600 & 17,000 & 4,500 & 3,800 & 3,800 & 3,800 \\
\hline $\begin{array}{l}\text { Recovered } \\
\text { Uranium } \\
\text { (Aqueous) }\end{array}$ & & 3,200 & 3,660 & 584 & 3,800 & & & \\
\hline $\begin{array}{l}\text { Recovered } \\
\text { Uranium (Metal) }\end{array}$ & & 1,520 & 1,190 & & & & & \\
\hline MOX SNF & & & 178 & 4,330 & & & & \\
\hline Thorium SNF & & & & & & 3,450 & & \\
\hline HWR SNF & & & & & 996 & & 2,500 & \\
\hline HTGR SNF & & & & & & & & 33,000 \\
\hline $\begin{array}{l}\text { Total Rail } \\
\text { Shipments }\end{array}$ & 10,800 & 151,000 & 146,000 & 136,000 & 23,000 & 11,900 & 9,650 & 40,200 \\
\hline $\begin{array}{l}\text { Fresh LWR } \\
\text { fuel }^{\text {a }}\end{array}$ & 26,300 & 19,700 & 21,000 & 3,670 & 23,500 & 16,800 & 11,300 & 11,300 \\
\hline $\begin{array}{l}\text { Transmutation } \\
\text { fuel }^{\text {a }}\end{array}$ & & 35,000 & 27,500 & & & & & \\
\hline Fresh MOX fuel $^{\mathrm{a}}$ & & & 4,380 & 107,000 & & & & \\
\hline $\begin{array}{l}\text { Fresh Thorium } \\
\text { fuel }^{\mathrm{a}}\end{array}$ & & & & & & 22,800 & & \\
\hline Fresh HWR fuel ${ }^{\text {a }}$ & & & & & 21,900 & & 55,600 & \\
\hline Fresh HTGR fuel ${ }^{\mathrm{a}}$ & & & & & & & & 105,000 \\
\hline $\begin{array}{l}\text { Total Truck } \\
\text { Shipments }\end{array}$ & 26,300 & 54,700 & 52,900 & 110,000 & 45,400 & 39,600 & 66,900 & 116,000 \\
\hline $\begin{array}{l}\text { Total Shipments } \\
\text { (Rail + Truck) } \\
\text { (Note 2) }\end{array}$ & 37,000 & 206,000 & 199,000 & 246,000 & 68,500 & 51,500 & 76,600 & 156,000 \\
\hline
\end{tabular}

Source: Appendix E

${ }^{a}$ All shipment of fresh nuclear fuel is assumed to be via truck transport.

Note 1: Thermal Reactor Recycle Alternative (Option 3) not included due to unavailability of data

Note 2: Total shipments rounded to three significant figures. 
TABLE 4.8-11-Summary of Handling Impacts for 50 Years of Implementation, All Programmatic Domestic Alternatives (Truck Transit)-200 Gigawatts Electric

\begin{tabular}{|c|c|c|c|c|c|c|}
\hline & \multicolumn{6}{|c|}{ Handling Impacts } \\
\hline & \multicolumn{2}{|c|}{ Loading } & \multicolumn{2}{|c|}{ Inspection } & \multicolumn{2}{|c|}{ Total } \\
\hline & person-rem & LCFs & person-rem & LCFs & person-rem & LCFs \\
\hline No Action & 36,700 & 22 & 6,430 & 4 & 43,200 & 26 \\
\hline Fast Reactor Recycle & 160,000 & 96 & 17,900 & 11 & 177,000 & 106 \\
\hline $\begin{array}{l}\text { Thermal/Fast Reactor } \\
\text { Recycle }\end{array}$ & 155,000 & 93 & 17,200 & 10 & 172,000 & 103 \\
\hline $\begin{array}{l}\text { Thermal Reactor } \\
\text { Recycle, Option } 1\end{array}$ & 198,000 & 119 & 23,800 & 14 & 222,000 & 133 \\
\hline $\begin{array}{l}\text { Thermal Reactor } \\
\text { Recycle, Option } 2\end{array}$ & 67,100 & 40 & 11,100 & 7 & 78,100 & 47 \\
\hline Thorium & 91,700 & 55 & 15,800 & 9 & 107,000 & 64 \\
\hline HWR & 67,500 & 40 & 11,700 & 7 & 79,100 & 47 \\
\hline HTGR & 693,000 & 416 & 119,000 & 71 & 812,000 & 487 \\
\hline
\end{tabular}

Source: Appendix E

Note 1: LCFs rounded to nearest whole number.

Note 2: Thermal Reactor Recycle Alternative (Option 3) not included due to unavailability of data.

TABLE 4.8-12 - Summary of Handling Impacts for 50 Years of Implementation, All Programmatic Domestic Alternatives (Truck and Rail Transit)_200 Gigawatts Electric

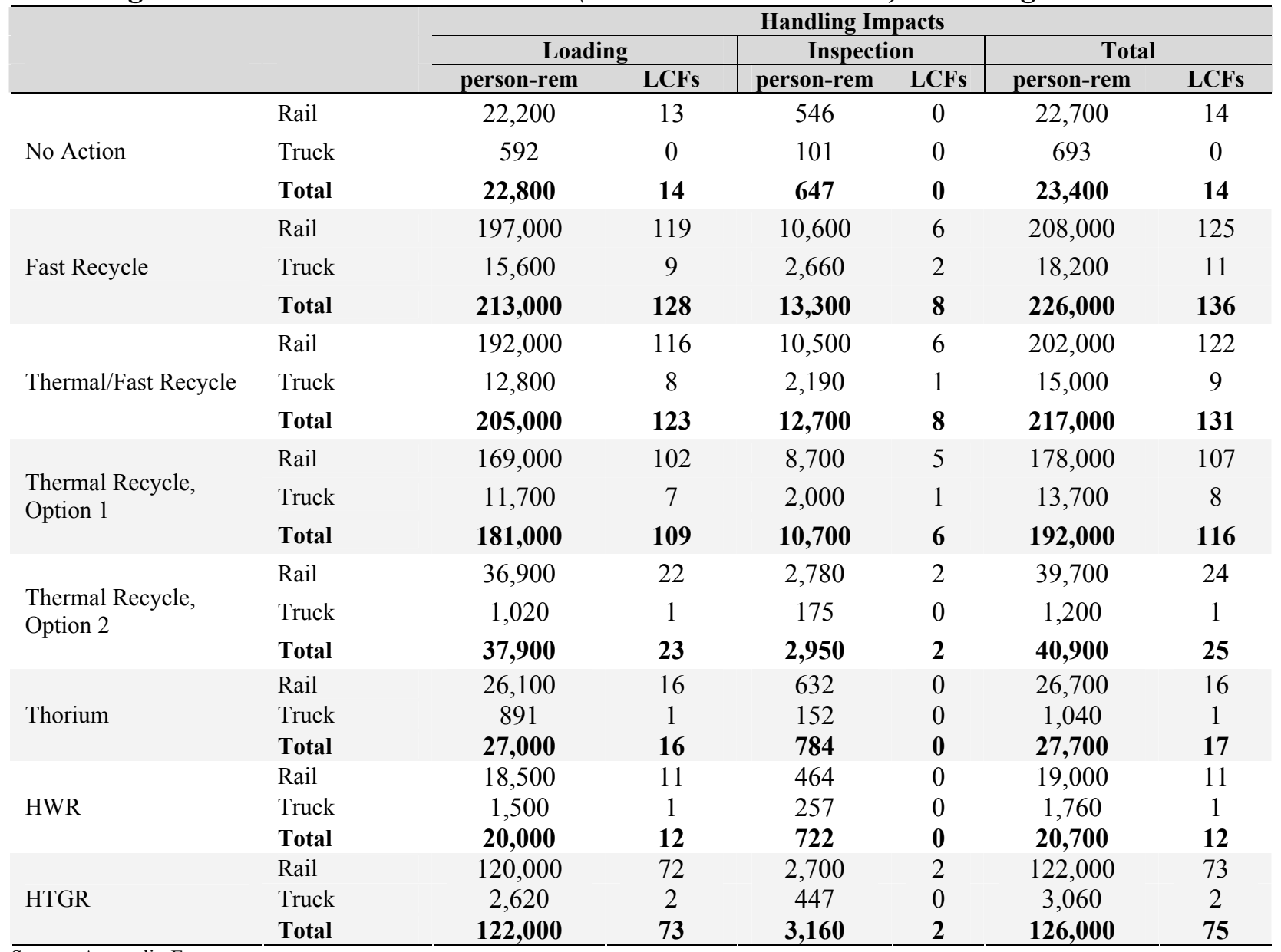

Source: Appendix E

Note 1: All LCFs rounded to nearest whole number

Note 2: Thermal Reactor Recycle Alternative (Option 3) not included due to unavailability of data 
The in-transit impacts are shown in Tables 4.8-13 (truck transit) and 4.8-14 (truck and rail transit) for the programmatic domestic fuel cycle alternatives. Unlike handling impacts, the intransit impacts are dependent on the distance that material would be transported. For each radiological shipment, the in-transit impacts presented in Tables 4.8-13 and 4.8-14 are assumed to be $2,100 \mathrm{mi}(3,380 \mathrm{~km})$ of transport. The impacts presented in Tables 4.8-13 and 4.8-14 would vary based on a variety of factors, including the distance that the radiological material would be transported, the specific routes that would be utilized, the population densities along those routes, and others. Of these factors, the transport distance is considered to be the most significant factor. DOE has analyzed how the impacts would change as a function of distance traveled. Although the in-transit impacts are not exactly "linear" (i.e., twice the impacts for twice the distance transported), that is a close approximation. Consequently, if the radiological material were transported $500 \mathrm{mi}(805 \mathrm{~km})$, all of the in-transit impacts presented in Tables 4.8-13 and 4.8-14 could be estimated by multiplying the values in those tables by $0.24(500 / 2,100)$.

TABLE 4.8-13-Summary of In-Transit Transportation Impacts for 50 Years of Implementation, All Programmatic Domestic Alternatives (Truck Transit) 200 Gigawatts Electric

\begin{tabular}{|c|c|c|c|c|c|c|c|c|}
\hline & \multicolumn{4}{|c|}{ In Transit Impacts (Note 1) } & \multirow{3}{*}{$\begin{array}{c}\text { Total } \\
\text { Incident-Free } \\
\text { LCFs }\end{array}$} & \multicolumn{3}{|c|}{ Accident Impacts } \\
\hline & \multicolumn{2}{|c|}{ Crew } & \multicolumn{2}{|c|}{ Public } & & & & \\
\hline & $\begin{array}{c}\text { person- } \\
\text { rem }\end{array}$ & LCFs & $\begin{array}{c}\text { person- } \\
\text { rem }\end{array}$ & LCFs & & $\begin{array}{l}\text { person- } \\
\text { rem }\end{array}$ & LCFs & Fatalities \\
\hline No Action & 14,900 & 9 & 71,300 & 42 & 52 & 1.37 & 0 & 11 \\
\hline $\begin{array}{l}\text { Fast Reactor } \\
\text { Recycle }\end{array}$ & 151,000 & 90 & 371,000 & 222 & 313 & 51.6 & 0 & 73 \\
\hline $\begin{array}{l}\text { Thermal/Fast } \\
\text { Reactor Recycle }\end{array}$ & 146,000 & 87 & 360,000 & 216 & 303 & 41.0 & 0 & 71 \\
\hline $\begin{array}{l}\text { Thermal Reactor } \\
\text { Recycle, Option } 1\end{array}$ & 157,000 & 94 & 441,000 & 265 & 359 & 2.97 & 0 & 84 \\
\hline $\begin{array}{l}\text { Thermal Reactor } \\
\text { Recycle, Option } 2\end{array}$ & 31,000 & 19 & 137,000 & 82 & 101 & 1.23 & 0 & 21 \\
\hline Thorium & 36,300 & 22 & 179,000 & 107 & 129 & 0.881 & 0 & 23 \\
\hline HWR & 26,600 & 16 & 130,000 & 78 & 94 & 0.597 & 0 & 20 \\
\hline HTGR & 271,000 & 162 & $1,360,000$ & 816 & 979 & 0.592 & 0 & 149 \\
\hline
\end{tabular}

Source: Appendix E

Note 1: LCFs rounded to nearest whole number.

Note 2: Thermal Reactor Recycle Alternative (Option 3) not included due to unavailability of data 
TABLE 4.8-14-Summary of In-Transit Transportation Impacts for 50 Years of Implementation, All Programmatic Domestic Alternatives (Truck and Rail Transit) 200 Gigawatts Electric

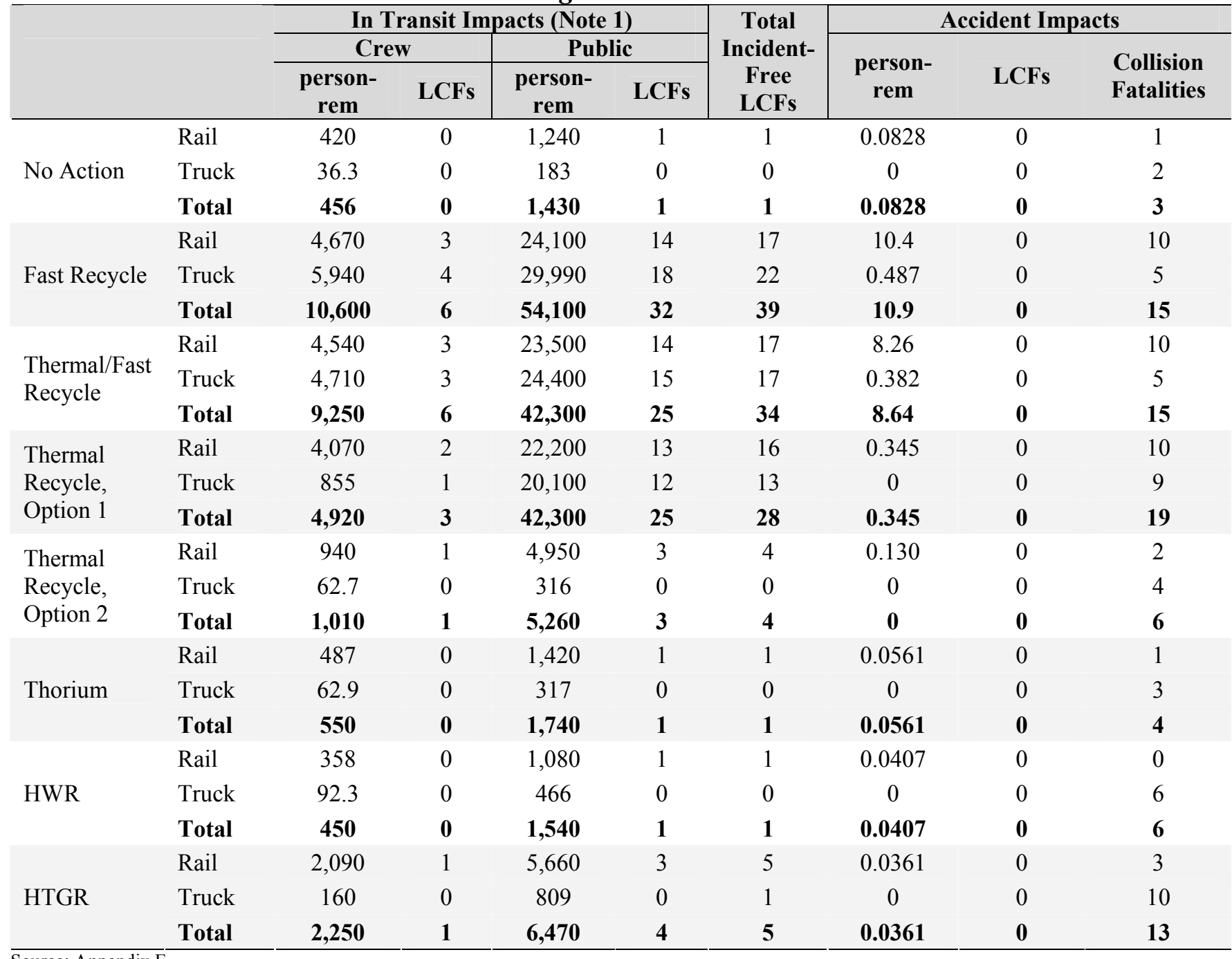

Source: Appendix E

Note 1) LCFs rounded to nearest whole number.

Note 2) Thermal Reactor Recycle Alternative (Option 3) not included due to unavailability of data.

As shown on Tables 4.8-13 and 4.8-14, there are potentially significant differences in impacts depending upon whether transportation occurs via truck or a combination of truck and rail. For all alternatives, truck and rail transport would result in smaller impacts than truck transport. This is due to the fact that there would be many fewer transportation shipments for truck and rail compared to truck only. This would directly affect the distance traveled and exposures to both crews and the public. Additionally, the number of accident fatalities (collisions) would be smaller for the truck and rail transport.

For truck transport, the HWR/HTGR Alternative (Option 2-all HTGR) would have the highest transportation impacts (incident-free and traffic fatalities), primarily due to the large number of shipments of spent fuel (more than 1.7 million shipments, as shown in Table 4.8-9). This relatively large number of shipments is caused primarily by the large volume of spent fuel 
associated with the graphite blocks in HTGRs. The Fast Reactor Recycle Alternative, Thermal/Fast Reactor Recycle Alternative and Thermal Reactor Recycle Alternative (Option 1) would have the next highest impacts.

As shown on Table 4.8-14, for truck and rail transport, the Fast Reactor Recycle Alternative, Thermal/Fast Reactor Recycle Alternative, and Thermal Reactor Recycle Alternative (Option 1) would have the highest expected transportation impacts. For truck and rail transport, these closed fuel cycle alternatives would have the most shipments, the highest handling impacts, and the highest in-transit impacts.

The reason why the HWR/HTGR Alternative (Option 2-all HTGR) would not have the highest transportation impacts for truck and rail transport is because the packaging of spent nuclear fuel potentially could allow for a reduction in the number of spent fuel shipments by a factor of approximately 45 (from 1,560,000 truck shipments of spent fuel to 33,000 rail shipments of spent fuel). By contrast, the transportation impacts of the closed fuel cycle alternatives (with the exception of the Thermal Reactor Recycle Alternative-Option 2) are dominated by Greaterthan-Class-C low-level radioactive waste shipments. When packaged for rail transportation, these waste shipments, while reduced compared to truck transport, would remain large.

\subsubsection{Potential Impacts on Design or Operation of a Future Geologic Repository}

The GNEP PEIS alternatives could have an impact on the design or operation of a future geologic repository by reducing the radiotoxicity, heat load, or volume of SNF and HLW. These reductions have the potential to decrease the regulatory uncertainty involved in predicting the long-term performance of such a repository, or to increase the public acceptability of geologic disposal, so that adequate disposal capacity can be found for future commercial nuclear waste inventories. These three areas are discussed below.

Potential Reduction in Radiotoxicity: SNF and HLW are toxic, primarily due to the presence of radioactive isotopes. A common way to describe the hazard of SNF and HLW is through the concept of "radiotoxicity," which is a measure of the adverse health effects caused by a radionuclide due to its radioactivity. Radiotoxicity varies greatly from one isotope to another because radiotoxicity is determined by the type and energy of radiation emitted during radioactive decay. In general, the radiotoxicity from a given isotope is a function of the nature of its radioactive decay and the amount (mass) of the isotope present in the SNF or HLW. Radiotoxicity is a function of time, in part, because the radiotoxicity from any isotope will be reduced to negligible levels as radioactive materials decay over time, although the decay process can require millions of years for some isotopes. One measure of the potential hazard of SNF and HLW is to compare the time required for the radiotoxicity of these radioactive materials to be reduced to that of the natural uranium ore ${ }^{70}$ used as the source material for the nuclear fuel. Such comparisons should not be construed to indicate that such wastes would not need to continue to be isolated in a geologic repository once the radiotoxicity of the wastes is comparable to natural uranium ore. Although such a comparison is informative, it should be noted that radiotoxicity is not a regulatory standard relevant to the disposal of SNF and HLW. Current U.S. regulatory

\footnotetext{
${ }^{70}$ Natural uranium is not without its own health hazards (see Section 4.1.1).
} 
standards that apply to SNF and HLW disposal are based on the estimated peak dose rate for the maximally reasonably exposed individual for the applicable time period. This estimated peak dose rate is based upon a site-specific performance assessment that takes into account the characteristics of the materials to be disposed, the repository characteristics, and the geologic setting.

Figure 4.8-5 shows the radiotoxicity of the various types of spent nuclear fuel and/or high-level radioactive waste relative to uranium ore as a function of time. Table 4.8-1 includes the time required for the spent nuclear fuel and high-level radioactive waste to decay to the radiotoxicity of natural uranium ore for each programmatic alternative.

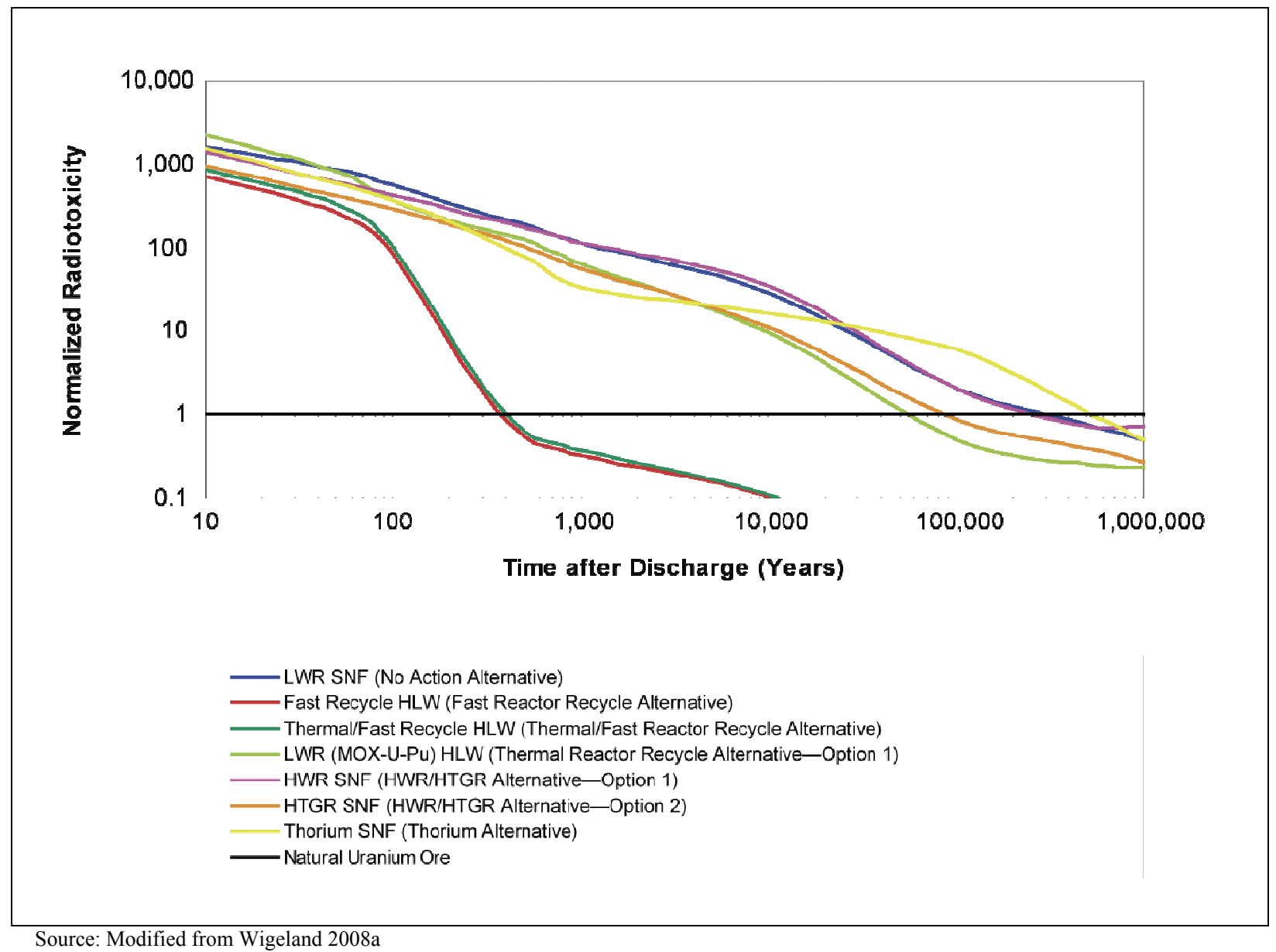

FIGURE 4.8-5-Radiotoxicity of Spent Nuclear Fuel and/or High-Level Waste Over Time

As shown, SNF from LWRs remains more radiotoxic than uranium ore for about 240,000 years. Alternatives that do not recycle SNF and transmute the long-lived actinides (with either fast reactors or thermal reactors) would generate waste that would remain more radiotoxic than the original natural uranium ore for approximately 85,000 to 525,000 years (Wigeland 2008a). Implementation of the Thermal Reactor Recycle Alternative (Option 1) could reduce the time period for which the radiotoxicity of the radioactive materials exceeds that of uranium ore to approximately 55,000 years, while implementation of the Fast Reactor Recycle Alternative or the 
Thermal/Fast Reactor Recycle Alternative could further reduce the longer-lived transuranic isotopes remaining in the radioactive wastes. Removal of uranium and transuranic elements via recycling could reduce the time period for which the radiotoxicity of the waste exceeds that of uranium ore from between approximately 85,000 and 525,000 years to perhaps less than one thousand years, depending on the amount of uranium and transuranic loss from all processes that eventually becomes part of the wastes destined for disposal.

Potential Reduction in Thermal Load: The thermal load from the SNF and HLW is caused by decay heat. Thermal load is a potentially relevant measure for geologic disposal because a repository would have thermal limits on both the engineered structures and the repository environment. For purposes of analysis in the PEIS, the thermal load reduction factor on a repository is 1.0 for the No Action Alternative, and the relative thermal load reduction of the action alternatives is compared to this value. For example, the high-level radioactive waste associated with the Fast Reactor Recycle Alternative and the Thermal/Fast Reactor Recycle Alternative would reduce the thermal loading on a repository by a factor of approximately 235 for the same total electricity generation (i.e., these alternatives could generate 235 times as much electricity as the No Action Alternative before producing the same thermal loading on a repository) (Table 4.8-1). However, other factors, including the specific geologic conditions of the repository, could affect the total amount of SNF and/or HLW that could be disposed of in the repository. With respect to the other action alternatives, DOE estimates that thermal load reduction factors would range between 0.9 and 2.0. While most alternatives show an improvement compared to the No Action Alternative, recycling light water reactor and fast reactor spent fuel would achieve the most significant improvements in repository thermal loading.

Potential Reduction in Volume: The volume of radioactive materials requiring geologic disposal can be determined by the mass of material to be disposed, times the concentration of waste in the final waste form, adjusted to reflect the volume of surrounding waste packaging. For example, one potential waste form is borosilicate glass, for which there is a maximum radionuclide concentration that would dissolve into the glass, which in turn would determine the maximum waste loading. The glass would then be put into a waste package, the design of which is yet to be determined for a future geologic repository.

As shown in Table 4.8-1, the annual volume of spent nuclear fuel generated by the open fuel cycle alternatives (e.g., No Action Alternative, HWR/HTGR Alternative) is much greater than that of the closed fuel cycle alternatives (e.g., Fast Recycle Alternative, Thermal/Fast Recycle Alternative) in which the spent fuel is recycled. In contrast, the closed fuel cycle alternatives would generate HLW requiring geologic disposal, and GTCC LLW, neither of which is generated by operations related to the open fuel cycle alternatives. The Department recognizes that the volume of high-level radioactive waste could be reduced by employing advanced methods to separate long-lived fission products (such as technetium and iodine) from potentially useful products (such as uranium and transuranic elements) and potentially from cesium and strontium.

Sensitivity of Analysis to Assumptions Related to Separations and Recovery Efficiency: In this PEIS analysis, the assumption has been made that for cases where SNF is recycled, the loss 
of desired materials into the waste streams is 0.1 percent. The losses can occur in a separations plant or during fuel fabrication. The sensitivity of the waste management metrics to a higher loss rate was evaluated (see Wigeland 2008b for details on this evaluation). A summary of that analysis is as follows:

- The volume of HLW is dominated by the fission products. The addition of a small amount of plutonium, such as would occur if the loss rate were 1 percent instead of 0.1 percent, would make little difference. This would also be true for GTCC LLW, as this is dominated by the cladding and assembly hardware from the SNF, along with other wastes from processing and operations. If the loss of transuranics was included in waste streams that would be designated LLW, such loss could increase the volume and/or activity of LLW, and could also increase the volume of GTCC LLW. This is because LLW requires very low concentrations of alpha radiation emitters, including plutonium (10 CFR 61.55). Higher concentrations of alpha radiation emitters would result in the waste being reclassified as GTCC LLW.

- Additional transuranic loss to the waste stream would increase the decay heat and have a negative impact on the thermal load.

- Higher losses to the HLW would significantly affect the radiotoxicity, since the reduction in radiotoxicity is mainly due to the much lower transuranic content. It can be estimated that if the loss of transuranics to the HLW were 1.0 percent instead of 0.1 percent, the increased radiotoxicity would delay the time at which the waste would decay to natural uranium ore (Wigeland 2008b).

\subsubsection{Major Differences in Impacts for Other Growth Scenarios}

For purposes of assessing environmental impacts, a 1.3 percent growth rate (approximately $200 \mathrm{GWe}$ of nuclear electricity capacity in approximately 2060-2070) was used as the reference scenario for this PEIS. This section discusses the major differences in environmental impacts for other growth rates (zero, 0.7, and 2.5 percent), which are included in this PEIS. Both construction and operation impacts are discussed below compared to the reference scenario.

Construction: Construction impacts would vary in direct proportion to any change in growth rate compared to the reference scenario. For example, in order to achieve a capacity of $400 \mathrm{GWe}$, twice as much capacity would need to be constructed for all fuel cycle alternatives. This would disturb twice as much land, produce twice the socioeconomic impacts, and use twice the amount of water. For the closed fuel cycle alternatives, twice as much recycling capacity would be required.

Operation: On a strictly annual basis, operational impacts would also vary in direct proportion to any change in the growth rate. At steady-state, operating twice as much capacity would produce twice as much electricity; would generate twice as much SNF; produce twice as much waste; and use twice as much water. However, cumulative, non-linear differences would occur over time as each alternative is implemented. This is due to the fact that the alternatives would all ramp-up from the same starting point (approximately $100 \mathrm{GWe}$ in 2010). Consequently, the cumulative impacts of growth annualized at 2.5 percent annually until 2060-2070 would be less than twice as much. 
Following the ROD for this PEIS, any facilities that might be constructed and operated would undergo decontamination and decommissioning (D\&D) at the end of their useful life. Because such D\&D is not likely to occur for many decades, there are many external factors (such as regulatory requirements and technology developments) that could affect the ultimate impacts associated with D\&D. The analysis that follows is based on an extrapolation of the environmental impacts that resulted from the recent D\&D of the 900-MWe Maine Yankee PWR plant. That nuclear power plant underwent a successful decommissioning from 1997 to 2005 with all plant structures removed to 3 feet below grade and the site restored to stringent clean-up standards. Maine Yankee was one of the first large U.S. commercial power reactors to complete decommissioning.

\subsubsection{Decontamination and Decommissioning of the Maine Yankee Reactor Plant}

As a point of reference, this section presents a summary of the impacts that resulted from the D\&D of the Maine Yankee reactor plant. This information was summarized from the Maine Yankee Decommissioning Experience Report, prepared by New Horizon Scientific, LLC for the Electric Power Research Institute and Maine Yankee in 2005 (Maine Yankee 2005).

Cleanup Level: Release criteria of $10 \mathrm{mrem} / \mathrm{yr}$ through all pathways and $4 \mathrm{mrem} / \mathrm{yr}$ through the groundwater pathway were the required clean-up levels. At these levels, the equipment, structures and portions of the facility and site containing radioactive contaminants would be removed or decontaminated to a level that would permit the property to be released for unrestricted use once the removal/cleanup work was finished. The site was cleaned-up to a level significantly lower than these criteria.

Area: Yankee Maine was located on an 820-acre (332-ha) site in Wiscasset, Maine. Approximately 179 acres (72 ha) were licensed by the NRC. Following D\&D, 200 acres (80 ha) of plant property were donated for conservation and environmental education, and 400 acres (160 ha) of plant property were transferred for economic development. Following D\&D, the NRC amended Maine Yankee's license, reducing the land under the license from approximately 179 acres (72ha) to the 12-acre (5-ha) Independent Spent Fuel Storage Installation, located on Bailey Point Peninsula.

Employment: Peak employment during D\&D was approximately 300 persons.

Radiological impacts to workers: The total radiation dose was estimated to be approximately 525 person-rem, which is less than 50 percent of the exposure limit in the decommissioning Generic EIS.

Nonradiological impacts to workers: The project completed over 2 million safe work hours without a lost time accident. Overall, the project completed approximately 5.4 million hours with a recordable incident rate of approximately 2.3 per 200,000 hours worked. 
Wastes: Approximately 198 tons of waste total.

- Approximately 75 tons of non-radioactive waste were generated as a result of the D\&D process. The largest component of this waste stream was concrete, with the remaining waste in the form of metals, recyclables, and construction and demolition debris. These non-radioactive wastes were shipped to appropriate state landfill site for disposal, in a manner similar to any other industrial site demolition. Approximately 80,000 cubic feet of asbestos waste was also removed.

- Approximately 123 tons of LLW were generated as a result of the D\&D of this facility. LLW at Maine Yankee included contaminated metal, concrete, dry active waste, soil and components of the Nuclear Steam Supply System (reactor vessel, steam generators, pressurizer, and reactor coolant pumps). This waste was packaged on-site and then shipped out-of-state to the EnergySolutions/Barnwell disposal site, a waste processor, for sorting and ultimate disposition. Of this, approximately 72 tons was concrete, 36 tons was soil, and 15 tons was components and commodities. Approximately 90 percent of the LLW was classified as "Class A," which has the lowest amount of radioactivity. Class C includes irradiated metal and some of the reactor vessel internals. Class $\mathrm{C}$ is the highest classification that can go into a licensed near-surface disposal facility. Maine Yankee has a small amount of GTCC LLW. This waste mainly consists of internal parts of the reactor vessel that will be segmented and removed. The plant's SNF, as well as its GTCC LLW (irradiated steel removed from the plant's reactor vessel), are stored in dry cask storage units at Maine Yankee's Independent Spent Fuel Storage Installation (ISFSI). The ISFSI was constructed during the decommissioning project.

\section{Transportation:}

- Number of truck shipments (nonradiological): 1,900

- Number of truck shipments (radiological): 330

- Number of train shipments (nonradiological): 80

- Number of train shipments (radiological): 160 


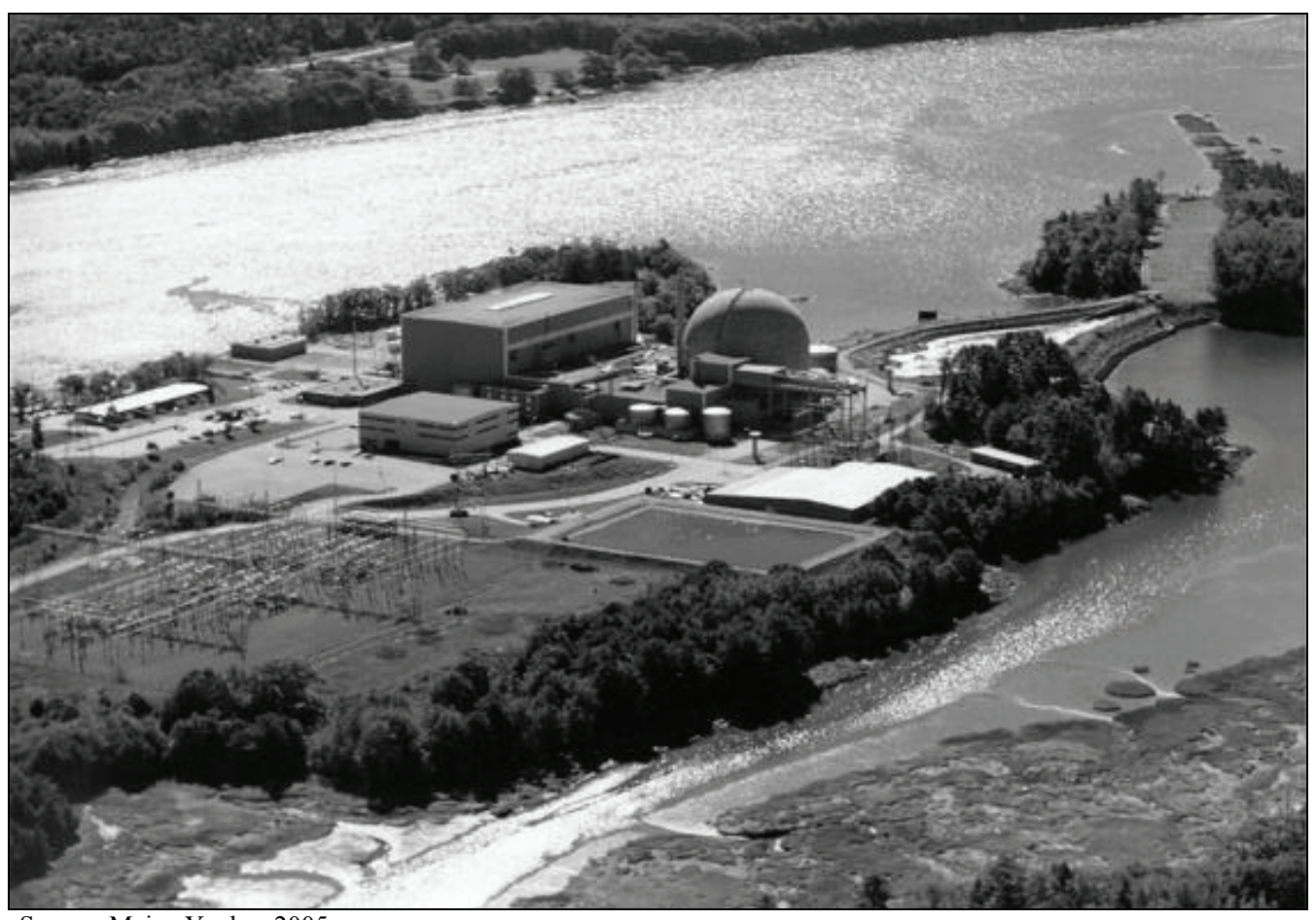

Source: Maine Yankee 2005

FIGURE 4.9-1—Maine Yankee Before Decontamination and Decommissioning

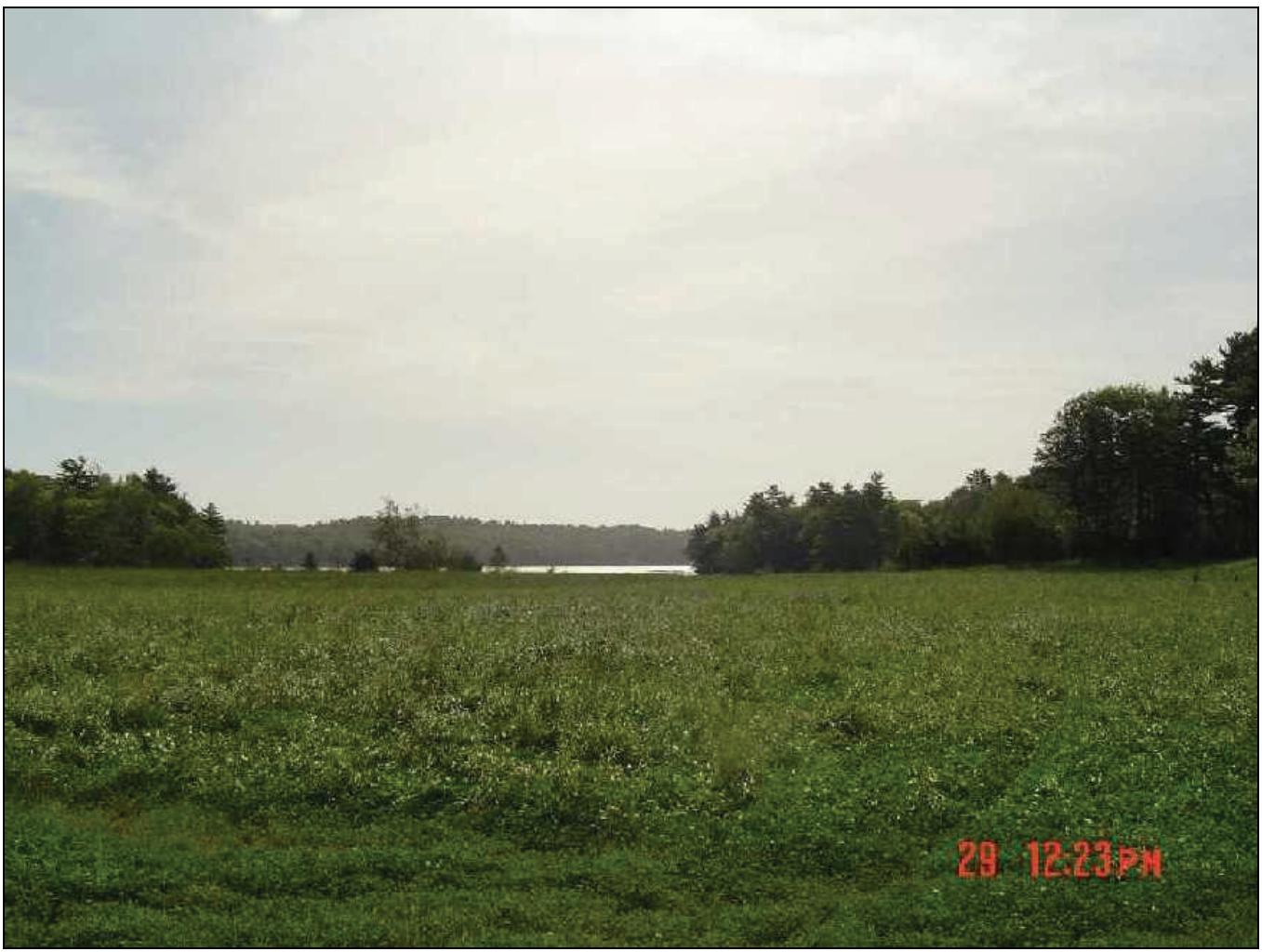

Source: Maine Yankee 2005

FIGURE 4.9-2-Maine Yankee After Decontamination and Decommissioning 


\subsubsection{Decontamination and Decommissioning Impacts Related to the Programmatic Environmental Impact Statement Alternatives}

D\&D is not expected to be a major discriminator among the PEIS alternatives because, on a national level, each of the alternatives would require similar resource commitments to achieve D\&D. This conclusion is based on the fact that D\&D impacts would largely be a function of the size of the facility associated with each alternative. In determining square footages of these facilities, the reactor facilities needed to produce $200 \mathrm{GWe}$ are expected to dominate the outcome. Although there are likely to be differences in the various reactor designs (i.e., LWRs, HWRs, advanced recycling reactors, and HTGRs), producing $200 \mathrm{GWe}$ with any of the reactor technologies should not significantly change the total square footage requirements for D\&D. Moreover, the fact that several of the alternatives (namely the Thermal/Fast Reactor Recycle Alternative and the Thermal Reactor Recycle Alternative [Options 1, 2, and 3]) would require SNF separation facilities should not change the overall conclusion, as the square footage of these facilities would be insignificant compared to the total square footage associated with reactor plant electricity production. This section presents a broad analysis of the D\&D impacts that would be applicable to each of the alternatives.

Land Use: D\&D activities should result in clean-up to applicable regulatory limits.

Employment: Peak employment during each D\&D job ${ }^{71}$ would be localized and could employ approximately 300 persons. On a national level, the D\&D employment would be less than construction employment and would be insignificant.

Radiological impacts to workers: The total radiation dose is estimated to be less than 1,000 person-rem for each D\&D job. Statistically, this worker dose would translate into an LCF risk of 0.6 for each D\&D job, meaning that $1 \mathrm{LCF}$ would be incurred for every 1.6 D\&D jobs. Assuming approximately 200 D\&D jobs, approximately 120 LCFs could result from all D\&D jobs.

Wastes: Assuming approximately 198 tons of waste would be generated from each D\&D job, approximately 59,400 tons of waste would be generated from all D\&D activities (for D\&D of $200 \mathrm{GWe}$ of new capacity and $100 \mathrm{GWe}$ of existing capacity). Of this, approximately 36,000 tons would be LLW. Most of this waste could likely be disposed of in a licensed shallow land burial facility. A small percentage of the LLW could be GTCC LLW. GTCC LLW from nuclear reactors is produced as a result of normal operations and becomes available for disposal during facility decommissioning. The majority of GTCC LLW generated by nuclear reactors is activated metal. This waste consists of components internal to the reactor that have become radioactive from exposure to a neutron flux, resulting in neutron absorption. It has been estimated that approximately $28,711 \mathrm{ft}^{3}\left(813 \mathrm{~m}^{3}\right)$ of GTCC LLW would be generated when the existing 104 commercial LWRs undergo D\&D (SNL 2007). Scaling those results to account for production of $200 \mathrm{GWe}$ of electricity via nuclear reactors, it is estimated that approximately $88,287 \mathrm{ft}^{3}\left(2,500 \mathrm{~m}^{3}\right)$ of GTCC LLW could result from D\&D of new and existing reactors. Disposal of GTCC LLW would occur at a facility yet to be determined by the DOE.

\footnotetext{
${ }^{71}$ As a point of reference and for purposes of the discussions in this section, a "D\&D job" is assumed to be similar in size, scope, and complexity to the D\&D of the Maine Yankee Reactor Plant (Section 4.9.1). D\&D of any major nuclear facility is considered a D\&D job.
} 
In addition to the wastes discussed above for reactors, D\&D of the facilities associated with a nuclear fuel recycling center would produce the following wastes:

- Demolition debris/Sanitary Waste (concrete, asphalt, wood, etc.)

- Recoverable Metals (steel, iron, etc.)

- LLW

- GTCC LLW

- Hazardous Waste

- Mixed Waste (small amounts)

HLW would not be anticipated unless a SNF separation facility could not successfully remove the HLW from equipment and other items used in the treatment and packaging of HLW or had not shipped all packaged HLW. Fuel fabrication facilities would not generate any HLW. These waste types are based on the assumption that all product and waste material would have been removed (e.g., SNF, product, packaged HLW wastes, etc.). With this assumption, there is no obvious difference in the types of waste that would result from D\&D of an LWR SNF separation facility, fuel fabrication facility, or fast reactor SNF separation facility (NRC 2008d, NEA 2002).

Transportation: Transportation activities could range from approximately 300 radiological material truck shipments per D\&D job to almost 2,000 non-radioactive material truck shipments. Train shipment would be less. On a national level, these shipments would be insignificant.

\subsection{UNAVOIDABLE ADVERSE IMPACTS}

As presented earlier in this chapter, all of the alternatives would result in unavoidable adverse impacts. Based on the continued use, and potential growth, of nuclear power, all alternatives would impact land (approximately 600,000 acres [243,000 ha] could be disturbed to support new facilities for $200 \mathrm{GWe}$ ); use water (approximately 3 to 6 billion gal [12 to 24 billion L] annually per GWe of capacity); impact human health through normal releases of radiation, direct exposure to radiation, and potential accidents; cause visual impacts from facility construction and operation (e.g., cooling tower plumes); and generate SNF and radioactive and nonradioactive wastes that could require transportation and could necessitate continued management for thousands of years, including the construction and operation of additional geologic repositories for ultimate disposal.

\subsection{RELATIONSHIP BETWEEN SHORT-TERM USES OF THE ENVIRONMENT AND THE Maintenance And Enhancement of Long-Term Productivity}

Each of the domestic programmatic alternatives would require additional land for the construction and operation of new reactors and the disposal of wastes. The closed fuel cycle alternatives would also require land for nuclear fuel recycling facilities. This land would no longer be available for other activities. However, based on the assumption that new electricity generating capacity would be needed in the United States in the future, whether via nuclear power or other means, land use would generally be required regardless of the means by which electricity is generated. The use of nuclear power to produce electricity would avoid the production of significant quantities of greenhouse gases, such as carbon dioxide, that would be 
produced by many other electricity generating technologies. However, the domestic programmatic alternatives would also increase the amount of radioactive wastes that would need to be managed. Some of these wastes would require management for thousands of years, and would need to have land devoted to this purpose. Each of the domestic programmatic alternatives would also commit resources such as concrete, steel, water, uranium, and thorium (for the Thorium Alternative) to produce electricity. Other technologies used to produce electricity would require many of these same types of resources, but would use a different energy source than uranium or thorium. The domestic programmatic closed fuel cycle alternatives would recycle SNF and improve the use of uranium, which would extend the supply of this resource.

\subsection{IRREVERSIBLE AND IRRETRIEVABLE RESOURCE COMMITMENTS}

Under all alternatives there would be construction and operation of new facilities that would cause short-term commitments of resources (e.g., concrete, steel, and water) and would permanently commit certain other resources such as land. Losses of terrestrial and aquatic habitats from natural productivity to accommodate new facilities and temporary disturbances required during construction would occur. Land clearing and construction activities resulting in large numbers of personnel and equipment moving about an area would disperse wildlife and temporarily eliminate habitats. Although some destruction would be inevitable during and after construction, these losses would be minimized by selection of mitigation measures developed through environmental reviews at the site-specific level.

\subsubsection{Land}

Any land, once committed to host a facility, would be irretrievable for the lifetime of the project. At the end of useful life of each facility, the land could be returned to open space uses once the buildings, roads, and other structures were removed, areas cleaned up, and the land re-vegetated. Section 4.9 discusses D\&D. Alternatively, the facilities could be modified for use in other nuclear programs. Therefore, the commitment of this land may not be completely irreversible for all sites. Land would also be committed for the construction of one or more geologic repositories to dispose of SNF and HLW.

\subsubsection{Energy}

Energy expended would generally be in the form of fuel for equipment and vehicles, electricity for facility operations, and either coal or natural gas for steam generation used for heating. However, because the facilities constructed would be net electricity producers, all alternatives would expand energy resources.

\subsubsection{Material}

The irreversible and irretrievable commitment of material resources during the entire lifecycle of the alternatives includes construction materials that cannot be recovered or recycled, materials that are rendered radioactive but cannot be decontaminated, and materials consumed or reduced to unrecoverable forms of waste. Significant quantities of steel, concrete and other building materials would be committed by expanding nuclear electricity production (see Chapter 5 for a 
discussion of these cumulative quantities). Materials such as uranium that would be consumed or reduced to unrecoverable forms of waste would also be irretrievably lost. The quantity of natural uranium needed to support a capacity of $200 \mathrm{GWe}$ would be a maximum of approximately 45,600 MT/yr (see Table 4.8-1). The 45,600 MT of natural uranium would represent approximately the amount of uranium that was mined in the world in 2006, and would be 28 times more than the quantities currently mined in the United States annually. The closed fuel cycle alternatives involve recycling certain materials (uranium and certain transuranic elements) that would extend the use of material resources.

\subsubsection{Water}

Water is a scarce resource in many parts of the United States. New construction and new electricity production would have large water requirements, even though they would use existing conservation technology and production practices to minimize water needs. The quantity of water needed to support a capacity of $200 \mathrm{GWe}$ would be approximately 600 to 1,200 billion $\mathrm{gal} / \mathrm{yr}(2,400$ to $4,800 \mathrm{billion} \mathrm{L} / \mathrm{yr}$ ), based on the use of approximately 3 to 6 billion gal/yr (12 to 24 billion L/yr) for each GWe of energy capacity. Cooling water technologies would be selected based on the local water availability and regulatory requirements. To the extent water could be recycled, this would be designed into the facility during the planning process. 


\subsection{REFERENCES}

10 CFR 2.390

U.S. Nuclear Regulatory Commission (NRC), "Public Inspections, Exemptions, Requests for Withholding," Code of Federal Regulations, Office of the Federal Register, National Archives and Records Administration, Washington, DC, Revised January 1, 2008.

10 CFR Part 20

NRC, "Standards for Protection Against Radiation," Code of Federal Regulations, Office of the Federal Register, National Archives and Records Administration, Washington, DC, Revised January 1, 2008.

10 CFR Part 60

NRC, "Disposal of High-Level Radioactive Wastes in Geologic Repositories," Code of Federal Regulations, Office of the Federal Register, National Archives and Records Administration, Washington, DC, Revised January 1, 2008.

10 CFR Part 61

U.S. Environmental Protection Agency (EPA), "Licensing Requirements for Land Disposal of Radioactive Waste," Code of Federal Regulations, Office of the Federal Register, National Archives and Records Administration, Washington, DC, Revised January 1, 2008.

10 CFR Part 63

NRC, "Disposal of High Level Radioactive Wastes in a Geologic Repository at Yucca Mountain, Nevada," Code of Federal Regulations, Office of the Federal Register, National Archives and Records Administration, Washington, DC, Revised January 1, 2008.

10 CFR Part 70

NRC, "Domestic Licensing of Special Nuclear Material," Code of Federal Regulations, Office of the Federal Register, National Archives and Records Administration, Washington, DC, Revised January 1, 2008.

10 CFR 100.11

NRC, "Determination of Exclusion Area, Low Population Zone, and Population Center Distance," Code of Federal Regulations, Office of the Federal Register, National Archives and Records Administration, Washington, DC, Revised January 1, 2008.

10 CFR Part 960

U.S. Department of Energy (DOE), "General Guidelines for the Preliminary Screening of Potential Sites for a Nuclear Waste Repository," Code of Federal Regulations, Office of the Federal Register, National Archives and Records Administration, Washington, DC, Revised January 1, 2008. 
10 CFR Part 963

40 CFR Part 61

40 CFR Part 190

40 CFR Part 191

40 CFR Part 197

42 U.S.C. 2021

42 U.S.C. 10101 et seq.

42 U.S.C. 15801

ANL 2002a

ANL 2002b
DOE, "Yucca Mountain Site Suitability Guidelines," Code of Federal Regulations, Office of the Federal Register, National Archives and Records Administration, Washington, DC, Revised January 1, 2008.

U.S. Environmental Protection Agency (EPA), "National Emission Standards for Hazardous Air Pollutants (NESHAPs)," Code of Federal Regulations, Office of the Federal Register, National Archives and Records Administration, Washington, DC, Revised January 1, 2007.

EPA, "Environmental Radiation Protection Standards for Nuclear Power Operations," Code of Federal Regulations, Office of the Federal Register, National Archives and Records Administration, Washington, DC, Revised July 1, 2007.

EPA, "Environmental Radiation Protection Standards for Management and Disposal of Spent Nuclear Fuel, High Level and Transuranic Radioactive Wastes," Code of Federal Regulations, Office of the Federal Register, National Archives and Records Administration, Washington, DC, Revised July 1, 2007.

EPA, "Public Health and Environmental Radiation Protection Standards for Yucca Mountain, Nevada," Code of Federal Regulations, Office of the Federal Register, National Archives and Records Administration, Washington, DC, Revised July 1, 2007.

"Low-Level Radioactive Waste Policy Amendments Act of 1985," LLRWPAA, United States Code, Washington, DC, January 15, 1986.

"Nuclear Waste Policy Act of 1982," NWPA, United States Code, Washington, DC, January 7, 1983.

"Energy Policy Act of 2005," EPACT, United States Code, Washington, DC, August 8, 2005.

Argonne National Laboratory (ANL), "Feasibility Study of a Proliferation Resistant Fuel Cycle for LWR Based Transmutation of Transuranics," T. A. Taiwo, T. K. Kim, and M. Salvatores, ANL-AAA-027, Argonne National Laboratory, 2002.

ANL, "Assessment of CORAIL-Pu Multi-Recycling in PWRs," T. K. Kim, ANL-AAA-018, Argonne National Laboratory, June 28, 2002. 
ANL 2004

Annett 2008

AUA 2007b

AAMMPC 2007

Bathke et al. 2008

Bayer 2007

Bowman 1991

Briggs et al. 2007

CEEDATA 2006
ANL, "Homogeneous Recycling Strategies in LWRs for Plutonium, Neptunium, and Americium Management," J.A. Stillman, ANL-AFCI-124, Argonne National Laboratory, August 31, 2004.

Email from John Annett, Tetra Tech to Jay Rose, Tetra Tech "Small Change to Nuclear Fuel Recycling Center MEI," February 27, 2008.

Australian Uranium Association (AUA), "In Situ Leach (ISL) Mining of Uranium," Briefing Paper 40, Australian Uranium Association, 2007. Accessed at http://www.uic.com.au/nip40.htm on October 20, 2007.

Australian Atlas of Mineral Resources, Mines and Processing Centers (AAMMPC), "Uranium Mineral FactSheets," Australian Atlas of Mineral Resources, Mines and Processing Centers, 2007. Accessed at http://www.australianminesatlas.gov.au/info/ factsheets/uranium.jspon January 14, 2008

Bathke, C.G., R.K. Wallace, J.R. Ireland, and M.W. Johnson, "An Assessment of the Proliferation Resistance of Materials in Advanced Nuclear Fuel Cycles," $8^{\text {th }}$ International Conference on Facility Operations - Safeguards Interface, Portland, OR, March 30-April 4, 2008.

Email from Cassandra Bayer, Savannah River National Laboratory (SRNL) to Jay Rose, Tetra Tech, "U/TRU Storage," July 26, 2007.

Bowman, A.L., "NPR MHTGR Generic Reactor Plant Description and Source Terms," Volume 1, EGG-NPR 8522, Rev. B, Idaho National Engineering Laboratory, U.S. Department of Energy, March 1991.

Briggs, L. L., J. E. Cahalan, L. W. Deitrich, T. H. Fanning, C. Grandy, R. Kellogg, T. K. Kim, and W. S. Yang, "Advanced Burner Reactor," NEPA Data Study, ANL-AFCI-183, Nuclear Engineering Division, Argonne National Laboratory, September 21, 2007.

CEEDATA Consulting, "Construction of a Nuclear Power Plant," April 2006. Accessed at www.iop.org/activity/groups/professional/ emg/Group_Events/file_6890.doc on November 14, 2007. 
Chandler 2006

DOE $1995 b$

DOE 1999d

DOE 2002i

DOE $2007 d d$

DOE 2008f

DOE 2008g
Chandler, S., "Comparison of Reprocessing Methods for Light Water Reactor Fuel," Georgia Institute of Technology, December 2006. Accessed at http://smartech.gatech.edu/bitstream/1853/ 14018/1/chandler_sharon_a_200612_mast.pdf on May 20, 2008.

DOE, "Final Programmatic Environmental Impact Statement for Tritium Supply and Recycling," DOE/EIS-0161, Office of Reconfiguration, U.S. Department of Energy, Washington, DC, October 1, 1995.

DOE, "Surplus Plutonium Disposition Final Environmental Impact Statement," DOE/EIS-0283, Office of Fissile Materials Disposition, U.S. Department of Energy,Washington, DC, November 1999.

DOE, "Final Environmental Impact Statement (FEIS) for a Geologic Repository for the Disposal of Spent Nuclear Fuel and High-Level Radioactive Waste at Yucca Mountain, Nye County, Nevada," DOE/EIS-0250, U.S. Department of Energy, Washington, DC, February 1, 2002.

DOE, "Current Assessment of the Benefits of Recycling in Thermal Reactors," U.S. Department of Energy, Washington, DC, February 28, 2007.

DOE, "Final Supplemental Environmental Impact Statement for a Geologic Repository for the Disposal of Spent Nuclear Fuel and High-Level Radioactive Waste at Yucca Mountain, Nye County, Nevada," DOE/EIS-0250F-S1, U.S. Department of Energy Office of Civilian Radioactive Waste Management, Las Vegas, NV, June 2008.

DOE, "Final Supplemental Environmental Impact Statement for a Geologic Repository for the Disposal of Spent Nuclear Fuel and High-Level Radioactive Waste at Yucca Mountain, Nye County, Nevada - Nevada Rail Transportation Corridor DOE/EIS-0250FS2 and Final Environmental Impact Statement for a Rail Alignment for the Construction and Operation of a Railroad in Nevada to a Geologic Repository at Yucca Mountain, Nye County, Nevada, DOE/EIS-0369," U.S. Department of Energy, Office of Civilian Radioactive Waste Management, Las Vegas, NV, June 2008. 
DOL 2008

EIA 2001

EIA 2006a

EIA 2007j

EIA 20071

Energy Solutions 2007

EPA 1983

EPA $1995 d$
Department of Labor (DOL), "Injury Trends in Mining", U.S. Department of Labor, Mine Safety and Health Administration, Washington, DC, 2008. Accessed at www.msha.gov/ MSHAINFO/FactSheets/MSHAFCT2.HTM on July 23, 2008.

Energy Information Administration (EIA), "Impact of U.S. Nuclear Generation on Greenhouse Gas Emissions," R.E. Hagen, J.R. Moens, and Z.D. Nikodem, Energy Information Administration, U.S. Department of Energy, Washington, DC, November 6-9, 2001.

EIA, "Annual Energy Outlook 2006: With Projections to 2030," DOE/EIA-0383(2006), Energy Information Administration, U.S. Department of Energy, Washington, DC, February 1, 2006. Accessed at http://www.eia.doe.gov/oiaf/archive/aeo06/index.html. on March 12, 2008.

EIA, "U.S. Nuclear Reactor List - Operational," Energy Information Administration, U.S. Department of Energy, Washington, DC, 2007. Accessed at http:/www.eia.doe.gov/ cneaf/nuclear/page/nuc_reactors/operational.xls on January 5, 2008.

EIA, "The Coal Transportation Rate Database," Energy Information Administration, U.S. Department of Energy, Washington, DC, 2007. Accessed at http:/www.eia.doe.gov/ cneaf/coal/ctrdb/database.html on October 10, 2007.

Energy Solutions, "Spent Fuel Reprocessing Options: Melding Advanced \& Current Technology," GNR2 Conference, Energy Solutions, June 13, 2007. Accessed at http://www.gnr2.org/ html/2007/6-29.pdf on May 20, 2008.

EPA, "Report to the Congress of the United States : Potential Health and Environmental Hazards of Uranium Mine Wastes," EPA 520/1-83-007, U.S. Environmental Protection Agency, Washington, DC, June 1983.

EPA, "Extraction and Beneficiation of Ores and Minerals," Technical Resource Document, Volume 5, Office of Solid Waste, Special Waste Branch, U.S. Environmental Protection Agency, Washington, DC, January 1, 1995. Accessed at http://www.epa. gov/epaoswer/other/mining/techdocs/uranium.pdf on December 19, 2007. 
EPA 2008c

EPRI 2002

FAS 1998

Fentiman et al. 2008

Finck 2007a

Finck 2007c

GAO 2008b

Geddes 2008

Gruppelaar et al. 2000
EPA, "Uranium Mining Wastes," U.S. Environmental Protection Agency, Washington, DC, 2008. Accessed at http://www.epa.gov/ rpdweb00/tenorm/uranium.html on May 16, 2008.

Electric Power Research Institute, Inc, (EPRI), "Water \& Sustainability (Volume 3): U.S. Water Consumption for Power Production-The Next Half Century," Electric Power Research Institute, March 2002. Accessed at http://www.epriweb.com/public/000000000001006786.pdf on May 21, 2008.

Federation of American Scientists (FAS), "Heavy Water Production," Federation of American Scientists, 1998. Accessed at http://www.fas.org/nuke/intro/nuke/heavy.htm on February 1, 2008.

Fentiman, A.W., J.A. Henkel, and R.J. Veley, "How Is Radioactive Waste Transported?" Ohio State University, 2008. Accessed at http://ohioline.osu.edu/ rer/rerhtml/rer_41.html on June 1, 2008.

Email from Phillip J. Finck, Idaho National Laboratory to Michael Todosow, Jay Rose (Tetra Tech) and Francis Schwartz (DOE), "RE: MOX-TRU in CLWRs," October 17, 2007.

Email from Phillip J. Finck, Idaho National Laboratory to Jay Rose, Tetra Tech, "Paper on LWR Targets: Minor Actinide Targets in LWRs," October 15, 2007.

U.S. Government Accountability Office (GAO), "Nuclear Material: DOE Has Several Potential Options for Dealing with Depleted Uranium Tails, Each of Which Could Benefit the Government," GAO-08-606R, U.S. Government Accountability Office, Washington, DC, March 31, 2008. Accessed at http://www.gao.gov/new.items/d08606r.pdf on May 6, 2008.

Email from Rick Geddes, Washington Savannah River Company, to Jay Rose, Tetra Tech "Cs/Sr Long-term Storage at Recycling Center," February 25, 2008.

Gruppelaar, H., P. W. Phlippen, G. Modolo, J. P. Schapira, B. Fourrest, J. Tommasi, A. F. Renard, P. A. Landeyro, and J. Magill, "Thorium Cycle as a Waste Management Option," (Ed.) EUR 19142 EN, European Commission 2000, ISBN 92-828-9253-0, 2000 . 
Halsey 2007

Health Canada 2008

Herald Tribune 2008

IAEA $2002 \mathrm{a}$

IAEA $2002 b$

IAEA 2004b

IAEA 2005a

IAEA $2005 b$

Maine Yankee 2005

Miller 2001
Email from Bill Halsey, Lawrence Livermore National Laboratory, to Jay Rose, Tetra Tech, “TRU Storage,” July 16, 2007.

Health Canada, "2007 Report on Occupational Radiation Exposures in Canada," Minister of Health, Canada, 2008. Accessed at http://www.hc-sc.gc.ca/ewh-semt/alt_formats/hecssesc/pdf/pubs/occup-travail/2007-report-rapport-eng.pdf on August 21, 2008.

Herald Tribune, "Companies Race to Open New Uranium Enrichment Facilities in U.S.," Herald Tribune, February 27, 2008. Accessed at www.iht.com/articles/2008/02/27/business/ uranium.php on July 23, 2008.

International Atomic Energy Agency (IAEA), "Environmental Aspects Based on Operational Performance of Nuclear Fuel Fabrication Facilities," IAEA-TECDOC-1306, International Atomic Energy Agency, Vienna, July 1, 2002.

IAEA, "Thorium Fuel Utilization: Options and Trends," IAEATECDOC-1319, International Atomic Energy Agency, Proceedings of Three IAEA Meetings Held in Vienna in 1997, 1998, and 1999, November 1, 2002.

IAEA, "Management of Waste Containing Tritium and Carbon14," Technical Report Series No 421, International Atomic Energy Agency, Vienna, 2004.

IAEA, "Thorium Fuel Cycle - Potential Benefits and Challenges," IAEA-TECDOC-1450, International Atomic Energy Agency, Vienna, May 1, 2005.

IAEA, "Status and Trends in Spent Fuel Reprocessing," IAEATECDOC-1467, International Atomic Energy Agency, Vienna September 2005.

Maine Yankee, "Maine Yankee Decommissioning Experience Report," New Horizon Scientific, LLC, Electric Power Research Institute and Maine Yankee, 2005.

Miller, A.I., 'Heavy Water: A Manufactures' Guide for the Hydrogen Century," Canadian Nuclear Society Bulletin, Vol. 22, No. 1, January 1, 2001. 
NAP 2005

NEA 2002

NEI 2007

NEI 2008

NRC 1990

NRC 1994b

NRC 1996

NRC 2005b

NRC 2005c
The National Academies Press (NAP), "Safety and Security of Commercial Spent Nuclear Fuel Storage," Board on Radioactive Waste Management, April 6, 2005.

Nuclear Energy Agency (NEA), "The Decommissioning and Dismantling of Nuclear Facilities: Status, Approaches, Challenges," Nuclear Energy Agency, 2002. Accessed at http://www.nea.fr/html/rwm/reports/2002/3714decommissioning.pdf on May 21, 2008.

Nuclear Energy Institute (NEI), "Nuclear Waste: Amounts and OnSite Storage," Nuclear Energy Institute, 2007. Accessed at http://nei.org/resourcesandstats/nuclear_statistics/nuclearwasteamo untsandonsitestorage/ on September 1, 2007.

NEI, "Low-Level Radioactive Waste," Nuclear Energy Institute, 2008. Accessed at http://www.nei.org/keyissues/ nuclearwastedisposal/lowlevelradioactivewaste/ on June 1, 2008.

US NRC, "Severe Accident Risks: An Assessment for Five U.S. Nuclear Power Plants," NUREG-1150, U.S. Nuclear Regulatory Commission, Washington, DC, December 1990. Accessed at http://www.nrc.gov/reading-rm/doc-collections/nuregs/staff/ sr1150/ on September 08, 2008.

NRC, "Standard Review Plan For The Review Of License Application For A Low-Level Radioactive Waste Disposal Facility," NUREG-1200, U.S. Nuclear Regulatory Commission, Washington, DC, April 1994.

NRC, "License Renewal Generic Environmental Impact Statement," NUREG-1437, U.S.Nuclear Regulatory Commission, Washington, DC, 1996. Accessed at http://www.nrc.gov/reading$\mathrm{rm} /$ doc-collections/nuregs/staff/sr1437/ on January 5, 2008.

NRC, "Environmental Impact Statement for the Proposed National Enrichment Facility in Lea County, NM," NUREG-1790, U.S. Nuclear Regulatory Commission, New Mexico, June 1, 2005.

NRC, "Environmental Impact Statement on the Construction and Operation of a Proposed Mixed Oxide Fuel Fabrication Facility at the Savannah River Site, South Carolina," NUREG-1767, U.S. Nuclear Regulatory Commission, Washington, DC, January 2005. 
NRC 2006b

NRC 2006d

NRC 2007b

NRC 2007c

NRC 2007f

NRC 2007g

NRC 20071

NRC 2007n

NRC 2007o
NRC, "Environmental Impact Statement for the Proposed American Centrifuge Plant in Piketon, OH," NUREG-1834, U.S. Nuclear Regulatory Commission, Washington, DC, April 1, 2006.

NRC, "Louisiana Energy Services (LES) Gas Centrifuge Facility,"TAC NOS. L31984 Safety, L31985 Environmental, and L31986 Safeguards, U.S. Nuclear Regulatory Commission, Washington, DC, June 23, 2006. Accessed at http://www.nrc.gov/materials/fuel-cycle-fac/lesfacility.html\#1 on April 30, 2008.

NRC, "Uranium Enrichment," Nuclear Materials, Fuel Cycle Facilities, U.S. Nuclear Regulatory Commission, Washington, DC, September 2007. Accessed at http://www.nrc.gov/materials/fuelcycle-fac/ur-enrichment.html\#3 on May 16, 2008.

NRC, "Fuel Fabrication," Nuclear Materials, Fuel Cycle Facilities, U.S. Nuclear Regulatory Commission, Washington, DC, February 2007. Accessed at www.nrc.gov/materials/fuel-cycle-fac/fuelfab.html on February 10, 2008.

NRC, "Fact Sheet on the Three Mile Island Accident," U.S Nuclear Regulatory Commission, Washington, DC, 2007. Accessed at http://www.nrc.gov/reading-rm/doc-collections/factsheets/3mile-isle.html on January 5, 2008.

NRC, "Year 2005 Low-Level Waste Disposal Statistics," U.S. Nuclear Regulatory Commission, Washington, DC, March 21, 2007.

NRC, "Occupational Radiation Exposure at Nuclear Power Reactors and Other Facilities 2006," Thirty-Ninth Annual Report, NUREG-0713, U.S. Nuclear Regulatory Commission, Washington, DC, December 2007.

NRC, "Fact Sheet on the Accident at the Chernobyl Nuclear Power Plant," U.S. Nuclear Regulatory Commission, Washington, DC, February 20, 2007. Accessed at http://www.nrc.gov/reading$\mathrm{rm} /$ doc-collections/fact-sheets/fschernobyl.html on May 5, 2008.

NRC, "Fact Sheet on Gaseous Diffusion," U.S. Nuclear Regulatory Commission, Washington, DC, February 20, 2007. Accessed at http://www.nrc.gov/reading-rm/doc-collections/factsheets/gaseous-diffusion.html on April 30, 2008. 
NRC 2007p

NRC 2007q

NRC 2008d

NRC 2008c

NRC 2008f

Parent 2003

PMC 1982

Reuters 2008

SCDHEC 2007
NRC, "Final Environmental Assessment for the Renewal of U.S. Regulatory Commission License No. SNM-1107 for the Westinghouse Columbia Fuel Fabrication Facility," Docket No. 70-1151, U.S. Nuclear Regulatory Commission, Washington, DC, April 2007.

NRC, "NRC Issues Final Supplemental Environmental Assessment For Diablo Canyon Spent Fuel Storage Facility," U.S. Nuclear Regulatory Commission, Washington, DC, August 31, 2007. Accessed at http://www.nrc.gov/reading-rm/doc-collections/ news/2007/07-110.html on July 30, 2008.

NRC, "Fact Sheet on Decommissioning Nuclear Power Plants," U.S. Nuclear Regulatory Commission, Washington, DC, January 22, 2008. Accessed at http:/www.nrc.gov/reading-rm/doccollections/fact-sheets/decommissioning.html on July 30, 2008.

NRC, "Backgrounder on Radiation Protection and the Tooth Fairy Issue," U.S. Nuclear Regulatory Commission, Washington, DC, February 20, 2007. Accessed at http://www.nrc.gov/reading$\mathrm{rm} /$ doc-collections/fact-sheets/tooth-fairy.html on June 1, 2008.

NRC, "Generic Environmental Impact Statement for In-Situ Leach Uranium Milling Facilities," NUREG-1910, Office of Federal and State Materials and Environmental Management Programs, U.S. Nuclear Regulatory Commission, Washington, DC, July 2008.

Parent, E., "Nuclear Fuel Cycles for Mid-Century Deployment," Massachusetts Institute of Technology, September 2003.

Project Management Corporation (PMC), "Clinch River Breeder Reactor Project - Preliminary Safety Analysis Report," Docket 50537, Volume 1-Volume 14, Project Management Corporation, May 1982.

Thomson Reuters, "AREVA Selects Bonneville County, Idaho, for its Uranium Enrichment Facility,” Thomson Reuters, May 6, 2008. Accessed at www.reuters.com/article/pressRelease/idUS171159+ 06-May-2008+PRN20080506) on July 23, 2008.

South Carolina Department of Health and Environmental Control (SCDHEC), "Commercial Low-Level Radioactive Waste Disposal in South Carolina," CR-000907, South Carolina Department of Health and Environmental Control, March 2007. Accessed at http://www.scdhec.gov/environment/lwm/forms/commercial_low_ level.pdf on May 21, 2008. 
Schwartz 2008

SNL 2007

Tetra Tech $2008 \mathrm{~g}$

Todosow 2003

Todosow $2007 \mathrm{~b}$

Todosow and Kazimi 2004

UNSCEAR 1993

UNSCEAR 2006

USEC 2008a

USEC 2008b
Email from Francis Schwartz, Department of Energy to Jay Rose, Tetra Tech "Chapter 4 Input from INL and ANL," July 29, 2008.

Sandia National Laboratory (SNL), "Greater-Than-Class C LowLevel Radioactive Waste and DOE Greater-Than-Class C-Like Waste Inventory Estimates," Sandia National Laboratory, July 2007.

Email from Mark Dimsha, Epsilon Systems Solutions Inc., to Jay Rose, Tetra Tech, "Annual Transportation Impacts for the Year 2060-2070," September 17, 2008.

Todosow, M., "Use of Thorium in Light Water Reactors", M. Todosow, Brookhaven National Laboratory, Advances in Nuclear Fuel Management III (ANFM 2003), Hilton Head Island, SC, American Nuclear Society, LaGrange Park, IL, October, 2003.

Email from Michael Todosow, Brookhaven National Laboratory to Jay Rose, Tetra Tech "PEIS Thorium," October 17, 2007.

Todosow M. and M. Kazimi, "Optimization of Heterogeneous Utilization of Thorium in PWRs to Enhance Proliferation Resistance and Reduce Waste," BNL-73152-2004/MIT-NFC-065, August 2004.

United Nations Scientific Committee on the Effects of Atomic Radiation (UNSCEAR), "UNSCEAR 1993 Report - Sources and Effects of Ionizing Radiation," Report to the UN General Assembly, Chartered by the United Nations, New York, 1993.

UNSCEAR, "Radiation Exposure for Uranium Industry Workers," United Nations Scientific Committee on the Effects of Atomic Radiation, Chartered by the United Nations, October 30, 2006.

United States Enrichment Corporation (USEC), "The American Centrifuge," United States Enrichment Corporation, 2008. Accessed at http://www.usec.com/americancentrifuge.htm on April 30, 2008.

USEC, "About the Corporation," United States Enrichment Corporation, 2008. Accessed at http://www.usec.com/ Downloads/NewsRoom/CorpKit.pdf on April 30, 2008. 
WEC 2006

Wigeland 2008a

Wigeland 2008b

Wigeland 2008c

WISE 2008

WNA 2008e

WSDH 2004

WSDH 2008
Westinghouse Electric Corporation (WEC), "Westinghouse Request for Additional Information Responses Regarding the Environmental Assessment Supporting SNM-1107 License Renewal (TAC 31911)," Westinghouse Electric Corporation, September 8, 2006.

Wigeland, R.A., "Performance Summary of Advanced Nuclear Fuel Cycles," GNEP-TIO-AI-AI-RT-2008-000268 Rev 1, Idaho National Laboratory, Nuclear Science \& Technology, June 2008.

Wigeland, R.A., "Sensitivity of Waste Management Results to Separations and Recovery Efficiency Assumptions," Idaho National Laboratory, Nuclear Science \& Technology, May 19, 2008.

Wigeland, R.A., "Cs/Sr Waste Volume Estimates," Addendum to the "Performance Summary of Advanced Nuclear Fuel Cycles," GNEP-TIO-AI-AI-RT-2008-000268, Revision 1, Idaho National Laboratory, Nuclear Science \& Technology, June 10, 2008.

World Information Service on Energy (WISE), "Uranium Project: Environmental Impacts of Uranium Mining and Milling, Slide Talk," World Information Service on Energy, 2008. Accessed at http://www.wise-uranium.org/stk.html?src=stkd01e on June 1, 2008.

World Nuclear Association (WNA), "World Uranium Mining," World Nuclear Association, July 2008. Accessed at http://www.world-nuclear.org/info/inf23.html on September 9, 2008.

Washington State Department of Health (WSDH), "Final Environmental Impact Statement: Commercial Low-Level Radioactive Waste Disposal Site, Richland, Washington," DOH Publication 320-031, Washington State Department of Health, May 28, 2004. Accessed at http://www5.doh.wa.gov/ ehp/rp/waste/final-eis.htm on May 21, 2008.

WSDH, "Commercial Low-Level Radioactive Waste Disposal," Division of Environmental Health, Office of Radiation Protection, Washington State Department of Health, 2008. Accessed at http://www5.doh.wa.gov/ehp/rp/waste/llwhm.htm on May 21, 2008. 
WSRC 2008a

WSRC 2008b

WSRC 2008c

WSRC 2008d
Washington Savannah River Company (WSRC), "Engineering Alternative Studies for Separations, NEPA Data Input Report," EAS-Q-NEP-G-00001, Revision 3, Washington Savannah River Company, April 2008.

WSRC, "Transmutation Fuel Fabrication Facility NEPA Data Input Report," EAS-Q-NEP-G-00003, Revision 2, Washington Savannah River Company, Washington Savannah River Company, April 2008.

WSRC, "Fast Reactor Spent Nuclear Fuel Recycling Facility NEPA Data Input Report," EAS-Q-NEP-G-00004, Revision 1, Washington Savannah River Company, April 2008.

WSRC, "Follow-on Engineering Alternative Studies Material Balance Bases and Assumptions," EAS-G-ESR-G-00062, Revision 0, Washington Savannah River Company, January 2008. 


\section{CHAPTER 5}

\section{CUMULATIVE ENVIRONMENTAL IMPACTS OF THE DOMESTIC PROGRAMMATIC ALTERNATIVES}





\section{CHAPTER 5 CUMULATIVE ENVIRONMENTAL IMPACTS OF THE DOMESTIC PROGRAMMATIC ALTERNATIVES}

Chapter 5 presents the cumulative environmental impacts of the domestic programmatic alternatives assessed in this Global Nuclear Energy Partnership (GNEP) Programmatic Environmental Impact Statement (PEIS). The potential cumulative impacts are based on the potential environmental impacts of the GNEP PEIS alternatives together with those of other past, present, and reasonably foreseeable future actions.

\subsection{INTRODUCTION}

The Global Nuclear Energy Partnership (GNEP) program is proposing to make decisions that would support new nuclear power generation in the United States. This Chapter assesses the potential cumulative environmental impacts in the United States of such new nuclear capacity. Chapter 4 of this Programmatic Environmental Impact Statement (PEIS) analyzes four growth scenarios for nuclear electricity capacity: zero growth (100 gigawatt-electric [GWe]); 1.3 percent annual growth $(200 \mathrm{GWe}) ; 0.7$ percent annual growth $(150 \mathrm{GWe})$; and 2.5 percent annual growth (400 GWe), including the construction and operation of new facilities, the replacement of existing plants, and the infrastructure necessary to support those plants, including mining, uranium enrichment and fuel fabrication facilities, and waste storage and disposal. This section describes the potential cumulative impacts associated with the programmatic alternatives when added to the impacts of other past, present, and reasonably foreseeable future actions. The analysis focuses on cumulative impacts to water, electricity supply and demand, radiological wastes, transportation, land use, air quality and greenhouse gases, and construction materials.

The approach to cumulative impacts analysis in this chapter is influenced by the nature of the programmatic alternatives. Implementation of any programmatic alternative would take several decades and impacts would be experienced over a long period of time (well beyond 50 years). Implementation could involve hundreds of new facilities. The U.S. Department of Energy (DOE), however, is not proposing to site, construct, or operate any particular facility; thus, impacts can not be analyzed for any specific location and, as Chapter 3 describes, the affected environment includes the entire United States, with emphasis on the contiguous 48 states ${ }^{1}$.

The Council on Environmental Quality guidance for cumulative impacts analysis states that an EIS should identify cause-and-effect relationships for specific resources, ecosystems and communities (CEQ 1997a). The analysis in this chapter provides the reader a view of reasonably foreseeable actions within the United States over approximately the next 50 years. It is therefore not possible to identify the cumulative impacts on some specific locations, resources, ecosystems, or communities for actions associated with the domestic programmatic fuel cycle alternatives discussed in Chapter 4. By necessity, this analysis is of a broader context, and takes

${ }^{1}$ Separately, Chapter 7 provides a qualitative analysis of the potential environmental impacts on the global commons and potential cumulative impacts in the United States of GNEP international initiatives, including a Reliable Fuel Services Program. 
into account the impacts of actions taking place within the entire United States in the foreseeable future (typically about 50 years - consistent with the analysis in Chapter 4). Potential cumulative impacts from the incremental contribution of the alternatives are assessed according to their potential locations, time frame of occurrence, and impact intensity when added to other reasonably foreseeable activities, projects, or plans.

\subsubsection{Methodology for Assessing Cumulative Impacts}

The methodology adopted to determine the potential cumulative impacts is as follows:

The region of influence is the geographic area of affected resources and the distances at which impacts associated with the alternatives may occur. Because this PEIS does not assess specific locations for any of the alternatives, the region of influence for the cumulative impacts analysis is the United States. Use of the entire United States is required because the specific locations of future nuclear power generating facilities and other potential facilities associated with any of the domestic programmatic alternatives is unknown. The geographic boundaries of areas of concern within the United States may vary based on the distance at which an impact may occur.

1. The time frame for this analysis generally extends through the next 50 years approximately. However, impacts on some resources, such as those affected by longer term storage or additional geologic repository capacity, could continue far beyond 50 years. To the extent practicable, this PEIS considers these longer-term cumulative impacts.

2. Reasonably foreseeable future actions are identified. These include trends that could affect environmental impacts within the United States over the next 50 years approximately. Reasonably foreseeable future actions are identified and listed in Table 5.1.2-1 and are described in Section 5.1.2.

3. Baseline conditions of natural resources and human receptors are characterized in Chapter 3.

4. Cumulative impacts on the resources and receptors are analyzed by considering the impacting factors due to the alternatives and their incremental contribution in the foreseeable future. The potential cumulative impacts on resources are described in Section 5.2.

\subsubsection{Reasonably Foreseeable Future Actions}

Reasonably foreseeable future actions include all the probable impacts of the activities, projects, or trends on the human and environmental resources within the defined time frame. As a part of the cumulative impact analysis, Table 5.1.2-1 presents the types of future actions that have been identified as reasonably foreseeable in the United States over approximately the next 50 years (until approximately 2060). 
TABLE 5.1.2-1-Reasonably Foreseeable Future Actions in the United States

\begin{tabular}{ll}
\hline \multicolumn{1}{c}{ Types of Actions } & Associated Activities and Facilities \\
\hline & - Increased water demand \\
Population Growth & - Increased electricity demand \\
& - Increased transportation demand \\
& - Increased air quality impacts \\
& - Increased use of construction materials \\
& - Changes in water demand, use, and supply \\
& - Changes in electricity demand, use, and supply \\
Technology Development & - Changes in transportation demand, use, and \\
& - infrastructure \\
& - Changes in land use \\
& - Changes in air quality impacts \\
&
\end{tabular}

Technology developments in the foreseeable future are expected to change the way citizens in the United States (and around the world) live and work. These changes could, in turn, affect impacts to the environment. New technologies and devices would likely transform manufacturing, computing, human health, transportation, and energy infrastructure. Technology changes in the next 50 years would ultimately depend on how new technologies are managed, adopted, and implemented. Economics and regulatory requirements would be expected to weigh heavily on these issues. While acknowledging that future changes could be significant, this PEIS does not identify or assess any specific technology developments that could produce these changes. Rather, this PEIS discusses general technology development and correlates reasonably foreseeable future changes based on past changes and trends. Technology development could affect water, electricity supply and demand, transportation, land use, and air quality as explained in the sub-sections below.

\subsubsection{Population Growth}

According to the U.S. Census Bureau, the current population in the United States is approximately 303 million people (USCB 2008a). The U.S. Census Bureau projects that the United States population would increase by approximately 0.9 percent annually until 2014 . Between 2015 and 2035, the U.S. Census Bureau expects the United States population to increase by approximately 0.8 percent annually, and then to increase by 0.7 percent annually between 2036 and 2050 (USCB 2008b). For this cumulative impact analysis, a 0.7 percent growth rate is assumed to continue after 2050 until approximately 2060, which is the approximate end point analyzed in this PEIS. Based on those increases, the total population in the United States would increase from approximately 303 million to approximately 450 million by the year 2060 (see Table 5.1.3-1). This PEIS notes that the forecast future population would be highly subject to behavioral decisions by individuals, possible unexpected developments in health and morbidity, and policy decisions by governments nationally and internationally. Population growth would cause impacts to water, electricity, transportation, land use, air quality, and the use of construction materials as explained in the sub-sections below. 
TABLE 5.1.3-1-Projected Future United States Population

\begin{tabular}{|c|c|c|c|c|c|c|c|c|}
\hline Year & $\begin{array}{c}\text { Number } \\
(\mathbf{1 , 0 0 0 )}\end{array}$ & $\begin{array}{l}\text { Percent } \\
\text { Change }\end{array}$ & Year & $\begin{array}{c}\text { Number } \\
(\mathbf{1 , 0 0 0 )}\end{array}$ & $\begin{array}{l}\text { Percent } \\
\text { Change }\end{array}$ & Year & $\begin{array}{c}\text { Number } \\
(1,000)\end{array}$ & $\begin{array}{l}\text { Percent } \\
\text { Change }\end{array}$ \\
\hline 2004 & 292,801 & 0.9 & 2023 & 343,921 & 0.8 & 2042 & 397,519 & 0.7 \\
\hline 2005 & 295,507 & 0.9 & 2024 & 346,669 & 0.8 & 2043 & 400,301 & 0.7 \\
\hline 2006 & 298,217 & 0.9 & 2025 & 349,439 & 0.8 & 2044 & 403,081 & 0.7 \\
\hline 2007 & 300,913 & 0.9 & 2026 & 352,229 & 0.8 & 2045 & 405,862 & 0.7 \\
\hline 2008 & 303,598 & 0.9 & 2027 & 355,035 & 0.8 & 2046 & 408,646 & 0.7 \\
\hline 2009 & 306,272 & 0.9 & 2028 & 357,862 & 0.8 & 2047 & 411,435 & 0.7 \\
\hline 2010 & 308,936 & 0.9 & 2029 & 360,711 & 0.8 & 2048 & 414,230 & 0.7 \\
\hline 2011 & 311,601 & 0.9 & 2030 & 363,584 & 0.8 & 2049 & 417,035 & 0.7 \\
\hline 2012 & 314,281 & 0.9 & 2031 & 366,466 & 0.8 & 2050 & 419,854 & 0.7 \\
\hline 2013 & 316,971 & 0.9 & 2032 & 369,336 & 0.8 & 2051 & 422,793 & 0.7 \\
\hline 2014 & 319,668 & 0.9 & 2033 & 372,196 & 0.8 & 2052 & 425,752 & 0.7 \\
\hline 2015 & 322,366 & 0.8 & 2034 & 375,046 & 0.8 & 2053 & 428,733 & 0.7 \\
\hline 2016 & 325,063 & 0.8 & 2035 & 377,886 & 0.8 & 2054 & 431,734 & 0.7 \\
\hline 2017 & 327,756 & 0.8 & 2036 & 380,716 & 0.7 & 2055 & 434,756 & 0.7 \\
\hline 2018 & 330,444 & 0.8 & 2037 & 383,537 & 0.7 & 2056 & 437,799 & 0.7 \\
\hline 2019 & 333,127 & 0.8 & 2038 & 386,348 & 0.7 & 2057 & 440,864 & 0.7 \\
\hline 2020 & 335,805 & 0.8 & 2039 & 389,151 & 0.7 & 2058 & 443,950 & 0.7 \\
\hline 2021 & 338,490 & 0.8 & 2040 & 391,946 & 0.7 & 2059 & 447,058 & 0.7 \\
\hline 2022 & 341,195 & 0.8 & 2041 & 394,734 & 0.7 & 2060 & 450,187 & 0.7 \\
\hline
\end{tabular}

Source: USCB 2008b for data through 2050, data from 2050 to 2060 derived from USCB 2008b

\subsection{CUMULATIVE IMPACTS}

\subsubsection{Water}

Population increases would be expected to increase the demands on water resources. Water use estimates in the United States indicate that about 408 billion gallons per day (gal/day) (1.5 trillion liters per day [L/day]) were withdrawn for all uses during 2000. This total is about 3 percent more than 1985, as withdrawals have stabilized for the two largest uses (i.e., irrigation and thermoelectric power) since the year 1990. Fresh groundwater withdrawals during 2000 were 83.3 billion gal/day ( 315 billion L/day), which is about 14 percent more than during 1985 . Fresh surface water withdrawals for 2000 were 262 billion gal/day ( 992 billion L/day), varying less than 2 percent since 1985 (USGS 2004a).

Total household water consumption in the United States was approximately 6.3 billion gal ( 23 billion L) in 1995, and is projected to be approximately 10 billion gal ( 38 billion L) by 2025 . The United States will be responsible for more than 10 percent of the global household water consumption in 2025 (IFPRI 2002). Water problems in the foreseeable future could include contamination of ground water, depletion of underground aquifers, salinization of irrigation water, siltation of impoundments, prolonged drought, and frequent flooding.

The amount of water consumption in the United States is projected to rise both due to population growth and greater per capita use. For purposes of this PEIS cumulative impact analysis, it is assumed that future increases in water use would be similar to the increases that have occurred since 1985 ( 3 percent increase over approximately 15 years, which equates to an annual growth 
rate of approximately 0.2 percent). Based on this growth rate, the United States water consumption is projected to increase to approximately 460 billion gal/day ( 1.7 trillion L/day) by approximately 2060.

Technology development could affect water use in the United States. According to data from the U.S. Geological Survey (USGS), agriculture is the largest user of fresh water, followed by electricity generation (NETL 2004). Because agriculture needs are largely driven by population demands, water use for agricultural use should grow commensurate with the population. While technology developments could improve the efficiency of agricultural use of water, it would be speculative to assign a specific value to such improvement.

For the $200 \mathrm{GWe}$ scenario, the alternatives in this PEIS would use approximately 3.3 billion gal/day (12.2 billion L/day), based on the use of approximately 6 billion gal/year ( 24 billion $\mathrm{L} /$ year) for each GWe of energy produced. Compared to the 460 billion gal (1.7 trillion L) of water that would be used daily by other sources in 2060, the alternatives in this PEIS would use approximately 0.7 percent of the water used in the United States. Approximately 99 percent of the water withdrawn for cooling would be returned to its source. The U.S. Census Bureau projections recognize increased growth rates in the southern and western United States, relative to the other regions. This would accentuate the demand for water in these two regions. Water resources are regionally sensitive in that not all regions have the same water availability. This is further complicated by other, larger water resources which are shared by several regions.

With respect to electricity generation, power plants' water requirements would likely rise as demand for electricity grows over the next five decades. However, the amount of water needed to generate each unit of electricity would likely decrease because companies are expected to install new technologies that require less water (e.g., the use of dry cooling technologies can reduce water use requirements by more than 90 percent for a typical $1 \mathrm{GWe}$ electrical-generating facility). Power plants consume only about 3 percent of the water they draw from a particular source while generating electricity. To generate electricity, most power plants burn a fuel to heat water and create steam. It is estimated that by 2020 power plants would need between 94 billion gal (356 billion L) less water (a reduction of 3 percent) per year and 576 billion gal (2.2 trillion L) more water (an increase of 17 percent) to meet future electricity demand (GAO 2002). The lower estimate assumes that all the additional demand would be met with dry cooling technology, while the higher number assumes that it would be met with wet cooling systems. Plants will likely use a combination of the two systems. Regardless, newer technologies will allow plants to consume less water per unit of electricity produced than they currently do, having less of an impact on the environment in the foreseeable future (GAO 2002).

\subsubsection{Electricity}

Electricity demands are a function of both population increases and economic growth. Electricity use in the United States is expected to continue to grow. In its most recent Energy Outlook Report, issued in June 2008, the Energy Information Administration (EIA), an independent organization within DOE, estimates that demand for electricity will increase by approximately 1.1 percent annually through 2030 (EIA 2008a). An early release of that report, issued in December 2007, estimated United States electricity growth at 1.3 percent annually through 2030 
(EIA 2007a). This Draft PEIS utilizes the higher 1.3 percent growth rate; however, in the Final PEIS, DOE will consider whether any changes to the document are warranted to account for the 1.1 percent growth rate or other relevant information that becomes available. Based on an annual growth rate of 1.3 percent, electricity use could increase by approximately 40 percent by 2030 , and if that annual rate were to continue, electricity use could double (relative to use in 2004) by approximately 2060 .

Currently, there is approximately $487 \mathrm{GWe}$ of installed electrical generating capacity in the United States. Of this, nuclear power accounts for approximately 19 percent of the total electricity supply, while 70 percent comes from fossil burning fuels (coal, natural gas, and oil) (EIA 2008a). Assuming that future electricity demands would increase by approximately 1.3 percent annually, by approximately 2060 the United States would need to have an installed capacity of approximately $929 \mathrm{GWe}$. This would equate to a need for approximately $442 \mathrm{GWe}$ of new electrical-generating capacity. Depending upon the energy sources used to supply this capacity, new electrical-generating capacity would affect land use, water use, air quality, biological resources, the visual environment, wastes generated, the transportation infrastructure, human health, global climate, and socioeconomics. The specific impacts associated with increased electrical supply and impacts to the electrical distribution network would be highly dependent upon the locations for any new electrical generating capacity, which are unknown.

Technology improvements could affect both electrical production and demand. Either of these could result in improvements in electricity generation. On the production side, the efficiency of electricity production is expected to continue to improve over time, as it has in the past. This is illustrated by the fact that plant capacity factors have risen in the past and will likely continue to increase. This is primarily due to improved technologies and improved maintenance practices. There is, however, a theoretical limit as to how high capacity factors can rise, and in the future it is expected that improvements in capacity factors will not be as great as in the past as the theoretical limit is approached. Future improvements in capacity factors would result in less need for new electrical-generating plants. Technology improvements could have a more meaningful affect on the electricity demand side. For example, by 2020, all light bulbs sold in the United States must be 70 percent more efficient than current bulbs (42 U.S.C. 6291). However, even with these technology improvements, electrical demand will be primarily driven by population increases and economic growth.

\subsubsection{Spent Nuclear Fuel and Radioactive Waste}

The alternatives in this PEIS would contribute to cumulative amounts of spent nuclear fuel (SNF) and radioactive wastes that would require management and disposal. This section discusses the following materials: 1) spent nuclear fuel and high-level radioactive waste; 2) Greater-than-Class-C low-level radioactive waste; and 3) low-level radioactive waste.

The Nuclear Waste Policy Act of 1982, as amended, provides for the disposal of commercial spent nuclear fuel and DOE spent nuclear fuel and high-level radioactive waste in the Nation's first proposed geologic repository to be located at Yucca Mountain, Nevada. The Nuclear Waste Policy Act limits the initial capacity of Yucca Mountain to 70,000 MTHM of spent nuclear fuel and high-level radioactive waste until such time as a second repository is in operation (42 U.S.C. 10101 et seq.). DOE has allocated this capacity between 63,000 MTHM of commercial spent 
nuclear fuel and 7,000 MTHM of DOE spent nuclear fuel and high-level radioactive waste. Disposal of more than 70,000 MTHM of spent nuclear fuel and high-level radioactive waste at the Yucca Mountain site prior to completion of a second repository would require a legislative change.

In its cumulative impacts analysis, the Yucca Mountain Supplemental Environmental Impact Statement (SEIS) (DOE 2008f), issued in June 2008, evaluated the disposal of up to approximately 130,000 MTHM of commercial spent nuclear fuel, ${ }^{2}$ equivalent to the amount projected from all existing commercial power reactors during all of their projected lifetimes. The Yucca Mountain SEIS also evaluated an alternative disposal case in which DOE would dispose of 63,000 MTHM of commercial spent nuclear fuel as spent fuel, as in the Yucca Mountain SEIS proposed action, but the balance of this commercial spent nuclear fuel inventory (approximately 67,000 MTHM) would be recycled and the resultant high-level radioactive waste would be transported to and disposed of at the Yucca Mountain geologic repository. This amount of commercial spent nuclear fuel (i.e., approximately 67,000 MTHM) also is a part of the commercial spent nuclear fuel inventory evaluated in the GNEP programmatic alternatives.

For the 200 GWe scenario, the GNEP closed fuel cycle alternatives could generate between 18,000 and 55,000 cubic meters of high-level radioactive waste that would require disposal in a geologic repository. (In addition, the Thermal Reactor Recycle Alternative (Option 2), while considered a closed fuel cycle alternative, could generate approximately 71,000 MTHM spent nuclear fuel.) $)^{3}$ For the $200 \mathrm{GWe}$ scenario, the GNEP open fuel cycle alternatives could generate between 99,000 and 280,000 MTHM spent nuclear fuel that would require disposal in a geologic repository.

Independent of the domestic programmatic alternatives, DOE is preparing an Environmental Impact Statement for the Disposal of Greater-than-Class-C Low-Level Radioactive Waste (DOE/EIS-0375) (72 FR 40135). DOE estimates that approximately 2,600 cubic meters of Greater-than-Class-C low-level radioactive waste will require management nationwide (72 FR 40135). In addition, DOE estimates that there will be certain wastes that will be generated from DOE activities which may not have an identified disposal path and will have characteristics similar to Greater-than-Class-C low-level radioactive waste. This DOE waste is estimated to be 3,000 cubic meters ( $72 \mathrm{FR}$ 40135). Thus, the total Greater-than-Class-C low-level radioactive waste that will require management is projected to be 5,600 cubic meters. For the $200 \mathrm{GWe}$ scenario, the GNEP closed fuel cycle alternatives could generate 9,700 to 416,500 cubic meters of Greater-than-Class-C low-level radioactive waste, while the open fuel cycle alternatives (including the No Action Alternative) could generate approximately 2,500 cubic meters. (The estimates DOE has developed for the GTCC EIS, as well as the estimates developed for the GNEP programmatic alternatives, include the quantities of Greater-than-Class-C low-level radioactive waste that would be generated from the decontamination and decommissioning of existing light water reactors.) Consequently, the closed fuel cycle alternatives would account for approximately 64 to 99 percent of the total

\footnotetext{
${ }^{2}$ The Yucca Mountain SEIS cumulative impacts analysis also evaluated the disposal of all DOE spent nuclear fuel (approximately 2,500 MTHM) and all DOE high-level radioactive waste (approximately 36,000 canisters).

${ }^{3}$ Insufficient data exists to estimate the amount of spent nuclear fuel from the Thermal Reactor Recycle Alternative (Option 3 ).
} 
Greater-than-Class-C low-level radioactive waste, while the open fuel cycle alternatives would account for approximately 31 percent of the total Greater-than-Class-C low-level radioactive waste (see Table 5.2.3-1).

In 2005 and 2006, the total amount of low-level radioactive waste disposed of at the three commercial disposal facilities in the United States was approximately 113,000-115,000 cubic meters annually (NRC 2007g, MIMS 2008). Of this low-level radioactive waste, in 2006, approximately 52,500 cubic meters was related to nuclear-generated electricity and 62,000 cubic meters was unrelated to nuclear-generated electricity (MIMS 2008). Assuming that low-level radioactive wastes unrelated to nuclear-generated electricity would continue at this rate, over the next 50 years, approximately 3,100,000 cubic meters of low-level radioactive waste would require disposal. For the $200 \mathrm{GWe}$ scenario, the GNEP closed fuel cycle alternatives ${ }^{4}$ could generate approximately 1,740,000-2,895,000 cubic meters of low-level radioactive waste, or approximately 36-48 percent of the total low-level radioactive waste that would require disposal (see Table 5.2.3-1). The open fuel cycle alternatives would generate approximately 150,000-585,000 cubic meters of low-level radioactive waste, or approximately 516 percent of the total low-level radioactive waste that would require disposal (see Table 5.2.3-1). As a result of recycling spent fuel, the closed fuel cycle alternatives generate much higher quantities of low-level radioactive waste. All of the estimates of low-level radioactive waste quantities assume that future reactors would generate low-level radioactive waste in quantities similar to existing commercial reactors.

Table 5.2.3-1—Cumulative Impacts of Radioactive Waste Generation

\begin{tabular}{lcc}
\hline & $\begin{array}{c}\text { Greater-Than Class-C } \\
\text { Radioactive Waste } \\
\text { (cubic meters) }\end{array}$ & $\begin{array}{c}\text { Low-Level Radioactive Waste } \\
\text { (cubic meters) }\end{array}$ \\
\hline Non-GNEP Inventory & $\begin{array}{c}\text { Closed Nuclear Fuel Cycle Alternatives } \\
5,600\end{array}$ & $\begin{array}{c}3,100,000 \\
\text { GNEP }\end{array}$ \\
TOTAL & 9,700 to 416,500 & $1,740,000$ to 2,895,000 \\
Percent of Total Waste & 15,300 to 422,100 & $3,840,000$ to $5,995,000$ \\
Attributed to GNEP & 64 to 99 & 36 to 48 \\
& Open Nuclear Fuel Cycle Alternatives & $3,100,000$ \\
Non-GNEP Inventory & 5,600 & 150,000 to 585,000 \\
GNEP & 2,500 & $3,250,000$ to $3,685,000$ \\
TOTAL & 8,100 & 5 to 16 \\
Percent of Total Waste & 31 & \\
Attributed to GNEP & &
\end{tabular}

\subsubsection{Transportation}

Nonradiological. Given the trends in population growth and related trends of increased industrial, commercial, and residential development, incremental increases in road traffic are likely for the United States in the foreseeable future. Demand for transportation is expected to be proportional to urban activities, economic growth, and population growth. For purposes of this

\footnotetext{
${ }^{4}$ Thermal Reactor Recycle Alternative (Option 2) not included due to lack of data for DUPIC fuel fabrication facility.
} 
PEIS cumulative impact analysis, it is assumed that future demands on the transportation infrastructure would be directly proportionate to population growth and could be expected to grow by approximately 48 percent by the year 2060 . These increased demands would require expansion of the U.S. transportation system, including the building of new roads, expansion of existing roads, and new interstate systems, airports, and other transportation systems. This would affect land use, water use, air quality, biological resources, the visual environment, human health, and socioeconomics. The specific impacts associated with expanding the U.S. transportation system would be highly dependent upon demographics and the associated localized demands, which are unknown. This PEIS acknowledges that improvements in, and expansions of, mass transit systems could mitigate impacts, but without specific proposals it is not possible to quantify how these initiatives could change the overall demands on the U.S. transportation infrastructure.

Development of more efficient transportation systems (e.g., cars, trains, airplanes, and mass transit) is expected to continue in the foreseeable future. Research and development could make possible the availability of drastic advancements in transportation technology. These new transportation technologies may lead to improvements in transportation efficiency, safety, and emissions, such as lightweight recyclable materials and catalysts for reducing exhaust pollution in the future. Increased research could also lead to the development of vehicles capable of up to three times greater fuel efficiency.

The alternatives in this PEIS would not have any meaningful effect on nonradiological transportation activities in the United States and would not contribute to cumulative impacts. In addition, funding for transportation projects is a political issue occurring at many levels and resulting in disproportionate regional expenditures regardless of growth. This would be expected to accentuate regional disparities in transportation infrastructure investment, over time.

Radiological. The Final Supplemental Environmental Impact Statement for a Geologic Repository for the Disposal of Spent Nuclear Fuel and High-Level Radioactive Waste at Yucca Mountain, Nye County, Nevada (hereafter The Yucca Mountain Final SEIS) (DOE 2008f) includes a detailed analysis of the cumulative transportation impacts associated with past, present, and future radiological shipments (including SNF and high-level radioactive waste to be disposed of at the Yucca Mountain repository). That analysis includes consideration of impacts from 1943 through 2073 (which falls within the approximate endpoint for implementation [20602070] in this GNEP PEIS). Based on the Yucca Mountain Final SEIS cumulative impact analysis, DOE estimated the cumulative transportation impacts shown in Table 5.2.4-1. 
TABLE 5.2.4-1—Potential Cumulative Transportation Impacts

\begin{tabular}{|c|c|c|c|c|c|}
\hline & \multicolumn{2}{|c|}{ Worker Dose } & \multicolumn{2}{|c|}{ General Population Dose } & \multirow[t]{2}{*}{$\begin{array}{c}\text { Traffic } \\
\text { Fatalities }\end{array}$} \\
\hline & person-rem & LCF & person-rem & LCF & \\
\hline \multicolumn{6}{|c|}{ Collective dose and traffic fatalities of non-GNEP transportation } \\
\hline $\begin{array}{l}\text { Historical DOE shipments and } \\
\text { reasonably foreseeable actions }\end{array}$ & 28,000 & 17 & 49,000 & 29 & 94 \\
\hline $\begin{array}{l}\text { General radioactive material } \\
\text { transportation }(1943 \text { to } 2073)^{\mathrm{c}}\end{array}$ & 350,000 & 210 & 300,000 & 180 & 28 \\
\hline $\begin{array}{l}\text { Yucca Mountain estimated } \\
\text { impacts }^{\mathrm{d}}\end{array}$ & $5,600-5,900$ & 3 & $1,100-1,200$ & 1 & 3 \\
\hline $\begin{array}{l}\text { Subtotal of non-GNEP } \\
\text { transportation impacts }\end{array}$ & 380,000 & 230 & 350,000 & 210 & 130 \\
\hline $\begin{array}{l}\text { GNEP Alternatives } \\
\text { (Low values are for No Action } \\
\text { Alternative, Truck and Rail } \\
\text { Scenario }^{\text {f; }} \text { High values are for } \\
\text { All-HTGR Alternative, Truck } \\
\text { Scenario }^{\text {e }}\end{array}$ & $450-270,000$ & $0-160$ & $1,540-1,400,000$ & $1-820$ & $3-150$ \\
\hline $\begin{array}{l}\text { Total Collective } \\
\text { Transportation Impacts }\end{array}$ & $\begin{array}{c}380,000- \\
650,000\end{array}$ & $230-390$ & $\begin{array}{l}350,000- \\
1,800,000\end{array}$ & $\begin{array}{l}210- \\
1,000\end{array}$ & $130-280$ \\
\hline
\end{tabular}

Source: DOE 2008f, Table 8-14

${ }^{\text {a }}$ The values provided in this column represent the number of expected vehicular accident fatalities. Additional fatalities due to release of radioactive materials are less than one percent of these impacts; therefore, these are not included. For comparison, there could be 28 expected fatalities over the 131-year period (1943-2073) based on the NRC traffic fatality rate of 0.213 traffic fatalities per year from radioactive material shipments (NRC 1977b).

${ }^{\mathrm{b}}$ The values provided in this row represent all known historical DOE shipments, starting in 1943 (the year operations began at the Hanford Site and Oak Ridge Reservation) and all reasonably foreseeable actions involving transportation of radioactive materials through 2073 (the assumed end date for Yucca Mountain shipments) provided in other NEPA documents. The values are based on in-transit impacts only. Table 8-14 of DOE $2008 \mathrm{f}$ is the source of the data provided.

${ }^{\mathrm{c}}$ This row represents an estimated collective dose due to transport of eight categories of radioactive materials [1) industrial, 2) radiography, 3) medical, 4) fuel cycle, 5) research and development, 6) unknown, 7) waste, and 8) other]. The values are based on in-transit impacts only.

${ }^{\mathrm{d}}$ Values provided represent the Yucca Mountain Supplemental EIS proposed action. The values are based on in-transit impacts only. Source: DOE 2008f, Table 8-14.

${ }^{\mathfrak{e}}$ The All-High Temperature Gas-Cooled Option, Truck Scenario represents the maximum estimated transportation impacts of the programmatic alternatives analyzed in the GNEP PEIS. The values are based on in-transit impacts only. Source: Table 4.8-13.

${ }^{\mathrm{f}}$ The No Action Alternative, Truck and Rail Scenario represents the minimum estimated transportation impacts of the programmatic alternatives analyzed in the GNEP PEIS. The values are based on in-transit impacts only. Source: Table 4.8-14.

Note: Numbers are rounded to two significant figures; therefore, totals may differ from sums.

\subsubsection{Land Use}

The U.S. population growth would lead to increased land development. This would disturb land that is currently undisturbed or used for other activities such as ranching and agriculture. As discussed in Chapter 3, land area of the continental United States covers about 1.94 billion acres (785 million hectares [ha]). Of this, developed land accounts for approximately 108 million acres (44 million ha) (approximately 5.6 percent of the total land area). Assuming that future land use requirements would be proportionate to population increases, the amount of developed land could increase to approximately 160 million acres (64 million ha) by approximately 2060 . Increased land development could affect air quality, the visual environment, biological resources, human health, and socioeconomics. The specific impacts associated with increased use would be highly dependent upon the locations disturbed, which are unknown. 
Urban land use in the United States continues to increase as the population increases and the economy expands. This trend is expected to continue in the foreseeable future. Besides providing many social and economic benefits, changes in land use patterns would continue to have impact on the natural environment. The role of technology as a potential cause of past and prospective changes in land use can be significant. Technological development can alter the usefulness and demand for different natural resources. The extension of basic transport infrastructure such as roads, railways, and airports, is estimated to open up previously inaccessible resources and lead to their exploitation and degradation in the future. Technological developments and their application such as improvements in methods of converting biomass into energy, use of information-processing technologies in crop and pest management, and the development of new plant and animal strains through research in biotechnology may lead to major shifts in land use in the foreseeable future (Brouwer et al. 1991).

The alternatives in this PEIS could result in land disturbances of approximately 600,000 acres (243,000 ha) for the $200 \mathrm{GWe}$ scenario. Future land use requirements associated with population growth are projected to result in the development of approximately 52 million acres ( 21 million ha) by approximately 2060 (from 108 million acres to 160 million acres [44 million to 65 million ha]). Consequently, the land use impacts from the PEIS alternatives would account for less than a 1.5 percent increase compared to the land use associated with population growth.

\subsubsection{Air Quality and Greenhouse Gases}

Regional air quality is primarily a function of pollutant emission levels in the nearby area. Air quality is generally much lower in urban and highly industrialized areas where a large number of pollutant emission sources are present in a relatively small area. To a lesser extent, weather patterns, topography, vegetation cover, and state air quality standards can affect regional air quality. As shown on Figure 3.2.1-1, most regions of the United States currently satisfy the National Ambient Air Quality Standards (NAAQS). Increased population would lead to increased impacts on air quality. Increased urban sprawl and industrialization would change visibility, and increase impairment in Class I areas, trace metal deposition, mercury dispersion and bioaccumulation, and atmospheric greenhouse gas levels. Adverse air quality impacts would result from a large number of mobile and stationary sources across a wide geographic domain.

Operation of some energy sources would generate greenhouse gas emissions and thus incrementally contribute to global atmospheric levels of these gases. Increased traffic and transportation demands would also contribute to incremental impacts on air quality. In 2006, the total U.S. carbon dioxide $\left(\mathrm{CO}_{2}\right)$ emissions from all sources were 5,935 million metric tons (MT). Carbon dioxide emissions in 2006 from power generation were approximately 2,344 million MT. Approximately 83 percent of this (1,938 million MT) was due to electricity generation from coal, and 15 percent (340 million MT) was due to electricity generation from natural gas (EIA 2007m).

Technology development could improve air quality by reducing the emissions from power plants and transportation systems. Most recent data shows that the United States produces about 22 percent of global carbon dioxide emissions, primarily because the United States economy is 
the largest in the world and the United States meets most of its energy needs through burning fossil fuels. While technology developments (e.g., low- and zero-emission vehicles and carbon sequestration for coal plants) could reduce the emissions in both the transportation and energy sectors, $\mathrm{CO}_{2}$ emissions in the United States are projected to continue rising (EIA 2007m).

The alternatives in this PEIS could have a positive impact on air quality and greenhouse gas emissions as nuclear power generation of electricity could replace a similar amount of fossil fuel generation of electricity. For every GWe produced by nuclear power, approximately $2,000,000 \mathrm{MT}$ of $\mathrm{CO}_{2}$ (typical coal plant) or $1,000,000 \mathrm{MT}$ of $\mathrm{CO}_{2}$ (typical natural gas plantsee Section 4.1.8) would not be emitted (assuming such plants were not engaging in carbon sequestration) (EIA 2001).

\subsubsection{Construction Materials}

Population increases would directly affect the use of construction materials such as steel and concrete. As shown in Chapter 3, the United States annually uses about 120 million MT of steel and 120 million MT of concrete. Population increases would require more housing, roads, office buildings, and other infrastructure. Assuming that the annual use of steel and concrete would be proportionate to increases in population, the United States could expect that the use of both steel and concrete would grow to approximately 178 million MT, each, in about 2060.

Although technology development could affect the use of construction materials such as steel and concrete, through the wider use of composite materials and new products, any effects would be difficult to quantify without understanding the nature of the technological development. As such, this PEIS does not estimate any changes in steel or concrete use due to technology developments but recognizes the potential to diminish requirements based on current construction material technology.

The alternatives in this PEIS could result in the construction of more than 200 major nuclear facilities for the $200 \mathrm{GWe}$ scenario over the approximate 50-year time period assessed. As described in Chapter 3, material requirements for a nuclear power plant would vary by design and site location, but requirements for a typical 1 GWe nuclear plant would include approximately $150,000 \mathrm{MT}$ of steel and $850,000 \mathrm{MT}$ of concrete. Constructing approximately 200 major new nuclear facilities over approximately 50 years would result in an average of 4 new major nuclear facilities annually. On an annual basis, these new nuclear facilities would use approximately 600,000 MT of steel and 3.4 million MT of concrete. Compared to the current usage of steel and concrete, these increases would amount to less than 1 percent (steel) and 2.8 percent (concrete).

\subsubsection{Impacts Beyond 50 Years}

Actions taken based on this PEIS would result in impacts that would extend well beyond a 50 -year implementation period. For example, all alternatives would generate SNF and/or high-level waste (HLW) which would need to be managed for hundreds and potentially thousands of years. The PEIS assesses the impacts of disposing of this SNF and/or HLW in a future geologic repository. In addition the closed fuel cycle alternatives could result in a 
disposition option to store cesium and strontium for more than 50 years. The PEIS analyzes the impacts for such storage in Chapter 4, Section 4.3.3. The PEIS recognizes that for each additional year of operation beyond the 50-year implementation period, SNF and/or HLW would be generated and require management. The potential impacts associated with such operations would be similar in nature to the impacts presented for the 50 -year implementation period. 


\subsection{REFERENCES}

72 FR 40135

42 U.S.C. 6291

42 U.S.C. 10101 et seq.

Brouwer et al. 1991

CEQ 1997a

DOE $2008 f$

EIA 2001

EIA 2007a
U.S. Department of Energy (DOE), "Notice of Intent to Prepare an Environmental Impact Statement for the Disposal of Greater-ThanClass-C Low-Level Radioactive Waste," Office of the Federal Register, National Archives and Records Administration, Washington, DC, July 23, 2007.

"Definitions: Renewable Fuels, Consumer Protection, and Energy Efficiency Act of 2007," United States Code, Washington, DC, May 17, 2007.

"Nuclear Waste Policy Act of 1982," (NWPA), United States Code, Washington, DC, January 7, 1983.

Brouwer, F.M., A.J Thomas, and M.J. Chadwick, "Land Use Changes in Europe: Processes of Change, Environmental Transformations, and Future Patterns," OSTI ID: 6281420, January 1, 1991.

Council on Environmental Quality (CEQ), "Considering Cumulative Effects Under the National Environmental Policy Act," Executive Office of the President, Council on Environmental Quality, Washington, DC, January 1997.

DOE, "Final Supplemental Environmental Impact Statement for a Geologic Repository for the Disposal of Spent Nuclear Fuel and High-Level Radioactive Waste at Yucca Mountain, Nye County, Nevada," DOE/EIS-0250F-S1, U.S. Department of Energy, Office of Civilian Radioactive Waste Management, Las Vegas, NV, June 2008.

Energy Information Administration (EIA), "Impact of U.S. Nuclear Generation on Greenhouse Gas Emissions," R.E. Hagen, J.R. Moens, and Z.D. Nikodem, Energy Information Administration, U.S. Department of Energy, Washington, DC, November 6-9, 2001.

EIA, "AEO2008, Annual Energy Outlook 2008 (Early Release)," DOE/EIA-0383, Energy Information Administration, U.S. Department of Energy, Washington, DC, December 2007. Accessed at http://www.eia.doe.gov/oiaf/aeo/pdf/earlyrelease.pdf on January 22, 2008. 
EIA $2007 \mathrm{~m}$

EIA 2008a

GAO 2002

IFPRI 2002

MIMS 2008

NETL 2004

NRC 1977b

NRC 2007g

USCB 2008a
EIA, "Emissions of Greenhouse Gases in the United States 2006," DOE/EIA-0573 (2006), Energy Information Administration, U.S. Department of Energy, Washington, DC, November 2007. Accessed at http://www.eia.doe.gov/oiaf/1605/ggrpt/index.html on May 2, 2008.

EIA, "Annual Energy Outlook 2008 with Projections To 2030," DOE/EIA-0383(2008), Energy Information Administration, U.S. Department of Energy, Washington, DC, June 2008. Accessed at http://www.eia.doe.gov/oiaf/aeo/ on August 20, 2008.

U.S. General Accounting Office (GAO), "Air Pollution: Meeting Future Electricity Demands Will Increase Emissions of Some Harmful Substances," Report to Congressional Requesters, U.S. General Accounting Office, Washington, DC, October 2002.

International Food Policy Research Institute (IFPRI), "Global Water Outlook to 2025 - Averting an Impending Crisis," M.W. Rosegrant, X. Cai, and S. A. Cline, Washington, DC, September 2002.

Manifest Information Management System (MIMS), "Volume and Activity Summary," U.S. Department of Energy, Washington, DC, 2008. Accessed at http://mims.apps.em.doe.gov/mims.asp\# on August 15, 2008.

National Energy Technology Laboratory (NETL), "Estimating Freshwater Needs to Meet 2025 Electricity: Generating Capacity Forecasts," J. Hoffmann, S. Forbes, and T. Feeley, U.S. Department of Energy, National Energy Technology Laboratory, June 2004.

U.S. Nuclear Regulatory Commission (NRC), "Final Environmental Statement on the Transportation of Radioactive Material by Air and Other Modes," NUREG-0170, Office of Standards Development, U.S. Nuclear Regulatory Commission, Washington, DC, December 1977.

NRC, "Year 2005 Low-Level Waste Disposal Statistics," U.S. Nuclear Regulatory Commission, Washington, DC, March 21, 2007.

U.S. Census Bureau (USCB), "U.S. and World Population Clocks - POPClocks," U.S. Census Bureau, Washington, DC, 2008. Accessed at http://www.census.gov/main/www/popclock.html on August 1, 2008. 
USCB 2008b

USGS 2004a
USCB, "International Database (IDB), Country Summary: United States," Table 094, U.S. Census Bureau, Washington, DC, 2008. Accessed at http://www.census.gov/ipc/www/idb/country/ usportal.html on February 10, 2008.

U.S. Geological Survey (USGS), "Estimated Use of Water in the United States in 2000," Survey Circular 1268, Hutson, Susan S., Nancy L. Barber, Joan F. Kenny, Kristin S. Linsey, Deborah S. Lumia, and Molly A. Maupin, U.S. Geological Survey, February 1, 2005. Accessed at http://pubs.usgs.gov/circ/2004/circ1268/ on January 5, 2008. 


\section{CHAPTER 6}

\section{COMPLIANCE, REGULATORY REQUIREMENTS, AND PERMITS FOR DOMESTIC PROGRAMMATIC ALTERNATIVES}





\section{CHAPTER 6 COMPLIANCE, REGULATORY REQUIREMENTS, AND PERMITS FOR DOMESTIC PROGRAMMATIC ALTERNATIVES}

Chapter 6 describes the environment, health and safety statutes and regulations, U.S. Department of Energy (DOE) Directives, and Executive Orders that potentially apply to the domestic programmatic alternatives in the Global Nuclear Energy Partnership (GNEP) Programmatic Environmental Impact Statement (PEIS). Concluding this chapter is a discussion of consultations relevant to the PEIS.

\subsection{INTRODUCTION}

This chapter provides information concerning the environmental standards that could impact proposed plans for the domestic programmatic alternatives presented in the Global Nuclear Energy Partnership (GNEP) Programmatic Environmental Impact Statement (PEIS). This section presents primary environment, health and safety compliance, licensing and other permit requirements that could affect the implementation of the alternatives. These requirements are found in Federal and state statutes, regulations, permits, approvals, and consultations, in Executive Orders, and in U.S. Department of Energy (DOE) Directives. The citations identify the standards to be used for evaluating the ability of the potential future actions to implement alternatives to meet environmental, safety, and health requirements and for obtaining required Federal permits and licenses.

\subsection{BACKGROUND}

In general, Federal statutes establish national policies, create legal requirements, and authorize Federal agencies to create regulations that conform to statutes. These statutes are administered by various Federal agencies including: DOE, Nuclear Regulatory Commission (NRC), Environmental Protection Agency (EPA), Department of Transportation (DOT), and Department of Labor (DOL). Executive Orders (EOs) are issued by the President and establish policies and requirements for Federal Executive Branch agencies. Some regulatory programs under EPA or NRC jurisdiction are administrated by state agencies in states having programs at least as stringent as the Federal program; however, both NRC and EPA retain oversight of the respective programs.

\subsection{Environmental Statutes, Orders, ANd Agreements}

The National Environmental Policy Act (NEPA) requires that agencies analyze and consider the potential environmental impacts of proposed major Federal actions and alternatives before decisions are made and before actions are taken. The analysis also identifies measures that could be taken to avoid or mitigate potential impacts. Regulatory environmental protection requirements are designed to protect human health and the environment, including the air, water, and land. Identification of environmental protection statutes, regulations, and orders with 
requirements that would be triggered by the alternatives is one means for examining actions that may harm the environment before making a decision to carry out an action. Principal requirements are identified by the applicable environmental statutes and regulations.

The Atomic Energy Act of 1954 (42 U.S.C. \$2011 et seq.) (the “Act"), provides a framework for regulatory authority over the production, possession, use, and disposal of source, special nuclear, and byproduct material as those terms are defined in the Act. DOE and the NRC are successor agencies to the Atomic Energy Commission established by the Act. DOE retained regulatory authority over activities conducted by or on its behalf, except where NRC is specifically authorized by statute to regulate DOE activities. DOE is authorized to establish standards that protect health and minimize danger to life or property from activities under DOE's jurisdiction (Section 161(b) of the Act). NRC was granted regulatory authority over commercial nuclear materials, facilities and activities. The NRC, or Agreement States to which NRC has transferred its regulatory authority, license commercial nuclear fuel facilities involved in the processing and fabrication of uranium ore into reactor fuel. Licenses for commercial nuclear power plants and their operators are also issued by the NRC and Agreement States. Licenses for other commercial activities involving radioactive materials, including waste management, are issued either by the NRC or by state governments under NRC-approved regulatory programs. The NRC focuses on protecting public health and safety, security, and the environment. Any new commercial nuclear facility (e.g., enrichment facility, fuel fabrication facility, spent nuclear fuel separations facility, or reactor) or technology addressed in the programmatic alternatives would be subject to permitting or licensing decisions by a number of different government agencies. Changes to the regulatory framework may be needed to enable the licensing of these nuclear facilities, some of which would be first-of-a-kind facilities.

The Federal Compliance with Pollution Control Standards, EO 12088 (43 FR 47707, October 13, 1978), requires Federal agencies, including DOE, to comply with applicable administrative and procedural pollution control standards established by, but not limited to, the Clean Air Act (CAA), Noise Control Act, Clean Water Act (CWA), Safe Drinking Water Act (SDWA), Toxic Substances Control Act (TSCA), and Resource Conservation and Recovery Act (RCRA). DOE Order 450.1B, the General Environmental Protection Program, establishes the environmental protection program requirements, authorities, and responsibilities for DOE operations. The Federal Facility Compliance Act waived sovereign immunity of the Federal government at Federal facilities under RCRA. 


\subsubsection{Federal Environmental Statutes and Regulations}

Applicable environmental statutes and regulations can be categorized by environmental pathways: air, water, and land (which includes waste management and pollution prevention), and the subsequent impacts to worker safety and health, the public, and the natural environment. Table 6.3.1-1 lists Federal statutes and EOs that pertain to the control, remediation, and/or regulation of the environment and worker safety, grouped by resources to which each requirement pertains. For most requirements identified, the statute and corresponding regulatory citations are listed. Description of the basic environmental actions subject to each Federal statute and EO is also provided. DOE is committed to comply with all applicable environmental statutes, regulatory requirements, and Executive and internal orders. Table 6.3.1-2 lists the most pertinent DOE directives (orders, manuals, and notices) for the implementation of environmental, safety and health requirements. 


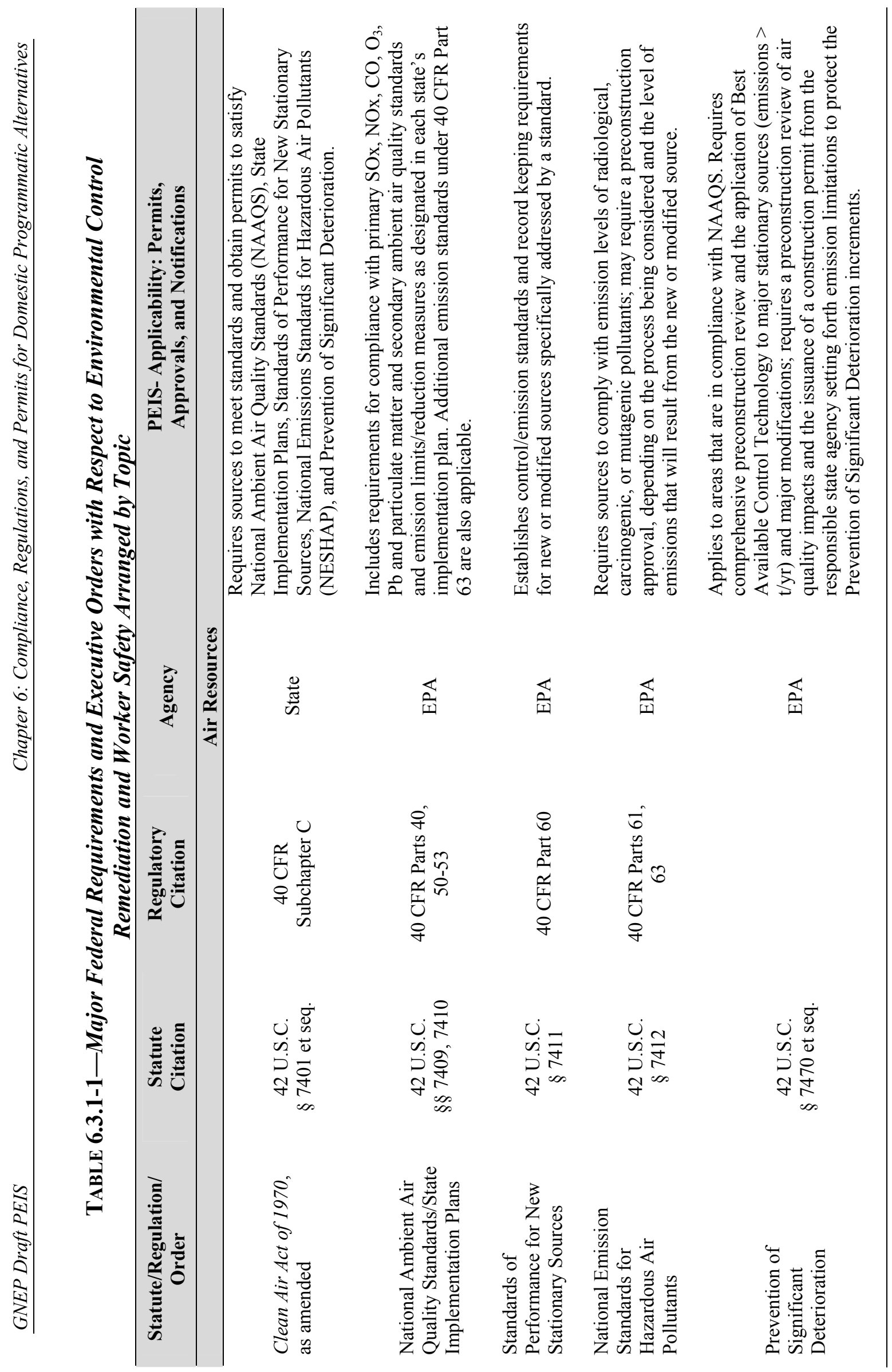




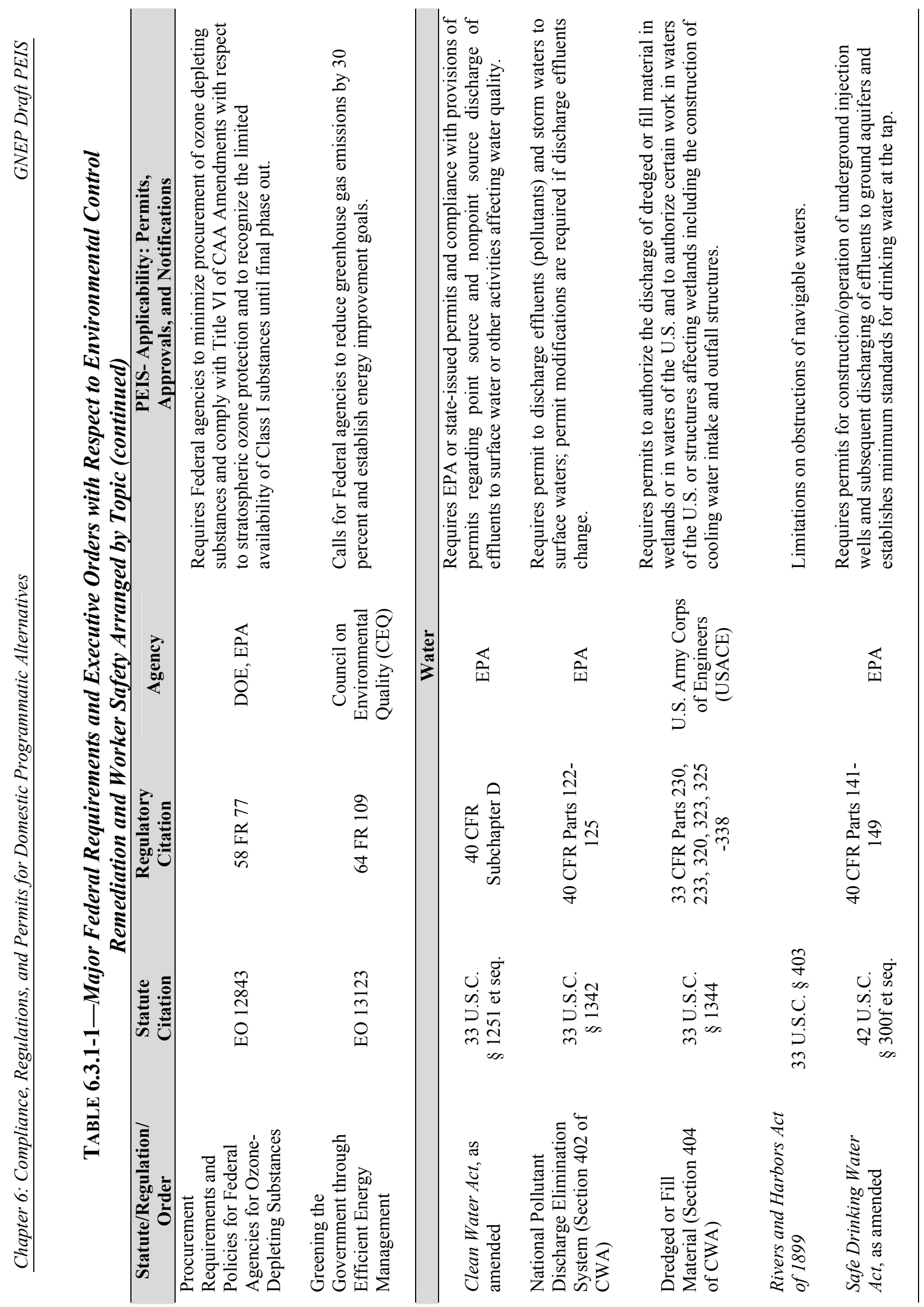




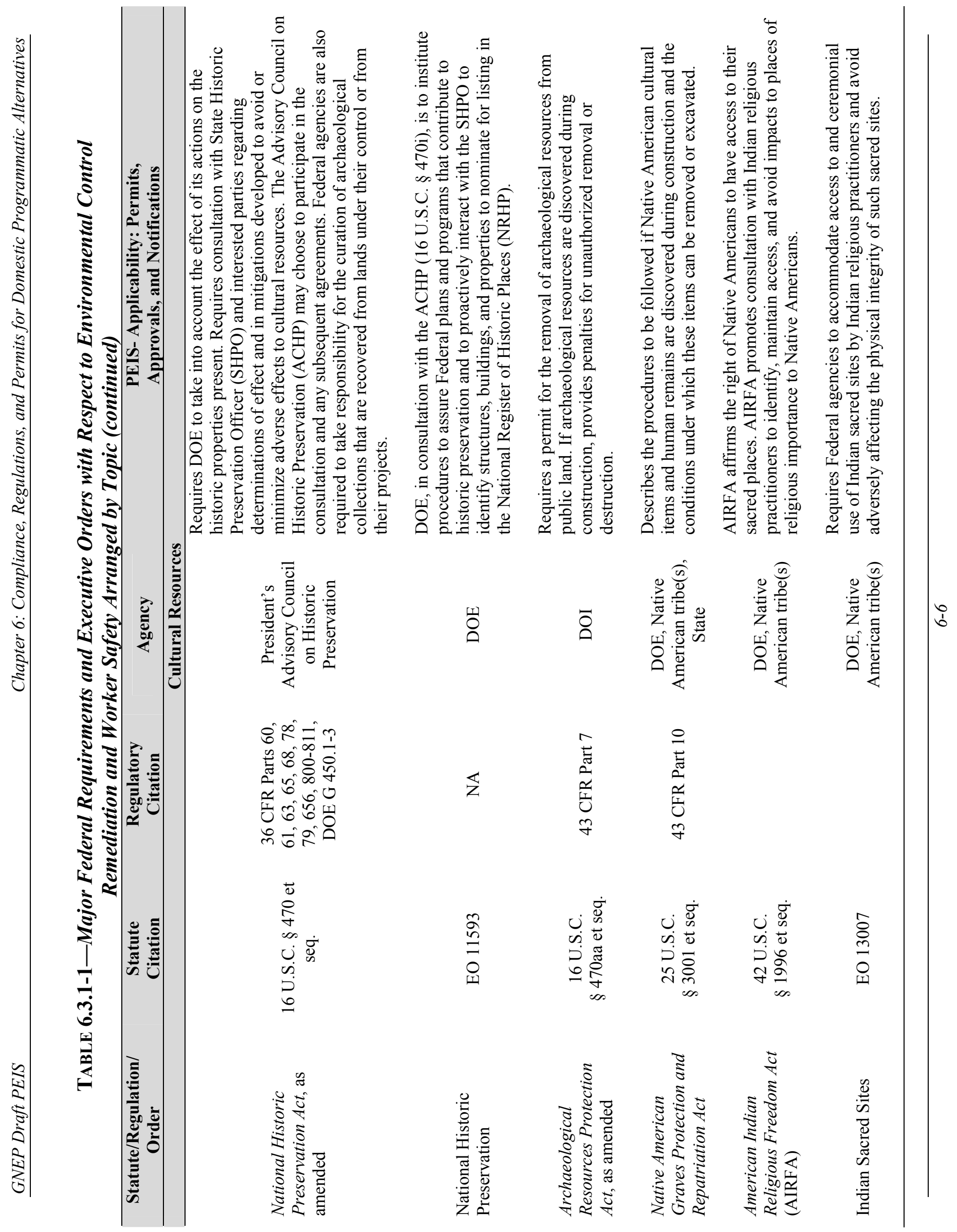




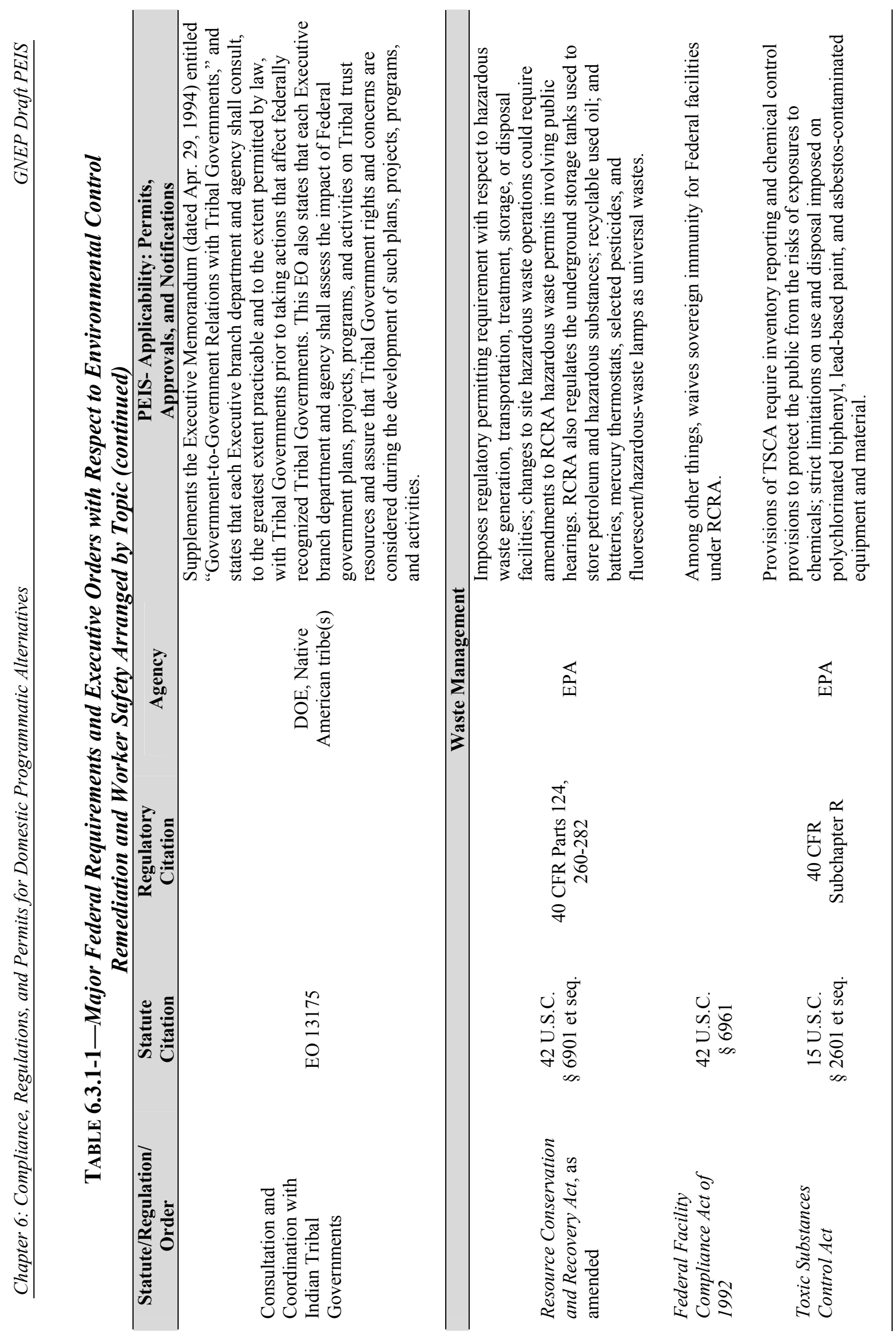




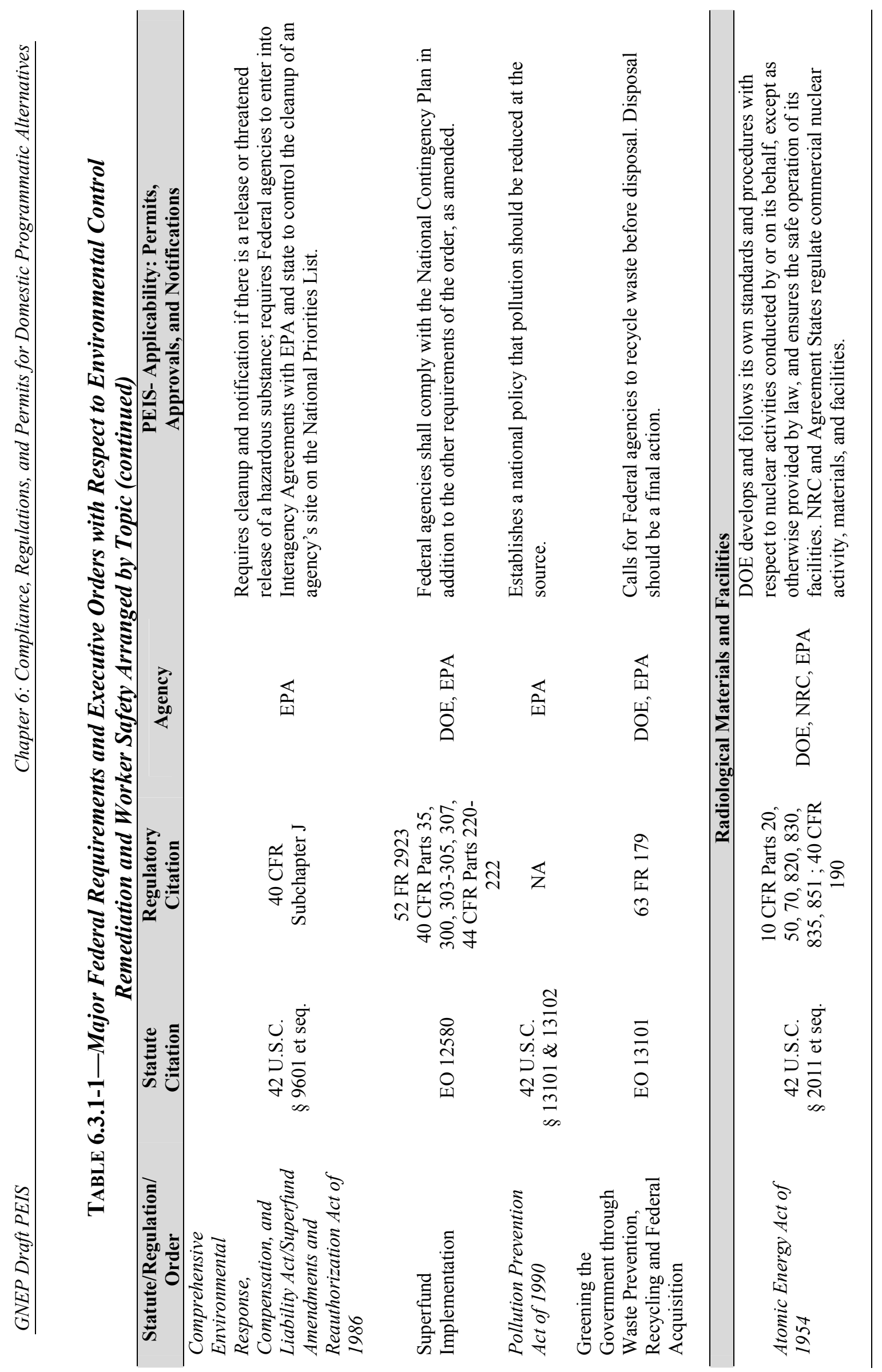




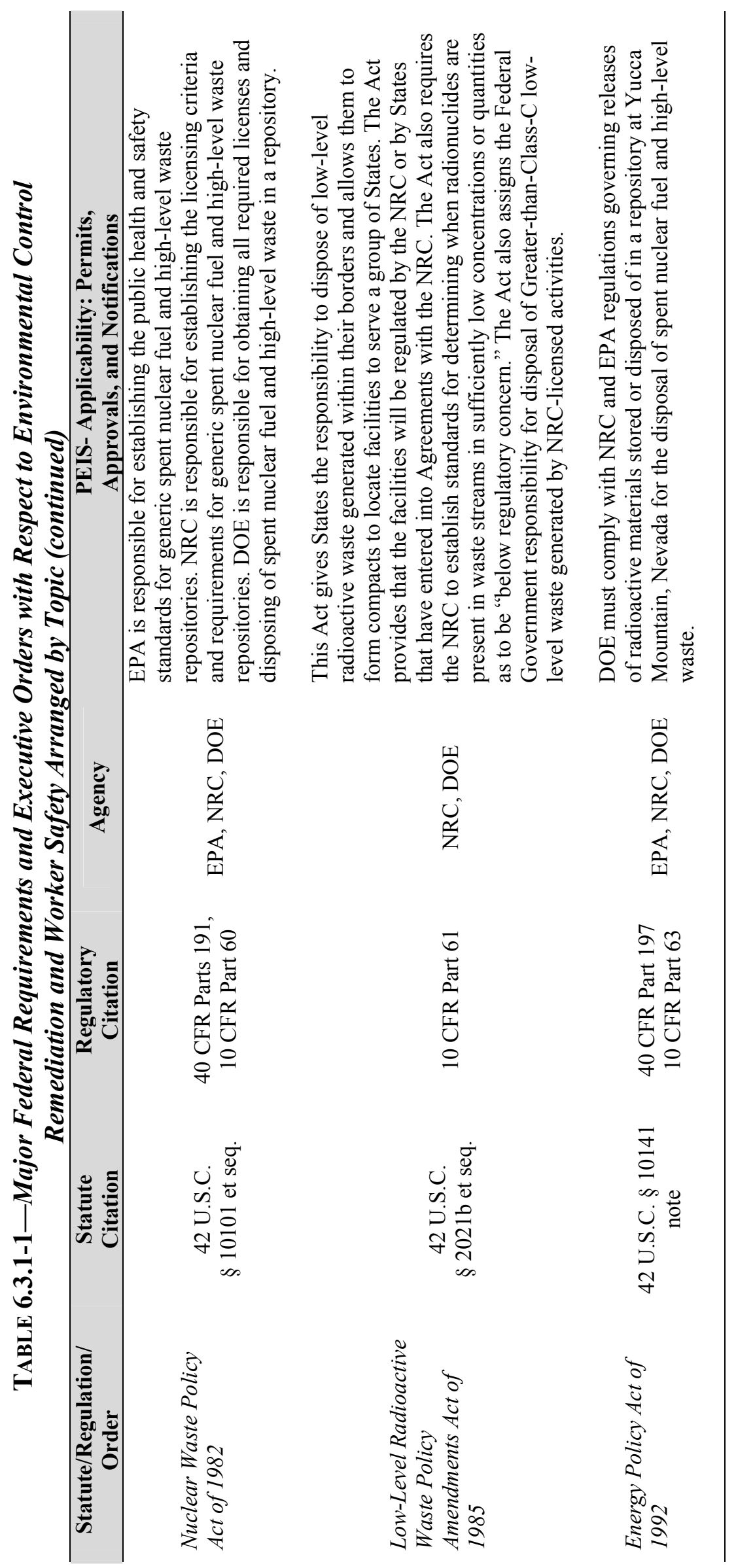




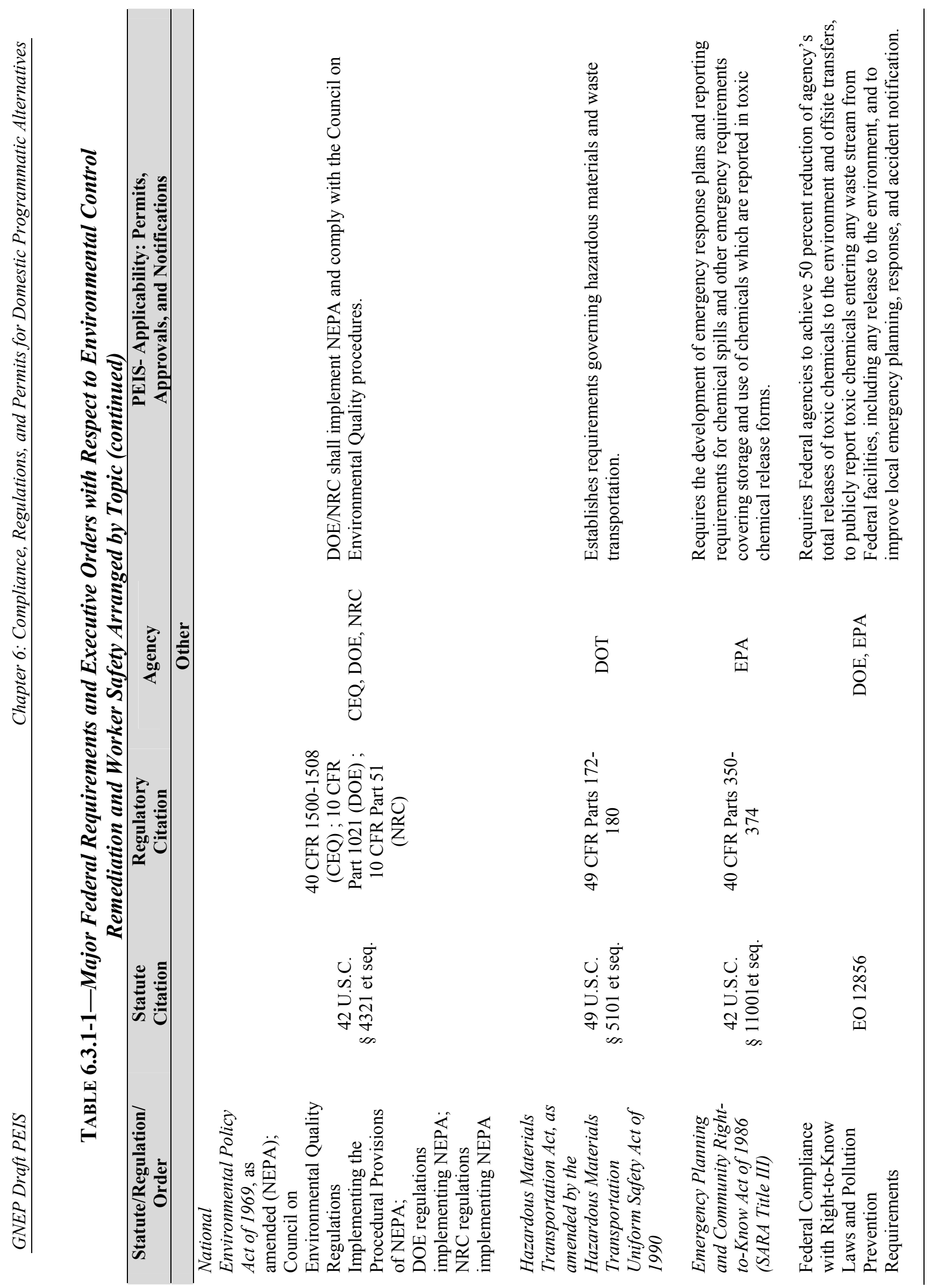




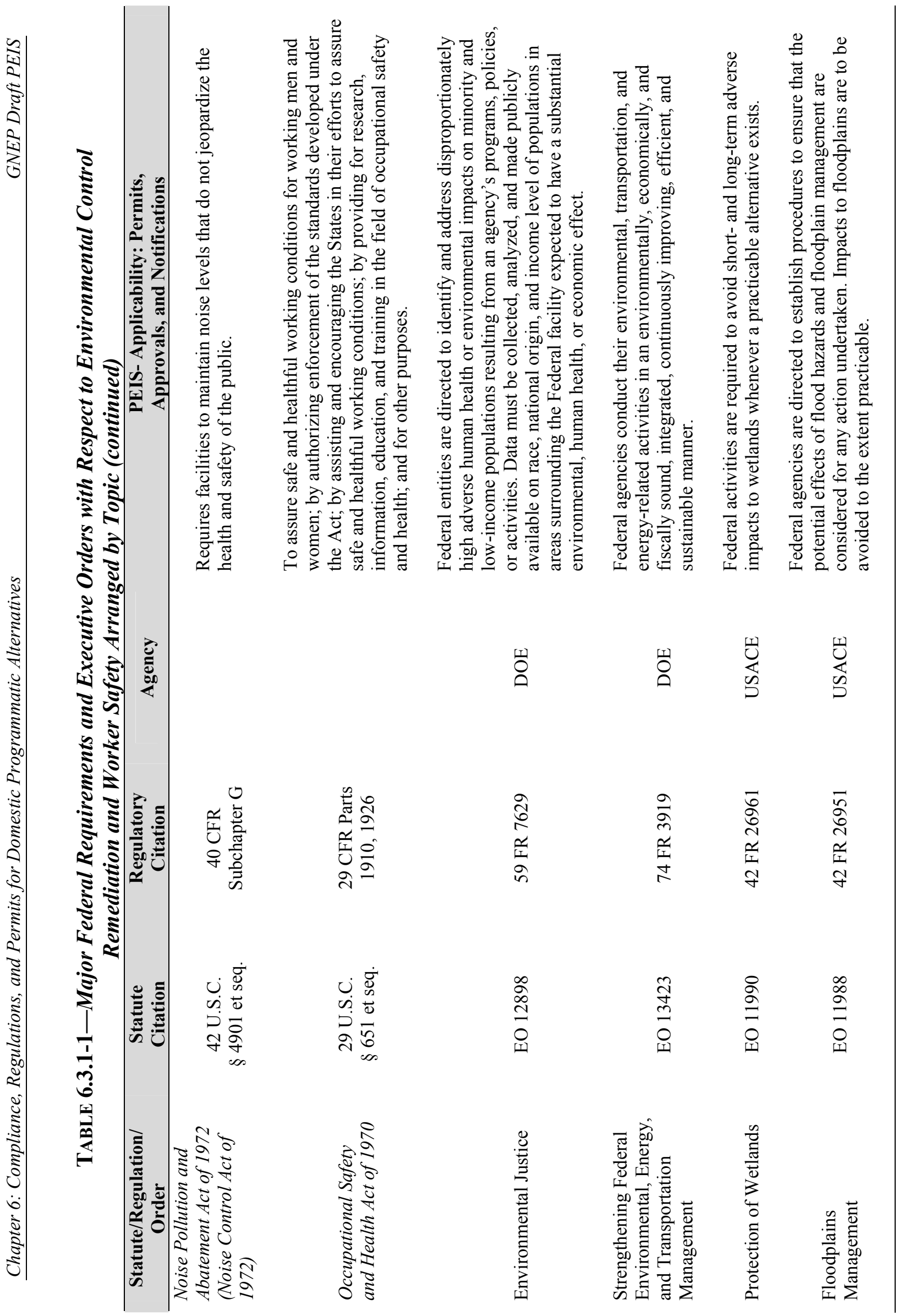



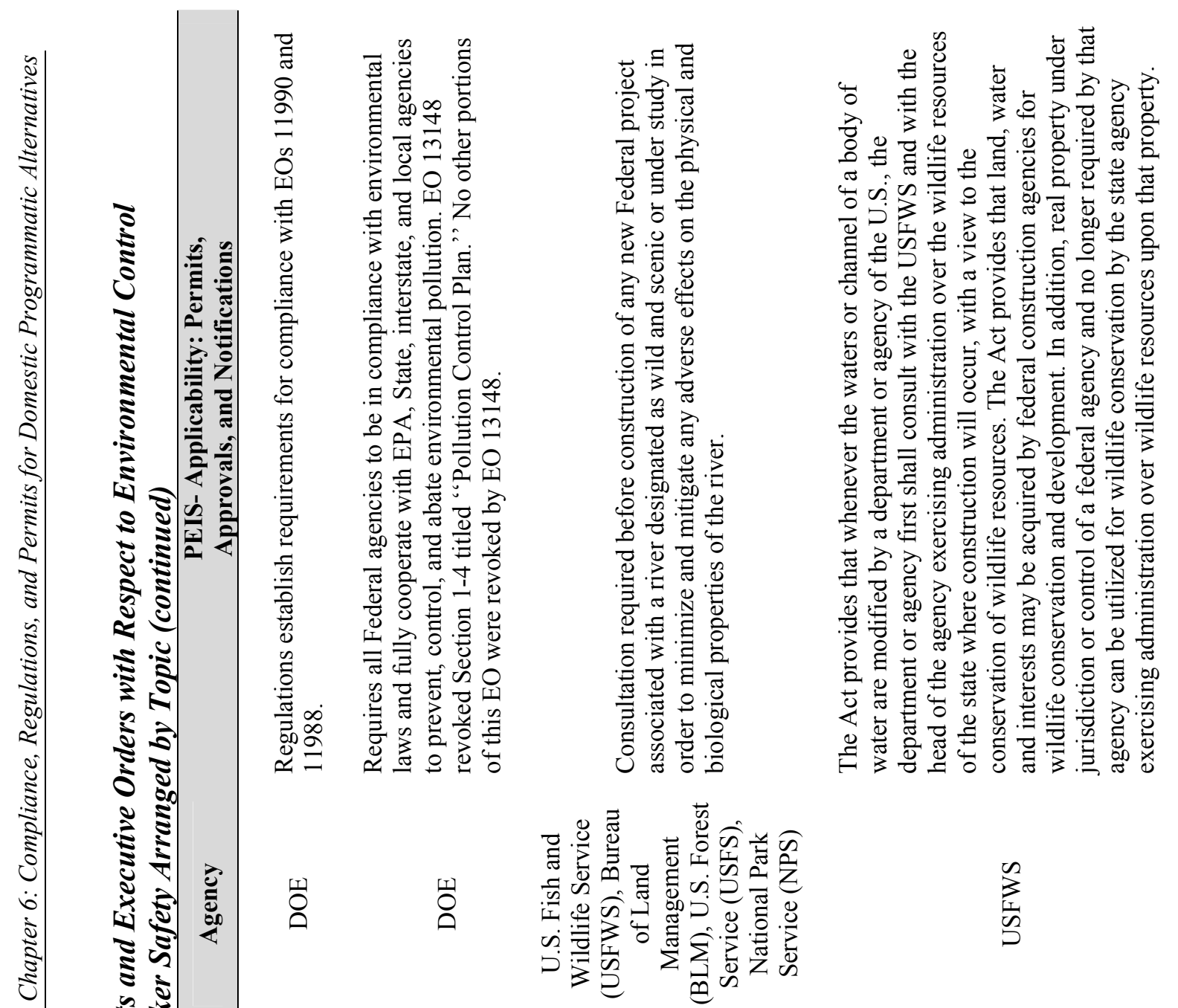

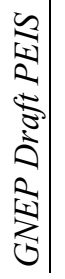
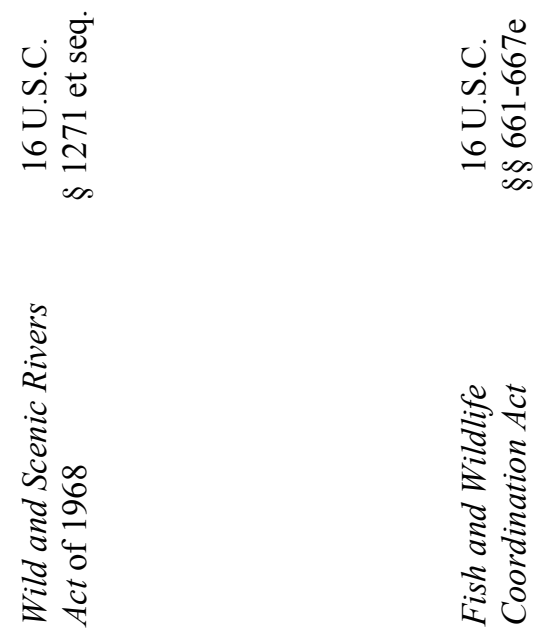


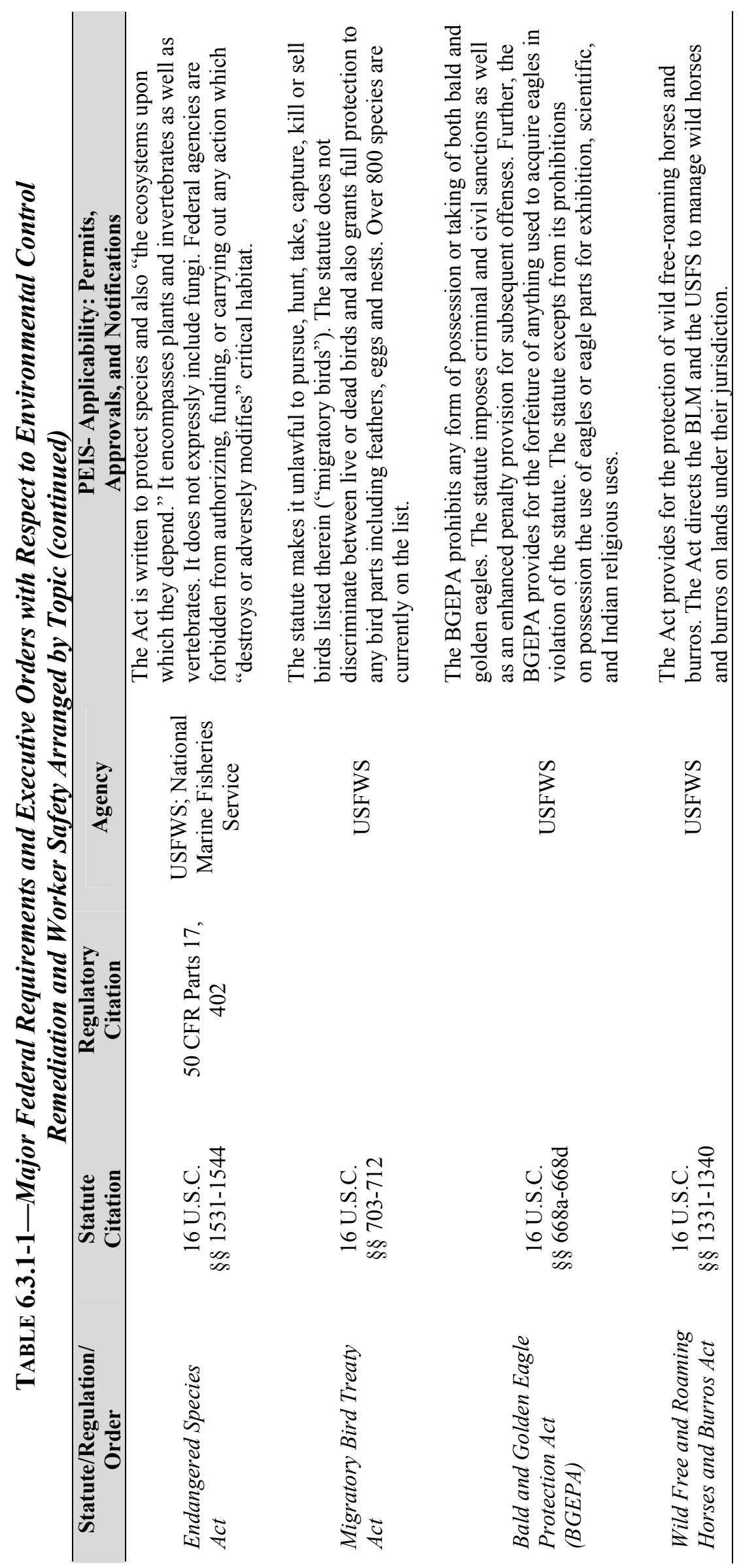




\section{TABLE 6.3.1-2_Selected Department of Energy Directives}

\begin{tabular}{|c|c|}
\hline DOE Directive & Directive Title \\
\hline 5400.5 & Radiation Protection of the Public and the Environment \\
\hline 5480.19 Chg. 2 & Conduct of Operations Requirements for DOE Facilities \\
\hline 5480.20A Chg 1 & $\begin{array}{l}\text { Personnel Selection, Qualification and Training Requirements for DOE Nuclear } \\
\text { Facilities }\end{array}$ \\
\hline 5530.3 Chg 1 & Radiological Assistance Program \\
\hline 5530.4 & Aerial Measuring System \\
\hline 5530.5 Chg 1 & Federal Radiological Monitoring and Assessment Center \\
\hline $5660.1 \mathrm{~B}$ & Management of Nuclear Materials \\
\hline 141.1 & Management of Cultural Resources \\
\hline 141.2 & Public Participation and Community Relations \\
\hline $151.1 \mathrm{C}$ & Comprehensive Energy Management System \\
\hline 153.1 & Departmental Radiological Emergency Response Assets \\
\hline $225.1 \mathrm{~A}$ & Accident Investigations \\
\hline M 231.1 Chg 2 & Environment, Safety and Health Reporting Manual \\
\hline 231.1A Chg 1 & Environment, Safety and Health Reporting \\
\hline 231.1-2 & Occurrence Reporting and Processing of Operations Information Manual \\
\hline 413.3A & Program and Project Management for the Acquisition of Capital Assets \\
\hline 414.1C & Quality Assurance \\
\hline $420.1 \mathrm{~B}$ & acility Safety \\
\hline $420.1-2$ & $\begin{array}{l}\text { Guide for the Mitigation of Natural Phenomena Hazards for DOE Nuclear Facilities } \\
\text { and Nonnuclear Facilities }\end{array}$ \\
\hline $425.1 \mathrm{C}$ & Start-up and Restart of Nuclear Facilities \\
\hline 430.1 & Land Use and Facility Planning \\
\hline 430.1B Chg 1 & Real Property Asset Management \\
\hline $430.2 \mathrm{~B}$ & Departmental Energy, Renewable Energy and Transportation Management \\
\hline 435.1 Chg 1 & Radioactive Waste Management \\
\hline 440.1B & $\begin{array}{l}\text { Worker Protection Program for DOE (Including the National Nuclear Security } \\
\text { Administration) Federal Employees }\end{array}$ \\
\hline 441.1 & Radiological Health and Safety Policy \\
\hline 441.1-1C & $\begin{array}{l}\text { Radiation Protection Programs Guide for Use with Title 10, Code of Federal } \\
\text { Regulations, Part 835, Occupational Radiation Protection }\end{array}$ \\
\hline $450.1 \mathrm{~A}$ & Environmental Protection Program \\
\hline 450.4 & Safety Management System Policy \\
\hline 451.1B Chg 1 & National Environmental Policy Act Compliance Program \\
\hline $460.1 \mathrm{~B}$ & Packaging and Transportation Safety \\
\hline $460.2 \mathrm{~A}$ & Departmental Materials Transportation and Packaging Management \\
\hline $470.2 \mathrm{~B}$ & Independent Oversight and Performance Assurance Program \\
\hline 470.4A & Safeguards and Security Program \\
\hline
\end{tabular}




\subsection{CONSUltation}

Some environmental laws and EOs are integrated into the NEPA process and establish guidelines for review. Pursuant to NEPA and DOE Regulations (10 CFR Part 1021), consultations are conducted with outside Federal, state, and tribal agencies having jurisdiction or special expertise. Agencies involved include those responsible for protecting significant resources, such as endangered species, critical habitats, historic resources, or tribal agreements.

\subsection{WASTE Classification}

Under the GNEP programmatic alternatives, regulatory issues relating to classification of waste streams would be taken into account, and future NEPA analyses would be required prior to determining the final disposition paths. For example, the separated cesium (Cs) and strontium (Sr) waste stream would need to be evaluated to determine whether the Cs and Sr, when decayed, would be considered HLW or LLW. Also, certain wastes generated by reprocessing activities, such as fuel assembly components and gases, would need to be evaluated for determination as HLW requiring disposition in a repository, or another waste categorization based upon hazard and disposal requirements. These waste streams are considered further in Chapter 4. 



\section{CHAPTER 7}

\section{INTERNATIONAL INITIATIVES AND IMPACTS OF THE PROGRAMMATIC ALTERNATIVES}





\section{CHAPTER 7 \\ INTERNATIONAL INITIATIVES \\ AND IMPACTS OF THE \\ PROGRAMMATIC ALTERNATIVES}

Chapter 7 describes the U.S. Department of Energy's (DOE)'s vision for two international elements of the Global Nuclear Energy Partnership initiative-Grid-Appropriate Reactors and Reliable Fuel Services. It also addresses how the selection of a domestic programmatic alternative (as discussed in Chapters 2 through 6 of this PEIS) could affect implementation of a Reliable Fuel Services Program.

\subsection{INTRODUCTION AND BACKGROUND}

At this time, the U.S. Department of Energy (DOE) has no specific proposals for the international component of the Global Nuclear Energy Partnership (GNEP). Rather, DOE is considering several potential international initiatives, none of which has risen to the level of a specific proposed action sufficiently advanced to require review in this programmatic environmental impact statement (PEIS). In this section, DOE describes the steps it has taken to initiate an international dialogue on GNEP principles and describes the various initiatives that it is considering. DOE also identifies the domestic resource areas that could be impacted by such international initiatives and discusses how such initiatives could also affect the global commons. As defined by Executive Order (EO) 12114, the term "global commons" refers to the environment outside the jurisdiction of any nation (e.g., the oceans or Antarctica) (EO 12114).

The international component of the GNEP Program is a cooperative program of those States that share the common vision of the necessity of the expansion of nuclear energy for peaceful purposes worldwide in a safe and secure manner. States participating in this cooperation do not give up any rights, and voluntarily engage to share the effort and gain the benefit of economical, peaceful nuclear energy. GNEP international engagement has built on existing U.S. Government programs in nonproliferation and international security, as well as advanced fuel cycle research and development (R\&D). DOE envisions the international goals embodied within GNEP, as the potential means to accomplish the following objectives:

- Expand nuclear power to help meet growing energy demand in a safe and sustainable manner.

- Establish international supply frameworks to enhance reliable, cost-effective fuel supplies to the world market while reducing the risk of nuclear proliferation by creating a viable alternative to the acquisition of sensitive fuel cycle technologies.

- Develop, demonstrate, and in due course deploy advanced fast reactors that consume transuranic elements from recycled spent nuclear fuel (SNF).

- Develop and demonstrate advanced technologies for recycling SNF with a long-term goal of ceasing separation of plutonium and eventually eliminating stocks of separated civilian plutonium.

- Promote the development of advanced, more proliferation-resistant nuclear power reactors appropriate for the power grids of developing countries and regions. 
- Continue, in cooperation with the International Atomic Energy Agency (IAEA), the development of enhanced nuclear safeguards and ensure nuclear energy systems are used only for peaceful purposes.

These objectives are laid out in a "Statement of Principles," which may be found by accessing the DOE GNEP website at: http://www.gnep.energy.gov/. As of June 2008, 21 nations have signed the Statement of Principles and agreed to be "partner nations." A partner nation is defined as a nation that has agreed to, and signed the GNEP Statement of Principles.

In support of the Statement of Principles, the United States has signed "Civil Nuclear Energy Bilateral Action Plans" with Japan, Russia, and China. One is currently pending with France and is expected to be signed by the end of 2008. These countries are referred to as "Fuel Cycle GNEP Partners." These Action Plans outline cooperative R\&D on advanced reactors, exportable small and medium power reactors, nuclear fuel cycle technologies, and nonproliferation, with the focus on achieving the long-term GNEP vision of the expansion of nuclear power in a manner that reduces proliferation risks. The most significant agreed upon areas of international cooperation are:

- Development of technologies for recycling SNF that do not separate pure plutonium, and

- Development of advanced burner reactors.

Through the multi-lateral GNEP program (referring to all 21 partner nations), two international working groups have been established:

- Reliable Fuel Services Working Group, to investigate nuclear fuel supply and take-back schemes that would eliminate the need for countries to establish their own enrichment and reprocessing capability.

- Infrastructure Working Group, to assist in the development of the requisite infrastructure (regulatory, technical, and administrative) for developing countries (as they acquire responsibility for operating civil nuclear power stations safely, securely, and in compliance with international agreements).

Specific environmental impacts to the United States and the global commons would be addressed at such time as specific international proposals are brought forward. With respect to potential international initiatives, DOE would consider actions to promote safe, secure nuclear power reactors appropriate for developing countries and to support nuclear fuel services for countries that refrain from pursuing enrichment or reprocessing technologies. This, in turn, could affect the types of international programs that would develop and the associated environmental impacts within the United States and the global commons resulting from such programs. The private sector in the United States currently supplies nuclear fuel, both domestically and internationally. Those activities are outside of the alternatives considered by this PEIS and may continue in the future, independent of any Federal actions made as a result of decisions based on this PEIS.

In support of international nonproliferation goals, the United States is considering a policy that promotes an alternative for countries that might otherwise consider developing uranium enrichment or SNF reprocessing capabilities, referred to in this PEIS as the Reliable Fuel 
Services Program. The Reliable Fuel Services concept envisions a group of fuel cycle GNEP partner nations ("supplier nations") that would supply fresh nuclear fuel, either through a fuel lease or other arrangement for supply, to recipients ("user nations") that agree not to pursue their own indigenous enrichment and reprocessing capabilities. The Reliable Fuel Services concept also contemplates return of the spent fuel from the user nations to one of the supplier nations for reprocessing or disposal.

All international cooperation activities are and will be subject to established international standards for safety, safeguards, physical protection, and export control. The domestic programmatic alternatives in this PEIS could influence the types of future international actions that might affect either the international supply of nuclear fuel and/or the reactor technologies used to produce electricity. Either of these could have secondary impacts on the United States. As background, this chapter begins with a discussion of the international energy demands projected over the next several decades. It then looks at some hypothetical activities resulting from actions that could be taken based on this GNEP PEIS, and then gives the reader a perspective on the impacts such actions could have on the United States and the global commons.

\subsubsection{International Energy Demand}

The Energy Information Administration projects that world electricity generation will nearly double from 16,424 billion kilowatt-hours (KWh) in 2004, to more than 30,364 billion $\mathrm{KWh}$ in 2030 (See Figure 7.1.1-1).

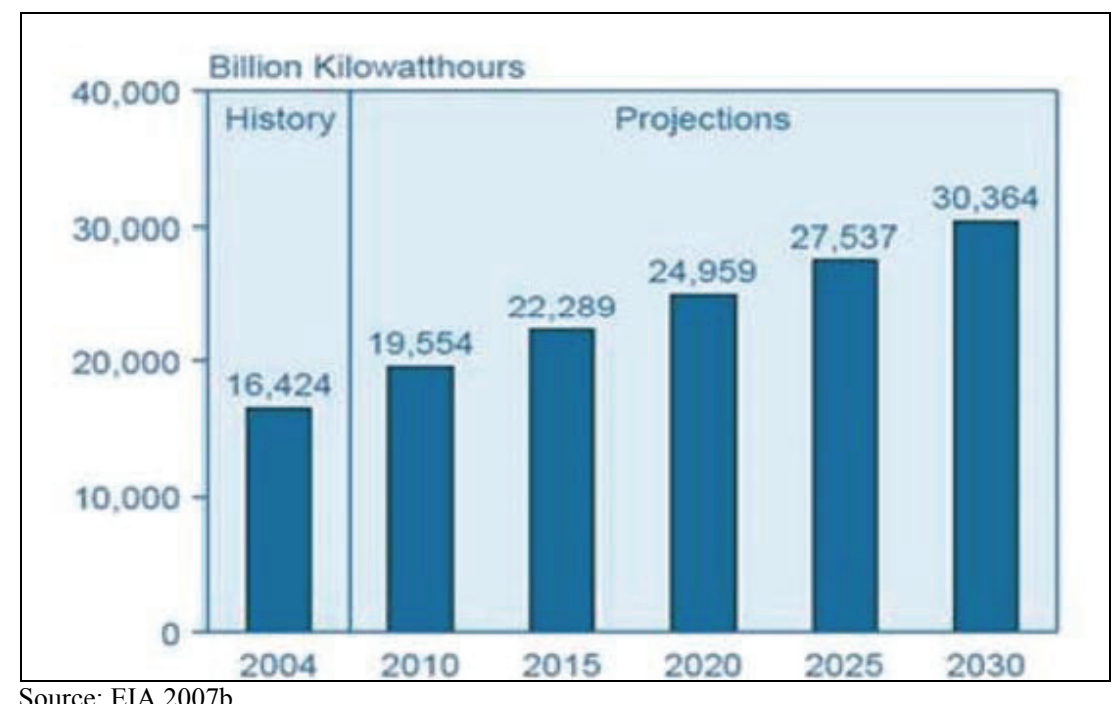

Figure 7.1.1-1-World Electric Power Generation

The Energy Information Administration projects that electricity generation from nuclear power will increase by around 40 percent, from 2,619 billion KWh in 2004 to 3,619 billion KWh in 2030. Higher fossil fuel prices, energy security concerns, improved reactor designs, and environmental considerations are expected to improve the prospects for new nuclear power plants in many parts of the world, and a number of countries are expected to build new nuclear power plants. In the International Energy Outlook 2007 reference case, the world's installed 
nuclear capacity is projected to grow from 368 gigawatts electric (GWe) in 2004, to $481 \mathrm{GWe}$ in 2030, a 31 percent increase (EIA 2007b). Declines in nuclear capacity are projected only among Organization for Economic Cooperation and Development ${ }^{1}$ (OECD) European nations, where several countries (such as Germany and Belgium) have either plans or mandates to phase out nuclear power, and some older reactors are expected to be retired and not replaced (EIA 2007b).

From 2004 to 2030, nuclear power generation in non-OECD countries is projected to increase by 4 percent per year. The largest increase in installed nuclear generating capacity is expected for non-OECD Asia, where annual increases in nuclear capacity are projected to average 6.3 percent and account for 68 percent of the total projected increase in nuclear power capacity for the non-OECD region as a whole. Of the $58 \mathrm{GWe}$ of additional installed nuclear generating capacity projected for non-OECD Asia between 2004 and 2030, 36 GWe is projected for China and $17 \mathrm{GWe}$ for India. Russia is also expected to add substantial nuclear generating capacity over the mid-term, increasing capacity by 20 GWe by 2030 (EIA 2007b).

Even with these increases, nuclear energy will only fulfill a portion of the projected need for electrical power. Fossil fuels, especially coal, will continue to provide the largest portion of new electrical power supply. Accordingly, world carbon dioxide $\left(\mathrm{CO}_{2}\right)$ emissions are expected to grow. High growth is expected from the non-OECD nations, mainly China and India (EIA 2007b). As the United States and Fuel Cycle GNEP Partners develop the technologies to support a Reliable Fuel Services Program, the United States would work with those Fuel Cycle GNEP Partners to provide user nations with reactor technologies, reactor fuel, and potentially fuel recycling services. This assistance would support the expansion of nuclear energy among developing countries.

\subsubsection{Grid-Appropriate Reactors}

DOE supports the development of grid-appropriate reactors, which are well suited to the capabilities and needs of developing countries. These reactors would be designed to achieve high standards of safety and security and would be sized to suit those countries with smaller and less developed power grids. The successful deployment of these reactors, coupled with reliable fuel services, would provide an attractive energy solution to many countries and reduce the incentive for them to develop the more proliferation-vulnerable parts of the nuclear fuel cycle (e.g., uranium enrichment facilities).

Smaller power plants (less than $500 \mathrm{MWe}$ ) are particularly suitable for expansion into less developed countries because they would match grid capacities better, offer simplified operations with greater margins of safety, require less capital outlay, allow countries to add capacity in smaller increments to better match demand growth, and be better suited to provide important non-electrical products such as process heat and fresh water through desalination.

\footnotetext{
${ }^{1}$ The Organization for Economic Cooperation and Development (OECD), established in 1961, is an international organization composed of the industrialized market economy countries, as well as some developing countries, which provides a forum to establish and coordinate policies. The OECD's 30 members are: Australia, Austria, Belgium, Canada, Czech Republic, Denmark, Finland, France, Germany, Greece, Hungary, Iceland, Ireland, Italy, Japan, Korea, Luxembourg, Mexico, the Netherlands, New Zealand, Norway, Poland, Portugal, Slovak Republic, Spain, Sweden, Switzerland, Turkey, the United Kingdom, and the United States (EIA 2007b).
} 
Besides the United States, several countries, including France, Russia, Japan, South Korea, South Africa, India, and Argentina, have already recognized the global market need for smaller-sized nuclear power plants and are moving forward with the development of small and medium-sized reactors. Because it is ultimately the responsibility of private industry to develop and market commercial nuclear power plants, one role of DOE could be to assist U.S. industry efforts to standardize reactor design and obtain U.S. Nuclear Regulatory Commission (NRC) licensing of one or more new small- and medium-sized reactors for export. Two examples of grid-appropriate reactors are: 1) the International Reactor Innovative and Secure (IRIS): a smaller-scale advanced light water reactor, being developed for near-term deployment (within the next decade) and, 2) the Pebble Bed Modular Reactor (PBMR): a high temperature gas-cooled reactor (HTGR) with a closed-cycle, gas turbine power conversion system.

A GNEP international working group is developing a Grid-Appropriate Reactors Program. Such a program would facilitate the international development, demonstration, licensing, and deployment of these simpler nuclear technologies and would facilitate the introduction of nuclear electricity generation through numerous features such as smaller, modular-type designs, fuel designs that could last the entire life of the reactor, effective and inexpensive safeguard approaches, standardized modular designs, and fully passive safety systems. Such a program would not propose to build or operate such reactors for another country, but instead would assist in developing the technologies, develop construction and operational plan packages, and demonstrate how such grid-appropriate reactors could satisfy energy needs while reducing electricity generation costs, $\mathrm{CO}_{2}$ emissions, and nuclear weapons proliferation concerns.

International safeguards are of paramount importance in developing new reactor technologies. The United States and other developed nations work closely with the IAEA in developing technologies that would help enable the IAEA to better assure nonproliferation compliance. Ensuring that such technologies are included in new reactor designs is a primary goal of the contemplated international Grid-Appropriate Reactors Program.

\subsubsection{Reliable Fuel Services}

The United States and other nuclear fuel supplier nations are cooperating to develop mechanisms to provide other countries pursuing nuclear power programs with an assured supply of fresh fuel for nuclear power plants. This effort builds on initiatives already underway to provide assurances of nuclear fuel supply, including the six-country proposal on Reliable Access to Nuclear Fuel at the IAEA and the established National Nuclear Security Administration program to blend down excess highly enriched uranium to create a fuel reserve to support a reliable fuel supply. In addition, a Reliable Fuel Services Program could help other countries manage the resulting SNF generated as described below.

The objective of a Reliable Fuel Services Program is to limit the spread of enrichment and reprocessing by offering countries an alternative to developing such facilities indigenously. Countries using such services would receive the benefit of having reliable access to nuclear fuel services without having to make the significant infrastructure investments required for enrichment and reprocessing. Figure 7.1.3-1 shows one potential concept for the Reliable Fuel Services Program. At this point in time, the Reliable Fuel Services Program is focused primarily 
on fuel for light water reactors (LWRs); however, once the program has been implemented it could be expanded to other types of reactors.

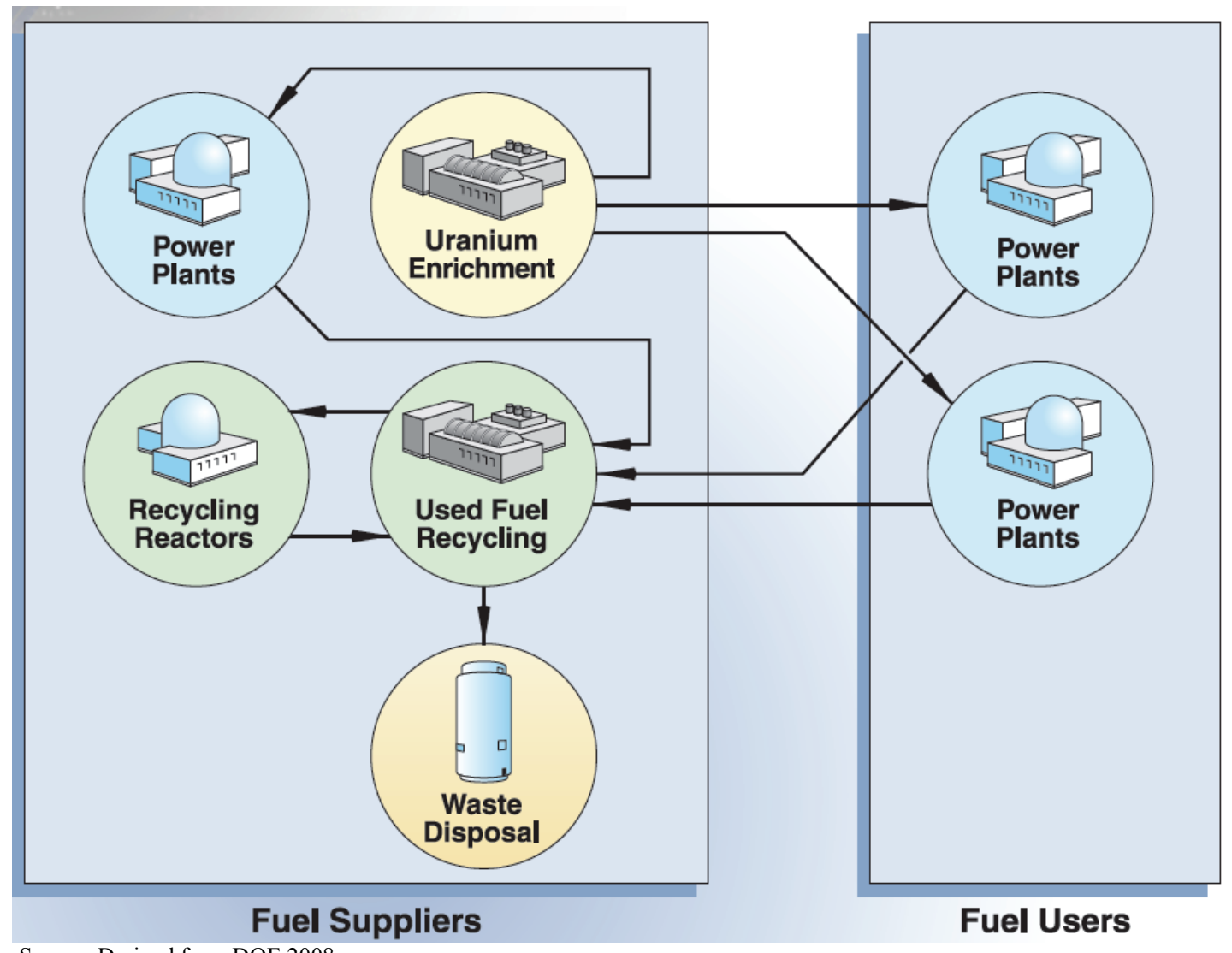

Source: Derived from DOE 2008e

FIGURE 7.1.3-1—One International Reliable Fuel Services Program Concept

\subsubsection{Spent Nuclear Fuel Disposition}

Under a Reliable Fuel Services Program, SNF could be returned to the country that supplied it or to another supplier nation. If the supplier nation taking the SNF had a closed fuel cycle, and if the SNF was suitable for recycling, then it could recycle that SNF. Uranium and usable transuranics could be separated and used for additional fuel fabrication. Wastes resulting from the recycling of the SNF would be packaged for transport and disposal, as discussed below. If the country accepting the SNF had a once-through fuel cycle, or if the SNF was not suitable for recycling, then it could store the SNF pending disposal in a geologic repository.

\subsubsection{Wastes from Spent Nuclear Fuel Recycling and Disposition}

The recycling of foreign reactor SNF from a Reliable Fuel Services Program would generate the same types of waste as the recycling of domestic SNF and could include hazardous wastes, lowlevel radioactive waste (LLW), Greater-than-Class-C (GTCC) LLW, and high-level radioactive waste (HLW). Just as these wastes must be responsibly managed within the United States, it is equally important that these wastes be managed responsibly by other countries, in accordance with the Joint Convention on the Safety of Spent Fuel Management and on the Safety of 
Radioactive Waste Management (IAEA 2001a). The radioactive wastes from recycling would be stored or disposed of either by the supplier nation (the nation that provided the fresh fuel), returned to the user nation (the nation that generated the SNF), or sent to a third-party supplier nation (a nation that neither supplied the fresh fuel nor generated the SNF but has facilities to responsibly manage the SNF). Additional information on the wastes generated by SNF separation processes and the management of such wastes may be found in Section 7.2.1.8, Section 7.2.1.9, and Appendix A.

\section{2}

\section{Potential ENVIRONMENTAL IMPACTS IN THE UNITEd STATES AND GLOBAL COMMONS FROM INTERNATIONAL ACTIONS}

DOE's underlying purpose and need is to support expansion of domestic and international nuclear energy production while reducing the risks of nuclear proliferation and to reduce the impacts associated with disposal of future SNF (e.g., by reducing the volume, thermal output, and/or radiotoxicity of waste requiring geologic disposal). The programmatic alternatives evaluated in this PEIS would have differing implications for the international initiatives of the GNEP Program. Since the international portion of the GNEP Program is still in its formative stage and no specific proposal exists, it is not possible to prepare a detailed analysis of the potential environmental consequences of each of these alternatives. Instead, this analysis is intended to provide a perspective of how each of the alternatives being considered by the GNEP PEIS could have implications for the international aspects of the GNEP Program which in turn could have environmental impacts within the United States or in the global commons.

\section{Methodology and Assumptions}

To standardize the impact of GNEP (relative to international nuclear power expansion), this chapter of the PEIS assesses the domestic environmental impacts and environmental impacts to the global commons associated with supporting SNF reprocessing, waste disposal requirements, and transportation requirements for $1 \mathrm{GWe}$ of foreign nuclear power production. It is expected that more than 1 GWe would be supported by a Reliable Fuel Services Program. Impacts associated with additional production would be multiples of the impact estimates presented in this chapter. Once operational, these foreign reactors would need to be supplied with fuel on a regular basis.

\subsubsection{Fast Reactor Recycle Alternative}

The following analysis presents the environmental impacts in the United States and the global commons that could result from an international Reliable Fuel Services Program based on the Fast Reactor Recycle Alternative. For purposes of this analysis, a future Reliable Fuel Services Program would support the nuclear fuel requirements for $1 \mathrm{GWe}$ foreign LWR production. Although these foreign reactors would likely be smaller, 1 GWe production provides a good scaling factor which may be used for comparing alternatives and for computing impacts associated with varying numbers of foreign reactors. 
Supporting a 1 GWe LWR production would require sufficient fresh fuel for initial start-up and steady-state operations. ${ }^{2}$ This could entail the manufacture of uranium-based reactor fuel in U.S. commercial fuel fabrication facilities. This fuel would be shipped to the foreign reactor where it would be used to power a LWR to generate electricity. The SNF resulting from reactor operations could then be returned to the United States or a partner nation, where it would be recycled in a nuclear fuel recycling center and separated into useful constituents and waste material. The useful constituents would be used again in the fuel fabrication process to provide fuel for advanced recycle reactors, and the waste material would be stabilized and packaged appropriately for storage or disposal.

Although fuel assemblies could be fabricated in any of the supplier nations, fuel fabrication is assumed to occur at any one or all of the U.S. commercial fuel fabrication facilities, since this analysis presents environmental impacts which could result within the United States or global commons. Once fabricated, the fuel assemblies would be placed into approved fuel shipping casks. For this analysis, several different NRC-certified and U.S. Department of Transportation (DOT) approved casks were analyzed, depending on the mode of transportation and the material being transported. These fuel assemblies would then be transported by truck to a U.S. port of exit. Information on U.S. fuel fabrication facilities may be found in Appendix A.

Previous environmental impact studies related to the global transportation of nuclear materials identified 10 ports in the United States with the capability and experience in handling the shipment of radioactive materials: Charleston, SC; Galveston, TX; Norfolk, VA; Jacksonville, FL; Military Ocean Terminal at Sunny Point, NC; Naval Weapon Station (NWS) at Concord, CA; Portland, OR; Savannah, GA; Tacoma, WA; and Wilmington, NC (DOE 1996c). In all likelihood, one of the east coast ports would be utilized for shipments to Europe, Central or South America, and Africa and one of the west coast ports utilized for shipments to Asia and the South Pacific.

Once the fuel assemblies expend their useful energy in the reactor (generally after about 3 years of full power operation), the SNF would be removed from the foreign reactor and stored for a period of time until cool enough to be placed in a specially designed container for shipment back to the United States or another supplier nation. For the receipt of the SNF returning to the United States from foreign reactors, the same ports used for shipment of the fresh fuel assemblies would probably be used as the ports of entry.

Although SNF could be transported to any supplier nation, it is assumed that the SNF would be returned to a U.S. port, since this analysis is intended to present the environmental impacts that could result within the United States or global commons. The SNF would then be loaded onto trucks, barges, or railcars and transported to a nuclear fuel recycling center. Here, the SNF would be recycled, the usable materials removed, and the waste products packaged and placed in the appropriate containers. The waste would either be retained by the United States, returned to the user nation, or be transported to a supplier nation for disposal or storage.

${ }^{2}$ DOE analyzed the steady-state impacts associated with annual operations; the initial start-up of a foreign reactor would require approximately 3-4 times as much start-up fuel as were analyzed for steady-state annual operations. 


\subsubsection{Transportation of Reactor Fuel to and from Foreign Reactors}

Transportation of reactor fuel would involve the delivery by truck or barge from the fuel fabrication facility to a port of exit where the fuel assemblies, already packed in special NRC/DOT/IAEA-approved casks, would be loaded onto a ship for transport to a foreign port. Once in the foreign nation, the casks would be taken off of the ship and transported to a foreign reactor, where it would be placed into the reactor core.

\section{Affected Environment}

U.S. interstate highways, federal and state highways, local roads, rail routes, barge routes, U.S. ports, and both the Atlantic and Pacific Oceans, are areas that could potentially be impacted by the potential international initiatives being considered by DOE. Because specific foreign participants, sites of the recycling centers, and designated ports have not been identified, it is not possible, at this time, to perform site-specific analysis. Generic routing parameters were utilized consistent with the methodology described in Appendix E.

\section{Domestic}

Within the United States, the affected environment would be determined by the location of any fuel fabrication facility(ies), the specific port of exit for the uranium or fuel assemblies, the specific port of entry for the SNF, the location of the SNF recycling center utilized, any domestic storage or disposal facilities for the waste, and the specific port of exit for any waste returning to a user nation or a supplier nation. Once these facilities are identified, transportation routes between them could be determined and specific environmental impacts identified. Areas impacted would include these transportation routes, the ports, and the areas around these routes and ports.

\section{Global Commons}

The Atlantic Ocean is the second largest of the world's oceans. The surface of the Atlantic Ocean is usually covered with sea ice in Labrador Sea, Denmark Strait, and coastal portions of the Baltic Sea from October to June. The Atlantic Ocean exhibits a clockwise warm-water gyre (broad, circular system of currents) in the northern Atlantic, and a counterclockwise warm-water gyre in the southern Atlantic. The ocean floor is dominated by the Mid-Atlantic Ridge, a rugged north-south centerline for the entire length of the Atlantic basin (CIA 2008a). Figure 7.2.1.1-1 shows the location of the Atlantic Ocean. 


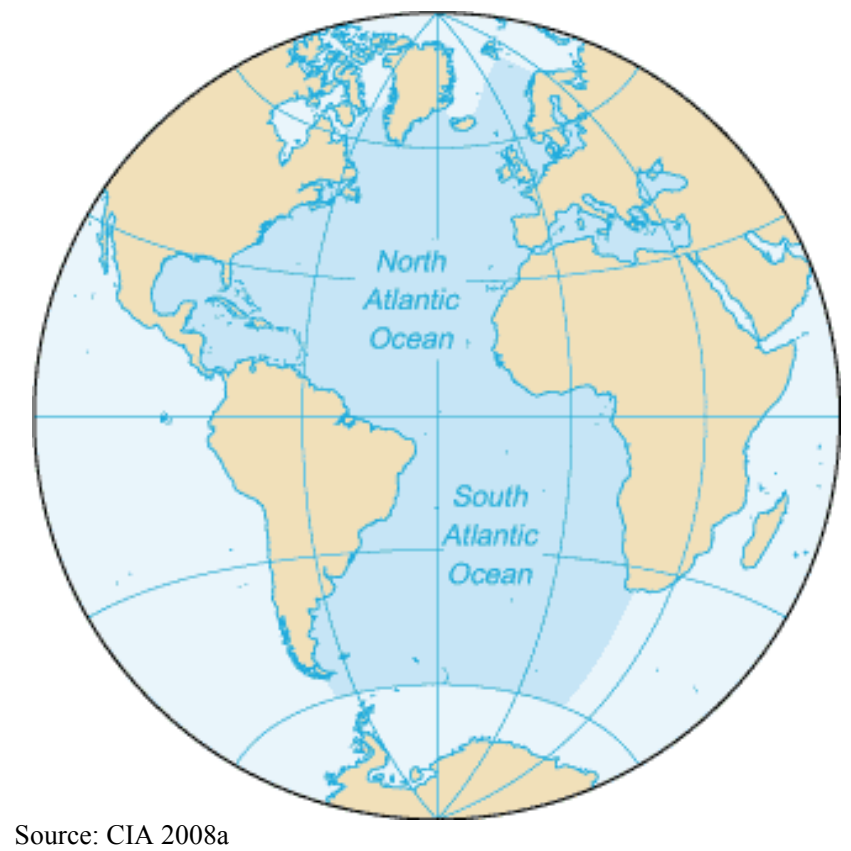

FIGURE 7.2.1.1-1-The Atlantic Ocean

The Pacific Ocean is the largest of the world's oceans. Surface currents in the northern Pacific are dominated by a clockwise, warm-water gyre (broad circular system of currents) and in the southern Pacific by a counterclockwise, cool-water gyre. In the northern Pacific, sea ice forms in the Bering Sea and Sea of Okhotsk in the winter. In the southern Pacific, sea ice from Antarctica reaches its northernmost extent in October. The ocean floor in the eastern Pacific is dominated by the East Pacific Rise, while the western Pacific is dissected by deep trenches, including the Mariana Trench, which is the world's deepest (CIA 2008b). Figure 7.2.1.1-2 shows the location of the Pacific Ocean.

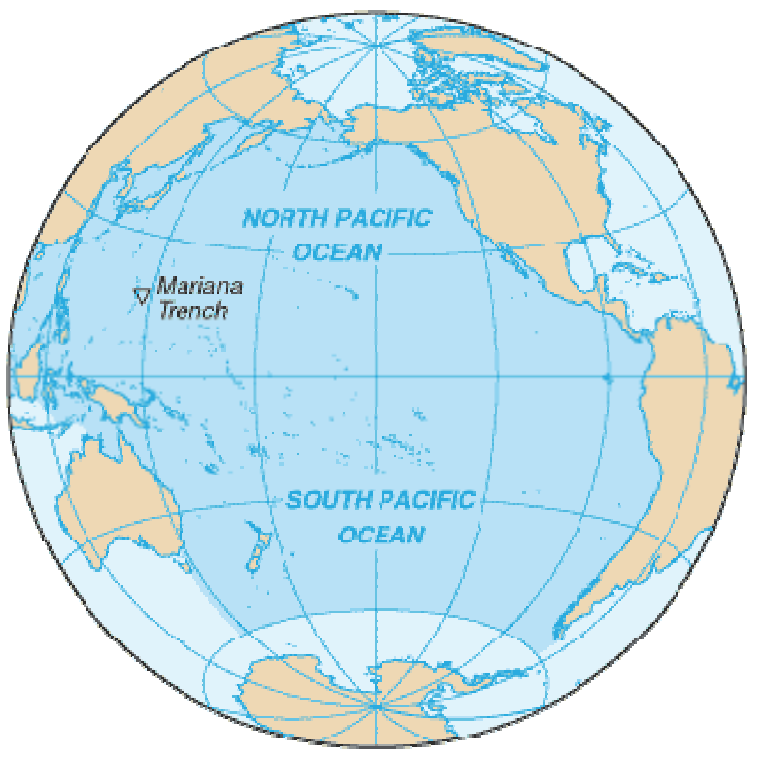

Source: CIA 2008b

FIGURE 7.2.1.1-2-The Pacific Ocean 
The North Atlantic Right Whale (Eubalaena glacialis) is on the Federal endangered species list and is also protected internationally under the Convention for the Regulation of Whaling. There are currently about 300 right whales in the North Atlantic, with ship strikes accounting for about 50 percent of their known deaths. Calving right whales usually winter in the waters between Savannah, GA, and West Palm Beach, FL, with an area of high density between Brunswick, GA, and St. Augustine, FL (NOAA 2008). The Maritime Safety Committee of the International Maritime Organization adopted a mandatory ship reporting system that became effective in 1999. This system requires ships to report whale sightings in the major shipping lanes from November 15 to April 15 off the southeastern coast of the United States so as to include the calving season for the right whales in this area, and operates throughout the year on the northeastern coast, where the whales have been sighted year-round. The sperm whale and all six species of sea turtles are on the Federal endangered species list and are found throughout the central and northern Pacific Ocean and the equatorial region of the Atlantic Ocean. Sperm whales migrate between mating and calving grounds near the equator and feeding areas in higher latitudes. Generally, however, females and their young stay in latitudes less than 40 , and only the males venture into the polar waters. The total number of sperm whales in the world is not well known, with estimates ranging from 200,000 to 2,000,000. The sea turtle is found throughout both the Atlantic Ocean and the Pacific Ocean but is usually only vulnerable to harm on coastal shores. In the United States, it is most prevalent on and just off the central Florida coast (USFWS 2007a). Endangered marine species in the Pacific Ocean also include the dugong, sea lion, sea otter, and seals (CIA 2008b).

\subsubsection{Transportation of Reactor Fuel Assemblies}

Route options for ground transportation to the ports of exit for any reactor fuel going to foreign reactors would depend on the location of the fuel assembly fabrication facility and the marine port to be used. As described in 10 CFR 51.52, it was assumed that all fresh fuel shipments would be conducted via truck transport. For purposes of this analysis a distance of 500 miles (mi) (805 kilometers $[\mathrm{km}]$ ) was assumed. Routing for shipments by truck would comply with all applicable DOT, NRC, and state regulatory requirements. The U.S. interstate highway system would be used to the extent possible, utilizing bypasses or beltways around cities. The selection of routes would be consistent with specific state requirements and declared preferences. All preshipment notifications and consultation requirements would also be met.

The analysis below addresses the shipment of 24 metric tons of heavy metal (MTHM) fresh fuel assemblies, which would be used to support the production of 1 GWe in LWRs annually. The 24 MTHM quantity represents the fewest number of full shipments (four shipments of 6 MTHM each) needed to provide 21.7 MTHM of fresh fuel annually for refueling. Shipment of these fresh fuel assemblies was analyzed as being shipped in a fuel cask capable of holding 12 assemblies, as described in NRC 2006c.

It is assumed that loading operations would be conducted by a crew of 13 persons during a 10-hour period. The external dose rate for the casks and containers containing the fresh fuel assemblies is assumed to be 0.1 millirem per hour $(\mathrm{mrem} / \mathrm{hr})$ at a distance of 3.3 feet (ft) (1 meter [m]) (NRC 2006c). Inspection would require one person at a distance of $6.6 \mathrm{ft}(2 \mathrm{~m})$ from the source for 1 hour (DOE 1996c). Table 7.2.1.2-1 shows the potential impacts from 
loading and transporting 24 metric tons of heavy metal (MTHM) of fresh fuel assemblies by truck from a fuel fabrication facility to a port, as expressed in person-rem and latent cancer fatalities (LCFs).

TABLE 7.2.1.2-1—Impacts of Shipping Fresh Fuel Assemblies from Manufacturer to a Port by Truck

\begin{tabular}{lcc}
\hline & $\begin{array}{c}\text { Transportation Impacts for 24 MTHM Fresh Fuel via Truck Transport } \\
\text { Fuel Fabrication Facility to Port (500 miles) } \\
\text { (Note 1) }\end{array}$ \\
\hline Person-rem & LCFs \\
\hline Crew & $1.24 \times 10^{-4}$ & $7.44 \times 10^{-8}$ \\
Population & $7.75 \times 10^{-4}$ & $4.65 \times 10^{-7}$ \\
Stops & $8.92 \times 10^{-7}$ & $5.35 \times 10^{-10}$ \\
Loading & 0.0900 & $5.40 \times 10^{-5}$ \\
Inspection & 0.0154 & $-23 \times 10^{-6}$ \\
Accident Risk ${ }^{\mathrm{a}}$ & -- & -- \\
Source: Tetra Tech 2008f & & \\
a Accident impacts are not provided for fresh fuel transportation, as information for nuclide inventory is not readily available. As \\
stated in the Environmental Impact Statement for an Early Site Permit (ESP) at the Exelon ESP Site (NRC 2006c), potential \\
impacts from the transportation of fresh fuels for contemporary reactor technologies tends to be orders of magnitude lower than \\
the impacts provided for SNF in 10 CFR 51.52. Additionally, accident impacts would be bounded by the impacts presented in \\
Table 7.2.1.7-1. \\
Note 1: No specific locations are assessed for the fuel fabrication facility or the port.
\end{tabular}

It is assumed that shipments by truck would require approximately one hour of stop time for rests and walk-around inspections per eight-hour driving shift. This assumption is more stringent than the Federal Motor Carrier Safety Administration requirement (49 CFR Part 395) and most state requirements. Transportation of fresh nuclear fuel across large distances by truck would result in greenhouse gas emissions that would have an impact on air quality. Though likely to be relatively small, the environmental impact of such emissions would be evaluated prior to making any decision on implementation of international elements of the GNEP Program.

\subsubsection{Marine Transport of Reactor Fuel Assemblies}

Information in this section was taken from the Final Environmental Impact Statement on a Proposed Nuclear Weapons Nonproliferation Policy Concerning Foreign Research Reactor Spent Nuclear Fuel, DOE/EIS-0218F (DOE 1996c). The information from that EIS is considered to be the best available information with respect to the marine transport of radiological materials. There are several types of ships that could be used to transport reactor fuel assemblies to foreign ports, as listed below.

Container vessels: These vessels are typically large ships specifically intended to transport containerized cargo. Some modern container ships can transport up to 5,000 containers, although a more typical capacity is in the range of from 800 to 1,000 containers. Container vessels usually transport containers between the larger, more widely-used ports of the world. Containers can be loaded or off-loaded from a container vessel at an average rate of about 45 containers per hour (DOE 1996c).

General cargo ships: General cargo ships are smaller vessels that typically transport cargo between the lesser used ports of the world. They usually have on-board cranes that can be used to 
load or off-load the vessel, should the dock not have any cranes. Cargo is usually stowed in separate cargo hold compartments (DOE 1996c).

Purpose-built ships: Purpose-built ships are specially designed ships for the purposes of transporting reactor fuel assemblies or SNF. They are designed to hold casks below decks in specially designed hold compartments. These vessels have double bottoms and hulls and collision-damage-resisting structures built into the hull. The crews are specifically trained in the handling of the transport casks and in emergency response (DOE 1996c).

The fuel assemblies would be shipped by chartered and/or regularly scheduled commercial ships from U.S. ports to foreign ports. Chartered shipments would be on purpose-built ships or general purpose commercial cargo ships that meet all appropriate International Maritime Organization regulations. Regularly scheduled commercial shipments would be on general purpose commercial ships carrying other cargo at the same time. Marine transport, as well as ground transport, would be conducted in approved and certified nuclear fuel casks. One ship could easily accommodate $5 \mathrm{NLI}-10 / 24,11$ GA-4/9 casks, or 4 fresh fuel casks needed to transport 21.7 MTHM of fuel. Vessels for charter are available from several steamship lines (DOE 1996c).

All ships entering U.S. territorial waters are required to comply with the U.S. Coast Guard safety regulations and are subject to U.S. Coast Guard inspection. In addition, international transportation of hazardous material is governed by the International Movement of Dangerous Goods Code, which is one of a series of safety codes associated with the International Maritime Organization (DOE 1996c). These requirements remain in effect today. As stated in Section 7.2.1, it is assumed that the reactor fuel could go to practically any country in the world. Once loaded, environmental impacts are a function of the miles traveled. For purposes of this analysis, a hypothetical maximal distance for a remote location was selected requiring a voyage duration of 31 days. A voyage of this duration would enable shipment between most foreign locations and U.S. ports.

The primary impact of incident-free marine transport of fuel assemblies is to the crew of the ships used to carry the casks. Due to the protective qualities of the transport cask, members of the general public and marine life would not receive any measurable dose from the fuel assemblies during incident-free marine transport. In addition to the protection provided by the transportation casks, further protection of the public and marine life would be provided by the ship's structure. Under incident-free conditions of transport, public exposure would be limited to the ship's crew, and their exposure would be limited to only those crew members exposed during the loading and off-loading of the casks and to crew members who, on a daily basis, are required to inspect cargo (to ensure secure stowage) and the vessel (DOE 1996c).

While loading the fuel assemblies onboard ships, inspectors, dockworkers, longshoremen, and crane operators would be exposed to radiation. This exposure would primarily be a function of the integrity of the regulatory design limits of the NRC/DOT-certified cask. It is assumed that loading operations would be conducted during an 8-hour period, and that five handlers would be involved in the loading operation at a distance of $16 \mathrm{ft}(5 \mathrm{~m})$ from the source. Four staging workers would be involved at a distance of $33 \mathrm{ft}(10 \mathrm{~m})$ from the source. One crane operator would be involved at a distance of $82 \mathrm{ft}(25 \mathrm{~m})$ from the source. After loading, it is assumed that 
one inspector would be at a distance of $6 \mathrm{ft}(2 \mathrm{~m})$ for a period of 4 hours. In transit, it is assumed that inspections would be made daily, amounting to 6 total hours of exposure for a 31-day voyage at a distance of $6 \mathrm{ft}(2 \mathrm{~m})$. In addition, it is assumed that a chief mate would be at a distance of $82 \mathrm{ft}(25 \mathrm{~m})$ and a bosun (an assistant to the chief mate) at a distance of $33 \mathrm{ft}(10 \mathrm{~m})$ during the loading and for brief periods during each day of the voyage (DOE 1996c).

While the reactor fuel was onboard the ship, individuals coming into close proximity of the casks, such as sailors on watch or sailors performing routine inspections, would receive minimal doses of radiation. Since these individuals would be performing required routine functions, the doses they would receive would be a function of the time of transportation. The expected incident-free maritime transport impacts associated with loading the fuel casks onto a ship and the transport of the fuel assemblies to port requiring a voyage duration of 31 days are shown in Tables 7.2.1.3-1 and 7.2.1.3-2.

TABLE 7.2.1.3-1—Impacts During Loading and Inspection at the Ports for 24 MTHM of Fresh Fuel

\begin{tabular}{lcc}
\hline & Person-rem & LCFs \\
\hline Handler & 0.00110 & $6.6 \times 10^{-7}$ \\
Staging & $4.32 \times 10^{-5}$ & $2.6 \times 10^{-8}$ \\
Crane & $2.70 \times 10^{-6}$ & $1.6 \times 10^{-9}$ \\
Inspector & 0.0154 & $9.2 \times 10^{-6}$
\end{tabular}

TABLE 7.2.1.3-2_Impacts During Voyage Between the Ports for 24 MTHM of Fresh Fuel-31-Day Voyage

\begin{tabular}{lcc}
\hline & \multicolumn{2}{c}{ Total Voyage (31 days) } \\
\hline Person-rem & LCFs \\
\hline Crew & $1.05 \times 10^{-5}$ & $6.3 \times 10^{-9}$ \\
Population & 0.00103 & $6.2 \times 10^{-7}$ \\
Chief Mate & $1.24 \times 10^{-4}$ & $7.4 \times 10^{-8}$ \\
Bosun & $7.75 \times 10^{-4}$ & $4.6 \times 10^{-7}$ \\
Engineer & 0.0192 & $1.2 \times 10^{-5}$ \\
Accident Risk & -- & -- \\
\hline
\end{tabular}

Source: Tetra Tech $2008 \mathrm{f}$

${ }^{a}$ Accident impacts are not provided for fresh fuel transportation, as information for nuclide inventory is not readily available. As stated in the Environmental Impact Statement for an Early Site Permit (ESP) at the Exelon ESP Site (NRC 2006c), potential impacts from the transportation of fresh fuels for contemporary reactor technologies tends to be orders of magnitude lower than the impacts provided for SNF in 10 CFR 51.52, and shown in

Table S.4-1. Additionally, accident impacts would be bounded by the impacts presented Table 7.2.1.7-1.

\subsubsection{Return of Spent Nuclear Fuel}

The production of $1 \mathrm{GWe}$ in LWRs would generate approximately 21.7 MT of SNF annually. After removing the SNF from the reactor, it would be stored, onsite, until cool enough for shipment. This SNF would then be placed in certified transport casks and taken to a foreign port of exit where it would be shipped back to the United States or to a supplier nation. Because this analysis assesses the potential impacts on the United States and the global commons, it is 
assumed these shipments would go to the United States. Once in the U.S. port of entry, the SNF would be off-loaded from the ship and placed on a truck, barge, or railcar for shipment to a recycling center. The fewest full cask loads for truck, barge, and rail shipments needed to transport 21.7 MTHM of spent fuel would represent 22 MTHM and 25 MTHM, respectively. The maritime shipment analysis assumed 22 MTHM, stored in 11 truck spent fuel casks (GA-4/9 casks).

\subsubsection{Marine Transport of Spent Nuclear Fuel}

The truck cask scenario was chosen to assess marine transport impacts because it represents the largest loading, unloading, and inspection impacts. The SNF would be shipped in the same types of ships as those that shipped the fuel assemblies to the foreign reactors, as detailed in Section 7.2.1.3. Once again, GA-4/9 and NLI-10/24 casks would be utilized for the SNF and 1 ship could easily accommodate the required truck casks and rail/barge casks. Although the composition of the SNF would be different from the fresh fuel, the volume of the fuel rod assemblies would remain the same and the same number of casks would be used for the return voyage. The external dose rate for the casks and containers containing the SNF is assumed to be 10 millirem per hour $(\mathrm{mrem} / \mathrm{hr})$ at a distance of $6.6 \mathrm{ft}(2 \mathrm{~m})$. While the SNF was onboard the ship, individuals coming into close proximity of the casks, such as sailors on watch or sailors performing routine inspections, would receive minimal doses of radiation. Exposure would be a function of the time of transport. Table 7.2.1.5-1 shows the impacts of transporting the SNF from a foreign nation back to a port in the United States.

TABLE 7.2.1.5-1-Impacts of Transporting Spent Nuclear Fuel Casks from Foreign Nation Back to a United States Port-31-Day Voyage

\begin{tabular}{lcc}
\hline & Total Voyage (31 days) \\
\hline & Person-rem & LCFs \\
\hline Crew $^{\mathrm{a}}$ & 0.00201 & $1.2 \times 10^{-6}$ \\
Population $^{\mathrm{b}}$ & 0.198 & $1.2 \times 10^{-4}$ \\
Chief Mate & 0.0239 & $1.4 \times 10^{-5}$ \\
Bosun & 0.146 & $8.7 \times 10^{-5}$ \\
Engineer & 3.72 & 0.0022 \\
Accident Risk & 0.00225 & $1.4 \times 10^{-6}$ \\
\hline Source: Tetra Tech 2008f \\
${ }^{\mathrm{a}}$ The values provided represent the daily and total voyage doses due to daily inspection processes. \\
${ }^{\mathrm{b}}$ The accident risk is for the total voyage.
\end{tabular}

Transportation of SNF across large distances by ship would result in greenhouse gas emissions that would have an impact on air quality. Though likely to be relatively small, the environmental impact of such emissions would be evaluated before making any decision on implementation of international elements of the GNEP Program.

\subsubsection{United States Ports}

Once the returning ship carrying the SNF arrived at a United States port of entry, the SNF casks would be off-loaded onto the dock. While the casks were in port and during the time they were off-loaded, port workers would be exposed to small levels of radiation. Table 7.2.1.6-1 shows the impacts of off-loading the SNF at a United States port. Once the casks, containing the SNF, were 
loaded onto a truck, barge, or railcar they would be shipped to a recycling center. No specific locations for a port or recycling center are assessed.

TABLE 7.2.1.6-1-Impacts During Loading and Inspection at a United States Port for 22 MTHM of Spent Nuclear Fuel

\begin{tabular}{lcc}
\hline \multicolumn{3}{c}{ Off-loading Impacts of 22 MT SNF at United States Port of Entry } \\
\hline & Person-rem & LCFs \\
\hline Handler & 0.605 & $3.6 \times 10^{-4}$ \\
Staging & 0.136 & $8.2 \times 10^{-5}$ \\
Crane & 0.00572 & $3.4 \times 10^{-6}$ \\
Inspector & 0.812 & $4.9 \times 10^{-4}$ \\
\hline Source: Tetra Tech 2008f & &
\end{tabular}

\subsubsection{Ground Transportation of Spent Nuclear Fuel}

The SNF would be loaded onto trucks, railcars, or barges, and transported to a SNF recycling center for processing. Once again, the GA-4/9 casks would be used for truck transport and the NLI-10/24 casks used for shipment by rail or barge. It is estimated that 11 truck shipments or 5 railcars ( 1 shipment with 5 freight cars and 4 spacer cars) would be required to transport the SNF. Route options for the potential ground transportation of the SNF would depend on the marine port to be used and the location of the yet-to-be proposed recycling center. For purposes of this analysis a distance of 500 miles was assumed.

Routing for shipments by truck would comply with all applicable DOT, NRC, and state regulatory requirements. The U.S. Interstate highway system would be used to the extent possible, utilizing bypasses or beltways around cities. The selection of routes would be consistent with specific state, local, and tribal requirements and declared preferences. All pre-shipment notifications and consultation requirements would be met. Table 7.2.1.7-1 shows the expected impacts of transporting the SNF from the U.S. port of entry to a recycling center by truck, barge, or rail.

TABLE 7.2.1.7-1—Impacts of Shipping Spent Nuclear Fuel from a United States Port of Entry to a Recycling Center by Truck, Rail, or Barge

$$
\text { Transportation Impacts: }
$$

Spent Nuclear Fuel from United States Port of Entry to a Recycling Center (500 mi)

(Note 1)

\begin{tabular}{lcccccc}
\hline & \multicolumn{2}{c}{ Truck (22 MTHM) } & \multicolumn{2}{c}{ Rail (25 MTHM) } & \multicolumn{2}{c}{ Barge (25 MTHM) } \\
\hline & Person-rem & LCFs & Person-rem & LCFs & Person-rem & LCFs \\
\hline Crew $^{\mathrm{a}}$ & 0.446 & $2.7 \times 10^{-4}$ & 0.0135 & $8.1 \times 10^{-6}$ & 0.00173 & $1.0 \times 10^{-6}$ \\
Population $^{\mathrm{a}}$ & 2.23 & 0.0013 & 0.0421 & $2.5 \times 10^{-5}$ & $1.38 \times 10^{-4}$ & $8.3 \times 10^{-8}$ \\
Stops & $1.12 \times 10^{-5}$ & $6.7 \times 10^{-9}$ & $1.78 \times 10^{-5}$ & $1.1 \times 10^{-8}$ & 0 & 0 \\
Loading & 4.75 & 0.0028 & 3.32 & 0.0020 & 3.32 & 0.0020 \\
Inspection & 0.812 & $4.9 \times 10^{-4}$ & 0.0738 & $4.4 \times 10^{-5}$ & 0.0738 & $4.4 \times 10^{-5}$ \\
Accident & $4.54 \times 10^{-6}$ & $2.7 \times 10^{-8}$ & $3.13 \times 10^{-6}$ & $1.9 \times 10^{-9}$ & $1.10 \times 10^{-4}$ & $6.6 \times 10^{-8}$ \\
\hline
\end{tabular}

Source: Tetra Tech 2008f

${ }^{\mathrm{a}}$ The impacts to crew and general population are based on unit risk factors for barge transportation provided in Table J-28 of DOE $2002 \mathrm{i}$.

Note 1: No specific locations are assessed for the port or recycling center. 
Transportation of SNF across large distances by ship, truck, and/or rail would result in greenhouse gas emissions that would have an impact on air quality. Though likely to be relatively small, the environmental impact of such emissions would need to be evaluated before making any future decisions on implementation of international elements of the GNEP Program.

\subsubsection{Disposition of Reusable Materials from Spent Nuclear Fuel}

Once at a SNF recycling center, the SNF returned from the foreign reactor would be separated into reusable and non-reusable constituents. This process would separate the undesirable wastes from the material suitable for fabricating reactor fuel. Table 4.8-4 provides estimates of the wastes and products for the various programmatic alternatives (note: Table 4.8-4 is based on $100 \mathrm{GWe}$ of production; for $1 \mathrm{GWe}$ of production, the waste and product numbers in Table 4.8-4 need to be divided by 100). The reusable material would be packaged in the appropriate NRC/DOT casks and shipped by truck, barge, or rail to a fuel fabrication center, unless the facilities were colocated.

\subsubsection{Disposition of Waste}

The recycling process for the SNF received from production of 1 GWe in LWRs would be expected to generate the following annual wastes: $0.25-9.2$ cubic meters $\left(\mathrm{m}^{3}\right)$ of HLW; $1.9-68.5 \mathrm{~m}^{3}$ of GTCC LLW; and $0.6-382 \mathrm{~m}^{3}$ of LLW. The HLW would produce 235 times less thermal load on a repository compared to spent fuel. The radiotoxicity of the HLW would decay to the radiotoxicity of natural uranium ore in 375 years (Wigeland 2008a). This waste would be processed and made ready for disposal. This waste could be returned to the user nation that generated the SNF, remain in the United States for storage or disposal, or be sent to a supplier nation. If this waste were to be returned to the country that generated the SNF or to a supplier nation, it would be placed in the appropriate NRC/DOT-approved casks and transported by rail or truck to a port. Here, it would be loaded onto a ship and transported back to the country of origin, or to another country, for storage or disposal. The international transport of the waste would utilize the appropriate NRC/DOT/IAEA-approved transport casks, transport routes, and undergo a similar handling and inspection regimen as the SNF shipments to the United States. Due to the integrity of the NRC/DOT/IAEA-approved casks (both the GA-4/9 and the NLI-10/24) and the reduced inventory of radionuclides in the materials being transported ${ }^{3}$, emissions and corresponding environmental impacts from the international transport of waste returned to the user nation or to a supplier nation are expected to be similar to, or smaller than, the emissions and corresponding environmental impacts from the transport of the SNF, as discussed in Sections 7.2.1.5 through 7.2.1.7.

\subsubsection{Accidents}

\subsection{Ground Transportation Accident}

Vehicular, rail, and barge accident impact estimates are included in the impact table for ground transportation of SNF, only, as shown in Table 7.2.1.7-1. Accident impacts are not provided for fresh fuel transportation, as information for nuclide inventory is not readily available. As stated

\footnotetext{
${ }^{3}$ The removal of uranium and transuranic elements during recycling reduces the inventory of radionuclides requiring transport.
} 
in the Environmental Impact Statement for an Early Site Permit (ESP) at the Exelon ESP Site (NRC 2006c), potential impacts from the transportation of fresh fuels for contemporary reactor technologies tend to be orders of magnitude lower than the impact estimates provided in 10 CFR 51.52. Additionally, accident impacts would be bounded by the impacts presented in Table 7.2.1.7-1. The transportation route between a U.S. port that handles radioactive materials and a SNF recycling center (yet to be proposed) was estimated to be a distance of 500 miles, for modeling purposes. The population densities used in this analysis are derived from the WebTRAGIS model (see Appendix E for a discussion of the population densities).

\subsection{Marine Accident}

Information in this section was taken from the Final Environmental Impact Statement on a Proposed Nuclear Weapons Nonproliferation Policy Concerning Foreign Research Reactor Spent Nuclear Fuel (DOE 1996c). The information from that EIS is considered to be the best available information with respect to accidents associated with the marine transport of radiological materials. The maximum reasonably foreseeable accident involving marine transportation of nuclear materials would involve the sinking of the ship with casks containing SNF. If the casks were to sink anywhere in U.S. coastal waters, under the provisions of the Marine Protection, Research, and Sanctuaries Act, Title I (MPRSA) they would be recovered, regardless of depth (33 U.S.C. 1401). U.S. coastal waters, in this case, refer to waters within the $12 \mathrm{mi}(19 \mathrm{~km})$ territorial limit. Elsewhere in the world, if the casks were to sink in coastal water (i.e., in water up to $660 \mathrm{ft}$. [201 m]), every effort would be made to recover them. In deeper waters, the recovery would be more problematic and recovery could not be guaranteed. The same casks loaded with about 5 MTHM of SNF were used for this analysis. The probability of a marine accident was estimated to be $5 \times 10^{-10}$ (DOE 1996c). The consequence of this analysis is shown in Table 7.2.1.10.2-1. The analysis in Table 7.2.1.10.2-1 is based on the loss of a single cask. If more than one cask were lost at sea, the impacts would be expected to increase linearly as a function of the number of casks lost (i.e., loss of 2 casks would double the impacts). For the annual transport of 21.7 MTHM, a total loss of these casks at sea would be expected to increase the impacts shown in Table 7.2.1.10.2-1 by approximately five times.

TABLE 7.2.1.10.2-1—Consequences Resulting from the Loss at Sea of a Rail Transportation Cask Containing Spent Nuclear Fuel

\begin{tabular}{lccc}
\hline & \multicolumn{2}{c}{ Coastal Waters } & Deep Ocean \\
\cline { 2 - 4 } & Undamaged Cask & Damaged Cask & Damaged Cask \\
\hline Peak Individual Dose (Man) rem/yr & 0.0003 & 0.019 & $1.5 \times 10^{-8}$ \\
Peak Biota Dose (Fish) rad/yr & 0.0001 & 0.0008 & 0.9 \\
Peak Biota Dose (Crustaceans) rad/yr & 0.0001 & 0.0009 & 1.2 \\
Peak Biota Dose (Mollusks) rad/yr & 0.0003 & 0.019 & 41 \\
\hline
\end{tabular}

Source: Tetra Tech $2008 \mathrm{f}$

\subsection{Port Accident}

The only port accident considered is one in which the ship carrying the SNF is struck by another ship. For accidents where ships ram a fixed structure or another ship, the damage would be limited to the prow and to the forward-most hold, and the forces exerted on cargo in the forward hold would not be expected to be sufficient to damage the shipping cask. Such forces would be 
substantially less than the forces exerted on cargo in the case where a striking ship impacts the cargo hold. For ships that might run aground in port, their keel structure is sufficient to limit damage to the cargo. Although a ship could sink, immersion to the depths of a harbor would not damage the integrity of the SNF cask or pose significant retrieval problems (DOE 1996c).

\subsubsection{Other Domestic Programmatic Alternatives}

This section discusses the potential environmental impacts in the United States and the global commons that could result from an international Reliable Fuel Services Program based on the domestic programmatic alternatives, other than the Fast Reactor Recycle Alternative. Under each of the domestic programmatic alternatives, an international Reliable Fuel Services Program would produce the following impacts:

- Transporting Fresh Fuel from the United States to a Foreign Reactor-these impacts would be the same as those presented in Sections 7.2.1.1, 7.2.1.2, and 7.2.1.3

- Transporting Spent Nuclear Fuel from a Foreign Reactor to a United States Port- these impacts would be the same as those presented in Sections 7.2.1.4, 7.2.1.5, and 7.2.1.6

- Potential Accidents - these potential impacts would be the same as those presented in Section 7.2.1.10

In addition, there are potential differences among the domestic programmatic alternatives for the impacts from disposition of foreign reactor SNF. These differences are shown in Table 7.2.2-1. 


\section{TABLe 7.2.2-1—Potential Differences Among the Domestic Programmatic Alternatives Related to Disposition of Foreign Reactor Spent Nuclear Fuel}

\begin{tabular}{|c|c|c|}
\hline & $\begin{array}{l}\text { Disposition of } \\
\text { Foreign Reactor } \\
\text { SNF }\end{array}$ & Impacts of Foreign Reactor SNF Disposition \\
\hline $\begin{array}{l}\text { Fast Reactor Recycle } \\
\text { Alternative }\end{array}$ & $\begin{array}{c}\text { Recycle at recycling } \\
\text { center }\end{array}$ & $\begin{array}{l}\text { The recycling process for the SNF received from production of } 1 \mathrm{GWe} \text { in LWRs } \\
\text { would be expected to generate the following annual wastes: } \\
\text { HLW: } 0.25-9.2 \mathrm{~m}^{3} \\
\text { GTCC LLW: } 1.9-68.5 \mathrm{~m}^{3} \\
\text { LLW: } 0.6-382 \mathrm{~m}^{3} \\
\text { The HLW would produce } 235 \text { times less thermal load on a repository compared to } \\
\text { spent fuel. } \\
\text { The radiotoxicity of the HLW would decay to the radiotoxicity of natural uranium } \\
\text { ore in } 375 \text { years. }\end{array}$ \\
\hline No Action Alternative & $\begin{array}{l}\text { Disposal in geologic } \\
\text { repository }\end{array}$ & $\begin{array}{l}\text { Approximately } 25 \mathrm{MT} \text { of SNF (annual maximum per } 1 \mathrm{GWe} \text { ) would require } \\
\text { disposal in a geologic repository. Impacts from transporting the SNF to a } \\
\text { geologic repository would depend upon the distance from the United States } \\
\text { port to the geologic repository (note } 1 \text { ). }\end{array}$ \\
\hline $\begin{array}{l}\text { Thermal/Fast Reactor } \\
\text { Recycle Alternative }\end{array}$ & $\begin{array}{c}\text { Recycle at recycling } \\
\text { center }\end{array}$ & $\begin{array}{l}\text { The recycling process for the SNF received from production of } 1 \mathrm{GWe} \text { in LWRs } \\
\text { would be expected to generate the following annual wastes: } \\
\text { HLW: } 0.25-9.0 \mathrm{~m}^{3} \\
\text { GTCC LLW: } 1.9-66 \mathrm{~m}^{3} \\
\text { LLW: } 0.5-344 \mathrm{~m}^{3} \\
\text { The HLW would produce } 235 \text { times less thermal load on a repository compared to } \\
\text { spent fuel. } \\
\text { The radiotoxicity of the HLW would decay to the radiotoxicity of natural uranium } \\
\text { ore in } 400 \text { years. }\end{array}$ \\
\hline $\begin{array}{l}\text { Thermal Reactor Recycle } \\
\text { Alternative (option 1) }\end{array}$ & $\begin{array}{c}\text { Recycle at recycling } \\
\text { center }\end{array}$ & $\begin{array}{l}\text { The recycling process for the SNF received from production of } 1 \text { GWe fin LWRs } \\
\text { would be expected to generate the following annual wastes: } \\
\text { HLW: } 0.3-17.4 \mathrm{~m}^{3} \\
\text { GTCC LLW: } 3.4-8.7 \mathrm{~m}^{3} \\
\text { LLW: } 0.2-260 \mathrm{~m}^{3} \\
\text { The HLW would produce } 1.8 \text { times less thermal load on a repository compared to } \\
\text { spent fuel. } \\
\text { The radiotoxicity of the HLW would decay to the radiotoxicity of natural uranium } \\
\text { ore in } 55,000 \text { years. }\end{array}$ \\
\hline $\begin{array}{l}\text { Thermal Reactor Recycle } \\
\text { Alternative (option 2) }\end{array}$ & $\begin{array}{c}\text { Recycle at recycling } \\
\text { center }\end{array}$ & $\begin{array}{l}\text { The recycling process for the SNF received from production of } 1 \mathrm{GWe} \text { in LWRs } \\
\text { would be expected to generate the following annual wastes: } \\
\text { HLW: maximum of } 8.0 \mathrm{~m}^{3} \\
\text { GTCC LLW: minimum of } 1.2 \mathrm{~m}^{3} \\
\text { LLW: no data } \\
\text { The HLW would produce } 1.6 \text { times less thermal load on a repository compared to } \\
\text { spent fuel. } \\
\text { The radiotoxicity of the HLW would decay to the radiotoxicity of natural uranium } \\
\text { ore in an unknown period. }\end{array}$ \\
\hline $\begin{array}{l}\text { Thermal Reactor Recycle } \\
\text { Alternative (option } 3 \text { ) }\end{array}$ & $\begin{array}{l}\text { Recycle at recycling } \\
\text { center }\end{array}$ & $\begin{array}{l}\text { There are no data to estimate the quantities of wastes produced, the thermal load } \\
\text { reduction, or the radiotoxicity reduction for this option. }\end{array}$ \\
\hline Thorium Alternative & $\begin{array}{l}\text { Disposal in geologic } \\
\text { repository }\end{array}$ & $\begin{array}{l}\text { Approximately } 25 \mathrm{MT} \text { of SNF (annual maximum per } 1 \mathrm{GWe} \text { ) would require } \\
\text { disposal in a geologic repository. Impacts from transporting the SNF to a } \\
\text { geologic repository would depend upon the distance from the United States } \\
\text { port to the geologic repository (note } 1 \text { ). }\end{array}$ \\
\hline $\begin{array}{l}\text { HWR/HTGR Alternative } \\
\text { (option } 1 \text {-All HWR) }\end{array}$ & $\begin{array}{l}\text { Disposal in geologic } \\
\text { repository }\end{array}$ & $\begin{array}{l}\text { Approximately } 25 \mathrm{MT} \text { of SNF (annual maximum per } 1 \mathrm{GWe} \text { ) would require } \\
\text { disposal in a geologic repository. Impacts from transporting the SNF to a } \\
\text { geologic repository would depend upon the distance from the United States } \\
\text { port to the geologic repository (note } 1 \text { ). }\end{array}$ \\
\hline $\begin{array}{l}\text { HWR/HTGR Alternative } \\
\text { (option 2-All HTGR) }\end{array}$ & $\begin{array}{l}\text { Disposal in geologic } \\
\text { repository }\end{array}$ & $\begin{array}{l}\text { Approximately } 25 \mathrm{MT} \text { of SNF (annual maximum per } 1 \mathrm{GWe} \text { ) would require } \\
\text { disposal in a geologic repository. Impacts from transporting the SNF to a } \\
\text { geologic repository would depend upon the distance from the United States } \\
\text { port to the geologic repository (note } 1 \text { ). }\end{array}$ \\
\hline
\end{tabular}

Note 1: If a repository were 500 miles $(804 \mathrm{~km})$ away from the port (which was the distance assumed for transporting the SNF from port to a recycling center for the Fast Reactor Recycle Alternative), the impacts would be the same as those presented in Table 7.2.1.7-1. For other distances, the impacts would generally vary linearly with distance. That is, if the distance from a port to a geologic repository were 1,000 miles $(1,608 \mathrm{~km})$, the impacts would be twice as much as those presented in Table 7.2.1.7-1. 


\subsection{REFERENCES}

10 CFR 51.52

49 CFR Part 395

33 U.S.C. 1401

EO 12114

CIA 2008a

CIA 2008 b

DOE 1996c

DOE 2008e
U.S. Nuclear Regulatory Commission (NRC), "Environmental Effects of Transportation of Fuel and Waste-Table S-4," Code of Federal Regulations, Office of the Federal Register, National Archives and Records Administration, Washington, DC, Revised January 1, 2008.

U.S. Department of Transportation (DOT), "Hours of Service of Drivers," Code of Federal Regulations, Office of the Federal Register, National Archives and Records Administration, Washington, DC, Revised October 2007.

"Marine Protection, Research, And Sanctuaries Act of 1972," MPRSA, United States Code, Washington, DC, December 29, 2000.

Executive Order (EO), "Environmental Effects Abroad of Major Federal Actions," President Jimmy Carter, Provisions of Executive Order, National Archives and Records Administration, Washington, DC, January 4, 1979.

Central Intelligence Agency (CIA), "The World Fact Book: Atlantic Ocean," Central Intelligence Agency, 2008. Accessed at https:/www.cia.gov/library/publications/the-world factbook/geos/zh.html on June 4, 2008.

CIA, "The World Fact Book: Pacific Ocean," Central Intelligence Agency, 2008. Accessed at https://www.cia.gov/library/ publications/the-world-factbook/geos/zn.html on June 27, 2008.

U.S. Department of Energy (DOE), "Final Environmental Impact Statement on a Proposed Nuclear Weapons Nonproliferation Policy Concerning Foreign Research Reactor Spent Nuclear Fuel," DOE/EIS-0218F, Office of Environmental Management, U.S. Department of Energy, Washington, DC, February 1996.

DOE, “A Reliable Fuel Services Program," 07-GA5057506, U.S. Department of Energy, Washington, DC, 2008. Accessed at http://www.gnep.energy.gov/pdfs/gnepRFSP.pdf on June 4, 2008. 
EIA $2007 b$

IAEA 2001a

NOAA 2008

NRC 2006c

Tetra Tech $2008 \mathrm{f}$

USFWS 2007a

Wigeland 2008a
Energy Information Administration (EIA), "Annual Energy Outlook 2007 With Projections to 2030," DOE/EIA-0383(2007), Energy Information Administration, U.S. Department of Energy, Washington, DC, 2007. Accessed at http://www.eia.doe.gov/oiaf/ archive/aeo07/index.html on December 21, 2007.

International Atomic Energy Agency (IAEA), "International Conventions \& Agreements: Joint Convention on the Safety of Spent Fuel Management and on the Safety of Radioactive Waste Management," International Atomic Energy Agency, June 2001.

National Oceanic and Atmospheric Administration (NOAA), "North Atlantic Right Whales (Eubalaena glacialis)," Office of Protected Resources, National Oceanic and Atmospheric Administration, 2008. Accessed at http://www.nmfs.noaa.gov/pr/ species/mammals/cetaceans/rightwhale northatlantic.htm on November 1, 2007.

NRC, "Environmental Impact Statement for an Early Site Permit (ESP) at the Exelon ESP Site," NUREG-1815, Office of Nuclear Reactor Regulation, U.S. Nuclear Regulatory Commission, Washington, DC, July 2006.

Tetra Tech Inc., "Supporting Calculations for the Transportation Analysis of the Programmatic Alternatives in the GNEP PEIS," M. Dimsha, Tetra Tech Inc., September 2008.

U.S. Fish and Wildlife Service (USFWS), "Sea Turtle Quick Facts," North Florida Field Office, 2007. Accessed at http://www.fws.gov/northflorida/SeaTurtles/turtle-facts-index.htm on July 31, 2008.

Wigeland, R.A., "Performance Summary of Advanced Nuclear Fuel Cycles," GNEP-TIO-AI-AI-RT-2008-000268 Rev 1; Idaho National Laboratory, Nuclear Science \& Technology, June 2008. 


\section{CHAPTER 8}

\section{INDEX}





\section{CHAPTER 8}

INDEX

Chapter 8 provides an index of key terms used in the Global Nuclear Energy Partnership (GNEP) Programmatic Environmental Impact Statement (PEIS).

$A$

Advance Notice of Intent (ANOI), 1-14, 1-25, 2-1, 2-5, 2-10, 2-12, 2-15, 2-24, 2-27, 2-29, G-1, G-5, G-8, G-27, H-1, H-8, J.1-1

Advanced Burner Reactor (ABR), 4-51, 4-166, 7-2, D-52, D-98, G-1, G-10, G-15, G-19, G-23

Advanced Energy Initiative (AEI), 1-2, 1-6, G-6, G-10, G-16, G-18, G-23, G-27, G-32, G-34, G-40, G-43, G-45

Advanced Fuel Cycle Facility (AFCF), 1-17, 4-54, A-92, D-32, D-103, E-18, E-23, E-40, E-50, G-3, G-11, G-16, G-19, G-30, H-4, H-6

Advanced Fuel Cycle Initiative (AFCI), 2-1, 2-6, 2-24, 2-27, 4-2, 4-27, 4-62, 4-89, A-1, A-57, F-7, G-26, G-29, G-47, H-2

Advanced Recycling Reactor (ARR), 1-3, 1-14, 2-1, 2-4, 2-8, 2-28, 2-35, A-9, A-13, A-26, A-29, A-38, A-41, A-46, A-49, A-52, B-4, B-6, G-23, G-33, G-38, G-41, G-44, G-46, H-4

Atomic Energy Commission (AEC), 1-3, 6-2, E-60, G-44

Aiken County, A-83, A-86

Ambient Air Quality Standards, 3-2, 3-16, 5-11, 6-4, J.13-1

American Indian Religious Freedom Act, 6-6

Aqueous, 2-27, 4-27, 4-52, 4-55, 4-62, 4-72, 4-78, 4-81, 4-85, 4-87, 4-143, 4-148, A-29 A-32, A-38, A-42, A-49, A-93, B-5, D-32, D-39, D-41, D-78, E-28

Argonne National Laboratory (ANL), 4-28, G-29, E-63

Atomic City, ID, 1-14, G-22, G-28, G-33

Atomic Energy Act, 1-7, 1-25, 6-2, 6-10, C-7

Augusta, G-30, J.3-5, J.12-1 


\section{$\boldsymbol{B}$}

Background radiation, C-1, C-3, C-8, J.2-5, J.3-5, J.5-7, J.6-7, J.8-8

Barnwell County, J.3-1, J.3-3

Bingham County, J.2-1, J.2-4

Boiling Water Reactors (BWR), 2-16, 2-27, 4-62, 4-67, E-8, E-13, E-39

Brayton Circle, G-17

Brownfield, 2-29

Bureau of Land Management (BLM), 6-12, J.2-1 J.7-1

Bureau of Labor Statistics (BLS), 3-11, 3-16, C-17, C-20, J.6-6, J.8-7

Burnup, 2-29, 4-32, 4-76, 4-85, 4-89, 4-91, 4-97, 4-100, 4-103, 4-107, 4-109, 4-113, 4-124, 4-130, 4-132, 4-134, 4-136, E-18, E-23, E-50

C

CANDU, CANada Deuterium Uranium Reactor, 2-16, 2-22, 2-35, 2-37, 4-83, 4-106, E-20, F-3

Carlsbad, NM, H-3

Clean Air Act (CAA), 3-2, 4-6, 6-2, 6-4, C-7, C-15

Clean Water Act (CWA), 4-6, 6-2, 6-5, C-15, J.3-3, J.5-3

Climate Change, 1-21

Clinch River Breeder Reactor Plant (CRBRP), 1-9, 1-28, D-48, D-101, D-103

Clinch River, 1-9, 1-28, 2-35, 4-53, D-2, D-48, D-51, D-101, D-103, J.8-1, J.8-6, J.8-8

Clive, UT, 4-23, G-35

COEX, co-extraction, 2-10, 4-62

Cold war, 2-28, J.5-6

Columbia River, J.5-1, J.5-8 
Comprehensive Environmental Response, Compensation and Liability Act (CERCLA), C-15, J.2-5, J.6-8

Consolidated Fuel Treatment Center, 1-14, G-1, G-10, G-23

Council on Environmental Quality (CEQ), 1-13, 1-24, 2-48,

Criteria Pollutants, 3-2, 4-21, 4-25, 4-40, J.4-2, J.5-2, J.7-2, J.8-2

\section{D}

Decontamination and Decommissioning (D\&D), 2-37, 4-46, 4-116, 4-123, 4-149, 4-157, 4-160, 5-7, F-5, G-6, G-30

DuPage County, G-29

Direct use of spent PWR fuel in CANDU (DUPIC), 2-16, 2-41, 2-43, 2-45, 2-47, 4-83, 4-107, 4-131, 4-133, 4-135, 4-137, 5-8, D-80, F-3

$\boldsymbol{E}$

East Tennessee Technology Park, J.8-1, J.8-3, J.8-8

Electrochemical, 1-20, 4-62, 4-85, D-32, D-41, D-80

Electrorefining, A-36

Emergency Planning and Community Right-to-Know Act, C-16

Endangered Species Act, C-15, J.6-5

Energy Information Administration (EIA), 1-1, 1-27, 2-33, 2-38, 3-1, 3-12, 3-17, 4-3, 4-40, 5-5, 5-11, 5-14, 7-3, 7-22, F-1, F-9, G-21, G-27, G-36

\section{$\boldsymbol{F}$}

Fast Flux Test Facility (FFTF), D-50, D-99, D-101

F-Canyon, H-3

Federal Register (FR), 2-48, 3-2, 3-16, 4-164, 5-14, 7-21, C-19, D-9, D-98, F-9, G-5, G-11, G-15, G-25, G-35 
Fuel Processing Restoration Facility (FPR), D-34

Fuels and Materials Examination Facility (FMEF), J.5-1

Funding Opportunity Announcement (FOA), 1-14, 1-26, 9-11, G-11, G-23, G-28, G-30, G-33, G-38, G-42, G-47, H-4, J.1-1, J.2-1, J.3-1, J.4-1, J.5-1, J.6-1, J.7-1, J.8-1, J.9-1, J.10-1, J.11-1

$\boldsymbol{G}$

Global warming, 1-29, 9-4, 9-11

Greater-Than-Class-C (GTCC), 2-5, 2-8, 2-11, 2-18, 2-23, 2-35, 2-37, 3-6, 3-16, 4-37, 4-45, 4-53, 4-71, 4-79, 4-86, 4-92, 4-98, 4-101, 4-107, 4-113, 4-123, 4-127, 4-131, 4-133, 4-135, 4-137, 4-139, 4-148, 4-155, 4-158, 4-160, 5-6, 5-14, 7-6, E-23, E-27, E-33, E-35, E-38, E-45, E-47, E-49, E-53, F-3

Greenfield, A-41

Greenhouse gases, 2-47, 3-3, 4-30, 4-161, 5-1, 5-11, 5-15, G-6, G-27

Grid appropriate reactor, 2-7, 7-1, 7-4

Grundy County, 11-15, J.4-1

\section{$\boldsymbol{H}$}

Half-life, 2-20, 2-37, 4-94, 4-98, C-2, F-5

Hanford Site, 2-28, 5-10, 7-12, E-15, G-22, G-28, G-33, J.5-1, J.5-5, J.13-4

Heavy Water Reactors (HWRs), 1-8, 2-2, 2-13, 2-15, 2-20, 2-28, 2-34, 2-40, 2-43, 2-45, 2-47, 4-1, 4-102, 4-107, 4-140, 4-142, 4-145, 4-147, 4-155, 4-160, 5-9, 7-20, B-8, C-11, D-79, E-17, E-20, E-22, E-25, E-27, E-31, E-34, E-40, E-44, E-46, E-48, E-52, E-55, F-1

High efficiency particulate air (HEPA) filters, 4-17, D-8, D-33, D-36, E-25, J.8-3

High-Level Waste (HLW), 1-3, 1-9, 1-18, 2-2, 2-5, 2-11, 2-13, 2-17, 2-27, 2-29, 2-32, 2-37, 3-2, 4-2, 4-20, 4-23, 4-31, 4-42, 4-53, 4-57, 4-59, 4-71, 4-75, 4-79, 4-86, 4-92, 4-123, 4-126, 4-130, 4-153, 4-161, 5-12, 6-9, 7-6, 7-17, D-34, D-99, E-13, E-23, E-27, E-40, E-49, E-53, E-57, F-3, F-5, H-6, J.13-4 
High Temperature Gas-cooled Reactors (HTGR), 1-8, 2-2, 2-13, 2-18, 2-28, 2-30, 2-34, 2-36, 2-40, 2-43, 2-45, 2-47, 4-1, 4-70, 4-74, 4-89, 4-102, 4-108, 4-114, 4-127, 4-130, 4-142, 4-145, 4-154, 4-160, 5-9, 7-5, 7-20, B-8, B-10, C-11, D-2, D-4, D-80, E-15, E-17, E-20, E-22, E-25, E-27, E-31, E-34, E-40, E-44, E-46, E-48, E-52, E-55, F-1

Highly Enriched Uranium (HEU), 1-25, 4-11, 4-96, 4-111, 7-5

Hobbs, NM, 1-14, 11-3, G-22, G-34

Hot cell, 1-21, 4-18, 4-28, 4-62, 4-86, G-7, J.8-3

\section{$\boldsymbol{I}$}

Idaho National Laboratory (INL), 1-10, 1-14, 2-6, 2-49, 3-21, 4-13, 4-28, 7-22, D-50, E-15, G-22, G-28, J.1-1, J.2-1, J.6-1, J.13-2, J.13-5, J.13-9

International Atomic Energy Agency (IAEA), 2-33, 2-50, 3-1, 3-18, 4-16, 4-84, 4-93, 4-98, 4-104, 4-167, 5-13, 7-2, 7-5, 7-7, 7-17, 7-23, D-104, E-5, E-50, F-2, G-40

$\boldsymbol{J}$

No Entries

$\boldsymbol{K}$

Korea Atomic Energy Research Institute (KAERI), 2-18

\section{$\boldsymbol{L}$}

Lea County, 4-12, G-30, J.7-1

Light Water Reactors (LWRs), 1-8, 1-12, 1-15, 1-25, 2-1, 2-22, 2-24, 2-26, 2-28, 2-31, 2-33, 2-40, 3-2, 3-14, 3-21, 4-1, 4-16, 4-31, 4-39, 4-46, 4-51, 4-57, 4-63, 4-74, 4-79, 4-83, 4-85, 4-89, 4-93, 4-98, 4-103, 4-105, 4-107, 4-109, 4-112, 4-117, 4-130, 4-142, 4-145, 4-154, 4-160, 4-166, 4-169, 4-174, 7-5, 7-11, 7-14, 7-17, 7-20, C-11, C-18, D-1, D-4, D-17, D-28, D-33, D-63, D-70, D-86, D-91, D-99, E-13, E15, E-22, E-25, E-31, E-34, E-40, E-44, E-46, E-48, E-52, E-55, F-4

Los Alamos National Laboratory (LANL), 1-12, 2-6, 4-28, G-29 
Los Alamos Neutron Science Center, A-68, A-71, A-73

Low-Level Radioactive Waste Policy Act, 1-12, 1-25, 6-9, 9-15, F-5, F-9

Low-Level Waste (LLW), 1-12, 2-5, 2-8, 2-11, 2-17, 2-23, 2-34, 2-37, 3-6, 3-14, 3-19, 4-2, 4-19, 4-22, 4-32, 4-34, 4-37, 4-45, 4-53, 4-59, 4-71, 4-79, 4-86, 4-92, 4-98, 4-101, 4-107, 4-113, 4-123, 4-127, 4-131, 4-133, 4-135, 4-137, 4-148, 4-156, 4-158, 4-160, 4-172, 5-13, 6-15, 7-6, 7-17, 7-20, 9-11, 9-15, E-3, E-24, E-27, E-33, E-35, E-38, E-45, E-47, E-49, E-53, F-3, F-5, F-6, G-19, G-35, J.3-5, J.9-5, J.9-6, J.12-8

\section{$M$}

Maximally Exposed Individual (MEI), 1-8, 4-25, 4-35, 4-42, 4-44, 4-52, 4-68, 4-106, 4-112, 4-141, 4-146, 4-166, 9-15, B-1, B-3, B-10, B-14, C-12, D-10, D-15, D-18, D-20, D-23, D-26, D-30, D-43, D-64, D-72, D-76, D-83, D-85, D-91, D-93, E-10, E-48, F-5, J.4-5, J.9-5, J.12-8

McCracken County, J.9-1, J.9-4, J.13-8

Mixed Oxide Fuel Fabrication Facility (MOX Facility), 4-171, E-19, J.13-7

Modified Mercalli Intensity (MMI) Scale, J.9-3, J.10-4

Molten Salt Reactor (MSR), 2-25, 2-28

Morris, IL, 1-4, 1-14, G-22, G-28, G-34, J.1-1, J.4-1, J.13-7

$N$

National Ambient Air Quality Standards (NAAQS), 3-2, 5-11, 6-4, J.5-2, J.7-2, J.8-2, J.10-2, J.12-2

National Environmental Policy Act (NEPA), 1-3, 1-10, 1-14, 1-19, 2-1, 2-7, 2-28, 2-35, 4-20, 4-59, 4-61, 4-175, 5-10, 5-14, 6-1, 6-10, 6-15, B-1, B-15, D-2, D-4, D-8, D-13, D-32, D-37, D-41, D-51, D-61, D-80, D-103, E-9, E-18, E-20, E-23, E-26, E-51, E-59, E-61, E-64, F-7, G-5, G-25, G-35, H-2, H-6, H-8, J.13-5

National Environmental Research Park, J.6-1, J.8-1

National Historic Preservation Act (NHPA), 6-6

National Park Service (NPS), 6-12 
National Pollutant Discharge Elimination System (NPDES), 4-10, A-72, C-15, J.8-4, J.10-2, J.12-3

National Register of Historic Places (NRHP), 6-6, J.3-4, J.5-6, J.6-6, J.9-4, J.12-6

Native American Graves Protection and Repatriation Act, 6-6

New Mexico Environmental Department (NMED), A-75, A-91, J.11-1

Next Generation Nuclear Plant (NGNP), 2-7, 2-23, 2-36, A-22, A-66

Nonproliferation Impact Assessment (NPIA), 1-8, 1-19, 2-28, H-6

Notice of Intent (NOI), 1-17, 2-1, 3-2, G-1, G-6, G-25, G-30, G-35, H-1, H-3

Nuclear fuel cycle, 2-1, 2-5, 2-22, 2-24, 2-27, 2-31

Nuclear Fuel Recycling Center, 1-3, 1-14, 1-18, 2-1, 2-8, 2-11, 2-13, 2-34, 4-46, 4-48, 4-51, 4-58, 4-61, 4-65, 4-69, 4-76, 4-78, 4-91, 4-130, 4-146, 7-8, A-41, B-1, B-4, B-8, D-4, D-15, D-17, D-31, D-44, D-78, D-82, F-2, F-4, G-23, J.1-1, J.3-3

Nuclear Regulatory Commission (NRC), 1-3, 1-6, 2-5, 2-7, 2-31, 2-34, 2-37, 3-3, 4-10, 4-14, 4-53, 6-1, 7-5, A-12, B-1, C-7, E-1, E-5, E-9, E-11, F-5, G-2

Nuclear Waste Policy Act (NWPA), 1-6, 2-5, 2-32, 4-21, 4-124, 5-6, 6-9

Nye County, NV, 1-6, 1-10, 3-2, 4-20, 5-9, B-11, E-8, E-14

\section{$\boldsymbol{O}$}

Oak Ridge Reservation (ORR), 1-12, 5-10, E-16, J.1-1, J.8-1, J.8-8, J.13-3, J.13-5

Oak Ridge National Laboratory (ORNL), 2-6, 2-48, 4-28, A-21, A-78, A-88, F-9, E-62, G-22, G-28, G-35, J.8-1, J.13-3, J.13-6

Occupational Safety and Health Act, 6-11

Occupational Safety and Health Administration (OSHA), C-16, C-19, C-22

Ogallala Aquifer, J.11-2

Ohio River, J.9-1, J.10-3, J.10-6 
Organization for Economic Cooperation and Development (OECD), 7-4

Oxidation and Reduction of Oxide Fuel (OREOX), 2-17, A-29, A-38

\section{$\boldsymbol{P}$}

Pacific Northwest National Laboratory (PNNL), 2-6, A-59, A-80, A-88

Paducah Gaseous Diffusion Plant, G-23, G-28, G-34

Paducah, KY, 1-14, A-6

Pebble Bed Modular Reactor (PBMR), 2-23, 7-5, A-22, A-89, E-18

Piketon, OH, 4-13, 4-171, A-6

Plutonium and Uranium Extraction Process (PUREX), 2-25, 2-28, A-4, A-29

Pollution Prevention Act, 6-8

Portsmouth Gaseous Diffusion Plant, G-23, G-28, G-34,

Portsmouth, OH, 1-15, 4-12

Pressurized water reactor (PWR), 2-16, 2-18, 2-20, 4-13, 4-43, 4-83, 4-85, 4-99, 4-157, A-11, A-15, A-18, A-39, A-42, B-12, B-15, D-1, D-37, D-80, E-8, E-13, E-19, E-40, F-3

Price-Anderson Amendments Act, C-7

$Q$

No Entries

\section{$\boldsymbol{R}$}

Radon, 3-3, 4-5, 4-7, 4-9, 4-94, A-10, C-2, C-6

Record of Decision (ROD), 1-8, 1-26, 2-35, 3-2, 3-16, 4-77, 4-157, A-70, G-7, H-2, H-6

Resource Conservation and Recovery Act (RCRA), 4-10, 6-2, 6-7, A-69, A-77, A-80, A-85, C-15, J.11-1, J.11-4, J.2-6, J.5-9, J.6-8, J.8-8 
Roane County, J.8-7

Region of Influence (ROI), 4-14, 5-2, J.2-4, J.5-7, J.6-6, J.7-4, J.8-7, J.9-4, J.10-5, J.11-3, J.12-6

$S$

1995 Settlement Agreement, J.6-8

Safe Drinking Water Act, 6-2, C-15

Sandia National Laboratories (SNL), 2-6, 4-28, E-63

Savannah River Site (SRS), A-92, E-16, E-19, J.13-8

Savannah River, 1-3, 1-12, 1-14, 1-24, 2-6, 2-8, A-12, A-18, A-80, A-82, A-92, D-34, D-99, D-104, E-16, E-19, E-63, G-23, G-28, G-34, J.1-1, J.3-1, J.12-1, J.12-5, J.12-8

Site Screening process, G-29

Slightly Enriched Uranium (SEU), 2-22, 4-103, A-19

Snake River Plain Aquifer, J.2-2, J.6-2, J.13-2

Snake River Plain, J.2-2, J.6-2, J.13-2

South Carolina Department of Health and Environmental Control (SCDHEC), 4-173, J.3-5

Spent Nuclear Fuel (SNF), 1-1, 1-3, 1-5, 1-10, 1-20, 1-25, 1-28, 2-1, 2-4, 2-8, 2-10, 2-15, 2-18, 2-25, 2-32, 2-36, 2-50, 3-1, 3-15, 4-2, 5-6, 5-9, 5-14, 6-2, 6-9, 7-1, 7-6, 7-12, 7-14, 7-18, A-1, A-3, A-28, A-39, A-41, A-48, A-57, A-82, A-88, A-93, B-4, B-11 B-15, C-11, D-32, D-34, D-53, D-55, D-64, D-99, E-1, E-5, E-7, E-13, E-18, E-22, E-25, E-35, E-39, E-44, E-52, F-1, G-3, G-5, G-9, G-15, G-18, G-23, G-25, G-31, G-38, G-50, H-1

State Historic Preservation Officer (SHPO), 6-6

Supercritical-Water-cooled Reactor (SCWR), 2-29 


\section{$T$}

Thorium, 1-9, 1-18, 2-4, 2-15, 2-18, 2-20, 2-25, 2-41, 2-43, 2-45, 2-47, 2-51, 4-1, 4-10, 4-92 4-118, 4-122, 4-124, 4-127, 4-130, 4-141, 4-148, 4-162, 4-169, 4-174, 7-20, A-1, A-7, A-9, A-15, A-19, A-24, A-51, A-87, A-90, A-92, B-9, B-17, C-2, C-6, C-11, D-4, D-81, D-103, E-17, E-19, E-22, E-25, E-27, E-31, E-34, E-40, E-44, E-46, E-48, E-52, E-55, F-1, F-3, F-6, H-5

Toxic Substances Control Act (TSCA), 6-2, A-85, C-15, J.8-9, J.10-7

Transuranic (TRU), 1-15, 2-6, 2-8, 2-11, 2-13, 2-15, 2-18, 2-28, 2-30, 2-49, 3-6, 4-47, 4-55, 4-57, 4-62, 4-74, 4-76, 4-89, 4-99, 4-109, 4-121, 4-126, 4-155, 4-163, 4-165, 7-1, 7-6, 7-17, A-2, A-8, A-16, A-23, A-26, A-28, A-32, A-41, A-43, A-50, A-54, A-57, A-60, A-71, A-75, A-78, A-80, A-85, A-87, B-8, D-2, D-34, D-78, D-83, E-24, E-29, E-32, E-34, E-40, E-45, E-48, E-53, E-55, F-6, G-3, G-5, G-10, G-15, G-23, G-26, G-31, G-34, G-38, G-44, H-1, H-6, J.2-5, J.5-8, J.8-8, J.10-7, J.12-9

Tritium, 4-27, 4-62, 4-105, 4-167, 4-170, A-19, A-34, A-39, A-61, A-80, B-3, B-7, B-15, D-1, D-24, D-54, D-77, D-83, D-91, D-98, J.3-2, J.5-2, J.5-4, J.5-2, J.8-3, J.12-2, J.12-8, J.13-2

$\boldsymbol{U}$

U.S. Enrichment Corporation (USEC), 4-12, 4-174, A-7, J.9-2, J.10-1

U.S. Fish and Wildlife Service (USFWS), 6-12, 7-22, J.3-3, J.6-5, J.13-2, J.13-9

U.S. Forest Service (USFS), 6-12, J.12-1

U.S. Army Corps of Engineers (USACE), 6-5, 6-11, G-21, J.3-3, J.11-3

U.S. Geological Survey (USGS), 3-6, 3-21, 5-5, 5-16, J.4-3

Uranium, 1-3, 1-6, 1-8, 1-13, 1-29, 2-1, 2-4, 2-8, 2-13, 2-19, 2-22, 2-25, 2-28, 2-37, 2-40, 2-48, 3-1, 3-8, 3-12, 3-17, 3-21, 4-1, 4-11, 4-31, 4-40, 4-47, 4-49, 4-54, 4-62, 4-65, 4-67, 4-71, 4-76, 4-79, 4-81, 4-83, 4-87, 4-90, 4-103, 4-106, 4-110, 4-112, 4-118, 4-124, 4-130, 4-132, 4-134, 4-142, 4-146, 4-153, 4-162, 4-166, 4-169, 5-1, 6-2, 7-2, 7-4, 7-8, 7-17, 7-20, A-1, A-15, A-23, A-28, A-32, A-46, A-51, A-68, A-74, A-80, A-89, B-2, B-6, C-2, C-6, C-11, D-17, D-34, D-69, D-71, D-79, E-17, E-20, E-23, E-25, E-27, E-33, E-35, E-37, E-40, E-45, E-47, E-53, F-1, F-3, F-5, G-6, G-16, G-18, G-23, G-26, G-34, H-2, J.9-5, J.10-1, J.10-3, J.10-6, J.13-3, J.13-8

UREX, 4-62, 4-85, G-6, G-20

UREX+Uranium Extraction Plus, G-6, G-20 
$V$

Volatile organic compound (VOC), 4-63, A-34, A-78, A-80, B-4, D-33, D-41, D-80

Voloxidation, 4-63, A-34, A-78, A-80, B-5, D-33, D-41, D-80

$\boldsymbol{W}$

Waste Isolation Pilot Plant (WIPP), 1-12, A-78, J.7-3, J.7-5

Waste minimization, A-43, G-20

$\boldsymbol{X}$

No Entries

$\boldsymbol{Y}$

Y-12 National Security Complex, A-78, J.8-1

Yucca Mountain, 1-6, 1-10 1-25, 3-2, 3-14, 4-2, 4-20, 4-31, 4-36, 4-38, 4-56, 4-73, 4-82, 4-88, 4-109, 4-115, 4-123, 4-164, 5-6, 5-9, 5-14, 6-9, B-11, B-15, E-8, E-16, E-20, E-29, E-36, E-39, E-52, E-55, E-61, G-27

$\boldsymbol{Z}$

No Entries 

CHAPTER 9

GLOSSARY 



\section{CHAPTER 9}

GLOSSARY

Chapter 9 provides definitions of technical terms used in the Global Nuclear Energy Partnership (GNEP) Programmatic Environmental Impact Statement (PEIS).

Absorbed dose: The amount of energy imparted to matter by ionizing radiation per unit mass of irradiated material (e.g., biological tissue), in which the absorbed dose is expressed in units of rad or gray $(1 \mathrm{rad}=0.01$ gray $)$.

Accelerator: An apparatus for imparting high velocities to charged particles (such as electrons, protons, and atomic nuclei).

Actinide: One of 15 elements that lie between actinium and lawrencium on the periodic table (atomic numbers 89-103). Both uranium and plutonium are actinides.

Activation products: Radionuclides formed by bombardment and adsorption in material with neutrons, protons, or other nuclear particles. For example, cobalt-60 is an activation product resulting from neutron activation of cobalt-59.

Action level: Defined by regulatory agencies, the level of pollutants which, if exceeded, requires regulatory action.

Acute exposure: A single, short-term exposure to radiation, a toxic substance, or other stressors that may result in biological harm.

Activity: In regard to radioactivity, the number of nuclear transformations occurring in a given quantity of material per unit time.

Administrative limit: A limit imposed by procedure on the quantity of a radionuclide permitted in a building or part of a building. This also refers to the limit allowed for radiation worker dose as well as accumulative radioactive material.

Air Quality Control Region (AQCR): An interstate or intrastate area designated by the U.S. Environmental Protection Agency (EPA) for the attainment and maintenance of National Ambient Air Quality Standards (NAAQS).

Air quality: Measure of the health-related and visual characteristics of the air, often derived from quantitative measurements of the concentrations of specific injurious or contaminating substances. Air quality standards are the prescribed level of constituents in the outside air that cannot be exceeded during a specific time in a specified area. 
Airborne Release Fraction (ARF): The coefficient used to estimate the amount of radioactive material that can be suspended in air and made available for airborne transport under a specific set of induced physical stresses. ARF is used, along with other factors, to determine the source term for an accident or event.

Alpha particle: A positively charged particle ejected spontaneously from the nucleus of an atom during radioactive decay, having mass and charge equal to those of a helium nucleus (two protons and two neutrons).

Ambient air: The surrounding atmosphere, usually the outside air, as it exists around people, plants, and structures; not considered for monitoring purposes when immediately adjacent to emission sources.

Americium: An artificial radioactive element (atomic number 95) produced by the beta decay of plutonium-241.

Aquifer: A body of permeable rock, rock fragments, or soil through which groundwater moves and is capable of yielding quantities of water to wells and/or springs.

As low as reasonably achievable (ALARA): An approach to radiation protection to manage and control worker and public exposures (both individual and collective) and releases of radioactive material to the environment to as far below applicable limits as social, technical, economic, practical, and public policy considerations permit. ALARA is not a specific dose limit, but a process for minimizing doses to as far below limits as reasonable.

Atmospheric dispersion: The spreading downwind of airborne material due to wind speed and atmospheric turbulence; the greater the spread, the greater the dilution and the smaller the airborne material concentrations.

Attainment area: An area that the EPA has designated as being in compliance with one or more of the NAAQS for sulfur dioxide, nitrogen dioxide, carbon monoxide, ozone, lead, and particulate matter. An area may be in attainment for some pollutants but not for others.

Atomic number: The number of positively charged protons in the nucleus of an atom. In an electrically neutral atom, the atomic number is the number of electrons.

Background radiation: Radiation from: 1) cosmic sources; 2) naturally occurring radioactive materials, including radon (except as a decay product of source, by-product or special nuclear material [SNM]); and 3) global fallout as it exists in the environment (e.g., from the testing of nuclear explosive devices).

Beryllium (Be): A toxic and extremely lightweight metallic element with the atomic number 4. It is sometimes used in reactors as a neutron reflector.

Beta particle: A negatively charged electron or a positively charged positron emitted from a nucleus during radioactive decay. 
Beyond-design-basis accident: A beyond-design-basis accident is a hypothetical postulated scenario more severe than a design-basis accident. It generally assumes multiple failures of engineered safety systems and would be expected to occur less than once in a million years.

Bioassay: Measurement of the amount or concentration of radioactive material in the body or in biological material excreted from or removed from the body and analyzed for the purposes of estimating the quantity of radioactive material in the body. This typically includes analysis of urine samples, fecal samples, and whole-body scans or lung counts.

Biota: The plant and animal life of a region.

Blowdown: Water discharged from cooling towers in order to control total dissolved solids concentrations by allowing make-up water to replenish cooling apparatuses.

Bounding analysis: A bounding analysis is an analysis designed to identify the range of potential impacts or risks, both upper and lower.

Breed: The process of producing more fissile material than is consumed.

Breeder Reactor: A nuclear reactor that produces more fissile material than it burns.

Burnup: Measurement of the fissile material consumed via fissioning during fuel irradiation.

By-product material: As defined in the Atomic Energy Act of 1954 (AEA), as amended, any radioactive material (except SNM) yielded in or made radioactive by exposure to the radiation incident to the process of producing or utilizing special nuclear material, and the tailings or wastes produced by the extraction or concentration of uranium or thorium from any ore processed primarily for its source material content.

Cadmium (Cd): A soft, bluish-white metallic element (atomic number 48) occurring primarily in zinc, copper, and lead ores, that is easily cut with a knife and is used in low-friction, fatigueresistant alloys, solders, dental amalgams, nickel-cadmium storage batteries, nuclear reactors shields, and in rustproof electroplating.

Cancer: A group of diseases characterized by uncontrolled cellular growth. Increased incidence of cancer can be caused by exposure to radiation or to certain chemicals at sufficient concentrations and exposure durations.

Candidate species: Species for which the U.S. Fish and Wildlife Service has enough substantive information on biological status and threats to support proposals to list them as threatened or endangered under the Endangered Species Act. Listing is anticipated but has been precluded temporarily by other listing activities.

CANDU: Canada Deuterium Uranium reactor, a pressurized heavy water-cooled power reactor that uses natural uranium or slightly enriched uranium fuel. 
Canister: A stainless-steel container used for the storage, transport, and/or disposal of nuclear materials.

Capacity factor: A power production performance measure that compares the amount of power actually produced per year to the maximum power output possible. This measure is typically expressed as a fraction or percentage of the megawatt hours (MWh) produced relative to the possible MWh that would have been produced had the unit or system operated every hour of the year.

Carbon dioxide $\left(\mathbf{C O}_{2}\right)$ : A colorless, odorless, atmospheric gas generated primarily through the combustion of fossil fuels and the most common of gases generally attributed to creating "global warming."

Carbon monoxide (CO): A colorless, odorless gas that is toxic if breathed in high concentrations over a period of time.

Carcinogen: A substance that directly or indirectly causes cancer.

Cask: A specially designed container used for shipping, storage, or disposal of radioactive material that affords protection from accidents and provides shielding for radioactive material. The design includes special shielding, handling, and sealing features to provide positive containment and minimize personnel exposure.

Cesium (Cs): A chemical element with the atomic number 55. A radioactive isotope of cesium, cesium-137, is a common fission product.

Chronic exposure: The absorption of radiation or intake of radioactive and/or chemical materials over a long period of time.

Cladding: The metal tube that forms the outer jacket of a nuclear fuel rod. It protects the fuel elements, provides structural support, and prevents the release of radioactive material into the coolant. Stainless steel and zirconium alloys are commonly used cladding materials.

Code of Federal Regulations (CFR): A codification of all regulations promulgated by Federal agencies.

Collective dose equivalent and collective committed effective dose equivalent: The sums of the dose equivalents or effective dose equivalents to all individuals in an exposed population within 50 miles (mi) (80 kilometers $[\mathrm{km}]$ ) of the radiation source. These are evaluated by multiplying the dose received by an individual at each location by the number of individuals receiving that dose, and summing over all such products for locations within $50 \mathrm{mi}(80 \mathrm{~km})$ of the source. They are expressed in units of person-rem or person-sievert. The collective effective dose equivalent (EDE) is also referred to as the "population dose." 
Committed effective dose equivalent (CEDE): The calculated effective dose to an individual after exposure to radiation summed over the life of the individual. CEDE assumes a 70-year exposure period for the general population and a 50-year exposure period for the worker population.

Confined aquifer: An aquifer bounded above and below by impermeable beds, or beds of distinctly lower permeability than that of the aquifer itself.

Consumptive water use: The difference in the volume of water withdrawn from a body of water and the amount released back into the body of water.

Containment barrier: In the context of a Spent Nuclear Fuel (SNF) shipment or a high-level waste repository, a barrier to release of radioactivity made by man, such as a corrosion-resistant container.

Control rod: A rod containing material such as boron that is used to modulate and control the power of the fuel of a nuclear reactor. By absorbing excess neutrons, a control rod prevents the neutrons from causing further fissions; i.e., increasing power.

Conversion ratio: A measure of the efficiency by which a fast reactor consumes transuranics.

Cooling water: Water pumped into a nuclear reactor or accelerator to cool components and prevents damage from the intense heat generated when the reactor or accelerator is operating.

Copper (Cu): A ductile, malleable, reddish-brown metallic element (atomic number 29) that is an excellent conductor of heat and electricity and is widely used for electrical wiring, water piping, and corrosion-resistant parts, either pure or in alloys such as brass and bronze.

Cosmic radiation: Radiation with very high energies originating outside the Earth's atmosphere which is one source contributing to natural background radiation.

Criteria Air Pollutants: In 40 CFR Part 50, the EPA has identified seven specific pollutants that have well-known adverse affects on human health and welfare. These seven pollutants are called criteria pollutants, and they include $\mathrm{CO}$, nitrogen dioxide $\left(\mathrm{NO}_{2}\right)$, various oxides of sulfur $\left(\mathrm{SO}_{\mathrm{x}}\right)$, ozone $\left(\mathrm{O}_{3}\right)$, lead $(\mathrm{Pb})$, and two categories of particulate matter $(\mathrm{PM}), \mathrm{PM}_{10}$ and $\mathrm{PM}_{2.5}$.

Critical habitat: "Specific area within the geographical area occupied by [an endangered or threatened] species..., essential to the conservation of the species and which may require special management considerations or protection; and specific areas outside the geographical area occupied by the species...that are essential for the conservation of the species" (Endangered Species Act, Section 3).

Criticality: A nuclear chain reaction that is self-sustaining. This occurs in a nuclear reactor as a controlled reaction to produce energy. 
Cultural resources (historic): Material remains, such as trash dumps and architectural features, including structures, foundations, basements, and wells; any other physical alteration of the landscape, such as ponds, roads, landscaping, and fences.

Cultural resources (prehistoric): Any material remains of items used or modified by people, such as artifacts of stone, bone, shellfish, or wood. Animal bone, fish remains, bird bone, or shellfish remains used for foods are included. Physical alteration of the landscape, such as hunting blinds, remains of structures, excavated house pits, and caches of artifacts or concentrations of stones (such as cooking stones) are also prehistoric cultural resources.

Curie (Ci): A unit of measurement of radioactivity defined as the amount of radioactive material in which the decay rate is $3.7 \times 10^{10}$ disintegrations per second or $2.22 \times 10^{12}$ disintegrations per minute: 1 curie is approximately equal to the decay rate of 1 gram of pure radium.

Damage Ratio (DR): The fraction of the material-at-risk impacted by accident-generated conditions.

Decay heat: The heat produced by the decay of certain radionuclides.

Decay, radioactive: The decrease in the amount of radioactive material with the passage of time, due to the spontaneous emission of either alpha or beta particles from the atomic nuclei, often accompanied by gamma radiation.

Decommissioning: The process of removing a facility from operation, followed by decontamination, entombment, dismantlement, or conversion to another use.

Decontamination: The actions taken to reduce or remove substances that pose a substantial present or potential hazard to human health or the environment-such as radioactive or chemical contamination of facilities, soil, or equipment-by washing, chemical action, mechanical cleaning, or other techniques.

Depleted uranium: Uranium which has a lower proportion of the fissile isotope U-235 than is found in naturally occurring uranium, i.e., less than approximately 0.711 percent by weight U-235.

Deposition: A comprehensive term used for the various ways that compounds precipitate from the atmosphere and deposit onto surfaces.

Derived Concentration Guide: Concentrations of radionuclides in water and air that could be continuously consumed or inhaled for one year and not exceed the U.S. Department of Energy (DOE) primary radiation standard to the public (100 mrem/year EDE).

Deterministic: With results determined by input assumptions and data, but without the probability of occurrence.

Deuterium: A hydrogen isotope that is twice the mass of ordinary hydrogen and that occurs naturally in water; also called heavy hydrogen. 
Dose: The energy imparted to matter by ionizing radiation; the unit of absorbed dose is the rad, equal to 0.01 joules per kilogram for irradiated material in any medium. Various technical terms - such as dose equivalent, effective dose equivalent, and collective dose - are used to evaluate the amount of radiation an exposed individual or population receives.

Dose equivalent: The product of absorbed dose in rad (or gray) in tissue and a quality factor representing the relative damage caused to living tissue by different kinds of radiation, and perhaps other modifying factors representing the distribution of radiation, etc., expressed in units of rem or sievert $(1 \mathrm{rem}=0.01$ sievert).

Dosimeter: A portable detection device for measuring the total accumulated exposure to ionizing radiation.

Dosimetry: The theory and application of the principles and techniques of measuring and recording radiation doses.

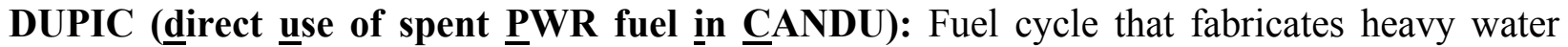
reactor fuel from pressurized water reactor (PWR) spent fuel by using dry thermal $/$ mechanical processes without separating stable fission products.

Effective dose equivalent: An estimate of the total risk of potential effects from radiation exposure, it is the summation of the products of the dose equivalent and weighting factor for each tissue. The weighting factor is the decimal fraction of the risk arising from irradiation of a selected tissue to the total risk when the whole body is irradiated uniformly to the same dose equivalent. These factors permit dose equivalents from nonuniform exposure of the body to be expressed in terms of an effective dose equivalent that is numerically equal to the dose from a uniform exposure of the whole body that entails the same risk as the internal exposure.

Effluent: A waste stream flowing into the atmosphere, surface water, ground water, or soil. Most frequently the term applies to wastes discharged to surface waters.

Emergency Response Planning Guidelines: Estimates of concentration ranges at which adverse effects can be expected if exposure to a specific chemical lasts more than 1 hour.

Emergency Response Planning Guidelines-1 (ERPG-1): The maximum airborne concentration below which it is believed that nearly all individuals could be exposed for up to 1 hour without experiencing other than mild transient and adverse health effects or perceiving a clearly defined, objectionable odor.

Emergency Response Planning Guidelines-2 (ERPG-2): The maximum airborne concentration below which it is believed that nearly all individuals could be exposed for up to 1 hour without experiencing or developing irreversible or other serious health effects or symptoms which could impair an individual's ability to take protective action. 
Emergency Response Planning Guidelines-3 (ERPG-3): The maximum airborne concentration below which it is believed that nearly all individuals could be exposed for up to 1 hour without experiencing or developing life-threatening health effects.

Emission sources: Based on the criteria pollutant emission potential, a stationary emission source is designated as either a minor source or a major source. This designation (minor or major) determines the applicable state and federal permit requirements, as well as the requirements for an impact analysis. A large emission source is generally required to apply for both a preconstruction permit and an operations permit. The major source emission thresholds for a preconstruction permit are not the same as major source emission thresholds for an operations permit. Therefore, a new source can be designated as minor with respect to preconstruction permit, but major with respect to the operations permit. In addition, a source can be designated as minor or major with respect to Hazardous Air Pollutants (HAPs) emissions. This designation determines the applicable National Emissions Standards for Hazardous Air Pollutants (NESHAP) requirements for the source.

Endangered species: Species of plants and animals that are threatened with either extinction or serious depletion in their range and that are formally listed as such by the U.S. Fish and Wildlife Service and that are legally protected.

Engineered barriers: Manmade components of a system designed to prevent the release of radionuclides into the environment. These barriers include the radioactive waste form, radioactive waste canisters, and other materials placed over and around such canisters.

Enriched uranium: Uranium, in which the proportion of U-235 to U-238 has been increased above the natural approximately 0.711 percent U-235. Reactor-grade uranium is usually 3 to 5 percent $U-235$.

Enrichment: The physical process of increasing the proportion (or ratio) of U-235 to U-238 to make the mixture more usable as nuclear fuel.

Environmental Impact Statement (EIS): The detailed written statement that is required by section 102(2)(C) of the National Environmental Policy Act (NEPA) for a proposed major Federal action significantly affecting the quality of the human environment. A DOE EIS is prepared in accordance with applicable requirements of the Council on Environmental Quality NEPA regulations in 40 CFR Parts 1500-1508, and the DOE NEPA regulations in 10 CFR Part 1021. The statement includes, among other information, discussions of the environmental impacts of the proposed action and all reasonable alternatives, adverse environmental effects that can not be avoided should the proposal be implemented, the relationship between short-term uses of the human environment and enhancement of long-term productivity, and any irreversible and irretrievable commitments of resources. 
Environmental justice: The fair treatment of people of all races, cultures, national origins, incomes, and educational levels with respect to the development, implementation, and enforcement of environmental laws, regulations, and policies. Fair treatment implies that no population of people should be forced to shoulder a disproportionate share of the negative environmental impacts of pollution or environmental hazards due to a lack of political or economic strength.

Exponential notation: A means of expressing large or small numbers in powers of 10. For example, $4.3 \times 10^{6}=4,300,000$ and $4.3 \times 10^{-5}=0.000043$. This relationship is also sometimes expressed in the form $4.3 \mathrm{E}+6=4,300,000$, and $4.3 \mathrm{E}-5=0.000043$.

Exposure: The condition of being made subject to the action of radiation or toxic material. Sometimes also used as a generic term to refer to the dose of radiation absorbed by an individual or population. Each exposure pathway includes a source or a release from a source, an exposure, and an exposure pathway or route.

Exposure assessment: The determination of the magnitude, frequency, duration, and route of exposure.

Exposure pathway: The course a chemical or physical agent takes from the source to the exposed organism. An exposure pathway describes a unique mechanism by which an individual or population is exposed to chemicals or physical agents at or originating from a release site.

Expression of Interest (EOI): An offer made by a supplier; usually in response to a publicly advertised invitation, for the supply of a specific requirement.

External exposure: Radiation exposure from sources outside of the body, e.g., from cloud passage, material deposited on the ground, and nearby surfaces.

Fast neutrons: A free neutron with a kinetic energy level close to 1 megaelectron-volt $(\mathrm{MeV})$ $(10 \mathrm{TJ} / \mathrm{kg})$, hence a speed of $14,000 \mathrm{~km} / \mathrm{s}$. The fast neutrons are distinguished from lower-energy thermal neutrons, and high-energy neutrons produced in cosmic showers or accelerators, in that they are produced by nuclear processes such as nuclear fission.

Fault (faultline): A fracture in the Earth's crust accompanied by displacement of one side of the fracture with respect to the other and in a direction parallel to the fracture.

Federal facility: A facility that is owned or operated by the Federal Government.

Federal Facility Agreement (FFA): A negotiated agreement that specifies required actions at a Federal facility as agreed upon by various agencies (e.g., EPA, a relevant state agency and DOE).

Federal Register: A document published daily by the Federal Government containing notification of government agency actions, including notification of EPA and DOE decisions concerning permit applications, NEPA actions, and rulemaking. 
Federally listed species: A species, which pursuant to the Endangered Species Act of 1973, has been determined by the U.S. Fish and Wildlife Service to be of concern. See "Threatened, endangered, candidate, or rare species."

Fertile material: A term used to describe nuclides which generally themselves do not undergo induced fissions (fissionable by thermal neutrons) but from which fissile material is generated by neutron absorption and subsequent nuclei conversions.

Fissile material/fissile isotope: An isotope that readily fissions after absorbing a neutron of any energy, either slow or fast.

Fission: The splitting of a heavy atomic nucleus into two or more nuclei of lighter elements, accompanied by the release of energy and the release of one or more neutrons. It can occur spontaneously or be induced by neutron bombardment. It is the fundamental principle by which nuclear power reactors work.

Fission Product: The atoms formed by the fission of heavy elements such as uranium.

Fissionable material: Material that will undergo nuclear fission when exposed to neutrons.

Floodplain: The valley floor adjacent to the incised channel of a stream, which may be flooded during high water.

Footprint: The area of ground covered or taken up by the layout of a facility on the ground; refers also to an area affected by release of radioactive materials.

Fuel assembly: A cluster of fuel rods that are inserted into a reactor core. Also called a fuel element.

Fuel Cycle: The progression of nuclear fuel through a series of differing stages. It consists of steps in the front end, which are the preparation of the fuel, steps in the service period in which the fuel is used during reactor operation, and steps in the back end, which are necessary to safely manage, contain, and either reprocess or dispose of SNF. If SNF is not reprocessed, the fuel cycle is referred to as an open fuel cycle (or a once-through fuel cycle). If the SNF is reprocessed, it is referred to as a closed fuel cycle.

Fuel rod: Nuclear reactor component that includes the fissile material, which combined with other fuel rods form the fuel assembly.

Fugitive dust: The dust released from activities such as construction, manufacturing, or transportation.

Fugitive emissions: Uncontrolled emissions to the atmosphere from pumps, valves, flanges, seals, and other process points not vented through a stack. Also includes emissions from area sources such as ponds, lagoons, landfills, and piles of stored material. 
Funding Opportunity Announcement (FOA): A publicly available document by which a Federal agency makes known its intentions to award discretionary grants or cooperative agreements, usually as a result of competition for funds. Funding opportunity announcements may be known as program announcements, requests for applications, notices of funding availability, solicitations, or other names depending on the agency and type of program.

Gamma radiation: Short-wavelength electromagnetic radiation emitted from the atomic nucleus with typical energies ranging from 10 kiloelectron-volts $(\mathrm{keV})$ to $9 \mathrm{MeV}$. Individual gammas considered as particles are also called photons. Gamma radiation frequently accompanies alpha and beta emissions and always accompanies fission. Gamma rays are very penetrating and are best stopped or shielded against by dense materials such as lead or uranium. Gamma rays are similar to x-rays, but are usually more energetic.

Gaussian plume: The distribution of material (a plume) in the atmosphere resulting from the release of pollutants from a stack or other source. The distribution of concentrations about the centerline of the plume, which is assumed to decrease as a function of its distance from the source and centerline (Gaussian distribution), depends on the mean wind speed and atmospheric stability.

Geologic repository: See "Repository."

Global commons: The environment outside the jurisdiction of any nation (e.g., the oceans or Antarctica).

Global warming: The theory that increasing concentrations of certain gases such as carbon dioxide, methane, and other gases in the Earth's atmosphere are effectively reducing radiant cooling, thus elevating the Earth's ambient temperatures.

Glovebox: A sealed box in which workers, while remaining outside and using gloves attached to and passing through openings in the box, can safely handle and work with radioactive materials, other hazardous materials, and non-hazardous air-sensitive compounds.

Gram (g): The standard metric measure of weight approximately equal to 0.035 ounce.

Greater-Than-Class-C low-level radioactive waste (GTCC LLW): As defined by the Nuclear Regulatory Commission in $10 \mathrm{CFR}$ 72.3, low-level radioactive waste that exceeds the concentration limits of radionuclides established for Class C waste in 10 CFR 61.55. GTCC LLW is generated by U.S. Nuclear Regulatory Commission (NRC) or Agreement Statelicensed activities.

Greenhouse gases: Thermal gases in the earth's atmosphere, which absorb heat radiation form the earth's surface and re-radiate it, thereby warming the earth. $\mathrm{CO}_{2}$, water vapor $\left(\mathrm{H}_{2} \mathrm{O}\right)$, and methane $\left(\mathrm{CH}_{4}\right)$ are the most important greenhouse gases. A higher level of greenhouse gases in the environment, i.e. due to the combustion of fossil fuels, can enhance the greenhouse effect and generally is considered to contribute to global warming. 
Grid-appropriate reactor: Small electricity producing reactor that could be used in countries with limited infrastructures.

Gross alpha: The concentration of all alpha-emitting radionuclides in a sample.

Gross beta: The concentration of all beta-emitting radionuclides in a sample.

Groundwater: Water below the ground surface in the saturated zone.

Habitat: Area in which a plant or an animal lives.

Half-life (biological): The time required for the body to eliminate one-half of an administered dosage of any substance by regular processes of elimination.

Half-life (ecological): The time required for the removal of one-half of the amount of a material deposited in the local environment.

Half-life (radiological): The time required for one-half the radioactive atoms in a given amount of material to decay; for example, after one half-life, half of the atoms will have decayed; after two half-lives, three-fourths; after three half-lives, seven-eighths; and so on, exponentially.

Hazardous Air Pollutants (HAPs): HAPs are any of the pollutants listed in or pursuant to Section 112(b) of the Clean Air Act.

Hazardous chemical: Any chemical that is a physical and/or a health hazard as defined by the Occupational Safety and Health Administration (29 CFR 1910.1201). For Superfund Amendments and Reauthorization Act (SARA) Title III, Section 311, the term is defined the same with certain named exceptions.

Hazardous material: A substance or material, including hazardous substances, which have been determined by the U.S. Secretary of Transportation to be capable of posing an unreasonable risk to health, safety, and property.

Hazardous waste: Waste regulated under the Resource Conservation and Recovery Act that, if managed improperly, could pose a threat to human health and the environment.

Heavy Water Reactor (HWR): Nuclear reactors using heavy water as a neutron moderator. Heavy water is deuterium oxide, $\mathrm{D}_{2} \mathrm{O}$. Deuterium is an isotope of hydrogen.

High-efficiency particulate air (HEPA) filter: An extended-media, dry type filter used to capture particulates from an air stream. HEPA collection efficiencies are at least 99.97 percent for 0.3 micrometer diameter particles.

High (or Highly) enriched uranium: Uranium whose content of the fissile isotope uranium-235 has been increased through enrichment to 20 percent or more (by weight). 
High-level radioactive waste (HLW): As defined by the Nuclear Waste Policy Act of 1982, as amended, means the highly radioactive material resulting from the reprocessing of spent nuclear fuel, including liquid waste produced directly in reprocessing and any solid material derived from such liquid waste that contains fission products in sufficient concentrations; and other highly radioactive material that $\mathrm{NRC}$, consistent with existing law, determines by rule requires permanent isolation.

High temperature gas-cooled reactor (HTGR): A nuclear reactor that is cooled by gas (usually helium) and is able to achieve relatively high operating temperatures compared to other reactor types.

Historic resources: The sites, districts, structures, and objects considered limited and nonrenewable because of their association with historic events, persons, social, or historic movements.

Hot cell: A heavily shielded room that is maintained at a negative pressure and contains remote handling equipment and viewing systems to support work with radioactive material.

Impact: The positive or negative effect, influence, or imprint of an activity on the environment including direct or primary effects, caused by the project and occurring at the same time and place, including indirect or secondary effects, and caused by the project and occurring later in time or farther removed in distance, but still reasonably foreseeable. Indirect or secondary effects may include growth-inducing or other effects related to the changes in the pattern of land use, population density, growth rate, and related effects on air and water and other natural systems, including ecosystems.

Infrastructure: Physical support systems needed to operate a facility including electric distribution systems, water supply systems, sewage disposal systems, roads, etc.

Ingestion dose: An internal dose resulting from the oral intake of food, water, soil, or other media contaminated with radioactive material.

Input parameters: Variables needed to run a mathematical model.

In-situ: Refers to conducting an activity in place without excavation, as in-place (in-situ) mining of uranium ore by leaching.

Internal exposure: Radiation exposure from sources inside the body from materials ingested, inhaled, or (in the case of tritium) absorbed through the skin.

International Atomic Energy Agency (IAEA): The world's center of cooperation in the nuclear field. It was set up as the world's "Atoms for Peace" organization in 1957 within the United Nations family. The Agency works with its Member States and multiple partners worldwide to promote safe, secure and peaceful nuclear technologies. 
International Commission on Radiological Protection (ICRP): An international organization that studies radiation, including its measurement and effects.

Inventory: The amount of a radioactive or hazardous material present in a building or a facility.

Involved worker: Worker who would participate in a proposed action.

Isoconcentration map: A map showing contours of equal concentration of a contaminant.

Isotopes: Forms of an element having the same number of protons in their nuclei, but with differing numbers of neutrons.

Joule: The basic Système International d'Unités (SI) unit of work or energy. The amount of energy exerted when a force of one Newton is applied over a displacement of one meter.

Laboratories, heavy: Laboratories characterized by high-bay construction, overhead cranes, and in some cases, shielding. Heavy laboratories are typically used for large research apparatus or large mechanical test equipment.

Laboratories, light: Laboratories characterized by small equipment and apparatus, typically used for direct bench-scale research.

Land use: The purpose or activity for which a piece of land and/or its buildings is designed, arranged, or intended, or for which it is occupied or maintained.

Laser: A device for producing monochromic (single-color) "light" in a coherent beam. This condition creates a beam with little scattering having a high concentration of energy per unit area of the beam.

Latent cancer fatality (LCF): The excess cancer fatalities in a population due to exposure to a carcinogen or ionizing radiation.

Lead (Pb): A soft, malleable, ductile, bluish-white, dense metallic element (atomic number 82) extracted chiefly from galena and used in containers and pipes for corrosives, solder and type metal, bullets, radiation shielding, paints and antiknock compounds. It is very resistant to corrosion but tarnishes upon exposure to air.

Leak Path Factor (LPF): The fraction of airborne materials transported from containment or confinement deposition or filtration mechanism (e.g., fraction of airborne material in a glovebox leaving the glovebox under static conditions, fraction of material passing through a HEPA filter). LPF is one of the factors used to calculate the source term for an accident or event.

Level of concern: The concentration of an extremely hazardous substance (EHS) in air above which there may be serious irreversible health effects or death as a result of a single exposure for a relatively short period of time. 
Light Water Reactor (LWR): A nuclear power reactor using water to cool the reactor and to moderate (slow down) neutrons. It belongs to the class of nuclear power plants called "thermal reactors."

Loss-of-coolant accident: An accident that results from the loss of reactor coolant because of a break in the reactor coolant system.

Low-enriched uranium (LEU): Uranium with uranium-235 enriched above the natural concentration (approximately 0.711 percent) but below 20 percent; highly enriched uranium (HEU) is enriched to 20 percent or higher U-235.

Low-income status: Based on Census Bureau data definitions of individuals below the poverty line. For the 2000 Census, for example, low-income status included individuals in 4-person families with 1999 income at or below $\$ 17,029$. Other poverty thresholds are provided by the Census Bureau for larger and smaller family sizes.

Low-level radioactive waste (LLW): As defined in the Low-Level Radioactive Waste Policy Amendments Act (LLRWPAA) of 1985, as amended, means radioactive material that is not highlevel radioactive waste, spent nuclear fuel, or byproduct material, as defined in section 11e.(2) of the Atomic Energy Act of 1954; and radioactive material that NRC, consistent with existing law and in accordance with paragraph (A) of section 2(9) of the LLRWPAA, classifies as low-level radioactive waste. The term "low-level radioactive waste" does not include byproduct material as defined in paragraphs (3) and (4) of section 11e. of the Atomic Energy Act of 1954.

Magnitude: A measure of the strength of an earthquake or the strain energy released by it; the logarithm of the amplitude of motion recorded on a seismograph.

Material-at-risk: The maximum amount of the referenced material that is involved in the process and thus at risk in the event of a postulated accident. Material locked in a secure storage is not considered to be material-at-risk.

Maximally exposed individual (MEI): A hypothetical member of the public at a fixed location who, over an entire year, receives the maximum effective dose equivalent (summed over all pathways) from a given source of radionuclide releases to air. Generally, the MEI is different for each source at a site.

Maximum credible accident: An accident that has the greatest offsite consequences from hazardous material release and that has a frequency of occurrence greater than $10^{-6}$ per year, when credit for mitigation is allowed. Such an accident is one of the set of reasonably foreseeable accidents.

Mercury (Hg): A metallic element primarily obtained by reduction from cinnabar, one of its ores. It is a heavy, opaque, glistening liquid (commonly called quicksilver), and is used in barometers, thermometers, etc., (atomic number 80 ). 
Meteorology: The science dealing with the atmosphere and its phenomena, especially as it relates to weather.

Metric tons of heavy metal (MTHM): Quantities of spent nuclear fuel are traditionally expressed in terms of metric tons of heavy metal (typically uranium), without the inclusion of other materials, such as cladding, alloy materials, and structural materials. A metric ton is 1,000 kilograms, which is equal to about 2,200 pounds.

Millirem (mrem): One-one-thousandth of a rem (see "Rem").

Minority populations: Includes individuals who report themselves as belonging to any of the following racial groups: Black (reported their race as "Black or Negro," or reported entries such as "African American, Afro-American, Black Puerto Rican, Jamaican, Nigerian, West Indian, or Haitian"); American Indian; Eskimo or Aleut; Asian or Pacific Islander; or "Other Race." In addition, individuals identifying themselves as Hispanic origin are also included in the minority category. Hispanics can be of any race, however. To avoid double-counting minority Hispanic individuals, only white Hispanics were included in the number of racially based minorities in a tabulation, since nonwhite Hispanics had already been counted under their minority racial classification. Minority populations exist where either: (a) the minority population of the affected area exceeds 50 percent or (b) the minority population percentage of the affected area is meaningfully greater than in the general population or other appropriate unit of geographic analysis (such as a governing body's jurisdiction, a neighborhood, census tract, or other similar unit). Minority populations include either a single minority group or the total of all minority persons in the affected area. They may consist of groups of individuals living in geographic proximity to one another or a geographically dispersed/transient set of individuals (such as migrant workers or Native Americans), where either type of group experiences common conditions of environmental exposure or effect. (See "environmental justice" and "low-income status".)

Mitigate: 1) To avoid an impact altogether by not taking a certain action or parts of an action; 2) to minimize impacts by limiting the degree or magnitude of an action and its implementation; 3) to rectify an impact by repairing, rehabilitating, or restoring the affected environment; 4) to reduce or eliminate the impact over time by preservation and maintenance operations during the life of an action; or 5) to compensate for an impact by replacing or providing substitute resources or environments.

Mixed fission products: The ensemble of fission products resulting from the fission of a heavy element such as uranium. See "Fission."

Mixed Oxide (MOX) Fuel: Reactor fuel made with a physical blend of oxides of different elements, such as uranium and plutonium.

Mixed waste: Radioactive waste that contains both (a) source, special nuclear, or by-product material subject to the Atomic Energy Act of 1954, as amended, and (b) a hazardous component subject to the Resource Conservation and Recovery Act (RCRA), as amended. 
Model: A conceptual, mathematical, or physical system obeying certain specified conditions, whose behavior is used to understand the physical system to which it is analogous.

Modular Helium-cooled Reactor (MHR): The MHR is a type of gas-cooled reactor that is a candidate for hydrogen production using either thermochemical or high temperature electrolysis (HTE) processes. The overall efficiencies of these processes depend strongly on their process temperatures. The MHR has the capability of delivering coolant at very high temperature.

Mutagen: A substance that causes genetic or inheritable defects.

National Ambient Air Quality Standards (NAAQS): Air quality standards established by the Clean Air Act, as amended. The primary NAAQS are intended to protect the public health with an adequate margin of safety, and the secondary NAAQS are intended to protect the public welfare from any known or anticipated adverse effects of a pollutant.

National Emission Standards for Hazardous Air Pollutants (NESHAP): A set of national emission standards for listed hazardous pollutants emitted from specific classes or categories of new and existing sources. These were implemented in the Clean Air Act Amendments of 1977.

National Environmental Policy Act (NEPA): NEPA is the basic national charter for protection of the environment. It establishes policy, sets goals (in Section 101), and provides means (in Section 102) for carrying out the policy. Section 102(2) contains "action-forcing" provisions to ensure that Federal agencies follow the letter and spirit of the Act. For major Federal actions significantly affecting the quality of the human environment, Section 102(2)(C) of NEPA requires Federal agencies to prepare a detailed statement that includes the environmental impacts of the proposed action and other specified information.

National Pollutant Discharge Elimination System (NPDES): Federal regulation under the Clean Water Act that requires permits for discharges into surface waterways.

National Register of Historic Places (NRHP): A register of districts, sites, buildings, structures, and objects significant in American history, architecture, archaeology, engineering, and culture. It is maintained by the Department of Interior and was established pursuant to the National Historic Preservation Act of 1966, as amended.

Natural uranium: Uranium as it occurs in nature. The natural substance is approximately 99.28 percent $\mathrm{U}-238,0.711$ percent $\mathrm{U}-235$, and 0.0055 percent $\mathrm{U}-234$.

Neutron: An uncharged elementary particle with a mass slightly greater than that of the proton, found in the nucleus of every atom heavier than hydrogen-1; a free neutron is unstable and decays with a half-life of about 13 minutes into an electron and a proton.

Nonattainment area: An air quality control region (or portion thereof) in which the EPA has determined that ambient air concentrations exceed national ambient air quality standards for one or more criteria pollutants. 
Nonhazardous wastes: Routinely generated, nonhazardous solid wastes include general facility refuse such as paper, cardboard, glass, wood, plastics, scrap, metal containers, dirt, and rubble.

Noninvolved worker: Worker who would be on the site of an action but would not participate in the action.

Non-ionizing radiation: Non-ionizing radiation includes the spectrum of ultraviolet (main sources are the sun and some industrial equipment such as welding arcs), visible light, infrared (sources are emitters of heat-for example, furnaces and heat lamps), microwave and radio frequency (sources include microwave ovens, radio emitters and cell phones), and extremely low frequency radiation (produced by power lines, electrical wiring, and electrical equipment).

Nonpoint source: Any nonconfined area from which pollutants are discharged into a body of water (e.g., agricultural runoff, construction runoff, and parking lot drainage), or into air (e.g., fugitive dust from construction sites).

Normal operations: All conditions that frequency estimation techniques indicate occur with a frequency of more than 0.1 event per year.

Nonproliferation: To prevent or impede proliferation. In the context of nuclear weapons, to limit the spread of nuclear weapons and related technology and capabilities .

Nuclear reaction: A process in which an element's atomic nucleus is transformed into another isotope of the same element or into another element altogether. The process always is accompanied by the release of particles or energy.

Nuclide: A species of atom characterized by the constitution of its nucleus. The nuclear constitution is specified by the number of protons, number of neutrons, and energy content; or, alternatively, by the atomic number, mass number, and atomic mass. To be regarded as a distinct nuclide, the atom must be capable of existing for a measurable length of time.

Numerical simulation: The use of mathematical formulas and models of physical processes to simulate through calculations the behavior or performance of a device or complex system.

Order of magnitude: A factor of 10 . When a measurement is made with a result such as $3 \times 10^{7}$, the exponent of 10 (here, 7) is the order of magnitude of that measurement. To say that this result is known to within an order of magnitude is to say that the true value lies (in this example) between $3 \times 10^{6}$ and $3 \times 10^{8}$.

Ozone $\left(\mathbf{O}_{3}\right)$ : The triatomic form of oxygen. In the stratosphere, ozone protects the Earth from the sun's ultraviolet rays; in the lower levels of the atmosphere, ozone is considered an air pollutant.

Packaging: In the NRC regulations governing the transportation of radioactive materials (10 CFR Part 71), the term "packaging" is used to mean the shipping container together with its radioactive contents. 
Particulate (airborne): Small particles that are emitted from fixed or mobile sources and dispersed in the atmosphere.

Parts per billion (ppb): A unit of measure for the concentration of a substance in its surrounding medium; for example, 1 billion grams of water containing 1 gram of salt has a salt concentration of 1 part per billion.

Parts per million (ppm): A unit of measure for the concentration of a substance in its surrounding medium; for example, 1 million grams of water containing 1 gram of salt has a salt concentration of 1 part per million.

Pasquill stability categories: Classification scheme that describes the degree of atmospheric turbulence. Categories range from extremely unstable (A) to extremely stable (F). Unstable conditions promote the rapid dispersion of atmospheric contaminants and result in lower air concentrations as compared with stable conditions.

Perennial stream: A surface water body that has constant flow.

Permeability: The degree of ease with which fluids and gases can pass through rock, sediment, soil, or other material.

Permissible Exposure Limit (PEL): Occupational exposure limit regulations endorsed by OSHA. A permissible exposure limit may be for short-term or 8-hour duration exposure.

Person-rem: A unit of collective dose commitment to a given population; it is the product of the average dose equivalent (in rem) to a given organ or tissue multiplied by the number of persons in the population of interest.

Plume: The spatial distribution of a release of airborne or waterborne material as it disperses in the environment.

Plutonium (Pu): A fissile element of atomic number 94. Defined as a heavy, radioactive, metallic element, that produces ionizing radiation in the form of alpha particles. Produced in a reactor by bombarding uranium with neutrons, plutonium is used in nuclear weapons and also can be used as fuel in fission reactors. The 15 radioactive plutonium isotopes have half-lives ranging from less than a second to thousands of years.

PM 2.5: Fine particulate matter with an aerodynamic diameter of 2.5 micrometers or less. A micrometer, also known as a micron, is a length equal to one-millionth of a meter. To put this in perspective, the diameter of human hair is generally between 20 and 180 micrometers.

$\mathbf{P M}_{10}$ : Fine particulate matter with an aerodynamic diameter of 10 micrometers or less. A micrometer, also known as a micron, is a length equal to one-millionth of a meter. To put this in perspective, the diameter of human hair is generally between 20 and 180 micrometers. 
Point source: As used in this PEIS, a single point of either industrial air emissions or water discharge, regulated under the Clean Air Act and Clean Water Act, respectively.

Population dose (population exposure): Summation of individual radiation doses received by all those exposed to the source or event being considered. The collective radiation dose received by a population group, and usually measured in units of person-rem.

Prehistoric resources: See "Cultural resources (prehistoric).”

Pressurized water reactors (PWRs): (also VVER if of Russian design): Generation II nuclear power reactors that use ordinary water under high pressure as coolant and neutron moderator. The primary coolant loop is kept under high pressure to prevent the water from reaching film boiling, hence the name. PWRs are the most common type of power producing reactor and are widely used all over the world.

Primary and secondary containment: Primary containment is that set of engineered safety features immediately around a radioactive or hazardous material designed to prevent its release; secondary containment is the set of backup features outside the primary containment.

Probabilistic: With results taking into account the probability of occurrence. Probabilistic calculations sometimes combine the results of several deterministic calculations, weighting their results by their probabilities. See "Deterministic."

Proliferation: To increase in number. In the context of nuclear weapons, any increase in the number of countries or persons possessing such weapons.

Prompt radiation: Gamma or neutron radiation emitted during the fission process is said to be prompt (within microseconds) as distinguished from delayed (as much as seconds).

Protective (Preventive) Action Guide: FDA-recommended levels of radiation exposure above which action should be taken to prevent or reduce the radioactive contamination of human food or animal feeds.

Quality assurance (QA): A system of activities whose purpose is to provide the assurance that standards of quality are attained with a stated level of confidence.

Quality factor: The factor by which the absorbed dose (rad) is multiplied to obtain a quantity that expresses (on a common scale for all ionizing radiation) the biological damage to exposed persons; usually used because some types of radiation, such as alpha particles, are biologically more damaging than others. Quality factors for alpha, beta, and gamma radiation are in the ratio $20: 1: 1$.

Rad: The unit of absorbed dose and the quantity of energy imparted by ionizing radiation to a unit mass of matter such as tissue, and equal to 0.01 joule per kilogram, or 0.01 gray. 
Radiation: The emitted particles or photons from the nuclei of radioactive atoms; including alpha, beta, gamma, and neutrons. Some elements are naturally radioactive; others are induced to become radioactive by bombardment in a reactor. Naturally occurring radiation is indistinguishable from induced radiation.

Radioactive decay: The spontaneous transformation of one radionuclide into a different nuclide (which may or may not be radioactive), or de-excitation to a lower energy state of the nucleus by emission of nuclear radiation, primarily alpha or beta particles, or gamma rays (photons).

Radioactive material: Any material having a specific activity greater than 0.002 microcuries per gram, as defined by 49 CFR 173.403(y).

Radioactive waste: Any waste that must be managed for its radioactive content.

Radioactivity: The spontaneous emission of nuclear radiation, generally alpha or beta particles, or gamma rays, from the nucleus of an unstable isotope.

Radiological risk: The magnitude (severity) of the adverse consequence (dose) and the probability of the occurrence; calculated by considering a wide range of occurrences, from highprobability, low-consequence events to low-probability, high-consequence events.

Radionuclide: An unstable nuclide. See "Nuclide" and "Radioactivity." One standard practice for naming a radionuclide is to use the name or atomic symbol of an element followed by its atomic weight (e.g., cobalt-60, a radionuclide of cobalt).

Radiotoxicity: A measure of the hazard to human health posed by radioactive material. It represents the potential biological damage to humans if they are exposed to a material (such as by proximity or breathing in air or drinking water contaminated with radionuclides). Because different radionuclides have different biological effects, the total radiotoxicity from a group of radionuclides is the sum of the radiotoxicity of each radionuclide.

Radon: A colorless, tasteless, and chemically inert radioactive gas (atomic number 86).

RADTRAN 5: An NRC-approved code for estimating the radiological impacts of transportation of radioactive materials.

Rare species: Populations and/or individuals occurring in very low numbers relative to other similar taxa in the state, although common or regularly occurring throughout much of their range. They may be found in a restricted geographic region or occur sparsely over a wider area. Although rare, populations are apparently stable.

RCRA Part B permit: A permit issued by EPA or an authorized state under the Resource Conservation and Recovery Act (RCRA), for a hazardous waste treatment, storage or disposal facility. 
Reactor: A device or apparatus in which a chain reaction of fissionable material is initiated and controlled; a nuclear reactor.

Reactor coolant system: The system used to modulate temperature through the transfer of energy from the reactor core either directly or indirectly to the heat rejection system.

Reactor core: The fuel assemblies including the fuel rods, control assemblies, blanket assemblies, safety rods, and coolant/moderator.

Reasonably foreseeable: An accident or action whose impacts "may have large or catastrophic consequences, even if their probability of occurrence is low, provided that the analysis of the impacts is supported by credible scientific evidence, is not based on pure conjecture, and is within the rule of reason" (40 CFR 1502.22(b)(4)).

Region of influence (ROI): A geographic area within which activities may affect a particular resource.

Release fraction: The fraction of the material-at-risk that is released in an accident.

Rem: A unit of radiation dose equivalent and effective dose equivalent describing the effectiveness of a type of radiation to produce biological effects; coined from the phrase "roentgen equivalent man." The product of the absorbed dose (rad) and a quality factor (Q).

Repository: As defined in the Nuclear Waste Policy Act of 1982, as amended, any system licensed by NRC that is intended to be used for, or may be used for, the permanent deep geologic disposal of high-level radioactive waste and spent nuclear fuel, whether or not, such system is designed to permit the recovery, for a limited period during initial operation, of any materials placed in such system. Includes both surface and subsurface areas at which high-level radioactive waste and spent nuclear fuel handling activities are conducted.

Request for an Expression of Interest (EOI): An advertisement or letter requesting responses from suitably qualified firms or individuals, usually by a set date and usually in response to an information package containing the Terms of Reference. The term is usually used in regards to the supply of professional services.

Respirable Fraction (RF): The fraction of airborne radionuclides, as particles, that can be transported through air and inhaled into the human respiratory system. This term is commonly assumed to include particles 10- $\mu \mathrm{m}$ (micron) Aerodynamic Equivalent Diameter and less.

Retention tanks: Tanks in which liquid wastes are held pending determination of what, if any, treatment they require before disposal.

Risk assessment: The use of established methods to measure the risks posed by an activity or exposure by evaluating the relationship between exposure to substances and the subsequent occurrence of health effects and the likelihood for that exposure to occur. 
Risk estimator: A number used to convert the measured or calculated effective dose equivalent to estimates of latent fatal cancers that can be attributed to the exposure.

Risk factor: Numerical estimate of the severity of harm associated with exposure to a particular risk agent.

Roentgen: A unit of exposure to ionizing x-rays or gamma radiation equal to or producing 1 electrostatic unit per cubic centimeter of air. It is approximately equal to $1 \mathrm{rad}$.

Sanitary waste: Most simply, waste generated by routine operations that is not regulated as hazardous or radioactive by state or Federal agencies.

Scenario: A particular chain of hypothetical circumstances that could, in principle, release radioactivity or hazardous chemicals from a storage and handling site, or during a transportation accident.

Scope: In a document prepared pursuant to the National Environmental Policy Act (NEPA), the range of actions, alternatives, and impacts to be considered.

Scoping: An early and open process for determining the scope of issues to be addressed in an EIS and for identifying the significant issues related to a Proposed Action. The scoping period begins after publication in the Federal Register of a Notice of Intent (NOI) to prepare an EIS. The public scoping process is that portion of the process where the public is invited to participate. DOE also conducts an early internal scoping process for environmental assessments or EISs. For EISs, this internal scoping process precedes the public scooping process. DOE's scoping procedures are found in 10 CFR 1021.311.

Seismicity: The phenomenon of earth movements; seismic activity. Seismicity is related to the location, size, and rate of occurrence of earthquakes.

Separative Work Unit: A measurement of the work expended during the uranium enrichment process.

Severity: Function of the magnitudes of the mechanical forces (impact) and thermal forces (fire) to which a package may be subjected during an accident; any sequence of events that results in an accident in which a transport package is subjected to forces within a certain range of values is assigned to the accident severity category associated with that range.

Shielding: Any material or obstruction (bulkheads, walls, or other constructions) that absorbs radiation in order to protect personnel or equipment.

Slightly enriched uranium: Nuclear fuel which has a U-235 concentration of from 0.9 percent to 2 percent.

Slow neutrons: Neutrons in thermal equilibrium with the surrounding medium, especially those produced by fission and slowed by a moderator. Also called thermal neutrons. 
Sludge: Precipitated solid matter produced by the use of a liquid in a treatment process.

Socioeconomics (analyses): Analyses of those parts of the human environment in a particular location that are related to existing and potential future economic and social conditions. The welfare of human beings as related to the production, distribution, and consumption of goods and services.

Solid waste: Any nonhazardous garbage, refuse, or sludge that is primarily solid, but may also include semisolid or contained gaseous material, resulting from residential, industrial, commercial, agricultural, or mining operations, and community activities.

Source: Any physical entity that may cause radiation or chemical exposure, for example by emitting ionizing radiation or releasing radioactive or hazardous material.

Source material: As defined in the Atomic Energy Act of 1954 (AEA), as amended, means uranium, thorium, or any other material which is determined by NRC pursuant to the provision of section 61 of the AEA to be source material; or ores containing one or more of the foregoing materials, in such concentration as NRC may by regulation determine from time to time.

Source term: In a calculation of contaminant dispersion, the amount of that contaminant assumed available to be dispersed. Source term is calculated as the product of material-at-risk (MAR), damage ratio (DR), respirable fraction (RF), airborne release fraction (ARF), and leak path factor (LPF).

Special nuclear material (SNM): As defined in the Atomic Energy Act of 1954 (AEA), as amended, means plutonium, uranium enriched in the isotope 233 or in the isotope 235, and any other material which NRC, pursuant to the provisions of section 51 of the AEA, determines to be special nuclear material, but does not include source material; or any material artificially enriched by any of the foregoing, but does not include source material.

Species of concern: Plants and animals whose conservation status may be of concern to the U.S. Fish and Wildlife Service, but do not have official or legal protection status under the provisions of the Endangered Species Act of 1973, as amended.

Specific activity: The amount of radioactivity per unit volume or mass.

Specific conductance: The measure of the ability of a material to conduct electricity; also called conductivity.

Spent Nuclear Fuel (SNF): As defined in the Nuclear Waste Policy Act of 1982, as amended, fuel that has been withdrawn from a nuclear reactor following irradiation, the constituent elements of which have not been separated by reprocessing.

Stability class: See "Pasquill stability categories." 
Standard deviation: A measure of dispersion used in statistical theory for the average variation of a random quantity, the root-mean-square deviation from an average value.

Stoichiometric: Pertaining to or involving substances that are in the exact proportions required for a given reaction.

Storage: As defined by the Nuclear Waste Policy Act of 1982, as amended, retention of radioactive waste, spent nuclear fuel, or transuranic waste with the intent to recover such waste or fuel for subsequent use, processing or disposal.

Stormwater Pollution Prevention Plan: A plan required by an NPDES permit for controlling stormwater pollution resulting from construction or industrial activities.

Strontium (Sr): Naturally occurring element with 38 protons in its nucleus. Some manmade isotopes of strontium are radioactive (e.g., strontium-89, strontium-90). Strontium-90 is a common fission product from a nuclear reactor.

Sulfur oxides: Chemical compounds containing sulfur and oxygen. Sulfur dioxide is a regulated criteria air pollutant under the NAAQS.

Système International d'Unités/International System of Units (SI): An international system of physical units which include meter (length), kilogram (mass), Kelvin (temperature), becquerel (radioactivity), gray (radioactive dose), and sievert (dose equivalent).

Tailings: Ground rock remaining after particular ore minerals, such as uranium oxides, are extracted.

Target: As used in this PEIS, refers to the non-uniform positioning of radioactive elements in a reactor core for the purpose of transmuting those elements.

Temporary Emergency Exposure Limits: The Temporary Emergency Exposure Limits were developed by the DOE Subcommittee on Consequences Assessment and Protective Actions (SCAPA) for chemicals where Emergency Response Planning Guidelines (ERPG) values are not available and serve as a temporary guidance until ERPGs can be developed.

Thermal neutron: A neutron in thermal equilibrium with the surrounding medium, especially one produced by fission and slowed by a moderator. Also called a slow neutron.

Thermoluminescent dosimeter (TLD): A device used to measure external beta or gamma radiation levels, and which contains a material that, after exposure to beta or gamma radiation, emits light when processed and heated.

Thorium: A silvery metallic element (atomic number 90).

Threatened species: A species that is likely to become an endangered species within the foreseeable future throughout all or a significant portion of its range that is legally protected. 
Threshold Limits Values/Time-Weighted Average (TLV ${ }^{\circledR} /$ WWA): Guidelines or recommendations that refer to airborne concentrations of potentially hazardous substances. A time-weighted average $\mathrm{TLV}^{\circledR}$ is an average for a normal 8-hour workday or 40-hour workweek, to which it is believed all workers may be repeatedly exposed, day after day, without adverse effect.

Time-weighted average (TWA): The average exposure to a substance which can be expected during 8 or 10 hours of work per day during a 40 -hour work week.

Topography: Topography refers to the shape of the land with respect to hills and valleys. Topography can have a strong influence on transport and dispersion of pollutant emissions. To accurately assess the impacts of a new emission source, computer models must include topographical data to identify the presence of buildings, large hills, mountains, or valleys near the source.

Toxicity assessment: Identification of the types of adverse health effects associated with exposures and the relationship between the magnitude of the exposure and of the adverse effects.

Transmutation: The conversion of one element to another by changing its atomic structure.

Transmutation fuel: Transmutation fuel is a mixture of uranium and various transuranic elements recovered from the reprocessing of spent nuclear fuel. These transuranic elements can consist of various isotopes of plutonium, neptunium, curium, and americium. In addition, various lanthanide elements may also be included in the transmutation fuel depending upon the LWR spent fuel recovery process. The physical form of the transmutation fuel is expected to be metal or oxide, near term. Other physical forms may be developed longer term.

Transportation Aging and Disposal Canister (TAD): SNF and HLW would arrive at the planned Yucca Mountain geologic repository in canisters, TADs, contained within transportation casks. The TADs would be removed from the transportation cask and placed into waste packages. The waste packages would then be sealed and prepared for emplacement in the geologic repository.

Transuranics: Any element with an atomic number greater that 92 (uranium).

Transuranic waste: As defined in the Waste Isolation Pilot Plant Land Withdrawal Act, as amended, transuranic waste means waste that contains more than 100 nanocuries (3700 becquerels) of alpha-emitting transuranic isotopes per gram of waste, with half-lives greater than 20 years, except for: high-level radioactive waste; waste that the Secretary of Energy has determined, with the concurrence of the Administrator of the Environmental Protection Agency, does not need the degree of isolation required by the 40 CFR Part 191 disposal regulations; or waste that the Nuclear Regulatory Commission has approved for disposal on a case-by case basis in accordance with 10 CFR Part 61 . Transuranic waste is a radioactive waste category that applies to waste owned or generated by DOE. 
Tritiated water: Water in which one of the hydrogen atoms has been replaced by a tritium atom; sometimes shown as HTO.

Tritium: The radioactive isotope of hydrogen, containing one proton and two neutrons in its nucleus, which decays at a half-life of 12.3 years by emitting a low-energy beta particle. Common symbols for this isotope are $\mathrm{H}-3$ and $\mathrm{T}$.

Type A packaging: Designed to retain the integrity of containment of the enclosed substances and shielding containers or canisters under normal conditions of transport as demonstrated by a water spray test, a free-drop test, a compression test, and a penetration test as defined by 49 CFR 173.403, 173.465.

Type B packaging: A DOE, U.S. Department of Transportation (DOT), and NRC certified container that must be used for the transport of transuranic waste containing more than 20 curies of plutonium per package. Type B packaging must be able to withstand both normal and accident conditions without releasing its radioactive contents. These containers are tested under severe, hypothetical accident conditions that demonstrate resistance to impact, puncture, fire, and submersion in water (49 CFR Part 173).

Uranium: A naturally occurring, heavy metallic element. Designated atomic number 92, uranium has many radioactive isotopes. Enriched uranium is most commonly used as a fuel for nuclear fission, while U-238 is the most abundant isotope in nature. See "Natural uranium."

Vitrification: A method of immobilizing waste (e.g., radioactive, hazardous, and mixed). This involves combining other materials and waste and melting the mixture into glass. The purpose of this process is to immobilize the waste so it can be isolated from the environment.

Volatile organic compound (VOC): Liquid or solid organic compounds that have a high vapor pressure at normal pressures and temperatures and thus tend to spontaneously pass into the vapor state.

Waste Isolation Pilot Plant (WIPP): A facility in southeastern New Mexico which was authorized under section 213 of the DOE National Security and Military Applications of Nuclear Energy Authorization Act of 1980 to demonstrate the safe disposal of radioactive waste materials generated by atomic energy defense activities. WIPP began accepting wastes on March 26, 1999.

Waste management: The planning, coordination, and direction of those functions related to the generation, handling, treatment, storage, transport, and disposal of waste, as well as associated surveillance and maintenance activities.

Waste minimization: Actions that economically avoid or reduce the generation of waste by source reduction, reducing the toxicity of hazardous waste, improving energy usage, or recycling. These actions will be consistent with the general goal of minimizing current and future threats to human health, safety, and the environment. 
Wastewater treatment plant: A collection of treatment processes and facilities designed and built to reduce the amount of suspended solids, bacteria, oxygen-demanding materials, and chemical constituents in wastewater.

Water table: The water-level surface below the ground at which the unsaturated zone ends and the saturated zone begins, and the level to which a well that is screened in the unconfined aquifer would fill with water.

Weapons grade: Refers to a substance that is pure enough to use in a weapon. Commonly used in reference to plutonium or uranium used in nuclear weapons, but also used for biological and chemical weapons.

Weapons of mass destruction: Umbrella term that includes nuclear, chemical, and biological weapons.

Wetland: An area that has water at or near the surface of the ground during normal circumstances (wetland hydrology). It supports or is capable of supporting plants that are adapted to wet habitats (hydrophytic vegetation) and has soils that have developed under wet conditions (hydric soils).

Whole-body radiation: The dose resulting from the uniform exposure of all organs and tissues in the human body.

X-rays: Penetrating electromagnetic radiations with wavelengths shorter than those of visible light, usually produced by irradiating a metallic target with large numbers of high-energy electrons. In nuclear reactions, it is customary to refer to photons originating outside the nucleus as $\mathrm{X}$-rays and those originating in the nucleus as gamma rays, even though they are the same.

Zoning: The division of city or county by legislative regulations into areas, or zones, that specify allowable uses for real property and size restrictions for buildings within these areas. 


\section{CHAPTER 10}

\section{LIST OF PREPARERS}





\section{CHAPTER 10 LIST OF PREPARERS}

Chapter 10 provides a list of the personnel primarily responsible for the preparation of the Global Nuclear Energy Partnership (GNEP) Programmatic Environmental Impact Statement (PEIS). The contractor technical personnel are listed, along with U.S. Department of Energy (DOE) personnel responsible for reviewing the PEIS.

\section{Document Preparers}

Annett, John, Air Quality and Noise, Tetra Tech

B.A., Mathematics, Hartwick College, 1969

Years of Experience: 38

Bailey, C. Lawson, Radiation and Hazardous Chemical Environment, Tetra Tech

B.S., Biology, Virginia Polytechnic Institute and State University, 1979

Years of Experience: 26

Bartram, Bart, Accident Analysis, Tetra Tech

M.S., Mechanical Engineering, George Washington University, 1976

M.S., Physics, University of Washington, 1971

B.S., Physics, Mount Union College, 1967

Years of Experience: 35

Boltz, Jacqueline K., Public Outreach Manager, Tetra Tech

M.B.A., General Business, Boston University, 1991

B.A., French Language and Literature, Boston University, 1991

Years of Experience: 17

Buenaflor, Delight, Biological Resources, Tetra Tech

B.A., Biology, McDaniel College (formerly Western Maryland College), 1996

Years of Experience: 10

Bulmahn, Ken, Accident Analysis

B.S., Mechanical Engineering, Purdue University, 1974

Years of Experience: 31

Connor, Steve, Advanced Fuel Cycle Facility Project Manager, Tetra Tech

M.S., Physics, Georgia Institute of Technology, 1974

B.S., Physics, Georgia Institute of Technology, 1973

Years of Experience: 30 
Dimsha, Mark, Radiological Transportation, Epsilon Systems Solution, Inc.

M.S., Nuclear Engineering (Radiation Protection), University of New Mexico, In Progress

M.S., Civil Engineering (Environmental), University of New Mexico, 2000

B.S., Biology, University of New Mexico, 1992

Years of Experience: 12

Feldt, Al, Programmatic Assessment, Tetra Tech

B.A., Economics, American University, 1971

Years of Experience: 36

Galer, Rose, Document Integration, References, Tetra Tech

B.S., Environmental Studies, University of Iowa, 2003

Years of Experience: 4

Garson, Henry, Quality Assurance, Tetra Tech

J.D., SUNY, Buffalo, 1967

B.S., Finance, SUNY, Buffalo, 1964

Years of Experience: 30

Hensley, Janice, Deputy Project Manager, Tetra Tech

M.S., Industrial Engineering, University of Tennessee, 1994

B.S., Chemical Engineering, University of Tennessee, 1983

Years of Experience: 22

Hoganson, Mary, Waste Management, Tetra Tech

M.S., Biology, Winthrop University, 1989

B.S., Biology, Newberry College, 1984

Years of Experience: 20

Human, Wayne, Project Manager, Tetra Tech

M.S., Civil Engineering, Tennessee Technological University, 1989

B.S., Civil Engineering, Tennessee Technological University, 1982

Years of Experience: 24

Ijaz, Tal, Accident Analysis, Tetra Tech

Ph.D., Nuclear Engineering (Radiological Engineering and Waste Management), University of Cincinnati, 1993

M.S., Nuclear Reactor Technology, University of Birmingham, England, 1988

B.S., (Honors), Nuclear Engineering, University of London, England, 1987

Years of Experience: 13

Itani, Maher, Document Manager, Tetra Tech

M.E.A., Engineering Administration, George Washington University, 1987

B.S., Civil Engineering, George Washington University, 1985

Years of Experience: 20 
Johnson, Eric, Quality Assurance Project Manager, Epsilon Systems Solution, Inc.

B.S., Marine Engineering, USNA, 1967

Years of Experience: 44

Lechel, David, Consultant, Lechel, Inc.

M.S., Fisheries Biology, Michigan State University, 1974

B.S., Fisheries Biology, Michigan State University, 1972

Years of Experience: 36

Matis, Lisa, Waste Management, Tetra Tech

M.S., Mechanical Engineering, Stevens Institute of Technology, 1989

B.S., Chemical Engineering, Stanford University, 1984

Years of Experience: 22

McMahan, Erin, Socioeconomics and Environmental Justice, Land Use and Visual Resources, Tetra Tech

M.S., Environmental Science and Policy, University of South Florida, 2006

B.A., Environmental Studies, Washington College, 2004

Years of Experience: 4

Nulton, Dave, Advanced Recycling Reactor Project Manager, Tetra Tech

M.S., Mechanical (Nuclear) Engineering, Stanford University, 1970

B.S., Mechanical Engineering, Drexel University, 1968

Years of Experience: 36

Purohit, Kirti, Document Integration, References, Tetra Tech

M.S., Environmental Science and Public Policy, George Mason University, 2007

M.S., Environmental Science, MDS University, 2002

B.S., Biology, Sophia College, 1999

Years of Experience: 2

Raymer, Heidi, Regulatory Compliance and Document Integration, Tetra Tech

B.S., Nursing, Marymount University, 2001

B.S., Environmental Occupational Safety and Health, California State University, Northridge, 1993

Years of Experience: 13

Rivera, Sergio, Water Resources, Tetra Tech

M.A., Project Management, Universidad para la Cooperación Internacional, San José, Costa Rica, 2005

B.S., Geology, Universidad de Costa Rica, 1990

Years of Experience: 16

Rose, Jay, Deputy Project Manager, Tetra Tech

J.D., Catholic University, 1994

B.S., Ocean Engineering, U.S. Naval Academy, 1983

Years of Experience: 20 
Roxlau, Kathy, Cultural and Paleontological Resources, Tetra Tech

M.A., Anthropology, Northern Arizona University, 1991

B.A., Anthropology, Colorado College, 1988

Years of Experience: 17

Skougard, Michael, Technical Integration, Tetra Tech

M.S., Botany, Brigham Young University, 1976

B.S., Law Enforcement, Brigham Young University, 1970

Years of Experience: 30

Smith, Mark, Principal-In-Charge, Tetra Tech

B.S., Civil Engineering, Carnegie Mellon University, 1987

Years of Experience: 20

Smouse, Debra, Task Manager/Document Manager

B.S., Communications, Texas Wesleyan University, 1989

Years of Experience: 18

Stanford, Tara, Production Manager/Graphics, Tetra Tech

B.A., Theater-Directing and Design, George Mason University, 1993

Years of Experience: 10

Theisen, Daniel, Site Infrastructure and Air Quality and Noise, Tetra Tech

B.S., Mechanical Engineering, Tennessee Technological University, 1988

Years of Experience: 17

Truesdale, Scott, Cumulative Impact, Methodology, Tetra Tech

B.A., Environmental Science/Geology, University of Virginia, 1984

Years of Experience: 23

Villacorta, Suzanne, Document Integration, Tetra Tech

J.D., Syracuse University, 1993

B.A., Anthropology, University of New York at Buffalo, 1987

Years of Experience: 14

Wertz, David, Geology and Soils, Tetra Tech

M.S., Geophysics, Boston College, 2001

B.S., Environmental Science, University of Rochester, 1998

Years of Experience: 8

Young, Phil, Nuclear Fuel Recycling Center Project Manager, Radiation and Hazardous Chemical Environment, and Accident Analysis, Tetra Tech

M.S., Health Physics, Georgia Institute of Technology, 1989

B.S., Radiation Health (Health Physics), Oregon State University, 1988

Years of Experience: 17 


\section{U.S. Department of Energy (DOE) Document Reviewers}

Boger, John, Physical Scientist, DOE

Ph.D., Nuclear Chemistry, SUNY, Stony Brook, 1991

B.A., Hunter College, 1981

Years of Experience: 20

Buschman, Nancy, General Engineer, DOE

M.S., Technical Management, Johns Hopkins University, 1990

B.S., Chemical Engineering, University of Maryland, 1979

Years of Experience: 20

Cohen, Adam, Senior Advisor to Under Secretary for Science Dr. Raymond Orbach

M.B.A., University of Chicago, 2000

Ph.D., Materials Science and Engineering, Northwestern University, 1997

B.S., Metallurgy, Columbia University, 1985

Year of Experience: 20

Depperschmidt, Jack, NEPA Compliance Officer, DOE

B.S., Wildlife Biology, Colorado State University, 1985

Years of Experience: 12

Golub, Sal, Director Fast Reactor Development, DOE

B.S., Civil and Environmental Engineering, Clarkson University, 1980

Years of Experience: 27

Griffith, Andrew, Acting Director AFCF, Nuclear Engineer, DOE

M.S., Technology Management, University of Maryland, 1997

B.S., Naval Architecture, U.S. Naval Academy, 1988

Years of Experience: 24

Jones, Leon, Project Management, DOE

B.S., Mechanical Engineering, University of Central Florida, 1983

Years of Experience: 20

Perry, Jeffery N., General Engineer, DOE

B.S., Mechanical Engineering, University of Texas at Austin, 1986

Years of Experience: 20

Savage, Buzz, Acting Associate Deputy Assistant Secretary for Fuel Cycle Management, Office of Nuclear Energy, DOE

M.S., Nuclear Physics, U.S. Naval Postgraduate School, 1971

B.S., U.S. Naval Academy, 1970

Years of Experience: 37 
Schwartz, Frank G., GNEP PEIS Document Manager, DOE

B.S., Mechanical Engineering, University of Idaho, 1982

Years of Experience: 24

Sharma, Rajendra K., Senior Environmental Scientist-NEPA Compliance Officer, DOE

Ph.D., Utah State University, 1968

Year of Experience: 38

Stark, Richard, Nuclear Engineer, DOE

M.S., Nuclear Engineering, Carnegie-Mellon University, 1975

B.S., Electrical Engineering, Carnegie-Mellon University, 1971

Years of Experience: 35

Stout, Daniel, Director, Light Water Reactor Spent Fuel Separations, DOE

M.S., Engineering Management, National Technological Institute, 1997

B.S., U.S. Naval Academy, 1985

Years of Experience: 20

Swichkow, Deborah, Program Analyst, DOE

M.A., Urban Studies, Roosevelt University, 1973

B.A., Political Science, Columbia University, 1971

Years of Experience: 35

Wheeler, John, General Engineer, DOE

M.S., Mechanical Engineering, Lehigh University, 1998

M.S., Policy Analysis, Pennsylvania State University, 1990

B.S., Nuclear Engineering, Pennsylvania State University, 1988

Years of Experience: 18 


\section{CHAPTER 11}

\section{DISTRIBUTION LIST}





\section{CHAPTER 11 DISTRIBUTION LIST}

Chapter 11 provides a list of the parties to whom the U.S. Department of Energy (DOE) distributed this Global Nuclear Energy Partnership (GNEP) Programmatic Environmental Impact Statement (PEIS).

The U.S. Department of Energy (DOE) provided copies of the Draft Global Nuclear Energy Partnership (GNEP ) Programmatic Environmental Impact Statement (PEIS), or the Summary of the Draft GNEP PEIS, to Federal, state, and local elected and appointed government officials and agencies; Native American representatives; national, state, and local environmental and public interest groups; and other organizations and individuals listed in this chapter. Approximately 500 printed copies of the complete Draft GNEP PEIS were sent to interested parties. Additionally, approximately 1,200 copies of the Summary, accompanied by an electronic copy (CD-ROM) of the complete Draft GNEP PEIS, were sent to interested parties. Printed copies of the complete Draft GNEP PEIS will be provided to others upon request. The Draft GNEP PEIS can be found on the worldwide web under the GNEP PEIS link at: http://www.gnep.energy.gov.

\section{United States Congress}

\section{U.S. House of Representatives}

Brian Baird, Washington

J. Gresham Barrett, South Carolina

Judy Biggert, Illinois

Earl Blumenauer, Oregon

Henry E. Brown, South Carolina

Paul Broun, Georgia

Peter DeFazio, Oregon

Norman Dicks, Washington

Doc Hastings, Washington

Darlene Hooley, Oregon

Bob Inglis, South Carolina

Jay Inslee, Washington

Jack Kingston, Georgia

Rick Larsen, Washington

Jim McDermott, Washington

Cathy McMorris Rodgers, Washington

Steve Pearce, New Mexico
Dave Reichert, Washington

Bill Sali, Idaho

Jean Schmidt, Ohio

Mike Simpson, Idaho

Adam Smith, Washington

Zachary Space, Ohio

John Spratt, South Carolina

Tom Udall, New Mexico

Greg Walden, Oregon

Zach Wamp, Tennessee

Jerry Weller, Illinois

Ed Whitfield, Kentucky

Charles "Charlie" Wilson, Ohio

Heather Wilson, New Mexico

Joe Wilson, South Carolina

David Wu, Oregon

\section{U.S. House of Representatives Committees}

Joe Barton, Ranking Member, Committee on Energy and Commerce

Rick Boucher, Chairman, Subcommittee on Energy and Air Quality, Committee on Energy and Commerce

John Dingell, Chairman, Committee on Energy and Commerce 
Fred Upton, Ranking Member, Subcommittee on Energy and Air Quality, Committee on Energy and Commerce

David Hobson, Ranking Member, Subcommittee on Energy and Water Development, Committee on Appropriations

Duncan Hunter, Committee on Armed Services

Ike Skelton, Committee on Armed Services

Peter Visclosky, Chairman, Subcommittee on Energy and Water Development, Committee on Appropriations

\section{U.S. Senate}

Lamar Alexander, Tennessee

Pete Domenici, New Mexico

Jeff Bingaman, New Mexico

Richard Durbin, Illinois

Sherrod Brown, Ohio

Jim Bunning, Kentucky

Maria Cantwell, Washington

Lindsey Graham, South Carolina

Saxby Chambliss, Georgia

Johnny Isakson, Georgia

Bob Corker, Tennessee

Mitch McConnell, Kentucky

Larry Craig, Idaho

Mike Crapo, Idaho

Jim DeMint, South Carolina

Patty Murray, Washington

Barack Obama, Illinois

Gordon Smith, Oregon

George Voinovich, Ohio

Ron Wyden, Oregon

\section{U.S. Senate Committees}

Jeff Bingaman, Chairman Committee on Energy and Natural Resources

Pete Domenici, Ranking Member Committee on Energy and Natural Resources; Ranking

Member, Subcommittee on Energy and Water Development, Committee on Appropriations

Byron Dorgan, Subcommittee on Energy, Committee on Energy and Natural Resources;

Chairman, Subcommittee on Energy and Water Development, Committee on Appropriations

Carl Levin, Committee on Armed Services

John McCain, Committee on Armed Services

Lisa Murkowski, Subcommittee on Energy, Committee on Energy and Natural Resources

\section{Governors, State Legislators, and Mayors}

\section{Governors}

Rod Blagojevich, Illinois

Phil Bredesen, Tennessee

Steve Beshear, Kentucky

Christine Gregoire, Washington

\section{State Senators}

Rod Adair, New Mexico

Tim Burchett, Tennessee

Jerome Delvin, Washington

Kirk Dillard, Illinois

Phil Griego, New Mexico

C. Hutto, South Carolina
C. L. "Butch" Otter, Idaho

Sonny Perdue, Georgia

Bill Richardson, New Mexico

Mark Sanford, South Carolina

Ted Strickland, Ohio

Tom Jensen, Kentucky

Gay Kernan, New Mexico

Tommy Kilby, Tennessee

Carroll H. Leavell, New Mexico

Randy McNally, Tennessee

Bob Morton, Washington 
Tom Niehaus, Ohio

W. Greg Ryberg, South Carolina

\section{State Representatives}

Jim Aslanides, Ohio

Patricia R. Bellock, Illinois

Judy Biggert, Illinois

Todd Book, Ohio Robert

Donald Bratton, New Mexico

William Clyburn, South Carolina

David Daniels, Ohio

Bill Dunn, Tennessee

Nora Espinoza, New Mexico

Candy Ezzell, New Mexico

Daniel Foley, New Mexico

Keith Gardner, New Mexico

Jim Gooch, Kentucky

William Gray, New Mexico

Larry Haler, Washington

\section{Mayors}

Brad Andersen, City of Iona, ID

Bruce Ard, City of Ammon, ID

James R. Beaver, City of Kennewick, WA

Tom Beehan, City of Oak Ridge, TN

David Blain, City of Ucon, ID

Bill Beck, City of St. Anthony, ID

Fred Cavanaugh, City of Aiken, SC

Roger W. Chase, City of Pocatello, ID

Eric R. Christensen, City of Shelley, ID

Moses L. Cohen, Jr., Town of Fairfax, SC

Deke Copenhaver, City of Augusta, GA

Glenn W. Dalling, Sugar City, ID

John Miller, City of Salmon, ID

Vernon Dunbar, City of New Ellenton, SC

Steven M. England, City of Chubbuck, ID

Todd Etheredge, Town of Jackson, SC
Gary Schroeder, Idaho

Nikki Setzler, South Carolina

Shirley Hankins, Washington

John A. Heaton, New Mexico

Lonnie Hosey, South Carolina

Russ Mathews, Idaho

Janice McGeachin, Idaho

Robert S. Perry, Jr., South Carolina

Dell Raybould, Idaho

Thomas Rhoad, South Carolina

Jerry Shively, Idaho

Roland Smith, South Carolina

Donald Smith, South Carolina

John A. Stevenson, Idaho

James Steward, South Carolina

Shirley Tyler, New Mexico

Jeannette O. Wallace, New Mexico

Jared Fuhriman, City of Idaho Falls, ID

Bob Forrest, City of Carlsbad, NM

Dale Jackson, City of West Richland, WA

Carol Jardine, City of Arco, ID

Lark Jones, City of North Augusta, SC

Jim Kalb, City of Portsmouth, OH

Alton McCollum, City of Bamberg, SC

James Micetich, Village of Coal City, IL

Gary Don Reagan, City of Hobbs, NM

Joyce Olson, City of Pasco, WA

Walter G. O'Rear, City of Olar, SC

William F. Paxton, III, City of Paducah, KY

John Rhoden, Town of Hampton, SC

Kathleen Moesle Weaver, City of Darien, IL John Fox, City of Richland, WA 


\section{Native American Tribes and Organizations}

Joe Garcia, Chairman, National Congress of American Indians

Amadeo Shije, Vice Chairman, All Indian Pueblo Council

James Roger Madalena, Director, Five Sandoval Indian Pueblos

John Gonzales, Director, Eight Northern Indian Pueblos Council

Levi Pesata, President, Jicarilla Apache Nation

Tyron Vicenti, Vice President, Jicarilla Apache Nation

Mark Chino, President, Mescalero Apache Tribe

Thora Padilla, Tribal Historic Preservation Officer, Mescalero Apache Tribe

Frederick Chino, Sr., Vice President, Mescalero Apache Tribe

David Conrad, National Tribal Environmental Council

Robert Gruenig, National Tribal Environmental Council

Ben Shelly, Vice President, Navajo Nation

Lawrence Morgan, Speaker of the House, Navajo Nation Council

Joe Shirley, Jr., President, Navajo Nation

Herman Shorty, Director, Commission on Emergency Management, Navajo Nation

Hope MacDonald Lone Tree, Chair, Public Safety Committee, 21st Navajo Nation Council

Gabe Bohnee, Nez Perce

Chandler Sanchez, Governor, Pueblo of Acoma

Mark Thompson, 1st Lieutenant Governor, Pueblo of Acoma

Ron Charlie, 2nd Lieutenant Governor, Pueblo of Acoma

Stanley Paytiamo, EPA Office, Pueblo of Acoma

Ernest Suina, Governor, Pueblo of Cochiti

Mike Pecos, Lieutenant Governor, Pueblo of Cochiti

Robert Benavidez, Governor, Pueblo of Isleta

Max Zuni, 1st Lieutenant Governor, Pueblo of Isleta

Frank Lujan, 2nd Lieutenant Governor, Pueblo of Isleta

Paul Chinana, Governor, Pueblo of Jemez

Joshua Madalena, 1st Lieutenant Governor, Pueblo of Jemez

Delbert Tafoya, 2nd Lieutenant Governor, Pueblo of Jemez

John Antonio, Sr., Governor, Pueblo of Laguna

Richard Luarkie, 1st Lieutenant Governor, Pueblo of Laguna

Pete Kasero, 2nd Lieutenant Governor, Pueblo of Laguna

Ernest Mirabel, Governor, Pueblo of Nambe

Arnold Garcia, Lieutenant Governor, Pueblo of Nambe

Craig Quanchello, Governor, Pueblo of Picuris

Richard Mermejo, Lieutenant Governor, Pueblo of Picuris

George Rivera, Governor, Pueblo of Pojoaque

Linda Diaz, Lieutenant Governor, Pueblo of Pojoaque

Robert Montoya, Governor, Pueblo of Sandia

Ryan Paisano, Lieutenant Governor, Pueblo of Sandia

Martin W. Aguilar, Governor, Pueblo of San Ildefonso

Erik Fender, 2nd Lieutenant Governor, Pueblo of San Ildefonso

Neil Weber, Director, Environmental and Cultural Preservation, Pueblo of San Ildefonso

Earl Salazar, Governor, Ohkay Owingeh 
Johnny Abeyta, 1st Lieutenant Governor, Ohkay Owingeh

Larry Phillips, Jr., 2nd Lieutenant Governor, Ohkay Owingeh

Ronald L. Tenorio, Governor, Pueblo of San Felipe

Bernie L. Chavez, Lieutenant Governor, Pueblo of San Felipe

Ulysses Leon, Governor, Pueblo of Santa Ana

Fred Armijo, Lieutenant Governor, Pueblo of Santa Ana

Michael Chavarria, Governor, Pueblo of Santa Clara

Stanley Tafoya, Lieutenant Governor, Pueblo of Santa Clara

Sisto Quintana, Governor, Pueblo Santo Domingo

David Garcia, Lieutenant Governor, Pueblo Santo Domingo

Paul T. Martinez, Sr., Governor, Pueblo of Taos

Robert Mora, Governor, Pueblo of Tesuque

Anthony Dorame, Lieutenant Governor, Pueblo of Tesuque

Ivan Pino, Governor, Pueblo of Zia

Fred Medina, Lieutenant Governor, Pueblo of Zia

Norman Cooeyate, Governor, Pueblo of Zuni

Dancy Simplicio, Lieutenant Governor, Pueblo of Zuni

Alonzo Coby, Chair, Tribal Business Council, Shoshone-Bannock Tribes

Willie Preacher, Tribal DOE Director, Shoshone-Bannock Tribes

Reginald Thorpe, Emergency Manager, Shoshone-Bannock Tribes

Stuart Harris, Confederated Tribes of the Umatilla Indian Reservation

Clifford Casseseka, Yakama Nation

Russel Jim, Yakama Nation

\section{Public Reading Rooms and Libraries}

U.S. Department of Energy

1000 Independence Avenue, SW, IE-90

Washington, D.C. 20585-0001

Phone: (202) 586-5955

Albuquerque Operations Office

FOIA Reading Room and DOE Reading

Rooms, Government Information

Department

Zimmerman Library

University of New Mexico

Albuquerque, New Mexico 87131-1466

Contact: Dan Barkley

Phone: (505) 277-7180

Fax: (505) 277-4097
Carlsbad Field Office

U.S. Department of Energy

WIPP Information Center

4021 National Parks Highway,

P.O. Box 2078

Carlsbad, New Mexico 88220

Phone: (800) 336-WIPP(9477)

Chicago Operations Office

U.S. Department of Energy, Office of

Science

Public Reading Room

Document Department, University Library

The University of Illinois at Chicago

801 South Morgan Street, 3rd Floor Center

Chicago, Illinois 60607

DOE Contact: Mr. John Schuler

Phone: (312) 413-2594 
Idaho Operations Office U.S. Department of Energy

Public Reading Room

1776 Science Center Drive

Idaho Falls, Idaho 83402

Reading Room Contact: Mr. Brad Bugger

Phone: (208) 526-0833

Los Alamos Site Office

LANL Public Reading Room

Technical Area 3, Building 207

P.O. Box 1663, M/S P 362

Los Alamos, New Mexico 87545

Phone: (505) 667-5809

Oak Ridge Operations Office

DOE Oak Ridge Information Center

475 Oak Ridge Turnpike

Oak Ridge, Tennessee 37830

Phone: (865) 241-4780

or (toll-free) 1(800) 382-6938, option 6

FAX: (865) 574-3521

Paducah Gaseous Diffusion Plant

DOE Environmental Information Center

115 Memorial Drive

Barkley Centre

Paducah, Kentucky 42001

Phone: (270) 554-6979
Portsmouth Gaseous Diffusion Plant

DOE Environmental Information Center

Ohio State University Endeavor Center

1862 Shyville Rd, Room 220

Piketon, Ohio 45661

Phone: (740) 289-8898

Richland Operations Office

U.S. Department of Energy

Public Reading Room

P.O. Box 999, MSIN H2-53

Richland, Washington 99352

Contact: Terri Traub

Phone: (509) 372-7443

FAX: (509) 372-7444

Savannah River Operations Office

Gregg-Graniteville Library

171 University Parkway

University of South Carolina-Aiken

Aiken, South Carolina 29801

Contact: Paul Lewis

Phone: (803) 641-3320

FAX: (803) 641-3302

\section{Federal Agencies}

James Hester, U.S. Agency for International Development

John Benjamin, Carlsbad Caverns National Park

John Contardi, Defense Nuclear Facilities Safety Board

Andrew Thibadeau, Defense Nuclear Facilities Safety Board Camille Mittelholtz, Dept. of Transportation Heinz Mueller, EPA Region IV Ken Westlake, EPA Region V Michael P. Jansky, EPA Region VI Nova Blazej, EPA Region IX Teena Reichgott, EPA Region X William Straw, FEMA R4
Jeanne Millin, FEMA R5

Donald Fairley, FEMA R6

Alessandro Amaglio, FEMA R9

Mark Eberlein, FEMA R10

Alexander Newcomer, Federal Railroad

Administration

Joseph Cook, General Accounting Office

Chris Kunitz, General Accounting Office

Cynthia Norris, General Accounting Office

Chris Steffen, NASA

Matthew Blevins, Nuclear Regulatory Commission/Office of Nuclear Material Security and Safeguards

Brent Clayton, Nuclear Regulatory

Commission 
Allen Croff, Nuclear Regulatory

Comission/Advisory Committee on

Nuclear Waste

Sam Hernandez, Nuclear Regulatory

Commission

Stewart Magruder, Nuclear Regulatory

Commission
Jeffrey Rikhoff, Nuclear Regulatory

Commission

Priya Yadow, Nuclear Regulatory

Commission

Laura Anderson, Plutonium Finishing Plant

Closure Project, DOE-Hanford

State Departments and Agencies

Ann Alexander, Environmental Council, Office of the Illinois Attorney General

Sharon Braswell, Washington Dept. of Ecology

Susan Burke, Idaho Div. of INL Oversight

\& Radiation Control

Nicole Burpo, Kentucky Dept. of

Environmental Protection

Rick Caldwell, South Carolina Dept. of Health \& Environmental Control

Ron Curry, New Mexico Environment Department

Nolan Curtis, Washington Dept. of Ecology

Ken Dewey, Ohio Environmental Protection Agency

Trent A. Dougherty, Ohio Environmental Council

Dirk A. Dunning, P.E., Oregon Dept. of Nuclear Safety \& Energy Siting Div.

Maria Galanti, Ohio Environmental Protection Agency

Susan Gawarecki, Oak Ridge Reservation Local Oversight Committee

James C. Hardeman, Georgia Dept. of Natural Resources

Jane A. Hedges, Washington Dept. of Ecology Nuclear Waste Program

Stephen Helmer, Ohio Dept. of Health

Abigail Johnson, Eureka County Yucca Mountain Information Office

Glenn A. Kellen, State of Tennessee

MarJean Kennedy, Ohio Dept. of Development

Tim Kreher, Kentucky Dept. of Fish \& Wildlife Resources

David Lipp, Ohio Dept. of Health
Robert Loux, Office of the Governor, Nevada Agency for Nuclear Projects

Graham Mitchell, Ohio Environmental

Protection Agency

Norman Mulvenon, Oak Ridge Reservation

Local Oversight Committee

Ken Niles, Oregon Dept. of Energy

John Owsley, Tennessee Dept. of

Environment \& Conservation

Willie Preacher, Idaho Air Quality Program

Barbara Ritchie, Washington Dept. of

Ecology

Ben Rusche, South Carolina Governor's

Nuclear Advisory Council

Mark Shanahan, Office of the Governor,

Ohio

Jack Shaner, Ohio Environmental Council

Shelly Sherritt, South Carolina Dept. of

Health \& Environmental Control

Ron Skinnarland, Washington Dept of

Ecology

Melody Stewart, Ohio Environmental

Protection Agency

Zofia Targosz, Nevada Department of

Administration

Larry Taylor, Kentucky Dept. of

Environmental Protection

Tim Thomas, Kentucky Environmental \&

Public Protection Cabinet

Judy Treichel, Nevada Nuclear Waste Task

Force

Boyce Wells, Kentucky Department for

Environmental Protection

David Wilson, South Carolina Dept. of

Health \& Environmental Control 


\section{Environmental Organizations}

Loraine McCosker, Appalachian Ohio Group of the Sierra Club

J. Cerami, Chicago Environmental Legal Clinic

Corinne and Ernest Whitehead, Coalition for Health Concern, Inc.

Jill Arens, Columbia River Gorge Commission

Tom Ascher, Columbia River Gorge Commission

Mary Jane and Walter Loehrke, Columbia River Gorge Commission

Greg DeBruler, Columbia Riverkeeper

Don Garringer, Committee for Pecos River Improvement

Kalliroi Matsakis, Concerned Citizens for Nuclear Safety

Lloyd Marbet, Don't Waste Oregon

Shannon Fisk, Environmental Law and Policy Center

Louisa Hamachek, Eugenians for a Safe Columbia River

Wolf Naegeli, Foundation for Global Substainability

Kate and Rich McBride, Friends of the Columbia Gorge

Jim Riccio, Greenpeace

Pam Larsen, Hanford Communities

Doug Riggs, Hanford Information Network Sabine Hilding, Hanford Watch

Paige Knight, Hanford Watch

Gerald Pollet, Heart of America Northwest

Natalie Troyer, Heart of America Northwest

Greg Mello, Los Alamos Study Group

Norman and Karen Meadow, Maryland Conservation Council

Geoff Fettus, Natural Resources Defense Council

Alyssa Go, Natural Resources Defense Council

Christopher Paine, Natural Resources Defense Council
Diane D'Arrigo, NIRS

Olivern Hannan, NRF

Nickolas Roth, Nuclear Age Peace Foundation

Claude Kimball, Nuclear Material Disposition

Thomas Cochran, Nuclear Program, Natural Resources Defense Council

Scott Kovac, Nuclear Watch of New Mexico John Witham, Nuclear Watch of New Mexico

Glenn Carroll, Nuclear Watch South

Emma Ogley-Oliver, Nuke Watch South/WAND

Therese Ann Brink, Peoria Area Peace Network

Robynne McWayne, Physicians for Social Responsibility

Jim Trombold, Physicians for Social Responsibility

Mary Pat Holtschlag, Prairie Streams Initiative

Elizabeth Dixon, Sierra Club

Robert Guld, Sierra Club

Beatrice Brailsford, Snake River Alliance

David Kipping, Snake River Alliance

Don Hancock, Southwest Research and Information Center

Maureen Headington, Stand UP Save Lives Campaign

John Ritter, Surfrider Foundation, Sierra Club

Don Safer, Tennessee Environmental Council

Edwin Lyman, Union of Concerned Scientists

Peter Chumbark, Veterans for Peace Gordon Sturrock, Veterans for Peace Susan Cundiff, WAND

Bobbie Paul, WAND

Caroline Rivard, WAND

Judith Stocker, WAND 


\section{Other Organizations}

Achilles Adamantiades, Infrastructure Capital Group

Rodney Adams, Adams Atomic Engines, Inc.

Lisa Aldrich, Portage Environmental

Ken Allen, Idaho National Laboratory

David Alley, Anna, Inc

Lane Allgood, PST

Jim Allred, Idaho National Laboratory

John Anderson, PADD

Tom Anderson, Battelle

Shane Andeson, C\&H Construction

Phelps Andrew, SunValley Energy

Ben Andrews, Oak Ridge Utility District

Jimmy Angelicos, Washington Savannah

River Co.

Jessica Armendariz, Chaves County

Lisa Armijo, Greater Pocatello Chamber of Commerce

Edmund Armstrong, Office of Jackson County Commissioners

Keith Arteburn, Idaho National Laboratory

Holly M. Ashley, Battelle Energy Alliance

Edward Askew, Carlsbad Environmental Monitoring Center

J. T. Atkinson, City Council of Barnwell

John N. Bach, John N. Bach \& Targhee

Powder Emporium, Inc.

Kathy Bahochek, Idaho National Laboratory

Frederic Bailly, OSEO

Sydney Baiman, NEIS

Char Baim-Poirier, Battelle Energy Alliance

Patricia Baker, CWI

Cari Baldwin, C-21 Home Planning

Kim W. Baldwin, Battelle Energy Alliance

Heidi Barber, Idaho National Lab/BEA

Sara Barczak, SACE

David E. Bare, Vietnam Veterans of

America

Brenda Barnett, Voorhees College

Lia Barnett, Washington TRU Solutions

Chip Barnhart, BWXT

Shanna Barwick, North American Young

Generation in Nuclear
William F. Bassham, North Augusta

Chamber of Commerce

Ray Battaglini, Hobbs Chamber of

Commerce

Cassandra Bayer, BSRI

Samuel E. Bays, Idaho National Laboratory

Ron Bazter, Jefferson County Commissioner

James Bcoodhart, E\&CS, Inc

Seth Beal, Butte County Commissioners

Kathi Bearden, Hobbs News-Sun

Dana Beck, Roswell Daily Reach

Donna Benfield, Rexburg Chamber of

Commerce

Paul Bennett, Sheet Metal Workers

Chuck Bernhant, BWXT Services

James Berry, Weldstar Company

Kenneth Berry, Roswell National Bank

Frances Berting, NNMCAB

Paul M. Bertsch, University of Georgia

Roger Betow, Hittman Transport

Bruce B. Bevard, Oak Ridge National

Laboratory

Jerry W. Beyer, McCracken County Fiscal

Court

Branden Bird, Bingham Economic

Development Corp.

Gretchen Birt, Barnwell County Chamber of

Commerce

Willis Bixby, Energy Solutions

David Blee, Forrestal Group

Robert Bodell, IBEW

Erin Bogner, CHWGI

Alan Bolind, LANL/UIUC

Karen Bonavita, CNTA

Kathleen Boutis, Southern Ohio Neighbors

Group

Tamara Bowden, CTAC

Harry Bradley, American Nuclear Society

Muike Breed, Plumbers \& Pipefitters

Landon Brittam, North American Young

Generation in Nuclear

P.A. Brodie, University Health Care

Foundation

Brenda Brooks, LES 
Jeanette Brooks, Savannah River Site Chapter, National Management Assoc.

Wayne T. Brower, Bingham County

Commissioners

Donald Brown, Quality Assurance

Steve Brown, Pocatello Development Authority

Sandy Burcenski, C.A.R.E.

W.B. Burden, Pike Co. General Health District

Edward Burgess, Community Development Services, Inc

Tim Burkhard, AMEC

Robert L. Burnham, Battelle Energy Alliance

Mill Butler, NFS Inc.

Meghan Butter, Philotechrics, Ltd.

William Buyers, Idaho National Laboratory

Larry and Cindy Callin, US Bank

Charles Callis, CDM

E. Michael Campbell, Energy Group

Jim Campbell, ETEC

Patricia Campbell, GE

Mario Carelli, Westinghouse Elec. Co.

James Carmain, Western Baptist Hospital

Ted L. Carpenter, OBRAS

Tom Carpenter, Government Accountability Project

Michael Carpenter, Idaho National Laboratory

Steven Carter, Scioto Economic Development Office

Rich Cartney, Idaho Falls Good Samaritan $\mathrm{Ctr}$

Lisa Carver, Portsmouth Area Chamber of Commerce

Annette Cary, Tri-City Herald

Rebecca Casper, Ball Ventures, LLC

Diane Cato, CWT

John Chabliss, IRC

Connie L. Chadwild, RDA

Yoon Chang, Argonne National Lab

Ernest Chaput, EDP

Art Chavez, WRES

Sandy Childers, LATA/Parallax
Robb Chiles, Greater Idaho Falls Chamber of Commerce

Hung-cheng Chiou, Washington TRU

Solutions

Sarah Chisholm, Carolina Chapter NAYGN

Roger Christensen, Bonneville County, Idaho Board of Commissioners

John Christenson, University of Cincinnati

Robert Chutman, Bamberg County

Development Commission

Jim Clark, Battelle Columbus

Randolph Clarke, WSRC Retired

Brooks Clements, Idaho National Lab/BEA

John Coffman, Denuke

Marshall Cohen, Nuclear Energy Institute

Mike Cohen, APR

Howard Cohen, Burns \& Roe

Sandy Colegrove, Pike Co. General Health

District

Kevin Coleman, WKKJ/WBEX

James Colson, Idaho National Laboratory

James Conca, New Mexico State University, CEMRC

Carl and Judith Connell, Fluor

Joan M. Connolly, North Wind Inc.

Gary Cooper, Pike Co. Chamber of

Commerce

Angie Copenhaver, ANR Group Inc.

Nancy Corn, Office of Senator Pete

Domenici

Elaine and Peter Cosgriff, Econoimc

Development Partnership

Errel Coungton, Bingham County

Kenneth Crase, Washington Savannah River

Co.

Dennis Cresswell, Citizen Multimedia

Newspapers, Inc.

Joe Cruz, BWXT

L. Mike Cuddy, SAIC

Bethe Cunningham, EDC of Lea Co.

Cindy Cunningham, Office of Congressman

Zack Space

Steve Curley, Squrl Music

Ray Dailey, New Page Corporation

William Ellie Daniel, Southen Company/

Plant Vogtle 
Raymond Danielson, RL Danielson \& Associates LLC

Matthew Danzico, Tokyo Shimbun

Brad Day, City Council of Carlsbad

Russ Dedrickson, Southern Nuclear

Robert Defer, Lakeview

Richard Denning, The Ohio State University

Kim Denton, Oak Ridge Economic

Partnership

Dona Dewey, Stoller

Jeffery Diamond, Diamond Law Firm

Rudolf Dian, Pine Parkway Homeowners Assoc.

Marilyn Dill, Economic Development of Lea County

Bob Dingethal, Office of Senator Maria Cantwell

Bill Dixon, Local 370 Operating Engineer

Ken Dobbin, West Richland City Council

J. Doersam, Doersam Marketing, Inc.

Jean Dolling, Network 4-K, WRIA 32

Mark Donham, RACE

Bob Donnell, Chaves County Development Foundation

Jeff Douthitt, GEO Consultants, LLC

Sid du Mont, Golder Association, Inc.

Marc Dunham, IPS

Fred J. Dunhour, The Fred Dunhour

Company

Raymond Durante, Durante Associates, Inc.

Robert W. Edward, Idaho Falls Realty

Keith Emmons, Paducah Water

Rob Ervin, United Steelworkers Local 550

Mary Erwin, Battelle Energy AllianceIdaho National Lab

Rudy Escher, Epsilon System

Darwin Eubanks, Trico Power LLC/

Budwine

D. Lynette Evans, United Steelworkers Local 5-689

Allan Exley, BBWI

David Falkingham, Idaho National Laboratory

Dick Farley, Cape Cod Today.com James Farmer, Knowles Fire Dept. John Farmer, Knowles Fire Dept.
Darrell P. Farrenstiel, Idaho National Laboratory

Clarence Fennell, HCEDC

Matt Fig, Idaho National Laboratory

Pete Fledderman, Washington Savannah

River Co.

Stephen Flemming, Roswell Artist-In-

Residence Program

John E. Flink, INL Retired Employees

Association

Mario H. Fontana, UT

Lawrence C. Ford, Idaho State University

Ben Forget, Idaho National Laboratory

Nancy Foster, Bamberg City Council

Lisa Corum, David \& Max Fox, First

Presbyterian Church

Norman Frank, CTAC

Steve Frankiewicz, Frankiewicz \&

Associates

Ronnie J. Freeman, McCracken County

Commissioner, 1st District

Steve Freeman, WKCTC

P.M. French, SRS Retiree Association

Kenneth Fresquez, OSE

Lynn Fusa, Foursquare Consulting Group,

LLC

Clint Galbraith, Interwest Cabinet

Shawn Galer, Le Ritz Hotel \& Suites

David Gallagher, Fulton County, Kentucky

S. R. Gamache, Battelle Energy Alliance-

Idaho National Lab

Jon and Dianna Gandy, Gandy Marley

Larry Gandy, Gandy Marley Inc.

Della Garcia, Energy Communities Alliance Eric Garcia, IBEW

John Garmon, NMSU-C

Ray Garrett, Chamber of Commerce

Richard Garwin, IBM Fellow Emeritus

James Gaver, Palmetto Partnership, LLC

Larry Gebhart, Idaho State University

Kristin Geiger, UIUC NPRE

Ceil Geitz, Wellston Chamber of Commerce

Donald George, S.M. Stoller Corp.

Mike Gerescher, WKCA-AGC

Bill Gerrish, Carpenters Union 
Mara Giglio, Appalachian Peace and Justice Network

Erroll Gillman, IBEW

Karen Golden, SAIC

Jal Goodman, ITTA, Inc.

Suzanne Goodson, USC Salkehatchie

D. Lee Gorman, Ascendent

Donald Grace, Burns \& Roe Enterprises, Inc.

Kim Granzow, NMED Dept. of Energy

Oversight Bureau

Gary Greene, First National Bank

Phil Gregory, Washington TRU Solutions

Preston Grisham, Office of Congressman

Joe Wilson

Lincoln Grisword, BBWI

Spencer Gross, Oak Ridge Site Specific Advisory Board

Ray Grosshans, INL/CAES

Gary Gruver, IBEW

Craig Guess, Vanguard Contractors

Mike Haensel, WCSJ/WJDR Radio

Abigail Hagel, Government Accountability Project

Blake Hall, East Idaho Partner in Growth

Jim Hall, Metropolis Planet

Thomas L. Hallman, Ph.D., University of

South Carolina, Aiken

Thomas Hally, City Council Idaho Falls

Chad Hammond, IE Productions

Betsy Hanks, Bonneville County

Tina Hanley, Gene S. Bobroff \& Assoc.

Carl Hanson, AREVA

Kristi Hanson, RACE

Greg Hansrote, WKCTC

Lon Ann Hanvey, IPS

Ida Hardcastle, City Council of Idaho Falls

Parker Hardy, Oak Ridge Chamber of Commerce

Lee Harley-Fitts, Town of Allendale

Doug Harnice, McCracken County Fiscal Court

Mike Hart, Communication Designs

Steve Hartenstein, Idaho National Laboratory

Jeremy Hartley, CWI-INL
Dan Harvey, City Council of Allendale

James R. Harvey, Idaho National Laboratory

Jo Hayes, New Mexico Junior College

Mark Haynes, General Atomics

Harold Heacock, TRIDEC

Vincent Headington, Vincent Headington, Ltd.

Ian Headley, Office of Senator Jim DeMint

John Hemmings, Ohio Valley Reg. Dev.

Comm.

Oren Hester, Battelle Energy Alliance

Cathy Hickey, ETABA

Debra Hicks, EDC of Lea Co.

Kipp Hicks, Grow Idaho Falls, Inc.

Andrew Hill, Benton Co. Fire Protection

District

Steve Hiller, Fluor

Dennis Hofer, WRS

Dean Hoffman, Washington Group

Michael Holland, Washington Savannah

River Co.

Rebecca Holland, Hanford Atomic Metal

Trades Council

Jason Hollern, North American Young

Generation in Nuclear-EIC

Jason M. Hollern, North American Young

Generation in Nuclear

Laurie Hollick, Washington Group

International

Chrissy Holliday, Allendale County

Chamber of Commerce

Scotty Holloman, Maddox, Holloman \&

Kirksey, P.C.

Kesha Holt, Carlsbad National Bank

Mark M. Holzmer, Epsilon System

Solutions

Ronda Hornbeck, Lincoln County Board of

Commissioners

Daniel Horner, McGraw-Hill

Bryan Howard, Los Alamos National

Laboratory

John Howartz, BWXT-Y-12

Robert Huff, Southern Ohio Growth

Partnership

Fred E. Humes, Economic Development

Partnership 
Michael Hunt, Sheriff of Aiken County

Matthew Hunter, Greater Pocatello Chamber of Commerce

Shin Ikeu, Tokyo Shimbun

John Isaaeson, Los Alamos National Laboratory

A.E. Ismail, Sandia National Laboratories

Rodney W. Jack, Teton Retinal Institute

Bill Jaco, Washington Group International

Richard T. Jacobsen, Idaho State University

Leslie Janssen, Comfort Keepers

Cash Jaszczak, Nye County, NV

Jeff Jay, Washington Savannah River Co.

Bobby Jeffers, Idaho National Laboratory

Stan J. Jennings, Scioto County Joint

Vocational School

Jeffrey Joe, Idaho National Laboratory

Darin Johnson, Energy Solutions

Howard C. Johnson, CWI

Merle Johnson, West Richland City Council

Stephen C. Johnson, Idaho National

Laboratory

Tricia Johnson, Intera Inc.

Bill Johnston, AFORR

Cleone Jolley, Bingham County

Colin Jones, Office of Senator Larry Craig

Darrell C. Jones, USEC

H. Matt Jones, Epsilon Systems Solutions

Jeffrey E. Jones, Bank of Idaho

Steve Jones, Atomic Trades and Labor Council

Tom Jones, Andrews County Chamber of Commerce

Granam Jonsson, Nexia Solutions

Jiguid M. Jorensen, Battelle Energy

Alliance-Idaho National Lab

Phil Joslin, Bannock Development Corp.

J. Kent Just, Idaho Chamber Alliance

K.D. Justyn, Aiken Regional Medical Center

Kathryn Kain, Idaho National Laboratory

Paula Kair, Idaho National Laboratory

Gayle Kaler, City Commission of Paducah

Jim Katzaroff, Advanced Medical Isotopes Corp.

Robert Kehrman, Washington Group

International
V. Rory Kenedy, Idaho National Laboratory

Chris Kent, North Wind

Don Keskey, Clark Hill PLC

David Kessel, Sandia National Laboratories

Lance Kinney, Knowles Fire Dept.

Tom Kirchner, CERC-NMSU

Dona Kirk, Benton Co.

Tom Klein, Washington Group International

Mark Kleinsteuber, Klein Security \& Safety Systems

Cathy Koon, Fremont County Economic

Development

Tetsuhito Koyasu, WPA

Ryan Kubbe, Idaho National Laboratory

Sunita Kumar, AREVA

Robert Kustra, Boise State University

Vincent Lahaye, Sierra Environmental, Inc.

Dany Lamb, Tatum Municipal Schools

Marsha Lambregts, Idaho National

Laboratory

Leroy Lane, Sowing Com

Kyle LaPierre, Home Builders Association

of Tri-Cities

Anthony Laporta, Idaho National

Laboratory

William Lapsansky, Epsilon Systems

Solutions, Inc.

TK Larson, Idaho National Laboratory

K.P. Lau, Senate Energy Committee

M.G. Lauback, KLCC-FM

Wm. Lawrence, Advisory Board

Jacob H. Lawson, Atomic Trades and Labor

Council

Michael Lehto, City Council of Idaho Falls

Barbara Lewis, Allendale County Chamber

of Development

Jackie M. and Giny Lewis, Idaho National

Laboratory

Kathleen Lewis, SICOG

Ron Liikala, STMC

Stefan and Renate Linden, Enrichment

Technologies US Inc.

Barb Lisk, Office of Congressman Doc Hastings

Eric Loewen, GE 
Cliff Long, Idaho Economic Development Association

Joe Lopez, NCI Information Systems

Teena Lord, Butte County Chamber of Commerce

Wendy Love, P2 Solutions

Jean-Francois Lucchini, Los Alamos National Laboratory

Mark Lupher, Epicenter

Guy Lutman, Eddy County Commission

Scott Lyman, Battelle Energy Alliance

Casey A. Lynn, USEC

Larry Lyon, Idaho Falls City Council

Scott MacGregor, Augusta Metro Chamber

Richard Magnus, Coalition 21

Beverly Majors, The Oak Ridger

G. Ivan Maldonado, University of Cincinnati

Taryn L. Malone, Shawnee State University James Maly, WRES

Charles J. Marcinkiewicz, North Wind Inc. Orin Marcumd, CWI

Kyle Marksteina, Current Argus

Bill Marley, GMI

Amy Marshall, North American Young

Generation in Nuclear

Doug Martin, East-Central Idaho

Development Company

Fay Martin, LOC/CAP

Kerry Martin, Portage

Stephen Martin, Pike Co. Career

Technology Center

Christi Mash, Office of Congressman

Charlie Wilson

Dwight A. Massie, First National Bank

Daniel Mast, Office of Congressman Ed Whitfield

Lynn Maxon, Shoats \& Weaks Inc.

Kay Maxwell, SCA

Elizabeth McAndrew-Benavides, North

American Young Generation in Nuclear

Grant McClellar, EG\&G

Randall McCormick, Lea County

Maria McCosh, Diversified Metal Products

Rod McCullum, Nuclear Energy Institute

Michael Mcguire, Battelle Energy Alliance
Sylvia McIver, Alderman, Ward 6

Laura McKenzie, The People Sentinel

J.M. "Mal" McKibben, CNTA

Nathan McMasters, Diversified Metal

Products

Rory McMinn, Sage Consulting, LCC

Rick McNelly, Office of Jackson County

Comissioners

Brian Meeley, Potomac Communications

Group

Bruce W. Meppen, Idaho National

Laboratory

S. Kenneth Merrill, PRC

Stan Michelson, Washington TRU Solutions

Thomas Mikey, CWI

Robert Miklos, Idaho National Laboratory

Matt Miller, Office of Representative Tom Udall

Takash Mizuno, Federation of Electric Power, Japan

Pamela Moffat, Diocese of Washington, Commission on Peace

Shane Mohundro, North American Young Generation in Nuclear

Rich Molenhouse, North American Young Generation in Nuclear

David Molnaa, Hanford Atomic Metal Trades Council

Chris Monetta, General Manager

Environment, Health \& Safety, General Electric Co.

Alvin Moore, WKCTC

Brent Moore, Sheet Metal Workers \#103

Jim Moore, Washington Savannah River Co.

Lathe Moore, Pike County Career

Technology Center

Steven Moore, Wastren Advantage, Inc

Amy Morgan, Idaho National Laboratory

Jim Morgan, SONIC, LLC

David Mosby, City Council of Oak Ridge

Brad Moss, Homeland Builders Inc.

Phillip Mottel, Washington TRU Solutions

Alice Q. Murphy, Energy Technology \&

Environmental Business Assoc.

Erin Murphy-Trobisk, Morris Mental \&

Healthcare Services 
William Murphy, North American Young

Generation in Nuclear, Carolinas

Chapter

William Murphy, University of Kentucky

Valerie Murrill, Carlsbad Dept. of

Development

Billie Jane Nauert, Tatum Rural

Revitalization

Robert Nei, Idaho National Laboratory

Nolan Neiting, Mountain View Homes, Inc.

Kristine Nelson, WRES

Wyman Nettles, Perot Systems Government Services

Joseph Nielsen, Battelle Energy AllianceIdaho National Lab

Dave Nigg, Idaho National Laboratory

John Noel, John Noel Company

Daren Norman, Idaho National Laboratory

Elizabeth Norseh, St. Andrews Womans

Willis Norton, Idaho Building and Trades

Council

Mike O'Bleness, Development Workshop

Inc.

Lisa Obrentz, Council on Foreign Relations

Brett Olaveson, Jefferson County

Claude Oliver, Benton County Commissioner

Paryl Olsen, Rexburg Chamber of Commerce

Mary Olson, NIRS

Charlotte O'Neil, SAIL

Makoto Ooka, Japan Atomic Energy Agency

Javier Ornelac, Century 21 Home Planning

Javier Ortensi, ISU

Anne Oswald, Allendale County

Lynn Palmore, Halliburton

Victoria Parker, Los Alamos National Laboratory

Bob Parks, City Council of Kennewick

Martin Parks, NMSU Carlsbad

Rich Parris, Mackay Chamber of Commerce

Dan Parsons, Pecos Valley Broadcasting

Lillie Penn, ACOOA

Danielle Perez, Idaho Falls University
Julia Perie, Highland County Community

Action Organization, Inc.

Donald Petersen, LAEG

Gary Petersen, TRIDEC

Beth Phillips, University of Tennessee

Jan Phillips, AREVA

Bill Phoenix, Idaho National Laboratory

Jeff Pinkerton, LATA/Parallax

James Pinkney, Allendale County

William Pirkle, USC Aiken

Danny Poindexter, USEC

Steve Polston, Swift \& Staley Corp.

Rebecca Ponkow, Advanced Energy

Michael Pope, Battelle Energy Alliance

Ty Pope, First American Title

Caroline L Portlock, Grundy County

Chamber of Commerce

John Poteraok Jr., Alderman, Ward 3, City of Darien

A. George Pradel, Dupage Mayors \&

Managers Conf

Lessie Price, Aiken City Council

Thomas Putnam, CTAC

Dave Radford, Bonneville County

Dave Radford, E.C.I.P.D.A.

David Rager, Greater Cincinnati Water

Works

Evelyn Rainey, North Wind

Brad Reed, Rexburg Area Chamber of

Commerce

Nathaniel Reen, STR

Sherry Reese, Carlsbad Medical Center

Ron Reeves, CEHMM

Bob Reid, Lea County

Carol Reid, Idaho National Laboratory

Blair Reinarman, CSIS

Tom Reiser, Scioto County Commission

Zana Renfro, Merk County

Commissioner/United Way Director

Cristy Renner, WGI/WSMS

Bruce Reynolds, Idaho National Laboratory

John W. Rice, Epsilon Systems Solutions

Wayne Rickman, Rickman Group

Kimber Ricks, Madison County

Harry A. Rider, Pike County Board of

Commissioners 
Ann Ridesel, Arco/Butte County Business Incubation Center

Walter and Joan Righton, Waterfall Glen Townhomes Assoc.

Kate Riley, Seattle Times

David E. Rivers, Medical Unviersity of South Carolina

Eric Roberts, CAB Office

William Robertson, Eastern Idaho Technical College

Bill Robinson, Allendale County

Robert Robinson, Center for Applied Research, Inc.

Ralph Robison, Madison County Commissioner

Shauna Rodgers, Western Commerce Bank Vince Rodriguez, Energy Solutions

F. Wayne Rogers, Lower Savannah Council of Governments

J. W. Rogers, Idaho National Laboratory

Kay Rogers, Roswell Livestock and Farm

Christopher Rojas, Exelon-NAYGN

Paul Romrell, Fremont County Office of Economic Development

Kenny Ruggles, Shawnee District Council Rick Runnels, Washington Savannah River Co.

Ann Rydalch, National Foundation for Women Legislators

Piyush Sabharwall, Idaho National Laboratory

Brian Sack, Idaho National Laboratory

David Samples, Tri-City \& Olympia Railroad Company

Lawrence Sanchez, Sandia National Laboratories

Buddy Sandifer, City Council of Bamberg Brad Sandy, Brady's Inc Mark Sanford, South Carolina

Vijay Sazawal, USEC

Dawn Scales, Idaho National Laboratory

Tim Schatzer, Triad, Inc

Robert Schenter, PhD, American Nuclear Society

Dale Schneider, The Childrens Center Gary Schubert, Lea County
Rose Scott, Washington TRU Solutions/Wipp

Geoffrey Sea, Southern Ohio Neighbors Group

Todd Sellmer, Washington TRU Solutions

Ronald Setina, Harborside Marina Inc.

Connie Sevier, Lovington Economic Development Corp.

Ben Shaw, IT Works, LL

Jeff Shearer, NECA/IBEW

Stacy Shelton, The Atlanta Journal-

Constitution

C.W. Sheward, TPMC, LLC

Tamara Shokes, Battelle Energy Alliance

Jim Shows, Shows Real Estate

Joel Siegel, Washington Group

Mike Simon, White Pine County Nuclear

Waste Project Office

Don Simonton, Pike Co. Emergency

Management Agency

Dave Simpson, USEC

Scott Singletary, EITC

Keith Sloan, Barnwell County Council

Richard Smalley, Energy Solutions

B. Smith, City of Paducah Commissioner

Charlene Smith, Idaho National Laboratory

David Smith, Central WA BCTC

Hoxie Smith, Midland College

Miles Smith, Energy Solutions

Norma Smith, Office of Congressman Steve Pearce

Rex Smith, Jim Smith Contracting Co, LLC

Sally Smith, Madison Economic Partners, Inc.

Svend Soeyland, Bellona USA

Tim Solomon, RDA

Stephanie Sparkman, The Energy Initiative

Laurie Sparks, LANL-Carlsbad

Henry Spitz, University of Cincinnati

Sharon Squassoni, CRS

Bill St. John, Diamond Law Firm

Mike Stears, Idaho National Laboratory

David Steele, Honeywell-MTW

E.A. Stevenson, Town of Allendale

Kay Still, Southern Carolina Alliance

Margie Stockton, North Wind Inc 
Stephen Stoddard, LAEG

Bill Stokes, CBCE

Barry Stone, Roswell National Bank

William Stratten, Los Alamos Education

Group

Steve Stricker, Village of Burr Ridge

Cliff Stroud, Los Alamos National Laboratory

Judy Stubbs, New Mexico Economic

Development

John Summers, New Wave Home

Improvement

David Swanson, Nye County Nuclear Waste

Repository Project Office

Jack Swickard, The Triton Group

Dorothy C. Tatum, Chair, Bamberg County Council

J'Tia Taylor, UIUC NPRE

Richard and Diane Taylor, County

Commission

Steven Taylor, INC

Harry Teague, Lea County Board of County Commissioners

William Terry, Idaho National Laboratory

Kent and Darlene Tew, Identity Theft

Solutions

Catherine Thomas, SEMA

Gerran Thomas, WPSD-TV

Dale Thompson, Laboratory Retiree Group

Eric Thompson, SRS Community Reuse

Organization

David Thomson, LA Center

Catherine Thorn, Allendale County

Mary Alice Thorn, Battelle Energy Alliance

Jana Thrift, GREEN

Denice Traina, Georgia Green Party

Kerry Tramerll, NAC

Paul Tremblay, Idaho National Laboratory

Steve Tribuzzi, Exelon Corp.

Rich Trout, Hobbs News-Sun

Leann Tuchett, Diversified Metal Products

Bruce Turner, US Bank

Barbara Turner, SRMS

David W. Turner, Pastor, Barnwell

Presbyterian Church

Arthur C. Vailas, Idaho State University
Melanie Valentine, SONIC, LLC

Michael Valeriano, Village of Godley

Gregory VanSoesr, LANL - Carlsbad

Joseph Ventura, Advantech Air

Conditioning \& Heating

Diane Venture, Office of Senator Jeff

Bingaman

David Vesco, AEA Tech

Gary Vine, EPRI

Vickie Viniard, Ballard Co. Fiscal Court

Mike Virtue, City Council of Blackfoot

Richard Volton, Idaho National Laboratory

Frank von Hippel, Princeton University

Bill Wabbersen, ANS

Emily Waddell, Oak Ridge Utility District

Kathryn Wade, Office of Congressman J.

Gresham Barrett

Cliff Waire, Parmor

Joe Walker, Paducah Sun

John Walsh, Idaho National Laboratory

Tom Walton, Office of Jackson County

Commissioners

Cliff Watkins, Navarro Research \&

Engineering

Bruce Watson, City of Bamberg

Katherine Way, Community Action

Committee of Pike County, Inc.

Kirk Weisbrod, LANS

Brett Welty, Portage

Gray West, Oak Ridge National Laboratory

Joseph West, EZ Net Tools

John R. Whalon, BWXT-Y-12

Robert M. Whan, Oak Ridge National

Laboratory

Brandon Whatley, Eastern New Mexico

University-Roswell

Miriam Whatley, Washington Group

International

Billy and Brenda White, BWXT-Y-12

Gregory White, Battelle Energy Alliance-

Idaho National Lab

Lynn White, Eunice News

Timothy White, University of Idaho

Garry Whitley, ATLC

Mark C. Whitlow, Whitlow, Roberts,

Houston \& Straub, PLLC 
Janell Whittock, Eddy County

Bill Wierzbide, WEI

Bill Wilburn, BWXT Y-12

Martie Wiles, Office of Senator Mitch McConnell

Art Williams, Allendale County

Cindy Willard, Office of Congressman

Steve Pearce

Arthur Williams, Allendale County

Government

Steve Williams, SRS-WSRC

Thomas Williams, Barnwell County Council

Chad Wilson, Honeywell

Chris Wilson, Bamberg City Council

Jeanne Wilson, Office of Senator Sherrod

Brown

Jeff Wilson, LATA
Pieen Wilson, Office of Congressman Jerry Weller

Rev. Charles Wiltshire, Sedan Baptist Church

Susan A. Winsor, Community Reuse Organization

Roy T. Witherow, Village of Lyons

Paul Wojtaszek, AREVA

Lisa Wolford, Battelle Energy Alliance

Alan Wood, USW-Local 652

Susan Wood, Citizens for Nuclear

Technology Awareness

Gerald Woodcock, American Nuclear

Society

Daniel York, Landsun Homes, Inc

Warren Zesiger, Z 5 Farms

James Zumwalt, City of Paducah

\section{Individuals}

\begin{tabular}{lll}
\hline P.J. Abell & Frank Avila & Janice Bertzer \\
Scott Ackerman & Martha Bacon & John Bigbee \\
David Adams & Elizabeth Baggs & Helen Bilson \\
Michelle Ajamian & Porter Bailey & August Binder \\
Don Alexander & Hannelore Baker & Chris Bingham \\
Linda Alexander & Tom Balhreg & Mary Birch \\
Connie and Doug Altman & Wayne Ballard & Bruce Biwer \\
Robert Alvarez & Mark Balzen & Natalie and Paul \\
Alex Amonette & Frank Barber & Blachowicz \\
Mark Andersen & Marianne Barisonek & Anne Blanco \\
Steve Andersen & Tom Barnett & Richard Bloom \\
Robert Anderson & Jack Barraclough & Alex Bohlin \\
Sheryl Anderson & Christopher Barry & James Boland \\
Bill Andrews & John and Margaret Barry & M. Bolt \\
Bruce Angle & Robert Bartholomeu & Sam Booher \\
Neil Archer & Hal Bateman & John Boonstra \\
Scott Archibald & Adam Batson & Lois Bounde \\
Rae Ann Archuleta & Robert Beach & William Bowen \\
Heather Armbrister & Victor D. Beaucaire & Alan Boyar, MD \\
Don and Kimberly Armour & Jane Becker & J. Blair Briggs \\
Judy Armstrong & Renata Beckner & Kenneth and Mary \\
Steve Arneson & Michael Bejarano & Brockman \\
Joyce Asfour & Melinda Bell & Steve Brown \\
Holly Ashley & Mary Benedict & Chris Brust \\
E.E. Attaya, O.D. & Ralph Bennett & Mike Bryan \\
Clay Atwood & Danny Berry & Mary Elizabeth Bundy
\end{tabular}


Wally Burden

Thomas Burke

Allen Burnett

Steve Burton

Thomas Butterbaugh

Dave Bybee

Ray Camp

David Cannon

J. Capozzelli

Mike Cappiello

Janet Carbary

Thomas Carlsoar

Tim Carlson

Jon Carmack

Thomas Carpenter

Aldo Carrasco

Francis Jerry Carrico

Madeline Carroll

Clint Carter

Andy Casella

Bertha Cassingham

Robert Caudle

Steve and Mary Chastaim

Robert Chatman

David Chichester

Cathryn Chucry

M. H. Churney

Cathy Cisco

Frederick and Francine

Clark

Michel Clement

Josh Clements

Jeff Cobb

Delia Cobos

Lance Cole

Bryan Coles

Vina Colley

Elizabeth A. Comeaux

Clay Condig

Kathleen Conley

Corey Conn

Elizabeth Connen

Arlene Coon

Roger Cooper

Scott Coren

Alison Corner
Becky Coronado

Bridget B. Correll

Judith Cosby

Joe Cosgrove

Anne Craig

Alex Creek

Kevin M. Croft

Janie Croswait

Susan Garrett Crowley

Julia Cullom

Deborah Cummings

Jim Curtis

Stewart Curtis

Catherine Cutcher

Holly Daggett

Judy Daggett

Ken Daggett

Katherine Daly

William Dantel

Hal Darrick

Stephanie Darrow

Jodi Dart

Donald Davidson

Teresa Davis-McKee

Gerald Dearmond

Janet Degan

Dreba Dennis

Genny Dennison

Glenn Denton

Rocky Deschamps

Shane Devins

Gregory Dewey

Marilyn Dickenson

Vincent Dolli

Pamela Dorlier

J. Dorny

Jo AnnTilley Dortch

Jason Draper

Jack Dresser

Kenhi Drewes

Rose N. Dubston-Elliott

Noel Duckwitz

Patricia Duffy

Dan Durocher

Millie Dyer

Norm Dyer
Michael and Donna

Eastlake

Sabrina Eckles

Gary Eder

Deborah Edmonds

Teri Ehresman

John Eisele

John Eisenmenyer

Robert Elliott

Don Engelman

Mark England

Ruby English

Joe and Barbara Epstein

Lindsey Eskeli

Earleen E. Eskildsen

Susan Evans

Erich Evered

Stephanie M. Fairchild

Jack Farber

Mary Farina

Bill and Meredith Farris

Eileen Farvin

Rebecca Logan Fay

Bill and Betty Ferguson

Gemma Ferguson

Kevin Ferguson

Tom Ferns

Jim Finlay

Eleanor Finney

Homer Fisher

Amy Fitzgerald

Dennis Fitzgerald

Nancy Fleming

Martha Fly

Fran Forgette

Brent Foster

Dianne Foster, RN, ARNP

Nancy Foster

Robert Foster

Marion Fox

Ann Fraley

Bill Franz

Larry Franz

Linwood Fraser

Peter and Elvida

Frothingham 


\begin{tabular}{|c|c|c|}
\hline Jim and Louise Fry & Sol Guttenberg & Hollis W. Hoffmeng \\
\hline Casey Gadburg & William Guzaski & James Hoge \\
\hline Jimi S. Gadzia & Jeanette Hakey & Charles Holden \\
\hline Jon Gahm & Morgan and Gaylyn Hall & Carl Holder \\
\hline Ron Galbraith & Kurt D. Hamman & Roger Holmen \\
\hline Larry Galuszka & Barbara Hanek-Reschke & Ben Holtzman \\
\hline Kris Gann & Bob Hansen & Cindy Hong \\
\hline Richard N. Garley & Audrey Hanson & Norman Hook \\
\hline Donald C. Gatchell & Larry Hanson & Michael D. Horton \\
\hline Larry and Mary Gates & George Harben & Donald W. and Janice E. \\
\hline Donald Gatlin & John Harber & Hoylman \\
\hline Michael Gaussa & John Harbin & Lee Huckins \\
\hline Richard Geddes & Russell Hardy & Leslie Huddleston \\
\hline Stephen Gedeon & Barbara Harper & Anezka Huff \\
\hline Robert Gelave & Christopher N. Harper & Leslie Hugo \\
\hline Kathy Gere & Dianne Harris & Dean and Kathryn \\
\hline April Gerstung & Richland and Shirley & Humphrys \\
\hline Peter Gibbons & Harvey & Ellen Hutchings \\
\hline Robert Gillette & Leonard and Nancy & James Hylko \\
\hline Gynii A. Gillian & Harville & Fred Ingram \\
\hline Weldon Gilmore & Cherie Haskins & Joe Jacobsen \\
\hline W.R. Goddard & Joanna Haskins & Bob Jacovec \\
\hline Charles Goergen & Garth Hassel & Ira James \\
\hline Mike Goff & Aafiz Heartsun & Mary Jean \\
\hline Rick Gold & Robert Hedlund & Ted Jely \\
\hline Lynn Goldman & Mary Heimert & Arlene Jenkins Cossels \\
\hline Marcia Goldstein & Charles T. Hein, Ph.D. & Thomas Jennings \\
\hline Carl Gooding & Connie Heinrich & Frances S. Jobasen \\
\hline Joan Govedare & Gerald W. Heinrich & Robert E. Johannesen \\
\hline Vernon F. Grady & Dorothy Behlen Heinrichs & Mark Johnson \\
\hline Jim Graham & Jack Heinzman & Michael Johnson \\
\hline Glen Graves & Debbie Henley & Kenneth Johnson \\
\hline Isabel Graziani, Ph.D. & Jerry Henrich & Ralph Johnson \\
\hline Joe Graziano & Neal S. Henry & Tiffany Johnson \\
\hline Jeffrey Greenwood & Roger Henry & Barbara Jones \\
\hline Richard J. Gregosky & Paul Henslee & Greg Jones \\
\hline Paula Grieves & Brian Herman & John Jones \\
\hline Michole Grilli & Tony Hernandez & Stewart Jones \\
\hline Richard Groendyke & David Herold & Arun Joshi \\
\hline Clinton Gross & Charles Herrmann & Bob Jurick \\
\hline Jason Grover & Bill Hewitt & Charles and Vicky Jurka \\
\hline Logan Guajardo & Peggy and Scott Hill & Carolina Jurovic \\
\hline Johne Gualming & Bruce Hilton & R. Kaester \\
\hline St. Clair P. Guess, III & Greg Hinkle & Dave Kahn \\
\hline Ed Gulfbrunsen & Brad and Dona Hippert & Pamela Kanner \\
\hline David Gunzel & Floyd Hodges & Joseph Kanney \\
\hline
\end{tabular}




\begin{tabular}{|c|c|c|}
\hline Blair D. Kay & Wayne Ledford & Jake Maxey \\
\hline Nancy Keene & Breanna Lee & Shirley Ann May \\
\hline Mike Keizer & Wayne Lei & Craig Maydale \\
\hline Jill Kekzisnik & Richard Lemire & James McBreen \\
\hline Deanna Kelley & Adam Levin & Don McBride \\
\hline Richard A. Kemmey & Diana Lewis & Rick McCain \\
\hline Merryman Kemp & Heidi Lhofer & Kate McCarthy \\
\hline Marcia Kerman & Cymantha Liakos & Justin McClendon \\
\hline Eric Kerzisnik & Daniel Lichtenwald & Loraine McCosker \\
\hline Ron King & Sylvia Lieb & John McCoy \\
\hline Bob Kingsbury & Patricia Lightstone & Kurt McCracken \\
\hline Gene Kinsey & Sandra Lilligren & Martin McDonough \\
\hline Dona Kirk & Mike Lilly & Jack McElroy \\
\hline Walter Kirkpatick & Jessika Lindfeldt & Shawn McEntire \\
\hline Shane Kirkwood & John N. Lindsay & David McGraw \\
\hline Janni Kirovac & Timothy L. Lingg, Jr. & Gerry McGuire \\
\hline Robert Klein & Diane Lipuma & Danny McIlwain \\
\hline Weni Klevan & Charles Little & Michael McKee \\
\hline D.B. Klos & Megan Lobaugh & Tyler McKee \\
\hline Robert Klouman & Robin Loeffler & John McKenze \\
\hline Jason Knopp & Heidi Logusz & Susan McKenzie \\
\hline Gary Kodman & Linda Long & Judy McLemore \\
\hline Kenneth D. Kok & Christopher C. Lowe & Anna McNabb \\
\hline Susanne and Curtis & David Lucoff & John McNabb \\
\hline Kooiker & Barbara Lund & Thomas and Joan McNeela \\
\hline Charlotte Kosek & Susan Lyons & Ed McPherson \\
\hline Jennifer Kozlowski & Nathan and Sarah & Jerri McTaggart \\
\hline Kenneth Krasin & Machiela & Richard Meadows \\
\hline Michael Kravitz & Paul MacMillan & Kathleen Mello-Nelson \\
\hline Jon Krenek & Tom Maddock & H. Jay Melnick \\
\hline Michele Collet Kriz & Ken Maddox & Mike Melville \\
\hline Adam M. Kulaga & Jonathan Maffay, Ph.D. & Donald Merrick \\
\hline Jonathan W. Kulaga & Teresa Mahan & M. Merrill \\
\hline Michael Kulaga & El Mahassni & Don Meyers \\
\hline Peter Kulik & Albert Majeske & Ian Migrate \\
\hline David Kump & William Mally & Diana Mika \\
\hline Bud Kunkel & Taryn Malone & David Mikkelson \\
\hline Jason Lacy & Jim Manhus & J. Michael Milam \\
\hline Michael Lafreniere & Patrick Manion & Linda H. Milam \\
\hline James Laidler & Carl Mansperger & Ariel Miller \\
\hline Brent Laird & Larry Marchesi & David W. and Shirley R. \\
\hline Sally Lamson & Patricia Marida & Miller \\
\hline William Lanouette & Frances Marshall & Gerry Moll \\
\hline Carter Latimer & Leigh Martin & Glenn and Gail Miller \\
\hline Susan Laughlin & Marshall C. Martin, Jr. & Kendall Miller \\
\hline Deb Layton & Jane Masters & Larry Miller \\
\hline
\end{tabular}




John Moon
Ken Moor
Claris Morgan
Martin Morris
Alva Morrison
Bruce Morson
Elizabeth Motter
Charles Mueller
Sean Mullaney
Manuel Munguia
Robert A. Murdock
Julie Murray
Ed Nabeel David
Autumn Najar
Desiree Najar
Jeff Neal
Robert Neilson
Karla Nelson
John Nelson
Morgan Nelson
Joanie Nichols
Nick Nichols
Christine and Don Nielsen
Robert Nielson, Jr.
William Novak
David Odfold
Gai Oglesbee
Marlene Oliver
Stacie Oliver
James T. O'Reilly
Mark O'Riley
Edmundo Orozco
Penelope Overton
Bill Owen
Jim and Sheryl Paglieri
Glenn Palmeri
Michael L. Paris
David T. Parn
Richard K. Patrick
Rick Patrick
Cliff Patterson
Russ Patterson
Jerry Peltier
Keith and Beverly Penny
Reward Perry

\begin{tabular}{|c|c|}
\hline Christina Petrykiw & Jack Ryan \\
\hline Patricia Pettit & James Ryckman \\
\hline Robert Phipps & John Saluke \\
\hline Roger Picitella & Gene Samberson \\
\hline Rosie Picklesimer & Kelly Sampson \\
\hline Al Pines & Todd Samuel \\
\hline Katherine and David & John J. Sandens \\
\hline Pirnik & Van Sandifer \\
\hline Jim Pletscher & William Schramm \\
\hline Herbert Plum & Joey Schueler \\
\hline Jonathan Podbielski & Lindon Schultz \\
\hline Andrew Poertner & Randall Scott \\
\hline Cheryl Polston & Don Segna \\
\hline John Popham & Linda Sejfulla \\
\hline Sharon Poteraske & Lewis A. Seller \\
\hline David Prawdzik & Charles Sessions \\
\hline Robert A. and Bonnie M. & Alwyn Settles \\
\hline Prots & Stacey Shaw \\
\hline Howard Pulley & Barry Shedrow \\
\hline Andrea Quintanar & Michelle and Kevin \\
\hline Carol Rainey & Sheffield \\
\hline Ron Ramsey & Janis Sherick \\
\hline Rich Rankin & Sham Shete \\
\hline Stefano Ratti & Diana Shipley \\
\hline Rita Rebhand & Kurt A. Shoemaker, PhD \\
\hline Ralph Reeves & Linda Short \\
\hline Gayle Reichert & Sheryl Silberman \\
\hline N.T. Rempe & Richard Simester \\
\hline Scott L. Reno & Carrie Simmons \\
\hline Bruce Renwick & Jeff Sinnard \\
\hline Fitz Reyes & Ellen Smith \\
\hline Neal Reynolds & Howard Smith \\
\hline Bryce L. Rich & Keith Smith \\
\hline Peter Rickards & Madeline Smith \\
\hline Lou Riepl & Miles Smith \\
\hline Paul Ring & Robert W. Smith \\
\hline Ralph Robinson & Richard Smith \\
\hline Francis Roddy & Sarah Smith \\
\hline John M. Roebuck & Timothy Solomon \\
\hline Paul Roeder & Edward Somers III \\
\hline Bridget Rorem & Mark Staffer \\
\hline Keith M. Roseland & George Stanford \\
\hline Sally Rosenberg & Tim and Maureen Stanley \\
\hline Cynthia Rosenburry & Carol Stark \\
\hline Sharon Russick & Denise Stark \\
\hline Bruce Ruttenburg & Carolyn Stauffer \\
\hline
\end{tabular}




\begin{tabular}{|c|c|c|}
\hline Mark Stauffer & Mary Toniolo & Jean Wightman \\
\hline Carolyn Steele & William Toth, Ph.D. & Lynn Wilber \\
\hline Carola Stepper & Tom Tramm & Deb and Bruce Wilcox \\
\hline Fred Stewart & Charles and Vicki Turks & Lynne and Mel Wilks \\
\hline Jan Stewart & Kaye Turner & Art Williams \\
\hline Katherine Stewart & Wayne Turucz & Gil Williams \\
\hline Scott Stoddard & Jaimes Valdez & Kent A. Williams \\
\hline Carlton Stoiber & Dianne Valentin & Lawrence Williams \\
\hline Scott Stone & Damian Valenzuela & Lonnie M. Williams \\
\hline Richard Stout & Carol A. Van Brunt & Ken Williams \\
\hline Jerry Straalsund & Gary Vander Boeck & Thomas R. Williams \\
\hline Corrine Stranski & Jasper B. Varn, Jr. & Vernal Ann Williams \\
\hline Jim Stubbins & David Vaughn & J. Holt Williamson, Ph.D \\
\hline Heather Sturgill & Ted Venetz & Matt Wills \\
\hline Chris Suiter & John von Reis & Jeffrey Wilson \\
\hline Nancy Sullivan & Gerald Wade & Jennifer Wilson \\
\hline Ellen O. Suna & James Waldo & Joyce Wiltshire \\
\hline Lorry Swain & Dick Wallach & Steven Winter \\
\hline John Swanson & Alan Waltar & Wiley and Melodie \\
\hline Reneé Swickard & Barbara A. Walton & Witherspoon \\
\hline Crow Swimsamay & Paul Waltz & Sybil Wolcott \\
\hline Marilyn Szewczyk & David H. Ward & Jill Wood \\
\hline Vera N. Tanner & Michael Waterland & Rick, Victoria and Patricl \\
\hline George Taylor & Lisa Watson & Woods \\
\hline Russell Taylor & Mike Watson & Mr. and Mrs. Tom Wood \\
\hline Johnda Tecoma & Dave Webster & Camille Wrona \\
\hline L. Edward Temple Jr. & Alan Weiner & Jim Wurtz \\
\hline Jim Testin & Jack and Linda Wellbaum & Ralph Young \\
\hline Roger Thiede & Marlin Wells & Robert Yriart \\
\hline Bobby Thomas & Donald Wendling & Kathy Yuracko \\
\hline Rick Thomas & Brook Westheimer & Dan Yurnman \\
\hline Rod Thomas & David Whealey & Paul A. Zagene \\
\hline Dale Thompson & Martin and Isabelle & Peter Zalupski \\
\hline Jeff Thompson & Wheeler & S. Zaman \\
\hline Jennifer Thompson & Mary Whelen & Edward and Carla \\
\hline T.K. Thompson & Joe Whetstone & Ziemianski \\
\hline Vanessa Thompson & Nancy White & Olivia Zivney \\
\hline Terie Tietjen & Robin J. White & \\
\hline Terry A. Tomberlin & Sean White & \\
\hline
\end{tabular}





\section{APPENDIX A}

\section{BACKGROUND INFORMATION ON NUCLEAR FUEL CYCLE TECHNOLOGIES AND THE ADVANCED FUEL CYCLE INITIATIVE}





\section{APPENDIX A BACKGROUND INFORMATION ON NUCLEAR FUEL CYCLE TECHNOLOGIES AND THE ADVANCED FUEL CYCLE INITIATIVE}

This appendix provides background information related to the domestic programmatic alternatives, including the Advanced Fuel Cycle Initiative (AFCI) (which would continue under any alternative), analyzed in this Global Nuclear Energy Partnership (GNEP) Programmatic Environmental Impact Statement (PEIS). The information in this appendix fulfills two primary objectives. First, this PEIS involves a technically complex subject matter. To make subjects such as nuclear fuel cycles, spent nuclear fuel (SNF), reprocessing, and transmutation of long-lived radiotoxic materials more easily understood, this appendix presents a background discussion of nuclear power concepts, technologies, and terminology.

Second, the analysis of potential environmental impacts associated with the domestic programmatic alternatives (contained primarily in Chapter 4) is based on broad implementation of several technologies. In general, that analysis is based on deployment of multiples of a single facility, or variations on the size of a facility. This appendix describes the reference facilities used as a basis for the programmatic analysis. For example, this appendix provides details about a typical light water reactor (LWR) (the type currently used for nuclear power in the United States). The programmatic analysis in Chapter 4 describes impacts associated with the deployment of about 100 to 400 such reactors.

The alternatives in this PEIS involve technologies that vary significantly in their state of development and commercial use. As a result, the amount of information available about these technologies also varies. Relatively less information is available regarding these technologies which are essential components of certain domestic programmatic alternatives: fast reactors, deep burn high temperature gas-cooled reactors (HTGRs), nuclear fuel recycling facilities, and fuel fabrication technologies for transmutation fuel and thorium-fuel. Where information is incomplete and unavailable, DOE developed preliminary design information and/or discussed technologies by comparison to other technologies for which sufficient information is available.

\section{A.1 Nuclear Fuel CyCle}

\section{What does the term "nuclear fuel cycle" mean?}

A "fuel cycle" refers to the life cycle of nuclear fuel, including the sources of fuel, its application, and disposition. The cycle consists of "front end" steps leading to the preparation of fuel for reactor operation and "back end" steps leading to the safe management and disposal of the highly radioactive SNF. The fuel cycle starts with mining and refining uranium ore. Generally, uranium (U) must be "enriched" (to approximately 3 to 5 percent) in the isotope U-235 which fissions more easily than other natural uranium isotopes. The enriched 
uranium is then made into fuel for use in a commercial nuclear power plant. This appendix discusses uranium mining, refining, enrichment, and the manufacture of nuclear fuel.

After an operating cycle (typically 18 months), the reactor is shut down for refueling. Although the SNF that comes out of a nuclear reactor is only partially consumed, it is highly radioactive and must be stored in specially designed pools, resembling large swimming pools, which provide both cooling (the SNF continues to generate heat as a result of residual radioactive decay) and shielding (to protect the environment from residual ionizing radiation) (see Figure A.1-1). After sufficient time has passed to reduce the SNF's thermal output (approximately 3 to 5 years), it may be desirable to store SNF in dry storage facilities (see Figure A.1-2). Eventually, the SNF would be disposed of in a geologic repository or recycled.

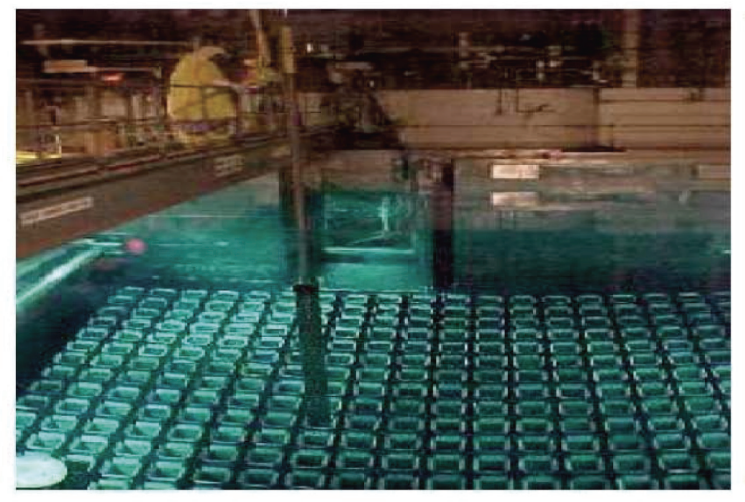

Source: Holtec 2008

Figure A.1-1—SNF Assemblies

Being Loaded Into a Typical SNF Pool

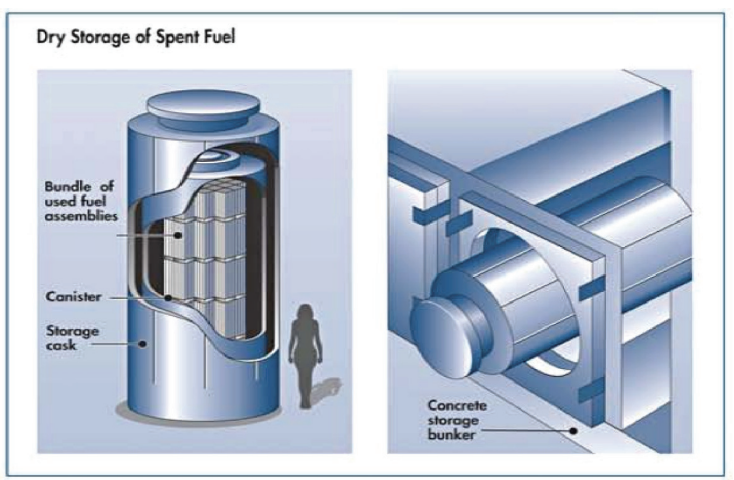

Source: NRC 2008b

FiguRE A.1-2-Typical Dry Cask Storage

As shown on Figure A.1-3, SNF from a typical commercial LWR fuel has three major components: uranium (96 percent), fission products (3 percent) such as cesium (Cs) and strontium ( $\mathrm{Sr}$ ), and transuranic (TRU) elements (1 percent) such as plutonium (Pu). Because SNF is approximately 96 percent uranium, removing this material for reuse or disposal as lowlevel waste (LLW) would result in a reduction in the volume of waste requiring geologic disposal. Compared to the transuranic elements, most of the fission products are relatively stable and short-lived and do not pose major disposal challenges if separated from the SNF. The transuranic elements contain significant amounts of stored energy and include a number of the longest-lived radiotoxic isotopes, some of which can be used in a nuclear weapon. Ultimately, the two strategies for managing SNF are to dispose of the used fuel as waste, or to separate and recycle the uranium and transuranic elements from the waste products. These two divergent strategies for managing SNF lead to two very different nuclear fuel cycles: "open cycle" and "closed cycle." 


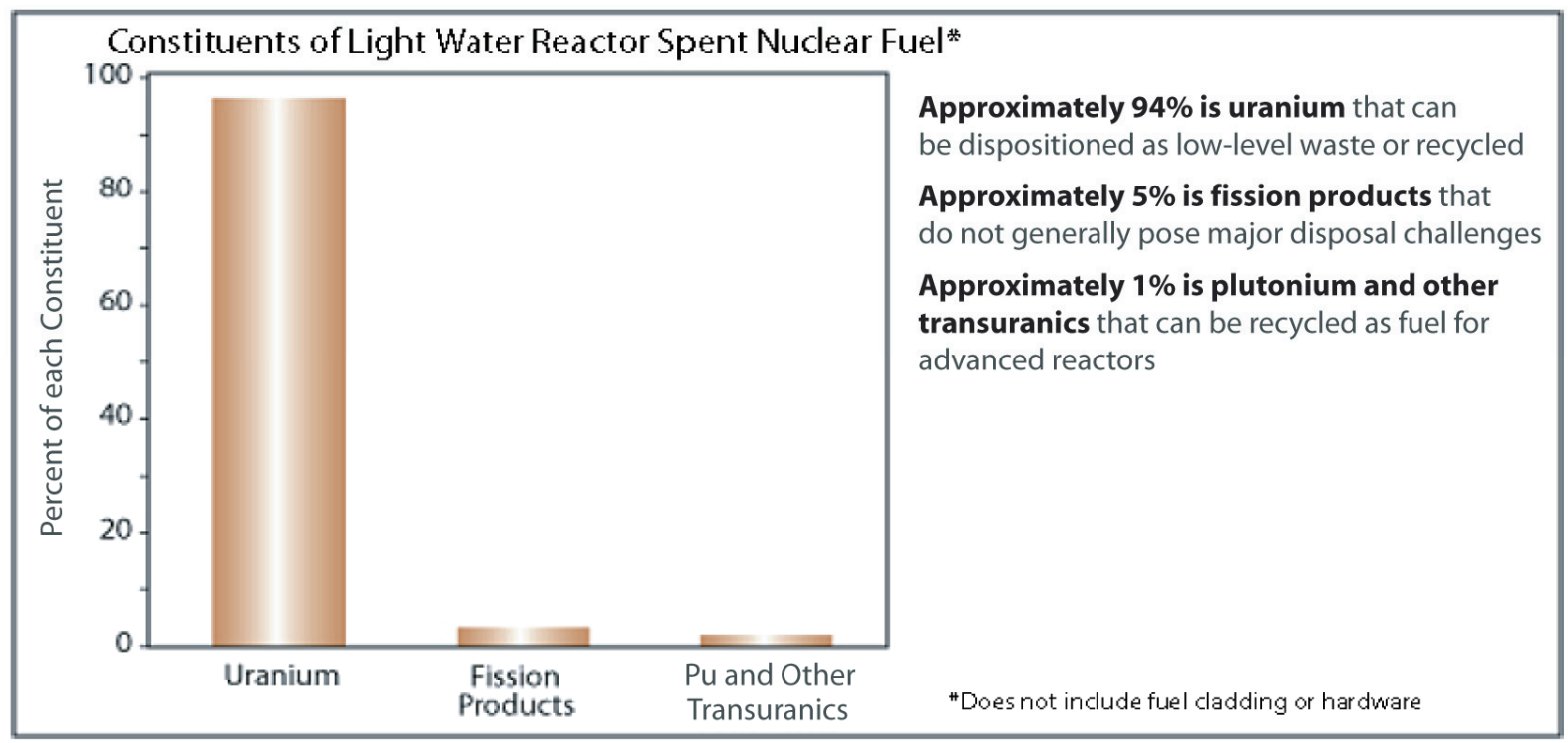

Source: Derived from DOE 2006u

FIGURE A.1-3-Constituents of Light Water Reactor Spent Nuclear Fuel

\section{What is the difference between an "open" and "closed" fuel cycle?}

Figure A.1-4 depicts both an open and closed nuclear fuel cycle. In the open fuel cycle (also known as the "once-through fuel cycle" and/or "direct disposal"), reactor fuel is used in a nuclear power plant only once. Although this approach to managing SNF accumulates liabilities such as transuranics, this is the simplest fuel cycle as no separation plants are needed and no fabrication of recycled material is needed. The United States and many other countries presently use this approach. 


\section{Current World Fuel Cycles}

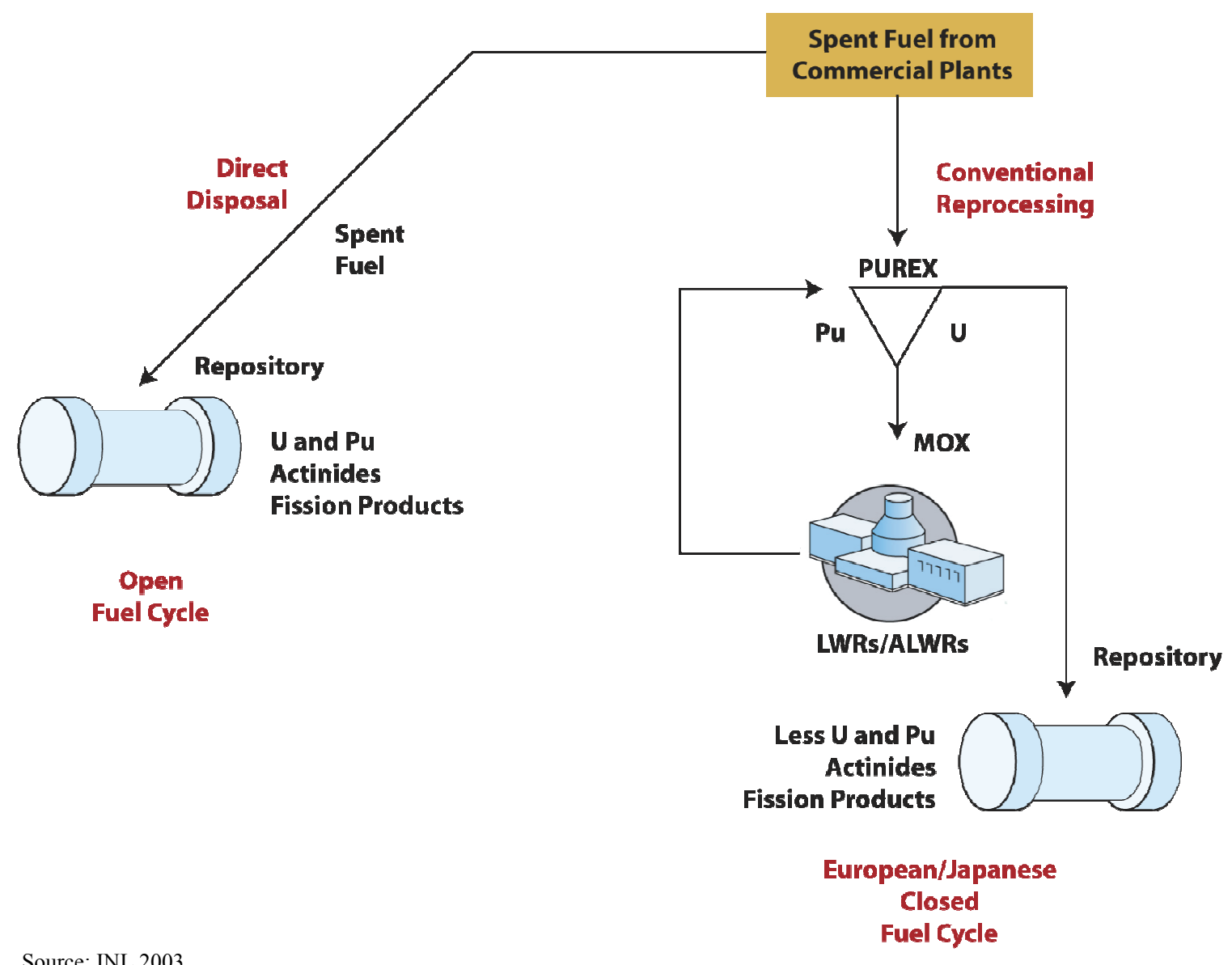

Figure A.1-4-Open and Closed Nuclear Fuel Cycle

SNF discharged from LWRs contains appreciable quantities of fissile material such as U-235 and $\mathrm{Pu}-239$, as well as other radioactive materials. These fissile materials can be separated and recovered from the SNF. In the closed fuel cycle, the SNF is recycled and some of the usable constituents are made into new reactor fuel (note: Figure A.1-4 identifies the Plutonium and Uranium Reduction and Extraction (PUREX) process for reprocessing SNF and producing mixed-oxide (MOX) fuel; however, there are several other reprocessing technologies that can be used to separate SNF and produce various types of reactor fuels with transuranic elements). By removing the uranium, fission products, and transuranics, recycling SNF can reduce the volume, radiotoxicity, and heat load of waste requiring geologic disposal.

As discussed in the next section, "transmutation" is the primary method of destroying the transuranic elements that are removed. In this process, the transuranic elements are consumed and converted into fission products and additional energy is produced. The closed fuel cycle extracts energy from the transuranic elements, thereby making them energy assets instead of waste liabilities. Countries such as France, the United Kingdom, Russia, and Japan use this approach. 


\section{A.2 Transuranic Elements}

Much of the discussion in this PEIS involves transuranic elements and the potential approaches to managing the transuranic elements that are contained in SNF. Transuranic elements are created in nuclear reactors when uranium in the fuel absorbs or captures neutrons. Transuranic elements constitute approximately 1 percent of SNF. Certain transuranic elements can be used in nuclear weapons. The transuranic elements are generally long-lived (tens of thousands to millions of years) and remain significantly more radiotoxic than the original uranium ore for hundreds of thousands of years. Certain transuranics also are significant contributors to the longterm thermal output of SNF. Additionally, transuranic elements and enriched uranium are the primary materials in SNF of concern for nuclear weapons proliferation. ${ }^{1}$

\section{Transuranic Elements}

All matter is divided into about 100 different chemical elements. The lightest element is hydrogen, \#1. Element \#92 is uranium, which is the heaviest element found in nature in significant amounts. Transuranic elements are man-made elements that are heavier than uranium, and include neptunium, plutonium, americium, and curium. Transuranic elements are created in nuclear power plants when uranium absorbs or captures neutrons. Transuranic elements are generally long-lived and radiotoxic, and certain transuranic elements can be used in nuclear weapons.

If the transuranics can be destroyed - through a process known as transmutation - then the waste hazard would be dominated by fission products. Fission products generally decay much more quickly (over a few hundred years for the more common fission products), thereby reducing the long-term hazard relative to transuranic elements. Transmutation is the conversion of one isotope to another by changing its structure, which can change both its nuclear and chemical properties. Transmutation can occur within a nuclear reactor, while generating electricity.

\section{A.3 Mining, ENRICHMENT, AND FUEL FABRICATION}

\section{Why Transuranic Elements Are Important}

- Transuranics have a major effect on long-term heat load and longterm radiotoxicity of SNF.

- Transuranics and enriched uranium are the primary materials in SNF of concern for nuclear weapons proliferation.

- Transuranics can be destroyed while producing energy if recycled in reactors.

\section{A.3.1 Uranium}

Uranium is a naturally-occurring element found at low levels in virtually all rock, soil, and water. Significant concentrations of uranium occur in some substances such as phosphate rock deposits, and minerals such as uraninite in uranium-rich ores. Because uranium has such a long radioactive half-life ( 4.5 billion years for U-238), the total amount of it on earth stays almost the same. When refined, uranium is a silvery white, weakly radioactive metal. Uranium metal has a

\footnotetext{
${ }^{1}$ By itself, low enriched uranium (LEU) is not usable for making a nuclear weapon; however, LEU in SNF could be a proliferation concern if used in a radiation dispersal device. LEU used to fuel reactors produces plutonium, which, if separated from SNF, can be used to make a nuclear weapon. Additionally, it is possible to use LEU as a feed material that could be enriched to high enough levels to make a nuclear weapon.
} 
very high density (65 percent more dense than lead). Uranium in ores can be extracted and chemically converted into uranium dioxide or other chemical forms usable in industry (EPA 2005b).

\section{A.3.1.1 Uranium Mining}

Uranium ore is mined either by the open pit method (to recover deposits near the surface of the earth) or by underground mining. Once recovered, the ore is crushed and then ground. Uranium ore rich in vanadium is usually roasted with sodium chloride (salt) or soda ash prior to grinding in order to facilitate extraction of the ore with water (EPA 2005a). Two methods are employed to extract uranium from ore: 1) acid leaching with sulfuric acid, or 2) alkaline leaching with a hot solution of sodium carbonate and sodium bicarbonate. This leaching can occur in situ, which involves injecting solutions into the permeable ore zone, or as solvent extraction, where the ore is placed in tanks and the same solutions are introduced. Ion exchange can also be used for both the in situ and solvent extraction methods, utilizing fixed organic resins (EPA 2005a).

\section{A.3.1.2 Uranium Milling and Extraction}

Concentrated uraniferous (uranium containing) ions from solvent extraction or ion exchange units are precipitated out of solution to produce a material referred to as "yellowcake." Uranium is usually precipitated from acid solutions by neutralization with ammonia or magnesia. Hydrogen peroxide may also be added to an acid pregnant stripping liquor or pregnant elution liquor to precipitate uranium peroxide (EPA 2005a). Additional chemical procedures fluoridate the yellowcake and then remove the fluoride to render relatively pure, uranium metal. If the uranium is to be enriched for purposes such as use as reactor fuel, the fluoride is not removed and the intermediary product uranium hexafluoride is used directly as a feedstock for the enrichment process.

\section{A.3.1.3 Uranium Enrichment}

For most reactor types, uranium needs to be enriched from the yellowcake state in order to produce material sufficiently concentrated to sustain a fission process which can generate the desired heat factor. Natural uranium primarily contains two isotopes, U-238 (99.3 percent) and U-235 (0.7 percent) (NRC 2007h). The concentration of U-235, the fissionable isotope in uranium, needs to be increased to 3 to 5 percent for practical use as a nuclear fuel in a LWR. Gaseous diffusion and gas centrifuges are the principal methods for enrichment (NRC 2007h).

In gaseous diffusion, uranium is converted into a gaseous form, uranium hexafluoride $\left(\mathrm{UF}_{6}\right)$, and passed through many stages of barriers that separate the uranium isotopes. In the United States, gaseous diffusion plants have operated in Oak Ridge, TN; Paducah, KY; and Piketon, OH. Currently, the only operating enrichment plant in the United States is the plant in Paducah (NRC 2007h).

Another way to enrich uranium is by using gas centrifuges. Gas centrifuges spin $\mathrm{UF}_{6}$ gas at high speeds creating a centrifugal force that separates the isotopes by forcing the heavier U-238 further outward in the centrifuge. Gas centrifuges have been used in Europe for about 30 years 
for enriching uranium (NRC 2007h) and two such facilities are under construction in the United States - a Louisiana Energy Services facility in Eunice, NM, and a U.S. Enrichment Corporation facility in Piketon, $\mathrm{OH}$. Gas centrifuge is currently preferred, in part, because it requires less electricity than gaseous diffusion.

Enrichment processes for LWRs generate a product from 3 to 5 percent U-235 for use as nuclear fuel and a byproduct of depleted uranium (about 0.3 percent U-235). Depleted uranium has some commercial applications in counterweights, antitank armaments, and ammunition; however, the commercial demand for depleted uranium is much less than the amounts generated (NRC 2007h). There are also hazardous and mixed wastes generated as a result of the enrichment process. These wastes must be managed in accordance with all applicable requirements.

\section{A.3.1.4 Uranium Fuel Fabrication}

This section discusses uranium fuel fabrication for the various fuel types that could be needed for the domestic programmatic alternatives. This section first discusses uranium oxide fuel fabrication for LWRs, which is the predominant fuel fabrication process used in the United States. This section also discusses uranium oxide fuel fabrication for heavy water reactors (HWRs) and high temperature gas-cooled reactors (HTGRs); mixed-oxide (MOX) fuel fabrication; and transmutation fuel fabrication. Thorium fuels are discussed in Section A.3.2.

Light Water Reactor Uranium Oxide Fuel. Fuel fabrication for LWRs typically begins with the receipt of $\mathrm{UF}_{6}$ in solid form from an enrichment plant. The $\mathrm{UF}_{6}$ is heated to a gaseous form, and the $\mathrm{UF}_{6}$ gas is chemically processed to form uranium dioxide $\left(\mathrm{UO}_{2}\right)$ powder. This powder is then pressed into pellets, sintered into ceramic form, loaded into zircaloy tubes, and constructed into fuel assemblies. Depending on the type of LWR, a fuel assembly may contain up to 264 fuel rods and have dimensions of 5 to 9 square inches $\left(\mathrm{in}^{2}\right)\left(32\right.$ to 58 square centimeters $\left.\left[\mathrm{cm}^{2}\right]\right)$ by about 12 feet (ft) (3.6 meters [m]) long (NRC 2007c). Figure A.3.1.4-1 shows a typical LWR fuel fabrication facility.

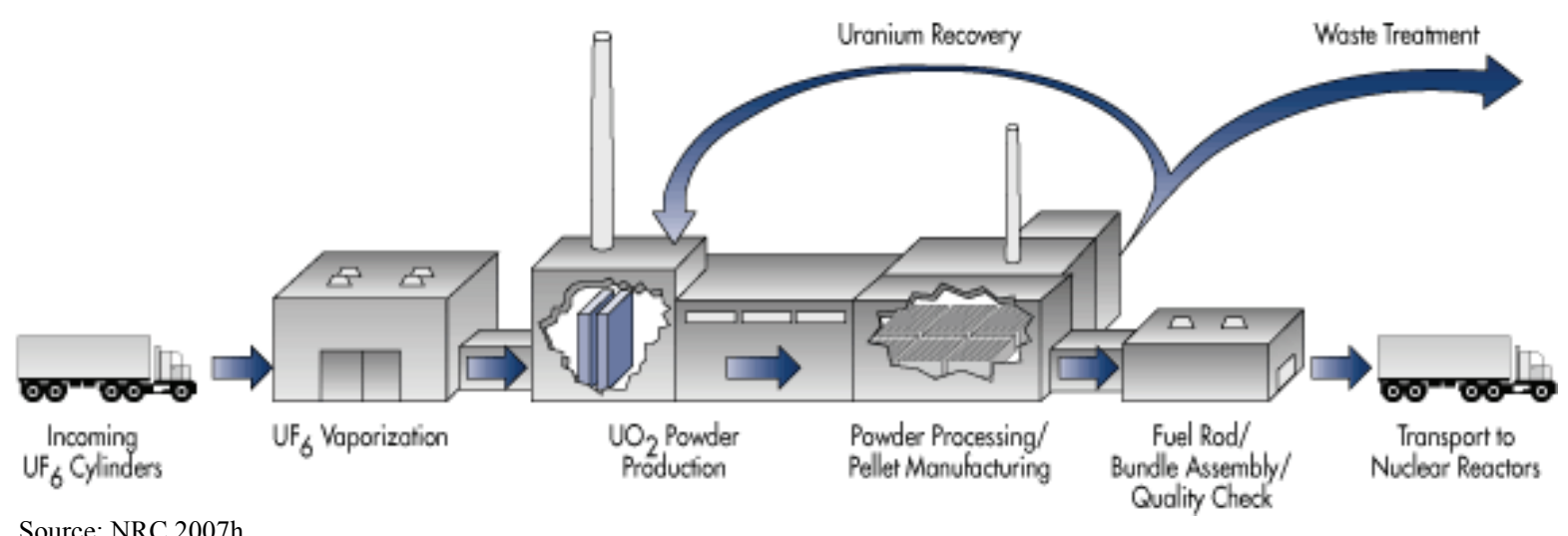

FIGURE A.3.1.4-1-Typical Nuclear Reactor Uranium Dioxide Fuel Fabrication Facility

Heavy Water Reactor Uranium Oxide Fuel. While LWRs utilize uranium in the form of $\mathrm{UF}_{6}$, so that it can be enriched to 3 to 5 percent, HWRs, such as the Canada Deuterium Uranium (CANDU) and Indian reactors, use $\mathrm{UO}_{2}$ which is normally not enriched. Current CANDU 
designs do not need enriched uranium to achieve criticality (due to their more efficient heavy water moderator), however, some newer concepts call for low enrichment to help reduce the size of the reactors (WNA 2008d). To make the fuel pellets for a HWR reactor, the uranium dioxide is compressed, then baked at high temperatures to yield hard, insoluble, ceramic cylinders about 0.6 inch (in) (14 millimeter [mm]) in diameter by $0.8 \mathrm{in}(20 \mathrm{~mm})$ long. These uranium dioxide pellets, which are about the same size as the $\mathrm{UF}_{6}$ pellets used in LWR fuel, are then stacked about 20 in $(500 \mathrm{~mm})$ long and 4 in $(100 \mathrm{~mm})$ in diameter and encapsulated in thin walled tubes of zirconium alloy (Canada 2008). Uranium dioxide is a very concentrated energy source. A number of such fuel tubes, usually referred to as pins, are assembled to form a fuel bundle that can be conveniently loaded into the reactor. Each bundle is roughly 44 pounds (lbs) (20 kilograms [kg]), and a typical core loading is on the order of 4500 bundles. See Section A.5.3 for a discussion of HWR fuel fabrication associated with the Thermal Recycle Alternative (Option 2).

High Temperature Gas-Cooled Reactor Uranium Oxide Fuel. In many respects, the fuel fabrication process for an HTGR would be similar to the fuel fabrication process described above for LWRs. Enriched uranium would be made into fuel rods, which would be bundled together into fuel assemblies for insertion into a reactor core. A major difference, however, would be the fuel particles that make up the fuel. Typical LWR fuel is made up of uranium powder that has been pressed into pellets, sintered, and loaded into zircaloy tubes. HTGR fuel would be made up of spherical fuel particles (known as kernels) of uranium that are coated with many layers of carbon. These carbon-coated fuel particles are the basic component of the HTGR fuel element (Shropshire and Herring 2004). The carbon layers provide space for gaseous fission products, provide structural strength, act as a containment barrier, and provide a bonding surface. These carbon-coated fuel particles are mixed together in a binder mixture (similar to "tar") to make fuel compacts (Del Cul et al. 2002). The compacts are sintered and inserted into a graphite sleeve to make a fuel rod, and these rods are assembled into graphite blocks to make fuel elements. Currently, only Japan has a fuel fabrication facility to make limited quantities of these carbon-coated fuel particles on a commercial basis.

Light Water Reactor Mixed Oxide Fuel. MOX fuel is fabricated in a similar manner, but differs from low enriched uranium fuel in that the dioxide powder from which the fuel pellets are pressed is a combination of $\mathrm{UO}_{2}$ and plutonium oxide $\left(\mathrm{PuO}_{2}\right)$. MOX fuel fabrication typically begins with blending and milling the plutonium dioxide powder to ensure general consistency in enrichment and isotopic concentration. The uranium and plutonium powders are then blended and milled together to ensure a uniform distribution of the plutonium in the MOX, and to adjust the particle size of the MOX powder. The MOX material, at this point, is placed into fuel rods similar to the LWR uranium fuel rods described above. In the case of a co-separated uranium-plutonium mixture, with or without additional transuranics, a similar approach could be used except that the U-Pu mixture would be blended and milled together with additional uranium in order to obtain the desired mix. Additional shielding might be needed depending on the isotopic composition.

Transmutation Fuel Fabrication. The Fast Recycle Alternative, Thermal/Fast Recycle Alternative, and Thermal Recycle Alternative (Option 3), and possibly Thermal Recycle Alternative (Options 1), would utilize transmutation fuel (fuel made up of transuranic elements 
with or without uranium) that would fuel advanced reactors such as the advanced recycling reactor and the deep burn HTGR. The uranium and transuranic products from the separations process would be the feed material for the transmutation fuel fabrication. Given the high radiation fields associated with the transuranic feed material, the fabrication of this fuel must be done remotely, in a shielded facility. Substantial experience exists for fabricating numerous types of reactor fuels, including fast reactor fuel with uranium and plutonium, in both metal and oxide fuel forms, however, these operations did not require the shielding or the remote operations that would apply to the transmutation fuel. The design of the transmutation fuel fabrication processes and facilities do not yet exist but can draw heavily on the past experience with fabricating fast reactor fuel, and would have some unique aspects to address regarding the transuranic fuel and the remote operation.

For a deep-burn HTGR, the transuranic products from the separations process would be the feed material for fuel fabrication. Given the high radiation fields associated with this transuranic product, the fabrication of this fuel must be done remotely, in a shielded facility. Some experience exists for fabricating fast HTGR fuel with uranium and thorium in oxide fuel forms, however, these operations did not require the shielding or the remote operations that would apply to the transuranic fuel. The design of the HTGR transuranic fuel fabrication processes and facilities do not yet exist but can draw on the past experience with fabricating HTGR fuel, and would have some unique aspects to address regarding transuranic fuel and the remote operation. See Section A.6.2 for a description of a transmutation fuel fabrication facility. That section is illustrative of the facility requirements, operations, and waste streams for a transmutation fuel fabrication facility.

\section{A.3.2 Thorium}

Thorium is a naturally occurring radioactive substance that can be used in nuclear fuel. Thorium is about three times as abundant as uranium in nature, but cannot, by itself, create or sustain the nuclear chain reaction ("criticality") needed to produce heat to generate electricity. In the environment, thorium exists in combination with other minerals, such as silica. Small amounts of thorium are present in all rocks, soil, water, plants, and animals. Soil contains an average of about 6 parts of thorium per million parts of soil (6 ppm) (ATSDR 1999). Thorium occurs most commonly in the rare earth mineral thorium phosphate (monazite), which contains approximately 12 percent high grade thorium dioxide $\left(\mathrm{ThO}_{2}\right)$. There is a large quantity of thorium in the United States and known reserves are extractable in other parts of the world. Table A.3.2-1 shows the world reserves of thorium. 


\begin{tabular}{lc} 
TABLE A.3.2-1-World Thorium Reserves \\
\hline \multicolumn{1}{c}{ Country } & Reserves (Tons) \\
\hline USA & 160,000 \\
Australia & 300,000 \\
Brazil & 16,000 \\
Canada & 100,000 \\
India & 290,000 \\
Malaysia & 4,500 \\
Norway & 170,000 \\
South Africa & 35,000 \\
Other Countries & 90,000 \\
Total World Deposits & $\mathbf{1 , 2 0 0 , 0 0 0}$ \\
\hline
\end{tabular}

Source: USGS 2007c

More than 99 percent of natural thorium exists in the form of thorium-232 (Th-232). As a result of the radioactive decay of $\mathrm{Th}-232$, other radioactive substances are produced. These include radium and radon. These substances give off radiation, including alpha and beta particles, and gamma radiation (ATSDR 1999).

\section{A.3.2.1 Thorium Mining}

Some rocks in underground mines contain thorium in a more concentrated form. After these rocks are mined, thorium is usually concentrated and changed into thorium dioxide or other chemical forms. After most of the thorium is removed, the rocks are called "depleted" ore or tailings. Thorium is used to make ceramics, gas lantern mantles, and metals used in the aerospace industry and in nuclear reactors (ATSDR 1999).

Domestic mine production of thorium-bearing monazite ceased in 1994 as world demand for ores containing naturally occurring radioactive thorium declined. Domestic demand for thorium ores, compounds, metals, and alloys has exhibited a long-term declining trend. No domestic thorium consumption was reported in the United States in 2005, according to the U.S. Geological Survey's canvass of mines and processors (USGS 2007c). Imports and existing stocks supplied essentially all thorium consumed in the United States in 2006.

\section{A.3.2.2 Thorium Use in a Nuclear Reactor}

Thorium can be used to produce fissile U-233 to fuel nuclear reactors. When Th-232 absorbs a neutron, it ultimately becomes U-233. The U-233 created in the reactor is a more effective fuel than U-235 or Pu-239 in a thermal neutron spectrum, and can provide a significant contribution to sustaining a reactor's operation.

Because thorium is a lighter element than uranium and plutonium, when thorium is used as a major component of reactor fuel, the production of transuranics (neptunium, plutonium, americium, and curium), the primary contributors to long-term waste toxicity and heat load in 
geologic repositories, is reduced relative to conventional uranium-based fuels (IAEA 2002b). However, U-233 has a longer half-life than Pu-239 and can also contribute to long-term radiotoxicity (IAEA 2002b).

Enriched uranium is generally used as the start-up fuel ${ }^{2}$ for a thorium-fueled reactor, where the U-235 would be enriched to approximately 19.9 percent (less than 20 percent, due to proliferation concerns) and a certain amount of U-238 would be inherently present. While this leads to some plutonium production (Todosow 2003), the quantity of the plutonium produced is significantly lower than in conventional uranium-based fuel, and distribution of the plutonium isotopes within the spent fuel is less attractive for potential use in a weapon. In addition, proliferation resistance is enhanced due to the presence of $\mathrm{U}-232^{3}$ and its strong gamma emitting daughter products, and the fact that the thorium can be mixed with uranium initially to "denature" the bred U-233 to keep its concentration below the accepted nonproliferation limits (IAEA 2005a).

The thermal conductivity of thorium is higher than that of uranium over a large temperature range. As a consequence, for the same power level, fuel-operating temperatures in a thorium-fueled reactor would be lower than those of a uranium-fueled reactor, and all thermally activated processes - such as diffusion of fission gas from the fuel-would be decreased. Alternatively, in a reactor fueled with thorium, reactor power could be increased, as could burnup, due to better fission product retention. Thorium dioxide $\left(\mathrm{ThO}_{2}\right)$ is chemically very stable and does not oxidize - a benefit for normal operation, postulated accidents, and in waste management (IAEA 2002b).

Several experimental and prototype power reactors were successfully operated during the mid-1960s through the 1980s using thorium fuels. In addition, the Indian Point-2 commercial pressurized water reactor (PWR) in New York successfully used thorium-based fuel, and thorium-based fuel was also used in several commercial HTGRs. However, despite the generally positive experience with these fuels, so far, thorium fuels have not been introduced commercially on a large scale, mainly because the estimated uranium resources have turned out to be sufficient to support the existing reactor fleets in a cost-effective manner.

The thorium open fuel cycle (see Figure A.3.2.2-1), while different in many aspects from the existing uranium once-through fuel cycle, can be characterized as a "new fuel design" rather than as a new reactor concept because it can be used with existing reactor technologies. In fact, based on recent studies, albeit generally not involving detailed designs, the thorium fuel cycle would be feasible for implementation in most existing commercial nuclear power plants without major modifications in the engineered systems (e.g., control rods and soluble boron control systems) (IAEA 2005a).

\footnotetext{
${ }^{2}$ Plutonium could also be used as a start-up fuel.

${ }^{3} \mathrm{U}-232$ is formed when Th-232 absorbs a neutron, and then decays to U-232.

${ }^{4}$ In this context, the term "denature" means ensuring that there is enough other non-fissile isotopes of uranium (such as U-238) to maintain the percentage of U-233 low enough to mitigate concerns from a weapons-usability standpoint.
} 


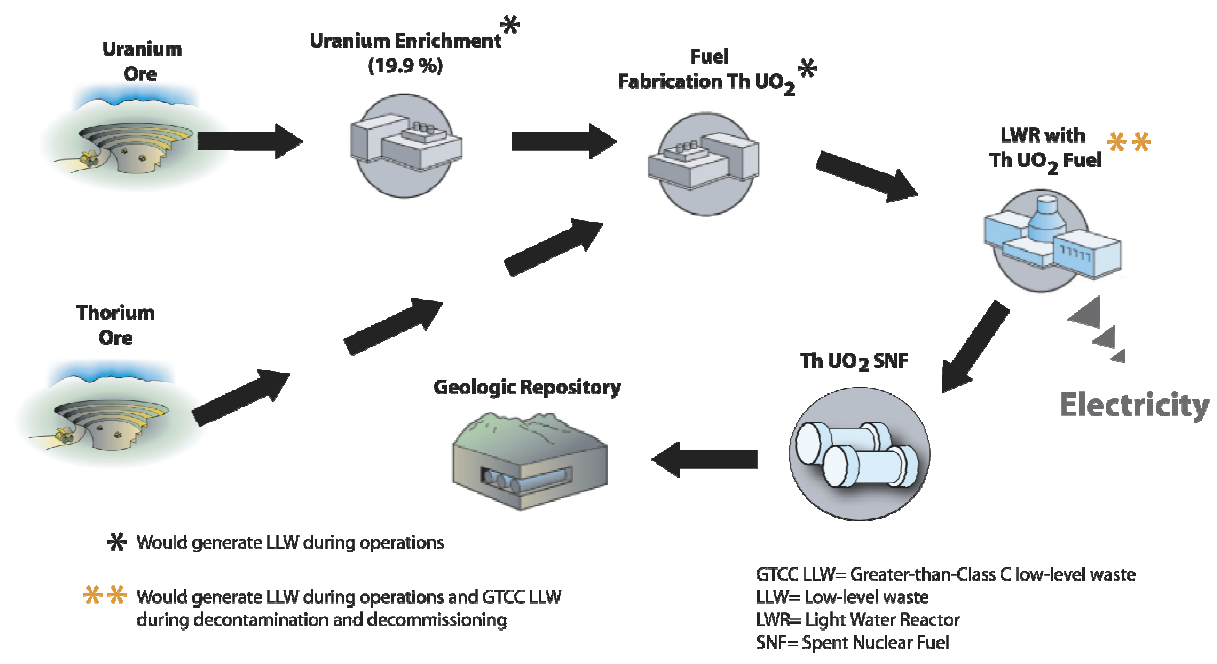

FIGURE A.3.2.2-1-Thorium Open Fuel Cycle

For purposes of this PEIS, only a thorium once-through fuel cycle as implemented in a LWR is assessed. While it is technically possible to recycle the SNF from a thorium-based fuel cycle, this is not assessed as a reasonable alternative in this PEIS for the reasons explained in Section 2.8.

\section{A.3.3 Characterization of Commercial Nuclear Fuel Fabrication Facilities}

\section{Overview of United States Facilities}

Table A.3.3-1 summarizes information about the fuel fabrication facilities in the United States. The table also includes information about a MOX fuel fabrication facility which has received U.S. Nuclear Regulatory Commission (NRC) authorization for design and construction and is currently undergoing the application process for an operating license (NRC 2007j). Construction of this MOX fuel fabrication facility began at DOE's Savannah River Site in 2007.

TABLE A.3.3-1—Summary of Commercial Fuel Fabrication Facilities

\begin{tabular}{|c|c|}
\hline Licensee & Location \\
\hline \multicolumn{2}{|c|}{ Uranium Fuel Fabrication Facilities } \\
\hline Global Nuclear Fuel-Americas, LLC & Wilmington, $\mathrm{NC}$ \\
\hline Westinghouse Electric Company, LLC & Columbia, SC \\
\hline Nuclear Fuel Services, Inc. & Erwin, TN \\
\hline BWX Technologies, Inc. & Lynchburg, VA \\
\hline AREVA NP, Inc. & Lynchburg, VA \\
\hline AREVA NP, Inc. & Richland, WA \\
\hline \multicolumn{2}{|c|}{ Mixed Oxide Fuel Fabrication Facilities } \\
\hline $\begin{array}{l}\text { Shaw AREVA MOX Services (formerly Duke } \\
\text { Cogema Stone and Webster) }\end{array}$ & Aiken, SC \\
\hline
\end{tabular}


It should be noted that Nuclear Fuel Services, Inc., BWX Technologies, Inc., and AREVA NP, Inc. Lynchburg, Virginia, although NRC licensed, do not presently have the capability of processing $\mathrm{UF}_{6}$ to $\mathrm{UO}_{2}$ powder.

\section{A.4 REACTORS}

This section provides additional information regarding reactor technologies that could be deployed following decisions made as a result of this GNEP PEIS. As presented in Chapter 2 of the PEIS, the fuel cycle alternatives addressed in this PEIS could utilize various technologies, including different reactor types and reactor fuels.

Reactors can be categorized based on the neutron energy levels present in the reactor. A thermal spectrum reactor has low neutron energy and a fast spectrum reactor has high neutron energy, or simply "thermal" and "fast" for short. Most reactors in the world today are thermal reactors, and more specifically, light water reactors (LWRs) fueled with uranium-oxide $\left(\mathrm{UO}_{2}\right)$. Section A.4.1 discusses various LWR technologies and Section A.4.2 discusses the advanced recycling reactor, which is the representative fast reactor technology presented in the PEIS.

\section{How does a typical U.S. commercial nuclear power plant work?}

A nuclear power plant generates electricity using a "reactor," which is a device designed to use the fission process (splitting of atoms) to turn a small amount of mass into energy in a controlled way. In a typical nuclear power plant, neutrons strike uranium fuel, which splits, or fissions. Each fission produces energy, neutrons, and fission products; the energy produced takes the form of heat. The neutrons cause additional fission reactions. The heat from the fission reaction is removed from the reactor by a primary coolant which carries the heat to a steam generator. The steam generator uses the heat in the primary coolant to create steam in a secondary loop, which drives a steam turbine and produces electricity (see Figure A.4-1). Thus, in a nuclear power plant, the fission of nuclear fuel plays the same role as the burning of coal, natural gas, or oil plays in fossil fuel power plants.

Uranium is contained in fuel rods, which are clustered into fuel assemblies; each reactor core contains many fuel assemblies. During the operation of the reactor, the uranium in the fuel rods is being "used" and eventually enough fission products accumulate to interfere with the efficiency of the nuclear reaction such that the fuel can no longer effectively produce energy. At this point (typically 18 months), the used fuel is said to be "spent" and must be replaced with new (fresh) fuel assemblies in order for the reactor to continue to produce electricity. Approximately one-third of the reactor's fuel is replaced during each refueling. 


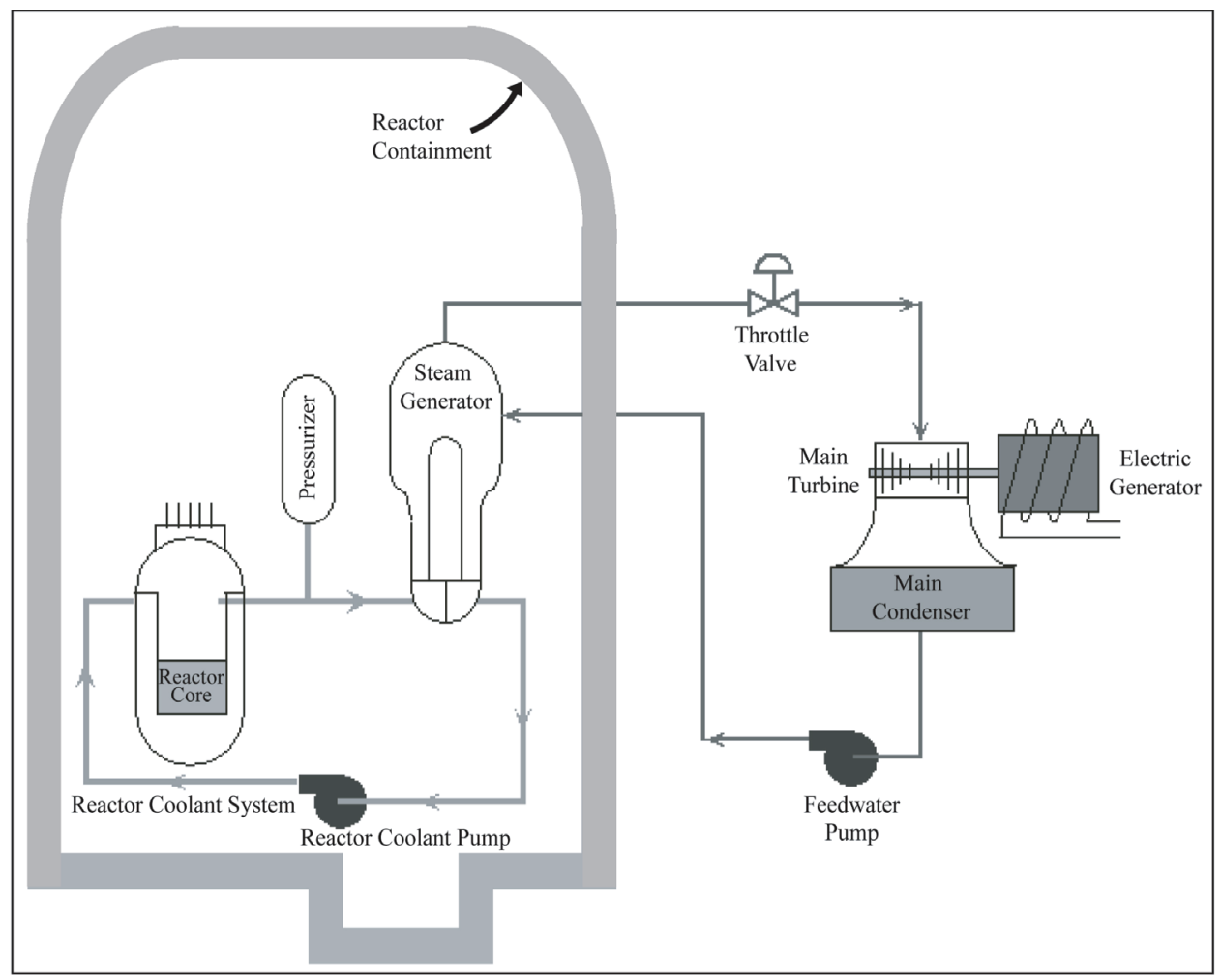

Source: FPL 2008

FIGURE A.4-1-Electricity Production in a Typical Commercial Nuclear Plant

Several technologies are available for rejecting heat from operating large power generation facilities (such as nuclear reactors): once-through cooling; evaporative cooling; and dry cooling. The estimates for annual make-up water are bounded on the high-end by once-through cooling with water (Briggs et al. 2007). While not currently used for a nuclear power generation facility, based on successful use of dry cooling systems in large fossil power generating stations (Nagel and Wurtz 2006), a dry cooling system may be used in arid areas to reduce the amount of water used by the reactor facility. Dry cooling systems are fundamentally the same system used to cool an automobile engine. Process fluid (for example, steam) is on the inside of pipes or coils; heat is transferred from the fluid through the metal wall of the pipe or coil, into the surrounding atmosphere. In a dry cooling system, there is no direct contact between the fluid and the atmosphere. Because a dry cooling system does not use water's latent heat of vaporization for dissipating heat, the dry system would be larger than either a once-through or evaporative cooling system, and therefore would have a higher initial cost for an equivalent cooling capacity. Additionally, a reactor facility design would need to address environmental concerns such as noise associated with any design using fans, and esthetic factors like the large size of a dry cooling system compared with once-through or evaporative systems.

\section{A.4.1 Thermal Reactors}

LWRs fueled with $\mathrm{UO}_{2}$ dominate world commercial nuclear power production because their technology is well known and has proven to be economical (see Section A.4.1.1). This section 
also discusses mixed-oxide (MOX) fueled LWRs (Section A.4.1.2), HWRs (Section A.4.1.3), HTGRs (Section A.4.1.4), and thorium fueled LWRs (Section A.4.1.5).

\section{A.4.1.1 Uranium-Oxide Fueled Light Water Reactors}

LWR technology was initially developed in the United States. This technology now is the predominant nuclear energy technology used throughout the world. In fact, approximately 80 percent of the nuclear power plants operating in the world are LWRs (IAEA 2004a). About 34 power reactors are currently being constructed in 11 countries, most notably China, South Korea, Japan and Russia (WNA 2008b). Most of these reactors are LWRs.

All 104 nuclear plants used in the United States for electric power production are LWRs. The last new nuclear reactor to come on line in the United States was the Watts Bar Unit 1 reactor in Tennessee, owned and operated by the Tennessee Valley Authority. Its operating license was granted in February 1996 and it began commercial service in May 1996 (EIA 2008d).

LWRs are fueled with $\mathrm{UO}_{2}$ fuel assemblies (Section A.3.1.4) that are enriched to approximately 3 to 5 percent U-235 (Section A.3.1.3). LWRs are classified as either PWRs or boiling-water reactors (BWRs), depending on whether the coolant water is kept under pressure or not. In a PWR, the pressurized water in the reactor creates steam by heating water in a steam generator (see Figure A.4-1). This steam turns a turbine to generate electricity. In a BWR, the reactor coolant boils and turns the turbine directly, without the need for a steam generator. In the United States, approximately 66 percent of the LWRs (69 out of 104) are PWRs and 34 percent (35 out of 104) are BWRs. Both PWRs and BWRs contain emergency cooling systems that would be utilized to maintain a safe reactor core temperature in the event of a loss-of-cooling situation.

The commercial nuclear power industry is currently pursuing the development of advanced LWRs (ALWRs) which are designed to incorporate improved safety features such as passive systems. Passive systems (such as gravity and natural circulation) are intended to simplify safety systems and reduce costs, improve reliability, and mitigate the effect of human errors and equipment failures by increasing the time operators have to cope with accident conditions. Passive systems would also reduce reliance on offsite and onsite power supplies in the event of a loss of power. ALWRs are being developed over a large range of power levels, from small ALWRs (less than 300 megawatts electric [MWe]), medium ALWRs (300 to $700 \mathrm{MWe}$ ), and large ALWRs (greater than $700 \mathrm{MWe}$ ). The largest ALWR under development is approximately 1,600 MWe (IAEA 2004a). The No Action Alternative, Fast Recycle Alternative, Thermal/Fast Recycle Alternative, and the Thermal Recycle Alternative (option 2 and 3) would include LWRs/ALWRs fueled with uranium-oxide. 


\section{A.4.1.2 Mixed Oxide Fueled Light Water Reactors}

The Thermal/Fast Recycle Alternative and the Thermal Recycle Alternative (Option 1) would involve thermal recycle in LWRs using a MOX fuel assembly concept. This fuel cycle would use a MOX fuel with either uranium-plutonium (MOX-U-Pu) $)^{5}$ or uranium-transuranics (MOX-U-TRU) (Pu, neptunium [Np], americium [Am], and curium [Cm]). The MOX-U-Pu fuel is discussed in this section. The MOX-U-Pu fuel assembly, which could be fabricated using existing fuel fabrication technology, would partially replace the $\mathrm{UO}_{2}$ fuel assemblies in LWRs. MOX fuel has been used extensively in the nuclear industry. MOX fuel was first used in a thermal reactor in 1963, but did not come into commercial use until the 1980s. So far about 2,200 tons (2,000 MT) of MOX fuel has been fabricated and loaded into power reactors. In 2006 about 198 tons (180 MT) of MOX fuel was loaded into over 30 reactors (mostly PWRs) in Europe. Today, MOX is widely used in Europe and is planned to be used in Japan. Currently about 40 reactors in Europe (Belgium, Switzerland, Germany, and France) are licensed to use MOX, and over 30 are doing so. Japan also plans to use MOX in up to 20 of its reactors. Most reactors use it as about one-third of their core, but some will accept up to 50 percent MOX assemblies. France aims to have all its 900 MWe series of reactors running with at least one-third MOX. Japan aims to have one-third of its reactors using MOX by 2010, and has approved construction of a new reactor with a complete fuel loading of MOX (WNA 2008c).

The assembly is made up of approximately two-thirds of $\mathrm{UO}_{2}$ rods on the inside, and of approximately one-third of MOX-U-Pu rods on the periphery. When irradiated in a thermal reactor, the assembly would have an approximately zero plutonium mass balance (i.e., the plutonium consumed in the MOX-U-Pu rods would be approximately the same as the plutonium produced in the $\mathrm{UO}_{2}$ rods). A MOX-U-Pu fuel assembly is displayed in Figure A.4.1.2-1.

\footnotetext{
${ }^{5}$ Neptunium could be added to the MOX-U-Pu fuel.
} 


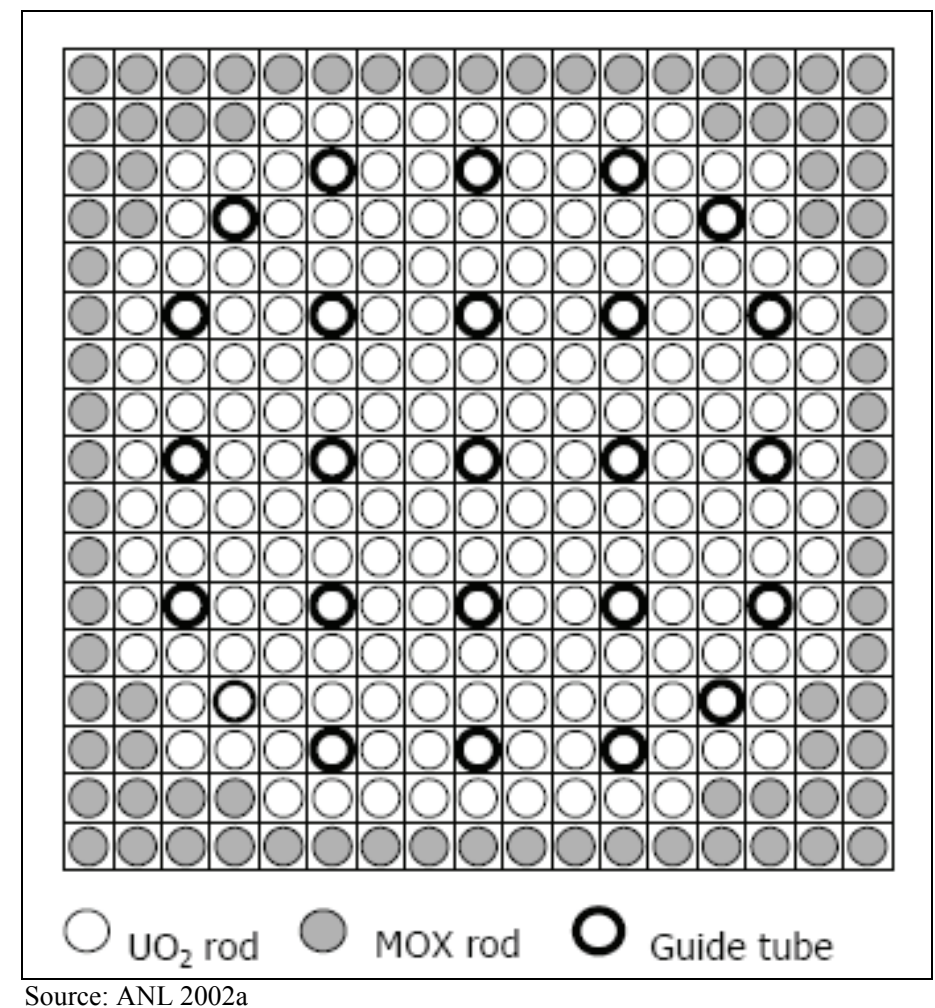

\section{FIGURE A.4.1.2-1—Pin Loading Pattern of Mixed Oxide-Uranium-Plutonium Assembly}

The plutonium would be multi-recycled in the Thermal Recycle (Option 1) concept with the aim of stabilizing the plutonium inventory. Following discharge of the assembly, the MOX-U-Pu rods would be recycled to recover the $\mathrm{U}-\mathrm{Pu}$ from the assembly. During the separation, most $\mathrm{U}-\mathrm{Pu}$ (more than 99 percent) would be recycled, while all fission products and the minor actinides ( $\mathrm{Np}$, Am, Cm, and higher) would be separated during fuel reprocessing between recycle passes and sent to waste storage and eventual disposal in a repository. The reusable material would then be used for fabricating the fuel for the next stage of the multi-recycle operation. Figure A.4.1.2-2 shows the flow diagram for the Thermal Recycle Alternative (Option 1).

Each recycle stage would take about 11.5 years in the design currently being evaluated. The fuel would be resident in the core for 4.5 years. A 5-year cooling time is assumed, after which fuel separation and fabrication would take place. An additional 2 years is assumed before the fuel would be loaded back into the reactor core. ${ }^{6}$ Each operational cycle would be 1.5 years and the fuel would accumulate approximately 15 gigawatt days (GWd) per metric ton (MT) of burnup in

\footnotetext{
${ }^{6}$ This additional 2 years is based on the realization that it takes time subsequent to fuel separation before the recovered fuel material is actually used in the reactor core. This time includes the elapsed time from fuel separation to fabrication into MOX fuel (which could occur at a different plant) and the re-introduction of the MOX fuel into a reactor core (at a different location). The times for transportation of materials/fuels between facilities and all associated wait times at the facilities are included. It is worth noting that each of the closed fuel cycle alternatives have more complicated logistics issues, compared to open fuel cycle alternatives, that could affect operational cycles.
} 
this period. This would result in a discharge burnup of $45 \mathrm{GWd} / \mathrm{MT}$ for the MOX-U-Pu assembly (ANL 2007). In this concept, only the fission products, minor actinides, and Pu lost during reprocessing would pass to the repository.

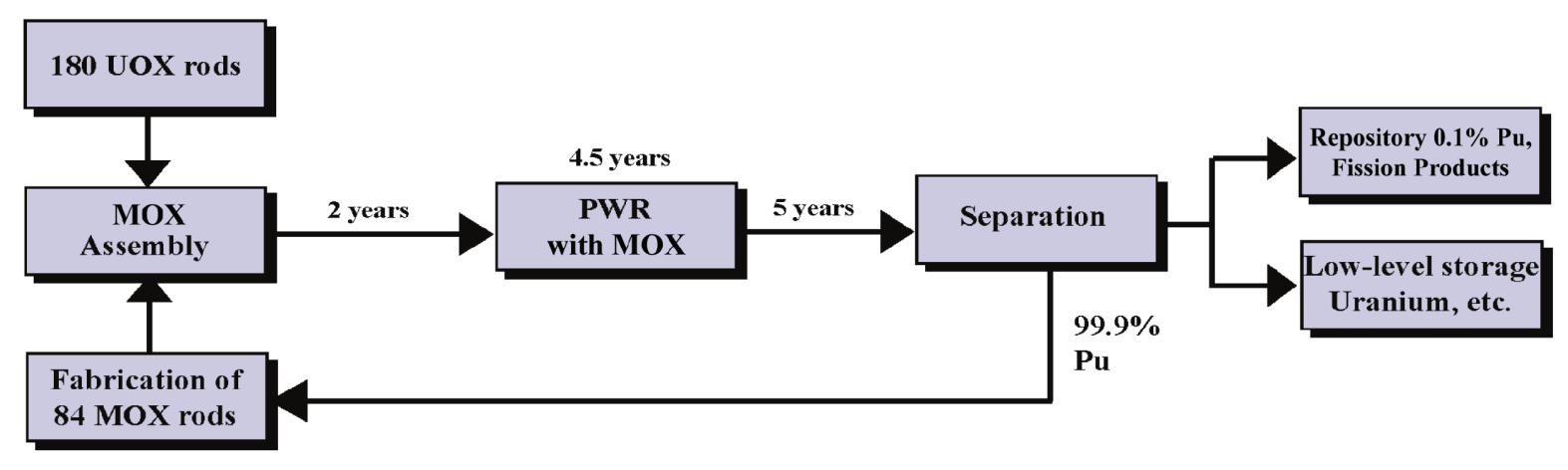

FIGURE A.4.1.2-2—Multi-Recycling of Plutonium in Light Water Reactors

\section{A.4.1.3 Heavy Water Reactors}

Two of the alternatives in the GNEP PEIS consider the use of HWRs: the Thermal Recycle Alternative (Option 2), which is also referred to as the "DUPIC (direct usse of spent PWR fuel in CANDU) fuel cycle," and the HWR/HTGR Once-Through Fuel Cycle Alternative (Option 1all HWRs). For each alternative, the HWR would operate the same. The major difference would involve the source of fuel for the HWR.

HWRs use deuterium-oxide (heavy water) as a moderator and coolant for their reactor core. Deuterium is a stable but rare isotope of hydrogen containing one proton and one neutron in its nucleus. Common hydrogen has only one proton in its nucleus. This makes deuterium twice as heavy as hydrogen. Heavy water has two deuterium atoms attached to an oxygen atom whereas natural water has two hydrogen atoms attached to an oxygen atom.

Chemically, the additional neutron in heavy water changes its characteristics only slightly, but in nuclear terms the difference is significant. The role of water as the moderator in a thermal reactor is to slow neutrons down to an energy level where they will cause fissions to occur in uranium atoms in the fuel. Since the natural water used in LWRs absorbs more neutrons than heavy water, LWR reactor fuel must be enriched to increase the amount of fissionable U-235 content needed to maintain a nuclear reaction. With fewer neutrons absorbed by heavy water (600 times fewer), more are available to fission with the uranium atoms in the fuel, and therefore, enrichment is not required. This enables natural uranium to be used for fuel in a HWR. For this reason, some proponents believe there is less risk of nuclear proliferation in a HWR. However, HWRs produce more weapons useable Pu-239 (from fertile U-238) because of the neutrons available, thereby offsetting the potential advantage of using natural uranium fuel (Miller 2001).

HWRs were first introduced in the United States in the early 1950s. Argonne National Laboratory (ANL) had two such reactors operating by 1950. These reactor designs served in large part as the design basis for the HWRs built at the Savannah River Site for the nuclear 
weapons program. Five HWRs were brought on line at the Savannah River Site between 1953 and 1955. Heavy water allowed the United States to produce both plutonium and tritium for weapons using the same reactor technology. In 1993, the last of these reactors (K Reactor) was placed in cold standby, and later shut down (SRS 2007).

Canada has played a major role in the development of the HWR and has a number of heavy water power reactors in operation and under continued development. Canada began HWR development after World War II and built some early research reactors. In the 1950s, they began development of the CANDU power reactor concept. CANDU is a pressurized heavy water reactor using natural uranium fuel. The selection of this concept built upon the Canadians' previous experience and allowed them to utilize indigenous uranium reserves. The use of natural uranium avoids the requirement for uranium enrichment capability and eliminates the creation of depleted uranium enrichment plant tails, which create a waste management problem (Canada 2007, Whitlock 2000, Boczar et al. 2002).

Canada's 20 MWe Nuclear Power Demonstration (NPD) reactor went into operation in 1962 and successively larger plants were designed and built thereafter including the $500 \mathrm{MWe}$ Pickering Station plants that went into operation in the early 1970s and the 800 MWe Bruce Station plants that went into operation in the late 1970s. Two models of the CANDU reactor have been marketed internationally; the CANDU-6 which has a capacity of approximately $700 \mathrm{MWe}$ and the CANDU-9 with a capacity of approximately 900 MWe. The Advanced CANDU Reactor (CANDU-ACR) is a third generation reactor incorporating innovative features and improvements. The 750 MWe ACR-700 and the 1080 to 1200 MWe ACR-1000 are the main focus of current Canadian design efforts.

While natural uranium fuel is used in Canada, a variety of enrichments and fissile loadings can be accommodated in existing CANDU designs. These include slightly enriched uranium (SEU), mixed oxides of plutonium/uranium or plutonium/thorium, and fuels containing no fertile material.

The CANDU reactors are refueled at full power, a capability created by the subdivision of the core into hundreds of separate pressure tubes that contain fuel. Each pressure tube holds a single row of fuel bundles sitting end to end, $1.6 \mathrm{ft}(0.5 \mathrm{~m})$ long and weighing approximately $44 \mathrm{lbs}$ $(20 \mathrm{~kg})$. The fuel bundles are surrounded by heavy water coolant within the pressure tubes, and the space between the pressure tubes is also filled with heavy water which serves as the reactor moderator. Several hundred pressure tubes form the fissile core within a cylindrical reactor vessel (the "calandria"). The calandria is horizontal, thus, making the CANDU core horizontal.

In order to refuel the CANDU, two refueling machines are used; one at each end of the core. One machine withdraws SNF as the second machine inserts fresh fuel from the opposite end. Six to 10 fuel bundles are shuffled each day of reactor operation. This reactor configuration and refueling scheme greatly reduces the cost of refueling. However, this reduction is offset by the need to periodically upgrade ("enrich") the heavy water moderator in the reactor. A purity decrease of only 0.1 percent can seriously affect the efficiency of fuel utilization in the reactor. Other advantages of on-power refueling include increased capacity factors, the ability to detect and remove defective fuel, and the ability to control power distribution in the core. The low 
excess reactivity of the natural uranium fuel cycle allows the CANDU core to be continuously refueled rather than changed out in a batch process, like conventional LWRs.

India is developing a 300 MWe Advanced Heavy Water Reactor (AHWR) as the third stage in its plan to utilize indigenous thorium reserves to fuel its overall nuclear power program. The AHWR uses a combination of thorium/uranium-233 oxide fuel and plutonium/thorium oxide fuel to extend core life.

Historically, heavy water for most HWRs has been extracted from ordinary water, where deuterium occurs naturally at a concentration of about 150 parts per million (deuterium to hydrogen). As an isotope of hydrogen, the separation of deuterium from normal hydrogen is relatively simple, but deuterium's low natural abundance requires processing large volumes of water and makes such separation expensive. A vacuum distillation process is a simple, attractive process for producing small quantities of heavy water; however, multiple process steps and high energy consumption make this manufacturing approach unattractive for fulfilling the needs of multiple, large reactors (Miller 2001, Suppiah and Spagnolo 1998).

For many years, the primary extraction process used for bulk commercial production of heavy water in Canada was the Girdler-Sulfide chemical process. Using an "extraction tower," ordinary water was passed over perforated trays through which hydrogen sulfide gas was bubbled. By increasing temperature in one section of the tower, deuterium migrated to the hydrogen sulfide gas, and then in a cold section of the tower, migrated back into the water. Using multiple towers, water with increasing deuterium content was passed through successive stages and then through a vacuum distillation process until "enrichment" to reactor grade heavy water was achieved. The Girdler-Sulfide process supplied heavy water for the CANDU reactors built from the 1960s to the 1980s, although it was expensive and required large quantities of toxic hydrogen sulfide gas. This process was discontinued in 1997.

For the CANDU reactors, Canada has worked extensively over several decades on the development of industrial chemical processes that exhibit attractive economic characteristics in order to develop a more cost effective approach to separating deuterium. More advanced processes pursued by Canada have included the combined electrolysis and catalytic exchange process and the combined industrial reforming and catalytic exchange process. Although combined electrolysis and catalytic exchange can produce heavy water at roughly half the cost of vacuum distillation, by itself it is suitable for producing only small quantities of heavy water. The Canadians are now pursuing a three stage process to produce heavy water: the combined industrial reforming and catalytic exchange process followed by a bi-thermal water-hydrogen second stage, and finally, a combined electrolysis and catalytic exchange third stage to bring heavy water enrichment to reactor grade. These catalyst technologies are more environmentally benign than the gas extraction process they replace and are capable of producing heavy water at a reasonable cost.

In the case of the CANDU reactors, a fuel bundle consists of sintered uranium dioxide pellets in zirconium alloy tubes fabricated into a fuel bundle. Each fuel bundle is relatively small and lightweight with six components: ceramic pellets, zirconium alloy tubes (with a lubricant coating inside), spacer pads, bearing pads, end caps, and end plates. Each fuel bundle is roughly 
20 inches (in) (50 centimeters $[\mathrm{cm}])$ in length, 4 in $(10 \mathrm{~cm})$ in diameter, and weighs approximately $44 \mathrm{lbs}(20 \mathrm{~kg})$. The fuel used in CANDU reactors has typically been natural uranium fabricated into 37 identical fuel pins arranged about the long axis of the fuel bundle. The newer CANFLEX (CANDU FLEXible fueling) fuel has 43 fuel pins with two pin sizes. It is also about 4 in $(10 \mathrm{~cm})$ in diameter, 20 in $(50 \mathrm{~cm})$ long, and $44 \mathrm{lbs}(20 \mathrm{~kg})$ in weight. The two different pin sizes produce two different power outputs but the same overall bundle output. Special geometry modifications enhance heat transfer between the fuel and the surrounding coolant. The CANFLEX fuel has been designed to provide greater operating and safety margins, extended plant life, and better plant economics (Whitlock 2000, Boczar et al. 2002). The light weight of the CANDU fuel bundles (when compared to LWR fuel) and the use of natural uranium, simplifies manufacturing and handling of the fuel.

For each GWe-year of operation, a HWR produces approximately 53 metric tons heavy metal (MTHM) of SNF. While this mass is approximately 2.5 times greater than the SNF from a comparable LWR, the radiotoxicity of the HWR SNF is less (Canada 2007).

\section{A.4.1.4 High Temperature Gas-Cooled Reactors (HTGRs)}

HTGRs use graphite as a moderator to slow down neutrons and gas circulation to remove heat from the reactor core. The initial development of gas cooled reactors began at the Oak Ridge National Laboratory (ORNL) in 1943 with the air cooled 3.5 megawatts thermal (MWth) X-10 reactor. Power reactor development for purposes of producing electricity began in Great Britain in the 1950s where carbon dioxide was used as a coolant. Magnox reactors were the first plant concepts built and operated in Britain. Twenty-six reactors of this design were constructed and the first of these, Calder Hall, was the first commercial nuclear power plant in the world. Two additional reactors were sold outside of Britain; one to Italy and one to Japan. Four of the British units remain in operation today, but are expected to be shutdown by 2010. Great Britain also developed the advanced gas-cooled reactor (AGR) after the Magnox reactors were deployed. In 2007, there were approximately 14 AGRs in operation (IAEA 2007a, IAEA 2007b).

The development of helium cooled gas reactors began in the 1960s with prototype power plants constructed in the United States, Great Britain, and Germany. Helium coolant allows the gas reactor to achieve higher operating temperatures and therefore higher efficiencies. The $13 \mathrm{MWe}$ AVR (Arbeitsgemeinschaft Versuchsreaktor) in Germany operated successfully for 21 years demonstrating the application of HTGR technology for electric power production. The $300 \mathrm{MWe}$ Thorium High Temperature Reactor (THTR-300) was another plant built and operated in Germany which helped demonstrate the HTGR concept. Both were pebble bed reactors that used U-235 and Th-232 fuel. Pebble bed reactors are fueled by spheres of graphite moderator with small particles of fuel dispersed throughout. These spheres are stacked in a close packed lattice and cooled by helium. The heated helium may then be used to create steam for electricity or drive a turbine generator directly.

HTGR reactors built and operated in the United States included the 40 MWe Peach Bottom plant in Pennsylvania, which went online in October 1974, and the 330 MWe Fort St. Vrain plant in Colorado, which operated from December 1973 to August 1989. Peach Bottom used a round graphite tube arrangement containing fuel particle compacts made from thorium and uranium 
fuel. Fort St. Vrain had a hexagonal (prismatic), graphite block core with thorium and uranium fuel. The fuel in a prismatic core is made of small particles pressed into graphite compacts that are placed into the graphite blocks (Ft. St. Vrain 1). All of the German and U.S. HTGR plants are now shut down.

More recent plants still in operation include the 30 MWth High Temperature Engineering Test Reactor (HTTR) in Japan which reached full power in 1999, and the 10 MWth High Temperature Gas Cooled Reactor (HTR-10) in China that achieved first criticality in 2000. The HTTR uses a hexagonal graphite block core like the U.S. designs. Japan is considering construction of a larger (300 MWe) reactor design (the Gas Turbine Helium Reactor [GTHR]-300) for hydrogen production. China is also considering construction of a larger reactor in the 300 to $400 \mathrm{MWth}$ range for electricity production, district heat production, and generation of process heat. The Chinese reactor would be a pebble bed design like their HTR-10 reactor and use either a steam or direct cycle turbine for electricity production.

A pebble bed modular reactor (PBMR) is being developed for commercial use by an international conglomerate that includes South African based ESKOM (a public utility established by the South African government in 1923). The initial objective of the conglomerate was to design and build a 116 MWe PBMR demonstration reactor in Kroeberg, South Africa around mid-2005. The design has evolved to the point where the preferred module size is now approximately $400 \mathrm{MWth}$, considerably larger than the original concept size. The PBMR is based on the German THTR-300 design, but updated to include passive safety features and modified to drive a Brayton cycle gas turbine. Construction of a single unit prototype demonstration reactor at Kroeberg is now scheduled to begin in 2009 with fuel loading in 2013. The first commercial units could start construction as early as 2016 (Gee 2002, Hargraves 2007).

The Netherlands has conducted studies on a small, simplified version of the South African PBMR called ACACIA (Advanced Atomic Cogenerator for Industrial Applications) for the purpose of heat and power cogeneration. Their reactor is a $40 \mathrm{MWth}$ pebble bed concept with a direct cycle helium turbine that is designed to produce 13.6 MWe. Several institutes and design agencies in the Netherlands, Germany, France, and other European countries are working together in a European HTGR program which is currently focused on fuel development, materials development, and licensing aspects of the HTGR.

The Republic of Korea has shown interest in high temperature applications of HTGR technology; specifically hydrogen production. They are pursuing work on HTGR fuel technology.

DOE has focused substantial resources over the past decade on the Generation IV Nuclear Energy Systems Initiative (Generation IV) wherein new reactor systems are being developed for deployment over the next 20 years. The Next Generation Nuclear Plant (NGNP) is planned to be an advanced nuclear reactor design that can improve upon the current generation of operating commercial nuclear power plants. In addition to producing electricity safely and economically, the NGNP will focus on establishing the feasibility of producing both electricity and hydrogen from a nuclear reactor. DOE is considering the Very High Temperature Reactor (VHTR), an HTGR, as a candidate reactor technology under the NGNP program. 
HTGRs, under the Thermal Recycle (Option 3), are also being considered for the deep-burn (relatively high consumption) of non-uranium based, transuranic fuel derived from LWR SNF, and a representative system is the deep burn modular helium reactor (DB-MHR) concept being developed by General Atomics (Kim et al. 2006, Hong et al. 2007). Under this concept, LWR spent fuel would be recycled in a nuclear fuel recycling facility to remove 99.9 percent of the actinides and 97 percent of the fission products. The removed actinides would then be used to manufacture fuel for a DB-MHR. For this concept, approximately 85 tons (77 MT) of spent LWR fuel would be required to manufacture 1.1 ton (1 MT) of fuel for the DB-MHR (ANL 2005). The essential feature of the concept would be the use of coated fuel particles (known as "TRISO") that are considered strong and highly resistant to irradiation (see Figure A.4.1.4-1). This would enable the fuel to remain in the reactor core for a long irradiation time (a burnup rate of more than $500 \mathrm{GWd} / \mathrm{MTHM}$ ) which would cause a relatively high destruction of the transuranic isotopes by fissions from thermal neutrons. Recent evaluations have indicated that a transuranic destruction level as high as approximately 60 percent is attainable in a single-pass in the DB-MHR system (Kim et al. 2006).

The recycle of spent HTGR fuel in fast reactors is an alternative considered but eliminated from detailed study in this PEIS. Possible approaches include using an additional recycle pass in the DB-MHR (found ineffective) or passing the spent fuel transuranics of the DB-MHR to a fast spectrum system for additional irradiation in a closed fuel cycle. Both cases would require the development of a technology to recycle the TRISO fuel.

Detailed core and plant design and safety studies are needed to confirm the feasibility of the DB-MHR. (One safety attraction is that the DB-MHR response is stable to coolant loss, contrary to LWRs with high transmutation fuel loading.) Additional research and development (R\&D) is also required to develop the non-uranium, transmutation fuel to ensure acceptable performance during irradiation. Other practical issues include the durability of the DB-MHR SNF in a repository setting, and the potentially large quantity of SNF material if fuel blocks are to be disposed in a geologic repository.

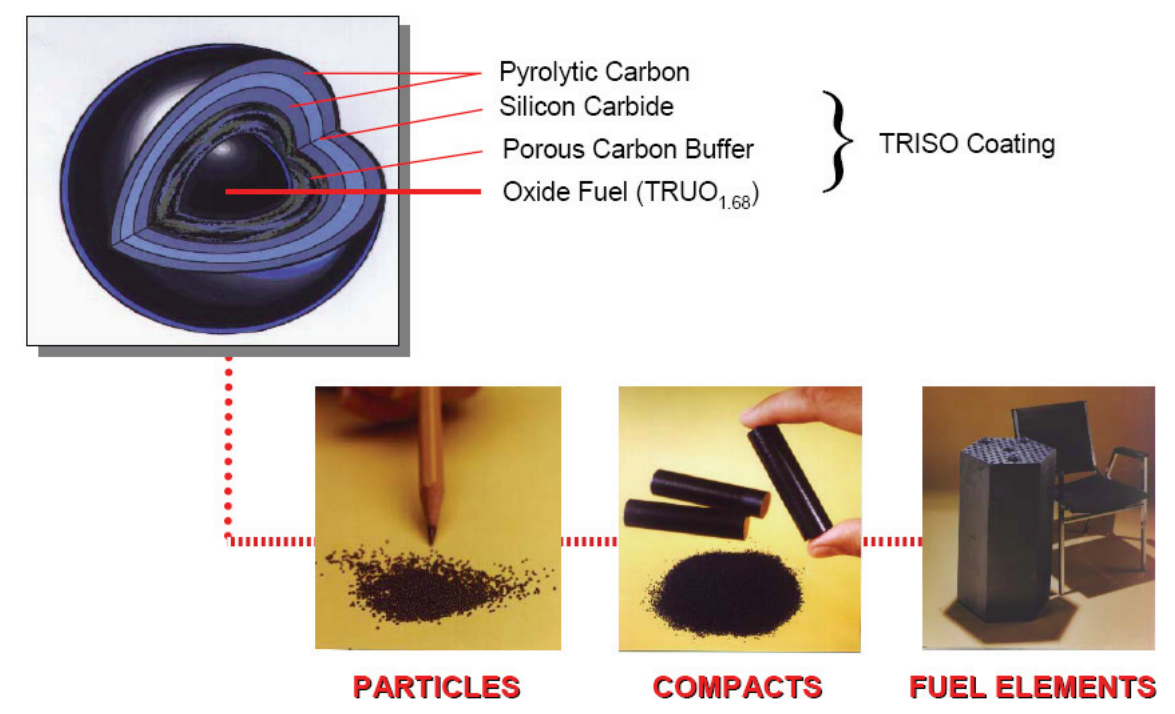

Source: ANL 2005

FIGURE A.4.1.4-1-TRISO Fuel Concept Showing the Fuel Particles, Fuel Compacts, and Fuel Assembly Blocks 


\section{A.4.1.5 Thorium-Fueled Light Water Reactors}

There are a variety of thorium-based fuel concepts that have been previously studied for use in existing LWRs. ${ }^{7}$ The basic idea would be to replace the standard/conventional $\mathrm{UO}_{2}$ fuel assemblies in the LWR with new fuel assemblies that would utilize enriched uranium and thorium. Because thorium does not have any fissile isotopes, its introduction into a reactor must be compensated for by uranium enriched to greater than the conventional level for LWRs (less than 5 percent), but still below the threshold for highly enriched uranium ( 20 percent). Also, the fact that uranium-233 (U-233) would be bred from the thorium requires that additional uranium be present to "denature" ${ }^{8}$ the bred U-233 to keep its concentration below the accepted non-proliferation limits (IAEA 2005a).

Two options that have been examined under the Nuclear Energy Research Initiative funded by DOE appear to offer potential benefits. The two approaches are: the seed-blanket unit, which employs a seed-blanket unit that is a one-for-one replacement for a conventional LWR fuel assembly; and the whole assembly seed and blanket, where the seed and blanket units each occupy one full-size LWR assembly and the assemblies are arranged in the core in a modified checkerboard array (See Figure A.4.1.5-1) (IAEA 2005a).

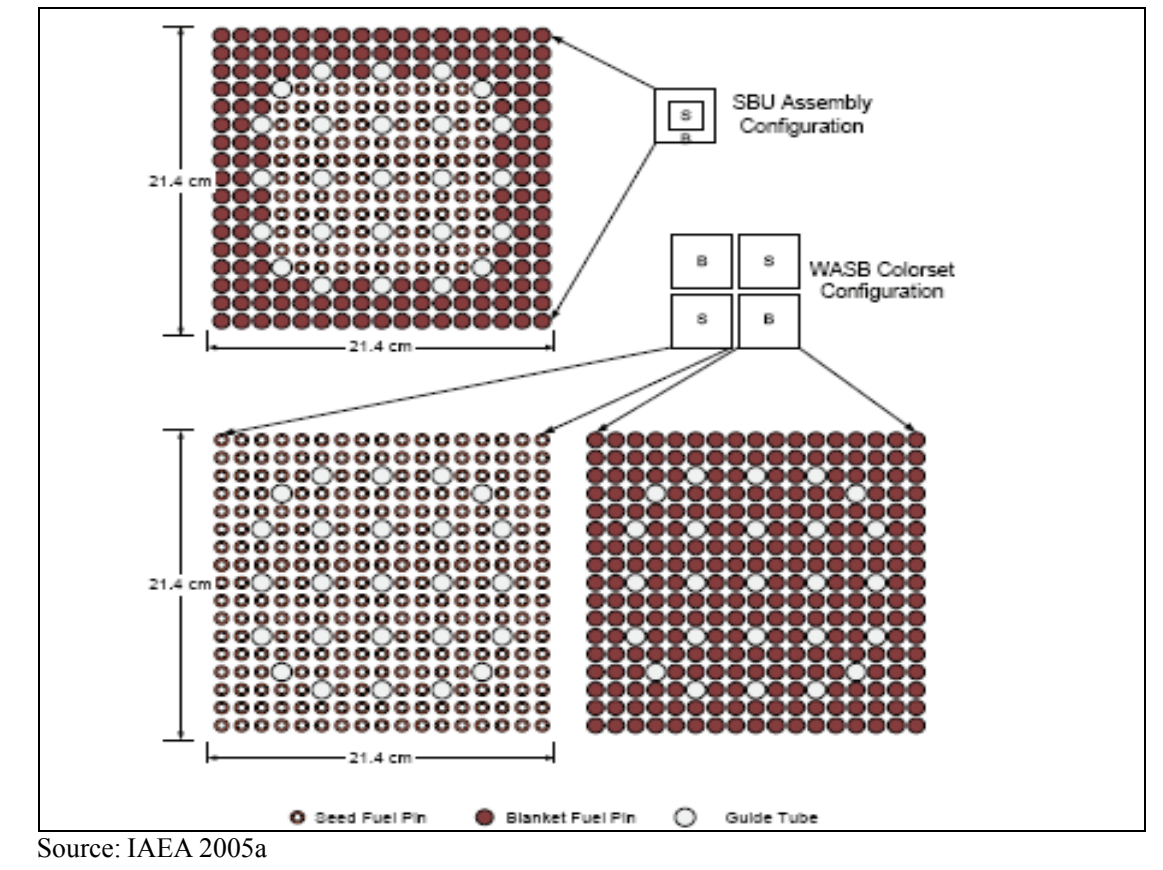

\section{FIGURE A.4.1.4-5—Seed-Blanket Unit and Whole Assembly Seed and Blanket Fuel Assembly Design}

\footnotetext{
${ }^{7}$ See, for example, Todosow 2003: "Use of Thorium in Light Water Reactors," M. Todosow, Brookhaven National Laboratory, Advances in Nuclear Fuel Management III (ANFM 2003), Hilton Head Island, SC, USA, October 5-8, 2003, on CD-ROM, American Nuclear Society, La Grange Park, IL (2003).

${ }^{8}$ In this context, the term "denature" means ensuring that there are enough other non-fissionable isotopes of uranium (such as U-238) to maintain the percentage of U-233 low enough, compared to the total uranium, so that the U-233 would not be a concern from a weapons-usability standpoint.
} 
Full-core implementation of the seed-blanket unit and whole assembly seed and blanket concepts has been considered. All of the fuel assemblies in the reactor are replaced with seed-blanket units or, in the whole assembly seed and blanket approach, with seed or blanket assemblies. In both concepts, the seed and blanket represent approximately 40 and 60 percent of the fuel area, respectively. Because there are distinct thorium-bearing (blanket) and uranium-bearing (seed) regions, separate fuel management schemes for these zones are possible to optimize performance. This approach allows for the efficient generation and in-situ consumption of U-233 in the blanket region of the reactor, with the seed supplying neutrons to the blanket in the most efficient way (i.e., with a minimal investment of uranium). Because the generation of U-233 in the blanket is relatively slow, a long residence time for the blanket is needed for optimal performance. Therefore, the blankets are typically assumed to remain in the core for 6 to 9 fuel cycles. With these long residence times, the blanket will achieve high burnup ${ }^{9}$ (on the order of 100 to $150 \mathrm{GWd} / \mathrm{MTHM}$ ). While the properties of thorium oxide and initial fuel performance analyses suggest that this is possible, acceptable fuel performance has yet to be demonstrated. The seed material would need shuffling similar to conventionally fueled enriched uranium reactors. For each cycle, a third of all seeds in the core would be replaced by fresh seeds, while the remaining two-thirds of the partially depleted seeds would be shuffled to maintain an acceptable power density distribution (IAEA 2002b).

In a seed-and-blanket core, the seeds must sustain power levels that are significantly above average, while the blanket assemblies experience less stressful conditions. Thus, the design of the fuel in the seed rods, and the cooling, must take this into account. These demands can be accommodated in various ways - for example, by allowing more coolant to flow through the seeds, by making the fuel materials less resistant to the flow of heat (increasing the thermal conductivity), or by modifying the fuel geometry. Seed-blanket concepts offer the possibility of producing up to approximately 40 percent of the power by the fission of U-233. This open fuel cycle concept for introducing thorium in nuclear power reactors is very attractive from the point of view of 'in situ' utilization of U-233 and avoiding the handling of U-233 outside of the core $\left(\right.$ IAEA 2005a) ${ }^{10}$. Initial studies have shown that safety and operational parameters and performance would be comparable to those of existing power plants; however, additional studies are needed to demonstrate this (IAEA 2002b). The fuel design would be based primarily on an existing (not necessarily commercial) fuel technology. The maximum allowable initial fuel enrichment would be kept below the non-proliferation limit of 20 percent of the U-235 content, and the combined U-233 and U-235 content in the blanket would also be kept below this non-proliferation limit.

For the higher burnups of the seed-blanket unit approach, analyses of SNF storage and disposal requirements indicate that the discharged fuel mass could be reduced by approximately

\footnotetext{
${ }^{9}$ Burnup is a measurement of the fissile material consumed via fissioning during fuel irradiation. It is normally quoted in either megawatt days per kilogram $(\mathrm{MWd} / \mathrm{kg})$ or gigawatt days per metric ton heavy metal (GWd/MTHM). Typical fuel assemblies in an LWR remain in the core for 3 to 4 cycles and achieve a burnup of approximately 45 to $51 \mathrm{GWd} / \mathrm{MTHM}$.

${ }^{10}$ A special feature of the thorium fuel cycle is the high gamma dose associated with the daughter products of U-232, which is always associated with U-233 and the high specific radioactivity of U-233. Hence, handling of thorium-based SNF require remote and automated operation in hot cells or shielded gloveboxes.
} 
50 percent (IAEA 2002b, Todosow 2003). This reduction indicates a potential for a reduction in the overall SNF storage requirements and associated costs. The total amount of plutonium that would be produced, annually, would be reduced by approximately 3 to 5 times, relative to the existing uranium-based fuel cycle (IAEA 2002b), and the plutonium isotopes would be less attractive as material for potential use in a weapon (IAEA 2005a). The use of Th-232 and highly enriched uranium (HEU) also produces fewer minor actinides than conventional low-enriched uranium (LEU) fuel, thereby reducing the radiotoxicity for the first several thousand years (IAEA 2002b).

\section{A.4.2 Fast Reactors}

In a fast reactor, the neutrons produced by fission are not slowed down significantly before they cause more fission reactions. This contrasts with thermal reactors (e.g., light water reactors, heavy water reactors, and graphite moderated reactors) in which water or graphite is used to slow (or "thermalize") neutrons. Thermal neutrons are more-efficient at producing a fission reaction in a limited number of "fissile" isotopes, whereas the higher-energy (fast) neutrons can fission all types of uranium and transuranic elements. This allows a fast reactor to consume or "transmute" the transuranics while generating electricity. This section describes the sodium-cooled fast reactor that is the representative fast reactor technology analyzed in this GNEP PEIS, elsewhere, this PEIS refers to this technology as the advanced recycling reactor.

\section{A.4.2.1 Sodium-Cooled Fast Reactor}

The sodium-cooled fast reactor is the "fast reactor" technology that has been developed and demonstrated by operational experience in the United States and other countries around the world for over 50 years. Over 25 of these reactors have been built and successfully operated for research purposes and many have produced electricity. Several reactors of this type outside the United States are still in operation. Safe, stable and predictable operation of liquid metal cooled fast reactors has been demonstrated worldwide, resulting in an understanding of the necessary safety requirements, design features, and operating practices.

Although some of these reactors encountered problems including component and fuel failures and coolant fires ${ }^{11}$, none of these problems had an impact to the public. In no case has there been an uncontrolled release of radioactive material, nor has there been any incident that resulted from a fundamental flaw in the concept of the liquid metal cooled fast reactor. Most of the reactors operated successfully and all provided a technology and experience base upon which new fast

\footnotetext{
${ }^{11}$ Two notable sodium cooled fast reactor accidents occurred. The first event took place on October 5, 1966, when the Fermi 1 reactor in Monroe County, Michigan, suffered a partial nuclear core meltdown. The accident was attributed to the interruption of cooling to a portion of the reactor core by a metal plate that had broken loose from a different part of the reactor. Two of the 105 fuel assemblies were partially melted and an additional four assemblies were damaged (GSU 2007). The second event occurred at the MONJU fast breeder reactor in Japan on Dec. 8, 1995, when a temperature measuring device in a pipe carrying sodium broke due to vibration. A subsequent sodium leak and fire occurred. The failure to detect the fire early led to significant sodium leakage and damage to the room where the failure occurred. The accident was caused by a design fault and made worse by the absence of an effective alarm system to notify plant operators (WISE Paris 2007). In the case of the Fermi 1 accident, no radiation was released off site. In the case of the MONJU accident, the leak was not in a radioactive system and therefore no radiation was released. Other reactor accidents, most notably the Chernobyl reactor accident in Ukraine and the Three Mile Island Accident near Harrisburg, Pennsylvania, were water cooled reactor accidents and provide extremely limited applicability to liquid metal reactor designs.
} 
reactors can be designed, built and operated safely. Advanced fast reactor designs continue to be developed by the United States and foreign countries.

Seven liquid metal fast reactors were built and operated in the United States beginning in the early 1950s. An eighth reactor project, the Clinch River Breeder Reactor Project (CRBRP), was initiated in the early 1970s but then terminated in 1983 due to a lack of economic need at that time and the proliferation concerns that were associated with the breeder reactor. Subsequent projects by DOE, including the Integral Fast Reactor project which focused on development of an advanced metallic fuel for the sodium-cooled fast reactor and the Advanced Liquid Metal Reactor which supported the development of the Power Reactor Innovative Small Module (PRISM) liquid-metal reactor by General Electric, resulted in advances in understanding of the characteristics of sodium-cooled fast reactors. By the end of these projects, it appeared feasible to design a sodium-cooled fast reactor that would meet all regulatory and environmental requirements for an advanced nuclear reactor, as evidenced by the PRISM Mod B design that was reviewed by the NRC. Remaining issues were mainly on design and operational choices, not on the fundamental concept of a sodium-cooled fast reactor, as discussed in the Pre-application Safety Evaluation Report (NRC 1994a).

\section{A.4.2.2 Plant Description}

A fast reactor is conceptually similar to a thermal reactor. Both fast and thermal reactors have a reactor core where fuel is used to generate heat by fission. Coolants are used to transfer heat from the reactor core to turbines for electricity generation. A significant difference for the fast reactor is the use of liquid sodium as the coolant for the core. As mentioned previously, coolants like water tend to slow the neutrons. As a result, fast reactors must use a coolant that does not thermalize neutrons and which has sufficient heat transfer capability. A number of high-heat transfer coolants, such as liquid sodium/potassium metal, liquid lead, and liquid lead/bismuth, may be used for this purpose. Even gas has been proposed as a fast reactor coolant. Several of these coolants continue to be studied worldwide however; liquid sodium still appears to be the best choice for a fast reactor coolant.

A significant difference for the sodium-cooled fast reactor is the use of an 'intermediate coolant loop', as shown in Figure A.4.2.2-1. One purpose of the intermediate loop is to isolate the primary coolant loop inside of the reactor vessel from the water and steam loop, because water and sodium react energetically if they come into contact. Under normal circumstances, the piping in the steam generator separates the sodium and water. The use of an intermediate loop is to provide a safety barrier in the event of a failure of the piping in the steam generator so that consequences of a leak in the steam generator piping would be confined to the steam system and the intermediate loop and would not affect the primary loop cooling the reactor core. The intermediate loop also reduces the impact of the activation of the primary sodium coolant, so that activated (radioactive) sodium coolant is retained within the primary vessel and is not transported to other parts of the plant. 


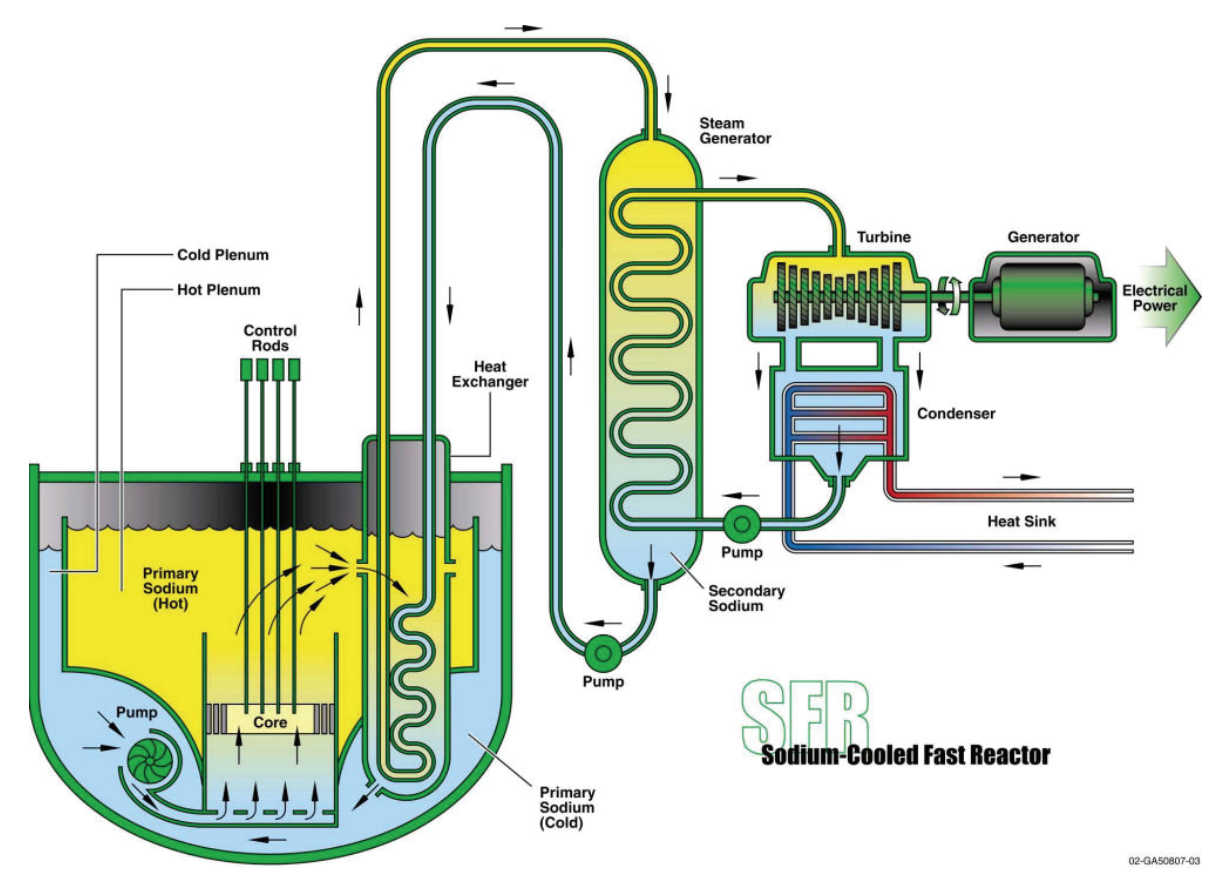

FIGURE A.4.2.2-1—Schematic of a Sodium-Cooled Fast Reactor (Pool-type)

Figure A.4.2.2-1 shows an example of what is called a 'pool-type' reactor because the reactor core and the entire primary coolant loop are contained in a large vessel using a pool of liquid sodium. This design is possible for a fast reactor because, unlike other reactors, the primary coolant loop of a sodium-cooled fast reactor operates at or near atmospheric pressure. A fast reactor can also be designed to be a 'loop-type' reactor, in which the primary loop reactor components are all connected by piping, as is done for light-water reactors, or as a combination of the two types. At this time it appears that it would be possible to design a successful sodium-cooled fast reactor with any of these design approaches.

\section{A.4.2.3 Reactor Fuel}

Fast reactor fuel is not necessarily the same as that used in a light water reactor. Although fast reactor fuel may be in oxide-form, it alternatively may be in metal, carbide, and nitride-form. If uranium fuel were used in a fast reactor, higher enrichment than for fuel used in a thermal reactor would be required, which would result in significant additional costs for preparing the fuel. Instead, fast reactors have been typically designed to operate with a fuel that is a mixture of natural uranium with about 15-30 percent plutonium. In the past, the focus had been on using the fast reactor to 'breed' more plutonium from natural uranium. In a "breeder reactor," more nuclear fuel is produced (by "transmuting" natural uranium) than was consumed in running the reactor. As a result, there is more plutonium in the reactor than was used in the fuel initially, essentially making more usable fuel. More recently, the effort has been on a different use for the fast reactor: to "consume" the transuranic materials from spent nuclear fuel to generate electricity as part of a closed fuel cycle. Fuel for this type of fast reactor is composed of a mixture of natural uranium and approximately 20-35 percent transuranic elements. The transuranic content may be higher depending on the desired rate of consumption of the transuranic elements. This configuration of a fast reactor is commonly referred to as a 'burner' 
reactor because it does not produce more fuel than it uses, and allows the fast reactor to "consume" transuranic elements, which are typically a major concern in the disposal of spent nuclear fuel.

Fast reactor fuel is contained in fuel pins with metallic cladding in a manner similar to light water reactor fuel, but the cladding is usually stainless steel instead of zircaloy. Groups of fuel pins are housed in stainless steel ducts of hexagonal cross-section called "hexcans." A hexcan with fuel pins inside is the fuel assembly for the fast reactor. The hexcans are used to channel coolant flow to all of the fuel pins in the assembly. The reactor core is constructed from a large number of these fuel assemblies. The number of fuel assemblies required for a fast reactor is determined by the desired reactor power output.

The amount of SNF produced from reactor operations is a function of cycle length, or time between shutdowns for refueling. In large fast reactors (typically greater than 1,000 MWth), the cycle length would be targeted at 1 year in order to minimize plant down time and increase the amount of time the reactor is operating (capacity factor). The target cycle length would be optimized based on the function of the reactor. An advanced recycling reactor, for example, could be designed primarily to optimize destruction of transuranic elements. This would be different from current LWRs, which are optimized for power production.

\section{A.5 REPROCESSING TECHNOLOGIES}

This section presents technical descriptions of various SNF separation processes that could be candidates for future use to separate LWR and fast reactor SNF. The two primary SNF separation processes, aqueous and electrochemical, are described. ${ }^{12}$ For further comparison information on aqueous and electrochemical processing, please refer to the WSRC 2008 Report (WSRC 2008a).

\section{A.5.1 Aqueous Processing}

Aqueous chemical treatment of various types of SNF has been practiced on a commercial scale in a number of countries. For example, PUREX was developed by the United States in the late $1950 \mathrm{~s}$ and is in active use on a commercial scale in France, Japan, Russia, and the United Kingdom. However, as previously mentioned, the PUREX process separates pure plutonium, which is a proliferation concern. One of the objectives of AFCI is to develop, demonstrate, and deploy advanced technologies for recycling SNF that do not separate plutonium, with the goal over time of ceasing separation of plutonium and eventually eliminating excess stocks of civilian plutonium and drawing down existing stocks of civilian SNF (DOE 20071). Examination of different aqueous processing technologies will include the requirement that SNF should only be

\footnotetext{
${ }^{12}$ In addition to the PUREX, COEX, NUEX, OREOX, and UREX processes, other processing technologies exist including: 1) Supercritical $\mathrm{CO}_{2}$ which is a solvent extraction method that employs supercritical $\mathrm{CO}_{2}$ with tributyl phosphate (TBP), similar to PUREX but without the organic diluent; and 2) UNEX which is the Universal Extraction process designed to remove all of the most troublesome radioisotopes ( $\mathrm{Sr}$, Cs, and minor actinides) from the HLW left after the extraction of uranium and plutonium.
} 
processed using a technology, consistent with U.S. policy, that would not result in a civilian nuclear fuel cycle producing separated plutonium.

Aqueous processing generates several types of waste streams. Gaseous wastes are generated from shearing and dissolution, vessel vents, and high activity liquid waste vitrification. Gaseous emissions must be treated and resulting wastes disposed of properly. Treatments include, but are not limited to, $\mathrm{NO}_{\mathrm{x}}$ scrubbing columns, iodine filters, mist filters, HEPA filters, condensers, and ruthenium absorption columns. The type of treatment depends on the gas composition.

Liquid LLW would also require treatment. Liquid LLW consists of low activity evaporator overheads, washroom water, laundry drains, equipment drains, water inside casks, floor drains, etc. The treatment processes used could include evaporation, solvent removal, filtration, solidification, and desalination. Once in a solid form, this LLW would be packaged in accordance with all applicable requirements and transported to an appropriate LLW management or disposal facility.

Liquid HLW must be treated to a solidified, leach-resistant waste form suitable for disposal in a geologic repository. Storage and cooling of the solidified HLW package, and packaging in accordance with all applicable requirements would be necessary prior to shipment to a geologic repository. To address concerns prompted by historical releases of liquid HLW from underground storage tanks, DOE would not support any long-term storage of liquid HLW.

In addition to the waste streams mentioned above, additional solid wastes would be generated as a result of aqueous processing. Greater-Than-Class-C (GTCC) low-level wastes, including those containing transuranics, may require treatment prior to packaging for disposal in a facility designated for such wastes. Other waste streams that would require management are solid LLWs, hazardous wastes, sanitary waste streams, and industrial waste streams.

\section{PUREX}

All of the currently operating reprocessing facilities use the PUREX process. The PUREX process (Figure A.5.1-1) is a proven technology that has been used by DOE since the 1950s and that has been used by U.S. commercial industry; ${ }^{13}$ however, it does not meet the GNEP program proliferation resistance goal because it separates pure plutonium.

\footnotetext{
${ }^{13}$ See Chapter 1 for a discussion of the history of reprocessing in the United States.
} 


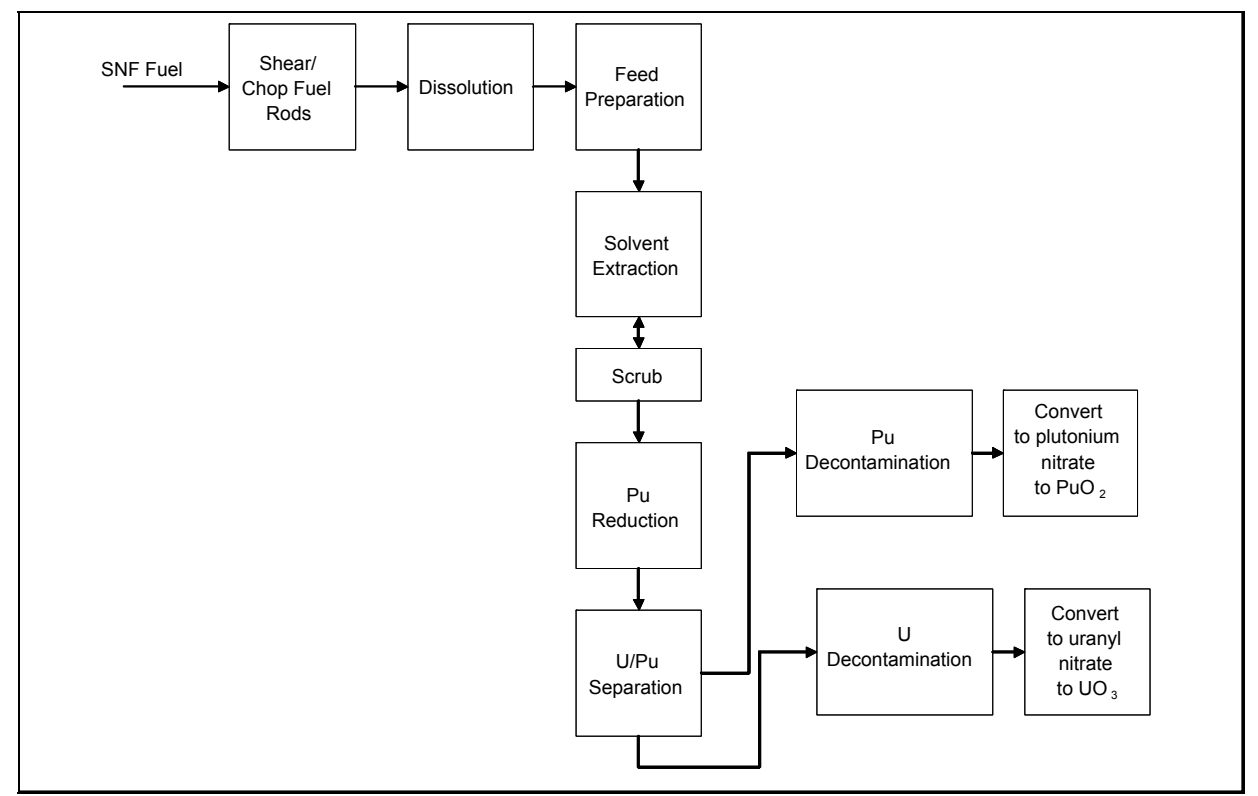

\section{FIGURE A.5.1-1—Plutonium Uranium Reduction and Extraction Flow Diagram}

The PUREX process was modified for the Japanese facility (Rokkasho), which is undergoing operational tests. In this process, some of the uranium product is blended with the plutonium (at a nominal 50:50 ratio) before the MOX product is sent to the fuel fabrication facility. The remaining uranyl nitrate solution produced by the PUREX process is converted to $\mathrm{UO}_{3}$ for storage (Figure A.5.1-2).

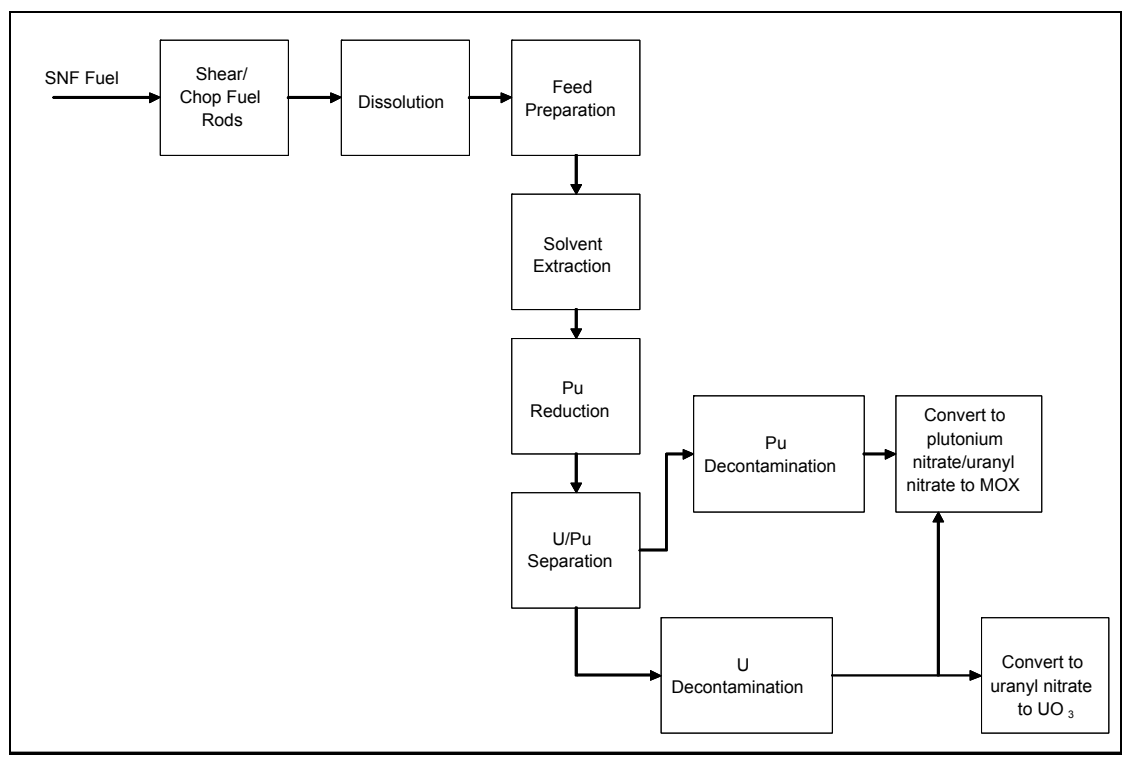

FIGURE A.5.1-2—Rokkasho Flow Diagram 


\section{$\operatorname{COEX}^{\circledR}$ and NUEX ${ }^{\circledR}$}

The French have developed a uranium-plutonium co-extraction process, COEX $^{\circledR}$, which is similar to the Rokkasho process, but does not produce a separated plutonium stream anywhere in the process line.

NUEX $^{\circledR}$ is a proprietary co-extraction technology developed by the British, and licensed to EnergySolutions, Inc. Like COEX ${ }^{\circledR}, \mathrm{NUEX}^{\circledR}$ produces a uranium-plutonium product stream and has no separated pure plutonium anywhere in the process line. It also separates the minor actinides.

Because both the COEX ${ }^{\circledR}$ and NUEX ${ }^{\circledR}$ processes are proprietary technologies, less information is publicly available for these separation processes than the PUREX and Uranium Reduction and Extraction (UREX) technologies presented in this section. However, because the COEX ${ }^{\circledR}$ and NUEX $^{\circledR}$ processes use similar processes to PUREX and UREX, the environmental impacts (e.g., emissions, radiation dose to workers, and wastes) would not be expected to differ significantly.

\section{UREX}

In the past few years, DOE has made significant advancements in SNF processing technology R\&D that has both important environmental and proliferation-resistant advantages over PUREX. This processing technology is known as UREX+ (for uranium extraction).

In the UREX+ process, plutonium, other transuranics, and fission products are extracted together in a single stream from which the transuranics could be extracted for reuse in nuclear fuel. The UREX+ reprocessing flowsheet differs from the PUREX reprocessing flowsheet in that plutonium is never isolated in the UREX+ scheme as it is in the PUREX scheme. Other actinide elements are kept with the plutonium and do not enter the HLW waste stream. This makes the material more difficult to use in a weapon. Additionally, because UREX+ does not place these actinides in the waste stream, there could be a reduction in the amount and activity levels of the HLW produced.

The analysis in this PEIS is based on a variation of the UREX+ process referred to as UREX+1a. Although UREX +1 a has not been used on a large scale, it is used as a representative process in this PEIS because it draws upon a wider body of knowledge available on aqueous processing, and incorporates advanced separations technology features based on UREX+1a R\&D work done to date. It also does not result in the separation of pure plutonium. The UREX+1a process leads to: a uranium stream, transuranic streams comprised of plutonium and other transuranic elements, and other streams comprised of fission products. Table A.5.1-1 lists other UREX+ separation variations. Depending on the number and types of separation processes employed, different products can result. For example, UREX +2 adds a step to separate plutonium and neptunium from the other transuranics (americium and curium). There is also an option to coextract uranium and plutonium in one step instead of several extraction steps. 
TABLE A.5.1-1-Uranium Reduction and Extraction Separations Processes

\begin{tabular}{|c|c|c|c|c|c|c|c|}
\hline Process & Product 1 & Product 2 & Product 3 & Product 4 & Product 5 & Product 6 & Product 7 \\
\hline UREX+1 & $\bar{U}$ & Tc & $\mathrm{Cs} / \mathrm{Sr}$ & TRU+Ln & F.P. & & \\
\hline UREX+1a & $\mathrm{U}$ & Tc & $\mathrm{Cs} / \mathrm{Sr}$ & TRU & All F.P. & & \\
\hline UREX+2 & $\mathrm{U}$ & $\mathrm{Tc}$ & $\mathrm{Cs} / \mathrm{Sr}$ & $\mathrm{Pu}+\mathrm{Np}$ & $\mathrm{Am}+\mathrm{Cm}+\mathrm{Ln}$ & F.P. & \\
\hline UREX+3 & $\mathrm{U}$ & $\mathrm{Tc}$ & $\mathrm{Cs} / \mathrm{Sr}$ & $\mathrm{Pu}+\mathrm{Np}$ & $\mathrm{Am}+\mathrm{Cm}$ & All F.P. & \\
\hline UREX+4 & $\mathrm{U}$ & Tc & $\mathrm{Cs} / \mathrm{Sr}$ & $\mathrm{Pu}+\mathrm{Np}$ & $\mathrm{Am}$ & $\mathrm{Cm}$ & All F.P. \\
\hline
\end{tabular}

Figure A.5.1-3 presents a block flow diagram of the basic UREX+ aqueous reprocessing technology. As can be seen from that figure, LWR SNF is chopped and then dissolved in nitric acid. The solution from the dissolver is clarified to remove any particulate material and then it goes into the first solvent extraction process which is called UREX. The process uses tributyl phosphate, the same extractant used in PUREX, but by adding acetohydroxamic acid, it does not extract plutonium. This process also does a very efficient job of extracting the technetium along with the uranium.

Next, the technetium is separated from the uranium using an ion exchange column. The next step is to extract the technetium from the resin, convert it to a zirconium alloy and combine it with the cladding hulls and the sludge from the dissolver to produce a metallic waste form. This is done in order to place technetium in a large mass of zirconium, thus it would remain in the metallic state rather than in the oxide state. The technetium, which has a relatively low solubility in the metal state, would then be less likely to migrate to groundwater and would be less mobile in a geologic repository. This could reduce potential dose-related issues for technetium with respect to a geologic repository with an oxidizing environment.

The uranium extracted in the UREX process is converted to an oxide and stored in a highly purified state. This uranium can be stored without any shielding requirement for radiation protection.

The next step is to extract the cesium (Cs) and strontium ( $\mathrm{Sr}$ ) (along with rubidium $[\mathrm{Rb}]$ and barium [Ba]) from the UREX process waste stream. Multiple alternatives for disposing of a separate $\mathrm{Cs} / \mathrm{Sr}$ waste stream might be considered. Under one alternative, the $\mathrm{Cs}$ and $\mathrm{Sr}$ would be stabilized and placed into decay storage for up to 300 years.

Next, the raffinate from the $\mathrm{Cs} / \mathrm{Sr}$ separation process is transferred to the Transuranic Extraction Process (TRUEX). TRUEX is a well-developed process that is used in commercial applications. The TRUEX process extracts transuranic elements and lanthanides (rare earth fission products). 


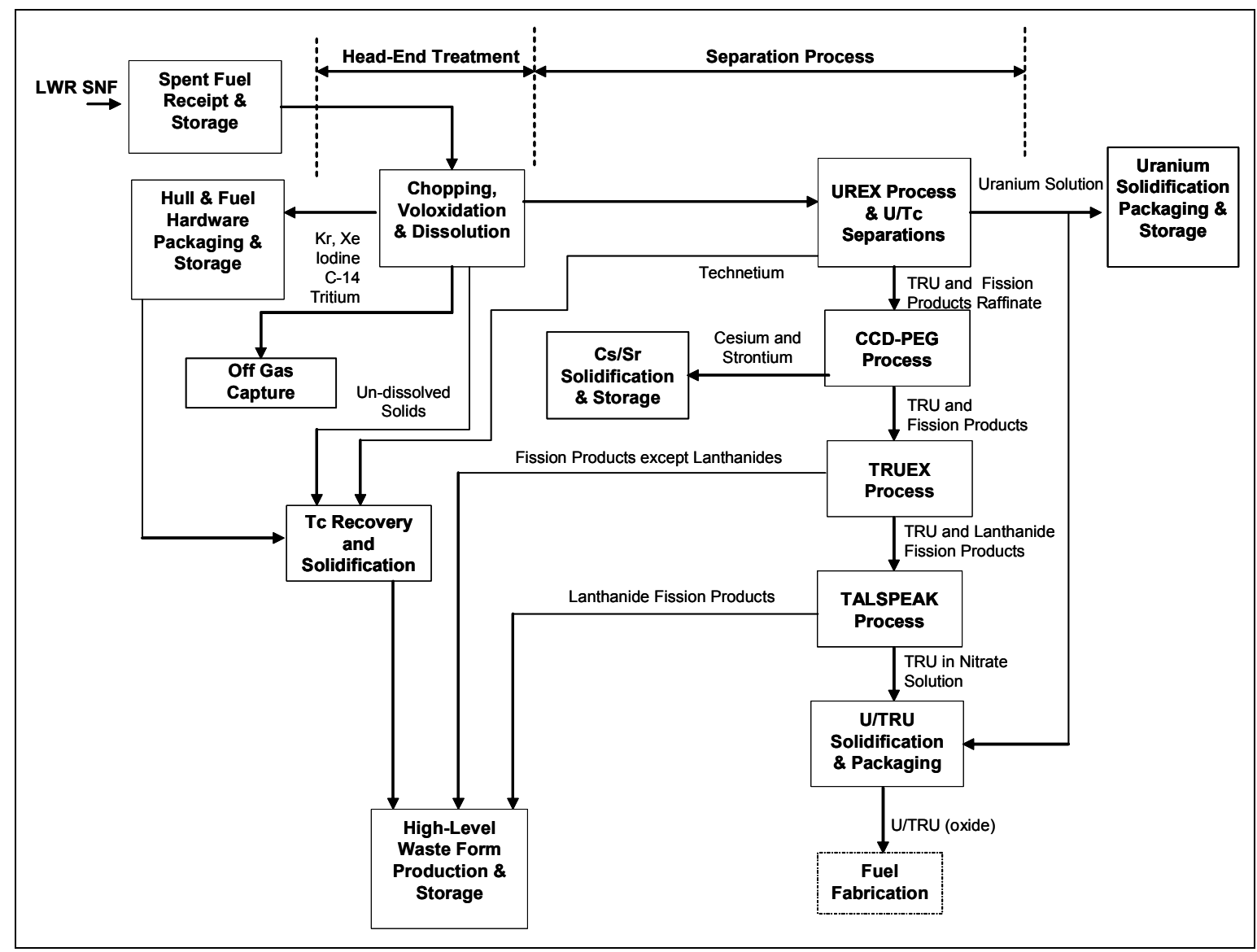

Source: WSRC 2008a

Note: $\mathrm{Kr}$ - Krypton; Xe - Xenon; C-14 - Carbon-14; UREX - Uranium Reduction and Extraction; Tc - Technetium; Cs - Cesium; Sr Strontium; CCD-PEG - Chlorinated Cobalt Dicarbollide/Polyethylene Glycol; TRUEX - Transuranic Extraction; TALSPEAK - Trivalent Actinide Lanthanide Separations by Phosphorusreagent Extraction from Aqueous Complexes; U - Uranium; TRU - Transuranics

\section{FigURE A.5.1-3-Uranium Reduction and Extraction Process Aqueous Reprocessing Technology Flow Diagram}

The TRU/lanthanide product from the TRUEX process is then transferred to the Trivalent Actinide Lanthanide Separations by Phosphorusreagent Extraction from Aqueous Complexes (TALSPEAK) process which is used to separate lanthanides from the transuranics. The lanthanides become part of the HLW stream. The transuranics then go to a step in which part of the uranyl nitrate solution from the UREX process is blended with the aqueous transuranic stream from the TALSPEAK process, which is then sent to the fuel conversion process where the liquid stream is converted to oxides. If the recycled fuel becomes an oxide, then the separation process is complete. If the fuel becomes metallic, then the oxides have to be reduced to metals. Finally, the oxides or metal go into fuel fabrication.

\section{Aqueous Separations Waste Processing}

There are three main waste streams generated from the UREX process: technetium (Tc), Cs/Sr, and fission products (including lanthanides). These are discussed below.

Technetium Recovery and Immobilization: As previously discussed, recovered metallic technetium would be alloyed with a portion of the fuel hulls and hardware to produce a metallic 
waste form that would immobilize the technetium. This HLW form would be packaged for onsite storage (assumed up to the end of facility life) awaiting shipment to a geologic repository for disposal.

Cs/Sr Solidification: The Cs/Sr solution would be evaporated and subsequently solidified. The current baseline process would be to stabilize the components with additives to produce a solid waste form. One option is to store this waste for up to 300 years (at the site of the facility or a different location) to allow sufficient decay to reduce radiation and thermal output, then the $\mathrm{Cs} / \mathrm{Sr}$ solid waste form would be disposed of in an appropriate facility. Another option for Cs/Sr would keep it with the fission product/lanthanide stream and make it into a borosilicate glass suitable for disposal in a high-level waste geologic repository.

Fission-Product/Lanthanide Solidification: The fission product waste streams from TRUEX and lanthanides from TALSPEAK separations processes must be treated to a solidified, leach-resistant waste form suitable for disposal in a HLW geologic repository. Storage and cooling of the solidified HLW package would be required prior to shipment to the geologic repository (WSRC 2007d).

The UREX+ suite of processes offer several options for dealing with the transuranics. Because of their high radioactivity and decay heat, some of the minor actinides may not prove suitable for transmutation fuels and may be placed in the waste streams with the fission products. Development of stable waste forms for transuranic bearing wastes is being evaluated in the AFCI R\&D program.

\section{A.5.2 Electrochemical Separations}

Electrochemical separations employs a molten salt electrorefiner to treat SNF. Electrochemical processing extracts two products, uranium by itself and uranium with all the transuranic elements together. It also produces several waste streams. Electrochemical processing has been in use for many years for purification of materials, including plutonium (Avens and Eller 2000). Electrochemical processing is a candidate process for recycling both fast reactor oxide and metal SNF and LWR oxide SNF. It was selected as the preferred method to treat 27.5 tons (25 MT) of DOE sodium-bonded metal fuel from Experimental Breeder Reactor-II (EBR-II) and Fast Flux Test Facility (FFTF) (DOE 2000e). Development tests for its application to LWR oxide fuel have been conducted at ANL and Idaho National Laboratory (INL) under the AFCI program, as well as DOE programs that preceded AFCI.

Figure A.5.2-1 presents a simplified block flow diagram of the basic process of electrochemical processing technology. This figure depicts an electrochemical process for both oxide and metal based fuel. The process is simpler for a metal based SNF because voloxidation and electroreduction would not be needed. The individual steps in the electrochemical treatment process are described below. 


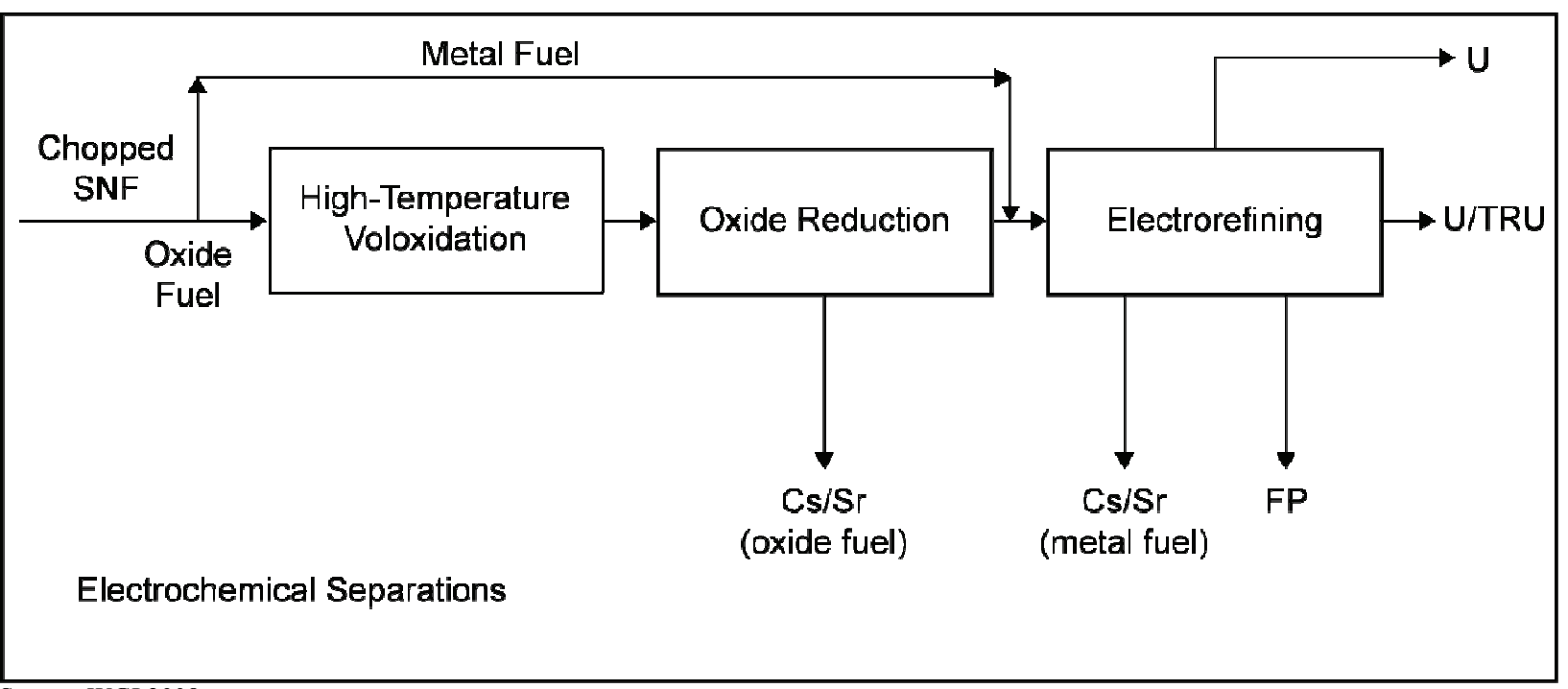

Source: WGI 2008a

Note: FP = fission products

FIGURE A.5.2-1—Simplified Schematic Block Flow Diagram of Electrochemical Separations

Disassembly and Fuel Element Chopping: The fuel elements that contain uranium and fission products are separated from the assembly hardware by cutting the assemblies and physically separating the fuel elements. The fuel elements are cut into small pieces and transferred to the voloxidation step. The assembly hardware is packaged for storage and disposal. This metal waste is remotely handled due to presence of highly radioactive activation products.

Voloxidation: To process oxide fuel through the electrorefiner, it must first be converted to metal using a combination of voloxidation and electrolytic reduction. Voloxidation, a process where the fuel is exposed to oxygen at elevated temperatures, converts $\mathrm{UO}_{2}$ to triuranium octaoxide $\left(\mathrm{U}_{3} \mathrm{O}_{8}\right)$, causing it to expand, break into small pieces, and separate from the cladding. Gaseous and volatile fission products are released to an off-gas capture system during this process. The fuel pieces are placed in porous metal baskets that become cathodes (negative electrodes where reduction of oxides to metals occurs) in the electroreduction step.

Electrolytic Reduction: Both metallic and oxide fuel could be treated in the electrorefining process. For oxide fuel, the separated oxide fuel particles must first be converted to metal by electrolytic reduction in a molten lithium chloride $(\mathrm{LiCl})$ salt, releasing oxygen in the process. $\mathrm{Cs}, \mathrm{Sr}, \mathrm{Ba}$, and $\mathrm{Rb}$ form chlorides and accumulate in the salt. Periodically they are removed via zeolite ion exchange and the cleaned salt is reused. The zeolite containing the $\mathrm{Cs}, \mathrm{Sr}, \mathrm{Ba}$, and $\mathrm{Rb}$ is converted to a stable waste form and packaged for disposal. Gaseous and volatile fission products are released to an off-gas capture system during this process. The now metallic SNF is treated in the electrorefining process.

Electrorefining: The electrorefiner is where the main separation processes occur (Figure A.5.2-2). An electrorefiner is a heated steel vessel that contains a molten mixture of salts, primarily lithium chloride, potassium chloride, and uranium trichloride. It has two or more electrodes: one or more anodes (positive electrodes where oxidation occurs) and one or more 
cathodes (negative electrodes where reduction occurs). The anodes are the baskets from electroreduction that hold the reduced SNF pieces, and each cathode consists of bare steel rods, where uranium metal is collected.

Upon application of an electric current between the anodes and cathodes, uranium is oxidized to ions at the anode and uranium ions are reduced and deposited as metal at the cathode. Plutonium, other transuranic elements, and the remaining active metal fission products are oxidized into the salt by chemical reactions that deplete the uranium chloride concentration by reducing uranium ions to metal at the fuel baskets. Solid dendritic uranium is deposited at the cathode until all the uranium in the anode baskets is oxidized. Then the uranium cathode product is raised into the gas space in the electrorefiner to allow molten salt to drain, although some salt adheres to the product. The cathode product is then removed from the electrorefiner. Uranium trichloride, produced by chlorinating some of the uranium product, is periodically added to the electrorefiner to replace the uranium reduced by the chemical reactions involving fission products and transuranics.

The cladding hulls and noble fission products remain undissolved in the anode baskets. They are removed from the electrorefiner and melted into waste-form ingots. The reactive fission products and transuranic elements accumulate in the electrorefiner salt. Additional electrorefining or electrolysis steps separate the transuranics from the reactive fission products.

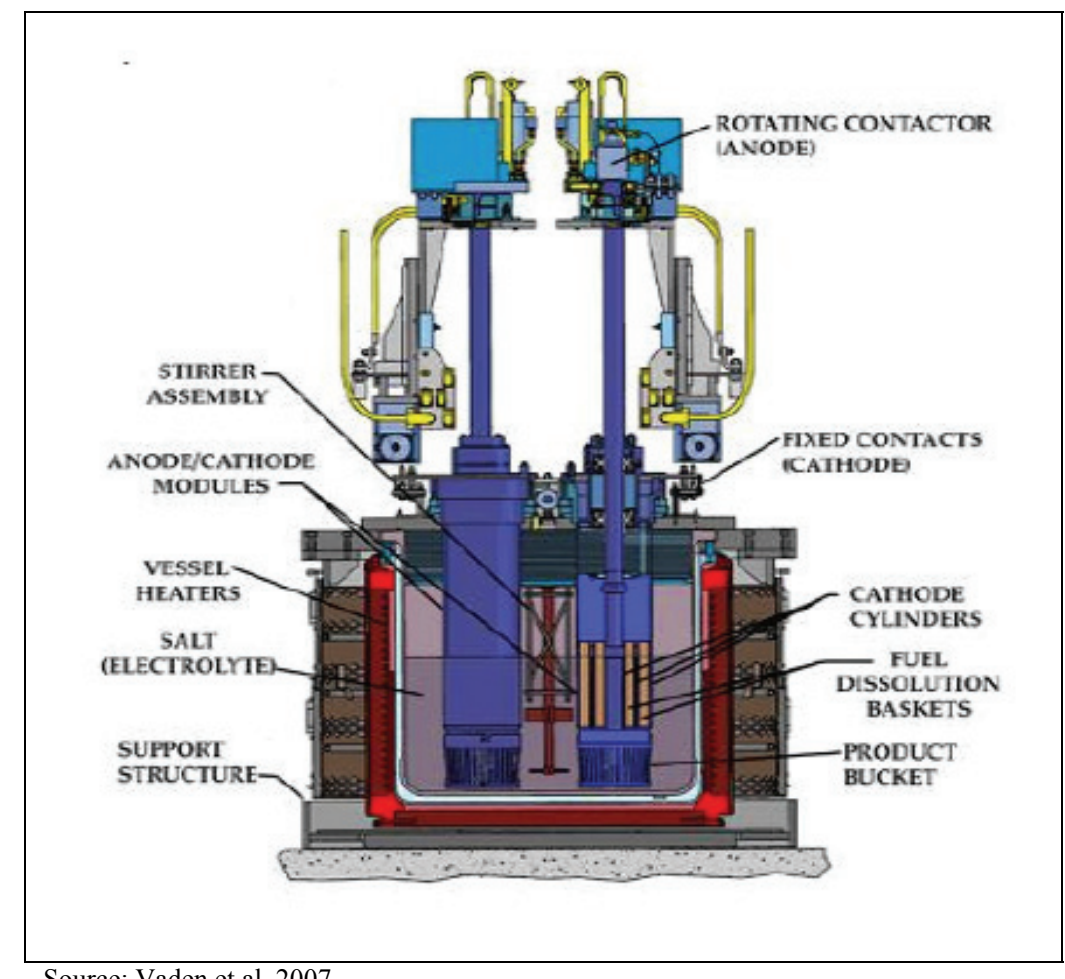

FigURE A.5.2-2-Diagram of Electrorefiner Used to Treat Experimental Breeder Reactor-II Fuel at INL

U/TRU Recovery: An electrolysis or electrorefining process is used to recover the uranium and transuranics as a mixed uranium/transuranic (U/TRU) metal product with some lanthanides. 
Following U/TRU recovery the salt is further processed to remove the remaining lanthanides and other fission products. The salts are recycled back to the electrorefiner and the fission product waste is converted to a glass-bonded ceramic for disposal.

Cathode Processing: The uranium and uranium-transuranic products are removed from the electrorefiner and treated to remove any adhering salt in the cathode processor, which is a specially designed retort furnace equipped with a vacuum system. The cathode product is heated under vacuum, separating the salt by distillation and melting the remaining metal into an ingot. The salt is recycled back to the electrorefiner.

In summary, electrochemical separations would produce two products and generate five waste streams from the processing of SNF. The two products would be a uranium metal and a U/TRU metal, which would be used for fabrication of fuel for the advanced recycling reactor. These metals can be converted to oxide and stored or kept in metal form. The five waste streams would be assembly hardware, fission-product off-gases, $\mathrm{Cs} / \mathrm{Sr}$ salt, cladding metal, and fission product salt wastes. The assembly hardware and off-gases would be stabilized and packaged for disposal using established radioactive waste treatment methods. The $\mathrm{Cs} / \mathrm{Sr}$ combined with the zeolite would be converted to a glass-like form and disposed of in a geologic repository or stored until it had sufficiently decayed for disposal at a LLW facility. The metal wastes would be converted to ingots and packaged for onsite storage awaiting shipment to a geologic repository for disposal. The fission product waste would be solidified in a glass matrix, packaged, and stored onsite awaiting shipment to a geologic repository.

\section{A.5.3 Oxidation and Reduction of Oxide Fuel (OREOX) Process}

The Thermal Reactor Recycle Alternative (Option 2) could utilize a dry recycling technology. This technology includes mechanical removal of the cladding followed by a thermal process to reduce the spent LWR fuel to powder, which is then sintered, and pressed into CANDU-sized pellets. This separation and fuel fabrication process has been termed the Oxidation and Reduction of Oxide Fuel (OREOX) process (Yang et. al. 2005). Because the OREOX process is part of a South Korean program, in a research stage, only open literature publications are available. Consequently, there is less information available for this fuel separation technology than many of the other technologies presented in Section A.5. However, because the OREOX process only uses mechanical and thermal processes (which are similar to the front end step used in both the aqueous and electrochemical separation processes), it is expected that the environmental impacts (e.g., emissions, radiation dose to workers, and wastes) would not be greater than those from other processes described above. While the OREOX process employs mechanical processes and a detailed process design must still be developed, the potential exists for the introduction of liquids for decontamination, process cleanup, or similar secondary operations. In the event liquids are used in this process and small quantities of liquid HLW are generated, appropriate treatment processes would be included to solidify these wastes such that no liquid HLW would be accumulated or require long term storage. Fuel fabrication is addressed in the following paragraphs.

The Korea Atomic Energy Research Institute (KAERI) has fabricated DUPIC fuel elements in a laboratory-scale remote fuel fabrication facility. KAERI has demonstrated the fuel performance 
in a research reactor, and has confirmed the operational feasibility and safety of a CANDU reactor loaded with the DUPIC fuel using conventional design and analysis tools, which will be the foundation of the future practical and commercial uses of DUPIC fuel (Yang et al. 2005). Figure A.5.3-1 depicts the DUPIC fuel fabrication process using OREOX.

A DUPIC Fuel Fabrication Facility would consist of the following five processes:

PWR Spent Nuclear Fuel Receiving and Storage: The LWR SNF would be transported to the DUPIC facility in a standard LWR SNF transport cask.

Spent Nuclear Fuel Disassembly and Decladding: The LWR SNF rods would be mechanically removed from the LWR fuel assembly. The fuel assembly structural material would be transferred to the solid waste treatment area and stored after going through the volume reduction and packaging process. The fuel rods would be punctured, chopped, or cut (depending on the specific technique selected) into an appropriate size by a mechanical and/or laser cutting method, and the oxide fuel material and cladding would be mechanically separated. The fission gases released in this process would be sent to the off-gas treatment system and would be stored. The cladding material would be cleaned and decontaminated for more than a 99 percent recovery of the fuel material.

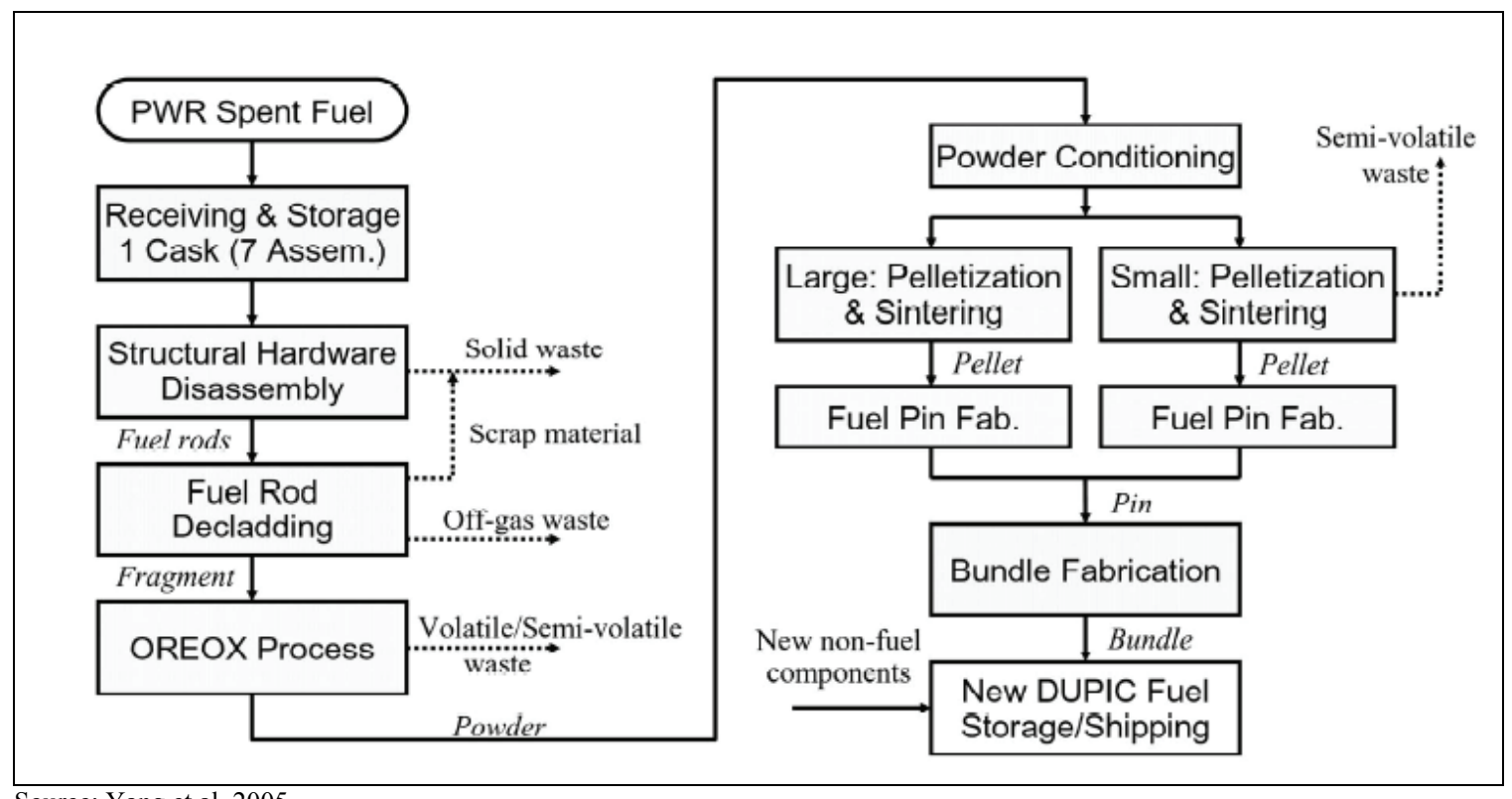

Source: Yang et al. 2005

Figure A.5.3-1—Direct Use of Spent Pressurized Water Reactor Fuel in Canada Deuterium Uranium Fuel Fabrication Process Using Oxidation and Reduction of Oxide Fuel

Fuel Powder Preparation: The LWR SNF materials would be treated by the OREOX process to form fuel powder that satisfies the powder characteristics requirements. The OREOX process consists of multiple (typically three) cycles of oxidation at $930^{\circ} \mathrm{F}\left(500^{\circ} \mathrm{C}\right)$ with air followed by reduction at $1,300^{\circ} \mathrm{F}\left(700^{\circ} \mathrm{C}\right)$ with hydrogen. OREOX processing removes the bulk (greater than 85 percent) of the volatile fission products (tritium, iodine, krypton/xenon, and carbon-14 [C-14]). The semi-volatiles (Cs and transition metals) are less affected by OREOX but are still 
partially (less than 50 percent) removed. A disposition path for these fission products would be required for their disposal/storage. Figure A.5.3-2 depicts the process of fabricating DUPIC fuel.

Fuel Pellet Fabrication: The DUPIC fuel pellets would be produced from the LWR SNF powder through the pre-compaction, granulation, final compaction, sintering, and the grinding processes.

Fuel Element Fabrication: The fuel pellets would be loaded into the cladding tube manufactured outside the hot cell and the end cap would be welded to form a fuel element. These fuel elements would then be bundled into fuel bundles and the fresh DUPIC fuel would be transported to a CANDU reactor. Although a fraction of the gamma radioactivity would be removed from the recycled fuel, gamma radioactivity would still be high enough to require all refabrication and handling to be done remotely in a shielded facility (Yang et al. 2005).

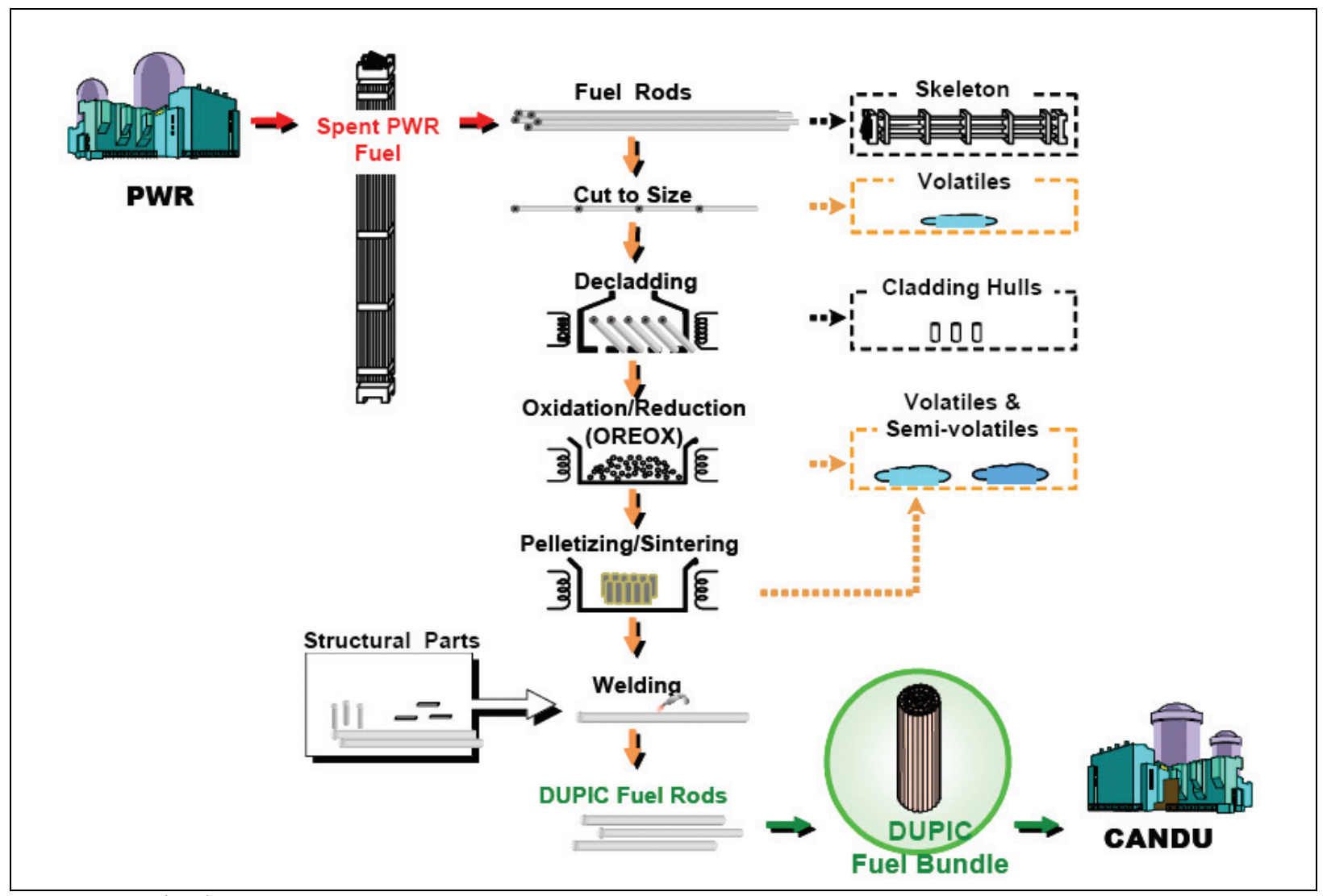

Source: Yang and Park 2006

Figure A.5.3-2—Direct Use of Spent Pressurized Water Reactors Fuel in Canada Deuterium Uranium Fuel Fabrication Process 


\section{A.6 Nuclear Fuel Recycling Centers}

Nuclear fuel recycling centers associated with the Fast Recycle Alternative, Thermal/Fast Recycle Alternative, and Thermal Recycle Alternative (options 1 and 3) could be comprised of as many as three individual components: 1) a LWR SNF separations facility; 2) a fuel fabrication facility for transmutation fuel and/or MOX-U-Pu fuel ${ }^{14}$; and 3) a separations facility for SNF from a fast reactor and/or MOX-U-Pu LWR ${ }^{15}$. These components would not necessarily all be in the same location. A nuclear fuel recycling center could be operated as a large centralized facility or smaller distributed facilities. Examples for each of the component facilities are described below.

\section{A.6.1 Light Water Reactor Spent Nuclear Fuel Recycling Facility}

A LWR SNF recycling facility would separate the SNF discharged from LWRs into its reusable components and waste components. Depending on the programmatic alternative and technology, this could include:

- Separation of high purity uranium from the SNF that would allow recycle for reenrichment or for other use or disposition.

- Separation and immobilization of long-lived fission products, including technetium and iodine, for disposal in a geologic repository.

- $\quad$ Potential extraction and storage (up to 300 years) of short-lived fission products (cesium and strontium).

- Separation of transuranic elements without separating pure plutonium for fabrication into fuel for an advanced recycling reactor and/or thermal-spectrum reactor (WSRC 2008a).

The LWR SNF recycling facility would be a self-sufficient operation located at a greenfield site or an existing facility. The following throughput options are analyzed for the nuclear fuel recycling center as a greenfield site: a lower bound of 100 MTHM per year and a base case of 800 MTHM per year. Selection of 800 MTHM per year as the base case was premised on existing separations facilities overseas. The 100 MTHM could be a demonstration size facility. This separations capacity is the basis for establishing the impacts at the production levels of 100 GWe, 150 GWe, 200 GWe, or 400 GWe.

\section{A.6.1.1 Separations Process Description}

The LWR SNF recycling facility would receive and manage SNF and use a separations process designed to recover the desired materials such as the examples discussed in the previous section. Key facility operations for recycling of LWR SNF include:

\footnotetext{
${ }^{14}$ This section presents information related to fuel fabrication facility for transmutation fuel. Fuel fabrication of MOX-U-Pu fuel is expected to be similar in terms of facility requirements. See Section A.3.1.4 for a discussion of MOX-U-Pu fuel fabrication.

${ }^{15}$ This section presents information related to separation of fast reactor SNF, which is representative of the facility requirements that would be expected for separating MOX-U-Pu SNF.
} 
- $\quad$ SNF receipt, storage, and transfer

- $\quad$ SNF preparation and head-end treatment

- $\quad$ Separations processing and purification

- Product handling-solidification, packaging, storage, and shipping of uranium and U/TRU oxides

- Waste processing and handling-packaging, storage and preparation for shipment of wastes

The base case alternative allows for a maximum of 800 MTHM of PWR fuel to be recycled each year. This would equate to approximately 1,820 SNF assemblies per year. The wet and dry storage areas would each have the capability to store approximately 1,820 SNF assemblies. The facility baseline would be able to store 2 years throughput in the combined wet and dry storage areas (WSRC 2008a). Table A.6.1.1-1 provides the maximum number of SNF assemblies to be processed annually under each scenario.

TABLE A.6.1.1-1—Maximum Number of Spent Nuclear Fuel Assemblies Processed Annually

\begin{tabular}{|c|c|c|}
\hline & 100 MTHМ/year Facility & 800 MTHM/year Facility \\
\hline Annual Number of PWR ${ }^{a}$ SNF Assemblies & 228 & 1,820 \\
\hline
\end{tabular}

Details on construction requirements and the environmental impacts would be developed at the time a specific proposal was being made for design and construction of a LWR SNF recycling facility.

\section{A.6.1.2 Facility Requirements}

Based on preconceptual design studies for a reprocessing plant using aqueous separations technologies, the total site area for the LWR SNF recycling facility within a property protection fence would be on the order of 500 acres (202 hectares [ha]) for an 800 MTHM per year facility. The 100 MTHM per year facility layout would be similar but occupy less total acreage (approximately 300 acres [121 ha]). An aqueous reprocessing facility is used as the representative technology for processing LWR SNF since there is no experience with other processing technologies at large scale.

The footprint for the processing areas is estimated to be on the order of 1,000,000 square feet $\left(\mathrm{ft}^{2}\right)\left(92,900\right.$ square meters $\left.\left[\mathrm{m}^{2}\right]\right)$ for the 800 MTHM facility. Table A.6.1.2-1 provides the footprint area for the LWR SNF recycling facility using aqueous separations technology (WSRC 2008a). 
TABLE A.6.1.2-1—Light Water Reactor Spent Nuclear Fuel Recycling Facility Building Footprint Based on Representative Technology

\begin{tabular}{lcc}
\hline & \multicolumn{2}{c}{ Area $\left(\mathbf{f t}^{2}\right)$} \\
\cline { 2 - 3 } & $\mathbf{1 0 0}$ MTHM/year Facility & $\mathbf{8 0 0}$ MTHM/year Facility \\
\hline Total Area of Main Processing Buildings & 520,000 & $1,040,000$ \\
Total Support Building Area & $1,140,000$ & $2,280,000$ \\
Total Building Area & $1,660,000$ & $3,320,000$ \\
\hline Source: WSRC 2008a & \multicolumn{2}{l}{}
\end{tabular}

\section{A.6.1.3 Operational Materials and Waste}

During normal operations, the LWR SNF recycling center would process SNF to recover uranium and transuranic products and produce waste materials. Throughputs and inventories for recovered uranium and transuranics products and waste materials are shown in Tables A.6.1.3-1 and A.6.1.3-2 (WSRC 2008a). Estimates of waste mass and volume, based on existing aqueous technologies and experience, are provided in Table A.6.1.3-3. Application of waste minimization, pollution prevention, and actual facility designs are expected to reduce these amounts. Additionally, the data for the LWR SNF recycling center were developed by assuming that the burnup of the LWR SNF would be $60 \mathrm{GWd} / \mathrm{MTHM}$, which is slightly higher than expected (51 GWd/MTHM-see Table 4.8-1). As a result, these data are expected to be conservative in estimating environmental impacts because higher burnup LWR SNF would produce larger quantities of fission products in the spent fuel. Advanced technologies already exist, and others are the subject of R\&D, that have the potential to reduce the mass or volume of some waste streams, but estimates for a facility that would use such technologies would be developed at the time a specific facility and processing approach was proposed. Table A.6.1.3-4 provides a summary of the operations data for the LWR SNF recycling facility.

TABLE A.6.1.3-1—Estimates of Fuel Processing Materials and Wastes from Light Water Reactor Spent Nuclear Fuel Recycling Facility Operations 100 Metric Tons Heavy Metal/Year Facility

\begin{tabular}{lcc}
\hline \multicolumn{1}{c}{ Feed/Product/Waste } & Annual Rate (kg) & Annual Bulk Container Rate \\
\hline LWR Fuel Feed (fuel portion only) & 113,073 & 228 assemblies \\
U Solidification and Storage Product & 106,847 & 26755 -gallon drums \\
U/TRU Solidification and Storage Product & 5,490 & 384 cans $^{\text {a }}$ \\
Fuel Hardware and Hulls Waste & 41,218 & 12 canisters $^{\mathrm{b}}$ \\
Tc Metal Alloy Waste Form & 2,380 & 1 canisters $^{\mathrm{b}}$ \\
Cs/Sr Waste Form & 9,408 & 510 canisters $^{\mathrm{c}}$ \\
FP/Lanthanide Vitrified Waste Form & 38,649 & 13 canisters $^{\mathrm{d}}$ \\
\hline
\end{tabular}

Source: WSRC 2008a

${ }^{\text {a }}$ Can holds $14.3 \mathrm{~kg}$ of material

${ }^{\mathrm{b}}$ Canister holds $3,600 \mathrm{~kg}$ of material

${ }^{\mathrm{c}}$ Canister holds $18.5 \mathrm{~kg}$ of material

${ }^{\mathrm{d}}$ Canister holds 2,900 kg of material 
TABLE A.6.1.3-2-Estimates of Fuel Processing Materials and Wastes from Light Water Reactor Spent Nuclear Fuel Recycling Facility Operations 800 Metric Tons Heavy Metal/Year Facility

\begin{tabular}{lcc}
\hline \multicolumn{1}{c}{ Feed/Product/Waste } & Annual Rate (kg) & Annual Bulk Container Rate \\
\hline LWR Fuel Feed (fuel portion only) & 903,850 & 1,820 assemblies \\
U Solidification and Storage Product & 853,920 & 2,13555 -gallon drums \\
U/TRU Solidification and Storage & 43,872 & 3,068 cans $^{\mathrm{a}}$ \\
Product & 329,410 & 92 canisters $^{\mathrm{b}}$ \\
Fuel Hardware and Hulls Waste & 19,022 & 6 canisters $^{\mathrm{b}}$ \\
Tc Metal Alloy Waste Form & 75,185 & 4,075 canisters $^{\mathrm{c}}$ \\
Cs/Sr Waste Form & 308,880 & 106 canisters $^{\mathrm{d}}$ \\
FP/Lanthanide Vitrified Waste Form & & \\
\hline Source: WSRC 2008a & & \\
${ }^{\mathrm{a}}$ Can holds 14.3 kg of material & \\
${ }^{\mathrm{b}}$ Canister holds 3,600 kg of material & \\
${ }^{\mathrm{C}}$ Canister holds 18.5 kg of material & & \\
${ }^{\mathrm{C}}$ Canister holds 2,900 kg of material & &
\end{tabular}

TABLE A.6.1.3-3-Estimates of Wastes from Light Water Reactor Spent Nuclear Fuel Recycling Facility Operations

\begin{tabular}{|c|c|c|}
\hline Waste Category & 100 MTHM/year Facility & 800 MTHM/year Facility \\
\hline & Annual & Annual \\
\hline \multicolumn{3}{|l|}{ LLW } \\
\hline Liquid (L) & 274 & 2,156 \\
\hline Solid $\left(\mathrm{m}^{3}\right)$ & 4,043 & 7,936 \\
\hline \multicolumn{3}{|l|}{ Mixed LLW } \\
\hline Solid $\left(\mathrm{m}^{3}\right)$ & 11 & 32 \\
\hline \multicolumn{3}{|l|}{ GTCC LLW } \\
\hline Solid $\left(\mathrm{m}^{3}\right)$ & 707 & 1,250 \\
\hline \multicolumn{3}{|l|}{ Mixed GTCC LLW } \\
\hline Solid $\left(\mathrm{m}^{3}\right)$ & 10 & 77 \\
\hline \multicolumn{3}{|l|}{ HLW } \\
\hline Solid $\left(\mathrm{m}^{3}\right)$ & 28 & 221 \\
\hline \multicolumn{3}{|l|}{ Hazardous } \\
\hline Liquid (L) & 70 & 100 \\
\hline Solid $\left(\mathrm{m}^{3}\right)$ & 32 & 93 \\
\hline \multicolumn{3}{|l|}{ Nonhazardous } \\
\hline Liquid (L) & $181,000,000$ & $248,000,000$ \\
\hline Solid $\left(\mathrm{m}^{3}\right)$ & 11,328 & 16,463 \\
\hline
\end{tabular}


TABLE A.6.1.3-4—Summary of Light Water Reactor Spent Nuclear Fuel Recycling Facility Operations Data Based on Representative Technology

\begin{tabular}{|c|c|c|}
\hline Data Required & $\begin{array}{c}100 \text { MTHM/year } \\
\text { Facility }\end{array}$ & $\begin{array}{c}800 \text { MTHM/year } \\
\text { Facility }\end{array}$ \\
\hline Flectrical Consumntion - daily and annual & $3.0 \mathrm{GWh}$ & $6.0 \mathrm{GWh}$ \\
\hline Electrical Consumpuron - darly and annual & $906 \mathrm{GWh}$ & $1,440 \mathrm{GWh}$ \\
\hline Peak electrical demand (MVA) - daily & 195 & 390 \\
\hline Diesel Fuel usage (gal) -annual & 121,750 & 243,500 \\
\hline Other Process Gas (N, Ar, etc.) - daily and annual & $\begin{array}{c}\text { 4,689 scf/day } \\
1,125,440 \mathrm{scf} / \text { year }\end{array}$ & $\begin{array}{c}14,068 \mathrm{scf} / \text { day } \\
3,376,320 \mathrm{scf} / \text { year }\end{array}$ \\
\hline Domestic Water (gal) - daily and annual & $\begin{array}{c}135,000 \\
40,770,000\end{array}$ & $\begin{array}{c}175,000 \\
42,000,000\end{array}$ \\
\hline Process Water (gal) - daily and annual & $\begin{array}{c}120,000 \\
36,240,000\end{array}$ & $\begin{array}{c}360,000 \\
108,720,000\end{array}$ \\
\hline Cooling Tower Makeup (gal) - daily and annual & $\begin{array}{c}249,600 \\
59,904,000\end{array}$ & $\begin{array}{c}748,800 \\
179,712,000\end{array}$ \\
\hline Steam (gal) - daily and annual & $\begin{array}{c}307,200 \\
73,728,000\end{array}$ & $\begin{array}{c}921,600 \\
221,184,000\end{array}$ \\
\hline Employment (total workers) & 2,500 & 3,100 \\
\hline Number of Radiological Workers & 1,070 & 2,226 \\
\hline Average annual dose to Radiological workers (mrem) & 250 & 250 \\
\hline Maximum annual worker dose (mrem) & 1,000 & 1,000 \\
\hline
\end{tabular}

Source: WSRC 2008a

Note: $\mathrm{scf}=$ standard cubic feet

The operation of fuel cycle facilities generates several different types of waste. Some are closely related to the process and throughput (e.g., fission products, used solvents, product packages and containers, and excess acid). Other waste streams (secondary wastes) are more closely related to staffing (e.g., sanitary waste) or plant systems and facilities (filters, laboratory wastes, and decontamination material). However, the largest source of secondary radioactive waste is typically associated with routine operation and maintenance of the nuclear facilities and equipment. Estimates of total waste were derived by combining "process-related" wastes directly related to throughput, with estimates of secondary waste made for each facility. Estimates of secondary wastes streams considered process conditions, personnel activities (entries into contamination areas and protective clothing requirements), and forecasts of equipment failures, repairs, and replacement. Detailed estimates considering forecasts of routine operations and both major and minor maintenance activities were prepared for each case. Since the total quantity of waste for any given case is impacted by all of these factors, and their relative contribution varies with the type of operation and source materials, comparisons between cases are unlikely to be directly proportional to throughput except for process wastes. Detailed estimating methodology and facility specific assumptions are described in the document Engineering Alternative Studies for Separations, Waste Generation Forecast and Characterization Study 800MT/Year UREX $+1 A$, (WSRC 2008e).

The current footprint for the $800 \mathrm{MTHM} /$ year LWR SNF recycling facility assumes only 1 year of storage for each of the types of waste. To account for the potential for additional storage capacity, the footprint for the LWR SNF recycling facility would need to be increased by the following values depending on waste stream. It is expected, however, that a disposal pathway for these wastes may be available while the facility is operating. If so, additional storage capacity would not be required. A phased construction plan with expandable capacity is envisioned to 
handle this waste and provide sufficient but not excess storage capacity. New capacity would be built every 5 to 10 years to accommodate a portion of the total waste that would be generated during the subsequent years of production. The need for the construction of new storage space would be reduced or eliminated when disposal paths for the various waste categories are decided. The following values represent the storage capacity required per year for wastes generated from the $800 \mathrm{MTHM} /$ year LWR SNF Recycling Facility.

- $3,260 \mathrm{ft}^{2} / \mathrm{yr}\left(300 \mathrm{~m}^{2} / \mathrm{yr}\right)$ for HLW storage (includes hulls and hardware)

- $8,150 \mathrm{ft}^{2} / \mathrm{yr}\left(760 \mathrm{~m}^{2} / \mathrm{yr}\right)$ for $\mathrm{Cs} / \mathrm{Sr}$ waste storage

- $13,600 \mathrm{ft}^{2} / \mathrm{yr}\left(1,300 \mathrm{~m}^{2} / \mathrm{yr}\right)$ for Greater-than-Class C (GTCC) LLW storage

- $111,260 \mathrm{ft}^{2} / \mathrm{yr}\left(10,340 \mathrm{~m}^{2} / \mathrm{yr}\right)$ for LLW storage (includes any grouted LLW)

- $2,300 \mathrm{ft}^{2} / \mathrm{yr}\left(200 \mathrm{~m}^{2} / \mathrm{yr}\right)$ for combined hazardous waste/mixed waste storage

Hulls and hardware would be GTCC LLW, but due to the need for remote handling they are assumed be placed in the same storage facility as the HLW to reduce the need for two storage facilities with remote handling capabilities (WSRC 2008a).

\section{A.6.2 Transmutation Fuel Fabrication Facility}

\section{A.6.2.1 Process Description}

The transmutation fuel fabrication facility would receive uranium and U/TRU product from one or more nuclear fuel recycling centers. The assumption has been made that the fuel for the advanced recycling reactors is a ceramic oxide to provide an example for evaluating environmental impacts in this GNEP PEIS. Other transmutation fuel types are available, such as metal, nitride, and carbide, and the selection of the fast reactor fuel type would be made as part of the development of the advanced recycling reactor, as discussed in the following section. Options also include using more than one composition for the transmutation fuel, such as $\mathrm{U} / \mathrm{Pu}$ for some of the fast reactor fuel, and retaining the minor actinides in other fast reactor "target" assemblies. Key facility operations for fuel fabrication are the same for different fuel types. The differences are in the development of the feedstock prior to arriving at the fuel fabrication facility.

Key facility operations for fabrication of transmutation fuel include:

- $\quad$ Oxide product receipt, storage, and transfer

- Conditioning and fabrication

- Dissolving, blending, and solidifying feedstock in an oxide form suitable for fuel fabrication

- Stoichiometry adjustment, mixing, milling, and binder addition

- Wet and dry scrap processing

- Pressing, sintering, and grinding of fuel pellets

- Fuel rod loading and fuel bundle assembly

- Fuel assembly, handling, and storage

- Waste processing and handling-packaging, storage, and preparation for shipment of wastes (WSRC 2008b) 
The United States currently has three NRC-licensed uranium fuel fabrication facilities capable of processing $\mathrm{UF}_{6}$ to $\mathrm{UO}_{2}$ powder and then fabricating $\mathrm{LWR}$ fuel assemblies from this $\mathrm{UO}_{2}$ powder. Three additional facilities, Nuclear Fuel Services, in Erwin, TN, BWX Technologies, in Lynchburg, VA, and Areva NP, in Lynchburg VA, are NRC licensed, but currently do not have the ability to process $\mathrm{UF}_{6}$ to $\mathrm{UO}_{2}$ powder. Table A.6.2-1 shows the capacity of the three facilities presently able to produce commercial LWR fuel assemblies. The current LWRs require approximately 2,400 tons $(2,170 \mathrm{MT})$ of fresh fuel assemblies annually.

TABLE A.6.2-1—United States Light Water Reactor Fuel Fabrication Capacity

\begin{tabular}{lcc}
\multicolumn{1}{c}{ Facility } & Location & $\begin{array}{c}\text { Capacity } \\
\text { (Metric Tons) }\end{array}$ \\
\hline Global Nuclear Fuel-Americas, LLC & Wilmington, NC & 1,200 \\
Westinghouse & Columbia, SC & 1,600 \\
Areva NP, Inc. & Richland, WA & 700 \\
TOTAL & & $\mathbf{3 , 5 0 0}$ \\
\hline
\end{tabular}

Source: NRC 2007c

For fast reactor fuel fabrication, a size of $100 \mathrm{MTHM} /$ year was used, assuming one centralized facility rather than a number of smaller distributed fuel fabrication facilities colocated with the fast reactors. A $100 \mathrm{MTHM} /$ year capacity will provide fast reactor fuel for $11 \mathrm{GWe}$ of fast reactor capacity (see Section 4.3.1). The assumed inventory of nuclear material contained in the various processes consists of approximately 1 year of $U$ and TRU feedstock storage and 2 years production of fuel assembly storage (WSRC 2008b).

\section{A.6.2.2 Facility Requirements}

The transmutation fuel fabrication facility includes process buildings and support buildings. The total site area within a property protection fence would be on the order of 100 acres (41 ha) for the $100 \mathrm{MTHM} /$ year transmutation fuel fabrication facility. The proposed concept places the fuel fabrication into one main building. However, this building would be separated into several parts and cells to accommodate the various processes. The storage areas may be in separate buildings, especially for the fuel assemblies (WSRC 2008b).

The footprint for the processing areas is estimated to be on the order of $520,000 \mathrm{ft}^{2}\left(48,300 \mathrm{~m}^{2}\right)$ for the $100 \mathrm{MTHM} / \mathrm{year}$ facility. The process area footprint provides space for processing area support functions and would include various tunnels for the transfer of materials between buildings and other colocated facilities (WSRC 2008b). Table A.6.2.2-1 provides the footprint area discussed above.

TABLE A.6.2.2-1-Transmutation Fuel Fabrication

\section{Facility Building Size Details}

\begin{tabular}{lr}
\hline & Area $\left(\mathbf{f t}^{2} \mathbf{)}\right.$ \\
\hline Total Area of Main Processing Buildings & 520,000 \\
Total Support Building Area & $1,840,000$ \\
Total Building Area & $2,360,000$ \\
\hline Source: WSRC 2008b &
\end{tabular}


Details of the construction requirements and the environmental impacts would be developed at the time a specific proposal was made for design and construction of a transmutation fuel fabrication facility.

\section{A.6.2.3 Operational Materials and Waste}

Throughputs and inventories of processing materials, shown in Table A.6.2.3-1, are based on the conceptual process flow sheets that are currently under development in the AFCI program (WSRC 2008b). Process storage requirements would approximately be one year for the U/TRU oxide feed stock, bulk fuel materials, and undissolved solids, with two years of product storage for completed fuel assemblies. Estimates of all the operations wastes, including process wastes, are provided in Table A.6.2.3-2 to the extent available.

TABle A.6.2.3-1-Estimates of Fuel Processing Materials and Wastes from Transmutation Fuel Fabrication Operations 100 Metric Tons Heavy Metal/Year Facility

\begin{tabular}{lcc}
\multicolumn{1}{c}{ Feed/Product/Waste } & $\begin{array}{c}\text { Annual Rate } \\
\text { (kg/year) }\end{array}$ & $\begin{array}{c}\text { Annual Bulk } \\
\text { Container Rate }\end{array}$ \\
\hline U/TRU Oxide Feed & 117,600 & See Note \\
Bulk Fuel (Ceramic Oxide) & 116,400 & $\mathrm{NA}^{\mathrm{a}}$ \\
Undissolved Solids & 120 & $\mathrm{NA}^{\mathrm{a}}$ \\
Fuel Assemblies (\# of assemblies) & 1,680 & $1,680 \mathrm{assemblies}$ \\
\hline Source: WSRC 2008b & & \\
a In process stream & & \\
Note: Uranium oxide would be stored in 55-gallon drums (400 $\mathrm{kg}$ per drum) and U/TRU would be stored in \\
containers that hold up to 14.8 kg of material.
\end{tabular}

TABLE A.6.2.3-2-Estimates of Wastes from Transmutation Fuel Fabrication Operations

\begin{tabular}{|c|c|}
\hline Waste Category & $\begin{array}{c}\text { Annual Volume } \\
100 \mathrm{MTHM} / \text { year Facility }\end{array}$ \\
\hline \multicolumn{2}{|l|}{ Low Level } \\
\hline Liquid (L) & 1,000 \\
\hline Solid $\left(\mathrm{m}^{3}\right)$ & 2,367 \\
\hline \multicolumn{2}{|l|}{ Mixed Low-level } \\
\hline Solid $\left(\mathrm{m}^{3}\right)$ & 18 \\
\hline \multicolumn{2}{|l|}{ GTCC LLW } \\
\hline Solid $\left(\mathrm{m}^{3}\right)$ & 500 \\
\hline \multicolumn{2}{|l|}{ Hazardous } \\
\hline Liquid (L) & 33 \\
\hline Solid $\left(\mathrm{m}^{3}\right)$ & 14.3 \\
\hline \multicolumn{2}{|l|}{ Nonhazardous } \\
\hline Liquid (L) & $55,300,000$ \\
\hline Solid $\left(\mathrm{m}^{3}\right)$ & 19,500 \\
\hline
\end{tabular}

\section{A.6.3 Fast Reactor Spent Nuclear Fuel Recycling Facility}

\section{A.6.3.1 Process Description}

A fast reactor SNF recycling facility would receive and manage fast reactor SNF, using one or more processing technologies to separate the various components of SNF. Consistent with the 
assumption for the transmutation fuel fabrication facility, the assumption has been made that the SNF from the advanced recycling reactor is a ceramic oxide. For the purpose of estimating environmental impacts from this facility, it has also been assumed that an aqueous separations technology (UREX+1a) is used, since there is no experience with other processing technologies at large scale and, for the purposes of this GNEP PEIS, this example provides an estimate of the potential environmental impacts from such a facility. If such facilities are eventually proposed, the detailed environmental impacts including construction data would need to be evaluated at that time.

Key facility operations for recycling of fast reactor SNF include:

- $\quad$ SNF receipt, storage, and transfer

- $\quad$ SNF preparation and head-end treatment

- $\quad$ Separations processing and purification

- Product handling - solidification, packaging, storage, and shipping of uranium and U/TRU oxides

- Waste processing and handling - packaging, storage, and preparation for shipment of wastes (WSRC 2008c)

The baseline process throughputs for $100 \mathrm{MTHM} / \mathrm{year}$ are calculated using a maximum 0.42 MTHM rate of fast reactor SNF per day (see Section A.6.1 for a description of the throughput rates for LWR and Fast Reactor separations.). These process throughputs were used to develop baseline equipment designs and layouts, which, in turn, were used to develop a theoretical plan for the entire facility. The inventory of nuclear material contained in the various separations and storage processes is presented in Table A.6.3.1-1 for the $100 \mathrm{MTHM} / \mathrm{year}$ facility, consistent with the fast reactor transmutation fuel fabrication facility (WSRC 2008c).

TABLE A.6.3.1-1-Fast Reactor Spent Nuclear Fuel Recycling Facility Inventory of Nuclear Materials for Defining the Operations Basis

\begin{tabular}{ll}
\hline \multicolumn{1}{c}{ Facility Description } & \multicolumn{1}{c}{$100 \mathrm{MTHM} /$ year Facility } \\
\hline \multirow{2}{*}{ Process Area } & Annual material processing throughput \\
& 250 GWD/MTHM, 1 year cooled, fast reactor SNF \\
& At the baseline rate of $100 \mathrm{MTHM} / \mathrm{yr}$, the 2-year storage \\
& capacity equates to receipt of 2,400 fast reactor SNF \\
assemblies. & Isolate and manage a minimum of 5 percent fuel assemblies \\
received that may be damaged or otherwise unsuitable for near- & \\
& term processing. \\
\hline Source: WSRC 2008c &
\end{tabular}

\section{A.6.3.2 Facility Requirements}

The fast reactor SNF recycling facility includes process buildings and support buildings. The total site area within a property protection fence is on the order of 250 acres (101 ha) (WSRC 2008c). The proposed concept would place most of the processes into as few buildings as possible. 
The footprint for the processing areas is estimated to be on the order of $624,000 \mathrm{ft}^{2}\left(58,000 \mathrm{~m}^{2}\right)$ for the $100 \mathrm{MTHM} / \mathrm{year}$ facility. The process area footprint provides space for processing area support functions. In the current concept, the shielded areas are placed below grade (ranging from 20 to $40 \mathrm{ft}$ [6 to $12 \mathrm{~m}]$ ), and the overhead cranes and other support equipment required for unloading and moving shipping casks and processing equipment extend to heights averaging $70 \mathrm{ft}(21 \mathrm{~m})$ above grade. Some buildings may require building heights greater than $70 \mathrm{ft}(21 \mathrm{~m})$ above grade. The process areas also include various tunnels for the transfer of materials between buildings (WSRC 2008c). Table A.6.3.2-1 provides the footprint area discussed above.

\begin{tabular}{lc}
$\begin{array}{c}\text { TABLE A.6.3.2-1-Fast Reactor Spent Nuclear Fuel } \\
\text { Recycling Facility Building Size Details }\end{array}$ \\
\hline & Area (ft $\left.{ }^{2}\right)$ \\
\hline Total Area of Main Processing & 620,000 \\
Buildings & 610,000 \\
Total Support Building Area & $1,230,000$ \\
Total Building Area &
\end{tabular}

Source: WSRC 2008c

Details of the construction requirements and the environmental impacts would be developed at the time a specific proposal was being made for design and construction of the fast reactor SNF recycling facility.

\section{A.6.3.3 Operational Materials and Waste}

During normal operations, the fast reactor SNF recycling facility would process SNF to produce uranium and transuranic products and waste materials. Estimated throughputs and inventories of these processing materials, shown in Table A.6.3.3-1, are based on the conceptual process flow sheets. Estimates of the operations data are provided in Table A6.3.3-2 to the extent available (WSRC 2008c).

TABLE A.6.3.3-1-Estimates of Fuel Processing Materials and Wastes from Fast Reactor Spent Nuclear Fuel Separations Operations (100 Metric Tons Heavy Metal/Year Facility)

\begin{tabular}{lcc}
\hline \multicolumn{1}{c}{ Feed/Product/Waste } & $\begin{array}{c}\text { Annual Rate } \\
(\mathbf{k g})\end{array}$ & $\begin{array}{c}\text { Annual Bulk } \\
\text { Container Rate }\end{array}$ \\
\hline Transmutation SNF (assemblies) & 223,000 & 1,200 assemblies \\
U Solidification and Storage Product & 30,000 & 75 \\
TRU Solidification and Storage Product & 55,900 & 3,910 \\
Fuel Hardware and Hulls Waste & 69,700 & 20 \\
Tc Metal Alloy Waste Form & 36,900 & 11 \\
Cs/Sr Waste Form & 24,800 & 1,340 \\
FP/Lanthanide Vitrified Waste Form & 414,000 & 143
\end{tabular}

Source: WSRC 2008c 
TABLE A.6.3.3-2-Estimates of Wastes from Fast Reactor Spent Nuclear Fuel Separations Operations

\begin{tabular}{|c|c|}
\hline \multirow[t]{2}{*}{ Waste Category } & $\begin{array}{c}\text { Annual Volume } \\
100 \text { MTHM/year Facility }\end{array}$ \\
\hline & Annual \\
\hline \multicolumn{2}{|l|}{ Low Level } \\
\hline Liquid (L) & 340 \\
\hline Solid $\left(\mathrm{m}^{3}\right)$ & 5,050 \\
\hline \multicolumn{2}{|l|}{ Mixed Low-level } \\
\hline Solid $\left(\mathrm{m}^{3}\right)$ & 50 \\
\hline \multicolumn{2}{|l|}{ GTCC LLW } \\
\hline Solid $\left(\mathrm{m}^{3}\right)$ & 880 \\
\hline \multicolumn{2}{|l|}{ Mixed GTCC LLW } \\
\hline Solid $\left(\mathrm{m}^{3}\right)$ & 10 \\
\hline \multicolumn{2}{|l|}{ HLW } \\
\hline Solid $\left(\mathrm{m}^{3}\right)$ & 220 \\
\hline \multicolumn{2}{|l|}{ Hazardous } \\
\hline Liquid (L) & 88 \\
\hline Solid $\left(\mathrm{m}^{3}\right)$ & 40 \\
\hline \multicolumn{2}{|l|}{ Nonhazardous } \\
\hline Liquid (L) & $223,000,000$ \\
\hline Solid $\left(\mathrm{m}^{3}\right)$ & 17,200 \\
\hline
\end{tabular}

\section{A.7 Fuel BURNuP}

This PEIS includes a number of fuel cycle alternatives. These alternatives range from the current fuel cycle to fuel cycles which have only been studied on paper. This has resulted in varying levels of optimism based on the data used for the different fuel cycles. One factor in particular is the burnup assumed for each type of fuel at the time of discharge from the reactor. Burnup refers to the amount of energy generated per initial mass of fuel, the metric tons of initial heavy metal (MTIHM). For fuel assemblies of equal initial mass and for a given total energy production, higher burnup fuels can reduce the total mass of SNF generated by providing more energy per fuel assembly. However, each assembly would also contain a greater inventory of fission products for all enriched uranium-based fuels ${ }^{16}$, and a greater inventory of heavier actinide elements. This section assesses and compares different discharge burnups and discusses the impact on a number of metrics, including SNF quantities generated, transportation required, raw materials utilization, and waste parameters (long-term heat and long-term radiotoxicity). The source of information in this section is "The Impact of Burnup on the Performance of Alternative Fuel Cycles" (Dixon and Wigeland 2008).

Table A.7-1 shows all of the alternatives that were analyzed in detail in the GNEP PEIS. Other alternatives were also discussed briefly in the text of the PEIS, such as the "deep burn" alternative for the HTGR. Since the neutron spectrum affects the probability of neutron capture (absorption) or fission, which in turn will affect the composition of the discharged fuel, rather

\footnotetext{
${ }^{16}$ This includes the specific fuel in the Thorium Alternative, which uses enriched uranium as a driver in both the seed and blanket. Thorium fuels can also use plutonium as a driver.
} 
than a discussion of each reactor type, the reactors can be grouped by their neutron spectrum characteristics to determine the general impact of burnup.

- Thermal spectrum-No Action, Thorium, HWR, HTGR, LWR portion of all recycle alternatives and HWR portion of DUPIC alternative

- Fast spectrum-Advanced recycling reactor portion of Fast and Thermal/Fast recycle alternatives

TABLE A.7-1-Programmatic Environmental Impact Statement Alternatives Indicating Assumed Reactor Mixes and Fuel Burnup Levels

\begin{tabular}{|c|c|c|c|c|c|c|c|c|}
\hline \multirow[t]{2}{*}{$\begin{array}{c}\text { Case } \\
\text { Description }\end{array}$} & \multirow{2}{*}{$\begin{array}{c}\text { No Action } \\
\text { (Once- } \\
\text { Through } \\
\text { Fuel } \\
\text { Cycle) }\end{array}$} & \multicolumn{2}{|c|}{$\begin{array}{c}\text { HWR or } \\
\text { HTGR } \\
\text { Alternative } \\
\text { (Once-Through } \\
\text { Fuel Cycle) } \\
\end{array}$} & \multirow{2}{*}{$\begin{array}{l}\text { Thorium } \\
\text { Alternative } \\
\text { (Once- } \\
\text { Through } \\
\text { Fuel Cycle) }\end{array}$} & \multicolumn{2}{|c|}{$\begin{array}{l}\text { Thermal Recycle } \\
\text { Alternative }\end{array}$} & \multirow[t]{2}{*}{$\begin{array}{c}\text { Fast Recycle } \\
\text { Alternative } \\
-\quad(C R=0.5)\end{array}$} & \multirow{2}{*}{$\begin{array}{c}\text { Thermal } \\
\text { /Fast } \\
\text { Recycle } \\
\text { Alternative } \\
\text { (CR=0.5) }\end{array}$} \\
\hline & & $\begin{array}{c}\text { All } \\
\text { HWR }\end{array}$ & $\begin{array}{c}\text { All } \\
\text { HTGR }\end{array}$ & & $\begin{array}{c}\text { Option 1- } \\
\text { LWR/LWR } \\
\text { (MOX-U-Pu) }\end{array}$ & $\begin{array}{l}\text { Option 2- } \\
\text { LWR/HWR } \\
\text { (DUPIC) }\end{array}$ & & \\
\hline \multicolumn{9}{|c|}{ Reactor Power Production (100 GWe) } \\
\hline LWR-UOX or & 100 & 100 & 100 & & & 73 & 60 & 63 \\
\hline HWR-UOX or & GWe & GWe & GWe & 0 & 0 & GWe & GWe & GWe \\
\hline $\begin{array}{l}\text { HTGR-UOX } \\
\text { LWR-MOX-U- }\end{array}$ & LWR & HWR & HTGR & & & LWR & LWR & LWR \\
\hline $\begin{array}{l}\text { Pu, or } \\
\text { LWR-HWR }\end{array}$ & 0 & 0 & 0 & 0 & 100 GWe LWR & 27 GWe HWR & 0 & 7 GWe LWR \\
\hline $\begin{array}{l}\text { Fast Advanced } \\
\text { Recycling } \\
\text { Reactor }\end{array}$ & 0 & 0 & 0 & 0 & 0 & 0 & $\begin{array}{l}40 \mathrm{GWe} \\
\text { ARR }\end{array}$ & $\begin{array}{l}30 \mathrm{GWe} \\
\text { ARR }\end{array}$ \\
\hline $\begin{array}{l}\text { LWR- } \\
\text { ThOX/UOX }\end{array}$ & 0 & 0 & 0 & $\begin{array}{l}100 \mathrm{GWe} \\
\mathrm{LWR}\end{array}$ & 0 & 0 & 0 & 0 \\
\hline $\begin{array}{l}\text { Fuel Burnup at } \\
\text { Discharge } \\
\text { (GWd/MTHM) }\end{array}$ & 51 & 21 & 100 & $\begin{array}{l}149 \text { (UOX) } \\
75 \text { (ThOX) }\end{array}$ & 45 & $\begin{array}{l}35 \text { (UOX) } \\
15 \text { (HWR) }\end{array}$ & $\begin{array}{l}51 \text { (LWR) } \\
107 \text { (ARR) }\end{array}$ & $\begin{array}{c}51(\mathrm{LWR}) \\
50(\mathrm{LWR}- \\
\mathrm{MOX} / \mathrm{Pu}) \\
105(\mathrm{ARR}) \\
\end{array}$ \\
\hline
\end{tabular}

\section{A.7.1 Thermal Spectrum Burnup Trends}

The greatest amount of data on thermal spectrum burnup and its impacts is available for uranium oxide (UOX) fuels used in LWRs. Therefore, this section begins with the No Action Alternative of UOX-fueled LWRs, which coincides with the current U.S. commercial nuclear fleet. The impact of burnup on HWR, Thorium and MOX fuels would follow the same general trends.

Historical U.S. commercial reactor operations show a steady trend toward higher burnup (Finck 2007b). The average improvement over the last 20 years is about $1 \mathrm{GWd} / \mathrm{MTIHM}$ per year. If this trend continues, burnup levels by 2020 will approach $60 \mathrm{GWd} / \mathrm{MTIHM}$. 


\section{Effects of Higher Burnup}

- Higher burnup means longer periods between refueling outages. Reactor owners complete significant maintenance during the refueling outages - the longer the time between outages, the more maintenance that builds up. Currently these outages occur every 18 months. (Higher burnup could be achieved while maintaining current refueling schedules if the fuel was left in the reactor for more cycles.)

- High burnup fuels tend to exhibit a greater frequency of cladding failures, suggesting the upper limit for current cladding material and manufacturing processes is being reached for the reactor fuel power density being used today.

- Current enrichment facilities are only licensed to achieve a 5 percent fuel enrichment for commercial applications. While the average enrichment in today's fuels is below the 5 percent limit, enrichment between assemblies and within assemblies varies to support load balancing. Portions of fuel elements are now at the 5 percent limit. (New enrichment facilities could be designed and licensed for higher enrichment, or it may be possible to relicense older facilities for production at higher enrichment.)

- Higher burnup requires higher enrichment. The enrichment levels for $51 \mathrm{GWd}$ /MTIHM and $100 \mathrm{GWd}$ /MTIHM UOX fuel average 4.3 percent and 8.5 percent respectively. So while the higher burnup produces approximately double the energy per unit of fuel, the increase in enrichment also is approximately double.

Higher burnup results in less SNF per unit of energy produced. The amount of SNF produced varies inversely to the SNF burnup - using the same reactor with the same thermal efficiency, increasing burnup by 50 percent decreases SNF by 33 percent (1.5 to 1.0) and doubling the burnup cuts SNF in half (2.0 to 1.0). The relationship is roughly linear over this range. This equates to fewer shipments of fresh fuel, but SNF shipments may not decrease linearly (or at all) due to the higher radiation and decay heat levels in the SNF. If the SNF shipments are volume limited, then half as much SNF may mean half as many shipments. But, if they are limited by decay heat or shielding requirements (or by weight, which is often driven by shielding), then the number of SNF shipments may not be reduced significantly. This is because, with higher burnup, the same number of fissions has taken place, but within fewer fuel assemblies - and those fewer assemblies still contain the same total masses of highly radioactive fission products. Since the fission products are more concentrated, each assembly is hotter (both radioactively and thermally) approximately in proportion to the increase in burnup. Appendix E of the PEIS indicates SNF shipments are limited by both volume and thermal considerations. The thermal impact can be somewhat reduced by storing the fuel longer before shipping, giving more time for the shorter-term fission products to decay.

Higher burnup also results in higher levels of heavier elements in the SNF. This is because there is more time for multiple neutron captures by the uranium atoms. Some of the created isotopes subsequently fission, such as some of the highly fissionable Pu-239 that is created through neutron capture by fertile U-238. This contributes to improved uranium utilization (since both U-235 and Pu-239 [produced from U-238] contribute to power production by fissioning). However, other heavier isotopes resulting from the capture of additional neutrons are typically long-lived and therefore contribute to both long-term decay heat and long-term radiotoxicity. 
These heavier isotopes and their initial decay products include the transuranics, additional uranium isotopes, and other actinides.

In summary, for UOX in the once-through case, for equivalent energy production higher burnup results in lower amounts of SNF (in terms of MTHM) in proportion to the increase in burnup, but roughly the same amount of natural uranium is required and each SNF fuel assembly is both hotter and more radiotoxic, not quite in proportion to the increase in burnup. As a result, there is limited benefit for direct disposal of the SNF with increasing burnup. Transportation shipments may not be reduced due to thermal limits on SNF shipments and the potential for greater shipping requirements on the fuel cycle front end (since very high burnups require more natural uranium per unit of energy produced, more ore and $\mathrm{UF}_{6}$ shipments would be needed). If the UOX fuel is recycled, the mass of radioactive materials in HLW is roughly the same per unit of energy produced (but much higher per MT of SNF). The amount of GTCC waste attributable to the cladding and assembly hardware scales closely with the MT of SNF recycled.

\section{A.7.2 Fast Spectrum Burnup Trends}

While the increase in burnup for the LWR was achieved by only increasing the initial fuel enrichment, the increase in burnup for the fast spectrum data was achieved either: 1) by increasing the mass of the core, reducing power density, and keeping about the same enrichment; or 2) by varying the enrichment, conversion ratio, and power density. Either approach makes it difficult to obtain results for all of the parameters of interest. The apparent trends related to fast spectrum burnup are as follows:

- The amount of uranium needed per equivalent energy production was not analyzed because for a burner fast reactor it is dependent on the LWR SNF that provides the transuranics and whether the uranium in the fast reactor fuel is recycled, natural, or depleted.

- SNF production per equivalent energy production trended similar to the thermal spectrum as burnup increased, but the changing heavy metal mass in the core makes the comparison difficult.

- Long term heat per equivalent energy production shows the same slightly downward trend as the other spectrums when varying the fluence ${ }^{17}$ limit, but was essentially unchanged when varying the conversion ratio. In both cases the calculation is based on the material that would be disposed after reprocessing, assuming 0.1 percent loss of actinides.

- Long term radiotoxicity was not assessed but should trend similar to long term heat.

The general conclusion on the effect of discharge burnup on spent fast reactor fuel is that the HLW resulting from processing will be relatively unaffected by changes in burnup, with the result that disposal needs will be unaltered, although handling, storage, and shipping may be affected in the same manner as for the other cases.

\footnotetext{
${ }^{17}$ Fluence refers to the number of radiation particles crossing a given area.
} 


\section{A.8}

\section{EXISTING REACTOR REPLACEMENTS}

Commercial LWRs are licensed by the NRC for 40 years of operation. NRC regulations also allow owner/operators to apply for 20-year license extensions. Table A.8-1 presents the operating license date for the commercial LWRs in the United States. As shown in that table, some of the existing LWRs in the United States have applied for, and received, license extensions. Additionally, other LWRs are likely to apply for, and receive, license extensions. This PEIS assumes that all existing LWRs, regardless of whether or not they receive license extensions, would require replacement during the time period analyzed (through approximately 2060).

TABLE A.8-1-Operating Licenses of United States Light Water Reactors

\begin{tabular}{|c|c|c|c|c|}
\hline Reactor Name & Reactor Unit & $\begin{array}{l}\text { Operating License } \\
\text { Expiration }\end{array}$ & $\begin{array}{c}\text { Operation License } \\
\text { Start Date }\end{array}$ & $\begin{array}{l}\text { Years of Operation } \\
\text { Expected }^{\mathrm{a}}\end{array}$ \\
\hline \multirow{2}{*}{ Arkansas Nuclear } & 1 & $5 / 20 / 2034$ & $5 / 21 / 1974$ & 60 \\
\hline & 2 & $7 / 17 / 2038$ & 9/1/1978 & 60 \\
\hline \multirow[t]{2}{*}{ Beaver Valley } & 1 & $1 / 29 / 2016$ & $7 / 2 / 1976$ & 40 \\
\hline & 2 & $5 / 27 / 2027$ & $8 / 14 / 1987$ & 40 \\
\hline \multirow{2}{*}{ Braidwood } & 1 & $10 / 17 / 2026$ & 7/2/1987 & 40 \\
\hline & 2 & $12 / 18 / 2027$ & $5 / 20 / 1988$ & 40 \\
\hline \multirow[t]{3}{*}{ Browns Ferry } & 1 & $12 / 20 / 2033$ & $12 / 20 / 1973$ & 60 \\
\hline & 2 & $6 / 28 / 2034$ & $8 / 2 / 1974$ & 60 \\
\hline & 3 & $7 / 2 / 2036$ & $8 / 18 / 1976$ & 60 \\
\hline \multirow[t]{2}{*}{ Brunswick } & 1 & $9 / 8 / 2036$ & $11 / 12 / 1976$ & 60 \\
\hline & 2 & $12 / 27 / 2034$ & $12 / 27 / 1974$ & 60 \\
\hline \multirow[t]{2}{*}{ Byron } & 1 & $10 / 31 / 2024$ & $2 / 14 / 1985$ & 40 \\
\hline & 2 & $11 / 6 / 2026$ & $1 / 30 / 1987$ & 40 \\
\hline Callaway & 1 & $10 / 18 / 2024$ & $10 / 18 / 1984$ & 40 \\
\hline \multirow[t]{2}{*}{ Calvert Cliffs } & 1 & $7 / 31 / 2034$ & $7 / 31 / 1974$ & 60 \\
\hline & 2 & $8 / 13 / 2036$ & $8 / 13 / 1976$ & 60 \\
\hline \multirow{2}{*}{ Catawba } & 1 & $12 / 5 / 2043$ & $1 / 17 / 1985$ & 59 \\
\hline & 2 & $12 / 5 / 2043$ & $5 / 15 / 1986$ & 58 \\
\hline Clinton & 1 & $9 / 29 / 2026$ & $4 / 17 / 1987$ & 40 \\
\hline Columbia & 1 & $12 / 20 / 2023$ & $4 / 13 / 1984$ & 40 \\
\hline \multirow[t]{2}{*}{ Comanche Peak } & 1 & $2 / 8 / 2030$ & $4 / 17 / 1990$ & 40 \\
\hline & 2 & $2 / 2 / 2033$ & $4 / 6 / 1993$ & 40 \\
\hline Cooper Station & 1 & $1 / 18 / 2014$ & $1 / 18 / 1974$ & 40 \\
\hline Crystal River & 3 & $12 / 3 / 2016$ & $1 / 28 / 1977$ & 40 \\
\hline Davis-Besse & 1 & $4 / 22 / 2017$ & 4/22/1977 & 40 \\
\hline \multirow[t]{2}{*}{ Diablo Canyon } & 1 & $11 / 2 / 2024$ & $11 / 2 / 1984$ & 40 \\
\hline & 2 & $8 / 20 / 2025$ & $8 / 26 / 1985$ & 40 \\
\hline \multirow{2}{*}{ Donald C. Cook } & 1 & $10 / 25 / 2034$ & $10 / 25 / 1974$ & 60 \\
\hline & 2 & $12 / 23 / 2037$ & $12 / 23 / 1977$ & 60 \\
\hline \multirow[t]{2}{*}{ Dresden } & 2 & $12 / 22 / 2029$ & 2/20/1971 & 60 \\
\hline & 3 & $1 / 12 / 2031$ & $1 / 12 / 1971$ & 60 \\
\hline Duane Arnold & 1 & $2 / 21 / 2014$ & $2 / 22 / 1974$ & 40 \\
\hline Enrico Fermi & 2 & $3 / 20 / 2025$ & $7 / 15 / 1985$ & 40 \\
\hline \multirow[t]{2}{*}{ Joseph Farley } & 1 & $6 / 25 / 2017$ & $6 / 25 / 1977$ & 40 \\
\hline & 2 & $3 / 31 / 2021$ & $3 / 31 / 1981$ & 40 \\
\hline Fitzpatrick & 1 & $10 / 17 / 2014$ & $10 / 10 / 1974$ & 40 \\
\hline Fort Calhoun & 1 & $8 / 9 / 2033$ & $8 / 9 / 1973$ & 60 \\
\hline Grand Gulf & 1 & $11 / 1 / 2024$ & $10 / 1 / 1984$ & 40 \\
\hline
\end{tabular}


TABLE A.8-1-Operating Licenses of United States Light Water Reactors (continued)

\begin{tabular}{|c|c|c|c|c|}
\hline Reactor Name & $\begin{array}{c}\text { Reactor } \\
\text { Unit }\end{array}$ & $\begin{array}{c}\text { Operating License } \\
\text { Expiration }\end{array}$ & $\begin{array}{c}\text { Operation License } \\
\text { Start Date }\end{array}$ & $\begin{array}{c}\text { Years of Operation } \\
\text { Expected }^{\mathrm{a}}\end{array}$ \\
\hline H. B. Robinson & 1 & $7 / 31 / 2030$ & 9/23/70 & 60 \\
\hline \multirow{2}{*}{ Edwin Hatch } & 1 & $8 / 6 / 2034$ & $10 / 13 / 1974$ & 60 \\
\hline & 2 & $6 / 13 / 2038$ & $6 / 13 / 1978$ & 60 \\
\hline Hope Creek & 1 & $4 / 11 / 2026$ & $7 / 25 / 1986$ & 40 \\
\hline \multirow[t]{2}{*}{ Indian Point } & 2 & $9 / 28 / 2013$ & $9 / 28 / 1973$ & 40 \\
\hline & 3 & $12 / 12 / 2015$ & $12 / 12 / 1975$ & 40 \\
\hline Kewaunee & 1 & $12 / 21 / 2013$ & $12 / 21 / 1973$ & 40 \\
\hline \multirow{2}{*}{ LaSalle County } & 1 & $4 / 17 / 2022$ & 4/17/1982 & 40 \\
\hline & 2 & $12 / 16 / 2023$ & $12 / 16 / 1983$ & 40 \\
\hline \multirow[t]{2}{*}{ Limerick } & 1 & $10 / 26 / 2024$ & $8 / 8 / 1985$ & 40 \\
\hline & 2 & $6 / 22 / 2029$ & $8 / 25 / 1989$ & 40 \\
\hline \multirow[t]{2}{*}{ McGuire } & 1 & $6 / 12 / 2041$ & 7/8/1981 & 60 \\
\hline & 2 & $3 / 3 / 2043$ & $5 / 27 / 1983$ & 60 \\
\hline \multirow{2}{*}{ Millstone } & 2 & 7/3/2035 & 9/26/1975 & 60 \\
\hline & 3 & $11 / 25 / 2045$ & $1 / 31 / 1986$ & 60 \\
\hline Monticello & 1 & 9/8/2030 & 1/9/1971 & 60 \\
\hline \multirow[t]{2}{*}{ Nine Mile Point } & 1 & $8 / 22 / 2029$ & $12 / 26 / 1974$ & 60 \\
\hline & 2 & $10 / 31 / 2046$ & 7/2/1987 & 60 \\
\hline \multirow[t]{2}{*}{ North Anna } & 1 & $4 / 1 / 2038$ & 4/1/1978 & 60 \\
\hline & 2 & $8 / 21 / 2040$ & $8 / 21 / 1980$ & 60 \\
\hline \multirow[t]{3}{*}{ Oconee } & 1 & $2 / 6 / 2033$ & 2/6/1973 & 60 \\
\hline & 2 & $10 / 6 / 2033$ & $10 / 6 / 1973$ & 60 \\
\hline & 3 & 7/19/2034 & 7/19/1974 & 60 \\
\hline Oyster Creek & 1 & $4 / 9 / 2009$ & $7 / 2 / 1969$ & 40 \\
\hline Palisades & 1 & $3 / 24 / 2031$ & $2 / 21 / 1971$ & 60 \\
\hline \multirow{3}{*}{ Palo Verde } & 1 & $6 / 1 / 2025$ & $6 / 1 / 1985$ & 40 \\
\hline & 2 & $4 / 24 / 2026$ & $4 / 24 / 86$ & 40 \\
\hline & 3 & $11 / 25 / 2027$ & $11 / 25 / 1987$ & 40 \\
\hline \multirow[t]{2}{*}{ Peach Bottom } & 2 & $8 / 8 / 2033$ & $10 / 25 / 1973$ & 60 \\
\hline & 3 & $7 / 2 / 2034$ & 7/2/1974 & 60 \\
\hline Perry & 1 & $3 / 18 / 2026$ & $11 / 13 / 1986$ & 40 \\
\hline Pilgrim & 1 & 6/8/2012 & 9/15/1972 & 40 \\
\hline \multirow[t]{2}{*}{ Point Beach } & 1 & $10 / 5 / 2030$ & $10 / 5 / 1970$ & 60 \\
\hline & 2 & $3 / 8 / 2033$ & $3 / 8 / 1973$ & 60 \\
\hline \multirow[t]{2}{*}{ Prairie Island } & 1 & $8 / 9 / 2013$ & $4 / 5 / 1974$ & 40 \\
\hline & 2 & $10 / 29 / 2014$ & 10/29/1974 & 40 \\
\hline \multirow{2}{*}{ Quad Cities } & 1 & $12 / 14 / 2032$ & $12 / 14 / 1972$ & 60 \\
\hline & 2 & $12 / 14 / 2032$ & $12 / 14 / 1972$ & 60 \\
\hline River Bend & 1 & $8 / 29 / 2025$ & $11 / 20 / 1985$ & 40 \\
\hline Robert E Ginna & 1 & 9/18/2029 & 9/19/1969 & 60 \\
\hline \multirow{2}{*}{ Salem } & 1 & $8 / 13 / 2016$ & $8 / 13 / 1976$ & 40 \\
\hline & 2 & $4 / 18 / 2020$ & $5 / 20 / 1981$ & 40 \\
\hline \multirow[t]{2}{*}{ San Onofre } & 1 & $2 / 16 / 2022$ & 2/16/1982 & 40 \\
\hline & 2 & $11 / 15 / 2022$ & $11 / 15 / 1982$ & 40 \\
\hline Seabrook & 1 & $3 / 15 / 2030$ & $3 / 15 / 1990$ & 40 \\
\hline \multirow[t]{2}{*}{ St. Lucie } & 1 & $3 / 1 / 2036$ & $3 / 1 / 1976$ & 60 \\
\hline & 2 & $4 / 6 / 2043$ & 6/10/1983 & 60 \\
\hline \multirow[t]{2}{*}{ Sequoyah } & 1 & $9 / 17 / 2020$ & $9 / 17 / 1980$ & 40 \\
\hline & 2 & $9 / 15 / 2021$ & 9/15/1981 & 40 \\
\hline \multirow{3}{*}{$\begin{array}{l}\text { Shearon Harris } \\
\text { South Texas } \\
\text { Project }\end{array}$} & 1 & $10 / 24 / 2026$ & $1 / 12 / 1987$ & 40 \\
\hline & 1 & $8 / 20 / 2027$ & $3 / 22 / 1988$ & 40 \\
\hline & 2 & $12 / 15 / 2028$ & $3 / 28 / 1989$ & 40 \\
\hline
\end{tabular}




\section{TABLE A.8-1-Operating Licenses of United States Light Water Reactors (continued)}

\begin{tabular}{|c|c|c|c|c|}
\hline Reactor Name & Reactor Unit & $\begin{array}{c}\text { Operating License } \\
\text { Expiration }\end{array}$ & $\begin{array}{c}\text { Operation License } \\
\text { Start Date }\end{array}$ & $\begin{array}{l}\text { Years of Operation } \\
\text { Expected }^{\mathrm{a}}\end{array}$ \\
\hline Virgil C. Summer & 1 & $8 / 6 / 2042$ & $11 / 12 / 1982$ & 60 \\
\hline \multirow[t]{2}{*}{ Surry } & 1 & $5 / 25 / 2032$ & $4 / 6 / 1973$ & 60 \\
\hline & 2 & $1 / 29 / 2033$ & $1 / 29 / 1973$ & 60 \\
\hline \multirow[t]{2}{*}{ Susquehanna } & 1 & $7 / 17 / 2022$ & $11 / 12 / 1982$ & 40 \\
\hline & 2 & $3 / 23 / 2024$ & $6 / 27 / 1984$ & 40 \\
\hline Three Mile Island & 1 & $4 / 19 / 2014$ & $4 / 19 / 1974$ & 40 \\
\hline \multirow[t]{2}{*}{ Turkey Point } & 3 & $7 / 19 / 2032$ & $7 / 19 / 1972$ & 60 \\
\hline & 4 & $4 / 10 / 2033$ & $4 / 10 / 1973$ & 60 \\
\hline Vermont Yankee & 1 & $3 / 21 / 2012$ & $2 / 28 / 1973$ & 39 \\
\hline \multirow[t]{2}{*}{ Vogtle } & 1 & $1 / 16 / 2027$ & $3 / 16 / 1987$ & 40 \\
\hline & 2 & 2/9/2029 & $3 / 31 / 1989$ & 40 \\
\hline Waterford & 3 & $12 / 18 / 2024$ & $3 / 16 / 1985$ & 40 \\
\hline Watts Bar & 1 & $11 / 9 / 2035$ & 2/7/1996 & 40 \\
\hline Wolf Creek & 1 & $3 / 11 / 2025$ & $6 / 4 / 1985$ & 40 \\
\hline
\end{tabular}

\section{A.9 AdVANCED Fuel CyCle Initiative—Sites AND Facilities}

As discussed in Chapter 2, the objective of the AFCI is to develop the technologies needed to: reduce the environmental consequences associated with spent nuclear fuel management, reduce the proliferation risk from the use of nuclear power, and extend uranium resources. Key elements of the initiative include:

- An Integration task, focused on providing overall consistency for the program and directing modeling and simulation and regulatory efforts for all tasks.

- A Systems Analysis task focused on investigating the interactions between program elements, evaluating deployment scenarios for various technical options, and identifying criteria that technologies would meet to allow the overall system to function effectively.

- A Separations task to develop and demonstrate advanced separations technologies for processing SNF, with an emphasis on LWR SNF.

- A Fuels task to develop and demonstrate transmutation fuels (including clad material) that could be used to destroy transuranic elements.

- A Waste Forms task to verify the long-term behavior of existing waste forms and develop new waste forms.

- A Safeguards task to develop and demonstrate new detection technologies and integrate them into high sensitivity nuclear protection systems.

- A Grid Appropriate Reactor task to develop and demonstrate small reactors that could be used in foreign countries with limited infrastructures. Such reactors also might be used within the United States. This task is an analytical activity that would eventually require the use of experimental facilities.

- A Reactor task to develop and demonstrate sodium-cooled fast reactor technologies that could be used for transmutation of nuclear wastes.

The AFCI relies on existing facilities, located mostly within DOE national laboratories. 
The facilities described in the following sections are multi-purpose facilities, so only a portion of the work performed in the facilities is associated with the AFCI. For the purposes of estimating the environmental impacts of the AFCI Program in this PEIS, it is assumed that 15 percent of the activities that take place in the facilities, and therefore 15 percent of the worker dose and 15 percent of the waste generated by the facilities, are associated with the AFCI. This assumption was made based on an estimate of the percentage of known AFCI activities and their associated impacts ongoing at the Materials and Fuels Complex (MFC) facility at INL.

\section{A.9.1 Argonne National Laboratory}

ANL has primary responsibility for the AFCI fast reactor development, waste form development, and modeling and simulation research. This research is supported by the laboratory's Sodium Test Loop Facility. Some additional activities associated with AFCI are performed in other ANL facilities used by the laboratory's Nuclear Engineering Division, but the Sodium Test Loop work is directly related to AFCI research.

\section{A.9.1.1 Sodium Test Loop}

\section{Basic description of facility and type of work performed:}

The purpose of the sodium test loop is to determine the plugging effect of flowing sodium in small channels similar to the small channels in advanced heat exchangers, such as printed circuit heat exchangers. Radiological materials are not used in the sodium test loop.

The Sodium Test Loop Facility consists of a main sodium loop including three test sections, a bypass sodium loop including a cold trap/economizer assembly, and an auxiliary system comprising argon and vacuum lines. The main loop and the bypass loop are constructed from $1 / 2$-inch $(1.2 \mathrm{~cm})$ thick, type 316 stainless steel tubing. Other major components include three electromagnetic flow controllers (one each for the three test sections), two electromagnetic pumps (one for the main loop and one for the bypass loop), five electromagnetic flow meters, and expansion and dump tanks.

The entire apparatus except the auxiliary system is placed over a stainless steel drip pan (100 in $\mathrm{x}$ 56 in $x 2$ in [2540 $\mathrm{mm} \times 1422 \mathrm{~mm} \times 51 \mathrm{~mm}])$. The sodium loop system is about $5.9 \mathrm{ft}(1.8 \mathrm{~m})$ tall and is heated by a number of ceramic band heaters. The capacity of the system is approximately 1-2 gallons of sodium.

\section{Number of employees in facility:}

The sodium test loop is a small experimental loop located in a large highbay structure in Building 370 at ANL. The sodium test loop has approximately three to four personnel that support the work, two experimentalists and two technicians (all part time).

\section{Types and quantities of radioactive wastes generated:}

There are no radioactive wastes generated as a result of work conducted in the sodium test loop. 


\section{Significant radionuclide emissions:}

There are zero radionuclide emissions because radiological materials are not used in the sodium test loop.

\section{Average person-rem for worker in facility:}

None

\section{Information on age of facility and plan for future use:}

The test loop was placed into operation during 2008 and will be used to perform AFCI experimental work for the foreseeable future.

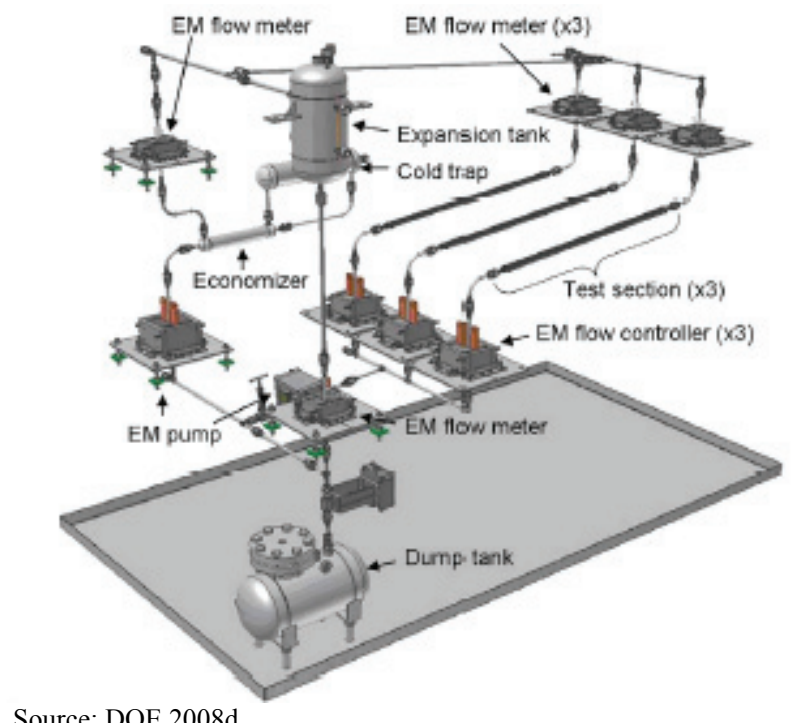

FIGURE A.9.1.1-1—Sodium Test Loop Schematic

\section{A.9.2 Hanford Site}

Pacific Northwest National Laboratory (PNNL) performs a wide range of AFCI research, including significant activities associated with advanced fuel development and waste form development, at DOE's Hanford Site (Hanford). Most of this AFCI research is performed at the site's 300 Area and the Applied Process Engineering Laboratory (APEL).

\section{A.9.2.1 $\quad 300$ Area}

\section{Basic description of facility and type of work performed:}

The 300 Area is comprised of approximately 700,000 $\mathrm{ft}^{2}\left(65,000 \mathrm{~m}^{2}\right)$ of space including approximately 50 percent of the PNNL's experimental space and all of its nuclear and radiological facilities. Four research and ancillary support buildings (Buildings 318, 325, 331, and 350) would be retained in the 300 Area if the PNNL Capability Replacement Laboratory 
project is implemented as planned. The Capability Replacement Laboratory project involves potential construction of nearly 350,000 square feet of modern laboratories by 2011 and extending the operating life of Building 325 in the 300 Area by 20 years.

Buildings $318,325,331$, and 350 are in relatively good condition but would require some upgrades. Building 325 is the Radiochemical Processing Laboratory where PNNL performs analytical radiochemistry verification and research support for complex materials. Building 331 is the Life Sciences Laboratory where PNNL performs a variety of biological sciences experiments. Building 318 is the Radiological Calibrations Building where PNNL performs calibration of radiation detection instruments and develops radiation dosimeters. Building 350 is the Plant Operations and Maintenance Facility that houses various shops.

As part of the Capability Replacement Laboratory project at PNNL, the Radiochemical Processing Laboratory is undergoing a series of upgrades to support future DOE missions. The upgrades include refurbishments of existing hot cells (including clean out and window replacement), six glovebox additions, and five modular hot cell additions with controlled atmosphere and inert gas capability to support irradiated material examinations. These upgrades also include facility infrastructure upgrades driven by the documented safety analysis for the facility, including ventilation blower modifications, seismic analysis and structural support, backup air compressor replacement, and contaminated exhaust duct replacement for worker dose control.

Of these facilities, the Radiochemical Processing Laboratory is best equipped to support AFCI missions of irradiated material examinations, separations research, and waste form development and qualification. The Radiochemical Processing Laboratory currently supports multiple program missions, including those of the Office of Science, National Nuclear Security Administration, Office of Environmental Management, and Office of Nuclear Energy. Currently less than 3 percent of the work performed at the facility is related to the AFCI. However, the facility has the capacity to support additional AFCI work. As a multi-program laboratory, future facility utilization is established and committed by contracts and work authorizations which are not approved until facility space and labor is reserved to perform the work.

\section{Number of employees in facility:}

Approximately 1,000 employees are directly linked to research currently performed in the 300 Area.

\section{Types and quantities of radioactive wastes generated:}

PNNL generates radioactive waste from its laboratory R\&D and operational activities. The types of waste generated include LLW, and transuranic and mixed transuranic wastes. The wastes are typical of laboratory research and analytical processes. Radioactive wastes generated at PNNL are generally processed and/or packaged in waste management areas located within the Building 325 prior to shipment for final disposal. Listed below is an annual estimate of radioactive waste shipped for disposal (estimate is based on fiscal years 2005-2007 data). All wastes are managed in accordance with all applicable requirements. 
LLW - 4,918 cubic feet $\left(\mathrm{ft}^{3}\right)\left(139\right.$ cubic meters $\left.\left[\mathrm{m}^{3}\right]\right)$

Mixed LLW $-536 \mathrm{ft}^{3}\left(15 \mathrm{~m}^{3}\right)$

TRU / Mixed TRU $-448 \mathrm{ft}^{3}\left(13 \mathrm{~m}^{3}\right)$

\section{Significant radionuclide emissions:}

The PNNL contribution to dose associated with Hanford's radioactive air emissions was about $6.6 \times 10^{-2}$ millirem (mrem) for Calendar year 2006 and represents greater than 99 percent of the point source emissions from Hanford. The primary isotope of concern is tritium from operations conducted in Building 325; tritium essentially makes up all of the offsite dose contribution. These releases are very small and within current permit limits, and none of the releases are associated with AFCI research, so it is estimated that no significant emissions have been produced by AFCI activities within the Hanford 300 Area.

\section{Average person-rem for worker in facility:}

The average dose to PNNL personnel, who received a measurable dose in 2006, was $73 \mathrm{mrem} /$ year. The average dose to PNNL personnel, who were monitored in 2006, was $8.5 \mathrm{mrem} / \mathrm{year}$. These should be considered approximate figures as actual doses vary from year to year, depending on activities.

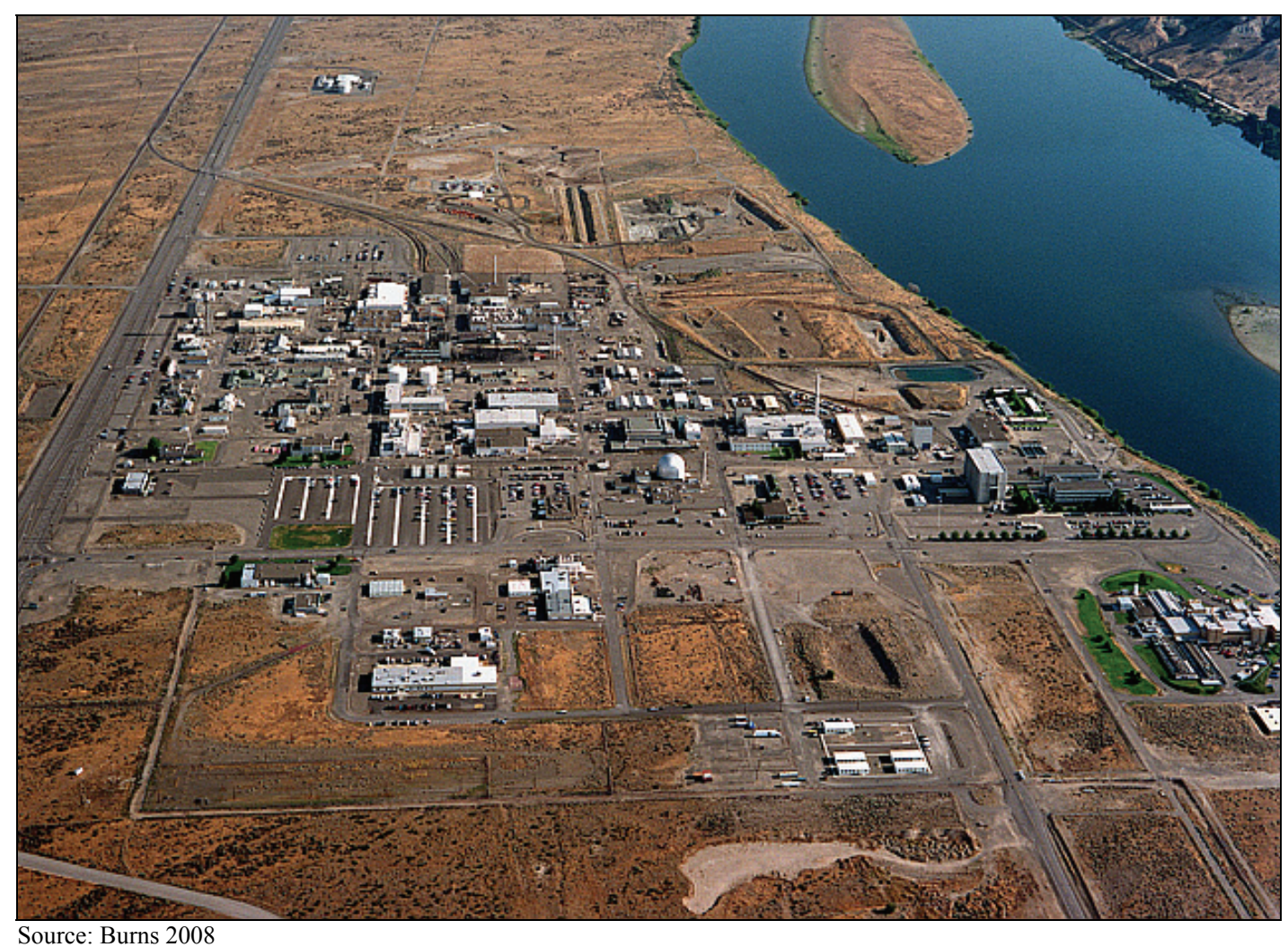

FIGURE A.9.2.1-1—Hanford Site 300 Area (Looking South to North) 


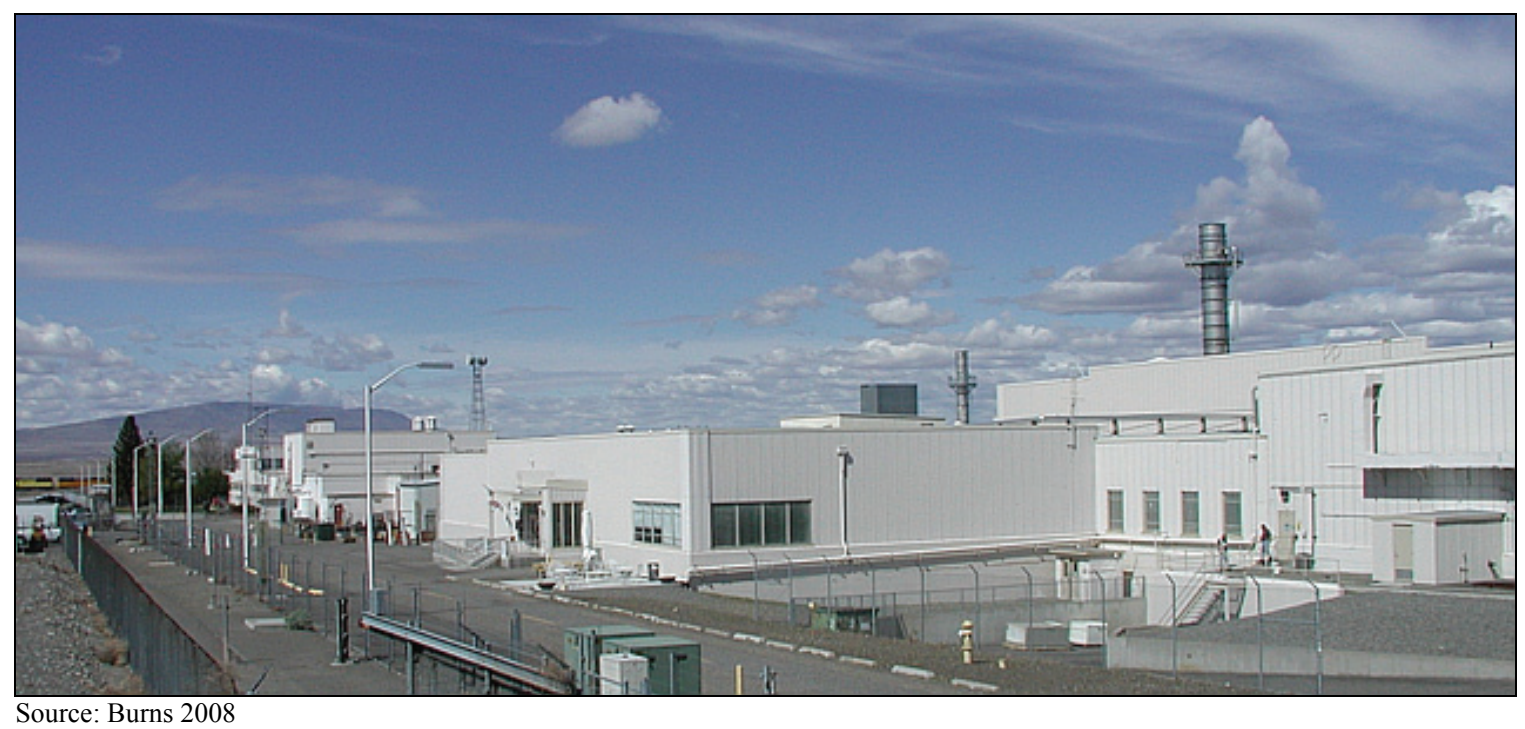

FIGURE A.9.2.1-2—Radiochemical Processing Laboratory

\section{Information on age of facility and plan for future use:}

The 300 Area is comprised of aging facilities, mostly built in the 1950s. PNNL is proposing that several new facilities be constructed on the main PNNL campus to replace 300 Area facilities.

PNNL is also proposing to build several new facilities within the 300 Area that could be used to support AFCI research. These facilities include:

- A Physical Sciences Facility-A 200,000 $\mathrm{ft}^{2}\left(19,000 \mathrm{~m}^{2}\right)$ laboratory that would house radiological, materials science, and chemical research capabilities.

- A Computational Sciences Facility-A 75,600 $\mathrm{ft}^{2}\left(7,000 \mathrm{~m}^{2}\right)$ facility that would house information analytics capabilities, computer laboratories, and electronics and instrumentation laboratories.

Construction and operation of the Physical Sciences Facility is analyzed in the Environmental Assessment for the Construction and Operation of a Physical Sciences Facility at the Pacific Northwest National Laboratory, (DOE/EA-1562) (DOE 2007e) and Finding of No Significant Impact for the Construction and Operation of a Physical Sciences Facility at the Pacific Northwest National Laboratory (DOE 2007ii).

\section{A.9.2.2 Applied Process Engineering Laboratory}

\section{Basic description of facility and type of work performed:}

The Applied Process Engineering Laboratory is an eastern Washington technology business startup user facility, sponsored in part by PNNL. APEL provides engineering- and manufacturing-scale space and chemical, biological, and electronic laboratories and equipment for developing, validating, and commercializing new products. Entrepreneurs, engineers, scientists, and university staff can access this facility. PNNL scientists, engineers, and other 
professional staff are available to APEL occupants for consulting, collaboration, or professional support.

The facility has a single story office wing on the south section, two floors of laboratories in the center section (which are serviced by an elevator), and a 28 -ft high bay along the north end with roll up door access.

The APEL facility houses the Glass Development Laboratory which is utilized by resident PNNL staff to design and test glass and ceramic waste forms. This laboratory is utilized in the AFCI project to develop and test waste forms for fission products that emerge from proposed spent fuel separations processes. Nonradioactive surrogates are used with sophisticated instrumentation and equipment designed to formulate, examine, and test various glass and ceramic waste forms.

\section{Number of employees in facility:}

The number of employees involved in AFCI research at the facility varies with the experiment being performed. Most experiments require fewer than 20 support personnel.

\section{Types and quantities of radioactive wastes generated:}

No radioactive wastes are generated as a result of AFCI research at the facility.

\section{Significant radionuclide emissions:}

There are no radionuclide emissions from the facility as a result of AFCI research.

Average person-rem for worker in facility:

AFCI research at the facility does not produce any worker dose.

\section{Information on age of facility and plan for future use:}

The APEL facility was built in 1975 and an existing structure was modified beginning in the summer of 1997 to contain wet labs, business startup bays, permitted high bay development space, and a computer center. The facility is expected to continue supporting AFCI research for the foreseeable future.

\section{A.9.3 Idaho National Laboratory}

INL has primary responsibility for AFCI research associated with systems analysis, advanced fuels development, and separations process development. INL's AFCI experimental research is performed at the Materials and Fuels Complex and Reactor Technology Complex. 


\section{A.9.3.1 Materials and Fuels Complex}

\section{Basic description of facility and type of work performed:}

The Materials and Fuels Complex (MFC) is located on a 1,700-acre (690 ha) tract of the INL about 35 miles (mi) (56 kilometers [km]) west of Idaho Falls. MFC contains 595,150 $\mathrm{ft}^{2}$ $\left(55,300 \mathrm{~m}^{2}\right)$ of floor space. This campus is dedicated to performing R\&D for reactor fuels, fuel cycle, and related materials.

Work at MFC predominantly involves fundamental research and technology development, with results disseminated openly and shared with the scientific community or made available to private industry. Other work includes training programs as well as Department of Homeland Security R\&D. Other research involves commercial interests.

Facilities housing major capabilities have been maintained and renovated over the years to support the pursuit of nuclear energy initiatives such as the AFCI. However, the MFC continues to face significant challenges from the normal aging of buildings and infrastructure, and a substantial need for upgraded laboratory facilities. Various proposals for upgrading MFC facilities are under development or under consideration, but AFCI research will continue at MFC for the foreseeable future even if these plans are not implemented.

\section{Number of employees in facility:}

The facility currently employs about 700 people.

\section{Types and quantities of radioactive wastes generated:}

Wastes generated at MFC generally include personnel protective equipment, laboratory wastes, and other materials contaminated with low levels of radionuclides. Small volumes of waste are periodically generated that have higher radionuclide and chemical contaminant concentrations but these wastes are typically still classified as low-level waste or mixed waste. Demolition and construction activities at the site also periodically produce significant volumes of building and construction debris. All wastes from the facility are managed in accordance with all applicable requirements.

\section{Significant radionuclide emissions:}

All emissions from MFC are well within allowable limits. The effective dose equivalent to the maximally exposed individual member of the public from all INL sources was $9.3 \times 10^{-2}$ millirem during 2007 (the latest year for which data is available) (DOE 2008i). This dose equivalent is less than the 10-millirem per year federal standard established under the National Emission Standards for Hazardous Air Pollutants (NESHAP). 


\section{Average person-rem for worker in facility:}

Personnel exposure at MFC is maintained as low as reasonably achievable, and controls such as additional training and management reviews of exposure are typically implemented for worker exposures greater than $100 \mathrm{mrem} /$ year. If $100 \mathrm{mrem} / \mathrm{year}$ is taken as the upper bound for average annual worker dose, and AFCI activities are assumed to account for 15 percent of worker dose at the facility, the upper bound average annual dose for AFCI work at MFC is estimated to be $15 \mathrm{mrem} / \mathrm{year}$.

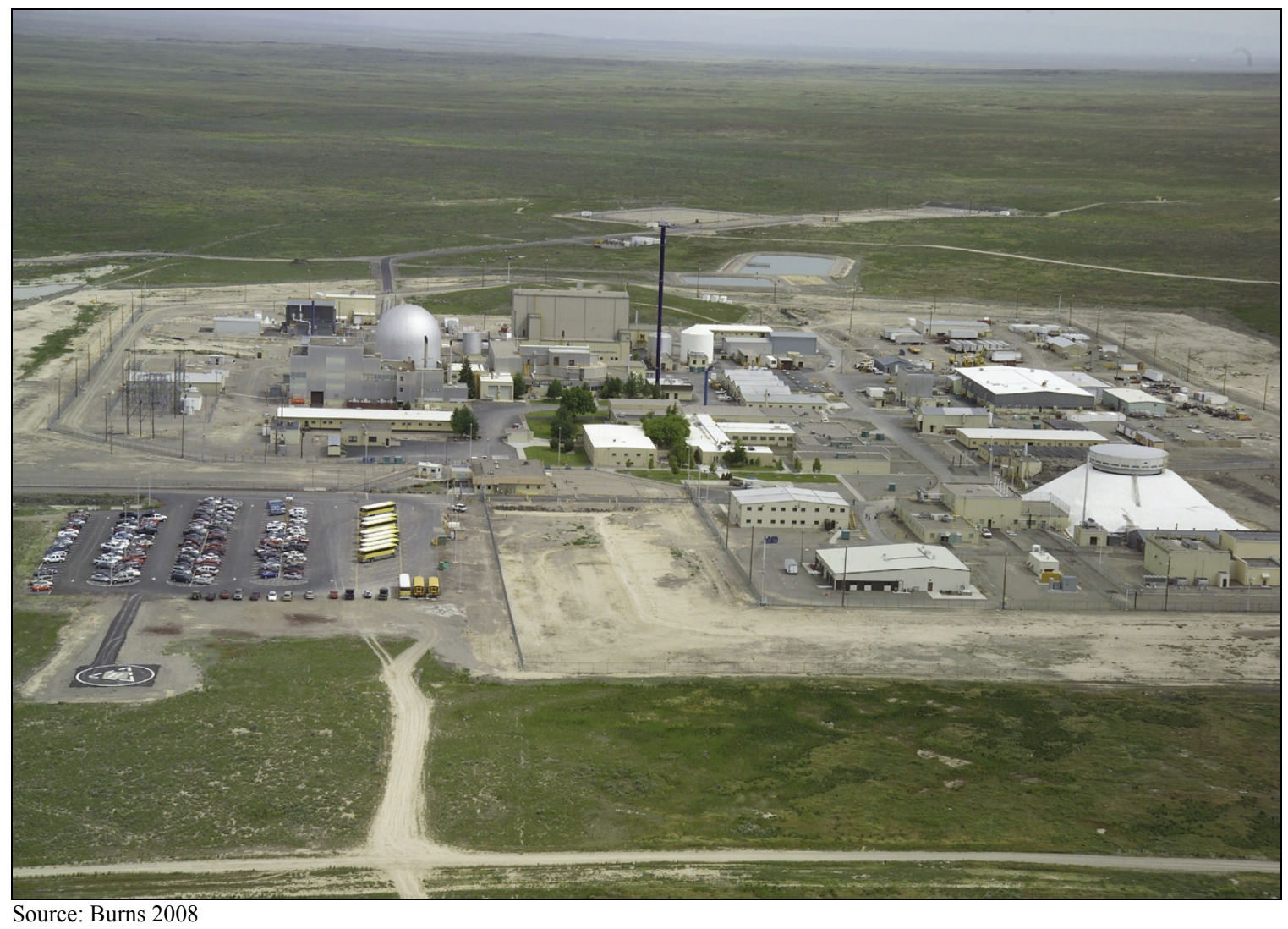

FIGURE A.9.3.1-1-Materials and Fuels Complex at INL (Looking West to East)

\section{Information on age of facility and plan for future use:}

Approximately 78 percent of MFC space is more than 30 years old. Planning for strategic modernization of MFC will focus on upgrading site-wide utilities, maintaining and modernizing major nuclear and radiological facilities, eliminating non-usable space and constructing modern facilities. Upgrade projects could include:

- Fuel fabrication facility upgrades

- Hot Fuel Examination Facility (HFEF) facility and infrastructure upgrades

- Transient Reactor Test Facility (TREAT) transient test restart and upgrade

- Fuel Cycle Facility (FCF) stack monitor and infrastructure upgrade 
- FCF remote fuel fabrication upgrade

- Analytical laboratory upgrade

The capabilities at the MFC provide support to the AFCI program, from fuel fabrication and post irradiation examination to recycle technology development and demonstration. For this reason, the FCF, HFEF, FMF, TREAT, and analytical laboratory facilities are the facilities where the R\&D activities of the AFCI program would be conducted.

\section{A.9.3.2 Reactor Technology Complex}

\section{Basic description of facility and type of work performed:}

The Reactor Technology Complex (RTC) is located on a 104-acre (42 ha) fenced complex on the INL Site about $47 \mathrm{mi}(76 \mathrm{~km})$ west of Idaho Falls, ID. RTC buildings contain approximately $620,000 \mathrm{ft}^{2}\left(57,600 \mathrm{~m}^{2}\right)$ of total floor space. The primary focus of RTC is continued operation of the Advanced Test Reactor (ATR) to conduct fuel and materials irradiation testing, nuclear safety research, and nuclear isotope production. These activities support development of advanced, safer, more efficient, and proliferation-resistant nuclear reactors, in addition to production of medical, commercial, and government-owned isotopes.

In April 2007, the DOE designated the ATR a National Scientific User Facility. As a Scientific User Facility, the ATR offers capabilities for nuclear fuel and reactor materials system development that universities, industry and regulatory agencies will be able to utilize. The ATR's core design allows many experiments to be conducted simultaneously, with each experiment receiving a different and carefully controlled level of radiation. Among the programs this research will support are AFCI and the Next Generation Nuclear Plant.

Much of the future work at RTC would involve research and technology development in collaboration with commercial and academic sectors, especially given the thrust to make ATR more accessible as a user facility. The environment necessary to efficiently foster such collaboration requires adapting the RTC area to a more campus-like layout, with enhanced access to commercial, academic, and foreign visitors and assignees, with whom active research partnering is encouraged.

\section{Number of employees in facility:}

The facility currently employs about 680 people.

\section{Types and quantities of radioactive wastes generated:}

Hazardous, LLW, and mixed LLW are generated at RTC and generally consist of personnel protective equipment, laboratory wastes, and other materials contaminated with low levels of hazardous materials and radionuclides. Small volumes of waste are periodically generated that have higher radionuclide and chemical contaminant concentrations. Demolition and construction activities at the site periodically produce significant volumes of building and construction debris. All wastes from the facility are managed in accordance with all applicable requirements. 


\section{Significant radionuclide emissions:}

All emissions from RTC are well within allowable limits. The effective dose equivalent to the maximally exposed individual member of the public from all INL sources was $9.3 \times 10^{-2}$ millirem during 2007 (the latest year for which data is available) (DOE 2008i). This dose equivalent is less than the 10-millirem per year federal standard, established under the National Emission Standards for Hazardous Air Pollutants (NESHAP).

\section{Average person-rem for worker in facility:}

The average dose to 502 people who received greater than 1 mrem at RTC during 2004, 2005, and 2006 was $86 \mathrm{mrem}$. If it is assumed that 15 percent of worker dose at RTC is associated with AFCI activities, an upper bound estimate of the average annual worker dose associated with AFCI activities at RTC is approximately $13 \mathrm{mrem} /$ year.

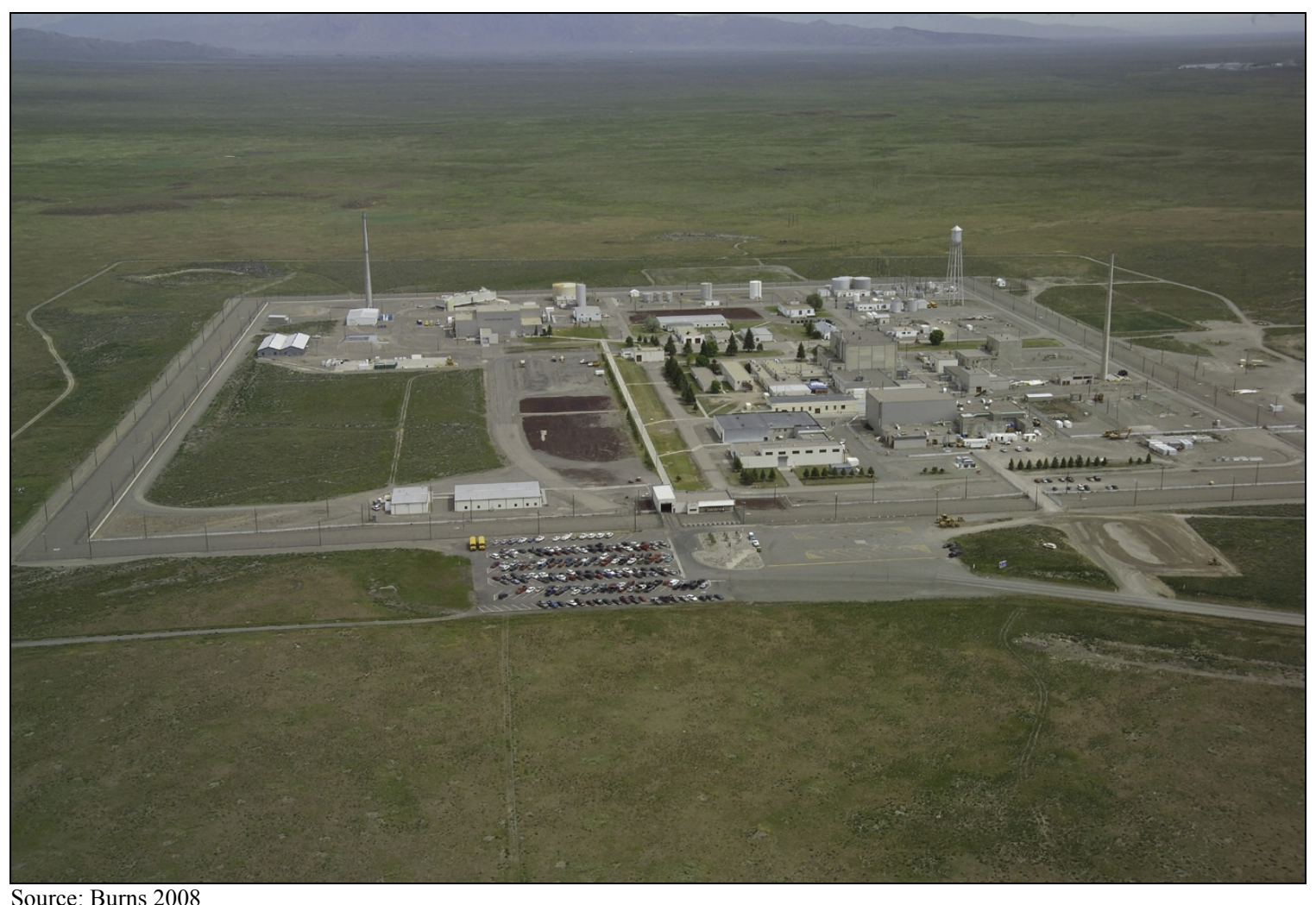

FIGURE A.9.3.2-1—Reactor Technology Complex at INL (Looking South to North)

\section{Information on age of facility and plan for future use:}

The majority of RTC facilities are more than 40 years old, with a high degree of deferred maintenance. While the ATR Life Extension Project, and other efforts, are beginning to address the need for enhanced investment in the primary ATR systems and capabilities, a substantial need remains for investment in maintenance and upgrading of major ATR support systems, facilities, and utilities. However, this situation also presents an opportunity to provide modern capabilities while eliminating dilapidated space and reducing maintenance liabilities through 
footprint reduction, space optimization, and strategic infrastructure investments. Primary upgrade needs include:

- Fast Spectrum Gas Test Loop upgrade

- ATR Life Extension Project

These upgrades would directly support the AFCI fuel irradiation and testing program. It is expected that over the duration of the AFCI the gas test loop would be used extensively by the program. Following the completion of the AFCI irradiation program however, the gas test loop would be available to other programs for use. The life extension project is a general support project that benefits all users of the ATR and as such approximately 20 percent of the utilization of the ATR could be attributed to the AFCI irradiation program over the duration of the project. Additional impacts of utilization at 20 percent versus the 15 percent currently utilized would be minimal.

\section{A.9.4 Los Alamos National Laboratory}

Los Alamos National Laboratory (LANL) supports all areas of AFCI research including major activities associated with advanced fuel development and safeguard system research. Facilities used to perform this research include the Chemistry and Metallurgy Research Building, the Los Alamos Neutron Science Center, Technical Area-35 (TA-35), and Technical Area-55 (TA-55).

\section{A.9.4.1 Chemistry and Metallurgy Research Building}

\section{Basic description of facility and type of work performed:}

The Chemistry and Metallurgy Research (CMR) Building is a research and experimental facility for analytical actinide chemistry, metallurgy, and materials science. The facility, located in Technical Area-3 (TA-3), currently houses research and experimental laboratories for analytical chemistry and plutonium and uranium chemistry and metallurgy.

CMR covers approximately 550,000 $\mathrm{ft}^{2}\left(51,100 \mathrm{~m}^{2}\right)$ divided among three stories. CMR consists of seven laboratory wings including one with heavily shielded hot cells with remote handling capabilities. CMR is the only LANL facility with full capability for analytical chemistry and metallurgical studies on small samples of plutonium and other special nuclear materials. Analyses performed at CMR are critical to DOE defense programs since they help ensure plutonium pit production and testing specifications are met.

\section{Number of employees in facility:}

More than 280 people are employed in the CMR area. 


\section{Types and quantities of radioactive wastes generated:}

The majority of research activities within the CMR laboratories involve various isotopes of uranium and plutonium. Other radionuclides, including mixed fission products, have also been used in the laboratories.

LLW arising from standard operations at CMR consists primarily of contaminated and potentially contaminated laboratory equipment, personnel protective equipment, and laboratory waste products. Construction upgrades within the building also produce LLW in the form of construction and building debris. All wastes from the facility are managed in accordance with all applicable requirements.

\section{Radiological contamination:}

Leaks and spills over the history of the CMR have resulted in various degrees of fixed and removable contamination. Alpha contamination found in the facility is typically the result of past spills of plutonium contaminated materials and beta/gamma contamination found in the facility is typically associated with past spills of uranium contaminated materials. These areas are decontaminated to the maximum extent possible when they are identified, but activities in CMR must be managed understanding the potential for radioactive contamination.

Wastes generated at CMR consist of hazardous waste, LLW, mixed LLW, TRU waste, and non-hazardous solid waste. These wastes are disposed of in accordance with all applicable requirements. The majority of the LLW is managed on-site with some quantities being shipped off-site to NTS and commercial LLW disposal facilities. The hazardous waste is shipped off-site to RCRA licensed commercial waste management facilities.

Emissions of radioactive particulate matter are sampled using a glass-fiber filter. A continuous sample of stack air is pulled through the filter, where small particles of radioactive material are captured. These samples are analyzed weekly using gross alpha/beta counting and gamma spectroscopy to identify any increase in emissions and to identify short-lived radioactive materials. Every six months, LANL takes composites of these samples for analysis at an off-site Laboratory. These composite samples are analyzed to determine the total activity of materials such as uranium-234/235/238, plutonium-238/239/240, and americium-241. These data are then combined with estimates of sampling losses and stack and sample flows to calculate emissions (LA-13732-ENV).

\section{Average person-rem for worker in facility:}

The average annual non-zero worker dose produced by activities within CMR is less than $100 \mathrm{mrem} /$ year. If $100 \mathrm{mrem} / \mathrm{year}$ is taken as the upper bound for average annual worker dose, and AFCI activities are assumed to account for 15 percent of worker dose at the facility, the upper bound average dose for AFCI work at CMR is estimated to be $15 \mathrm{mrem} / \mathrm{year}$. 


\section{Picture/schematic of facility:}

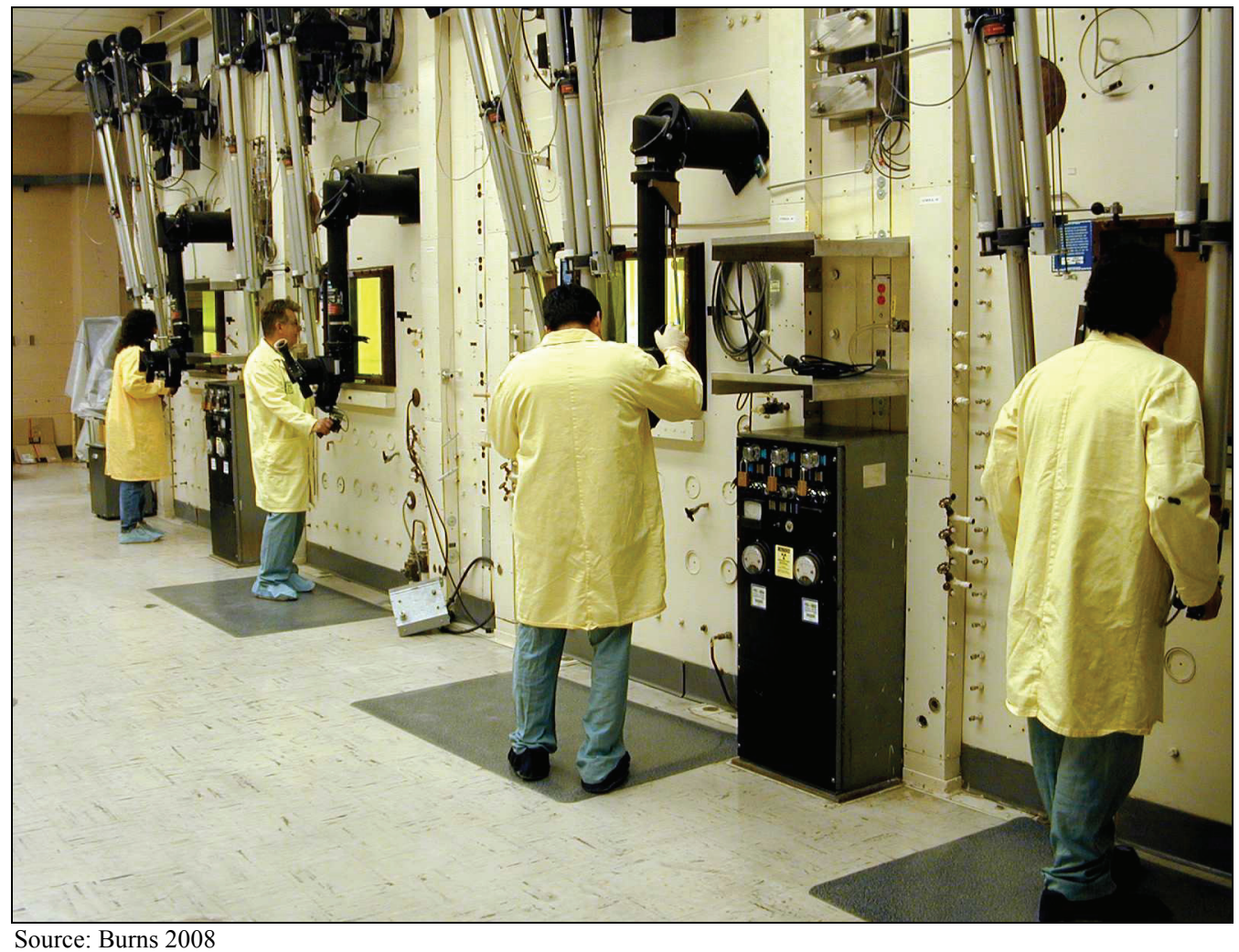

FIGURE A.9.4.1-1-Operation of Hot Cell Equipment Within the Chemistry and Metallurgy Research Building

\section{Information on age of facility and plan for future use:}

The CMR, located within TA-3, at LANL, consists of seven wings that were constructed in 1952; a new wing was added in 1960 for activities that must be performed in hot cells. The three story building is a multiple-user facility in which specific wings are associated with different activities. It is the only LANL facility with full capabilities for performing special nuclear material analytical chemistry and materials science.

The National Nuclear Security Administration (NNSA) issued a Record of Decision (ROD) on the proposed replacement of the existing CMR Building in 2004. The ROD was based upon the information contained in the Environmental Impact Statement for the Proposed Chemistry and Metallurgy Research Building Replacement Project, Los Alamos National Laboratory, Los Alamos, New Mexico, DOE/EIS-0350 (CMRR EIS), and documented the decision to build a CMR Replacement (CMRR) facility at TA-55 (DOE 2003c). The new CMRR facility would include a single, above-ground, consolidated special nuclear material-capable laboratory building (known as the CMRR-Nuclear Facility), with a separate administrative office and support functions building. The existing CMR building at LANL would be decontaminated, decommissioned, and demolished in its entirety. 
NNSA is continuing the preliminary design of the CMRR nuclear facility. NNSA will decide whether to construct this nuclear facility after completion of the Complex Transformation Supplemental Programmatic Environmental Impact Statement (SPEIS) (DOE/EIS-0236-S4) and subsequent decisions regarding plutonium manufacturing and R\&D activities (DOE 2007z). Should a site other than LANL be selected, the CMRR might still be constructed at LANL in order to provide metallurgy chemical activities in support of an interim pit production capability until a new pit production facility is available, as well as to support the special metallurgical needs of other DOE programs, such as AFCI. In any case, NNSA has determined that preliminary design of the CMRR nuclear facility would be applicable to any future pit production facility at any site analyzed in the Complex Transformation SPEIS.

\section{A.9.4.2 Los Alamos Neutron Science Center}

\section{Basic description of facility and type of work performed:}

The Los Alamos Neutron Science Center (LANSCE) lies entirely within TA-53. The facility has more than 400 buildings, including one of the largest at LANL (Building 53-3), which houses a linear accelerator and has $316,000 \mathrm{ft}^{2}\left(29,400 \mathrm{~m}^{2}\right)$ of floor space under roof. Activities at the facility consist of neutron science and nuclear physics research, proton radiography, the development of accelerators and diagnostic instruments, and production of medical radioisotopes.

The majority of the LANSCE facility is composed of the 800-million electron-volt linear accelerator, a Proton Storage Ring, and three major experimental areas: the Manuel Lujan Neutron Scattering Center, the Weapons Neutron Research (WNR) facility, and Experimental Area C. Experimental Area $\mathrm{C}$ is the location of proton radiography experiments for the Stockpile Stewardship Program. A new experimental facility for the production of ultracold neutrons is nearing completion in Area B. Experimental Area A, formerly used for materials irradiation experiments and isotope production, is currently inactive; construction of a new Isotope Production Facility was completed in CY 2002 and commissioning occurred in 2003.

The LANSCE facility includes three nuclear activities: experiments using neutron scattering by transuranics in Experimental Area ER-1/ER-2, the 1L neutron production target in Building 53-7, and Area A East in Building 53-3M, which is used for passive storage of activated materials. In 2001, TA-53-945 and 53-954 were placed on the LANL Radiological Facility List (LANL 2002). Facilities on this list satisfy the definition of radiological facility. Experimental Area ER-1/ER-2 is categorized as a Moderate Hazard facility. The remainder of the LANSCE facility is categorized as Low Hazard.

\section{Number of employees in facility:}

Tens to hundreds of people work in the LANSCE facility depending on scheduled work activities. 


\section{Types and quantities of radioactive wastes generated:}

The LANSCE facility includes four National Pollutant Discharge Elimination System (NPDES) permitted outfalls associated with operation of the facility's cooling towers (three in Los Alamos Canyon and one in Sandia Canyon). The outfalls produce a total estimated annual discharge of 29.5 million gallons (111.7 million liters) per year (DOE 2008c). Radionuclide concentrations in the outfall water are typically less than detectable concentrations.

The LANSCE facility produces approximately 1,400 cubic yards $\left(\mathrm{yd}^{3}\right)\left(1070\right.$ cubic meters $\left.\left[\mathrm{m}^{3}\right]\right)$ of LLW and $1 \mathrm{yd}^{3}\left(0.8 \mathrm{~m}^{3}\right)$ of mixed LLW per year (DOE 2008c). The waste is disposed of at permitted onsite or offsite disposal facilities. The facility also produces approximately 135,000 gallons (511,000 liters) of radioactive liquid waste per year that are treated at the facility. All wastes are managed in accordance with all applicable requirements.

\section{Significant radionuclide emissions:}

The emission stacks at the LANSCE facility in TA-53 are the primary source of LANL airborne radionuclide emissions. However, emissions from the stack meet current permit requirements. Estimates of annual emissions from the stacks are shown in Appendix C of the Final Site-Wide Environmental Impact Statement for Continued Operation of Los Alamos National Laboratory, Los Alamos, New Mexico (LANL Site-wide Environmental Impact Statement) (DOE 2008c).

\section{Average person-rem for worker in facility:}

The average annual non-zero worker dose produced by activities within the LANSCE facility is less than $100 \mathrm{mrem} / \mathrm{year}$. If $100 \mathrm{mrem} / \mathrm{year}$ is taken as the upper bound for average annual worker dose, and AFCI activities are assumed to account for 15 percent of worker dose at the facility, the upper bound average dose for AFCI work at the LANSCE facility is estimated to be $15 \mathrm{mrem} /$ year. 


\section{Picture/schematic of facility:}

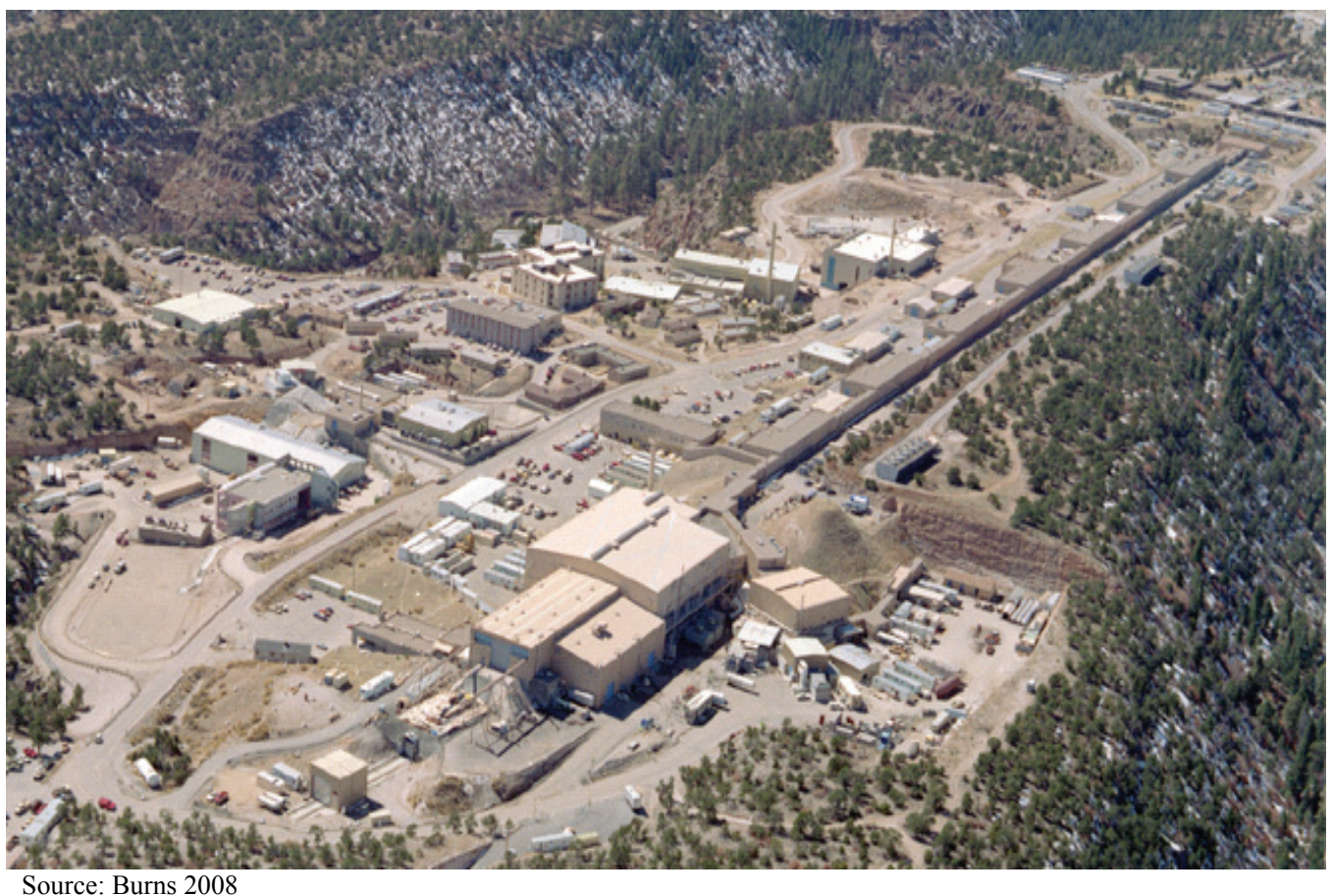

Figure A.9.4.2-1-The Los Alamos Neutron Science Center (Looking East to West)

\section{Information on age of facility and plan for future use:}

Since the LANSCE linear accelerator first accelerated protons in 1972, the facility mission has evolved considerably. However, investment in the physical infrastructure and technology has not been adequate to ensure long-term sustainable operation at high reliability. The LANSCE Refurbishment Project has received preliminary funding for design and is on schedule to progress to the architectural design stage during fiscal year 2008. The project proposes to sustain reliable facility operations well into the next decade. The LANSCE Refurbishment Project will address the following priorities: 1) replacing facility equipment where necessary to address code compliance or end-of life issues that could severely impact facility operations; 2) enhancing cost-effectiveness by system refurbishments or improvements that stabilize decreasing facility reliability and maintainability; 3 ) stabilizing the overall beam availability and reliability in a manner that is sustainable over the longer term; and 4) accomplishing the above with minimal disruption to scheduled user programs. The LANSCE Refurbishment Project could support the AFCI Program by providing proton beam power and reliability needed to support testing and qualification of advanced reactor fuels.

Upgrade work associated with the Materials Test Station (MTS) is also planned at LANSCE. The MTS is part of a fast neutron source capability project that has received preliminary approval from DOE. The project is expected to produce a non-reactor source of fast neutrons that can be used for long-term irradiation testing to support AFCI experiments. 


\section{A.9.4.3 Technical Area -35}

\section{Basic description of facility and type of work performed:}

Technical Area-35 (TA-35) is located in the north central portion of LANL. The facility is used for nuclear safeguards R\&D, primarily in the areas of lasers, physics, and materials development. Additional activities at TA-35 include research in reactor safety, optical science, and pulsed-power systems, as well as metallurgy, ceramic technology, and chemical plating. The facility was formerly the site of the Atlas project; the Atlas removal project has been completed, and the building is now available as storage space. Additionally, there are some Biosafety Level 1 and 2 laboratories at TA-35.

The Target Fabrication Facility, located at TA-35, conducts precision machining and target fabrication, polymer synthesis, and chemical and physical vapor deposition. The facility is comprised of three buildings (35-213, 35-455, and 35-458). The main building is a two-story structure encompassing approximately $61,000 \mathrm{ft}^{2}\left(5,700 \mathrm{~m}^{2}\right)$ of floor space housing activities related to weapons production and laser fusion research. The Target Fabrication Facility is located immediately to the east of Technical Area-55 (TA-55) and directly north of Technical Area-50 (TA-50). This facility is categorized as a low hazard non-nuclear facility, although low levels of radioactive material are used. Exhaust air from process equipment is filtered prior to exhaust to the atmosphere. Sanitary waste is piped to the sanitary waste disposal plant located in Technical Area-46 (TA-46). Radioactive liquid waste and liquid chemical waste are transported to the TA-50 Radioactive Liquid Waste Treatment Facility using a direct pipeline.

The Nuclear Safeguards Research Building is a three-story sheet metal, steel, and concrete block building containing approximately $45,000 \mathrm{ft}^{2}\left(4,200 \mathrm{~m}^{2}\right)$ of floor space. Levels 2 and 3 are underground. The primary activities in Building 27 are nuclear safeguards research, development, and training, which address new ways of conducting nondestructive analysis tests on samples of many different sizes and shapes to determine their uranium and plutonium content. This R\&D is supported by electronics development, mechanical design and fabrication, and administrative activities. All radioactive sources and special nuclear materials within the building are encapsulated to prevent any contamination of workers or the facility. The uranium in the facility is singly contained, and plutonium is doubly contained. No nuclear material is processed, and samples remain sealed at all times, including when they are used in instruments. Special nuclear material is used as a radiation source for calibrating and testing the performance of prototype and finished instruments, as well as for the Nuclear Safeguards Technology Training Program.

\section{Number of employees in facility:}

More than 165 people are employed at TA-35.

\section{Types and quantities of radioactive wastes generated:}

Approximately $13 \mathrm{yd}^{3}\left(10 \mathrm{~m}^{3}\right)$ of LLW and $0.5 \mathrm{yd}^{3}\left(0.4 \mathrm{~m}^{3}\right)$ of mixed LLW are generated at TA-35 per year (DOE 2008c). 


\section{Significant radionuclide emissions:}

Contaminants have been released from outfalls, air stack emissions, and cooling water and septic system discharges at TA-35. From 1951 until 1963, the wastewater treatment facility discharged effluent into Ten Site Canyon. Spills occurred from leaks in pipelines, structures, and container storage areas. Potential contaminants include metals, PCBs, volatile organic compounds, and radionuclides (NMED 2006).

Wastes currently generated at TA-35 are managed accordance with all applicable requirements.

\section{Average person-rem for worker in facility:}

The average annual non-zero worker dose produced by activities within TA-35 is less than $100 \mathrm{mrem} /$ year. If $100 \mathrm{mrem} /$ year is taken as the upper bound for average annual worker dose, and AFCI activities are assumed to account for 15 percent of worker dose at the facility, the upper bound average dose for AFCI work at TA-35 is estimated to be $15 \mathrm{mrem} / \mathrm{year}$.

\section{Information on age of facility and plan for future use:}

TA-35 has been in operation for nearly 30 years. Nuclear research activities are expected to continue at the site for the foreseeable future.

\section{A.9.4.4 Technical Area - 55}

\section{Basic description of facility and type of work performed:}

Facilities in TA-55 support pit manufacturing and surveillance and special plutonium recovery. To meet the varied needs of research, development, and plutonium processing programs at LANL, TA-55 provides chemical and metallurgical processes for recovering, purifying, and converting plutonium and other transuranics into many compounds and forms. Additional capabilities include the means to safely and securely ship, receive, handle, and store nuclear materials, as well as manage the waste and residues produced by TA-55 operations.

Core capabilities include basic and applied research into the chemistry of plutonium and other transuranics, study of nuclear materials, and a strong technology base in nuclear materials separations, processing, and recovery. The facility also supports research in plutonium metallurgy; actinide surface studies; plutonium-component fabrication technologies, including pit manufacturing and surveillance; and actinide ceramics for heat sources and MOX fuels.

Core competencies are maintained for every type of plutonium-processing activity along with the ability to convert recovered material into plutonium metal. In addition, analytical capabilities, techniques for materials control and accountability, and substantial R\&D capabilities are available to support these core competencies.

TA-55 houses a sophisticated system for nuclear materials accounting, management, and modeling; a measurement support operation; and a non-destructive assay laboratory. A nuclear 
materials packaging and transfer operation receives nuclear material at the facility and transfers shipments from the facility. Safe nuclear materials storage is also provided. All nuclear materials in process or stored on site are monitored to ensure that material balances are properly maintained and inventoried on a real-time basis. A small portion of these capabilities, mostly associated with ceramic fuel development work, are used to support the AFCI program.

\section{Number of employees in facility:}

More than 1,000 people are employed at TA-55.

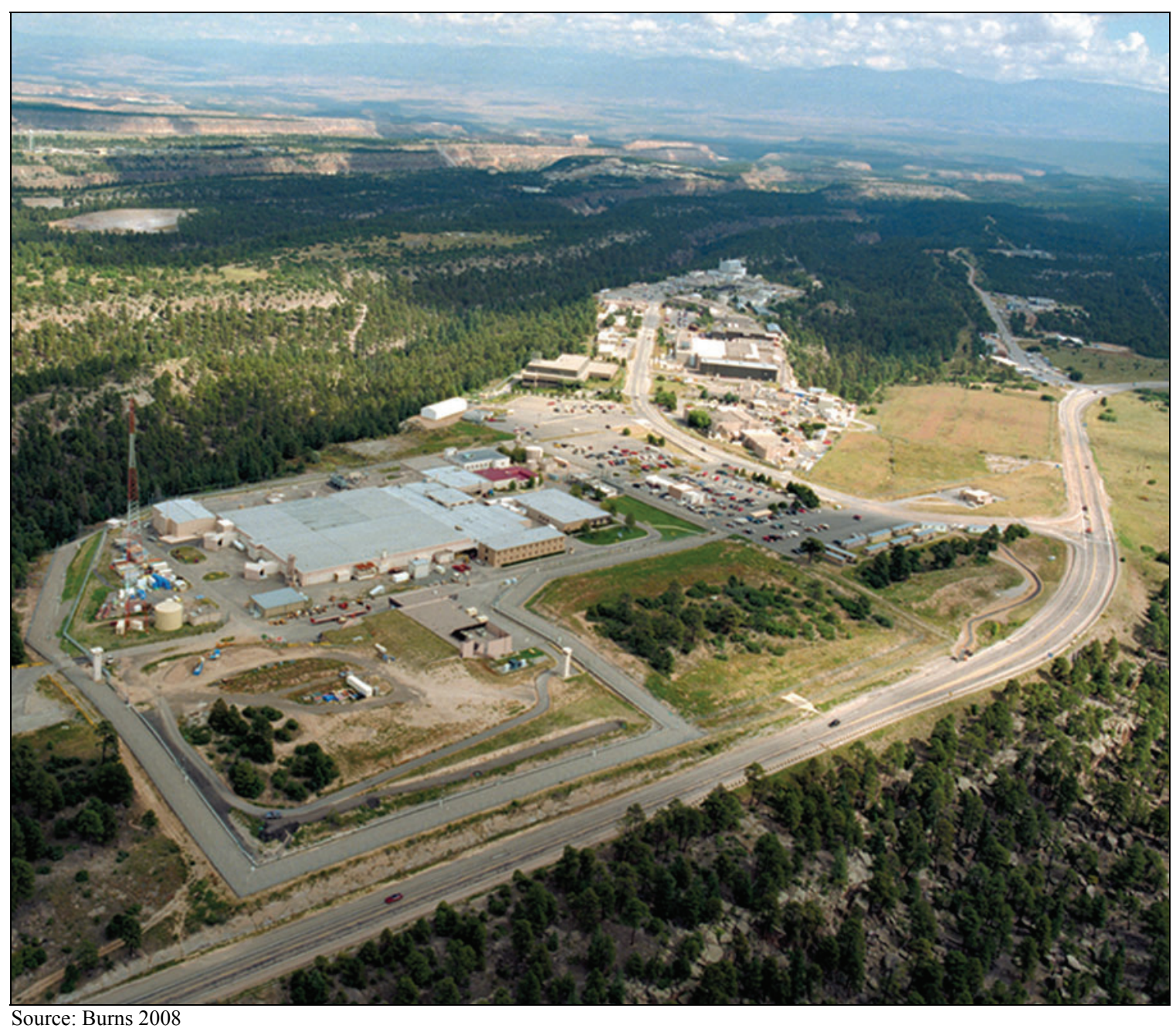

FIGURE A.9.4.4-1—Technical Area - 55 at LANL (Looking West to East)

\section{Types and quantities of radioactive wastes generated:}

Virtually all items currently disposed as LLW from TA-55 have been contaminated with plutonium and plutonium progeny (primarily Am-241). The only exceptions have been for disposal of spent radioactive calibration sources. Most waste items are described as either compactable boxed room trash (e.g., small laboratory items, personnel protective equipment, 
paper, etc.) or building debris (e.g., wood, plastic, metal, paper, rubber, glass, waste rags, absorbed liquids, equipment, concrete, and other general building debris).

\section{Radioactive waste management:}

Wastes generated at TA-55 are managed in accordance with all applicable requirements. A significant portion of waste management operations take place in facilities designed for and dedicated to waste management. Liquid wastes are treated in the Sanitary Wastewater Systems Plant, the High Explosives Wastewater Treatment Facility, and the Radioactive Liquid Waste Treatment Facility. Specialized facilities in Technical Area-50 (TA-50) and Technical Area-54 (TA-54) house a variety of chemical and radioactive waste management operations, including size reduction, compaction, assaying, and storage. Many hazardous wastes are now accumulated for up to 90 days at consolidated storage facilities and are then shipped directly offsite to RCRA permitted commercial waste facilities. Four of these consolidated storage facilities exist at LANL and two more are planned (DOE 2007z).

Most low-level radioactive waste generated at LANL is disposed onsite at TA-54, Area G. Disposal operations were expanded into Zone 4, providing sufficient capacity for operational wastes for the long term. Although there were several instances of individual facilities exceeding 1999 projections, overall LANL low-level radioactive waste generation was well below those levels predicted in 1999 for five years of the six-year period (DOE 2007z).

\section{Average person-rem for worker in facility:}

The average annual non-zero worker dose produced by activities within TA-55 is less than $100 \mathrm{mrem} / \mathrm{year}$. If $100 \mathrm{mrem} / \mathrm{year}$ is taken as the upper bound for average annual worker dose, and AFCI activities are assumed to account for 15 percent of worker dose at the facility, the upper bound average dose for AFCI work at TA-55 is estimated to be $15 \mathrm{mrem} / \mathrm{year}$.

\section{Information on age of facility and plan for future use:}

The TA-55 Plutonium Facility Complex consists of six primary buildings and a number of support, storage, security, and training structures located throughout the main complex at TA-55. Constructed in the mid-1970s, it has been in operation for approximately 30 years, and had a recent modification which became operational in November 2005. Although systems in this complex function as designed, many are near the end of their design lives and have become increasingly difficult and expensive to maintain. The National Nuclear Security Administration (NNSA) has determined that an investment is needed in the near term to upgrade electrical, mechanical, safety, and other selected facility-related systems that are approaching the end of life. Several construction projects and upgrades were planned for the Plutonium Facility Complex and analyzed in the 1999 LANL Site-wide Environmental Impact Statement. The upgrades considered in this document would support all programs conducted in the facility, including fabrication and characterization of advanced fuels for the AFCI. 


\section{A.9.5 Oak Ridge National Laboratory}

The Oak Ridge National Laboratory (ORNL) is one of the three primary installations on the DOE Oak Ridge Reservation (ORR) in Oak Ridge, Tennessee. The other installations are the Y-12 National Security Complex and the East Tennessee Technology Park (formerly the K-25 Site). ORNL performs AFCI research associated with separations and advanced fuel development, and the laboratory has primary responsibility for AFCI grid appropriate reactor research. Oak Ridge facilities used to perform AFCI research include the Radiochemical Engineering Development Center (REDC) and the Irradiated Fuel Examination Laboratory (IFEL).

\section{A.9.5.1 Irradiated Fuel Examination Laboratory}

\section{Basic description of facility and type of work performed:}

Destructive testing of SNF is performed at the IFEL. The facility is used for receipt, segmentation, and testing of SNF, and includes equipment used for voloxidation experiments and fission gas capture. Fuel is typically processed through IFEL before being transferred to REDC for chemical processing.

\section{Number of employees in facility:}

Approximately 10 personnel work in IFEL on a full time basis.

\section{Types and quantities of radioactive wastes generated:}

Wastes generated at IFEL typically include:

- $\quad 0$ to $10 \mathrm{ft}^{3}\left(0\right.$ to $\left.0.3 \mathrm{~m}^{3}\right)$ per year of highly irradiated metal from fuel testing. The metal typically includes significant quantities of Co-60, iron isotopes, and aluminum isotopes.

- Approximately 400 to $500 \mathrm{ft}^{3}$ (11 to $14 \mathrm{~m}^{3}$ ) per year of solid low level waste contaminated with mixed fission products.

- $\quad$ One 55-gallon (208-liter) drum of contact handled transuranic waste per year.

- $\quad$ Less than 2 ounces (50 grams) of SNF residue per year.

The majority of waste management facilities at Oak Ridge are operated by NNSA. Waste management facilities are located in buildings, or on sites, dedicated to their individual functions, or are colocated with other waste management facilities or operations. Many of the facilities are used for more than one waste stream. Hazardous waste is managed in accordance with all applicable regulatory requirements and is shipped off site to a RCRA permitted commercial facility. LLW and non-hazardous solid wastes are managed on site. TRU waste is packaged according to the Waste Isolation Pilot Plant (WIPP) Waste Acceptance Criteria and shipped to the WIPP for disposal. 


\section{Significant radionuclide emissions:}

Air emissions, including 1 to 3 curies of radioactive gases per year, are typically discharged from the facility's stack. Air discharges comply with current permit levels.

\section{Average person-rem for worker in facility:}

Approximately 200 mrem/year

\section{Information on age of facility and plan for future use:}

The IFEL was built in 1964 and has been in continuous use since it began operation. The facility is expected to continue operation for the foreseeable future.

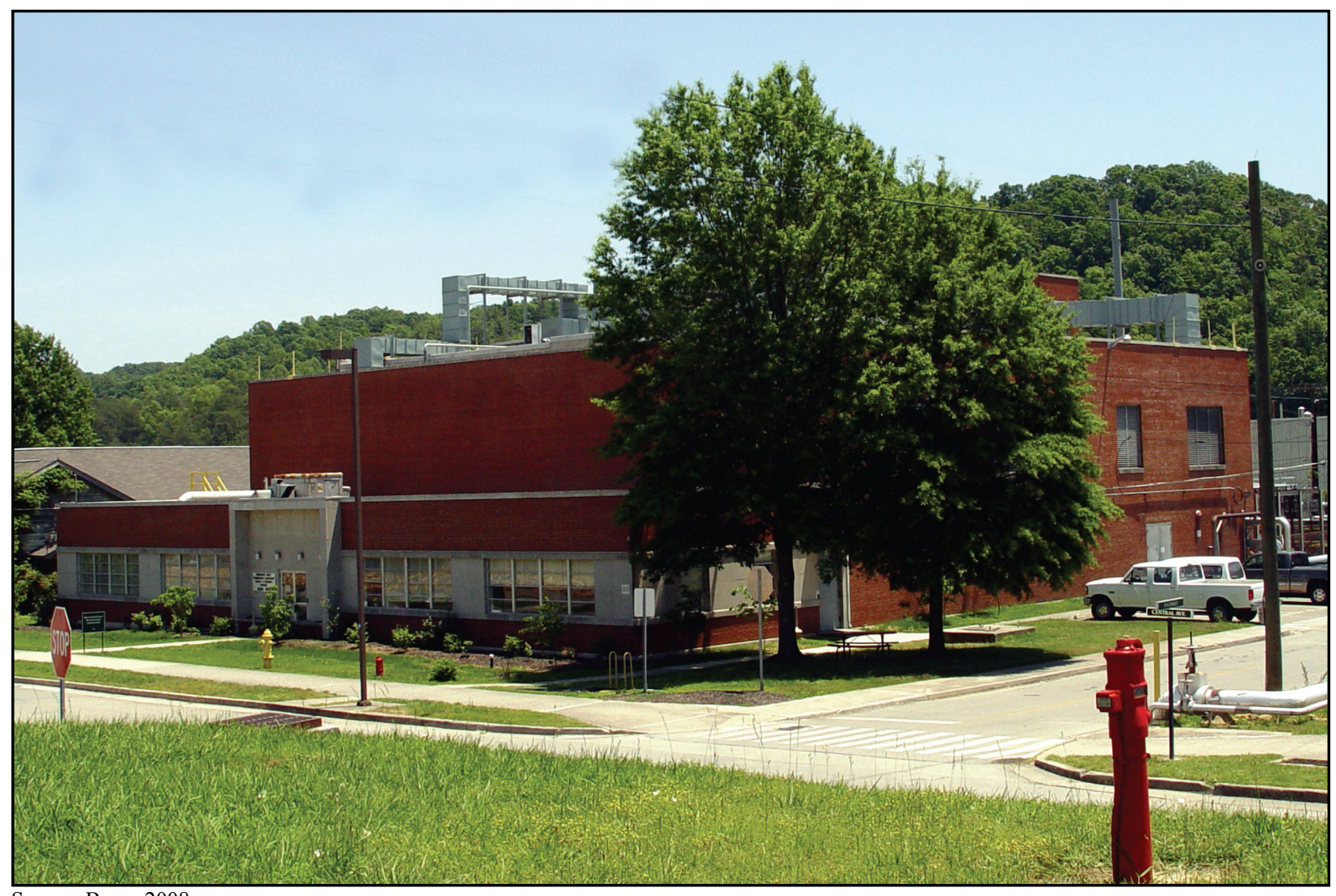

Source: Burns 2008

FIGURE A.9.5.1-1—Exterior of the Irradiated Fuel Examination Laboratory

\section{A.9.5.2 Radiochemical Engineering Development Center}

\section{Basic description of facility and type of work performed:}

The REDC at ORNL processes irradiated targets for research and industrial users. In a typical processing campaign, dekagram quantities of curium are recovered for recycle into targets for subsequent irradiation and processing, decigram quantities of californium are recovered for 
fabrication into neutron sources, and milligram quantities of einsteinium and berkelium, as well as picogram quantities of fermium, are recovered for distribution to the research community.

The heart of the REDC is a battery of nine heavily shielded hot cells housed in a two-story building. Of the nine cells, four contain chemical processing equipment for dissolution, solvent extraction, ion exchange, and precipitation operations. Three contain equipment for the preparation and inspection of transuranic element targets. One cell is used for analytical chemistry operations, and another is used for waste collection and sorting.

The Coupled End to End (CETE) experiment is a demonstration that supports development of Uranium Extraction Plus (UREX+). The CETE experiment takes single rods from an irradiated SNF bundle, and performs a number of small-scale processes on the fuel. The processes performed in the demonstration include:

- Voloxidation

- Fuel Dissolution

- Off-gas capture and treatment

- Solvent extraction

- Product solidification (U or $\mathrm{U} / \mathrm{Pu}$ or $\mathrm{U} / \mathrm{Pu} / \mathrm{Np})$

Waste products are collected, solidified (if necessary) and sent to other national laboratories including Savannah River National Laboratory, Sandia National Laboratory, Pacific Northwest National Laboratory, Los Alamos National Laboratory, and Idaho National Laboratory, for development and demonstration of immobilization processes and waste form characterization.

\section{Number of employees in facility:}

The facilities used for AFCI research are located in the complex with the High Flux Isotope Reactor (HFIR) and other isotope production facilities. The facility used for the head-end processing is also used for extensive fuels examination work. Several hundred employees work within the facilities but only about 60 to 70 percent of the employees are involved in AFCI research, on a full or part-time basis.

\section{Types and quantities of radioactive wastes generated:}

Depending on the flowsheet being used, the various streams are being collected for subsequent work on development of the waste forms. The project generates wastes all of which are managed in accordance with applicable requirements. The majority of the wastes generated at Oak Ridge are managed by NNSA. LLW is disposed of on-site, and hazardous materials are shipped off-site to RCRA licensed commercial waste management facilities.

\section{Significant radionuclide emissions:}

There are no significant radionuclide emissions from the facility. Iodine, krypton, xenon, and tritium are trapped within the facility for use in waste form development research. 


\section{Average person-rem for worker in facility:}

Approximately $50 \mathrm{mrem} /$ year

\section{A.9.6 Sandia National Laboratories/New Mexico}

Sandia National Laboratories/New Mexico (SNL/NM) has primary responsibility for AFCI activities associated with regulatory and safety research, and the laboratory supports fast reactor development. Research activities are performed at the laboratory's Brayton Cycle Demonstration Facility.

\section{A.9.6.1 Brayton Cycle Demonstration}

\section{Basic description of facility and type of work performed:}

Brayton cycles are promising power conversion systems for the higher outlet temperatures of advanced reactors but there is little experience with closed Brayton-cycle systems coupled to reactor systems. The Sandia Brayton Cycle Demonstration Facility was developed to provide a closed Brayton cycle test facility to investigate the mechanisms for control and system behavior under dynamically varying loads, during startup and shut down conditions, including the capabilities for near autonomous operation. The test-loop was first operational in fiscal year 2005 and is used to provide model validation data and simulate nuclear reactor operation with gas turbine power conversion systems. The current closed Brayton cycle test bed operates with a range of working fluids and mixtures at a nominal few bar pressures.

The turbo machinery is based on a commercially available Capstone micro-turbine power plant (30 kilowatt electric [kWe]). The Capstone open cycle gas turbine system was selected largely because it was readily adapted to a closed system with an electric heater (approximately 80 kilowatt thermal [ $\mathrm{kWth}]$ ) with an outlet temperature of $1300^{\circ} \mathrm{F}\left(730^{\circ} \mathrm{C}\right)$. Improved heater systems that better simulate the thermal hydraulics of nuclear reactors and that are capable of providing higher temperatures and more power can be used in the future. At the present time the heater is limited to $63 \mathrm{~kW}$ and $1200^{\circ} \mathrm{F}\left(630^{\circ} \mathrm{C}\right)$ outlet temperatures. The Figure A.9.6.1-1 shows an engineering drawing of the Brayton loop and an actual photo as installed at Sandia with the insulation added to the loop.

\section{Number of employees in facility:}

The Brayton Facility requires only a single trained operator to run most experiments.

\section{Types and quantities of radioactive wastes generated:}

There is no routine waste generation at the facility. When alternate working fluids are used in experiments $\left(\mathrm{CO}_{2}\right.$, inert gases, or mixtures) the gases are generally vented when the series is completed. Working fluids used to date have not required special environmental safety and health procedures. There are no radioactive materials or radiological issues with this facility. Small quantities of hazardous materials are used in general cleaning and maintenance activities. 
These materials are collected and managed on-site. Hazardous and LLW at SNL/NM is processed at 5 facilities: the, the Thermal Treatment Facility (TTF), the HWMF, the RMWMF, the Manzano Storage Bunkers (MSB), and the Solid Waste Transfer Facility (SWTF).

\section{Significant radionuclide emissions:}

There are no routine radiological emissions during operation.

\section{Average person-rem for worker in facility:}

The facility does not produce any worker exposure.
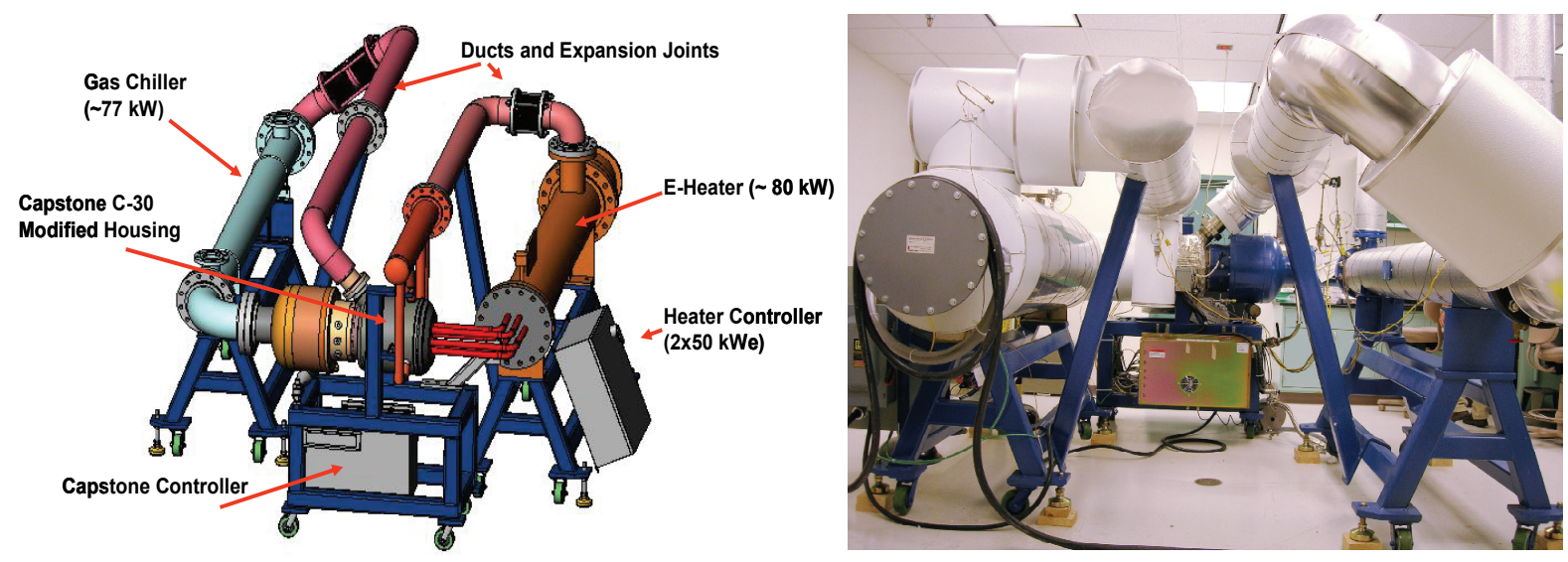

Source: Burns 2008

FIGURE A.9.6.1-1—Engineering Layout Drawing of Spent Nuclear Fuel Closed Brayton Loop (left) and Picture of Brayton Loop with Full Insulation

\section{Information on age of facility and plan for future use:}

The current closed Brayton loop would continue to be used as a test bed for investigation of control strategies, alternate working fluids and coupled reactor dynamics studies. The current priority for Brayton cycle studies is on the supercritical $\mathrm{CO}_{2}$ power conversion system for sodium or other intermediate temperature reactor systems. A series of $\mathrm{S}-\mathrm{CO}_{2}$ test loops are being developed under the Generation IV program to provide the capability for investigation of supercritical $\mathrm{CO}_{2}$ systems at the megawatt level. The first unit would be a single compressor loop to study compression near the critical point of $\mathrm{CO}_{2}$. Additional components for split flow compressor tests and power producing $\mathrm{S}-\mathrm{CO}_{2}$ Brayton systems would be added to allow full investigation of the $\mathrm{S}-\mathrm{CO}_{2}$ cycle for advanced reactors. The first $\mathrm{S}-\mathrm{CO}_{2}$ compressor tests were conducted during fiscal year 2008 with full Brayton cycle capabilities available in fiscal year 2009.

\section{A.9.7}

Savannah River National Laboratory

The Savannah River National Laboratory (SRNL) supports a wide range of AFCI research including activities associated with advanced separations, safeguards, and waste form development. Most AFCI research is performed at the laboratory's 773-A building, with some 
non-radioactive process development work performed at the Aiken County Technology Laboratory. The SRNL is part of DOE's Savannah River Site (SRS) which operates the country's only full scale reprocessing facility and has operating support facilities including a broad spectrum of waste management operations, SNF receipt and storage capabilities, and actinide stabilization and storage processes. These facilities have available laboratory space and could provide additional support to the AFCI program in the future.

\section{A.9.7.1 Building 773-A}

\section{Basic description of facility and type of work performed:}

SRNL's main laboratory building (773-A) is comprised of approximately 290,000 $\mathrm{ft}^{2}$ $\left(27,000 \mathrm{~m}^{2}\right)$ of space. The facility contains both radiological and non-radiological laboratory modules.

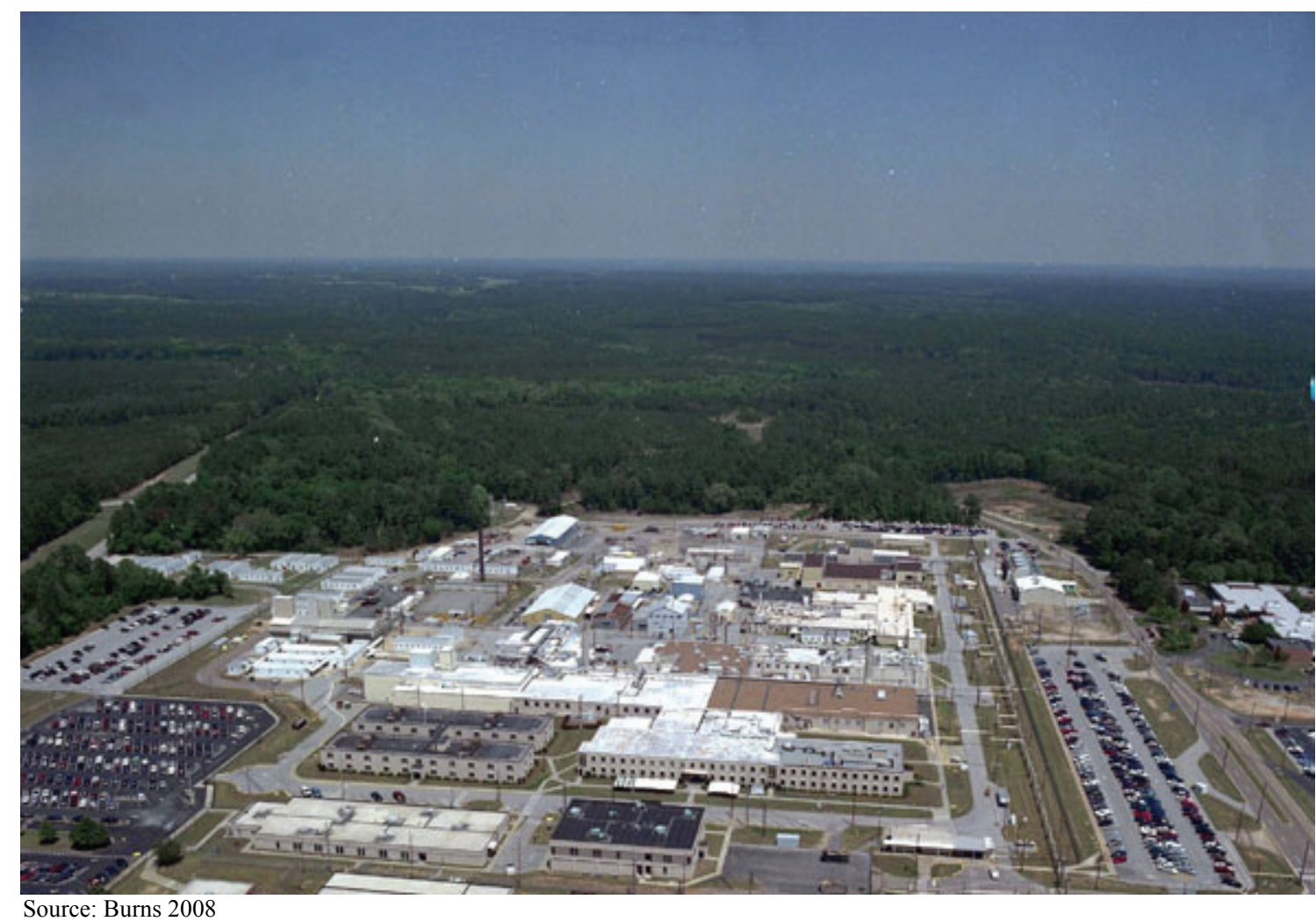

FIGURE A.9.7.1-1—The Savannah River National Laboratory

The Shielded Cells Facility within 773-A contains 16 cells that are designed to remotely handle material with doses as high as $10,000 \mathrm{rem} /$ hour. The cells provide $576 \mathrm{ft}^{2}\left(54 \mathrm{~m}^{2}\right)$ of cell footprint. The Shielded Cells were used for a demonstration of the UREX process in 2002 and would be used when high dose rate materials are handled for the AFCI R\&D, such as demonstration of the separations processes and waste form development. 


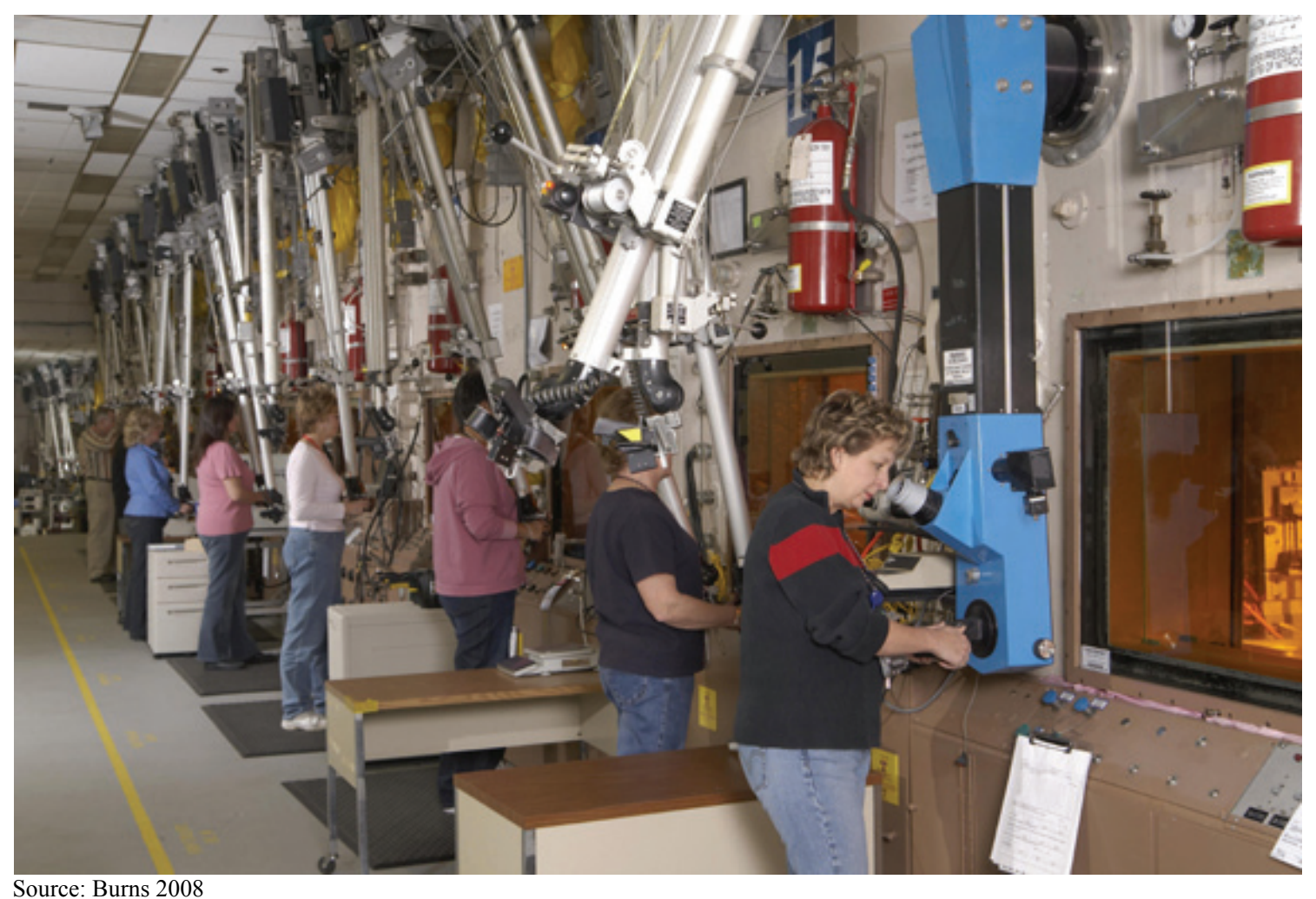

FIGURE A.9.7.1-2—The Shielded Cells Facility at the Savannah River National Laboratory

773-A also has the Intermediate Level Cells (ILC), consisting of two cells totaling $72 \mathrm{ft}^{2}\left(7 \mathrm{~m}^{2}\right)$ of cell floor space, designed to shield the radiation from a $5 \mathrm{Ci} \mathrm{Cs}^{137}$ source. These ILCs were used for experiments involving the decontamination of the zircaloy hulls resulting after dissolution of the reactor fuel. Future experiments involving fuel hulls and undissolved solids (UDS) could be performed in the ILC.

\section{A.9.7.2 Aiken County Technology Laboratory}

\section{Basic description of facility and type of work performed:}

The Aiken County Technology Laboratory (ACTL) is a laboratory facility leased by SRNL at the Savannah River Research Campus. The ACTL provides $21,000 \mathrm{ft}^{2}\left(2,000 \mathrm{~m}^{2}\right)$ of laboratories and is designated for non-radioactive work exclusively. R\&D work at ACTL that is in support of the AFCI would involve cold chemical demonstration of equipment and processes prior to deployment in the radioactive environments at Building 773-A, specifically the separations and waste development R\&D efforts.

\section{Number of employees in the facilities:}

Approximately 700 of the 900 SRNL employees at the ACTL are directly linked to R\&D work. 


\section{Types and quantities of radioactive wastes generated:}

SRNL generates radioactive waste from its laboratory R\&D and operational activities. The types of waste generated include sanitary waste, hazardous waste, LLW, transuranic waste, chemical substances listed under the Toxic Substances Control Act (TSCA) (15 U.S.C. 2601 et seq.) and mixed LLW. The wastes are typical of laboratory research and analytical processes. Radioactive wastes generated at SRNL are generally processed and/or packaged in waste management areas located within the 700 Area. DOE uses a number of methods for treating and disposing of LLW at SRS, depending on the waste form and activity. Some LLW that is not technically or economically suitable for disposal at SRS is shipped to the NTS or the EnergySolutions Disposal Facility in Utah, for disposal. At present, DOE stores hazardous wastes in three buildings and on three pads that have RCRA permits. SRS hazardous waste streams consist of a variety of materials, including mercury, chromate, lead, paint solvents, and various laboratory equipment. Hazardous waste is sent to offsite treatment and disposal facilities. DOE TRU waste is to be disposed of at the WIPP in New Mexico. SRS stores transuranic waste from past DOE onsite and offsite operations on concrete pads. In 2001, SRS initiated its program to re-package TRU waste and ship it to the WIPP.

TABLE A.9.7.2-1-Fiscal Year 2008 Forecasted Volume of Radioactive Waste

\begin{tabular}{lc}
\hline Waste Category & Fiscal Year \\
\hline Sanitary Waste & 20.4 \\
Hazardous Waste & 4.48 \\
Low Level Waste & 390 \\
Transuranic Waste & $\mathbf{3})$ \\
TSCA Waste & 7.64 \\
Mixed Low Level Waste & 0.12 \\
\hline
\end{tabular}

With the AFCI R\&D work currently representing only approximately 1 percent of the SRNL R\&D budget, it can be concluded that the AFCI work has a small impact on the existing waste volumes. All wastes are managed in accordance with applicable requirements.

\section{Significant radionuclide emissions:}

The SRNL contribution to the SRS's overall air emissions has been historically less than 1 percent. The radionuclide fraction from SRNL has historically been comparably small. With the AFCI R\&D work currently representing only approximately 1 percent of the SRNL R\&D budget, it is a credible conclusion that no significant emissions are produced by AFCI activities within the SRNL 700 Area.

\section{Average person-rem for worker in facility:}

The average dose to SRS personnel who were monitored in 2007 was $15 \mathrm{mrem} / \mathrm{year}$. The average dose to the SRNL personnel who were monitored in 2007 was $5 \mathrm{mrem} /$ year. 
With the AFCI R\&D work currently representing only approximately 1 percent of the SRNL R\&D budget, it can be concluded that the AFCI work has a small impact on the existing dose rates.

\section{Information on age of facility and plan for future use:}

Building 773-A (and its associated buildings) was built in the 1950s as part of the development of the SRS. Upgrades and replacements throughout their history have kept them serviceable. They are in compliance with all regulatory requirements and have a current approved safety basis.

Future plans are to continue to maintain and use the 773-A facilities for the foreseeable future. ACTL opened in 2001. SRNL has a long-term ACTL lease with Aiken County. 


\section{A.10 REFERENCES}

15 U.S.C. 2601 et seq. "Toxic Substance Control Act," United States Code, Washington, DC, January 3, 2006.

ANL 2002a

Argonne National Laboratory (ANL), "Feasibility Study of a Proliferation Resistant Fuel Cycle for LWR Based Transmutation of Transuranics," T.A. Taiwo, T.K. Kim, and M. Salvatores, ANL-AAA-027, Argonne National Laboratory, 2002.

ANL 2005

ANL, "Modeling of the Repository Behavior of TRISO Fuel," E.E. Morris and T.A. Bauer, ANL-AFCI-160, Argonne National Laboratory, September 2005.

ANL 2007

ANL, "Mass Flow Data for PEIS-Part II," T.K. Kim, and T.A. Taiwo, Argonne National Laboratory, September 28, 2007.

ATSDR 1999

Agency for Toxic Substances and Disease Registry (ATSDR), "ToxFAQs for Thorium," Agency for Toxic Substances and Disease Registry, July 1999.

Avens and Eller 2000

Avens, L.R. and P.G. Eller, "A Vision for Environmentally Conscious Plutonium Processing," Los Alamos Science Number 26, 2000.

Boczar et al. 2002

Boczar, P.G., G. Dyck, J. D. Sullivan, D.S. Cox, W.W.R. Inch, and P.J. Fehrenba, "CANDU Advanced Fuels and Fuel Cycles," Atomic Energy of Canada Limited, Chalk River Laboratories, Chalk River, Ontario, Canada, 2002.

Briggs et al. 2007

Briggs, L.L., J.E. Cahalan, L.W. Deitrich, T.H. Fanning, C. Grandy, R. Kellogg, T.K. Kim, and W.S. Yang, "Advanced Burner Reactor Preliminary NEPA Data Study,” ANL-AFCI-183, Nuclear Engineering Division, Argonne National Laboratory, September 21, 2007.

Burns 2008

Email from Douglas E. Burns, Idaho National Laboratory to Jeffrey Perry, U.S. Department of Energy, "FW: References," May 22, 2008.

Canada 2007

The Canadian Nuclear FAQ, "CANDU Nuclear Power Technology," The Canadian Nuclear FAQ, 2007. Accessed at www.nuclearfaq.ca/cnf_sectionA.htm on August 22, 2007. 
Canada 2008

Del Cul et al. 2002

Dixon and Wigeland 2008

DOE 2000e

DOE 2003c

DOE 2006u

DOE 2007e

DOE 20071

DOE $2007 z$
The Canadian Encyclopedia, "CANDU Reactors," J.A.L. Robinson, The Canadian Encyclopedia, 2008. Accessed at http:// www.thecanadianencyclopedia.com/index.cfm?PgNm=TCE\&Para ms=A1SEC 825457 on June 27, 2008.

Del Cul, G.D., B.B. Spencer, C.W. Forsberg, E.D. Collins and W.S. Rickman, "TRISO-Coated Fuel Processing to Support HighTemperature Gas-Cooled Reactors," ORNL/TM-2002/156, Oak Ridge National Laboratory, September 2002.

Dixon, B. and R. Wigeland, "The Impact of Burnup on the Performance of Alternative Fuel Cycles," Report No. GNEPSYSA-AI-NE-RT-2008-000252, Idaho National Laboratory, April 28, 2008.

U.S. Department of Energy (DOE), "Final Environmental Impact Statement for the Treatment and Management of Sodium-Bonded Spent Nuclear Fuel," DOE/EIS-0306, U.S. Department of Energy, Washington, DC, July 2000.

DOE, "Final Environmental Impact Statement for the Chemistry and Metallurgy Research Building Replacement Project at Los Alamos National Laboratory (CMRR EIS)," DOE/EIS-0350, Office of Nuclear Energy, Science and Technology, U.S. Department of Energy, Washington, DC, 2003.

DOE, "Report to Congress: Spent Nuclear Fuel Recycling Program Plan,” U.S. Department of Energy, Washington, DC, May 2006.

DOE, "Environmental Assessment for the Construction and Operation of a Physical Sciences Facility at the Pacific Northwest National Laboratory," DOE/EA-1562, U.S. Department of Energy, Washington, DC, January 2007.

DOE, "Global Nuclear Energy Partnership Strategic Plan" U.S. Department of Energy, Washington, DC, January 2007.

DOE, "Draft Complex Transformation Supplemental Programmatic Environmental Impact Statement (Complex Transformation SPEIS)," DOE/EIS-0236-S4, National Nuclear Security Administration, U.S. Department of Energy, Washington, DC, December 2007. 
DOE 2007ii

DOE 2008c

DOE 2008d

DOE 2008i

EIA 2008d

EPA 2005a

EPA 2005b

Finck 2007b

FPL 2008

Gee 2002

GSU 2007
DOE, "Finding of No Significant Impact for the Construction and Operation of a New Physical Sciences Facility at the Pacific Northwest National Laboratory," Pacific Northwest Site Office, Richland, WA, February 15, 2007.

DOE, "Site-Wide Environmental Impact Statement for Continued Operation of Los Alamos National Laboratory," DOE/EIS-0380, U.S. Department of Energy, Los Alamos Site Office, Los Alamos, NM, May 2008.

DOE, "Interim Report on Sodium Plugging Test," GNEP-ANLAFCI-232, Global Nuclear Energy Partnership, U.S. Department of Energy, Washington, DC, April 30, 2008.

DOE, "National Emission Standards for Hazardous Air Pollutants-Calendar Year 2007 INL Report for Radionuclides," DOE/ID-10890 (08), Idaho Operations Office, U.S. Department of Energy, Washington, DC, June, 2008.

Energy Information Administration (EIA), "U.S. Nuclear Reactors," Energy Information Administration, Washington, DC, 2008. Accessed at http://www.eia.doe.gov/cneaf/nuclear/page/ nuc_reactors/reactsum.html on May 9, 2008.

U.S. Environmental Protection Agency (EPA), "Uranium," Washington, DC, September 15, 2005.

EPA, "Uranium the Basics," U.S. Environmental Protection Agency, Washington, DC, September 2005.

Email from Phillip J. Finck, Idaho National Laboratory to Jay Rose, Tetra Tech and Francis Schwartz, DOE, "High Burn-up Write up," October 15, 2007.

Florida Power \& Light Company (FPL), "Nuclear Power Serves You," Florida Power \& Light Company, 2008. Accessed at http://www.fpl.com/environment/nuclear/

nuclear_power_serves_you.shtml on September 5, 2008.

Gee, D., “The Pebble Bed Modular Reactor," Spring 2002, EEE 460 Web Project, March 16, 2002.

Georgia State University (GSU), "Fermi I Breeder Reactor," Department of Physics and Astronomy, Georgia State University, 2007. Accessed at http://hyperphysics.phy-astr.gsu.edu/hbase/ nucene/nucacc.html on June 29, 2007. 
Hargraves 2007

Holtec 2008

Hong et al. 2007

IAEA $2002 b$

IAEA 2004a

IAEA 2005a

IAEA 2007a

IAEA $2007 b$

INL 2003

Kim et al. 2006
Hargraves, R., "Pebble Bed Reactor: Solving the U.S. Energy Crisis," April 13, 2007.

Holtec International, "SNF Assemblies Being Loaded into a Typical SNF Pool," Holtec International, 2008. Accessed at http://www.holtecinternational.com/ on January 30, 2008.

Hong, G.S., Y. Kim, and F. Venneri, "Neutronic Characterization of Sodium-Cooled fast reactors in an MHR-SFR Synergy for TRU Transmutation," Proceedings of ICAPP 2007, Nice, France, May 13-18, 2007.

International Atomic Energy Agency (IAEA), "Thorium Fuel Utilization: Options and Trends," IAEA-TECDOC-1319, Proceedings of three IAEA meetings held in Vienna in 1997, 1998 and 1999, November 1, 2002.

IAEA, "Status of Advanced Light Water Reactor Designs," IAEATECDOC-1391, International Atomic Energy Agency, Vienna, May 2004.

IAEA, "Thorium Fuel Cycle_-Potential Benefits and Challenges," IAEA-TECDOC-1450, International Atomic Energy Agency, Vienna, May 1, 2005.

IAEA, "HTGR Knowledge Base, Topical Article 6, Power Plants," International Atomic Energy Agency, Vienna 2007. Accessed at www.iaea.org/inisnkm/nkm/aws/htgr/topics/article_06.html on January 5, 2008.

IAEA, "HTGR Knowledge Base; Conference Article: Licensing of HTGRs in the United States," International Atomic Energy Agency, 2007. Accessed at http://www.iaea.org/inisnkm/nekr/ htgr/countries/abst_iwggcrl_22.html on March 12, 2008.

Idaho National Laboratory (INL), "Nuclear Fuel Cycle Closure," John Ryskamp, Idaho National Laboratory, April 2003.

Kim, T.K., T.A. Taiwo, W.S. Yang, R.N. Hill and F. Venneri, "Assessment of Deep Burnup Concept Based on Graphite Moderated Gas-Cooled Thermal Reactor," Proc. PHYSOR 2006 Advances in Nuclear Analysis and Simulation, Vancouver, British Columbia, Canada, American Nuclear Society, La Grange Park, IL, September 10-14, 2006. 
LANL 2002

Miller 2001

Nagel and Wurtz 2006

NMED 2006

NRC 1994a

NRC 2007c

NRC 2007h

NRC 2007i

NRC 2007j

NRC 2008b
Los Alamos National Laboratory (LANL), "Radiological Facility List," PS-OAB-403, Revision 1, Los Alamos National Laboratory, NM, November 14, 2002.

Miller, A.I., "Heavy Water: A Manufactures' Guide for the Hydrogen Century," Canadian Nuclear Society Bulletin, Vol. 22, No. 1, January 1, 2001.

Nagel, P. and W. Wurtz, "Dry Cooling for Power Plants and Innovative Modularization Concept," SPX Cooling Technologies, 2006. Accessed at http://spxcooling.com/pdf/PowerGen-Euro2006.pdf on May 6, 2008.

New Mexico Environment Department (NMED), "2006 New Mexico Solid Waste Annual Report," New Mexico Environment Department, July 2006. Accessed at http://www.nmenv.state. nm.us/SWB/pdf/2006SWBAnnualReport.pdf on March 22, 2007.

U.S. Nuclear Regulatory Commission (NRC), "Pre-application Safety Evaluation Report for the Power Reactor Innovative Small Module (PRISM) Liquid-Metal Reactor," NUREG-1368, Office of Nuclear Reactor Regulation, U.S. Nuclear Regulatory Commission, Washington, DC, February 1994.

NRC, "Fuel Fabrication," Nuclear Materials, Fuel Cycle Facilities, U.S. Nuclear Regulatory Commission, Washington, DC, February 2007. Accessed at www.nrc.gov/materials/fuel-cycle-fac/fuelfab.html on February 10, 2008.

NRC, "Frequently Asked Questions about Gas Centrifuge Enrichment Plants," U.S. Nuclear Regulatory Commission, Washington, DC, February 13, 2007.

NRC, "List of Power Reactor Units," U.S. Nuclear Regulatory Commission, Washington, DC, November 14, 2007.

NRC, "Locations of Fuel Cycle Facilities," U.S. Nuclear Regulatory Commission, Washington, DC, August 29, 2007. Accessed at www.nrc.gov/info-finder/materials/fuel-cycle/ on March 12, 2008.

NRC, "Fact Sheet on Mixed Oxide Fuel," U.S. Nuclear Regulatory Commission, Washington, DC, 2008. Accessed at http:/www.nrc. gov/reading-rm/doc-collections/fact-sheets/mox.html on January 30, 2008. 
Shropshire and Herring 2004 Shropshire, D.E and J.S. Herring, "Fuel-Cycle and Nuclear Material Disposition Issues Associated with High-Temperature Gas Reactors," Idaho National Laboratory, October 2004.

SRS 2007

Savannah River Site (SRS), "Savannah River Site History Highlights," 2007. Accessed at http://www.srs.gov/general/about/ history1.htm on September 17, 2008.

Suppiah and Spagnolo 1998 Suppiah, S. and D.A. Spagnolo, "Heavy Water Production Through Catalytic Exchange," Atomic Energy of Canada Limited, Chalk River Laboratories, Canadian Chapter Meeting, 1998.

Todosow 2003

Todosow, M., "Use of Thorium in Light Water Reactors," Brookhaven National Laboratory, Advances in Nuclear Fuel Management III (ANFM 2003), Hilton Head Island, SC, American Nuclear Society, La Grange Park, IL, October 5-8, 2003.

USGS 2007c

United States Geological Survey (USGS), "Mineral Commodity Summaries 2007," United States Geological Survey, U.S. Department of the Interior, Washington, DC, January 2007.

Vaden et al. 2007

Vaden, D., S.X. Li, B.R. Westphal, K.B. Davies, T.A. Johnson, and D.M. Pace, "Engineering-Scale Liquid Cadmium Cathode Experiments," Idaho National Laboratory, July 28, 2007.

WGI 2008a

Washington Group International (WGI), "Advanced Fuel Cycle Facility Conceptual Design and NEPA Support Activities (NEPA Data Study)," AFCF-ST-001, Rev. 1, Washington Group International, Western Operations Center, Denver, CO, April 2, 2008.

Whitlock 2000

Whitlock, J.J., "The Evolution of CANDU Fuel Cycles and Their Potential Contribution to World Peace," Presented at the International Youth Nuclear Congress 2000, Bratislava, Slovakia, April 9-14, 2000.

WISE Paris 2007

The World Information Service on Energy (WISE) Paris, "Two Accidents Have Left Their Traces: Monju and Tokai," The World Information Service on Energy Paris 2007. Accessed at http://www.wise-paris.org/english/ournewsletter/2/page7.html on June 29, 2007.

WNA 2008b

World Nuclear Association (WNA), "Plans for New Reactors Worldwide," World Nuclear Association, March 2008. Accessed at http://www.world-nuclear.org/info/inf17.html on May 9, 2008. 
WNA 2008c

WNA 2008d

WSRC 2007d

WSRC 2008a

WSRC $2008 b$

WSRC 2008c

WSRC 2008e

Yang et al. 2005

Yang and Park 2006
WNA, "Mixed Oxide Fuel," World Nuclear Association, February 2008. Accessed at http://www.world-nuclear.org/info/inf29.html on June 30, 2008.

WNA, "Fuel Fabrication," World Nuclear Association, 2008. Accessed at http://www.world-nuclear.org/how/

fuelfabrication.html on June 27, 2008.

Washington Savannah River Company (WSRC), "Environmental Impacts of Aqueous Process Alternatives," EAS-G-ESR-00064, Revision 0, Washington Savannah River Company, October 1, 2007.

WSRC, "Engineering Alternative Studies for Separations, NEPA Data Input Report," EAS-Q-NEP-G-00001, Revision 3, Washington Savannah River Company, April 2008.

WSRC, "Transmutation Fuel Fabrication Facility NEPA Data Input Report," EAS-Q-NEP-G-00003, Revision 2, Washington Savannah River Company, April 2008.

WSRC, "Fast Reactor Spent Nuclear Fuel Recycling Facility NEPA Data Input Report," EAS-Q-NEP-G-00004, Revision 1, Washington Savannah River Company, April 2008.

WSRC, "Engineering Alternative Studies for Separations, Waste Generation Forecast and Characterization Study - 800MT/Year UREX +1A," WH-G-ESR-G-00051, Revision 1, Washington Savannah River Company, May 2008.

Yang, M.S., H. Choi, C.J. Jeong, K.C. Song, J.W. Lee, G.I. Park, H.D. Kim, W.I. Ko, J.J. Park, K.H. Kim, H.H. Lee and J.H. Park, "The Status and Prospect of DUPIC Fuel Technology," Korean Atomic Energy Research Institute, September 1, 2005.

Yang, M.S., and J.H. Park, "Korean Assessment of the Proliferation Resistance on the Whole Fuel Cycle of DUPIC," Korean Atomic Energy Research Institute, 2006. 



\section{APPENDIX B}

\section{INTENTIONAL DESTRUCTIVE ACTS}





\section{APPENDIX B INTENTIONAL DESTRUCTIVE ACTS}

\section{B.1 INTRODUCTION}

This appendix provides an analysis of the potential public health consequences of scenarios involving intentional destructive acts, such as terrorism events, associated with alternatives analyzed in this Global Nuclear Energy Partnership (GNEP) Programmatic Environmental Impact Statement (PEIS). This appendix relies directly on the results of accident analyses presented in Appendix D for reactors and a nuclear fuel recycling center and on accident analyses presented in Appendix E for transportation of nuclear materials. However, unlike accident analysis, the analysis of intentional destructive acts provides an estimate of the potential consequences of such events, without attempting to estimate the frequency or probability that an intentional destructive act would be attempted or would succeed. This is because there is no accepted basis for estimating the frequency of intentional destructive acts, and all facilities and activities associated with alternatives analyzed in this PEIS would be protected by professional guard forces and other security measures to help prevent such attacks.

Similar to the accidents analyzed in Appendix D of this PEIS, if an intentional destructive act were to occur that involved the release of radioactive materials, workers, members of the public, and the environment would be at risk. Workers in the facility where the act occurs would be particularly vulnerable to the effects of the act because of their location. The offsite public and surrounding environment would also be at risk of exposure to the extent that meteorological conditions exist for the atmospheric dispersion of released hazardous materials.

Consequences of radiological releases were determined using the MELCOR (Methods for

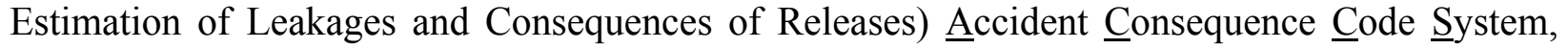
version 2 (MACCS2) computer code (Chanin and Young 1998). MACCS2 is a U.S. Department of Energy (DOE)/U.S. Nuclear Regulatory Commission (NRC)-sponsored computer code that has been widely used in support of probabilistic risk assessments for the nuclear power industry and in support of safety and National Environmental Policy Act (NEPA) documentation for facilities throughout the DOE complex.

DOE estimated radiological impacts at each of six generic representative sites. The sites were chosen to represent permutations of locations with small, medium and large surrounding populations together with meteorology representing large and small dispersion (atmospheric mixing). Impacts to three receptors were analyzed at each of these sites: 1) the maximally exposed offsite individual (MEI), assumed to be a distance of 3,020 feet (ft) (920 meters [m]) from the hypothesized release at each site; 2) the offsite population within 50 miles (mi) (80 kilometers $[\mathrm{km}])$ of each site; and, 3) a noninvolved worker $328 \mathrm{ft}(100 \mathrm{~m})$ from the release. See Section D.1.6 for a further discussion of these generic sites.

The calculation of population consequences was performed by distributing the population as appropriate for the hypothetical site into a radial grid. Ten radial rings and 16 uniform direction sectors were used to calculate the collective dose to the offsite population. Starting at the distribution center, the radial rings were every mile up to $5 \mathrm{mi}(8 \mathrm{~km})$, a ring at $10 \mathrm{mi}(16 \mathrm{~km})$, 
and a ring every $10 \mathrm{mi}(16 \mathrm{~km})$ from 10 to $50 \mathrm{mi}(16$ to $80 \mathrm{~km})$. Appendix D, Section D.1.5.1 provides details of the methodology used for radiological material release calculations.

\section{B.2 Domestic Programatic Alternatides}

Based on the analysis in Appendix D, the accident type with the greatest potential impact for each reactor type and a nuclear fuel recycling center is used as the basis for the intentional destructive act analysis. This PEIS assumes that it could be possible for an intentional destructive act to produce similar consequences because no credit is given for steps to prevent such threats or mitigate the consequences. For all facilities, except the light water reactor (LWR), the unmitigated aircraft crash presents the highest potential consequences. For the low-enriched uranium (LEU) and MOX-U-Pu fueled LWR, an internally initiated event presents the highest potential consequences.

The unmitigated aircraft crash analyses take no credit for the reactor containment. A study performed for the Nuclear Energy Institute (NEI 2002) determined that a commercial aircraft is not capable of penetrating a reactor's containment. However, a variety of potential secondary effects, such as damage to interfacing systems, could result from an aircraft crash and lead to reduced containment effectiveness. Rather than attempting to assess a degree of containment degradation, Appendix D evaluated the aircraft crash both with intact containment and without containment. This appendix only addresses the unmitigated cases, where the containment is assumed to fail. Containment survival is not a function of the reactor type, so partial or full containment after an aircraft crash is assumed to affect all reactor technologies similarly.

\section{B.2.1 No Action Alternative}

The No Action Alternative involves the construction and operation of new and replacement LWRs. This intentional destructive act analysis assumes that these would be both existing LWRs and advanced LWRs (ALWR) fueled with conventional LEU. Impacts would be dependent on many factors, including the type of act, site characteristics, and the distribution of population in the surrounding environment.

LWRs typically used in the U.S. commercial industry are designed to withstand off-normal events that could be postulated to occur, and if unmitigated, could lead to damage of nuclear fuel and release of radioactivity. This reactor concept uses a "defense in depth" approach to design where multiple levels of protection are provided against the release of radioactive material. Protective measures include the use of independent safety systems, fault detection and correction, and multiple physical barriers to the release of radioactivity from an accident. These multiple barriers limit the potential of intentional destructive acts from occurring and limit the effects in the event that one does occur.

\section{B.2.1.1 Low Enriched Uranium Fueled Light Water Reactor}

The impact of potential accidents at LWRs utilizing LEU fuel was evaluated for the Surplus Plutonium Disposition Environmental Impact Statement (hereafter SPD EIS) (DOE 1999d). The SPD EIS evaluated accidents at three existing LWR sites utilizing conventional LWR LEU fuel. 
Appendix D, Section D.2.3.1 shows the "Interfacing System Loss of Coolant Accident (Interfacing System LOCA)" is the highest consequence event for LWRs using LEU fuel. An "Interfacing System LOCA" could be caused by an intentional destructive act. Table B.2.1.1-1 presents the consequences for the LEU fueled LWR "Interfacing System LOCA." The results presented include estimates of the incremental latent cancer fatalities (LCFs) for each receptor class at the six generic sites.

TABLE B.2.1.1-1-Potential Consequences - Intentional Destructive Acts for a Low Enriched Uranium Fueled Light Water Reactor

\begin{tabular}{ccccccc}
\hline Site & \multicolumn{2}{c}{$\begin{array}{c}\text { Offsite Population } \\
\text { Dose (person-rem) }\end{array}$} & $\begin{array}{c}\text { LCFs }^{\mathbf{d}} \\
\text { MEI }\end{array}$ & Dose (rem) $^{\mathbf{a}}$ & LCFs $^{\mathbf{c}}$ & \multicolumn{2}{c}{ Noninvolved Worker $^{\mathrm{b}}$ Dose (rem) $^{\mathbf{c}}$} & LCFs $^{\mathbf{c}}$ \\
\hline Generic Site 1 $^{\mathrm{e}}$ & $1 \times 10^{6}$ & 900 & $2 \times 10^{4}$ & $1^{\mathrm{k}}$ & $2 \times 10^{5}$ & $1^{\mathrm{k}}$ \\
Generic Site 2 $^{\mathrm{f}}$ & $4 \times 10^{6}$ & 2,000 & $2 \times 10^{4}$ & $1^{\mathrm{k}}$ & $2 \times 10^{5}$ & $1^{\mathrm{k}}$ \\
Generic Site 3 $^{\mathrm{g}}$ & $2 \times 10^{7}$ & $1 \times 10^{4}$ & $2 \times 10^{4}$ & $1^{\mathrm{k}}$ & $2 \times 10^{5}$ & $1^{\mathrm{k}}$ \\
Generic Site 4 $^{\mathrm{h}}$ & $7 \times 10^{6}$ & 4,000 & $1 \times 10^{5}$ & $1^{\mathrm{k}}$ & $5 \times 10^{5}$ & $1^{\mathrm{k}}$ \\
Generic Site 5 $^{\mathrm{i}}$ & $1 \times 10^{7}$ & 8,000 & $1 \times 10^{5}$ & $1^{\mathrm{k}}$ & $5 \times 10^{5}$ & $1^{\mathrm{k}}$ \\
Generic Site 6 $^{\mathrm{j}}$ & $6 \times 10^{7}$ & $4 \times 10^{4}$ & $1 \times 10^{5}$ & $1^{\mathrm{k}}$ & $5 \times 10^{5}$ & $1^{\mathrm{k}}$ \\
\hline
\end{tabular}

${ }^{a} 3,020 \mathrm{ft}(920 \mathrm{~m})$ from the hypothesized release

${ }^{\mathrm{b}} 328 \mathrm{ft}(100 \mathrm{~m})$ from the hypothesized release

${ }^{\mathrm{c}}$ Increased likelihood of a latent cancer fatality, calculated using the factor of $6 \times 10^{-4} \mathrm{LCFs}$ per rem, doubled for receptors exposed to doses greater than $20 \mathrm{rem}$, and truncated at 1

${ }^{\mathrm{d}}$ Increased number of latent cancer fatalities, calculated using the factor of $6 \times 10^{-4} \mathrm{LCFs}$ per person-rem

${ }^{\mathrm{e}}$ Large atmospheric dispersion with a population of 304,000 within $50 \mathrm{mi}(80 \mathrm{~km})$ of the site

${ }^{\mathrm{f}}$ Large atmospheric dispersion with a population of 1,660,000 within $50 \mathrm{mi}(80 \mathrm{~km})$ of the site

${ }^{g}$ Large atmospheric dispersion with a population of $8,230,000$ within $50 \mathrm{mi}(80 \mathrm{~km})$ of the site

${ }^{\mathrm{h}}$ Small atmospheric dispersion with a population of 304,000 within $50 \mathrm{mi}(80 \mathrm{~km})$ of the site

${ }^{\mathrm{i}}$ Small atmospheric dispersion with a population of 1,660,000 within $50 \mathrm{mi}(80 \mathrm{~km})$ of the site

${ }^{\mathrm{j}}$ Small atmospheric dispersion with a population of $8,230,000$ within $50 \mathrm{mi}(80 \mathrm{~km})$ of the site

${ }^{\mathrm{k}}$ Calculated radiation dose to this individual is estimated to result in acute health effects

Using the dose-to-risk conversion factor of $6 \times 10^{-4} \mathrm{LCFs}$ per person-rem the collective population dose is estimated to result in a range of 900 to $4 \times 10^{4}$ additional LCFs depending on dispersion and population size and the potential of prompt fatalities. These consequences are consistent with the results of the NRC's Severe Accident Risks: An Assessment for Five U.S. Nuclear Power Plants, NUREG-1150 (NRC 1990) and the Surplus Plutonium Disposition Final Environmental Impact Statement, DOE/EIS-0283 (DOE 1999d) when differences in population and meteorology are considered. The higher consequences for this accident than for other reactors are the result of differences in reactor power levels and differences in assumed release parameters. These values represent an upper bound of expected consequences from any new reactor built at any likely location. For the MEI and the noninvolved worker, the calculated radiation dose to this individual is estimated to result in acute health effects (e.g., damage to the central nervous system and death).

\section{B.2.1.2 Low Enriched Uranium Fueled Advanced Light Water Reactor}

As discussed in Appendix D, Section D.2.1.2, DOE has previously analyzed accidents associated with ALWRs at a variety of locations in the Final Programmatic Environmental Impact Statement for Tritium Supply and Recycling (hereafter Tritium Supply and Recycling Final PEIS) (DOE 1995b) and that PEIS is the basis used for the accidents analyzed in Appendix D. For the ALWR, the highest consequence accident is an "Unmitigated Aircraft Crash" (Appendix D, Section D.2.1). The "Unmitigated Aircraft Crash" could also be initiated by an intentional 
destructive event, so it is also the highest consequence intentional destructive act for the ALWR. Table B.2.1.2-1 presents the accident consequences for the LEU fueled ALWR.

TABLE B.2.1.2-1-Potential Consequences - Intentional Destructive Acts for a Low Enriched Uranium Fueled Advanced Light Water Reactor

\begin{tabular}{ccccccc}
\hline Site & \multicolumn{2}{c}{$\begin{array}{c}\text { Offsite Population } \\
\text { Dose (person-rem) }\end{array}$} & LCFs $^{\mathbf{d}}$ & $\begin{array}{c}\text { MEI }^{\mathbf{a}} \\
\text { Dose (rem) }\end{array}$ & LCFs $^{\mathbf{c}}$ & \multicolumn{2}{c}{ Noninvolved Worker $^{\mathrm{b}}$} \\
Dose (rem) & LCFs $^{\mathbf{c}}$ \\
\hline Generic Site 1 $^{\mathrm{e}}$ & $2 \times 10^{5}$ & 100 & 3,000 & $1^{\mathrm{k}}$ & $3 \times 10^{4}$ & $1^{\mathrm{k}}$ \\
Generic Site 2 $^{\mathrm{f}}$ & $5 \times 10^{5}$ & 300 & 3,000 & $1^{\mathrm{k}}$ & $3 \times 10^{4}$ & $1^{\mathrm{k}}$ \\
Generic Site 3 $^{\mathrm{g}}$ & $2 \times 10^{6}$ & 1,000 & 3,000 & $1^{\mathrm{k}}$ & $3 \times 10^{4}$ & $1^{\mathrm{k}}$ \\
Generic Site 4 $^{\mathrm{h}}$ & $1 \times 10^{6}$ & 600 & $2 \times 10^{4}$ & $1^{\mathrm{k}}$ & $2 \times 10^{5}$ & $1^{\mathrm{k}}$ \\
Generic Site 5 $^{\mathrm{i}}$ & $2 \times 10^{6}$ & 1,000 & $2 \times 10^{4}$ & $1^{\mathrm{k}}$ & $2 \times 10^{5}$ & $1^{\mathrm{k}}$ \\
Generic Site 6 $^{\mathrm{j}}$ & $8 \times 10^{6}$ & 5,000 & $2 \times 10^{4}$ & $1^{\mathrm{k}}$ & $2 \times 10^{5}$ & $1^{\mathrm{k}}$ \\
\hline
\end{tabular}

${ }^{a} 3,020 \mathrm{ft}(920 \mathrm{~m})$ from the hypothesized release

b $328 \mathrm{ft}(100 \mathrm{~m})$ from the hypothesized release

${ }^{\mathrm{c}}$ Increased likelihood of a latent cancer fatality, calculated using the factor of $6 \times 10^{-4}$ LCFs per rem, doubled for receptors exposed to doses greater than 20 rem, and truncated at 1

${ }^{\mathrm{d}}$ Increased number of latent cancer fatalities, calculated using the factor of $6 \times 10^{-4} \mathrm{LCF}$ ser person-rem

${ }^{\mathrm{e}}$ Large atmospheric dispersion with a population of 304,000 within $50 \mathrm{mi}(80 \mathrm{~km})$ of the site

${ }^{\mathrm{f}}$ Large atmospheric dispersion with a population of $1,660,000$ within $50 \mathrm{mi}(80 \mathrm{~km})$ of the site

${ }^{\mathrm{g}}$ Large atmospheric dispersion with a population of $8,230,000$ within $50 \mathrm{mi}(80 \mathrm{~km})$ of the site

${ }^{\mathrm{h}}$ Small atmospheric dispersion with a population of 304,000 within $50 \mathrm{mi}(80 \mathrm{~km})$ of the site

${ }^{\mathrm{i}}$ Small atmospheric dispersion with a population of $1,660,000$ within $50 \mathrm{mi}(80 \mathrm{~km})$ of the site

${ }^{\mathrm{j}}$ Small atmospheric dispersion with a population of $8,230,000$ within $50 \mathrm{mi}(80 \mathrm{~km})$ of the site

${ }^{\mathrm{k}}$ Calculated radiation dose to this individual is estimated to result in acute health effects

Using the dose-to-risk conversion factor of $6 \times 10^{-4} \mathrm{LCF}$ per person-rem, the collective population dose is estimated to result in a range of 100 to 5,000 additional LCFs. For the MEI and noninvolved worker, the calculated radiation dose to this individual is estimated to result in acute health effects (e.g., damage to the central nervous system or death).

\section{B.2.2 Fast Reactor Recycle Alternative}

This section presents the impacts of potential intentional destructive acts associated with facilities under the Fast Reactor Recycle Alternative. This section is further sub-divided into the impacts of these events at two facilities: the nuclear fuel recycling center, and the advanced recycling reactor.

\section{B.2.2.1 Nuclear Fuel Recycling Center}

As described in Chapter 2 of this PEIS, the programmatic alternatives being considered involve a variety of open and closed fuel cycles. The closed fuel cycles would include spent nuclear fuel (SNF) separations, fuel fabrication, and waste management activities. Appendix D, Section D.2.2.1 concluded for the nuclear fuel recycling center that the impacts associated with the separations activities are more significant than those of the other activities and, based on this conclusion, this intentional destructive acts analysis focuses only on the separation activities. Separations activities are considered to represent a greater potential impact than the fuel fabrication and waste management activities because of the inventories, material forms, and hazards of the processes involved.

Rather than analyze many variations in separations technology, process steps, and equipment selection, this analysis is based on a separations design that is enveloping for the options being 
considered. The aqueous separations evaluation is based on consideration of the voloxidation step that produces a very fine powder, use of extraction columns, and vessels each sized for a full day of throughput. These design assumptions are considered enveloping for not only electrochemical separation, but also for variations in aqueous separations implementation. Therefore, the intentional destructive acts analysis results in this section for the nuclear fuel recycling center are expected to be at least as great as the consequences associated with any activities that may be used for any of the closed fuel cycle alternatives and options being considered.

Appendix D provides an analysis of facility accidents for the nuclear fuel recycling center. The highest consequence accident is an "Unmitigated Aircraft Crash," which could also be caused by an intentional destructive act. The results for the "Unmitigated Aircraft Crash" for the nuclear fuel recycling center are provided below in Table B.2.2.1-1.

TABLE B.2.2.1-1—Potential Consequences - Intentional Destructive Acts at a Nuclear Fuel Recycling Center

\begin{tabular}{|c|c|c|c|c|c|c|}
\hline \multirow[t]{2}{*}{ Site } & \multicolumn{2}{|c|}{ Offsite Population } & \multicolumn{2}{|c|}{ MEI $^{\mathbf{a}}$} & \multicolumn{2}{|c|}{ Noninvolved Worker ${ }^{b}$} \\
\hline & Dose (person-rem) & $\mathrm{LCFs}^{\mathrm{d}}$ & Dose (rem) & $\mathrm{LCFs}^{\mathrm{c}}$ & Dose (rem) & $\mathrm{LCFs}^{\mathrm{c}}$ \\
\hline Generic Site $1^{\mathrm{e}}$ & 7,000 & 4 & 60 & 0.07 & 500 & 0.6 \\
\hline Generic Site $2^{\mathrm{f}}$ & $2 \times 10^{4}$ & 10 & 60 & 0.07 & 500 & 0.6 \\
\hline Generic Site $3^{\mathrm{g}}$ & $9 \times 10^{4}$ & 60 & 60 & 0.07 & 500 & 0.6 \\
\hline Generic Site $4{ }^{\mathrm{h}}$ & $1 \times 10^{4}$ & 8 & 70 & 0.09 & 90 & 0.1 \\
\hline Generic Site $5^{\mathrm{i}}$ & $4 \times 10^{4}$ & 20 & 70 & 0.09 & 90 & 0.1 \\
\hline Generic Site $6^{\mathrm{j}}$ & $2 \times 10^{5}$ & 100 & 70 & 0.09 & 90 & 0.1 \\
\hline
\end{tabular}

${ }^{\mathrm{a}} 3,020 \mathrm{ft}(920 \mathrm{~m})$ from the hypothesized release

b $328 \mathrm{ft}(100 \mathrm{~m})$ from the hypothesized release

${ }^{\mathrm{c}}$ Increased likelihood of a latent cancer fatality, calculated using the factor of $6 \times 10^{-4}$ LCFs per rem, doubled for receptors exposed to doses greater than $20 \mathrm{rem}$, and truncated at 1

${ }^{\mathrm{d}}$ Increased number of latent cancer fatalities, calculated using the factor of $6 \times 10^{-4}$ LCFs per person-rem

${ }^{\mathrm{e}}$ Large atmospheric dispersion with a population of 304,000 within $50 \mathrm{mi}(80 \mathrm{~km})$ of the site

${ }^{\mathrm{f}}$ Large atmospheric dispersion with a population of $1,660,000$ within $50 \mathrm{mi}(80 \mathrm{~km})$ of the site

${ }^{\mathrm{g}}$ Large atmospheric dispersion with a population of $8,230,000$ within $50 \mathrm{mi}(80 \mathrm{~km})$ of the site

${ }^{\mathrm{h}}$ Small atmospheric dispersion with a population of 304,000 within $50 \mathrm{mi}(80 \mathrm{~km})$ of the site

${ }^{\mathrm{i}}$ Small atmospheric dispersion with a population of $1,660,000$ within $50 \mathrm{mi}(80 \mathrm{~km})$ of the site

${ }^{\mathrm{j}}$ Small atmospheric dispersion with a population of $8,230,000$ within $50 \mathrm{mi}(80 \mathrm{~km})$ of the site

Using the dose-to-risk conversion factor of $6 \times 10^{-4}$ LCFs per person-rem, the collective population dose is estimated to result in a range of 4 additional LCFs to 100 additional LCFs. The MEI has a probability range of 0.07 to 0.09 of a LCF should this scenario occur. The noninvolved worker has a probability range of 0.1 to 0.6 of a LCF should this scenario occur.

\section{B.2.2.2 Advanced Recycling Reactors}

DOE selected a representative event to analyze with regard to potential intentional destructive acts at the advanced recycling reactor. The "Unmitigated Aircraft Crash" is the accident with the greatest impacts to all receptors. Since the "Unmitigated Aircraft Crash" could be caused by an intentional destructive act, it is selected as the intentional destructive act for analysis. Table B.2.2.2-1 presents the "Unmitigated Aircraft Crash" for the advanced recycling reactor at each site. 


\section{TABLE B.2.2.2-1-Potential Consequences - Intentional \\ Destructive Acts at an Advanced Recycling Reactor}

\begin{tabular}{|c|c|c|c|c|c|c|}
\hline \multirow[t]{2}{*}{ Site } & \multicolumn{2}{|c|}{ Offsite Population } & \multicolumn{2}{|c|}{ MEI $^{\mathrm{a}}$} & \multicolumn{2}{|c|}{ Noninvolved Worker } \\
\hline & Dose (person-rem) & $L C F s^{d}$ & Dose (rem) & LCFs $s^{\mathrm{c}}$ & Dose (rem) & $\mathrm{LCFs}^{\mathrm{c}}$ \\
\hline Generic Site $1^{\mathrm{e}}$ & $6 \times 10^{5}$ & 400 & 6,000 & $1^{\mathrm{k}}$ & $8 \times 10^{4}$ & $1^{\mathrm{k}}$ \\
\hline Generic Site $2^{\mathrm{f}}$ & $1 \times 10^{6}$ & 800 & 6,000 & $1^{\mathrm{k}}$ & $8 \times 10^{4}$ & $1^{\mathrm{k}}$ \\
\hline Generic Site $3^{g}$ & $7 \times 10^{6}$ & 4,000 & 6,000 & $1^{\mathrm{k}}$ & $8 \times 10^{4}$ & $1^{\mathrm{k}}$ \\
\hline Generic Site $4^{\mathrm{h}}$ & $3 \times 10^{6}$ & 2,000 & $5 \times 10^{4}$ & $1^{\mathrm{k}}$ & $4 \times 10^{5}$ & $1^{\mathrm{k}}$ \\
\hline Generic Site $5^{\mathrm{i}}$ & $5 \times 10^{6}$ & 3,000 & $5 \times 10^{4}$ & $1^{\mathrm{k}}$ & $4 \times 10^{5}$ & $1^{\mathrm{k}}$ \\
\hline Generic Site $6^{\mathrm{j}}$ & $2 \times 10^{7}$ & $1 \times 10^{4}$ & $5 \times 10^{4}$ & $1^{\mathrm{k}}$ & $4 \times 10^{5}$ & $1^{\mathrm{k}}$ \\
\hline
\end{tabular}

${ }^{\mathrm{a}} 3,020 \mathrm{ft}(920 \mathrm{~m})$ from the hypothesized release

b $328 \mathrm{ft}(100 \mathrm{~m})$ from the hypothesized release

${ }^{\mathrm{c}}$ Increased likelihood of a latent cancer fatality, calculated using the factor of $6 \times 10^{-4}$ LCFs per rem, doubled for receptors exposed to doses greater than 20 rem, and truncated at 1

${ }^{\mathrm{d}}$ Increased number of latent cancer fatalities, calculated using the factor of $6 \times 10^{-4} \mathrm{LCFs}$ per person-rem

${ }^{\mathrm{e}}$ Large atmospheric dispersion with a population of 304,000 within $50 \mathrm{mi}(80 \mathrm{~km})$ of the site

${ }^{\mathrm{f}}$ Large atmospheric dispersion with a population of $1,660,000$ within $50 \mathrm{mi}(80 \mathrm{~km})$ of the site

${ }^{\mathrm{g}}$ Large atmospheric dispersion with a population of $8,230,000$ within $50 \mathrm{mi}(80 \mathrm{~km})$ of the site

${ }^{\mathrm{h}}$ Small atmospheric dispersion with a population of 304,000 within $50 \mathrm{mi}(80 \mathrm{~km})$ of the site

${ }^{\mathrm{i}}$ Small atmospheric dispersion with a population of $1,660,000$ within $50 \mathrm{mi}(80 \mathrm{~km})$ of the site

${ }^{\mathrm{j}}$ Small atmospheric dispersion with a population of $8,230,000$ within $50 \mathrm{mi}(80 \mathrm{~km})$ of the site

${ }^{\mathrm{k}}$ Calculated radiation dose to this individual is estimated to result in acute health effects

Using the dose-to-risk conversion factor of $6 \times 10^{-4} \mathrm{LCFs}$ per person-rem the collective population dose is estimated to result in a range of 400 to $1 \times 10^{4}$ additional LCFs within the entire surrounding population. For the MEI and noninvolved worker, the calculated radiation dose to this individual is estimated to result in acute health effects (e.g., damage to the central nervous system or death).

\section{B.2.3 Thermal/Fast Reactor Recycle Alternative}

This section presents the impacts of potential intentional destructive acts associated with facilities under the Thermal/Fast Reactor Recycle Alternative. The impacts for the Thermal/Fast Reactor Recycle Alternative would be the same as the Fast Reactor Recycle Alternative, with the exception of the potential for LWR events associated with MOX-U-Pu fuel.

\section{B.2.3.1 Mixed Oxide-Uranium-Plutonium Fueled Light Water Reactor}

The impact of potential accidents at LWRs utilizing MOX-U-Pu fuel was evaluated for the SPD EIS (DOE 1999d). The SPD EIS evaluated accidents at three existing LWR sites utilizing conventional LWR LEU fuel, as well as cores consisting of 40 percent mixed oxide (MOX) fuel and 60 percent conventional LWR fuel. This section evaluates the LWR using the MOX-U-Pu fuel. The SPD EIS considered both design basis and beyond design basis events, both of which are considered here. While design basis events are considered, this analysis is focused on the highest consequence scenario, which is a beyond design basis event. Table B.2.3.1-1 presents the consequences for the MOX-U-Pu fueled LWR "Interfacing System LOCA," which could be caused by an intentional destructive act. Appendix D, Section D.2.3.1 "Interfacing System LOCA" provides the details of its analysis. The results presented include estimates of the incremental LCFs for each receptor at the six generic sites. 
TABLE B.2.3.1-1-Potential Consequences - Intentional Destructive Acts for a Mixed Oxide-Uranium-Plutonium Light Water Reactor

\begin{tabular}{|c|c|c|c|c|c|c|}
\hline \multirow[t]{2}{*}{ Site } & \multicolumn{2}{|c|}{ Offsite Population } & \multicolumn{2}{|c|}{ MEI $^{\mathrm{a}}$} & \multicolumn{2}{|c|}{ Noninvolved Worker } \\
\hline & Dose (person-rem) & $\mathrm{LCFs}^{\mathrm{d}}$ & Dose (rem) & $\mathrm{LCFs}^{\mathrm{c}}$ & Dose (rem) & $\mathrm{LCFs}^{\mathrm{c}}$ \\
\hline Generic Site $1^{\mathrm{e}}$ & $2 \times 10^{6}$ & 1,000 & $2 \times 10^{4}$ & $1^{\mathrm{k}}$ & $2 \times 10^{5}$ & $1^{\mathrm{k}}$ \\
\hline Generic Site $2^{\mathrm{f}}$ & $4 \times 10^{6}$ & 2,000 & $2 \times 10^{4}$ & $1^{\mathrm{k}}$ & $2 \times 10^{5}$ & $1^{\mathrm{k}}$ \\
\hline Generic Site $3^{g}$ & $2 \times 10^{7}$ & $1 \times 10^{4}$ & $2 \times 10^{4}$ & $1^{\mathrm{k}}$ & $2 \times 10^{5}$ & $1^{\mathrm{k}}$ \\
\hline Generic Site $4^{h}$ & $7 \times 10^{6}$ & 4,000 & $1 \times 10^{5}$ & $1^{\mathrm{k}}$ & $5 \times 10^{5}$ & $1^{\mathrm{k}}$ \\
\hline Generic Site $5^{\mathrm{i}}$ & $2 \times 10^{7}$ & 9,000 & $1 \times 10^{5}$ & $1^{\mathrm{k}}$ & $5 \times 10^{5}$ & $1^{\mathrm{k}}$ \\
\hline Generic Site $6^{\mathrm{j}}$ & $6 \times 10^{7}$ & $4 \times 10^{4}$ & $1 \times 10^{5}$ & $1^{\mathrm{k}}$ & $5 \times 10^{5}$ & $1^{\mathrm{k}}$ \\
\hline
\end{tabular}

${ }^{a} 3,020 \mathrm{ft}(920 \mathrm{~m})$ from the hypothesized release

b $328 \mathrm{ft}(100 \mathrm{~m})$ from the hypothesized release

${ }^{c}$ Increased likelihood of a latent cancer fatality, calculated using the factor of $6 \times 10^{-4} \mathrm{LCFs}$ per rem, doubled for receptors exposed to doses greater than 20 rem, and truncated at 1

${ }^{\mathrm{d}}$ Increased number of latent cancer fatalities, calculated using the factor of $6 \times 10^{-4} \mathrm{LCFs}$ per person-rem

${ }^{\mathrm{e}}$ Large atmospheric dispersion with a population of 304,000 within $50 \mathrm{mi}(80 \mathrm{~km})$ of the site

${ }^{\mathrm{f}}$ Large atmospheric dispersion with a population of $1,660,000$ within $50 \mathrm{mi}(80 \mathrm{~km})$ of the site

${ }^{g}$ Large atmospheric dispersion with a population of $8,230,000$ within $50 \mathrm{mi}(80 \mathrm{~km})$ of the site

${ }^{\mathrm{h}}$ Small atmospheric dispersion with a population of 304,000 within $50 \mathrm{mi}(80 \mathrm{~km})$ of the site

${ }^{\mathrm{i}}$ Small atmospheric dispersion with a population of $1,660,000$ within $50 \mathrm{mi}(80 \mathrm{~km})$ of the site

${ }^{j}$ Small atmospheric dispersion with a population of $8,230,000$ within $50 \mathrm{mi}(80 \mathrm{~km})$ of the site

${ }^{\mathrm{k}}$ Calculated radiation dose to this individual is estimated to result in acute health effects

Using the dose-to-risk conversion factor of $6 \times 10^{-4}$ LCFs per person-rem, the collective population dose is estimated to result in a range of 1,000 to $4 \times 10^{4}$ additional LCFs. For the MEI and noninvolved worker, the calculated radiation dose to this individual is estimated to result in acute health effects (e.g., damage to the central nervous system or death).

\section{B.2.3.2 Mixed Oxide-Uranium-Plutonium Fueled Advanced Light Water Reactor}

As discussed in Appendix D, DOE has previously analyzed accidents associated with ALWRs using LEU fuel at a variety of locations in the Tritium Supply and Recycling Final PEIS (DOE 1995b); however, DOE did not analyze the ALWR with MOX-U-Pu fuel. For this GNEP PEIS, DOE has re-analyzed those ALWR accident scenarios for LEU fuel (see Appendix D, Section D.2.3.2) for the six generic programmatic sites. The accident scenarios are not affected by the type of fissile material in the fuel, so the LEU fueled ALWR scenarios are applicable to a MOX-U-Pu fueled ALWR. A description of each LEU ALWR accident is presented in the Tritium Supply and Recycling Final PEIS (DOE 1995b).

While the scenarios are not affected by the fuel type, the consequences are affected by the fuel type. The SPD EIS (DOE 1999d) evaluated an LEU fueled LWR and a MOX-U-Pu fueled LWR and determined that the MOX-U-Pu fueled LWR impacts average about 5 percent greater than the corresponding impacts for an LEU fueled LWR with some variation from scenario to scenario. The effect different fuel types have on the impacts is expected to be similar for an LWR and an ALWR, so it is expected that a MOX-U-Pu fueled ALWR would have impacts that are about 5 percent greater on average than the impacts for an LEU fueled ALWR. The LEU fueled ALWR impacts reported in Table B.2.1.2-1 are used directly for the MOX-U-Pu fueled ALWR. 


\section{B.2.4 Thermal Reactor Recycle Alternative}

This alternative includes analysis of the impacts of constructing and operating Thermal Reactor Recycle Alternative facilities, including the construction of one or more nuclear fuel recycling centers, operations to recycle SNF and produce nuclear fuel, transportation of fuel to reactors, and waste management facilities. Section B.2.2.1 presents the impacts for an "Unmitigated Aircraft Crash" (the highest consequence event), at a variety of sites, for a nuclear fuel recycling center for the Fast Recycle Alternative. This analysis is representative of the types of impacts that could result from these facilities.

This alternative includes three recycle reactor options: 1) recycle in LWRs, 2) recycle in heavy water reactors (HWRs), and 3) recycle in high-temperature gas-cooled reactors (HTGRs). Each of these three reactor types is addressed below.

\section{B.2.4.1 Recycle in Light Water Reactors (Option 1)}

This option involves the recycling of fuel in LWRs or ALWRs. Section B.2.3.1 addresses the impacts associated with the use of MOX-U-Pu fuel in a LWR. Section B.2.3.2 addresses the impacts associated with the use of MOX-U-Pu fuel in an ALWR. There are differences between the weapons-grade plutonium used in the SPD EIS (DOE 1999d) analysis and the transuranics that would be used under this alternative, but these differences are not expected to invalidate the conclusion that the impacts would be only slightly greater. Therefore, the impacts for recycled fuel are expected to also be approximately the same as the results for the MOX-U-Pu fueled reactors.

\section{B.2.4.2 Recycle in Heavy Water Reactors (Option 2)}

This option involves the recycling of fuel in HWRs. DOE has previously analyzed accidents associated with HWRs utilizing enriched uranium fuels at a variety of locations in the Tritium Supply and Recycling Final PEIS (DOE 1995b). The accidents identified in the Tritium Supply and Recycling Final PEIS (DOE 1995b) were re-analyzed for this PEIS and the results are summarized in Section B.2.6.1. Use of recycled fuel could increase the transuranic inventory and increase the consequences somewhat; however, the SPD EIS found that use of MOX-U-Pu in LWRs with its increased transuranic inventory increased risk an average of 5 percent (DOE 1999d). There are differences between the weapons-grade plutonium used in the SPD EIS (DOE 1999d) analysis and the transuranics that would be used under this alternative, but these differences are not expected to invalidate the conclusion that the impacts would be only slightly greater. Therefore, the impacts for recycled fuel, including DUPIC, are expected to also be approximately the same as the results for the uranium fueled reactors. Therefore, the results presented in Section B.2.6.1 are appropriate for recycling of fuel in an HWR.

\section{B.2.4.3 Recycle in High Temperature Gas-Cooled Reactors (Option 3)}

DOE has previously analyzed accidents associated with HTGRs at a variety of locations in the Tritium Supply and Recycling Final PEIS (DOE 1995b). In this PEIS, DOE has re-analyzed the consequences of the scenarios presented in DOE (1995b) and the results are summarized in 
Section B.2.6.2. Use of recycled fuel could increase the transuranic inventory and increase the consequences somewhat; however, the SPD EIS found that use of MOX-U-Pu in LWRs with its increased transuranic inventory increased risk an average of 5 percent (DOE 1999d). There are differences between the weapons-grade plutonium used in the SPD EIS (DOE 1999d) analysis and the transuranics that would be used under this alternative, but these differences are not expected to invalidate the conclusion that the impacts would be only slightly greater. Therefore, the impacts for recycled fuel are expected to also be approximately the same as the results for the uranium fueled reactors. The results presented in Section B.2.6.2 are appropriate for recycling of fuel in an HTGR.

\section{B.2.5 Thorium Alternative}

As described in Section 2.4 of this PEIS, the thorium once-through fuel cycle, while different in many aspects from the existing uranium once-through fuel cycle, can be characterized as a "new fuel design" rather than a new reactor concept, because the thorium fuel cycle would be compatible with existing and future thermal reactors (e.g., LWRs, HWRs, and HTGRs). Existing and future commercial reactors (e.g., LWRs, HWRs, and HTGRs) could accept a thorium-based fuel without requiring fundamental modification. For purposes of this PEIS, the analysis of the thorium open fuel cycle is focused on LWRs since LWRs are the predominant commercial electricity producing technology that exists in the world today.

Accident analyses for two heterogeneous "seed-blanket" implementation schemes for thorium fueled LWR have been performed by Brookhaven National Laboratory and the Massachusetts Institute of Technology (Todosow and Kazimi 2004). The two concepts are the seed-blanket-unit where the seed and blanket occupy the same space as a conventional assembly, and the wholeassembly-seed-blanket where the seed and blanket rods are located in distinct assemblies. Several "bounding" accidents were evaluated, for each concept: 1) large break loss-of-coolant accident; 2) loss of primary flow; and 3) loss of offsite power. The results for safety-related parameters were comparable to those for a conventional uranium-fueled LWR. It was concluded for accidents that the consequences of the Thorium Alternative are comparable to the consequences of the LEU fueled LWR (see Section D.2.5) and this same conclusion is applied to intentional destructive acts. For other reactor types, use of thorium reactor fuel is expected to result in consequences that are comparable to the consequences for the use of LEU fuel in the same reactor. For the HWR and HTGR, the highest consequence event would be an "Unmitigated Aircraft Crash" and its consequences are reported in Section B.2.6 and they are less than the consequences for a LWR.

\section{B.2.6 Heavy Water Reactor/High Temperature Gas-Cooled Reactor Alternative}

\section{B.2.6.1 Heavy Water Reactors (Option 1)}

DOE has previously analyzed accidents associated with HWRs at a variety of locations in the Tritium Supply and Recycling Final PEIS (DOE 1995b). In this PEIS, DOE has re-analyzed the risks of the accident scenarios presented in the Tritium Supply and Recycling Final PEIS at the six generic sites in Appendix D. The accident with the highest consequence is the "Unmitigated Aircraft Crash," which could also be the result of an intentional destructive act. Therefore, the 
"Unmitigated Aircraft Crash" is also the intentional destructive act with the highest consequence. Appendix D provides details of the consequence analysis for this event. Table B.2.6.1-1 presents the "Unmitigated Aircraft Crash" consequences for the HWR at each of these six generic sites.

TABLE B.2.6.1-1-Potential Consequences -

Intentional Destructive Acts at a Heavy Water Reactor

\begin{tabular}{ccccccc}
\hline Site & \multicolumn{2}{c}{$\begin{array}{c}\text { Offsite Population } \\
\text { Dose (person-rem) }\end{array}$} & LCFs $^{\mathbf{d}}$ & $\begin{array}{c}\text { MEI }^{\mathbf{a}} \\
\text { Dose (rem) }\end{array}$ & LCFs $^{\mathbf{c}}$ & \multicolumn{2}{c}{ Noninvolved Worker $^{\mathbf{b}}$ Dose (rem) $^{\mathbf{c}}$} & LCFs $^{\mathbf{c}}$ \\
\hline Generic Site 1 $^{\mathrm{e}}$ & $8 \times 10^{4}$ & 50 & 900 & $1^{\mathrm{k}}$ & $1 \times 10^{4}$ & $1^{\mathrm{k}}$ \\
Generic Site 2 $^{\mathrm{f}}$ & $2 \times 10^{5}$ & 100 & 900 & $1^{\mathrm{k}}$ & $1 \times 10^{4}$ & $1^{\mathrm{k}}$ \\
Generic Site 3 $^{\mathrm{g}}$ & $9 \times 10^{5}$ & 500 & 900 & $1^{\mathrm{k}}$ & $1 \times 10^{4}$ & $1^{\mathrm{k}}$ \\
Generic Site 4 $^{\mathrm{h}}$ & $4 \times 10^{5}$ & 200 & 7,000 & $1^{\mathrm{k}}$ & $6 \times 10^{4}$ & $1^{\mathrm{k}}$ \\
Generic Site 5 $^{\mathrm{i}}$ & $7 \times 10^{5}$ & 400 & 7,000 & $1^{\mathrm{k}}$ & $6 \times 10^{4}$ & $1^{\mathrm{k}}$ \\
Generic Site 6 $^{\mathrm{j}}$ & $3 \times 10^{6}$ & 2,000 & 7,000 & $1^{\mathrm{k}}$ & $6 \times 10^{4}$ & $1^{\mathrm{k}}$ \\
\hline
\end{tabular}

${ }^{\mathrm{a}} 3,020 \mathrm{ft}(920 \mathrm{~m})$ from the hypothesized release.

b $328 \mathrm{ft}(100 \mathrm{~m})$ from the hypothesized release.

${ }^{\mathrm{c}}$ Increased likelihood of a latent cancer fatality, calculated using the factor of $6 \times 10^{-4}$ LCFs per rem and doubled for receptors exposed to doses greater than 20 rem and truncated at 1 .

d Increased number of latent cancer fatalities, calculated using the factor of $6 \times 10^{-4} \mathrm{LCF}$ s per person-rem.

${ }^{\mathrm{e}}$ Large atmospheric dispersion with a population of 304,000 within $50 \mathrm{mi}(80 \mathrm{~km})$ of the site

${ }^{\mathrm{f}}$ Large atmospheric dispersion with a population of $1,660,000$ within $50 \mathrm{mi}(80 \mathrm{~km})$ of the site

${ }^{\mathrm{g}}$ Large atmospheric dispersion with a population of $8,230,000$ within $50 \mathrm{mi}(80 \mathrm{~km})$ of the site

${ }^{\mathrm{h}}$ Small atmospheric dispersion with a population of 304,000 within $50 \mathrm{mi}(80 \mathrm{~km})$ of the site

${ }^{\mathrm{i}}$ Small atmospheric dispersion with a population of $1,660,000$ within $50 \mathrm{mi}(80 \mathrm{~km})$ of the site

${ }^{\mathrm{j}}$ Small atmospheric dispersion with a population of $8,230,000$ within $50 \mathrm{mi}(80 \mathrm{~km})$ of the site

${ }^{\mathrm{k}}$ Calculated radiation dose to this individual is estimated to result in acute health effects

Using the dose-to-risk conversion factor of $6 \times 10^{-4} \mathrm{LCFs}$ per person-rem the collective population dose is estimated to result in a range of 50 additional LCFs to 2,000 additional LCFs. For the MEI and noninvolved worker, the calculated radiation dose to this individual is estimated to result in acute health effects (e.g., internal bleeding, damage to the central nervous system, or death).

\section{B.2.6.2 High Temperature Gas-Cooled Reactors (Option 2)}

DOE has previously analyzed accidents associated with HTGRs at a variety of locations in the Tritium Supply and Recycling Final PEIS (DOE 1995b). In this PEIS, DOE has re-analyzed the risks of the accident scenarios presented in the Tritium Supply and Recycling Final PEIS at the six generic sites. The accident with the highest consequence is the "Unmitigated Aircraft Crash," which could also be the result of an intentional destructive act. Therefore, the "Unmitigated Aircraft Crash" is also the intentional destructive act with the highest consequence. Appendix D provides details of the consequence analysis for this event. Table B.2.6.2-1 presents the consequences for the HTGR "Unmitigated Aircraft Crash" at each of these six generic sites. 
TABLE B.2.6.2-1—Potential Consequences - Intentional Destructive Acts at a High Temperature Gas-Cooled Reactor

\begin{tabular}{|c|c|c|c|c|c|c|}
\hline \multirow[t]{2}{*}{ Site } & \multicolumn{2}{|c|}{ Offsite Population } & \multicolumn{2}{|c|}{ MEI $^{\mathbf{a}}$} & \multicolumn{2}{|c|}{ Noninvolved Worker } \\
\hline & Dose (person-rem) & $\mathrm{LCFs}^{\mathrm{d}}$ & Dose (rem) & $\mathrm{LCFs}^{\mathrm{c}}$ & Dose (rem) & $\mathrm{LCFs}^{\mathrm{c}}$ \\
\hline Generic Site $1^{\mathrm{e}}$ & $4 \times 10^{4}$ & 20 & 400 & 0.5 & 5,000 & $1^{\mathrm{k}}$ \\
\hline Generic Site $2^{f}$ & $9 \times 10^{4}$ & 50 & 400 & 0.5 & 5,000 & $1^{\mathrm{k}}$ \\
\hline Generic Site $3^{\mathrm{g}}$ & $4 \times 10^{5}$ & 200 & 400 & 0.5 & 5,000 & $1^{\mathrm{k}}$ \\
\hline Generic Site $4^{h}$ & $2 \times 10^{5}$ & 100 & 3,000 & $1^{\mathrm{k}}$ & $3 \times 10^{4}$ & $1^{\mathrm{k}}$ \\
\hline Generic Site $5^{\mathrm{i}}$ & $3 \times 10^{5}$ & 200 & 3,000 & $1^{\mathrm{k}}$ & $3 \times 10^{4}$ & $1^{\mathrm{k}}$ \\
\hline Generic Site $6^{\mathrm{j}}$ & $1 \times 10^{6}$ & 800 & 3,000 & $1^{\mathrm{k}}$ & $3 \times 10^{4}$ & $1^{\mathrm{k}}$ \\
\hline
\end{tabular}

${ }^{a} 3,020 \mathrm{ft}(920 \mathrm{~m})$ from the hypothesized release.

b $328 \mathrm{ft}(100 \mathrm{~m})$ from the hypothesized release.

${ }^{\mathrm{c}}$ Increased likelihood of a latent cancer fatality, calculated using the factor of $6 \times 10^{-4} \mathrm{LCFs}$ per rem, doubled for receptors exposed to doses greater than $20 \mathrm{rem}$, and truncated at 1.

${ }^{\mathrm{d}}$ Increased number of latent cancer fatalities, calculated using the factor of $6 \times 10^{-4} \mathrm{LCFs}$ per person-rem.

${ }^{\mathrm{e}}$ Large atmospheric dispersion with a population of 304,000 within $50 \mathrm{mi}(80 \mathrm{~km})$ of the site

${ }^{\mathrm{f}}$ Large atmospheric dispersion with a population of $1,660,000$ within $50 \mathrm{mi}(80 \mathrm{~km})$ of the site

${ }^{g}$ Large atmospheric dispersion with a population of $8,230,000$ within $50 \mathrm{mi}(80 \mathrm{~km})$ of the site

${ }^{\mathrm{h}}$ Small atmospheric dispersion with a population of 304,000 within $50 \mathrm{mi}(80 \mathrm{~km})$ of the site

${ }^{\mathrm{i}}$ Small atmospheric dispersion with a population of $1,660,000$ within $50 \mathrm{mi}(80 \mathrm{~km})$ of the site

${ }^{\mathrm{j}}$ Small atmospheric dispersion with a population of $8,230,000$ within $50 \mathrm{mi}(80 \mathrm{~km})$ of the site

${ }^{\mathrm{k}}$ Calculated radiation dose to this individual is estimated to result in acute health effects

Using the dose-to-risk conversion factor of $6 \times 10^{-4} \mathrm{LCFs}$ per person-rem the collective population dose is estimated to result in a range of 50 additional LCFs to 800 additional LCFs. For the MEI, the calculated radiation dose to this individual is estimated to result in a likelihood of 0.5 (Sites 1 thorough 3) to acute health effects (Sites 4 through 6) of an LCF. For the noninvolved worker, the calculated radiation dose to this individual is estimated to result in acute health effects (e.g., damage to the central nervous system or death).

\section{B.3 NuClear Materials Transportation}

\section{B.3.1 Methodology}

For potential intentional destructive acts associated with transportation of nuclear materials, DOE has chosen to analyze events associated with transportation of LWR SNF. The LWR SNF was selected for analysis because it is the risk dominant fuel. While the impacts from the MOXU-Pu SNF are higher than for the LEU LWR SNF, the number of LEU LWR shipments is much greater so its risks are greater. For this analysis, DOE is incorporating the analysis presented in the Supplemental Environmental Impact Statement for a Geologic Repository for the Disposal of Spent Nuclear Fuel and High-Level Radioactive Waste at Yucca Mountain, Nye County, Nevada (DOE 2008f) and its supporting calculation package (BMI 2007). Appendix E (see Table E.2.5-12) provides the maximum reasonably foreseeable transportation accidents for all SNF and high-level radioactive waste associated with the GNEP operations without intentional destructive acts. While the Appendix E values are not directly comparable to the results of this section, they do provide a basis for relative comparison of the potential waste form impacts. 
DOE used the following assumptions to estimate the consequence of transportation sabotage events (Jason Technologies 2001):

- A breathing rate for individuals of $367,272.5$ cubic feet $\left(\mathrm{ft}^{3}\right)$ per year $(10,400$ cubic meters $\left[\mathrm{m}^{3}\right]$ per year) (5.23 gallons [gal] per minute [19.8 liters $\{\mathrm{L}\}$ per minute]). This breathing rate was estimated from data contained in International Commission on Radiological Protection (ICRP) Publication 23 (ICRP 1975).

- A short-term exposure time to airborne contaminants of 2 hours.

- A long-term exposure time to contamination deposited on the ground of 1 year, with no interdiction.

- Because it is not possible to estimate the specific atmospheric conditions that would exist during a sabotage event, consequences were determined using moderate wind speeds and neutral atmospheric conditions (a wind speed of $14.67 \mathrm{ft}$ per second [ $4.47 \mathrm{~m}$ per second] and Class D stability).

- The release of both respirable and nonrespirable material was evaluated. The deposition velocity for respirable material was $0.03 \mathrm{ft}$ per second $(0.01 \mathrm{~m}$ per second $)$. The deposition velocity for nonrespirable material was $0.3 \mathrm{ft}$ per second $(0.1$ meter per second).

- It is expected that in a sabotage event, there would be an initial explosive release involving releases of radioactive material at varying release heights. For 4 percent of the release, a release height of $3 \mathrm{ft}(1 \mathrm{~m})$ was estimated; for 16 percent of the release, a release height of $52 \mathrm{ft}(16 \mathrm{~m})$ was estimated; for 25 percent of the release, a release height of $105 \mathrm{ft}(32 \mathrm{~m})$ was estimated; for 35 percent of the release, a release height of $157 \mathrm{ft}(48 \mathrm{~m})$ was estimated; and for 20 percent of the release, a release height of $210 \mathrm{ft}$ (64 m) was estimated.

DOE plans to operate the repository using a primarily canistered approach that calls for packaging most commercial SNF in transportation, aging and disposal canisters (TAD), which would hold 21 PWR SNF assemblies. However, no credit was taken for the TAD. The TAD will be shipped inside a cask. The shipment configuration is similar to the rail shipment configuration assumed in Appendix E. The radionuclide inventory for a single SNF assembly in this cask is listed in Table B.3.1-1. Appendix E, Section E.2.2.1 describes the shipment of spent fuel, including fresh and spent fast reactor fuel. Shipment of other wastes is discussed in Appendix E, Section E.2.2.2.

DOE evaluated the consequences of sabotage events using previously published release fraction data (Luna et al. 1999, DOE 2002i). For rail casks, a sabotage event using the high energy density device (HEDD1) yielded the largest radiation doses. Additional data from sabotage experiments conducted in Germany were used by DOE to update the release fractions for HEDD1 (Luna 2006) used to estimate the consequences of sabotage events in the Final Supplemental Environmental Impact Statement for a Geologic Repository for the Disposal of Spent Nuclear Fuel and High-Level Radioactive Waste at Yucca Mountain, Nye County, Nevada - Nevada Rail Transportation Corridor and the Final Environmental Impact Statement for a Rail Alignment for the Construction and Operation of a Railroad in Nevada to a Geologic Repository at Yucca Mountain, Nye County, Nevada (Rail Alignment EIS) (DOE 2008g). Table B.3.1-2 lists these release fractions. 
TABLE B.3.1-1-Radionuclide Inventories for Commercial Spent Nuclear Fuel Shipped in Rail Casks ${ }^{a}$

\begin{tabular}{|c|c|c|c|c|}
\hline Radionuclide & $\begin{array}{c}\text { Pressurized water } \\
\text { reactor commercial spent } \\
\text { nuclear fuel assembly } \\
\text { inventory }(\mathrm{Ci}){ }^{b}\end{array}$ & $\begin{array}{l}\text { Pressurized water } \\
\text { reactor commercial } \\
\text { spent nuclear fuel } \\
\text { total inventory }(\mathbf{C i}){ }^{b}\end{array}$ & $\begin{array}{l}\text { Boiling water reactor } \\
\text { commercial spent } \\
\text { nuclear fuel assembly } \\
\text { inventory }(\mathrm{Ci})^{\mathrm{c}}\end{array}$ & $\begin{array}{l}\text { Boiling water reactor } \\
\text { commercial spent } \\
\text { nuclear fuel total } \\
\text { inventory }(\mathbf{C i}){ }^{c}\end{array}$ \\
\hline Am-241 & 1,280 & $1.11 \times 10^{8}$ & 373 & $4.61 \times 10^{7}$ \\
\hline Am-242m & 7.99 & $6.96 \times 10^{5}$ & 2.88 & $3.56 \times 10^{5}$ \\
\hline Am-243 & 39.3 & $3.42 \times 10^{6}$ & 8.63 & $1.07 \times 10^{6}$ \\
\hline C-14 & 0.435 & $3.79 \times 10^{4}$ & 0.169 & $2.09 \times 10^{4}$ \\
\hline $\mathrm{Cd}-113 \mathrm{~m}$ & 23.4 & $2.03 \times 10^{6}$ & 6.23 & $7.69 \times 10^{5}$ \\
\hline $\mathrm{Ce}-144$ & 69.9 & $6.09 \times 10^{6}$ & 17.3 & $2.14 \times 10^{6}$ \\
\hline $\mathrm{Cm}-242$ & 6.60 & $5.75 \times 10^{5}$ & 2.38 & $2.94 \times 10^{5}$ \\
\hline $\mathrm{Cm}-243$ & 24.8 & $2.16 \times 10^{6}$ & 5.55 & $6.86 \times 10^{5}$ \\
\hline $\mathrm{Cm}-244$ & 5,850 & $5.09 \times 10^{8}$ & 923 & $1.14 \times 10^{8}$ \\
\hline $\mathrm{Cm}-245$ & 0.816 & $7.10 \times 10^{4}$ & 0.0907 & $1.12 \times 10^{4}$ \\
\hline $\mathrm{Cm}-246$ & 0.407 & $3.54 \times 10^{4}$ & 0.0426 & 5,260 \\
\hline Co-60 & 2,170 & $1.89 \times 10^{8}$ & 114 & $1.41 \times 10^{7}$ \\
\hline Co-60 & $(\text { Crud })^{d}$ & 16.9 & $1.47 \times 10^{6}$ & 56.6 \\
\hline Cs-134 & 5,430 & $4.73 \times 10^{8}$ & 1,310 & $1.62 \times 10^{8}$ \\
\hline Cs-137 & $7.16 \times 10^{4}$ & $6.23 \times 10^{9}$ & $2.41 \times 10^{4}$ & $2.98 \times 10^{9}$ \\
\hline Eu-154 & 3,010 & $2.62 \times 10^{8}$ & 779 & $9.62 \times 10^{7}$ \\
\hline Eu-155 & 642 & $5.59 \times 10^{7}$ & 193 & $2.39 \times 10^{7}$ \\
\hline $\mathrm{Fe}-55$ & (Crud) ${ }^{\mathrm{d}}$ & 209 & $1.82 \times 10^{7}$ & 98.4 \\
\hline $\mathrm{H}-3$ & 305 & $2.66 \times 10^{7}$ & 105 & $1.30 \times 10^{7}$ \\
\hline I-129 & 0.0276 & 2,400 & 0.00922 & 1,140 \\
\hline $\mathrm{Kr}-85$ & 3,390 & $2.95 \times 10^{8}$ & 1,170 & $1.45 \times 10^{8}$ \\
\hline Np-237 & 0.294 & $2.56 \times 10^{4}$ & 0.0874 & $1.08 \times 10^{4}$ \\
\hline Pm-147 & 6,060 & $5.28 \times 10^{8}$ & 2,110 & $2.61 \times 10^{8}$ \\
\hline $\mathrm{Pu}-238$ & 3,980 & $3.46 \times 10^{8}$ & 1,020 & $1.26 \times 10^{8}$ \\
\hline $\mathrm{Pu}-239$ & 175 & $1.52 \times 10^{7}$ & 54.1 & $6.68 \times 10^{6}$ \\
\hline $\mathrm{Pu}-240$ & 363 & $3.16 \times 10^{7}$ & 127 & $1.57 \times 10^{7}$ \\
\hline $\mathrm{Pu}-241$ & $5.64 \times 10^{4}$ & $4.91 \times 10^{9}$ & $1.57 \times 10^{4}$ & $1.94 \times 10^{9}$ \\
\hline $\mathrm{Pu}-242$ & 2.48 & $2.16 \times 10^{5}$ & 0.708 & $8.75 \times 10^{4}$ \\
\hline Ru-106 & 404 & $3.52 \times 10^{7}$ & 90.5 & $1.12 \times 10^{7}$ \\
\hline $\mathrm{Sb}-125$ & 520 & $4.53 \times 10^{7}$ & 145 & $1.79 \times 10^{7}$ \\
\hline Sr-90 & $4.51 \times 10^{4}$ & $3.93 \times 10^{9}$ & $1.66 \times 10^{4}$ & $2.05 \times 10^{9}$ \\
\hline U-232 & 0.0361 & 3,140 & 0.00874 & 1,080 \\
\hline U-234 & 0.524 & $4.56 \times 10^{4}$ & 0.239 & $2.95 \times 10^{4}$ \\
\hline U-236 & 0.177 & $1.54 \times 10^{4}$ & 0.0745 & 9,200 \\
\hline U-238 & 0.146 & $1.27 \times 10^{4}$ & 0.0624 & 7,710 \\
\hline Y-90 & $4.51 \times 10^{4}$ & $3.93 \times 10^{9}$ & $1.66 \times 10^{4}$ & $2.05 \times 10^{9}$ \\
\hline \multicolumn{5}{|c|}{$\begin{array}{l}\text { a Sources: BSC 2004, BSC } 2003 \\
\text { b Total inventory for pressurized water reactor spent nuclear fuel shipped in rail casks is based on 87,057 assemblies (calculated from rail } \\
\text { shipments and cask capacities from BSC } 2007 \\
\text { c Total inventory for boiling water reactor spent nuclear fuel shipped in rail casks is based on 123,537 assemblies (calculated from rail shipments } \\
\text { and cask capacities from BSC } 2007 \\
\text { d Chalk River Unknown Deposit (CRUD) (generic term for various residues deposited on fuel rod surfaces, originally coined by Atomic Energy } \\
\text { of Canada, Ltd. (AECL) to describe deposits observed on fuel removed from the test reactor at Chalk River) }\end{array}$} \\
\hline
\end{tabular}


TABLE B.3.1-2_Release Fractions for Transportation Sabotage Event ${ }^{\text {a }}$

\begin{tabular}{|c|c|c|c|c|c|c|}
\hline \multirow[b]{2}{*}{ Material } & \multicolumn{6}{|c|}{ Release Fraction } \\
\hline & Particulates & Ruthenium ${ }^{b}$ & Cesium $^{c}$ & Iodine $^{c}$ & Gas & Crud \\
\hline Respirable & $7.19 \times 10^{-7}$ & $7.19 \times 10^{-7}$ & $7.15 \times 10^{-6 \mathrm{~d}}$ & $7.15 \times 10^{-6 \mathrm{~d}}$ & $4.05 \times 10^{-4 \mathrm{~d}}$ & $5.17 \times 10^{-7}$ \\
\hline Nonrespirable & $1.75 \times 10^{-4}$ & $1.75 \times 10^{-4}$ & & & & $5.16 \times 10^{-8}$ \\
\hline
\end{tabular}

Radiation doses for the sabotage event scenario were estimated using the RISKIND (Radioactive Waste Transport Risk Code) computer code (Yuan et al. 1995). RISKIND has been verified for estimating radiation doses from releases of radioactive material during transportation (Maheras and Pippen 1995, Biwer et al. 1997). Radiation doses were determined for the inhalation, groundshine, immersion, and resuspension pathways. Radiation doses were estimated using the ICRP inhalation dose coefficients (ICRP 2001) and the EPA groundshine and immersion dose coefficients (EPA 2002a). These dose coefficients are based on the recommendations in the ICRP Publication 60 (ICRP 1991) and incorporate the dose coefficients from ICRP Publication 72 (ICRP 1996).

\section{B.3.2 Results}

Table B.3.2-1 lists the consequences of a potential sabotage event. The MEI would be located $330 \mathrm{ft}(100 \mathrm{~m})$ from the sabotage event, at the location of maximum downwind air concentration. The radiation dose for the MEI is estimated to be $27 \mathrm{rem}$. Using the dose-to-risk conversion factor of twice $6 \times 10^{-4}$ per person-rem for individual doses greater than $20 \mathrm{rem}$, the MEI dose has a increased likelihood of 0.032 (or 1 chance in 31 of a LCF).

\section{TABLE B.3.2-1-Consequences of a Radiological Transportation Sabotage Event ${ }^{a}$}

\begin{tabular}{lc}
\hline Maximally exposed individual (rem) & 27 \\
Latent cancer fatality & 0.032 \\
\hline${ }^{\mathrm{a}}$ Consequences based on moderate wind speeds and neutral atmospheric conditions \\
${ }^{\mathrm{b}}$ Increased likelihood of a latent cancer fatality
\end{tabular}




\section{B.4 REFERENCES}

Biwer et al.1997

BSC 2003

BSC 2004

BSC 2007

BMI 2007

Chanin and Young 1998

DOE 1995b

DOE 1999d

DOE 2002i
Biwer, B.M, J.J. Arnish, S. Kamboj, and S.Y. Chen, "RISKIND Verification and Benchmark Comparisons," ANL/EAD/TM-74, Argonne National Laboratory, Argonne, IL, 1997.

Bechtel SAIC Company (BSC), "BWR Source Term Generation and Evaluation," 000-00C-MGR0-00200-000-00A, Bechtel SAIC Company, Las Vegas, NV, 2003.

BSC, "PWR Source Term Generation and Evaluation," 000-00CMGR0-00100-000-00B, Bechtel SAIC Company, Las Vegas, NV, 2004.

BSC, "Recommended Values for HLW Glass for Consistent Usage on the Yucca Mountain Project," 000-00A-MGR0-00200-00000A, Bechtel SAIC Company, Las Vegas, NV, 2007.

Battelle Memorial Institute (BMI), "Calculation Report for the Transportation Impacts for the Draft Supplemental Impact Statement for a Geologic Repository for the Disposal of Spent Nuclear Fuel and High Level Radioactive Waste at Yucca Mountain Nye County, Nevada," Calculation Report No. BCO006, Battelle Memorial Institute, Columbus, OH, October 4, 2007.

Chanin, D. and M.L. Young, "Code Manual for MACCS2: Volume 1, User's Guide," NUREG/CR-6613, Vol. 1, SAND970594, May 19, 1998.

U.S. Department of Energy (DOE), "Final Programmatic Environmental Impact Statement for Tritium Supply and Recycling," DOE/EIS-0161, Office of Reconfiguration, U.S. Department of Energy, Washington, DC, October 1995.

DOE, "Surplus Plutonium Disposition Final Environmental Impact Statement," DOE/EIS-0283, Office of Fissile Materials Disposition, U.S. Department of Energy, Washington, DC, November 1999.

DOE, "Final Environmental Impact Statement for a Geologic Repository for the Disposal of Spent Nuclear Fuel and High-Level Radioactive Waste at Yucca Mountain, Nye County, Nevada," DOE/EIS-0250, U.S. Department of Energy, Washington, DC, February 2002. 
DOE 2008f

DOE 2008g

EPA 2002a

ICRP 1975

ICRP 1991

ICRP 1996

ICRP 2001
DOE, "Final Supplemental Environmental Impact Statement for a Geologic Repository for the Disposal of Spent Nuclear Fuel and High-Level Radioactive Waste at Yucca Mountain, Nye County, Nevada," DOE/EIS-0250F-S1, U.S. Department of Energy Office of Civilian Radioactive Waste Management, Las Vegas, NV, July 2008.

DOE, "Final Supplemental Environmental Impact Statement for a Geologic Repository for the Disposal of Spent Nuclear Fuel and High-Level Radioactive Waste at Yucca Mountain, Nye County, Nevada - Nevada Rail Transportation Corridor DOE/EIS-0250FS2 and Final Environmental Impact Statement for a Rail Alignment for the Construction and Operation of a Railroad in Nevada to a Geologic Repository at Yucca Mountain, Nye County, Nevada DOE/EIS-0369," U.S. Department of Energy, Office of Civilian Radioactive Waste Management, Las Vegas, NV, June 2008.

U.S. Environmental Protection Agency (EPA), "Cancer Risk Coefficients for Environmental Exposure to Radionuclides," 402C-99-001, Rev. 1, Federal Guidance Report 13, U.S. Environmental Protection Agency, Washington, DC, 2002.

International Commission on Radiological Protection (ICRP), "Report of the Task Group on Reference Man: A Report Prepared by a Task Group of Committee 2 of the International Commission on Radiological Protection," ICRP Number 23, Tarrytown, NY: Elsevier, 1975.

ICRP, "1990 Recommendations of the International Commission on Radiological Protection," Volume 21, No. 1-3 of Annals of the ICRP, ICRP Publication 60, New York, NY: Pergamon Press, 1991.

ICRP, "Age-Dependent Doses to Members of the Public from Intake of Radionuclides: Part 5 Compilation of Ingestion and Inhalation Dose Coefficients," Volume 26, No. 1 of Annals of the ICRP. Smith, H., ed. ICRP Publication 72. New York, NY: Pergamon Press, 1996.

ICRP, "The ICRP Database of Dose Coefficients: Workers and Members of the Public," ICRP Publication 72, New York, NY: Elsevier, 2001. 
Jason Technologies 2001 Jason Technologies, "Transportation Health and Safety Calculation/Analysis Documentation in Support of the Final EIS for Yucca Mountain Repository," CAL-HSS-ND-000003, Las Vegas, NV, 2001.

Luna et al. 1999

Luna, R.E., K.S. Neuhauser, and M.G. Vigil, "Projected Source Terms for Potential Sabotage Events Related to Spent Fuel Shipments," SAND99-0963, Sandia National Laboratories, Albuquerque, NM, June 1, 1999.

Luna 2006

Luna, R.E., "Release Fractions from Multi-Element Spent Fuel Casks Resulting from HEDD Attack," WM'06 Conference, Tucson, AZ: WM Symposia, February 26-March 2, 2006.

Maheras and Pippen 1995

Maheras, S.J. and H.K. Pippen, "Validation of the Transportation Computer Codes HIGHWAY, INTERLINE, RADTRAN 4, and RISKIND," DOE/ID-10511, U.S. Department of Energy, Idaho Operations Office, 1995.

NEI 2002

Nuclear Energy Institute (NEI), "Deterring Terrorism: Aircraft Crash Impact Analyses Demonstrate Nuclear Power Plant's Structural Strength," Nuclear Energy Institute, December 2002. Accessed at http://www.nei.org/filefolder/EPRI_Nuclear_Plant_ Structural_Study_2002.pdf on June 24, 2008.

Todosow and Kazimi

Todosow M. and M. Kazimi, "Optimization of Heterogeneous 2004

Utilization of Thorium in PWRs to Enhance Proliferation Resistance and Reduce Waste," BNL-73152-2004/MIT-NFC-065, August 2004.

Yuan et al. 1995

Yuan, Y.C., S.Y. Chen, B.M. Biwer, D.J. LePoire, "RISKIND - A Computer Program for Calculating Radiological Consequences and Health Risks from Transportation of Spent Nuclear Fuel," ANL/EAD-1, Argonne National Laboratory, Argonne, IL, Argonne National Laboratory, 1995. 



\section{APPENDIX C}

\section{HUMAN HEALTH AND WORKER SAFETY}





\section{APPENDIX C HUMAN HEALTH AND WORKER SAFETY}

This appendix to the Global Nuclear Energy Partnership (GNEP) Programmatic Environmental Impact Statement (PEIS) provides supplemental information pertaining to potential human health impacts associated with radiation exposures, chemical exposures, and worker safety issues related to implementation of the domestic programmatic alternatives.

\section{C.1 Radiological ImPaCts ON Human HeAlth}

\section{C.1.1 Radiation and Radioactivity}

Humans are constantly exposed to naturally occurring radiation through sources such as the solar system and the earth's rocks and soils. This type of radiation is referred to as background radiation, and it always surrounds us. Background radiation remains relatively constant over time. In addition, anthropogenic (manmade) sources of radiation have been developed since the Industrial Revolution. Manmade sources of radiation include medical and dental x-rays, household smoke detectors, materials released from nuclear and coal-fired power plants, and the residues from atmospheric nuclear weapon testing activities (NCRP 1987). The following sections describe some important principles concerning the nature, types, sources, and effects of radiation and radioactivity.

\section{C.1.1.1 What Is Ionizing Radiation?}

Atoms lose or gain electrons in a process known as ionization. Ionization results in the formation of an ion pair: the positively charged particle (positive ion) and the negatively charged particle (typically a free electron). Ionizing radiation has enough energy to detach electrons from atoms, creating ions that could cause biological damage (Gollnick 1988). Additionally, when ionization of an atom existing in a molecular chemical bond occurs, free radicals may be formed. These free radicals are highly reactive due to the presence of unpaired electrons (Cember 1996). Although it is potentially harmful to human health, ionizing radiation is used in a variety of ways, many of which are familiar to us in our everyday lives. An x-ray machine is a source of one form of ionizing radiation. Likewise, most home smoke detectors use a small source of ionizing radiation to detect smoke particles in the room's air. Types of ionizing radiation include alpha, beta, gamma, and neutron radiation (Shapiro 1990).

Alpha radiation occurs when a particle consisting of two protons and two neutrons is emitted from the nucleus. Alpha particles, because of their relatively large size, do not travel very far and do not penetrate materials well. Alpha particles lose their energy almost as soon as they collide with anything, and therefore a sheet of notebook paper or the skin's surface can be used to block the penetration of most alpha particles. Alpha particles only become a source of radiation dose after they are inhaled, ingested, or otherwise taken into the body (Shapiro 1990).

Beta radiation occurs when an electron or positron is emitted from an atom. Beta particles are much lighter than alpha particles and therefore can travel faster and farther. Greater precautions 
must be taken to stop beta radiation. Beta particles can pass through a sheet of paper, but can be stopped by a thin sheet of aluminum foil or glass. Most of the radiation dose from beta particles occurs in the first tissue they penetrate, such as the skin or tissues of internal organs following intake into the human body (Shapiro 1990).

Gamma and x-ray radiation are known as electromagnetic radiation and are emitted as energy packets called photons, similar to light and radio waves, but from a different energy region of the electromagnetic spectrum. Gamma rays are emitted from the nucleus as waves of pure energy, whereas x-rays originate from the electron field surrounding the nucleus. Gamma rays and x-rays are indistinguishable from each other. Gamma rays travel at the speed of light, and because they are so penetrating, concrete, water, lead, or steel is required to shield them (Shapiro 1990). For example, to absorb 95 percent of the gamma energy from a cobalt-60 source, 2 inches (in) (5 centimeters $[\mathrm{cm}])$ of lead, 4 in $(10 \mathrm{~cm})$ of iron, 13 in $(33 \mathrm{~cm})$ of concrete or 24 in $(60 \mathrm{~cm})$ of water would be needed (USDHEW 1970).

The neutron is another particle that contributes to radiation exposure, both directly and indirectly. Indirect exposure is associated with the gamma rays and alpha particles that are emitted following neutron capture in matter. A neutron has about a quarter of the weight of an alpha particle and can travel 2.5 times faster than an alpha particle. Neutrons are more penetrating than beta particles, but less penetrating than gamma rays. They can be shielded effectively by water, graphite, paraffin, or concrete. For example, to absorb 90 percent of the energy from a neutron source, 10 in $(25.4 \mathrm{~cm})$ of water or 12 in $(30 \mathrm{~cm})$ of concrete would be needed (Shapiro 1990).

Some elements such as uranium, radium, plutonium, and thorium share a common characteristic: they are unstable or radioactive. These radioactive isotopes are called radionuclides or radioisotopes. As unstable atoms, radioisotopes attempt to reach a more stable configuration by releasing excess energy in the form of ionizing radiation. This radiation can be in the form of particles (e.g., alpha, beta, and neutron) or as electromagnetic energy (e.g., gamma and x-rays). This process is known as radioactive decay. The time it takes to reduce the number of radioactive atoms present to half of the original amount is known as its half-life. Each radioactive isotope has a characteristic half-life. The half-life may vary from a millionth of a second to millions of years, depending upon the radionuclide (Cember 1996).

As a radioactive element emits radioactivity, it often changes into an entirely different element that may or may not be radioactive. Eventually, however, a stable element is formed. This transformation may require several steps, known as a decay chain. Radium, for example, is a naturally occurring radioactive element with a half-life of 1,622 years. It emits an alpha particle and becomes radon, a radioactive gas with a half-life of only 3.8 days. Radon decays to polonium and, through a series of steps, to bismuth, and ultimately to stable lead (USDHEW 1970).

\section{C.1.1.2 What Are the Units of Radioactivity?}

Scientists and engineers use a variety of units to measure radiation and radioactivity. These different units can be used to determine the amount of radioactivity and intensity of radiation. The curie $(\mathrm{Ci})$ describes the activity of radioactive material. The rate of decay of 1 gram $(\mathrm{g})$ of 
radium is the basis of this unit of measure. It is equal to $3.7 \times 10^{10}$ disintegrations (decays) per second (Cember 1996).

In the International System of Units (SI) the Ci has been replaced by the becquerel (Bq), where:

$$
1 \text { becquerel }=1 \text { radioactive decay per second }=2.7 \times 10^{-11} \mathrm{Ci} \text {. }
$$

The magnitude of radiation exposures is specified in terms of the radiation dose. There are two important categories of dose:

The absorbed dose, sometimes also known as the physical dose, is defined by the amount of energy deposited in a unit mass in human tissue or other media. The original unit is the rad $(100 \mathrm{erg} / \mathrm{g})$; it is now being widely replaced by the SI unit, the gray (Gy) (1 Joule/kg), where 1 gray $=100 \mathrm{rad}$ (Cember 1996).

The biological dose, sometimes also known as the dose equivalent, is expressed in units of rem or, in the SI system, sievert (Sv). This dose reflects the fact that the biological damage caused by a particle depends not only on the total energy deposited but also on the rate of energy loss per unit distance traversed by the particle (or "linear energy transfer"). For example, alpha particles do much more damage per unit energy deposited than do electrons. This effect can be represented, in rough overall terms, by a quality factor, Q. Over a wide range of incident energies, Q is taken to be 1.0 for electrons (and for X-rays and gamma rays, both of which produce electrons) and 20 for alpha particles. For neutrons, the adopted quality factor varies from 5 to 20, depending on neutron energy (Shapiro 1990).

The biological impact is specified by the dose equivalent $(\mathrm{H})$, which is the product of the absorbed dose (D) and the quality factor (Q):

$$
\mathrm{H}=\mathrm{Q} \mathrm{D} .
$$

The unit for the dose equivalent is the rem if the absorbed dose is in rads and the sievert ( $\mathrm{Sv}$ ) if the absorbed dose is in grays. Thus, $1 \mathrm{~Sv}=100 \mathrm{rem}$. One rem is roughly the average dose received by an individual in 3 years of exposure to background radiation (NCRP 1987).

\section{C.1.1.3 How Does Radiation Affect the Human Body?}

Ionizing radiation affects the body through two basic mechanisms. The ionization of atoms can generate chemical changes in body fluids and cellular material. Also, in some cases the amount of energy transferred can be sufficient to actually alter the atom and its chemical bonds, again resulting in chemical changes. These chemical changes can lead to alteration or disruption of the normal function of the affected area.

Potential biological effects depend on how much and how fast a radiation dose is received. Radiation doses can be grouped into two categories, acute and chronic dose. 
An acute radiation dose is defined as a large dose (10 rad or greater, to the whole body) delivered during a short period of time (on the order of a few days at the most). If large enough, it may result in effects which are observable within a period of hours to weeks (Blend 1998). However, as in most illnesses, the specific symptoms, the therapy that a doctor might prescribe, and the prospects for recovery vary from one person to another and are related to the age and general health of the individual.

Radiation sickness symptoms are apparent following acute doses greater than 100 rad. Acute whole body doses of greater than 450 rad may result in a statistical expectation that 50 percent of the population exposed will die within 60 days without medical attention (Blend 1998). Exposures to radiation at these levels are quite rare and are almost always due to accidental circumstances.

Blood-forming organ (bone marrow) syndrome (greater than $100 \mathrm{rad}$ ) is characterized by damage to cells that divide at the most rapid pace (such as bone marrow, the spleen, and lymphatic tissue). Symptoms include internal bleeding, fatigue, bacterial infections, and fever (Blend 1998).

Gastrointestinal tract syndrome (greater than $1000 \mathrm{rad}$ ) is characterized by damage to cells that divide less rapidly (such as the linings of the stomach and intestines). Symptoms include nausea, vomiting, diarrhea, dehydration, electrolytic imbalance, loss of digestion ability, bleeding ulcers, and the symptoms of blood-forming organ syndrome (Blend 1998).

Central nervous system syndrome (greater than $5000 \mathrm{rad}$ ) is characterized by damage to cells that do not reproduce such as nerve cells. Symptoms include loss of coordination, confusion, coma, convulsions, shock, and the symptoms of the blood forming organ and gastrointestinal tract syndromes. Scientists now have evidence that death under these conditions is not caused by actual radiation damage to the nervous system, but rather from complications caused by internal bleeding, and fluid and pressure build-up on the brain (Blend 1998).

As a group, the effects caused by acute doses are called deterministic. Broadly speaking, this means that severity of the effect is determined by the amount of dose received. Deterministic effects usually have some threshold level below which the effect will probably not occur, but above which the effect is expected. When the dose is above the threshold, the severity of the effect increases as the dose increases (Cember 1996).

A chronic dose is a relatively small amount of radiation received over a long period of time. The body is better equipped to tolerate a chronic dose than an acute dose. The body has time to repair damage because a smaller percentage of the cells need repair at any given time. The body also has time to replace dead or non-functioning cells with new, healthy cells. This is the type of dose received as occupational exposure. At chronic exposure levels, such as the levels experienced in an occupational or environmental setting, these chemical changes are very small and the body's natural repair mechanisms are able to repair the cell damage before there is a harmful effect. The body has a wide variety of mechanisms that repair the damage induced. However, occasionally, these changes can cause irreparable damage that could ultimately lead to initiation of a cancer, or change to genetic material that could be passed to the next generation. The probability for the 
occurrence of health effects of this nature depends upon the type and amount of radiation received, and the sensitivity of the part of the body receiving the dose (Cember 1996).

For low levels of radiation exposure, the probabilities for induction of various cancers or genetic effects have been extensively studied by both national and international expert groups. The problem is that the potential for health effects at low levels is extremely difficult to determine without extremely large, well-characterized populations. For example, to get a statistically valid estimate of the number of cancers caused by an external dose equivalent of $1 \mathrm{rem}, 10$ million people would be required for the test group, with another 10 million for the control group. This large population is required because the current incidence of cancer is fairly high (approximately 20 percent of all deaths are due to cancer) and the additional risk incurred by low level radiation exposure is low. Also, it is important to account for the many nonradiation-related mechanisms for cancer induction, such as smoking, diet, lifestyle, chemical exposure, and genetic predisposition. These multiple factors also make it difficult to establish cause-and-effect relationships that could attribute high or low cancer rates to specific initiators.

The most significant ill-health effects that result from environmental and occupational radiation exposure are cancer fatalities. These ill-health effects are referred to as "latent" cancer fatalities (LCFs) because the cancer may take many years to develop and for death to occur.

Health impacts from radiation exposure, whether from sources external or internal to the body, generally are identified as somatic (affecting the individual exposed) or genetic (affecting descendants of the exposed individual). Radiation is more likely to produce somatic effects rather than genetic effects. The somatic risks of most importance are the induction of cancers (Cember 1996).

\section{C.1.1.4 What Are Some Types of Radiation Dose Measurements?}

The amount of ionizing radiation that the individual receives during an exposure is referred to as dose. An external dose is delivered only during the actual time of exposure to the external radiation source. An internal dose, however, continues to be delivered as long as the radioactive source is in the body, although both radioactive decay and elimination of the radionuclide by ordinary metabolic processes decrease the dose rate with the passage of time. The measurement of radiation dose is called radiation dosimetry and is completed by a variety of methods depending upon the characteristics of the incident radiation (Cember 1996).

External radiation is measured as a value called deep dose equivalent. This is defined as the external whole-body exposure dose equivalent at a tissue depth of $1 \mathrm{~cm}\left(1000 \mathrm{mg} / \mathrm{cm}^{2}\right)$. Internal radiation is stated in terms of the committed effective dose equivalent (CEDE), which incorporates a scientific estimate of the dose an individual is "committed" to receive (for up to 50 years for some radionuclides) from radioactive material in the body. The sum of the two contributions (deep dose equivalent and CEDE) provides the total dose to the individual, called the total effective dose equivalent (TEDE). For calculation, regulatory, and recordkeeping purposes, all of the "committed" dose is assigned to the year when intake occurred. Often the radiation dose to a selected group or population is of interest and is referred to as the collective 
dose equivalent, with the measurement units of person-rem (Cember 1996). Ten people exposed to 1 rem each would be reported as 10 person-rem.

\section{C.1.1.5 What Are Some Sources of Radiation?}

Many different sources of radiation have been identified. The majority of the radiation sources are naturally occurring or background sources, which can be categorized as cosmic, terrestrial, or internal radiation sources. Manmade radiation sources include consumer products, medical sources, and other miscellaneous sources. The average American receives a total of about 360 millirem (mrem) per year from all sources of radiation, both natural and manmade (NCRP 1987).

Cosmic radiation is ionizing radiation resulting from energetically charged particles from space that continuously hit the earth's atmosphere. Because the atmosphere provides some shielding against cosmic radiation, the intensity of this radiation increases with altitude above sea level. For example, a person in Denver, $\mathrm{CO}$ is exposed to more cosmic radiation than a person in New Orleans, LA. The average annual dose to persons in the United States from cosmic radiation is about 27 mrem. The average cosmogenic dose contribution (mostly due to carbon-14) adds another $1 \mathrm{mrem}$. Cosmogenic dose is attributable to isotopes that are produced by interaction of cosmic rays with atoms in the earth's atmosphere (NCRP 1987).

Terrestrial radiation is radiation emitted from the radioactive materials in the earth's rocks, soils, and minerals. Radon, radon progeny, potassium, isotopes of thorium, and isotopes of uranium are the elements responsible for most terrestrial radiation. The average annual dose from terrestrial radiation is about $28 \mathrm{mrem}$, but the dose varies geographically across the country. Typically reported values are about 16 mrem on the Atlantic and Gulf Coastal Plains and about 63 mrem on the eastern slopes of the Rocky Mountains (NCRP 1987).

Internal radiation arises from the human body metabolizing natural radioactive material that has entered the body by inhalation, ingestion, or through an open wound. Natural radionuclides in the body include isotopes of uranium, thorium, radium, radon, bismuth, polonium, potassium, rubidium, and carbon. The major contributors to the annual dose equivalent for internal radioactivity are the short-lived decay products of radon which contribute about $200 \mathrm{mrem}$ per year. The average dose from other internal radionuclides is about 39 mrem per year, most of which results from potassium-40 and polonium-210 (NCRP 1987).

Consumer products also contain sources of ionizing radiation. In some products, like smoke detectors and airport x-ray machines, the radiation source is essential to the operation of the product. In other products, such as televisions and tobacco products, the radiation occurs incidentally to the product function. The average annual dose from consumer products is about 10 mrem (NCRP 1987).

Medical source radiation is an important diagnostic tool and is the main source of exposure to the public from manmade radiation. Exposure is deliberate and directly beneficial to the patient exposed. In general, medical exposures from diagnostic or therapeutic x-rays result from beams directed to specific areas of the body. Thus, all body organs generally are not irradiated 
uniformly. Nuclear medicine examinations and treatments involve the internal administration of radioactive compounds or radiopharmaceuticals by injection, inhalation, consumption, or insertion. Even then, radionuclides are not always distributed uniformly throughout the body. Diagnostic x-rays result in an average annual exposure of $39 \mathrm{mrem}$. Nuclear medical procedures result in an average annual exposure of $14 \mathrm{mrem}$. It is recognized that the averaging of medical doses over the entire population does not account for the potentially significant variations in annual dose among individuals, where greater doses are received by older or less healthy members of the population (NCRP 1987).

A few additional sources of radiation contribute minor doses to individuals in the United States. The average public dose from nuclear fuel cycle facilities, such as uranium mines, mills, fuel processing plants, nuclear power plants, and transportation routes, is less than 1 mrem per year. Radioactive fallout from atmospheric atomic bomb tests and emissions of radioactive material from U.S. Department of Energy (DOE) facilities contribute less than 1 mrem per year to the average individual dose. Air travel contributes approximately 1 mrem per year to the average dose (NCRP 1987).

\section{C.1.2 How Is Radiation Exposure Regulated?}

As described in Chapter 6 of this PEIS, the U.S. Nuclear Regulatory Commission (NRC) would have oversight of any new facility under the domestic programmatic alternatives if the facility is not a DOE operated or DOE regulated facility. The paragraphs below describe the methods that both agencies use to regulate radiation exposure of workers and the public.

The release of radioactive materials and the potential level of radiation doses to workers and the public are regulated by DOE for its contractor facilities. Under conditions of the Atomic Energy Act (1954) (as amended by the Price-Anderson Amendments Act of 1988), DOE is authorized to establish Federal rules controlling radiological activities at DOE sites. The act also authorizes DOE to impose civil and criminal penalties for violations of these requirements.

Occupational radiation protection is regulated by 10 CFR Part 835, Occupational Radiation Protection. DOE has set occupational dose limits for an individual worker at 5,000 mrem per year. Individual DOE sites have set administrative control levels at a fraction of this dose limit to help enforce the goal to manage and control worker exposure to radiation and radioactive material to a level as low as reasonably achievable (ALARA).

Environmental radiation protection at DOE sites is addressed by DOE Order 5400.5. This Order sets annual dose standards to members of the public, as a consequence of routine DOE operations, of $100 \mathrm{mrem}$ through all exposure pathways. The Order requires that no member of the public receive an annual dose greater than 10 mrem per year from the airborne pathway and 4 mrem per year from the ingestion of drinking water. Similarly, the Radionuclide National Emission Standards for Hazardous Air Pollutants (Rad-NESHAP) (40 CFR Part 61), adopted under the Clean Air Act (CAA), limits exposure of an individual member of the public to airborne releases of radionuclides to a maximum of 10 mrem per year. 
For commercial facilities, the dose to workers and the public are regulated by the NRC under the Atomic Energy Act, and limitations established by NRC rules are imposed in NRC licenses. Under 10 CFR Part 20, each licensee is required to conduct operations so that the TEDE to individual members of the public does not exceed 100 mrem in a year. Furthermore, 10 CFR Part 20 requires that power reactor licensees comply with the U.S. Environmental Protection Agency (EPA) environmental radiation standards contained in 40 CFR Part 190 (i.e., 25 mrem to whole body, 75 mrem to the thyroid, and 25 mrem to any other organ of any members of the public from the uranium fuel cycle).

\section{C.2 RISK CHARACTERIZATION AND INTERPRETATION OF RADIOLOGICAL DATA}

Current DOE guidance (DOE 2002h) for estimating public and worker cancer risk from exposure to ionizing radiation recommends using a conversion factor of $6 \times 10^{-4}$ fatal cancers per rem, and a factor of $8 \times 10^{-4}$ per rem for estimating excess cancer morbidity (incidence). Based on this guidance, the probability of an individual worker or member of the public contracting a fatal cancer is $6 \times 10^{-7}$ per mrem. These conversion factors are based on a technical report issued by the Interagency Steering Committee on Radiation Standards. In this PEIS, only fatal cancers are presented.

This approach estimates excess cancer fatalities (i.e., those above the naturally occurring annual rate). The current national rate of deaths from cancer is 171.4 per 100,000 people annually (Ries et al. 2003). Estimates of expected LCFs from radiation exposures are calculated from the effective dose equivalent, which weights the impacts on particular organs so that the dose to different organs (i.e., in the body, different radionuclides can affect different organs) can be compared. All doses in this PEIS are effective dose equivalent unless otherwise noted.

Sometimes calculations of the number of excess cancer fatalities associated with radiation exposure do not yield whole numbers and, especially in regard to public exposure from normal operations, may yield numbers less than 1.0. For example, if a population of 100,000 were exposed to a total dose of only $0.001 \mathrm{rem}$, the collective dose would be 100 person-rem, and the corresponding estimated number of cancer fatalities would be $0.06(100,000$ persons $\times 0.001 \mathrm{rem}$ $\times 0.0006$ cancer fatalities/person-rem $=0.06$ fatal cancers).

A fractional cancer fatality estimate, such as 0.06 , should be interpreted as a statistical estimate. That is, 0.06 is interpreted as the average number of deaths that would result if the same exposure situation were applied to many different groups of 100,000 people. In most groups, no person ( 0 people) would incur a cancer fatality from the average 0.001 rem dose each member would have received. In a small fraction of the groups, one fatal cancer would result; in exceptionally few groups, two or more fatal cancers would occur. The average number of deaths over all the groups would be 0.06 fatal cancers (just as the average of $0,0,0$, and 1 is $1 / 4$, or 0.25 ). The most likely outcome is 0 cancer fatalities.

These same concepts are assumed to apply to estimating the effects of radiation exposure on a single individual. Consider the effects, for example, of exposure to background radiation over a lifetime. The "number of cancer fatalities" corresponding to a single individual's exposure over a (presumed) 70 -year lifetime to 0.3 rem per year is the following: 


$$
\begin{aligned}
1 \text { person } \times 0.3 \mathrm{rem} / \mathrm{year} & \times 70 \text { years } \times 0.0006 \text { cancer fatalities } / \text { person-rem } \\
& =0.013 \text { cancer fatalities }
\end{aligned}
$$

This could be interpreted that the estimated effect of background radiation exposure on the exposed individual would produce a 1.3 percent chance that the individual might incur a fatal cancer caused by the exposure.

\section{C.3 RISK ESTIMATES AND HEALTH EFFECTS FOR RADIATION EXPOSURES TO WORKERS}

For the purpose of evaluating radiation exposure, workers may be designated as radiation workers or general employees (based upon the potential level of exposure they are expected to encounter in performing their work assignments), or as visitors. Within a given worker population, collective dose data are presented in units of person-rem. The average radiation dose to this worker population can be calculated from this collective dose by simply dividing the collective dose (person-rem) by the number of workers (persons).

Radiation workers are those employees whose job assignments place them in proximity to radiation-producing equipment and/or radioactive materials. These workers are trained for unescorted access to radiological areas. These workers are assigned to areas that could potentially result in them receiving an annual TEDE of more than 100 mrem per year. All trained radiation workers wear dosimeters. Dosimeters are radiation detection devices used to record the external radiation dose received by the wearer. The primary type of dosimeter used to measure occupational radiation dose is the thermoluminescent dosimeter (TLD) (Shapiro 1990). TLDs are processed on a routine basis; however, they may be retrieved for special processing more frequently if necessary. TLDs are sensitive to beta, gamma, and in some applications, neutron radiation. Personal exposure records are maintained for all monitored radiation workers to ensure personnel doses are maintained within regulatory limits and to track radiation exposure over time. Other types of dosimeters such as extremity dosimeters (for monitoring dose to areas of the body such as hands and arms) or neutron dosimeters may be worn when circumstances warrant.

For DOE facilities, potential exposure to radiation is controlled by limiting access to areas where radiation or radioactive materials may be present. These areas are characterized to determine their potential radiation hazard and are posted as one or more of the following, as applicable (10 CFR Part 835):

- Controlled area: Any area to which access is managed by or for DOE to protect individuals from exposure to radiation and/or radioactive material.

- Airborne radioactivity area: Any area, accessible to individuals, where:

- The concentration of airborne radioactivity, above natural background, exceeds or is likely to exceed the derived air concentration (DAC) values listed in 10 CFR Part 835.

- An individual present in the area without respiratory protection could receive an intake exceeding 12 DAC-hours in a week. 
- Contamination area: Any area, accessible to individuals, where removable surface contamination levels exceed or are likely to exceed the removable surface contamination values specified in Appendix D of 10 CFR Part 835, but do not exceed 100 times those values.

- Radiation area: Any area accessible to individuals in which radiation levels could result in an individual receiving a deep dose equivalent in excess of 0.005 rem in 1 hour at 12 in $(30 \mathrm{~cm})$ from the source or from any surface that the radiation penetrates.

- High radiation area: Any area, accessible to individuals, in which radiation levels could result in an individual receiving a deep dose equivalent in excess of 0.1 rem in 1 hour at 12 in $(30 \mathrm{~cm})$ from the radiation source or from any surface that the radiation penetrates.

- Very high radiation area: Any area accessible to individuals in which radiation levels could result in an individual receiving an absorbed dose in excess of 500 rads in 1 hour at 3.3 feet $(\mathrm{ft})(1 \mathrm{~meter}[\mathrm{~m}])$ from a radiation source or from any surface that the radiation penetrates.

NRC requirements for posting and access control for radiological areas are contained in 10 CFR Part 20, and are similar to the DOE requirements in 10 CFR Part 835.

General employees are those employees who are not currently trained as radiation workers but whose job assignment may require their occasional presence within a controlled area with an escort. They may be exposed to transient radiation fields as they pass by or through a particular area, but their job assignments are such that annual dose equivalents in excess of $100 \mathrm{mrem}$ are unlikely.

Visitors are individuals who do not perform routine work at nuclear facilities. They are not trained radiation workers and are not expected to receive $100 \mathrm{mrem}$ in a year. Their presence in radiological areas is limited, in terms of time and access. These individuals generally enter specified radiological areas on a limited basis for walk-through or tours with a trained escort. As appropriate, visitors participate in dosimetry monitoring when requested by the host site.

For facilities under the domestic programmatic alternatives, DOE began by reviewing occupational radiation dose data for currently operating commercial reactors. In 2006, approximately 116,000 individuals working in commercial nuclear plants in the United States were monitored, and approximately 59,000 received a measurable dose (hereafter, workers who received a measurable dose will be referred to as "radiation workers"). During 2006, these radiation workers incurred a collective dose of approximately 11,000 person-rem, which represents a 4 percent decrease from the 2005 value. The average dose to radiation workers was approximately 190 mrem (NRC 20071). These data were then used, in conjunction with the expected number of employees anticipated to be required to implement the domestic programmatic alternatives, to calculate the collective radiation dose (person-rem) to these employees and the corresponding number of LCFs. Chapter 4 presents the results of this analysis.

For the reference case, this PEIS assumes that all programmatic alternatives could be implemented to achieve a capacity of approximately 200 gigawatts electric $(\mathrm{GWe})$. The nuclear fuel cycles would be different for each of the programmatic alternatives. For example, the No 
Action Alternative would produce electricity using light water reactors (LWRs) in a once-through fuel cycle, while the Fast Reactor Recycle Alternative would produce electricity using a mix of LWRs and fast reactors in a closed fuel cycle in which the separated LWR spent nuclear fuel provides the transmutation fuel for the fast reactors.

For all alternatives considered by the GNEP PEIS, existing U.S. enrichment and fuel fabrication capacities would be inadequate to support a capacity of $200 \mathrm{GWe}$. For all alternatives, existing and planned enrichment and fuel fabrication capacities would need to be increased by nearly 50 percent. In addition to increased uranium fuel fabrication capacity, the Thorium Alternative would also require a fuel fabrication facility for thorium. The closed fuel cycle alternatives (Fast Reactor Recycle Alternative, Thermal/Fast Reactor Recycle Alternative, and the Thermal Reactor Recycle Alternative (all options) would require LWR separation facilities/fuel fabrication facilities. Finally, the Thermal Reactor Recycle Alternative (Option 2) and the Heavy Water Reactor (HWR)/High Temperature Gas-Cooled Reactor (HTGR) Alternative (Option 1-all-HWR) would require one or more facilities to produce heavy water.

\section{C.4 Risk Estimates AND Health EFFECTS For Radiation EXPOSURES TO Members of The Public}

EPA regulations for radionuclides (40 CFR Part 61, Subpart $\mathrm{H}$ for DOE facilities) require continuous emission sampling of sources that could potentially contribute more than $0.1 \mathrm{mrem}$ per year effective dose equivalent to an off-site individual from internal and external radiation exposure pathways of released radionuclides. This regulation also sets a limit on the emission of radionuclides that ensures no member of the public receives an effective dose equivalent of more than 10 mrem per year.

For NRC licensed facilities, the NRC regulations in 10 CFR Part 20 limit radiation exposure to individual members of the public to less than 100 mrem per year. The NRC regulations in 10 CFR Part 20 also state that the NRC may impose additional restrictions on radiation levels in unrestricted areas and on the total quantity of radionuclides that a licensee may release in effluents in order to restrict the collective dose. For example, Appendix I to 10 CFR Part 50 states that the calculated annual total quantity of all radioactive material above background to be released from each LWR to the atmosphere will not result in an estimated annual air dose from gaseous effluents at any location near ground level which could be occupied by individuals in unrestricted areas in excess of 10 millirads for gamma radiation or 20 millirads for beta radiation. Similarly, the calculated annual total quantity of all radioactive iodine and radioactive material in particulate form above background to be released from each LWR in effluents to the atmosphere will not result in an estimated annual dose or dose commitment from such radioactive iodine and radioactive material in particulate form for any individual in an unrestricted area from all pathways of exposure in excess of 15 millirem to any organ.

This section discusses the potential impacts to the public from normal operations for each of the domestic programmatic alternatives. Impacts are presented in terms of radiological doses to the public. If more than one facility were to be located on the same site (for example a reactor and a separations facility were colocated), the radiation dose from the entire site would need to be less than the 100 mrem per year standard from 10 CFR Part 20. This means that each individual 
facility would have its radionuclide emissions limited to a level that would result in a fraction of the 100 mrem per year standard.

The Clean Air Assessment Package computer code, CAP88-PC Version 2.1 (CAP88) (EPA 2002b) was applied to projected radiological effluents to estimate the potential impacts of airborne radioactive releases from facilities associated with the domestic programmatic alternatives under normal operations. CAP88 is an EPA-approved computer code designed to estimate the effective dose equivalent to the regional human population due to the release of radionuclides from a source. There are three primary pathways for exposure from an atmospheric release of radiological material: ingestion, inhalation, and external exposure. Ingestion would generally be from consumption of plants, animals, fish, or water contaminated with radionuclides. Inhalation could occur if a person were in the path of a radiological plume or from resuspension of previously deposited material. External exposure could occur for people who hunt, fish, or play in areas where the ground or water has been exposed to radiological materials. CAP88 accounts for the various modes of exposure and applies biokinetic models (i.e., the manner in which radionuclides affect various organs of the body) and metabolic parameters (i.e., the typical rates for human body processes) established by the International Commission on Radiological Protection (ICRP).

The effective dose equivalent received by the hypothetical maximally exposed individual (MEI) along with the estimated probability that this dose will result in an LCF are presented in Chapter 4 of this PEIS for the domestic programmatic alternatives. The MEI is defined as a hypothetical individual who, because of proximity, activities, or living habits, could potentially receive the maximum possible dose of radiation or of a hazardous chemical from a given event or process. The collective total effective dose equivalent to the population residing within 50 miles (mi) (80 kilometers [km]) of each postulated facility location along with the calculated number of excess LCFs in this population is also presented in Chapter 4 of this PEIS for the domestic programmatic alternatives.

Public exposures would vary depending on many factors, but would predominantly be affected by prevailing weather patterns and the proximity of the facilities to local population centers. For the domestic programmatic alternatives, as described in Section D.1.6, DOE developed six generic sites to assess the impacts of potential radiological releases associated with normal operations of facilities. These sites provide a range of values for two parameters: offsite (within $50 \mathrm{mi}[80 \mathrm{~km}])$ population and meteorological conditions that would directly affect the offsite consequences of radiological releases. The size of the $50 \mathrm{mi}(80 \mathrm{~km})$ population has a direct effect on the collective dose received in the area surrounding the site. The environmental concentrations which would result from radiological releases would depend on the meteorological mechanisms of advection and dispersion that a release would experience as it is transported downwind.

The distance to the site boundary was also considered as a site differentiator. This distance affects the dose to the MEI. In general, the greater the distance to the site boundary, the smaller the dose will be to the MEI. DOE obtained information regarding the exclusion distance for all currently operating commercial nuclear power plants in the United States from Appendix A, "General Characteristics and Environmental Settings of Domestic Nuclear Power Plants" in the 
Generic Environmental Impact Statement for License Renewal of Nuclear Plants (NUREG-1437 Vol. 2) (NRC 1996). This appendix lists the exclusion distance (km) for every site with an operating reactor.

The mean value for the exclusion distance is 3,018 feet ( $\mathrm{ft}$ ) (920 meters [m]), with a standard deviation of $1,280 \mathrm{ft}(390 \mathrm{~m})$. The median exclusion distance is $2,986 \mathrm{ft}(910 \mathrm{~m})$. The exclusion distances ranged from a low of $886 \mathrm{ft}(270 \mathrm{~m})$ to a high of 6,660 ft $(2,030 \mathrm{~m})$. Based on this data, DOE selected the mean distance of $3,018 \mathrm{ft}(920 \mathrm{~m})$ as the distance to site boundary for analysis at the generic sites presented in this PEIS. Selection of this mean distance provides an analysis that reflects the expected characteristics of any new commercial nuclear facility and, when combined with the conservatism in the calculation of the quantity of radioactivity released to the atmosphere from these facilities and the conservative assumption that the MEI resides on the site boundary, leads to a calculated radiation dose to the MEI that likely overestimates the dose that this individual would actually be expected to receive.

\section{C.5 Hazardous Chemical Impacts to Human Health}

\section{C.5.1 Chemicals and Human Health}

Chemicals used in industrial settings are often found in quantities and concentrations that may affect the health of individuals in the workplace and in the surrounding community. The following sections describe both the carcinogenic and noncarcinogenic effects of chemicals on the body and how these effects are assessed.

\section{C.5.1.1 How Do Chemicals Affect the Body?}

Industrial pollutants may be released to the environment either intentionally or accidentally in quantities that could result in health effects to those who come in contact with them. Chemicals that are airborne, or released from stacks and vents, can migrate in the prevailing wind direction for many miles. The public may then be exposed by inhaling chemical gases, vapors or particles of dust contaminated by the pollutants. Additionally, the pollutants may be deposited on the surface soil and biota (plants and animals) and subsequent human exposure could occur. Chemicals may also be released from industries as liquid waste (effluent) or solid waste and can migrate or be transported from the point of release to a location where exposure could occur.

Exposure is defined as the contact of a person with a chemical or physical agent. For exposure to occur, a chemical source or contaminated media such as soil, water, or air must exist. This source may serve as a point of exposure, or contaminants may be transported away from the source to a point where exposure could occur (AIHA 1998). In addition, an individual (receptor) must come into either direct or indirect contact with the contaminant. Contact with a chemical can occur through ingestion, inhalation, dermal contact, or external exposure. The exposure may occur over a short (acute or subchronic) or long (chronic) period of time. These methods of contact are typically referred to as exposure routes. The process of assessing all of the methods by which an individual might be exposed to a chemical is referred to as an exposure assessment (AIHA 1998). 
Once an individual is exposed to a hazardous chemical, the body's metabolic processes typically alter the chemical structure of the compound in its efforts to expel the chemical from the system. For example, when compounds are inhaled into the lungs they may be absorbed depending on their size (for particulates) or solubility (for gases and vapors) through the lining of the lungs directly into the blood stream. After absorption, chemicals are distributed in the body and may be metabolized, usually by the liver, into metabolites that may be more toxic than the parent compound. The compound may reach its target tissue, organ, or portion of the body where it will exert an effect, before it is excreted. The relative toxicity of a compound is affected by the physical and chemical characteristics of the contaminant, the physical and chemical processes ongoing in the human body and the overall health of an individual (AIHA 1998). For example, infants, the elderly, individuals with weakened immune systems and pregnant women are considered more susceptible to certain chemicals.

Chemicals have various types of effects on the body. Generally, when considering human health, chemicals are divided into two broad categories: chemicals that cause health effects but do not cause cancer (noncarcinogens) and chemicals that cause cancer (carcinogens). Note that exposure to some chemicals can result in the manifestation of both noncarcinogenic health effects and an increased risk of cancer (AIHA 1998).

\section{C.5.1.2 Chemical Noncarcinogens}

Chemical noncarcinogens are chemicals or compounds that when introduced to the human body via ingestion, inhalation, or dermal absorption may result in a systemic effect if the intake exceeds a level that can be effectively eliminated. For example, a noncarcinogenic chemical or compound may affect the central nervous system, renal (kidney) function, or other systems that have an effect on the body's metabolic processes. They may also cause milder effects such as irritation to the eyes or skin, or asthmatic attacks. The levels of the effects are directly related both to the chemical and the level of exposure (AIHA 1998).

For many noncarcinogenic substances, the body is equipped with protective mechanisms that must be overcome before an adverse effect is manifested from a chronic, subchronic, or acute chemical exposure. For example, where a large number of cells perform the same or similar function, the cell population may have to be significantly depleted before an effect is seen. The body can tolerate a range of exposure where there is essentially no change in expression of adverse effects. This is known as the "threshold" or "nonstochastic" concept and has been observed in multiple animal studies. The results of these animal studies are a set of guidelines that serve as the basis for the development of noncarcinogenic toxicity values (AIHA 1998). The No Observed Adverse Effect Level (NOAEL) is the highest exposure level at which there are no statistically or biologically significant increases in the frequency or severity of adverse effect between the exposed population and its appropriate control; some effects may be produced at this level, but they are not considered adverse, nor precursors to adverse effects (IUPAC 2007). The Lowest Observed Adverse Effect Level (LOAEL) is the lowest exposure levels at which there are statistically or biologically significant increases in frequency or severity of adverse effects between the exposed population and its appropriate control group. It is also referred to as the lowest-effect level (IUPAC 2007). 


\section{C.5.1.3 Chemical Carcinogens}

Over the past century, many chemicals have been identified that cause cancer in humans. Examples of these carcinogens include asbestos in insulation, vinyl chloride in the rubber industry, and benzene in solvents. Cancers caused by industrial chemicals can occur in any organ in the body, including the respiratory tract, bladder, bone marrow, gastrointestinal tract, or liver.

Currently, EPA categorizes chemicals as either confirmed human carcinogens, suspected human carcinogens, or confirmed animal carcinogens. For cancer agents (including all radionuclides), EPA provides toxicity information that can be used to determine the probability that cancer may occur. The toxicity factors used to assess exposures to carcinogens are referred to as cancer slope factors (CSFs). The CSFs represent the slope of the dose-response curve from various toxicity studies. Most of the CSFs for nonradionuclides were developed based on the data from chemical-specific 2-year animal studies (ACGIH 1991).

The CSFs for chemicals are the upper-bound estimate of the probability of a response per unit intake of a chemical over a lifetime. This slope factor is expressed in units of $\mathrm{mg} / \mathrm{kg}$-day. Because the slope factors are the 95th percentile upper confidence limit on the probability of a carcinogenic response, the carcinogenic risk estimate represents an upper confidence bound estimate. Therefore, a 5 percent probability exists that the actual risk will be higher than the estimate presented, and the actual risk may well be less than the estimate (EPA 2007g).

\section{C.5.2 How Is Chemical Exposure Regulated?}

\section{C.5.2.1 Environmental Protection Standards}

The Federal Government regulates the exposure to members of the public and the environment from hazardous chemicals through a variety of laws and regulations. Applicable Federal and state environmental acts/agreements include:

- Resource Conservation and Recovery Act (RCRA)

- Comprehensive Environmental Response, Compensation, and Liability Act (CERCLA) as amended by the Superfund Amendments and Reauthorization Act (SARA)

- Federal Facility Compliance Agreements

- Endangered Species Act

- Safe Drinking Water Act

- Clean Water Act (CWA) (which resulted in the establishment of the National Pollutant Discharge Elimination System (NPDES) and pretreatment regulations for Publicly Owned Treatment Works)

- Clean Air Act (CAA) (Title III, Hazardous Air Pollutants, Asbestos NESHAP)

- Toxic Substances Control Act (TSCA)

- Federal Insecticide, Fungicide, and Rodenticide Act

Many of these acts/agreements include environmental standards that must be met to ensure the protection of the public and the environment. Most of the acts/agreements require completed permit applications in order to treat, store, dispose of, or release contaminants to the 
environment. The applicable environmental standards and reporting requirements are set forth in the issued permits and must be met to ensure compliance.

The Emergency Planning and Community Right-To-Know Act (42 U.S.C. 11001 et seq.), also referred to as SARA Title III, requires reporting of emergency planning information, hazardous chemical inventories, and environmental releases to Federal, state, and local authorities. The annual Toxic Release Inventory Report addresses releases of toxic chemicals into the environment, waste management activities, and pollution prevention activities associated with those chemicals.

DOE Order 450.1 establishes environmental protection program requirements, authorities, and responsibilities for DOE operations to ensure compliance with applicable Federal, state, and local environmental protection laws and regulations, executive orders, and internal DOE policies. The Order specifically defines the mandatory environmental protection standards (including those imposed by Federal and state statues), establishes reporting of environmental occurrences and periodic routine significant environmental protection information, and provides requirements and guidance for environmental monitoring programs (DOE O 450.1).

\section{C.5.2.2 Regulated Occupational Exposure Limits}

Occupational limits for hazardous chemicals are regulated by the Occupational Safety and Health Administration (OSHA). The permissible exposure limits (PELs) represent the legal concentration levels set by OSHA that are safe for 8-hour exposures without causing noncancer health effects. Other agencies, including the National Institute for Occupational Safety and Health (NIOSH) and the American Conference of Governmental Industrial Hygienists (ACGIH) provide guidelines. The NIOSH guidelines are Recommended Exposure Limits (NIOSH 2005) and the ACGIH guidelines are Threshold Limit Values (TLVs) (ACGIH 2001). Occupational limits are further defined as time-weighted averages (TWAs), or concentrations for a conventional 8-hour workday and a 40-hour workweek, to which it is believed nearly all workers may be exposed, day after day, without adverse effects. Often ceiling limits, or airborne concentrations that should not be exceeded during any part of the workday, are also specified. In addition to the TWA and ceiling limit, short-term exposure limits may be set. Short-term exposure limits are 15-minute TWA exposures that should not be exceeded at any time during a workday, even if the 8-hour TWA is within limits. OSHA also uses action levels to trigger certain provisions of a standard, for instance appropriate workplace precautions, training, and medical surveillance, for workers whose exposures could approach the PEL (OSHA 2007).

\section{C.6 INDUSTRIAL SAFETY}

Worker risks from radiation and chemical hazards are closely controlled by health and safety requirements. In addition to these risks, workers would have the potential for industrial accidents, injuries, and illnesses due to everyday operations. Evaluation of these potential impacts is included in this PEIS. 


\section{C.6.1 Regulation of Worker Safety}

For NRC-regulated facilities, industrial safety is regulated by 29 CFR Part 1910, Occupational Safety and Health Standards, which identifies such items as occupational health and environmental control, hazardous material control, and personal protective equipment. The requirements contained in 29 CFR Part 1926 define the safety and health regulations for construction activities.

For DOE facilities, DOE Order 440.1B, Worker Protection Management for DOE Federal and Contractor Employees, regulates the health and safety of workers at all DOE sites. This comprehensive standard directs the contractor facilities to establish the framework for an effective worker protection program that will reduce or prevent injuries, illnesses, and accidental losses by providing DOE federal and contractor workers with a safe and healthful workplace. Baseline exposure assessments are outlined in this requirement, along with health and safety responsibilities. 10 CFR Part 851, Worker Safety and Health Program, is applicable to non-federal employees. 10 CFR 851.23 requires that all DOE sites comply with the PELs unless a lower (more protective) limit exists in the ACGIH TLVs.

Safety Programs at DOE facilities implement an Integrated Safety Management System pursuant to DOE Policy 450.4, Safety Management System Policy. The objective of an Integrated Safety Management System is to provide a safe workplace to perform work safely while protecting the worker, the public, and the environment. Integrated Safety Management System principles are the responsibility of line management to ensure safety, competence commensurate with responsibilities, balanced priorities, clear roles and responsibilities, identification of safety standards and requirements, hazard controls tailored to work being performed, and operations authorization.

\section{C.6.1.1 Construction}

Construction of new facilities or modification of existing facilities would involve risk to workers from accidents or occupational illnesses. These risks could result from construction accidents (e.g., falls and burns), exposure to toxic or oxygen-replacing gases, and other causes. The Bureau of Labor Statistics (BLS) maintains records of total recordable cases (TRC) and cases of lost work days (LWD), which are a measure of work-related injuries or illnesses that include days away from work, restricted work activity, medical treatment beyond first aid, and other criteria. The 2006 nationwide TRC rate published by the BLS for heavy and civil engineering construction is 5.3 per 100 workers and the LWD rate is 3 (BLS 2007b). These values were used to calculate the TRC and LWD incidences for facility construction under the domestic programmatic alternatives.

All of the domestic programmatic alternatives would require a significant amount of new construction in order to achieve the base case nuclear generating capacity of $200 \mathrm{GWe}$. Although there would be differences among the alternatives in the amount of new construction (i.e., some alternatives would require recycling facilities, others would require support facilities such as a heavy water production facility), these differences would be minor. This is because the construction of approximately $200 \mathrm{GWe}$ of reactor capacity, which is common to all the alternatives, would dominate construction requirements. Consequently, the analysis of worker 
injuries and lost work day incidences would be essentially the same for all of the domestic programmatic alternatives. Table C.6.1.1-1 presents these impacts. The construction of these facilities is not expected to introduce hazards in excess of generic construction activities.

TABLE C.6.1.1-1-Annual Worker Injury and Lost Work Day Incidences for Construction Activities-All Domestic Programmatic Alternatives

\begin{tabular}{lcc}
\hline & $\begin{array}{c}\text { Total Recordable } \\
\text { Case Incidence }\end{array}$ & Lost Work Day Incidence \\
\hline${\text { Average } \text { Annual }^{\mathrm{a}}}_{\text {Peak }^{\mathrm{b}}}$ & 239 & 135 \\
${ }^{\mathrm{a}}$ Assumes an average annual workforce of $1,000 /$ facility & 270 \\
\hline
\end{tabular}

${ }^{\mathrm{b}}$ Assumes a peak annual workforce of 2,000/facility

\section{C.6.1.2 Operations}

Similar to construction, operation of facilities would involve risks to workers from accidents or occupational illnesses. The 2006 nationwide TRC rate published by the BLS for nuclear electrical generating operations is 1 per 100 workers and the LWD rate is 0.4 (BLS 2007b).

Under the domestic programmatic alternatives, DOE assumes that an additional 1,000 workers would be required for each GWe of new nuclear generation ${ }^{1}$ (NRC 20071). The $200 \mathrm{GWe}$ assumed for the domestic programmatic alternatives results in the estimated total workforce of 200,000 workers. This value, along with the TRC and LWD incidence rates discussed above, was used to project the injuries/illnesses for facility operations under the domestic programmatic alternatives, as shown in Table C.6.1.2-1.

TABLE C.6.1.2-1—Annual Calculated Nonfatal Total Recordable Cases and Lost Workdays for Operations-All Domestic Programmatic Alternatives

\begin{tabular}{ccc}
\hline Number of Workers ${ }^{\mathrm{a}}$ & $\begin{array}{c}\text { Total Recordable } \\
\text { Case Incidence }\end{array}$ & $\begin{array}{c}\text { Lost Work Day } \\
\text { Incidence }\end{array}$ \\
\hline 200,000 & 2,000 & 800 \\
\hline${ }^{a}$ Assumes 1,000 workers per GWe of nuclear production &
\end{tabular}

\footnotetext{
${ }^{1}$ In calendar year 2006, the annual collective dose per reactor for LWR licensees was 106 person-rem. This represents a 4 percent decrease from the value reported for 2005 (110). The number of monitored workers refers to the total number of workers that the NRC licensees (who are covered by 10 CFR Part 20) reported as being monitored for exposure to external and internal radiation during the year. This number includes all workers for whom monitoring is required and may include visitors, service representatives, contract workers, clerical workers, and any other workers for whom the licensee determines that monitoring devices should be provided. Between 2000 and 2006, a range of 105,000 to 116,000 workers at the 104 LWRs were monitored for exposures. This equates to approximately 1,010 to 1,115 workers per reactor. For purposes of the PEIS analysis, it is assumed that approximately 1,000 workers would be required for each GWe of reactor capacity.
} 


\section{C.7 REFERENCES}

10 CFR Part 20

10 CFR Part 50

10 CFR Part 835

10 CFR Part 851

29 CFR Part 1910

29 CFR Part 1926

40 CFR Part 61

40 CFR Part 190

42 U.S.C. 11001 et seq.
U.S. Nuclear Regulatory Commission (NRC), "Standards for Protection Against Radiation," Code of Federal Regulations, Office of the Federal Register, National Archives and Records Administration, Washington, DC, Revised January 1, 2008.

NRC, "Domestic Licensing of Production And Utilization Facilities," Code of Federal Regulations, Office of the Federal Register, National Archives and Records Administration, Washington, DC, Revised January 1, 2008.

U.S. Department of Energy (DOE), "Occupational Radiation Protection," Code of Federal Regulations, Office of the Federal Register, National Archives and Records Administration, Washington, DC, Revised January 1, 2008.

DOE, "Worker Safety and Health Program," Code of Federal Regulations, Office of the Federal Register, National Archives and Records Administration, Washington, DC, Revised January 1, 2008.

Occupational Safety and Health Administration (OSHA), "Occupational Safety and Health Standards," Code of Federal Regulations, Office of the Federal Register, National Archives and Records Administration, Washington, DC, Revised July 1, 2007.

OSHA, "Safety and Health Regulations for Construction," Code of Federal Regulations, Office of the Federal Register, National Archives and Records Administration, Washington, DC, Revised July 1, 2007.

Environmental Protection Agency (EPA), "National Emission Standards for Hazardous Air Pollutants (NESHAPs)," Code of Federal Regulations, Office of the Federal Register, National Archives and Records Administration, Washington, DC, Revised July 1, 2007.

EPA, "Environmental Radiation Protection Standards for Nuclear Power Operations," Code of Federal Regulations, Office of the Federal Register, National Archives and Records Administration, Washington, DC, Revised July 1, 2007.

"Emergency Planning and Community Right To Know Act," United States Code, Washington, DC, October 17, 1986. 
ACGIH 1991

ACGIH 2001

AIHA 1998

Blend 1998

BLS 2007b

Cember 1996

DOE 2002h

DOE O 440.1B

DOE O 450.1

DOE O 5400.5
American Conference of Governmental Industrial Hygienists (ACGIH), "Documentation of the Threshold Limit Value and Biological Exposure Indices," 6th Edition, American Conference of Governmental Industrial Hygienists, Cincinnati, OH, 1991.

ACGIH, "Guide to Occupational Exposure Values 2001," American Conference of Governmental Industrial Hygienist, Cincinnati, OH, 2001.

American Industrial Hygiene Association (AIHA), "The Occupational Environment-Its Evaluation and Control," AIHA Press, Fairfax, VA, 1998.

Blend, M.J. "Course Notes in Medical Radiation Biology," Radiology Department, University of Illinois, Chicago, IL, 1998. Accessed at http://www.uic.edu/com/uhrd/manual/Contents.html on January 30, 2008.

Bureau of Labor Statistics (BLS), "Number Of Fatal Work Injuries, 1992-2006," Bureau of Labor Statistics, U.S. Department of Labor, Washington, DC, 2007. Accessed at http://stats.bls.gov/iif/oshcfoil.htm on November 1, 2007.

Cember, H., "Introduction to Health Physics," Third Edition, McGraw-Hill, New York, NY, 1996.

DOE, "Estimating Radiation Risk from Total Effective Dose Equivalent (TEDE)," DOE/EH-412/0015/0802 Rev. 1, Office of Environmental Policy and Guidance, U.S. Department of Energy, Washington, DC, August 9, 2002.

DOE Order 440.1B, "Worker Protection Program for DOE (including the National Nuclear Security Administration) Federal Employees," Office of Health, Safety and Security, U.S. Department of Energy, Washington, DC, May 17, 2007.

DOE Order 450.1, "Environmental Protection Program," Office of Nuclear Safety and Environment, U.S. Department of Energy, Washington, DC, January 3, 2007.

DOE Order 5400.5, "Radiation Protection of the Public and the Environment," Office of Environment, Safety and Health, U.S. Department of Energy, Washington, DC, January 7, 1993. 
DOE P 450.4

EPA 2002b

EPA 2007g

Gollnick 1988

IUPAC 2007

NCRP 1987

NIOSH 2005

NRC 1996

NRC 20071
DOE Policy 450.4, "Safety Management System Policy," U.S. Department of Energy, Washington, DC, October 15, 1996. Accessed at http://www.directives.doe.gov/pdfs/doe/doetext/ neword/450/p4504.pdf on April 14, 2008.

EPA, "CAP88-PC Version 2.1 User Guide," Draft Revision 1, 68-D-00-210, Office of Radiation and Indoor Air (ORIA), U.S. Environmental Protection Agency, Washington, DC, May 2002.

EPA, "Radionuclide Carcinogenicity Slope Factors: Health Effects Assessment Summary Tables (HEAST)," U.S. Environmental Protection Agency, Washington, DC, 2007. Accessed at http://www.epa.gov/rpdweb00/heast/ on January 28, 2008.

Gollnick, D. A. "Basic Radiation Protection Technology," Second Edition, Pacific Radiation Corporation, Altadena, CA, 1988.

International Union of Pure and Applied Chemistry (IUPAC), "IUPAC Compendium of Chemical Terminology-The Gold Book," International Union of Pure and Applied Chemistry, 2007. Accessed at http://goldbook.iupac.org/ on January 28, 2008.

National Council on Radiation Protection and Measurements (NCRP), "Ionizing Radiation Exposure of the Population of the United States," NCRP Report No. 93, National Council on Radiation Protection and Measurements, Washington, DC, 1987.

National Institute for Occupational Safety and Health (NIOSH), "NIOSH Pocket Guide To Chemical Hazards," DHHS (NIOSH) Publication No. 2005-149, Centers for Disease Control and Prevention, National Institute for Occupational Safety and Health, Cincinnati, OH, 2005.

NRC, "License Renewal Generic Environmental Impact Statement," NUREG-1437, Office of Nuclear Regulatory Research, U.S. Nuclear Regulatory Commission, Washington, DC, June 1996. Accessed at http://www.nrc.gov/reading-rm/doccollections/nuregs/staff/sr1437/ on January 30, 2008.

NRC, "Occupational Radiation Exposure at Commercial Nuclear Power Reactors and Other Facilities 2006," NUREG-0713, Vol. 28, Office of Nuclear Regulatory Research, U.S. Nuclear Regulatory Commission Washington, DC, December 2007. 
OSHA 2007

Ries et al. 2003

Shapiro 1990

USDHEW 1970
OSHA, "Permissible Exposure Limits (PELs)," Occupational Safety and Health Administration, 2007. Accessed at http://www.osha.gov/SLTC/pel/index.html on January 28, 2008.

Ries, L.G., M.E. Reichman, D.R. Lewis, B.F. Hankey, and B.K. Edwards, "Cancer Survival and Incidence from the Surveillance, Epidemiology, and End Results (SEER) Program," Surveillance Research Program, DCCPS, National Cancer Institute, Bethesda, MD, 2003.

Shapiro, J. "Radiation Protection, A Guide for Scientists and Physicians," Third Edition, Harvard University Press, Cambridge, MA, 1990.

United States Department of Health, Education and Welfare (USDHEW), "Radiological Health Handbook," United States Department of Health, Education and Welfare, Public Health Service, Washington, DC, 1970. 


\section{APPENDIX D}

\section{FACILITY ACCIDENT SCENARIOS}





\section{APPENDIX D FACILITY ACCIDENT SCENARIOS}

This appendix presents the estimated consequences of accidents that could occur at facilities performing operations for the various alternatives being considered for the Global Nuclear Energy Partnership (GNEP) Programmatic Environmental Impact Statement (PEIS). The scenarios described here were chosen to define a representative set of accident conditions such that any other reasonably foreseeable accident associated with these activities would be expected to have smaller risks and/or consequences.

This appendix describes how locations or operations were selected for analysis, the computer codes used to estimate consequences, the development of the scenarios and assumptions about source terms, the selection of computer modeling and a description of the results, and potential health effects.

This appendix presents accident impacts for facilities and operations associated with the domestic programmatic alternatives, which are described in Chapter 2 of this PEIS.

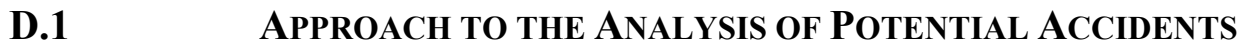

\section{D.1.1 Overview}

The analysis of accidents followed a systematic four-step process that included: 1) identification of potentially hazardous conditions associated with the specific facilities being considered, 2) selection and definition of a representative set of accident scenarios, 3) development of data requirements (source term, release duration, and estimate of frequency of accident condition), and 4) calculation of possible accident consequences for the environment, members of the public and site workers.

This analysis considers existing light water reactor (LWR) designs as well as new designs with advanced safety systems. New reactors that could be built as a result of the GNEP Program would be required to meet the safety standards of the U.S. Nuclear Regulatory Commission's (NRC's) Advanced Reactor Policy (NRC 1986). As of June 2008, NRC has issued design certifications for four advanced LWR (ALWR) designs and is reviewing another seven (NRC 2008e). U.S. Department of Energy (DOE) has previously analyzed accidents associated with ALWRs in the Final Programmatic Environmental Impact Statement for Tritium Supply and Recycling, DOE/EIS-0161 (hereafter Tritium Supply and Recycling Final PEIS or DOE/EIS-0161) (DOE 1995b), which considered a large and a small pressurized water reactor (PWR) and a large and a small boiling water reactor at a variety of locations. The reactors considered in DOE/EIS-0161 included two reactors for which the NRC has issued design certifications (i.e., the Advanced Boiling Water Reactor and the AP600) and one that is a predecessor of a design the NRC is reviewing (i.e., the Simplified Boiling Water Reactor). The ALWR analyses in this PEIS are based on a single design, the Simplified Boiling Water Reactor, because it had the greatest consequence and risk for a composite of high consequence accidents. In addition, this PEIS considers conceptual reactor designs that have not been submitted to or 
approved by the NRC, but which have been evaluated by DOE in other National Environmental Policy Act (NEPA) documents. Table D.1.1-1 lists the reactors that are addressed in this analysis and their power level in thermal megawatts (MWth).

\section{TABLE D.1.1-1-Power Level of Reactors Evaluated}

\begin{tabular}{lc}
\hline \multicolumn{1}{c}{ Reactor } & $\begin{array}{c}\text { Power Level } \\
\text { (MWth) }\end{array}$ \\
\hline Advanced light water reactor (ALWR) $^{\mathrm{a}}$ & $3,900^{\mathrm{b}}$ \\
Advanced recycling reactor $^{\mathrm{c}}$ & 2,000 \\
Heavy water reactor (HWR) $^{\mathrm{a}}$ & 990 \\
High temperature gas-cooled reactor (HTGR) & 350 \\
Light water reactor (LWR) $^{\mathrm{d}}$ & 3,411 \\
${ }^{\mathrm{a}}$ This reactor was analyzed in the Final Programmatic Environmental Impact Statement \\
for Tritium Supply and Recycling DOE/EIS-0161 (DOE 1995b). \\
${ }^{\mathrm{b}}$ The power level is reported as 1,300 megawatts electric (MWe), which is multiplied by \\
three to obtain an approximate thermal power level based on an assumed efficiency of \\
33 percent typical of LWRs. \\
${ }^{\mathrm{c}}$ As discussed in Section D.2.2.2, analysis of internally initiated events is based on the \\
975 MWth Clinch River Breeder Reactor because relatively detailed analyses are \\
available for that reactor. Analysis of externally initiated and natural phenomena events \\
resulting in core damage are based on a 2,000 MWth reactor core inventory developed \\
for this PEIS (Kim and Yang, 2008), which is greater than the Clinch River Breeder \\
Reactor power level. Since the internally initiated events do not involve core damage, this \\
difference in power levels does not invalidate their relevance for this analysis. \\
${ }_{\mathrm{d}}$ This reactor was analyzed in the Surplus Plutonium Disposition Environmental Impact \\
Statement DOE/EIS-0283 (DOE 1999d).
\end{tabular}

The accident consequences and risks associated with a given reactor are dependent upon many factors, including the reactor power level, and fuel and plant design. The NEPA documents and documents supporting NEPA documents used as the bases for this PEIS took these and other factors into account when identifying scenarios relevant for their designs. This PEIS evaluates the scenarios identified in those NEPA documents using the standardized analytical approaches described in this appendix, in order to facilitate consistent internal comparisons of reactor alternatives. No attempt was made to adjust/normalize reactor power levels because that may invalidate the accident selection and scenario progression described in the relevant NEPA documents. Adjustment/normalization of reactor power levels has the potential to invalidate the results because a reactor design of different power levels may respond differently to the same accident initiator. For example, a smaller reactor may be able to use passive features to conduct decay heat to the ground while a reactor with 10 times the power level may not be able to conduct that much heat to the ground. Without reactor designs and reactor response evaluations for common reactor power levels, it is necessary to use the analyses for the reactor designs as they existed in the corresponding NEPA documents.

Another factor that affects direct comparisons of reactor impacts is the mission of the reactor. An advanced recycling reactor, assumed to be a fast reactor, would contain a higher loading of transuranic materials, since the mission of the reactor is consumption of these materials. As a result, the consequences and risks associated with an advance recycling reactor may be greater than the consequences and risks associated with a similar reactor that does not have a high initial loading of transuranic material. 
Accident scenarios have been chosen to reflect the broad range of accidents that might occur at the facilities associated with the alternatives being considered. The scenarios are specific to particular buildings and operations. The following terms are used to define the scenarios:

- A reasonably foreseeable accident not only includes events that may be expected, but could include an accident with "impacts which have catastrophic consequences, even if their probability of occurrence is low, provided that the analysis of the impacts is supported by credible scientific evidence, is not based on pure conjecture, and is within the rule of reason" (40 CFR 1502.22). "Credible" means having reasonable grounds for believability. The "rule of reason" means that the analysis is based on scientifically sound judgment.

- An accident is bounding if no reasonably foreseeable accident with greater consequences can be identified. A bounding envelope is a set of individual bounding accidents covering the range of probabilities and possible consequences. Bounding accidents must be credible and be based on the rule of reason.

An accident is a sequence of one or more unplanned events with potential outcomes that endanger the health and safety of workers, the public, or the environment. An accident can involve a combined release of energy and hazardous materials (radiological or chemical) that might cause prompt or latent health effects. The sequence usually begins with an initiating event, such as a human error, equipment failure, or earthquake, followed by a succession of other events that could be dependent or independent of the initial event, which dictates the accident's progression and the extent of materials released. Initiating events fall into three categories:

- Internal initiators normally originate in and around the facility, but are always a result of facility operations. Examples include equipment or structural failures and human errors.

- External initiators are independent of facility operations and normally originate from outside the facility. Some external initiators affect the ability of the facility to maintain its confinement of hazardous materials because of potential structural damage. Examples include aircraft crashes, vehicle crashes, nearby explosions, and toxic chemical releases at nearby facilities that affect worker performance.

- Natural phenomena initiators are natural occurrences that may affect the facility and its operations. Examples include earthquakes, high winds, floods, lightning, and snow. Natural phenomena initiators can also affect nearby facilities, which in turn can affect the primary facility under review.

The analysis considers accidents that result in both radiological and nonradiological releases. Radiological releases can include the release of radioactive material or direct exposure of workers. Nonradiological releases include the release of chemically hazardous materials. Standard industrial hazards were considered for their potential as initiators; their direct impacts are presented in Appendix C. Appendix B, Intentional Destructive Acts, provides an impact analysis of terrorist acts. 
If an accident were to occur involving the release of radioactive or chemical materials, workers, members of the public and the environment would be at risk. Workers in the facility where the accident occurs would be particularly vulnerable to the effects of the accident because of their location. The offsite public would also be at risk of exposure to the extent that meteorological conditions exist for the atmospheric dispersion of released hazardous materials. Using approved computer models, which are routinely used by DOE and meet its safety software quality assurance requirements (DOE 2007w), the dispersion of released hazardous materials and their effects are predicted. However, prediction of latent potential health effects becomes increasingly difficult to quantify for facility workers as the distance between the accident location and the worker decreases. This is because the individual worker exposure cannot be precisely defined with respect to the presence of shielding and other protective features. The worker also may be injured or killed by physical effects of the accident itself.

\section{D.1.2 Accident Selection Methodology}

The steps involved in selecting and defining scenarios to be analyzed for an advanced recycling reactor (a fast reactor, as described in Section D.2.2.2 for the Fast Reactor Recycle Alternative) and a nuclear fuel recycling center (as described in Section D.2.2.1 for the Fast Reactor Recycle Alternative) are as follows:

- Assemble and review available information and technical resources applicable to the facility and operations,

- Identify potential hazards (form, type, quantity, and location of materials) and accident conditions and define a preliminary set of candidate accidents, and

- Select a final set of accidents, develop scenarios, and derive applicable data for the accident analysis.

Each of these steps is discussed in the following subsections.

For the other reactor facilities being considered for the programmatic alternatives, the approach was modified to take advantage of existing NEPA documents in which candidate scenarios and accidents were previously identified. In these cases, the identification of candidate scenarios and the selection of accidents for analysis are not repeated; instead, the internally initiated accidents selected in those relevant NEPA documents were used directly as the basis for this analysis. This applies specifically to the other reactor options (i.e., ALWR, heavy water reactor [HWR], high temperature gas-cooled reactor [HTGR], LWR, and thorium LWR).

The methodologies used in the NEPA documents for the reactors and their fuels in the programmatic alternatives (with the exception of an advanced recycling reactor) are similar in intent but varied somewhat from the methodology used here. For example, the frequency categories used in the selection of accidents was different, and the higher frequency events are not always identified. Higher frequency accident events for the other reactors are generally related to non-reactor activities such as fuel handling, which are not highly reactor dependent. Therefore, higher frequency accidents presented here may be relevant to the other reactor designs as well. The source terms identified in the NEPA documents for the other reactors and their fuels in the programmatic alternatives were used directly for this analysis. Details of the methodology 
used for development of these airborne releases in the NEPA documents may have been different, for example in the degree of conservatism. While there are differences among the accident selection and airborne release methodologies used for the other reactors, the resulting analyses presented here are considered appropriate for a programmatic comparison of alternatives.

In some cases, natural phenomena events and externally initiated events were not considered in the existing NEPA documents for reactors, so an alternative approach was applied. A common external event (an aircraft crash) and a common natural phenomena event (a beyond design basis earthquake) were used for all reactors. The analyses performed for these initiators are based on the use of the same release parameters and frequencies for all reactors without consideration of differences in fuel designs, preventive measures, and mitigation potential. These analyses were performed to provide insight into potential differences in impacts, primarily with respect to core inventory. Therefore, these reactor "Aircraft Crash" and "Beyond Design Basis Earthquake" analyses should be used as a basis for programmatic comparison and should not be viewed as actual scenarios or consequences.

Independent of how the accident scenarios were chosen for the different facilities, the consequence and risk for all scenarios reported in this appendix were calculated using the methodology described below in Section D.1.5.

Nonradiological hazards are not addressed for reactors because the types and quantities of hazardous chemicals used at a reactor would result in much less risk than those chemicals used at the fuel cycle facilities. While there may be differences between the potential chemical accidents for the reactors, these differences would be minor in comparison to radiological accident differences and would not affect the overall comparison of alternatives.

\section{D.1.2.1 Assembly of Available Information}

The first step in the accident analysis process was the assembly and review of available information. The following information sources were reviewed where available and relevant.

- Facility information is essential to define the facility design, scope and nature of activities, material inventories, and potential hazards. Reports and meetings and discussions with representatives provided the necessary facility information. Where available, facility hazard evaluations were reviewed.

- Relevant NEPA and safety basis documents provide insight into the accidents considered for similar facilities. DOE has a long history of nuclear activities and there are numerous DOE NEPA documents for activities similar to those analyzed in the GNEP PEIS. NEPA documents relevant to the alternatives being considered by the GNEP PEIS are available at both a programmatic and a project-specific level. The relevant NEPA documents and supporting documents used for this analysis are listed in the appropriate sections. The scope of nuclear activities in any given NEPA document may not correspond to the full scope of the activities being considered, but other relevant documents may cover these activities. NEPA documents frequently rely heavily on safety basis documents as the basis for the identification of candidate accidents. 
- Occurrence reports provide insight into events that have actually occurred at similar facilities. DOE's Occurrence Reporting and Processing System database (DOE 2007u) provides a searchable means of identifying events that have occurred at facilities with similar operations.

- Hazard checklists have been developed to support preparation of authorization basis documents. This review was primarily performed to ensure that nonradiological hazards and all potential initiators of radiological events are adequately considered.

\section{D.1.2.2 Identification of Candidate Scenarios}

After a review of the available information, a list of candidate accidents to be considered for analysis was developed. The list of candidate scenarios includes the scenarios identified in relevant documents as well as any additional scenarios identified for the facilities associated with the alternatives being considered by the GNEP PEIS. This spectrum of accidents includes low consequence/high frequency events and high consequence/low frequency events.

\section{D.1.2.3 Selection of Accidents for Analysis}

From the list of candidate accidents, a set of bounding accidents was identified for analysis. The selection process included a qualitative assessment of the frequency and consequences of each candidate accident. Based on the frequency and consequence estimates, most of the candidate accidents were screened from further consideration. The accident selection process involves a combination of data, evaluation, and engineering judgment.

The general guidelines listed below were followed in the selection of accidents for analysis.

- Potential hazardous and accident conditions should include the largest source terms at risk and the least favorable locations for workers and the public.

- The accident scenarios selected should cover a spectrum of accident situations ranging from high frequency/low consequence events to low frequency/high consequence events.

- $\quad$ For each frequency range, the accident with bounding consequences should be selected as representative for the range.

- The accident scenarios should reflect differences resulting from site specific initiators, meteorology, and characteristics (e.g., distance from site boundary and other adjacent facilities).

The accidents selected for analysis were judged to provide an adequate representation of the reasonably foreseeable accidents that might occur at the facilities associated with the alternatives being considered by the GNEP PEIS.

\section{D.1.3 Accident Frequencies}

In this analysis four frequency categories are defined. The frequency ranges are selected based on DOE guidance for safety analyses and NEPA documents for facilities with similar operations, which include consideration of historical operating experience in similar heavily shielded facilities. Here, the frequency estimate includes both the initiating event and conditional 
events/conditions leading to the release. For example, the aircraft crash includes not only the frequency of an aircraft impacting the facility, but also the probability of the containment being breached and system damage resulting in core damage. The accident analysis considers accident scenarios that represent the spectrum of reasonably foreseeable accidents, including low frequency/high consequence accidents and higher frequency/(usually) lower consequence accidents. Typically, accidents with a frequency of less than $10^{-7}$ per year are not considered reasonably foreseeable and do not need to be examined. However, because of the effectiveness of advanced reactor safety systems, in this PEIS, accidents with a frequency of less than $10^{-7}$ per year are considered for reactors in order to address accidents with greater impacts.

Table D.1.3-1 presents the ranges of frequencies, return periods, and probability of occurrence during the facility life for each category and is based on Table 3-4 in Preparation Guide for U.S. Department of Energy Nonreactor Nuclear Facility Safety Analysis Reports (DOE-STD-3009-94) (DOE 2006p). The fidelity of accident frequency estimates are lower when exact facility designs and operations have not been finalized. Also, the number of processes and equipment trains can affect the frequency for some scenarios. Therefore, quantitative frequency estimates are not always available. When only a frequency category is available for an accident scenario, the logarithmic midpoint of the category is used for the risk calculations (i.e., 0.03, 0.001, and $10^{-5}$ per year are used for the Anticipated, Unlikely, and Extremely Unlikely categories). A frequency estimate is required for all Beyond Extremely Unlikely scenarios.

TABLE D.1.3-1-Accident Frequency Categories

\begin{tabular}{lccc}
\hline \multicolumn{1}{c}{ Frequency Category } & $\begin{array}{c}\text { Frequency Range } \\
(/ \mathbf{y r})\end{array}$ & $\begin{array}{c}\text { Return Period } \\
\text { (yrs) }\end{array}$ & $\begin{array}{c}\text { Probability During Facility } \\
\text { Life (50 yrs) }\end{array}$ \\
\hline Anticipated & $0.01 \leq f \leq 0.1$ & $100 \geq \mathrm{T} \geq 10$ & $0.4 \leq \mathrm{P}<1$ \\
Unlikely & $10^{-4} \leq f<0.01$ & $10^{4} \geq \mathrm{T}>100$ & $0.005 \leq \mathrm{P}<0.4$ \\
Extremely Unlikely & $10^{-6} \leq f<10^{-4}$ & $10^{6} \geq \mathrm{T}>10^{4}$ & $5 \times 10^{-5} \leq \mathrm{P}<0.005$ \\
Beyond Extremely Unlikely & $f<10^{-6}$ & $\mathrm{~T}>10^{6}$ & $\mathrm{P}<5 \times 10^{-5}$ \\
\hline
\end{tabular}

Notes: $\leq=$ less than or equal to; $<=$ less than; $\geq=$ greater than or equal to; $>=$ greater than

\section{D.1.4 Source Term}

The source term is the amount of material, in grams or curies, released to the air. This section summarizes the methodology described in Section 1.2 of DOE Handbook-Airborne Release/Rates and Respirable Fractions for Nonreactor Nuclear Facilities (hereafter DOE-HDBK-3010-94) (DOE 2000i) for calculation of the source term. The source term is calculated by the equation:

Source Term $=$ MAR x ARF x RF x DR x LPF, where:

MAR Material-at-Risk: the amount of radioactive materials (in grams or curies of activity for each radionuclide) available to be acted on by a given physical stress.

DR Damage Ratio: the fraction of material at risk impacted by the actual accident-generated conditions under evaluation. 
ARF Airborne Release Fraction: the coefficient used to estimate the amount of a radioactive material that can be suspended in air and made available for airborne transport under a specific set of induced physical stresses.

RF Respirable Fraction: the fraction of airborne radionuclides as particles that can be transported through air and inhaled into the human respiratory system and is commonly assumed to include particles $10-\mu \mathrm{m}$ Aerodynamic Equivalent Diameter and less.

LPF Leak Path Factor: the fraction of airborne materials transported from containment or confinement deposition or filtration mechanism (e.g., fraction of airborne material in a glovebox leaving the glovebox under static conditions, fraction of material passing through a high-efficiency particulate air [HEPA] filter).

The above equation is used for all radiological analyses of non-reactor nuclear facilities, advanced recycling reactor internally initiated accidents, and externally initiated accidents at all reactors. However, for the other reactor analyses, the relevant NEPA documents report the source term for the internally initiated accidents, which is used directly without recreating the source term with the above calculation.

The NRC has developed a set of general release parameters for accidents involving significant core damage, which are presented in Alternative Radiological Source Terms for Evaluating Design Basis Accidents at Nuclear Power Reactors, Regulatory Guide 1.183 (NRC 2000b). The release parameters from Table 2 of Regulatory Guide 1.183 are used for the "Beyond Design Basis Earthquake" and "Aircraft Crash" scenarios for all reactors regardless of the design. These analyses do not take the reactor or fuel designs into account, but merely apply release parameters in a consistent manner. In order to provide a range of consequences for these accidents, the consequences are analyzed both with and without the mitigating effect of the containment building. These release parameters are applied to the end of life core inventory for each reactor, as reported in the following sections addressing each reactor. Table D.1.4-1 presents the release parameters used for analysis of the reactor "Beyond Design Basis Earthquake" and "Aircraft Crash" scenarios. 
TABLE D.1.4-1—Release Parameters for Reactor Beyond Design Basis Earthquakes and Aircraft Crashes

\begin{tabular}{|c|c|c|}
\hline Parameter & Value & Basis/Comments \\
\hline Release point & $\begin{array}{c}\text { Ground } \\
\text { level }\end{array}$ & $\begin{array}{c}\text { This is the default value used for all reactor accidents to } \\
\text { provide a common basis. }\end{array}$ \\
\hline \multicolumn{3}{|l|}{ Release duration: } \\
\hline Containment intact & $24 \mathrm{hr}$ & Evacuation of the area could be implemented in this time. \\
\hline Containment failed & $1 \mathrm{hr}$ & $\begin{array}{l}\text { The duration reported in Table } 4 \text { of Regulatory Guide } 1.183 \\
\text { (NRC 2000b) was rounded down. }\end{array}$ \\
\hline \multicolumn{3}{|l|}{$\begin{array}{l}\text { Release to containment (DR x ARF } \\
\mathrm{x} \text { RF): }\end{array}$} \\
\hline Noble gases $(\mathrm{Xe}, \mathrm{Kr})$ & 1.0 & Based on Table 2 of Regulatory Guide 1.183 (NRC 2000b) \\
\hline Halogens $(\mathrm{I}, \mathrm{Br})$ & 0.4 & Based on Table 2 of Regulatory Guide 1.183 (NRC 2000b) \\
\hline Alkali metals (Cs, $\mathrm{Rb})$ & 0.3 & Based on Table 2 of Regulatory Guide 1.183 (NRC 2000b) \\
\hline$(\mathrm{Te}, \mathrm{Sb}, \mathrm{Se})$ & 0.05 & Based on Table 2 of Regulatory Guide 1.183 (NRC 2000b) \\
\hline $\mathrm{Ba}, \mathrm{Sr}$ & 0.02 & Based on Table 2 of Regulatory Guide 1.183 (NRC 2000b) \\
\hline $\begin{array}{l}\text { Noble metals (Ru, Rh, Pd, Mo, } \\
\text { Tc, Co) }\end{array}$ & $2.5 \times 10^{-3}$ & Based on Table 2 of Regulatory Guide 1.183 (NRC 2000b) \\
\hline Cerium group $(\mathrm{Ce}, \mathrm{Pu}, \mathrm{Np})$ & $5 \times 10^{-4}$ & Based on Table 2 of Regulatory Guide 1.183 (NRC 2000b) \\
\hline $\begin{array}{l}\text { Lanthanides (La, Zr, Nd, Eu, Nb, } \\
\text { Pm, Pr, Sm, Y, Cm, Am) }\end{array}$ & $2 \times 10^{-4}$ & Based on Table 2 of Regulatory Guide 1.183 (NRC 2000b) \\
\hline \multicolumn{3}{|l|}{ Leak path factor: } \\
\hline Mitigated & $0.001 /$ day & $\begin{array}{l}\text { Based on Federal Register, Vol. 60, No. } 186 \text { (NRC 1995), this } \\
\text { is a typical value acceptable for pressurized water reactors } \\
\text { (PWRs). }\end{array}$ \\
\hline Unmitigated & 1 & Conservative value that assumes total containment failure. \\
\hline
\end{tabular}

\section{D.1.5 Consequence Analysis}

\section{D.1.5.1 Radioactive Material Releases}

A deterministic, nonprobabilistic approach was used to analyze the consequences of the accident scenarios. The wide range of postulated accidents characterizes the range of impacts associated with the operation of the facilities being considered. The postulated accident scenarios for radioactive material can be reasonably evaluated in terms of the effective dose equivalent, and from this, the bounding scenario can be determined.

The consequences of accidental radiological releases were determined using version 1.13 .1 of the MACCS2 computer code (Chanin and Young 1998). Melcor (Methods for Estimation of Leakages and Consequences of Releases) Accident Consequences Code $\underline{\text { System, version } 2}$ (MACCS2) is a DOE/NRC-sponsored computer code that has been widely used in support of probabilistic risk assessments for the nuclear power industry and in support of safety and NEPA documentation for facilities throughout the DOE complex. As previously stated (Section D.1.1), the code meets DOE safety software assurance requirements.

The MACCS2 code uses three distinct modules for consequence calculations: ATMOS, EARLY, and CHRONC. The ATMOS module performs atmospheric transport calculations, including 
dispersion, deposition, and decay. A straight-line Gaussian plume model is applied, with each hour's transport governed by the meteorology during that hour. Multiple calculations are performed for each release that include all sequential hourly meteorological conditions throughout the year. The EARLY module performs exposure calculations corresponding to the period immediately following the release; this module also includes the capability to simulate evacuation from areas surrounding the release. The EARLY module exposure pathways include inhalation, cloudshine (external exposure from the passing atmospheric plume), and groundshine (external exposure from nuclides deposited on the ground by the atmospheric plume). The CHRONC module considers the time period following the early phase (i.e., after the plume has passed). CHRONC exposure pathways include groundshine, resuspension inhalation, and ingestion of contaminated food and water. Land use interdiction (e.g., decontamination) can be simulated in this module. Other supporting input files include a meteorological data file and a site data file containing distributions of the population and agriculture surrounding the release site (Chanin and Young 1998). Melcor Accident Consequence Code System (MACCS), Model Description presents a more detailed description of the model's methodology (Jow et al. 1990).

Because of the conservativeness of the assumptions used in this PEIS analysis, not all of the code's capabilities were used. For example, it was conservatively assumed that there would be no evacuation or protection of the surrounding population following an accidental release of radionuclides. Another conservative assumption was that wet and dry depositions of all radioactive material would be zero for individual receptors (maximally exposed individual [MEI] and noninvolved worker). These receptors are exposed for the duration of the release; suppressing deposition increases inhalation and cloudshine dose (increasing negative health effects) by keeping the radioactive material airborne (rather than depleting the plume by deposition) and available for inhalation. Deposition was also assumed to be zero for population impact analyses. These assumptions maximize exposure to the release. One non-conservative assumption is that long-term exposure pathways were not considered. Ground level releases are assumed for all reactor accidents for consistency. Figure D.1.5.1-1 illustrates the release and exposure pathways modeled in this analysis. 


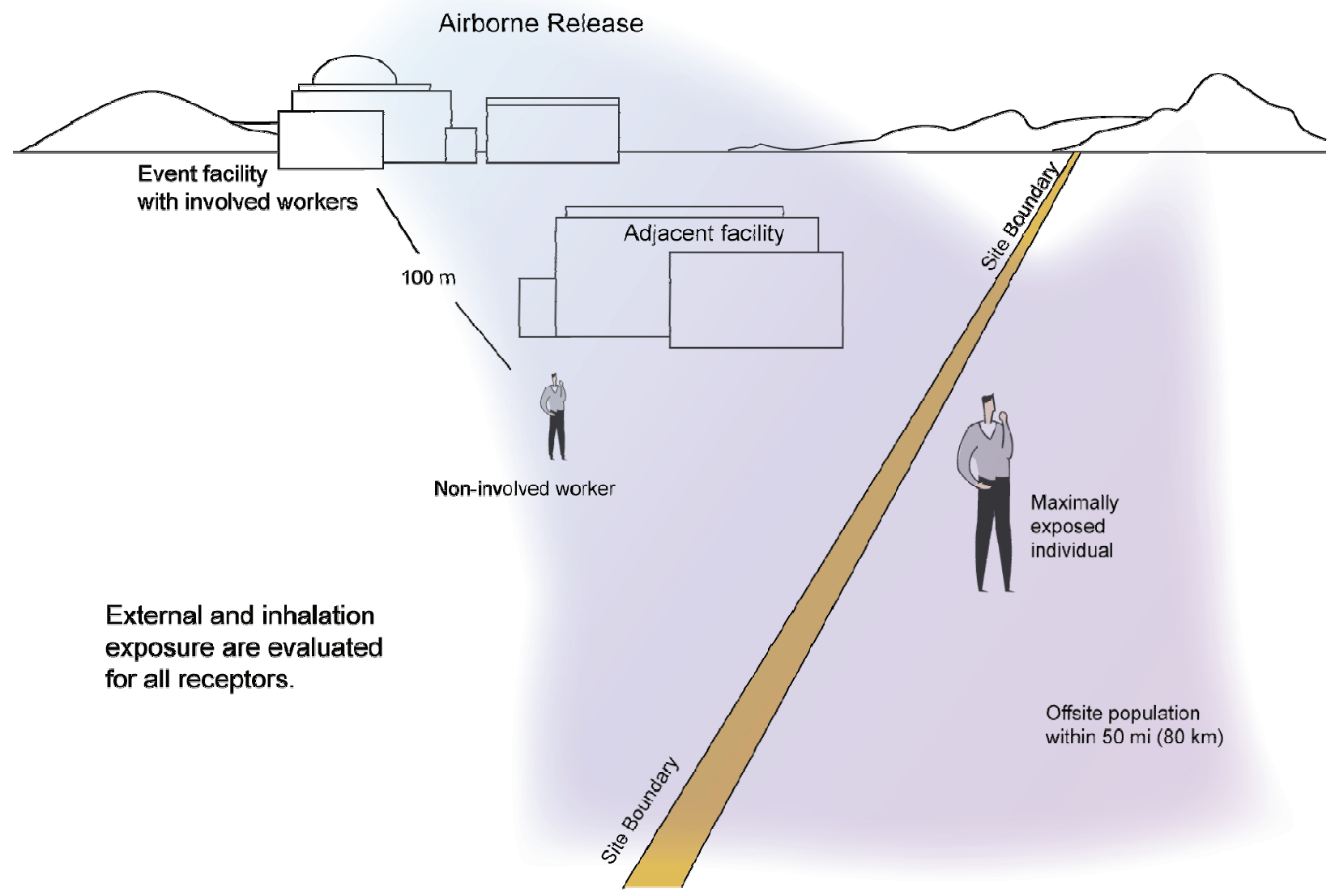

FIGURE D.1.5.1-1—Release and Exposure Pathways

Ten radial rings and 16 uniform direction sectors were used to calculate the collective dose to the offsite population. The radial rings were every mile (mi) from 1 to $5 \mathrm{mi}$ (2 to 8 kilometers $[\mathrm{km}])$, a ring at $10 \mathrm{mi}(16 \mathrm{~km})$, and a ring every $10 \mathrm{mi}(16 \mathrm{~km})$, from 10 to $50 \mathrm{mi}(16$ to $80 \mathrm{~km})$ starting at the distribution center. The location of the offsite MEI was assumed to be along the site boundary or, for elevated or buoyant releases, at the point of greatest offsite consequence. Similarly, the onsite noninvolved worker location was taken as 328 feet (ft) (100 meters [m]) from the release in any direction.

MEI and noninvolved worker doses were calculated using conservative assumptions, including locating the MEI at the site boundary nearest to the release in each wind direction, and assuming that the MEI and noninvolved worker receptors were always located along the plume centerline. Population and individual (MEI and noninvolved worker) doses were statistically sampled by assuming an equally likely accident start time during any hour of the year. All hours were sampled, resulting in the mean results which are presented in this PEIS.

The doses (50-year committed effective dose equivalent) were converted into latent cancer fatality (LCF) using the factor of $6 \times 10^{-4} \mathrm{LCFs}$ per person-rem for both members of the public and workers (DOE 2002h). This factor was doubled for individual (MEI and noninvolved worker) receptors exposed to doses greater than $20 \mathrm{rem}$ (DOE 2002h). LCF values are truncated at 1 because the probability of an LCF for an individual cannot exceed 1. Section C.2 provides additional information on the calculation and meaning of LCFs. Members of the public and 
workers are assumed to be exposed for the duration of the release; they or DOE would take protective or mitigative actions thereafter if required by the size of the release. Table D.1.5.1-1 presents some MACCS2 parameter values that were used in the analysis (Chanin and Young 1998). To calculate the increased risk or likelihood of an LCF, an estimate of the accident annual probability must be known (i.e., Risk = Radiation Dose $\mathrm{x}$ LCF/Dose $\mathrm{x}$ Accident Annual Probability).

TABLE D.1.5.1-1-General MACCS2 Analysis Assumptions

\begin{tabular}{|c|c|c|}
\hline Parameter & Selection & Comments \\
\hline MACCS2 & & Version 1.13.1 \\
\hline Population & $\begin{array}{l}\text { SECPOP2000 (NRC 2003) } 1990 \\
\text { and } 2000 \text { census general } \\
\text { population distributions } \\
\text { extrapolated to } 2060 \text {. Centered at } \\
\text { accident source facility. }\end{array}$ & $\begin{array}{c}\text { See topical reports for further } \\
\text { discussion of extrapolation } \\
\text { methodology. (Tetra Tech } 2008 \mathrm{~b} \text { and e) }\end{array}$ \\
\hline Population Ring Boundaries & $\begin{array}{c}1,2,3,4,5,10,20,30,40,50 \mathrm{mi} \\
(1.6,3.2,4.8,6.4,8,16,32,48,64 \\
80 \mathrm{~km})\end{array}$ & General population to $50 \mathrm{mi}(80 \mathrm{~km})$ \\
\hline $\begin{array}{l}\text { Inhalation and external exposure } \\
\text { from plume }\end{array}$ & Yes & \\
\hline $\begin{array}{l}\text { Inhalation and external exposure } \\
\text { from deposition and resuspension }\end{array}$ & No & $\begin{array}{l}\text { Deposition turned off to maximize } \\
\text { downwind plume concentrations }\end{array}$ \\
\hline Breathing rate & $16 \mathrm{in}^{3}\left(2.66 \times 10^{-4} \mathrm{~m}^{3}\right)$ per second & $\begin{array}{c}\text { Normal breathing rate, Chanin and } \\
\text { Young } 1998\end{array}$ \\
\hline Evacuation & No & Assume no protective actions taken \\
\hline Relocation & No & Assume no protective actions taken \\
\hline Cloud shielding factor & 0.75 & Chanin and Young 1998 \\
\hline Protection factor for inhalation & 0.41 & Chanin and Young 1998 \\
\hline Skin protection factor & 0.41 & Chanin and Young 1998 \\
\hline Ground shielding factor & 0.33 & Chanin and Young 1998 No deposition \\
\hline Wet deposition & No & $\begin{array}{c}\text { No wet deposition, maximize } \\
\text { downwind plume concentrations. }\end{array}$ \\
\hline Dry deposition & No & $\begin{array}{l}\text { No dry deposition, maximize downwind } \\
\text { plume concentrations }\end{array}$ \\
\hline $\begin{array}{l}\text { Sigma-y, Sigma-z (dispersion } \\
\text { parameters) }\end{array}$ & Tadmor-Gur Tables & Chanin and Young 1998 \\
\hline $\begin{array}{l}\text { Surface roughness length } \\
\text { correction }\end{array}$ & $\begin{array}{l}1.27 \text { (general population), } 2.02 \\
\text { (MEI and noninvolved worker) }\end{array}$ & $\begin{array}{c}\text { Corresponds to } \mathrm{z} 0=10 \text { centimeters } \\
\text { (rural) for general population and } \\
\mathrm{z} 0=100 \text { centimeters (urban) for } \\
\text { individuals }\end{array}$ \\
\hline Plume meander time base & 600 seconds & Chanin and Young 1998 \\
\hline $\begin{array}{l}\text { xpfac1 (exponential factor used in } \\
\text { calculating the plume meander } \\
\text { expansion factor) }\end{array}$ & 0.2 & $\begin{array}{l}\text { Plume meander exponential factor for } \\
\text { time less than break point ( } 1 \text { hour) } \\
\text { Chanin and Young } 1998\end{array}$ \\
\hline
\end{tabular}


TABLE D.1.5.1-1-General MACCS2 Analysis Assumptions (continued)

\begin{tabular}{|c|c|c|}
\hline Parameter & Selection & Comments \\
\hline $\begin{array}{l}\text { xpfac2 (exponential factor used in } \\
\text { calculating the plume meander } \\
\text { expansion factor) }\end{array}$ & 0.25 & $\begin{array}{c}\text { Chanin and Young 1998; plume } \\
\text { meander exponential factor for times } \\
\text { greater than } 1 \text { hour }\end{array}$ \\
\hline Plume segment reference time & 0.5 & $\begin{array}{l}\text { Plume segment reference at center of } \\
\text { release segment (for dispersion, } \\
\text { deposition, decay calculations) }\end{array}$ \\
\hline Atmospheric mixing height & $\begin{array}{c}\text { Seasonal afternoon range (in 100s } \\
\text { of meters): Sites 1-3 (11.8-27), } \\
\text { Sites 4-6 (15.1-18.6) }\end{array}$ & Holzworth 1972 \\
\hline Wind shift without rotation & Yes & $\begin{array}{l}\text { Plume direction follows wind direction } \\
\text { every hour }\end{array}$ \\
\hline $\begin{array}{l}\text { metcod (meteorological sampling } \\
\text { option) }\end{array}$ & 5 & $\begin{array}{c}\text { Stratified random samples for each day } \\
\text { of the year (see nsmpls in the row } \\
\text { below) }\end{array}$ \\
\hline $\begin{array}{l}\text { nsmpls (the number of weather } \\
\text { sequences to be chosen from each } \\
\text { day of the year) }\end{array}$ & 24 & $\begin{array}{l}24 \text { Meteorology samples per day } \\
\text { (sample each hour) }\end{array}$ \\
\hline $\begin{array}{l}\text { Boundary conditions used in last } \\
\text { ring }\end{array}$ & No & $\begin{array}{l}\text { Hourly meteorology applied throughout } \\
\text { model domain }\end{array}$ \\
\hline Dose conversion factors & FGR 11,12 & \\
\hline Presented dose results & TEDE-mean & $\begin{array}{l}\text { Total Effective Does Equivalent } \\
\text { (TEDE) }\end{array}$ \\
\hline Health risk & $6 \times 10^{-4}$ & $\begin{array}{l}\text { Fatal cancers per rem (TEDE) } \\
\text { (DOE } 2002 \mathrm{~h}) 1.2 \times 10^{-3} \text { for individuals } \\
\text { exposed to doses greater than } 20 \text { rem }\end{array}$ \\
\hline
\end{tabular}

The impacts on an additional individual who is in the immediate vicinity of an accident, the involved worker who works at the facility where the accident is hypothesized to occur, are calculated using different methods than for the receptors described here. They are described in Section D.2.2.1.4.

The GNEP PEIS relied on relevant NEPA documents and documents supporting NEPA documents for selection and characterization of accident scenarios (see Sections D.1.2.1 and D.1.2.2). These documents analyzed reactor designs for a specific purpose and the designs that would ultimately be used for GNEP operations may be somewhat different. As discussed in Section D.1.1, differences in reactor designs, such as differences in power levels, would affect the source terms and accident consequences. The NEPA documents relied upon for the reactor information also may have used somewhat different levels of conservatism in estimating the source terms. These differences mean the source terms for the various reactor accidents have some inherent differences for which this analysis cannot adjust. However, the GNEP PEIS relies upon the best available reactor information available to provide reasonable comparisons between the alternatives. In terms of the consequence calculation methodology, the GNEP PEIS used the standardized analytical approaches described in this Appendix in order to facilitate consistent internal comparisons between alternatives. As a result, while the GNEP PEIS results can be compared directly with each other within the limitations of the source term information, they will 
differ from results presented in the NEPA source documents. The consistent, and sometimes simplified, assumptions used in the GNEP PEIS are appropriate for the high-level programmatic comparisons in the GNEP PEIS.

\section{D.1.5.2 Hazardous Chemical Releases}

The consequences of accidental releases of hazardous chemicals were calculated using the Areal Location of Hazardous Atmospheres (ALOHA) code, version 5.4.1 (EPA 2007d). ALOHA is an EPA/National Oceanic and Atmospheric Administration-sponsored computer code that has been widely used in support of chemical accident responses and also in support of safety and NEPA documentation for DOE facilities. ALOHA is one of the codes designated by DOE's former Office of Environment, Safety and Health as a toolbox code for safety analysis, as identified in ALOHA Computer Code Application Guidance for Documented Safety Analysis Final Report (DOE 2004h).

The ALOHA code is a deterministic representation of atmospheric releases of toxic and hazardous chemicals. The code can predict the rate at which chemical vapors escape (e.g., from puddles or leaking tanks) into the atmosphere; a specified release rate is also an option. In the case of the analyses performed here, the liquid chemical releases were determined based on the total chemical inventories, with ALOHA then predicting the chemical release rates from puddles.

Either of two dispersion algorithms is applied by the code, depending on whether the release is neutrally buoyant or heavier than air. The former is modeled similarly to radioactive releases in that the plume is assumed to advect (i.e., convey horizontally) with the wind velocity while dispersing laterally (horizontally perpendicular to the wind direction) and vertically. The latter considers the initial slumping and spreading of the release because of its density. As a heavier than air release becomes more dilute, its behavior tends towards that of a neutrally buoyant release.

The ALOHA code uses a constant set of meteorological conditions (e.g., wind speed, stability class) to determine the downwind atmospheric concentrations (EPA 2007d). Average conditions (mean wind speed and median stability class) were determined for each meteorological data set (see discussion of Radioactive Materials Release, above). This is roughly equivalent to the conditions corresponding to the mean radiological dose estimates of MACCS2 where the average results from hourly meteorological conditions were used. Accidental chemical release concentrations were calculated for the closest site boundary and at $328 \mathrm{ft}(100 \mathrm{~m})$ from the release at each site.

ALOHA contains physical and toxicological properties for approximately 1,000 chemicals. The physical properties were used to determine which of the dispersion models and accompanying parameters were applied. Acute Exposure Guideline Levels (AEGL)-2 and 3 (SCAPA 2007) are used to define the footprint of concern. Because the meteorological conditions specified do not account for wind direction (i.e., it is not known a priori in which direction the wind would be blowing in the event of an accident) the areas of concern are defined by a circle of radius equivalent to the downwind distance at which the concentration decreases to levels less than the level of concern. 


\section{D.1.6 Sites Selected for Analysis}

Generic sites were developed to assess the consequences of routine operation and potential accident scenarios associated with the facilities under the domestic programmatic alternatives. These sites provide a range of values for two parameters: offsite $50 \mathrm{mi}(80 \mathrm{~km})$ population and meteorological conditions that would directly affect the offsite consequences of an accident. The $50 \mathrm{mi}(80 \mathrm{~km})$ population has a direct effect on the collective dose received in the area surrounding the site. The environmental concentrations which would result from releases depend on the meteorological mechanisms of advection and dispersion that a release would experience as it is transported downwind.

To help determine a reasonable range for offsite population, DOE reviewed the range of populations presented in Table 5.3 Generic Environmental Impact Statement for License Renewal of Nuclear Reactors (NUREG-1437 Vol. 2) (NRC 1996). That table contains populations projected to either year 2030 or 2050 (depending on the particular plant site). No attempt was made to further refine the numerical population projections in that table. The NRC table includes entries for each power plant at each site; sites with multiple plants have multiple entries. The table was edited so that there was only a single entry for the population surrounding each site and thus each site was considered equally. From this data set, three total populations were selected to represent "small" (fifth percentile), "medium" (fiftieth percentile) and "large" (ninety-fifth percentile) surrounding population sites. Each of these total populations was spatially distributed within a $50 \mathrm{mi}(80 \mathrm{~km})$ radius according to a composite of the distributions from four NRC licensed sites with similar surrounding populations. The composite distributions were then escalated to a year 2060 equivalent.

To help determine a reasonable range of meteorological conditions, more than 20 annual meteorological data sets representing various NRC-licensed and DOE sites were considered. These data sets are made up of wind speed, wind direction, stability class and precipitation for each hour of the year. A sample accident (Beyond Design Basis Earthquake at the nuclear fuel recycling center) was chosen and the total collective dose to all of the three hypothetical population distributions was calculated for each meteorological data set. The three meteorological data sets resulting in the smallest collective dose (indicative of large atmospheric mixing) were composited by choosing four months of data (i.e., one-third of a year) from each and linking them together. The resulting data set was designated as the "large atmospheric mixing" meteorological data set. The three sets resulting in the largest collective dose (indicative of small atmospheric mixing) were similarly composited and designated as the "small atmospheric mixing" meteorological data set.

An additional parameter, the distance to the site boundary, was also considered as a site differentiator. This distance affects the dose to the MEI. In general, the larger the distance from the source, the less dose that this particular individual could receive. There are no current regulatory minimum distances, which apply to facility siting.

To determine a representative distance to the site boundary for existing commercial nuclear facilities, DOE obtained information regarding the exclusion distance for all currently operating commercial nuclear power plants in the United States from Appendix A, "General 
Characteristics and Environmental Settings of Domestic Nuclear Power Plants" in the Generic Environmental Impact Statement for License Renewal of Nuclear Plants (hereafter NUREG1437) (NRC 1996). The NUREG-1437 appendix lists the exclusion distance (m) for every site with an operating reactor. DOE then entered the values into a spreadsheet for evaluation.

The mean value for the exclusion distance for these reactors is 3,020 feet (ft) (920 meters [m]), with a standard deviation of $1,280 \mathrm{ft}(390 \mathrm{~m})$. The median exclusion distance is $2,986 \mathrm{ft}(910 \mathrm{~m})$. The exclusion distances ranged from a low of $886 \mathrm{ft}(270 \mathrm{~m})$ to a high of $6,660 \mathrm{ft}(2,030 \mathrm{~m})$. Based on these data, DOE has selected the mean distance of $3,020 \mathrm{ft}(920 \mathrm{~m})$ as the distance to site boundary for analysis at the generic sites presented in this PEIS. The mean value was selected for the exclusion distance because there is a trend towards a general increase in exclusion distances over time, so new reactors are expected to have an exclusion distance equal to or greater than the mean of existing plants. Exclusion distances less than 3,020 $\mathrm{ft}(920 \mathrm{~m})$ would generally increase the MEI consequences and distances greater than 3,020 ft $(920 \mathrm{~m})$ would generally decrease MEI consequences. There are many factors affecting the consequenceto-distance relationship, but a rough approximation is that the consequence is inversely related to the square of the distance.

Table D.1.6-1 shows the six generic sites and some of the important site parameters affecting dose and health impacts to the surrounding population. Parameter combinations were chosen to range from generally favorable (large atmospheric mixing and small population) to unfavorable (small atmospheric mixing and large population). The generic sites represent the range of dose and health impacts to the surrounding population that would be found at most real sites that might house either a separations facility or reactor facility. The same generic sites are used to represent either type of facility because similar physical and constituent releases (i.e., gaseous and particulate radionuclides) could result from a hypothetical accidental release from either facility. The population for each of the generic sites was based on a composite of actual reactor sites and projected to 2060, which is approximately the end of the analytical period for the programmatic alternatives.

TABLE D.1.6-1—Characteristics of Generic Sites Selected for Accident Analysis

\begin{tabular}{ccccc}
\hline Site & 50-Mile Population & Mean Wind Speed (m/s) & Median Stability Class & Distance to MEI (ft) \\
\hline 1 & 300,000 (small) & 4.1 (large mixing) & D (large mixing) & $3,020(920 \mathrm{~m})$ \\
2 & $1,700,000$ (medium) & 4.1 (large mixing) & D (large mixing) & $3,020(920 \mathrm{~m})$ \\
3 & $8,200,000$ (large) & 4.1 (large mixing) & D (large mixing) & $3,020(920 \mathrm{~m})$ \\
4 & 300,000 (small) & 1.4 (small mixing) & E (small mixing) & $3,020(920 \mathrm{~m})$ \\
5 & $1,700,000$ (medium) & 1.4 (small mixing) & E (small mixing) & $3,020(920 \mathrm{~m})$ \\
6 & $8,200,000$ (large) & 1.4 (small mixing) & E (small mixing) & $3,020(920 \mathrm{~m})$ \\
\hline
\end{tabular}

\section{D.2 FACILITY ACCIDENTS}

The following sections provide the relevant facility accident analyses for each alternative as described in Chapter 2. A given alternative may have multiple facility types (e.g., more than one reactor type plus one or more fuel reprocessing and fuel fabrication facilities). The analysis for each facility type is presented only once in this appendix even though it may apply in more than one alternative. For example, Section D.2.2.1 addresses a nuclear fuel recycling facility, which is included in multiple alternatives. In addition, accident impacts are not added for all facilities in the alternative because the facilities may not be colocated, and if colocated: 
- It is not credible that a receptor will experience consequences from multiple independent events because of the low frequency of most independent accidents. Initiators such as an earthquake do have the potential of impacting multiple facilities concurrently; however, the facilities merely have a vulnerability, not a certainty, of being impacted should an earthquake occur, so the frequency for multiple facilities being impacted is significantly lower than for the single facility events reported here.

- The number, selection, and relative positions of colocated facilities are speculative, so addition of impacts could substantially overstate the real effects.

\section{D.2.1 No Action Alternative}

The No Action Alternative, as described in Section 2.2 of Chapter 2, involves the construction and operation of new and replacement LWRs and new ALWRs. This is a once-through alternative, so nuclear fuel recycling center accidents are not relevant for this alternative. It is assumed that the LWRs and ALWRs would be fueled with low-enriched uranium (LEU). This analysis considers two reactor options: LEU fueled LWR, and LEU fueled ALWR.

LWRs typically used in the U.S. commercial industry are designed to withstand off normal events that could be postulated to occur, and if unmitigated, could lead to damage of nuclear fuel and release of radioactivity. This reactor concept uses a "defense in depth" approach to design where multiple levels of protection are provided against the release of radioactive material. Protective measures include the use of independent safety systems, fault detection and correction, and multiple physical barriers to the release of radioactivity from an accident. The goal is to limit the potential of accidents occurring and to limit the effects of an accident in the event one does occur.

ALWR designs differ from LWR designs by increased use of active and passive safety features that lower the frequency of accidents and/or design features such as scrubbers that mitigate the consequence of accidents. For example, a fuel damaging Loss of Coolant Accident (LOCA) event is less likely in an ALWR than in an LWR due to the safety systems and the resulting release might pass through a scrubber to mitigate the consequences. As a result, the accident scenarios selected for analysis and their consequences will differ between the LWR and the ALWR.

\section{D.2.1.1 Low Enriched Uranium Fueled Light Water Reactor}

The Surplus Plutonium Disposition Final Environmental Impact Statement (hereafter SPD EIS or DOE/EIS-0283) (DOE 1999d) evaluated accidents at three existing LWR sites utilizing conventional LEU fuel (as well as MOX-U-Pu fuel). The SPD EIS considered design basis and beyond design basis events, both of which are included here. A description of each accident is presented in the SPD EIS (DOE 1999d) and is not repeated here. In this PEIS, DOE has reanalyzed the consequences of the accident scenarios presented in the SPD EIS for the Catawba reactor at the six generic sites described in Section D.1.6. The accidents for the Catawba reactor were selected for evaluation here because it is a large LWR with a radioactive source term that equals or exceeds the source term of the other reactors analyzed in the SPD EIS, thereby resulting in the greatest consequences. The consequences for the MOX-U-Pu fueled LWR 
accidents (see Section D.2.3.1) were recalculated for this GNEP PEIS based on the SPD EIS source terms. For each LEU fueled LWR scenario, the MOX-U-Pu LWR results are scaled based on the ratios reported in the SPD EIS for each accident scenario. Table D.2.1.1-1 lists the ratios reported in the SPD EIS. The MOX-U-Pu fueled LWR accident impacts reported in Section D.2.3.1 are divided by the appropriate value below to obtain the LEU fueled LWR results.

TABLE D.2.1.1-1—Ratio of Accident Impacts for Mixed Oxide-Uranium-Plutonium Fueled and Low Enriched Uranium Fueled Light Water Reactors (Mixed Oxide-Uranium-Plutonium Impacts/Low Enriched Uranium Impacts)

\begin{tabular}{lccc}
\hline \multicolumn{1}{c}{ Accident (Frequency) } & Offsite Population & MEI & Noninvolved Worker \\
\hline LOCA $\left(7.5 \times 10^{-6} / \mathrm{yr}\right)$ & 1.033 & 1.028 & 1.019 \\
Fuel Handling Accident $\left(1 \times 10^{-4} / \mathrm{yr}\right)$ & 0.977 & 0.949 & 0.953 \\
SG Tube Rupture $\left(6.31 \times 10^{-10} / \mathrm{yr}\right)$ & 1.042 & 1.061 & $1.05^{\mathrm{a}}$ \\
Early Containment Failure $\left(3.42 \times 10^{-8} / \mathrm{yr}\right)$ & 1.048 & 1.007 & $1.05^{\mathrm{a}}$ \\
Late Containment Failure $\left(1.21 \times 10^{-5} / \mathrm{yr}\right)$ & 0.964 & 1.071 & $1.05^{\mathrm{a}}$ \\
Interfacing System LOCA $\left(6.9 \times 10^{-8} / \mathrm{yr}\right)$ & 1.083 & 1.143 & $1.05^{\mathrm{a}}$ \\
Beyond Design Basis Earthquake, mitigated $\left(1 \times 10^{-5} / \mathrm{yr}\right)$ & $1.05^{\mathrm{b}}$ & $1.05^{\mathrm{b}}$ & $1.05^{\mathrm{b}}$ \\
Beyond Design Basis Earthquake, unmitigated & $1.05^{\mathrm{b}}$ & $1.05^{\mathrm{b}}$ & $1.05^{\mathrm{b}}$ \\
$\left(1 \times 10^{-5} / \mathrm{yr}\right)$ & $1.05^{\mathrm{b}}$ & $1.05^{\mathrm{b}}$ & $1.05^{\mathrm{b}}$ \\
Aircraft Crash, mitigated $\left(1 \times 10^{-7} / \mathrm{yr}\right)$ & $1.05^{\mathrm{b}}$ & $1.05^{\mathrm{b}}$ & $1.05^{\mathrm{b}}$ \\
Aircraft Crash, unmitigated $\left(1 \times 10^{-7} / \mathrm{yr}\right)$ & &
\end{tabular}

${ }^{a}$ Impacts for the noninvolved worker are not calculated in the SPD EIS for beyond design basis events, but they are calculated in this GNEP PEIS. The average ratio of 1.05 , as reported in the SPD EIS, is assumed here.

${ }^{\mathrm{b}}$ This scenario was not analyzed in the SPD EIS so a scenario-specific ratio is not available. The average ratio of 1.05, as reported in the SPD EIS, is used here.

Tables D.2.1.1-2 through D.2.1.1-4 present the accident risks for the LEU fueled LWR at the six generic sites described in Section D.1.6 for the offsite population, MEI, and noninvolved worker. Because the results are reported to one significant digit, the LEU fueled LWR values are generally, but not always, identical to the MOX-U-Pu fueled LWR. 
TABLE D.2.1.1-2 — Low Enriched Uranium Fueled Light Water Reactor Accident Risks ${ }^{a}$ to the Offsite Population (All Sites)

\begin{tabular}{|c|c|c|c|c|c|c|}
\hline Accident (Frequency) & $\begin{array}{c}\text { Generic } \\
\text { Site 1 }\end{array}$ & $\begin{array}{l}\text { Generic } \\
\text { Site } 2\end{array}$ & $\begin{array}{l}\text { Generic } \\
\text { Site } 3\end{array}$ & $\begin{array}{l}\text { Generic } \\
\text { Site } 4\end{array}$ & $\begin{array}{l}\text { Generic } \\
\text { Site } 5\end{array}$ & $\begin{array}{c}\text { Generic } \\
\text { Site } 6\end{array}$ \\
\hline LOCA $\left(7.5 \times 10^{-6} / \mathrm{yr}\right)$ & $6 \times 10^{-7}$ & $1 \times 10^{-6}$ & $7 \times 10^{-6}$ & $3 \times 10^{-6}$ & $6 \times 10^{-6}$ & $2 \times 10^{-5}$ \\
\hline $\begin{array}{l}\text { Fuel Handling Accident } \\
\left(1 \times 10^{-4} / \mathrm{yr}\right)\end{array}$ & $7 \times 10^{-7}$ & $2 \times 10^{-6}$ & $7 \times 10^{-6}$ & $2 \times 10^{-6}$ & $4 \times 10^{-6}$ & $1 \times 10^{-5}$ \\
\hline $\begin{array}{l}\text { SG Tube Rupture } \\
\left(6.31 \times 10^{-10} / \mathrm{yr}\right)\end{array}$ & $3 \times 10^{-7}$ & $8 \times 10^{-7}$ & $4 \times 10^{-6}$ & $1 \times 10^{-6}$ & $3 \times 10^{-6}$ & $1 \times 10^{-5}$ \\
\hline $\begin{array}{l}\text { Early Containment Failure } \\
\left(3.42 \times 10^{-8} / \mathrm{yr}\right)\end{array}$ & $3 \times 10^{-7}$ & $1 \times 10^{-6}$ & $6 \times 10^{-6}$ & $5 \times 10^{-7}$ & $2 \times 10^{-6}$ & $1 \times 10^{-5}$ \\
\hline $\begin{array}{l}\text { Late Containment Failure } \\
\left(1.21 \times 10^{-5} / \mathrm{yr}\right)\end{array}$ & $1 \times 10^{-5}$ & $5 \times 10^{-5}$ & $2 \times 10^{-4}$ & $2 \times 10^{-5}$ & $9 \times 10^{-5}$ & $4 \times 10^{-4}$ \\
\hline $\begin{array}{l}\text { Interfacing System LOCA } \\
\left(6.9 \times 10^{-8} / \mathrm{yr}\right)\end{array}$ & $6 \times 10^{-5}$ & $1 \times 10^{-4}$ & $7 \times 10^{-4}$ & $3 \times 10^{-4}$ & $6 \times 10^{-4}$ & 0.002 \\
\hline $\begin{array}{l}\text { Beyond Design Basis } \\
\text { Earthquake, mitigated } \\
\left(1 \times 10^{-5} / \mathrm{yr}\right)\end{array}$ & $2 \times 10^{-6}$ & $4 \times 10^{-6}$ & $2 \times 10^{-5}$ & $8 \times 10^{-6}$ & $1 \times 10^{-5}$ & $6 \times 10^{-5}$ \\
\hline $\begin{array}{l}\text { Beyond Design Basis } \\
\text { Earthquake, unmitigated } \\
\left(1 \times 10^{-5} / \mathrm{yr}\right)\end{array}$ & 0.002 & 0.005 & 0.02 & 0.009 & 0.02 & 0.07 \\
\hline $\begin{array}{l}\text { Aircraft Crash, mitigated } \\
\left(1 \times 10^{-7} / \mathrm{yr}\right)\end{array}$ & $2 \times 10^{-8}$ & $4 \times 10^{-8}$ & $2 \times 10^{-7}$ & $8 \times 10^{-8}$ & $1 \times 10^{-7}$ & $6 \times 10^{-7}$ \\
\hline $\begin{array}{l}\text { Aircraft Crash, unmitigated } \\
\left(1 \times 10^{-7} / \mathrm{yr}\right)\end{array}$ & $2 \times 10^{-5}$ & $5 \times 10^{-5}$ & $2 \times 10^{-4}$ & $9 \times 10^{-5}$ & $2 \times 10^{-4}$ & $7 \times 10^{-4}$ \\
\hline
\end{tabular}

The accident with the highest risk to the offsite populations is the "Unmitigated Beyond Design Basis Earthquake" scenario. The collective risk to the offsite population for this scenario would range from 0.002 expected LCFs per year of operation in the Site-1 offsite population (300,000 people) to 0.07 expected LCFs per year of operation in the Site- 6 offsite population $(8,200,000$ people). 
TABLE D.2.1.1-3 - Low Enriched Uranium Fueled Light Water Reactor Accident Risks ${ }^{a}$ to the Maximally Exposed Individual (All Sites)

\begin{tabular}{|c|c|c|c|c|c|c|}
\hline Accident (Frequency) & $\begin{array}{l}\text { Generic } \\
\text { Site } 1\end{array}$ & $\begin{array}{l}\text { Generic } \\
\text { Site } 2\end{array}$ & $\begin{array}{l}\text { Generic } \\
\text { Site } 3\end{array}$ & $\begin{array}{l}\text { Generic } \\
\text { Site } 4\end{array}$ & $\begin{array}{l}\text { Generic } \\
\text { Site } 5\end{array}$ & $\begin{array}{l}\text { Generic } \\
\text { Site } 6\end{array}$ \\
\hline LOCA $\left(7.5 \times 10^{-6} / y r\right)$ & $7 \times 10^{-9}$ & $7 \times 10^{-9}$ & $7 \times 10^{-9}$ & $5 \times 10^{-8}$ & $5 \times 10^{-8}$ & $5 \times 10^{-8}$ \\
\hline $\begin{array}{l}\text { Fuel Handling Accident } \\
\left(1 \times 10^{-4} / \mathrm{yr}\right)\end{array}$ & $1 \times 10^{-8}$ & $1 \times 10^{-8}$ & $1 \times 10^{-8}$ & $6 \times 10^{-8}$ & $6 \times 10^{-8}$ & $6 \times 10^{-8}$ \\
\hline $\begin{array}{l}\text { SG Tube Rupture } \\
\left(6.31 \times 10^{-10} / \mathrm{yr}\right)\end{array}$ & $6 \times 10^{-10}$ & $6 \times 10^{-10}$ & $6 \times 10^{-10}$ & $6 \times 10^{-10}$ & $6 \times 10^{-10}$ & $6 \times 10^{-10}$ \\
\hline $\begin{array}{l}\text { Early Containment Failure } \\
\left(3.42 \times 10^{-8} / \mathrm{yr}\right)\end{array}$ & $9 \times 10^{-10}$ & $9 \times 10^{-10}$ & $9 \times 10^{-10}$ & $2 \times 10^{-9}$ & $2 \times 10^{-9}$ & $2 \times 10^{-9}$ \\
\hline $\begin{array}{l}\text { Late Containment Failure } \\
\left(1.21 \times 10^{-5} / \mathrm{yr}\right)\end{array}$ & $3 \times 10^{-8}$ & $3 \times 10^{-8}$ & $3 \times 10^{-8}$ & $5 \times 10^{-8}$ & $5 \times 10^{-8}$ & $5 \times 10^{-8}$ \\
\hline $\begin{array}{l}\text { Interfacing System LOCA } \\
\left(6.9 \times 10^{-8} / \mathrm{yr}\right)\end{array}$ & $7 \times 10^{-8}$ & $7 \times 10^{-8}$ & $7 \times 10^{-8}$ & $7 \times 10^{-8}$ & $7 \times 10^{-8}$ & $7 \times 10^{-8}$ \\
\hline $\begin{array}{l}\text { Beyond Design Basis } \\
\text { Earthquake, mitigated } \\
\left(1 \times 10^{-5} / \mathrm{yr}\right)\end{array}$ & $1 \times 10^{-8}$ & $1 \times 10^{-8}$ & $1 \times 10^{-8}$ & $8 \times 10^{-8}$ & $8 \times 10^{-8}$ & $8 \times 10^{-8}$ \\
\hline $\begin{array}{l}\text { Beyond Design Basis } \\
\text { Earthquake, unmitigated } \\
\left(1 \times 10^{-5} / \mathrm{yr}\right)\end{array}$ & $1 \times 10^{-5}$ & $1 \times 10^{-5}$ & $1 \times 10^{-5}$ & $1 \times 10^{-5}$ & $1 \times 10^{-5}$ & $1 \times 10^{-5}$ \\
\hline $\begin{array}{l}\text { Aircraft Crash, mitigated } \\
\left(1 \times 10^{-7} / \mathrm{yr}\right)\end{array}$ & $1 \times 10^{-10}$ & $1 \times 10^{-10}$ & $1 \times 10^{-10}$ & $8 \times 10^{-10}$ & $8 \times 10^{-10}$ & $8 \times 10^{-10}$ \\
\hline $\begin{array}{l}\text { Aircraft Crash, unmitigated } \\
\left(1 \times 10^{-7} / \mathrm{yr}\right)\end{array}$ & $1 \times 10^{-7}$ & $1 \times 10^{-7}$ & $1 \times 10^{-7}$ & $1 \times 10^{-7}$ & $1 \times 10^{-7}$ & $1 \times 10^{-7}$ \\
\hline
\end{tabular}

For the MEI, the "Unmitigated Beyond Design Basis Earthquake" scenario would result in an increased LCF risk of $1 \times 10^{-5}$ per year of operation; which corresponds numerically to the annual probability of that accident occurring (i.e., the consequence is 1 LCF so the risk [probability $\mathrm{x}$ consequence] equals the annual probability, or numerically equals the frequency, of the accident). 
TABLE D.2.1.1-4 - Low Enriched Uranium Fueled Light Water Reactor Accident Risks ${ }^{a}$ to the Noninvolved Worker (All Sites)

\begin{tabular}{|c|c|c|c|c|c|c|}
\hline Accident (Frequency) & $\begin{array}{c}\text { Generic Site } \\
1\end{array}$ & $\begin{array}{c}\text { Generic } \\
\text { Site } 2\end{array}$ & $\begin{array}{l}\text { Generic } \\
\text { Site } 3\end{array}$ & $\begin{array}{l}\text { Generic } \\
\text { Site } 4\end{array}$ & $\begin{array}{l}\text { Generic } \\
\text { Site } 5\end{array}$ & $\begin{array}{l}\text { Generic } \\
\text { Site } 6\end{array}$ \\
\hline LOCA $\left(7.5 \times 10^{-6} / \mathrm{yr}\right)$ & $8 \times 10^{-8}$ & $8 \times 10^{-8}$ & $8 \times 10^{-8}$ & $8 \times 10^{-7}$ & $8 \times 10^{-7}$ & $8 \times 10^{-7}$ \\
\hline $\begin{array}{l}\text { Fuel Handling Accident } \\
\left(1 \times 10^{-4 /} \mathrm{yr}\right)\end{array}$ & $6 \times 10^{-8}$ & $6 \times 10^{-8}$ & $6 \times 10^{-8}$ & $3 \times 10^{-7}$ & $3 \times 10^{-7}$ & $3 \times 10^{-7}$ \\
\hline $\begin{array}{l}\text { SG Tube Rupture } \\
\left(6.31 \times 10^{-10} / \mathrm{yr}\right)\end{array}$ & $6 \times 10^{-10}$ & $6 \times 10^{-10}$ & $6 \times 10^{-10}$ & $6 \times 10^{-10}$ & $6 \times 10^{-10}$ & $6 \times 10^{-10}$ \\
\hline $\begin{array}{l}\text { Early Containment Failure } \\
\left(3.42 \times 10^{-8} / \mathrm{yr}\right)\end{array}$ & $8 \times 10^{-9}$ & $8 \times 10^{-9}$ & $8 \times 10^{-9}$ & $3 \times 10^{-9}$ & $3 \times 10^{-9}$ & $3 \times 10^{-9}$ \\
\hline $\begin{array}{l}\text { Late Containment Failure } \\
\left(1.21 \times 10^{-5} / \mathrm{yr}\right)\end{array}$ & $6 \times 10^{-7}$ & $6 \times 10^{-7}$ & $6 \times 10^{-7}$ & $9 \times 10^{-8}$ & $9 \times 10^{-8}$ & $9 \times 10^{-8}$ \\
\hline $\begin{array}{l}\text { Interfacing System LOCA } \\
\left(6.9 \times 10^{-8} / \mathrm{yr}\right)\end{array}$ & $7 \times 10^{-8}$ & $7 \times 10^{-8}$ & $7 \times 10^{-8}$ & $7 \times 10^{-8}$ & $7 \times 10^{-8}$ & $7 \times 10^{-8}$ \\
\hline $\begin{array}{l}\text { Beyond Design Basis } \\
\text { Earthquake, mitigated } \\
\left(1 \times 10^{-5} / \mathrm{yr}\right)\end{array}$ & $3 \times 10^{-7}$ & $3 \times 10^{-7}$ & $3 \times 10^{-7}$ & $2 \times 10^{-6}$ & $2 \times 10^{-6}$ & $2 \times 10^{-6}$ \\
\hline $\begin{array}{l}\text { Beyond Design Basis } \\
\text { Earthquake, unmitigated } \\
\left(1 \times 10^{-5} / \mathrm{yr}\right)\end{array}$ & $1 \times 10^{-5}$ & $1 \times 10^{-5}$ & $1 \times 10^{-5}$ & $1 \times 10^{-5}$ & $1 \times 10^{-5}$ & $1 \times 10^{-5}$ \\
\hline $\begin{array}{l}\text { Aircraft Crash, mitigated } \\
\left(1 \times 10^{-7} / \mathrm{yr}\right)\end{array}$ & $3 \times 10^{-9}$ & $3 \times 10^{-9}$ & $3 \times 10^{-9}$ & $2 \times 10^{-8}$ & $2 \times 10^{-8}$ & $2 \times 10^{-8}$ \\
\hline $\begin{array}{l}\text { Aircraft Crash, unmitigated } \\
\left(1 \times 10^{-7} / \mathrm{yr}\right)\end{array}$ & $1 \times 10^{-7}$ & $1 \times 10^{-7}$ & $1 \times 10^{-7}$ & $1 \times 10^{-7}$ & $1 \times 10^{-7}$ & $1 \times 10^{-7}$ \\
\hline
\end{tabular}

For the onsite noninvolved worker, the "Unmitigated Beyond Design Basis Earthquake" scenario would result in an increased risk of $1 \times 10^{-5}$ per year of operation; which corresponds to the annual probability of that accident occurring.

Tables D.2.1.1-5 through D.2.1.1-7 present the accident consequences for the LEU fueled LWR at the six generic sites described in Section D.1.6 for the offsite population, MEI, and noninvolved worker. 


\begin{tabular}{|c|c|c|c|c|c|c|}
\hline Accident (Frequency) & $\begin{array}{l}\text { Generic } \\
\text { Site } 1 \\
\end{array}$ & $\begin{array}{l}\text { Generic } \\
\text { Site } 2 \\
\end{array}$ & $\begin{array}{l}\text { Generic } \\
\text { Site } 3\end{array}$ & $\begin{array}{l}\text { Generic } \\
\text { Site } 4\end{array}$ & $\begin{array}{l}\text { Generic } \\
\text { Site } 5\end{array}$ & $\begin{array}{l}\text { Generic } \\
\text { Site } 6\end{array}$ \\
\hline LOCA $\left(7.5 \times 10^{-6} / \mathrm{yr}\right)$ & $100 / 0.08$ & $300 / 0.2$ & $2,000 / 0.9$ & $600 / 0.4$ & $1,000 / 0.8$ & $5,000 / 3$ \\
\hline $\begin{array}{l}\text { Fuel Handling Accident } \\
\left(1 \times 10^{-4} / \mathrm{yr}\right)\end{array}$ & $10 / 0.007$ & $30 / 0.02$ & $100 / 0.07$ & $30 / 0.02$ & $60 / 0.04$ & $200 / 0.1$ \\
\hline $\begin{array}{l}\text { SG Tube Rupture } \\
\left(6.31 \times 10^{-10} / \mathrm{yr}\right)\end{array}$ & $8 \times 10^{5} / 500$ & $\begin{array}{c}2 \times 10^{6} / \\
1,000\end{array}$ & $\begin{array}{c}1 \times 10^{7} / \\
6,000\end{array}$ & $\begin{array}{c}4 \times 10^{6} / \\
2,000\end{array}$ & $\begin{array}{c}8 \times 10^{6} / \\
5,000\end{array}$ & $\begin{array}{l}3 \times 10^{7} / \\
20,000\end{array}$ \\
\hline $\begin{array}{l}\text { Early Containment Failure } \\
\left(3.42 \times 10^{-8} / \mathrm{yr}\right)\end{array}$ & $1 \times 10^{4} / 8$ & $6 \times 10^{4} / 40$ & $\begin{array}{c}3 \times 10^{5} / \\
200\end{array}$ & $3 \times 10^{4} / 20$ & $1 \times 10^{5} / 60$ & $\begin{array}{c}5 \times 10^{5} / \\
300\end{array}$ \\
\hline $\begin{array}{l}\text { Late Containment Failure } \\
\left(1.21 \times 10^{-5} / \mathrm{yr}\right)\end{array}$ & $2,000 / 1$ & $7,000 / 4$ & $3 \times 10^{4} / 20$ & $3,000 / 2$ & $1 \times 10^{4} / 7$ & $\begin{array}{c}6 \times 10^{4} / \\
30\end{array}$ \\
\hline $\begin{array}{l}\text { Interfacing System LOCA } \\
\left(6.9 \times 10^{-8} / \mathrm{yr}\right)\end{array}$ & $1 \times 10^{6} / 900$ & $\begin{array}{c}4 \times 10^{6} / \\
2,000\end{array}$ & $\begin{array}{l}2 \times 10^{7} / \\
10,000\end{array}$ & $\begin{array}{l}7 \times 10^{6} / \\
4,000\end{array}$ & $\begin{array}{c}1 \times 10^{7} / \\
8,000\end{array}$ & $\begin{array}{l}6 \times 10^{7} / \\
40,000\end{array}$ \\
\hline $\begin{array}{l}\text { Beyond Design Basis } \\
\text { Earthquake, mitigated } \\
\left(1 \times 10^{-5} / \mathrm{yr}\right)\end{array}$ & $300 / 0.2$ & $600 / 0.4$ & $3,000 / 2$ & $1,000 / 0.8$ & $2,000 / 1$ & $1 \times 10^{4} / 6$ \\
\hline $\begin{array}{l}\text { Beyond Design Basis } \\
\text { Earthquake, unmitigated } \\
\left(1 \times 10^{-5} / \mathrm{yr}\right)\end{array}$ & $3 \times 10^{5} / 200$ & $\begin{array}{c}8 \times 10^{5} / \\
500\end{array}$ & $\begin{array}{c}4 \times 10^{6} / \\
2,000\end{array}$ & $\begin{array}{c}2 \times 10^{6} / \\
900\end{array}$ & $\begin{array}{c}3 \times 10^{6} / \\
2,000\end{array}$ & $\begin{array}{c}1 \times 10^{7} / \\
7,000\end{array}$ \\
\hline $\begin{array}{l}\text { Aircraft Crash, mitigated } \\
\left(1 \times 10^{-7} / \mathrm{yr}\right)\end{array}$ & $300 / 0.2$ & $600 / 0.4$ & $3,000 / 2$ & $1,000 / 0.8$ & $2,000 / 1$ & $1 \times 10^{4} / 6$ \\
\hline $\begin{array}{l}\text { Aircraft Crash, unmitigated } \\
\left(1 \times 10^{-7} / \mathrm{yr}\right)\end{array}$ & $3 \times 10^{5} / 200$ & $\begin{array}{l}8 \times 10^{5} / \\
500\end{array}$ & $\begin{array}{c}4 \times 10^{6} / \\
2,000\end{array}$ & $\begin{array}{c}2 \times 10^{6} / \\
900\end{array}$ & $\begin{array}{c}3 \times 10^{6} / \\
2,000\end{array}$ & $\begin{array}{l}1 \times 10^{7} / \\
7,000\end{array}$ \\
\hline
\end{tabular}

The accidents with the highest consequence to the offsite population would be the "Interfacing System LOCA." Using the dose-to-risk conversion factor of $6 \times 10^{-4}$ per person-rem, these collective population doses could result in 900 to 40,000 additional LCFs in the surrounding population for this Beyond Extremely Unlikely accident. These consequences are consistent with the results of the NRC's Severe Accident Risks: An Assessment for Five U.S. Nuclear Power Plants, NUREG-1150 (NRC 1990) and the SPD EIS (DOE 1999d) when the high population and least favorable meteorological conditions used in this analysis are considered. The higher consequences for this accident are not the result of differences in the fuels relative to other reactors, but are instead the result of the use of high release parameters and an assumption that all containment and filter systems would fail. 


\section{TABLE D.2.1.1-6 - Low Enriched Uranium Fueled Light Water Reactor Accident Health Consequences (Dose in Rem/Increased Likelihood of a Latent Cancer Fatality) ${ }^{a}$} to the Maximally Exposed Individual (All Sites)

\begin{tabular}{|c|c|c|c|c|c|c|}
\hline Accident (Frequency) & $\begin{array}{l}\text { Generic } \\
\text { Site } 1\end{array}$ & $\begin{array}{l}\text { Generic } \\
\text { Site } 2\end{array}$ & $\begin{array}{l}\text { Generic } \\
\text { Site } 3\end{array}$ & $\begin{array}{l}\text { Generic } \\
\text { Site } 4\end{array}$ & $\begin{array}{l}\text { Generic } \\
\text { Site } 5\end{array}$ & $\begin{array}{c}\text { Generic } \\
\text { Site } 6\end{array}$ \\
\hline $\operatorname{LOCA}\left(7.5 \times 10^{-6} / \mathrm{yr}\right)$ & $2 / 9 \times 10^{-4}$ & $2 / 9 \times 10^{-4}$ & $2 / 9 \times 10^{-4}$ & $10 / 0.007$ & $10 / 0.007$ & $10 / 0.007$ \\
\hline $\begin{array}{l}\text { Fuel Handling Accident } \\
\left(1 \times 10^{-4} / \mathrm{yr}\right)\end{array}$ & $\begin{array}{c}0.2 / \\
1 \times 10^{-4}\end{array}$ & $\begin{array}{c}0.2 / \\
1 \times 10^{-4}\end{array}$ & $\begin{array}{c}0.2 / \\
1 \times 10^{-4}\end{array}$ & $1 / 6 \times 10^{-4}$ & $1 / 6 \times 10^{-4}$ & $1 / 6 \times 10^{-4}$ \\
\hline $\begin{array}{l}\text { SG Tube Rupture } \\
\left(6.31 \times 10^{-10} / \mathrm{yr}\right)\end{array}$ & $9,000 / 1$ & $9,000 / 1$ & $9,000 / 1$ & $6 \times 10^{4} / 1$ & $6 \times 10^{4} / 1$ & $6 \times 10^{4} / 1$ \\
\hline $\begin{array}{l}\text { Early Containment Failure } \\
\left(3.42 \times 10^{-8} / \mathrm{yr}\right)\end{array}$ & $20 / 0.03$ & $20 / 0.03$ & $20 / 0.03$ & $50 / 0.06$ & $50 / 0.06$ & $50 / 0.06$ \\
\hline $\begin{array}{l}\text { Late Containment Failure } \\
\left(1.21 \times 10^{-5} / \mathrm{yr}\right)\end{array}$ & $4 / 0.003$ & $4 / 0.003$ & $4 / 0.003$ & $7 / 0.004$ & $7 / 0.004$ & $7 / 0.004$ \\
\hline $\begin{array}{l}\text { Interfacing System LOCA } \\
\left(6.9 \times 10^{-8} / \mathrm{yr}\right)\end{array}$ & $2 \times 10^{4} / 1$ & $2 \times 10^{4} / 1$ & $2 \times 10^{4} / 1$ & $1 \times 10^{5} / 1$ & $1 \times 10^{5} / 1$ & $1 \times 10^{5} / 1$ \\
\hline Beyond Design Basis & & & & & & \\
\hline $\begin{array}{l}\text { Earthquake, mitigated } \\
\left(1 \times 10^{-5} / \mathrm{yr}\right)\end{array}$ & $2 / 0.001$ & $2 / 0.001$ & $2 / 0.001$ & $10 / 0.008$ & $10 / 0.008$ & $10 / 0.008$ \\
\hline $\begin{array}{l}\text { Beyond Design Basis } \\
\text { Earthquake, unmitigated } \\
\left(1 \times 10^{-5} / \mathrm{yr}\right)\end{array}$ & $4,000 / 1$ & $4,000 / 1$ & $4,000 / 1$ & $3 \times 10^{4} / 1$ & $3 \times 10^{4} / 1$ & $3 \times 10^{4} / 1$ \\
\hline $\begin{array}{l}\text { Aircraft Crash, mitigated } \\
\left(1 \times 10^{-7} / \mathrm{yr}\right)\end{array}$ & $2 / 0.001$ & $2 / 0.001$ & $2 / 0.001$ & $10 / 0.008$ & $10 / 0.008$ & $10 / 0.008$ \\
\hline $\begin{array}{l}\text { Aircraft Crash, unmitigated } \\
\left(1 \times 10^{-7} / \mathrm{yr}\right)\end{array}$ & $4,000 / 1$ & $4,000 / 1$ & $4,000 / 1$ & $3 \times 10^{4} / 1$ & $3 \times 10^{4} / 1$ & $3 \times 10^{4} / 1$ \\
\hline
\end{tabular}

For the MEI, four Beyond Extremely Unlikely scenarios- "Steam Generator Tube Rupture," "Interfacing System LOCA," "Unmitigated Beyond Design Basis Earthquake," and "Unmitigated Aircraft Crash"-would likely result in prompt fatality. When probability is taken into account, the MEI has an increased risk of contracting a fatal cancer of about $6 \times 10^{-10}$ to $1 \times 10^{-5}$ per year of reactor operation for these scenarios at site 6 . 


\section{TABLE D.2.1.1-7-Low Enriched Uranium Fueled Light Water Reactor Accident Health} Consequences (Dose in Rem/Increased Likelihood of a Latent Cancer Fatality) ${ }^{a}$ to the Noninvolved Worker (All Sites)

\begin{tabular}{lcccccc}
\hline \multicolumn{1}{c}{ Accident (Frequency) } & $\begin{array}{c}\text { Generic Site } \\
\mathbf{1}\end{array}$ & $\begin{array}{c}\text { Generic } \\
\text { Site 2 }\end{array}$ & $\begin{array}{c}\text { Generic } \\
\text { Site 3 }\end{array}$ & $\begin{array}{c}\text { Generic } \\
\text { Site 4 }\end{array}$ & $\begin{array}{c}\text { Generic } \\
\text { Site 5 }\end{array}$ & $\begin{array}{c}\text { Generic } \\
\text { Site 6 }\end{array}$ \\
\hline LOCA $\left(7.5 \times 10^{-6} / \mathrm{yr}\right)$ & $20 / 0.01$ & $20 / 0.01$ & $20 / 0.01$ & $90 / 0.1$ & $90 / 0.1$ & $90 / 0.1$ \\
$\begin{array}{l}\text { Fuel Handling Accident } \\
\left(1 \times 10^{-4} / \mathrm{yr}\right)\end{array}$ & $1 / 6 \times 10^{-4}$ & $1 / 6 \times 10^{-4}$ & $1 / 6 \times 10^{-4}$ & $5 / 0.003$ & $5 / 0.003$ & $5 / 0.003$ \\
$\begin{array}{l}\text { SG Tube Rupture } \\
\left(6.31 \times 10^{-10} / \mathrm{yr}\right)\end{array}$ & $1 \times 10^{5} / 1$ & $1 \times 10^{5} / 1$ & $1 \times 10^{5} / 1$ & $2 \times 10^{5} / 1$ & $2 \times 10^{5} / 1$ & $2 \times 10^{5} / 1$ \\
$\begin{array}{l}\text { Early Containment Failure } \\
\left(3.42 \times 10^{-8} / \mathrm{yr}\right)\end{array}$ & $200 / 0.2$ & $200 / 0.2$ & $200 / 0.2$ & $80 / 0.09$ & $80 / 0.09$ & $80 / 0.09$ \\
$\begin{array}{l}\text { Late Containment Failure } \\
\left(1.21 \times 10^{-5} / \mathrm{yr}\right)\end{array}$ & $40 / 0.05$ & $40 / 0.05$ & $40 / 0.05$ & $10 / 0.007$ & $10 / 0.007$ & $10 / 0.007$ \\
$\begin{array}{l}\text { Interfacing System LOCA } \\
\left(6.9 \times 10^{-8} / \mathrm{yr}\right)\end{array}$ & $2 \times 10^{5} / 1$ & $2 \times 10^{5} / 1$ & $2 \times 10^{5} / 1$ & $5 \times 10^{5} / 1$ & $5 \times 10^{5} / 1$ & $5 \times 10^{5} / 1$ \\
$\begin{array}{l}\text { Beyond Design Basis } \\
\text { Earthquake, mitigated } \\
\left(1 \times 10^{-5} / \mathrm{yr}\right)\end{array}$ & $30 / 0.03$ & $30 / 0.03$ & $30 / 0.03$ & $100 / 0.2$ & $100 / 0.2$ & $100 / 0.2$ \\
$\begin{array}{l}\text { Beyond Design Basis } \\
\text { Earthquake, unmitigated } \\
\left(1 \times 10^{-5} / \mathrm{yr}\right)\end{array}$ & $4 \times 10^{4} / 1$ & $4 \times 10^{4} / 1$ & $4 \times 10^{4} / 1$ & $2 \times 10^{5} / 1$ & $2 \times 10^{5} / 1$ & $2 \times 10^{5} / 1$ \\
$\begin{array}{l}\text { Aircraft Crash, mitigated } \\
\left(1 \times 10^{-7} / \mathrm{yr}\right)\end{array}$ & $30 / 0.03$ & $30 / 0.03$ & $30 / 0.03$ & $100 / 0.2$ & $100 / 0.2$ & $100 / 0.2$ \\
$\begin{array}{l}\text { Aircraft Crash, unmitigated } \\
\left(1 \times 10^{-7} / \mathrm{yr}\right)\end{array}$ & $4 \times 10^{4} / 1$ & $4 \times 10^{4} / 1$ & $4 \times 10^{4} / 1$ & $2 \times 10^{5} / 1$ & $2 \times 10^{5} / 1$ & $2 \times 10^{5} / 1$ \\
\hline $\begin{array}{l}\text { a } \\
\text { The dose in rem is reported before the slash and the increased likelihood of an LCF is presented after the slash. }\end{array}$
\end{tabular}

For the noninvolved worker, these same four Beyond Extremely Unlikely scenarios - "Steam Generator Tube Rupture," "Interfacing System LOCA," "Unmitigated Beyond Design Basis Earthquake," and "Unmitigated Aircraft Crash"-likely would result in prompt fatality. When probability is taken into account, the MEI has an increased risk of contracting a fatal cancer of about $6 \times 10^{-10}$ to $1 \times 10^{-5}$ per year of reactor operation for these scenarios at site 6 .

\section{D.2.1.2 Low Enriched Uranium Fueled Advanced Light Water Reactor}

DOE has previously analyzed accidents associated with ALWRs using LEU fuel at a variety of locations in the Tritium Supply and Recycling Final PEIS (DOE 1995b). For this PEIS, DOE has re-analyzed those ALWR accident scenarios for the six generic sites described in Section D.1.6. A description of each accident is presented in DOE 1995b. The parameters used for this reanalysis are presented in Table D.2.1.2-1. Tables D.2.1.2-2 through D.2.1.2-4 present the accident risks for an ALWR at all sites to the offsite population, MEI, and noninvolved worker. 


\section{TABLE D.2.1.2-1—Low Enriched Uranium Fueled Advanced Light Water Reactor} Accident Release Parameters for Accidents

\begin{tabular}{|c|c|c|}
\hline Parameter & Value & Basis/Comment \\
\hline \multicolumn{3}{|l|}{ Release Point: } \\
\hline All scenarios & Ground level & $\begin{array}{l}\text { This is the default value used when information is not } \\
\text { available. }\end{array}$ \\
\hline \multicolumn{3}{|l|}{ Duration: } \\
\hline $\begin{array}{l}\text { Beyond Design Basis } \\
\text { Earthquake }\end{array}$ & See Table D.1.4-1 & See Table D.1.4-1. \\
\hline Aircraft Crash & See Table D.1.4-1 & See Table D.1.4-1. \\
\hline All other scenarios & 1 hour & $\begin{array}{l}\text { This is the default value used when information is not } \\
\text { available. }\end{array}$ \\
\hline \multicolumn{3}{|l|}{ Source terms: } \\
\hline $\begin{array}{l}\text { Beyond Design Basis } \\
\text { Earthquake }\end{array}$ & $\begin{array}{c}\text { DOE/EIS-0161 } \\
\text { (DOE 1995b) for core } \\
\text { inventory. } \\
\text { Table D.1.4-1 for } \\
\text { release parameters. }\end{array}$ & $\begin{array}{l}\text { Release parameters were selected consistent with the } \\
\text { values used for all reactors (see Table D.1.4-1) and } \\
\text { applied to the core inventory for this reactor DOE/EIS- } \\
0161 \text { (DOE 1995b). }\end{array}$ \\
\hline Aircraft Crash & $\begin{array}{c}\text { DOE/EIS-0161 } \\
\text { (DOE 1995b) for core } \\
\text { inventory. } \\
\text { Table D.1.4-1 for } \\
\text { release parameters. }\end{array}$ & $\begin{array}{l}\text { Release parameters were selected consistent with the } \\
\text { values used for all reactors (see Table D.1.4-1) and } \\
\text { applied to the core inventory for this reactor DOE/EIS- } \\
0161 \text { (DOE 1995b). }\end{array}$ \\
\hline All other scenarios. & $\begin{array}{l}\text { DOE/EIS-0161 } \\
\text { (DOE 1995b) }\end{array}$ & $\begin{array}{l}\text { DOE/EIS-0161 (DOE 1995b) provides source terms for } \\
\text { each scenario. }\end{array}$ \\
\hline All other scenarios & $\begin{array}{l}\text { Values were taken } \\
\text { from DOE/EIS-0161 } \\
\text { (DOE 1995b) }\end{array}$ & $\begin{array}{l}\text { The source terms are taken directly from DOE/EIS-0161 } \\
\text { (DOE 1995b) since it is the basis for this ALWR accident } \\
\text { information. }\end{array}$ \\
\hline \multicolumn{3}{|l|}{ Frequency $(/ \mathrm{yr})$ : } \\
\hline $\begin{array}{l}\text { Failure of Small Primary } \\
\text { Coolant Line Outside } \\
\text { Containment }\end{array}$ & 0.001/yr (Unlikely) & $\begin{array}{l}\text { The frequency is taken directly from DOE/EIS-0161 } \\
\text { (DOE 1995b) since it is the basis for the ALWR accident } \\
\text { information. }\end{array}$ \\
\hline Fuel Handling Accident & $\begin{array}{l}1 \times 10^{-5} / \mathrm{yr}(\text { Extremely } \\
\text { Unlikely) }\end{array}$ & $\begin{array}{l}\text { The frequency is taken directly from DOE/EIS- } 0161 \\
\text { (DOE 1995b) since it is the basis for the ALWR accident } \\
\text { information. }\end{array}$ \\
\hline $\begin{array}{l}\text { Low Pressure Core Melt with } \\
\text { Loss of Short-Term Coolant } \\
\text { Makeup and Normal } \\
\text { Containment Leakage }\end{array}$ & $\begin{array}{l}7 \times 10^{-8} / \mathrm{yr} \text { (Beyond } \\
\text { Extremely Unlikely) }\end{array}$ & $\begin{array}{l}\text { The frequency is taken directly from DOE/EIS- } 0161 \\
\text { (DOE 1995b) since it is the basis for the ALWR accident } \\
\text { information. }\end{array}$ \\
\hline $\begin{array}{l}\text { Low Pressure Core Melt with } \\
\text { Loss of Long-Term Coolant } \\
\text { Makeup and Normal } \\
\text { Containment Leakage }\end{array}$ & $\begin{array}{l}6.4 \times 10^{-8} / \mathrm{yr} \text { (Beyond } \\
\text { Extremely Unlikely) }\end{array}$ & $\begin{array}{l}\text { The frequency is taken directly from DOE/EIS- } 0161 \\
\text { (DOE 1995b) since it is the basis for the ALWR accident } \\
\text { information. }\end{array}$ \\
\hline $\begin{array}{l}\text { Low Pressure Core Melt with } \\
\text { Loss of Short-Term Coolant } \\
\text { Makeup and Containment } \\
\text { Vessel }\end{array}$ & $\begin{array}{l}1.1 \times 10^{-8} / \mathrm{yr} \text { (Beyond } \\
\text { Extremely Unlikely) }\end{array}$ & $\begin{array}{l}\text { The frequency is taken directly from DOE/EIS-0161 } \\
\text { (DOE 1995b) since it is the basis for the ALWR accident } \\
\text { information. }\end{array}$ \\
\hline
\end{tabular}




\section{TABLE D.2.1.2-1—Low Enriched Uranium Fueled Advanced Light Water Reactor} Accident Release Parameters for Accidents (continued)

\begin{tabular}{|c|c|c|}
\hline Parameter & Value & Basis/Comment \\
\hline $\begin{array}{l}\text { Low Pressure Core Melt } \\
\text { with Loss of Long-Term } \\
\text { Coolant Makeup and } \\
\text { Containment Vessel }\end{array}$ & $\begin{array}{l}1.1 \times 10^{-8} / \mathrm{yr} \text { (Beyond } \\
\text { Extremely Unlikely) }\end{array}$ & $\begin{array}{l}\text { The frequency is taken directly from DOE/EIS- } 0161 \\
\text { (DOE } 1995 \mathrm{~b} \text { ) since it is the basis for the ALWR accident } \\
\text { information. }\end{array}$ \\
\hline $\begin{array}{l}\text { Beyond Design Basis } \\
\text { Earthquake }\end{array}$ & $\begin{array}{c}1 \times 10^{-5} / \mathrm{yr} \text { (Extremely } \\
\text { Unlikely) }\end{array}$ & $\begin{array}{l}\text { The median frequency of a safe shutdown earthquake for } \\
\text { current LWRs is } 1.0 \times 10^{-5} / \mathrm{yr} \text { per Regulatory Guide } 1.165 \\
\text { (NRC 1997). The frequency is expected to be no greater } \\
\text { for an ALWR than for current LWRs, so an event } \\
\text { frequency of } 10^{-5} \text { is used in this analysis. }\end{array}$ \\
\hline Aircraft Crash & $\begin{array}{l}1 \times 10^{-7} / \mathrm{yr} \text { (Beyond } \\
\text { Extremely Unlikely) }\end{array}$ & $\begin{array}{l}\text { The facility must be licensed by the NRC, so it will be } \\
\text { required to meet NRC Aircraft Hazards criteria (NRC } \\
2007 \mathrm{k} \text { ), which requires the frequency of exceeding } \\
\text { exposure guidelines is less than } 10^{-7} / \mathrm{yr} \text {. Therefore, an } \\
\text { event frequency of } 10^{-7} / \mathrm{yr} \text { is used in this analysis. }\end{array}$ \\
\hline
\end{tabular}

TABLE D.2.1.2-2—Low Enriched Uranium Fueled Advanced Light Water Reactor Accident Risks ${ }^{a}$ to the Offsite Population (All Sites)

\begin{tabular}{|c|c|c|c|c|c|c|}
\hline Accident (Frequency) & $\begin{array}{c}\text { Generic } \\
\text { Site } 1 \\
\end{array}$ & $\begin{array}{l}\text { Generic } \\
\text { Site } 2 \\
\end{array}$ & $\begin{array}{c}\text { Generic } \\
\text { Site } 3 \\
\end{array}$ & $\begin{array}{c}\text { Generic } \\
\text { Site } 4 \\
\end{array}$ & $\begin{array}{c}\text { Generic } \\
\text { Site } 5 \\
\end{array}$ & $\begin{array}{c}\text { Generic } \\
\text { Site } 6 \\
\end{array}$ \\
\hline $\begin{array}{l}\text { Failure of Small Primary Coolant Line } \\
\text { Outside Containment }(0.001 / \mathrm{yr})\end{array}$ & $2 \times 10^{-7}$ & $4 \times 10^{-7}$ & $2 \times 10^{-6}$ & $7 \times 10^{-7}$ & $1 \times 10^{-6}$ & $6 \times 10^{-6}$ \\
\hline Fuel Handling Accident $\left(1 \times 10^{-5} / \mathrm{yr}\right)$ & $5 \times 10^{-9}$ & $1 \times 10^{-8}$ & $6 \times 10^{-8}$ & $2 \times 10^{-8}$ & $5 \times 10^{-8}$ & $2 \times 10^{-7}$ \\
\hline $\begin{array}{l}\text { Low Pressure Core Melt with Loss of } \\
\text { Short-Term Coolant Makeup and } \\
\text { Normal Containment Leakage } \\
\left(7 \times 10^{-8} / \mathrm{yr}\right)\end{array}$ & $6 \times 10^{-9}$ & $1 \times 10^{-8}$ & $7 \times 10^{-8}$ & $3 \times 10^{-8}$ & $6 \times 10^{-8}$ & $2 \times 10^{-7}$ \\
\hline $\begin{array}{l}\text { Low Pressure Core Melt with Loss of } \\
\text { Long-Term Coolant Makeup and } \\
\text { Normal Containment Leakage } \\
\left(6.4 \times 10^{-8} / \mathrm{yr}\right)\end{array}$ & $6 \times 10^{-9}$ & $2 \times 10^{-8}$ & $7 \times 10^{-8}$ & $3 \times 10^{-8}$ & $6 \times 10^{-8}$ & $2 \times 10^{-7}$ \\
\hline $\begin{array}{l}\text { Low Pressure Core Melt with Loss of } \\
\text { Short-Term Coolant Makeup and } \\
\text { Containment Vessel }\left(1.1 \times 10^{-8} / \mathrm{yr}\right)\end{array}$ & $5 \times 10^{-8}$ & $1 \times 10^{-7}$ & $5 \times 10^{-7}$ & $2 \times 10^{-7}$ & $3 \times 10^{-7}$ & $1 \times 10^{-6}$ \\
\hline $\begin{array}{l}\text { Low Pressure Core Melt with Loss of } \\
\text { Long-Term Coolant Makeup and } \\
\text { Containment Vessel }\left(1.1 \times 10^{-8} / \mathrm{yr}\right)\end{array}$ & $6 \times 10^{-8}$ & $1 \times 10^{-7}$ & $6 \times 10^{-7}$ & $2 \times 10^{-7}$ & $4 \times 10^{-7}$ & $2 \times 10^{-6}$ \\
\hline $\begin{array}{l}\text { Beyond Design Basis Earthquake, } \\
\text { mitigated }\left(1 \times 10^{-5} / \mathrm{yr}\right)\end{array}$ & $1 \times 10^{-6}$ & $2 \times 10^{-6}$ & $1 \times 10^{-5}$ & $5 \times 10^{-6}$ & $9 \times 10^{-6}$ & $4 \times 10^{-5}$ \\
\hline $\begin{array}{l}\text { Beyond Design Basis Earthquake, } \\
\text { unmitigated }\left(1 \times 10^{-5} / \mathrm{yr}\right)\end{array}$ & 0.001 & 0.003 & 0.01 & 0.006 & 0.01 & 0.05 \\
\hline Aircraft Crash, mitigated $\left(1 \times 10^{-7} / \mathrm{yr}\right)$ & $1 \times 10^{-8}$ & $2 \times 10^{-8}$ & $1 \times 10^{-7}$ & $5 \times 10^{-8}$ & $9 \times 10^{-8}$ & $4 \times 10^{-7}$ \\
\hline Aircraft Crash, unmitigated $\left(1 \times 10^{-7} / \mathrm{yr}\right)$ & $1 \times 10^{-5}$ & $3 \times 10^{-5}$ & $1 \times 10^{-4}$ & $6 \times 10^{-5}$ & $1 \times 10^{-4}$ & $5 \times 10^{-4}$ \\
\hline
\end{tabular}

The accident with the highest risk to the offsite population, MEI, and noninvolved worker is the "Unmitigated Beyond Design Basis Earthquake" scenario. The collective risk to the offsite population for this scenario would range from 0.001 expected LCFs per year of operation in the Site-1 offsite population $(300,000$ people) to 0.05 expected LCFs per year of operation in the Site-6 offsite population $(8,200,000$ people) . 


\section{TABLE D.2.1.2-3—Low Enriched Uranium Fueled Advanced Light Water Reactor Accident} Risks ${ }^{a}$ to the Maximally Exposed Individual (All Sites)

\begin{tabular}{|c|c|c|c|c|c|c|}
\hline Accident (Frequency) & $\begin{array}{l}\text { Generic } \\
\text { Site } 1\end{array}$ & $\begin{array}{l}\text { Generic } \\
\text { Site } 2 \\
\end{array}$ & $\begin{array}{c}\text { Generic } \\
\text { Site } 3\end{array}$ & $\begin{array}{c}\text { Generic } \\
\text { Site } 4 \\
\end{array}$ & $\begin{array}{l}\text { Generic } \\
\text { Site } 5\end{array}$ & $\begin{array}{c}\text { Generic } \\
\text { Site } 6\end{array}$ \\
\hline $\begin{array}{l}\text { Failure of Small Primary Coolant Line } \\
\text { Outside Containment }(0.001 / \mathrm{yr})\end{array}$ & $2 \times 10^{-9}$ & $2 \times 10^{-9}$ & $2 \times 10^{-9}$ & $1 \times 10^{-8}$ & $1 \times 10^{-8}$ & $1 \times 10^{-8}$ \\
\hline Fuel Handling Accident $\left(1 \times 10^{-5} / \mathrm{yr}\right)$ & $6 \times 10^{-11}$ & $6 \times 10^{-11}$ & $6 \times 10^{-11}$ & $4 \times 10^{-10}$ & $4 \times 10^{-10}$ & $4 \times 10^{-10}$ \\
\hline $\begin{array}{l}\text { Low Pressure Core Melt with Loss of } \\
\text { Short-Term Coolant Makeup and } \\
\text { Normal Containment Leakage } \\
\left(7 \times 10^{-8} / \mathrm{yr}\right)\end{array}$ & $7 \times 10^{-11}$ & $7 \times 10^{-11}$ & $7 \times 10^{-11}$ & $5 \times 10^{-10}$ & $5 \times 10^{-10}$ & $5 \times 10^{-10}$ \\
\hline $\begin{array}{l}\text { Low Pressure Core Melt with Loss of } \\
\text { Long-Term Coolant Makeup and } \\
\text { Normal Containment Leakage } \\
\left(6.4 \times 10^{-8} / \mathrm{yr}\right)\end{array}$ & $7 \times 10^{-11}$ & $7 \times 10^{-11}$ & $7 \times 10^{-11}$ & $5 \times 10^{-10}$ & $5 \times 10^{-10}$ & $5 \times 10^{-10}$ \\
\hline $\begin{array}{l}\text { Low Pressure Core Melt with Loss of } \\
\text { Short-Term Coolant Makeup and } \\
\text { Containment Vessel }\left(1.1 \times 10^{-8} / \mathrm{yr}\right)\end{array}$ & $1 \times 10^{-9}$ & $1 \times 10^{-9}$ & $1 \times 10^{-9}$ & $8 \times 10^{-9}$ & $8 \times 10^{-9}$ & $8 \times 10^{-9}$ \\
\hline $\begin{array}{l}\text { Low Pressure Core Melt with Loss of } \\
\text { Long-Term Coolant Makeup and } \\
\text { Containment Vessel }\left(1.1 \times 10^{-8} / \mathrm{yr}\right)\end{array}$ & $2 \times 10^{-9}$ & $2 \times 10^{-9}$ & $2 \times 10^{-9}$ & $1 \times 10^{-8}$ & $1 \times 10^{-8}$ & $1 \times 10^{-8}$ \\
\hline $\begin{array}{l}\text { Beyond Design Basis Earthquake, } \\
\text { mitigated }\left(1 \times 10^{-5} / \mathrm{yr}\right)\end{array}$ & $7 \times 10^{-9}$ & $7 \times 10^{-9}$ & $7 \times 10^{-9}$ & $5 \times 10^{-8}$ & $5 \times 10^{-8}$ & $5 \times 10^{-8}$ \\
\hline $\begin{array}{l}\text { Beyond Design Basis Earthquake, } \\
\text { unmitigated }\left(1 \times 10^{-5} / \mathrm{yr}\right)\end{array}$ & $1 \times 10^{-5}$ & $1 \times 10^{-5}$ & $1 \times 10^{-5}$ & $1 \times 10^{-5}$ & $1 \times 10^{-5}$ & $1 \times 10^{-5}$ \\
\hline Aircraft Crash, mitigated $\left(1 \times 10^{-7} / \mathrm{yr}\right)$ & $7 \times 10^{-11}$ & $7 \times 10^{-11}$ & $7 \times 10^{-11}$ & $5 \times 10^{-10}$ & $5 \times 10^{-10}$ & $5 \times 10^{-10}$ \\
\hline Aircraft Crash, unmitigated $\left(1 \times 10^{-7} / \mathrm{yr}\right)$ & $1 \times 10^{-7}$ & $1 \times 10^{-7}$ & $1 \times 10^{-7}$ & $1 \times 10^{-7}$ & $1 \times 10^{-7}$ & $1 \times 10^{-7}$ \\
\hline
\end{tabular}

${ }^{a}$ Increased likelihood of a LCF per year of operation.

For the MEI, the same scenario, an "Unmitigated Beyond Design Basis Earthquake," would result in an increased risk of an LCF of $1 \times 10^{-5}$ per year of operation. 
TABLE D.2.1.2-4-Low Enriched Uranium Fueled Advanced Light Water Reactor Accident Risks ${ }^{a}$ to the Noninvolved Worker (All Sites)

\begin{tabular}{|c|c|c|c|c|c|c|}
\hline Accident (Frequency) & $\begin{array}{c}\text { Generic } \\
\text { Site } 1\end{array}$ & $\begin{array}{c}\text { Generic } \\
\text { Site } 2\end{array}$ & $\begin{array}{l}\text { Generic } \\
\text { Site } 3\end{array}$ & $\begin{array}{c}\text { Generic } \\
\text { Site } 4\end{array}$ & $\begin{array}{l}\text { Generic } \\
\text { Site } 5\end{array}$ & $\begin{array}{l}\text { Generic } \\
\text { Site } 6\end{array}$ \\
\hline $\begin{array}{l}\text { Failure of Small Primary Coolant Line } \\
\text { Outside Containment }(0.001 / \mathrm{yr})\end{array}$ & $2 \times 10^{-8}$ & $2 \times 10^{-8}$ & $2 \times 10^{-8}$ & $1 \times 10^{-7}$ & $1 \times 10^{-7}$ & $1 \times 10^{-7}$ \\
\hline Fuel Handling Accident $\left(1 \times 10^{-5} / \mathrm{yr}\right)$ & $6 \times 10^{-10}$ & $6 \times 10^{-10}$ & $6 \times 10^{-10}$ & $3 \times 10^{-9}$ & $3 \times 10^{-9}$ & $3 \times 10^{-9}$ \\
\hline $\begin{array}{l}\text { Low Pressure Core Melt with Loss of } \\
\text { Short-Term Coolant Makeup and } \\
\text { Normal Containment Leakage }\left(7 \times 10^{-8} / \mathrm{yr}\right)\end{array}$ & $8 \times 10^{-10}$ & $8 \times 10^{-10}$ & $8 \times 10^{-10}$ & $8 \times 10^{-9}$ & $8 \times 10^{-9}$ & $8 \times 10^{-9}$ \\
\hline $\begin{array}{l}\text { Low Pressure Core Melt with Loss of } \\
\text { Long-Term Coolant Makeup and Normal } \\
\text { Containment Leakage }\left(6.4 \times 10^{-8} / \mathrm{yr}\right)\end{array}$ & $2 \times 10^{-9}$ & $2 \times 10^{-9}$ & $2 \times 10^{-9}$ & $9 \times 10^{-9}$ & $9 \times 10^{-9}$ & $9 \times 10^{-9}$ \\
\hline $\begin{array}{l}\text { Low Pressure Core Melt with Loss of } \\
\text { Short-Term Coolant Makeup and } \\
\text { Containment Vessel }\left(1.1 \times 10^{-8} / \mathrm{yr}\right)\end{array}$ & $9 \times 10^{-9}$ & $8 \times 10^{-9}$ & $8 \times 10^{-9}$ & $1 \times 10^{-8}$ & $1 \times 10^{-8}$ & $1 \times 10^{-8}$ \\
\hline $\begin{array}{l}\text { Low Pressure Core Melt with Loss of } \\
\text { Long-Term Coolant Makeup and } \\
\text { Containment Vessel }\left(1.1 \times 10^{-8} / \mathrm{yr}\right)\end{array}$ & $1 \times 10^{-8}$ & $1 \times 10^{-8}$ & $1 \times 10^{-8}$ & $1 \times 10^{-8}$ & $1 \times 10^{-8}$ & $1 \times 10^{-8}$ \\
\hline $\begin{array}{l}\text { Beyond Design Basis Earthquake, } \\
\text { mitigated }\left(1 \times 10^{-5} / \mathrm{yr}\right)\end{array}$ & $1 \times 10^{-7}$ & $1 \times 10^{-7}$ & $1 \times 10^{-7}$ & $1 \times 10^{-6}$ & $1 \times 10^{-6}$ & $1 \times 10^{-6}$ \\
\hline $\begin{array}{l}\text { Beyond Design Basis Earthquake, } \\
\text { unmitigated }\left(1 \times 10^{-5} / \mathrm{yr}\right)\end{array}$ & $1 \times 10^{-5}$ & $1 \times 10^{-5}$ & $1 \times 10^{-5}$ & $1 \times 10^{-5}$ & $1 \times 10^{-5}$ & $1 \times 10^{-5}$ \\
\hline Aircraft Crash, mitigated $\left(1 \times 10^{-7} / \mathrm{yr}\right)$ & $1 \times 10^{-9}$ & $1 \times 10^{-9}$ & $1 \times 10^{-9}$ & $1 \times 10^{-8}$ & $1 \times 10^{-8}$ & $1 \times 10^{-8}$ \\
\hline Aircraft Crash, unmitigated $\left(1 \times 10^{-7} / \mathrm{yr}\right)$ & $1 \times 10^{-7}$ & $1 \times 10^{-7}$ & $1 \times 10^{-7}$ & $1 \times 10^{-7}$ & $1 \times 10^{-7}$ & $1 \times 10^{-7}$ \\
\hline
\end{tabular}

For the onsite noninvolved worker, this scenario, an "Unmitigated Beyond Design Basis Earthquake," would result in an increased risk of a LCF of $1 \times 10^{-5}$ per year of operation.

Tables D.2.1.2-5 through D.2.1.2-7 present the accident consequences to the offsite population, MEI, and noninvolved worker for an ALWR at the six generic sites described in Section D.1.6. 
TABLE D.2.1.2-5 - Low Enriched Uranium Fueled Advanced Light Water Reactor Accident Health Consequences (Dose in Person-Rem/Increased Number of Latent Cancer Fatalities) ${ }^{a}$ to the Offsite Population (All Sites)

\begin{tabular}{|c|c|c|c|c|c|c|}
\hline Accident (Frequency) & $\begin{array}{c}\text { Generic } \\
\text { Site } 1 \\
\end{array}$ & $\begin{array}{c}\text { Generic } \\
\text { Site 2 } \\
\end{array}$ & $\begin{array}{c}\text { Generic } \\
\text { Site } 3 \\
\end{array}$ & $\begin{array}{c}\text { Generic } \\
\text { Site } 4 \\
\end{array}$ & $\begin{array}{c}\text { Generic } \\
\text { Site } 5 \\
\end{array}$ & $\begin{array}{c}\text { Generic } \\
\text { Site } 6 \\
\end{array}$ \\
\hline $\begin{array}{l}\text { Failure of Small Primary Coolant } \\
\text { Line Outside Containment } \\
(0.001 / \mathrm{yr})\end{array}$ & $\begin{array}{c}0.3 / \\
2 \times 10^{-4}\end{array}$ & $\begin{array}{c}0.6 / \\
4 \times 10^{-4}\end{array}$ & $3 / 0.002$ & $1 / 7 \times 10^{-4}$ & $2 / 0.001$ & $9 / 0.006$ \\
\hline Fuel Handling Accident ( $\left.1 \times 10^{-5} / \mathrm{yr}\right)$ & $\begin{array}{c}0.8 / \\
5 \times 10^{-4}\end{array}$ & $2 / 0.001$ & $10 / 0.006$ & $4 / 0.002$ & $8 / 0.005$ & $30 / 0.02$ \\
\hline $\begin{array}{l}\text { Low Pressure Core Melt with Loss } \\
\text { of Short-Term Coolant Makeup and } \\
\text { Normal Containment Leakage } \\
\left(7 \times 10^{-8} / \mathrm{yr}\right)\end{array}$ & $100 / 0.09$ & $300 / 0.2$ & $2,000 / 1$ & $700 / 0.4$ & $\begin{array}{c}1,000 / \\
0.8\end{array}$ & $6,000 / 3$ \\
\hline $\begin{array}{l}\text { Low Pressure Core Melt with Loss } \\
\text { of Long-Term Coolant Makeup and } \\
\text { Normal Containment Leakage } \\
\left(6.4 \times 10^{-8} / \mathrm{yr}\right)\end{array}$ & $200 / 0.1$ & $400 / 0.2$ & $2,000 / 1$ & $800 / 0.5$ & $\begin{array}{c}2,000 / \\
0.9\end{array}$ & $6,000 / 4$ \\
\hline $\begin{array}{l}\text { Low Pressure Core Melt with Loss } \\
\text { of Short-Term Coolant Makeup and } \\
\text { Containment Vented }\left(1.1 \times 10^{-8} / \mathrm{yr}\right)\end{array}$ & $7,000 / 4$ & $\begin{array}{c}2 \times 10^{4} / \\
10\end{array}$ & $\begin{array}{c}8 \times 10^{4} / \\
50\end{array}$ & $\begin{array}{c}3 \times 10^{4} / \\
20\end{array}$ & $\begin{array}{c}5 \times 10^{4} / \\
30\end{array}$ & $\begin{array}{c}2 \times 10^{5} / \\
100\end{array}$ \\
\hline $\begin{array}{l}\text { Low Pressure Core Melt with Loss } \\
\text { of Long-Term Coolant Makeup and } \\
\text { Containment Vented }\left(1.1 \times 10^{-8} / \mathrm{yr}\right)\end{array}$ & $9,000 / 5$ & $\begin{array}{c}2 \times 10^{4} / \\
10\end{array}$ & $\begin{array}{c}1 \times 10^{5} / \\
60\end{array}$ & $\begin{array}{c}3 \times 10^{4} / \\
20\end{array}$ & $\begin{array}{c}6 \times 10^{4} / \\
40\end{array}$ & $\begin{array}{c}3 \times 10^{5} / \\
200\end{array}$ \\
\hline $\begin{array}{l}\text { Beyond Design Basis Earthquake, } \\
\text { mitigated }\left(1 \times 10^{-5} / \mathrm{yr}\right)\end{array}$ & $200 / 0.1$ & $400 / 0.2$ & $2,000 / 1$ & $800 / 0.5$ & $\begin{array}{c}2,000 / \\
0.9\end{array}$ & $7,000 / 4$ \\
\hline $\begin{array}{l}\text { Beyond Design Basis Earthquake, } \\
\text { unmitigated }\left(1 \times 10^{-5} / \mathrm{yr}\right)\end{array}$ & $\begin{array}{c}2 \times 10^{5} / \\
100\end{array}$ & $\begin{array}{c}5 \times 10^{5} / \\
300\end{array}$ & $\begin{array}{c}2 \times 10^{6} / \\
1,000\end{array}$ & $\begin{array}{c}1 \times 10^{6} / \\
600\end{array}$ & $\begin{array}{c}2 \times 10^{6} / \\
1,000\end{array}$ & $\begin{array}{c}8 \times 10^{6} / \\
5,000\end{array}$ \\
\hline Aircraft Crash, mitigated $\left(1 \times 10^{-7} / \mathrm{yr}\right)$ & $200 / 0.1$ & $400 / 0.2$ & $2,000 / 1$ & $800 / 0.5$ & $\begin{array}{c}2,000 / \\
0.9\end{array}$ & $7,000 / 4$ \\
\hline $\begin{array}{l}\text { Aircraft Crash, unmitigated } \\
\left(1 \times 10^{-7} / \mathrm{yr}\right)\end{array}$ & $\begin{array}{c}2 \times 10^{5} / \\
100\end{array}$ & $\begin{array}{c}5 \times 10^{5} / \\
300\end{array}$ & $\begin{array}{c}2 \times 10^{6} / \\
1,000\end{array}$ & $\begin{array}{c}1 \times 10^{6} / \\
600\end{array}$ & $\begin{array}{c}2 \times 10^{6} / \\
1,000\end{array}$ & $\begin{array}{c}8 \times 10^{6} / \\
5,000\end{array}$ \\
\hline
\end{tabular}

The accidents with the highest consequence to the offsite populations would be the "Unmitigated Beyond Design Basis Earthquake" and "Unmitigated Aircraft Crash." The collective population doses would result in 100 to 5,000 additional LCFs in the surrounding population for these Extremely Unlikely and Beyond Extremely Unlikely accidents. 


\begin{tabular}{|c|c|c|c|c|c|c|}
\hline Accident (Frequency) & $\begin{array}{l}\text { Generic } \\
\text { Site } 1\end{array}$ & $\begin{array}{l}\text { Generic } \\
\text { Site } 2\end{array}$ & $\begin{array}{l}\text { Generic } \\
\text { Site } 3\end{array}$ & $\begin{array}{l}\text { Generic } \\
\text { Site } 4\end{array}$ & $\begin{array}{l}\text { Generic } \\
\text { Site } 5\end{array}$ & $\begin{array}{l}\text { Generic } \\
\text { Site } 6\end{array}$ \\
\hline $\begin{array}{l}\text { Failure of Small Primary Coolant } \\
\text { Line Outside Containment } \\
(0.001 / \mathrm{yr})\end{array}$ & $\begin{array}{l}0.003 / \\
2 \times 10^{-6}\end{array}$ & $\begin{array}{l}0.003 / \\
2 \times 10^{-6}\end{array}$ & $\begin{array}{l}0.003 / \\
2 \times 10^{-6}\end{array}$ & $\begin{array}{l}0.02 / \\
1 \times 10^{-5}\end{array}$ & $\begin{array}{l}0.02 / \\
1 \times 10^{-5}\end{array}$ & $\begin{array}{l}0.02 / \\
1 \times 10^{-5}\end{array}$ \\
\hline Fuel Handling Accident $\left(1 \times 10^{-5} / \mathrm{yr}\right)$ & $\begin{array}{l}0.009 / \\
6 \times 10^{-6}\end{array}$ & $\begin{array}{l}0.009 / \\
6 \times 10^{-6}\end{array}$ & $\begin{array}{l}0.009 / \\
6 \times 10^{-6}\end{array}$ & $\begin{array}{l}0.07 / \\
4 \times 10^{-5}\end{array}$ & $\begin{array}{l}0.07 / \\
4 \times 10^{-5}\end{array}$ & $\begin{array}{l}0.07 / \\
4 \times 10^{-5}\end{array}$ \\
\hline $\begin{array}{l}\text { Low Pressure Core Melt with Loss } \\
\text { of Short-Term Coolant Makeup and } \\
\text { Normal Containment Leakage } \\
\left(7 \times 10^{-8} / \mathrm{yr}\right)\end{array}$ & $2 / 0.001$ & $2 / 0.001$ & $2 / 0.001$ & $10 / 0.007$ & $10 / 0.007$ & $10 / 0.007$ \\
\hline $\begin{array}{l}\text { Low Pressure Core Melt with Loss } \\
\text { of Long-Term Coolant Makeup and } \\
\text { Normal Containment Leakage } \\
\left(6.4 \times 10^{-8} / \mathrm{yr}\right)\end{array}$ & $2 / 0.001$ & $2 / 0.001$ & $2 / 0.001$ & $10 / 0.008$ & $10 / 0.008$ & $10 / 0.008$ \\
\hline $\begin{array}{l}\text { Low Pressure Core Melt with Loss } \\
\text { of Short-Term Coolant Makeup and } \\
\text { Containment Vented }\left(1.1 \times 10^{-8} / \mathrm{yr}\right)\end{array}$ & $100 / 0.1$ & $100 / 0.1$ & $100 / 0.1$ & $600 / 0.7$ & $600 / 0.7$ & $600 / 0.7$ \\
\hline $\begin{array}{l}\text { Low Pressure Core Melt with Loss } \\
\text { of Long-Term Coolant Makeup and } \\
\text { Containment Vented }\left(1.1 \times 10^{-8} / \mathrm{yr}\right)\end{array}$ & $100 / 0.1$ & $100 / 0.1$ & $100 / 0.1$ & $800 / 0.9$ & $800 / 0.9$ & $800 / 0.9$ \\
\hline $\begin{array}{l}\text { Beyond Design Basis Earthquake, } \\
\text { mitigated }\left(1 \times 10^{-5} / \mathrm{yr}\right)\end{array}$ & $1 / 7 \times 10^{-4}$ & $1 / 7 \times 10^{-4}$ & $1 / 7 \times 10^{-4}$ & $9 / 0.005$ & $9 / 0.005$ & $9 / 0.005$ \\
\hline $\begin{array}{l}\text { Beyond Design Basis Earthquake, } \\
\text { unmitigated }\left(1 \times 10^{-5} / \mathrm{yr}\right)\end{array}$ & $3,000 / 1$ & $3,000 / 1$ & $3,000 / 1$ & $2 \times 10^{4} / 1$ & $2 \times 10^{4} / 1$ & $2 \times 10^{4} / 1$ \\
\hline Aircraft Crash, mitigated $\left(1 \times 10^{-7} / \mathrm{yr}\right)$ & $1 / 7 \times 10^{-4}$ & $1 / 7 \times 10^{-4}$ & $1 / 7 \times 10^{-4}$ & $9 / 0.005$ & $9 / 0.005$ & $9 / 0.005$ \\
\hline $\begin{array}{l}\text { Aircraft Crash, unmitigated } \\
\left(1 \times 10^{-7} / \mathrm{yr}\right)\end{array}$ & $3,000 / 1$ & $3,000 / 1$ & $3,000 / 1$ & $2 \times 10^{4} / 1$ & $2 \times 10^{4} / 1$ & $2 \times 10^{4} / 1$ \\
\hline
\end{tabular}

$\frac{}{a}$ The dose in rem is reported before the slash and the increased likelihood of a LCF is presented after the slash.

For the MEI, the "Unmitigated Beyond Design Basis Earthquake" and "Unmitigated Aircraft Crash" scenarios would be the accidents with the highest consequences. These scenarios would likely result in prompt radiation fatality. 


\begin{tabular}{|c|c|c|c|c|c|c|}
\hline Accident (Frequency) & $\begin{array}{l}\text { Generic } \\
\text { Site } 1\end{array}$ & $\begin{array}{l}\text { Generic } \\
\text { Site } 2\end{array}$ & $\begin{array}{l}\text { Generic } \\
\text { Site } 3\end{array}$ & $\begin{array}{l}\text { Generic } \\
\text { Site } 4\end{array}$ & $\begin{array}{l}\text { Generic } \\
\text { Site } 5\end{array}$ & $\begin{array}{l}\text { Generic } \\
\text { Site } 6\end{array}$ \\
\hline Failure of Small Primary Coolant & $0.03 /$ & $0.03 /$ & $0.03 /$ & $0.2 /$ & $0.2 /$ & $0.2 /$ \\
\hline Line Outside Containment $(0.001 / \mathrm{yr})$ & $2 \times 10^{-5}$ & $2 \times 10^{-5}$ & $2 \times 10^{-5}$ & $1 \times 10^{-4}$ & $1 \times 10^{-4}$ & $1 \times 10^{-4}$ \\
\hline Fuel Handling Accident ( $\left.1 \times 10^{-5} / \mathrm{yr}\right)$ & $\begin{array}{c}0.1 / \\
6 \times 10^{-5}\end{array}$ & $\begin{array}{c}0.1 / \\
6 \times 10^{-5}\end{array}$ & $\begin{array}{c}0.1 / \\
6 \times 10^{-5}\end{array}$ & $\begin{array}{c}0.6 / \\
3 \times 10^{-4}\end{array}$ & $\begin{array}{c}0.6 / \\
3 \times 10^{-4}\end{array}$ & $\begin{array}{c}0.6 / \\
3 \times 10^{-4}\end{array}$ \\
\hline $\begin{array}{l}\text { Low Pressure Core Melt with Loss } \\
\text { of Short-Term Coolant Makeup and } \\
\text { Normal Containment Leakage } \\
\left(7 \times 10^{-8} / \mathrm{yr}\right)\end{array}$ & $20 / 0.01$ & $20 / 0.01$ & $20 / 0.01$ & $100 / 0.1$ & $100 / 0.1$ & $100 / 0.1$ \\
\hline $\begin{array}{l}\text { Low Pressure Core Melt with Loss } \\
\text { of Long-Term Coolant Makeup and } \\
\text { Normal Containment Leakage } \\
\left(6.4 \times 10^{-8} / \mathrm{yr}\right)\end{array}$ & $20 / 0.03$ & $20 / 0.03$ & $20 / 0.03$ & $100 / 0.1$ & $100 / 0.1$ & $100 / 0.1$ \\
\hline $\begin{array}{l}\text { Low Pressure Core Melt with Loss } \\
\text { of Short-Term Coolant Makeup and } \\
\text { Containment Vented }\left(1.1 \times 10^{-8} / \mathrm{yr}\right)\end{array}$ & $700 / 0.8$ & $700 / 0.8$ & $700 / 0.8$ & $3,000 / 1$ & $3,000 / 1$ & $3,000 / 1$ \\
\hline $\begin{array}{l}\text { Low Pressure Core Melt with Loss } \\
\text { of Long-Term Coolant Makeup and } \\
\text { Containment Vented }\left(1.1 \times 10^{-8} / \mathrm{yr}\right)\end{array}$ & $900 / 1$ & $900 / 1$ & $900 / 1$ & $4,000 / 1$ & $4,000 / 1$ & $4,000 / 1$ \\
\hline $\begin{array}{l}\text { Beyond Design Basis Earthquake, } \\
\text { mitigated }\left(1 \times 10^{-5} / \mathrm{yr}\right)\end{array}$ & $20 / 0.01$ & $20 / 0.01$ & $20 / 0.01$ & $100 / 0.1$ & $100 / 0.1$ & $100 / 0.1$ \\
\hline $\begin{array}{l}\text { Beyond Design Basis Earthquake, } \\
\text { unmitigated }\left(1 \times 10^{-5} / \mathrm{yr}\right)\end{array}$ & $3 \times 10^{4} / 1$ & $3 \times 10^{4} / 1$ & $3 \times 10^{4} / 1$ & $2 \times 10^{5} / 1$ & $2 \times 10^{5} / 1$ & $2 \times 10^{5} / 1$ \\
\hline Aircraft Crash, mitigated $\left(1 \times 10^{-7} / \mathrm{yr}\right)$ & $20 / 0.01$ & $20 / 0.01$ & $20 / 0.01$ & $100 / 0.1$ & $100 / 0.1$ & $100 / 0.1$ \\
\hline $\begin{array}{l}\text { Aircraft Crash, unmitigated } \\
\left(1 \times 10^{-7} / \mathrm{yr}\right)\end{array}$ & $3 \times 10^{4} / 1$ & $3 \times 10^{4} / 1$ & $3 \times 10^{4} / 1$ & $2 \times 10^{5} / 1$ & $2 \times 10^{5} / 1$ & $2 \times 10^{5} / 1$ \\
\hline
\end{tabular}

${ }^{a}$ The dose in rem is reported before the slash and the increased likelihood of a LCF is presented after the slash.

For the noninvolved worker, the "Low Pressure Core Melt with Loss of Short-Term Coolant Makeup and Containment Vented," "Low Pressure Core Melt with Loss of Long-Term Coolant Makeup and Containment Vented," "Unmitigated Design Basis Earthquake," and "Unmitigated Aircraft Crash" scenarios would be the accidents with the highest consequences, and would likely result in prompt radiation fatality.

\section{D.2.2 Fast Reactor Recycle Alternative}

This section presents the impacts of potential accident scenarios associated with facilities under the Fast Reactor Recycle Alternative, which is described in Section 2.3 of Chapter 2. This section is further sub-divided into the impacts of postulated accidents at two facilities: the nuclear fuel recycling center, and an advanced recycling reactor. The nuclear fuel recycling center includes LWR and fast reactor fuel separations and fast reactor fuel fabrication.

\section{D.2.2.1 Nuclear Fuel Recycling Center}

The general methodology for the nuclear fuel recycling center accident identification, selection, and analysis process is described in Section D.1. The alternative throughputs for the nuclear fuel recycling center are 100 metric tons of heavy metal per year (MTHM/yr) and $800 \mathrm{MTHM} / \mathrm{yr}$. 
Consequences are reported for the $800 \mathrm{MTHM} / \mathrm{yr}$ baseline, but a conversion factor (i.e., 30 percent) is provided for a $100 \mathrm{MTHM} / \mathrm{yr}$ capacity based on the daily throughput ${ }^{1}$. This section provides a summary of the nuclear fuel recycling center accident analysis presented in Topical Report, Nuclear Fuel Recycling Center Accident Analyses as Part of the Global Nuclear Energy Partnership Programmatic Environmental Impact Statement (Tetra Tech 2008b).

A variety of non-reactor nuclear facilities will be associated with this alternative, including LWR fuel separations, recycled fuel fabrication, and fast reactor fuel separations facilities. The Topical Report, Advanced Fuel Cycle Facility Accident Analyses as Part of the Global Nuclear Energy Partnership Programmatic Environmental Impact Statement (Tetra Tech 2008a) accident analysis included consideration of the full scope of fuel reprocessing and fuel fabrication activities and concluded that the separations activities envelope the consequences of the other activities. Based on the Advanced Fuel Cycle Facility (AFCF) evaluation (Tetra Tech 2008a), evaluations in other NEPA documents (see relevant NEPA documents list in Section D.2.2.1.1), and consideration of the fuel recycling activities involved, this accident analysis focuses only on the separation activities. Separations activities are considered to have the potential for a greater impact from an accident perspective than the fuel fabrication and waste management activities because of the inventories, material forms, and hazards of the processes involved. Separations activities envelope the other activities because:

- Fuel fabrication and waste management activities include only a subset of the radionuclide inventory that was partitioned in the separations process. Therefore, the separations inventory envelopes the inventory of the other activities.

- The separations technologies have spent nuclear fuel (SNF) in highly dispersible forms (e.g., fine powders and liquids) that are at least as vulnerable as the forms involved in fuel fabrication and waste management.

- The separations technologies involve chemical, thermal, and electrical processes that are comparable to or more challenging in terms of their potential to initiate accidents than the other activities.

There are differences between the alternative separations technologies (e.g., aqueous or electrochemical separations). For example, the risks associated with electrochemical separations differ from those of aqueous separations in a number of respects. This appendix only analyzes aqueous separations and not electrochemical separations because:

- Aqueous separation is more complex in terms of the number of process vessels and process steps involved, so there are more potential accident initiators.

- Aqueous separation includes use of flammable organics capable of explosions and fires, so there is more potential for severe accidents.

- The material at risk is expected to be greater for aqueous separations so the potential impacts are greater.

- The release fractions for a bounding aqueous explosion and fire are greater than for a bounding electrochemical melter eruption (Tetra Tech 2008a).

${ }^{1}$ A $100 \mathrm{MTHM} / \mathrm{yr}$ facility is expected to operate 100 days per year and an $800 \mathrm{MTHM} / \mathrm{yr}$ facility is expected to operate 240 days per year, so the daily inventory for the $100 \mathrm{MTHM} / \mathrm{yr}$ facility is roughly 30 percent of the daily inventory for the $800 \mathrm{MTHM} / \mathrm{yr}$ facility. (Tetra Tech 2008b) 
- $\quad$ Neither aqueous nor electrochemical separations accidents are expected to fail all HEPA filtration, so they will have comparable release points and mitigation.

The impacts of a bounding aqueous separations explosion and fire are more than an order of magnitude greater than a bounding electrochemical melter eruption and both events are in the same frequency category (Tetra Tech 2008a). Other separation technologies are also expected to be enveloped by the aqueous separations impacts.

There are also different process steps that may be used within a technology, and different equipment that may be used for a given process step. For example, there are different head-end processes needed to convert the fuel to a form suitable for the separations technology being used. An aqueous separations process for LWR fuel could utilize either a chop-leach process that leaves the fuel in relatively large pieces prior to dissolution or it could utilize the voloxidation process that produces a very fine powder prior to dissolution. In addition to head-end differences, there are also equipment variations that could affect the relative accident risk posed by the various separations technologies. For example, aqueous separations could be performed with extraction columns per past practice or it could utilize the much more compact centrifugal contactors.

Rather than analyze many variations in separations technology, process steps, and equipment selection, this analysis is based on a separations design that is encompassing of all options being considered. The aqueous separations evaluation is based on consideration of the voloxidation step that produces a very fine powder, use of extraction columns, and vessels each sized for a full day of throughput. These design assumptions are considered enveloping for not only electrochemical separation, but also for variations in aqueous separation implementation. Therefore, the accident analysis results in this section are enveloping for any separations activities that may be used for any of the closed cycle alternatives and options being considered.

\section{D.2.2.1.1 Accident Selection Process}

The unique information sources, facility functions, accident phenomena types, and scope of alternatives for the nuclear fuel recycling center accident analysis are addressed in the following subsections.

\section{Review of Available Information}

The following information sources were used in the identification of candidate accidents.

Nuclear fuel recycling center design and operations information-The following documents provided design information for the accident analysis:

- $\quad$ The Engineering Alternative Studies for Separations: NEPA Data Input Report (WSRC 2008a), referred to hereafter as EAS NEPA Data Input Report 
Relevant NEPA documents-The following NEPA documents and documents that support NEPA documents are considered especially relevant to the proposed action and were used as the basis for identifying candidate scenarios:

- $\quad$ Environmental Impact Statement for the Treatment and Management of SodiumBonded Spent Nuclear Fuel, DOE/EIS-0306, August 2000 (DOE 2000e), referred to hereafter as the Sodium-Bonded SNF EIS

- Environmental Assessment: Fuel Processing Restoration at the Idaho National Engineering Laboratory, DOE/EA-0306, August 1987 (DOE 1987), referred to hereafter as the FPR EA

- Idaho High-Level Waste and Facilities Disposition: Environmental Impact Statement DOE/EIS-0287; September 2002 (DOE 2002e), referred to hereafter as the IHLW EIS

- Environmental and Other Evaluations of Alternatives for Siting, Construction, and Operating New Production Reactor Capacity, DOE/NP-0014, September 1992 (DOE 1992c), referred to hereafter as the NPR Rpt.

- Accident Assessments for Idaho National Engineering Laboratory Facilities, DOE/ID-10471, March 1995 (DOE 1995a)

- Savannah River Site Spent Nuclear Fuel Management Environmental Impact Statement, DOE/EIS-0279, March 2000 (DOE 2000f), referred to hereafter as the SRS SNF EIS

\section{Scope of Activities}

The primary facility functions would include materials receipt, storage, and shipping; aqueous separations, including head-end preparation and material conditioning; electrochemical separations; and waste treatment and storage. While all primary functions are addressed in existing NEPA documents and documents that support NEPA documents, a more detailed review was performed to determine if there are process differences that might warrant further evaluation. The voloxidation, partial separations, and equipment differences addressed for the AFCF (Tetra Tech 2008a) also apply for the nuclear fuel recycling center. The following paragraphs address the process differences that might affect the selection of accidents.

Voloxidation-The nuclear fuel recycling center would include a voloxidation step not explicitly addressed in the other NEPA documents. The voloxidation step converts the $\mathrm{UO}_{2}$ pellets to a $\mathrm{U}_{3} \mathrm{O}_{8}$ powder that is considerably more dispersible. Fires and explosions are already considered for the head-end process, so voloxidation does not result in a new accident type, but it may affect the consequences. The evaluation of consequences takes into account the potential dispersibility of the voloxidation product.

Partial separations-The nuclear fuel recycling center aqueous processing could include multiple partial separations steps not specifically addressed in the other NEPA documents. These partial separations processes include Uranium Extraction (UREX) process for uranium and technetium extraction, Chlorinated Cobalt Dicarbollide-Polyethlene Glycol (CCD-PEG) process for cesium and strontium extraction, Transuranic Extraction (TRUEX) process for transuranic and lanthanide extraction, and Trivalent Actinide Lanthanide Separations by 
Phosphorous-reagent Extraction for Aqueous Complexes (TALSPEAK) process for partitioning of fission products from transuranics. No new accidents have been identified as a result of these process differences, though the composition of the material at risk would be affected. Since all separations steps after the initial step involve a subset of the original inventory, it is conservative to base analyses on the full SNF inventory prior to separations.

Equipment differences-The nuclear fuel separations center aqueous separations process is expected to use centrifugal contactors rather than extraction columns, which were the basis in the other NEPA documents. Centrifuges are smaller and contain a smaller volume of fuel than the extraction columns, so the consequences of a given accident may be lower. This analysis is conservatively based on the overall volume of dissolved fuel in the extraction system in order to cover either equipment option and is not necessarily based on the volume in a contactor.

Segregation of waste streams-Several of the relevant NEPA documents address processing and storage of high-level radioactive waste (HLW) from reprocessing activities and show that waste management activity consequences and risks are enveloped by separations activities (e.g., the Sodium-Bonded SNF EIS [DOE 2000e] and the SRS SNF EIS [DOE 2000f]). Unlike most of the facilities addressed in these relevant NEPA documents, the nuclear fuel recycling center may separate some or all of the waste forms (e.g., the technetium, cesium/strontium, and fission product/lanthanide wastes, see Section 2.3.6 of the EAS NEPA Data Input Report [WSRC 2008a]). This potential segregated storage of waste does not invalidate the conclusion that separations activities envelope and may even enhance this conclusion because the segregated waste streams are a subset of the consolidated waste stream.

Onsite waste storage-Onsite storage of some segregated waste streams is also a part of the nuclear fuel recycling facility scope. Cesium/strontium storage is a passive activity with mineralized and containerized waste form. The design of these waste forms and their storage has not been decided, but there are design options, such as the use of high integrity containers and an underground storage facility design, that could be used to provide the level of protection desired. Therefore, cesium/strontium storage is expected to pose minimal additional long-term risk and is not specifically analyzed.

\section{D.2.2.1.2 Accidents Selected for Analysis}

The methodology described in the previous section resulted in the selection of the accidents summarized in Table D.2.2.1.2-1 for analysis. The accidents shown are applicable to all sites although some reflect unique site-specific conditions. The event frequency categories are based on frequencies for events in NEPA documents for similar facilities (Tetra Tech 2008b). The frequency for the "Beyond Design Basis Earthquake" and "Aircraft Crash" are based on the values used for the reactor facilities since a nuclear fuel recycling center is expected to be evaluated using similar criteria. Accidents for electrochemical separations were considered but were not selected because they are bounded by the aqueous separations (Tetra Tech 2008a). 
TABLE D.2.2.1.2-1-Nuclear Fuel Recycling Center Accidents Selected for Analysis

\begin{tabular}{|c|c|c|c|c|}
\hline $\begin{array}{l}\text { Accident } \\
\text { Title }\end{array}$ & $\begin{array}{l}\text { Frequency } \\
\text { Category }\end{array}$ & $\begin{array}{l}\text { Accident } \\
\text { Initiator }\end{array}$ & $\begin{array}{c}\text { Accident } \\
\text { Phenomena }\end{array}$ & Comments \\
\hline \multicolumn{5}{|c|}{ Radiological Accidents } \\
\hline $\begin{array}{l}\text { Fuel Handling } \\
\text { Accident }\end{array}$ & $\begin{array}{c}\text { Anticipated } \\
(0.03 / \mathrm{yr} \text { is used } \\
\text { for this category })\end{array}$ & $\begin{array}{c}\text { Internal } \\
\text { Natural } \\
\text { phenomena }\end{array}$ & Spill & $\begin{array}{c}\text { Fuel or cask handling accidents have the } \\
\text { potential to substantially impact workers, } \\
\text { as addressed in several EISs. }\end{array}$ \\
\hline $\begin{array}{l}\text { Explosion and } \\
\text { Fire in } \\
\text { Aqueous } \\
\text { Separations }\end{array}$ & $\begin{array}{l}\text { Unlikely }(0.001 / \mathrm{yr} \\
\text { is used for this } \\
\text { category) }\end{array}$ & Internal & Explosion & $\begin{array}{l}\text { This is one of the bounding scenarios in } \\
\text { aqueous processing EISs. }\end{array}$ \\
\hline $\begin{array}{l}\text { Beyond } \\
\text { Design Basis } \\
\text { Earthquake }\end{array}$ & $\begin{array}{l}\text { Extremely } \\
\text { Unlikely } \\
\left(1 \times 10^{-5} / \mathrm{yr}\right)\end{array}$ & $\begin{array}{c}\text { Natural } \\
\text { phenomena }\end{array}$ & Earthquake & $\begin{array}{l}\text { This is one of the bounding scenarios in } \\
\text { the EISs reviewed. The magnitude of the } \\
\text { earthquake is site specific and the } \\
\text { capacity of existing facilities may differ } \\
\text { from the capacity of new facilities. }\end{array}$ \\
\hline $\begin{array}{l}\text { Nuclear } \\
\text { Criticality }\end{array}$ & $\begin{array}{l}\text { Extremely } \\
\text { Unlikely } \\
\left(1 \times 10^{-5} / \mathrm{yr} \text { is used }\right. \\
\text { for this category })\end{array}$ & $\begin{array}{l}\text { Internal } \\
\text { Natural } \\
\text { phenomena }\end{array}$ & Criticality & $\begin{array}{l}\text { A nuclear criticality has the potential for } \\
\text { bounding worker impacts. }\end{array}$ \\
\hline Aircraft Crash & $\begin{array}{l}\text { Beyond Extremely } \\
\text { Unlikely } \\
\left(1 \times 10^{-7} / \mathrm{yr}\right)\end{array}$ & External & $\begin{array}{l}\text { Fire } \\
\text { Spill }\end{array}$ & $\begin{array}{l}\text { This is one of the bounding scenarios in } \\
\text { several EISs reviewed. }\end{array}$ \\
\hline $\begin{array}{l}\text { Nitric Acid } \\
\text { Release from } \\
\text { Bulk Storage }\end{array}$ & $\begin{array}{l}\text { Unlikely }(0.001 / \mathrm{yr} \\
\text { is used for this } \\
\text { category) }\end{array}$ & $\begin{array}{l}\text { Internal } \\
\text { External } \\
\text { Natural } \\
\text { phenomena }\end{array}$ & Spill & $\begin{array}{l}\text { This is one of the bounding chemical } \\
\text { releases in at least one of the EISs } \\
\text { reviewed and bounded other acid } \\
\text { releases. }\end{array}$ \\
\hline
\end{tabular}

A textual description of each accident providing additional details and alternative-specific variations where appropriate follows.

\section{Fuel Handling Accident}

A fuel assembly or cask drop event can result in cladding failure and release of radioactive material from SNF. The SNF assembly or cask drop event can be the result of internal initiators such as operator error or equipment failure, or an external initiator such as an earthquake. In populated areas, SNF assemblies are only handled in robust shielded containers such as transportation casks, so an event involving a bare assembly in an occupied area is not credible. Transportation casks are designed to withstand the likely drop events and not expected to be damaged by a facility drop event. While there are many scenarios that cause minor damage to one or more fuel assemblies, the event analyzed is the drop of a fuel assembly during handling operations because the assembly may experience the maximum damage and release.

The "Fuel Handling Accident" is a $10 \mathrm{ft}(3 \mathrm{~m})$ free-fall drop of a single assembly. No credit is taken for the confinement of the fuel cladding, though even failed cladding provides considerable confinement. Credit is only taken for one stage of HEPA filtration even though there would be at least two stages. Inclusion of a second stage of HEPA filtration would reduce particulate releases by about two orders of magnitude (LANL 1986).

Given that there would be potentially tens of thousands of fuel handling operations in a nuclear fuel recycling center each year, the accident frequency category is estimated to be anticipated. 
The noninvolved worker and offsite individuals could be exposed to airborne radioactive material released after partial filtration through the ventilation system. Since fuel handling operations are performed in shielded cells with ventilation systems, facility workers would not be exposed to excess direct radiation doses or radioactive material. The release parameters used to analyze the consequences of this accident, along with the basis for using these values, are presented in Table D.2.2.1.2-2.

TABLE D.2.2.1.2-2-Nuclear Fuel Recycling Center Release Parameters for the Fuel Handling Accident

\begin{tabular}{|c|c|c|}
\hline Parameter & Value & Basis/Comment \\
\hline $\begin{array}{l}\text { Release } \\
\text { Point }\end{array}$ & Ground level & $\begin{array}{c}\text { The event is conservatively assumed to occur with the doors open, } \\
\text { which maximizes nearby impacts. }\end{array}$ \\
\hline Duration & 1 minute & $\begin{array}{l}\text { A short duration release is conservatively assumed to ensure all } \\
\text { receptors are present for the entire release. }\end{array}$ \\
\hline $\begin{array}{l}\text { Material at } \\
\text { risk }\end{array}$ & $\begin{array}{l}1 \text { LWR assembly (EAS } \\
\text { NEPA Data Input Report } \\
\text { Appendix A-2 } \\
\text { [WSRC 2008a]), } \\
\text { Ci/MTHM column } \\
\text { adjusted to one } \\
\text { assembly) }\end{array}$ & $\begin{array}{l}\text { The inventory values in Appendix A-2 of the EAS NEPA Data Input } \\
\text { Report (WSRC 2008a) are provided per MTHM, which are then } \\
\text { converted to assembly inventory basis by multiplying by } 0.5 \text { MTIHM } \\
\text { per PWR assembly (WGI 2008a). }\end{array}$ \\
\hline $\begin{array}{l}\text { Damage } \\
\text { ratio }\end{array}$ & 1 & It is conservative to assume the entire material at risk is involved. \\
\hline $\begin{array}{l}\text { Airborne } \\
\text { release } \\
\text { fraction }\end{array}$ & $\begin{array}{c}1 \text { volatiles } \\
7 \times 10^{-5} \text { particulates }\end{array}$ & $\begin{array}{l}\text { All volatiles in the cladding gap could be released from failed fuel. } \\
\text { The airborne release fraction times the respirable fraction for } \\
\text { particulates is based on Equation (4-1) of DOE-HDBK-3010-94 } \\
\text { (DOE 2000i) using a 10-ft ( } 3 \mathrm{~m} \text { ) drop height. The energy absorbing } \\
\text { effects of the assembly structure and the partial confining effects of } \\
\text { damaged cladding are not included in the analysis. }\end{array}$ \\
\hline $\begin{array}{l}\text { Respirable } \\
\text { fraction }\end{array}$ & $\begin{array}{l}\text { included in the airborne } \\
\text { release fraction }\end{array}$ & This factor is included with the airborne release fraction value above. \\
\hline $\begin{array}{l}\text { Leak path } \\
\text { factor }\end{array}$ & $\begin{array}{c}1 \text { gases } \\
0.001 \text { particulates }\end{array}$ & $\begin{array}{c}\text { This value is based on item (a) for the } 1^{\text {st }} \text { stage of HEPA filtration in } \\
\text { Table IX of LA-10294-MS (LANL 1986). }\end{array}$ \\
\hline
\end{tabular}

\section{Explosion and Fire in Aqueous Separations}

A red oil explosion can occur when an organic solution, typically tri-n-butyl phosphate, and its diluents come in contact with concentrated nitric acid at a concentration greater than 10 moles/liter and a temperature above $266^{\circ} \mathrm{F}\left(130^{\circ} \mathrm{C}\right)$ without sufficient venting. Red oil is relatively stable below $266^{\circ} \mathrm{F}\left(130^{\circ} \mathrm{C}\right)$, but it can decompose explosively when its temperature is raised above $266^{\circ} \mathrm{F}\left(130^{\circ} \mathrm{C}\right)$. Control of Red Oil Explosions in Defense Nuclear Facilities (DNFSB 2003) provides additional details on the conditions and control measures for potential red oil explosions. A red oil explosion is possible in aqueous separations in equipment such as evaporators, acid concentrators, denitrators, and steam jets.

As a result of the reaction, the equipment ruptures and radioactive material is released. A fire involving the organic solution and its diluents could result from the event. The release could overwhelm the vessel and cell filtration system but is not expected to incapacitate the largercapacity final HEPA system. There would be insufficient energy in the explosion to damage the 
facility structure, so facility workers would not be exposed to the release. Controls for prevention or mitigation of a red oil explosion may include controls on temperature, pressure, mass, and/or concentration.

The release phenomena could involve liquid sprays and a subsequent fire. After such an accident, the equipment contents are released and the final ventilation fans draw the airborne materials through a single stage of HEPA filtration. The noninvolved worker and offsite individuals could be exposed to airborne radioactive material released after partial filtration through the ventilation system, but facility workers are not expected to be directly exposed because facility walls are not damaged. The frequency category of this event is estimated to be Unlikely. The facility may have either a single or multiple trains of equipment depending upon the facility throughput and final design, but this analysis assumes the maximum inventory, which is a single train. The release parameters used to analyze the consequences of this accident are presented in Table D.2.2.1.2-3 along with the basis for using these values.

TABLE D.2.2.1.2-3-Nuclear Fuel Recycling Center Release Parameters for the Aqueous Separations Explosion and Fire Accident

\begin{tabular}{|c|c|c|}
\hline Parameter & Value & Basis/Comment \\
\hline $\begin{array}{l}\text { Release } \\
\text { Point }\end{array}$ & $50 \mathrm{~m}$ stack & $\begin{array}{l}\text { The event does not result in failure of the building structure or stack, } \\
\text { so the release is from the stack. }\end{array}$ \\
\hline Duration & 1 minute & $\begin{array}{l}\text { The explosion is an instantaneous event and a resulting fire could } \\
\text { occur promptly, so a short duration release model is appropriate. }\end{array}$ \\
\hline $\begin{array}{l}\text { Material at } \\
\text { risk }\end{array}$ & $\begin{array}{c}\text { EAS NEPA Data Input } \\
\text { Report (WSRC 2008a), } \\
\text { Appendix A-2 values } \\
\text { multiplied by } 1 \\
\text { MTHM/day for the } \\
100 \mathrm{MTHM} / \mathrm{yr} \text { design and } \\
\text { by } 3.33 \mathrm{MTHM} / \text { day } \\
\text { column for the } \\
800 \mathrm{MTHM} / \mathrm{yr} \text { design }\end{array}$ & $\begin{array}{l}\text { The bounding batch size is assumed to be the same as the daily } \\
\text { process rate. The material at risk includes all radionuclides in the } \\
\text { inventory even though some radionuclides are removed prior to some } \\
\text { partitioning stages. The inventory is multiplied by } 1 \mathrm{MTHM} / \text { day for } \\
\text { the } 100 \mathrm{MTHM} / \mathrm{yr} \text { design and by } 3.33 \mathrm{MTHM} / \text { day for the } \\
800 \mathrm{MTHM} / \mathrm{yr} \text { design. }\end{array}$ \\
\hline $\begin{array}{l}\text { Damage } \\
\text { ratio }\end{array}$ & - & It is conservative to assume the entire material at risk is involved \\
\hline $\begin{array}{l}\text { Airborne } \\
\text { release } \\
\text { fraction }\end{array}$ & $\begin{array}{l}1 \text { volatiles } \\
\text { (including iodine) } \\
0.01 \text { non-volatiles }\end{array}$ & $\begin{array}{l}\text { The values for volatiles and nonvolatiles are based on organic fires as } \\
\text { reported in Sections 3.3.1 and 3.3.2 of DOE-HDBK-3010-94 } \\
\text { (DOE 2000i). }\end{array}$ \\
\hline $\begin{array}{l}\text { Respirable } \\
\text { fraction }\end{array}$ & 1 & It is conservative to assume the entire release is respirable \\
\hline $\begin{array}{l}\text { Leak path } \\
\text { factor }\end{array}$ & $\begin{array}{l}1 \text { gases } \\
0.001 \text { particulates }\end{array}$ & $\begin{array}{c}\text { This value is based on item (a) for the } 1^{\text {st }} \text { stage of HEPA filtration in } \\
\text { Table IX of LA-10294-MS (LANL 1986). }\end{array}$ \\
\hline
\end{tabular}

\section{Beyond Design Basis Earthquake}

A "Beyond Design Basis Earthquake" may cause equipment malfunctions and result in a variety of events. A nuclear fuel recycling center would have a robust, non-flammable facility design with combustible loading controls, so a facility-wide fire is not credible. The earthquake has the potential to damage the ventilation system and produce cracks in the cell enclosure, thereby resulting in a partially mitigated release. More severe events that result in damage to the confinement boundary or stack may increase consequences to nearby receptors but would have minimal effect on the population impacts. The most impacting event that could be caused by an 
earthquake is the "Explosion and Fire in the Aqueous Separation" process, so it is selected as the phenomena type for the bounding "Beyond Design Basis Earthquake" scenario. The "Beyond Design Basis Earthquake" scenario as analyzed here includes a compromise in the confinement boundary that results in a leak path factor mid-way between total failure and intact performance of the HEPA filters.

One or more facility workers could be killed as a direct result of the earthquake, for example from falling debris. The noninvolved worker and the public may be exposed to the release. No credit is taken for the fire suppression efforts and equipment since the earthquake could incapacitate them. The magnitude of the earthquake is site specific. For current nuclear reactors, the median frequency of occurrence for a safe shutdown earthquake is $1.0 \times 10^{-5} / \mathrm{yr}$ (NRC 1997). It is expected that a nuclear fuel recycling center would be built to similar seismic standards; therefore, the $1.0 \times 10^{-5} / \mathrm{yr}$ frequency (which is in the Extremely Unlikely category) is assumed here for a nuclear fuel recycling center.

The release parameters used to analyze the consequences of this accident are presented in Table D.2.2.1.2-4 along with the basis for using these values.

\section{TABLE D.2.2.1.2-4-Nuclear Fuel Recycling Center Release Parameters} for the Beyond Design Basis Earthquake Accident

\begin{tabular}{|c|c|c|}
\hline Parameter & Value & Basis/Comment \\
\hline $\begin{array}{l}\text { Release } \\
\text { Point }\end{array}$ & $50 \mathrm{~m}$ stack & $\begin{array}{l}\text { The event does not result in failure of the building structure or stack, } \\
\text { so the release is from the stack. }\end{array}$ \\
\hline Duration & 1 minute & $\begin{array}{l}\text { The fire induced explosion is an instantaneous event and a resulting } \\
\text { fire could occur promptly. A short duration release model is used, } \\
\text { which assumes the majority of the release occurs from the explosion. }\end{array}$ \\
\hline $\begin{array}{l}\text { Material at } \\
\text { risk }\end{array}$ & $\begin{array}{c}\text { EAS NEPA Data Input } \\
\text { Report (WSRC 2008a), } \\
\text { Appendix A-2 values } \\
\text { multiplied by } \\
1 \mathrm{MTHM} / \text { day for the } \\
100 \mathrm{MTHM} / \mathrm{yr} \text { design and } \\
\text { by } 3 \mathrm{MTHM} / \text { day for the } \\
800 \mathrm{MTHM} / \mathrm{yr} \text { design }\end{array}$ & $\begin{array}{l}\text { The bounding batch size is assumed to be the same as the daily } \\
\text { process rate. The material at risk includes all radionuclides in the } \\
\text { inventory even though some radionuclides are removed prior to some } \\
\text { partitioning stages. The inventory is multiplied by } 1 \mathrm{MTHM} / \text { day for } \\
\text { the } 100 \mathrm{MTHM} / \mathrm{yr} \text { design and by the } 3 \mathrm{MTHM} / \text { day for the } \\
800 \mathrm{MTHM} / \mathrm{yr} \text { design. }\end{array}$ \\
\hline $\begin{array}{l}\text { Damage } \\
\text { ratio }\end{array}$ & 1 & It is conservative to assume the entire material at risk is involved. \\
\hline $\begin{array}{l}\text { Airborne } \\
\text { release } \\
\text { fraction }\end{array}$ & $\begin{array}{l}1 \text { volatiles (including } \\
\text { iodine) } \\
0.01 \text { non-volatiles }\end{array}$ & $\begin{array}{l}\text { The values for volatiles and nonvolatiles are based on organic fires as } \\
\text { reported in Sections 3.3.1 and 3.3.2 of DOE-HDBK-3010-94 } \\
\text { (DOE 2000i). }\end{array}$ \\
\hline $\begin{array}{l}\text { Respirable } \\
\text { fraction }\end{array}$ & 1 & se is respirable. \\
\hline $\begin{array}{l}\text { Leak path } \\
\text { factor }\end{array}$ & $\begin{array}{c}1 \text { gases } \\
0.03 \text { particulates }\end{array}$ & $\begin{array}{l}\text { This value reflects the degraded filtration system condition and is } \\
\text { based on the geometric mean of } 1 \text { (i.e., no filtration) and item (a) for } \\
\text { the } 1^{\text {st }} \text { stage of HEPA filtration (i.e., 0.001) in Table IX of LA-10294- } \\
\text { MS (LANL 1986). }\end{array}$ \\
\hline
\end{tabular}

\section{Nuclear Criticality}

An inadvertent nuclear criticality is possible in a facility such as a nuclear fuel recycling center that contains substantial quantities of fissile material in various forms, including SNF, solutions, powders, solids, and unirradiated nuclear fuel. A nuclear criticality can result if the quantity, 
concentration, configuration, moderation, or reflection of the fissile material sufficiently exceeds the criticality limits. The criticality limits could be violated due to initiators such as operator errors, equipment failures, process upsets, or a seismic event. A few examples of the types of criticality events that are possible include collapse of a storage vault/rack due to an earthquake, process upsets that result in concentration of fissile solutions in a process vessel, and operator error resulting in addition of a moderator (e.g., water) to a product storage vault.

A criticality involving dissolved SNF is assumed to be the bounding nuclear fuel recycling center criticality event because: 1) solution events are considered more likely and have a large number of fissions, 2) solid fissile forms retain pre-existing and generated fission products much more effectively than solutions, and 3) unirradiated materials do not contain pre-existing fission products, which may also be released in the event. The criticality event selected is a solution criticality assumed to involve $1 \times 10^{19}$ total fissions, which results in a maximum evaporation of $26 \mathrm{gal}(100 \mathrm{~L})$ of solution (DOE 2000i). Events of this type are frequently modeled as an initial fission burst followed by smaller excursions over an 8-hour period (e.g., see DOE-HDBK-3010-94 [DOE 2000i] Section 6.1), but for simplicity, the event is assumed to result in a uniform release over a 1-hour period in this analysis. The "Nuclear Criticality" event does not involve an abrupt energy release sufficient to fail multiple banks of HEPA filtration, so a single stage of HEPA filtration is assumed to filter the release. Filtration by a second stage of HEPA filtration would reduce the particulate release by roughly two orders of magnitude but would not affect gaseous releases.

The noninvolved worker and offsite individuals could be exposed to dose from inhalation and immersion in the plume of released nuclides from this event. Facility workers are not expected to be directly exposed to the release because facility walls are not damaged. Operations involving SNF solutions are performed behind shielding walls and the event would be promptly alarmed, so the increased direct radiation exposure to facility workers are not lethal. The release parameters used to analyze the consequences of this accident are presented in Table D.2.2.1.2-5 along with the basis for using these values. 
TABLE D.2.2.1.2-5—Nuclear Fuel Recycling Center Release Parameters for the Nuclear Criticality Accident

\begin{tabular}{|c|c|c|}
\hline Parameter & Value & Basis/Comment \\
\hline $\begin{array}{l}\text { Release } \\
\text { Point }\end{array}$ & $50 \mathrm{~m}$ stack & $\begin{array}{c}\text { The event does not result in failure of the building structure or stack, } \\
\text { so the release is from the stack. }\end{array}$ \\
\hline \multirow[t]{2}{*}{ Duration } & 1 hour & $\begin{array}{l}\text { The release is assumed to be uniform over a 1-hour period. } \\
\text { Section } 6.1 \text { of DOE-HDBK-3010-94 (DOE 2000i) uses an initial } \\
\text { burst with smaller subsequent excursions over an } 8 \text {-hour period. This } \\
\text { 1-hour release assumption simplifies the analysis and is more } \\
\text { conservative. }\end{array}$ \\
\hline & $\begin{array}{l}\text { DOE-HDBK-3010-94 } \\
\text { (DOE 2000i) Table 6-7 }\end{array}$ & This reference is applicable since it is for SNF solutions. \\
\hline $\begin{array}{l}\text { Material at } \\
\text { risk }\end{array}$ & $\begin{array}{l}\text { See EAS NEPA Data Input } \\
\text { Report (WSRC 2008a), } \\
\text { Appendix A-2, multiplied } \\
\text { by } 0.1 \text { MTHM. }\end{array}$ & $\begin{array}{l}\text { Section 6.1 DOE-HDBK-3010-94 (DOE 2000i) provides a basis for } \\
\text { assuming release from } 100 \mathrm{~L} \text { of solution. The concentration of } \\
\text { radionuclides is dependent upon the process stage involved, but is } \\
\text { conservatively assumed to have a heavy metal concentration of } \\
1,000 \mathrm{~g} / \mathrm{L} \text {, which is several times the expected value. The } 26 \text { gallons } \\
(100 \mathrm{~L}) \text { of solution evaporated would therefore contain the } \\
\text { radionuclide inventory of } 0.1 \text { MTHM. }\end{array}$ \\
\hline $\begin{array}{l}\text { Damage } \\
\text { ratio }\end{array}$ & 1 & It is conservative to assume the entire material at risk is involved. \\
\hline $\begin{array}{l}\text { Airborne } \\
\text { release } \\
\text { fraction }\end{array}$ & $\begin{array}{l}1 \text { noble gas } \\
0.25 \text { iodine } \\
0.001 \text { ruthenium } \\
5 \times 10^{-4} \text { other }\end{array}$ & $\begin{array}{l}\text { These values are consistent with the values used in Section } 6.3 .1 \text { of } \\
\text { DOE-HDBK-3010-94 (DOE 2000i). }\end{array}$ \\
\hline $\begin{array}{l}\text { Respirable } \\
\text { fraction }\end{array}$ & 1 & It is conservative to assume the entire release is respirable. \\
\hline $\begin{array}{l}\text { Leak path } \\
\text { factor }\end{array}$ & $\begin{array}{c}1 \text { gases } \\
0.001 \text { particulates }\end{array}$ & $\begin{array}{c}\text { This value is based on item (a) for the } 1^{\text {st }} \text { stage of HEPA filtration in } \\
\text { Table IX of LA-10294-MS (LANL 1986). }\end{array}$ \\
\hline
\end{tabular}

\section{Aircraft Crash}

This scenario involves an aircraft crashing into a nuclear fuel recycling center resulting in a breach of confinement. The crash could damage engineered barriers and may result in a criticality, fire, or spill event. Because of the robustness of the facility, there are a limited number of aircraft types capable of penetrating the shielding walls. Because of the very low likelihood of a penetrating crash and the small conditional probability that the event would be aligned to penetrate multiple cell walls, it is not credible that the crash would affect multiple processes (e.g., both the electrochemical and aqueous separation processes). Each of the process steps contains fuel in a vulnerable form so all aqueous processes are vulnerable. The head-end process includes the voloxidation step, which transforms the fuel into a highly dispersible and respirable particulate form, and the dissolution step. The release fraction for the "Aircraft Crash" accident is based on release from the voloxidation process. The release fraction from the aqueous separation product would be similar to the voloxidation process (DOE 2006q).

One or more facility workers could be killed as a direct result of the crash. The noninvolved worker and the public may be exposed to the release. The release would not be filtered since the facility confinement barrier is breached. No credit is taken for the mitigating effects of fire suppression efforts and equipment. The frequency is taken to be $1.0 \times 10^{-7}$ per year (a Beyond Extremely Unlikely event) because the facility is expected to be required to meet a standard 
similar to the NRC Aircraft Hazards criteria (NRC 2007k) for reactors. The release parameters used to analyze the consequences of this accident are presented in Table D.2.2.1.2.5-1 along with the basis for using these values.

TABLE D.2.2.1.2-6-Nuclear Fuel Recycling Center Release Parameters for the Aircraft Crash Accident

\begin{tabular}{|c|c|c|}
\hline Parameter & Value & Basis/Comment \\
\hline $\begin{array}{l}\text { Release } \\
\text { Point }\end{array}$ & Ground level & $\begin{array}{l}\text { Because the confinement barrier is breached, the release point could } \\
\text { be at ground level. }\end{array}$ \\
\hline Duration & 1 minute & $\begin{array}{c}\text { The release could occur over a short duration, so a short duration } \\
\text { release model is appropriate. }\end{array}$ \\
\hline $\begin{array}{l}\text { Material at } \\
\text { risk }\end{array}$ & $\begin{array}{c}\text { EAS NEPA Data Input } \\
\text { Report (WSRC 2008a), } \\
\text { Appendix A-2 values } \\
\text { multiplied by } \\
1 \mathrm{MTHM} / \text { day for the } \\
100 \mathrm{MTHM} / \mathrm{yr} \text { design and } \\
\text { by } 3.33 \mathrm{MTHM} / \text { day for } \\
\text { the } 800 \mathrm{MTHM} / \mathrm{yr} \text { design. }\end{array}$ & $\begin{array}{l}\text { Table A-2 of the EAS NEPA Data Input Report (WSRC 2008a) } \\
\text { provides the bounding daily throughput, which is assumed to be the } \\
\text { bounding inventory. The inventory is multiplied by } 1 \mathrm{MTHM} / \text { day for } \\
\text { the } 100 \mathrm{MTHM} / \mathrm{yr} \text { design and by } 3.33 \mathrm{MTHM} / \text { day for the } \\
800 \mathrm{MTHM} / \mathrm{yr} \text { design. }\end{array}$ \\
\hline \multirow{3}{*}{$\begin{array}{l}\text { Damage } \\
\text { ratio } \\
\text { Airborne } \\
\text { release } \\
\text { fraction }\end{array}$} & 1 & It is conservative to assume the entire material at risk is involved \\
\hline & 1 volatiles & Table II of Accident Analysis for Aircraft Crash Into Hazardous \\
\hline & 0.002 non-volatiles & $\begin{array}{l}\text { Facilities, DOE-STD-3014-96 (DOE 2006q) provides this value for } \\
\text { evaluation of powder or aqueous liquid releases from aircraft crashes. }\end{array}$ \\
\hline $\begin{array}{l}\text { Respirable } \\
\text { fraction }\end{array}$ & 1 & It is conservative to assume the entire release is respirable. \\
\hline $\begin{array}{l}\text { Leak path } \\
\text { factor }\end{array}$ & 1 & It is conservative to assume all airborne material is released. \\
\hline
\end{tabular}

\section{Nitric Acid Release from Bulk Storage}

A nuclear fuel recycling center would utilize a variety of hazardous chemicals in significant quantities. An accidental release of nitric acid from bulk storage is postulated as the bounding hazardous chemical event. Nitric acid is corrosive and can cause severe burns to all parts of the body. Its vapors are corrosive to the respiratory tract and may cause pulmonary edema which could prove fatal.

The leak could be the result of equipment failure, mechanical impact, or human error. The bulk storage building has precautions such as secondary confinement to mitigate the consequences of a nitric acid spill. However, it is possible for a spill associated with a delivery truck to occur where these precautions are not available.

The usage of nitric acid ranges from $1.6 \times 10^{3}$ gal $\left(5.9 \times 10^{3} \mathrm{~L}\right)$ per day for a $100 \mathrm{MTHM} / \mathrm{yr}$ facility to $5.2 \times 10^{3}$ gal $\left(2.0 \times 10^{4} \mathrm{~L}\right)$ per Table 20 of the EAS NEPA Data Input Report (WSRC 2008a). The maximum storage of bulk chemicals is assumed to be equal to their annual usage, so the nitric storage capacity ranges from $1.6 \times 10^{5}$ gal $\left(5.9 \times 10^{5} \mathrm{~L}\right)$ for a $100 \mathrm{MTHM} / \mathrm{yr}$ facility operated 100 days/yr to $1.3 \times 10^{6}$ gal $\left(4.8 \times 10^{6} \mathrm{~L}\right)$ for an $800 \mathrm{MTHM} / \mathrm{yr}$ facility operated 240 days/yr. However, the consequence of this event is less dependent upon the volume of nitric acid spilled 
than on the surface area and temperature of the resulting pool. The bounding event is assumed to be an outdoor spill of nitric acid sufficient to result in a $1.1 \times 10^{4} \mathrm{ft}^{2}\left(1,000 \mathrm{~m}^{2}\right)$ pool of nitric acid with ambient and acid temperatures of $90^{\circ} \mathrm{F}\left(32^{\circ} \mathrm{C}\right)$. The nitric acid evaporates and is transported by the wind to all receptors. The DOE Protective Action Criteria, 60-minute AEGL-2 and 3 for nitric acid, are 24 and 92 parts per million (ppm) (SCAPA 2007). The estimated frequency category of this accident is estimated to be Unlikely.

\section{D.2.2.1.3 Results}

\section{Radioactive Material Releases}

The risk from all accidents at all sites to the offsite population (Table D.2.2.1.3-1), MEI (Table D.2.2.1.3-2), and noninvolved worker (Table D.2.2.1.3-3) follows.

\section{TABLE D.2.2.1.3-1-Nuclear Fuel Recycling Center Accident Risks ${ }^{a}$} to the Offsite Population (All Sites)

\begin{tabular}{|c|c|c|c|c|c|c|}
\hline Accident (Frequency) & $\begin{array}{c}\text { Generic } \\
\text { Site 1 } \\
\end{array}$ & $\begin{array}{c}\text { Generic } \\
\text { Site } 2 \\
\end{array}$ & $\begin{array}{c}\text { Generic } \\
\text { Site } 3 \\
\end{array}$ & $\begin{array}{c}\text { Generic } \\
\text { Site } 4 \\
\end{array}$ & $\begin{array}{c}\text { Generic } \\
\text { Site } 5 \\
\end{array}$ & $\begin{array}{c}\text { Generic } \\
\text { Site } 6 \\
\end{array}$ \\
\hline $\begin{array}{l}\text { Fuel Handling Accident }{ }^{b} \\
(0.03 / y r)\end{array}$ & $1 \times 10^{-6}$ & $2 \times 10^{-6}$ & $1 \times 10^{-5}$ & $5 \times 10^{-6}$ & $9 \times 10^{-6}$ & $4 \times 10^{-5}$ \\
\hline $\begin{array}{l}\text { Explosion and Fire in Aqueous } \\
\text { Separations }^{c}(0.001 / \mathrm{yr})\end{array}$ & $2 \times 10^{-5}$ & $6 \times 10^{-5}$ & $3 \times 10^{-4}$ & $7 \times 10^{-5}$ & $2 \times 10^{-4}$ & $9 \times 10^{-4}$ \\
\hline $\begin{array}{l}\text { Beyond Design Basis } \\
\text { Earthquake }^{\mathrm{c}}\left(1 \times 10^{-5} / \mathrm{yr}\right)\end{array}$ & $5 \times 10^{-6}$ & $2 \times 10^{-5}$ & $9 \times 10^{-5}$ & $2 \times 10^{-5}$ & $6 \times 10^{-5}$ & $3 \times 10^{-4}$ \\
\hline Nuclear Criticality $\left(1 \times 10^{-5} / \mathrm{yr}\right)$ & $8 \times 10^{-10}$ & $2 \times 10^{-9}$ & $1 \times 10^{-8}$ & $2 \times 10^{-9}$ & $5 \times 10^{-9}$ & $2 \times 10^{-8}$ \\
\hline Aircraft $\operatorname{Crash}^{\mathrm{c}}\left(1 \times 10^{-7} / \mathrm{yr}\right)$ & $4 \times 10^{-7}$ & $1 \times 10^{-6}$ & $6 \times 10^{-6}$ & $8 \times 10^{-7}$ & $2 \times 10^{-6}$ & $1 \times 10^{-5}$ \\
\hline
\end{tabular}

${ }^{a}$ Increased number of expected LCFs per year of operation.

${ }^{\mathrm{b}}$ Applicable to facility throughput of from 100 to $800 \mathrm{MTHM} / \mathrm{yr}$.

${ }^{\mathrm{c}}$ Applicable to facility throughput of $800 \mathrm{MTHM} / \mathrm{yr}$. The risks for $100 \mathrm{MTHM} / \mathrm{yr}$ would be 30 percent of the table values.

The accident with the highest risk to the offsite population, MEI, and noninvolved worker is the "Explosion and Fire in Aqueous Separations" scenario. The collective risk to the offsite population for this scenario would range from $2 \times 10^{-5}$ expected LCFs per year of operation in the Site- 1 offsite population (300,000 people) to $9 \times 10^{-4}$ expected LCFs per year of operation in the Site- 6 offsite population $(8,200,000$ people). 


\section{TABLE D.2.2.1.3-2 - Nuclear Fuel Recycling Center Accident Risks ${ }^{a}$ to the} Maximally Exposed Individual (All Sites)

\begin{tabular}{|c|c|c|c|c|c|c|}
\hline Accident (Frequency) & $\begin{array}{c}\text { Generic } \\
\text { Site } 1\end{array}$ & $\begin{array}{l}\text { Generic } \\
\text { Site } 2\end{array}$ & $\begin{array}{c}\text { Generic } \\
\text { Site } 3 \\
\end{array}$ & $\begin{array}{l}\text { Generic } \\
\text { Site } 4\end{array}$ & $\begin{array}{c}\text { Generic } \\
\text { Site } 5\end{array}$ & $\begin{array}{l}\text { Generic } \\
\text { Site } 6\end{array}$ \\
\hline $\begin{array}{l}\text { Fuel Handling Accident }{ }^{\mathrm{b}} \\
(0.03 / \mathrm{yr})\end{array}$ & $1 \times 10^{-8}$ & $1 \times 10^{-8}$ & $1 \times 10^{-8}$ & $1 \times 10^{-7}$ & $1 \times 10^{-7}$ & $1 \times 10^{-7}$ \\
\hline $\begin{array}{l}\text { Explosion and Fire in } \\
\text { Aqueous Separations } \\
(0.001 / \mathrm{yr})\end{array}$ & $2 \times 10^{-7}$ & $2 \times 10^{-7}$ & $2 \times 10^{-7}$ & $8 \times 10^{-7}$ & $8 \times 10^{-7}$ & $8 \times 10^{-7}$ \\
\hline $\begin{array}{l}\text { Beyond Design Basis } \\
\text { Earthquake }^{\mathrm{c}}\left(1 \times 10^{-5} / \mathrm{yr}\right)\end{array}$ & $5 \times 10^{-8}$ & $5 \times 10^{-8}$ & $5 \times 10^{-8}$ & $5 \times 10^{-7}$ & $5 \times 10^{-7}$ & $5 \times 10^{-7}$ \\
\hline $\begin{array}{l}\text { Nuclear Criticality } \\
\left(1 \times 10^{-5} / \mathrm{yr}\right)\end{array}$ & $8 \times 10^{-12}$ & $8 \times 10^{-12}$ & $8 \times 10^{-12}$ & $4 \times 10^{-11}$ & $4 \times 10^{-11}$ & $4 \times 10^{-11}$ \\
\hline $\operatorname{Aircraft} \operatorname{Crash}^{\mathrm{c}}\left(1 \times 10^{-7} / \mathrm{yr}\right)$ & $7 \times 10^{-9}$ & $7 \times 10^{-9}$ & $7 \times 10^{-9}$ & $9 \times 10^{-9}$ & $9 \times 10^{-9}$ & $9 \times 10^{-9}$ \\
\hline
\end{tabular}

${ }^{\mathrm{b}}$ Applicable to facility throughput of from 100 to $800 \mathrm{MTHM} / \mathrm{yr}$.

${ }^{\mathrm{c}}$ Applicable to facility throughput of $800 \mathrm{MTHM} / \mathrm{yr}$. The risks for $100 \mathrm{MTHM} / \mathrm{yr}$ would be 30 percent of the table values.

For the MEI, the "Explosion and Fire in Aqueous Separations" scenario would result in an increased risk of an LCF of $2 \times 10^{-7}$ per year of operation to $8 \times 10^{-7}$ per year of operation.

TABLE D.2.2.1.3-3-Nuclear Fuel Recycling Center Accident Risks ${ }^{a}$ to the Noninvolved Worker (All Sites)

\begin{tabular}{|c|c|c|c|c|c|c|}
\hline Accident (Frequency) & $\begin{array}{l}\text { Generic } \\
\text { Site } 1\end{array}$ & $\begin{array}{l}\text { Generic } \\
\text { Site } 2\end{array}$ & $\begin{array}{l}\text { Generic } \\
\text { Site } 3\end{array}$ & $\begin{array}{c}\text { Generic } \\
\text { Site } 4\end{array}$ & $\begin{array}{l}\text { Generic } \\
\text { Site } 5\end{array}$ & $\begin{array}{l}\text { Generic } \\
\text { Site } 6\end{array}$ \\
\hline $\begin{array}{l}\text { Fuel Handling Accident }{ }^{b} \\
(0.03 / y r)\end{array}$ & $1 \times 10^{-7}$ & $1 \times 10^{-7}$ & $1 \times 10^{-7}$ & $7 \times 10^{-7}$ & $7 \times 10^{-7}$ & $7 \times 10^{-7}$ \\
\hline $\begin{array}{l}\text { Explosion and Fire in } \\
\text { Aqueous Separations }{ }^{\mathrm{c}} \\
(0.001 / \mathrm{yr})\end{array}$ & $2 \times 10^{-7}$ & $2 \times 10^{-7}$ & $2 \times 10^{-7}$ & $9 \times 10^{-8}$ & $9 \times 10^{-8}$ & $9 \times 10^{-8}$ \\
\hline $\begin{array}{l}\text { Beyond Design Basis } \\
\text { Earthquake }^{c}\left(1 \times 10^{-5} / \mathrm{yr}\right)\end{array}$ & $6 \times 10^{-8}$ & $6 \times 10^{-8}$ & $6 \times 10^{-8}$ & $3 \times 10^{-8}$ & $3 \times 10^{-8}$ & $3 \times 10^{-8}$ \\
\hline $\begin{array}{l}\text { Nuclear Criticality } \\
\left(1 \times 10^{-5} / \mathrm{yr}\right)\end{array}$ & $2 \times 10^{-11}$ & $2 \times 10^{-11}$ & $2 \times 10^{-11}$ & $4 \times 10^{-11}$ & $4 \times 10^{-11}$ & $4 \times 10^{-11}$ \\
\hline Aircraft $\operatorname{Crash}^{\mathrm{c}}\left(1 \times 10^{-7} / \mathrm{yr}\right)$ & $6 \times 10^{-8}$ & $6 \times 10^{-8}$ & $6 \times 10^{-8}$ & $1 \times 10^{-8}$ & $1 \times 10^{-8}$ & $1 \times 10^{-8}$ \\
\hline
\end{tabular}

${ }^{\mathrm{b}}$ Applicable to facility throughput of from 100 to $800 \mathrm{MTHM} / \mathrm{yr}$.

${ }^{\mathrm{c}}$ Applicable to facility throughput of $800 \mathrm{MTHM} / \mathrm{yr}$. The risks for $100 \mathrm{MTHM} / \mathrm{yr}$ would be 30 percent of the table values.

This same scenario, "Explosion and Fire in Aqueous Separations," would result in a risk of a LCF to the noninvolved worker of $9 \times 10^{-8}$ to $2 \times 10^{-7}$ per year of operation.

The risks to the onsite and offsite individuals and populations from the "Explosion and Fire in Aqueous Separations" scenario for facility throughput of $100 \mathrm{MTHM} / \mathrm{yr}$ are 30 percent of the values described above.

Tables D.2.2.1.3-4 through D.2.2.1.3-6 present the accident consequences for the nuclear fuel recycling center at the six generic sites described in Section D.1.6 for the offsite population, MEI, and noninvolved worker. 
TABLE D.2.2.1.3-4-Nuclear Fuel Recycling Center Accident Health Consequences (Dose in Person-Rem/Increased Number of Latent Cancer Fatalities) ${ }^{a}$ to the Offsite Population (All Sites)

\begin{tabular}{|c|c|c|c|c|c|c|}
\hline $\begin{array}{c}\text { Accident } \\
\text { (Frequency) }\end{array}$ & $\begin{array}{c}\text { Generic } \\
\text { Site } 1 \\
\end{array}$ & $\begin{array}{c}\text { Generic Site } \\
2 \\
\end{array}$ & $\begin{array}{c}\text { Generic Site } \\
\mathbf{3} \\
\end{array}$ & $\begin{array}{c}\text { Generic Site } \\
4 \\
\end{array}$ & $\begin{array}{c}\text { Generic Site } \\
5 \\
\end{array}$ & $\begin{array}{c}\text { Generic } \\
\text { Site } 6 \\
\end{array}$ \\
\hline $\begin{array}{l}\text { Fuel Handling } \\
\text { Accident } \mathrm{t}^{\mathrm{b}} \\
\left(1 \times 10^{-7} / \mathrm{yr}\right)\end{array}$ & $0.05 / 3 \times 10^{-5}$ & $0.1 / 8 \times 10^{-5}$ & $0.6 / 4 \times 10^{-4}$ & $0.3 / 2 \times 10^{-4}$ & $0.5 / 3 \times 10^{-4}$ & $2 / 0.001$ \\
\hline $\begin{array}{l}\text { Explosion and } \\
\text { Fire in Aqueous } \\
\text { Separations }{ }^{c} \\
(0.001 / y r)\end{array}$ & $30 / 0.02$ & $100 / 0.06$ & $500 / 0.3$ & $100 / 0.07$ & $300 / 0.2$ & $2,000 / 0.9$ \\
\hline $\begin{array}{l}\text { Beyond Design } \\
\text { Basis } \\
\text { Earthquake } \\
\left(1 \times 10^{-5} / \mathrm{yr}\right)\end{array}$ & $900 / 0.5$ & $3,000 / 2$ & $2 \times 10^{4} / 9$ & $4,000 / 2$ & $1 \times 10^{4} / 6$ & $4 \times 10^{4} / 30$ \\
\hline $\begin{array}{l}\text { Nuclear } \\
\text { Criticality } \\
\left(1 \times 10^{-5} / \mathrm{yr}\right)\end{array}$ & $0.1 / 8 \times 10^{-5}$ & $0.4 / 2 \times 10^{-4}$ & $2 / 0.001$ & $0.4 / 2 \times 10^{-4}$ & $0.9 / 5 \times 10^{-4}$ & $4 / 0.002$ \\
\hline $\begin{array}{l}\text { Aircraft Crash } \\
\left(1 \times 10^{-7} / \mathrm{yr}\right)\end{array}$ & $7,000 / 4$ & $2 \times 10^{4} / 10$ & $9 \times 10^{4} / 60$ & $1 \times 10^{4} / 8$ & $4 \times 10^{4} / 20$ & $2 \times 10^{5} / 100$ \\
\hline
\end{tabular}

${ }^{a}$ The dose in person-rem is reported before the slash and the increased number of LCFs is presented after the slash.

${ }^{\mathrm{b}}$ Applicable to facility throughput of from 100 to $800 \mathrm{MTHM} / \mathrm{yr}$.

${ }^{\mathrm{c}}$ Applicable to facility throughput of $800 \mathrm{MTHM} / \mathrm{yr}$. The consequences for $100 \mathrm{MTHM} / \mathrm{yr}$ would be 30 percent of the table values.

The accident with the highest consequence to the offsite population would be the "Unmitigated Aircraft Crash" scenario. Using the dose-to-risk conversion factor of $6 \times 10^{-4}$ per person-rem, the collective population dose for this Beyond Extremely Unlikely accident is estimated to result in 4 additional LCFs to 100 additional LCFs.

TABLE D.2.2.1.3-5-Nuclear Fuel Recycling Center Accident Health Consequences (Dose in Rem/Increased Likelihood of a Latent Cancer Fatality) ${ }^{a}$ to the Maximally Exposed Individual (All Sites)

\begin{tabular}{lcccccc}
\hline \multicolumn{1}{c}{ Accident (Frequency) } & $\begin{array}{c}\text { Generic } \\
\text { Site 1 }\end{array}$ & $\begin{array}{c}\text { Generic } \\
\text { Site 2 }\end{array}$ & $\begin{array}{c}\text { Generic } \\
\text { Site 3 }\end{array}$ & $\begin{array}{c}\text { Generic } \\
\text { Site 4 }\end{array}$ & $\begin{array}{c}\text { Generic } \\
\text { Site 5 }\end{array}$ & $\begin{array}{c}\text { Generic } \\
\text { Site 6 }\end{array}$ \\
\hline $\begin{array}{l}\text { Fuel Handling Accident } \\
\text { (0.03/yr) }\end{array}$ & $7 \times 10^{-4} /$ & $7 \times 10^{-4} /$ & $7 \times 10^{-4} /$ & $0.005 /$ & $0.005 /$ & $0.005 /$ \\
Explosion and Fire in & $4 \times 10^{-7}$ & $4 \times 10^{-7}$ & $4 \times 10^{-7}$ & $3 \times 10^{-6}$ & $3 \times 10^{-6}$ & $3 \times 10^{-6}$ \\
$\begin{array}{l}\text { Aqueous Separations } \\
\text { ( }\end{array}$ & $0.3 / 2 \times 10^{-4}$ & $0.3 / 2 \times 10^{-4}$ & $0.3 / 2 \times 10^{-4}$ & $1 / 8 \times 10^{-4}$ & $1 / 8 \times 10^{-4}$ & $1 / 8 \times 10^{-4}$ \\
Beyond Design Basis & & & & & & \\
Earthquake $^{\mathrm{c}}\left(1 \times 10^{-5} / \mathrm{yr}\right)$ & $9 / 0.005$ & $9 / 0.005$ & $9 / 0.005$ & $40 / 0.05$ & $40 / 0.05$ & $40 / 0.05$ \\
Nuclear Criticality $^{\mathrm{b}}$ & $0.001 /$ & $0.001 /$ & $0.001 /$ & $0.006 /$ & $0.006 /$ & $0.006 /$ \\
$\left(1 \times 10^{-5} / \mathrm{yr}^{-4}\right)$ & $8 \times 10^{-7}$ & $8 \times 10^{-7}$ & $8 \times 10^{-7}$ & $4 \times 10^{-6}$ & $4 \times 10^{-6}$ & $4 \times 10^{-6}$ \\
Aircraft Crash $^{\mathrm{c}}\left(1 \mathrm{x} 10^{-7} / \mathrm{yr}\right)$ & $60 / 0.07$ & $60 / 0.07$ & $60 / 0.07$ & $70 / 0.09$ & $70 / 0.09$ & $70 / 0.09$ \\
\hline
\end{tabular}

a The dose in rem is reported before the slash and the increased likelihood of a LCF is presented after the slash.

${ }^{\mathrm{b}}$ Applicable to facility throughput of from 100 to $800 \mathrm{MTHM} / \mathrm{yr}$.

${ }^{\mathrm{c}}$ Applicable to facility throughput of $800 \mathrm{MTHM} / \mathrm{yr}$. The consequences for $100 \mathrm{MTHM} / \mathrm{yr}$ would be 30 percent of the table values.

Using the dose-to-risk conversion factor of $6 \times 10^{-4}$ per person-rem (or twice $6 \times 10^{-4}$ per personrem for individual doses greater than $20 \mathrm{rem}$ ), the MEI dose is expected to result in an increased LCF likelihood of 0.07 to 0.09 for the "Unmitigated Beyond Extremely Unlikely Aircraft Crash" accident. 
TABLE D.2.2.1.3-6-Nuclear Fuel Recycling Center Accident Health Consequences (Dose in Rem/Increased Likelihood of a Latent Cancer Fatality) ${ }^{a}$ to the Noninvolved Worker

(All Sites)

\begin{tabular}{|c|c|c|c|c|c|c|}
\hline Accident (Frequency) & $\begin{array}{l}\text { Generic } \\
\text { Site } 1\end{array}$ & $\begin{array}{c}\text { Generic } \\
\text { Site 2 } \\
\end{array}$ & $\begin{array}{l}\text { Generic } \\
\text { Site } 3 \\
\end{array}$ & $\begin{array}{c}\text { Generic } \\
\text { Site } 4 \\
\end{array}$ & $\begin{array}{l}\text { Generic } \\
\text { Site } 5 \\
\end{array}$ & $\begin{array}{c}\text { Generic Site } \\
6 \\
\end{array}$ \\
\hline $\begin{array}{l}\text { Fuel Handling Accident }{ }^{b} \\
(0.03 / y r)\end{array}$ & $\begin{array}{l}0.008 / \\
5 \times 10^{-6}\end{array}$ & $\begin{array}{l}0.008 / \\
5 \times 10^{-6}\end{array}$ & $\begin{array}{l}0.008 / \\
5 \times 10^{-6}\end{array}$ & $\begin{array}{l}0.04 / \\
2 \times 10^{-5}\end{array}$ & $\begin{array}{l}0.04 / \\
2 \times 10^{-5}\end{array}$ & $0.04 / 2 \times 10^{-5}$ \\
\hline $\begin{array}{l}\text { Explosion and Fire in } \\
\text { Aqueous Separations } \\
(0.001 / \mathrm{yr})\end{array}$ & $0.3 / 2 \times 10^{-4}$ & $0.3 / 2 \times 10^{-4}$ & $0.3 / 2 \times 10^{-4}$ & $0.1 / 9 \times 10^{-5}$ & $0.1 / 9 \times 10^{-5}$ & $0.1 / 9 \times 10^{-5}$ \\
\hline $\begin{array}{l}\text { Beyond Design Basis } \\
\text { Earthquake }^{\mathrm{c}}\left(1 \times 10^{-5} / \mathrm{yr}\right)\end{array}$ & $10 / 0.006$ & $10 / 0.006$ & $10 / 0.006$ & $4 / 0.003$ & $4 / 0.003$ & $4 / 0.003$ \\
\hline $\begin{array}{l}\text { Nuclear Criticality } \\
\left(1 \times 10^{-5} / \mathrm{yr}\right)\end{array}$ & $\begin{array}{l}0.003 / \\
2 \times 10^{-6}\end{array}$ & $\begin{array}{l}0.003 / \\
2 \times 10^{-6}\end{array}$ & $\begin{array}{l}0.003 / \\
2 \times 10^{-6}\end{array}$ & $\begin{array}{l}0.007 / \\
4 \times 10^{-6}\end{array}$ & $\begin{array}{l}0.007 / \\
4 \times 10^{-6}\end{array}$ & $0.007 / 4 \times 10^{-6}$ \\
\hline Aircraft $\operatorname{Crash}^{\mathrm{c}}\left(1 \times 10^{-7} / \mathrm{yr}\right)$ & $500 / 0.6$ & $500 / 0.6$ & $500 / 0.6$ & $90 / 0.1$ & $90 / 0.1$ & $90 / 0.1$ \\
\hline
\end{tabular}

For the noninvolved worker, the radiation dose for this event is expected to result in an increased LCF likelihood of 0.1 to 0.6 per year of operation.

The consequences from these scenarios for a facility throughput of $100 \mathrm{MTHM} / \mathrm{yr}$ would be 30 percent of the values indicated above.

\section{Hazardous Chemical Releases}

Table D.2.2.1.3-7 presents the impacts of a release caused by a hypothetical spill of nitric acid at each of the six generic sites. Evaporation from the pool of acid caused by the Unlikely spill would result in downwind airborne concentrations which can exceed DOE Protective Action Criteria. As shown in the table, the noninvolved worker $328 \mathrm{ft}(100 \mathrm{~m})$ downwind of the spill sites at any of the sites would be exposed to levels in excess of nitric acid's AEGL-3 concentration; life-threatening health effects up to death would likely occur. Concentrations below AEGL-3 would be experienced at downwind distances greater than $1,000 \mathrm{ft}(310 \mathrm{~m})$ at Sites 1 to 3 and $1,600 \mathrm{ft}(490 \mathrm{~m})$ at Sites 4 to 6 . The MEI at Sites 4 to 6 would be exposed to levels in excess of the AEGL-2 concentration; long lasting adverse health effects could occur. Concentrations below AEGL-2 would be experienced at downwind distances greater than 2,100 $\mathrm{ft}(640 \mathrm{~m})$ at Sites 1 to 3 and 3,800 $\mathrm{ft}(1,200 \mathrm{~m})$ at Sites 4 to 6 . The impacts shown in Table D.2.2.1.3-7, which are dependent on spill area, would apply to facility throughputs of from 100 to $800 \mathrm{MTHM} / \mathrm{yr}$. 


\section{TABLE D.2.2.1.3-7-Nuclear Fuel Recycling Center Nitric Acid Spill Impacts}

\begin{tabular}{|c|c|c|c|c|}
\hline \multirow[b]{2}{*}{ Site } & \multirow[b]{2}{*}{$\begin{array}{l}\text { Distance to } \\
\text { AEGL-2 }^{\mathrm{a}} \\
\text { (feet) }\end{array}$} & \multirow[b]{2}{*}{$\begin{array}{l}\text { Distance to AEGL-3 } \\
\text { (feet) }\end{array}$} & \multicolumn{2}{|c|}{ Concentration at } \\
\hline & & & $\begin{array}{c}\text { Noninvolved } \\
\text { Worker }^{\mathrm{c}} \\
\text { (ppm) }\end{array}$ & $\operatorname{MEI}^{\mathrm{d}}(\mathbf{p p m})$ \\
\hline Generic Site 1 & 2,100 & 1,000 & 430 & 13 \\
\hline Generic Site 2 & 2,100 & 1,000 & 430 & 13 \\
\hline Generic Site 3 & 2,100 & 1,000 & 430 & 13 \\
\hline Generic Site 4 & 3,800 & 1,600 & 1,400 & 34 \\
\hline Generic Site 5 & 3,800 & 1,600 & 1,400 & 34 \\
\hline Generic Site 6 & 3,800 & 1,600 & 1,400 & 34 \\
\hline
\end{tabular}

${ }^{a}$ AEGL-2 concentration for nitric acid is 24 ppm. AEGL-2 is the airborne concentration above which it is predicted that the general population, including susceptible individuals, could experience irreversible or other serious, long-lasting adverse health effects or an impaired ability to escape.

${ }^{\mathrm{b}}$ AEGL-3 concentration for nitric acid is $92 \mathrm{ppm}$. AEGL-3 is the airborne concentration above which it is predicted that the general population, including susceptible individuals, could experience life-threatening health effects or death.

${ }^{\mathrm{c}}$ Located $328 \mathrm{ft}(100 \mathrm{~m})$ from the release.

${ }^{\mathrm{d}}$ Located at the nearest site boundary, $3,020 \mathrm{ft}(920 \mathrm{~m})$ from the release.

\section{D.2.2.1.4 Involved Worker Impacts}

Workers in the facility where the accident occurs would be particularly vulnerable to the effects of the accident because of their location. For all of the accidents, there is a potential for injury or death to involved workers in the vicinity of the accident. However, prediction of latent potential health effects becomes increasingly difficult to quantify for facility workers as the distance between the accident location and the worker decreases. This is because the individual worker exposure cannot be precisely defined with respect to the presence of shielding and other protective features. The worker also may be injured or killed by physical effects of the accident itself.

The facility ventilation system may control dispersal of the airborne radiological debris from the accident, depending upon factors such as whether the ventilation system is damaged by the accident. Following initiation of accident/site emergency alarms, workers would evacuate the area in accordance with site emergency operating procedures and would not be vulnerable to additional radiological injury.

The bounding case radiological accident for involved workers is an inadvertent criticality. Severe worker exposures could occur inside the facility as a result of a criticality, due primarily to the effects of prompt neutrons and gammas. A criticality would be detected by the criticality alarm system, and an evacuation alarm would be sounded. All personnel would immediately evacuate the building.

Personnel close to the criticality event (within the building) may incur prompt external exposures. Depending on distance and the amount of intervening shielding material, lethal doses composed of neutron and gamma radiation could be delivered. The dose due to prompt gamma and neutron radiation at a distance can be evaluated by the following formulas (DOE 2005n):

Prompt gamma dose: $\mathrm{D}_{\mathrm{g}}=2.1 \times 10^{-20} \mathrm{~N} \mathrm{~d}^{-2} \mathrm{e}^{-3.4 \mathrm{~d}}$

Prompt neutron dose: $\mathrm{D}_{\mathrm{n}}=7.0 \times 10^{-20} \mathrm{~N} \mathrm{~d}^{-2} \mathrm{e}^{-5.2 \mathrm{~d}}$ 
Where:

$$
\begin{aligned}
& D_{g}=\text { gamma dose }(\mathrm{rem}) \\
& D_{n}=\text { neutron dose }(\text { rem })(\text { neutron quality factor }=20) \\
& N=\text { number of fissions } \\
& d=\text { distance from source }(\mathrm{km}) \\
& \mathrm{e}=\text { base of the natural logarithm (i.e., approximately } 2.718)
\end{aligned}
$$

At a distance of $32 \mathrm{ft}(10 \mathrm{~m})$, the combined prompt gamma and neutron radiation dose to personnel from a criticality event $\left(1 \times 10^{19}\right.$ fissions $)$ would be $8.7 \times 10^{3}$ rem $\left(D_{g}=2,030\right.$ rem plus $\left.\mathrm{D}_{\mathrm{n}}=6,645 \mathrm{rem}\right)$. A dose of approximately $450 \mathrm{rem}$ received in a short period of time would result in death to 50 percent of the exposed population within 30 days if there is no medical intervention (DOE 1999e). Thus, the potential for lethal exposure exists. On average, there could be two workers in a room who could be exposed to this radiation.

The facility interior concrete walls would provide substantial shielding, except through the doors. In the event of a criticality, this shielding and rapid evacuation from the facility would reduce doses to personnel not in the immediate vicinity of the criticality excursion.

Direct exposure to airborne fission products produced during the criticality event would contribute only a small fraction of the total dose to a worker. Because of ventilation system operation, other personnel inside the building would not likely incur radiation dose resulting from the inhalation of airborne radioactive materials or immersion in the plume. If the ventilation system were unavailable, this dose would be small in comparison to the direct dose received at the time of the burst. The workers immediately involved would act appropriately according to training and emergency procedures.

\section{D.2.2.2 Advanced Recycling Reactor}

The general methodology for the advanced recycling reactor accident identification, selection, and analysis process is described in Section D.1. Aspects of the analysis unique to an advanced recycling reactor and the results of the analysis are described in the following sections. This section provides a summary of the accident analysis presented in "Topical Report, Advanced Recycle Reactor (ARR) Accident Analyses as Part of the Global Nuclear Energy Partnership Programmatic Environmental Impact Statement" (Tetra Tech 2008e).

\section{D.2.2.2.1 Accident Selection Process}

Currently, the advanced recycling reactor is at the pre-conceptual design stage, with aspects such as fuel type and primary system configuration not yet fixed (Briggs et al. 2007). Estimates for construction and operations data rely largely on generalization of available information from existing plants and from the environmental report assembled for the Clinch River Breeder Reactor Plant (CRBRP) design. Design choices such as configuration (pool versus loop), conventional steam cycle versus carbon dioxide $\left(\mathrm{CO}_{2}\right)$, reactor output (250 to 2,000 $\mathrm{MWth}$ ), startup fuel type (metal versus mixed-oxide), fuel handling equipment design and procedures, incore fuel inventory, and in-vessel storage capacity have not been finalized, but they can affect 
the potential accidents and their consequences. This accident analysis selects representative accidents that encompass all facets of the reactor design as well as all potential radiological sources that are susceptible to atmospheric release.

Use of the CRBRP data as a basis for estimating the construction and operations data is reasonable, but use of a three decade old design for accident selection fails to fully account for advances in design concepts. An advanced recycling reactor would have advanced safety provisions, including passive safety features, which would reduce the risk of accidental releases of radioactive material relative to CRBRP. In some cases, the advanced safety features would eliminate potential scenarios or reduce their likelihood by orders of magnitude. Therefore, this analysis selection process provides scenarios that are clearly bounding for an advanced recycling reactor and should not be viewed as estimates of the actual risks posed.

All potential accident scenarios that were reviewed and selected are pertinent to reactor safety regardless of reactor design. Selected scenarios encompass multiple integrated systems of the reactor including both primary and secondary coolants, heat transfer systems, fuel handling systems and radioactive waste processes as well as all radiological source materials that, upon an atmospheric release, could lead to potential radiological risks.

The list of fast reactors from both the United States and foreign members of the International Atomic Energy Agency was compiled from available information to assess the relevancy of these reactor designs to an advanced recycling reactor. This list is presented in Table D.2.2.2.1-1.

Note that this list is not definitive as other nations with smaller programs were not researched. A literature investigation was conducted to compile and assess safety and accident analysis resources for inclusion in this report. The available compiled information that was used is referenced throughout this report. Note that limited information was found for non-U.S. installations; however, unusual occurrences for fast reactor operations reported to the International Atomic Energy Agency were reviewed and compiled (IAEA 1996). 
TABLE D.2.2.2.1-1—Fast Reactors-United States and Foreign

\begin{tabular}{|c|c|c|c|c|c|c|c|}
\hline Reactor & Nation & Output & Location & Type & Coolant & Criticality & Shutdown \\
\hline Clementine & U.S. & $\begin{array}{l}0.25 \\
\text { MWth }\end{array}$ & Los Alamos, NM & Loop & $\mathrm{Hg}$ & 1947 & 1953 \\
\hline EBR-I & U.S. & $\begin{array}{l}\text { 1.4 MWth, } \\
0.2 \mathrm{MWe}\end{array}$ & INL & Loop & $\mathrm{NaK}$ & 1951 & 1963 \\
\hline LAMPRE & U.S. & $\begin{array}{l}1 \text { MWth } \\
62.5\end{array}$ & Los Alamos, NM & Loop & $\mathrm{Na}$ & 1961 & 1963 \\
\hline EBR-II & U.S. & $\begin{array}{l}\text { MWth, } 20 \\
\text { MWe } \\
200\end{array}$ & INL & Pool & $\mathrm{Na}$ & 1961 & 1994 \\
\hline Fermi & U.S. & $\begin{array}{l}\text { MWth, } 61 \\
\text { MWe }\end{array}$ & Newport, MI & Loop & $\mathrm{Na}$ & 1963 & 1972 \\
\hline SEFOR & U.S. & 20 MWth & Strickler, AR & Loop & $\mathrm{Na}$ & 1969 & 1972 \\
\hline FFTF & U.S. & $\begin{array}{l}400 \text { MWth } \\
975\end{array}$ & Hanford, WA & Loop & $\mathrm{Na}$ & 1980 & 1992 \\
\hline CRBRP & U.S. & $\begin{array}{c}\text { MWth, } \\
380 \mathrm{MWe} \\
840\end{array}$ & Oak Ridge, TN & Loop & $\mathrm{Na}$ & \multicolumn{2}{|c|}{ Pre-conceptual } \\
\hline PRISM & U.S. & $\begin{array}{l}\text { MWth, } \\
311 \mathrm{MWe}\end{array}$ & Conceptual & Pool & $\mathrm{Na}$ & \multicolumn{2}{|c|}{ Pre-conceptual } \\
\hline DFR & U.K. & $\begin{array}{c}60 \mathrm{MWth} \text {, } \\
15 \mathrm{MWe} \\
650\end{array}$ & Dounreay, UK & Loop & $\mathrm{NaK}$ & 1959 & 1977 \\
\hline PFR & U.K. & $\begin{array}{l}\text { MWth, } \\
250 \mathrm{MWe}\end{array}$ & Dounreay, UK & Pool & $\mathrm{Na}$ & 1974 & 1994 \\
\hline Rapsodie & France & $\begin{array}{l}40 \text { MWth } \\
563 \text {, }\end{array}$ & Cadarache, France & Loop & $\mathrm{Na}$ & 1967 & 1983 \\
\hline Phenix & France & $\begin{array}{c}\text { MWth, } \\
250 \text { MWe } \\
2990\end{array}$ & Marcoule, France & Pool & $\mathrm{Na}$ & 1973 & Operating \\
\hline SuperPhenix & France & $\begin{array}{l}\text { MWth, } \\
1242 \\
\text { MWe }\end{array}$ & $\begin{array}{c}\text { Crey Malville, } \\
\text { France }\end{array}$ & Pool & $\mathrm{Na}$ & & 1996 \\
\hline KNK II & Germany & $\begin{array}{l}58 \mathrm{MWth}, \\
20 \mathrm{MWe} \\
762\end{array}$ & Karlsruhe, Germany & Loop & $\mathrm{Na}$ & 1972 & 1991 \\
\hline SNR-300 & Germany & $\begin{array}{l}\text { MWth, } \\
327 \text { MWe }\end{array}$ & Kalkar, Germany & Loop & $\mathrm{Na}$ & \multicolumn{2}{|c|}{ Never Operated } \\
\hline JOYO & Japan & 140 MWth & $\begin{array}{l}\text { Oarai Eng. Ctr., } \\
\text { Japan }\end{array}$ & Loop & $\mathrm{Na}$ & 1977 & Operating \\
\hline Monju & Japan & $\begin{array}{c}714 \\
\text { MWth, } \\
280 \mathrm{MWe} \\
750\end{array}$ & Tsuruga, Japan & Loop & $\mathrm{Na}$ & 1995 & Suspended ${ }^{\mathrm{a}}$ \\
\hline $\mathrm{BN}-350$ & Russia & $\begin{array}{c}\text { MWth, } \\
350 \mathrm{MWe} \\
1470\end{array}$ & Aktau, Kazakhstan & Loop & $\mathrm{Na}$ & 1972 & 1999 \\
\hline BN-600 & Russia & $\begin{array}{l}\text { MWth, } \\
600 \text { MWe }\end{array}$ & Beloyarsk, Russia & Pool & $\mathrm{Na}$ & 1980 & Operating \\
\hline BOR-60 & Russia & $\begin{array}{l}55 \mathrm{MWth}, \\
12 \mathrm{MWe}\end{array}$ & $\begin{array}{c}\text { Dimitrovgrad, } \\
\text { Russia }\end{array}$ & Loop & $\mathrm{Na}$ & 1968 & Operating \\
\hline
\end{tabular}

${ }^{a}$ Operations suspended in 1995. Scheduled for restart in 2008. 
The first step in the accident analysis process is the assembly and review of available information. NEPA documents frequently rely heavily on authorization basis documents as the basis for the identification of candidate accidents. Authorization basis documents are not available for an advanced recycling reactor so this accident analysis also relies on information from assessments conducted for similar reactor designs. The following information sources are used in the identification of candidate accidents.

- Advanced Recycling Reactor NEPA data study-Information relevant to the accident analysis from the Advanced Recycling Reactor Preliminary NEPA Data Study (Briggs et al. 2007) was reviewed to define the scope and nature of activities and identify material inventories and potential hazards. Note that the advanced recycling reactor is currently in the pre-conceptual design stage and as such specifications of operations, primary system configuration and fuel design have not been determined. Therefore, most of the operational characteristics have been based on available information from existing plants and on assessments conducted for the Clinch River Breeder Reactor Plant (CRBRP).

- Relevant Safety Analysis and Environmental Reports-A comprehensive Preliminary Safety Analysis Report (PMC 1982) was prepared for the CRBRP and, along with the precursor Environmental Report (PMC 1975) for the CRBRP, form the basis for most of the accident analysis information used in this report. These assessments identified the full range of accidents considered appropriate for the scope of their activities. In general, these assessments broadly cover the operational characteristics of a functional fast reactor and therefore encompass the spectrum of credible accidents and consequences.

- Incident Occurrences for Fast Reactors - In addition, fast reactors, both pre-conceptual as well as operational, present a long history of reactor operations that were reviewed and assessed for relevancy. A review of both U.S. and foreign reactor accidents was conducted to identify potential accident scenarios to be considered for an advanced recycling reactor.

- Probabilistic Risk Assessments - Available probabilistic risk assessments were reviewed for source of risks associated with the operation of a fast reactor.

The list of documents reviewed for the various types of fast reactors under consideration are presented in Table D.2.2.2.1-2. Note that the scope and intent of these documents are diverse and do not include a significant quantity of data relevant for this analysis. Probabilistic Risk Assessment and hazard summary documentation identified for the EBR-II reactor is a controlled distribution document and hence could not be referenced or quoted for this report. Similarly, safety analysis reports for the Power Reactor Innovative Small Module (PRISM) reactor were of limited availability due to the proprietary nature of the reports. Therefore, the available data for PRISM was extracted from the NRC Preapplication Safety Evaluation Report which was limited in detail and not a significant source of information. 
TABLE D.2.2.2.1-2—Documents Reviewed for Accident Related Information for Fast Reactors

\begin{tabular}{|c|c|}
\hline Reactor Design & Report Title \\
\hline ARR & Advanced Burner Reactor Preliminary NEPA Data Study (Briggs et al. 2007) \\
\hline CRBRP & Clinch River Breeder Reactor Plant_Environmental Report Vol. I-V. (PMC 1975) \\
\hline CRBRP & $\begin{array}{l}\text { Environmental Statement related to the Construction and Operation of the Clinch River } \\
\text { Breeder Reactor Plant (PMC 1982) }\end{array}$ \\
\hline CRBRP & $\begin{array}{l}\text { Environmental Statement related to the Construction and Operation of the Clinch River } \\
\text { Breeder Reactor Plant-Supplement. Vol. 1-2 (NRC 1982) } \\
\text { Draft Programmatic Environmental Imnact Statement for Accomnlishing Exnanded }\end{array}$ \\
\hline FFTF & $\begin{array}{l}\text { Civilian Nuclear Energy Research and Development and Isotope Production Missions in } \\
\text { the United States, Including the Role of the Fast Flux Test Facility. Vol. I and II. } \\
\text { (DOE 2000m). }\end{array}$ \\
\hline FFTF & $\begin{array}{l}\text { Draft Environmental Impact Statement for the Proposed Construction of Nuclear } \\
\text { Operations Related to Production of Radioisotope Power Systems (DOE 2005b). }\end{array}$ \\
\hline FFTF & $\begin{array}{l}\text { Safety Evaluation Report by the Office of Nuclear Reactor Regulation U.S. NRC for the } \\
\text { DOE Fast Flux Test Facility_-Project No. } 448 \text { (NRC 1978). }\end{array}$ \\
\hline Foreign & Unusual Occurrences during LMFR Operation (IAEA 2000) \\
\hline PRISM & $\begin{array}{l}\text { Preapplication Safety Evaluation Report for the Power Reactor Innovative Small Module } \\
\text { (PRISM) Liquid-Metal Reactor (NRC 1994a) }\end{array}$ \\
\hline
\end{tabular}

Each of the various data resources and pertinent information derived from this analysis is presented in each section below.

\section{D.2.2.2.2 Accidents Selected for Analysis}

Based on a review and assessment of previously conducted safety analyses for similarly designed systems, seven accident classes were compiled for applicability to this accident analysis. The majority of this information has been derived from the Preliminary Safety Analysis Report and the Environmental Report, both prepared for the CRBRP (PMC 1975, PMC 1982). Accident analyses for other comparable systems have been reviewed and have been discussed in prior sections of this report. The Preliminary Safety Analysis Report (PMC 1982) and Environmental Report (PMC 1975) represent the most complete and detailed assessments of all the available information that can be utilized for the purposes of this assessment. These two sources were examined for credibility of scenarios, applicability to an advanced recycling reactor, and the ability to reproduce these scenarios with sufficient detail so as to be applicable to an advanced recycling reactor accident analysis.

The selection criteria for the accident scenarios also attempts to ensure that these representative accidents encompass all facets of the reactor design as well as all potential radiological sources that are susceptible to atmospheric release. All of the accident scenarios from both the Preliminary Safety Analysis Report (PMC 1982) and Environmental Report (PMC 1975) were reviewed. A number of events were similar in the postulated sequence of events. Differences between the two resources were reconciled with the focus towards being conservative.

All potential accident scenarios that were reviewed and selected have been classified into seven classes. These classes encompass multiple integrated systems of the reactor including both primary and secondary coolants, heat transfer systems, fuel handling systems and radioactive waste processes. While these do not represent all sub-systems, the review of the Preliminary 
Safety Analysis Report (PMC 1982), as discussed in prior sections, shows that only a finite group of events lead to a radiological release.

The accidents selected for further analysis within the seven classes of accidents, as well as natural phenomena and external events, are summarized in Table D.2.2.2.2-1. Selection of the events was described in the previous sections of the report. Table D.2.2.2.2-1 presents the selected accident for each accident class, the fault level (accident frequency) and the materials at risk.

TABLE D.2.2.2.2-1—Advanced Recycling Reactor Accidents Selected for Analysis

\begin{tabular}{|c|c|c|c|}
\hline Accident Class & Representative Event & Frequency & Material at Risk \\
\hline Undercooling & $\begin{array}{l}\text { UC-1: Turbine Trip_-Release through } \\
\text { Steam Dump }\end{array}$ & Anticipated & $\begin{array}{c}\text { Steam Generating } \\
\text { System }\end{array}$ \\
\hline Fuel Handling & $\begin{array}{l}\text { FH-2: Spent Nuclear Fuel Cladding } \\
\text { Failure in the Ex-Vessel Transfer Machine }\end{array}$ & $\begin{array}{l}\text { Extremely } \\
\text { Unlikely }\end{array}$ & Fission Gas Release \\
\hline Refueling & $\begin{array}{l}\text { RF-2: Cover Gas Release During } \\
\text { Refueling }\end{array}$ & Unlikely & $\begin{array}{l}\text { Cover Gas during } \\
\text { Maintenance }\end{array}$ \\
\hline $\begin{array}{l}\text { Sodium Spills- } \\
\text { Primary }\end{array}$ & $\begin{array}{l}\text { SP-2: Failure of Ex-Containment Primary } \\
\text { Sodium Storage Tank }\end{array}$ & $\begin{array}{l}\text { Extremely } \\
\text { Unlikely }\end{array}$ & Primary Sodium \\
\hline $\begin{array}{l}\text { Sodium Spills_-Ex- } \\
\text { Vessel Transfer } \\
\text { Machine }\end{array}$ & $\begin{array}{l}\text { SE-1: Failure of Ex-Vessel Storage Tank } \\
\text { Sodium Cooling System During Operation }\end{array}$ & $\begin{array}{l}\text { Extremely } \\
\text { Unlikely }\end{array}$ & $\begin{array}{l}\text { Ex-Vessel Storage } \\
\text { Tank Sodium }\end{array}$ \\
\hline $\begin{array}{l}\text { Sodium Spills- } \\
\text { Intermediate Heat } \\
\text { Transport System }\end{array}$ & $\begin{array}{l}\text { SI-1: Intermediate Heat Transport System } \\
\text { Piping Leak }\end{array}$ & $\begin{array}{l}\text { Extremely } \\
\text { Unlikely }\end{array}$ & $\begin{array}{l}\text { Intermediate } \\
\text { Sodium }\end{array}$ \\
\hline Cover Gas System & $\begin{array}{l}\text { CG-1: Rupture of the Radioactive Argon } \\
\text { Processing System Cold Box }\end{array}$ & Unlikely & $\begin{array}{l}\text { Cover Gas during } \\
\text { Operation }\end{array}$ \\
\hline Natural Phenomena & Beyond Design Basis Earthquake & $\begin{array}{l}\text { Extremely } \\
\text { Unlikely }\end{array}$ & Core inventory \\
\hline External Event & Aircraft Crash & $\begin{array}{l}\text { Beyond } \\
\text { Extremely } \\
\text { Unlikely }\end{array}$ & Core inventory \\
\hline
\end{tabular}

As noted earlier, the advanced recycling reactor is in the pre-conceptual design phase and therefore details of the materials at risk, release quantities and release locations for the accidents summarized in Table D.2.2.2.2-1 are based on the CRBRP studies. While the CRBRP studies specified stack releases for some scenarios, the analyses here assume ground level releases in order to provide consistency among the different reactors. Note that these scenarios were generated before the conceptual design of the CRBRP was completed and are therefore generalized for a commercial scale fast reactor. The advance safety provisions of the advanced recycling reactor are not accounted for in this analysis, hence this analysis selection process results in scenarios that are clearly bounding for the advanced recycling reactor and should not be viewed as estimates of the actual risks posed.

Accident sequences, postulated variables, quantities of materials at risk and release estimates were reviewed and differences reconciled. A source term for each scenario was developed using conservative parameters. 
Specific release quantities such as water/steam in the Steam Generator System and sodium inventories within coolant loops and storage tanks were based on specifications for the CRBRP (PMC 1975, PMC 1982). Note that the CRBRP was designed as a 975 MWth plant; this is within the design specifications proposed for the advanced recycling reactor (250 to 2,000 MWth). An area of uncertainty is the quantity of aerosols generated by the combustion of spilled sodium. The quantity of $\mathrm{Na}_{2} \mathrm{O}$ generated is highly dependent upon available oxygen content, spill size, temperature and spill geometry. This analysis was performed for the Preliminary Safety Analysis Report (PMC 1982) and Environmental Report (PMC 1975) using computer models and the ability to use such models for the advanced recycling reactor are not possible given the lack of design information.

Radiological inventories for water/steam, fuel assemblies, primary sodium and cover gas systems are all inter-related and would be generated after the overall reactor design has been determined. The inventories used for the generation of source terms for this assessment were based on such data generated for the CRBRP (PMC 1975, PMC 1982). Wherever possible, a conservative approach to the selection of data was used (i.e. maximum power assembly versus average power assembly). Radiological inventories used for water/steam and primary sodium were estimated based on end-of-plant-life characteristics.

For each of the selected events, a scenario-specific table identifying the specific release parameters accompanies the description of each scenario provided below. Assumptions made for parameter selection are also presented.

\section{Undercooling Event (UC-1): Turbine Trip and Release Through Steam Dump}

A turbine trip would initiate a steam by-pass which means that heat removal has to be accomplished via steam venting to the atmosphere through actuation of the Power Relief Valve. A failure of the main condenser would also require a steam dump through the Power Relief Valve. This venting would continue until the heat load is sufficiently reduced for secondary systems to effectively function. This scenario results in the complete ejection of steam/water from the Steam Generator System including the deaerator, condenser hotwell, condensate and feedwater piping, condensate storage tank and steam generator loops to atmosphere. Generally, this scenario would result in the largest release of steam from the Steam Generator System.

A total of 450,000 pounds (lbs) $(204,117$ kilograms [kg]) of water/steam was postulated for the CRBRP by the Environmental Report (PMC 1975). The assumed maximum concentration of tritium in the water/steam system was 0.25 microcurie/gram $(\mu \mathrm{Ci} / \mathrm{g})$ which is the estimated tritium concentration in the steam/water system after 30 years of plant operation, the assumed plant life of the CRBRP. While the advanced recycling reactor is expected to have a longer operating life, the 30-year value is an above-average inventory. Table D.2.2.2.2-2 presents the release parameters for the "Turbine Trip and Release Through Steam Dump" event. 


\section{TABLE D.2.2.2.2-2-Advanced Recycling Reactor Release}

Parameters for the Turbine Trip Event

\begin{tabular}{|c|c|c|}
\hline Parameter & Value & Basis/Comment \\
\hline $\begin{array}{l}\text { Release } \\
\text { Point }\end{array}$ & Ground level & $\begin{array}{l}\text { All reactor accidents are based on a ground level release to provide a } \\
\text { common basis. }\end{array}$ \\
\hline Duration & 1.5 hours & $\begin{array}{l}\text { Assumed release rate by CRBRP Environmental Report (PMC 1975). } \\
\text { Steam/water inventory for the advanced recycling reactor has not yet }\end{array}$ \\
\hline $\begin{array}{l}\text { Material at } \\
\text { risk }\end{array}$ & $\begin{array}{c}450,000 \mathrm{lbs} \text { of } \\
\text { water/steam } \\
\text { Concentration of } \\
\text { tritium in the } \\
\text { water/steam system was } \\
0.25 \mu \mathrm{Ci} / \mathrm{g}\end{array}$ & $\begin{array}{c}\text { been determined so specifications of the CRBRP are used instead. } \\
\text { A total of } 450,000 \text { lbs of water/steam was postulated for CRBRP } \\
\text { (PMC 1975). This is the entire inventory of the Steam Generator } \\
\text { System. The assumed maximum concentration of tritium in the } \\
\text { water/steam system was } 0.25 \mu \mathrm{Ci} / \mathrm{g} \text { which is the estimated tritium } \\
\text { concentration in the steam/water system after } 30 \text { years of plant } \\
\text { operation. Source term from CRBRP in lieu of available data for } \\
\text { advanced recycling reactor. }\end{array}$ \\
\hline $\begin{array}{l}\text { Damage } \\
\text { ratio }\end{array}$ & 1 & Assuming the entire material at risk is involved is conservative. \\
\hline $\begin{array}{l}\text { Airborne } \\
\text { release } \\
\text { fraction }\end{array}$ & 1 & Vapor \\
\hline $\begin{array}{l}\text { Respirable } \\
\text { fraction }\end{array}$ & $\begin{array}{l}\text { included in the airborne } \\
\text { release fraction }\end{array}$ & This factor is included with the airborne release fraction value above. \\
\hline $\begin{array}{l}\text { Leak path } \\
\text { factor }\end{array}$ & 1 & Assuming all airborne material is released is conservative. \\
\hline Frequency & $\begin{array}{l}\text { Anticipated ( } 0.03 / \mathrm{yr} \text { is } \\
\text { used for this category) }\end{array}$ & (PMC 1982) \\
\hline
\end{tabular}

\section{Fuel Handling Event (FH-2): Spent Fuel Cladding Failure in the Ex-Vessel Transfer Machine}

The likely causes of fuel cladding failure are mechanical damage (e.g., dropping, improper loading, and sequencing of refueling motions) and inadequate cooling (e.g., loss of power, system failure). The largest postulated fission gas release to the atmosphere from failed fuel is most likely to occur in the Ex-Vessel Transfer Machine as other locations within the fuel handling system such as the reactor vessel, Ex-Vessel Storage Tank and the fuel handling cell are likely to have gas-cleanup systems which could capture and process fission gases prior to release. The failure within the Ex-Vessel Transfer Machine would result in the immediate release of 100 percent of the noble gas and halogen inventory from a single fuel assembly to the Ex-Vessel Transfer Machine interior. After the immediate release of 100 percent of the noble gas and halogen inventory to the Ex-Vessel Transfer Machine interior, the gases can slowly diffuse through the seals of the Ex-Vessel Transfer Machine to the Reactor Containment Building and Reactor Service Building where they can be ventilated to the atmosphere.

The earliest possible time that any core component could be handled is 36 hours after shut-down. For fuel assembly removal, this cool-down period would be a minimum of 87 hours, but it is conservatively assumed for the Extremely Unlikely scenario that the accident occurs 36 hours after shutdown. The maximum fuel assembly fission gas inventory for a maximum powered fuel assembly at 36 hours after shutdown would be $6 \times 10^{5} \mathrm{Ci}$ which includes all noble gas and halogen inventories (PMC 1982). Table D.2.2.2.2-3 presents the release parameters for the "Spent Nuclear Fuel Cladding Failure in the Ex-Vessel Transfer Machine" event. 


\section{TABLE D.2.2.2.2-3-Advanced Recycling Reactor Release Parameters for the Spent Fuel Cladding Failure in the Ex-Vessel Transfer Machine Event (FH-2)}

\begin{tabular}{|c|c|c|}
\hline Parameter & Value & Basis/Comment \\
\hline $\begin{array}{l}\text { Release } \\
\text { Point }\end{array}$ & Ground level & $\begin{array}{l}\text { All reactor accidents are based on a ground level release to provide } \\
\text { a common basis. }\end{array}$ \\
\hline Duration & 3 hours & $\begin{array}{c}\text { CRBRP Environmental Report estimates travel time of Ex-Vessel } \\
\text { Transfer Machine from reactor vessel to Ex-Vessel Storage Tank } \\
\text { and cover gas cleanup system (PMC 1975). }\end{array}$ \\
\hline $\begin{array}{l}\text { Material at } \\
\text { risk }\end{array}$ & $\begin{array}{l}\text { Fission gas inventory in the } \\
\text { Ex-Vessel Transfer Machine } \\
\text { and release rates to the } \\
\text { Reactor Containment } \\
\text { Building with } 36 \text { hours of } \\
\text { decay time. }\end{array}$ & $\begin{array}{l}\text { Accident assumes immediate release of } 100 \text { percent of noble gas } \\
\text { and halogen inventory from single fuel assembly to Ex-Vessel } \\
\text { Transfer Machine interior. The fission gas inventory for a } \\
\text { maximum powered fuel assembly at } 36 \text { hours after shutdown was } \\
\text { used [6x10 } 5 \text { Ci of noble gas and halogen inventories (PMC 1982)]. } \\
\text { Gases slowly diffuse through the seals of Ex-Vessel Transfer } \\
\text { Machine to the Reactor Containment Building. Estimates of } \\
\text { inventory and release rates from the Ex-Vessel Storage Tank to the } \\
\text { Reactor Containment Building for CRBRP (PMC 1982) extracted } \\
\text { for CRBRP in lieu of available data for advanced recycling reactor. }\end{array}$ \\
\hline $\begin{array}{l}\text { Damage } \\
\text { ratio }\end{array}$ & 1 & It is conservative to assume the entire material at risk is involved. \\
\hline $\begin{array}{l}\text { Airborne } \\
\text { release } \\
\text { fraction }\end{array}$ & 1 volatiles and iodine & $\begin{array}{l}\text { The release fraction from the fuel assembly is assumed to be } 1 \text { for } \\
\text { noble gases and iodine (PMC 1982). }\end{array}$ \\
\hline $\begin{array}{l}\text { Respirable } \\
\text { fraction }\end{array}$ & 1 & This is appropriate for noble gases and iodine. \\
\hline $\begin{array}{l}\text { Leak path } \\
\text { factor }\end{array}$ & 1 & $\begin{array}{c}\text { It is conservative to assume there is no holdup in the reactor } \\
\text { building. }\end{array}$ \\
\hline Frequency & $\begin{array}{l}\text { Extremely Unlikely }\left(10^{-5} / \mathrm{yr} \text { is }\right. \\
\text { used for this category) }\end{array}$ & $($ PMC 1982) \\
\hline
\end{tabular}

\section{Refueling Event (RF-2): Cover Gas Released During Refueling}

The design basis is for the breakaway of the Auxiliary Handling Machine from the floor valve on the Small Rotating Plug. The breakaway could potentially happen at the moment that the floor valve is in the open position, resulting in a release of cover gas through the Small Rotating Plug into the Reactor Containment Building. It was conservatively assumed that the release occurred 30 hours after shutdown. The reactor cover gas is the largest potential source of radioactive gas and it is conservatively assumed that the gas inventory also contains fission gases from 1 percent failed fuel. The cover gas would be released to the Reactor Containment Building and it is conservatively assumed that it is instantaneously released from the Reactor Containment Building to the atmosphere through the exhaust system. Table D.2.2.2.2-4 presents the release parameters for the "Cover Gas Released During Refueling" event. 
TABLE D.2.2.2.2-4-Advanced Recycling Reactor Release Parameters for the Cover Gas Released During Refueling Event (RF-2)

\begin{tabular}{|c|c|c|}
\hline Parameter & Value & Basis/Comment \\
\hline $\begin{array}{l}\text { Release } \\
\text { Point }\end{array}$ & Ground level & $\begin{array}{l}\text { All reactor accidents are based on a ground level release to provide a common } \\
\text { basis. }\end{array}$ \\
\hline Duration & 1 minute & $\begin{array}{c}\text { Instantaneous event and it is conservatively assumed that material is } \\
\text { immediately exhausted to atmosphere (PMC 1982). }\end{array}$ \\
\hline $\begin{array}{l}\text { Material at } \\
\text { risk }\end{array}$ & $\begin{array}{l}\text { Reactor covers } \\
\text { gas inventory } 30 \text { - } \\
\text { hours after } \\
\text { shutdown. }\end{array}$ & $\begin{array}{l}\text { The reactor cover gas is conservatively assumed to also contain fission gases } \\
\text { from } 1 \text { percent failed fuel. } 100 \text { percent of cover gas inventory is released } \\
\text { through port. Data extracted for CRBRP in lieu of available data for the } \\
\text { advanced recycling reactor. Cover gas inventory after } 30 \text { hours of decay time } \\
\text { from CRBRP Environmental Report (PMC 1975). }\end{array}$ \\
\hline $\begin{array}{l}\text { Damage } \\
\text { ratio }\end{array}$ & 1 & Assuming the entire material at risk is involved is conservative. \\
\hline $\begin{array}{l}\text { Airborne } \\
\text { release } \\
\text { fraction }\end{array}$ & $\begin{array}{l}1 \text { volatiles } \\
\text { (including iodine) }\end{array}$ & $\begin{array}{l}\text { It is conservatively assumed that all of the gases are released to the reactor } \\
\text { containment building. }\end{array}$ \\
\hline $\begin{array}{l}\text { Respirable } \\
\text { fraction }\end{array}$ & 1 & It is conservative to assume the entire release is respirable \\
\hline $\begin{array}{l}\text { Leak path } \\
\text { factor }\end{array}$ & 1 & It is conservative to assume all airborne material is released. \\
\hline Frequency & $\begin{array}{l}\text { Unlikely } \\
(0.001 / \mathrm{yr} \text { is used } \\
\text { for this category) }\end{array}$ & (PMC 1982) \\
\hline
\end{tabular}

\section{Primary Sodium Spill Event (SP-2): Failure of Ex-Containment Primary Sodium Tank}

A complete failure of one of two primary sodium storage tanks located in cells at the lowest level of the Intermediate Bay of the Steam Generator Building is postulated to release 50,000 gal $(189,270 \mathrm{~L})$ of primary sodium. These tanks are used to store the primary sodium in the event that maintenance requires access to one of the primary sodium loops. This scenario pertains to loop-type reactors and is not relevant for pool-type reactors. The spilled primary sodium reacts with the available oxygen generating $\mathrm{Na}_{2} \mathrm{O}$ aerosols; it is assumed that the cell is inerted (approximately 2 percent oxygen). It was assumed that the fission product and activation inventory of the primary sodium concentrations was based on 30 years of plant operation with 10 days decay time. The over-pressurization results in leakage into the intermediate bay of the Steam Generator Building. The Steam Generator Building ventilation system continues to operate during the accident. Sodium fire analysis and estimates of Reactor Containment Building pressure indicate that a total release of $82.9 \mathrm{lbs}(37.6 \mathrm{~kg})$ of $\mathrm{Na}_{2} \mathrm{O}$, containing $61.1 \mathrm{lbs}(27.7 \mathrm{~kg})$ of primary sodium would be released to the atmosphere (PMC 1982). Table D.2.2.2.2-5 presents the release parameters for the "Failure of Ex-Containment Primary Sodium Tank" event. 


\begin{tabular}{lcc}
\multicolumn{2}{c}{ TABLE D.2.2.2.2-5-Advanced Recycling Reactor Release Parameters for the Failure of } \\
Ex-Containment Primary Sodium Tank (SP-2)
\end{tabular}

\section{Ex-Vessel Storage Tank Sodium Spill Event (SE-1): Failure of Ex-Vessel Storage Tank Sodium Cooling System during Operation}

There are two sodium cooling circuits used to cool the sodium circulating through the Ex-Vessel Storage Tank. These tanks are located below grade in the Reactor Service Building in cells adjacent to the Ex-Vessel Storage Tank. Pump suction lines exit the Ex-Vessel Storage Tank at or above the normal sodium level. The internal downcomer inside the Ex-Vessel Storage Tank extends to below the sodium level; a rupture of the pump suction line in the cooling circuit is postulated to occur at a low point of the pump suction line which siphons the sodium out of the tank to the level of the internal downcomer. The accident is postulated to occur after 30 years of plant operation. It was assumed that the concentration in the aerosol equals the concentration in primary sodium spilled and that there is no loss due to radioactive decay or plating-out. Table D.2.2.2.2-6 presents the release parameters for the "Failure of Ex-Vessel Storage Tank Sodium Cooling System During Operation" event based on the CRBRP design. 


\begin{tabular}{|c|c|c|}
\hline Parameter & Value & Basis/Comment \\
\hline $\begin{array}{l}\text { Release } \\
\text { Point }\end{array}$ & Ground level & $\begin{array}{l}\text { All reactor accidents are based on a ground level release to } \\
\text { provide a common basis. }\end{array}$ \\
\hline Duration & 8 hours & $\begin{array}{c}\text { Release rate estimates from Preliminary Safety Analysis Report } \\
\text { (PMC 1982) estimate that } 99 \text { percent of the } 33.8 \mathrm{~kg} \text { of } \\
\text { Ex-Vessel Storage Tank sodium would be released within the } \\
\text { first } 8 \text { hours. }\end{array}$ \\
\hline $\begin{array}{l}\text { Material at } \\
\text { risk }\end{array}$ & $\begin{array}{l}\text { Radioactive content of Ex- } \\
\text { Vessel Storage Tank sodium } \\
\text { (30 years of plant operation). } \\
33.8 \mathrm{~kg} \text { of Ex-Vessel Storage } \\
\text { Tank sodium released to } \\
\text { atmosphere. }\end{array}$ & $\begin{array}{l}\text { Spilled sodium burns to } \mathrm{Na}_{2} \mathrm{O} \text { as aerosol generating } 100 \mathrm{lb} \\
\text { (45.4 kg) of } \mathrm{Na}_{2} \mathrm{O} \text { of which } 74.5 \mathrm{lb}(33.8 \mathrm{~kg} \text { ) is Ex-Vessel } \\
\text { Storage Tank sodium (PMC 1982). } \\
\text { Radioactive content of Ex-Vessel Storage Tank sodium based } \\
\text { on } 30 \text { years of plant operation (PMC 1982). Data extracted for } \\
\text { CRBRP in lieu of available data for advanced recycling reactor. }\end{array}$ \\
\hline $\begin{array}{l}\text { Damage } \\
\text { ratio }\end{array}$ & 1 & $\begin{array}{c}\text { It is conservative to assume the entire material at risk is } \\
\text { involved. }\end{array}$ \\
\hline $\begin{array}{l}\text { Airborne } \\
\text { release } \\
\text { fraction }\end{array}$ & $\begin{array}{l}1 \text { noble gas } \\
0.25 \text { iodine } \\
5 \times 10^{-4} \text { other }\end{array}$ & $\begin{array}{l}\text { These values are consistent with the values used in Section } \\
6.3 .1 \text { of DOE-HDBK-3010-94 (DOE 2000i). }\end{array}$ \\
\hline $\begin{array}{l}\text { Respirable } \\
\text { fraction }\end{array}$ & 1 & It is conservative to assume the entire release is respirable. \\
\hline $\begin{array}{l}\text { Leak path } \\
\text { factor }\end{array}$ & 1 & It is conservative to assume all airborne material is released. \\
\hline Frequency & $\begin{array}{l}\text { Extremely Unlikely }\left(10^{-5} / \mathrm{yr} \text { is }\right. \\
\text { used for this category) }\end{array}$ & (PMC 1982) \\
\hline
\end{tabular}

\section{Intermediate Heat Transport System Sodium Spill Event (SI-1): Intermediate Heat Transport System Piping Leak}

A sodium leak in the 24 in $(61 \mathrm{~cm})$ main loop hot leg piping is assumed to occur while the Intermediate Heat Transport System is at maximum operating temperature and pressure. The break location was postulated to be at the low point of the main loop thereby maximizing spill volume. A high velocity sodium jet would be converted into a spray. The Preliminary Safety Analysis Report (PMC 1982) estimates the total spill quantity of $300,000 \mathrm{lbs}(136,077 \mathrm{~kg})$ of sodium over a 5.5 hour period. The sodium in the Intermediate Heat Transport System is nonradioactive and leakage of primary sodium into the Intermediate Heat Transport System is prevented by a pressure differential. Once the Intermediate Heat Transport System is depressurized, in-leakage could potentially occur. Therefore to maximize radiological impact it was conservatively assumed that a maximum undetected leak rate of $0.78 \mathrm{gal} / \mathrm{min}(2.95 \mathrm{~L} / \mathrm{min})$ from the primary to the Intermediate Heat Transport System had occurred for 2 hours (PMC 1982). For two exclusion zone doses, this equates to 94 gal (356 L) of primary sodium in 39,000 gal (147,631 L) of Intermediate Heat Transport System sodium. The analysis presented in the Preliminary Safety Analysis Report (PMC 1982) modeled a high velocity sodium jet that was converted into a spray. For 2-hour exclusion area boundary doses, it was assumed that 10 percent of sodium is burned, which would include 9.5 gal $(35.0 \mathrm{~L})$ of primary sodium. Of this primary sodium, 27 percent is released as $\mathrm{Na}_{2} \mathrm{O}$ aerosol which is entirely released from the Steam Generator Building at ground level. Table D.2.2.2.2-7 presents the release parameters for the "Intermediate Heat Transport System Piping Leak" event. 


TABLE D.2.2.2-7-Advanced Recycling Reactor Release Parameters Intermediate Heat
Transport System Piping Leak (SI-1)

\section{Cover Gas Systems Event (CG-1): Rupture in the Radioactive Argon Processing System Cold Box}

The Radioactive Argon Processing System Cold Box includes a cryogenic still used to extract krypton and xenon from the reactor cover gas. A postulated rupture of the cryostill would release liquid argon from the Radioactive Argon Processing System (along with the $\mathrm{Kr}$ and $\mathrm{Xe}$ constituents) and the liquid nitrogen coolant into the cold box cell. It was conservatively assumed that the reactor has been operating with 1 percent failed fuel and the cover gas has reached its steady-state isotopic concentration. Quantities of gases released to the cell include 1,935 standard cubic feet (scf) of nitrogen and 1,190 scf of argon for a total of 3,125 scf. The radioactive content is primarily Xe-133, Xe- 135 and $\mathrm{Kr}-88$ with a total inventory of $5.57 \times 10^{5} \mathrm{Ci}$. It is assumed that a connection between the cell and the Reactor Containment Building exists at the time of the accident and a total release is vented through the Reactor Containment Building vent. The total radioactivity released in 2 hours is assumed to be $4.62 \times 10^{4} \mathrm{Ci}$ (PMC 1982).

Release in the cell is assumed to exhaust through the Reactor Service Building (PMC 1975), but no credit is taken for dispersion resulting from a stack release. Table D.2.2.2.2-8 presents the release parameters for the "Rupture in the Radioactive Argon Processing System Cold Box" event based on the CRBRP design. 


\begin{tabular}{|c|c|c|}
\hline Parameter & Value & Basis/Comment \\
\hline $\begin{array}{l}\text { Release } \\
\text { Point }\end{array}$ & Ground level & $\begin{array}{c}\text { All reactor accidents are based on a ground level release to provide a common } \\
\text { basis. }\end{array}$ \\
\hline Duration & 2 hours & (PMC 1982). \\
\hline $\begin{array}{l}\text { Material at } \\
\text { risk }\end{array}$ & $\begin{array}{c}\text { Release } \\
\text { estimates: } \\
\text { Xe-133: } \\
3.92 \times 10^{4} \mathrm{Ci} \\
\mathrm{Xe}-135: \\
6.89 \times 10^{3} \mathrm{Ci} \\
\mathrm{Kr}-88: \\
1.11 \times 10^{2} \mathrm{Ci}\end{array}$ & $\begin{array}{l}\text { The radioactive content in cold box is primarily Xe- } 133, \mathrm{Xe}-135 \text { and } \mathrm{Kr}-88 \text { with } \\
\text { a total inventory of } 5.57 \times 10^{5} \mathrm{Ci} \text {. It is assumed that a connection between the cell } \\
\text { and the Reactor Containment Building exists at the time of the accident and a } \\
\text { total release is vented through the Reactor Containment Building vent. The total } \\
\text { radioactivity released in } 2 \text { hours in } 4.62 \times 10^{4} \mathrm{Ci} \text { (PMC 1982). Data from CRBRP } \\
\text { assumed in place of unavailable advanced recycling reactor design data. }\end{array}$ \\
\hline $\begin{array}{l}\text { Damage } \\
\text { ratio }\end{array}$ & 1 & It is conservative to assume the entire material at risk is involved. \\
\hline $\begin{array}{l}\text { Airborne } \\
\text { release } \\
\text { fraction }\end{array}$ & 1 & It is conservative to assume all material becomes airborne \\
\hline $\begin{array}{l}\text { Respirable } \\
\text { fraction }\end{array}$ & 1 & It is conservative to assume the entire release is respirable. \\
\hline $\begin{array}{l}\text { Leak path } \\
\text { factor }\end{array}$ & 1 & It is conservative to assume all airborne material is released. \\
\hline Frequency & $\begin{array}{l}\text { Unlikely } \\
(0.001 / \mathrm{yr} \text { is } \\
\text { used for this } \\
\text { category) }\end{array}$ & (PMC 1982) \\
\hline
\end{tabular}

\section{Beyond Design Basis Accidents}

As described in the Advanced Recycling Reactor Preliminary NEPA Data Study (Briggs et al. 2007) in this and the following two paragraphs, three beyond-design-basis accident sequences, each involving failure of both reactor scram systems, have received attention in past licensing safety assessments. In the Unprotected Loss-Of-Flow sequence, it is assumed that power is lost to all primary and secondary coolant pumps, and the reactor scram systems fail to activate. In the Unprotected Transient Overpower sequence, it is assumed that one or more inserted control rods are withdrawn, plus the reactor scram systems fail to operate. In the unprotected Loss-Of-Heat-Sink accident, it is assumed that heat removal through the power conversion system is lost, and the reactor scram systems do not activate. Taken collectively, these three accident initiators encompass all the ways that an operating reactor can be perturbed (i.e., by a change in coolant flow, by a change in reactivity, or by a change in coolant inlet temperature).

The NEPA Data Study (Briggs et al. 2007) concludes that a sodium-cooled fast reactor would be capable of accommodating these beyond-design-basis accident initiators without producing high temperatures and conditions that might lead to a severe accident, such as coolant boiling, cladding failures, or fuel melting. The inherent neutronic, hydraulic, and thermal performance characteristics of such a reactor provide self-protection in beyond-design-basis sequences to limit accident consequences without activation of engineered systems or operator actions. This characteristic has been termed 'inherent passive safety.' 
The efficacy of such passive safety was demonstrated through two landmark tests conducted on the Experimental Breeder Reactor-II (EBR-II), namely loss-of-flow without scram and loss-ofheat-sink without scram tests. With the automated safety systems disabled, the two most demanding accident initiating events were deliberately induced with the reactor at full power, first one, and then the other. Each time the reactor simply coasted to a safe, low power state without any damage at all to the fuel or any reactor component. These tests (Unprotected LossOf-Flow and Loss-Of-Heat-Sink) proved conclusively that passive safety design is achievable for metallic-fueled fast reactors with sodium cooling. Rods stops or other devices are expected to be used to limit the amount of excess reactivity inserted during an Unprotected Transient Overpower event. Consequently, for an advanced recycling reactor, beyond-design-basis accidents need to be considered only in the context of probabilistic risk assessments, in which such events are analyzed with best-estimate scoping methods that demonstrate safety margins beyond the normal design basis without requiring the use of deterministic analyses (Briggs et al. 2007).

As discussed in Section D.1, beyond design basis accidents, as related to earthquakes and aircraft crashes, are presented below.

Beyond Design Basis Earthquake-An Operational Basis Earthquake could result in loss of off-site power, which would cause loss of power to pumps. Compounding the effect are the changes in core configuration resulting in the closing of radial gaps and hence reactivity insertion. Changes in core configuration can also lead to a reduced control rod insertion rate. The event was assessed by the Preliminary Safety Analysis Report (PMC 1982) and it concluded that such an event would result in a maximum fuel cladding temperature of $1440^{\circ} \mathrm{F}\left(782^{\circ} \mathrm{C}\right)$, which would generate no significant additional degradation of cladding lifetime capability and was within the acceptance criteria for the Preliminary Safety Analysis Report.

A "Beyond Design Basis Earthquake" may cause equipment malfunctions and result in a disruptive core event. Note that the major systems of an advanced recycling reactor including the reactor vessel containing the reactor core and the primary sodium coolant, the intermediate heat transport system, and the power conversion systems would be located below grade on a nuclear island which may be seismically isolated from its foundations (Briggs et al. 2007). Therefore the consequences of a Beyond Design Basis Earthquake would be mitigated substantially.

No assessments for a Beyond Design Basis Earthquake were completed by the Environmental Report (PMC 1975) or the Preliminary Safety Analysis Report (PMC 1982) for the CRBRP. Such assessments were considered outside the bounds of these analyses. For this PEIS, this scenario is analyzed consistent with the guidance provided in Sections D.1.2 and D.1.4 of this appendix for reactor "Beyond Design Basis Earthquake" events.

Preliminary isotopic inventories were estimated by Kim and Yang (Kim and Yang 2008) for a conceptual 2,000 MWth reactor core design. This reactor configuration is at the upper bound of the current range considered for an advanced recycling reactor. Inventories were estimated for recycled oxide fuel, startup oxide fuel, recycled metal fuel and startup metal fuel. Core inventories included assemblies within in-vessel storage. The highest isotopic inventories for 
fission products and plutonium isotopes were estimated for the recycled oxide fuel. These isotopic inventories were used for this assessment. Estimates for a core at end of equilibrium cycle were used.

For current reactors, the median frequency of earthquakes for a Safe Shutdown Earthquake is $1.0 \times 10^{-5}$ per year (see Appendix B, "Reference Probability for the Exceedance Level of the Safe Shutdown Earthquake Ground Motion," of Regulatory Guide 1.165 [NRC 1997]). Therefore this value is used as a conservative estimate of the frequency of this "Beyond Design Basis Earthquake" event. Table D.2.2.2.2-9 presents the release parameters for the "Beyond Design Basis Earthquake."

TABLE D.2.2.2.2-9—Advanced Recycling Reactor Release Parameters for the Beyond Design Basis Earthquake

\begin{tabular}{|c|c|c|}
\hline Parameter & Value & Basis/Comment \\
\hline Release Point & Ground level & $\begin{array}{l}\text { All reactor accidents are based on a ground level release to } \\
\text { provide a common basis. }\end{array}$ \\
\hline Duration & See Table D.1.4-1 & See Table D.1.4-1. \\
\hline Material at risk & $\begin{array}{l}\text { Core inventory from } \\
\text { Kim and Yang } 2008\end{array}$ & $\begin{array}{l}\text { Kim and Yang } 2008 \text { provides the inventory for the design being } \\
\text { evaluated. }\end{array}$ \\
\hline $\begin{array}{l}\text { Release } \\
\text { parameters }\end{array}$ & See Table D.1.4-1 & $\begin{array}{l}\text { Release parameters were selected consistent with the values used } \\
\text { for all reactors (see Table D.1.4-1). }\end{array}$ \\
\hline Frequency & $\begin{array}{l}1 \times 10^{-5} / \mathrm{yr} \text { (Extremely } \\
\text { Unlikely) }\end{array}$ & $\begin{array}{l}\text { The median frequency of a safe shutdown earthquake for current } \\
\text { LWRs is } 1.0 \times 10^{-5} / \mathrm{yr} \text { per Regulatory Guide } 1.165 \text { (NRC 1997). } \\
\text { The frequency is expected to be no greater for an advanced } \\
\text { recycling reactor than for current LWRs, so an event frequency of } \\
10^{-5} / \mathrm{yr} \text { is used in this analysis. }\end{array}$ \\
\hline
\end{tabular}

Beyond Design Basis Aircraft Crash-This scenario is analyzed consistent with the methodology described in Sections D.1.2 and D.1.4 for an "Aircraft Crash." Because the NRC must license the facility, the site will be required to meet NRC Aircraft Hazards criteria (NRC 2007k). Therefore, an event frequency of $1 \times 10^{-7}$ per year is used in this analysis. Table D.2.2.2.2-10 presents the release parameters for the Beyond Design Basis "Aircraft Crash."

TABLE D.2.2.2.2-10-Advanced Recycling Reactor Release Parameters for the Beyond Design Basis Aircraft Crash

\begin{tabular}{|c|c|c|}
\hline Parameter & Value & Basis/Comment \\
\hline $\begin{array}{l}\text { Release } \\
\text { Point }\end{array}$ & Ground level & $\begin{array}{c}\text { All reactor accidents are based on a ground level release to provide a common } \\
\text { basis. }\end{array}$ \\
\hline Duration & See Table D.1.4-1 & See Table D.1.4-1. \\
\hline $\begin{array}{l}\text { Material at } \\
\text { risk }\end{array}$ & $\begin{array}{l}\text { Core inventory } \\
\text { from Kim and } \\
\text { Yang } 2008\end{array}$ & Kim and Yang 2008 provides the inventory for the design being evaluated. \\
\hline $\begin{array}{l}\text { Release } \\
\text { parameters }\end{array}$ & See Table D.1.4-1 & $\begin{array}{l}\text { Release parameters were selected consistent with the values used for all } \\
\text { reactors (see Table D.1.4-1). }\end{array}$ \\
\hline Frequency & $\begin{array}{l}1 \times 10^{-7} / \mathrm{yr}(\text { Beyond } \\
\text { Extremely } \\
\text { Unlikely) }\end{array}$ & $\begin{array}{l}\text { The facility must be licensed by the NRC, so it will be required to meet NRC } \\
\text { Aircraft Hazards criteria (NRC } 2007 \mathrm{k}) \text {. Therefore, an event frequency of } \\
\qquad 10^{-7} / \mathrm{yr} \text { is used in this analysis. }\end{array}$ \\
\hline
\end{tabular}




\section{D.2.2.2.3 Results}

Tables D.2.2.2.3-1 through D.2.2.2.3-3 present the accident risks from all accidents at all sites to the offsite population, MEI, and noninvolved worker.

TABLE D.2.2.2.3-1-Advanced Recycling Reactor Accident Risks ${ }^{a}$ to the Offsite Population (All Sites)

\begin{tabular}{|c|c|c|c|c|c|c|}
\hline Accident (Frequency) & $\begin{array}{l}\text { Generic } \\
\text { Site } 1\end{array}$ & $\begin{array}{c}\text { Generic } \\
\text { Site } 2\end{array}$ & $\begin{array}{l}\text { Generic } \\
\text { Site } 3\end{array}$ & $\begin{array}{l}\text { Generic } \\
\text { Site } 4\end{array}$ & $\begin{array}{l}\text { Generic } \\
\text { Site } 5\end{array}$ & $\begin{array}{c}\text { Generic Site } \\
\quad 6\end{array}$ \\
\hline Turbine Trip $(0.03 / \mathrm{yr})$ & $1 \times 10^{-8}$ & $3 \times 10^{-8}$ & $2 \times 10^{-7}$ & $7 \times 10^{-8}$ & $1 \times 10^{-7}$ & $5 \times 10^{-7}$ \\
\hline $\begin{array}{l}\text { Spent Nuclear Fuel Cladding } \\
\text { Failure }\left(10^{-5} / \mathrm{yr}\right)\end{array}$ & $1 \times 10^{-10}$ & $3 \times 10^{-10}$ & $1 \times 10^{-9}$ & $5 \times 10^{-10}$ & $1 \times 10^{-9}$ & $4 \times 10^{-9}$ \\
\hline $\begin{array}{l}\text { Cover Gas Release During } \\
\text { Refueling }(0.001 / \mathrm{yr})\end{array}$ & $9 \times 10^{-11}$ & $3 \times 10^{-10}$ & $1 \times 10^{-9}$ & $3 \times 10^{-10}$ & $7 \times 10^{-10}$ & $3 \times 10^{-9}$ \\
\hline $\begin{array}{l}\text { Ex-Containment Primary } \\
\text { Sodium Tank Failure } \\
\left(10^{-5} / \mathrm{yr}\right)\end{array}$ & $6 \times 10^{-11}$ & $1 \times 10^{-10}$ & $7 \times 10^{-10}$ & $3 \times 10^{-10}$ & $5 \times 10^{-10}$ & $2 \times 10^{-9}$ \\
\hline $\begin{array}{l}\text { Ex-Vessel Storage Tank } \\
\text { Sodium Cooling System } \\
\text { Failure }\left(10^{-5} / \mathrm{yr}\right)\end{array}$ & $3 \times 10^{-13}$ & $7 \times 10^{-13}$ & $3 \times 10^{-12}$ & $2 \times 10^{-12}$ & $3 \times 10^{-12}$ & $1 \times 10^{-11}$ \\
\hline $\begin{array}{l}\text { Intermediate Heat Transport } \\
\text { System Pipe Leak }\left(10^{-5} / \mathrm{yr}\right)\end{array}$ & $7 \times 10^{-10}$ & $2 \times 10^{-9}$ & $9 \times 10^{-9}$ & $3 \times 10^{-9}$ & $6 \times 10^{-9}$ & $2 \times 10^{-8}$ \\
\hline $\begin{array}{l}\text { Radioactive Argon } \\
\text { Processing System Cold Box } \\
\text { Rupture }(0.001 / \mathrm{yr})\end{array}$ & $1 \times 10^{-7}$ & $3 \times 10^{-7}$ & $2 \times 10^{-6}$ & $4 \times 10^{-7}$ & $9 \times 10^{-7}$ & $4 \times 10^{-6}$ \\
\hline $\begin{array}{l}\text { Beyond Design Basis } \\
\text { Earthquake, mitigated } \\
\left(1 \times 10^{-5} / \mathrm{yr}\right)\end{array}$ & $3 \times 10^{-6}$ & $8 \times 10^{-6}$ & $4 \times 10^{-5}$ & $2 \times 10^{-5}$ & $3 \times 10^{-5}$ & $1 \times 10^{-4}$ \\
\hline $\begin{array}{l}\text { Beyond Design Basis } \\
\text { Earthquake, unmitigated } \\
\left(1 \times 10^{-5} / \mathrm{yr}\right)\end{array}$ & 0.004 & 0.008 & 0.04 & 0.02 & 0.03 & 0.1 \\
\hline $\begin{array}{l}\text { Aircraft Crash, mitigated } \\
\left(1 \times 10^{-7} / \mathrm{yr}\right)\end{array}$ & $3 \times 10^{-8}$ & $8 \times 10^{-8}$ & $4 \times 10^{-7}$ & $2 \times 10^{-7}$ & $3 \times 10^{-7}$ & $1 \times 10^{-6}$ \\
\hline $\begin{array}{l}\text { Aircraft Crash, unmitigated } \\
\left(1 \times 10^{-7} / \mathrm{yr}\right)\end{array}$ & $4 \times 10^{-5}$ & $8 \times 10^{-5}$ & $4 \times 10^{-4}$ & $2 \times 10^{-4}$ & $3 \times 10^{-4}$ & 0.001 \\
\hline
\end{tabular}

The accident with the highest risk to the offsite population, MEI, and noninvolved worker is the "Unmitigated Beyond Design Basis Earthquake" scenario. The collective risk to the offsite population for this scenario would range from 0.004 expected LCFs per year of operation in the Site-1 offsite population (300,000 people) to 0.1 expected LCFs per year of operation in the Site-6 offsite population $(8,200,000$ people) . 
TABLE D.2.2.2.3-2 - Advanced Recycling Reactor Accident Risks ${ }^{a}$ to the Maximally Exposed Individual (All Sites)

\begin{tabular}{|c|c|c|c|c|c|c|}
\hline Accident (Frequency) & $\begin{array}{l}\text { Generic } \\
\text { Site } 1\end{array}$ & $\begin{array}{l}\text { Generic } \\
\text { Site } 2\end{array}$ & $\begin{array}{l}\text { Generic } \\
\text { Site } 3\end{array}$ & $\begin{array}{l}\text { Generic } \\
\text { Site } 4\end{array}$ & $\begin{array}{l}\text { Generic } \\
\text { Site } 5\end{array}$ & $\begin{array}{l}\text { Generic } \\
\text { Site } 6\end{array}$ \\
\hline Turbine Trip (0.03/yr) & $1 \times 10^{-10}$ & $1 \times 10^{-10}$ & $1 \times 10^{-10}$ & $9 \times 10^{-10}$ & $9 \times 10^{-10}$ & $9 \times 10^{-10}$ \\
\hline $\begin{array}{l}\text { Spent Nuclear Fuel Cladding } \\
\text { Failure }\left(10^{-5} / \mathrm{yr}\right)\end{array}$ & $9 \times 10^{-13}$ & $9 \times 10^{-13}$ & $9 \times 10^{-13}$ & $7 \times 10^{-12}$ & $7 \times 10^{-12}$ & $7 \times 10^{-12}$ \\
\hline $\begin{array}{l}\text { Cover Gas Release During } \\
\text { Refueling }(0.001 / \mathrm{yr})\end{array}$ & $1 \times 10^{-12}$ & $1 \times 10^{-12}$ & $1 \times 10^{-12}$ & $7 \times 10^{-12}$ & $7 \times 10^{-12}$ & $7 \times 10^{-12}$ \\
\hline $\begin{array}{l}\text { Ex-Containment Primary } \\
\text { Sodium Tank Failure }\left(10^{-5} / \mathrm{yr}\right)\end{array}$ & $4 \times 10^{-13}$ & $4 \times 10^{-13}$ & $4 \times 10^{-13}$ & $3 \times 10^{-12}$ & $3 \times 10^{-12}$ & $3 \times 10^{-12}$ \\
\hline $\begin{array}{l}\text { Ex-Vessel Storage Tank } \\
\text { Sodium Cooling System } \\
\text { Failure }\left(10^{-5} / \mathrm{yr}\right)\end{array}$ & $2 \times 10^{-15}$ & $2 \times 10^{-15}$ & $2 \times 10^{-15}$ & $2 \times 10^{-14}$ & $2 \times 10^{-14}$ & $2 \times 10^{-14}$ \\
\hline $\begin{array}{l}\text { Intermediate Heat Transport } \\
\text { System Pipe Leak }\left(10^{-5} / \mathrm{yr}\right)\end{array}$ & $7 \times 10^{-12}$ & $7 \times 10^{-12}$ & $7 \times 10^{-12}$ & $5 \times 10^{-11}$ & $5 \times 10^{-11}$ & $5 \times 10^{-11}$ \\
\hline $\begin{array}{l}\text { Radioactive Argon Processing } \\
\text { System Cold Box Rupture } \\
(0.001 / \mathrm{yr})\end{array}$ & $1 \times 10^{-9}$ & $1 \times 10^{-9}$ & $1 \times 10^{-9}$ & $8 \times 10^{-9}$ & $8 \times 10^{-9}$ & $8 \times 10^{-9}$ \\
\hline $\begin{array}{l}\text { Beyond Design Basis } \\
\text { Earthquake, mitigated } \\
\left(1 \times 10^{-5} / \mathrm{yr}\right)\end{array}$ & $2 \times 10^{-8}$ & $2 \times 10^{-8}$ & $2 \times 10^{-8}$ & $3 \times 10^{-7}$ & $3 \times 10^{-7}$ & $3 \times 10^{-7}$ \\
\hline $\begin{array}{l}\text { Beyond Design Basis } \\
\text { Earthquake, unmitigated } \\
\left(1 \times 10^{-5} / \mathrm{yr}\right)\end{array}$ & $1 \times 10^{-5}$ & $1 \times 10^{-5}$ & $1 \times 10^{-5}$ & $1 \times 10^{-5}$ & $1 \times 10^{-5}$ & $1 \times 10^{-5}$ \\
\hline $\begin{array}{l}\text { Aircraft Crash, mitigated } \\
\left(1 \times 10^{-7} / \mathrm{yr}\right)\end{array}$ & $2 \times 10^{-10}$ & $2 \times 10^{-10}$ & $2 \times 10^{-10}$ & $3 \times 10^{-9}$ & $3 \times 10^{-9}$ & $3 \times 10^{-9}$ \\
\hline $\begin{array}{l}\text { Aircraft Crash, unmitigated } \\
\left(1 \times 10^{-7} / \mathrm{yr}\right)\end{array}$ & $1 \times 10^{-7}$ & $1 \times 10^{-7}$ & $1 \times 10^{-7}$ & $1 \times 10^{-7}$ & $1 \times 10^{-7}$ & $1 \times 10^{-7}$ \\
\hline
\end{tabular}

For the MEI, the "Unmitigated Beyond Design Basis Earthquake" scenario would result in an increased LCF risk of $1 \times 10^{-5}$ per year of operation. 
TABLE D.2.2.2.3-3-Advanced Recycling Reactor Accident Risks ${ }^{a}$ To The Noninvolved Worker (All Sites)

\begin{tabular}{|c|c|c|c|c|c|c|}
\hline Accident (Frequency) & $\begin{array}{c}\text { Generic } \\
\text { Site 1 }\end{array}$ & $\begin{array}{c}\text { Generic } \\
\text { Site 2 }\end{array}$ & $\begin{array}{c}\text { Generic } \\
\text { Site } 3\end{array}$ & $\begin{array}{c}\text { Generic } \\
\text { Site } 4\end{array}$ & $\begin{array}{c}\text { Generic } \\
\text { Site } 5\end{array}$ & $\begin{array}{l}\text { Generic } \\
\text { Site } 6\end{array}$ \\
\hline Turbine Trip (0.03/yr) & $2 \times 10^{-9}$ & $2 \times 10^{-9}$ & $2 \times 10^{-9}$ & $9 \times 10^{-9}$ & $9 \times 10^{-9}$ & $9 \times 10^{-9}$ \\
\hline $\begin{array}{l}\text { Spent Nuclear Fuel Cladding } \\
\text { Failure }\left(10^{-5} / \mathrm{yr}\right)\end{array}$ & $1 \times 10^{-11}$ & $1 \times 10^{-11}$ & $1 \times 10^{-11}$ & $7 \times 10^{-11}$ & $7 \times 10^{-11}$ & $7 \times 10^{-11}$ \\
\hline $\begin{array}{l}\text { Cover Gas Release During } \\
\text { Refueling }(0.001 / \mathrm{yr})\end{array}$ & $5 \times 10^{-12}$ & $5 \times 10^{-12}$ & $5 \times 10^{-12}$ & $2 \times 10^{-11}$ & $2 \times 10^{-11}$ & $2 \times 10^{-11}$ \\
\hline $\begin{array}{l}\text { Ex-Containment Primary } \\
\text { Sodium Tank Failure Sodium } \\
\text { Tank Failure }\left(10^{-5} / \mathrm{yr}\right)\end{array}$ & $6 \times 10^{-12}$ & $6 \times 10^{-12}$ & $6 \times 10^{-12}$ & $3 \times 10^{-11}$ & $3 \times 10^{-11}$ & $3 \times 10^{-11}$ \\
\hline $\begin{array}{l}\text { Ex-Vessel Storage Tank Sodium } \\
\text { Cooling System Failure }\left(10^{-5} / \mathrm{yr}\right)\end{array}$ & $3 \times 10^{-14}$ & $3 \times 10^{-14}$ & $3 \times 10^{-14}$ & $2 \times 10^{-13}$ & $2 \times 10^{-13}$ & $2 \times 10^{-13}$ \\
\hline $\begin{array}{l}\text { Intermediate Heat Transport } \\
\text { System Pipe Leak }\left(10^{-5} / \mathrm{yr}\right)\end{array}$ & $7 \times 10^{-11}$ & $7 \times 10^{-11}$ & $7 \times 10^{-11}$ & $3 \times 10^{-10}$ & $3 \times 10^{-10}$ & $3 \times 10^{-10}$ \\
\hline $\begin{array}{l}\text { Radioactive Argon Processing } \\
\text { System Cold Box Rupture } \\
(0.001 / \mathrm{yr})\end{array}$ & $7 \times 10^{-9}$ & $7 \times 10^{-9}$ & $7 \times 10^{-9}$ & $3 \times 10^{-8}$ & $3 \times 10^{-8}$ & $3 \times 10^{-8}$ \\
\hline $\begin{array}{l}\text { Beyond Design Basis } \\
\text { Earthquake, mitigated } \\
\left(1 \times 10^{-5} / \mathrm{yr}\right)\end{array}$ & $6 \times 10^{-7}$ & $6 \times 10^{-7}$ & $6 \times 10^{-7}$ & $4 \times 10^{-6}$ & $4 \times 10^{-6}$ & $4 \times 10^{-6}$ \\
\hline $\begin{array}{l}\text { Beyond Design Basis } \\
\text { Earthquake, unmitigated } \\
\left(1 \times 10^{-5} / \mathrm{yr}\right)\end{array}$ & $1 \times 10^{-5}$ & $1 \times 10^{-5}$ & $1 \times 10^{-5}$ & $1 \times 10^{-5}$ & $1 \times 10^{-5}$ & $1 \times 10^{-5}$ \\
\hline $\begin{array}{l}\text { Aircraft Crash, mitigated } \\
\left(1 \times 10^{-7} / \mathrm{yr}\right)\end{array}$ & $6 \times 10^{-9}$ & $6 \times 10^{-9}$ & $6 \times 10^{-9}$ & $4 \times 10^{-8}$ & $4 \times 10^{-8}$ & $4 \times 10^{-8}$ \\
\hline $\begin{array}{l}\text { Aircraft Crash, unmitigated } \\
\left(1 \times 10^{-7} / \mathrm{yr}\right)\end{array}$ & $1 \times 10^{-7}$ & $1 \times 10^{-7}$ & $1 \times 10^{-7}$ & $1 \times 10^{-7}$ & $1 \times 10^{-7}$ & $1 \times 10^{-7}$ \\
\hline
\end{tabular}

For the onsite noninvolved worker, the "Unmitigated Beyond Design Basis Earthquake" scenario would result in an increased risk of a LCF of $1 \times 10^{-5}$ per year of operation.

Tables D.2.2.2.3-4 through D.2.2.2.3-6 present the accident consequences for an advanced recycling reactor at the six generic sites described in Section D.1.6 for the offsite population, MEI, and noninvolved worker. 
TABLE D.2.2.2.3-4-Advanced Recycling Reactor Accident Health Consequences (Dose in Person-Rem/Increased Number of Latent Cancer Fatalities) ${ }^{a}$ to the Offsite Population (All Sites)

\begin{tabular}{|c|c|c|c|c|c|c|}
\hline Accident (Frequency) & $\begin{array}{c}\text { Generic } \\
\text { Site } 1\end{array}$ & $\begin{array}{l}\text { Generic } \\
\text { Site } 2\end{array}$ & $\begin{array}{l}\text { Generic } \\
\text { Site } 3\end{array}$ & $\begin{array}{l}\text { Generic } \\
\text { Site } 4\end{array}$ & $\begin{array}{l}\text { Generic } \\
\text { Site } 5\end{array}$ & $\begin{array}{c}\text { Generic } \\
\text { Site } 6\end{array}$ \\
\hline \multirow{2}{*}{ Turbine Trip $(0.03 / y r)$} & $7 \times 10^{-4} /$ & $0.002 /$ & $0.008 /$ & $0.004 /$ & $0.007 /$ & $0.03 /$ \\
\hline & $4 \times 10^{-7}$ & $1 \times 10^{-6}$ & $5 \times 10^{-6}$ & $2 \times 10^{-6}$ & $4 \times 10^{-6}$ & $2 \times 10^{-5}$ \\
\hline Spent Nuclear Fuel Cladding & $0.02 /$ & $0.04 /$ & $0.2 /$ & $0.09 /$ & $0.2 /$ & $0.7 /$ \\
\hline Failure $\left(10^{-5} / \mathrm{yr}\right)$ & $1 \times 10^{-5}$ & $3 \times 10^{-5}$ & $1 \times 10^{-4}$ & $5 \times 10^{-5}$ & $1 \times 10^{-4}$ & $4 \times 10^{-4}$ \\
\hline Cover Gas Release During & $2 \times 10^{-4} /$ & $4 \times 10^{-4} /$ & $0.002 /$ & $6 \times 10^{-4} /$ & $0.001 /$ & $0.005 /$ \\
\hline Refueling $(0.001 / \mathrm{yr})$ & $9 \times 10^{-8}$ & $3 \times 10^{-7}$ & $1 \times 10^{-6}$ & $3 \times 10^{-7}$ & $7 \times 10^{-7}$ & $3 \times 10^{-6}$ \\
\hline Ex-Containment Primary & $0.01 /$ & $0.02 /$ & $0.1 /$ & $0.05 /$ & $0.09 /$ & $0.4 /$ \\
\hline Sodium Tank Failure $\left(10^{-5} / \mathrm{yr}\right)$ & $6 \times 10^{-6}$ & $1 \times 10^{-5}$ & $7 \times 10^{-5}$ & $3 \times 10^{-5}$ & $5 \times 10^{-5}$ & $2 \times 10^{-4}$ \\
\hline Ex-Vessel Storage Tank & $5 \times 10^{-5} /$ & $1 \times 10^{-4} /$ & $6 \times 10^{-4} /$ & $2 \times 10^{-4} /$ & $5 \times 10^{-4} /$ & $0.002 /$ \\
\hline $\begin{array}{l}\text { Sodium Cooling System } \\
\text { Failure }\left(10^{-5} / \mathrm{yr}\right)\end{array}$ & $3 \times 10^{-8}$ & $7 \times 10^{-8}$ & $3 \times 10^{-7}$ & $2 \times 10^{-7}$ & $3 \times 10^{-7}$ & $1 \times 10^{-6}$ \\
\hline $\begin{array}{l}\text { Intermediate Heat Transport } \\
\text { System Pipe Leak }\left(10^{-5} / \mathrm{yr}\right)\end{array}$ & $\begin{array}{c}0.1 / \\
7 \times 10^{-5}\end{array}$ & $\begin{array}{c}0.3 / \\
2 \times 10^{-4}\end{array}$ & $1 / 9 \times 10^{-4}$ & $\begin{array}{c}0.5 / \\
3 \times 10^{-4}\end{array}$ & $1 / 6 \times 10^{-4}$ & $4 / 2 \times 10^{-3}$ \\
\hline $\begin{array}{l}\text { Radioactive Argon Processing } \\
\text { System Cold Box Rupture } \\
(0.001 / \mathrm{yr})\end{array}$ & $\begin{array}{c}0.2 / \\
1 \times 10^{-4}\end{array}$ & $\begin{array}{c}0.5 / \\
3 \times 10^{-4}\end{array}$ & $2 / 0.001$ & $\begin{array}{c}0.7 / \\
4 \times 10^{-4}\end{array}$ & $2 / 9 \times 10^{-4}$ & $6 / 0.004$ \\
\hline $\begin{array}{l}\text { Beyond Design Basis } \\
\text { Earthquake, mitigated } \\
\left(1 \times 10^{-5} / \mathrm{yr}\right)\end{array}$ & $500 / 0.3$ & $1,000 / 0.8$ & $6,000 / 4$ & $3,000 / 2$ & $5,000 / 3$ & $2 \times 10^{4} / 10$ \\
\hline $\begin{array}{l}\text { Beyond Design Basis } \\
\text { Earthquake, unmitigated } \\
\left(1 \times 10^{-5} / \mathrm{yr}\right)\end{array}$ & $\begin{array}{c}6 \times 10^{5} / \\
400\end{array}$ & $\begin{array}{c}1 \times 10^{6} / \\
800\end{array}$ & $\begin{array}{l}7 \times 10^{6} / \\
4,000\end{array}$ & $\begin{array}{l}3 \times 10^{6} / \\
2,000\end{array}$ & $\begin{array}{c}5 \times 10^{6} / \\
3,000\end{array}$ & $\begin{array}{l}2 \times 10^{7} / \\
10,000\end{array}$ \\
\hline $\begin{array}{l}\text { Aircraft Crash, mitigated } \\
\left(1 \times 10^{-7} / \mathrm{yr}\right)\end{array}$ & $500 / 0.3$ & $1,000 / 0.8$ & $6,000 / 4$ & $3,000 / 2$ & $5,000 / 3$ & $2 \times 10^{4} / 10$ \\
\hline $\begin{array}{l}\text { Aircraft Crash, unmitigated } \\
\left(1 \times 10^{-7} / \mathrm{yr}\right)\end{array}$ & $\begin{array}{c}6 \times 10^{5} / \\
400\end{array}$ & $\begin{array}{c}1 \times 10^{6} / \\
800\end{array}$ & $\begin{array}{l}7 \times 10^{6} / \\
4,000\end{array}$ & $\begin{array}{c}3 \times 10^{6} / \\
2,000\end{array}$ & $\begin{array}{c}5 \times 10^{6} / \\
3,000\end{array}$ & $\begin{array}{l}2 \times 10^{7} / \\
10,000\end{array}$ \\
\hline
\end{tabular}

${ }^{a}$ The dose in person-rem is reported before the slash and the increased number of LCFs is presented after the slash.

The accidents with the highest consequence to the offsite population, MEI, noninvolved worker would be the "Unmitigated Beyond Design Basis Earthquake" and "Unmitigated Aircraft Crash" scenarios. Using the dose-to-risk conversion factor of $6 \times 10^{-4}$ per person-rem, these accidents would result in 400 to 10,000 additional LCFs in the surrounding population for these Extremely Unlikely and Beyond Extremely Unlikely accidents. 
TABLE D.2.2.2.3-5-Advanced Recycling Reactor Accident Health Consequences (Dose in Person-Rem /Increased Likelihood of a Latent Cancer Fatality) to the Maximally Exposed Individual (All Sites)

\begin{tabular}{|c|c|c|c|c|c|c|}
\hline Accident (Frequency) & $\begin{array}{l}\text { Generic } \\
\text { Site } 1\end{array}$ & $\begin{array}{c}\text { Generic } \\
\text { Site } 2\end{array}$ & $\begin{array}{c}\text { Generic } \\
\text { Site } 3\end{array}$ & $\begin{array}{l}\text { Generic } \\
\text { Site } 4\end{array}$ & $\begin{array}{l}\text { Generic } \\
\text { Site } 5\end{array}$ & $\begin{array}{c}\text { Generic } \\
\text { Site } 6\end{array}$ \\
\hline Turbine Trip $(0.03 / \mathrm{yr})$ & $\begin{array}{c}7 \times 10^{-6} / \\
4 \times 10^{-9}\end{array}$ & $\begin{array}{c}7 \times 10^{-6} / \\
4 \times 10^{-9}\end{array}$ & $\begin{array}{c}7 \times 10^{-6} / \\
4 \times 10^{-9}\end{array}$ & $\begin{array}{c}5 \times 10^{-5} / \\
3 \times 10^{-8}\end{array}$ & $\begin{array}{c}5 \times 10^{-5} / \\
3 \times 10^{-8}\end{array}$ & $\begin{array}{c}5 \times 10^{-5} / \\
3 \times 10^{-8}\end{array}$ \\
\hline Spent Nuclear Fuel Cladding & $2 \times 10^{-4} /$ & $2 \times 10^{-4} /$ & $2 \times 10^{-4} /$ & $0.001 /$ & $0.001 /$ & $0.001 /$ \\
\hline Failure $\left(10^{-5} / \mathrm{yr}\right)$ & $9 \times 10^{-8}$ & $9 \times 10^{-8}$ & $9 \times 10^{-8}$ & $7 \times 10^{-7}$ & $7 \times 10^{-7}$ & $7 \times 10^{-7}$ \\
\hline Cover Gas Release During & $2 \times 10^{-6} /$ & $2 \times 10^{-6} /$ & $2 \times 10^{-6} /$ & $1 \times 10^{-5} /$ & $1 \times 10^{-5} /$ & $1 \times 10^{-5} /$ \\
\hline Refueling $(0.001 / \mathrm{yr})$ & $1 \times 10^{-9}$ & $1 \times 10^{-9}$ & $1 \times 10^{-9}$ & $7 \times 10^{-9}$ & $7 \times 10^{-9}$ & $7 \times 10^{-9}$ \\
\hline Ex-Containment Primary & $7 \times 10^{-5} /$ & $7 \times 10^{-5} /$ & $7 \times 10^{-5} /$ & $5 \times 10^{-4} /$ & $5 \times 10^{-4} /$ & $5 \times 10^{-4} /$ \\
\hline Sodium Tank Failure $\left(10^{-5} / \mathrm{yr}\right)$ & $4 \times 10^{-8}$ & $4 \times 10^{-8}$ & $4 \times 10^{-8}$ & $3 \times 10^{-7}$ & $3 \times 10^{-7}$ & $3 \times 10^{-7}$ \\
\hline Ex-Vessel Storage Tank & $3 \times 10^{-7} /$ & $3 \times 10^{-7} /$ & $3 \times 10^{-7} /$ & $3 \times 10^{-6} /$ & $3 \times 10^{-6} /$ & $3 \times 10^{-6} /$ \\
\hline $\begin{array}{l}\text { Sodium Cooling System } \\
\text { Failure }\left(10^{-5} / \mathrm{yr}\right)\end{array}$ & $2 \times 10^{-10}$ & $2 \times 10^{-10}$ & $2 \times 10^{-10}$ & $2 \times 10^{-9}$ & $2 \times 10^{-9}$ & $2 \times 10^{-9}$ \\
\hline Intermediate Heat Transport & $0.001 /$ & $0.001 /$ & $0.001 /$ & $0.008 /$ & $0.008 /$ & $0.008 /$ \\
\hline System Pipe Leak $\left(10^{-5} / \mathrm{yr}\right)$ & $7 \times 10^{-7}$ & $7 \times 10^{-7}$ & $7 \times 10^{-7}$ & $5 \times 10^{-6}$ & $5 \times 10^{-6}$ & $5 \times 10^{-6}$ \\
\hline Radioactive Argon Processing & $0.002 /$ & $0.002 /$ & $0.002 /$ & $0.01 /$ & $0.01 /$ & $0.01 /$ \\
\hline $\begin{array}{l}\text { System Cold Box Rupture } \\
(0.001 / \mathrm{yr})\end{array}$ & $1 \times 10^{-6}$ & $1 \times 10^{-6}$ & $1 \times 10^{-6}$ & $8 \times 10^{-6}$ & $8 \times 10^{-6}$ & $8 \times 10^{-6}$ \\
\hline Beyond Design Basis & & & & & & \\
\hline $\begin{array}{l}\text { Earthquake, mitigated } \\
\left(1 \times 10^{-5} / \mathrm{yr}\right)\end{array}$ & $3 / 0.002$ & $3 / 0.002$ & $3 / 0.002$ & $30 / 0.03$ & $30 / 0.03$ & $30 / 0.03$ \\
\hline Beyond Design Basis & & & & & & \\
\hline $\begin{array}{l}\text { Earthquake, unmitigated } \\
\left(1 \times 10^{-5} / \mathrm{yr}\right)\end{array}$ & $6,000 / 1$ & $6,000 / 1$ & $6,000 / 1$ & $5 \times 10^{4} / 1$ & $5 \times 10^{4} / 1$ & $5 \times 10^{4} / 1$ \\
\hline $\begin{array}{l}\text { Aircraft Crash, mitigated } \\
\left(1 \times 10^{-7} / \mathrm{yr}\right)\end{array}$ & $3 / 0.002$ & $3 / 0.002$ & $3 / 0.002$ & $30 / 0.03$ & $30 / 0.03$ & $30 / 0.03$ \\
\hline $\begin{array}{l}\text { Aircraft Crash, unmitigated } \\
\left(1 \times 10^{-7} / \mathrm{yr}\right)\end{array}$ & $6,000 / 1$ & $6,000 / 1$ & $6,000 / 1$ & $5 \times 10^{4} / 1$ & $5 \times 10^{4} / 1$ & $5 \times 10^{4} / 1$ \\
\hline
\end{tabular}

Using the dose-to-risk conversion factor of $6 \times 10^{-4}$ per person-rem (or twice $6 \times 10^{-4}$ per person-rem for individual doses greater than $20 \mathrm{rem}$ ) for the Extremely Unlikely "Unmitigated Beyond Design Basis Earthquake" and the Beyond Extremely Unlikely "Unmitigated Aircraft Crash" accidents, the MEI doses are estimated to result in a prompt radiation fatality. 


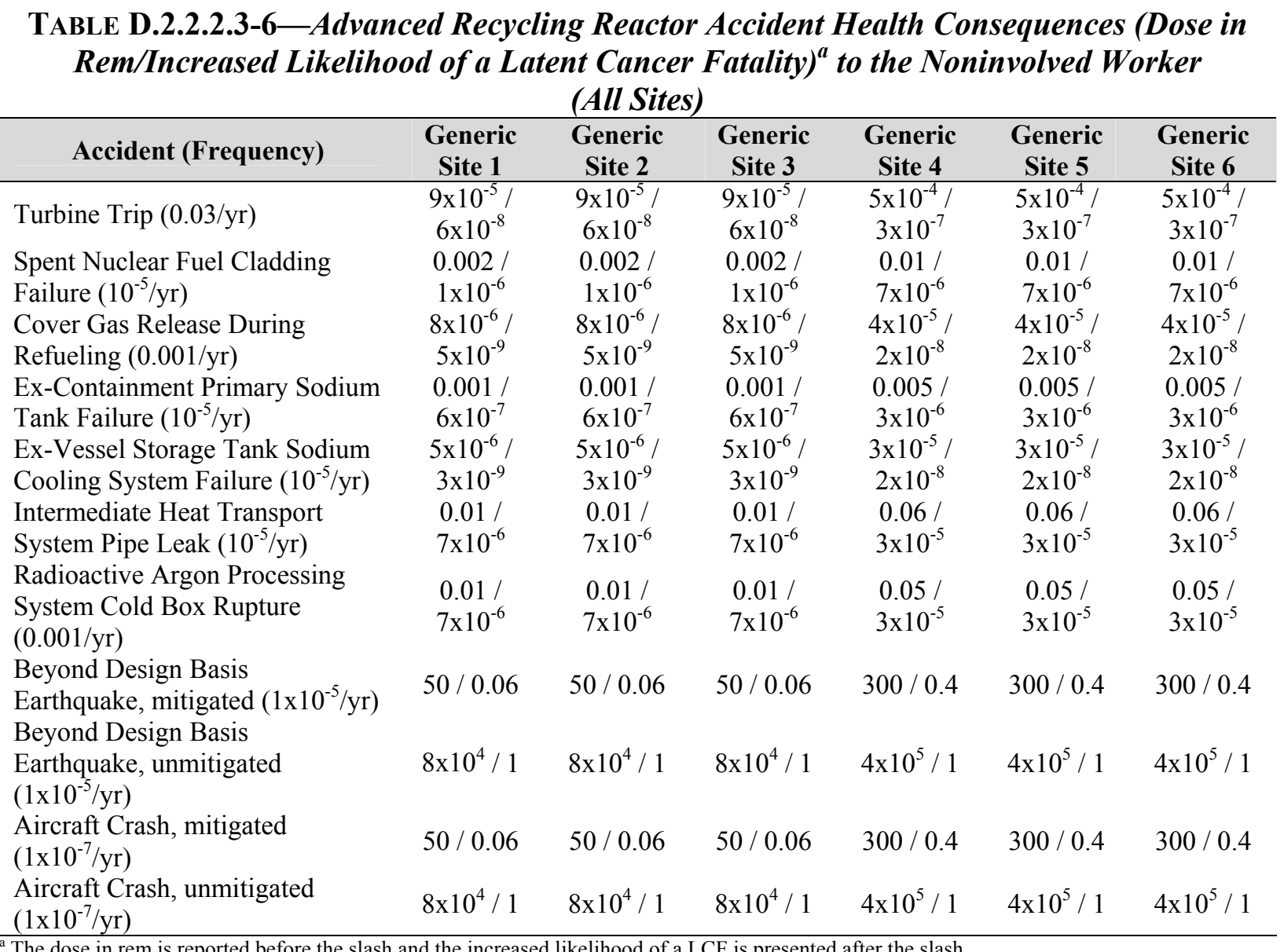

${ }^{a}$ The dose in rem is reported before the slash and the increased likelihood of a LCF is presented after the slash.

For the noninvolved worker, the Extremely Unlikely "Unmitigated Beyond Design Basis Earthquake" and the Beyond Extremely Unlikely "Unmitigated Aircraft Crash" accidents would result in a prompt radiation fatality.

\section{D.2.3 Thermal/Fast Reactor Recycle Alternative}

This section presents the impacts of potential accident scenarios associated with facilities under the Thermal/Fast Reactor Recycle Alternative, which is described in Section 2.3 of Chapter 2. The Thermal/Fast Reactor Recycle Alternative is similar to the Fast Reactor Recycle Alternative (Section D.2.2) with the addition of recycling in a thermal reactor prior to recycling in an advanced recycling reactor. The thermal reactor used for recycling is assumed to be either an LWR or an ALWR. The impacts associated with an advanced recycling reactor are presented in Section D.2.2.2 and are not repeated here. This section is sub-divided into the impacts of postulated accidents at three facilities: the nuclear fuel recycling center, a MOX-U-Pu fueled LWR, and a MOX-U-Pu fueled ALWR.

\section{D.2.3.1 Mixed Oxide-Uranium-Plutonium Fueled Light Water Reactor}

The impact of potential accidents at light water reactors utilizing MOX-U-Pu fuel was evaluated for the SPD EIS (DOE 1999d). The SPD EIS evaluated accidents at three existing LWR sites 
utilizing LEU fuel, as well as cores consisting of 40 percent mixed oxide (MOX) fuel and 60 percent conventional LWR fuel. This section evaluates the LWR using the MOX-U-Pu fuel. The SPD EIS considered both design basis and beyond design basis events, both of which are included here. A description of each accident is presented in the SPD EIS (DOE 1999d) and is not repeated here. In this GNEP PEIS, DOE has re-analyzed the consequences of the accident scenarios presented in the SPD EIS for the Catawba reactor for the six generic sites described in Section D.1.6. The accidents for the Catawba reactor were selected for evaluation here because it is a large LWR with a radioactive source term that equals or exceeds the source term of the other reactors analyzed in the SPD EIS. The frequency estimates for Catawba are sometimes less than the frequencies for the other reactors, but the consequences are always greater than or equal to the consequences for the other reactors. The consequences for the MOX-U-Pu fueled LWR accidents were recalculated for this GNEP PEIS based on the SPD EIS source terms. The parameters used for this analysis are presented in Table D.2.3.1-1. 


\section{TABLE D.2.3.1-1-Release Parameters for Mixed Oxide-Uranium-Plutonium Fueled Light Water Reactor Accidents}

\begin{tabular}{|c|c|c|}
\hline Parameter & Value & Basis/Comment \\
\hline \multicolumn{3}{|l|}{ Release Point } \\
\hline All scenarios & Ground level & $\begin{array}{c}\text { This is the default value used for all reactor accidents to } \\
\text { provide a common basis. }\end{array}$ \\
\hline \multicolumn{3}{|l|}{ Duration } \\
\hline $\begin{array}{l}\text { Early } \\
\text { Containment } \\
\text { Failure }\end{array}$ & $0.5 \mathrm{hr}$. & DOE $1999 \mathrm{~d}$ is the basis for the release durations. \\
\hline $\begin{array}{l}\text { Late Containment } \\
\text { Failure }\end{array}$ & $0.5 \mathrm{hr}$. & DOE $1999 \mathrm{~d}$ is the basis for the release durations. \\
\hline $\begin{array}{l}\text { Beyond Design } \\
\text { Basis Earthquake }\end{array}$ & See Table D.1.4-1 & See Table D.1.4-1. \\
\hline Aircraft Crash & See Table D.1.4-1 & See Table D.1.4-1. \\
\hline $\begin{array}{l}\text { All other } \\
\text { scenarios }\end{array}$ & $1 \mathrm{hr}$. & $\begin{array}{l}\text { This is the default value used when information is not } \\
\text { available. }\end{array}$ \\
\hline \multicolumn{3}{|l|}{ Source terms } \\
\hline $\begin{array}{l}\text { Design basis } \\
\text { events }\end{array}$ & $\begin{array}{l}\text { Source terms taken directly from } \\
\text { DOE 1999d. }\end{array}$ & $\begin{array}{l}\text { DOE 1999d provides the source terms for each design } \\
\text { basis scenario. }\end{array}$ \\
\hline $\begin{array}{l}\text { Beyond Design } \\
\text { Basis Earthquake }\end{array}$ & $\begin{array}{l}\text { Core inventory was taken from } \\
\text { DOE 1999d. Release parameters } \\
\text { taken from Table D.1.4-1. }\end{array}$ & $\begin{array}{l}\text { Release parameters were selected consistent with the } \\
\text { values used for all reactors (see Table D.1.4-1) and } \\
\text { applied to the core inventory for this reactor } \\
\text { (DOE 1999d). }\end{array}$ \\
\hline Aircraft Crash & $\begin{array}{l}\text { Core inventory was taken from } \\
\text { DOE 1999d. Release parameters } \\
\text { taken from Table D.1.4-1. }\end{array}$ & $\begin{array}{l}\text { Release parameters were selected consistent with the } \\
\text { values used for all reactors (see Table D.1.4-1) and } \\
\text { applied to the core inventory for this reactor } \\
\text { (DOE 1999d). }\end{array}$ \\
\hline $\begin{array}{l}\text { All other beyond } \\
\text { design basis } \\
\text { events }\end{array}$ & $\begin{array}{c}\text { Core inventory and release } \\
\text { parameters taken from DOE } \\
\text { 1999d. }\end{array}$ & $\begin{array}{l}\text { DOE } 1999 \text { d provides the core inventory and release } \\
\text { parameters for each beyond design basis event. }\end{array}$ \\
\hline \multicolumn{3}{|l|}{ Frequency $(/ \mathrm{yr})$} \\
\hline LOCA & $7.5 \times 10^{-6} / \mathrm{yr}$ (Extremely Unlikely) & DOE $1999 \mathrm{~d}$ is the basis for the frequency estimate. \\
\hline $\begin{array}{l}\text { Fuel Handling } \\
\text { Accident }\end{array}$ & $1 \times 10^{-4} / \mathrm{yr}$ (Unlikely) & DOE 1999 d is the basis for the frequency estimate. \\
\hline SG Tube Rupture & $\begin{array}{l}6.31 \times 10^{-10} / \mathrm{yr} \text { (Beyond Extremely } \\
\text { Unlikely) }\end{array}$ & DOE $1999 \mathrm{~d}$ is the basis for the frequency estimate. \\
\hline
\end{tabular}




\section{TABLE D.2.3.1-1—Release Parameters for Mixed Oxide-Uranium-Plutonium} Fueled Light Water Reactor Accidents (continued)

\begin{tabular}{|c|c|c|}
\hline Parameter & Value & Basis/Comment \\
\hline $\begin{array}{l}\text { Early Containment } \\
\text { Failure }\end{array}$ & $\begin{array}{l}3.42 \times 10^{-8} / \mathrm{yr} \text { (Beyond } \\
\text { Extremely Unlikely) }\end{array}$ & DOE $1999 \mathrm{~d}$ is the basis for the frequency estimate. \\
\hline $\begin{array}{l}\text { Late Containment } \\
\text { Failure }\end{array}$ & $\begin{array}{c}1.21 \times 10^{-5} \mathrm{yr} \text { (Extremely } \\
\text { Unlikely) }\end{array}$ & DOE $1999 \mathrm{~d}$ is the basis for the frequency estimate. \\
\hline $\begin{array}{l}\text { Interfacing System } \\
\text { LOCA }\end{array}$ & $\begin{array}{c}6.9 \times 10^{-8 /} \mathrm{yr} \text { (Beyond Extremely } \\
\text { Unlikely) }\end{array}$ & DOE $1999 \mathrm{~d}$ is the basis for the frequency estimate. \\
\hline $\begin{array}{l}\text { Beyond Design } \\
\text { Basis Earthquake }\end{array}$ & $\begin{array}{l}1 \times 10^{-5} / \mathrm{yr} \text { (Extremely } \\
\text { Unlikely) }\end{array}$ & $\begin{array}{c}\text { The median frequency of a safe shutdown earthquake } \\
\text { for current LWRs is } 1.0 \times 10^{-5} / \mathrm{yr} \text { per Regulatory Guide } \\
1.165 \text { (NRC 1997). The frequency is expected to be no } \\
\text { greater for use of MOX-U-Pu fuel than for current } \\
\text { LWRs, so an event frequency of } 10^{-7} / \mathrm{yr} \text { is used in this } \\
\text { analysis. }\end{array}$ \\
\hline Aircraft Crash & $\begin{array}{l}1 \times 10^{-7} / \mathrm{yr} \text { (Beyond Extremely } \\
\text { Unlikely) }\end{array}$ & $\begin{array}{c}\text { The facility must be licensed by the NRC, so it will be } \\
\text { required to meet NRC Aircraft Hazards criteria (NRC } \\
2007 \mathrm{k} \text { ). Therefore, an event frequency of } 10^{-7} / \mathrm{yr} \text { is } \\
\text { used in this analysis. }\end{array}$ \\
\hline
\end{tabular}

Tables D.2.3.1-2 through D.2.3.1-4 present the accident risks for the MOX-U-Pu fueled LWR at the six generic sites described in Section D.1.6 for the offsite population, MEI, and noninvolved worker.

TABLE D.2.3.1-2—Mixed Oxide-Uranium-Plutonium Fueled Light Water Reactor Accident Risks to the Offsite Population (All Sites)

\begin{tabular}{|c|c|c|c|c|c|c|}
\hline Accident (Frequency) & $\begin{array}{l}\text { Generic } \\
\text { Site } 1\end{array}$ & $\begin{array}{l}\text { Generic } \\
\text { Site } 2\end{array}$ & $\begin{array}{l}\text { Generic } \\
\text { Site } 3\end{array}$ & $\begin{array}{c}\text { Generic } \\
\text { Site } 4\end{array}$ & $\begin{array}{c}\text { Generic Site } \\
5\end{array}$ & $\begin{array}{l}\text { Generic } \\
\text { Site } 6\end{array}$ \\
\hline LOCA $\left(7.5 \times 10^{-6} / \mathrm{yr}\right)$ & $6 \times 10^{-7}$ & $2 \times 10^{-6}$ & $7 \times 10^{-6}$ & $3 \times 10^{-6}$ & $6 \times 10^{-6}$ & $2 \times 10^{-5}$ \\
\hline $\begin{array}{l}\text { Fuel Handling Accident } \\
\left(1 \times 10^{-4} / \mathrm{yr}\right)\end{array}$ & $7 \times 10^{-7}$ & $2 \times 10^{-6}$ & $7 \times 10^{-6}$ & $2 \times 10^{-6}$ & $4 \times 10^{-6}$ & $1 \times 10^{-5}$ \\
\hline $\begin{array}{l}\text { SG Tube Rupture } \\
\left(6.31 \times 10^{-10} / \mathrm{yr}\right)\end{array}$ & $3 \times 10^{-7}$ & $8 \times 10^{-7}$ & $4 \times 10^{-6}$ & $2 \times 10^{-6}$ & $3 \times 10^{-6}$ & $1 \times 10^{-5}$ \\
\hline $\begin{array}{l}\text { Early Containment Failure } \\
\left(3.42 \times 10^{-8} / \mathrm{yr}\right)\end{array}$ & $3 \times 10^{-7}$ & $1 \times 10^{-6}$ & $7 \times 10^{-6}$ & $6 \times 10^{-7}$ & $2 \times 10^{-6}$ & $1 \times 10^{-5}$ \\
\hline $\begin{array}{l}\text { Late Containment Failure } \\
\left(1.21 \times 10^{-5} / \mathrm{yr}\right)\end{array}$ & $1 \times 10^{-5}$ & $5 \times 10^{-5}$ & $2 \times 10^{-4}$ & $2 \times 10^{-5}$ & $9 \times 10^{-5}$ & $4 \times 10^{-4}$ \\
\hline $\begin{array}{l}\text { Interfacing System LOCA } \\
\left(6.9 \times 10^{-8} / \mathrm{yr}\right)\end{array}$ & $7 \times 10^{-5}$ & $2 \times 10^{-4}$ & $8 \times 10^{-4}$ & $3 \times 10^{-4}$ & $6 \times 10^{-4}$ & $3 \times 10^{-3}$ \\
\hline $\begin{array}{l}\text { Beyond Design Basis } \\
\text { Earthquake, mitigated } \\
\left(1 \times 10^{-5} / \mathrm{yr}\right)\end{array}$ & $2 \times 10^{-6}$ & $4 \times 10^{-6}$ & $2 \times 10^{-5}$ & $8 \times 10^{-6}$ & $2 \times 10^{-5}$ & $6 \times 10^{-5}$ \\
\hline $\begin{array}{l}\text { Beyond Design Basis } \\
\text { Earthquake, unmitigated } \\
\left(1 \times 10^{-5} / \mathrm{yr}\right)\end{array}$ & 0.002 & 0.005 & 0.02 & 0.01 & 0.02 & 0.08 \\
\hline $\begin{array}{l}\text { Aircraft Crash, mitigated } \\
\left(1 \times 10^{-7} / \mathrm{yr}\right)\end{array}$ & $2 \times 10^{-8}$ & $4 \times 10^{-8}$ & $2 \times 10^{-7}$ & $8 \times 10^{-8}$ & $2 \times 10^{-7}$ & $6 \times 10^{-7}$ \\
\hline $\begin{array}{l}\text { Aircraft Crash, unmitigated } \\
\left(1 \times 10^{-7} / \mathrm{yr}\right)\end{array}$ & $2 \times 10^{-5}$ & $5 \times 10^{-5}$ & $2 \times 10^{-4}$ & $1 \times 10^{-4}$ & $2 \times 10^{-4}$ & $8 \times 10^{-4}$ \\
\hline
\end{tabular}


The accident with the highest risk to the offsite populations is the "Unmitigated Beyond Design Basis Earthquake" scenario. The collective risk to the offsite population for this scenario would range from 0.002 expected LCFs per year of operation in the Site-1 offsite population $(300,000$ people) to 0.08 expected LCFs per year of operation in the Site- 6 offsite population $(8,200,000$ people).

TABLE D.2.3.1-3-Mixed Oxide-Uranium-Plutonium Fueled Light Water Reactor Accident Risks ${ }^{a}$ to the Maximally Exposed Individual (All Sites)

\begin{tabular}{|c|c|c|c|c|c|c|}
\hline Accident (Frequency) & $\begin{array}{l}\text { Generic } \\
\text { Site } 1\end{array}$ & $\begin{array}{l}\text { Generic } \\
\text { Site } 2\end{array}$ & $\begin{array}{l}\text { Generic } \\
\text { Site } 3 \\
\end{array}$ & $\begin{array}{c}\text { Generic } \\
\text { Site } 4\end{array}$ & $\begin{array}{l}\text { Generic } \\
\text { Site } 5\end{array}$ & $\begin{array}{c}\text { Generic } \\
\text { Site } 6\end{array}$ \\
\hline LOCA $\left(7.5 \times 10^{-6} / \mathrm{yr}\right)$ & $7 \times 10^{-9}$ & $7 \times 10^{-9}$ & $7 \times 10^{-9}$ & $5 \times 10^{-8}$ & $5 \times 10^{-8}$ & $5 \times 10^{-8}$ \\
\hline Fuel Handling Accident $\left(1 \times 10^{-4} / \mathrm{yr}\right)$ & $1 \times 10^{-8}$ & $1 \times 10^{-8}$ & $1 \times 10^{-8}$ & $6 \times 10^{-8}$ & $6 \times 10^{-8}$ & $6 \times 10^{-8}$ \\
\hline SG Tube Rupture $\left(6.31 \times 10^{-10} / \mathrm{yr}\right)$ & $6 \times 10^{-10}$ & $6 \times 10^{-10}$ & $6 \times 10^{-10}$ & $6 \times 10^{-10}$ & $6 \times 10^{-10}$ & $6 \times 10^{-10}$ \\
\hline Early Containment Failure $\left(3.42 \times 10^{-8} / \mathrm{yr}\right)$ & $9 \times 10^{-10}$ & $9 \times 10^{-10}$ & $9 \times 10^{-10}$ & $2 \times 10^{-9}$ & $2 \times 10^{-9}$ & $2 \times 10^{-9}$ \\
\hline Late Containment Failure $\left(1.21 \times 10^{-5} / \mathrm{yr}\right)$ & $3 \times 10^{-8}$ & $3 \times 10^{-8}$ & $3 \times 10^{-8}$ & $6 \times 10^{-8}$ & $6 \times 10^{-8}$ & $6 \times 10^{-8}$ \\
\hline Interfacing System LOCA $\left(6.9 \times 10^{-8} / \mathrm{yr}\right)$ & $7 \times 10^{-8}$ & $7 \times 10^{-8}$ & $7 \times 10^{-8}$ & $7 \times 10^{-8}$ & $7 \times 10^{-8}$ & $7 \times 10^{-8}$ \\
\hline $\begin{array}{l}\text { Beyond Design Basis Earthquake, mitigated } \\
\left(1 \times 10^{-5} / \mathrm{yr}\right)\end{array}$ & $1 \times 10^{-8}$ & $1 \times 10^{-8}$ & $1 \times 10^{-8}$ & $8 \times 10^{-8}$ & $8 \times 10^{-8}$ & $8 \times 10^{-8}$ \\
\hline $\begin{array}{l}\text { Beyond Design Basis Earthquake, unmitigated } \\
\left(1 \times 10^{-5} / \mathrm{yr}\right)\end{array}$ & $1 \times 10^{-5}$ & $1 \times 10^{-5}$ & $1 \times 10^{-5}$ & $1 \times 10^{-5}$ & $1 \times 10^{-5}$ & $1 \times 10^{-5}$ \\
\hline Aircraft Crash, mitigated $\left(1 \times 10^{-7} / \mathrm{yr}\right)$ & $1 \times 10^{-10}$ & $1 \times 10^{-10}$ & $1 \times 10^{-10}$ & $8 \times 10^{-10}$ & $8 \times 10^{-10}$ & $8 \times 10^{-10}$ \\
\hline Aircraft Crash, unmitigated $\left(1 \times 10^{-7} / \mathrm{yr}\right)$ & $1 \times 10^{-7}$ & $1 \times 10^{-7}$ & $1 \times 10^{-7}$ & $1 \times 10^{-7}$ & $1 \times 10^{-7}$ & $1 \times 10^{-7}$ \\
\hline
\end{tabular}

${ }^{\mathrm{a}}$ Increased likelihood of a LCF per year of operation.

For the MEI, the "Unmitigated Beyond Design Basis Earthquake" scenario would result in an increased LCF risk of $1 \times 10^{-5}$ per year of operation, which corresponds to the annual probability of that accident occurring (i.e., the consequence is 1 LCF so the risk [probability $\mathrm{x}$ consequence] equals the annual probability, or numerically equals the frequency, of the accident). 
TABLE D.2.3.1-4-Mixed Oxide-Uranium-Plutonium Fueled Light Water Reactor Accident Risks ${ }^{a}$ to the Noninvolved Worker (All Sites)

\begin{tabular}{|c|c|c|c|c|c|c|}
\hline Accident (Frequency) & $\begin{array}{c}\text { Generic } \\
\text { Site } 1\end{array}$ & $\begin{array}{l}\text { Generic } \\
\text { Site } 2\end{array}$ & $\begin{array}{l}\text { Generic } \\
\text { Site } 3\end{array}$ & $\begin{array}{l}\text { Generic } \\
\text { Site } 4\end{array}$ & $\begin{array}{l}\text { Generic } \\
\text { Site } 5\end{array}$ & $\begin{array}{l}\text { Generic } \\
\text { Site } 6\end{array}$ \\
\hline LOCA $\left(7.5 \times 10^{-6} / \mathrm{yr}\right)$ & $8 \times 10^{-8}$ & $8 \times 10^{-8}$ & $8 \times 10^{-8}$ & $9 \times 10^{-7}$ & $9 \times 10^{-7}$ & $9 \times 10^{-7}$ \\
\hline $\begin{array}{l}\text { Fuel Handling Accident } \\
\left(1 \times 10^{-4} / \mathrm{yr}\right)\end{array}$ & $6 \times 10^{-8}$ & $6 \times 10^{-8}$ & $6 \times 10^{-8}$ & $3 \times 10^{-7}$ & $3 \times 10^{-7}$ & $3 \times 10^{-7}$ \\
\hline $\begin{array}{l}\text { SG Tube Rupture } \\
\left(6.31 \times 10^{-10} / \mathrm{yr}\right)\end{array}$ & $6 \times 10^{-10}$ & $6 \times 10^{-10}$ & $6 \times 10^{-10}$ & $6 \times 10^{-10}$ & $6 \times 10^{-10}$ & $6 \times 10^{-10}$ \\
\hline $\begin{array}{l}\text { Early Containment Failure } \\
\left(3.42 \times 10^{-8} / \mathrm{yr}\right)\end{array}$ & $8 \times 10^{-9}$ & $8 \times 10^{-9}$ & $8 \times 10^{-9}$ & $3 \times 10^{-9}$ & $3 \times 10^{-9}$ & $3 \times 10^{-9}$ \\
\hline $\begin{array}{l}\text { Late Containment Failure } \\
\left(1.21 \times 10^{-5} / \mathrm{yr}\right)\end{array}$ & $6 \times 10^{-7}$ & $6 \times 10^{-7}$ & $6 \times 10^{-7}$ & $9 \times 10^{-8}$ & $9 \times 10^{-8}$ & $9 \times 10^{-8}$ \\
\hline $\begin{array}{l}\text { Interfacing System LOCA } \\
\left(6.9 \times 10^{-8} / \mathrm{yr}\right)\end{array}$ & $7 \times 10^{-8}$ & $7 \times 10^{-8}$ & $7 \times 10^{-8}$ & $7 \times 10^{-8}$ & $7 \times 10^{-8}$ & $7 \times 10^{-8}$ \\
\hline $\begin{array}{l}\text { Beyond Design Basis } \\
\text { Earthquake, mitigated } \\
\left(1 \times 10^{-5} / \mathrm{yr}\right)\end{array}$ & $3 \times 10^{-7}$ & $3 \times 10^{-7}$ & $3 \times 10^{-7}$ & $2 \times 10^{-6}$ & $2 \times 10^{-6}$ & $2 \times 10^{-6}$ \\
\hline $\begin{array}{l}\text { Beyond Design Basis } \\
\text { Earthquake, unmitigated } \\
\left(1 \times 10^{-5} / \mathrm{yr}\right)\end{array}$ & $1 \times 10^{-5}$ & $1 \times 10^{-5}$ & $1 \times 10^{-5}$ & $1 \times 10^{-5}$ & $1 \times 10^{-5}$ & $1 \times 10^{-5}$ \\
\hline $\begin{array}{l}\text { Aircraft Crash, mitigated } \\
\left(1 \times 10^{-7} / \mathrm{yr}\right)\end{array}$ & $3 \times 10^{-9}$ & $3 \times 10^{-9}$ & $3 \times 10^{-9}$ & $2 \times 10^{-8}$ & $2 \times 10^{-8}$ & $2 \times 10^{-8}$ \\
\hline $\begin{array}{l}\text { Aircraft Crash, unmitigated } \\
\left(1 \times 10^{-7} / \mathrm{yr}\right)\end{array}$ & $1 \times 10^{-7}$ & $1 \times 10^{-7}$ & $1 \times 10^{-7}$ & $1 \times 10^{-7}$ & $1 \times 10^{-7}$ & $1 \times 10^{-7}$ \\
\hline
\end{tabular}

For the onsite noninvolved worker, the "Unmitigated Beyond Design Basis Earthquake" scenario would result in an increased risk of $1 \times 10^{-5}$ per year of operation, which corresponds to the annual probability of that accident occurring (i.e., the consequence is 1 LCF so the risk [probability $\mathrm{x}$ consequence] equals the annual probability, or numerically equals the frequency, of the accident).

Tables D.2.3.1-5 through D.2.3.1-7 present the accident consequences for the MOX-U-Pu fueled LWR at the six generic sites described in Section D.1.6 for the offsite population, MEI, and noninvolved worker. 
TABLE D.2.3.1-5-Mixed Oxide-Uranium-Plutonium Fueled Light Water Reactor Accident Health Consequences (Dose in Person-Rem/Increased Number of Latent Cancer Fatalities) ${ }^{a}$ to the Offsite Population (All Sites)

\begin{tabular}{|c|c|c|c|c|c|c|}
\hline Accident (Frequency) & $\begin{array}{l}\text { Generic } \\
\text { Site } 1\end{array}$ & $\begin{array}{l}\text { Generic } \\
\text { Site } 2\end{array}$ & $\begin{array}{l}\text { Generic } \\
\text { Site } 3\end{array}$ & $\begin{array}{l}\text { Generic } \\
\text { Site } 4\end{array}$ & $\begin{array}{l}\text { Generic } \\
\text { Site } 5\end{array}$ & $\begin{array}{l}\text { Generic } \\
\text { Site } 6\end{array}$ \\
\hline LOCA $\left(7.5 \times 10^{-6} / \mathrm{yr}\right)$ & $100 / 0.09$ & $300 / 0.2$ & $2,000 / 1$ & $700 / 0.4$ & $1,000 / 0.8$ & $5,000 / 3$ \\
\hline $\begin{array}{l}\text { Fuel Handling Accident } \\
\left(1 \times 10^{-4} / \mathrm{yr}\right)\end{array}$ & $10 / 0.007$ & $30 / 0.02$ & $100 / 0.07$ & $30 / 0.02$ & $60 / 0.04$ & $200 / 0.1$ \\
\hline $\begin{array}{l}\text { SG Tube Rupture } \\
\left(6.31 \times 10^{-10} / \mathrm{yr}\right)\end{array}$ & $\begin{array}{l}9 \times 10^{5} / \\
500\end{array}$ & $\begin{array}{c}2 \times 10^{6} / \\
1,000\end{array}$ & $\begin{array}{c}1 \times 10^{7} / \\
6,000\end{array}$ & $\begin{array}{c}4 \times 10^{6} / \\
2,000\end{array}$ & $\begin{array}{c}8 \times 10^{6} / \\
5,000\end{array}$ & $\begin{array}{l}3 \times 10^{7} / \\
20,000\end{array}$ \\
\hline $\begin{array}{l}\text { Early Containment Failure } \\
\left(3.42 \times 10^{-8} / \mathrm{yr}\right)\end{array}$ & $2 \times 10^{4} / 9$ & $6 \times 10^{4} / 40$ & $\begin{array}{c}3 \times 10^{5} / \\
200\end{array}$ & $3 \times 10^{4} / 20$ & $1 \times 10^{5} / 70$ & $\begin{array}{c}5 \times 10^{5} / \\
300\end{array}$ \\
\hline $\begin{array}{l}\text { Late Containment Failure } \\
\left(1.21 \times 10^{-5} / \mathrm{yr}\right)\end{array}$ & $2,000 / 1$ & $6,000 / 4$ & $3 \times 10^{4} / 20$ & $3,000 / 2$ & $1 \times 10^{4} / 7$ & $6 \times 10^{4} / 30$ \\
\hline $\begin{array}{l}\text { Interfacing System LOCA } \\
\left(6.9 \times 10^{-8} / \mathrm{yr}\right)\end{array}$ & $\begin{array}{c}2 \times 10^{6} / \\
1,000\end{array}$ & $\begin{array}{l}4 \times 10^{6} / \\
2,000\end{array}$ & $\begin{array}{l}2 \times 10^{7} / \\
10,000\end{array}$ & $\begin{array}{l}7 \times 10^{6} / \\
4,000\end{array}$ & $\begin{array}{c}2 \times 10^{7} / \\
9,000\end{array}$ & $\begin{array}{l}6 \times 10^{7} / \\
4 \times 10^{4}\end{array}$ \\
\hline $\begin{array}{l}\text { Beyond Design Basis } \\
\text { Earthquake, mitigated } \\
\left(1 \times 10^{-5} / \mathrm{yr}\right)\end{array}$ & $300 / 0.2$ & $600 / 0.4$ & $3,000 / 2$ & $1,000 / 0.8$ & $3,000 / 2$ & $1 \times 10^{4} / 6$ \\
\hline $\begin{array}{l}\text { Beyond Design Basis } \\
\text { Earthquake, unmitigated } \\
\left(1 \times 10^{-5} / \mathrm{yr}\right)\end{array}$ & $\begin{array}{c}4 \times 10^{5} / \\
200\end{array}$ & $\begin{array}{l}8 \times 10^{5} / \\
500\end{array}$ & $\begin{array}{c}4 \times 10^{6} / \\
2,000\end{array}$ & $\begin{array}{c}2 \times 10^{6} / \\
1,000\end{array}$ & $\begin{array}{c}3 \times 10^{6} / \\
2,000\end{array}$ & $\begin{array}{l}1 \times 10^{7} / \\
8,000\end{array}$ \\
\hline $\begin{array}{l}\text { Aircraft Crash, mitigated } \\
\left(1 \times 10^{-7} / \mathrm{yr}\right)\end{array}$ & $300 / 0.2$ & $600 / 0.4$ & $3,000 / 2$ & $1,000 / 0.8$ & $3,000 / 2$ & $1 \times 10^{4} / 6$ \\
\hline $\begin{array}{l}\text { Aircraft Crash, unmitigated } \\
\left(1 \times 10^{-7} / \mathrm{yr}\right)\end{array}$ & $\begin{array}{c}4 \times 10^{5} / \\
200\end{array}$ & $\begin{array}{l}8 \times 10^{5} / \\
500\end{array}$ & $\begin{array}{c}4 \times 10^{6} / \\
2,000\end{array}$ & $\begin{array}{c}2 \times 10^{6} / \\
1,000\end{array}$ & $\begin{array}{c}3 \times 10^{6} / \\
2,000\end{array}$ & $\begin{array}{l}1 \times 10^{7} / \\
8,000\end{array}$ \\
\hline
\end{tabular}

The accidents with the highest consequence to the offsite population would be the "Interfacing System LOCA." Using the dose-to-risk conversion factor of $6 \times 10^{-4}$ per person-rem, these collective population doses could result in 1,000 to 40,000 additional LCFs in the surrounding population for this Beyond Extremely Unlikely accident. These consequences are consistent with the results of the NRC's Severe Accident Risks: An Assessment for Five U.S. Nuclear Power Plants, NUREG-1150 (NRC 1990) and the SPD EIS (DOE 1999d) when differences in population and meteorology are considered. The higher consequences for this accident are not the result of differences in the fuels relative to other reactors, but are instead the result of an assumption that all containment and filter systems would fail and that the accident occurs in a highly populated area with unfavorable meteorology. 


\begin{tabular}{|c|c|c|c|c|c|c|}
\hline Accident (Frequency) & $\begin{array}{c}\text { Generic } \\
\text { Site 1 } \\
\end{array}$ & $\begin{array}{l}\text { Generic } \\
\text { Site } 2 \\
\end{array}$ & $\begin{array}{c}\text { Generic } \\
\text { Site } 3 \\
\end{array}$ & $\begin{array}{c}\text { Generic } \\
\text { Site } 4 \\
\end{array}$ & $\begin{array}{c}\text { Generic } \\
\text { Site } 5 \\
\end{array}$ & $\begin{array}{c}\text { Generic } \\
\text { Site } 6 \\
\end{array}$ \\
\hline LOCA $\left(7.5 \times 10^{-6} / \mathrm{yr}\right)$ & $2 / 0.001$ & $2 / 0.001$ & $2 / 0.001$ & $10 / 0.007$ & $10 / 0.007$ & $10 / 0.007$ \\
\hline $\begin{array}{l}\text { Fuel Handling Accident } \\
\left(1 \times 10^{-4} / \mathrm{yr}\right)\end{array}$ & $\begin{array}{c}0.2 / \\
1 \times 10^{-4}\end{array}$ & $\begin{array}{c}0.2 / \\
1 \times 10^{-4}\end{array}$ & $\begin{array}{c}0.2 / \\
1 \times 10^{-4}\end{array}$ & $1 / 6 \times 10^{-4}$ & $1 / 6 \times 10^{-4}$ & $1 / 6 \times 10^{-4}$ \\
\hline $\begin{array}{l}\text { SG Tube Rupture } \\
\left(6.31 \times 10^{-10} / \mathrm{yr}\right)\end{array}$ & $1 \times 10^{4} / 1$ & $1 \times 10^{4} / 1$ & $1 \times 10^{4} / 1$ & $6 \times 10^{4} / 1$ & $6 \times 10^{4} / 1$ & $6 \times 10^{4} / 1$ \\
\hline $\begin{array}{l}\text { Early Containment Failure } \\
\left(3.42 \times 10^{-8} / \mathrm{yr}\right)\end{array}$ & $20 / 0.03$ & $20 / 0.03$ & $20 / 0.03$ & $50 / 0.06$ & $50 / 0.06$ & $50 / 0.06$ \\
\hline $\begin{array}{l}\text { Late Containment Failure } \\
\left(1.21 \times 10^{-5} / \mathrm{yr}\right)\end{array}$ & $5 / 0.003$ & $5 / 0.003$ & $5 / 0.003$ & $8 / 0.005$ & $8 / 0.005$ & $8 / 0.005$ \\
\hline $\begin{array}{l}\text { Interfacing System LOCA } \\
\left(6.9 \times 10^{-8} / \mathrm{yr}\right)\end{array}$ & $2 \times 10^{4} / 1$ & $2 \times 10^{4} / 1$ & $2 \times 10^{4} / 1$ & $1 \times 10^{5} / 1$ & $1 \times 10^{5} / 1$ & $1 \times 10^{5} / 1$ \\
\hline $\begin{array}{l}\text { Beyond Design Basis } \\
\text { Earthquake, mitigated } \\
\left(1 \times 10^{-5} / \mathrm{yr}\right)\end{array}$ & $2 / 0.001$ & $2 / 0.001$ & $2 / 0.001$ & $10 / 0.008$ & $10 / 0.008$ & $10 / 0.008$ \\
\hline $\begin{array}{l}\text { Beyond Design Basis } \\
\text { Earthquake, unmitigated } \\
\left(1 \times 10^{-5} / \mathrm{yr}\right)\end{array}$ & $4,000 / 1$ & $4,000 / 1$ & $4,000 / 1$ & $3 \times 10^{4} / 1$ & $3 \times 10^{4} / 1$ & $3 \times 10^{4} / 1$ \\
\hline $\begin{array}{l}\text { Aircraft Crash, mitigated } \\
\left(1 \times 10^{-7} / \mathrm{yr}\right)\end{array}$ & $2 / 0.001$ & $2 / 0.001$ & $2 / 0.001$ & $10 / 0.008$ & $10 / 0.008$ & $10 / 0.008$ \\
\hline $\begin{array}{l}\text { Aircraft Crash, unmitigated } \\
\left(1 \times 10^{-7} / \mathrm{yr}\right)\end{array}$ & $4,000 / 1$ & $4,000 / 1$ & $4,000 / 1$ & $3 \times 10^{4} / 1$ & $3 \times 10^{4} / 1$ & $3 \times 10^{4} / 1$ \\
\hline
\end{tabular}

${ }^{a}$ The dose in rem is reported before the slash and the increased likelihood of an LCF is presented after the slash.

For the MEI, four Beyond Extremely Unlikely scenarios- "Steam Generator Tube Rupture," "Interfacing System LOCA," "Unmitigated Beyond Design Basis Earthquake," and "Unmitigated Aircraft Crash"-likely would result in prompt fatality. 
TABLE D.2.3.1-7-Mixed Oxide-Uranium-Plutonium Fueled Light Water Reactor Accident Health Consequences (Dose in Rem/Increased Likelihood of a Latent Cancer Fatality) ${ }^{a}$ to the Noninvolved Worker (All Sites)

\begin{tabular}{|c|c|c|c|c|c|c|}
\hline Accident (Frequency) & $\begin{array}{l}\text { Generic } \\
\text { Site } 1\end{array}$ & $\begin{array}{l}\text { Generic } \\
\text { Site } 2\end{array}$ & $\begin{array}{l}\text { Generic } \\
\text { Site } 3\end{array}$ & $\begin{array}{l}\text { Generic } \\
\text { Site } 4\end{array}$ & $\begin{array}{l}\text { Generic } \\
\text { Site } 5\end{array}$ & $\begin{array}{l}\text { Generic } \\
\text { Site } 6\end{array}$ \\
\hline $\operatorname{LOCA}\left(7.5 \times 10^{-6} / \mathrm{yr}\right)$ & $20 / 0.01$ & $20 / 0.01$ & $20 / 0.01$ & $100 / 0.1$ & $100 / 0.1$ & $100 / 0.1$ \\
\hline $\begin{array}{l}\text { Fuel Handling Accident } \\
\left(1 \times 10^{-4} / \mathrm{yr}\right)\end{array}$ & $1 / 6 \times 10^{-4}$ & $1 / 6 \times 10^{-4}$ & $1 / 6 \times 10^{-4}$ & 4 / 0.003 & $4 / 0.003$ & 4 / 0.003 \\
\hline $\begin{array}{l}\text { SG Tube Rupture } \\
\left(6.31 \times 10^{-10} / \mathrm{yr}\right)\end{array}$ & $1 \times 10^{5} / 1$ & $1 \times 10^{5} / 1$ & $1 \times 10^{5} / 1$ & $3 \times 10^{5} / 1$ & $3 \times 10^{5} / 1$ & $3 \times 10^{5} / 1$ \\
\hline $\begin{array}{l}\text { Early Containment Failure } \\
\left(3.42 \times 10^{-8} / \mathrm{yr}\right)\end{array}$ & $200 / 0.2$ & $200 / 0.2$ & $200 / 0.2$ & $80 / 0.1$ & $80 / 0.1$ & $80 / 0.1$ \\
\hline $\begin{array}{l}\text { Late Containment Failure } \\
\left(1.21 \times 10^{-5} / \mathrm{yr}\right)\end{array}$ & $40 / 0.05$ & $40 / 0.05$ & $40 / 0.05$ & $10 / 0.008$ & $10 / 0.008$ & $10 / 0.008$ \\
\hline $\begin{array}{l}\text { Interfacing System LOCA } \\
\left(6.9 \times 10^{-8} / \mathrm{yr}\right)\end{array}$ & $2 \times 10^{5} / 1$ & $2 \times 10^{5} / 1$ & $2 \times 10^{5} / 1$ & $5 \times 10^{5} / 1$ & $5 \times 10^{5} / 1$ & $5 \times 10^{5} / 1$ \\
\hline $\begin{array}{l}\text { Beyond Design Basis } \\
\text { Earthquake, mitigated } \\
\left(1 \times 10^{-5} / \mathrm{yr}\right)\end{array}$ & $30 / 0.03$ & $30 / 0.03$ & $30 / 0.03$ & $200 / 0.2$ & $200 / 0.2$ & $200 / 0.2$ \\
\hline $\begin{array}{l}\text { Beyond Design Basis } \\
\text { Earthquake, unmitigated } \\
\left(1 \times 10^{-5} / \mathrm{yr}\right)\end{array}$ & $5 \times 10^{4} / 1$ & $5 \times 10^{4} / 1$ & $5 \times 10^{4} / 1$ & $2 \times 10^{5} / 1$ & $2 \times 10^{5} / 1$ & $2 \times 10^{5} / 1$ \\
\hline $\begin{array}{l}\text { Aircraft Crash, mitigated } \\
\left(1 \times 10^{-7} / \mathrm{yr}\right)\end{array}$ & $30 / 0.03$ & $30 / 0.03$ & $30 / 0.03$ & $200 / 0.2$ & $200 / 0.2$ & $200 / 0.2$ \\
\hline $\begin{array}{l}\text { Aircraft Crash, unmitigated } \\
\left(1 \times 10^{-7} / \mathrm{yr}\right)\end{array}$ & $5 \times 10^{4} / 1$ & $5 \times 10^{4} / 1$ & $5 \times 10^{4} / 1$ & $2 \times 10^{5} / 1$ & $2 \times 10^{5} / 1$ & $2 \times 10^{5} / 1$ \\
\hline
\end{tabular}

${ }^{a}$ The dose in rem is reported before the slash and the increased likelihood of an LCF is presented after the slash.

For the noninvolved worker, these same four Beyond Extremely Unlikely scenarios- "Steam Generator Tube Rupture," "Interfacing System LOCA," "Unmitigated Beyond Design Basis Earthquake," and "Unmitigated Aircraft Crash"-likely would result in prompt fatality.

\section{D.2.3.2 Mixed Oxide-Uranium-Plutonium Fueled Advanced Light Water Reactor}

As discussed in Section D.2.1.2, DOE has previously analyzed accidents associated with ALWRs using LEU fuel at a variety of locations in the Tritium Supply and Recycling Final PEIS (DOE/EIS-0161) (DOE 1995b); however, DOE did not analyze the ALWR with MOX-U-Pu fuel. For this GNEP PEIS, DOE has re-analyzed those ALWR accident scenarios for LEU fuel (see Section D.2.1.2) for the six generic sites described in Section D.1.6. The accident scenarios are not affected by the type of fissile material in the fuel, so the LEU fueled ALWR scenarios are applicable to a MOX-U-Pu fueled ALWR. A description of each LEU fueled ALWR accident is presented in the Tritium Supply and Recycling Final PEIS (DOE/EIS-0161) (DOE 1995b).

While the scenarios are not affected by the fuel type, the consequences are affected by the fuel type. The SPD EIS (DOE 1999d) evaluated an LEU fueled LWR and a MOX-U-Pu fueled LWR and determined that the MOX-U-Pu fueled LWR impacts average about 5 percent greater than the corresponding impacts for an LEU fueled LWR, with some variation from scenario to 
scenario. The effect different fuel types have on the accident impacts is expected to be similar for an LWR and an ALWR, so it is expected that a MOX-U-Pu fueled ALWR would have impacts that are about 5 percent greater on average than the impacts for an LEU fueled ALWR. There are differences between the weapons-grade plutonium used in the SPD EIS (DOE 1999d) analysis and the transuranics that would be used under this alternative, but these differences are not expected to invalidate the conclusion that the impacts would be only slightly greater. Since the ALWR scenarios differ from the LWR scenarios, the LWR scenario specific impact ratios in Table D.2.1.1-1 cannot be used for the ALWR, so the average value is appropriate. The LEU fueled ALWR impacts are used directly for the MOX-U-Pu fueled ALWR rather than recalculating them because reporting a nominal 5 percent increase in impacts to one significant digit generally results in no reported change, with a few instances where the change can appear to be from 10 to 100 percent because of rounding to one significant figure. For example, a value of $1.11 \times 10^{-5}$ is reported as $1 \times 10^{-5}$ when reported to one significant figure regardless of whether it is increased by 5 percent or not; however, $1.49 \times 10^{-5}$ is reported as $1 \times 10^{-5}$ but increasing it by 5 percent results in $2 \times 10^{-5}$ when reported to one significant figure.

Therefore, Tables D.2.1.2-2 through D.2.1.2-7 can be used directly for the MOX-U-Pu ALWR, recognizing that there would be a small increase.

\section{D.2.3.3 Nuclear Fuel Recycling Center}

The nuclear fuel recycling center includes LWR and fast reactor fuel separations and fast reactor fuel fabrication. As discussed previously (see Section D.2.2.1), fuel fabrication capabilities are enveloped by the aqueous separations capability from an accident perspective. Therefore, the nuclear fuel recycling center accident analyses performed for the Fast Reactor Recycle Alternative apply directly to Thermal/Fast Reactor Recycle Alternative and are not repeated here.

\section{D.2.4 Thermal Reactor Recycle Alternative}

The Thermal Reactor Recycle Alternative has three options that are quite similar. Option 1 of the Thermal Reactor Recycle Alternative includes analysis of the accident impacts from a nuclear fuel recycling center and operation of one or more LWRs or ALWRs. Option 2 of this alternative is similar to Option 1 except that it uses a different separations process for SNF and recycles in HWRs rather than ALWRs/LWRs. Option 3 is similar to the Option 1 except that it recycles in HTGRs rather than ALWRs/LWRs.

\section{D.2.4.1 Thermal Recycle in Light Water Reactors (Option 1)}

The Thermal Recycle in LWRs option includes use of MOX-U-Pu fuel in one or more existing or future LWRs or ALWRs and a nuclear fuel recycling center. The nuclear fuel recycling center activities include fuel separations and fuel fabrication. The facility accidents associated with the LWR, ALWR, and nuclear fuel recycling center are addressed below. 


\section{D.2.4.1.1 Mixed Oxide-Uranium-Plutonium Fueled Light Water Reactor}

Option 1 of the Thermal Reactor Recycle Alternative may recycle fuel in LWRs. Facility accident impacts associated with the use of MOX-U-Pu fuel in an LWR are part of the Thermal/Fast Reactor Recycle Alternative and are repeated here. See Sections D.2.3.2 for the facility accident impacts of a MOX-U-Pu fueled LWR.

\section{D.2.4.1.2 Mixed Oxide-Uranium-Plutonium Fueled Advanced Light Water Reactor}

Option 1 of the Thermal Reactor Recycle Alternative may recycle fuel in ALWRs. Facility accident impacts associated with the use of MOX-U-Pu fuel in an ALWR are part of the Thermal/Fast Reactor Recycle Alternative and are repeated here. See Section D.2.3.2 for the facility accident impacts of a MOX-U-Pu fueled ALWR.

\section{D.2.4.1.3 Nuclear Fuel Recycling Center}

This option will include LWR or ALWR fuel separations and recycle fuel fabrication capabilities. The analyses performed for the nuclear fuel recycling center (see Section D.2.2.1) apply directly for the LWR or ALWR separations capability addressed here. As discussed in Section 2.2.1, from an accident perspective, fuel fabrication capabilities are enveloped by the aqueous separations capability addressed for the nuclear fuel recycling center. Therefore, the nuclear fuel recycling center accident analyses (Section D.2.2.1) provide a reasonable basis for the accident impacts associated with nuclear fuel recycling center activities for this option.

\section{D.2.4.2 Thermal Recycle in Heavy Water Reactors (Option 2)}

This Thermal Reactor Recycle Alternative option includes recycling of LWR fuel in one or more HWRs and a nuclear fuel recycling center. The nuclear fuel recycling center activities include fuel separations and fuel fabrication. The facility accidents associated with the HWR and the nuclear fuel recycling center are addressed below.

\section{D.2.4.2.1 Heavy Water Reactor}

Accidents associated with HWRs are addressed in Section D.2.6.1 for the once-through alternative. The types and frequencies of accidents associated with an HWR will be the same for the recycle and open cycle alternatives, but the fuel would be different. The MOX-U-Pu LWR accident analysis concluded that use of fuel with initial plutonium loadings results in impacts that average 5 percent greater than the impacts from a once-through fuel (DOE 1999d). There are differences between the weapons-grade plutonium used in the SPD EIS (DOE 1999d) analysis and the transuranics that would be used under this alternative, but these differences are not expected to invalidate the conclusion that the impacts would be only slightly greater. Therefore, the accident impacts for HWR in this recycle alternative are expected to also be approximately the same as the results for use of once-through fuel. See Section D.2.6.1 for the HWR accident impacts for this option. 


\section{D.2.4.2.2 Nuclear Fuel Recycling Center}

This PEIS assumes that this fuel cycle would use the Oxidation and Reduction of Oxide Fuel

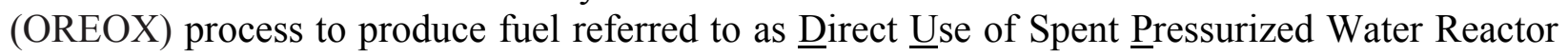
(PWR) Fuel in Canada Deuterium Uranium (CANDU) reactors, or DUPIC fuel (see Section 2.5.2 of Chapter 2 for a description). The OREOX process includes decladding, fuel powder preparation, fuel pellet fabrication, and fuel element fabrication. The decladding and fuel powder preparation activities are comparable to the fuel preparation and voloxidation activities that may be involved in either aqueous or electrochemical separations; however, the OREOX process does not include the dissolution and aqueous-organic separations involved in the aqueous process or the melting and electrochemical separations involved in electrochemical process. DOE has not previously evaluated use of DUPIC fuel or use of the OREOX process and there is very little available information on potential accident impacts for the process. Consistent with the Council on Environmental Quality's (CEQ) NEPA provisions for incomplete and unavailable information (40 CFR 1502.22), evaluation of the OREOX process is limited to a qualitative assessment. Because the OREOX process includes process steps that involve SNF in highly dispersible forms, the maximum potential consequences are roughly comparable to those for aqueous separations. Because its process is less complex and it does not include as many vulnerable steps, the likelihood of OREOX process accidents may be slightly lower than for aqueous separations. Therefore, the OREOX process risk and consequences are enveloped by aqueous separations, and the analyses performed in Section 2.2.1 for the nuclear fuel recycling center are appropriate for the fuel recycling facilities in this alternative.

\section{D.2.4.3 Thermal Recycle in High Temperature Gas-Cooled Reactors (Option 3)}

As described in Section 2.6.3, the HTGR options being considered include a deep burn modular helium reactor (DB-MHR) for consumption of transuranics as well as fuel recycling facilities for fabrication of fuel for the HTGR.

\section{D.2.4.3.1 High Temperature Gas-Cooled Reactors}

The HTGR used in this option could be similar to the reactor addressed for the HTGR oncethrough cycle in Section D.2.6.2. However, the fuel used for this option will include recycled transuranics, which is a difference from the HTGR fuel evaluated in the once-through cycle. As discussed for HWRs (see Section D.2.4.2.1), the effect of recycling fuel is not expected to have a large effect on consequences. For the MOX-U-Pu fuel in an LWR, the effect of using recycled fuel was a 5 percent increase in the consequences (DOE 1999d). There are differences between the weapons-grade plutonium used in the SPD EIS (DOE 1999d) analysis and the transuranics that would be used under this alternative, but these differences are not expected to invalidate the conclusion that the impacts would be only slightly greater. Therefore, the accident impacts for the HWR/HTGR Alternative (all-HTGR option) discussed in Section D.2.6.2 provide a reasonable basis for the accident impacts of the Thermal Recycle in HTGRs (Option 3). 


\section{D.2.4.3.2 Nuclear Fuel Recycling Center}

This option will include LWR separations and HTGR fuel fabrication capabilities. The analyses performed for the nuclear fuel recycling center (see Section D.2.2.1) apply directly to the LWR separations capability addressed here. As discussed previously, from an accident perspective, fuel fabrication capabilities are enveloped by the aqueous separations capability addressed for the nuclear fuel recycling center. Therefore, the nuclear fuel recycling center accident analyses (Section D.2.2.1) provide a reasonable basis for the accident impacts associated with fuel recycling activities for this option.

\section{D.2.5 Thorium Alternative}

As described in Section 2.6 of Chapter 2 of this PEIS, the thorium once-through fuel cycle, while different in many aspects from the existing uranium once-through fuel cycle, can be characterized as a "new fuel design" rather than a new reactor concept, because the thorium fuel cycle would be compatible with existing or future thermal reactors (e.g., LWRs, HWRs, and HTGRs). Existing or future commercial reactors (e.g., LWRs, HWRs, and HTGRs) could accept a thorium-based fuel without requiring fundamental modification. For the purposes of this PEIS, the analysis of the thorium open fuel cycle is based on pressurized water reactors (PWRs) since this LWR is the predominant commercial electricity producing technology that exists in the world today.

For purposes of this PEIS analysis, the Thorium Alternative would represent a fundamental shift in the fuel used for U.S. commercial reactors. Rather than being fueled solely by enriched (3 to 5 percent) uranium, U.S. commercial reactors would transition to a fuel composed of thorium and enriched uranium (less than 20 percent).

As a result of the thorium fuel cycle, existing facilities would operate differently, and might require modifications or dedicated new facilities depending on the economics and other considerations. For example, fuel fabrication operations would involve higher enrichments than are currently conducted at most commercial fuel fabrications facilities. This might entail changes in operations, and different risks to workers.

Operations at commercial reactors would also be different due to the use of thorium-based fuel. For example, refueling operations would be different because the thorium-containing blanket would stay in the reactor for more cycles than the seeds. In addition, while the replacement of seed rods in the seed-blanket-unit concept anticipates taking advantage of the technology developed to address failed fuel rods, its implementation for this application would be much more extensive. At the back end of the fuel cycle, although thorium-based SNF would contain less transuranics than uranium-based SNF, longer onsite pool storage time would be required due to initially higher residual heat on an assembly basis.

Accident analyses for two heterogeneous "seed-blanket" implementation schemes for thorium fueled LWRs have been performed by Brookhaven National Laboratory and the Massachusetts Institute of Technology (Todosow and Kazimi 2004). The two concepts are the seed-blanket-unit where the seed and blanket occupy the same space as a conventional assembly, and the whole- 
assembly-seed-blanket where the seed and blanket rods are located in distinct assemblies. Several accidents were evaluated, for each concept: 1) large break loss-of-coolant; 2) loss of primary flow; and 3) loss of offsite power. The results for safety-related parameters were comparable to those for a conventional uranium-fueled LWR, and were well below limits. Because this previous study shows that thorium-fueled and uranium-fueled reactor accident impacts are comparable, DOE has not reanalyzed the thorium-fueled accidents, but instead concludes that they are comparable to the impacts for a conventional uranium-fueled LWR.

\section{D.2.6 Heavy Water Reactor/High Temperature Gas-Cooled Alternative}

This alternative is a once-through uranium fuel cycle using HWRs or HTGRs. Option 1 of this alternative utilizes HWRs and Option 2 utilizes HTGRs. Since this is a once-through alternative, there is no nuclear fuel recycling center.

\section{D.2.6.1 Heavy Water Reactor (Option 1)}

With respect to accidents, impacts would be dependent on many factors, including the type of accident, site characteristics, and the distribution of population in the surrounding environment. Although HWRs have substantially different design and operating features than LWRs typically used in the U.S. commercial industry, both are designed to withstand off normal events that could be postulated to occur, and if unmitigated, could lead to damage of nuclear fuel and release of radioactivity. Both reactor concepts use a "defense in depth" approach to design where multiple levels of protection are provided against the release of radioactive material. Protective measures include the use of independent safety systems, fault detection and correction, and multiple physical barriers to the release of radioactivity from an accident. The goal for both designs is to limit the potential of accidents occurring and to limit the effects of an accident in the event one does occur.

Both HWRs and LWRs are PWRs. However, where LWRs have vertical fuel rods surrounded by a natural water moderator/coolant in a single pressure vessel, many HWRs (such as the CANDU HWRs) have a substantially different configuration. They have horizontal fuel bundles in multiple pressurized tubes, filled with heavy water or light water coolant (depending on the design). These horizontal tubes are surrounded by heavy water moderator in a horizontal tank. LWRs shut down for refueling whereas CANDUs refuel while operating. Both reactor designs have some initiating events that are similar and could lead to a release of radioactivity if unmitigated (e.g., loss of coolant, loss of coolant flow, loss of secondary side heat sinks). However, the differences in design would lead to different event progressions, different mitigation measures, and different outcomes. As a result, the accident scenarios and potential consequences for the two reactor designs are different.

The CANDU HWR has the advantage of having relatively cold heavy water moderator surrounding the pressure tubes. This provides a heat sink in the event of the loss of coolant inside the pressure tubes (Loss of Coolant Accident). Additionally, the use of natural uranium fuel and the longer neutron lifetime associated with heavy water help in a loss of coolant accident. Other HWR design concepts using higher uranium enrichments could also be utilized. 
DOE has previously analyzed accidents associated with HWRs utilizing enriched uranium fuels at a variety of locations in the Tritium Supply and Recycling Final PEIS (DOE 1995b). In this PEIS, DOE has re-analyzed the risks of the accident scenarios at the six generic sites described in Section D.1.6. A description of each accident is presented in the Tritium Supply and Recycling Final PEIS (DOE 1995b). The parameters used for this analysis are presented in Table D.2.6-1. Tables D.2.6.1-2 through D.2.6.1-4 present the risk from all accidents at all sites to the offsite population, MEI, and noninvolved worker. Use of lower enriched fuels could increase the transuranic inventory and therefore increase the consequences somewhat. However, the Surplus Plutonium Disposition Final Environmental Impact Statement found that use of MOX-U-Pu with its increased transuranic inventory increased risk an average of 5 percent (DOE 1999d). 


\section{TABLE D.2.6.1-1—Release Parameters for Heavy Water Reactor Accidents}

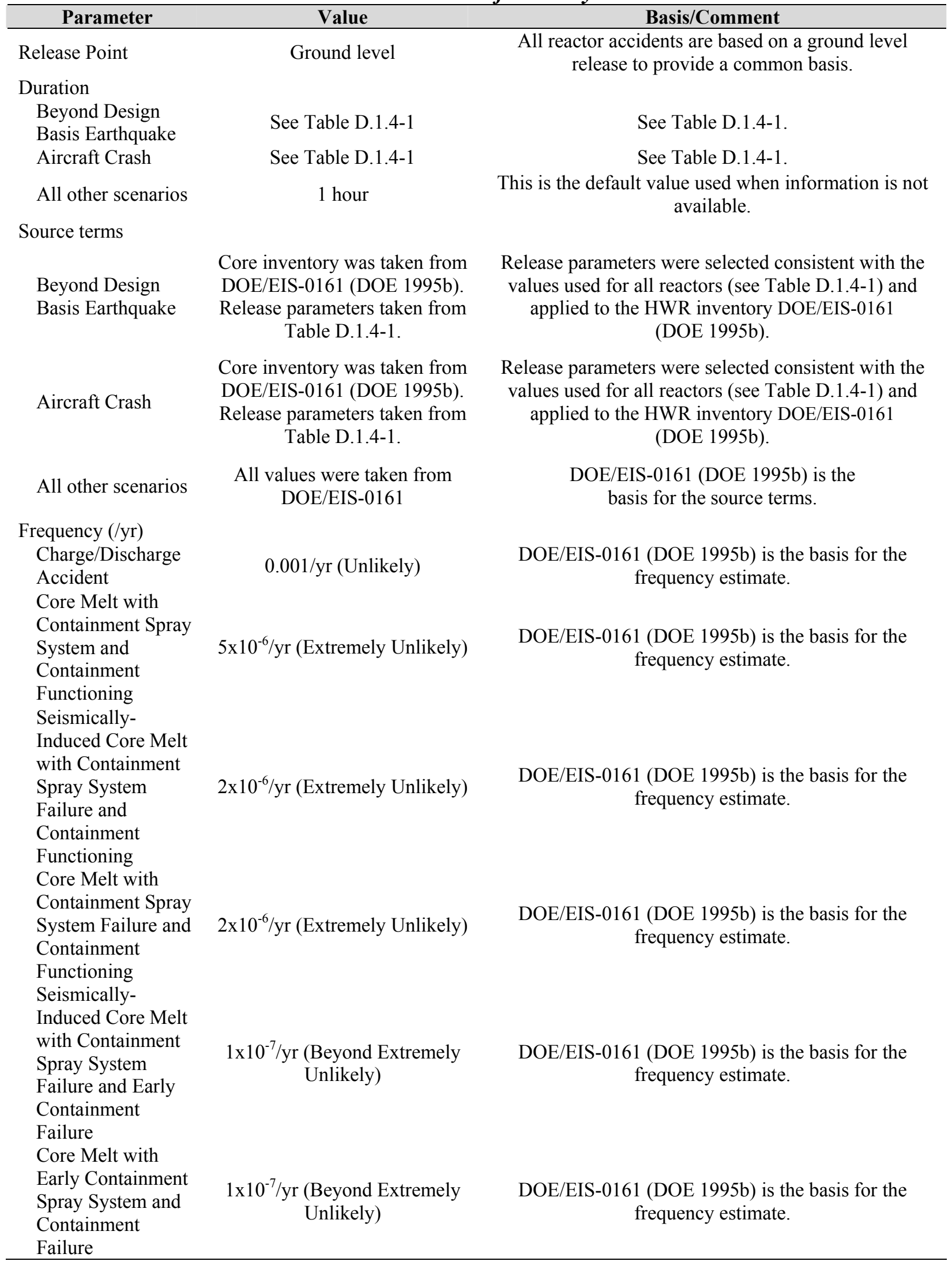




\section{TABLE D.2.6.1-1-Release Parameters for Heavy Water Reactor Accidents (continued)}

Parameter

Beyond Design

Basis Earthquake

$1 \times 10^{-5} / \mathrm{yr}$ (Extremely

Unlikely)

Aircraft Crash

Value
Basis/Comment

The median frequency of a safe shutdown earthquake for current LWRs is $1.0 \times 10^{-5} / \mathrm{yr}$ per Regulatory Guide 1.165 (NRC 1997). The frequency is expected to be no greater for an HWR than for current LWRs, so an event frequency of $10^{-7} / \mathrm{yr}$ is used in this analysis.

The facility must be licensed by the NRC, so it will be required to meet NRC Aircraft Hazards criteria (NRC $2007 \mathrm{k}$ ). Therefore, an event frequency of $10^{-7} / \mathrm{yr}$ is used in this analysis.

TABLE D.2.6.1-2 - Heavy Water Reactor Accident Risks ${ }^{a}$ to the Offsite Population (All Sites)

\begin{tabular}{|c|c|c|c|c|c|c|}
\hline Accident (Frequency) & $\begin{array}{l}\text { Generic } \\
\text { Site } 1 \\
\end{array}$ & $\begin{array}{l}\text { Generic } \\
\text { Site } 2 \\
\end{array}$ & $\begin{array}{c}\text { Generic } \\
\text { Site } 3 \\
\end{array}$ & $\begin{array}{l}\text { Generic } \\
\text { Site } 4\end{array}$ & $\begin{array}{l}\text { Generic } \\
\text { Site } 5 \\
\end{array}$ & $\begin{array}{c}\text { Generic } \\
\text { Site } 6 \\
\end{array}$ \\
\hline $\begin{array}{l}\text { Charge/Discharge Accident } \\
(0.001 / \mathrm{yr})\end{array}$ & $4 \times 10^{-7}$ & $9 \times 10^{-7}$ & $4 \times 10^{-6}$ & $2 \times 10^{-6}$ & $4 \times 10^{-6}$ & $2 \times 10^{-5}$ \\
\hline $\begin{array}{l}\text { Core Melt with Containment Spray } \\
\text { System and Containment } \\
\text { Functioning }\left(5 \times 10^{-6} / \mathrm{yr}\right)\end{array}$ & $2 \times 10^{-6}$ & $4 \times 10^{-6}$ & $2 \times 10^{-5}$ & $8 \times 10^{-6}$ & $2 \times 10^{-5}$ & $7 \times 10^{-5}$ \\
\hline $\begin{array}{l}\text { Seismically-Induced Core Melt with } \\
\text { Containment Spray System Failure } \\
\text { and Containment Functioning } \\
\left(2 \times 10^{-6} / \mathrm{yr}\right)\end{array}$ & $7 \times 10^{-7}$ & $2 \times 10^{-6}$ & $8 \times 10^{-6}$ & $3 \times 10^{-6}$ & $7 \times 10^{-6}$ & $3 \times 10^{-5}$ \\
\hline $\begin{array}{l}\text { Core Melt with Containment Spray } \\
\text { System Failure and Containment } \\
\text { Functioning }\left(2 \times 10^{-6} / \mathrm{yr}\right)\end{array}$ & $7 \times 10^{-7}$ & $2 \times 10^{-6}$ & $8 \times 10^{-6}$ & $3 \times 10^{-6}$ & $7 \times 10^{-6}$ & $3 \times 10^{-5}$ \\
\hline $\begin{array}{l}\text { Seismically-Induced Core Melt with } \\
\text { Containment Spray System Failure } \\
\text { and Early Containment Failure } \\
\left(1 \times 10^{-7} / \mathrm{yr}\right)\end{array}$ & $5 \times 10^{-7}$ & $1 \times 10^{-6}$ & $5 \times 10^{-6}$ & $2 \times 10^{-6}$ & $3 \times 10^{-6}$ & $1 \times 10^{-5}$ \\
\hline $\begin{array}{l}\text { Core Melt with Early Containment } \\
\text { Spray System and Containment } \\
\text { Failure }\left(1 \times 10^{-7} / \mathrm{yr}\right)\end{array}$ & $5 \times 10^{-7}$ & $1 \times 10^{-6}$ & $5 \times 10^{-6}$ & $2 \times 10^{-6}$ & $3 \times 10^{-6}$ & $1 \times 10^{-5}$ \\
\hline $\begin{array}{l}\text { Beyond Design Basis Earthquake, } \\
\text { mitigated }\left(1 \times 10^{-5} / \mathrm{yr}\right)\end{array}$ & $4 \times 10^{-7}$ & $9 \times 10^{-7}$ & $4 \times 10^{-6}$ & $2 \times 10^{-6}$ & $3 \times 10^{-6}$ & $1 \times 10^{-5}$ \\
\hline $\begin{array}{l}\text { Beyond Design Basis Earthquake, } \\
\text { unmitigated }\left(1 \times 10^{-5} / \mathrm{yr}\right)\end{array}$ & $5 \times 10^{-4}$ & 0.001 & 0.005 & 0.002 & 0.004 & 0.02 \\
\hline Aircraft Crash, mitigated $\left(1 \times 10^{-7} / \mathrm{yr}\right)$ & $4 \times 10^{-9}$ & $9 \times 10^{-9}$ & $4 \times 10^{-8}$ & $2 \times 10^{-8}$ & $3 \times 10^{-8}$ & $1 \times 10^{-7}$ \\
\hline $\begin{array}{l}\text { Aircraft Crash, unmitigated } \\
\left(1 \times 10^{-7} / \mathrm{yr}\right)\end{array}$ & $5 \times 10^{-6}$ & $1 \times 10^{-5}$ & $5 \times 10^{-5}$ & $2 \times 10^{-5}$ & $4 \times 10^{-5}$ & $2 \times 10^{-4}$ \\
\hline
\end{tabular}

The accident with the highest risk to the offsite population, MEI, and noninvolved worker is the "Unmitigated Beyond Design Basis Earthquake" scenario. The collective risk to the offsite population for this scenario would range from $5 \times 10^{-4}$ expected LCFs per year of operation in the Site-1 offsite population (300,000 people) to 0.02 expected LCFs per year of operation in the Site- 6 offsite population $(8,200,000$ people) . 
TABLE D.2.6.1-3-Heavy Water Reactor Accident Risks ${ }^{a}$ to the Maximally Exposed Individual (All Sites)

\begin{tabular}{|c|c|c|c|c|c|c|}
\hline Accident (Frequency) & $\begin{array}{l}\text { Generic } \\
\text { Site } 1\end{array}$ & $\begin{array}{l}\text { Generic } \\
\text { Site } 2\end{array}$ & $\begin{array}{l}\text { Generic } \\
\text { Site } 3\end{array}$ & $\begin{array}{l}\text { Generic } \\
\text { Site } 4\end{array}$ & $\begin{array}{l}\text { Generic } \\
\text { Site } 5\end{array}$ & $\begin{array}{l}\text { Generic } \\
\text { Site } 6\end{array}$ \\
\hline $\begin{array}{l}\text { Charge/Discharge Accident } \\
(0.001 / \mathrm{yr})\end{array}$ & $4 \times 10^{-9}$ & $4 \times 10^{-9}$ & $4 \times 10^{-9}$ & $3 \times 10^{-8}$ & $3 \times 10^{-8}$ & $3 \times 10^{-8}$ \\
\hline $\begin{array}{l}\text { Core Melt with Containment Spray } \\
\text { System and Containment Functioning } \\
\left(5 \times 10^{-6} / \mathrm{yr}\right)\end{array}$ & $2 \times 10^{-8}$ & $2 \times 10^{-8}$ & $2 \times 10^{-8}$ & $3 \times 10^{-7}$ & $3 \times 10^{-7}$ & $3 \times 10^{-7}$ \\
\hline $\begin{array}{l}\text { Seismically-Induced Core Melt with } \\
\text { Containment Spray System Failure } \\
\text { and Containment Functioning } \\
\left(2 \times 10^{-6} / \mathrm{yr}\right)\end{array}$ & $8 \times 10^{-9}$ & $8 \times 10^{-9}$ & $8 \times 10^{-9}$ & $1 \times 10^{-7}$ & $1 \times 10^{-7}$ & $1 \times 10^{-7}$ \\
\hline $\begin{array}{l}\text { Core Melt with Containment Spray } \\
\text { System Failure and Containment } \\
\text { Functioning }\left(2 \times 10^{-6} / \mathrm{yr}\right)\end{array}$ & $8 \times 10^{-9}$ & $8 \times 10^{-9}$ & $8 \times 10^{-9}$ & $1 \times 10^{-7}$ & $1 \times 10^{-7}$ & $1 \times 10^{-7}$ \\
\hline $\begin{array}{l}\text { Seismically-Induced Core Melt with } \\
\text { Containment Spray System Failure } \\
\text { and Early Containment Failure } \\
\left(1 \times 10^{-7} / \mathrm{yr}\right)\end{array}$ & $1 \times 10^{-8}$ & $1 \times 10^{-8}$ & $1 \times 10^{-8}$ & $8 \times 10^{-8}$ & $8 \times 10^{-8}$ & $8 \times 10^{-8}$ \\
\hline $\begin{array}{l}\text { Core Melt with Early Containment } \\
\text { Spray System and Containment } \\
\text { Failure }\left(1 \times 10^{-7} / \mathrm{yr}\right)\end{array}$ & $1 \times 10^{-8}$ & $1 \times 10^{-8}$ & $1 \times 10^{-8}$ & $8 \times 10^{-8}$ & $8 \times 10^{-8}$ & $8 \times 10^{-8}$ \\
\hline $\begin{array}{l}\text { Beyond Design Basis Earthquake, } \\
\text { mitigated }\left(1 \times 10^{-5} / \mathrm{yr}\right)\end{array}$ & $2 \times 10^{-9}$ & $2 \times 10^{-9}$ & $2 \times 10^{-9}$ & $2 \times 10^{-8}$ & $2 \times 10^{-8}$ & $2 \times 10^{-8}$ \\
\hline $\begin{array}{l}\text { Beyond Design Basis Earthquake, } \\
\text { unmitigated }\left(1 \times 10^{-5} / \mathrm{yr}\right)\end{array}$ & $1 \times 10^{-5}$ & $1 \times 10^{-5}$ & $1 \times 10^{-5}$ & $1 \times 10^{-5}$ & $1 \times 10^{-5}$ & $1 \times 10^{-5}$ \\
\hline Aircraft Crash, mitigated $\left(1 \times 10^{-7} / \mathrm{yr}\right)$ & $2 \times 10^{-11}$ & $2 \times 10^{-11}$ & $2 \times 10^{-11}$ & $2 \times 10^{-10}$ & $2 \times 10^{-10}$ & $2 \times 10^{-10}$ \\
\hline $\begin{array}{l}\text { Aircraft Crash, unmitigated } \\
\left(1 \times 10^{-7} / \mathrm{yr}\right)\end{array}$ & $1 \times 10^{-7}$ & $1 \times 10^{-7}$ & $1 \times 10^{-7}$ & $1 \times 10^{-7}$ & $1 \times 10^{-7}$ & $1 \times 10^{-7}$ \\
\hline
\end{tabular}

For the MEI, the "Unmitigated Beyond Design Basis Earthquake" scenario would result in an increased LCF risk of $1 \times 10^{-5}$ per year of operation. 
TABLE D.2.6.1-4-Heavy Water Reactor Accident Risks ${ }^{a}$ to the Noninvolved Worker

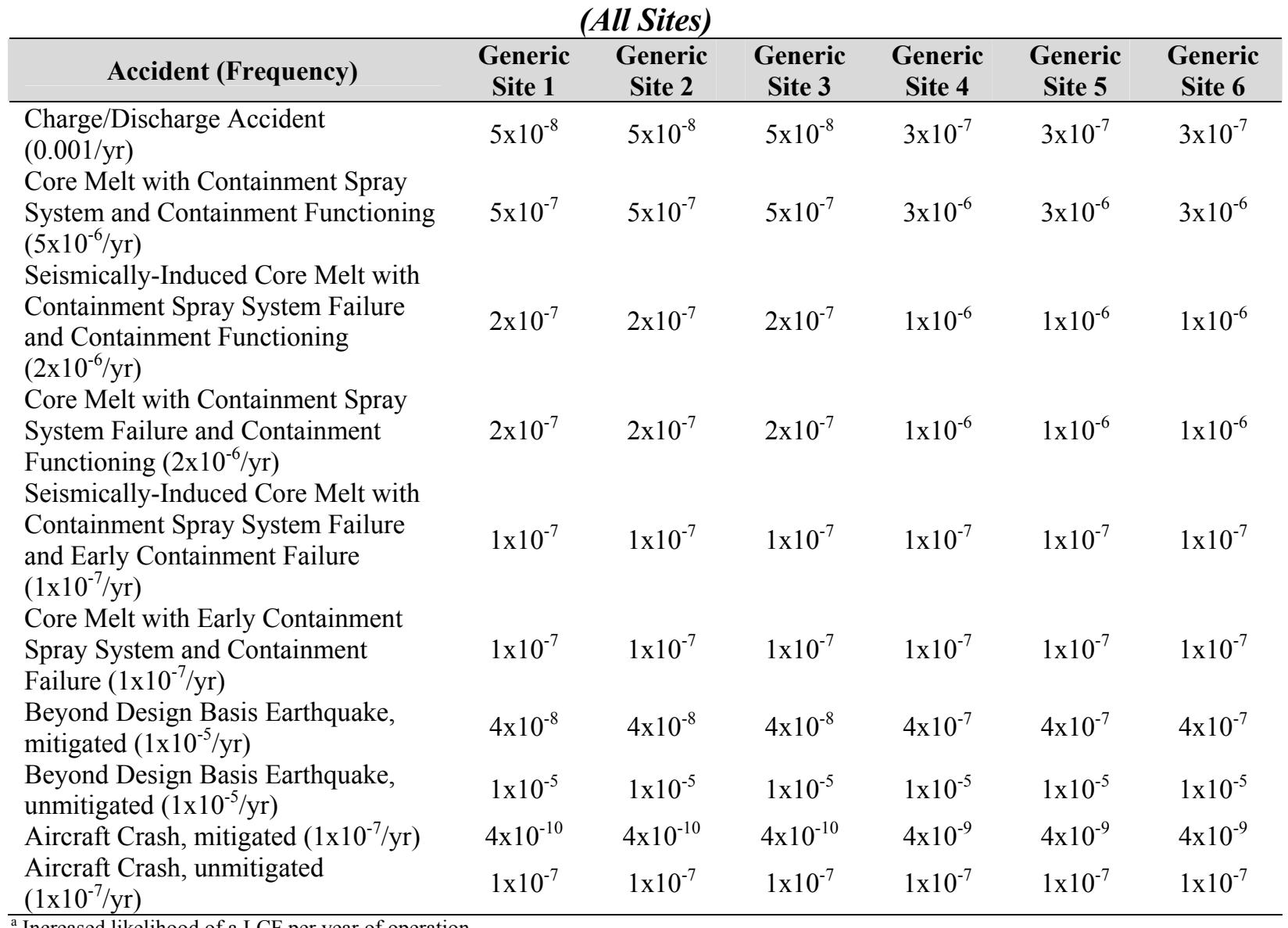

${ }^{\mathrm{a}}$ Increased likelihood of a LCF per year of operation.

For the onsite noninvolved worker, the "Unmitigated Beyond Design Basis Earthquake" accident would result in an increased risk of $1 \times 10^{-5}$ of a LCF per year of operation, which corresponds to the annual probability of that accident occurring (i.e., the consequence is 1 LCF so the risk [probability $\mathrm{x}$ consequence] equals the annual probability, or numerically equals the frequency, of the accident).

Tables D.2.6.1-5 through D.2.6.1-7 present the accident consequences for the HWR at the six generic sites described in Section D.1.6 for the offsite population, MEI, and noninvolved worker. 


\begin{tabular}{|c|c|c|c|c|c|c|}
\hline Accident (Frequency) & $\begin{array}{l}\text { Generic } \\
\text { Site } 1\end{array}$ & $\begin{array}{l}\text { Generic } \\
\text { Site } 2\end{array}$ & $\begin{array}{l}\text { Generic } \\
\text { Site } 3\end{array}$ & $\begin{array}{l}\text { Generic } \\
\text { Site } 4\end{array}$ & $\begin{array}{l}\text { Generic } \\
\text { Site } 5\end{array}$ & $\begin{array}{l}\text { Generic } \\
\text { Site } 6\end{array}$ \\
\hline Charge/Discharge Accident (0.001/yr) & $\begin{array}{c}0.7 / \\
4 \times 10^{-4}\end{array}$ & $\begin{array}{c}2 / \\
9 \times 10^{-4}\end{array}$ & $7 / 0.004$ & $3 / 0.002$ & $6 / 0.004$ & $30 / 0.02$ \\
\hline $\begin{array}{l}\text { Core Melt with Containment Spray } \\
\text { System and Containment Functioning } \\
\left(5 \times 10^{-6} / \mathrm{yr}\right)\end{array}$ & $600 / 0.4$ & $\begin{array}{l}1,000 / \\
0.8\end{array}$ & $7,000 / 4$ & $3,000 / 2$ & $6,000 / 3$ & $2 \times 10^{4} / 10$ \\
\hline $\begin{array}{l}\text { Seismically-Induced Core Melt with } \\
\text { Containment Spray System Failure } \\
\text { and Containment Functioning } \\
\left(2 \times 10^{-6} / \mathrm{yr}\right)\end{array}$ & $600 / 0.4$ & $\begin{array}{l}1,000 / \\
0.8\end{array}$ & $7,000 / 4$ & $3,000 / 2$ & $6,000 / 3$ & $2 \times 10^{4} / 10$ \\
\hline $\begin{array}{l}\text { Core Melt with Containment Spray } \\
\text { System Failure and Containment } \\
\text { Functioning }\left(2 \times 10^{-6} / \mathrm{yr}\right)\end{array}$ & $600 / 0.4$ & $\begin{array}{l}1,000 / \\
0.8\end{array}$ & $7,000 / 4$ & $3,000 / 2$ & $6,000 / 3$ & $2 \times 10^{4} / 10$ \\
\hline $\begin{array}{l}\text { Seismically-Induced Core Melt with } \\
\text { Containment Spray System Failure } \\
\text { and Early Containment Failure } \\
\left(1 \times 10^{-7} / \mathrm{yr}\right)\end{array}$ & $8,000 / 5$ & $\begin{array}{c}2 \times 10^{4} / \\
10\end{array}$ & $\begin{array}{c}8 \times 10^{4} / \\
50\end{array}$ & $\begin{array}{c}3 \times 10^{4} / \\
20\end{array}$ & $\begin{array}{c}5 \times 10^{4} / \\
30\end{array}$ & $2 \times 10^{5} / 100$ \\
\hline $\begin{array}{l}\text { Core Melt with Early Containment } \\
\text { Spray System and Containment } \\
\text { Failure }\left(1 \times 10^{-7} / \mathrm{yr}\right)\end{array}$ & $8,000 / 5$ & $\begin{array}{c}2 \times 10^{4} / \\
10\end{array}$ & $\begin{array}{c}8 \times 10^{4} / \\
50\end{array}$ & $\begin{array}{c}3 \times 10^{4} / \\
20\end{array}$ & $\begin{array}{c}5 \times 10^{4} / \\
30\end{array}$ & $2 \times 10^{5} / 100$ \\
\hline $\begin{array}{l}\text { Beyond Design Basis Earthquake, } \\
\text { mitigated }\left(1 \times 10^{-5} / \mathrm{yr}\right)\end{array}$ & $60 / 0.04$ & $\begin{array}{l}100 / \\
0.09\end{array}$ & $700 / 0.4$ & $300 / 0.2$ & $600 / 0.3$ & $2,000 / 1$ \\
\hline $\begin{array}{l}\text { Beyond Design Basis Earthquake, } \\
\text { unmitigated }\left(1 \times 10^{-5} / \mathrm{yr}\right)\end{array}$ & $\begin{array}{l}8 \times 10^{4} / \\
50\end{array}$ & $\begin{array}{c}2 \times 10^{5} / \\
100\end{array}$ & $\begin{array}{c}9 \times 10^{5} / \\
500\end{array}$ & $\begin{array}{l}4 \times 10^{5} / \\
200\end{array}$ & $\begin{array}{c}7 \times 10^{5} / \\
400\end{array}$ & $\begin{array}{c}3 \times 10^{6} / \\
2,000\end{array}$ \\
\hline Aircraft Crash, mitigated $\left(1 \times 10^{-7} / \mathrm{yr}\right)$ & $60 / 0.04$ & $\begin{array}{l}100 / \\
0.09\end{array}$ & $700 / 0.4$ & $300 / 0.2$ & $600 / 0.3$ & $2,000 / 1$ \\
\hline Aircraft Crash, unmitigated $\left(1 \times 10^{-7} / \mathrm{yr}\right)$ & $\begin{array}{c}8 \times 10^{4} / \\
50\end{array}$ & $\begin{array}{c}2 \times 10^{5} / \\
100\end{array}$ & $\begin{array}{c}9 \times 10^{5} / \\
500\end{array}$ & $\begin{array}{c}4 \times 10^{5} / \\
200\end{array}$ & $\begin{array}{l}7 \times 10^{5} / \\
400\end{array}$ & $\begin{array}{c}3 \times 10^{6} / \\
2,000\end{array}$ \\
\hline
\end{tabular}

${ }^{\mathrm{a}}$ The dose in person-rem is reported before the slash and the increased number of LCFs is presented after the slash.

The accidents with the highest consequence to the offsite population and MEI would be the "Unmitigated Beyond Design Basis Earthquake" and "Unmitigated Aircraft Crash." Using the dose-to-risk conversion factor of $6 \times 10^{-4}$ per person-rem, the collective population doses would result in 50 to 2,000 additional LCFs in the surrounding population for these Extremely Unlikely and Beyond Extremely Unlikely accidents. 
TABLE D.2.6.1-6-Heavy Water Reactor Accident Health Consequences (Dose in Rem/Increased Likelihood of a Latent Cancer Fatality) ${ }^{a}$ to the Maximally Exposed Individual (All Sites)

\begin{tabular}{|c|c|c|c|c|c|c|}
\hline Accident (Frequency) & $\begin{array}{c}\text { Generic } \\
\text { Site } 1 \\
\end{array}$ & $\begin{array}{c}\text { Generic } \\
\text { Site } 2 \\
\end{array}$ & $\begin{array}{c}\text { Generic } \\
\text { Site } 3 \\
\end{array}$ & $\begin{array}{c}\text { Generic } \\
\text { Site } 4 \\
\end{array}$ & $\begin{array}{c}\text { Generic } \\
\text { Site } 5 \\
\end{array}$ & Generic Site 6 \\
\hline $\begin{array}{l}\text { Charge/Discharge Accident } \\
(0.001 / \mathrm{yr}) \\
\text { Core Melt with Containment }\end{array}$ & $\begin{array}{l}0.007 / \\
4 \times 10^{-6}\end{array}$ & $\begin{array}{l}0.007 / \\
4 \times 10^{-6}\end{array}$ & $\begin{array}{l}0.007 / \\
4 \times 10^{-6}\end{array}$ & $\begin{array}{l}0.05 / \\
3 \times 10^{-5}\end{array}$ & $\begin{array}{l}0.05 / \\
3 \times 10^{-5}\end{array}$ & $0.05 / 3 \times 10^{-5}$ \\
\hline $\begin{array}{l}\text { Spray System and } \\
\text { Containment Functioning } \\
\left(5 \times 10^{-6} / \mathrm{yr}\right)\end{array}$ & $7 / 0.004$ & $7 / 0.004$ & $7 / 0.004$ & $50 / 0.06$ & $50 / 0.06$ & $50 / 0.06$ \\
\hline $\begin{array}{l}\text { Seismically-Induced Core } \\
\text { Melt with Containment Spray }\end{array}$ & & & & & & \\
\hline $\begin{array}{l}\text { System Failure and } \\
\text { Containment Functioning } \\
\left(2 \times 10^{-6} / \mathrm{yr}\right)\end{array}$ & $7 / 0.004$ & $7 / 0.004$ & $7 / 0.004$ & $50 / 0.06$ & $50 / 0.06$ & $50 / 0.06$ \\
\hline $\begin{array}{l}\text { Core Melt with Containment } \\
\text { Spray System Failure and } \\
\text { Containment Functioning } \\
\left(2 \times 10^{-6} / \mathrm{yr}\right)\end{array}$ & $7 / 0.004$ & $7 / 0.004$ & $7 / 0.004$ & $50 / 0.06$ & $50 / 0.06$ & $50 / 0.06$ \\
\hline $\begin{array}{l}\text { Seismically-Induced Core } \\
\text { Melt with Containment Spray }\end{array}$ & & & & & & \\
\hline $\begin{array}{l}\text { System Failure and Early } \\
\text { Containment Failure } \\
\left(1 \times 10^{-7} / \mathrm{yr}\right) \\
\text { Core Melt with Early }\end{array}$ & $100 / 0.1$ & $100 / 0.1$ & $100 / 0.1$ & $700 / 0.8$ & $700 / 0.8$ & $700 / 0.8$ \\
\hline $\begin{array}{l}\text { Containment Spray System } \\
\text { and Containment Failure } \\
\left(1 \times 10^{-7} / \mathrm{yr}\right)\end{array}$ & $100 / 0.1$ & $100 / 0.1$ & $100 / 0.1$ & $700 / 0.8$ & $700 / 0.8$ & $700 / 0.8$ \\
\hline $\begin{array}{l}\text { Beyond Design Basis } \\
\text { Earthquake, mitigated } \\
\left(1 \times 10^{-5} / \mathrm{yr}\right)\end{array}$ & $\begin{array}{c}0.4 / \\
2 \times 10^{-4}\end{array}$ & $\begin{array}{c}0.4 / \\
2 \times 10^{-4}\end{array}$ & $\begin{array}{c}0.4 / \\
2 \times 10^{-4}\end{array}$ & $3 / 0.002$ & $3 / 0.002$ & $3 / 0.002$ \\
\hline Beyond Design Basis & & & & & & \\
\hline $\begin{array}{l}\text { Earthquake, unmitigated } \\
\left(1 \times 10^{-5} / \mathrm{yr}\right)\end{array}$ & $900 / 1$ & $900 / 1$ & $900 / 1$ & $7,000 / 1$ & $7,000 / 1$ & $7,000 / 1$ \\
\hline $\begin{array}{l}\text { Aircraft Crash, mitigated } \\
\left(1 \times 10^{-7} / \mathrm{yr}\right)\end{array}$ & $\begin{array}{c}0.4 / \\
2 \times 10^{-4}\end{array}$ & $\begin{array}{c}0.4 / \\
2 \times 10^{-4}\end{array}$ & $\begin{array}{c}0.4 / \\
2 \times 10^{-4}\end{array}$ & $3 / 0.002$ & $3 / 0.002$ & $3 / 0.002$ \\
\hline $\begin{array}{l}\text { Aircraft Crash, unmitigated } \\
\left(1 \times 10^{-7} / \mathrm{yr}\right)\end{array}$ & $900 / 1$ & $900 / 1$ & $900 / 1$ & $7,000 / 1$ & $7,000 / 1$ & $7,000 / 1$ \\
\hline
\end{tabular}

For the MEI, the Extremely Unlikely "Unmitigated Beyond Design Basis Earthquake" and Beyond Extremely Unlikely "Unmitigated Aircraft Crash" scenarios would result in prompt radiation health effects up to fatality. 
TABLE D.2.6.1-7-Heavy Water Reactor Accident Health Consequences (Dose in Rem/Increased Likelihood of a Latent Cancer Fatality) ${ }^{a}$ to the Noninvolved Worker (All Sites)

\begin{tabular}{|c|c|c|c|c|c|c|}
\hline Accident (Frequency) & $\begin{array}{l}\text { Generic } \\
\text { Site } 1\end{array}$ & $\begin{array}{l}\text { Generic } \\
\text { Site } 2\end{array}$ & $\begin{array}{l}\text { Generic } \\
\text { Site } 3\end{array}$ & $\begin{array}{l}\text { Generic } \\
\text { Site } 4\end{array}$ & $\begin{array}{l}\text { Generic } \\
\text { Site } 5\end{array}$ & $\begin{array}{c}\text { Generic } \\
\text { Site } 6\end{array}$ \\
\hline $\begin{array}{l}\text { Charge/Discharge Accident } \\
(0.001 / \mathrm{yr})\end{array}$ & $\begin{array}{l}0.09 / \\
5 \times 10^{-5}\end{array}$ & $\begin{array}{l}0.09 / \\
5 \times 10^{-5}\end{array}$ & $\begin{array}{l}0.09 / \\
5 \times 10^{-5}\end{array}$ & $\begin{array}{r}0.5 / \\
3 \times 10^{-4}\end{array}$ & $\begin{array}{r}0.5 / \\
3 \times 10^{-4}\end{array}$ & $\begin{array}{r}0.5 / \\
3 \times 10^{-4}\end{array}$ \\
\hline $\begin{array}{l}\text { Core Melt with Containment Spray } \\
\text { System and Containment } \\
\text { Functioning }\left(5 \times 10^{-6} / \mathrm{yr}\right)\end{array}$ & $80 / 0.09$ & $80 / 0.09$ & $80 / 0.09$ & $400 / 0.5$ & $400 / 0.5$ & $400 / 0.5$ \\
\hline $\begin{array}{l}\text { Seismically-Induced Core Melt with } \\
\text { Containment Spray System Failure } \\
\text { and Containment Functioning } \\
\left(2 \times 10^{-6} / \mathrm{yr}\right)\end{array}$ & $80 / 0.09$ & $80 / 0.09$ & $80 / 0.09$ & $400 / 0.5$ & $400 / 0.5$ & $400 / 0.5$ \\
\hline $\begin{array}{l}\text { Core Melt with Containment Spray } \\
\text { System Failure and Containment } \\
\text { Functioning }\left(2 \times 10^{-6} / \mathrm{yr}\right)\end{array}$ & $80 / 0.09$ & $80 / 0.09$ & $80 / 0.09$ & $400 / 0.5$ & $400 / 0.5$ & $400 / 0.5$ \\
\hline $\begin{array}{l}\text { Seismically-Induced Core Melt with } \\
\text { Containment Spray System Failure } \\
\text { and Early Containment Failure } \\
\left(1 \times 10^{-7} / \mathrm{yr}\right)\end{array}$ & $900 / 1$ & $900 / 1$ & $900 / 1$ & $4,000 / 1$ & $4,000 / 1$ & $4,000 / 1$ \\
\hline $\begin{array}{l}\text { Core Melt with Early Containment } \\
\text { Spray System and Containment } \\
\text { Failure }\left(1 \times 10^{-7} / \mathrm{yr}\right)\end{array}$ & $900 / 1$ & $900 / 1$ & $900 / 1$ & $4,000 / 1$ & $4,000 / 1$ & $4,000 / 1$ \\
\hline $\begin{array}{l}\text { Beyond Design Basis Earthquake, } \\
\text { mitigated }\left(1 \times 10^{-5} / \mathrm{yr}\right)\end{array}$ & $6 / 0.004$ & $6 / 0.004$ & $6 / 0.004$ & $40 / 0.04$ & $40 / 0.04$ & $40 / 0.04$ \\
\hline $\begin{array}{l}\text { Beyond Design Basis Earthquake, } \\
\text { unmitigated }\left(1 \times 10^{-5} / \mathrm{yr}\right)\end{array}$ & $1 \times 10^{4} / 1$ & $1 \times 10^{4} / 1$ & $1 \times 10^{4} / 1$ & $6 \times 10^{4} / 1$ & $6 \times 10^{4} / 1$ & $6 \times 10^{4} / 1$ \\
\hline Aircraft Crash, mitigated $\left(1 \times 10^{-7} / \mathrm{yr}\right)$ & $6 / 0.004$ & $6 / 0.004$ & $6 / 0.004$ & $40 / 0.04$ & $40 / 0.04$ & $40 / 0.04$ \\
\hline $\begin{array}{l}\text { Aircraft Crash, unmitigated } \\
\left(1 \times 10^{-7} / \mathrm{yr}\right)\end{array}$ & $1 \times 10^{4} / 1$ & $1 \times 10^{4} / 1$ & $1 \times 10^{4} / 1$ & $6 \times 10^{4} / 1$ & $6 \times 10^{4} / 1$ & $6 \times 10^{4} / 1$ \\
\hline
\end{tabular}

${ }^{a}$ The dose in rem is reported before the slash and the increased likelihood of a LCF is presented after the slash.

For the noninvolved worker, the "Seismically-Induced Core Melt with Containment Spray System Failure and Early Containment Failure," "Core Melt with Early Containment Spray System and Containment Failure," "Unmitigated Beyond Design Basis Earthquake," and "Unmitigated Aircraft Crash" would result in prompt radiation health effects up to fatality.

\section{D.2.6.2 High Temperature Gas-Cooled Reactor (Option 2)}

With respect to accidents, impacts would be dependent on many factors, including the type of accident, site characteristics, and the distribution of population in the surrounding environment. HTGRs have substantially different design and operating features than the LWRs currently used in the commercial industry. An LWR uses ceramic pellet fuel in metal tubes and is both cooled and moderated by water. A HTGR uses particle fuel in graphite spheres, or in compacts loaded into graphite blocks. Graphite serves as the moderator and helium serves as the reactor coolant. These differences make the safety characteristics of the two reactor options substantially different. 
Having recognized these differences, both reactors have to deal with challenging accident scenarios, some of which are similar. Some of the most challenging include accidents involving loss of coolant and loss of coolant flow. In the case of LWRs, if a coolant leak is encountered, emergency core cooling water must be introduced into the reactor to prevent overheating and fuel melting. An LWR core must remain covered with coolant at all times and the coolant must maintain flow through the core to remove heat produced by the fuel. In the case of a HTGR, the helium coolant must remain pressurized and must continue to flow through the core to remove heat as in the case of an LWR. In the event of a loss of flow, local fuel heating would occur and in the case of a leak and depressurization, fuel temperatures would rise even further. In the case of a leak and depressurization, air can potentially flow into the reactor cooling system. This can cause oxidation of the graphite and the generation of additional heat.

The HTGR graphite moderator has a high heat capacity (ability to absorb heat) and the fuel particle coatings have the ability to withstand high temperatures without failing. This provides more time than would be available in a water reactor (LWR or HWR) to take corrective action.

The differences in the LWR and HTGR reactor concepts (i.e., the design, materials, coolants, and moderators) make the accident scenarios and potential consequences different. The goal for both the LWR and HTGR designs is to limit the potential of accidents occurring and to limit the effects of an accident in the event one does occur.

DOE has previously analyzed accidents associated with HTGRs at a variety of locations in the Tritium Supply and Recycling Final PEIS (DOE 1995b). In this PEIS, DOE has re-analyzed the risks of the accident scenarios presented in DOE (1995b) at the six generic sites described in Section D.1.6. A description of each accident is presented in DOE (1995b) and is not repeated here. The parameters used for this analysis are presented in Table D.2.6.2-1. Tables D.2.6.2-2 through D.2.6.2-4 present the accident risks for the HTGR from all accidents at all sites to the offsite population, MEI, and noninvolved worker. 
TABLE D.2.6.2-1—Release Parameters for High Temperature Gas-Cooled Reactor Accidents

\begin{tabular}{|c|c|c|}
\hline Parameter & Value & Basis/Comment \\
\hline Release Point & Ground level & $\begin{array}{c}\text { All reactor accidents are based on a ground level release } \\
\text { to provide a common basis. }\end{array}$ \\
\hline Duration: & 1 hour & $\begin{array}{c}\text { This is the default value used when information is not } \\
\text { available. }\end{array}$ \\
\hline $\begin{array}{l}\text { Beyond Design Basis } \\
\text { Earthquake }\end{array}$ & See Table D.1.4-1 & \\
\hline Aircraft Crash & See Table D.1.4-1 & \\
\hline All other scenarios & 1 hour & $\begin{array}{l}\text { This is the default value used when information is not } \\
\text { available. }\end{array}$ \\
\hline \multicolumn{3}{|l|}{ Source terms: } \\
\hline $\begin{array}{l}\text { Beyond Design Basis } \\
\text { Earthquake }\end{array}$ & $\begin{array}{l}\text { Core inventory was taken } \\
\text { from DOE/EIS-0161 } \\
\text { (DOE 1995b). Release } \\
\text { parameters taken from } \\
\quad \text { Table D.1.4-1. }\end{array}$ & $\begin{array}{c}\text { Release parameters were selected consistent with the } \\
\text { values used for all reactors DOE/EIS-0161 (see Table } \\
\text { D.1.4-1) and applied to the HTGR inventory } \\
\text { (DOE 1995b). }\end{array}$ \\
\hline Aircraft Crash & $\begin{array}{l}\text { Core inventory was taken } \\
\text { from DOE/EIS-0161 } \\
\text { (DOE 1995b). Release } \\
\text { parameters taken from } \\
\text { Table D.1.4-1. }\end{array}$ & $\begin{array}{l}\text { Release parameters were selected consistent with the } \\
\text { values used for all reactors (see Table D.1.4-1) and } \\
\text { applied to the HTGR inventory DOE/EIS-0161 } \\
\text { (DOE 1995b). }\end{array}$ \\
\hline All other scenarios & $\begin{array}{l}\text { Values were taken from } \\
\text { DOE/EIS-0161 (DOE 1995b) }\end{array}$ & $\begin{array}{l}\text { The source terms are used directly from DOE/EIS- } 0161 \\
\text { (DOE 1995b) since it is the basis for this HTGR accident } \\
\text { information. }\end{array}$ \\
\hline \multicolumn{3}{|l|}{ Frequency $(/ \mathrm{yr})$ : } \\
\hline $\begin{array}{l}\text { Depressurized Conduction } \\
\text { Cooldown With Reactor } \\
\text { Cavity Cooling System } \\
\text { Functioning } \\
\text { Depressurized Conduction }\end{array}$ & $\begin{array}{l}6 \times 10^{-6} / \mathrm{yr} \text { (Extremely } \\
\text { Unlikely) }\end{array}$ & $\begin{array}{l}\text { DOE/EIS-0161 (DOE 1995b) is the basis for the } \\
\text { frequency estimate. }\end{array}$ \\
\hline $\begin{array}{l}\text { Cooldown Without } \\
\text { Reactor Cavity Cooling } \\
\text { System Functioning }\end{array}$ & $\begin{array}{l}6 \times 10^{-6} / \mathrm{yr} \text { (Extremely } \\
\text { Unlikely) }\end{array}$ & $\begin{array}{l}\text { DOE/EIS-0161 (DOE 1995b) is the basis for the } \\
\text { frequency estimate. }\end{array}$ \\
\hline Air Ingress & $\begin{array}{l}2 \times 10^{-6} / \text { yr (Extremely } \\
\text { Unlikely) }\end{array}$ & $\begin{array}{l}\text { DOE/EIS-0161 (DOE 1995b) is the basis for the } \\
\text { frequency estimate. }\end{array}$ \\
\hline Moisture Ingress & $\begin{array}{l}2 \times 10^{-6} / \mathrm{yr} \text { (Extremely } \\
\text { Unlikely) }\end{array}$ & $\begin{array}{l}\text { DOE/EIS-0161 (DOE 1995b) is the basis for the } \\
\text { frequency estimate. }\end{array}$ \\
\hline $\begin{array}{l}\text { Small Primary System } \\
\text { Break }\end{array}$ & 0.1/yr (Anticipated) & $\begin{array}{l}\text { DOE/EIS-0161 (DOE 1995b) reports a value of } 1 / \mathrm{yr} \text { but } \\
\text { this value is considered unrealistically high. A value of } \\
0.1 / \mathrm{yr} \text {, the highest frequency addressed in this evaluation, } \\
\text { is assigned. }\end{array}$ \\
\hline $\begin{array}{l}\text { Moderate Primary System } \\
\text { Break }\end{array}$ & 0.025/yr (Unlikely) & $\begin{array}{l}\text { DOE/EIS-0161 (DOE 1995b) is the basis for the } \\
\text { frequency estimate. }\end{array}$ \\
\hline $\begin{array}{l}\text { Beyond Design Basis } \\
\text { Earthquake }\end{array}$ & $\begin{array}{l}1 \times 10^{-7} / \mathrm{yr} \text { (Beyond Extremely } \\
\text { Unlikely) }\end{array}$ & $\begin{array}{c}\text { The median frequency of a safe shutdown earthquake for } \\
\text { current LWRs is } 1.0 \times 10^{-5} / \mathrm{yr} \text { per Regulatory Guide } 1.165 \\
\text { (NRC 1997). The frequency is expected to be no greater } \\
\text { for an HTGR than for current LWRs, so an event } \\
\text { frequency of } 10^{-7} / \mathrm{yr} \text { is used in this analysis. } \\
\text { The facility must be licensed by the NRC, so it will be } \\
\text { required to meet NRC Aircraft Hazards criteria } \\
\text { (NRC } 2007 \mathrm{k} \text { ). Therefore, an event frequency of } 10^{-7} / \mathrm{yr} \text { is } \\
\text { used in this analysis. }\end{array}$ \\
\hline
\end{tabular}


TABLE D.2.6.2-2 — High Temperature Gas-Cooled Reactor Accident Risks ${ }^{a}$ to the Offsite Population (All Sites)

\begin{tabular}{|c|c|c|c|c|c|c|}
\hline Accident (Frequency) & $\begin{array}{l}\text { Generic } \\
\text { Site } 1\end{array}$ & $\begin{array}{l}\text { Generic } \\
\text { Site } 2\end{array}$ & $\begin{array}{l}\text { Generic } \\
\text { Site } 3\end{array}$ & $\begin{array}{l}\text { Generic } \\
\text { Site } 4\end{array}$ & $\begin{array}{l}\text { Generic } \\
\text { Site } 5\end{array}$ & $\begin{array}{l}\text { Generic } \\
\text { Site } 6\end{array}$ \\
\hline $\begin{array}{l}\text { Depressurized Conduction Cooldown With } \\
\text { Reactor Cavity Cooling System } \\
\text { Functioning }\left(6 \times 10^{-6} / \mathrm{yr}\right)\end{array}$ & $3 \times 10^{-7}$ & $7 \times 10^{-7}$ & $3 \times 10^{-6}$ & $1 \times 10^{-6}$ & $3 \times 10^{-6}$ & $1 \times 10^{-5}$ \\
\hline $\begin{array}{l}\text { Depressurized Conduction Cooldown } \\
\text { Without Reactor Cavity Cooling System } \\
\text { Functioning }\left(6 \times 10^{-6} / \mathrm{yr}\right)\end{array}$ & $2 \times 10^{-7}$ & $4 \times 10^{-7}$ & $2 \times 10^{-6}$ & $9 \times 10^{-7}$ & $2 \times 10^{-6}$ & $7 \times 10^{-6}$ \\
\hline Air Ingress $\left(2 \times 10^{-6} / \mathrm{yr}\right)$ & $9 \times 10^{-8}$ & $2 \times 10^{-7}$ & $1 \times 10^{-6}$ & $5 \times 10^{-7}$ & $9 \times 10^{-7}$ & $4 \times 10^{-6}$ \\
\hline Moisture Ingress $\left(2 \times 10^{-6} / \mathrm{yr}\right)$ & $6 \times 10^{-8}$ & $1 \times 10^{-7}$ & $7 \times 10^{-7}$ & $3 \times 10^{-7}$ & $6 \times 10^{-7}$ & $2 \times 10^{-6}$ \\
\hline Small Primary System Break $(0.1 /$ yr $)$ & $3 \times 10^{-9}$ & $7 \times 10^{-9}$ & $3 \times 10^{-8}$ & $1 \times 10^{-8}$ & $3 \times 10^{-8}$ & $1 \times 10^{-7}$ \\
\hline Moderate Primary System Break (0.025/yr) & $2 \times 10^{-8}$ & $4 \times 10^{-8}$ & $2 \times 10^{-7}$ & $8 \times 10^{-8}$ & $1 \times 10^{-7}$ & $6 \times 10^{-7}$ \\
\hline $\begin{array}{l}\text { Beyond Design Basis Earthquake, mitigated } \\
\left(1 \times 10^{-5} / \mathrm{yr}\right)\end{array}$ & $2 \times 10^{-7}$ & $4 \times 10^{-7}$ & $2 \times 10^{-6}$ & $8 \times 10^{-7}$ & $2 \times 10^{-6}$ & $7 \times 10^{-6}$ \\
\hline $\begin{array}{l}\text { Beyond Design Basis Earthquake, } \\
\text { unmitigated }\left(1 \times 10^{-5} / \mathrm{yr}\right)\end{array}$ & $2 \times 10^{-4}$ & $5 \times 10^{-4}$ & 0.002 & 0.001 & 0.002 & 0.008 \\
\hline Aircraft Crash, mitigated $\left(1 \times 10^{-7} / \mathrm{yr}\right)$ & $2 \times 10^{-9}$ & $4 \times 10^{-9}$ & $2 \times 10^{-8}$ & $8 \times 10^{-9}$ & $2 \times 10^{-8}$ & $7 \times 10^{-8}$ \\
\hline Aircraft Crash, unmitigated $\left(1 \times 10^{-7} / \mathrm{yr}\right)$ & $2 \times 10^{-6}$ & $5 \times 10^{-6}$ & $2 \times 10^{-5}$ & $1 \times 10^{-5}$ & $2 \times 10^{-5}$ & $8 \times 10^{-5}$ \\
\hline
\end{tabular}

The accident with the highest risk to the offsite population, MEI, and noninvolved worker is the "Unmitigated Beyond Design Basis Earthquake" scenario. The collective risk to the offsite population for this scenario would range from $2 \times 10^{-4}$ expected LCFs per year of operation in the Site-1 offsite population (300,000 people) to 0.008 expected LCFs per year of operation in the Site-6 offsite population $(8,200,000$ people).

TABLE D.2.6.2-3 - High Temperature Gas-Cooled Reactor Accident Risks ${ }^{a}$ to the Maximally Exposed Individual (All Sites)

\begin{tabular}{|c|c|c|c|c|c|c|}
\hline Accident (Frequency) & $\begin{array}{l}\text { Generic } \\
\text { Site } 1\end{array}$ & $\begin{array}{l}\text { Generic } \\
\text { Site } 2\end{array}$ & $\begin{array}{l}\text { Generic } \\
\text { Site } 3\end{array}$ & $\begin{array}{l}\text { Generic } \\
\text { Site } 4\end{array}$ & $\begin{array}{l}\text { Generic } \\
\text { Site } 5\end{array}$ & $\begin{array}{l}\text { Generic } \\
\text { Site } 6\end{array}$ \\
\hline $\begin{array}{l}\text { Depressurized Conduction Cooldown With } \\
\text { Reactor Cavity Cooling System } \\
\text { Functioning }\left(6 \times 10^{-6} / \mathrm{yr}\right)\end{array}$ & $3 \times 10^{-9}$ & $3 \times 10^{-9}$ & $3 \times 10^{-9}$ & $2 \times 10^{-8}$ & $2 \times 10^{-8}$ & $2 \times 10^{-8}$ \\
\hline $\begin{array}{l}\text { Depressurized Conduction Cooldown } \\
\text { Without Reactor Cavity Cooling System } \\
\text { Functioning }\left(6 \times 10^{-6} / \mathrm{yr}\right)\end{array}$ & $2 \times 10^{-9}$ & $2 \times 10^{-9}$ & $2 \times 10^{-9}$ & $2 \times 10^{-8}$ & $2 \times 10^{-8}$ & $2 \times 10^{-8}$ \\
\hline Air Ingress $\left(2 \times 10^{-6} / \mathrm{yr}\right)$ & $1 \times 10^{-9}$ & $1 \times 10^{-9}$ & $1 \times 10^{-9}$ & $8 \times 10^{-9}$ & $8 \times 10^{-9}$ & $8 \times 10^{-9}$ \\
\hline Moisture Ingress $\left(2 \times 10^{-6} / \mathrm{yr}\right)$ & $7 \times 10^{-10}$ & $7 \times 10^{-10}$ & $7 \times 10^{-10}$ & $5 \times 10^{-9}$ & $5 \times 10^{-9}$ & $5 \times 10^{-9}$ \\
\hline Small Primary System Break (0.1/yr) & $3 \times 10^{-11}$ & $3 \times 10^{-11}$ & $3 \times 10^{-11}$ & $2 \times 10^{-10}$ & $2 \times 10^{-10}$ & $2 \times 10^{-10}$ \\
\hline Moderate Primary System Break (0.025/yr) & $2 \times 10^{-10}$ & $2 \times 10^{-10}$ & $2 \times 10^{-10}$ & $2 \times 10^{-9}$ & $2 \times 10^{-9}$ & $2 \times 10^{-9}$ \\
\hline $\begin{array}{l}\text { Beyond Design Basis Earthquake, } \\
\text { mitigated }\left(1 \times 10^{-5} / \mathrm{yr}\right)\end{array}$ & $1 \times 10^{-9}$ & $1 \times 10^{-9}$ & $1 \times 10^{-9}$ & $9 \times 10^{-9}$ & $9 \times 10^{-9}$ & $9 \times 10^{-9}$ \\
\hline $\begin{array}{l}\text { Beyond Design Basis Earthquake, } \\
\text { unmitigated }\left(1 \times 10^{-5} / \mathrm{yr}\right)\end{array}$ & $5 \times 10^{-6}$ & $5 \times 10^{-6}$ & $5 \times 10^{-6}$ & $1 \times 10^{-5}$ & $1 \times 10^{-5}$ & $1 \times 10^{-5}$ \\
\hline Aircraft Crash, mitigated $\left(1 \times 10^{-7} / \mathrm{yr}\right)$ & $1 \times 10^{-11}$ & $1 \times 10^{-11}$ & $1 \times 10^{-11}$ & $9 \times 10^{-11}$ & $9 \times 10^{-11}$ & $9 \times 10^{-11}$ \\
\hline Aircraft Crash, unmitigated $\left(1 \times 10^{-7} / \mathrm{yr}\right)$ & $5 \times 10^{-8}$ & $5 \times 10^{-8}$ & $5 \times 10^{-8}$ & $1 \times 10^{-7}$ & $1 \times 10^{-7}$ & $1 \times 10^{-7}$ \\
\hline
\end{tabular}

For the MEI, the "Unmitigated Beyond Design Basis Earthquake" scenario would result in an increased LCF risk of $5 \times 10^{-6}$ per year of operation to $1 \times 10^{-5}$ per year of operation. 
TABLE D.2.6.2-4—High Temperature Gas-Cooled Reactor Accident Risks ${ }^{\text {a }}$ to the Noninvolved Worker (All Sites)

\begin{tabular}{|c|c|c|c|c|c|c|}
\hline Accident (Frequency) & $\begin{array}{l}\text { Generic } \\
\text { Site } 1\end{array}$ & $\begin{array}{l}\text { Generic } \\
\text { Site } 2\end{array}$ & $\begin{array}{l}\text { Generic } \\
\text { Site } 3\end{array}$ & $\begin{array}{l}\text { Generic } \\
\text { Site } 4\end{array}$ & $\begin{array}{l}\text { Generic } \\
\text { Site } 5\end{array}$ & $\begin{array}{l}\text { Generic } \\
\text { Site } 6\end{array}$ \\
\hline $\begin{array}{l}\text { Depressurized Conduction } \\
\text { Cooldown With Reactor Cavity } \\
\text { Cooling System Functioning } \\
\left(6 \times 10^{-6} / \mathrm{yr}\right)\end{array}$ & $4 \times 10^{-8}$ & $4 \times 10^{-8}$ & $4 \times 10^{-8}$ & $4 \times 10^{-7}$ & $4 \times 10^{-7}$ & $4 \times 10^{-7}$ \\
\hline $\begin{array}{l}\text { Depressurized Conduction } \\
\text { Cooldown Without Reactor Cavity } \\
\text { Cooling System Functioning } \\
\left(6 \times 10^{-6} / \mathrm{yr}\right)\end{array}$ & $2 \times 10^{-8}$ & $2 \times 10^{-8}$ & $2 \times 10^{-8}$ & $3 \times 10^{-7}$ & $3 \times 10^{-7}$ & $3 \times 10^{-7}$ \\
\hline $\begin{array}{l}\text { Air Ingress }\left(2 \times 10^{-6} / \mathrm{yr}\right) \\
\text { Moisture Ingress }\left(2 \times 10^{-6} / \mathrm{yr}\right)\end{array}$ & $\begin{array}{l}1 \times 10^{-8} \\
8 \times 10^{-9}\end{array}$ & $\begin{array}{l}1 \times 10^{-8} \\
8 \times 10^{-9}\end{array}$ & $\begin{array}{l}1 \times 10^{-8} \\
8 \times 10^{-9}\end{array}$ & $\begin{array}{l}1 \times 10^{-7} \\
9 \times 10^{-8}\end{array}$ & $\begin{array}{l}1 \times 10^{-7} \\
9 \times 10^{-8}\end{array}$ & $\begin{array}{l}1 \times 10^{-7} \\
9 \times 10^{-8}\end{array}$ \\
\hline $\begin{array}{l}\text { Small Primary System Break } \\
(0.1 / \mathrm{yr})\end{array}$ & $4 \times 10^{-10}$ & $4 \times 10^{-10}$ & $4 \times 10^{-10}$ & $2 \times 10^{-9}$ & $2 \times 10^{-9}$ & $2 \times 10^{-9}$ \\
\hline $\begin{array}{l}\text { Moderate Primary System Break } \\
(0.025 / \mathrm{yr})\end{array}$ & $2 \times 10^{-9}$ & $2 \times 10^{-9}$ & $2 \times 10^{-9}$ & $1 \times 10^{-8}$ & $1 \times 10^{-8}$ & $1 \times 10^{-8}$ \\
\hline $\begin{array}{l}\text { Beyond Design Basis Earthquake, } \\
\text { mitigated }\left(1 \times 10^{-5} / \mathrm{yr}\right)\end{array}$ & $2 \times 10^{-8}$ & $2 \times 10^{-8}$ & $2 \times 10^{-8}$ & $1 \times 10^{-7}$ & $1 \times 10^{-7}$ & $1 \times 10^{-7}$ \\
\hline $\begin{array}{l}\text { Beyond Design Basis Earthquake, } \\
\text { unmitigated }\left(1 \times 10^{-5} / \mathrm{yr}\right)\end{array}$ & $1 \times 10^{-5}$ & $1 \times 10^{-5}$ & $1 \times 10^{-5}$ & $1 \times 10^{-5}$ & $1 \times 10^{-5}$ & $1 \times 10^{-5}$ \\
\hline Aircraft Crash, mitigated $\left(1 \times 10^{-7} / \mathrm{yr}\right)$ & $2 \times 10^{-10}$ & $2 \times 10^{-10}$ & $2 \times 10^{-10}$ & $1 \times 10^{-9}$ & $1 \times 10^{-9}$ & $1 \times 10^{-9}$ \\
\hline $\begin{array}{l}\text { Aircraft Crash, unmitigated } \\
\left(1 \times 10^{-7} / \mathrm{yr}\right)\end{array}$ & $1 \times 10^{-7}$ & $1 \times 10^{-7}$ & $1 \times 10^{-7}$ & $1 \times 10^{-7}$ & $1 \times 10^{-7}$ & $1 \times 10^{-7}$ \\
\hline
\end{tabular}

For the onsite noninvolved worker, the "Unmitigated Beyond Design Basis Earthquake" scenario would result in an increased risk of a LCF of $1 \times 10^{-5}$ per year of operation; this corresponds to the annual probability of that accident occurring (i.e., the consequence is 1 LCF so the risk [probability $\mathrm{x}$ consequence] equals the annual probability, or numerically equals the frequency, of the accident).

Tables D.2.6.2-5 through D.2.6.2-7 present the accident consequences for the HTGR at the six generic sites described in Section D.1.6 for the offsite population, MEI, and noninvolved worker. 


\begin{tabular}{|c|c|c|c|c|c|c|}
\hline Accident (Frequency) & $\begin{array}{l}\text { Generic } \\
\text { Site } 1 \\
\end{array}$ & $\begin{array}{l}\text { Generic } \\
\text { Site } 2 \\
\end{array}$ & $\begin{array}{l}\text { Generic } \\
\text { Site } 3 \\
\end{array}$ & $\begin{array}{l}\text { Generic } \\
\text { Site } 4 \\
\end{array}$ & $\begin{array}{c}\text { Generic } \\
\text { Site } 5 \\
\end{array}$ & $\begin{array}{c}\text { Generic } \\
\text { Site } 6 \\
\end{array}$ \\
\hline $\begin{array}{l}\text { Depressurized Conduction Cooldown } \\
\text { With Reactor Cavity Cooling System } \\
\text { Functioning }\left(6 \times 10^{-6} / \mathrm{yr}\right)\end{array}$ & $80 / 0.05$ & $200 / 0.1$ & $900 / 0.5$ & $400 / 0.2$ & $700 / 0.4$ & $3,000 / 2$ \\
\hline $\begin{array}{l}\text { Depressurized Conduction Cooldown } \\
\text { Without Reactor Cavity Cooling } \\
\text { System Functioning }\left(6 \times 10^{-6} / \mathrm{yr}\right)\end{array}$ & $50 / 0.03$ & $\begin{array}{l}100 / \\
0.07\end{array}$ & $600 / 0.3$ & $300 / 0.2$ & $500 / 0.3$ & $2,000 / 1$ \\
\hline Air Ingress $\left(2 \times 10^{-6} / \mathrm{yr}\right)$ & $80 / 0.05$ & $200 / 0.1$ & $900 / 0.5$ & $400 / 0.2$ & $700 / 0.4$ & $3,000 / 2$ \\
\hline Moisture Ingress $\left(2 \times 10^{-6} / \mathrm{yr}\right)$ & $50 / 0.03$ & $\begin{array}{l}100 / \\
0.07\end{array}$ & $600 / 0.3$ & $300 / 0.2$ & $500 / 0.3$ & $2,000 / 1$ \\
\hline Small Primary System Break (0.1/yr) & $\begin{array}{l}5 \times 10^{-5} / \\
3 \times 10^{-8}\end{array}$ & $\begin{array}{l}1 \times 10^{-4} / \\
7 \times 10^{-8}\end{array}$ & $\begin{array}{l}5 \times 10^{-4} / \\
3 \times 10^{-7}\end{array}$ & $\begin{array}{l}2 \times 10^{-4} / \\
1 \times 10^{-7}\end{array}$ & $\begin{array}{l}4 \times 10^{-4} / \\
3 \times 10^{-7}\end{array}$ & $\begin{array}{l}0.002 / \\
1 \times 10^{-6}\end{array}$ \\
\hline $\begin{array}{l}\text { Moderate Primary System Break } \\
\text { Moderate Primary System Break } \\
(0.025 / \mathrm{yr})\end{array}$ & $\begin{array}{l}0.001 / \\
7 \times 10^{-7}\end{array}$ & $\begin{array}{l}0.003 / \\
2 \times 10^{-6}\end{array}$ & $\begin{array}{l}0.01 / \\
8 \times 10^{-6}\end{array}$ & $\begin{array}{l}0.005 / \\
3 \times 10^{-6}\end{array}$ & $\begin{array}{l}0.009 / \\
6 \times 10^{-6}\end{array}$ & $\begin{array}{c}0.04 / 2 \\
\times 10^{-5}\end{array}$ \\
\hline $\begin{array}{l}\text { Beyond Design Basis Earthquake, } \\
\text { mitigated }\left(1 \times 10^{-5} / \mathrm{yr}\right)\end{array}$ & $30 / 0.02$ & $70 / 0.04$ & $300 / 0.2$ & $\begin{array}{l}100 / \\
0.08\end{array}$ & $300 / 0.2$ & $\begin{array}{c}1,000 / \\
0.7\end{array}$ \\
\hline $\begin{array}{l}\text { Beyond Design Basis Earthquake, } \\
\text { unmitigated }\left(1 \times 10^{-5} / \mathrm{yr}\right)\end{array}$ & $\begin{array}{c}4 \times 10^{4} / \\
20\end{array}$ & $\begin{array}{l}9 \times 10^{4} / \\
50\end{array}$ & $\begin{array}{c}4 \times 10^{5} / \\
200\end{array}$ & $\begin{array}{c}2 \times 10^{5} / \\
100\end{array}$ & $\begin{array}{l}3 \times 10^{5} / \\
200\end{array}$ & $\begin{array}{c}1 \times 10^{6} / \\
800\end{array}$ \\
\hline Aircraft Crash, mitigated $\left(1 \times 10^{-7} / \mathrm{yr}\right)$ & $30 / 0.02$ & $70 / 0.04$ & $300 / 0.2$ & $\begin{array}{l}100 / \\
0.08\end{array}$ & $300 / 0.2$ & $\begin{array}{c}1,000 / \\
0.7\end{array}$ \\
\hline Aircraft Crash, unmitigated $\left(1 \times 10^{-7} / \mathrm{yr}\right)$ & $\begin{array}{c}4 \times 10^{4} / \\
20\end{array}$ & $\begin{array}{c}9 \times 10^{4} / \\
50\end{array}$ & $\begin{array}{c}4 \times 10^{5} / \\
200\end{array}$ & $\begin{array}{c}2 \times 10^{5} / \\
100\end{array}$ & $\begin{array}{l}3 \times 10^{5} / \\
200\end{array}$ & $\begin{array}{c}1 \times 10^{6} / \\
800\end{array}$ \\
\hline
\end{tabular}

${ }^{\mathrm{a}}$ The dose in rem is reported before the slash and the increased number of LCFs is presented after the slash.

The accidents with the highest consequences to the offsite population, MEI, and noninvolved worker would be the "Unmitigated Beyond Design Basis Earthquake" and "Unmitigated Aircraft Crash." Using the dose-to-risk conversion factor of $6 \times 10^{-4}$ per person-rem, the collective population doses would result in 20 to 800 additional LCFs in the surrounding population for these Extremely Unlikely and Beyond Extremely Unlikely accidents. 
TABLE D.2.6.2-6-High Temperature Gas-Cooled Reactor Accident Health Consequences (Dose in Rem/Increased Likelihood of a Latent Cancer Fatality) ${ }^{a}$ to the Maximally Exposed Individual (All Sites)

\begin{tabular}{|c|c|c|c|c|c|c|}
\hline Accident (Frequency) & $\begin{array}{l}\text { Generic } \\
\text { Site } 1\end{array}$ & $\begin{array}{l}\text { Generic } \\
\text { Site } 2\end{array}$ & $\begin{array}{l}\text { Generic } \\
\text { Site } 3\end{array}$ & $\begin{array}{c}\text { Generic } \\
\text { Site } 4\end{array}$ & $\begin{array}{l}\text { Generic } \\
\text { Site } 5\end{array}$ & $\begin{array}{c}\text { Generic } \\
\text { Site } 6\end{array}$ \\
\hline $\begin{array}{l}\text { Depressurized Conduction Cooldown With } \\
\text { Reactor Cavity Cooling System Functioning } \\
\left(6 \times 10^{-6} / \mathrm{yr}\right)\end{array}$ & $\begin{array}{c}0.9 / \\
5 \times 10^{-4}\end{array}$ & $\begin{array}{c}0.9 / \\
5 \times 10^{-4}\end{array}$ & $\begin{array}{c}0.9 / \\
5 \times 10^{-4}\end{array}$ & $\begin{array}{c}6 / \\
0.004\end{array}$ & $\begin{array}{c}6 / \\
0.004\end{array}$ & $\begin{array}{c}6 / \\
0.004\end{array}$ \\
\hline $\begin{array}{l}\text { Depressurized Conduction Cooldown } \\
\text { Without Reactor Cavity Cooling System } \\
\text { Functioning }\left(6 \times 10^{-6} / \mathrm{yr}\right)\end{array}$ & $\begin{array}{c}0.6 / \\
3 \times 10^{-4}\end{array}$ & $\begin{array}{c}0.6 / \\
3 \times 10^{-4}\end{array}$ & $\begin{array}{c}0.6 / \\
3 \times 10^{-4}\end{array}$ & $\begin{array}{c}4 / \\
0.002\end{array}$ & $\begin{array}{c}4 / \\
0.002\end{array}$ & $\begin{array}{c}4 / \\
0.002\end{array}$ \\
\hline Air Ingress $\left(2 \times 10^{-6} / \mathrm{yr}\right)$ & $\begin{array}{c}0.9 / \\
5 \times 10^{-4}\end{array}$ & $\begin{array}{c}0.9 / \\
5 \times 10^{-4}\end{array}$ & $\begin{array}{c}0.9 / \\
5 \times 10^{-4}\end{array}$ & $\begin{array}{c}6 / \\
0.004\end{array}$ & $\begin{array}{c}6 / \\
0.004\end{array}$ & $\begin{array}{c}6 / \\
0.004\end{array}$ \\
\hline Moisture Ingress $\left(2 \times 10^{-6} / \mathrm{yr}\right)$ & $\begin{array}{c}0.6 / \\
3 \times 10^{-4}\end{array}$ & $\begin{array}{c}0.6 / \\
3 \times 10^{-4}\end{array}$ & $\begin{array}{c}0.6 / \\
3 \times 10^{-4}\end{array}$ & $\begin{array}{c}4 / \\
0.002\end{array}$ & $\begin{array}{c}4 / \\
0.002\end{array}$ & $\begin{array}{c}4 / \\
0.002\end{array}$ \\
\hline Small Primary System Break (0.1/yr) & $\begin{array}{l}5 \times 10^{-7} / \\
3 \times 10^{-10}\end{array}$ & $\begin{array}{l}5 \times 10^{-7} / \\
3 \times 10^{-10}\end{array}$ & $\begin{array}{l}5 \times 10^{-7} / \\
3 \times 10^{-10}\end{array}$ & $\begin{array}{c}4 \times 10^{-6} / \\
2 \times 10^{-9}\end{array}$ & $\begin{array}{l}4 \times 10^{-6} / \\
2 \times 10^{-9}\end{array}$ & $\begin{array}{l}4 \times 10^{-6} / \\
2 \times 10^{-9}\end{array}$ \\
\hline Moderate Primary System Break (0.025/yr) & $\begin{array}{l}1 \times 10^{-5} / \\
9 \times 10^{-9}\end{array}$ & $\begin{array}{l}1 \times 10^{-5} / \\
9 \times 10^{-9}\end{array}$ & $\begin{array}{l}1 \times 10^{-5} / \\
9 \times 10^{-9}\end{array}$ & $\begin{array}{l}1 \times 10^{-4} / \\
6 \times 10^{-8}\end{array}$ & $\begin{array}{l}1 \times 10^{-4} / \\
6 \times 10^{-8}\end{array}$ & $\begin{array}{l}1 \times 10^{-4} / \\
6 \times 10^{-8}\end{array}$ \\
\hline $\begin{array}{l}\text { Beyond Design Basis Earthquake, mitigated } \\
\left(1 \times 10^{-5} / \mathrm{yr}\right)\end{array}$ & $\begin{array}{c}0.2 / \\
1 \times 10^{-4}\end{array}$ & $\begin{array}{c}0.2 / \\
1 \times 10^{-4}\end{array}$ & $\begin{array}{c}0.2 / \\
1 \times 10^{-4}\end{array}$ & $\begin{array}{c}1 / \\
9 \times 10^{-4}\end{array}$ & $\begin{array}{c}1 / \\
9 \times 10^{-4}\end{array}$ & $\begin{array}{c}1 / \\
9 \times 10^{-4}\end{array}$ \\
\hline $\begin{array}{l}\text { Beyond Design Basis Earthquake, } \\
\text { unmitigated }\left(1 \times 10^{-5} / \mathrm{yr}\right)\end{array}$ & $\begin{array}{c}400 / \\
0.5\end{array}$ & $\begin{array}{c}400 / \\
0.5\end{array}$ & $\begin{array}{c}400 / \\
0.5\end{array}$ & $\begin{array}{c}3,000 / \\
1\end{array}$ & $\begin{array}{c}3,000 / \\
1\end{array}$ & $\begin{array}{c}3,000 / \\
1\end{array}$ \\
\hline Aircraft Crash, mitigated $\left(1 \times 10^{-7} / \mathrm{yr}\right)$ & $\begin{array}{c}0.2 / \\
1 \times 10^{-4}\end{array}$ & $\begin{array}{c}0.2 / \\
1 \times 10^{-4}\end{array}$ & $\begin{array}{c}0.2 / \\
1 \times 10^{-4}\end{array}$ & $\begin{array}{c}1 / \\
9 \times 10^{-4}\end{array}$ & $\begin{array}{c}1 / \\
9 \times 10^{-4}\end{array}$ & $\begin{array}{c}1 / \\
9 \times 10^{-4}\end{array}$ \\
\hline Aircraft Crash, unmitigated $\left(1 \times 10^{-7} / \mathrm{yr}\right)$ & $\begin{array}{c}400 / \\
0.5\end{array}$ & $\begin{array}{c}400 / \\
0.5\end{array}$ & $\begin{array}{c}400 / \\
0.5\end{array}$ & $\begin{array}{c}3,000 / \\
1\end{array}$ & $\begin{array}{c}3,000 / \\
1\end{array}$ & $\begin{array}{c}3,000 / \\
1\end{array}$ \\
\hline
\end{tabular}

The MEI dose for the Extremely Unlikely "Unmitigated Beyond Design Basis Earthquake" and Beyond Extremely Unlikely "Unmitigated Aircraft Crash" accidents would result in prompt radiation health effects up to fatality. 


\begin{tabular}{|c|c|c|c|c|c|c|}
\hline Accident (Frequency) & $\begin{array}{c}\text { Generic } \\
\text { Site } 1 \\
\end{array}$ & $\begin{array}{c}\text { Generic } \\
\text { Site } 2 \\
\end{array}$ & $\begin{array}{c}\text { Generic } \\
\text { Site } 3 \\
\end{array}$ & $\begin{array}{c}\text { Generic } \\
\text { Site } 4 \\
\end{array}$ & $\begin{array}{l}\text { Generic } \\
\text { Site } 5 \\
\end{array}$ & $\begin{array}{c}\text { Generic } \\
\text { Site } 6 \\
\end{array}$ \\
\hline $\begin{array}{l}\text { Depressurized Conduction Cooldown } \\
\text { With Reactor Cavity Cooling System } \\
\text { Functioning }\left(6 \times 10^{-6} / \mathrm{yr}\right)\end{array}$ & $\begin{array}{c}10 / \\
0.006\end{array}$ & $\begin{array}{c}10 / \\
0.006\end{array}$ & $\begin{array}{c}10 / \\
0.006\end{array}$ & $60 / 0.07$ & $60 / 0.07$ & $60 / 0.07$ \\
\hline $\begin{array}{l}\text { Depressurized Conduction Cooldown } \\
\text { Without Reactor Cavity Cooling System } \\
\text { Functioning }\left(6 \times 10^{-6} / \mathrm{yr}\right)\end{array}$ & $7 / 0.004$ & $7 / 0.004$ & $7 / 0.004$ & $40 / 0.04$ & $40 / 0.04$ & $40 / 0.04$ \\
\hline Air Ingress $\left(2 \times 10^{-6} / \mathrm{yr}\right)$ & $\begin{array}{l}10 / \\
0.006\end{array}$ & $\begin{array}{c}10 / \\
0.006\end{array}$ & $\begin{array}{c}10 / \\
0.006\end{array}$ & $60 / 0.07$ & $60 / 0.07$ & $60 / 0.07$ \\
\hline Moisture Ingress $\left(2 \times 10^{-6} / \mathrm{yr}\right)$ & $7 / 0.004$ & $7 / 0.004$ & $7 / 0.004$ & $40 / 0.04$ & $40 / 0.04$ & $40 / 0.04$ \\
\hline Small Primary System Break (0.1/yr) & $\begin{array}{l}6 \times 10^{-6} / \\
4 \times 10^{-9}\end{array}$ & $\begin{array}{l}6 \times 10^{-6} / \\
4 \times 10^{-9}\end{array}$ & $\begin{array}{c}6 \times 10^{-6} / \\
4 \times 10^{-9}\end{array}$ & $\begin{array}{l}3 \times 10^{-5} / \\
2 \times 10^{-8}\end{array}$ & $\begin{array}{l}3 \times 10^{-5} / \\
2 \times 10^{-8}\end{array}$ & $\begin{array}{l}3 \times 10^{-5} / \\
2 \times 10^{-8}\end{array}$ \\
\hline $\begin{array}{l}\text { Moderate Primary System Break } \\
(0.025 / \mathrm{yr})\end{array}$ & $\begin{array}{l}1 \times 10^{-4} / \\
8 \times 10^{-8}\end{array}$ & $\begin{array}{l}1 \times 10^{-4} / \\
8 \times 10^{-8}\end{array}$ & $\begin{array}{l}1 \times 10^{-4} / \\
8 \times 10^{-8}\end{array}$ & $\begin{array}{l}7 \times 10^{-4} / \\
4 \times 10^{-7}\end{array}$ & $\begin{array}{l}7 \times 10^{-4} / \\
4 \times 10^{-7}\end{array}$ & $\begin{array}{l}7 \times 10^{-4} / \\
4 \times 10^{-7}\end{array}$ \\
\hline $\begin{array}{l}\text { Beyond Design Basis Earthquake, } \\
\text { mitigated }\left(1 \times 10^{-5} / \mathrm{yr}\right)\end{array}$ & $3 / 0.002$ & $3 / 0.002$ & $3 / 0.002$ & $20 / 0.01$ & $20 / 0.01$ & $20 / 0.01$ \\
\hline $\begin{array}{l}\text { Beyond Design Basis Earthquake, } \\
\text { unmitigated }\left(1 \times 10^{-5} / \mathrm{yr}\right)\end{array}$ & $5,000 / 1$ & $5,000 / 1$ & $5,000 / 1$ & $3 \times 10^{4} / 1$ & $3 \times 10^{4} / 1$ & $3 \times 10^{4} / 1$ \\
\hline Aircraft Crash, mitigated $\left(1 \times 10^{-7} / \mathrm{yr}\right)$ & $3 / 0.002$ & $3 / 0.002$ & $3 / 0.002$ & $20 / 0.01$ & $20 / 0.01$ & $20 / 0.01$ \\
\hline Aircraft Crash, unmitigated $\left(1 \times 10^{-7} / \mathrm{yr}\right)$ & $5,000 / 1$ & $5,000 / 1$ & $5,000 / 1$ & $3 \times 10^{4} / 1$ & $3 \times 10^{4} / 1$ & $3 \times 10^{4} / 1$ \\
\hline
\end{tabular}

For the noninvolved worker the Extremely Unlikely "Unmitigated Beyond Design Basis Earthquake" and Beyond Extremely Unlikely "Unmitigated Aircraft Crash" scenarios would likely result in a prompt radiation fatality. 


\section{D.3 REFERENCES}

40 CFR 1502.22

Briggs et al. 2007

Chanin and Young 1998

DNFSB 2003

DOE 1987

DOE 1992c

DOE 1995a

DOE $1995 b$
Council on Environmental Quality (CEQ), "Incomplete or Unavailable Information," Code of Federal Regulations, Office of the Federal Register, National Archives and Records Administration, Washington, DC, July 1, 2007.

Briggs L.L., J.E. Cahalan, L.W. Deitrich, T.H. Fanning, C. Grandy, R. Kellogg, T.K. Kim, and W.S. Yang, "Advanced Burner Reactor Preliminary NEPA Data Study," ANL-AFCI-183, Nuclear Engineering Division, Argonne National Laboratory, September 21, 2007.

Chanin, D. and M.L. Young, "Code Manual for MACCS2: Volume 1, User's Guide," NUREG/CR-6613, Vol. 1, SAND970594, May 19, 1998.

Defense Nuclear Facilities Safety Board (DNFSB), "Control of Red Oil Explosions in Defense Nuclear Facilities," DNFSB/TECH-33, Technical Report, November 2003. Accessed at http://www.dnfsb.gov/pub_docs/dnfsb/tr_20031113.pdf on November 1, 2007.

U.S. Department of Energy (DOE), "Environmental Assessment: Fuel Processing Restoration at the Idaho National Engineering Laboratory," DOE/EA-0306, U.S. Department of Energy, Washington, DC, August 1987.

DOE, "Environmental and Other Evaluations of Alternatives for Siting, Construction, and Operating New Production Reactor Capacity," DOE/NP-0014, U.S. Department of Energy, Washington, DC, September 1992.

DOE, "Accident Assessments for Idaho National Engineering Laboratory Facilities," DOE/ID-10471, Idaho National Engineering Laboratory, U.S. Department of Energy, Washington, DC, March 1995.

DOE, "Final Programmatic Environmental Impact Statement for Tritium Supply and Recycling," DOE/EIS-0161, U.S. Department of Energy, Washington, DC, October 1995. 
DOE 1999d

DOE 1999e

DOE 2000e

DOE 2000f

DOE 2000i

DOE 2000m

DOE 2002e

DOE 2002h
DOE, "Surplus Plutonium Disposition Final Environmental Impact Statement," DOE/EIS-0283, November 1999, Office of Fissile Materials Disposition, U.S. Department of Energy, Washington, DC, 1999.

DOE, "Radiological Control Technician Training," DOE-HDBK1122-99, Module 1.08, Biological Effects of Radiation, U.S. Department of Energy, Washington, DC, June 1999 (Reaffirmed November 2004). Accessed at http://hss.energy.gov/NuclearSafety/ techstds/standard/hdbk1122-04/rad.html on January 15, 2008.

DOE, "Final Environmental Impact Statement for the Treatment and Management of Sodium-Bonded Spent Nuclear Fuel," DOE/EIS-0306, U.S. Department of Energy, Washington, DC, July 2000.

DOE, "Savannah River Site Spent Nuclear Fuel Management Final Environmental Impact Statement," DOE/EIS-0279, Savannah River Operations Office, U.S. Department of Energy, April 2000. Accessed at http://www.osti.gov/bridge/product.biblio.jsp?osti_id $=769549$ on January 15, 2008 .

DOE, "DOE Handbook-Airborne Release Fractions/Rates and Respirable Fractions for Nonreactor Nuclear Facilities," DOEHDBK-3010-94, U.S. Department of Energy, Washington, DC, December 1994, Change Notice 1, March 2000.

DOE, "Draft Programmatic Environmental Impact Statement for Accomplishing Expanded Civilian Nuclear Energy Research and Development and Isotope Production Missions in the United States, Including the Role of the Fast Flux Test Facility (FFTF)," DOE/EIS-0310D, Office of Nuclear Energy, U.S. Department of Energy, Washington, DC, December 2000.

DOE, "Idaho High-Level Waste \& Facilities Disposition, Final Environmental Impact Statement," DOE/EIS-0287, U.S. Department of Energy, Washington, DC, September 2002. Accessed at http://gc.energy.gov/NEPA/nepa_documents/ EIS/EIS0287/0287TOC.html on September 16, 2008.

DOE, "Estimating Radiation Risk from Total Effective Dose Equivalent (TEDE)," DOE/EH-412/0015/0802 Rev.1, Office of Environmental Policy and Guidance, U.S. Department of Energy, Washington, DC, August 9, 2002. 
DOE 2004h

DOE 2005b

DOE 2005n

DOE 2006p

DOE $2006 q$

DOE $2007 u$

DOE 2007w

EPA 2007d
DOE, "ALOHA Computer Code Application Guidance for Documented Safety Analysis," DOE-EH-4.2.1.3-ALOHA Code Guidance, Office of Environment, Safety and Health, U.S. Department of Energy, Washington, DC, June 2004. Accessed at http://www.hss.energy.gov/CSA/CSP/sqa/central_registry/ ALOHA/Final_ALOHA_Guidance Reportv52404.pdf on September 16, 2008.

DOE, "Draft Environmental Impact Statement for the Proposed Consolidation of Nuclear Operations Related to Production of Radioisotope Power Systems," DOE/EIS-0373D, U.S. Department of Energy, Washington, DC, June 2005.

DOE, "Final Site-wide Environmental Impact Statement for Continued Operation of Lawrence Livermore National Laboratory and Supplemental Stockpile Stewardship and Management Programmatic Environmental Impact Statement," DOE/EIS-0348, and DOE/EIS-0236-S3, U.S. Department of Energy, Washington, DC, March 2005.

DOE, "Preparation Guide for U.S. Department of Energy Nonreactor Nuclear Facility Safety Analysis Reports," DOE-STD3009-94, U.S. Department of Energy, Washington, DC, July 1994, Change Notice No.1, January, 2000, Change Notice No.2, April 2002, Change Notice No.3, March 2006.

DOE, "Accident Analysis for Aircraft Crash into Hazardous Facilities," DOE-STD-3014-2006, U.S. Department of Energy, Washington, DC, May 2006.

DOE, "Occurrence Reporting and Processing System (ORPS)," U.S. Department of Energy, Washington, DC, 2007. Accessed at http://www.hss.energy.gov/CSA/analysis/orps/orps.html on December 19, 2007.

DOE, "SQA Directives and Guidance," Software Quality Assurance, U.S. Department of Energy, Washington, DC, Accessed at http://www.hss.energy.gov/csa/csp/sqa/dir.htm on January 16, 2008.

U.S. Environmental Protection Agency (EPA), "ALOHA-User's Manual," Office of Emergency Management, U.S. Environmental Protection Agency, Washington, DC, February 2007. 
Holzworth 1972

IAEA 1996

IAEA 2000

Jow et al. 1990

Kim and Yang 2008

LANL 1986

NRC 1978

NRC 1982
Holzworth, G.C., "Mixing Heights, Wind Speeds, and Potential or Urban Air Pollution Throughout the Contiguous United States," PB-207 103, U.S. Environmental Protection Agency, Research Triangle Park, NC, 1972.

International Atomic Energy Agency (IAEA), "Conditioning and Interim Storage of Spent Radium Sources," IAEA-TECDOC-886, International Atomic Energy Agency, Vienna, 1996.

IAEA, "Unusual Occurrences during LMFR Operation," Proceedings of a Technical Committee Meeting held in Vienna, November 1998, IAEA-TECDOC-1180, International Atomic Energy Agency, Vienna, October, 2000. Accessed at http://www.iaea.org/worldatom/Programmes/Nuclear_Energy/NE NP/NPTDS/docs.html on January 15, 2008.

Jow, H-N, J.L. Sprung, L.T. Ritchie, J.A. Rollstin, and D.I. Chanin, "Melcor Accident Consequence Code System (MACCS), Model Description," NUREG/CR-4691, Vol. 2, SAND86-1562, February 1, 1990.

Kim, T.K. and W.S. Yang, "Preliminary Estimation of Isotopic Inventories of 2000 MWt ABR," Revision 1, ANL-AFCI-220, Nuclear Engineering Division, Argonne National Laboratory, April 23, 2008.

Los Alamos National Laboratory (LANL), "A Guide to Radiological Accident Considerations for Siting and Design of DOE Nonreactor Nuclear Facilities," LA-10294-MS, U.S. Department of Energy, Los Alamos National Laboratory, January 1986. Accessed at http://www.fas.org/sgp/othergov/doe/lanl/libwww/la-pubs/00206602.pdf on January 30, 2008.

U.S. Nuclear Regulatory Commission (NRC), "Safety Evaluation Report by the Office of Nuclear Reactor Regulation, U.S. Nuclear Regulatory Commission for the DOE Fast Flux Test Facility (FFTF)," Project No. 448, NUREG-0358, U.S. Nuclear Regulatory Commission, Washington, DC, August 1978. Accessed at http://www.osti.gov/bridge/product.biblio.jsp?query_id=1\& page $=0 \&$ osti_id $=6638636$ on January 30, 2008.

NRC, "Supplement to Final Environmental Statement Related to Construction and Operation of Clinch River Breeder Reactor Plant," NUREG-0139-Suppl.1-Vol.2, U.S. Nuclear Regulatory Commission, Washington, DC, October 1, 1982. 
NRC 1986

NRC 1990

NRC 1994a

NRC 1995

NRC 1996

NRC 1997

NRC 2000b

NRC 2003

NRC 2007k
NRC, "Regulation of Advanced Nuclear Power Plants; Statement of Policy," Final Policy Statement, U.S. Nuclear Regulatory Commission, Washington, DC, August 7, 1986.

NRC, "Severe Accident Risks: An Assessment for Five U.S. Nuclear Power Plants," NUREG-1150, U.S. Nuclear Regulatory Commission, Washington, DC, December 1990. Accessed at http://www.nrc.gov/reading-rm/doc-collections/nuregs/staff/ sr1150/ on September 08, 2008.

NRC, "Preapplication Safety Evaluation Report for the Power Reactor Innovative Small Module (PRISM) Liquid-Metal Reactor," NUREG-1368, U.S. Nuclear Regulatory Commission, Washington, DC, February 1994.

NRC, "Primary Reactor Containment Leakage Testing for WaterCooled Power Reactors," U.S. Nuclear Regulatory Commission, Washington, DC, September 26, 1995.

NRC, "License Renewal Generic Environmental Impact Statement," NUREG-1437, Office of Nuclear Regulatory Research, U.S. Nuclear Regulatory Commission, Washington, DC, June 1996. Accessed at http://www.nrc.gov/reading-rm/doccollections/nuregs/staff/sr1437/ on January 30, 2008.

NRC, "Regulatory Guide 1.165-Identification and Characterization of Seismic Sources and Determination of Safe Shutdown Earthquake Ground Motion," U.S. Nuclear Regulatory Commission, Washington, DC, March 1997.

NRC, "Regulatory Guide 1.183-Alternative Radiological Source Terms for Evaluating Design Basis Accidents at Nuclear Power Reactors," DG-1081, U.S. Nuclear Regulatory Commission, Washington, DC, July 2000.

NRC, "SECPOP2000: Sector Population, Land Fraction, and Economic Estimation Program," NUREG/CR-6525, Rev. 1, Office of Nuclear Regulatory Research, U.S. Nuclear Regulatory Commission, Washington, DC, August 2003. Accessed at http://www.nrc.gov/reading-rm/doc-collections/nuregs/contract/ cr6525/ on January 30, 2008.

NRC, "Standard Review Plan, 3.5.1.6 Aircraft Hazards," NUREG0800, Revision 3, U.S. Nuclear Regulatory Commission, Washington, DC, March 2007. 
NRC 2008e

PMC 1975

PMC 1982

SCAPA 2007

Tetra Tech 2008a

Tetra Tech $2008 b$

Tetra Tech $2008 \mathrm{e}$

Todosow and Kazimi 2004
NRC, "Design Certifications_-Licensing Reviews," U.S. Nuclear Regulatory Commission, Washington, DC, May 2, 2008. Accessed at http://www.nrc.gov/reactors/new-licensing/design-cert.html on July 2, 2008.

Project Management Corporation (PMC), "Clinch River Breeder Reactor Plant-Environmental Report Vol. I-V," Project Management Corporation, 1975.

PMC, "Clinch River Breeder Reactor Project-Preliminary Safety Analysis Report," Volume 1-Volume 14, Project Management Corporation, May 1982.

Subcommittee on Consequence Assessment and Protective Action (SCAPA), "Protective Action Criteria for Chemicals-Including AEGLs, ERPGs, \& TEELs," National Nuclear Security Administration, U.S. Department of Energy, Washington, DC, 2007. Accessed at http://orise.orau.gov/emi/scapa/teels.htm on December 19, 2007.

Tetra Tech Inc., "Topical Report, Advanced Fuel Cycle Facility Accident Analyses as Part of the Global Nuclear Energy Partnership Programmatic Environmental Impact Statement," P.L. Young, A.L. Toblin, and K.D. Bulmahn, GNEP-01-08, Revision 0, May 2008.

Tetra Tech Inc., "Topical Report, Nuclear Fuel Recycling Center Accident Analyses as Part of the Global Nuclear Energy Partnership Programmatic Environmental Impact Statement," P.L. Young, A.L. Toblin, and K.D. Bulmahn, GNEP-02-08, Revision 0, May 2008.

Tetra Tech Inc., "Topical Report, Advanced Recycling Reactor (ARR) Accident Analyses as Part of the Global Nuclear Energy Partnership Programmatic Environmental Impact Statement," P.L. Young, T. Ijaz, A. Toblin, and K.D. Bulmahn, GNEP-03-08, Revision 1, August 2008.

Todosow M. and M. Kazimi, "Optimization of Heterogeneous Utilization of Thorium in PWRs to Enhance Proliferation Resistance and Reduce Waste," BNL-73152-2004/MIT-NFC-065, August 2004. 
WGI 2008a

WSRC 2008a
Washington Group International (WGI), “Advanced Fuel Cycle Facility Conceptual Design and NEPA Support Activities (NEPA Data Study)," AFCF-ST-001, Rev. 1, Washington Group International, Western Operations Center, Denver, CO, April 2, 2008.

Washington Savannah River Company (WSRC), "Engineering Alternative Studies for Separations, NEPA Data Input Report," EAS-Q-NEP-G-00001, Revision 3, Washington Savannah River Company, April 2008. 


\section{APPENDIX E}

\section{TRANSPORTATION}





\section{APPENDIX E TRANSPORTATION}

\section{E.1 INTRODUCTION}

This appendix summarizes the methods for and results of the analyses of the environmental impacts of radioactive materials transportation using public highways and rail systems. The impacts are presented by alternative and include radiation doses and health effects as follows:

Section E.1 provides general information regarding transportation of radioactive materials that apply to all alternatives studied in this Global Nuclear Energy Partnership (GNEP) Programmatic Environmental Impact Statement (PEIS). This information includes a listing of applicable transportation regulations, methodologies used to assess the environmental impacts due to the transportation of radioactive materials, and a description of the modeling software used in this PEIS.

Section E. 2 provides a description of the methodologies and input parameters that apply to the transportation assessment of the domestic programmatic alternatives of this PEIS. The assessment of the domestic programmatic alternatives used generic input parameters in which no specific site identification was assumed. Generic population densities were derived based on one set of data used to analyze the transport of spent nuclear fuel (SNF) across the continental United States.

Section E.3 describes the methodologies and input parameters used to assess the transportation impacts associated with the international initiatives.

\section{E.1.1 Transportation Regulations}

The Hazardous Materials Transportation Act, as amended (49 U.S.C. 1501 et seq.), directs the U.S. Department of Transportation (DOT) to develop transportation safety standards for hazardous materials, including radioactive materials. Title 49 of the Code of Federal Regulations contains DOT standards and requirements for the packaging, transporting, and handling of radioactive materials for all modes of transportation. In addition, the U.S. Nuclear Regulatory Commission (NRC) regulates design and performance standards for packages that carry radioactive materials (10 CFR Part 71, DOE 2008f).

If shipments are undertaken by private commercial entities, those shipments are subject to regulation by DOT, the NRC, and other entities, as appropriate. If shipments are undertaken by or on behalf of DOE, all DOE shipments would meet or exceed the requirements and standards of DOT and the NRC that apply to comparable commercial shipments, except where there is a determination that national security or another critical interest requires different action. This policy is set forth in DOE Orders 460.1B, Packaging and Transportation Safety, 460.2A, Departmental Materials Transportation and Packaging Management, and 470.4A, Safeguards and Security Program. 


\section{E.1.2 Packaging}

The regulatory standards for packaging and transporting radioactive materials in 10 CFR Part 71 and 49 CFR Parts 173 to 178 are designed to achieve four primary objectives:

- Protect persons and property from radiation emitted from packages during transportation, by placing specific limitations on the allowable radiation levels.

- Provide proper containment of the radioactive material in the package achieved by packaging design requirements based on performance-oriented packaging integrity tests and environmental criteria.

- Prevent nuclear criticality, an unplanned nuclear chain reaction that may occur as a result of concentrating too much fissile material in one place.

- Provide physical protection against theft and sabotage during transit (DOE 1995e).

The DOT regulates the transportation of hazardous materials in interstate commerce by land, by air, and on navigable water. As outlined in a 1979 Memorandum of Understanding (MOU) with the NRC, the DOT specifically regulates the carriers of radioactive materials and the conditions of transport such as routing, handling and storage, and vehicle and driver requirements (44 FR 38690). The DOT regulates the packaging, labeling, classification, and marking of radioactive material packages. The DOT also has requirements that help reduce transportation impacts and specify the maximum dose rate associated with radioactive material shipments, which help reduce incident-free transportation doses (see 49 CFR Parts 171-180).

The NRC regulates the packaging and transport of radioactive material for its licensees, which includes commercial shippers of radioactive materials. Under the same agreement referred to above, the NRC (in consultation with the DOT) sets the standards for packages containing fissile materials and Type B packages, discussed below. The NRC also establishes safeguards and security regulations to minimize theft, diversion, or attack on certain shipments (10 CFR Parts 71,73$)$.

Through its management directives, orders, and contractual agreements, DOE ensures the protection of public health and safety by providing oversight and implementation of its transportation standards and orders that are equivalent to those of the NRC and the DOT. DOE has the authority to certify DOE-owned packages. DOE may design, procure, and certify its own packages, for use by DOE and its contractors, if the packages provide for a level of safety that is equivalent to that provided in 10 CFR Part 71.

Radioactive materials are transported in the following types of packages. The amount of radioactivity determines which package must be used.

- Excepted Packages: Excepted packages are used to transport materials with extremely low levels of radioactivity and must meet only general design requirements.

- Industrial Packages: Industrial packages are used to transport materials that present a limited hazard to the public and environment. Examples include contaminated equipment and radioactive waste solidified in materials such as concrete. 
- Type A Packages: Type A packages are used to transport radioactive materials with higher concentrations of radioactivity such as low-level waste (LLW). Type A packages are designed to retain their radioactive contents in normal transport. Under normal conditions, a Type A package must withstand:

- Hot $\left(158^{\circ} \mathrm{F}\left[70^{\circ} \mathrm{C}\right]\right)$ and cold $\left(-40^{\circ} \mathrm{F}\left[-40^{\circ} \mathrm{C}\right]\right)$ temperatures

- Pressure changes of 3.6 pounds per square inch $\left(\mathrm{lbs} / \mathrm{in}^{2}\right)(25$ kilopascal $[\mathrm{kPa}])$

- Normal vibration experienced during transportation

- Simulated rainfall of 2 inch (in) (5 centimeter [cm]) per hour for 1 hour

- Free drop from 1 to 3.3 feet (ft) (0.3 to 1 meter [m]), depending on the package weight

- Corner drop test

- Compression test

- Impact of a 13.2 pounds (lbs) (6 kilograms [kg]) steel cylinder with rounded ends dropped from $3.3 \mathrm{ft}(1 \mathrm{~m})$ onto the most vulnerable surface of the cask (10 CFR Part 71)

- Type B Packages: Type B packages are used to transport materials with radioactivity levels higher than those allowed for Type A packages. Type B packages are designed to retain their radioactive contents in normal and accident conditions (49 CFR Part 173). In addition to the normal conditions outlined above, under accident conditions a Type B package must withstand:

- Free drop from $30 \mathrm{ft}(9 \mathrm{~m})$ onto an unyielding surface in a way most likely to cause damage to the cask

- For some low-density, light-weight packages, a dynamic crush test consisting of dropping a 1,100 lbs $(500 \mathrm{~kg})$ mass from $30 \mathrm{ft}(9 \mathrm{~m})$ onto the package resting on an unyielding surface

- Free drop from 40 in $(1 \mathrm{~m})$ onto the end of a 6 in $(15 \mathrm{~cm})$ diameter vertical steel bar

- Exposure for not less than 30 minutes to temperatures of $1,475^{\circ} \mathrm{F}\left(800^{\circ} \mathrm{C}\right)$

- For all packages, immersion in at least $50 \mathrm{ft}(15 \mathrm{~m})$ of water for 8 hours

- For fissile material packages, immersion in at least $3 \mathrm{ft}(0.9 \mathrm{~m})$ of water for 8 hours in an orientation most likely to result in leakage (10 CFR Part 71)

- Immersion tests at a depth of at least $660 \mathrm{ft}(200 \mathrm{~m})$ of water for 1 hour to evaluate undamaged package performance

Compliance with these requirements is demonstrated by using computer modeling techniques, or full-scale or scale-model testing of casks (DOE 1995e).

\section{E.1.3 Emergency Management}

States and tribes along shipping routes are primarily responsible for protecting the public and the environment in their jurisdictions. If an emergency involving a DOE radioactive materials shipment occurs, an incident command will be established based on the procedures and policies of the state, tribe, or local jurisdiction. If requested by civil authorities, DOE will provide technical advice and assistance including access to teams of experts in radiological monitoring and related technical areas. DOE staffs eight Regional Coordinating Offices 24 hours a day, 
365 days a year with teams of nuclear engineers, health physicists, industrial hygienists, public affairs specialists, and other professionals.

The Department of Homeland Security (DHS) coordinates the overall Federal Government response to radiological Incidents of National Significance in accordance with Homeland Security Presidential Directive-5 (HSPD-5) (White House 2003) and the National Response Framework (DHS 2008). Based on HSPD-5 criteria, an Incident of National Significance is an actual or potential high-impact event that requires a coordinated and effective response by an appropriate combination of Federal, state, local, tribal, nongovernmental, or private-sector entities to save lives and minimize damage, and to provide the basis for long-term community recovery and mitigation activities (DOE 2008f).

In HSPD-5, the President designates the Secretary of Homeland Security as the principal Federal official for domestic incident management and empowers the Secretary to coordinate federal resources used in response to terrorist attacks, major disasters, or other emergencies in specific cases. The Directive establishes a single, comprehensive National Incident Management System that unifies Federal, state, territorial, tribal, and local lines of government into one coordinated effort. This system encompasses much more than the Incident Command System, which is nonetheless a critical component of the National Incident Management System. That system also provides a common foundation for training and other preparedness efforts, communicating and sharing information with other responders and with the public, ordering resources to assist with a response effort, and integrating new technologies and standards to support incident management. The Incident Command System uses as its base the local first responder protocols; that use does not eliminate the required agreements and coordination among all levels of government (DOE 2008f).

In HSPD-5, the President directed the development of the new National Response Framework to align federal coordination structures, capabilities, and resources into a unified approach to domestic incident management. The Framework is built on the template of the National Incident Management System and provides a comprehensive, all-hazards approach to domestic incident management. All Federal departments and agencies must adopt the National Incident Management System and use it in their individual domestic incident management and emergency prevention, preparedness, response, recovery, and mitigation activities, as well as in support of all actions taken to assist state or local entities (DOE 2008f).

DOE supports the DHS as the coordinating agency for incidents that involve the transportation of radioactive materials by or for DOE. DOE is otherwise responsible for the radioactive material, facility, or activity in the incident. DOE is part of the Unified Command, which is an application of the Incident Command System used when there is more than one agency with incident jurisdiction or when incidents cross political jurisdictions. DOE coordinates the Federal radiological response activities as appropriate. Agencies work together through the designated members of the Unified Command, often the senior person from agencies or disciplines that participate in the Unified Command, to establish a common set of objectives and strategies (DOE 2008f). 
DOE, as the transporter of radiological material, would notify state and tribal authorities and the Homeland Security Operations Center. The Department of Homeland Security and DOE coordinate federal response and recovery activities for the radiological aspects of an incident. DOE reports information and intelligence in relation to situational awareness and incident management to the Homeland Security Operations Center.

DHS and DOE are responsible for coordination of security activities for federal response operations. While spent nuclear fuel and high-level radioactive waste shipments are in transit, state, local, and tribal governments could provide security for a radiological transportation incident that occurred on public lands. The Department of Homeland Security, with DOE as the coordinating agency, approves issuance of all technical data to state, local, and tribal governments.

DOE maintains national and regional coordination offices at points of access to federal radiological emergency assistance. Requests for Radiological Assessment Program teams go directly to the DOE Emergency Operations Center in Washington, D.C. If the situation requires more assistance than a team can provide, DOE alerts or activates additional resources. DOE can respond with additional resources including the Aerial Measurement System to provide widearea radiation monitoring and Radiation Emergency Assistance Center/Training Site medical advisory teams. Some participating federal agencies have radiological planning and emergency responsibilities as part of their statutory authority, as well as established working relationships with state counterparts. The monitoring and assessment activity, which DOE coordinates, does not alter these responsibilities but complements them by providing coordination of the initial federal radiological monitoring and assessment response activities.

The Department of Homeland Security and DOE, as the coordinating agency, oversee the development of Federal Protective Action Recommendations. In this capacity, the departments provide advice and assistance to state, tribal, and local governments, which can include advice and assistance on measures to avoid or reduce exposure of the public to radiation from a release of radioactive material and advice on emergency actions such as sheltering and evacuation.

State, local, and tribal governments are encouraged to follow closely the National Response Framework (DHS 2008), the Nuclear/Radiological Incident Annex, and the National Incident Management System protocols and procedures. As established, all federal, state, local, and tribal responders agree to and follow the Incident Command System (DOE 2008f).

\section{E.1.4 Safeguards and Security Regulatory Environment}

The risk of sabotage or other intentional destructive acts during the transport of nuclear materials is controlled and regulated by safeguards and security requirements, domestically and internationally, as well as by export controls for international shipments. The regulations and guidance of interest for transportation of nuclear materials are listed below.

\section{U.S. Nuclear Regulatory Commission}

10 CFR Part 71: Packaging and Transportation of Radioactive Material 10 CFR Part 73: Physical Protection of Plants and Materials 
10 CFR Part 74: Material Control and Accounting of Special Nuclear Material

10 CFR Part 110: Export and Import of Nuclear Equipment and Material

\section{U.S. Department of Transportation}

49 CFR Part 172: Hazardous Materials Table ... and Training Requirements

49 CFR Part 173: Shippers-General Requirements for Shipments and Packaging

49 CFR Part 174: Carriage by Rail

49 CFR Part 175: Carriage by Aircraft

49 CFR Part 176: Carriage by Vessel

49 CFR Part 177: Carriage by Public Highway

49 CFR Part 178: Specifications for Packagings

49 CFR Part 179: Specifications for Tank Cars

49 CFR Part 180: Continuing Qualification and Maintenance of Packagings

\section{U.S. Department of Energy}

10 CFR Part 810: Assistance to Foreign Atomic Energy Activities

DOE-Policy-470: Integrated Safeguards and Security Management (ISSM) Policy

\section{U.S. Department of Commerce}

15 CFR Parts 730 to 744: Export Administration Regulations (EAR)

\section{International Agencies}

Amended Convention on the Physical Protection of Nuclear Material United Nations Security Council Resolution (UNSCR) 1540

International Atomic Energy Agency Information Circular (IAEA INFCIRC)/153: The Structure and Content of Agreements between the Agency and States required in connection with the Treaty on Non-Proliferation of Nuclear Weapons

IAEA INFCIRC/540: Model Protocol Additional to the Agreement(s) between States and the IAEA for the Application of Safeguards

IAEA-TS-R-1: Regulations for the Safe Transport of Radioactive Material

IAEA-INFCIRC/225: The Physical Protection of Nuclear Material and Nuclear Facilities

\section{E.1.5 Transportation Routes}

DOE used the TRAGIS computer program (Johnson and Michelhaugh 2003) to identify the generic rail and truck routes used in the analysis. TRAGIS is a Web-based geographic information system transportation routing computer code. The TRAGIS rail network is developed from a 1-to-100,000-scale rail network derived from the United States Geological Survey digital line graphs. This network currently represents more than 150,000 mi $(240,000 \mathrm{~km})$ of rail lines in the continental United States and has over 28,000 segments (links) and over 4,000 intersections (nodes). All rail lines with the exception of industrial spurs are included. The rail network includes nodes for nuclear reactor sites, DOE sites, and military bases 
that have rail access. The rail network has been extensively modified and is revised on a regular schedule to reflect rail line abandonment, company mergers, short line spin-offs, and new rail construction.

The TRAGIS computer code predicts highway routes for transporting radioactive materials within the United States. The TRAGIS database is a computerized road atlas that currently describes approximately $240,000 \mathrm{mi}(390,000 \mathrm{~km})$ of roads. Complete descriptions of the interstate highway system, U.S. highways, most of the principal state highways, and a number of local and community highways are identified in the database.

The TRAGIS computer code calculates routes that maximize the use of interstate highways. This feature allows the user to determine routes for shipment of radioactive materials that conform to the DOT regulations, as specified in 49 CFR Part 397. The calculated routes conform to applicable guidelines and regulations and represent routes that could be used. The routes represent a reasonable prediction of future routes, or are typical of what would be used in the period of study. The code is updated periodically to reflect current road conditions and has been benchmarked against reported mileages and observations of commercial truck firms (Johnson and Michelhaugh 2003).

For all routes traveled by legal-weight truck and heavy-haul truck (inter-modal transfer vehicle used to transport rail SNF casks), the model assumed that highway route-controlled quantities of radioactive materials (HRCQ) carriers would be used, as specified by 49 CFR 397.101. The representative routes for HRCQ carriers selected by TRAGIS are mostly interstate highways or large U.S. highways.

To calculate rail routes, the TRAGIS computer program uses rules that are designed to simulate routing practices that have been historically used by railroad companies in moving regular freight and dedicated trains in the United States. The basic rule used to calculate rail routes causes the program to attempt to identify the shortest route from an origin to a destination. Another rule used in the program biases the lengths of route segments that have the highest density of rail traffic to make these segments appear, for purposes of calculation, to be shorter. The effect of the bias is to prioritize selection of routes that use railroad main lines, which have the highest traffic density. As a general rule, routing along the high traffic lines replicates railroad operational practices. A third rule constrains the program to select routes used by an individual railroad company to lines the company owns or over which has permission to operate. This rule ensures the number of interchanges between railroads that the TRAGIS computer program calculates for a route is correct. The number of interchanges between railroads is a significant consideration when determining a realistic and representative route.

Another rule used in the TRAGIS computer program to calculate a rail route determines the sequence of different railroad companies whose rail lines would be linked to form the route. Because a delay and additional operations are involved in transferring a shipment (interchanging) from one railroad to another, in order to provide efficient service, railroads typically route shipments to minimize the number of interchanges that occur. Reducing the number of interchanges also tends to reduce the time a shipment is in transit. This practice is simulated in the TRAGIS computer program by imposing a penalty for each interchange that is identified for 
a route. The interchange penalties cause the TRAGIS computer program to increase the calculated length of routes when more than one railroad company's lines are linked. As a consequence, the algorithm used in the TRAGIS computer program to identify routes that have the least apparent length gives advantage to routes that also have the fewest interchanges between railroads and the fewest involved railroad companies.

Last, a rule in the TRAGIS computer program is designed to simulate the commercial behavior of railroad companies to maximize their portion of revenues from shipments. The effect of this behavior is that routing is often affected by originating railroads, who control the selection of routes on their lines to realize as much of a shipment's revenue as possible. The result is that originating railroads transport shipments as far as possible (in the direction of the destination) on their systems before interchanging the shipments with other railroads. This behavior is simulated in the TRAGIS computer program by imposing a bias on the length of the originating railroad's lines to give the railroad an advantage when calculating a route. In evaluating the length of the route, the model treats 1 mile of travel on the originating railroad as being "less" than 1 mile on other railroads (DOE 2008f).

\section{E.1.6 Shipments}

Radioactive material shipments associated with the proposed alternatives are assumed to be transported by truck, rail, or barge modes of transport. At this time, insufficient data exist to determine what fraction of shipments would be shipped by either transport mode.

Several types of containers were assumed to be used to transport the radioactive waste evaluated in this PEIS. In this transportation assessment, a shipment is defined as the amount of waste transported on a single truck or a single train voyage. The number of railcars per shipment is provided in each campaign description provided below.

\section{E.1.7 Loading Operations}

Loading operations typically represent the largest exposure impacts involved with the transportation of nuclear materials. As in the Final Supplemental Environmental Impact Statement for a Geologic Repository for the Disposal of Spent Nuclear Fuel and High-Level Radioactive Waste at Yucca Mountain, Nye County, Nevada (hereafter Yucca Mountain SEIS) (DOE 2008f), DOE assumed that loading operations would require a staff of 13 workers, working 2.3 and 2.5 shift-days for pressurized water reactor (PWR) and boiling water reactor (BWR) casks respectively. Loading truck casks would require 1.3 and 1.4 shift-days for PWR and BWR casks, respectively (DOE 2008f). Personnel requirements and duration of loading operations were estimated for other material types based on the number and types of containers used for each shipment.

\section{E.1.8 Incident-Free Transportation}

Radiological dose during normal, incident-free transportation of radioactive materials would result from exposure to the external radiation from the shipping containers. The dose to a receptor is a function of proximity to the radiation source, exposure time and the intensity (source strength) of the radiation. 
Consistent with methods of analysis for DOE and NRC operations, most packages were assumed to have the regulatory maximum exposure rate of 10 millirem per hour (mrem/hr) at a distance of $6.6 \mathrm{ft}(2 \mathrm{~m})$ from the source. Although this assumption is conservative, it provides a metric decision makers can use to compare the impacts of the different alternatives. For those materials known to generate much lower external exposure rates, lower (but still conservative) rates were assumed. A more detailed description of the assumptions concerning the external exposure rates of transportation containers is provided in the programmatic alternatives discussion in Section E.2.

Table E.1.8-1 provides the suggested vehicle speeds for truck and rail transport for use in RADTRAN analysis as provided in Neuhauser et al. (2003) and Chen et al. (2002). The vehicle speed is used in the incident-free portion of the risk assessment. In conjunction with the distance traveled, the vehicle speed determines the amount of time the transportation crew, the on-link population and the off-link population are exposed to external radiation from the shipping package.

\begin{tabular}{lcc}
\multicolumn{3}{c}{ TABLE E.1.8-1-RADTRAN Suggested } \\
Vehicle Speeds
\end{tabular}

\section{E.1.8.1 Worker and General Populations}

Radiation doses were determined for workers, including vehicle crews, and the general population from normal, incident-free transportation. The truck crew was the vehicle drivers. For rail shipments, the crew was defined as workers in close proximity to the shipping containers during inspection or classification of railcars. The general population were the individuals within $2,625 \mathrm{ft}(800 \mathrm{~m})$ of the road or railway (off-link), sharing the road or railway (on-link), and at stops. Collective doses for the crew and general population were calculated using the RADTRAN 5.6/RADCAT 2.3 computer codes (Weiner et al 2006).

The scenarios for worker and public populations analyzed in this PEIS are similar to those provided in the Final Environmental Impact Statement for a Geologic Repository for the Disposal of Spent Nuclear Fuel and High-Level Radioactive Waste at Yucca Mountain, Nye County, Nevada (hereafter Yucca Mountain FEIS) (DOE 2002i) and the Yucca Mountain SEIS (DOE 2008f). These scenarios are consistent with other DOE and NRC NEPA analyses.

For the worker populations, the following scenarios were analyzed:

- An inspector working at a distance of $3.3 \mathrm{ft}(1 \mathrm{~m})$ from the rail or truck container. It was assumed that this inspector would be exposed to the SNF casks for 1 hour per cask. For other shipping configurations, it was assumed that an inspector would be exposed to each trailer for 1 hour (Jason Technologies 2001). 
- A truck driver and passenger, serving as an escort, that would be expected to drive radioactive shipments for 1,000 hours (hr) per year (yr) and unload shipments for 1,000 hr/yr (Jason Technologies 2001, BMI 2007).

- A rail yard worker working at a distance of $33 \mathrm{ft}(10 \mathrm{~m})$ from the shipping container for 2 hours.

For rail shipments, the following scenarios for members of the public were considered:

- A resident living $98 \mathrm{ft}(30 \mathrm{~m})$ from the rail line where the shipping container was being transported.

- A resident living $656 \mathrm{ft}(200 \mathrm{~m})$ from a rail stop where the shipping container was sitting for 20 hours.

For truck shipments, the three scenarios for members of the public were:

- A person caught in traffic and located $4 \mathrm{ft}(1.2 \mathrm{~m})$ away from the surface of the shipping container for 1 hour;

- A service station worker working at a distance of $66 \mathrm{ft}(20 \mathrm{~m})$ from the shipping container for 1 hour;

- Area residents near the truck stop/service station. The resident population included those that would live within a distance 0.5 mile (mi) $(0.8$ kilometer $[\mathrm{km}])$ of the stop;

- A resident living $98 \mathrm{ft}(30 \mathrm{~m})$ from the highway used to transport the shipping container. This population is considered to be "Nearby Residents."

The assumed frequency of rail and truck stops in this PEIS is consistent with those used in the Yucca Mountain FEIS and SEIS analyses. Two-hour rail stops were assumed to occur at $170-\mathrm{mi}(277-\mathrm{km})$ intervals, or a rate of $0.012 \mathrm{hr} / \mathrm{mi}(0.0072 \mathrm{hr} / \mathrm{km})($ BMI 2007). Truck stops were assumed to occur at a rate of $0.018 \mathrm{hr} / \mathrm{mi}(0.011 \mathrm{hr} / \mathrm{km})$ (Jason Technologies 2001).

Dose to maximally exposed individuals (MEI) and impacts were estimated for the cumulative operations of the alternatives analyzed. For the scenario involving an individual caught in traffic next to a truck, the radiological exposures were calculated for only one event because it was considered unlikely that the same individual would be caught in traffic next to all containers for all shipments. For truck shipments, the maximum exposed transportation worker is the driver who was assumed to drive shipments for up to 1,000 hours per year. In the maximum exposed individual scenarios, the exposure rate for the shipments depended on the type of waste being transported. External exposure rates for the transportation packages are provided in Table 2.2.2-1. The different container exposure rates yielded a range of calculated exposure impacts during loading/handling and in-transit shipments. The maximum exposure rate for the truck driver was $2 \mathrm{mrem} / \mathrm{hr}(10 \mathrm{CFR} 71.47[\mathrm{~b}][4])$.

\section{E.1.8.2 Incident-Free Exposure to Escorts}

Transporting SNF and other selected radioactive materials requires the use of physical security and other escorts for the shipments. Regulations require that at least two individuals serve as escorts for truck shipments traveling through highly populated, urban areas (10 CFR 73.37). At 
least one of the escorts is required in a vehicle separate from the shipment vehicle. For rail shipments in urban areas, at least two escorts are required in order to maintain visual surveillance of a shipment from a railcar that accompanies a cask car.

For legal-weight truck shipments, the analysis assumed that a second driver, a member of the vehicle crew, serves as an escort in all areas. The analysis assigned a second escort assuming this escort would occupy a vehicle that followed or led the transport vehicle by at least $197 \mathrm{ft}(60 \mathrm{~m})$. The analysis assumed that the dose rate at a location $6.5 \mathrm{ft}(2 \mathrm{~m})$ behind the vehicle would be $10 \mathrm{mrem} / \mathrm{hr}$, which is the limit allowed by the DOT regulations (49 CFR 173.441).

Using this information, the analysis used the RISKIND computer code to calculate a dose rate of $0.11 \mathrm{mrem} / \mathrm{hr}$ for the escort located $197 \mathrm{ft}(60 \mathrm{~m})$ behind the transport vehicle (Yuan et al. 1995). The value for an escort vehicle ahead of the transport vehicle would be lower. Because the dose rate in the occupied crew area of the transport vehicle would be less than $2 \mathrm{mrem} / \mathrm{hr}$, the dose rate $6.5 \mathrm{ft}(2 \mathrm{~m})$ in front of the vehicle would be much less than $10 \mathrm{mrem} / \mathrm{hr}$, the value assumed for a location $6.5 \mathrm{ft}(2 \mathrm{~m})$ behind the vehicle. The value of $2 \mathrm{mrem} / \mathrm{hr}$ in normally occupied areas of transport vehicles is the maximum allowed by the DOT regulations (49 CFR 173.441). This exposure analysis for escorts follows methods used in the Yucca Mountain FEIS and Yucca Mountain SEIS assessments (Jason Technologies 2001, BMI 2007).

For rail shipments, the escorts were assumed to be $98 \mathrm{ft}(30 \mathrm{~m})$ away from the shipping cask. This is due to the length of a buffer car $50 \mathrm{ft}(15 \mathrm{~m})$, the normal separation between cars $(6.5 \mathrm{ft}$ [2 $\mathrm{m}]$ for two cars), the distance from the end of a cask to the end of the rail car $(16.5 \mathrm{ft}[5 \mathrm{~m}])$, and the assumed distance from the escort car's near end to the occupants (nearly $33 \mathrm{ft}[10 \mathrm{~m}]$ ). Using the assumed dose rate of $10 \mathrm{mrem} / \mathrm{hr}$ at a distance of $6.5 \mathrm{ft}(2 \mathrm{~m})$ from the cask, RISKIND calculated an estimated dose rate of $0.46 \mathrm{mrem} / \mathrm{hr}$ for the occupied area of the escort car. Twohour stops were assumed to occur every $170 \mathrm{mi}(277 \mathrm{~km})$ (BMI 2007). Visual surveillance must be maintained at all rail yard transfers. Escorts would be present in the escort car from the time the train was assembled at the generator site until it reached its final destination.

\section{E.1.8.3 Nonradiological Vehicle Emissions}

Incident-free nonradiological vehicle emission fatalities were estimated using unit risk factors. These fatalities would result from exhaust and fugitive dust emissions from highway and rail traffic and are associated with 10-micrometer particles. The nonradiological unit risk factors were adopted from the transportation analysis conducted for the Yucca Mountain FEIS (DOE 2002i). The unit risk factors used in this analysis are $1.5 \times 10^{-11}$ and $2.6 \times 10^{-11}$ fatalities per kilometer per persons per square kilometer $\left(\mathrm{km}^{2}\right)$ for diesel truck and rail modes of transport respectively (Jason Technologies 2001).

\section{E.1.9 Transportation Accidents}

The offsite transportation accident analysis considers the impacts of accidents during the transportation of materials by truck or rail. Under accident conditions, impacts to human health and the environment may result from the release and dispersal of radioactive material. Transportation accident impacts have been assessed using accident analysis methodologies developed by the NRC. 
This section provides an overview of the methodologies (NRC 1977b, Fischer et al. 1987, NRC 2000a). Accidents, some of which could potentially breach the shipping container, are represented by a spectrum of accident severities and releases of radioactive material. Historically, most transportation accidents involving radioactive materials have resulted in little or no release of radioactive material from the shipping container. Consequently, the analysis of accident risks takes into account a spectrum of accidents ranging from high-probability accidents of low severity to hypothetical high-severity accidents that have a correspondingly low probability of occurrence. This accident analysis calculates the risks and consequences from this spectrum of accidents.

Two types of analyses were performed. An accident risk assessment was performed that takes into account the probabilities and consequences of a spectrum of potential accident severities (NRC 1977b, Fischer et al. 1987, NRC 2000a). For the spectrum of accidents considered in the analysis, accident consequences in terms of collective dose to the population within $50 \mathrm{mi}$ $(80 \mathrm{~km})$ were multiplied by the accident probabilities to yield collective dose risk using the RADTRAN 5.6/RadCat 2.3 computer codes (Weiner et al. 2006).

The impacts for specific alternatives were calculated in units of dose and collective dose. Impacts are further expressed in terms of estimated latent cancer fatalities (LCF). Dose estimates are converted to LCFs using a conversion factor of $6 \times 10^{-4} \mathrm{LCF}$ per person-rem (DOE 2002h).

\section{E.1.9.1 Transportation Accident Rates}

For calculating accident risks and consequences, state-specific accident rates were taken from data provided in Saricks and Tompkins (1999) for rail, barge, and heavy combination trucks. The rates, provided in Saricks and Tompkins, are based on state-specific accident and fatality rate data for 1994 to 1996. Subsequent studies by the Federal Motor Carrier Safety Administration found that accidents were under-reported by approximately 39 percent and fatalities were underreported by approximately 36 percent (UMTRI 2003). To account for the under-reporting, DOE increased the state-specific truck and fatality accident rates from Saricks and Tompkins by factors of 1.57 and 1.64, respectively, in its analysis for the Yucca Mountain SEIS (DOE 2008f). For analysis of truck shipments, these multipliers also were used in this PEIS. For cases where generic routing characteristics were assumed, the 1.57 and 1.64 factors were applied to the U.S. average accident and fatality rates, respectively.

\section{E.1.9.2 Conditional Probabilities and Release Fractions}

Accident severity categories for potential radioactive waste transportation accidents are described in three NRC reports:

- Final Environmental Impact Statement on the Transportation of Radioactive Material by Air and Other Modes (hereafter NUREG-0170) (NRC 1977b) for radioactive waste in general

- Shipping Container Response to Severe Highway and Railway Accident Conditions, also known as the Modal Study (Fischer et al. 1987)

- Reexamination of Spent Fuel Shipment Risk Estimate, (NRC 2000a) 
The second and third reports address only SNF. The Modal Study represents a refinement of the NUREG-0170 methodology, and the reassessment analysis, Reexamination of Spent Fuel Shipment Risk Estimates (NRC 2000a), which compares more recent results to NUREG-0170, represents a further refinement of both studies. This later reference was the basis for the conditional probabilities and release fractions used in this analysis.

Reexamination of Spent Fuel Shipment Risk Estimates (NRC 2000a) represents the severe accident environment as a matrix, with one dimension as the temperature of the radioactive material and the other the velocity of impact onto an unyielding surface. The matrix contains 19 cases for the truck accidents and 21 cases for rail accidents. The unique feature of the most recent analysis is the specification of a fire-only case. The result is ultimately reduced to a conditional probability of occurrence for each accident case or category, and a set of radionuclide release fractions for each accident case or category.

\section{E.1.9.3 Severe Transportation Accidents}

In addition to analyzing the radiological and nonradiological risks of transporting SNF and highlevel waste (HLW), DOE assessed the consequences of severe transportation accidents. Severe transportation accidents with a frequency of approximately $1 \times 10^{-7}$ per year are known as maximum reasonably foreseeable transportation accidents (MRFA). According to DOE guidance, accidents that have a frequency of less than $1 \times 10^{-7}$ rarely need to be examined (DOE 2002d).

The analysis was based on the 21 rail accident severity categories identified in Reexamination of Spent Fuel Shipment Risk Estimates (NRC 2000a). Each of the 21 accident cases has an associated conditional probability of occurrence (NRC 2000a). Combining the conditional probabilities analyzed in the domestic programmatic alternatives, only Cases 4 and 20 of the document have occurrence frequencies greater than $1 \times 10^{-7}$ per year, with expected annual frequencies of $5 \times 10^{-6}$ and $3 \times 10^{-6}$ respectively (NRC 2000a).

The Case 20 event is a long-duration high-temperature fire event that engulfs the entire cask. The event is assumed to last many hours (NRC 2000a). Case 20 was estimated to have the higher consequences and was thus assumed to be the maximum reasonably foreseeable transportation accident.

Case 4 assumes a moderate-speed impact (30 to 60 miles per hour [48 to 97 kilometers per hour]) into a hard surface such as granite, severe enough to cause failure of casks seals. The impact would be followed by an engulfing fire lasting from 0.5 hour to a few hours (NRC 2000a).

Rail shipments were estimated to have higher accident impacts given the higher material inventories per shipment. The PWR light water reactor (LWR) SNF case is analyzed because the maximum load is larger than the BWR (5.0 metric tons heavy metal [MTHM]/cask compared to 4.8 MTHM/cask). The following assumptions, parallel to those provided in the Yucca Mountain SEIS, were made in analyzing the impacts of the maximum reasonably foreseeable accident scenarios: 
- A release height of the plume of $33 \mathrm{ft}(10 \mathrm{~m})$ for fire and impact-related accidents. In the case of an accident with fire, a $33 \mathrm{ft}(10 \mathrm{~m})$ release height with no plume rise from the buoyancy of the plume due to fire conditions would yield higher estimates of consequences than accounting for the buoyancy of the plume from the fire.

- A breathing rate for individuals of $3.67 \times 10^{5}$ cubic feet $\left(\mathrm{ft}^{3}\right)\left(1.04 \times 10^{4}\right.$ cubic meters $\left.\left[\mathrm{m}^{3}\right]\right)$ per year (Neuhauser et al. 2003).

- A short-term exposure to airborne contaminants of 2 hours.

- A long-term exposure time to contamination deposited on the ground for 1 year with no interdiction or cleanup (BMI 2007).

- Low wind speeds and stable atmospheric conditions (a wind speed of $2 \mathrm{~m} / \mathrm{hr}[0.89 \mathrm{~m} / \mathrm{s}$ ] and Class $\mathrm{F}$ stability). The atmospheric concentrations estimated from these conditions would be exceeded only 5 percent of the time.

DOE used the RISKIND 2.0 code (Yuan et al. 1995) to estimate the radiation doses for the inhalation, groundshine ${ }^{1}$, immersion, and re-suspension pathways.

The analysis assumed that the severe transportation accidents could occur anywhere. Generally, in transportation analyses, population densities in rural areas are assumed to range from 0 to 139 people per $\mathrm{km}^{2}$. Consistent with Yucca Mountain FEIS and SEIS analyses, DOE based the analysis for a rural area on a population density of six people per $\mathrm{km}^{2}$. For analysis of the Yucca Mountain Project transportation impacts, DOE estimated the population density in an urban area by identifying the 20 urban areas in the United States with the largest populations using 2000 census data, determining the population density in annular rings around the center of each urban area, escalating these population densities to 2067, and averaging the population densities in each successive annular ring. These values were assumed for the maximum reasonably foreseeable impact assessment for this PEIS and are the same values assumed in the Yucca Mountain Final SEIS analyses. The values are provided in Table E.1.9.3-1.

\section{TABLE E.1.9.3-1-Population Density in Urban Areas}

\begin{tabular}{lc}
\hline Annular Distance (mi) & Population Density $\left(/ \mathbf{m i}^{\mathbf{2}} \mathbf{l} / \mathbf{k m}^{\mathbf{2}} \mathbf{]}\right)$ \\
\hline 0 to $5(0$ to $8.05 \mathrm{~km})$ & $12,980(5,012)$ \\
5 to $10(8.05$ to $16.09 \mathrm{~km})$ & $7,656(2,956)$ \\
10 to $15(16.09$ to $24.14 \mathrm{~km})$ & $5,470(2,112)$ \\
15 to $20(24.14$ to $32.19 \mathrm{~km})$ & $3,476(1,342)$ \\
20 to $25(32.19$ to $40.23 \mathrm{~km})$ & $2,330(899)$ \\
25 to $50(40.23$ to $80.47 \mathrm{~km})$ & $774(299)$ \\
\hline Source: DOE 2008 f
\end{tabular}

The State of Nevada provided analyses in response to a previous document prepared by DOE proposing similar transportation modes and routes, and utilizing similar analytical methods. The State of Nevada indicated that the consequences of severe transportation accidents would be much higher than those resulting from the accident analysis preformed by DOE. These comments and DOE's response can be found in the Final EIS for Geological Repository for the Disposal of SNF and High Level Radioactive Waste at Yucca Mountain in Nye County, Nevada (DOE 2002i). As an example, the State estimated that a rail accident in an urban area could result

${ }^{1}$ Groundshine is defined as gamma radiation emitted from radioactive materials deposited on the ground. 
in 13 to 40,868 LCFs in the exposed population while DOE estimated that about 9 LCFs would occur in the exposed population.

The State estimated these consequences using computer programs that DOE developed and uses. However, the state's analysis used values for parameters that would be at or near their maximum values. DOE guidance for the evaluation of accidents in environmental impact statements (DOE 2002d) specifically cautions against the evaluation of scenarios for which conservative (or bounding) values are selected for multiple parameters because the approach yields unrealistically high results due to built-in conservatism in the model.

DOE's approach to accident analysis estimates the consequences of severe accidents having a frequency as low as $1 \times 10^{-7}$ per year ( 1 in 10 million) (DOE 2002d) using realistic yet cautious methods and data. DOE believes that the State of Nevada estimates are unrealistically high and that they do not represent the reasonably foreseeable consequences of severe transportation accidents.

\section{E.2 Transportation Analysis of the Domestic Programmatic Alternatives}

This section describes the methodologies used to assess the transportation impacts due to the transportation of nuclear materials associated with the domestic programmatic alternatives described in Chapter 2, Domestic Programmatic Alternatives. One alternative, the Thermal Reactor Recycle Fuel Cycle Alternative, Option 3, which involves recycling LWR SNF to produce fuel for high temperature gas-cooled reactors (HTGRs), has not been quantitatively analyzed because DOE does not have enough data to perform the analysis at this time. The per-shipment transportation effects of the deep burn HTGR are assumed to be similar to the HTGR discussed in Section 4.7.2, All-HTGRs (Option 2). The number of SNF shipments for the deep burn HTGR, however, would be significantly less because only 5,000 MTHM of SNF would require transport to a future geologic repository versus 55,000 MTHM discussed in Section 4.7.2, All-HTGRs (Option 2). Transportation effects of the deep burn HTGR SNF should be approximately 10 percent as much as those presented in Section 4.7.2, All-HTGRs (Option 2).

\section{E.2.1 Routing Analysis for Domestic Programmatic Alternatives}

Potential locations have not been identified for facilities that would be associated with implementation of any of the programmatic alternatives. As one input to the assessment of the impacts of material transportation relative to the programmatic alternatives, DOE calculated average fractions of rural, suburban, and urban zones adjacent to certain transportation routes, including the population densities corresponding to the three zone types. These values were calculated for the route characteristics of the transportation analysis in the DOE Programmatic Spent Nuclear Fuel Management and INEL Environmental Restoration and Waste Management Programs Final Environmental Impact Statement, DOE/EIS-0203, or Spent Nuclear Fuel EIS (DOE 1995e). The Spent Nuclear Fuel EIS data set was chosen due to its large size-61 reactor origin sites and 5 DOE facility destinations - and its wide geographic coverage. The five DOE sites evaluated as destinations were Hanford Site, Idaho National Laboratory, Nevada Test Site, 
Oak Ridge Reservation, and the Savannah River Site. The 61 origin sites provide a diverse geographical array of sites throughout the continental United States.

The routes were analyzed using the routing computer code TRAGIS (Johnson and Michelhaugh 2003), standard routing practices, and applicable routing regulations and guidelines. Route characteristics include total shipment distance between each origin and destination and the fractions of travel in rural, suburban, and urban population density zones. Population densities were determined using Census 2000 data.

The minimum value of $150 \mathrm{mi}(241 \mathrm{~km})$ was chosen as it represented the minimum shipment distance evaluated in the Spent Nuclear Fuel EIS. The maximum distance evaluated in the EIS was approximately $3,000 \mathrm{mi}(4,828 \mathrm{~km})$. The intermediate values were chosen to provide comparison of other transportation distances. Table E.2.1-1 provides a summary of the routing inputs used to analyze the transportations impacts related to the domestic programmatic alternatives.

For the Yucca Mountain FEIS (DOE 2002i), DOE entered the route distances of all the SNF shipment routes to be analyzed. The upper bound shipment was found to be 3,100 mi $(5,000 \mathrm{~km})$ long, and the median value was approximately 2,100 mi $(3,380 \mathrm{~km})$ (SNL 2005). By comparison, the average rail distance between the commercial LWR SNF origin and the Caliente destination site was 2,160 mi $(3,480 \mathrm{~km})$ in the Yucca Mountain SEIS transportation analysis (BMI 2007). Shipments were analyzed at the $2,100 \mathrm{mi}(3,380 \mathrm{~km})$ distance for both truck and rail transport for use as the representative case for the domestic programmatic alternatives analyses. The population density values for all five distances were updated to reflect Census 2000 data. 
TABLE E.2.1-1—Summary of Routing Inputs for Generic Domestic Programmatic Alternatives Analysis

\begin{tabular}{|c|c|c|c|c|c|c|}
\hline \multirow{2}{*}{$\begin{array}{c}\text { Route } \\
\text { Distance } \\
\text { (miles }[\mathrm{km}] \text { ) }\end{array}$} & \multicolumn{3}{|c|}{ Distance within Population Zone (miles [km]) } & \multicolumn{3}{|c|}{ Population Density $\left(/ \mathrm{mi}^{2}\left[/ \mathrm{km}^{2}\right]\right)$} \\
\hline & Rural & Suburban & Urban & Rural & Suburban & Urban \\
\hline \multicolumn{7}{|c|}{ Legal Weight Truck Option } \\
\hline $150(241)$ & 109.6(176.4) & $38.5(62.0)$ & $1.9(3.1)$ & $28.7(11.1)$ & $838.4(323.7)$ & $\begin{array}{c}6,143.5 \\
(2,372.0)\end{array}$ \\
\hline $500(805)$ & $365.3(587.9)$ & $128.3(206.5)$ & $6.4(10.3)$ & $28.7(11.1)$ & $838.4(323.7)$ & $\begin{array}{c}6,143.5 \\
(2,372.0)\end{array}$ \\
\hline $1,500(2414)$ & $\begin{array}{c}1,096.0 \\
(1,764.0)\end{array}$ & $385.0(619.6)$ & $19.0(30.6)$ & $28.7(11.1)$ & $838.4(323.7)$ & $\begin{array}{c}6,143.5 \\
(2,372.0)\end{array}$ \\
\hline $\begin{array}{l}2,100 \\
(3,380)\end{array}$ & $\begin{array}{c}1,534.0 \\
(2,469.0)\end{array}$ & $539.0(867.4)$ & $27.0(43.5)$ & $28.7(11.1)$ & $838.4(323.7)$ & $\begin{array}{c}6,143.5 \\
(2,372.0)\end{array}$ \\
\hline $\begin{array}{l}3,000 \\
(4,828) \\
\end{array}$ & $\begin{array}{c}2,192.0 \\
(3,528.0) \\
\end{array}$ & $770.0(1,239)$ & $38.0(61.2)$ & $28.7(11.1)$ & $838.4(323.7)$ & $\begin{array}{c}6,143.5 \\
(2,372.0) \\
\end{array}$ \\
\hline \multicolumn{7}{|c|}{ Rail Option } \\
\hline $150(241)$ & $114.9(184.9)$ & $32.9(52.9)$ & $2.2(3.5)$ & $22.4(8.65)$ & $\begin{array}{l}1,061.4 \\
(409.8)\end{array}$ & $\begin{array}{c}6,308.4 \\
(2,435.7)\end{array}$ \\
\hline $500(805)$ & $383.0(616.4)$ & $109.7(176.5)$ & 7.3(11.8) & $22.4(8.65)$ & $\begin{array}{l}1,061.4 \\
(409.8)\end{array}$ & $\begin{array}{c}6,308.4 \\
(2,435.7)\end{array}$ \\
\hline $\begin{array}{l}1,500 \\
(2,414)\end{array}$ & $1,149.0(1,849.0)$ & $329.0(529.5)$ & $22.0(35.4)$ & $22.4(8.65)$ & $\begin{array}{l}1,061.4 \\
(409.8)\end{array}$ & $\begin{array}{c}6,308.4 \\
(2,435.7)\end{array}$ \\
\hline $\begin{array}{l}2,100 \\
(3,380)\end{array}$ & $1,609.0(2,589.0)$ & $460.6(741.2)$ & $30.4(48.9)$ & $22.4(8.65)$ & $\begin{array}{l}1,061.4 \\
(409.8)\end{array}$ & $\begin{array}{c}6,308.4 \\
(2,435.7)\end{array}$ \\
\hline $\begin{array}{l}3,000 \\
(4,828)\end{array}$ & $2,298.0(3,698.0)$ & $658.0(1,059.0)$ & $44.0(70.8)$ & $22.4(8.65)$ & $\begin{array}{l}1,061.4 \\
(409.8)\end{array}$ & $\begin{array}{c}6,308.4 \\
(2,435.7)\end{array}$ \\
\hline
\end{tabular}

Source: Tetra Tech $2008 \mathrm{f}$

Note: Due to rounding of values, the sum of the parts may not equal the total represented in the leftmost column.

Note 2: Conversion between miles and kilometers was conducted by spreadsheet software assuming one decimal point precision, which creates up to 5 significant figures, which is higher precision than other calculations in the analyses.

\section{E.2.2 Shipment Data for Domestic Programmatic Alternatives}

For this PEIS, not all fresh fuel types were analyzed for the radiological impacts of transportation accidents. Transportation accident impacts associated with MOX fuel and transmutation fuels were analyzed for this PEIS. The other fresh fuel types-LWR, thorium cycle, HWR, and HTGR-were not analyzed for accident impacts due to the unavailability of documented fresh fuel nuclide inventories. As noted in a World Nuclear Transport Institute report, the impacts of transporting fabricated uranium fuel assemblies are considered small (WNTI 2007). The fuel for the majority of nuclear reactors consists of assemblies of rods, each filled with ceramic uranium oxide pellets enriched with U-235 to less than five percent. It is assumed impacts due to incidentfree shipment of fresh (unirradiated) fuel would be equivalent on a per-shipment basis for all fuel types. There would be little variance in accident impacts between the different fuel types. This assumption is based upon the transportation analysis provided in, Environmental Impact Statement for an Early Site Permit (ESP) at the Exelon ESP Site, hereafter NUREG 1815 (NRC 2006c). As with all enriched uranium intermediate fuel materials, the primary hazard is radiological, in the event of a criticality excursion such as an unwanted nuclear chain reaction. This type of event is prevented by the design of the package and the configuration of the packages in transport. 
NUREG 1815 provides relative transportation impact estimates for fresh fuels for the different advanced LWR reactor types that correspond to reactor types considered in this PEIS. The values provided in NUREG 1815 Table G-1 reflect the expected number of truck shipments needed for each reactor for initial core loading, normal operations, and cumulative for an estimated 40-year reactor lifespan. NUREG 1815 Table G-3 provides the lifetime normalized annual radiological impacts due to transportation of fresh fuels associated with the reactor technologies. The NUREG 1815 analysis calculates impacts that are three orders of magnitude lower than those provided in 10 CFR 51.52, Table S-4. The NUREG 1815 normalized values were compared to Table S-4 to meet the conditions for an Early Site Permit described in 10 CFR 51.52(a) (10 CFR 51.52).

The NUREG 1815 analyses assumed the same per-shipment incident-free exposure risks for the transportation of fresh fuel. Cumulative annual dose risks were therefore a function of the expected number of shipments. Please note that because of the increased number of shipments attributable to low volume-to-heavy metal mass ratios, the reactor designs corresponding to the HTGR design (i.e., gas turbine modular helium reactor [GT-MHR] and the pebble bed modular reactor $[\mathrm{PBMR}])$ have higher impacts than the designs associated with the other programmatic alternatives provided in this PEIS (NRC 2006c).

NUREG 1815 states that accident risks associated with transportation of fresh advanced LWR reactors would be much lower than Table S-4 conditions, making such accident analysis unnecessary to meet Early Site Permit conditions. As stated in NUREG 1815:

Accidents involving unirradiated fuel shipments are also addressed in Table $S-4$. Accident risks are the product of accident frequency times consequence. Accident frequencies are likely to be lower than those used in the analysis in WASH-1238 (AEC 1972) because traffic accident, injury, and fatality rates have fallen over the past 30 years. Consequences of accidents that are severe enough to result in a release of unirradiated fuel particles are not significantly different for advanced LWRs because the fuel form, cladding, and packaging are similar to those analyzed in WASH-1238. Consequently, the impacts of accidents during transport of unirradiated fuel to advanced LWR sites would be smaller than the WASH-1238 results that formed the basis for Table $S$-4.

Considering this, it has been assumed that the accident impacts due to transportation of fresh fuels would be much lower than the accident impacts associated with the SNF types analyzed in this PEIS.

\section{E.2.2.1 Fresh and Spent Nuclear Fuel Shipments}

For the PEIS transportation analysis, nuclide inventories for commercial LWR SNF were based on the Advanced Fuel Cycle Facility Conceptual Design and NEPA Support Activities NEPA Data Study (hereafter AFCF NEPA Data Study) (WGI 2008a). The assumption was that the SNF transported would consist of fuel with a burnup of 100 gigawatt-days per metric ton uranium (GWd/MTU), with a minimum of 5 years cooling. The end-of-life effective enrichment, defined 
as the percentage of fissile material remaining in the heavy metal, is approximately 2.6 percent. The nuclide inventory is provided in Appendix 2 of the AFCF NEPA Data Study (WGI 2008a).

For truck transport of commercial spent nuclear fuel, the GA-4/9 cask is assumed. This cask has the capacity of four PWR assemblies. As provided in WGI 2008a, each PWR assembly is assumed to have a mass of 0.5 MTHM, so each truck cask would hold a total of 2.0 MTHM. For rail transport, the NLI-10/24 cask is assumed. This cask has a capacity of 10 PWR assemblies, or 5.0 MTHM of commercial spent nuclear fuel. Each train was assumed to be comprised of five rail cask cars so that approximately 25 MTHM SNF was transported in each rail shipment.

The AFCF NEPA Data Study provides the nuclide inventories and packaging assumptions used for the analysis of transportation of fast reactor spent fuel and fresh transmutation fuel. The fast reactor spent fuel was assumed to have a burnup of $250 \mathrm{GWd} / \mathrm{MTU}$ and a minimum cooling time of one year (WGI 2008a). Due to high activities of both the fresh and spent fuel (as well as high thermal load for the spent fuel), it was assumed that both would be transported in devalued GA 4/9 NLI-1/2 casks. It was assumed that 0.4 MTHM of the spent and fresh fuel could be transported in one assembly within the casks. The inventories for the fast reactor spent fuel and fresh transmutation fuel are provided in Appendix A-3 and Table 25 of the AFCF NEPA Data Study, respectively (WGI 2008a). The transportation of fresh transmutation fuel, and all other fresh nuclear fuels, was assumed to be conducted via truck transport only as discussed in 10 CFR 51.52.

For analysis in this PEIS, the nuclide inventory and shipping configuration of unirradiated (fresh) MOX fuel was provided by the Environmental Impact Statement on the Construction and Operation of a Mixed Oxide Fuel Fabrication Facility at the Savannah River Site, South Carolina, or MOX Fuel Fabrication Facility EIS (NRC 2005c). In the MOX Fuel Fabrication Facility EIS, fresh MOX fuel was assumed to be transported in a cask with a capacity of three fuel assemblies, with a heavy metal mass of approximately 1.37 MTHM (NRC 2005c). The MOX Fuel Fabrication Facility EIS did not analyze the transportation of MOX spent fuel, so the assumptions in the following paragraphs were used to assess the transportation of MOX and other programmatic spent fuels.

For shipment of fresh LWR fuel, it was assumed that the shipment configuration would be analogous with the advanced PWR (AP1000) fuel shipments analyzed in NRC 2006c. In the NRC document, it was assumed that 12 fresh fuel assemblies would be transported per shipment. Given the assumption of 0.5 MTHM per PWR assembly provided in WGI 2008a, each fresh LWR fuel shipment analyzed in the GNEP PEIS, were assumed to have 6 MTHM (12 assemblies $\times 0.5 \mathrm{MTHM} /$ shipment $=6 \mathrm{MTHM})$.

Based on data provided in Chapter 2 of the GNEP PEIS, the initial U-235 enrichment is 12.2 percent for the thorium fuel and 19.9percent for the blanket fuel material, or 2.8-4.5 times higher than the 4.4 percent assumed for LEU LWR fuel. Assuming an average scaling factor of 3.65 , compared to LWR fuel, there would be $6 \mathrm{MTHM} / 3.65=1.7 \mathrm{MTHM} / \mathrm{shipment}$ of fresh thorium fuel. This provides relatively the same mass of U-235 per transportation cask, and thus, the same assumed external dose rate of $0.1 \mathrm{mrem} / \mathrm{hr}$ at $1 \mathrm{~m}$ as provided in the analysis supporting the 10 CFR 51.52 assumptions (NRC 2006c). 
NRC 2006c states that each ACR-700 (Advanced CANDU Reactor) fuel assembly contains 18 $\mathrm{kg}$ of uranium. This is analogous to the HWR reactor design assumed for the GNEP PEIS. Each fresh fuel shipment is assumed to hold 180 to 240 assemblies per shipment. For sake of conservativeness, the lower shipment quantity was assumed. For the HWR fresh shipments, 3.24 MTHM per shipment is assumed $(18 \mathrm{~kg}$ U/assembly $\times 240$ assemblies $/$ shipment $=3240 \mathrm{~kg}$ $\mathrm{U} /$ shipment $=3.24 \mathrm{MTHM} /$ shipment $)$.

For the reactor design analogous to the HTGR design (the GT-MHR), NRC 2006c assumes the spent fuel shipments would hold 6 assemblies for a total of 0.023 MTHM. This translates to $0.00383 \mathrm{MTHM} /$ assembly. NRC 2006c also states that each truck shipment of fresh fuel would be comprised of 80 assemblies. Therefore for the GNEP PEIS, it is assumed that each fresh HTGR fuel shipment would hold 0.307 MTHM of fuel $(0.00383$ MTHM/assembly $\times 80$ assemblies/shipment $=0.307 \mathrm{MTHM} /$ shipment).

The exact composition and physical attributes of the SNF from each programmatic alternative have not yet been determined. For the Thermal/Fast Reactor Recycle Alternative, SNF and other material characteristics were assumed to be the same as those provided in the AFCF NEPA Data Study. For the remaining programmatic alternatives, SNF from each alternative has been assigned nuclide inventories from Source Term Estimates for DOE Spent Nuclear Fuels (DOE 2004j). In this report, DOE SNF was organized into 34 groups based on fuel enrichment, fuel cladding material, and fuel cladding condition. The characteristics of the SNF, including percent enrichment, decay time, and burnup, affects the radionuclide inventory and, as a result, the radiation dose. A general sensitivity analysis of burnup and cooling times is provided in Chapter 4.

In determining the effects on human health from normal operations and accidents, the radionuclide inventories assumed in the transportation analyses are based on the best available data. As described in Appendices C, D, and E, these reference documents generally include previous NEPA documents, safety basis documents, and hazard analyses for similar facilities. As a result, the radionuclide inventories used to estimate impacts due to transportation accident releases may not be based on the same burnup values provided in Table 4.8-1. Given the conservative assumptions that have been made, and other variables that could affect the results presented, any differences in burnup values are considered minor.

Table E.2.2.1-1 provides the per canister nuclide concentration of the fuel groups, in curies, used to represent the SNF generated in the programmatic alternatives. These inventories were calculated for the Yucca Mountain FEIS (BMI 2007). Each fuel group provided in the source terms document (DOE 2004j) represents many different SNF types currently stored by DOE. Each fuel group has a variety of end-of-life enrichments and nuclide inventories. The fuel groups chosen best represent the reactor types and enrichment requirements associated with the domestic programmatic alternatives.

Each DOE rail cask is assumed to hold nine DOE spent fuel canisters. Therefore, each rail cask is assumed to hold the equivalent of nine truck shipments. With five rail cars per shipment, each rail shipment is assumed to transport the equivalent of 45 truck shipments of this material. It should be also noted that other spent fuel casks may be used for the transportation of the spent 
fuels analyzed in this PEIS. The DOE spent fuel canisters and casks were assumed due to the availability of information regarding these containers. As with most shipping configurations, transportation by rail provides for larger per-shipment capacity due to larger weight limits, which provides for greater cargo capacity, including the added weight of shielding for greater thermal and radioactivity loads. 
TABLE E.2.2.1-1—Nuclide Inventories of the Programmatic Alternative Nuclear Fuels ${ }^{a}$

\begin{tabular}{|c|c|c|c|c|c|c|c|c|}
\hline Nuclide & $\begin{array}{l}\text { LWR } \\
\text { SNF }^{\mathbf{b}}\end{array}$ & $\begin{array}{c}\text { Fast } \\
\text { Reactor } \\
\text { SNF }^{\mathbf{b}}\end{array}$ & $\begin{array}{c}\text { Fresh } \\
\text { Transmutation }^{\text {Fuel }^{\mathbf{b}}}\end{array}$ & $\begin{array}{c}\text { Fresh } \\
\text { MOX } \\
\text { Fuel }\end{array}$ & $\begin{array}{c}\text { Thorium } \\
\text { Cycle } \\
\text { Fuel } \\
\text { (Group } \\
\text { 26) }\end{array}$ & $\begin{array}{c}\text { Thermal } \\
\text { Recycle } \\
\text { Fuel } \\
\text { (Group } \\
\text { 23) }\end{array}$ & $\begin{array}{c}\text { HWR } \\
\text { SNF } \\
\text { (Group 2) }\end{array}$ & $\begin{array}{c}\text { HTGR } \\
\text { SNF } \\
\text { (Group } \\
\text { 19) }\end{array}$ \\
\hline Ac-227 & $8.8 \times 10^{-4}$ & $2.5 \times 10^{-7}$ & & & 7.4 & 0.042 & $5.8 \times 10^{-4}$ & 2.6 \\
\hline Am-241 & $4.2 \times 10^{4}$ & 27 & $8.4 \times 10^{-9}$ & & 7,100 & $2.5 \times 10^{5}$ & $2.1 \times 10^{4}$ & 2,300 \\
\hline $\begin{array}{l}\text { Am- } \\
242 \mathrm{~m}\end{array}$ & 220 & 530 & $8.7 \times 10^{4}$ & & 16 & 2,100 & 34 & 2.2 \\
\hline Am-243 & 720 & 140 & 1,500 & & 15 & 440 & 6.4 & 40 \\
\hline C-14 & 17 & 0.12 & & & 1.2 & 8,300 & 2,000 & 20 \\
\hline $\mathrm{Cl}-36$ & & & & & 2.2 & 49 & 37 & 0.92 \\
\hline $\mathrm{Cm}-243$ & 520 & 160 & 1,100 & & 1.0 & 580 & 6.6 & 30 \\
\hline $\mathrm{Cm}-244$ & $1.9 \times 10^{5}$ & $3.1 \times 10^{4}$ & $3.9 \times 10^{5}$ & & 220 & 7,700 & 89 & 9,000 \\
\hline Co-60 & $4.4 \times 10^{4}$ & 50 & & & $9.5 \times 10^{4}$ & $3.5 \times 10^{6}$ & $4.6 \times 10^{5}$ & 2,300 \\
\hline Cs- 134 & $3.0 \times 10^{5}$ & $1.7 \times 10^{4}$ & & & 11 & $4.1 \times 10^{4}$ & 150 & 3,700 \\
\hline Cs- 135 & 12 & 0.48 & & & 2.6 & 49 & 1.9 & 21 \\
\hline Cs-137 & $1.4 \times 10^{6}$ & $2.9 \times 10^{4}$ & & & $1.4 \times 10^{5}$ & $2.3 \times 10^{6}$ & $2.2 \times 10^{5}$ & $1.5 \times 10^{6}$ \\
\hline Eu-154 & $9.4 \times 10^{4}$ & 1,600 & & & 3,200 & $1.1 \times 10^{5}$ & 1,200 & $3.9 \times 10^{4}$ \\
\hline Eu-155 & $2.5 \times 10^{4}$ & 3,500 & & & 300 & $6.7 \times 10^{4}$ & 770 & 5,900 \\
\hline $\mathrm{Fe}-55$ & $1.1 \times 10^{4}$ & 6,900 & & & 3,800 & $4.8 \times 10^{5}$ & 6,200 & 1.6 \\
\hline $\mathrm{H}-3$ & 9,000 & 170 & & & 550 & $1.7 \times 10^{4}$ & 4,200 & 6,900 \\
\hline I-129 & 0.39 & 0.013 & & & 0.13 & 1.3 & 0.13 & 0.87 \\
\hline $\mathrm{Kr}-85$ & $1.0 \times 10^{5}$ & 5.6 & & & 5,800 & $8.5 \times 10^{4}$ & 7,500 & $7.9 \times 10^{4}$ \\
\hline Np-237 & 7.6 & 0.62 & & & 0.15 & 5.6 & 1.9 & 11 \\
\hline $\mathrm{Pa}-231$ & 0.0012 & $3.3 \times 10^{-7}$ & & & 9.1 & 0.061 & 0.0011 & 4.1 \\
\hline $\mathrm{Pb}-210$ & $3.9 \times 10^{-5}$ & $1.710^{-6}$ & & & 0.0011 & $3.2 \times 10^{-4}$ & $3.6 \times 10^{-4}$ & $7.3 \times 10^{-4}$ \\
\hline Pm-147 & $3.2 \times 10^{5}$ & $3.4 \times 10^{4}$ & & & 230 & $2.2 \times 10^{5}$ & $1.6 \times 10^{4}$ & 5,200 \\
\hline $\mathrm{Pu}-238$ & $1.0 \times 10^{5}$ & $1.9 \times 10^{4}$ & $2.2 \times 10^{5}$ & 430 & 2,900 & $3.8 \times 10^{4}$ & 3,600 & $1.5 \times 10^{5}$ \\
\hline $\mathrm{Pu}-239$ & 2,600 & 370 & 5,600 & 4,900 & 380 & $1.5 \times 10^{5}$ & 7,100 & 120 \\
\hline $\mathrm{Pu}-240$ & 4,000 & 1,400 & 8,400 & 1,100 & 270 & $1.1 \times 10^{5}$ & 3,500 & 220 \\
\hline $\mathrm{Pu}-241$ & $1.1 \times 10^{6}$ & $1.4 \times 10^{5}$ & $2.3 \times 10^{6}$ & $4.3 \times 10^{4}$ & $7.1 \times 10^{4}$ & $4.2 \times 10^{6}$ & $1.4 \times 10^{5}$ & $3.1 \times 10^{4}$ \\
\hline $\mathrm{Pu}-242$ & 38 & 4.6 & 78.4 & 0.096 & 2.2 & 44 & 1.9 & 3.4 \\
\hline Ra-226 & $1.1 \times 10^{6}$ & $5.3 \times 10^{-6}$ & & & 0.0017 & $4.2 \times 10^{6}$ & $9.7 \times 10^{-4}$ & 0.0012 \\
\hline Ra-228 & & $2.7 \times 10^{-12}$ & & & 0.35 & 0.012 & $2.4 \times 10^{-5}$ & 0.78 \\
\hline Ru-106 & $1.7 \times 10^{5}$ & $8.2 \times 10^{4}$ & & & 0.0035 & $1.2 \times 10^{4}$ & 1,100 & 0.65 \\
\hline Se-79 & 1.1 & & & & 2.9 & 13 & 3.1 & 18 \\
\hline Sn-126 & & 0.40 & & & 3.2 & 40 & 2.5 & 19 \\
\hline Sr-90 & $1.1 \times 10^{6}$ & 9,600 & & & $1.4 \times 10^{5}$ & $1.2 \times 10^{6}$ & $1.6 \times 10^{5}$ & $1.5 \times 10^{6}$ \\
\hline Tc-99 & 180 & 4.0 & & & 31 & 480 & 59 & 290 \\
\hline Th-229 & $2.2 \times 10^{-5}$ & $4.3 \times 10^{-7}$ & & & 4.9 & 0.029 & $1.8 \times 10^{-4}$ & 5.8 \\
\hline Th-230 & 0.010 & $6.5 \times 10^{-4}$ & & & 0.090 & 0.096 & 0.088 & 0.12 \\
\hline Th-232 & & $3.7 \times 10^{-12}$ & & & 0.80 & 0.013 & $2.4 \times 10^{-5}$ & 2.5 \\
\hline Tl-208 & & & & & 1,100 & 2.5 & 0.020 & 580 \\
\hline U-232 & 0.86 & $5.2 \times 10^{-5}$ & 0.039 & & 2,900 & 6.7 & 0.054 & 1,600 \\
\hline U-233 & 0.0022 & $1.5 \times 10^{-4}$ & $9.9 \times 10^{-5}$ & & 2,500 & 7.7 & 0.039 & 1,800 \\
\hline U-234 & 26 & 2.5 & 1.2 & & 74 & 270 & 190 & 240 \\
\hline U-235 & 0.29 & $4.6 \times 10^{-5}$ & 0.013 & 0.0071 & 0.53 & 12 & 0.082 & 3.6 \\
\hline U-236 & 5.7 & 0.0025 & 0.26 & & 0.22 & 5.1 & 2.8 & 7.4 \\
\hline U-238 & 1.4 & 0.0034 & 0.066 & 0.44 & 0.11 & 5.0 & 2.1 & 0.045 \\
\hline
\end{tabular}

Source: WGI 2008a, NRC 2005c, BMI 2007

${ }^{\mathrm{a}}$ All values in curies.

$\mathrm{b}$ The inventories provided are truncated to match the nuclide list following nuclide screening provided in BMI 2007 . The full inventories for the LWR and fast reactor fuels are provided in WGI 2008a. 
The fuel groups represented in this table are described below.

- Group 2: Uranium Metal, Non-Zirconium Alloy Clad, Low-Enriched Uranium. This group contains uranium metal fuel compounds with no known zirconium alloy cladding. The average end-of-life enrichment, used in this PEIS analysis, is 0.47 percent. The cladding is assumed to be in good to poor condition.

- Group 19: Thorium/Uranium Carbide, TRISO or BISO-Coated Particles in Graphite. This group contains thorium/uranium carbide fuel compounds with TRISO (tri-structural isotopic) or BISO (bi-structural isotopic)-coated particles. TRISO-coated particles consist of an isotropic pyrocarbon outer layer, a silicon carbide layer, an isotropic carbon layer, and a porous carbon buffer inner layer. BISO-coated particles consist of an isotropic pyrocarbon outer layer and a low density porous carbon buffer inner layer. The average end-of-life enrichment, used in this PEIS analysis, is 6.62 percent. The coating is assumed to be in good condition.

- Group 23: Mixed Oxide, Stainless-Steel Clad. This group contains plutonium/uranium and plutonium oxide fuel compounds with stainless steel cladding. The average end-oflife enrichment, used in this PEIS analysis, is 51.0 percent. The cladding is assumed to be in good condition.

- Group 26: Thorium/Uranium, Stainless-Steel Clad. This group contains thorium/uranium oxide fuel compounds with stainless-steel cladding. The average end-of-life enrichment, used in this PEIS analysis, is 3.17 percent. The cladding is assumed to be in good to fair condition.

The end-of-life enrichment values were calculated for each of the fuel groups listed above based on the U-235 mass relative to the total heavy metal mass.

The SNF from the fast recycling reactors is assumed to have a burnup of $250 \mathrm{GWd} / \mathrm{MT}$, with a 1 year cooling period. As with the LWR SNF, the end-of-life effective enrichment is approximately 2.6 percent. The nuclide inventory is provided in Appendix A-3 of the AFCF NEPA Data Study. Nuclide inventories of other materials and wastes analyzed are provided in Section 3 of the AFCF NEPA Data Study (WGI 2008a).

\section{E.2.2.2 Separation Process Material and Waste Shipments}

Material and waste volumes and physical attributes, including nuclide inventory, were based on the AFCF NEPA Data Study (WGI 2008a). Packaging assumptions for the materials were based on the following source documents:

- AFCF NEPA Data Study (WGI 2008a)

- Engineering Alternative Studies for Separations NEPA Data Input Report (WSRC 2008a)

- AFCF Waste Volumes Estimation White Paper (WGI 2008c)

Table E.2.2.2-1 provides a summary of the containers by material type and other input parameters used in this PEIS transportation analysis. These values are based on the AFCF NEPA Data Study and Estimation of AFCF HLW and GTCC Waste Volumes to Support the GNEP PEIS (hereafter the AFCF Waste Volumes Estimation White Paper) (WGI 2008a, WGI 2008c). 
Volumes per container type also are provided in the table as well as the limiting factor used to determine the bulk container volumes. The transportation analysis was conducted using a conservative package type for transuranic wastes due to unknowns of specific waste acceptance criteria for a future receiving disposal location and limited process design detail that identifies the percentage of waste which could require a less rigorous package. It should be noted that there are some volume differences in HLW canister volume largely due to differences in void space between the various waste forms.

For the shipment of greater-than-Class-C (GTCC) LLW, this analysis assumes transport in a HLW canister with a volume of $28.1 \mathrm{ft}^{3}\left(0.795 \mathrm{~m}^{3}\right)$ per canister. An alternative package for shipping remote handled transuranic waste by DOE is a RH-72B cask, which has a volume of $22 \mathrm{ft}^{3}\left(0.624 \mathrm{~m}^{3}\right)$ per cask. Both of these options are limited to a single canister/cask per shipment. If the transuranic waste is determined to be contact handled waste, a container such as a standard waste box could be used for shipment. The standard waste box has a capacity of $67 \mathrm{ft}^{3}$ $\left(1.9 \mathrm{~m}^{3}\right.$ or four 55-gallon drums) per box and when loaded into a DOE TRUPACT II shipping container, has a potential for six standard waste boxes per shipment. The use of standard waste boxes in shipping contact handled transuranics would greatly reduce the number of shipments needed. The actual number of shipments needed would be determined based on the specific waste types and DOT regulations. If contact handled waste is transported in a waste package, such as the standard waste box rather than the HLW canister, the number of shipments could be reduced by a factor of approximately 13 , which would also result in a reduction of the associated transportation impacts by the same factor. 
TABLE E.2.2.2-1—Transportation Containers for Analyzed Shipments by Material Type

\begin{tabular}{|c|c|c|c|c|c|}
\hline Material to be Transported & $\begin{array}{l}\text { Name of } \\
\text { Canister or } \\
\text { Cask }\end{array}$ & $\begin{array}{l}\text { Volume or } \\
\text { Mass per } \\
\text { Container }\end{array}$ & $\begin{array}{l}\text { Number of } \\
\text { Containers per } \\
\text { Shipment } \\
\text { Truck (Rail) }\end{array}$ & $\begin{array}{l}\text { Limiting } \\
\text { Factor }\end{array}$ & $\begin{array}{c}\text { External } \\
\text { Exposure } \\
(\mathrm{mrem} / \mathrm{hr} \text { at } 2 \\
\text { m) }\end{array}$ \\
\hline LWR SNF & $\begin{array}{l}\text { GA- } 4 / 9 \text { or } \\
\text { NLI- } 10 / 24\end{array}$ & $\begin{array}{l}\text { truck 2- } \\
\text { MTHM } \\
\text { rail-5 } \\
\text { MTHM }\end{array}$ & $1(5)$ & $\begin{array}{l}\text { Volume and } \\
\text { thermal }\end{array}$ & 10 \\
\hline Fresh LWR fuel $^{\mathrm{a}}$ & -- & 6 МТНM & 1 & $\begin{array}{l}\text { Volume and } \\
\text { criticality }\end{array}$ & 0.0521 \\
\hline $\begin{array}{l}\text { SNF from MOX, thorium, HWR, } \\
\text { and HTGR cycles }\end{array}$ & $\begin{array}{l}\text { DOE SNF } \\
\text { cask }\end{array}$ & $\begin{array}{l}\text { truck-1 } \\
\text { assembly } \\
\text { rail-9 } \\
\text { assemblies }\end{array}$ & $1(5)$ & $\begin{array}{l}\text { Volume and } \\
\text { Thermal }\end{array}$ & 10 \\
\hline Fresh MOX fuel ${ }^{a, b}$ & $\begin{array}{l}\text { Class B } \\
\text { cylindrical } \\
\text { container }\end{array}$ & 3 assemblies & 1 & $\begin{array}{l}\text { Volume and } \\
\text { criticality }\end{array}$ & 2.52 \\
\hline Fresh transmutation fuel & NLI-1/2 & 0.4 МТНМ & 1 & $\begin{array}{l}\text { Thermal } \\
\text { and } \\
\text { Criticality }\end{array}$ & 10 \\
\hline Fresh thorium fuels ${ }^{a}$ & -- & 1.7 МТНМ & 1 & $\begin{array}{l}\text { Volume and } \\
\text { criticality }\end{array}$ & 0.0521 \\
\hline Fresh HWR fuel $^{\mathrm{a}}$ & -- & 3.24 МТНМ & 1 & $\begin{array}{l}\text { Volume and } \\
\text { criticality }\end{array}$ & 0.0521 \\
\hline Fresh HTGR fuel ${ }^{\text {a }}$ & -- & 0.307 & 1 & $\begin{array}{l}\text { Volume and } \\
\text { criticality }\end{array}$ & 0.0521 \\
\hline Recovered uranium (oxide) & $\begin{array}{l}\text { Class B } 9975 \\
\text { drums }\end{array}$ & $13.5 \mathrm{~kg}$ total $\mathrm{U}$ & $15(75)$ & Criticality & 5 \\
\hline Recovered uranium (metal) & $\begin{array}{l}\text { Class B } 9975 \\
\text { drums }\end{array}$ & $17.2 \mathrm{~kg}$ & $18(90)$ & Criticality & 5 \\
\hline Fast reactor SNF & $\mathrm{NLI}-1 / 2^{\mathrm{c}}$ & 1 assembly & $1(5)$ & Thermal & 10 \\
\hline $\begin{array}{l}\text { Technetium, un-dissolved solids } \\
\text { (UDS), and fuel cladding hulls in } \\
\text { metal waste form }{ }^{\mathrm{d}, \mathrm{e}}\end{array}$ & $\begin{array}{l}\text { HLW } \\
\text { canister }\end{array}$ & $0.77 \mathrm{~m}^{3}$ & $1(5)$ & Volume & 10 \\
\hline $\begin{array}{l}\text { Lanthanides and other fission } \\
\text { product waste } \\
\text { d }\end{array}$ & $\begin{array}{l}\text { HLW } \\
\text { canister }^{f}\end{array}$ & $1.29 \mathrm{~m}^{3}$ & $1(5)$ & Volume & 10 \\
\hline $\begin{array}{l}\text { Cesium/strontium in hydroceramic } \\
\text { waste form }\end{array}$ & $\begin{array}{l}\text { Waste cans } \\
\text { (3" IDx10' } \\
\text { long) }\end{array}$ & $0.067 \mathrm{~m}^{3}$ & $1(5)$ & Thermal & 10 \\
\hline $\begin{array}{l}\text { GTCC LLW including } \\
\text { absorbed/stabilized volatile fission } \\
\text { products, spent equipment, and } \\
\text { compacted HEPA filters. }\end{array}$ & $\begin{array}{l}\text { HLW } \\
\text { canister }\end{array}$ & $0.79 \mathrm{~m}^{3}$ & $1(5)$ & Volume & 10 \\
\hline $\begin{array}{l}\text { Low-level radioactive waste and } \\
\text { mixed low-level radioactive waste. }\end{array}$ & B-25 Box & $2.55 \mathrm{~m}^{3}$ & $12(60)$ & Volume & 2 \\
\hline
\end{tabular}

Source: WGI 2008a, WGI 2008c

${ }^{a}$ Transportation of fresh nuclear fuel is assumed to be via truck transport only. No specific transportation casks have yet been identified for the LWR, thorium, HWR, and HTGR fresh fuels transportation.

${ }^{\mathrm{b}}$ Source NRC 2005c

${ }^{c}$ Currently the NLI-1/2 is only certified for truck shipments. It is assumed that this cask or a similar model will be certified for rail transportation by the operational timeframe of this program.

d The HLW described in Chapter 4 is represented by two different waste streams; the Tc/UDS/hulls and Ln/fission product wastes. Tc/UDS/hulls wastes comprise approximately 45 percent of the total HLW by volume, and Ln/FP wastes comprise 55 percent.

${ }^{\mathrm{e}}$ The metal hulls in this waste stream are assumed to be melted with the technetium and undissolved solids to act as a binding material.

${ }^{\mathrm{f}}$ For the purposes of this analysis, some waste streams were assumed to be packaged in HLW canisters that would not be classified as HLW. Waste classification and selection of specific transportation casks would be completed as the facility design and waste characteristics are further developed. 
Table E.2.2.2-2 provides the estimated number of truck shipments over approximately a 50-year period associated with achieving a nuclear electricity capacity of 200 GWe in approximately 2060-2070, based on a 1.3 percent annual growth rate. The PEIS assumes that new LWR capacity would begin to come on-line in approximately 2015 and that the programmatic action alternatives would be implemented over this timeframe.

Table E.2.2.2-3 provides the number of rail shipments needed to meet the same $200 \mathrm{GWe}$ capacity over the same timeframe. The numbers of shipments provided in the table were calculated based on the source documents listed in Section E.2.2.2. These values were calculated on the basis of all shipments containing the same mass and volumes provided in the source documents. If the fast reactors and the recycling facility are colocated, the inter-site transportation of fresh fast reactor fuel and spent fast reactor fuel would be eliminated. This would result in substantial decreases in the transportation impacts.

The transportation impact values provided in Chapter 4 represent total exposure impacts over the entire affected population during the program period. It should not be assumed that affected populations, including workers, driving crews, and on-link traffic, receive multiple exposures. The exposure values, calculated in person-rem, represent a collective dose to the population within $0.5 \mathrm{mi}(800 \mathrm{~m})$ of the transportation routes analyzed. To provide comparison of impacts between the different alternatives, the cumulative exposure numbers were multiplied by the $6 \times 10^{-4}$ dose conversion factor (DOE 2002h) to provide an estimate of LCFs due to the transportation of the radioactive materials.

A more complete description of the amount of SNF processed and the basis for materials generated by each domestic programmatic alternative are provided in Chapter 4 . The mass or volume values provided were then used to calculate the necessary number of containers based on the NEPA source documents provided at the introduction to this section. 
TABLE E.2.2.2-2—Number of Shipments per Material Type-All-Truck Scenario200 Gigawatts Electric

\begin{tabular}{|c|c|c|c|c|c|c|c|c|}
\hline $\begin{array}{c}\text { Material/Waste } \\
\text { Type }\end{array}$ & $\begin{array}{l}\text { No Action } \\
\text { Alternative }\end{array}$ & $\begin{array}{l}\text { All-Fast } \\
\text { Recycle }\end{array}$ & $\begin{array}{c}\text { Thermal/ } \\
\text { Fast }\end{array}$ & $\begin{array}{l}\text { Thermal } \\
\text { Option } 1\end{array}$ & $\begin{array}{c}\text { Thermal } \\
\text { Option } \\
2 \\
\end{array}$ & $\begin{array}{c}\text { Thorium } \\
\text { Cycle }\end{array}$ & $\begin{array}{l}\text { All- } \\
\text { HWR }\end{array}$ & $\begin{array}{c}\text { All- } \\
\text { HTGR }\end{array}$ \\
\hline LWR SNF & $7.90 \times 10^{4}$ & $5.90 \times 10^{4}$ & $6.30 \times 10^{4}$ & $1.10 \times 10^{4}$ & $7.05 \times 10^{4}$ & $5.05 \times 10^{4}$ & $3.40 \times 10^{4}$ & $3.40 \times 10^{4}$ \\
\hline Fast reactor SNF & & $3.50 \times 10^{4}$ & $2.75 \times 10^{4}$ & & & & & \\
\hline $\mathrm{Cs} / \mathrm{Sr}$ waste & & $1.08 \times 10^{4}$ & $1.08 \times 10^{4}$ & $1.08 \times 10^{4}$ & & & & \\
\hline $\begin{array}{l}\text { Ln/fission product } \\
\text { waste }^{\text {a }}\end{array}$ & & $2.25 \times 10^{4}$ & $2.21 \times 10^{4}$ & $2.13 \times 10^{4}$ & $1.30 \times 10^{4}$ & & & \\
\hline Tc/UDS/hulls waste & & $3.11 \times 10^{4}$ & $3.06 \times 10^{4}$ & $2.94 \times 10^{4}$ & $1.80 \times 10^{4}$ & & & \\
\hline $\begin{array}{l}\text { GTCC LLW AND } \\
\text { MLLW }\end{array}$ & 3,200 & $5.24 \times 10^{5}$ & $5.04 \times 10^{5}$ & $5.13 \times 10^{5}$ & $1.00 \times 10^{4}$ & 3,200 & 3,200 & 3,200 \\
\hline LLW AND MLLW & $1.90 \times 10^{4}$ & $9.34 \times 10^{4}$ & $8.32 \times 10^{4}$ & $8.40 \times 10^{4}$ & $2.30 \times 10^{4}$ & $1.90 \times 10^{4}$ & $1.90 \times 10^{4}$ & $1.90 \times 10^{4}$ \\
\hline $\begin{array}{l}\text { Recovered uranium } \\
\text { (oxide) }\end{array}$ & & $1.64 \times 10^{4}$ & $1.83 \times 10^{4}$ & 2,920 & $1.90 \times 10^{4}$ & & & \\
\hline $\begin{array}{l}\text { Recovered uranium } \\
\text { (metal) }\end{array}$ & & 7,580 & 5,960 & & & & & \\
\hline MOX SNF $^{b}$ & & & 8,000 & $1.95 \times 10^{5}$ & & & & \\
\hline Thorium SNF & & & & & & $1.55 \times 10^{5}$ & & \\
\hline HWR SNF & & & & & $4.48 \times 10^{4}$ & & $1.14 \times 10^{5}$ & \\
\hline HTGR SNF & & & & & & & & $1.56 \times 10^{6}$ \\
\hline Fresh LWR fuel & $2.63 \times 10^{4}$ & $1.97 \times 10^{4}$ & $2.10 \times 10^{4}$ & 3,670 & $2.35 \times 10^{4}$ & $1.68 \times 10^{4}$ & $1.13 \times 10^{4}$ & $\begin{array}{l}1.13 \\
\times 10^{4}\end{array}$ \\
\hline $\begin{array}{l}\text { Fresh } \\
\text { transmutation fuel }\end{array}$ & & $3.50 \times 10^{4}$ & $2.75 \times 10^{4}$ & & & & & \\
\hline Fresh MOX fuel ${ }^{c}$ & & & 4,380 & $1.07 \times 10^{5}$ & & & & \\
\hline Fresh thorium fuel & & & & & & $2.28 \times 10^{4}$ & & \\
\hline Fresh HWR fuel & & & & & $2.19 \times 10^{4}$ & & $5.56 \times 10^{4}$ & \\
\hline Fresh HTGR fuel & & & & & & & & $1.05 \times 10^{5}$ \\
\hline \multicolumn{9}{|c|}{$\begin{array}{l}\text { Source: Tetra Tech } 2008 \mathrm{f} \\
\text { a These two sources are combined in Chapter } 4 \text { analysis to represent high-level waste, or HLW. } \\
\mathrm{b} \text {. For this PEIS, HTGR SNF was assumed to be disposed in the form of whole fuel elements. This process has the disadvantage of requiring } \\
\text { considerably more volume of storage of a unit weight of fuel and fission product isotopes. A typical DOE canister is sized to contain spent } \\
\text { nuclear fuel assemblies equivalent to a spent nuclear fuel quantity of about } 1 \text { MTHM. By comparison, an equivalent waste canister would contain } \\
\text { a vertical stack of four fuel blocks (Fort St. Vrain type), or approximately } 40 \mathrm{~kg} \text { of heavy metal, requiring many more shipments of SNF when } \\
\text { compared to other fuel cycle options (Shropshire and Herring } 2004 \text { ). } \\
\text { c The MOX spent fuel was assumed to be transported in DOE spent fuel canisters, with a capacity of } 0.75 \text { MTHM per container. Fresh MOX fuel } \\
\text { was assumed to be transported in Class B containers as described in NRC } 2005 \mathrm{c} \text {. These containers have a capacity of } 1.37 \text { MTHM per shipment } \\
\text { and are not appropriate for the shipment of spent fuel. Considering this, there would be approximately } 83 \text { percent more spent fuel shipments than } \\
\text { fresh for the same amount of fuel. Shipment of the other fresh fuels assumed the same container as their spent fuel counterpart, with the same } \\
\text { capacities. }\end{array}$} \\
\hline
\end{tabular}


TABLE E.2.2.2-3—Number of Shipments per Material Type-All-Rail Scenario200 Gigawatts Electric

\begin{tabular}{|c|c|c|c|c|c|c|c|c|}
\hline $\begin{array}{c}\text { Material/Waste } \\
\text { Type }\end{array}$ & $\begin{array}{l}\text { No } \\
\text { Action }\end{array}$ & $\begin{array}{l}\text { All-Fast } \\
\text { Recycle }\end{array}$ & $\begin{array}{l}\text { Thermal/ } \\
\text { Fast }\end{array}$ & $\begin{array}{l}\text { Thermal } \\
\text { Option } 1\end{array}$ & $\begin{array}{c}\text { Thermal } \\
\text { Option } \\
2 \\
\end{array}$ & $\begin{array}{l}\text { Thorium } \\
\text { Cycle }\end{array}$ & $\begin{array}{l}\text { All- } \\
\text { HWR }\end{array}$ & $\begin{array}{c}\text { All- } \\
\text { HTGR }\end{array}$ \\
\hline LWR SNF & 6,320 & 4,720 & 5,280 & 880 & 5,640 & 4,040 & 2,720 & 2,720 \\
\hline Fast reactor SNF & & 7,000 & 5,500 & & & & & \\
\hline $\begin{array}{l}\mathrm{Cs} / \mathrm{Sr} \text { waste } \\
\text { (aqueous process) }\end{array}$ & & 2,150 & 2,150 & 2,150 & & & & \\
\hline $\begin{array}{l}\mathrm{Ln} / \text { fission product } \\
\text { waste }^{\text {a }}\end{array}$ & & 4,500 & 4,420 & 4,240 & 2,600 & & & \\
\hline Tc/UDS/hulls waste ${ }^{a}$ & & 6,200 & 6,120 & 5,860 & 3,600 & & & \\
\hline $\begin{array}{l}\text { GTCC LLW AND } \\
\text { MLLW }\end{array}$ & 630 & $1.03 \times 10^{5}$ & $1.01 \times 10^{5}$ & $1.01 \times 10^{5}$ & 2,000 & 630 & 630 & 630 \\
\hline LLW AND MLLW & 3,800 & $1.89 \times 10^{4}$ & $1.66 \times 10^{4}$ & $1.70 \times 10^{4}$ & 4,500 & 3,800 & 3,800 & 3,800 \\
\hline $\begin{array}{l}\text { Recovered uranium } \\
\text { (oxide) }\end{array}$ & & 3,200 & 3,660 & 584 & 3,800 & & & \\
\hline $\begin{array}{l}\text { Recovered uranium } \\
\text { (metal) }\end{array}$ & & 1,520 & 1,190 & & & & & \\
\hline MOX SNF & & & 178 & 4,330 & & & & \\
\hline Thorium SNF & & & & & & 3,450 & & \\
\hline HWR SNF & & & & & 996 & & 2,500 & \\
\hline HTGR SNF & & & & & & & & $3.30 \times 10^{4}$ \\
\hline \multicolumn{9}{|c|}{ Truck shipments of fresh fuel } \\
\hline $\begin{array}{l}\text { Fresh LWR } \\
\text { fuel }^{\mathrm{b}}\end{array}$ & $2.63 \times 10^{4}$ & $1.97 \times 10^{4}$ & $2.10 \times 10^{4}$ & 3,670 & $2.35 \times 10^{4}$ & $1.68 \times 10^{4}$ & $1.13 \times 10^{4}$ & $1.13 \times 10^{4}$ \\
\hline $\begin{array}{l}\text { Fresh transmutation } \\
\text { fuel }^{\text {b }}\end{array}$ & & $3.50 \times 10^{4}$ & $2.75 \times 10^{4}$ & & & & & \\
\hline Fresh MOX fuel $^{\mathrm{b}}$ & & & 4,380 & $1.07 \times 10^{5}$ & & & & \\
\hline Fresh thorium fuel ${ }^{b}$ & & & & & & $2.28 \times 10^{4}$ & & \\
\hline Fresh HWR fuel ${ }^{b}$ & & & & & $2.19 \times 10^{4}$ & & $5.56 \times 10^{4}$ & \\
\hline Fresh HTGR fuel $^{\mathrm{b}}$ & & & & & & & & $1.05 \times 10^{5}$ \\
\hline
\end{tabular}

Source: Tetra Tech $2008 \mathrm{f}$

${ }^{a}$ These two sources are combined in Chapter 4 analysis to represent high-level waste, or HLW

${ }^{\mathrm{b}}$ All shipment of fresh nuclear fuel is assumed be to via truck transport. 


\section{E.2.3 Loading Operations-Domestic Programmatic Alternatives}

Loading operations typically represent the largest exposure impacts involved with the transportation of nuclear materials. As in the Yucca Mountain FEIS and SEIS (DOE 2002i, DOE 2008f), DOE assumed that exposure due to loading operations would total approximately 0.432 person-rem and 0.663 person-rem for truck and rail SNF casks respectively. The values provided in the Yucca Mountain documents are based on actual exposure values provided in industry documents detailing loading operations of commercial SNF.

Estimation of loading operation impacts of other materials and waste products was based on the size and number of packages per load. Table E.2.3-1 provides the input parameters for estimation of impacts of loading operations for non-SNF domestic programmatic materials. These parameters, along with the exposure rates provided in Table 2.2.2-1, were used to calculate the range of exposure rates provided in subsequent sections and tables.

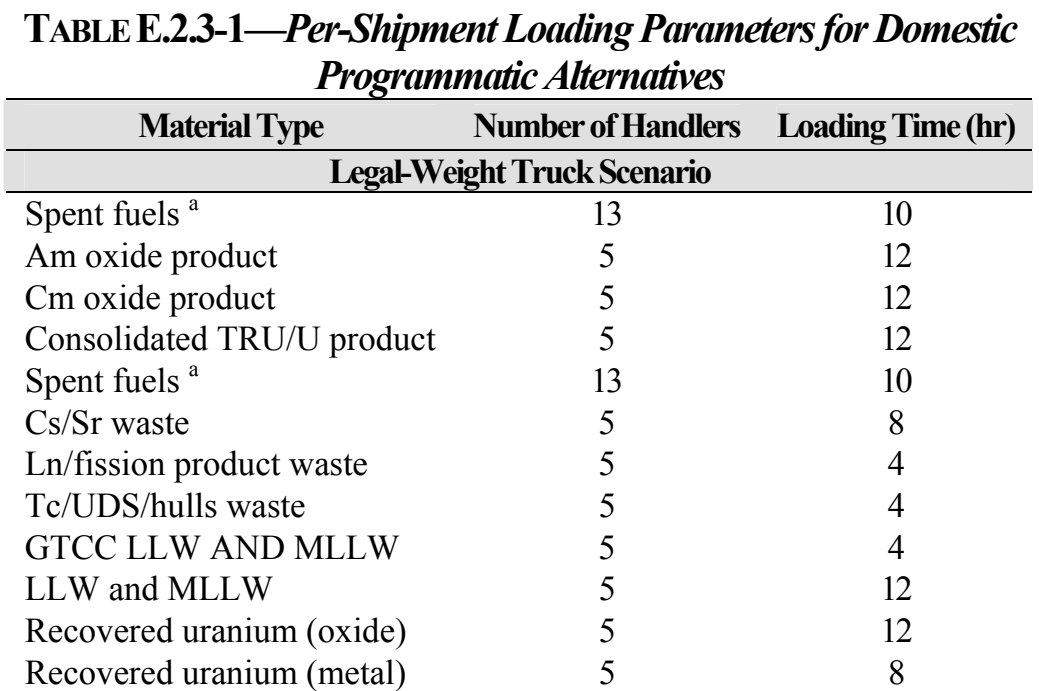

\begin{tabular}{lcc}
\multicolumn{1}{c}{ Mostly-Rail Scenario $^{\text {c }}$} & 8 \\
\hline Spent fuels & 13 & 90 \\
Am oxide product & 5 & 60 \\
Cm oxide product & 5 & 60 \\
Cs/Sr waste & 5 & 40 \\
Ln/Fission Product waste & 5 & 20 \\
Tc/UDS/hulls waste & 5 & 20 \\
GTCC LLW AND MLLW & 5 & 20 \\
LLW and MLLW & 5 & 60 \\
Recovered uranium (oxide) & 5 & 60 \\
Recovered uranium (metal) & 5 & 40 \\
\hline Source: Tetra Tech 2008f & \\
${ }^{a}$ The loading impacts are equal to the loading impacts provided in the Yucca Mountain \\
SEIS (DOE 2008f). The loading operations in the Yucca Mountain SEIS assume a crew of \\
13 workers conducting multiple tasks at various distances to the source and for various \\
times. \\
${ }^{b}$ Loading of fresh fuel shipments assumed to have the same labor and time requirements as \\
spent fuel shipments. \\
${ }^{c}$ Fresh fuels shipments were assumed to be conducted by truck only, including in the rail \\
scenario. These shipments represent the only truck shipments included in the mostly rail \\
scenario.
\end{tabular}




\section{E.2.4 Incident-Free Transportation Impacts-Domestic Programmatic} Alternatives

Incident-free impacts associated with the domestic programmatic alternatives were conducted on a per-shipment basis with the input parameters discussed in Section E.1.4 above. The pershipment risk results are provided in Tables E.2.4-1 through E.2.4-8. The crew impacts provided in these tables are for the truck drivers or the rail crew present on the shipments. Exposure impacts to escorts are provided in Tables E.2.4-9 and E.2.4-10.

TABLE E.2.4-1—Per-Shipment Radiological Exposure Handling Impacts and Impacts at Stops-Domestic Programmatic Alternative Scenarios-Spent Nuclear FuelAll-Truck Option

\begin{tabular}{|c|c|c|c|c|c|c|c|c|}
\hline \multirow{3}{*}{ Mileage } & \multicolumn{4}{|c|}{ Handling Impacts } & \multicolumn{4}{|c|}{ Impacts at Stops } \\
\hline & \multicolumn{2}{|c|}{ Loading $^{\text {a }}$} & \multicolumn{2}{|c|}{ Inspection } & \multicolumn{2}{|c|}{ Truck Stop } & \multicolumn{2}{|c|}{ Nearby Residents } \\
\hline & $\begin{array}{c}\text { Person- } \\
\text { Rem }\end{array}$ & LCFs & $\begin{array}{c}\text { Person- } \\
\text { Rem }\end{array}$ & LCFs & $\begin{array}{c}\text { Person- } \\
\text { Rem }\end{array}$ & LCFs & $\begin{array}{l}\text { Person- } \\
\text { Rem }\end{array}$ & LCFs \\
\hline 150 & 0.432 & $3 \times 10^{-4}$ & 0.0738 & $4 \times 10^{-5}$ & $3.06 \times 10^{-7}$ & $2 \times 10^{-10}$ & $4.63 \times 10^{-6}$ & $3 \times 10^{-9}$ \\
\hline 500 & 0.432 & $3 \times 10^{-4}$ & 0.0738 & $4 \times 10^{-5}$ & $1.02 \times 10^{-6}$ & $6 \times 10^{-10}$ & $1.55 \times 10^{-5}$ & $9 \times 10^{-9}$ \\
\hline 1,500 & 0.432 & $3 \times 10^{-4}$ & 0.0738 & $4 \times 10^{-5}$ & $3.06 \times 10^{-6}$ & $2 \times 10^{-9}$ & $4.63 \times 10^{-5}$ & $3 \times 10^{-8}$ \\
\hline 2,100 & 0.432 & $3 \times 10^{-4}$ & 0.0738 & $4 \times 10^{-5}$ & $4.29 \times 10^{-6}$ & $3 \times 10^{-9}$ & $6.48 \times 10^{-5}$ & $4 \times 10^{-8}$ \\
\hline 3,000 & 0.432 & $3 \times 10^{-4}$ & 0.0738 & $4 \times 10^{-5}$ & $6.13 \times 10^{-6}$ & $4 \times 10^{-9}$ & $9.26 \times 10^{-5}$ & $6 \times 10^{-8}$ \\
\hline
\end{tabular}

TABLE E.2.4-2_Per-Shipment In-Transit Incident-Free Impacts-Domestic Programmatic Alternative Scenarios-Spent Nuclear Fuel-All-Truck Option

\begin{tabular}{|c|c|c|c|c|c|}
\hline \multirow{2}{*}{ Mileage } & \multicolumn{2}{|c|}{ Crew Impacts } & \multicolumn{2}{|c|}{ Impacts to Public } & \multirow{2}{*}{$\begin{array}{c}\text { Nonradiological } \\
\text { Emission Fatalities }\end{array}$} \\
\hline & Person-Rem & LCFs & Person-Rem & LCFs & \\
\hline 150 & 0.0121 & $7 \times 10^{-6}$ & 0.0609 & $4 \times 10^{-5}$ & $3.62 \times 10^{-9}$ \\
\hline 500 & 0.0405 & $2 \times 10^{-5}$ & 0.203 & $1 \times 10^{-4}$ & $1.21 \times 10^{-8}$ \\
\hline 1,500 & 0.121 & $7 \times 10^{-5}$ & 0.608 & $4 \times 10^{-4}$ & $3.62 \times 10^{-8}$ \\
\hline 2,100 & 0.169 & $1 \times 10^{-4}$ & 0.851 & $5 \times 10^{-4}$ & $5.07 \times 10^{-8}$ \\
\hline 3,000 & 0.243 & $2 \times 10^{-4}$ & 1.22 & $7 \times 10^{-4}$ & $7.24 \times 10^{-8}$ \\
\hline
\end{tabular}

Source: Tetra Tech 2008f 
TABLE E.2.4-3-Per-Shipment Loading Impacts Associated with Thermal/Fast Reactor Recycle Alternative-All-Truck Option

\begin{tabular}{|c|c|c|c|c|c|c|c|c|c|}
\hline & \multirow{3}{*}{ Mileage } & \multicolumn{4}{|c|}{ Handling Impacts } & \multicolumn{4}{|c|}{ Impacts at Stops } \\
\hline & & \multicolumn{2}{|c|}{ Loading } & \multicolumn{2}{|c|}{ Inspection } & \multicolumn{2}{|c|}{ Truck Stop } & \multicolumn{2}{|c|}{ Nearby Residents } \\
\hline & & $\begin{array}{c}\text { Person- } \\
\text { Rem }\end{array}$ & LCFs & $\begin{array}{c}\text { Person- } \\
\text { Rem }\end{array}$ & LCFs & $\begin{array}{c}\text { Person- } \\
\text { Rem } \\
\end{array}$ & LCFs & $\begin{array}{c}\text { Person- } \\
\text { Rem } \\
\end{array}$ & LCFs \\
\hline \multirow{5}{*}{$\begin{array}{l}\text { Fresh } \\
\text { transmutation } \\
\text { fuel }\end{array}$} & 150 & 0.432 & $3 \times 10^{-4}$ & 0.0738 & $4 \times 10^{-5}$ & $3.06 \times 10^{-7}$ & $2 \times 10^{-10}$ & $4.63 \times 10^{-6}$ & $3 \times 10^{-9}$ \\
\hline & 500 & 0.432 & $3 \times 10^{-4}$ & 0.0738 & $4 \times 10^{-5}$ & $1.02 \times 10^{-6}$ & $6 \times 10^{-10}$ & $1.55 \times 10^{-5}$ & $9 \times 10^{-9}$ \\
\hline & 1,500 & 0.432 & $3 \times 10^{-4}$ & 0.0738 & $4 \times 10^{-5}$ & $3.06 \times 10^{-6}$ & $2 \times 10^{-9}$ & $4.63 \times 10^{-5}$ & $3 \times 10^{-8}$ \\
\hline & 2,100 & 0.432 & $3 \times 10^{-4}$ & 0.0738 & $4 \times 10^{-5}$ & $4.28 \times 10^{-6}$ & $3 \times 10^{-9}$ & $6.48 \times 10^{-5}$ & $4 \times 10^{-8}$ \\
\hline & 3,000 & 0.432 & $3 \times 10^{-4}$ & 0.0738 & $4 \times 10^{-5}$ & $6.13 \times 10^{-6}$ & $4 \times 10^{-9}$ & $9.25 \times 10^{-5}$ & $6 \times 10^{-8}$ \\
\hline \multirow{5}{*}{$\begin{array}{l}\text { Fresh MOX } \\
\text { fuel }\end{array}$} & 150 & 0.109 & $7 \times 10^{-5}$ & 0.0186 & $1 \times 10^{-5}$ & $7.71 \times 10^{-8}$ & $5 \times 10^{-11}$ & $1.77 \times 10^{-6}$ & $7 \times 10^{-10}$ \\
\hline & 500 & 0.109 & $7 \times 10^{-5}$ & 0.0186 & $1 \times 10^{-5}$ & $2.57 \times 10^{-7}$ & $2 \times 10^{-10}$ & $3.91 \times 10^{-6}$ & $2 \times 10^{-9}$ \\
\hline & 1,500 & 0.109 & $7 \times 10^{-5}$ & 0.0186 & $1 \times 10^{-5}$ & $7.71 \times 10^{-7}$ & $5 \times 10^{-10}$ & $1.77 \times 10^{-5}$ & $7 \times 10^{-9}$ \\
\hline & 2,100 & 0.109 & $7 \times 10^{-5}$ & 0.0186 & $1 \times 10^{-5}$ & $1.08 \times 10^{-6}$ & $6 \times 10^{-10}$ & $1.63 \times 10^{-5}$ & $1 \times 10^{-8}$ \\
\hline & 3,000 & 0.109 & $7 \times 10^{-5}$ & 0.0186 & $1 \times 10^{-5}$ & $1.54 \times 10^{-6}$ & $9 \times 10^{-10}$ & $2.33 \times 10^{-5}$ & $1 \times 10^{-8}$ \\
\hline \multirow{5}{*}{$\begin{array}{l}\text { Fresh LWR, } \\
\text { thorium, } \\
\text { HWR, } \\
\text { HTGR fuels }\end{array}$} & 150 & 0.0225 & $1 \times 10^{-5}$ & 0.00384 & $2 \times 10^{-6}$ & $1.59 \times 10^{-8}$ & $1 \times 10^{-11}$ & $2.41 \times 10^{-7}$ & $1 \times 10^{-10}$ \\
\hline & 500 & 0.0225 & $1 \times 10^{-5}$ & 0.00384 & $2 \times 10^{-6}$ & $5.31 \times 10^{-8}$ & $3 \times 10^{-11}$ & $8.08 \times 10^{-7}$ & $5 \times 10^{-10}$ \\
\hline & 1,500 & 0.0225 & $1 \times 10^{-5}$ & 0.00384 & $2 \times 10^{-6}$ & $1.59 \times 10^{-7}$ & $1 \times 10^{-10}$ & $2.41 \times 10^{-6}$ & $1 \times 10^{-9}$ \\
\hline & 2,100 & 0.0225 & $1 \times 10^{-5}$ & 0.00384 & $2 \times 10^{-6}$ & $2.23 \times 10^{-7}$ & $1 \times 10^{-10}$ & $3.38 \times 10^{-6}$ & $2 \times 10^{-9}$ \\
\hline & 3,000 & 0.0225 & $1 \times 10^{-5}$ & 0.00384 & $2 \times 10^{-6}$ & $3.19 \times 10^{-7}$ & $2 \times 10^{-10}$ & $4.82 \times 10^{-6}$ & $3 \times 10^{-9}$ \\
\hline \multirow{5}{*}{$\begin{array}{l}\text { Am oxide } \\
\text { product }\end{array}$} & 150 & 0.154 & $9 \times 10^{-5}$ & 0.0641 & $4 \times 10^{-5}$ & $1.29 \times 10^{-7}$ & $8 \times 10^{-11}$ & $1.74 \times 10^{-6}$ & $1 \times 10^{-9}$ \\
\hline & 500 & 0.154 & $9 \times 10^{-5}$ & 0.0641 & $4 \times 10^{-5}$ & $4.31 \times 10^{-7}$ & $3 \times 10^{-10}$ & $5.81 \times 10^{-6}$ & $3 \times 10^{-9}$ \\
\hline & 1,500 & 0.154 & $9 \times 10^{-5}$ & 0.0641 & $4 \times 10^{-5}$ & $1.29 \times 10^{-6}$ & $8 \times 10^{-10}$ & $1.74 \times 10^{-5}$ & $1 \times 10^{-8}$ \\
\hline & 2,100 & 0.154 & $9 \times 10^{-5}$ & 0.0641 & $4 \times 10^{-5}$ & $1.81 \times 10^{-6}$ & $1 \times 10^{-9}$ & $2.44 \times 10^{-5}$ & $1 \times 10^{-8}$ \\
\hline & 3,000 & 0.154 & $9 \times 10^{-5}$ & 0.0641 & $4 \times 10^{-5}$ & $2.58 \times 10^{-6}$ & $2 \times 10^{-9}$ & $3.48 \times 10^{-5}$ & $2 \times 10^{-8}$ \\
\hline \multirow{5}{*}{$\begin{array}{l}\text { Cm oxide } \\
\text { product }\end{array}$} & 150 & 0.154 & $9 \times 10^{-5}$ & 0.0641 & $4 \times 10^{-5}$ & $1.29 \times 10^{-7}$ & $8 \times 10^{-11}$ & $1.74 \times 10^{-6}$ & $1 \times 10^{-9}$ \\
\hline & 500 & 0.154 & $9 \times 10^{-5}$ & 0.0641 & $4 \times 10^{-5}$ & $4.31 \times 10^{-7}$ & $3 \times 10^{-10}$ & $5.81 \times 10^{-6}$ & $3 \times 10^{-9}$ \\
\hline & 1,500 & 0.154 & $9 \times 10^{-5}$ & 0.0641 & $4 \times 10^{-5}$ & $1.29 \times 10^{-6}$ & $8 \times 10^{-10}$ & $1.74 \times 10^{-5}$ & $1 \times 10^{-8}$ \\
\hline & 2,100 & 0.154 & $9 \times 10^{-5}$ & 0.0641 & $4 \times 10^{-5}$ & $1.81 \times 10^{-6}$ & $1 \times 10^{-9}$ & $2.44 \times 10^{-5}$ & $1 \times 10^{-8}$ \\
\hline & 3,000 & 0.154 & $9 \times 10^{-5}$ & 0.0641 & $4 \times 10^{-5}$ & $2.58 \times 10^{-6}$ & $2 \times 10^{-9}$ & $3.48 \times 10^{-5}$ & $2 \times 10^{-8}$ \\
\hline
\end{tabular}


TABLE E.2.4-3-Per-Shipment Loading Impacts Associated with Thermal/Fast Reactor Recycle Alternative-All-Truck Option (continued)

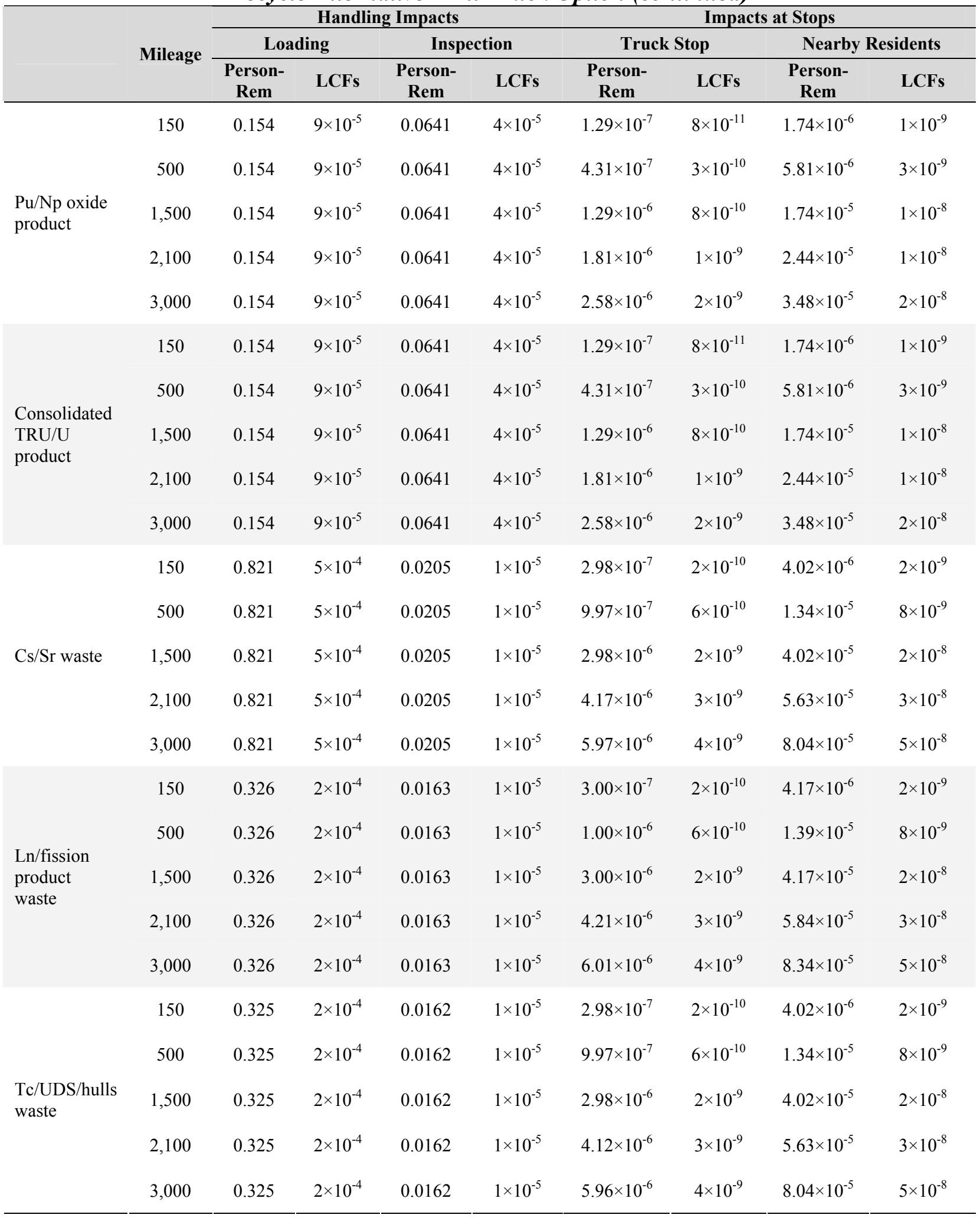


TABLE E.2.4-3 - Per-Shipment Loading Impacts Associated with Thermal/Fast Reactor Recycle Alternative-All-Truck Option (continued)

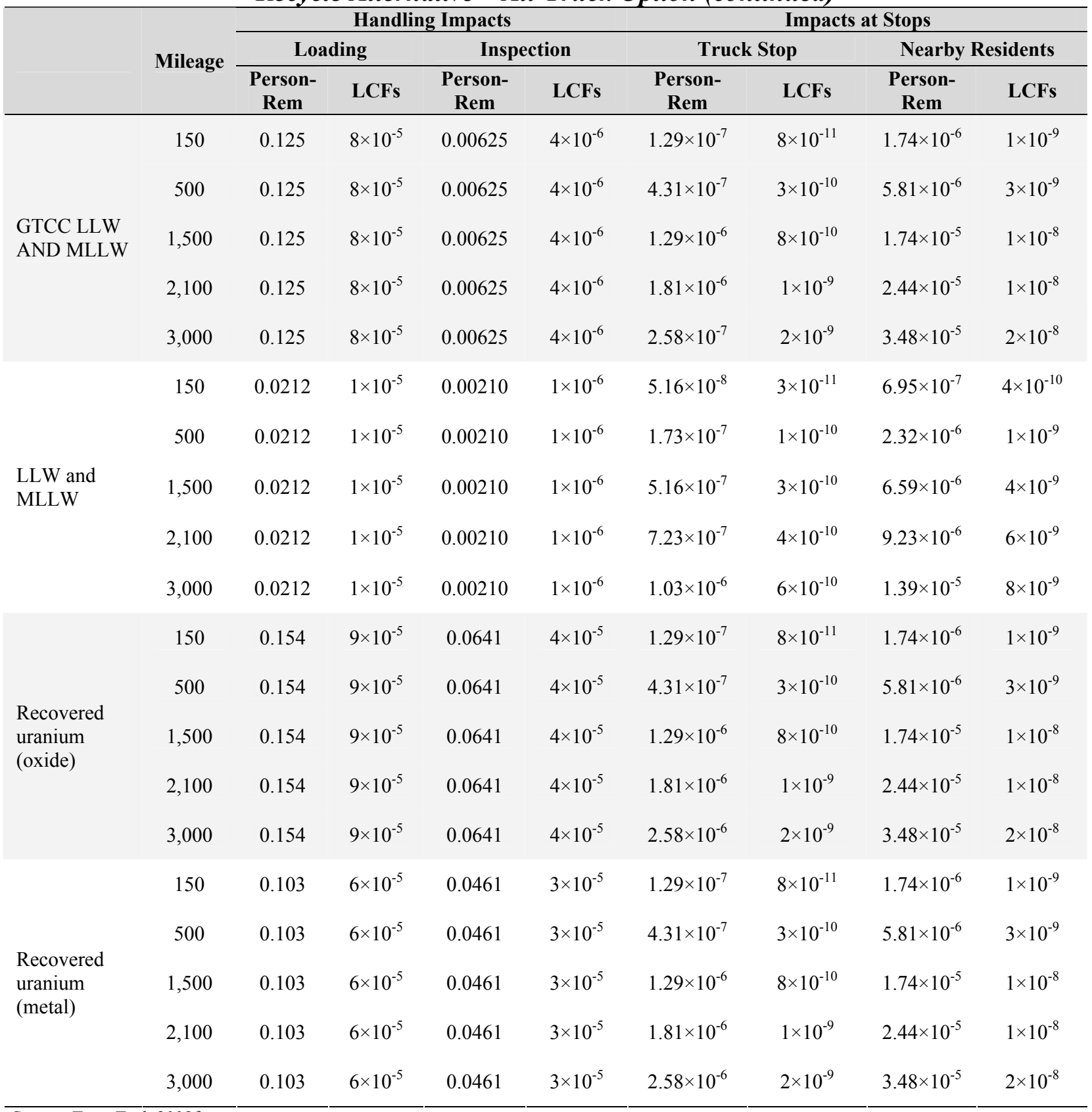

Source: Tetra Tech $2008 \mathrm{f}$ 
TABLE E.2.4-4-Per-Shipment Incident-Free In-Transit Impacts-

Thermal/Fast Reactor Recycle Alternative-All-Truck Option

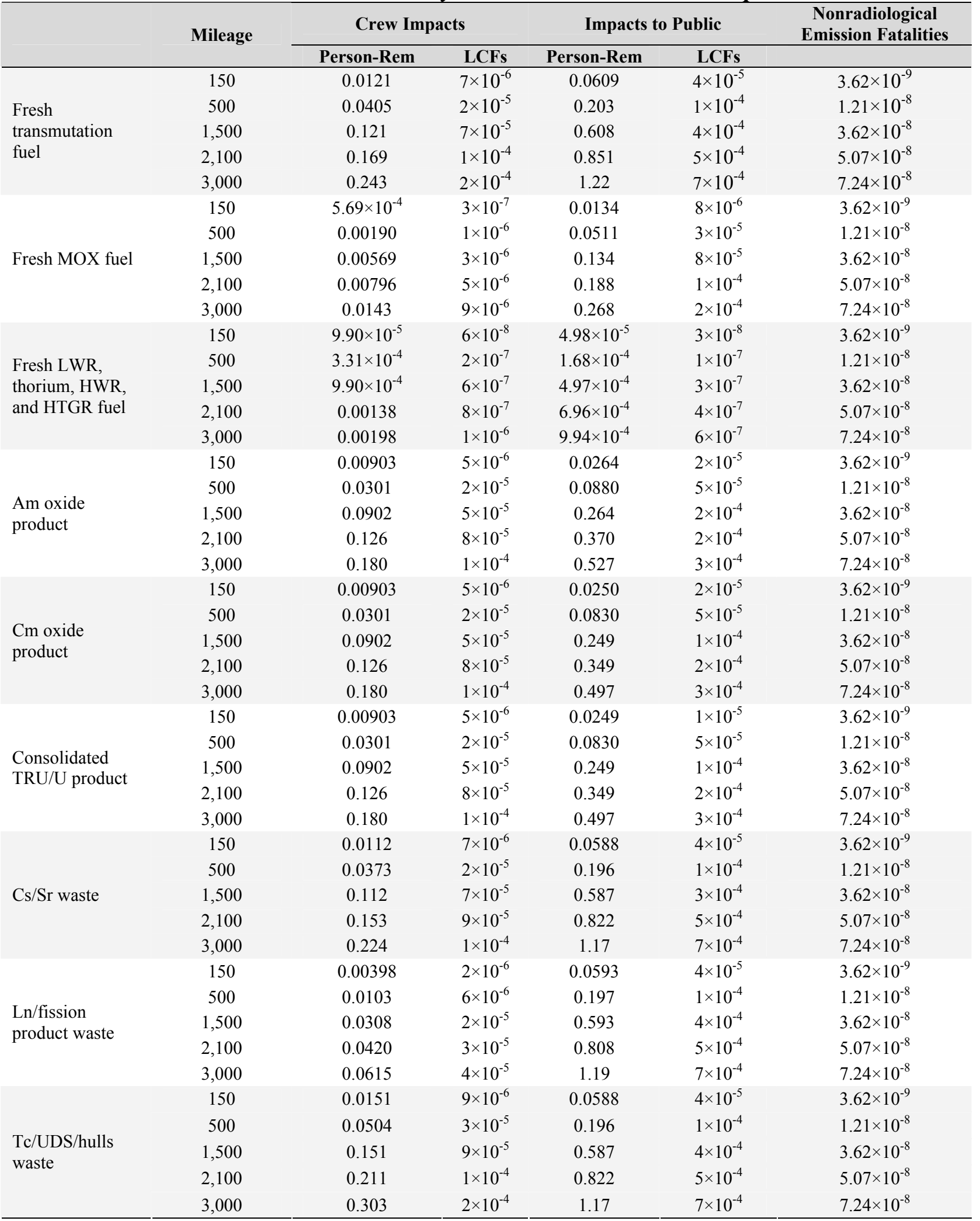


TABLE E.2.4-4-Per-Shipment Incident-Free In-Transit ImpactsThermal/Fast Reactor Recycle Alternative-All-Truck Option (continued)

\begin{tabular}{|c|c|c|c|c|c|c|}
\hline & \multirow{2}{*}{ Mileage } & \multicolumn{2}{|c|}{ Crew Impacts } & \multicolumn{2}{|c|}{ Impacts to Public } & \multirow[t]{2}{*}{$\begin{array}{c}\text { Nonradiological } \\
\text { Emission Fatalities }\end{array}$} \\
\hline & & Person-Rem & LCFs & Person-Rem & LCFs & \\
\hline \multirow{5}{*}{$\begin{array}{l}\text { GTCC LLW } \\
\text { AND MLLW }\end{array}$} & 150 & 0.0151 & $9 \times 10^{-6}$ & 0.0254 & $2 \times 10^{-5}$ & $3.62 \times 10^{-9}$ \\
\hline & 500 & 0.0504 & $3 \times 10^{-5}$ & 0.0846 & $5 \times 10^{-5}$ & $1.21 \times 10^{-8}$ \\
\hline & 1,500 & 0.151 & $9 \times 10^{-5}$ & 0.254 & $2 \times 10^{-4}$ & $3.62 \times 10^{-8}$ \\
\hline & 2,100 & 0.211 & $1 \times 10^{-4}$ & 0.356 & $2 \times 10^{-4}$ & $5.07 \times 10^{-8}$ \\
\hline & 3,000 & 0.303 & $2 \times 10^{-4}$ & 0.507 & $3 \times 10^{-4}$ & $7.24 \times 10^{-8}$ \\
\hline \multirow{5}{*}{$\begin{array}{l}\text { LLW AND } \\
\text { MLLW }\end{array}$} & 150 & 0.00320 & $2 \times 10^{-6}$ & 0.0102 & $6 \times 10^{-6}$ & $3.62 \times 10^{-9}$ \\
\hline & 500 & 0.0107 & $6 \times 10^{-6}$ & 0.0339 & $2 \times 10^{-5}$ & $1.21 \times 10^{-8}$ \\
\hline & 1,500 & 0.0320 & $2 \times 10^{-5}$ & 0.102 & $6 \times 10^{-5}$ & $3.62 \times 10^{-8}$ \\
\hline & 2,100 & 0.0448 & $2 \times 10^{-5}$ & 0.143 & $8 \times 10^{-5}$ & $5.07 \times 10^{-8}$ \\
\hline & 3,000 & 0.0640 & $4 \times 10^{-5}$ & 0.203 & $1 \times 10^{-4}$ & $7.24 \times 10^{-8}$ \\
\hline \multirow{5}{*}{$\begin{array}{l}\text { Recovered } \\
\text { uranium (oxide) }\end{array}$} & 150 & 0.0147 & $9 \times 10^{-6}$ & 0.0249 & $1 \times 10^{-5}$ & $3.62 \times 10^{-9}$ \\
\hline & 500 & 0.0504 & $3 \times 10^{-5}$ & 0.0846 & $5 \times 10^{-5}$ & $1.21 \times 10^{-8}$ \\
\hline & 1,500 & 0.147 & $9 \times 10^{-5}$ & 0.249 & $1 \times 10^{-4}$ & $3.62 \times 10^{-8}$ \\
\hline & 2,100 & 0.206 & $1 \times 10^{-4}$ & 0.347 & $2 \times 10^{-4}$ & $5.07 \times 10^{-8}$ \\
\hline & 3,000 & 0.294 & $2 \times 10^{-4}$ & 0.496 & $3 \times 10^{-4}$ & $7.24 \times 10^{-8}$ \\
\hline \multirow{5}{*}{$\begin{array}{l}\text { Recovered } \\
\text { uranium (metal) }\end{array}$} & 150 & 0.0147 & $9 \times 10^{-6}$ & 0.0249 & $1 \times 10^{-5}$ & $3.62 \times 10^{-9}$ \\
\hline & 500 & 0.0504 & $3 \times 10^{-5}$ & 0.0846 & $5 \times 10^{-5}$ & $1.21 \times 10^{-8}$ \\
\hline & 1,500 & 0.147 & $9 \times 10^{-5}$ & 0.249 & $1 \times 10^{-4}$ & $3.62 \times 10^{-8}$ \\
\hline & 2,100 & 0.206 & $1 \times 10^{-4}$ & 0.347 & $2 \times 10^{-4}$ & $5.07 \times 10^{-8}$ \\
\hline & 3,000 & 0.294 & $2 \times 10^{-4}$ & 0.496 & $3 \times 10^{-4}$ & $7.24 \times 10^{-8}$ \\
\hline
\end{tabular}

Source: Tetra Tech $2008 \mathrm{f}$

TABLE E.2.4-5-Per-Shipment Radiological Exposure Handling Impacts and Impacts at Stops-Domestic Programmatic Alternative Scenarios-Spent Nuclear FuelAll-Rail Option

\begin{tabular}{ccccccccc}
\hline & \multicolumn{3}{c}{ Handling Impacts } & \multicolumn{3}{c}{ Impacts at Stops } \\
\cline { 2 - 9 } Mileage & \multicolumn{2}{c}{ Loading $^{\text {a }}$} & \multicolumn{2}{c}{ Inspection } & \multicolumn{2}{c}{ Railyard Workers } & \multicolumn{2}{c}{ Nearby Residents } \\
\cline { 2 - 9 } & $\begin{array}{c}\text { Person- } \\
\text { Rem }\end{array}$ & LCFs & $\begin{array}{c}\text { Person- } \\
\text { Rem }\end{array}$ & LCFs & $\begin{array}{c}\text { Person- } \\
\text { Rem }\end{array}$ & LCFs & $\begin{array}{c}\text { Person- } \\
\text { Rem }\end{array}$ & LCFs \\
\hline 150 & 3.32 & 0.002 & 0.185 & $1 \times 10^{-4}$ & $1.27 \times 10^{-6}$ & $8 \times 10^{-10}$ & $2.38 \times 10^{-4}$ & $1 \times 10^{-7}$ \\
500 & 3.32 & 0.002 & 0.185 & $1 \times 10^{-4}$ & $4.22 \times 10^{-6}$ & $3 \times 10^{-9}$ & $7.95 \times 10^{-4}$ & $5 \times 10^{-7}$ \\
1,500 & 3.32 & 0.002 & 0.185 & $1 \times 10^{-4}$ & $1.27 \times 10^{-5}$ & $8 \times 10^{-9}$ & 0.00238 & $1 \times 10^{-6}$ \\
2,100 & 3.32 & 0.002 & 0.185 & $1 \times 10^{-4}$ & $1.78 \times 10^{-5}$ & $1 \times 10^{-8}$ & 0.00333 & $2 \times 10^{-6}$ \\
3,000 & 3.32 & 0.002 & 0.185 & $1 \times 10^{-4}$ & $2.53 \times 10^{-5}$ & $2 \times 10^{-8}$ & 0.00476 & $3 \times 10^{-6}$ \\
\hline
\end{tabular}

Source: Tetra Tech $2008 \mathrm{f}$

${ }^{a}$ Loading exposure values from Yucca Mountain FEIS (DOE 2002i)

TABLE E.2.4-6-Per-Shipment Incident-Free In-Transit Impacts—Domestic Programmatic Alternative Scenarios-Spent Nuclear Fuel ${ }^{\text {a }}$ - All-Rail Option

\begin{tabular}{cccccc}
\hline \multirow{2}{*}{ Mileage } & \multicolumn{2}{c}{ Crew Impacts } & \multicolumn{2}{c}{ Impacts to Public } & Nonradiological \\
\cline { 2 - 5 } & Person-Rem & LCFs & Person-Rem & LCFs & \\
Emission Fatalities
\end{tabular}


TABLE E.2.4-7-Per-Shipment Loading Impacts Associated with Thermal/Fast Reactor Recycle Alternative-All-Rail Option

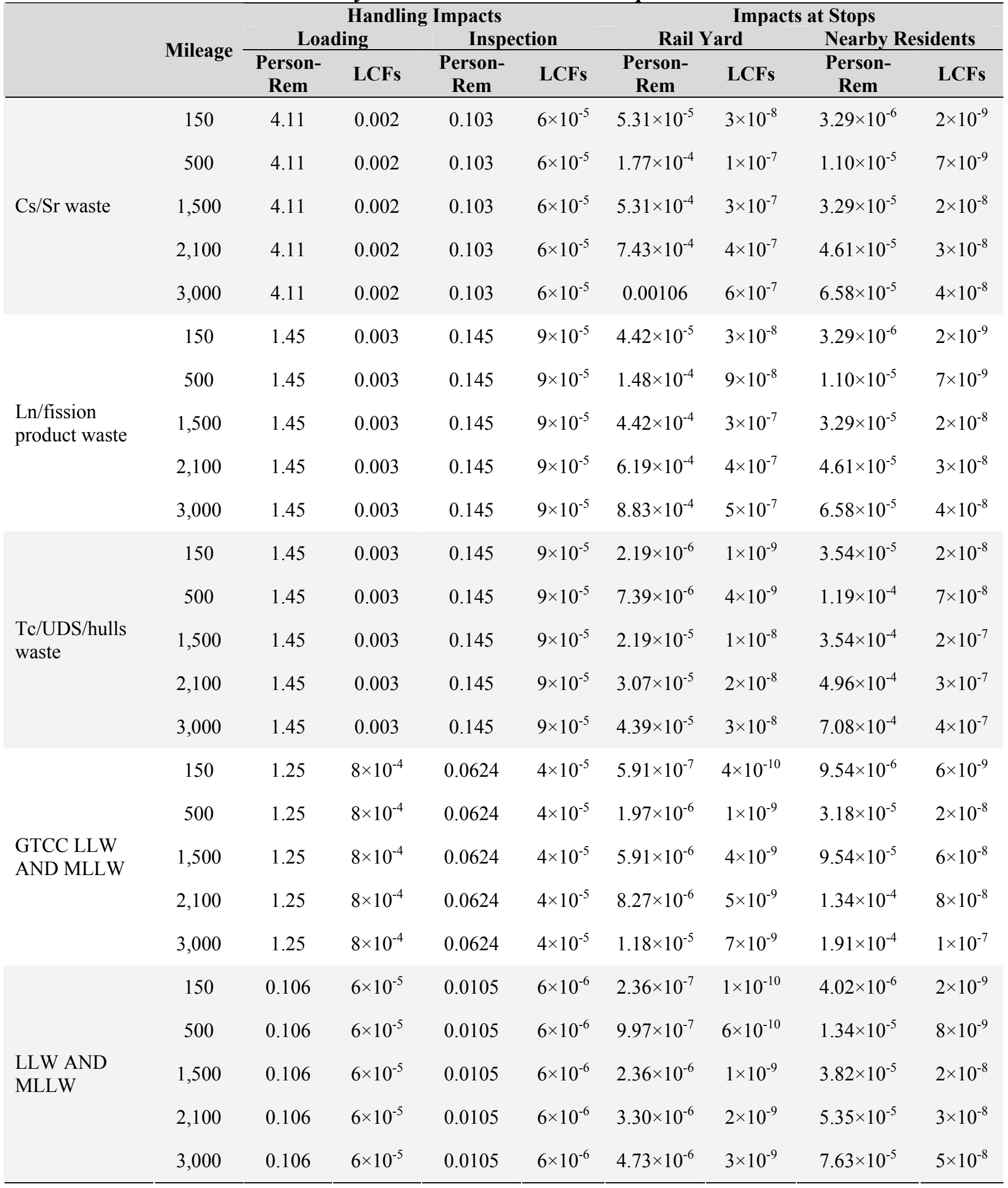


TABLE E.2.4-7-Per-Shipment Loading Impacts Associated with Thermal/Fast Reactor Recycle Alternative-All-Rail Option (continued)

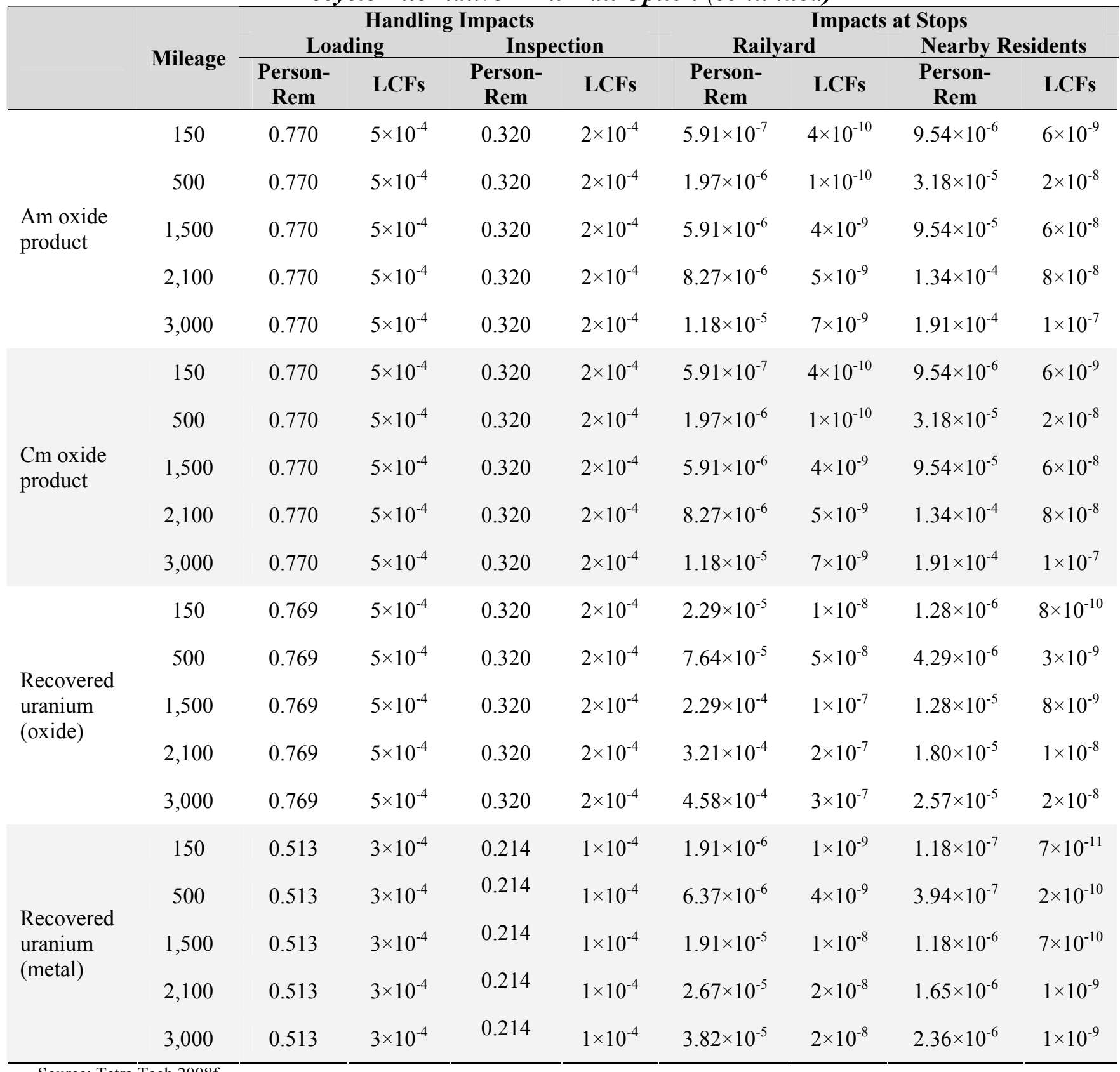


TABLE E.2.4-8-Per-Shipment Incident-Free In-Transit Impacts-

Thermal/Fast Reactor Recycle Alternative-All-Rail Option

\begin{tabular}{|c|c|c|c|c|c|c|}
\hline & \multirow[b]{2}{*}{ Mileage } & \multicolumn{2}{|c|}{ Crew Impacts $^{\text {a }}$} & \multicolumn{2}{|c|}{ Impacts to Public } & \multirow{2}{*}{$\begin{array}{c}\text { Nonradiological } \\
\text { Emission } \\
\text { Fatalities } \\
\end{array}$} \\
\hline & & $\begin{array}{c}\text { Person- } \\
\text { Rem }\end{array}$ & LCFs & $\begin{array}{c}\text { Person- } \\
\text { Rem }\end{array}$ & LCFs & \\
\hline \multirow{5}{*}{$\mathrm{Cs} / \mathrm{Sr}$ waste } & 150 & 0.00406 & $2 \times 10^{-6}$ & 0.0329 & $3 \times 10^{-5}$ & $6.28 \times 10^{-9}$ \\
\hline & 500 & 0.0135 & $8 \times 10^{-6}$ & 0.109 & $7 \times 10^{-5}$ & $2.09 \times 10^{-8}$ \\
\hline & 1,500 & 0.0406 & $2 \times 10^{-5}$ & 0.336 & $2 \times 10^{-4}$ & $6.28 \times 10^{-8}$ \\
\hline & 2,100 & 0.0568 & $3 \times 10^{-5}$ & 0.470 & $3 \times 10^{-4}$ & $8.79 \times 10^{-8}$ \\
\hline & 3,000 & 0.0812 & $5 \times 10^{-5}$ & 0.658 & $4 \times 10^{-4}$ & $1.26 \times 10^{-7}$ \\
\hline \multirow{5}{*}{$\begin{array}{l}\mathrm{Ln} / \text { fission } \\
\text { product waste }\end{array}$} & 150 & 0.00406 & $2 \times 10^{-6}$ & 0.0586 & $4 \times 10^{-5}$ & $6.28 \times 10^{-9}$ \\
\hline & 500 & 0.0135 & $8 \times 10^{-6}$ & 0.194 & $1 \times 10^{-4}$ & $2.09 \times 10^{-8}$ \\
\hline & 1,500 & 0.0406 & $2 \times 10^{-5}$ & 0.584 & $4 \times 10^{-4}$ & $6.28 \times 10^{-8}$ \\
\hline & 2,100 & 0.0568 & $3 \times 10^{-5}$ & 0.817 & $5 \times 10^{-4}$ & $8.79 \times 10^{-8}$ \\
\hline & 3,000 & 0.0812 & $5 \times 10^{-5}$ & 1.16 & $7 \times 10^{-4}$ & $1.26 \times 10^{-7}$ \\
\hline \multirow{5}{*}{$\begin{array}{l}\text { Tc/UDS/hulls } \\
\text { waste }\end{array}$} & 150 & 0.00406 & $2 \times 10^{-6}$ & 0.0493 & $3 \times 10^{-5}$ & $6.28 \times 10^{-9}$ \\
\hline & 500 & 0.0135 & $8 \times 10^{-6}$ & 0.164 & $1 \times 10^{-4}$ & $2.09 \times 10^{-8}$ \\
\hline & 1,500 & 0.0406 & $2 \times 10^{-5}$ & 0.493 & $3 \times 10^{-4}$ & $6.28 \times 10^{-8}$ \\
\hline & 2,100 & 0.0568 & $3 \times 10^{-5}$ & 0.586 & $4 \times 10^{-4}$ & $8.79 \times 10^{-8}$ \\
\hline & 3,000 & 0.0812 & $5 \times 10^{-5}$ & 0.986 & $6 \times 10^{-4}$ & $1.26 \times 10^{-7}$ \\
\hline \multirow{5}{*}{$\begin{array}{l}\text { GTCC LLW } \\
\text { AND MLLW }\end{array}$} & 150 & 0.00203 & $1 \times 10^{-6}$ & 0.0105 & $6 \times 10^{-6}$ & $6.28 \times 10^{-9}$ \\
\hline & 500 & 0.00663 & $4 \times 10^{-6}$ & 0.0350 & $2 \times 10^{-5}$ & $2.09 \times 10^{-8}$ \\
\hline & 1,500 & 0.0203 & $1 \times 10^{-5}$ & 0.105 & $6 \times 10^{-5}$ & $6.28 \times 10^{-8}$ \\
\hline & 2,100 & 0.0284 & $2 \times 10^{-5}$ & 0.147 & $9 \times 10^{-5}$ & $8.79 \times 10^{-8}$ \\
\hline & 3,000 & 0.0406 & $2 \times 10^{-5}$ & 0.210 & $1 \times 10^{-4}$ & $1.26 \times 10^{-7}$ \\
\hline \multirow{5}{*}{$\begin{array}{l}\text { LLW AND } \\
\text { MLLW }\end{array}$} & 150 & $8.12 \times 10^{-4}$ & $5 \times 10^{-7}$ & 0.00421 & $3 \times 10^{-6}$ & $6.28 \times 10^{-9}$ \\
\hline & 500 & 0.00265 & $2 \times 10^{-6}$ & 0.0140 & $8 \times 10^{-6}$ & $2.09 \times 10^{-8}$ \\
\hline & 1,500 & 0.0812 & $5 \times 10^{-6}$ & 0.0420 & $3 \times 10^{-5}$ & $6.28 \times 10^{-8}$ \\
\hline & 2,100 & 0.0114 & $7 \times 10^{-6}$ & 0.0588 & $4 \times 10^{-5}$ & $8.79 \times 10^{-8}$ \\
\hline & 3,000 & 0.0162 & $1 \times 10^{-5}$ & 0.0807 & $5 \times 10^{-5}$ & $1.26 \times 10^{-7}$ \\
\hline \multirow{5}{*}{$\begin{array}{l}\text { Am oxide } \\
\text { product }\end{array}$} & 150 & 0.0472 & $3 \times 10^{-5}$ & 0.00579 & $3 \times 10^{-6}$ & $6.28 \times 10^{-9}$ \\
\hline & 500 & 0.0669 & $4 \times 10^{-5}$ & 0.0193 & $1 \times 10^{-5}$ & $2.09 \times 10^{-8}$ \\
\hline & 1,500 & 0.123 & $7 \times 10^{-5}$ & 0.0579 & $3 \times 10^{-5}$ & $6.28 \times 10^{-8}$ \\
\hline & 2,100 & 0.157 & $9 \times 10^{-5}$ & 0.0810 & $5 \times 10^{-5}$ & $8.79 \times 10^{-8}$ \\
\hline & 3,000 & 0.207 & $1 \times 10^{-4}$ & 0.116 & $7 \times 10^{-5}$ & $1.26 \times 10^{-7}$ \\
\hline \multirow{5}{*}{$\begin{array}{l}\text { Cm oxide } \\
\text { product }\end{array}$} & 150 & 0.0472 & $3 \times 10^{-5}$ & 0.00579 & $3 \times 10^{-6}$ & $6.28 \times 10^{-9}$ \\
\hline & 500 & 0.0669 & $4 \times 10^{-5}$ & 0.0193 & $1 \times 10^{-5}$ & $2.09 \times 10^{-8}$ \\
\hline & 1,500 & 0.123 & $7 \times 10^{-5}$ & 0.0579 & $3 \times 10^{-5}$ & $6.28 \times 10^{-8}$ \\
\hline & 2,100 & 0.157 & $9 \times 10^{-5}$ & 0.0810 & $5 \times 10^{-5}$ & $8.79 \times 10^{-8}$ \\
\hline & 3,000 & 0.207 & $1 \times 10^{-4}$ & 0.116 & $7 \times 10^{-5}$ & $1.26 \times 10^{-7}$ \\
\hline \multirow{5}{*}{$\begin{array}{l}\text { Recovered } \\
\text { uranium } \\
\text { (oxide) }\end{array}$} & 150 & 0.00203 & $1 \times 10^{-6}$ & 0.00579 & $3 \times 10^{-6}$ & $6.28 \times 10^{-9}$ \\
\hline & 500 & 0.00663 & $4 \times 10^{-6}$ & 0.00197 & $1 \times 10^{-5}$ & $2.09 \times 10^{-8}$ \\
\hline & 1,500 & 0.0203 & $1 \times 10^{-5}$ & 0.0579 & $3 \times 10^{-5}$ & $6.28 \times 10^{-8}$ \\
\hline & 2,100 & 0.0284 & $2 \times 10^{-5}$ & 0.0810 & $5 \times 10^{-5}$ & $8.79 \times 10^{-8}$ \\
\hline & 3,000 & 0.0406 & $2 \times 10^{-5}$ & 0.116 & $7 \times 10^{-5}$ & $1.26 \times 10^{-7}$ \\
\hline \multirow{5}{*}{$\begin{array}{l}\text { Recovered } \\
\text { uranium } \\
\text { (metal) }\end{array}$} & 150 & 0.00203 & $1 \times 10^{-6}$ & 0.00521 & $3 \times 10^{-6}$ & $6.28 \times 10^{-9}$ \\
\hline & 500 & 0.00663 & $4 \times 10^{-6}$ & 0.0177 & $1 \times 10^{-5}$ & $2.09 \times 10^{-8}$ \\
\hline & 1,500 & 0.0203 & $1 \times 10^{-5}$ & 0.0521 & $3 \times 10^{-5}$ & $6.28 \times 10^{-8}$ \\
\hline & 2,100 & 0.0284 & $2 \times 10^{-5}$ & 0.0729 & $4 \times 10^{-5}$ & $8.79 \times 10^{-8}$ \\
\hline & 3,000 & 0.0406 & $2 \times 10^{-5}$ & 0.104 & $6 \times 10^{-5}$ & $1.26 \times 10^{-7}$ \\
\hline
\end{tabular}

Source: Tetra Tech 2008

${ }^{a}$ Crew impacts are equivalent to the impacts expected for two security escorts accompanying each shipment (see Table E.2.4-9). As provided in the Yucca Mountain SEIS (DOE 2008f) and the RADTRAN User's Manual (Weiner et al. 2006), there would be no dose to the conductors and engineer present in the locomotive. This is due to distance (up to $150 \mathrm{~m}$ from the source) and the shielding provided by the locomotive and the other cars between the source and the inhabitants of the locomotive. Although not all material types would require security escorts, the crew impacts provided in this table provide a conservative estimate of what could be expected. 
Tables E.2.4-9 and E.2.4-10 provide the estimated incident-free impacts to escorts associated with the shipment of spent fuel and fresh transmutation and MOX fuels from the domestic programmatic alternatives, in terms of radiological exposure and additional LCFs. Table E.2.4-11 provides the nonradiological impacts to the general public due to the escort vehicle traffic. The emission fatalities values represent additional public fatalities due to increased ambient fugitive dust and gasoline or diesel exhaust emissions attributed to the escort vehicles. The collision fatalities represent additional fatalities due to accidents related to the escort vehicles.

TABLE E.2.4-9—Per-Shipment Incident-Free Radiation Doses to EscortsShipments of Spent Nuclear Fuel and Fresh Transmutation Fuel-Domestic Programmatic Alternatives

\begin{tabular}{ccccc}
\hline \multirow{2}{*}{$\begin{array}{c}\text { Shipment } \\
\text { Mileage }\end{array}$} & \multicolumn{2}{c}{ All-Truck Scenario } & \multicolumn{2}{c}{ All-Rail Scenario } \\
\cline { 2 - 5 } & Person-Rem & LCFs & Person-Rem & LCFs \\
\hline 150 & $4.13 \times 10^{-4}$ & $2 \times 10^{-7}$ & 0.00406 & $2 \times 10^{-6}$ \\
500 & 0.00138 & $8 \times 10^{-7}$ & 0.0135 & $8 \times 10^{-6}$ \\
1,500 & 0.00413 & $2 \times 10^{-6}$ & 0.0406 & $2 \times 10^{-5}$ \\
2,100 & 0.00578 & $3 \times 10^{-6}$ & 0.0568 & $3 \times 10^{-5}$ \\
3,000 & 0.00826 & $5 \times 10^{-6}$ & 0.0812 & $5 \times 10^{-5}$ \\
\hline
\end{tabular}

Source: Tetra Tech $2008 \mathrm{f}$

Note: Fresh transmutation fuel would only be transported by truck, as described in 10 CFR 51.52.

TABLE E.2.4-10_Per-Shipment Incident-Free Radiation Doses to EscortsFresh MOX Fuel Shipments-Domestic Programmatic Alternatives

\begin{tabular}{ccc}
\hline Shipment & \multicolumn{2}{c}{ All-Truck Scenario } \\
\cline { 2 - 3 } Mileage & Person-Rem & LCFs \\
\hline 150 & $3.55 \times 10^{-6}$ & $2 \times 10^{-9}$ \\
500 & $1.18 \times 10^{-5}$ & $7 \times 10^{-9}$ \\
1,500 & $3.55 \times 10^{-5}$ & $2 \times 10^{-8}$ \\
2,100 & $4.96 \times 10^{-5}$ & $3 \times 10^{-8}$ \\
3,000 & $7.08 \times 10^{-5}$ & $4 \times 10^{-8}$ \\
\hline
\end{tabular}

Source: Tetra Tech $2008 \mathrm{f}$

Note: Fresh MOX fuel would only be transported by truck, as described in 10 CFR 51.52.

TABLE E.2.4-11—Per-Shipment Nonradiological Impacts to General Population due to Escort Vehicle Traffic_Fresh and Spent Nuclear Fuel Shipments-Domestic Programmatic Alternatives

\begin{tabular}{ccccc}
\hline \multirow{2}{*}{ Shipment Mileage } & \multicolumn{2}{c}{ All-Truck Scenario } & \multicolumn{2}{c}{ All-Rail Scenario } \\
\cline { 2 - 5 } & Emission Fatalities & Collision Fatalities & Emission Fatalities & Collision Fatalities \\
\hline 150 & $2.81 \times 10^{-7}$ & $6.13 \times 10^{-6}$ & $1.56 \times 10^{-6}$ & $1.02 \times 10^{-5}$ \\
500 & $9.35 \times 10^{-7}$ & $2.04 \times 10^{-5}$ & $2.81 \times 10^{-6}$ & $3.41 \times 10^{-5}$ \\
1,500 & $2.81 \times 10^{-6}$ & $6.13 \times 10^{-5}$ & $8.43 \times 10^{-6}$ & $2.65 \times 10^{-4}$ \\
2,100 & $3.93 \times 10^{-6}$ & $8.58 \times 10^{-5}$ & $1.18 \times 10^{-5}$ & $3.71 \times 10^{-4}$ \\
3,000 & $5.61 \times 10^{-6}$ & $1.23 \times 10^{-4}$ & $1.69 \times 10^{-5}$ & $5.30 \times 10^{-4}$ \\
\hline
\end{tabular}

Source: Tetra Tech $2008 \mathrm{f}$

\section{E.2.5 Accident Analysis-Domestic Programmatic Alternative}

The NRC developed release fractions for commercial SNF from BWR and PWR (NRC 2000a). The analysis estimated the amount of radioactive material released from a cask in an accident by multiplying the approximate release fraction by the number of fuel assemblies in a cask and the 
radioactivity of a SNF assembly. For this analysis, the release fractions developed in Reexamination of Spent Fuel Shipment Risk Estimate (NRC 2000a) for commercial PWR fuel were used, which is more conservative than the assumption of release fractions associated with BWR fuel groups. For the LWR SNF shipments, it was assumed that the same per mass nuclide inventory based on SNF inventory data provided by the AFCF NEPA Data Study, and the mass per cask, was similar for the PWR and BWR fuels. For truck shipments, the mass of PWR and BWR SNF were 2.0 MTHM and 1.8 MTHM, respectively. For the rail shipment analyses, PWR and BWR SNF masses per cask were 5.0 MTHM and 4.8 MTHM, respectively.

As stated in the West Valley Demonstration Project (WVDP) Waste Management Final Environmental Impact Statement (hereafter WVDP FEIS) (DOE 2004f), the two studies described above can be applied to waste types other than SNF. In the WVDP FEIS, release fractions and conditional probabilities are provided for a wide range of materials and the corresponding transportation containers. Tables E.2.5-1 through E.2.5-6 provide the conditional probabilities and release fractions associated with the domestic programmatic SNF shipments. Table E.2.5-7 and Table E.2.5-8 provide conditional probabilities and release fractions used for shipments containing HLW canisters and 9975 containers, respectively. Table E.2.5-9 provides the conditional probabilities and release fractions associated with the Class $\mathrm{B}$ casks used to transport fresh MOX fuel, as provided in NRC 2005c. The term "CRUD" is defined as Chalk River Undefined Deposits, which represent oxide deposits that form on the exterior of zirconium clad SNF rods. These deposits are usually composed of cobalt and iron among others.

The per-shipment accident analysis impacts for the domestic programmatic alternatives are provided in Tables E.2.5-10 and Table E.2.5-11. These per-shipment values can be multiplied by the appropriate factors to estimate the impacts of varying configurations to meet different alternatives. For the truck impact values provided in Table E.2.5-10, accident and fatality rates were calculated by multiplying the national average rates provided in Saricks and Tompkins (1999) by 1.54 and 1.67 , for accidents and fatalities respectively.

Table E.2.5-12 provides the maximum foreseeable accident impacts results for the materials transported in the domestic programmatic alternatives. These impacts represent the consequences of an accident at a population center and an accident in a rural setting. Materials associated with the thermal recycle processes include the wastes generated in the separations and other processes, recovered uranium and transuranic products, LWR SNF, and MOX SNF. The fast recycle process materials include the process wastes, recovered uranium product, LWR SNF, fresh ARR fuel, and ARR SNF. The materials associated with Thorium Cycle, All-HWR, and All-HTGR Alternatives are represented by their respective SNFs, since no recycle processes are associated with these alternatives.

The analysis was based on the 21 rail accident severity categories identified in Reexamination of Spent Fuel Shipment Risk Estimate (NRC 2000a. Each of the 21 accident cases has an associated conditional probability of occurrence (NRC 2000a). Combining the conditional probabilities analyzed in the domestic programmatic alternatives, only the Case 4 event and the Case 20 event have occurrence frequencies greater than $1 \times 10^{-7}$ per year, with expected annual frequencies of $5 \times 10^{-6}$ and $3 \times 10^{-6}$, respectively (NRC 2000a). 
The Case 20 event is a long-duration event high-temperature fire event that engulfs the entire cask. This event is assumed to last many hours (NRC 2000a).

The Case 4 event assumes a moderate-speed impact (30 to 60 miles per hour [48 to 97 kilometers per hour]) into a hard surface such as granite severe enough to cause failure of casks seals. This impact would be followed by an engulfing fire lasting from 0.5 hour to a few hours (NRC 2000a).

The Case 20 event was estimated to have the higher consequences and was thus assumed to be the maximum reasonably foreseeable transportation accident. As reflected in the data provided in Table E.2.5-12 the LWR and MOX SNF materials present the largest potential impacts.

For analysis of routine transportation accident risk, DOE combined the 21 accident cases for rail transport (and 19 accident cases for truck transport) into six accident categories, based on accident conditions and consequences. The six categories represent the summation of conditional probabilities and the weighted average release fractions of the associated material types.

TABLE E.2.5-1-Conditional Probabilities and Release Fractions for Light Water Reactor, Mixed-Oxide, and Thorium Cycle Spent Nuclear Fuel Shipments-Truck Cask

\begin{tabular}{ccccccc}
\hline Accident & Conditional & \multicolumn{5}{c}{ Release Fraction } \\
\cline { 3 - 7 } Severity Cat. & Probability & Inert Gas & Cesium & Ruthenium & Particulates & Crud \\
\hline 1 & 0.99993 & 0.0 & 0.0 & 0.0 & 0.0 & 0.0 \\
2 & $6.06 \times 10^{-5}$ & $1.36 \times 10^{-1}$ & $4.09 \times 10^{-9}$ & $1.02 \times 10^{-7}$ & $1.02 \times 10^{-7}$ & $1.36 \times 10^{-3}$ \\
3 & $5.86 \times 10^{-6}$ & $8.39 \times 10^{-1}$ & $1.68 \times 10^{-5}$ & $6.71 \times 10^{-8}$ & $6.71 \times 10^{-8}$ & $2.52 \times 10^{-3}$ \\
4 & $4.95 \times 10^{-7}$ & $4.49 \times 10^{-1}$ & $1.35 \times 10^{-6}$ & $3.37 \times 10^{-7}$ & $3.37 \times 10^{-7}$ & $1.83 \times 10^{-3}$ \\
5 & $7.49 \times 10^{-7}$ & $8.35 \times 10^{-1}$ & $3.60 \times 10^{-5}$ & $3.77 \times 10^{-6}$ & $3.77 \times 10^{-6}$ & $3.16 \times 10^{-3}$ \\
6 & $3.00 \times 10^{-10}$ & $8.40 \times 10^{-1}$ & $2.40 \times 10^{-5}$ & $2.15 \times 10^{-5}$ & $5.01 \times 10^{-6}$ & $3.17 \times 10^{-3}$ \\
\hline
\end{tabular}

TABle E.2.5-2_Conditional Probabilities and Release Fractions for Heavy Water Reactor Spent Nuclear Fuel Shipments-Truck Cask

\begin{tabular}{ccccccc}
\hline Accident & Conditional & \multicolumn{5}{c}{ Release Fraction } \\
\cline { 3 - 7 } Severity Cat. & Probability & Inert Gas & Cesium & Ruthenium & Particulates & Crud \\
\hline 1 & 0.99993 & 0.0 & 0.0 & 0.0 & 0.0 & 0.0 \\
2 & $6.22 \times 10^{-5}$ & $5.66 \times 10^{-5}$ & $3.54 \times 10^{-7}$ & $2.29 \times 10^{-8}$ & $1.83 \times 10^{-9}$ & $5.71 \times 10^{-6}$ \\
3 & $5.59 \times 10^{-6}$ & 0.0 & 0.0 & 0.0 & 0.0 & 0.0 \\
4 & $5.60 \times 10^{-7}$ & $7.86 \times 10^{-4}$ & $1.42 \times 10^{-7}$ & $6.63 \times 10^{-8}$ & $5.80 \times 10^{-8}$ & $1.93 \times 10^{-4}$ \\
5 & $6.99 \times 10^{-8}$ & $4.00 \times 10^{-3}$ & $7.87 \times 10^{-5}$ & $4.72 \times 10^{-6}$ & $3.20 \times 10^{-8}$ & $6.35 \times 10^{-5}$ \\
6 & $2.24 \times 10^{-10}$ & $7.70 \times 10^{-3}$ & $2.74 \times 10^{-4}$ & $7.57 \times 10^{-5}$ & $3.68 \times 10^{-7}$ & $1.13 \times 10^{-3}$ \\
\hline
\end{tabular}


TABLE E.2.5-3-Conditional Probabilities and Release Fractions for High Temperature GasCooled Reactor Spent Nuclear Fuel Shipments-Truck Cask

\begin{tabular}{ccccccc}
\hline Accident & Conditional & \multicolumn{5}{c}{ Release Fraction } \\
\cline { 3 - 7 } Severity Cat. & Probability & Inert Gas & Cesium & Ruthenium & Particulates & Crud \\
\hline 1 & 0.99993 & 0.0 & 0.0 & 0.0 & 0.0 & 0.0 \\
2 & $6.22 \times 10^{-5}$ & 0.0 & 0.0 & 0.0 & 0.0 & 0.0 \\
3 & $5.59 \times 10^{-6}$ & 0.0 & 0.0 & 0.0 & 0.0 & 0.0 \\
4 & $5.60 \times 10^{-7}$ & $7.50 \times 10^{-4}$ & $5.63 \times 10^{-10}$ & $5.63 \times 10^{-10}$ & $5.63 \times 10^{-10}$ & 0.0 \\
5 & $6.99 \times 10^{-8}$ & 0.0 & 0.0 & 0.0. & 0.0 & 0.0 \\
6 & $2.24 \times 10^{-10}$ & $3.52 \times 10^{-3}$ & $2.72 \times 10^{-9}$ & $2.64 \times 10^{-9}$ & $2.64 \times 10^{-9}$ & 0.0 \\
\hline
\end{tabular}

Source: BMI 2007

TABLE E 2.5-4-Conditional Probabilities and Release Fractions for Light Water Reactor Spent Nuclear Fuel, Mixed-Oxide Spent Nuclear Fuel, and Thorium Cycle Spent Nuclear Fuel Shipments-Rail Cask

\begin{tabular}{ccccccc}
\hline Accident & Conditional & \multicolumn{5}{c}{ Release Fraction } \\
\cline { 3 - 7 } Severity Cat. & Probability & Inert Gas & Cesium & Ruthenium & Particulates & Crud \\
\hline 1 & 0.9991 & 0.0 & 0.0 & 0.0 & 0.0 & 0.0 \\
2 & $3.87 \times 10^{-5}$ & $1.96 \times 10^{-1}$ & $5.87 \times 10^{-9}$ & $1.34 \times 10^{-7}$ & $1.34 \times 10^{-7}$ & $1.37 \times 10^{-3}$ \\
3 & $4.91 \times 10^{-5}$ & $8.39 \times 10^{-1}$ & $1.68 \times 10^{-5}$ & $2.52 \times 10^{-7}$ & $2.52 \times 10^{-7}$ & $9.44 \times 10^{-3}$ \\
4 & $5.77 \times 10^{-7}$ & $8.00 \times 10^{-1}$ & $8.71 \times 10^{-6}$ & $1.32 \times 10^{-5}$ & $1.32 \times 10^{-5}$ & $4.42 \times 10^{-3}$ \\
5 & $1.10 \times 10^{-7}$ & $8.35 \times 10^{-1}$ & $3.60 \times 10^{-5}$ & $4.63 \times 10^{-5}$ & $1.37 \times 10^{-5}$ & $5.36 \times 10^{-3}$ \\
6 & $8.52 \times 10^{-10}$ & $8.47 \times 10^{-1}$ & $5.71 \times 10^{-5}$ & $1.43 \times 10^{-5}$ & $1.43 \times 10^{-5}$ & $1.59 \times 10^{-2}$ \\
\hline Source: BMI 2007 & & & & & &
\end{tabular}

TABLE E.2.5-5-Conditional Probabilities and Release Fractions for Heavy Water Reactor Spent Nuclear Fuel Shipments-Rail Cask

\begin{tabular}{ccccccc}
\hline Accident & Conditional & \multicolumn{5}{c}{ Release Fraction } \\
\cline { 3 - 7 } Severity Cat. & Probability & Inert Gas & Cesium & Ruthenium & Particulates & Crud \\
\hline 1 & 0.9991 & 0.0 & 0.0 & 0.0 & 0.0 & 0.0 \\
2 & $3.87 \times 10^{-5}$ & $2.84 \times 10^{-4}$ & $1.71 \times 10^{-6}$ & $3.91 \times 10^{-7}$ & $1.10 \times 10^{-8}$ & $2.96 \times 10^{-5}$ \\
3 & $4.91 \times 10^{-5}$ & 0.0 & 0.0 & 0.0 & 0.0 & 0.0 \\
4 & $5.77 \times 10^{-7}$ & $2.13 \times 10^{-3}$ & $2.36 \times 10^{-6}$ & $3.55 \times 10^{-6}$ & $3.55 \times 10^{-6}$ & $1.18 \times 10^{-2}$ \\
5 & $1.10 \times 10^{-7}$ & $4.00 \times 10^{-3}$ & $7.87 \times 10^{-5}$ & $1.77 \times 10^{-5}$ & $9.68 \times 10^{-8}$ & $1.61 \times 10^{-4}$ \\
6 & $8.52 \times 10^{-10}$ & $4.68 \times 10^{-2}$ & $9.63 \times 10^{-4}$ & $2.47 \times 10^{-4}$ & $2.73 \times 10^{-6}$ & $7.17 \times 10^{-3}$ \\
\hline Source: BMI 2007 & & & & & &
\end{tabular}

TABLE E.2.5-6-Conditional Probabilities and Release Fractions for High Temperature Gas-Cooled Reactor Spent Nuclear Fuel Shipments-Rail Cask

\begin{tabular}{ccccccc}
\hline Accident & Conditional & \multicolumn{5}{c}{ Release Fraction } \\
\cline { 3 - 7 } Severity Cat. & Probability & Inert Gas & Cesium & Ruthenium & Particulates & Crud \\
\hline 1 & 0.9991 & 0.0 & 0.0 & 0.0 & 0.0 & 0.0 \\
2 & $3.87 \times 10^{-5}$ & $1.02 \times 10^{-4}$ & $6.12 \times 10^{-11}$ & $6.12 \times 10^{-11}$ & $6.12 \times 10^{-11}$ & 0.0 \\
3 & $4.91 \times 10^{-5}$ & 0.0 & 0.0 & 0.0 & 0.0 & 0.0 \\
4 & $5.77 \times 10^{-7}$ & $4.77 \times 10^{-3}$ & $7.89 \times 10^{-8}$ & $7.89 \times 10^{-8}$ & $7.89 \times 10^{-8}$ & 0.0 \\
5 & $1.10 \times 10^{-7}$ & 0.0 & 0.0 & 0.0 & 0.0 & 0.0 \\
6 & $8.52 \times 10^{-10}$ & $1.70 \times 10^{-3}$ & $2.84 \times 10^{-8}$ & $2.62 \times 10^{-8}$ & $2.62 \times 10^{-8}$ & 0.0 \\
\hline
\end{tabular}


TABLE E.2.5-7-Conditional Probabilities and Release Fractions for High-Level Radioactive Waste Canister Shipments

\begin{tabular}{ccccc}
\hline Severity & \multicolumn{2}{c}{ Truck } & \multicolumn{2}{c}{ Rail } \\
\cline { 2 - 5 } Category & Conditional Probability & Release Fraction & Conditional Probability & Release Fraction \\
\hline 1 & 0.99993 & 0 & 0.99991 & 0 \\
2 & $6.2 \times 10^{-5}$ & $3.4 \times 10^{-8}$ & $3.9 \times 10^{-5}$ & $6.2 \times 10^{-8}$ \\
3 & $5.6 \times 10^{-6}$ & 0 & $4.9 \times 10^{-5}$ & 0 \\
4 & $5.2 \times 10^{-7}$ & $2.4 \times 10^{-7}$ & $5.8 \times 10^{-7}$ & $7.9 \times 10^{-6}$ \\
5 & $7.0 \times 10^{-8}$ & $9.3 \times 10^{-8}$ & $1.1 \times 10^{-7}$ & $9.3 \times 10^{-8}$ \\
6 & $2.2 \times 10^{-10}$ & $3.0 \times 10^{-7}$ & $8.5 \times 10^{-10}$ & $2.7 \times 10^{-6}$ \\
\hline
\end{tabular}

Source: DOE 2004f

TABLE E.2.5-8 - Conditional Probabilities and Release Fractions for 9975 Container Shipments

\begin{tabular}{ccccc}
\hline \multirow{2}{*}{$\begin{array}{c}\text { Severity } \\
\text { Category }\end{array}$} & Truck & \multicolumn{2}{c}{ Rail } \\
\cline { 2 - 5 } & Conditional Probability & Release Fraction & Conditional Probability & Release Fraction \\
\hline 1 & 0.99993 & 0 & 0.99991 & 0 \\
2 & $6.2 \times 10^{-5}$ & $2.6 \times 10^{-5}$ & $3.9 \times 10^{-5}$ & $2.5 \times 10^{-5}$ \\
3 & $5.6 \times 10^{-6}$ & $2.4 \times 10^{-5}$ & $4.9 \times 10^{-5}$ & $5.6 \times 10^{-6}$ \\
4 & $5.2 \times 10^{-7}$ & $2.6 \times 10^{-5}$ & $5.8 \times 10^{-7}$ & $5.2 \times 10^{-7}$ \\
5 & $7.0 \times 10^{-8}$ & $6.2 \times 10^{-5}$ & $1.1 \times 10^{-7}$ & $7.0 \times 10^{-8}$ \\
6 & $2.2 \times 10^{-10}$ & $6.7 \times 10^{-5}$ & $8.5 \times 10^{-10}$ & $2.2 \times 10^{-10}$ \\
\hline
\end{tabular}

Source: DOE 2004f

TABLE E.2.5-9—Conditional Probabilities and Release Fractions for Class B Cask for Fresh MOX Fuel

\begin{tabular}{ccc}
\hline \multirow{2}{*}{$\begin{array}{c}\text { Severity } \\
\text { Category }\end{array}$} & \multicolumn{2}{c}{ Truck } \\
\cline { 2 - 3 } & Conditional Probability & Release Fraction \\
\hline 1 & 0.99993 & 0 \\
3 & $6.2 \times 10^{-5}$ & $6 \times 10^{-8}$ \\
4 & $5.6 \times 10^{-6}$ & $2 \times 10^{-7}$ \\
5 & $5.2 \times 10^{-7}$ & $2 \times 10^{-6}$ \\
6 & $7.0 \times 10^{-8}$ & $2 \times 10^{-5}$ \\
Source: NRC 2005c & $2.2 \times 10^{-10}$ & $2 \times 10^{-5}$ \\
\hline
\end{tabular}


TABLE E.2.5-10—Per-Shipment Accident Impacts-Domestic Programmatic Alternative Scenarios-All-Truck Option

\begin{tabular}{|c|c|c|c|c|c|}
\hline \multirow{2}{*}{ Material Type } & \multirow{2}{*}{ Mileage } & \multicolumn{2}{|c|}{ Radiological Accident Impacts } & \multirow{2}{*}{$\begin{array}{c}\text { Estimated } \\
\text { Number of } \\
\text { Accidents }\end{array}$} & \multirow{2}{*}{$\begin{array}{c}\text { Collision } \\
\text { Fatalities } \\
\text { (Nonradiological) }\end{array}$} \\
\hline & & Person-Rem & LCFs & & \\
\hline \multirow{5}{*}{ LWR SNF } & 150 & $1.24 \times 10^{-6}$ & $7 \times 10^{-10}$ & $1.14 \times 10^{-4}$ & $6.13 \times 10^{-6}$ \\
\hline & 500 & $4.13 \times 10^{-6}$ & $2 \times 10^{-9}$ & $3.89 \times 10^{-4}$ & $2.04 \times 10^{-5}$ \\
\hline & 1,500 & $1.25 \times 10^{-5}$ & $7 \times 10^{-9}$ & 0.00117 & $6.13 \times 10^{-5}$ \\
\hline & 2,100 & $1.69 \times 10^{-5}$ & $1 \times 10^{-8}$ & 0.00164 & $8.58 \times 10^{-5}$ \\
\hline & 3,000 & $2.48 \times 10^{-5}$ & $1 \times 10^{-8}$ & 0.00234 & $1.23 \times 10^{-4}$ \\
\hline \multirow{5}{*}{ MOX SNF } & 150 & $9.94 \times 10^{-7}$ & $6 \times 10^{-10}$ & $1.14 \times 10^{-4}$ & $6.13 \times 10^{-6}$ \\
\hline & 500 & $3.31 \times 10^{-6}$ & $2 \times 10^{-9}$ & $3.89 \times 10^{-4}$ & $2.04 \times 10^{-5}$ \\
\hline & 1,500 & $9.93 \times 10^{-6}$ & $6 \times 10^{-9}$ & 0.00117 & $6.13 \times 10^{-5}$ \\
\hline & 2,100 & $1.39 \times 10^{-5}$ & $8 \times 10^{-9}$ & 0.00164 & $8.58 \times 10^{-5}$ \\
\hline & 3,000 & $1.99 \times 10^{-5}$ & $1 \times 10^{-8}$ & 0.00234 & $1.23 \times 10^{-4}$ \\
\hline \multirow{5}{*}{$\begin{array}{l}\text { Thorium cycle } \\
\text { SNF }\end{array}$} & 150 & $6.32 \times 10^{-8}$ & $4 \times 10^{-11}$ & $1.14 \times 10^{-4}$ & $6.13 \times 10^{-6}$ \\
\hline & 500 & $2.10 \times 10^{-7}$ & $1 \times 10^{-10}$ & $3.89 \times 10^{-4}$ & $2.04 \times 10^{-5}$ \\
\hline & 1,500 & $6.31 \times 10^{-7}$ & $4 \times 10^{-10}$ & 0.00117 & $6.13 \times 10^{-5}$ \\
\hline & 2,100 & $8.83 \times 10^{-7}$ & $5 \times 10^{-10}$ & 0.00164 & $8.58 \times 10^{-5}$ \\
\hline & 3,000 & $1.26 \times 10^{-6}$ & $8 \times 10^{-10}$ & 0.00234 & $1.23 \times 10^{-4}$ \\
\hline \multirow{5}{*}{ HWR SNF } & 150 & $2.14 \times 10^{-8}$ & $1 \times 10^{-11}$ & $1.14 \times 10^{-4}$ & $6.13 \times 10^{-6}$ \\
\hline & 500 & $7.12 \times 10^{-8}$ & $4 \times 10^{-11}$ & $3.89 \times 10^{-4}$ & $2.04 \times 10^{-5}$ \\
\hline & 1,500 & $2.14 \times 10^{-7}$ & $1 \times 10^{-10}$ & 0.00117 & $6.13 \times 10^{-5}$ \\
\hline & 2,100 & $3.00 \times 10^{-7}$ & $2 \times 10^{-10}$ & 0.00164 & $8.58 \times 10^{-5}$ \\
\hline & 3,000 & $4.27 \times 10^{-7}$ & $3 \times 10^{-10}$ & 0.00234 & $1.23 \times 10^{-4}$ \\
\hline \multirow{5}{*}{ HTGR SNF } & 150 & $3.75 \times 10^{-12}$ & $2 \times 10^{-15}$ & $1.14 \times 10^{-4}$ & $6.13 \times 10^{-6}$ \\
\hline & 500 & $1.25 \times 10^{-11}$ & $8 \times 10^{-15}$ & $3.89 \times 10^{-4}$ & $2.04 \times 10^{-5}$ \\
\hline & 1,500 & $3.75 \times 10^{-11}$ & $2 \times 10^{-14}$ & 0.00117 & $6.13 \times 10^{-5}$ \\
\hline & 2,100 & $5.24 \times 10^{-11}$ & $3 \times 10^{-14}$ & 0.00164 & $8.58 \times 10^{-5}$ \\
\hline & 3,000 & $7.48 \times 10^{-11}$ & $4 \times 10^{-14}$ & 0.00234 & $1.23 \times 10^{-4}$ \\
\hline \multirow{5}{*}{$\begin{array}{l}\text { Fresh } \\
\text { Transmutation } \\
\text { Fuel }\end{array}$} & 150 & $9.91 \times 10^{-7}$ & $6 \times 10^{-10}$ & $1.14 \times 10^{-4}$ & $6.13 \times 10^{-6}$ \\
\hline & 500 & $3.30 \times 10^{-6}$ & $2 \times 10^{-9}$ & $3.89 \times 10^{-4}$ & $2.04 \times 10^{-5}$ \\
\hline & 1,500 & $9.85 \times 10^{-6}$ & $6 \times 10^{-9}$ & 0.00117 & $6.13 \times 10^{-5}$ \\
\hline & 2,100 & $1.39 \times 10^{-5}$ & $8 \times 10^{-9}$ & 0.00164 & $8.58 \times 10^{-5}$ \\
\hline & 3,000 & $1.97 \times 10^{-5}$ & $1 \times 10^{-8}$ & 0.00234 & $1.23 \times 10^{-4}$ \\
\hline \multirow{5}{*}{ Fresh MOX Fuel } & 150 & $1.06 \times 10^{-11}$ & $6 \times 10^{-15}$ & $1.14 \times 10^{-4}$ & $6.13 \times 10^{-6}$ \\
\hline & 500 & $3.54 \times 10^{-11}$ & $2 \times 10^{-14}$ & $3.89 \times 10^{-4}$ & $2.04 \times 10^{-5}$ \\
\hline & 1,500 & $1.06 \times 10^{-10}$ & $6 \times 10^{-14}$ & 0.00117 & $6.13 \times 10^{-5}$ \\
\hline & 2,100 & $1.49 \times 10^{-10}$ & $9 \times 10^{-14}$ & 0.00164 & $8.58 \times 10^{-5}$ \\
\hline & 3,000 & $2.12 \times 10^{-10}$ & $1 \times 10^{-13}$ & 0.00234 & $1.23 \times 10^{-4}$ \\
\hline \multirow{5}{*}{$\begin{array}{l}\text { Am oxide } \\
\text { product }\end{array}$} & 150 & $2.93 \times 10^{-8}$ & $2 \times 10^{-11}$ & $1.14 \times 10^{-4}$ & $6.13 \times 10^{-6}$ \\
\hline & 500 & $9.74 \times 10^{-8}$ & $6 \times 10^{-11}$ & $3.89 \times 10^{-4}$ & $2.04 \times 10^{-5}$ \\
\hline & 1,500 & $2.92 \times 10^{-7}$ & $2 \times 10^{-10}$ & 0.00117 & $6.13 \times 10^{-5}$ \\
\hline & 2,100 & $4.10 \times 10^{-7}$ & $2 \times 10^{-10}$ & 0.00164 & $8.58 \times 10^{-5}$ \\
\hline & 3,000 & $5.84 \times 10^{-7}$ & $4 \times 10^{-10}$ & 0.00234 & $1.23 \times 10^{-4}$ \\
\hline \multirow{5}{*}{$\mathrm{Cm}$ oxide product } & 150 & $1.77 \times 10^{-7}$ & $1 \times 10^{-10}$ & $1.14 \times 10^{-4}$ & $6.13 \times 10^{-6}$ \\
\hline & 500 & $5.90 \times 10^{-7}$ & $4 \times 10^{-10}$ & $3.89 \times 10^{-4}$ & $2.04 \times 10^{-5}$ \\
\hline & 1,500 & $1.76 \times 10^{-6}$ & $1 \times 10^{-9}$ & 0.00117 & $6.13 \times 10^{-5}$ \\
\hline & 2,100 & $2.48 \times 10^{-6}$ & $1 \times 10^{-9}$ & 0.00164 & $8.58 \times 10^{-5}$ \\
\hline & 3,000 & $3.52 \times 10^{-6}$ & $2 \times 10^{-9}$ & 0.00234 & $1.23 \times 10^{-4}$ \\
\hline \multirow{5}{*}{$\begin{array}{l}\mathrm{Pu} / \mathrm{Np} \text { oxide } \\
\text { product }\end{array}$} & 150 & $8.19 \times 10^{-8}$ & $4 \times 10^{-11}$ & $1.14 \times 10^{-4}$ & $6.13 \times 10^{-6}$ \\
\hline & 500 & $2.73 \times 10^{-7}$ & $2 \times 10^{-10}$ & $3.89 \times 10^{-4}$ & $2.04 \times 10^{-5}$ \\
\hline & 1,500 & $8.14 \times 10^{-7}$ & $5 \times 10^{-10}$ & 0.00117 & $6.13 \times 10^{-5}$ \\
\hline & 2,100 & $1.15 \times 10^{-6}$ & $7 \times 10^{-10}$ & 0.00164 & $8.58 \times 10^{-5}$ \\
\hline & 3,000 & $1.63 \times 10^{-6}$ & $1 \times 10^{-9}$ & 0.00234 & $1.23 \times 10^{-4}$ \\
\hline
\end{tabular}


TABLE E.2.5-10—Per-Shipment Accident Impacts-Domestic Programmatic Alternative Scenarios-All-Truck Option (continued)

\begin{tabular}{|c|c|c|c|c|c|}
\hline \multirow[b]{2}{*}{ Material Type } & \multirow[b]{2}{*}{ Mileage } & \multicolumn{2}{|c|}{ Radiological Accident Impacts } & \multirow{2}{*}{$\begin{array}{l}\text { Estimated } \\
\text { Number of } \\
\text { Accidents }\end{array}$} & \multirow{2}{*}{$\begin{array}{c}\text { Collision } \\
\text { Fatalities } \\
\text { (Nonradiological) }\end{array}$} \\
\hline & & Person-Rem & LCFs & & \\
\hline \multirow{5}{*}{$\begin{array}{l}\text { Consolidated } \\
\text { TRU/U product }\end{array}$} & 150 & $9.09 \times 10^{-9}$ & $5 \times 10^{-12}$ & $1.14 \times 10^{-4}$ & $6.13 \times 10^{-6}$ \\
\hline & 500 & $3.03 \times 10^{-8}$ & $2 \times 10^{-11}$ & $3.89 \times 10^{-4}$ & $2.04 \times 10^{-5}$ \\
\hline & 1,500 & $9.03 \times 10^{-8}$ & $5 \times 10^{-11}$ & 0.00117 & $6.13 \times 10^{-5}$ \\
\hline & 2,100 & $1.27 \times 10^{-7}$ & $8 \times 10^{-11}$ & 0.00164 & $8.58 \times 10^{-5}$ \\
\hline & 3,000 & $1.81 \times 10^{-7}$ & $1 \times 10^{-10}$ & 0.00234 & $1.23 \times 10^{-4}$ \\
\hline \multirow{5}{*}{$\mathrm{Cs} / \mathrm{Sr}$ waste } & 150 & $7.11 \times 10^{-7}$ & $4 \times 10^{-10}$ & $1.14 \times 10^{-4}$ & $6.13 \times 10^{-6}$ \\
\hline & 500 & $2.36 \times 10^{-6}$ & $1 \times 10^{-9}$ & $3.89 \times 10^{-4}$ & $2.04 \times 10^{-5}$ \\
\hline & 1,500 & $7.09 \times 10^{-6}$ & $4 \times 10^{-9}$ & 0.00117 & $6.13 \times 10^{-5}$ \\
\hline & 2,100 & $9.69 \times 10^{-6}$ & $6 \times 10^{-9}$ & 0.00164 & $8.58 \times 10^{-5}$ \\
\hline & 3,000 & $1.42 \times 10^{-5}$ & $9 \times 10^{-9}$ & 0.00234 & $1.23 \times 10^{-4}$ \\
\hline \multirow{5}{*}{$\begin{array}{l}\text { Ln/fission } \\
\text { products waste }\end{array}$} & 150 & $2.06 \times 10^{-9}$ & $1 \times 10^{-12}$ & $1.14 \times 10^{-4}$ & $6.13 \times 10^{-6}$ \\
\hline & 500 & $6.87 \times 10^{-9}$ & $4 \times 10^{-12}$ & $3.89 \times 10^{-4}$ & $2.04 \times 10^{-5}$ \\
\hline & 1,500 & $2.06 \times 10^{-8}$ & $1 \times 10^{-11}$ & 0.00117 & $6.13 \times 10^{-5}$ \\
\hline & 2,100 & $2.92 \times 10^{-8}$ & $2 \times 10^{-11}$ & 0.00164 & $8.58 \times 10^{-5}$ \\
\hline & 3,000 & $4.12 \times 10^{-8}$ & $2 \times 10^{-11}$ & 0.00234 & $1.23 \times 10^{-4}$ \\
\hline \multirow{5}{*}{$\begin{array}{l}\text { Tc/UDS/hulls } \\
\text { waste }\end{array}$} & 150 & $1.92 \times 10^{-8}$ & $1 \times 10^{-11}$ & $1.14 \times 10^{-4}$ & $6.13 \times 10^{-6}$ \\
\hline & 500 & $6.38 \times 10^{-8}$ & $4 \times 10^{-11}$ & $3.89 \times 10^{-4}$ & $2.04 \times 10^{-5}$ \\
\hline & 1,500 & $1.92 \times 10^{-7}$ & $1 \times 10^{-10}$ & 0.00117 & $6.13 \times 10^{-5}$ \\
\hline & 2,100 & $2.14 \times 10^{-7}$ & $2 \times 10^{-10}$ & 0.00164 & $8.58 \times 10^{-5}$ \\
\hline & 3,000 & $3.83 \times 10^{-7}$ & $2 \times 10^{-10}$ & 0.00234 & $1.23 \times 10^{-4}$ \\
\hline \multirow{5}{*}{$\begin{array}{l}\text { GTCC LLW } \\
\text { AND MLLW }\end{array}$} & 150 & $1.17 \times 10^{-10}$ & $7 \times 10^{-14}$ & $1.14 \times 10^{-4}$ & $6.13 \times 10^{-6}$ \\
\hline & 500 & $3.88 \times 10^{-10}$ & $2 \times 10^{-13}$ & $3.89 \times 10^{-4}$ & $2.04 \times 10^{-5}$ \\
\hline & 1,500 & $1.16 \times 10^{-9}$ & $7 \times 10^{-13}$ & 0.00117 & $6.13 \times 10^{-5}$ \\
\hline & 2,100 & $1.62 \times 10^{-9}$ & $9 \times 10^{-13}$ & 0.00164 & $8.58 \times 10^{-5}$ \\
\hline & 3,000 & $2.33 \times 10^{-9}$ & $1 \times 10^{-12}$ & 0.00234 & $1.23 \times 10^{-4}$ \\
\hline \multirow{5}{*}{ Fast reactor SNF } & 150 & $1.02 \times 10^{-4}$ & $6 \times 10^{-8}$ & $1.14 \times 10^{-4}$ & $6.13 \times 10^{-6}$ \\
\hline & 500 & $3.40 \times 10^{-4}$ & $2 \times 10^{-7}$ & $3.89 \times 10^{-4}$ & $2.04 \times 10^{-5}$ \\
\hline & 1,500 & $1.02 \times 10^{-3}$ & $6 \times 10^{-7}$ & 0.00117 & $6.13 \times 10^{-5}$ \\
\hline & 2,100 & $1.43 \times 10^{-3}$ & $9 \times 10^{-7}$ & 0.00164 & $8.58 \times 10^{-5}$ \\
\hline & 3,000 & $2.04 \times 10^{-3}$ & $1 \times 10^{-6}$ & 0.00234 & $1.23 \times 10^{-4}$ \\
\hline \multirow{5}{*}{$\begin{array}{l}\text { Recovered } \\
\text { uranium oxides }\end{array}$} & 150 & $9.87 \times 10^{-14}$ & $6 \times 10^{-17}$ & $1.14 \times 10^{-4}$ & $6.13 \times 10^{-6}$ \\
\hline & 500 & $3.28 \times 10^{-13}$ & $2 \times 10^{-16}$ & $3.89 \times 10^{-4}$ & $2.04 \times 10^{-5}$ \\
\hline & 1,500 & $9.85 \times 10^{-13}$ & $6 \times 10^{-16}$ & 0.00117 & $6.13 \times 10^{-5}$ \\
\hline & 2,100 & $1.38 \times 10^{-12}$ & $8 \times 10^{-16}$ & 0.00164 & $8.58 \times 10^{-5}$ \\
\hline & 3,000 & $1.97 \times 10^{-12}$ & $1 \times 10^{-15}$ & 0.00234 & $1.23 \times 10^{-4}$ \\
\hline \multirow{5}{*}{$\begin{array}{l}\text { Recovered } \\
\text { uranium metal }\end{array}$} & 150 & $1.11 \times 10^{-13}$ & $7 \times 10^{-17}$ & $1.14 \times 10^{-4}$ & $6.13 \times 10^{-6}$ \\
\hline & 500 & $3.70 \times 10^{-13}$ & $2 \times 10^{-16}$ & $3.89 \times 10^{-4}$ & $2.04 \times 10^{-5}$ \\
\hline & 1,500 & $1.11 \times 10^{-12}$ & $7 \times 10^{-16}$ & 0.00117 & $6.13 \times 10^{-5}$ \\
\hline & 2,100 & $1.55 \times 10^{-12}$ & $9 \times 10^{-16}$ & 0.00164 & $8.58 \times 10^{-5}$ \\
\hline & 3,000 & $2.22 \times 10^{-12}$ & $1 \times 10^{-15}$ & 0.00234 & $1.23 \times 10^{-4}$ \\
\hline
\end{tabular}

Source: Tetra Tech 2008f 
TABLE E.2.5-11-Per-Shipment Accident Impacts-Domestic Programmatic Alternative Scenarios-All-Rail Option

\begin{tabular}{|c|c|c|c|c|c|}
\hline \multirow{2}{*}{ Material Type } & \multirow{2}{*}{ Mileage } & \multicolumn{2}{|c|}{ Radiological Accident Impacts } & \multirow{2}{*}{$\begin{array}{l}\text { Estimated Number } \\
\text { of Accidents }\end{array}$} & \multirow{2}{*}{$\begin{array}{l}\text { Collision Fatalities } \\
\text { (Nonradiological) }\end{array}$} \\
\hline & & Person-Rem & LCFs & & \\
\hline \multirow{5}{*}{ LWR SNF } & 150 & $9.43 \times 10^{-7}$ & $6 \times 10^{-10}$ & $2.65 \times 10^{-5}$ & $1 \times 10^{-5}$ \\
\hline & 500 & $3.13 \times 10^{-6}$ & $2 \times 10^{-9}$ & $8.84 \times 10^{-5}$ & $3 \times 10^{-5}$ \\
\hline & 1,500 & $9.37 \times 10^{-6}$ & $6 \times 10^{-9}$ & $2.65 \times 10^{-4}$ & $1 \times 10^{-4}$ \\
\hline & 2,100 & $1.31 \times 10^{-5}$ & $8 \times 10^{-9}$ & $3.71 \times 10^{-4}$ & $1 \times 10^{-4}$ \\
\hline & 3,000 & $1.87 \times 10^{-5}$ & $1 \times 10^{-8}$ & $5.30 \times 10^{-4}$ & $2 \times 10^{-4}$ \\
\hline \multirow{5}{*}{ MOX SNF } & 150 & $3.14 \times 10^{-6}$ & $2 \times 10^{-9}$ & $2.65 \times 10^{-5}$ & $1 \times 10^{-5}$ \\
\hline & 500 & $1.04 \times 10^{-5}$ & $6 \times 10^{-9}$ & $8.84 \times 10^{-5}$ & $3 \times 10^{-5}$ \\
\hline & 1,500 & $3.12 \times 10^{-5}$ & $2 \times 10^{-9}$ & $2.65 \times 10^{-4}$ & $1 \times 10^{-4}$ \\
\hline & 2,100 & $4.37 \times 10^{-5}$ & $3 \times 10^{-9}$ & $3.71 \times 10^{-4}$ & $1 \times 10^{-4}$ \\
\hline & 3,000 & $6.24 \times 10^{-5}$ & $4 \times 10^{-8}$ & $5.30 \times 10^{-4}$ & $2 \times 10^{-4}$ \\
\hline \multirow{5}{*}{$\begin{array}{l}\text { Thorium cycle } \\
\text { SNF }\end{array}$} & 150 & $3.90 \times 10^{-7}$ & $2 \times 10^{-10}$ & $2.65 \times 10^{-5}$ & $1 \times 10^{-5}$ \\
\hline & 500 & $1.30 \times 10^{-6}$ & $8 \times 10^{-10}$ & $8.84 \times 10^{-5}$ & $3 \times 10^{-5}$ \\
\hline & 1,500 & $3.88 \times 10^{-6}$ & $2 \times 10^{-9}$ & $2.65 \times 10^{-4}$ & $1 \times 10^{-4}$ \\
\hline & 2,100 & $5.43 \times 10^{-6}$ & $3 \times 10^{-9}$ & $3.71 \times 10^{-4}$ & $1 \times 10^{-4}$ \\
\hline & 3,000 & $7.76 \times 10^{-6}$ & $5 \times 10^{-8}$ & $5.30 \times 10^{-4}$ & $2 \times 10^{-4}$ \\
\hline \multirow{5}{*}{ HWR SNF } & 150 & $5.55 \times 10^{-7}$ & $3 \times 10^{-10}$ & $2.65 \times 10^{-5}$ & $1 \times 10^{-5}$ \\
\hline & 500 & $1.84 \times 10^{-6}$ & $1 \times 10^{-9}$ & $8.84 \times 10^{-5}$ & $3 \times 10^{-5}$ \\
\hline & 1,500 & $5.52 \times 10^{-6}$ & $3 \times 10^{-9}$ & $2.65 \times 10^{-4}$ & $1 \times 10^{-4}$ \\
\hline & 2,100 & $7.73 \times 10^{-6}$ & $5 \times 10^{-9}$ & $3.71 \times 10^{-4}$ & $1 \times 10^{-4}$ \\
\hline & 3,000 & $1.10 \times 10^{-5}$ & $7 \times 10^{-9}$ & $5.30 \times 10^{-4}$ & $2 \times 10^{-4}$ \\
\hline \multirow{5}{*}{ HTGR SNF } & 150 & $9.45 \times 10^{-10}$ & $6 \times 10^{-13}$ & $2.65 \times 10^{-5}$ & $1 \times 10^{-5}$ \\
\hline & 500 & $3.13 \times 10^{-9}$ & $2 \times 10^{-12}$ & $8.84 \times 10^{-5}$ & $3 \times 10^{-5}$ \\
\hline & 1,500 & $9.39 \times 10^{-9}$ & $6 \times 10^{-12}$ & $2.65 \times 10^{-4}$ & $1 \times 10^{-4}$ \\
\hline & 2,100 & $1.31 \times 10^{-8}$ & $8 \times 10^{-12}$ & $3.71 \times 10^{-4}$ & $1 \times 10^{-4}$ \\
\hline & 3,000 & $1.88 \times 10^{-8}$ & $1 \times 10^{-11}$ & $5.30 \times 10^{-4}$ & $2 \times 10^{-4}$ \\
\hline \multirow{5}{*}{ Am oxide product } & 150 & $2.78 \times 10^{-6}$ & $2 \times 10^{-9}$ & $2.65 \times 10^{-5}$ & $1 \times 10^{-5}$ \\
\hline & 500 & $9.28 \times 10^{-6}$ & $6 \times 10^{-9}$ & $8.84 \times 10^{-5}$ & $3 \times 10^{-5}$ \\
\hline & 1,500 & $2.80 \times 10^{-5}$ & $2 \times 10^{-8}$ & $2.65 \times 10^{-4}$ & $1 \times 10^{-4}$ \\
\hline & 2,100 & $3.89 \times 10^{-5}$ & $2 \times 10^{-8}$ & $3.71 \times 10^{-4}$ & $1 \times 10^{-4}$ \\
\hline & 3,000 & $5.59 \times 10^{-5}$ & $3 \times 10^{-8}$ & $5.30 \times 10^{-4}$ & $2 \times 10^{-4}$ \\
\hline \multirow{5}{*}{$\mathrm{Cm}$ oxide product } & 150 & $1.14 \times 10^{-5}$ & $7 \times 10^{-9}$ & $2.65 \times 10^{-5}$ & $1 \times 10^{-5}$ \\
\hline & 500 & $3.81 \times 10^{-5}$ & $2 \times 10^{-8}$ & $8.84 \times 10^{-5}$ & $3 \times 10^{-5}$ \\
\hline & 1,500 & $1.15 \times 10^{-4}$ & $7 \times 10^{-8}$ & $2.65 \times 10^{-4}$ & $1 \times 10^{-4}$ \\
\hline & 2,100 & $1.59 \times 10^{-4}$ & $1 \times 10^{-7}$ & $3.71 \times 10^{-4}$ & $1 \times 10^{-4}$ \\
\hline & 3,000 & $2.29 \times 10^{-4}$ & $1 \times 10^{-7}$ & $5.30 \times 10^{-4}$ & $2 \times 10^{-4}$ \\
\hline \multirow{5}{*}{$\mathrm{Cs} / \mathrm{Sr}$ waste } & 150 & $6.06 \times 10^{-6}$ & $4 \times 10^{-9}$ & $1.33 \times 10^{-5}$ & $5.12 \times 10^{-6}$ \\
\hline & 500 & $2.01 \times 10^{-5}$ & $1 \times 10^{-8}$ & $4.42 \times 10^{-5}$ & $1.71 \times 10^{-5}$ \\
\hline & 1,500 & $6.04 \times 10^{-5}$ & $4 \times 10^{-8}$ & $1.33 \times 10^{-4}$ & $5.12 \times 10^{-5}$ \\
\hline & 2,100 & $8.46 \times 10^{-5}$ & $5 \times 10^{-8}$ & $1.86 \times 10^{-4}$ & $7.17 \times 10^{-5}$ \\
\hline & 3,000 & $1.21 \times 10^{-4}$ & $7 \times 10^{-8}$ & $2.65 \times 10^{-4}$ & $1.02 \times 10^{-4}$ \\
\hline
\end{tabular}


TABLE E.2.5-11-Per-Shipment Accident Impacts-Domestic Programmatic Alternative Scenarios-All-Rail Option (continued)

\begin{tabular}{|c|c|c|c|c|c|}
\hline \multirow{2}{*}{ Material Type } & \multirow{2}{*}{ Mileage } & \multicolumn{2}{|c|}{ Radiological Accident Impacts } & \multirow{2}{*}{$\begin{array}{l}\text { Estimated Number } \\
\text { of Accidents }\end{array}$} & \multirow{2}{*}{$\begin{array}{l}\text { Collision Fatalities } \\
\text { (Nonradiological) }\end{array}$} \\
\hline & & Person-Rem & LCFs & & \\
\hline \multirow{5}{*}{$\begin{array}{l}\mathrm{Ln} / \text { fission } \\
\text { products waste }\end{array}$} & 150 & $5.02 \times 10^{-7}$ & $3 \times 10^{-10}$ & $1.33 \times 10^{-5}$ & $5.12 \times 10^{-6}$ \\
\hline & 500 & $1.67 \times 10^{-6}$ & $1 \times 10^{-9}$ & $4.42 \times 10^{-5}$ & $1.71 \times 10^{-5}$ \\
\hline & 1,500 & $5.01 \times 10^{-6}$ & $3 \times 10^{-9}$ & $1.33 \times 10^{-4}$ & $5.12 \times 10^{-5}$ \\
\hline & 2,100 & $7.05 \times 10^{-6}$ & $4 \times 10^{-9}$ & $1.86 \times 10^{-4}$ & $7.17 \times 10^{-5}$ \\
\hline & 3,000 & $1.00 \times 10^{-5}$ & $6 \times 10^{-9}$ & $2.65 \times 10^{-4}$ & $1.02 \times 10^{-4}$ \\
\hline \multirow{5}{*}{$\begin{array}{l}\text { Tc/UDS/hulls } \\
\text { waste }\end{array}$} & 150 & $7.18 \times 10^{-7}$ & $4 \times 10^{-10}$ & $1.33 \times 10^{-5}$ & $5.12 \times 10^{-6}$ \\
\hline & 500 & $2.38 \times 10^{-6}$ & $1 \times 10^{-9}$ & $4.42 \times 10^{-5}$ & $1.71 \times 10^{-5}$ \\
\hline & 1,500 & $7.16 \times 10^{-6}$ & $4 \times 10^{-9}$ & $1.33 \times 10^{-4}$ & $5.12 \times 10^{-5}$ \\
\hline & 2,100 & $1.00 \times 10^{-5}$ & $6 \times 10^{-9}$ & $1.86 \times 10^{-4}$ & $7.17 \times 10^{-5}$ \\
\hline & 3,000 & $1.43 \times 10^{-5}$ & $9 \times 10^{-9}$ & $2.65 \times 10^{-4}$ & $1.02 \times 10^{-4}$ \\
\hline \multirow{5}{*}{$\begin{array}{l}\text { GTCC LLW AND } \\
\text { MLLW }\end{array}$} & 150 & $2.98 \times 10^{-8}$ & $2 \times 10^{-11}$ & $1.33 \times 10^{-5}$ & $5.12 \times 10^{-6}$ \\
\hline & 500 & $9.91 \times 10^{-8}$ & $6 \times 10^{-11}$ & $4.42 \times 10^{-5}$ & $1.71 \times 10^{-5}$ \\
\hline & 1,500 & $2.97 \times 10^{-7}$ & $2 \times 10^{-10}$ & $1.33 \times 10^{-4}$ & $5.12 \times 10^{-5}$ \\
\hline & 2,100 & $5.56 \times 10^{-7}$ & $3 \times 10^{-10}$ & $1.86 \times 10^{-4}$ & $7.17 \times 10^{-5}$ \\
\hline & 3,000 & $5.94 \times 10^{-7}$ & $4 \times 10^{-10}$ & $2.65 \times 10^{-4}$ & $1.02 \times 10^{-4}$ \\
\hline \multirow{5}{*}{ Fast reactor SNF } & 150 & $4.63 \times 10^{-5}$ & $3 \times 10^{-8}$ & $1.33 \times 10^{-5}$ & $5.12 \times 10^{-6}$ \\
\hline & 500 & $1.54 \times 10^{-4}$ & $9 \times 10^{-8}$ & $4.42 \times 10^{-5}$ & $1.71 \times 10^{-5}$ \\
\hline & 1,500 & $4.61 \times 10^{-4}$ & $3 \times 10^{-7}$ & $1.33 \times 10^{-4}$ & $5.12 \times 10^{-5}$ \\
\hline & 2,100 & $6.45 \times 10^{-4}$ & $4 \times 10^{-7}$ & $1.86 \times 10^{-4}$ & $7.17 \times 10^{-5}$ \\
\hline & 3,000 & $9.22 \times 10^{-4}$ & $6 \times 10^{-7}$ & $2.65 \times 10^{-4}$ & $1.02 \times 10^{-4}$ \\
\hline \multirow{5}{*}{$\begin{array}{l}\text { Recovered } \\
\text { uranium oxide }\end{array}$} & 150 & $9.24 \times 10^{-12}$ & $6 \times 10^{-15}$ & $1.33 \times 10^{-5}$ & $5.12 \times 10^{-6}$ \\
\hline & 500 & $3.07 \times 10^{-11}$ & $2 \times 10^{-14}$ & $4.42 \times 10^{-5}$ & $1.71 \times 10^{-5}$ \\
\hline & 1,500 & $4.13 \times 10^{-11}$ & $2 \times 10^{-14}$ & $1.33 \times 10^{-4}$ & $5.12 \times 10^{-5}$ \\
\hline & 2,100 & $5.78 \times 10^{-11}$ & $3 \times 10^{-14}$ & $1.86 \times 10^{-4}$ & $7.17 \times 10^{-5}$ \\
\hline & 3,000 & $1.84 \times 10^{-10}$ & $1 \times 10^{-13}$ & $2.65 \times 10^{-4}$ & $1.02 \times 10^{-4}$ \\
\hline \multirow{5}{*}{$\begin{array}{l}\text { Recovered } \\
\text { uranium metal }\end{array}$} & 150 & $3.68 \times 10^{-11}$ & $1 \times 10^{-14}$ & $1.33 \times 10^{-5}$ & $5.12 \times 10^{-6}$ \\
\hline & 500 & $1.23 \times 10^{-10}$ & $4 \times 10^{-14}$ & $4.42 \times 10^{-5}$ & $1.71 \times 10^{-5}$ \\
\hline & 1,500 & $3.66 \times 10^{-10}$ & $1 \times 10^{-13}$ & $1.33 \times 10^{-4}$ & $5.12 \times 10^{-5}$ \\
\hline & 2,100 & $5.12 \times 10^{-10}$ & $2 \times 10^{-13}$ & $1.86 \times 10^{-4}$ & $7.17 \times 10^{-5}$ \\
\hline & 3,000 & $7.32 \times 10^{-10}$ & $3 \times 10^{-13}$ & $2.65 \times 10^{-4}$ & $1.02 \times 10^{-4}$ \\
\hline
\end{tabular}

Source: Tetra Tech $2008 \mathrm{f}$ 
TABLE E.2.5-12—Maximum Reasonably Foreseeable Accident ImpactsDomestic Programmatic Alternatives

\begin{tabular}{|c|c|c|c|c|c|}
\hline \multirow[t]{2}{*}{ Material Type } & \multirow{2}{*}{$\begin{array}{c}\text { Impact } \\
\text { Scenario }\end{array}$} & \multicolumn{2}{|c|}{$\begin{array}{l}\text { Accident Exposure } \\
\text { (person-rem) }\end{array}$} & \multicolumn{2}{|c|}{$\begin{array}{c}\text { Exposure Impacts } \\
\text { (LCFs) }\end{array}$} \\
\hline & & Acute & Total & Acute & Total \\
\hline \multirow{3}{*}{ LWR SNF ${ }^{\text {a.b }}$} & Rural & 5.85 & 18.4 & 0.0035 & 0.011 \\
\hline & Urban & 4680 & $1.47 \times 10^{4}$ & 2.81 & 8.81 \\
\hline & MEI & 10.4 & 32.3 & 0.0062 & 0.019 \\
\hline \multirow{3}{*}{$\operatorname{MOX~SNF}^{a}$} & Rural & 14.1 & 40.0 & 0.0085 & 0.024 \\
\hline & Urban & $1.13 \times 10^{4}$ & $3.19 \times 10^{4}$ & 6.80 & 19.2 \\
\hline & MEI & 24.1 & 135 & 0.0144 & 0.081 \\
\hline \multirow{3}{*}{$\begin{array}{l}\text { Thorium Cycle } \\
\text { SNF }^{c}\end{array}$} & Rural & 0.404 & 1.64 & 0.194 & 0.786 \\
\hline & Urban & 323 & 1310 & 1.99 & 4.09 \\
\hline & MEI & 0.996 & 2.78 & $5.98 \times 10^{-4}$ & 0.00167 \\
\hline \multirow{3}{*}{ HWR SNF $^{\mathrm{d}}$} & Rural & 0.374 & 0.831 & $2.24 \times 10^{-4}$ & $3.99 \times 10^{-4}$ \\
\hline & Urban & 300 & 665 & 0.180 & 0.399 \\
\hline & MEI & 0.635 & 2.19 & $3.81 \times 10^{-4}$ & 0.00131 \\
\hline \multirow{3}{*}{ HTGR SNF ${ }^{\mathrm{e}}$} & Rural & 0.344 & 0.574 & $2.07 \times 10^{-4}$ & $3.44 \times 10^{-4}$ \\
\hline & Urban & 275 & 460 & 0.165 & 0.276 \\
\hline & MEI & 0.583 & 1.63 & $3.50 \times 10^{-4}$ & $9.81 \times 10^{-4}$ \\
\hline \multirow{3}{*}{ Fast reactor $\mathrm{SNF}^{\mathrm{b}}$} & Rural & 0.869 & 1.87 & $5.21 \times 10^{-4}$ & 0.0011 \\
\hline & Urban & 695 & 1495 & 0.417 & 0.897 \\
\hline & MEI & 1.13 & 2.62 & $6.78 \times 10^{-4}$ & 0.0016 \\
\hline \multirow{3}{*}{$\begin{array}{l}\text { Fresh } \\
\text { Transmutation fuel }\end{array}$} & Rural & 1.34 & 2.16 & $8.04 \times 10^{-4}$ & 0.00130 \\
\hline & Urban & 1,060 & 1,730 & 0.639 & 1.04 \\
\hline & MEI & 2.27 & 3.66 & 0.00136 & 0.00220 \\
\hline \multirow{3}{*}{ Fresh MOX fuel } & Rural & 0.155 & 0.250 & $9.30 \times 10^{-5}$ & $1.50 \times 10^{-4}$ \\
\hline & Urban & 123 & 200 & 0.0740 & 0.120 \\
\hline & MEI & 0.269 & 0.487 & $1.58 \times 10^{-4}$ & $2.92 \times 10^{-4}$ \\
\hline \multirow{3}{*}{ Am oxide product } & Rural & 0.0787 & 4.78 & $4.72 \times 10^{-5}$ & 0.0611 \\
\hline & Urban & 62.9 & 102 & 0.0378 & 0.0611 \\
\hline & MEI & 0.133 & 0.215 & $7.98 \times 10^{-5}$ & $1.29 \times 10^{-4}$ \\
\hline \multirow{3}{*}{$\mathrm{Cm}$ oxide product } & Rural & 0.306 & 18.3 & $1.84 \times 10^{-4}$ & 0.0110 \\
\hline & Urban & 245 & 396 & 0.147 & 0.238 \\
\hline & MEI & 0.519 & 0.838 & $3.11 \times 10^{-4}$ & $5.03 \times 10^{-4}$ \\
\hline \multirow{3}{*}{$\begin{array}{l}\mathrm{Pu} / \mathrm{Np} \text { oxide } \\
\text { product }\end{array}$} & Rural & 0.114 & 6.87 & $6.84 \times 10^{-5}$ & 0.00412 \\
\hline & Urban & 91.0 & 148 & 0.0885 & 0.132 \\
\hline & MEI & 0.193 & 0.312 & $1.16 \times 10^{-4}$ & $1.87 \times 10^{-4}$ \\
\hline \multirow{3}{*}{$\begin{array}{l}\text { Consolidated } \\
\text { TRU/U product }\end{array}$} & Rural & 0.274 & 16.3 & $1.64 \times 10^{-4}$ & 0.00978 \\
\hline & Urban & 219 & 353 & 0.132 & 0.212 \\
\hline & MEI & 0.465 & 0.749 & $2.79 \times 10^{-4}$ & $4.49 \times 10^{-4}$ \\
\hline \multirow{3}{*}{$\begin{array}{l}\text { Recovered uranium } \\
\text { oxides }^{\text {a }}\end{array}$} & Rural & $5.76 \times 10^{-5}$ & $6.63 \times 10^{-5}$ & $3.44 \times 10^{-8}$ & $3.98 \times 10^{-8}$ \\
\hline & Urban & 0.0247 & 0.0318 & $1.48 \times 10^{-5}$ & $1.91 \times 10^{-5}$ \\
\hline & MEI & $2.52 \times 10^{-5}$ & $4.03 \times 10^{-5}$ & $1.51 \times 10^{-8}$ & $2.42 \times 10^{-8}$ \\
\hline \multirow{3}{*}{$\begin{array}{l}\text { Recovered uranium } \\
\text { metal }^{\text {a }}\end{array}$} & Rural & $7.00 \times 10^{-4}$ & 0.00112 & $4.20 \times 10^{-7}$ & $6.72 \times 10^{-7}$ \\
\hline & Urban & 0.549 & 0.885 & $3.29 \times 10^{-4}$ & $5.31 \times 10^{-4}$ \\
\hline & MEI & 0.00115 & 0.00186 & $6.90 \times 10^{-7}$ & $1.12 \times 10^{-6}$ \\
\hline \multirow{3}{*}{$\underset{\mathrm{a}}{\mathrm{Tc}} \mathrm{C} / \mathrm{UDS} /$ hulls waste } & Rural & 1.73 & 2.80 & 0.00104 & 0.00168 \\
\hline & Urban & 1381 & 2235 & 0.829 & 1.34 \\
\hline & MEI & 2.93 & 4.74 & 0.00176 & 0.00284 \\
\hline \multirow{3}{*}{$\begin{array}{l}\text { Fission Product } \\
\text { Wastes a }^{\text {a }}\end{array}$} & Rural & 0.404 & 1.82 & $2.42 \times 10^{-4}$ & 0.00109 \\
\hline & Urban & 323 & 1455 & 0.194 & 0.873 \\
\hline & MEI & 0.686 & 3.08 & $4.12 \times 10^{-4}$ & 0.00185 \\
\hline
\end{tabular}


TABLE E.2.5-12-Maximum Reasonably Foreseeable Accident ImpactsDomestic Programmatic Alternatives (continued)

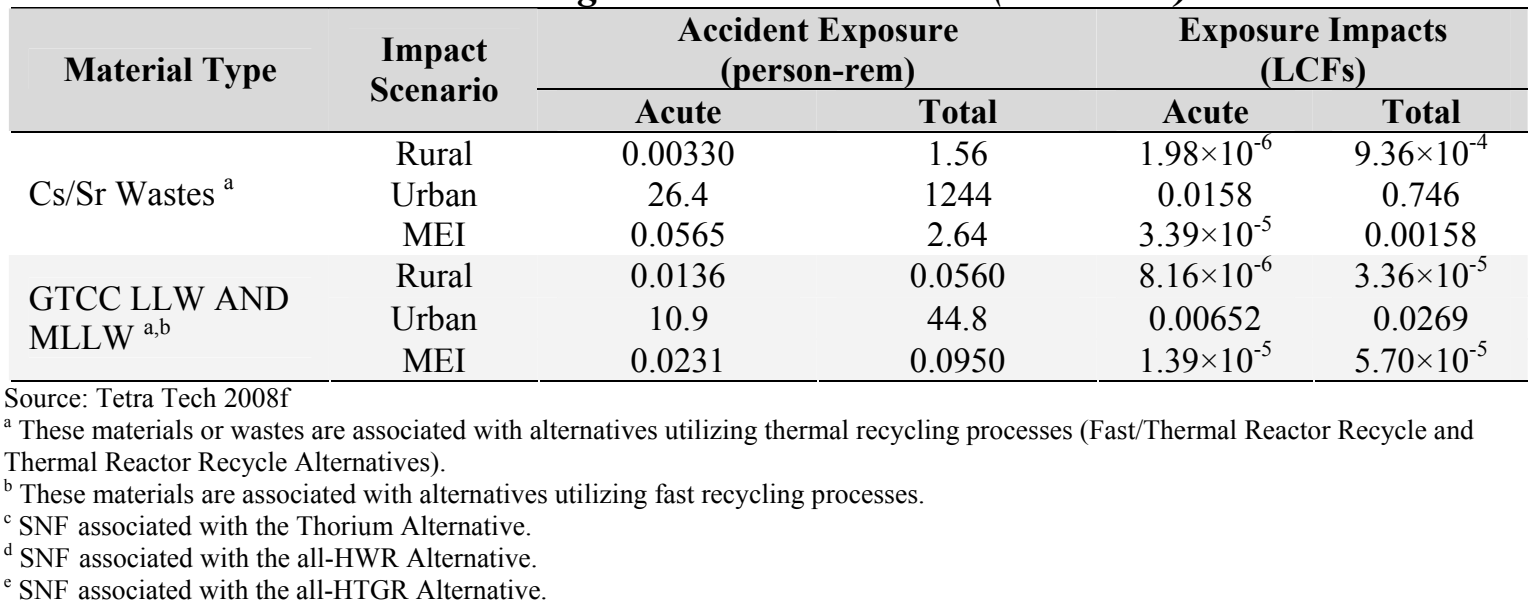

\section{E.3 INTERNATIONAL TRANSPORTATION ANALYSIS}

\section{E.3.1 Routing Analysis for International Shipments}

As described in Chapter 7, DOE analyzed the transportation impacts associated with the shipment of nuclear materials and wastes associated with the overseas construction, operation, and waste management of 1 GWe capacity in LWR reactors, although other reactor types are also possible. SNF generated in these reactors could be transported back to the United States or to a third party partner nation. The SNF could be disposed in a geologic repository, or it could be reprocessed. If reprocessed, the resulting HLW could be transported back to the user nation or to an international partner country.

Within the United States, the affected environment could be determined by the fuel fabrication facility location, the specific port of exit for the fuel rod assemblies, the specific port of entry for the SNF, the location of any SNF recycling center used, the location of any future repository, and the specific port of exit for any waste returning to a foreign nation. To date, these locations have not been identified. Once these facilities have been identified, transportation routes between them would be determined and specific environmental impacts identified. Areas impacted include the transportation routes, the ports and the surrounding areas around these routes and ports.

Domestic transportation was assumed to follow the routing parameters associated with the domestic alternatives analysis provided in the previous sections of this appendix. For the domestic transportation portions of the international shipments (fresh fuel shipments from the fuel fabrication facility to the port and spent fuel from the port to the recycling center), the 500mile distance was assumed.

To determine the distance and voyage times between the international ports, DOE determined a shipping route that would best represent the maximum distance and voyage time for an international shipment from a U.S. port. For analysis purposes, the voyage time was rounded up 
to the nearest day (WSR 2007). Transportation between the United States and international port was estimated to be $7,200 \mathrm{mi}(11,600 \mathrm{~km})$ long and estimated to require approximately 31 days at sea.

\section{E.3.2 International Program Shipments}

For purposes of analysis, the international shipments were assumed to support the implementation and operation of LWRs. International shipments could involve shipment of materials associated with other nuclear reactor types. The fresh LWR fuel assemblies destined for the international reactors would be enriched to approximately 3 percent U-235. The external dose rate of the fresh fuel containers was assumed to be $0.0521 \mathrm{mrem} / \mathrm{hr}$ at a distance of $6.6 \mathrm{ft}$ $(2 \mathrm{~m})$. It was assumed that the SNF transported would consist of fuel with a burnup of $100 \mathrm{GWd} / \mathrm{MTU}$, with a minimum of 5 years cooling. The end-of-life effective enrichment is approximately 2.6 percent. The nuclide inventory is provided in Appendix 2 of the AFCF NEPA Data Study (WGI 2008a). LWR SNF would assume an external dose rate of $10 \mathrm{mrem} / \mathrm{hr}$ at a distance of $6.6 \mathrm{ft}(2 \mathrm{~m})$. All assemblies are assumed to be transported in GA-4 and NLI-10 casks for truck and rail shipments respectively. All waste streams from the recycling processes would use the same containers assumed for the domestic alternatives considered.

\section{E.3.3 Loading and Inspection Impacts and Incident-Free Impacts of International Shipments}

The primary effect of incident-free marine transport of fuel assemblies would be on the crew of the ships used to carry the casks. Due to the protective qualities of the transport cask, members of the general public and marine life would not receive any measurable dose from the fuel assemblies during marine transport. In addition to the protection provided by the transportation casks, further protection for the public and marine life is provided by the ship's structure. Under incident-free conditions of transport, public exposure would be limited to the ship's crew, and the ship's crew exposure would be limited to only those crew members exposed during loading and offloading of casks and to crew members who are required to inspect cargo on a daily basis to ensure secure stowage and the vessel.

While loading the fuel assemblies on board ships, inspectors, dockworkers, longshoremen, and crane operators would be exposed to radiation. This exposure is based on the regulatory limits of the NRC/DOT certified cask. Accordingly, it is expected that the exposure impacts would be the same for the returning SNF and the fresh fuel shipments. Based on existing loading operations, it is assumed that:

- Five handlers would be involved in the loading operation at a distance of $16 \mathrm{ft}(5 \mathrm{~m})$ from the source.

- Four staging personnel would be involved at a distance of $33 \mathrm{ft}$ (10 m) from the source.

- One crane operator would be involved at a distance of $82 \mathrm{ft}(25 \mathrm{~m})$ from the source.

- One inspector is assumed to be present after loading at a distance of $6.6 \mathrm{ft}(2 \mathrm{~m})$ for a period of 4 hours. 
In transit, inspections would be made daily requiring 6 hours of exposure at a distance of $6.6 \mathrm{ft}$ $(2 \mathrm{~m})$. In addition, it is assumed that a chief mate would be at a distance of $82 \mathrm{ft}(25 \mathrm{~m})$ and a bosun at a distance of $33 \mathrm{ft}(10 \mathrm{~m})$ during the loading and for brief periods during each day of the voyage.

While the reactor fuel is onboard, individuals coming into close proximity of the casks, such as sailors on watch, or sailors performing routine inspections, would receive doses of radiation. The doses are a function of the time of transportation. As mentioned above, the shipment between the United States and international port is assumed to be 30 days.

\section{E.4 SUMmary OF AsSUmptions USED In Transportation AnALYSES}

Table E.4-1 provides a summary of the assumptions applied to the transportation analyses conducted for this PEIS. Where applicable, these assumptions were consistent with the analyses performed for the Yucca Mountain SEIS transportation assessments.

Table E.4-1 provides the assumptions for six assessment categories

1. Routing

2. Packaging/shipping configuration

3. Loading and inspection impacts

4. Dose scenarios associated with incident-free transportation

5. Transportation accident risks

6. Severe transportation accident impacts 
TABLE E.4-1—Summary of Transportation Analysis Assumptions

\begin{tabular}{l|l|l}
\hline 1. Routing & \multicolumn{3}{l}{ Rationale } & References \\
\hline Parameter & $\begin{array}{l}\text { Route characteristics for the 61 origin sites and five destination sites } \\
\text { considered in the Spent Nuclear Fuel EIS were used to calculate the } \\
\text { percentage breakdown of rural, suburban, and urban population zones for } \\
\text { the truck and rail scenarios (DOE 1995e). These percentages were applied } \\
\text { to distances analyzed. These distances were developed based on analysis } \\
\text { of the shipment characteristics assessed in the Yucca Mountain FEIS } \\
\text { (DOE 2002i). The minimum shipment in this document was }\end{array}$ & $\begin{array}{l}\text { DOE 2005 } \\
\text { Dist, SNL } \\
\text { approximately 150 miles. The maximum was approximately 3,000 miles, } \\
\text { with a median distance of 2,100 miles (SNL 2005). }\end{array}$ \\
\hline $\begin{array}{l}\text { Population } \\
\text { density }\end{array}$ & $\begin{array}{l}\text { Average population densities for the rural, suburban, and urban population } \\
\text { zones were calculated for the Spent Nuclear Fuel EIS data set described }\end{array}$ & DOE 1995e \\
\hline
\end{tabular}

\begin{tabular}{|c|c|c|c|c|c|c|}
\hline \multicolumn{7}{|c|}{ 2. Packaging/Shipping Configuration } \\
\hline \multicolumn{7}{|c|}{ Truck Shipments } \\
\hline Material & $\begin{array}{c}\text { Nuclide } \\
\text { Inventory } \\
\text { Source }\end{array}$ & Container & $\begin{array}{c}\text { Mass or } \\
\text { Volume per } \\
\text { Container }^{\text {a }}\end{array}$ & $\begin{array}{c}\text { Containers } \\
\text { per } \\
\text { Shipment }\end{array}$ & $\begin{array}{c}\text { Mass or } \\
\text { Volume per } \\
\text { Shipment }\end{array}$ & $\begin{array}{c}\text { External } \\
\text { Exposure Rate } \\
(\mathrm{mrem} / \mathrm{hr} \text { at } 2 \mathrm{~m})\end{array}$ \\
\hline $\begin{array}{l}\text { LWR spent } \\
\text { fuel }\end{array}$ & WGI 2008a & GA-4/9 cask & 2 МТНМ & 1 & 2 МТНМ & 10 \\
\hline $\begin{array}{l}\text { Fast reactor } \\
\text { spent fuel }\end{array}$ & WGI 2008a & $\begin{array}{c}\text { NLI-1/2 } \\
\text { cask }\end{array}$ & 0.4 МTHМ & 1 & 0.4 МТНМ & 10 \\
\hline $\begin{array}{l}\text { Thorium } \\
\text { cycle spent } \\
\text { fuel }\end{array}$ & $\begin{array}{l}\text { DOE 2004j, } \\
\text { BMI } 2007\end{array}$ & $\begin{array}{l}\text { DOE spent } \\
\text { fuel canister }\end{array}$ & $\begin{array}{l}0.6525 \\
\text { MTHM }\end{array}$ & 1 & $\begin{array}{l}0.6525 \\
\text { MTHM }\end{array}$ & 10 \\
\hline $\begin{array}{l}\text { MOX spent } \\
\text { fuel }{ }^{b}\end{array}$ & $\begin{array}{l}\text { DOE } 2004 \mathrm{j}, \\
\text { BMI } 2007\end{array}$ & $\begin{array}{l}\text { DOE spent } \\
\text { fuel canister }\end{array}$ & 0.75 MTHM & 1 & 0.75 МТHМ & 10 \\
\hline $\begin{array}{l}\text { HWR spent } \\
\text { fuel }^{\mathrm{b}}\end{array}$ & $\begin{array}{l}\text { DOE } 2004 \mathrm{j}, \\
\text { BMI } 2007\end{array}$ & $\begin{array}{l}\text { DOE spent } \\
\text { fuel canister }\end{array}$ & $1.58 \mathrm{MTHM}$ & 1 & $1.58 \mathrm{MTHM}$ & 10 \\
\hline $\begin{array}{l}\text { HTGR spent } \\
\text { fuel }^{b}\end{array}$ & $\begin{array}{l}\text { DOE } 2004 \mathrm{j}, \\
\text { BMI } 2007\end{array}$ & $\begin{array}{l}\text { DOE spent } \\
\text { fuel canister }\end{array}$ & $\begin{array}{l}0.02067 \\
\text { MTHM }\end{array}$ & 1 & $\begin{array}{l}0.02067 \\
\text { MTHM }\end{array}$ & 10 \\
\hline $\begin{array}{l}\text { Fresh } \\
\text { transmutation } \\
\text { fuel }\end{array}$ & WGI 2008a & $\begin{array}{l}\text { NLI-1/2 } \\
\text { cask }\end{array}$ & 0.4 МТНM & 1 & 0.4 МТНМ & 10 \\
\hline $\begin{array}{l}\text { Fresh MOX } \\
\text { fuel }\end{array}$ & NRC 2005c & $\begin{array}{c}\text { Class B } \\
\text { cylindrical } \\
\text { cask }\end{array}$ & 1.37 MTHM & 1 & 1.37 MTHM & 2.52 \\
\hline $\begin{array}{l}\text { Fresh LWR } \\
\text { fuel }\end{array}$ & $\begin{array}{c}\text { Nuclide } \\
\text { inventory } \\
\text { not currently } \\
\text { available }\end{array}$ & $\begin{array}{c}\text { Not } \\
\text { specified }\end{array}$ & 6 МТHМ & 1 & $6 \mathrm{MTHM}$ & 0.0521 \\
\hline $\begin{array}{l}\text { Fresh thorium } \\
\text { fuel }\end{array}$ & $\begin{array}{l}\text { Nuclide } \\
\text { inventory } \\
\text { not currently } \\
\text { available }\end{array}$ & $\begin{array}{c}\text { Not } \\
\text { specified }\end{array}$ & 1.7 МТНМ & 1 & 1.7 МТНМ & 0.0521 \\
\hline $\begin{array}{l}\text { Fresh HWR } \\
\text { fuel }\end{array}$ & $\begin{array}{l}\text { Nuclide } \\
\text { inventory } \\
\text { not currently } \\
\text { available }\end{array}$ & $\begin{array}{c}\text { Not } \\
\text { specified }\end{array}$ & 3.24 MTHM & 1 & 3.24 МТНМ & 0.0521 \\
\hline $\begin{array}{l}\text { Fresh HTGR } \\
\text { fuel }\end{array}$ & $\begin{array}{l}\text { Nuclide } \\
\text { inventory } \\
\text { not currently } \\
\text { available }\end{array}$ & $\begin{array}{c}\text { Not } \\
\text { specified }\end{array}$ & $\begin{array}{c}0.307 \\
\text { MTHM }\end{array}$ & 1 & $\begin{array}{c}0.307 \\
\text { MTHM }\end{array}$ & 0.0521 \\
\hline
\end{tabular}


TABLE E.4-1—Summary of Transportation Analysis Assumptions (continued)

\begin{tabular}{|c|c|c|c|c|c|c|}
\hline \multicolumn{7}{|c|}{ 2. Packaging/Shipping Configuration } \\
\hline \multicolumn{7}{|c|}{ Truck Shipments } \\
\hline Material & $\begin{array}{c}\text { Nuclide } \\
\text { Inventory } \\
\text { Source } \\
\end{array}$ & Container & $\begin{array}{c}\text { Mass or } \\
\text { Volume per } \\
\text { Container }^{\text {a }} \\
\end{array}$ & $\begin{array}{c}\text { Containers } \\
\text { per } \\
\text { Shipment } \\
\end{array}$ & $\begin{array}{c}\text { Mass or } \\
\text { Volume per } \\
\text { Shipment } \\
\end{array}$ & $\begin{array}{c}\text { External } \\
\text { Exposure Rate } \\
(\mathrm{mrem} / \mathrm{hr} \text { at } 2 \mathrm{~m}) \\
\end{array}$ \\
\hline $\begin{array}{l}\text { Am oxide } \\
\text { product }\end{array}$ & WGI 2008a & $\begin{array}{c}\text { Class B } \\
\text { drum-like } \\
\text { containers }\end{array}$ & $1.39 \mathrm{~kg}$ & 25 & $34.8 \mathrm{~kg}$ & 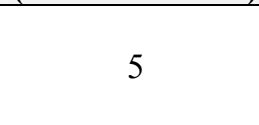 \\
\hline $\begin{array}{l}\text { Cm oxide } \\
\text { product }\end{array}$ & WGI 2008a & $\begin{array}{c}\text { Class B } \\
\text { drum-like } \\
\text { containers }\end{array}$ & $0.407 \mathrm{~kg}$ & 25 & $10.2 \mathrm{~kg}$ & 5 \\
\hline $\begin{array}{l}\mathrm{Pu} / \mathrm{Np} \text { oxide } \\
\text { product }\end{array}$ & WGI 2008a & $\begin{array}{c}\text { Class B } \\
\text { drum-like } \\
\text { containers }\end{array}$ & $5.00 \mathrm{~kg}$ & 25 & $125 \mathrm{~kg}$ & 5 \\
\hline $\begin{array}{l}\text { TRU/U } \\
\text { product }\end{array}$ & WGI 2008a & $\begin{array}{c}\text { Class B } \\
\text { drum-like } \\
\text { containers } \\
\end{array}$ & $3.51 \mathrm{~kg}$ & 25 & $87.7 \mathrm{~kg}$ & 5 \\
\hline $\mathrm{Cs} / \mathrm{Sr}$ waste & $\begin{array}{l}\text { WGI 2008a, } \\
\text { WGI 2008c }\end{array}$ & $\begin{array}{c}\text { Waste can } \\
\left(3^{\prime \prime} \text { IDx } 10^{\prime}\right. \\
\text { long })\end{array}$ & $0.067 \mathrm{~m}^{3}$ & 1 & $0.067 \mathrm{~m}^{3}$ & 10 \\
\hline $\begin{array}{l}\text { Tc/UDS/hulls } \\
\text { waste }\end{array}$ & WGI 2008a & $\begin{array}{c}\text { HLW } \\
\text { canister }^{c}\end{array}$ & $0.77 \mathrm{~m}^{3}$ & 1 & $0.77 \mathrm{~m}^{3}$ & 10 \\
\hline $\begin{array}{l}\text { Ln/fission } \\
\text { product waste }\end{array}$ & $\begin{array}{l}\text { WGI 2008a, } \\
\text { WSRC } \\
2008 \mathrm{a}\end{array}$ & $\begin{array}{c}\text { HLW } \\
\text { canister }^{c}\end{array}$ & $1.29 \mathrm{~m}^{3}$ & 1 & $1.29 \mathrm{~m}^{3}$ & 10 \\
\hline $\begin{array}{l}\text { GTCC-LLW } \\
\text { AND MLLW }\end{array}$ & $\begin{array}{l}\text { WGI 2008a, } \\
\text { WSRC } \\
2008 \mathrm{a}\end{array}$ & $\begin{array}{c}\text { HLW } \\
\text { canister }^{c}\end{array}$ & $0.79 \mathrm{~m}^{3}$ & 1 & $0.79 \mathrm{~m}^{3}$ & 10 \\
\hline $\begin{array}{l}\text { LLW AND } \\
\text { MLLW }\end{array}$ & $\begin{array}{l}\text { WGI 2008a, } \\
\text { WSRC } \\
2008 \mathrm{a} \\
\end{array}$ & B-25 box & $2.55 \mathrm{~m}^{3}$ & 12 & $30.60 \mathrm{~m}^{3}$ & 2 \\
\hline $\begin{array}{l}\text { Uranium } \\
\text { oxide product }\end{array}$ & WGI 2008a & $\begin{array}{l}\text { Class B } \\
\text { drum }\end{array}$ & $\begin{array}{c}13.5 \mathrm{~kg} \\
(\text { total U) }\end{array}$ & 15 & $337.5 \mathrm{~kg}$ & 5 \\
\hline $\begin{array}{l}\text { Uranium } \\
\text { metal product }\end{array}$ & WGI 2008a & $\begin{array}{l}\text { Class B } \\
\text { drum }\end{array}$ & $17.2 \mathrm{~kg}$ & 18 & $430 \mathrm{~kg}$ & 5 \\
\hline \multicolumn{7}{|l|}{ Rail shipments } \\
\hline Material & $\begin{array}{c}\text { Nuclide } \\
\text { Inventory } \\
\text { Source } \\
\end{array}$ & Container & $\begin{array}{c}\text { Mass or } \\
\text { Volume per } \\
\text { Container }^{\text {a }} \\
\end{array}$ & $\begin{array}{c}\text { Containers } \\
\text { per } \\
\text { Shipment }^{\text {d }} \\
\end{array}$ & $\begin{array}{c}\text { Mass or } \\
\text { Volume per } \\
\text { Shipment } \\
\end{array}$ & $\begin{array}{c}\text { External } \\
\text { Exposure Rate } \\
(\mathrm{mrem} / \mathrm{hr}) \\
\end{array}$ \\
\hline $\begin{array}{l}\text { LWR spent } \\
\text { fuel }\end{array}$ & WGI 2008a & $\begin{array}{c}\text { NLI-10/24 } \\
\text { cask }\end{array}$ & 5 МТНМ & 5 & 25 МТНМ & 10 \\
\hline $\begin{array}{l}\text { Fast reactor } \\
\text { spent fuel }\end{array}$ & WGI 2008a & GA-4/9 cask & 0.4 МТНМ & 5 & 2 МТНM & 10 \\
\hline $\begin{array}{l}\text { Thorium cycle } \\
\text { spent fuel }\end{array}$ & $\begin{array}{l}\text { DOE 2004j, } \\
\text { BMI } 2007\end{array}$ & $\begin{array}{l}\text { DOE spent } \\
\text { fuel cask }\end{array}$ & $\begin{array}{l}5.8725 \\
\text { MTHM }\end{array}$ & 5 & $\begin{array}{c}29.36 \\
\text { MTHM }\end{array}$ & 10 \\
\hline $\begin{array}{l}\text { MOX spent } \\
\text { fuel }^{b}\end{array}$ & $\begin{array}{l}\text { DOE } 2004 j, \\
\text { BMI } 2007\end{array}$ & $\begin{array}{l}\text { DOE spent } \\
\text { fuel cask }\end{array}$ & $\begin{array}{c}6.75 \\
\text { MTHM } \\
\end{array}$ & 5 & 33.7 МТНМ & 10 \\
\hline $\begin{array}{l}\text { HWR spent } \\
\text { fuel }^{b}\end{array}$ & $\begin{array}{l}\text { DOE } 2004 j, \\
\text { BMI } 2007\end{array}$ & $\begin{array}{l}\text { DOE spent } \\
\text { fuel cask }\end{array}$ & $\begin{array}{c}14.22 \\
\text { MTHM }\end{array}$ & 5 & 71.1 МТНМ & 10 \\
\hline $\begin{array}{l}\text { HTGR spent } \\
\text { fuel }^{\mathrm{b}}\end{array}$ & $\begin{array}{l}\text { DOE } 2004 j, \\
\text { BMI } 2007\end{array}$ & $\begin{array}{l}\text { DOE spent } \\
\text { fuel cask }\end{array}$ & $\begin{array}{c}0.186 \\
\text { MTHM }\end{array}$ & 5 & 0.93 МТНМ & 10 \\
\hline $\begin{array}{l}\text { Am oxide } \\
\text { product }\end{array}$ & WGI 2008a & $\begin{array}{c}\text { Class B } \\
\text { drum-like } \\
\text { containers }\end{array}$ & $1.39 \mathrm{~kg}$ & 125 & $174 \mathrm{~kg}$ & 5 \\
\hline
\end{tabular}


TABLE E.4-1-Summary of Transportation Analysis Assumptions (continued)

\begin{tabular}{|c|c|c|c|c|c|c|c|}
\hline \multicolumn{8}{|l|}{ Rail shipments } \\
\hline Material & \multicolumn{2}{|c|}{$\begin{array}{l}\text { Nuclide } \\
\text { Inventory } \\
\text { Source }\end{array}$} & Container & $\begin{array}{c}\text { Mass or } \\
\text { Volume per } \\
\text { Container }^{\text {a }} \\
\end{array}$ & $\begin{array}{l}\text { Containers } \\
\text { per } \\
\text { Shipment }^{d}\end{array}$ & $\begin{array}{c}\text { Mass or } \\
\text { Volume per } \\
\text { Shipment } \\
\end{array}$ & $\begin{array}{c}\text { External } \\
\text { Exposure Rate } \\
\text { (mrem/hr) }\end{array}$ \\
\hline $\begin{array}{l}\text { Cm oxide } \\
\text { product }\end{array}$ & \multicolumn{2}{|c|}{ WGI 2008a } & $\begin{array}{c}\text { Class B } \\
\text { drum-like } \\
\text { containers }\end{array}$ & $0.407 \mathrm{~kg}$ & 125 & $51.0 \mathrm{~kg}$ & 5 \\
\hline $\mathrm{Cs} / \mathrm{Sr}$ waste & \multicolumn{2}{|c|}{$\begin{array}{l}\text { WGI 2008a, } \\
\text { WGI 2008c }\end{array}$} & $\begin{array}{l}\text { Waste can } \\
\text { (3” IDx10' } \\
\text { long) }\end{array}$ & $0.067 \mathrm{~m}^{3}$ & 5 & $0.333 \mathrm{~m}^{3}$ & 10 \\
\hline $\begin{array}{l}\text { Tc/UDS/hulls } \\
\text { waste }\end{array}$ & \multicolumn{2}{|c|}{ WGI 2008a } & $\begin{array}{c}\text { HLW } \\
\text { canister }^{c}\end{array}$ & $0.77 \mathrm{~m}^{3}$ & 5 & $3.85 \mathrm{~m}$ & 10 \\
\hline $\begin{array}{l}\text { Ln/fission } \\
\text { product waste }\end{array}$ & \multicolumn{2}{|c|}{$\begin{array}{l}\text { WGI 2008a, } \\
\text { WSRC } \\
2008 \mathrm{a}\end{array}$} & $\begin{array}{c}\text { HLW } \\
\text { canister }^{c}\end{array}$ & $1.29 \mathrm{~m}^{3}$ & 5 & $6.45 \mathrm{~m}^{3}$ & 10 \\
\hline $\begin{array}{l}\text { GTCC-LLW } \\
\text { AND MLLW }\end{array}$ & \multicolumn{2}{|c|}{$\begin{array}{l}\text { WGI 2008a, } \\
\text { WSRC } \\
2008 \mathrm{a}\end{array}$} & $\begin{array}{c}\text { HLW } \\
\text { canister }\end{array}$ & $0.79 \mathrm{~m}^{3}$ & 5 & $19.75 \mathrm{~m}^{3}$ & 10 \\
\hline $\begin{array}{l}\text { LLW AND } \\
\text { MLLW }\end{array}$ & \multicolumn{2}{|c|}{$\begin{array}{l}\text { WGI 2008a, } \\
\text { WSRC } \\
\text { 2008a }\end{array}$} & B-25 box & $2.55 \mathrm{~m}^{3}$ & 60 & $153 \mathrm{~m}^{3}$ & 2 \\
\hline $\begin{array}{l}\text { Uranium } \\
\text { oxide product }\end{array}$ & \multicolumn{2}{|c|}{ WGI 2008a } & $\begin{array}{c}\text { Class B } \\
\text { drum }\end{array}$ & $\begin{array}{l}13.5 \mathrm{~kg} \\
\text { (total U) }\end{array}$ & 75 & $1687.5 \mathrm{~kg}$ & 5 \\
\hline $\begin{array}{l}\text { Uranium } \\
\text { metal product }\end{array}$ & \multicolumn{2}{|c|}{ WGI 2008a } & $\begin{array}{c}\text { Class B } \\
\text { drum }\end{array}$ & $17.2 \mathrm{~kg}$ & 90 & $2150 \mathrm{~kg}$ & 5 \\
\hline \multicolumn{8}{|c|}{ 3. Per-Shipment Loading and Inspection Exposure Impacts } \\
\hline \multicolumn{8}{|c|}{ Truck Shipments } \\
\hline \multicolumn{2}{|l|}{ Material } & \multicolumn{2}{|c|}{$\begin{array}{l}\text { Loading } \\
\text { Exposure } \\
\text { (person-rem) }\end{array}$} & $\begin{array}{l}\begin{array}{l}\text { Inspection } \\
\text { Exposure }\end{array} \\
\text { (person-rem) }\end{array}$ & \multicolumn{3}{|c|}{ Loading Exposure Rationale } \\
\hline \multicolumn{2}{|l|}{ Spent fuel ${ }^{g}$} & & 0.432 & 0.0738 & \multicolumn{3}{|c|}{$\begin{array}{l}\text { The loading exposures assumed in the GNEP PEIS } \\
\text { are the same assumed in the Yucca Mountain SEIS, } \\
\text { which are based on actual exposure values provided } \\
\text { in industry documents detailing loading of } \\
\text { commercial spent fuel. Assumes a crew of } 13 \\
\text { workers for a 10-hour period. }\end{array}$} \\
\hline \multicolumn{2}{|l|}{$\mathrm{Cs} / \mathrm{Sr}$ waste } & \multicolumn{2}{|r|}{0.821} & 0.0205 & \multicolumn{3}{|c|}{$\begin{array}{l}\text { For this waste stream and the other wastes/materials } \\
\text { listed below, estimation of loading impacts was } \\
\text { based on the size and number of packages per load. } \\
\text { The exposure impacts reflect RADTRAN } \\
\text { calculation for the worker population at a distance } \\
\text { of } 2 \mathrm{~m} \text { and exposure rates provided above. For } \\
\text { Cs/Sr, it was assumed that five workers would take } \\
\text { eight hours to load a truck shipment. }\end{array}$} \\
\hline \multicolumn{2}{|c|}{ Tc/UDS/hulls waste } & & 0.325 & 0.0162 & \multicolumn{3}{|c|}{$\begin{array}{l}\text { Assumes a crew of five workers for a four-hour } \\
\text { period. }\end{array}$} \\
\hline \multicolumn{2}{|c|}{$\begin{array}{l}\mathrm{Ln} / \text { fission product } \\
\text { waste }\end{array}$} & \multicolumn{2}{|r|}{0.326} & 0.0163 & \multicolumn{3}{|c|}{$\begin{array}{l}\text { Assumes a crew of five workers for a four-hour } \\
\text { period. }\end{array}$} \\
\hline $\begin{array}{l}\text { GTCC-LLW A } \\
\text { MLLW }\end{array}$ & & & 0.125 & 0.00625 & $\begin{array}{l}\text { Assumes a crev } \\
\text { period. }\end{array}$ & of five workers & or a four-hour \\
\hline LLW AND M & $\mathrm{CW}$ & & .0212 & 0.00210 & $\begin{array}{l}\text { Assumes a crev } \\
\text { period. }\end{array}$ & of five workers & or a 12-hour \\
\hline $\begin{array}{l}\text { Fresh transmu } \\
\text { fuel }\end{array}$ & & & 0.432 & 0.0738 & Assumes a crev & of 13 workers & r a 10-hour period \\
\hline
\end{tabular}


TABLE E.4-1—Summary of Transportation Analysis Assumptions (continued)

\begin{tabular}{|c|c|c|c|}
\hline \multicolumn{4}{|l|}{ Truck Shipments } \\
\hline Material & $\begin{array}{l}\text { Loading } \\
\text { Exposure } \\
\text { (person-rem) }\end{array}$ & $\begin{array}{l}\text { Inspection } \\
\text { Exposure } \\
\text { (person-rem) }\end{array}$ & Loading Exposure Rationale \\
\hline Fresh MOX fuel & 0.109 & 0.0186 & Assumes a crew of 13 workers for a 10 -hour period \\
\hline $\begin{array}{l}\text { Fresh LWR, thorium, } \\
\text { HWR, HTGR fuel }\end{array}$ & 0.0225 & 0.00384 & Assumes a crew of 13 workers for a 10 -hour period \\
\hline $\begin{array}{l}\mathrm{Am}, \mathrm{Cm} \text {, and } \mathrm{Pu} / \mathrm{Np} \\
\text { oxide products }\end{array}$ & 0.154 & 0.0641 & $\begin{array}{l}\text { Assumes a crew of five workers for a 12-hour } \\
\text { period }\end{array}$ \\
\hline TRU/U oxide product & 0.154 & 0.0641 & $\begin{array}{l}\text { Assumes a crew of five workers for a 12-hour } \\
\text { period }\end{array}$ \\
\hline Uranium oxide product & 0.154 & 0.0641 & $\begin{array}{l}\text { Assumes a crew of five workers for a 12-hour } \\
\text { period. }\end{array}$ \\
\hline Uranium metal product & 0.103 & 0.0461 & $\begin{array}{l}\text { Assumes a crew of five workers for an eight-hour } \\
\text { period. }\end{array}$ \\
\hline \multicolumn{4}{|l|}{ Rail Shipments } \\
\hline Material & $\begin{array}{c}\text { Loading } \\
\text { Exposure } \\
\text { (person-rem) }\end{array}$ & $\begin{array}{c}\text { Inspection } \\
\text { Exposure f,h } \\
\text { (person-rem) }\end{array}$ & Loading Exposure Rationale \\
\hline Spent fuel ${ }^{\mathrm{g}}$ & 3.32 & 0.185 & $\begin{array}{l}\text { The loading exposures assumed in the GNEP PEIS } \\
\text { are the same assumed in the Yucca Mountain SEIS, } \\
\text { which are based on actual exposure values provided } \\
\text { in industry documents detailing loading of } \\
\text { commercial spent fuel. Assumes a crew of } 13 \\
\text { workers for a 90-hour period. }\end{array}$ \\
\hline $\mathrm{Cs} / \mathrm{Sr}$ waste & 4.11 & 0.103 & $\begin{array}{l}\text { Assumes a crew of five workers for a } 40 \text {-hour } \\
\text { period. }\end{array}$ \\
\hline Tc/UDS/hulls waste & 1.45 & 0.145 & $\begin{array}{l}\text { Assumes a crew of five workers for a } 20 \text {-hour } \\
\text { period. }\end{array}$ \\
\hline $\begin{array}{l}\text { Ln/fission product } \\
\text { waste }\end{array}$ & 1.45 & 0.145 & $\begin{array}{l}\text { Assumes a crew of five workers for a } 20 \text {-hour } \\
\text { period. }\end{array}$ \\
\hline $\begin{array}{l}\text { GTCC-LLW AND } \\
\text { MLLW }\end{array}$ & 1.25 & 0.00624 & $\begin{array}{l}\text { Assumes a crew of five workers for a } 20 \text {-hour } \\
\text { period. }\end{array}$ \\
\hline LLW AND MLLW & 0.106 & 0.0105 & $\begin{array}{l}\text { Assumes a crew of five workers for a } 60 \text {-hour } \\
\text { period. }\end{array}$ \\
\hline $\begin{array}{l}\text { Am and } \mathrm{Cm} \text { oxide } \\
\text { product }\end{array}$ & 0.770 & 0.320 & $\begin{array}{l}\text { Assumes a crew of five workers for a } 60 \text {-hour } \\
\text { period. }\end{array}$ \\
\hline Uranium oxide product & 0.769 & 0.320 & $\begin{array}{l}\text { Assumes a crew of five workers for a } 60 \text {-hour } \\
\text { period. }\end{array}$ \\
\hline Uranium metal product & 0.513 & 0.214 & $\begin{array}{l}\text { Assumes a crew of five workers for a 40-hour } \\
\text { period. }\end{array}$ \\
\hline \multicolumn{4}{|c|}{ 4. Dose Scenarios Associated with Incident-Free Transportation } \\
\hline \multicolumn{4}{|l|}{ Worker Populations } \\
\hline \multicolumn{3}{|c|}{ Population } & $\begin{array}{c}\begin{array}{c}\text { Consistent with Yucca Mountain SEIS? } \\
\text { (as provided in BMI 2007) }\end{array} \\
\end{array}$ \\
\hline \multicolumn{3}{|c|}{$\begin{array}{l}\text { An inspector working at a distance of } 3.3 \mathrm{ft}(1 \mathrm{~m}) \text { from the } \\
\text { rail or truck container for one hour per trailer or rail } \\
\text { container. }\end{array}$} & Yes \\
\hline \multicolumn{3}{|c|}{$\begin{array}{l}\text { A truck driver and passenger, expected to drive radioactive } \\
\text { shipments for } 1,000 \text { hours per year and unload shipments for } \\
1,000 \text { hours per year. }\end{array}$} & Yes \\
\hline \multicolumn{3}{|c|}{$\begin{array}{l}\text { Escort for truck shipments assumed to be present for entire } \\
\text { shipment. }\end{array}$} & Yes \\
\hline
\end{tabular}


TABLE E.4-1—Summary of Transportation Analysis Assumptions (continued)

Worker Populations

\section{Population}

Escort for rail shipments assumed to be present for entire shipment, including transfer periods at rail yards.
Consistent with Yucca Mountain SEIS?

(as provided in BMI 2007)

Rail escort in GNEP PEIS assumed to be $98 \mathrm{ft}(30$

m) from source. Yucca Mountain SEIS (DOE

2008f) assumes a distance of $90 \mathrm{ft}(27 \mathrm{~m})$.

General Population

A person caught in traffic and located $4 \mathrm{ft}(1.2 \mathrm{~m})$ from

shipping container for one hour.

A service station worker working at a distance of $66 \mathrm{ft}(20 \mathrm{~m})$

from the shipping container for one hour.

Yes

No, Yucca Mountain SEIS assumes person at service station exposed for 49 minutes at a distance of $52 \mathrm{ft}(16 \mathrm{~m})$. The GNEP analysis is consistent with Yucca Mountain FEIS analysis, which assumed a station worker at a distance of $66 \mathrm{ft}(20 \mathrm{~m})$.

\begin{tabular}{|c|c|c|c|}
\hline \multicolumn{2}{|c|}{$\begin{array}{l}\text { Area residents near truck stop/service station, within } 0.5 \\
\text { mile }(0.8 \mathrm{~km}) \text { from stop. }\end{array}$} & \multicolumn{2}{|l|}{ Yes } \\
\hline \multicolumn{2}{|c|}{$\begin{array}{l}\text { Resident living } 98 \mathrm{ft}(30 \mathrm{~m}) \text { from the highway or rail line } \\
\text { used to transport shipping container. }\end{array}$} & \multicolumn{2}{|l|}{ Yes } \\
\hline \multicolumn{2}{|c|}{$\begin{array}{l}\text { Resident } 660 \mathrm{ft}(200 \mathrm{~m}) \text { from the rail stop where shipping } \\
\text { container was sitting for } 20 \text { hours. }\end{array}$} & \multicolumn{2}{|l|}{ Yes } \\
\hline \multicolumn{4}{|c|}{ Frequency of Stops } \\
\hline \multicolumn{2}{|c|}{ Description of Stop } & \multicolumn{2}{|c|}{$\begin{array}{l}\text { Consistent with Yucca Mountain SEIS? } \\
\text { (as provided in BMI 2007) }\end{array}$} \\
\hline \multicolumn{2}{|c|}{$\begin{array}{l}\text { Two-hour rail stops assumed to occur at } 170-\mathrm{mile}(277-\mathrm{km}) \\
\text { intervals, or at a rate of } 0.012 \mathrm{hr} / \mathrm{mile}(0.0072 \mathrm{hr} / \mathrm{km}) .\end{array}$} & \multicolumn{2}{|l|}{ Yes } \\
\hline \multicolumn{2}{|c|}{$\begin{array}{l}\text { Truck stops assumed to occur at a rate of } 0.018 \mathrm{hr} / \mathrm{mile} \\
(0.011 \mathrm{hr} / \mathrm{km}) \text {. }\end{array}$} & \multicolumn{2}{|l|}{ Yes } \\
\hline \multicolumn{4}{|c|}{ Vehicle Emission Impacts } \\
\hline \multicolumn{3}{|c|}{ Description } & $\begin{array}{l}\text { Consistent with Yucca } \\
\text { Mountain SEIS? }\end{array}$ \\
\hline \multicolumn{3}{|c|}{$\begin{array}{l}\text { Incident-free nonradiological vehicle emission fatalities were estimated using unit } \\
\text { risk factors. These fatalities would result from exhaust and fugitive dust emissions } \\
\text { from highway and rail traffic and are associated with } 10 \text {-micrometer particles. The } \\
\text { nonradiological unit risk factors were adopted from the transportation analysis } \\
\text { conducted for the Yucca Mountain FEIS (DOE } 2002 \mathrm{i}) \text {. The unit risk factors used in } \\
\text { this analysis are } 1.5 \times 10^{-11} \text { and } 2.6 \times 10^{-11} \text { fatalities per kilometer per persons per } \\
\text { square kilometer }\left(\mathrm{km}^{2}\right) \text { for diesel truck and rail modes of transport respectively } \\
\text { (Jason Technologies 2001). }\end{array}$} & Yes \\
\hline \multicolumn{4}{|c|}{ 5. Transportation Accident Risk Assessment Assumptions } \\
\hline \multicolumn{4}{|c|}{ Accident and Fatality Rates } \\
\hline Mode & \multicolumn{2}{|l|}{ Description } & $\begin{array}{l}\text { Consistent with Yucca } \\
\text { Mountain SEIS? }\end{array}$ \\
\hline Truck & \multicolumn{2}{|c|}{$\begin{array}{l}\text { Saricks and Tompkins } 1999 \text { rates with factors of } 1.57 \\
\text { and } 1.64 \text { applied to account for underreporting of } \\
\text { accident and fatality rates, respectively, as suggested by } \\
\text { UMTRI } 2003 \text {. }\end{array}$} & Yes \\
\hline Rail and barge & Saricks and Tompkins 1999 rates & & Yes \\
\hline \multicolumn{4}{|c|}{ Conditional Probabilities and Release Fraction - Truck Scenario ${ }^{i}$} \\
\hline \multicolumn{2}{|c|}{ Materials/container type } & \multicolumn{2}{|l|}{ Source Document } \\
\hline \multicolumn{2}{|c|}{ LWR, MOX, and thorium cycle spent fuels } & \multicolumn{2}{|c|}{ Jason Technologies 2001} \\
\hline \multicolumn{2}{|l|}{ HWR spent fuel } & \multicolumn{2}{|l|}{ BMI 2007} \\
\hline \multicolumn{2}{|c|}{ HTGR spent fuel } & \multicolumn{2}{|l|}{ BMI 2007} \\
\hline
\end{tabular}


TABLE E.4-1—Summary of Transportation Analysis Assumptions (continued)

\begin{tabular}{|c|c|c|c|}
\hline \multicolumn{2}{|l|}{ Materials/container type } & \multicolumn{2}{|c|}{ Source Document } \\
\hline \multirow{2}{*}{\multicolumn{2}{|c|}{$\begin{array}{l}\text { Fresh MOX fuel } \\
\text { HLW canister }\end{array}$}} & \multicolumn{2}{|l|}{ NRC $2005 \mathrm{c}$} \\
\hline & & \multicolumn{2}{|l|}{ DOE 2004f } \\
\hline \multicolumn{2}{|l|}{9975 Class B waste drum } & \multicolumn{2}{|l|}{ DOE 2004f } \\
\hline \multicolumn{4}{|c|}{ Conditional Probabilities and Release Fraction - Rail Scenario ${ }^{i}$} \\
\hline \multicolumn{2}{|l|}{ Materials/container type } & \multicolumn{2}{|c|}{ Source Document } \\
\hline \multicolumn{2}{|l|}{ LWR, MOX, and thorium cycle spent fuels } & \multicolumn{2}{|l|}{ BMI 2007} \\
\hline \multicolumn{2}{|l|}{ HWR spent fuel } & \multicolumn{2}{|l|}{ BMI 2007} \\
\hline \multicolumn{2}{|l|}{ HTGR spent fuel } & \multicolumn{2}{|l|}{ BMI 2007} \\
\hline \multicolumn{2}{|l|}{ HLW canister } & \multicolumn{2}{|l|}{ DOE 2004f } \\
\hline \multirow{2}{*}{\multicolumn{2}{|c|}{$\begin{array}{l}9975 \text { Class B waste drum } \\
\text { Severe Accident Transportation Accident Impacts }\end{array}$}} & \multicolumn{2}{|l|}{ DOE $2004 \mathrm{f}$} \\
\hline & & \multicolumn{2}{|c|}{ Severe Accident Transportation Accident Impacts ${ }^{j}$} \\
\hline Parameter & & & $\begin{array}{c}\text { Consistent with Yucca } \\
\text { Mountain SEIS? }\end{array}$ \\
\hline Plume release height & 33 & $10 \mathrm{~m})$ & Yes \\
\hline Breathing rate & $3.67 \times 10^{5} \mathrm{f}$ & $\left.1.04 \times 10^{5} \mathrm{~m}^{3}\right)$ & Yes \\
\hline Short-term exposure time & & urs & Yes \\
\hline Long-term exposure time & & & Yes \\
\hline Wind speed & 2 mile/l & $0.89 \mathrm{~m} / \mathrm{s})$ & Yes \\
\hline Atmospheric conditions & Pasquill S & ility Class F & Yes \\
\hline Urban population density & $\begin{array}{r}\text { As prov } \\
\mathrm{E} .\end{array}$ & d in Table & Yes \\
\hline Rural population density & $\begin{array}{l}15.5 \mathrm{p} \\
(6 \mathrm{pel}\end{array}$ & $\begin{array}{l}\mathrm{ons} / \mathrm{mi}^{2} \\
\left.\mathrm{~ns} / \mathrm{km}^{2}\right)\end{array}$ & Yes \\
\hline
\end{tabular}

${ }^{a}$ The container capacities for each material type was based upon volume, criticality, or thermal loading limits. Table E.2.2.2-1 provides the limiting factor for each material type and container. For the non-spent fuel material shipping, WGI 2008a and WGI 2008c were used as source documents.

${ }^{b}$ For this spent fuel type, it was assumed that DOE spent fuel canisters would be employed. The per-canister mass was calculated by dividing the total mass of the particular type by the total number of canisters, as provided in BMI 2007.

${ }^{c}$ For the purposes of this analysis, some waste streams were assumed to be packaged in HLW canisters that would not be classified as HLW. Waste classification and selection of specific transportation casks would be completed as the facility design and waste characteristics are further developed.

${ }^{\mathrm{d}}$ It was assumed that five rail cars per shipment would be used for all materials, including spent fuels. In the Yucca Mountain SEIS, three rail cars per commercial spent fuel shipment and five rail cars per DOE spent fuel shipment were assumed. As with the Yucca Mountain SEIS assessment, spacer cars were added for spent fuel shipments. Spacer cars were also assumed for $\mathrm{Cs} / \mathrm{Sr}$ waste shipments.

For non-spent fuel material and waste shipments, it was assumed that five rail cars per shipment would be used. Each rail car would have the same capacity of one truckload. This assumption is consistent with other DOE NEPA analyses including the Waste Management Programmatic EIS (DOE 1997) and the Idaho HLW and Facilities FEIS (DOE 2002e).

${ }^{\mathrm{e}}$ Each DOE rail cask is assumed to hold nine DOE spent fuel canisters. Therefore, each rail cask is assumed to hold the equivalent of nine truck shipments. With five rail cars per shipment, each rail shipment is assumed to transport the equivalent of 45 truck shipments of this material.

${ }^{\mathrm{f}}$ Inspection exposure analysis assumes that an inspector is located at a distance of $1 \mathrm{~m}$ from each truck trailer or rail car for a period of one hour.

${ }^{\mathrm{g}}$ It was assumed that the loading impacts for all spent fuel types analyzed in this PEIS would be the same on a per-shipment basis

${ }^{\mathrm{h}}$ It was assumed that inspection of rail shipments would occur at the origin and at the destination, for a total of two hours per rail car.

${ }^{\mathrm{i}}$ The conditional probabilities and release fractions for the spent fuel types were provided by the Yucca Mountain SEIS and FEIS analyses. For the HLW and Class B drum containers, this information was taken from the WVDP Waste Management EIS.

${ }^{j}$ Severe transportation accidents, those with a frequency of approximately $1 \times 10^{-7}$ per year, were analyzed using the RISKIND 2.0 computer code, consistent with the methodologies provided in BMI 2007. 


\section{E.5 REFERENCES}

10 CFR 51.52

10 CFR Part 71

10 CFR 73.37

10 CFR 71.47

49 CFR Part 171

49 CFR Part 172

49 CFR Part 173

49 CFR 173.441
U.S. Nuclear Regulatory Commission (NRC), "Environmental Effects of Transportation of Fuel and Waste--Table S-4," Code of Federal Regulations, Office of the Federal Register, National Archives and Records Administration, Washington, DC, Revised January 1, 2008.

NRC, "Packaging and Transportation of Radioactive Material," Code of Federal Regulations, Office of the Federal Register, National Archives and Records Administration, Washington, DC, Revised January 1, 2008.

NRC, "Requirements for Physical Protection of Irradiated Reactor Fuel in Transit," Code of Federal Regulations, Office of the Federal Register, National Archives and Records Administration, Washington, DC, Revised January 1, 2008.

NRC, "External Radiation Standards for All Packages," Code of Federal Regulations, Office of the Federal Register, National Archives and Records Administration, Washington, DC, Revised January 1, 2008.

U.S. Department of Transportation (DOT), "Annual Fees for Reactor Licenses, Including Holders of Certificates of Compliance, Registrations, and Quality Assurance Program Approvals and Government Agencies Licensed by the NRC," Code of Federal Regulations, Office of the Federal Register, National Archives and Records Administration, Washington, DC, Revised October 1, 2007.

DOT, "Hazardous Materials Table, Special Provisions, Hazardous Materials Communications, Emergency Response Information, and Training Requirements," Code of Federal Regulations, Office of the Federal Register, National Archives and Records Administration, Washington, DC, Revised October 1, 2007.

DOT, "Shippers-General Requirements for Shipments and Packagings," Code of Federal Regulations, Office of the Federal Register, National Archives and Records Administration, Washington, DC, Revised October 1, 2007.

DOT, "Radiation Level Limitations," Code of Federal Regulations, Office of the Federal Register, National Archives and Records Administration, Washington, DC, Revised October 1, 2007. 
49 CFR Part 174

49 CFR Part 175

49 CFR Part 176

49 CFR Part 177

49 CFR Part 178

49 CFR Part 179

49 CFR Part 180

49 CFR Part 397

49 CFR 397.101

44 FR 38690
DOT, "Carriage by Rail," Code of Federal Regulations, Office of the Federal Register, National Archives and Records Administration, Washington, DC, Revised October 1, 2007.

DOT, "Carriage by Aircraft," Code of Federal Regulations, Office of the Federal Register, National Archives and Records Administration, Washington, DC, Revised October 1, 2007.

DOT, "Carriage by Vessel," Code of Federal Regulations, Office of the Federal Register, National Archives and Records Administration, Washington, DC, Revised October 1, 2007.

DOT, "Carriage by Public Highway," Code of Federal Regulations, Office of the Federal Register, National Archives and Records Administration, Washington, DC, Revised January 28, 2008 .

DOT, "Specifications for Packagings," Code of Federal Regulations, Office of the Federal Register, National Archives and Records Administration, Washington, DC, Revised January 28, 2008.

DOT, "Specifications for Tank Cars," Code of Federal Regulations, Office of the Federal Register, National Archives and Records Administration, Washington, DC, Revised January 28, 2008.

DOT, "Continuing Qualification and Maintenance of Packagings," Code of Federal Regulations, Office of the Federal Register, National Archives and Records Administration, Washington, DC, Revised January 28, 2008.

DOT, "Transportation of Hazardous Materials; Driving and Parking Rules," Code of Federal Regulations, Office of the Federal Register, National Archives and Records Administration, Washington, DC, Revised October 1, 2007.

DOT, “ Routing of Class 7 Radioactive Materials: Requirements for Motor Carriers and Drivers," Code of Federal Regulations, Office of the Federal Register, National Archives and Records Administration, Washington, DC, Revised October 1, 2007.

DOT, "Transportation of Radioactive Materials, Memorandum of Understanding," Office of the Federal Register, National Archives and Records Administration, Washington, DC, July 2, 1979. 
49 U.S.C. 5101 et seq.

AEC 1972

BMI 2007

Chen et al. 2002

DHS 2008

DOE $1995 \mathrm{e}$

DOE 1997

DOE 2002d
"Federal Hazardous Materials Transportation Law," United States Code, Washington, DC, November 25, 2002.

U.S. Atomic Energy Commission (AEC), "Environmental Survey of Transportation of Radioactive Materials to and from Nuclear Power Plants,” WASH-1238, Washington, DC, December 1972.

Battelle Memorial Institute (BMI), "Calculation Report for the Transportation Impacts for the Draft Supplemental Environmental Impact Statement for a Geological Repository for the Disposal of Spent Nuclear Fuel and High-Level Radioactive Waste at Yucca Mountain, Nye County, Nevada," Calculation Report Number BCO-006, Battelle Memorial Institute, Columbus, OH, October 4, 2007.

Chen, S.Y., F. Monette, and B.M. Biwer, "A Resource Handbook on DOE Transportation Risk Assessment," DOE/EM/NTP/HB-01, National Transportation Program, U.S. Department of Energy, Albuquerque Office, Albuquerque, NM, July 2002.

U.S. Department of Homeland Security (DHS), "National Response Framework," U.S. Department of Homeland Security, Washington, DC, March 2008.

DOE, "Programmatic Spent Nuclear Fuel Management and Idaho National Engineering Laboratory Environmental Restoration and Waste Management Programs Final Environmental Impact Statement," DOE/EIS-0203, U.S. Department of Energy, Washington, DC, 1995.

DOE, "Final Waste Management Programmatic Environmental Impact Statement for Management, Treatment, Storage, and Disposal of Radioactive and Hazardous Waste," DOE/EIS-0200-F, U.S. Department of Energy, Office of Environmental Management, Washington, DC, May, 1997.

DOE, "Recommendations for Analyzing Accidents Under the National Environmental Policy Act," Office of NEPA Policy and Compliance, U.S. Department of Energy, Washington, DC, July 2002. Accessed at: http://gc.energy.gov/NEPA/nepa documents/ TOOLS/GUIDANCE/Volume2/2-8-accidents.pdf on September 16, 2008. 
DOE 2002e

DOE 2002h

DOE $2002 \mathrm{i}$

DOE 2004f

DOE $2004 j$

DOE $2008 f$

DOE O 460.1B

DOE O 460.2A

DOE 470.4A
DOE, "Idaho High-Level Waste and Facilities Disposition, Final Environmental Impact Statement," DOE/EIS-0287F, Idaho Operations Office, U.S. Department of Energy, Washington, DC, September, 2002.

DOE, "Estimating Radiation Risk from Total Effective Dose Equivalents (TEDE)," DOE/EH-412/0015/0802 Rev. 1, Office of Environmental Policy and Guidance, U.S. Department of Energy, Washington, DC, August 9, 2002.

DOE, "Final Environmental Impact Statement for a Geologic Repository for the Disposal of Spent Nuclear Fuel and High-Level Radioactive Waste at Yucca Mountain, Nye County, Nevada," DOE/EIS-0250, U.S. Department of Energy, Washington, DC, February 2002.

DOE, "West Valley Demonstration Project Final Waste Management Environmental Impact Statement," DOE/EIS-0337, West Valley Area Office, U.S. Department of Energy, Washington, DC, January 2004.

DOE, "Source Term Estimates for DOE Spent Nuclear Fuels," DOE/SNF/REP-078, Rev. 1, U.S. Department of Energy, Idaho Operations Office, Idaho Falls, ID, 2004.

DOE, "Final Supplemental Environmental Impact Statement for a Geologic Repository for the Disposal of Spent Nuclear Fuel and High-Level Radioactive Waste at Yucca Mountain, Nye County, Nevada," DOE/EIS-0250F-S1, U.S. Department of Energy, Office of Civilian Radioactive Waste Management, Las Vegas, NV, July 2008.

DOE Order 460.1B, "Packaging and Transportation Safety," U.S. Department of Energy, Washington, DC, April 4, 2003.

DOE Order 460.2A, "Departmental Materials Transportation and Packaging Management," U.S. Department of Energy, Washington, DC, December 22, 2004.

DOE Order 470.4A, "Safeguards and Security Program," U.S. Department of Energy, Washington, DC, May 25, 2007. 
Fischer et al. 1987

Jason Technologies 2001

Johnson and Michelhaugh 2003

Neuhauser et al. 2003

NRC 1977b

NRC 2000a

NRC 2005c

NRC 2006c

Saricks and Tompkins 1999
Fischer, L.E. C.K. Chou, M.A. Gerhard, C.Y. Kimura, R.W. Martin, R.W. Mensing, M.E. Mount, and M.C. Witte, "Shipping Container Response to Severe Highway and Railway Accident Conditions," NUREG/CR-4829, U.S. Nuclear Regulatory Commission, Washington, DC, 1987.

Jason Technologies, "Transportation Health and Safety Calculation/Analysis Documentation in Support of the Final EIS for Yucca Mountain Repository," CAL-HSS-ND-000003, Las Vegas, NV, 2001.

Johnson, P.E., and R.D. Michelhaugh, "Transportation Routing Analysis Geographic Information System (TRAGIS) User's Manual," Report No ORNL/NTRC-006, Revision 0, Oak Ridge National Laboratory, Oak Ridge, TN, June 2003.

Neuhauser, K.S., F.L., Kanipe, and R.F. Weiner, "RADTRAN 5, User Guide," SAND2003-2354, Sandia National Laboratories, Albuquerque, NM, July 2003.

NRC, "Final Environmental Statement on the Transportation of Radioactive Material by Air and Other Modes," NUREG-0170, Office of Standards Development, U.S. Nuclear Regulatory Commission, Washington, DC, December 1977.

NRC, "Reexamination of Spent Fuel Shipment Risk Estimates," J.L. Sprung, D.J. Ammerman, N.L.Breivik, R.J. Dukart, F.L. Kanipe, J.A. Koski, G.S. Mills, K.S. Neuhauser, H.D. Radloff, R.F. Weiner, and H.R. Yoshimura, NUREG/CR-6672, U.S. Nuclear Regulatory Commission, Washington, DC, March 2000.

NRC, "Environmental Impact Statement on the Construction and Operation of a Mixed Fuel Fabrication Facility at the Savannah River Site, South Carolina," NUREG-1767, Office of Nuclear Reactor Regulation, U.S. Nuclear Regulatory Commission, Washington, DC, February 2005.

NRC, "Environmental Impact Statement for an Early Site Permit (ESP) at the Exelon ESP Site," NUREG-1815, Office of Nuclear Reactor Regulation, U.S. Nuclear Regulatory Commission, Washington, DC, July 2006.

Saricks, C.L., and M.M. Tompkins, "State-Level Accident Rates of Surface Freight Transportation: A Reexamination," Report No. ANL/ESD/TM-150, Argonne National Laboratory, Argonne, IL, 1999. 
Shropshire and Herring 2004

SNL 2005

Tetra Tech $2008 f$

UMTRI 2003

Weiner et al. 2006

WGI 2008a

WGI 2008c

White House 2003

WNTI 2007
Shropshire, D.E., and S.J. Herring, "Fuel-Cycle and Nuclear Material Disposition Issues Associated with High-Temperature Gas Reactors," Idaho National Laboratory, October 2004.

Sandia National Laboratories (SNL), "Distance Distribution Distance between Power Plant and Repository," Sandia National Laboratories, Albuquerque, NM, May 2005.

Tetra Tech Inc., "Supporting Calculations for the Transportation Analysis of the Programmatic Alternatives in the GNEP PEIS," M. Dimsha, Tetra Tech, Inc., September 2008.

University of Michigan Transportation Institute (UMTRI), "Evaluation of the Motor Carrier Management Information System Crash File, Phase One," UMTRI-2003-6, University of Michigan, Ann Arbor, MI, 2003.

Weiner, R.F. D.M. Osborn, G.S. Mills, D. Hinojosa, T.J. Heames, and D.J. Orcutt, "RadCat 2.3 User Guide," Report No. SAND2006-6315, Sandia National Laboratories, Albuquerque, NM, October 2006.

Washington Group International (WGI), “Advanced Fuel Cycle Facility Conceptual Design and NEPA Support Activities (NEPA Data Study)," AFCF-ST-001, Rev. 1, Washington Group International, Western Operations Center, Denver, CO, April 2, 2008.

WGI, "Estimation of AFCF HLW, LLW and TRU-Contaminated Waste Volumes to Support the GNEP PEIS," AFCF-WP-00-003, Rev. A, Washington Group International, Western Operations Center, Denver, CO, April 8, 2008.

The White House, "Management of Domestic Incidents," Homeland Security Presidential Directive/HSPD-5, Office of the Press Secretary, Washington, DC, 2003.

World Nuclear Transport Institute (WNTI), "Nuclear Fuel Cycle Transport: The IAEA Regulations and their Relevance to Severe Accidents," Information Paper \#3, World Nuclear Transport Institute, 2007. Accessed at http://www.wnti.co.uk/UserFiles/ File/public/publications/informationpapers/wnti_info-3.pdf on March 13, 2008. 
WSR 2007

WSRC 2008a

Yuan et al. 1995
World Shipping Register (WSR), "Sea Distances-Voyage Calculator," World Shipping Register, 2007. Accessed at http://e-ships.net/dist.htm on October 15, 2007.

Washington Savannah River Company (WSRC), "Engineering Alternative Studies for Separations, NEPA Data Input Report," EAS-Q-NEP-G-00001, Revision 3, Washington Savannah River Company, April 2008.

Yuan, Y.C., S.Y. Chen, B.M. Biwer, and D.J. LePoire, "RISKIND - A Computer Program for Calculating Radiological Consequences and Health Risks from Transportation of Spent Nuclear Fuel," ANL/EAD-1, Argonne, IL, Argonne National Laboratory, 1995. 


\section{APPENDIX F}

\section{ENVIRONMENTAL IMPACT METHODOLOGY}





\section{APPENDIX F ENVIRONMENTAL IMPACT METHODOLOGY}

This appendix summarizes the methodology used to prepare the environmental impact analyses in this Global Nuclear Energy Partnership (GNEP) Programmatic Environmental Impact Statement (PEIS). A more detailed discussion of the methodology for certain impact analyses is contained in separate appendices, specifically Intentional Destructive Acts (Appendix B), Human Health and Worker Safety (Appendix C), Facility Accident Scenarios (Appendix D), and Transportation (Appendix E). The methodology used for the Domestic Programmatic Alternatives analysis is provided in Section F.1, and that used for the International Activities analysis is provided in Section F.2.

\section{F.1 ENVIRONMENTAL IMPACT METHODOLOGY FOR THE DOMESTIC Programmatic Alternatives Analysis}

This GNEP PEIS analyzes the potential environmental impacts associated with the current United States (U.S.) commercial nuclear fuel cycle and broad implementation of alternative nuclear fuel cycles. As a result, the analysis is necessarily broad and long-term, focusing on the potential impacts that could result from implementing each of the programmatic alternatives over many decades.

As described in Chapter 2, six domestic programmatic alternatives are analyzed in this PEIS:

- $\quad$ No Action Alternative-Continue Existing Once-Through Uranium Fuel Cycle

- Fast Reactor Recycle Alternative

- Thermal/Fast Reactor Recycle Alternative

- Thermal Reactor Recycle Fuel Cycle Alternative

- Once-Through Fuel Cycle Alternative Using Thorium

- Once-Through Fuel Cycle Alternative Using Heavy Water Reactors (HWRs) or High Temperature Gas-cooled Reactors (HTGRs)

\section{F.1.1 Electricity Projections, Nuclear Share of the Electricity Market, and Planning Period}

This PEIS analyzes broad implementation of each programmatic alternative in terms of total nuclear generating capacity. Data from the Energy Information Administration were used to determine electricity growth projections. Each year, the Energy Information Administration publishes the Annual Energy Outlook, which provides projections and analysis of domestic energy consumption, supply, prices, and carbon emissions, among other factors. The most recent version of the Annual Energy Outlook (the 2008 Release) provides such projections through 2030 (EIA 2008a). The Energy Information Administration's estimates assume the continuation of known trends in demographics and technology improvements and also assume that no changes occur in current laws, regulations, and policies. Assumptions regarding future electricity demand and nuclear power's share of the market affect estimates of the potential quantities of spent nuclear fuel (SNF) that would be generated and require management. The amount of SNF is an 
important parameter as it drives, among other factors, the amount of transportation, the potential capacity of future recycling facilities, the requirements for future geologic repository capacity, and other radioactive waste disposal capacity.

In this PEIS, the U.S. Department of Energy (DOE) assesses programmatic alternatives that would support an increase in nuclear electricity production. While DOE acknowledges that market forces (i.e., economics) would likely be the biggest factor influencing future nuclear electricity production, market forces are beyond the scope of this PEIS. This PEIS assumes that factors beyond the scope of this PEIS would not be barriers to the widespread implementation of any reasonable domestic programmatic alternatives. Further, DOE recognizes that a commitment by DOE to one or more of the programmatic alternatives could impact how the market views the economics of nuclear power.

Because of uncertainty with respect to the rate of growth in nuclear generating capacity, the GNEP PEIS considers a range of growth rates: zero growth, 0.7 percent annual growth, 1.3 percent annual growth, and 2.5 percent annual growth. ${ }^{1}$

To allow time for broad implementation of the alternatives, the projections for nuclear-generated electricity growth were extended through approximately 2060 to 2070 . Based on the growth rates set forth above, all of the PEIS alternatives were assessed at capacities of 100 gigawatts electric (GWe) (zero growth), $150 \mathrm{GWe}(0.7$ percent annual growth), $200 \mathrm{GWe}(1.3$ percent annual growth), and $400 \mathrm{GWe}$ (2.5 percent annual growth). Each alternative was analyzed to determine what facilities and capacities would be necessary to achieve these generating capacities. Certain decisions could have significant environmental impacts well beyond 50 years, particularly in terms of impact on the capacity requirements for future geologic disposal. To the extent practical, this PEIS considers these impacts, typically in a qualitative manner.

\section{F.1.2 Facilities and Capacities Needed to Meet the Demand and Data Quality}

For each programmatic alternative, DOE determined the facilities, capacities, infrastructure, and other activities that would be needed to meet its assumed demand discussed in Section F.1.1. Once facilities were identified, DOE used the best available data to define the resource requirements and potential environmental impacts of construction and operation of the facilities and activities. These data were generally pre-conceptual information developed specifically for this PEIS or existing data developed for similar facilities. The quantity and quality of data concerning each alternative varies. Some facilities (such as SNF storage facilities) are operational and have actual data available; other facilities (such as a nuclear fuel recycling center that uses the UREX process to separate SNF into usable products and waste and makes transmutation fuel from the usable constituents) have never been operated on a commercial scale. Some data were obtained from sources within the United States, while other data were obtained from foreign sources, including the International Atomic Energy Agency (IAEA) and the Korean Atomic Energy Research Institute. For example, much of the information for the

\footnotetext{
${ }^{1}$ The 0.7 percent and 1.3 percent annual growth rates are based on Energy Information Administration estimates for nuclear generating capacity and total electricity demand as of December 2007 (EIA 2007a). As this draft PEIS was being prepared for issuance, the Energy Information Administration revised these estimates to 0.6 percent and 1.1 percent, respectively (EIA 2008a). DOE will address these, and any newer Energy Information Administration estimates, in the final PEIS, as appropriate.
} 
DUPIC $^{2}$ fuel cycle was obtained from Korean and Canadian resources. In all cases, DOE used judgments of engineers and researchers to identify and utilize the best data available.

DOE used these data to estimate the amount of land required for the various potential facilities, the types and quantities of wastes that would be generated, the number of employees that would be required for construction and operation, the amount of water the facilities would use, and other resource requirements. DOE then used this information to estimate environmental impacts. The PEIS analysis focuses on the annual resource requirements for nuclear power reactors (e.g., uranium and/or thorium), the amount of waste that would be generated and need to be disposed, the amount of uranium and other actinides that could be recycled, human health and accident impacts, and the impacts of radiological materials transportation.

\section{F.1.3 Facility Locations}

For certain PEIS analyses (e.g., impacts to human health from normal operations and accidents), DOE defined the characteristics of six generic sites to assess the potential impacts associated with the facilities under the domestic programmatic alternatives. These sites provide a range of values for two parameters - offsite (50 miles [mi] [80 kilometers $\{\mathrm{km}\}]$ ) population and meteorological conditions - that would directly affect the offsite impacts. Appendix D provides more details on these generic sites.

All of the GNEP programmatic alternatives, including the No Action Alternative, would produce materials (e.g., either SNF, high-level waste [HLW], or both) that would need to be isolated in a deep geologic repository as a means of final disposition. The PEIS analyzes the generic impacts of siting, constructing, and operating future geologic repository capacity and the impacts associated with transporting these materials to a geologic repository (see Section F.1.5). Some of the closed fuel cycle alternatives could also separate cesium (Cs) and strontium (Sr) wastes that would require transportation to a storage or disposal facility or be stored onsite. The PEIS assesses both of these alternative scenarios. Additionally, this PEIS assesses the impacts of storage and transportation associated with other radioactive wastes (e.g., low-level waste [LLW] and Greater-than-Class-C [GTCC] LLW). Transportation of these wastes to future disposal facilities is analyzed.

\section{F.1.4 Resource Analyses}

In general, the PEIS analyses were tailored to the decisions to be made following completion of the PEIS. Consequently, the PEIS presents the "types of impacts" that could result, while acknowledging that the specific impacts could be site dependent. For example, the PEIS indicates the amount of water that a facility might require but does not estimate what the impacts of using this much water would be, as that would be a function of the facility location. A facility that requires 1 billion gallons $\left(3.8\right.$ million $\left.\mathrm{m}^{3}\right)$ of water annually might have small impacts at a site where a large volume of water is readily available. Also, actual water requirements could vary based on future design considerations (e.g., related to cooling systems).

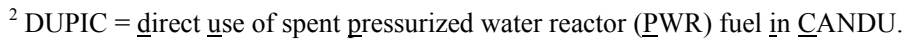


A screen of all relevant resources was conducted to identify those potential impacts that could be meaningfully evaluated at a programmatic level. For several resource areas, DOE decided that a meaningful programmatic analysis was not possible, particularly in the absence of site-specific information. For example, impacts to cultural and paleontological resources were not analyzed at the programmatic level because impacts would be inherently site-specific and a programmatic assessment would not provide meaningful data for the decision maker. Other resource areas similarly screened from this programmatic analysis are biological resources, environmental justice, geology and soils, noise, and site infrastructure. Chapter 4 of this PEIS includes a discussion of the following resource areas:

Land Resources: Impacts to land would be site dependent. As such, impacts were assessed based on the amount of land that would be associated with implementation of each alternative.

Visual Resources: Impacts to visual resources would be site dependent. As such, impacts were assessed by determining whether any impacts, beyond the facilities themselves, would affect visual resources at relatively large distances. For example, if a facility generated a visible water vapor plume from cooling tower operations, this would be identified.

Water Resources: Impacts to water resources would be site dependent. The PEIS presents the amounts of water that could be required for facilities.

Air Resources: Impacts to nonradiological air quality would be site dependent. The PEIS provides qualitative discussions of potential impacts to nonradiological air quality. Radiological impacts associated with air emissions are discussed below under "Human Health (Normal Operations)."

Socioeconomic Impacts: Impacts to socioeconomics would be site dependent and would occur primarily in communities in the vicinity of any future facility. The PEIS provides estimates of the number of workers required for both construction and operation.

Human Health (Normal Operations): Impacts related to health and safety would be both site dependent and site independent. For example, impacts to workers at a facility would occur regardless of the location. DOE estimated the impacts to workers and presented them in terms of potential latent cancer fatalities (LCFs) from radiological exposures during normal operations. Estimates of potential impacts were based on data for existing facilities (e.g., worker exposure data from existing reactor operations) or pre-conceptual data developed for proposed facilities (e.g., for a nuclear fuel recycling center, worker exposure data were specifically developed). For differing reactor technologies, the PEIS assumed that worker doses would not be significantly different than the average doses to workers at existing light water reactors (LWRs); no data were discovered that invalidated this assumption.

With respect to potential impacts to the public, exposures would vary depending on many factors, including radiological releases from facilities, prevailing weather patterns, and the proximity of the facilities to local population centers. The availability of data to estimate impacts to the public varied among the alternatives. Based on modeling results for generic sites, the 
impacts (in terms of dose and LCFs to the maximally exposed individual and the surrounding $50 \mathrm{mi}[80 \mathrm{~km}]$ population) from normal operations are presented.

For some alternatives, specific radiological release data were not available. In these instances, DOE estimated public exposures based on compliance with expected licensing regulations. For example, any new commercial nuclear facility would be required to comply with the U.S. Nuclear Regulatory Commission (NRC) regulations. Title 10 Code of Federal Regulations (CFR) Part 20 (10 CFR Part 20) requires that each licensee conduct operations so that the total effective dose equivalent to individual members of the public from the licensed operations does not exceed 100 millirem (mrem) in a year. Furthermore, 10 CFR Part 20 requires that power reactor licensees comply with the U.S. Environmental Protection Agency's (EPA's) environmental radiation standards contained in 40 CFR Part 190 (i.e., 25 mrem to the whole body, $75 \mathrm{mrem}$ to the thyroid, and $25 \mathrm{mrem}$ to any other organ of any member of the public from the uranium fuel cycle).

Accidents: Accident impacts would also be dependent on many factors, including the types of accidents, radionuclides released, site characteristics, and the distribution of population in the surrounding environment. Appendix D explains the methodology that was employed to estimate the impacts for a range of accidents at six generic sites for the various facilities analyzed in the PEIS. These accident analyses are representative of the types of accident impacts that could result from these facilities. The PEIS presents a range of impacts associated with accidents (e.g., impacts from both high probability/low consequence accidents and low probability/high consequence accidents).

Intentional Destructive Acts: In addition to the accident analysis, DOE prepared an impact analysis of terrorist acts, Appendix B.

SNF and Wastes: Impacts from wastes and SNF were analyzed based on estimates of the amount of material that would be generated for each of the four analyzed growth rates during a period of approximately 50 to 60 years and of annual generation at the four analyzed nuclear generating capacities identified above. SNF and wastes would be managed in accordance with regulatory requirements. For SNF and some wastes, such as HLW, this PEIS analyzes impacts associated with the transportation of these materials to a geologic repository (see Section F.1.5).

As mentioned in Section F.1.3, Cs and Sr, if separated from LWR SNF, could be transported to a storage or disposal facility or stored at a recycling facility for extended time frames up to approximately 10 "half-lives" 3 following recycle (approximately 300 years). If stored at the recycling facility, institutional controls to safeguard this material would be required during this time period. The PEIS assesses these alternative scenarios.

All of the alternatives would generate GTCC LLW, either during normal operations or during decontamination and decommissioning. The Low Level Radioactive Waste Policy Amendments Act of 1985 assigns the responsibility for the disposal of GTCC LLW to the Federal Government (DOE) (42 U.S.C. 2021). This legislation specified that the GTCC LLW must be disposed in a

\footnotetext{
${ }^{3}$ Radioactive materials decay over time. "Half-life" refers to the time required for the quantity of a radioactive material to decay to half of its initial value. After approximately 10 half-lives, there would be approximately a 99.9 percent reduction (or a factor of 1,000 reduction) in the amount of the isotope present.
} 
facility licensed by the NRC. There are no facilities currently licensed by NRC for disposal of GTCC LLW. This PEIS assesses the transportation impacts of GTCC LLW to a hypothetical disposal site using a range of distances to account for the unknown origin and destination of this material.

Resource Requirements: DOE analyzed the resources that would be needed to support the programmatic alternatives. For example, this PEIS assesses the amount of uranium and thorium (as appropriate) that each alternative would require and discusses the availability of that resource.

Sensitivity Analyses: This PEIS includes sensitivity analyses, as appropriate, for each alternative. For example, for the Fast Reactor Recycle Alternative and the Thermal/Fast Reactor Recycle Alternative, the ultimate deployment of fast reactors could be affected by the conversion ratio $(\mathrm{CR})^{4}$ of fast reactors. Because the $\mathrm{CR}$ is essentially a measure of the efficiency by which a fast reactor consumes transuranics, it could directly affect how many fast reactors would be deployed, the percentage of transuranics that would be consumed, and how much SNF and HLW would require disposal in a geologic repository. This PEIS assesses how the impacts presented could change depending on changes in the CR. Other sensitivity analyses include a discussion of differing SNF separation technologies and the use of differing mixed-oxide reactor fuels.

\section{F.1.5 Impacts of Transportation}

A transportation analysis was prepared to determine the potential impacts associated with transporting all radiological materials (i.e., fuels and waste) associated with the domestic programmatic alternatives. The transportation analysis determined the number of radiological shipments (i.e., for both rail and truck, broken down by material to be transported) that would be required for each alternative.

The routes were analyzed using the routing computer code WebTRAGIS (Johnson and Michelhaugh 2003). The routes were calculated using current routing practices and applicable routing regulations and guidelines. Route characteristics include total shipment distance between each origin and destination and the fractions of travel in rural, suburban, and urban population density zones. Population densities were determined using data from the 2000 census.

The PEIS considered route characteristics for truck and rail transport over distances of 150, 500, $1,500,2,100$, and $3,000 \mathrm{mi}(241,805,2,414,3,380$, and 4,828 $\mathrm{km})$. Of the values provided above, shipments analyzed at the $2,100 \mathrm{mi}(3,380 \mathrm{~km})$ distance are used as the representative case for the domestic programmatic alternatives analyses. The population density values for all five scenarios were updated to reflect census 2000 data. Appendix E provides additional details regarding the methodology that was used to perform the transportation analysis.

\footnotetext{
${ }^{4}$ As used in this PEIS, the "conversion ratio" (CR) of a fast reactor is the ratio of the amount of transuranic elements produced to the amount that is consumed in the reactor during the time the fuel is in the reactor. The CR determines the number of fast reactors required to consume transuranics separated from the LWR SNF. At a CR of 0.5 , approximately 20 percent of the transuranics would be destroyed per fast reactor recycle pass. The PEIS also includes a sensitivity analysis of changing the $\mathrm{CR}$.
} 
Transportation impacts are presented in terms of radiological impacts (expressed in person-rem and converted to LCFs using a dose-to-risk conversion factor of 600 fatal cancers per $10^{6}$ person-rem, which equates to $6 \times 10^{-4} \mathrm{LCFs}$ per person-rem [DOE 2002h]). The results of the transportation analysis are presented in two sets of tables for each alternative. The first set of tables presents the impacts associated with handling (loading and inspection). The impacts of handling are independent of the distance that the material would be transported. As such, the handling impacts would be the same whether the SNF is transported, for example, $500 \mathrm{mi}$ $(805 \mathrm{~km}), 2,100 \mathrm{mi}(3,380 \mathrm{~km})$, or any other distance. For this reason, these impacts were presented separately from the in-transit impacts (which are presented in the second set of tables).

Unlike handling impacts, the in-transit impacts are dependent on the distance that material would be transported. The locations of future facilities (e.g., reactors, nuclear fuel recycling centers, and a geologic repository) are unknown. The in-transit impacts for the transportation of SNF or HLW to a geologic repository are based on $2,100 \mathrm{mi}(3,380 \mathrm{~km})$ of transport. This distance was selected because it is the average distance that has been analyzed previously (in National Environmental Policy Act [NEPA] documents) for all SNF and HLW considered for geologic disposal. The in-transit impacts would vary based on a variety of factors, including the distance that the radiological materials would be transported, the specific routes that would be utilized, the population densities along those routes, and others. Of these factors, the transport distance is considered to be the most significant factor. This PEIS analyzes how the impacts would change as a function of distance traveled. Although the in-transit impacts are not exactly "linear" (i.e., twice the impacts for twice the distance transported), it is a close approximation. Consequently, if the radiological materials were transported $500 \mathrm{mi}(805 \mathrm{~km})$, all of the in-transit impacts could be calculated by multiplying the values in those tables by $0.24(500 / 2,100)$. Appendix $\mathrm{E}$ provides additional information regarding the assumptions, methodology, and impacts for the transportation analysis for the programmatic alternatives.

\section{F.1.6 Common Impacts}

DOE identified actions and impacts that would be common to all of the domestic programmatic alternatives. Such things as uranium mining, uranium enrichment, uranium fuel fabrication, and continuation of the Advanced Fuel Cycle Initiative (AFCI) fit into this category. Although the associated impacts would be common, this does not mean impacts would be exactly the same for each alternative. For example, although each alternative would require uranium enrichment, both the quantities of uranium requiring enrichment and the percentage of enrichment could be different. Those differences, where notable, are discussed in the PEIS. DOE used the best available information to estimate these impacts, including existing NEPA documentation. For example, for uranium enrichment, DOE used a recent (2006) EIS prepared by the NRC to estimate the types of impacts that would result from uranium enrichment (NRC 2006b).

\section{F.1.7 Cumulative Impacts}

A cumulative impact analysis was prepared for the domestic programmatic alternatives. The methodology for that analysis is described in Chapter 5. 


\section{F.2 ENVIRONMENTAL IMPACT METHODOLOGY FOR THE INTERNATIONAL ACTIVITIES ANALYSIS}

Impacts associated with international activities related to GNEP are discussed in Chapter 7, which includes a qualitative analysis of transportation in the United States and across the world's oceans, as well as other types of potential impacts. The methodology used for this analysis is described in Chapter 7, Section 7.2. 


\section{F.3 REFERENCES}

10 CFR Part 20

40 CFR Part 190

42 U.S.C. 2021

DOE 2002h

EIA 2007a

EIA 2008a

Johnson and Michelhaugh 2003

NRC 2006b
U.S. Nuclear Regulatory Commission (NRC), "Standards for Protection Against Radiation," Code of Federal Regulations, Office of the Federal Register, National Archives and Records Administration, Washington, DC, Revised January 1, 2008.

Environmental Protection Agency (EPA), "Environmental Radiation Protection Standards for Nuclear Power Operations," Code of Federal Regulations, Office of the Federal Register, National Archives and Records Administration, Washington, DC, Revised July 1, 2007.

"Low Level Radioactive Waste Policy Act, Amended," LLRWPA, United States Code, Washington, DC, January 15, 1986.

U.S. Department of Energy (DOE), "Estimating Radiation Risk from Total Effective Dose Equivalents (TEDE)," DOE/EH412/0015/0802 Rev. 1, Office of Environmental Policy and Guidance, U.S. Department of Energy, Washington, DC, August 9, 2002.

Energy Information Administration (EIA), "AEO2008, Annual Energy Outlook 2008 (Early Release)," DOE/EIA-0383, Energy Information Administration, U.S. Department of Energy, Washington, DC, December 2007. Accessed at http://www.eia.doe.gov/oiaf/aeo/pdf/earlyrelease.pdf on January 22, 2008.

EIA, "Annual Energy Outlook 2008 With Projections to 2030," DOE/EIA-0383 (2008), Energy Information Administration, U.S. Department of Energy, Washington, DC, June 2008. Accessed at http://www.eia.doe.gov/oiaf/aeo/pdf/0383(2008).pdf on July 3, 2008.

Johnson, P.E., and R.D. Michelhaugh, "Transportation Routing Analysis Geographic Information System (TRAGIS) User's Manual," Report No. ORNL/NTRC-006, Revision 0, Oak Ridge National Laboratory, Oak Ridge, TN, June 2003.

NRC, "Environmental Impact Statement for the Proposed American Centrifuge Plant in Piketon, Ohio," NUREG-1834, U.S. Nuclear Regulatory Commission, Washington, DC, 2006. 



\section{APPENDIX G}

\section{PROJECT NOTICES}





\section{APPENDIX G PROJECT NOTICES}

This Appendix includes the following project notices:

- Request for Expressions of Interest Global Nuclear Energy Partnership (GNEP) Technology Demonstration Program-March 17, 2006

- Advance Notice of Intent to Prepare an Environmental Impact Statement for the Global Nuclear Energy Partnership Technology Demonstration Program-March 22, 2006

- Modified Request for Expressions of Interest to Perform Site Evaluation Studies in support of the Global Nuclear Energy Partnership (GNEP) Technology Demonstration Program-May 16, 2006

- Department of Energy (DOE) Press Release "DOE Continues Path Forward on Global Nuclear Energy Partnership: Department Announces \$20 Million for GNEP Siting Studies and Seeks Further Coordination with Industry"-August 3, 2006

- Notice of Request for Expressions of Interest for \$20 million to conduct detailed siting studies for public or commercial entities to host GNEP facilities-August 3, 2006

- Notice of Request for Expressions of Interest in an Advanced Burner Reactor to Support the Global Nuclear Energy Partnership_-August 7, 2006

- Notice of Request for Expressions of Interest in a Consolidated Fuel Treatment Center to Support the Global Nuclear Energy Partnership_August 7, 2006

- DOE Press Release "Department of Energy Selects Recipients of GNEP Siting Grants" November 29, 2006

- Notice of Intent to Prepare a Programmatic Environmental Impact Statement for the Global Nuclear Energy Partnership_January 4, 2007

- DOE Press Release "Department of Energy Releases Global Nuclear Energy Partnership Strategic Plan"-January 10, 2007

- DOE Press Release "Department of Energy Awards Over \$10 Million for GNEP Siting Grants"-_January 30, 2007

- Notice of Extension of Time to Submit Scoping Comments on the Programmatic Environmental Impact Statement for the Global Nuclear Energy PartnershipApril 3, 2007 
- Financial Assistance Opportunity for the Global Nuclear Energy Partnership Deployment Studies-May 9, 2007

- DOE Press Release "Department of Energy and Nuclear Regulatory Commission Increase Cooperation to Advance Global Nuclear Energy Partnership"—July 17, 2007

- DOE Press Release "Department of Energy to Award \$16 Million for GNEP Studies"July 30,2007

- DOE Press Release "Department of Energy Awards More than \$16 Million for GNEP Technology Development Plans"-October 1, 2007

- DOE Press Release "United States, France and Japan Increase Cooperation on SodiumCooled Fast Reactor Prototypes"-February 1, 2008

- DOE Press Release "DOE Awards \$18.3 Million to Nuclear Industry Consortia for GNEP Studies"-March 28, 2008

- DOE Press Release "DOE Seeks to Invest up to $\$ 15$ Million in Funding for Nuclear Fuel Cycle Technology Research and Development"-April 17, 2008

- DOE Press Release "U.S. Department of Energy and Tennessee Valley Authority Increase Cooperation on Nuclear Fuel Cycle Data"-April 24, 2008 


\section{R--EOI - GNEP Technology Demonstration Program}

Solicitation Number: DE-RP07-06ID14760

Agency: Department of Energy

Office: Federal Locations

Location: All DOE Federal Contracting Offices

Notice Type:

Presolicitation

Posted Date:

March 17, 2006

Response Date:

March 31, 2006

Archiving Policy:

Automatic, on specified date

Archive Date:

September 30, 2006

Original Set Aside:

N/A

Set Aside:

N/A

Classification Code:

$\mathrm{R}$-- Professional, administrative, and management support services

\section{Synopsis:}

Added: March 17, 2006

REQUEST FOR EXPRESSIONS OF INTEREST - GLOBAL NUCLEAR ENERGY PARTNERSHIP (GNEP) TECHNOLOGY DEMONSTRATION PROGRAM The U.S. Department of Energy (DOE), Office of Nuclear Energy, Science and Technology (NE) is seeking Expressions of Interest (EOI) from entities interested in competing, on a full and open basis, for the award of one or more contracts to perform site evaluation studies. These studies will evaluate prospective locations to host one or more demonstration projects in support of the Global Nuclear Energy Partnership (GNEP). A total of up to \$20 million may be available for the site evaluation studies, with no single award exceeding $\$ 5$ million. The anticipated period of performance for site evaluation study contracts is 90 calendar days. The GNEP Technology Demonstration Program would demonstrate certain technologies that could change the way spent nuclear fuel from commercial light-water nuclear power reactors is managed. DOE intends to demonstrate three key elements that would comprise a proliferation-resistant closed fuel cycle. These key elements are: (1) a proliferation-resistant process to separate usable elements in commercial spent nuclear fuel from its waste elements; (2) the conversion of transuranics; and (3) an advanced fuel cycle facility. The DOE GNEP web home page contains further information about the GNEP program. The home page web link is http://www.gnep.energy.gov/. The anticipated deliverable under each site evaluation study 
contract is a site evaluation study report containing detailed information about: the proposed site location (to be chosen by the entity submitting a contract offer and to which the offeror has a legally enforceable commitment to perform the project from the site that will be evaluated in the siting study); facilities (existing or new) that will be used in the demonstration project; federal, state and local regulatory and permitting requirements; project milestones; estimated project costs, including fees associated with meeting regulatory requirements; and other factors that may affect project success, including legislative or regulatory requirements and public perception issues. The site evaluation study will be used to provide information to support the preparation of an Environmental Impact Statement (EIS) that DOE is initiating to evaluate the potential environmental impacts associated with the GNEP Technology Demonstration Program. Given the importance of these studies in supporting preparation of the EIS, the technical, regulatory and public outreach expertise of site evaluation study contractors will be of paramount importance. In addition to siting studies, successful offerors may also be tasked to provide technical evaluation and reporting services to the EIS contractor during EIS preparation, public meetings, and the preparation of responses to comments. Collaborative arrangements for submitting site evaluation study contract proposals are encouraged. These arrangements may include, to the extent permitted by law, domestic private companies, not for profit institutions, state or local governments and agencies, academic institutions, non-government organizations, trade associations, etc. The location of demonstration project facilities is not limited to DOE sites, but may include other federal and non-federal sites on a strictly voluntary basis. This $\mathrm{EOI}$ is intended to encourage an open exchange of ideas regarding the solicitation, award, and administration of site evaluation study contracts. Entities interested in submitting a proposal for a site evaluation study contract are requested to submit a response to this EOI that identifies the entity [organization name, type of organization (private company, not for profit institution, government contractor, etc)] and a point of contact (including an e-mail address and telephone number). Entities submitting a response to this EOI are also encouraged to provide their thoughts and suggestions through the comment form on how DOE should conduct the acquisition and award and administer the site evaluation study contracts. In particular, DOE is seeking input on: Contract type, content of the statement of work, and specific contract terms or conditions - Evaluation criteria and selection considerations, including any qualification criteria - Other considerations DOE should address during the acquisition (e.g., organizational conflict of interest issues associated with an entity supporting the DOE EIS and working on a site study contract) or after contract award The comment submittal form is available on the GNEP Technology Demonstration Program solicitation website located at www.id.doe.gov. Written responses to this EOI must not exceed four pages and must be received by not later than 4:00 PM, Mountain Time, on March 31, 2006. Send responses by email to Ms. Janet Surrusco, Contract Specialist, United States Department of Energy, Idaho Operations Office, at surrusjk@id.doe.gov Confidential or business sensitive information contained in the submission must be identified and marked accordingly. DOE will protect this information from public disclosure to the extent permitted by law. This EOI is not a formal solicitation requesting proposals and does not represent a commitment by the Government to award a contract. The Government does not intend to formally respond to information submitted in response to this EOI. The Government is not responsible for costs incurred to submit a response to this EOI, conducting other activities associated with pre-solicitation planning, or submitting a proposal in response to a solicitation if issued.

\section{Contracting Office Address:}

850 Energy Drive (MS-1221) Idaho Falls, ID

\section{Point of Contact(s):}

Wade Hillebrant, Contracting Officer, 208-526-0547, hillebtw@id.doe.gov; Janet Surrusco, Contract Specialist, 208-526-5477, surrusjk@id.doe.gov Janet Surrusco, Contract Specialist 
turtles, provide information on population dynamics to improve stock assessments, and to better understand the distribution of turtles in time and space. Turtles that are incidentally captured during resource assessment cruises would be used by the SEFSC in their assessments of distribution and abundance of turtles, as well as the cumulative impact of the relevant fishery on the stocks. The incidental capture would accrue to and be authorized by the fisheries being researched. The SEFSC would annually handle, identify, examine, measure, weigh, photograph, flipper tag, passive integrated transponder (PIT) tag, skin biopsy, and release or salvage the carcass, tissue, and parts of up to 6 green, 17 loggerhead, 8 Kemp's ridley, 6 hawksbill, 6 olive ridley, 6 unidentified hardshell, and 17 leatherback sea turtles. Research would occur in the Atlantic Ocean, Gulf of Mexico, Caribbean Sea, and their tributaries. The permit would be issued for five years.

Dated: March 16, 2006.

Stephen L. Leathery,

Chief, Permits, Conservation and Education Division, Office of Protected Resources,

National Marine Fisheries Service.

[FR Doc. E6-4159 Filed 3-21-06; 8:45 am]

BILLING CODE 3510-22-S

\section{DEPARTMENT OF DEFENSE}

\section{GENERAL SERVICES ADMINISTRATION}

\section{NATIONAL AERONAUTICS AND SPACE ADMINISTRATION}

[OMB Control No. 9000-0026]

\section{Federal Acquisition Regulation; Submission for OMB Review; Change Order Accounting}

AGENCIES: Department of Defense (DOD), General Services Administration (GSA), and National Aeronautics and Space Administration (NASA).

ACTION: Notice of request for public comments regarding an extension to an existing OMB clearance (9000-0026).

SUMMARY: Under the provisions of the Paperwork Reduction Act of 1995 (44 U.S.C. Chapter 35), the Federal

Acquisition Regulation (FAR)

Secretariat has submitted to the Office of Management and Budget (OMB) a request to review and approve an extension of a currently approved information collection requirement concerning change order accounting. A request for public comments was published in the Federal Register at 71
FR 2914, January 18, 2006. No comments were received.

Public comments are particularly invited on: Whether this collection of information is necessary for the proper performance of functions of the FAR, and whether it will have practical utility; whether our estimate of the public burden of this collection of information is accurate, and based on valid assumptions and methodology; ways to enhance the quality, utility, and clarity of the information to be collected; and ways in which we can minimize the burden of the collection of information on those who are to respond, through the use of appropriate technological collection techniques or other forms of information technology. DATES: Submit comments on or before April 21, 2006.

ADDRESSES: Submit comments regarding this burden estimate or any other aspect of this collection of information, including suggestions for reducing this burden to: FAR Desk Officer, OMB, Room 10102, NEOB, Washington, DC 20503, and a copy to the General Services Administration, FAR Secretariat (VIR), 1800 F Street, NW., Room 4035, Washington, DC 20405. FOR FURTHER INFORMATION CONTACT: Jeritta Parnell, Contract Policy Division, GSA (202) 501-4082.

\section{SUPPLEMENTARY INFORMATION:}

\section{A. Purpose}

FAR clause 52.243-6, Change Order Accounting, requires that, whenever the estimated cost of a change or series of related changes exceed $\$ 100,000$, the contracting officer may require the contractor to maintain separate accounts for each change or series of related changes. The account shall record all incurred segregable, direct costs (less allocable credits) of work, both changed and unchanged, allocable to the change. These accounts are to be maintained until the parties agree to an equitable adjustment for the changes or until the matter is conclusively disposed of under the Disputes clause. This requirement is necessary in order to be able to account properly for costs associated with changes in supply and research and development contracts that are technically complex and incur numerous changes.

\section{B. Annual Reporting Burden}

Respondents: 8,750.

Responses Per Respondent: 18.

Annual Responses: 157,500.

Hours Per Response: .084.

Total Burden Hours: 13,230.

\section{Annual Recordkeeping Burden}

Recordkeepers: 8,750.
Hours Per Recordkeeper: 1.5.

Total Recordkeeping Burden Hours: 13,125.

Total Burden Hours: 26,355.

Obtaining Copies of Proposals: Requesters may obtain a copy of the information collection documents from the General Services Administration, FAR Secretariat (VIR), Room 4035, Washington, DC 20405, telephone (202) 501-4755. Please cite OMB Control No. 9000-0026, Change Order Accounting, in all correspondence.

Dated: March 14, 2006.

\section{Gerald Zaffos,}

Director, Contract Policy Division.

[FR Doc. 06-2751 Filed 3-21-06; 8:45 am] BILLING CODE 6820-EP-S

\section{DEPARTMENT OF ENERGY}

Advance Notice of Intent To Prepare an Environmental Impact Statement for the Global Nuclear Energy Partnership Technology Demonstration Program

AGENCY: Department of Energy.

ACTION: Advance notice of intent.

SUMmARY: The U.S. Department of Energy (DOE) is providing this Advance Notice of Intent (ANOI) to prepare an Environmental Impact Statement (EIS) pursuant to the National Environmental Policy Act (NEPA) for the Global Nuclear Energy Partnership (GNEP) Technology Demonstration Program. The GNEP Technology Demonstration Program would demonstrate certain technologies that could change the way spent nuclear fuel from commercial light-water nuclear power reactors is managed. This EIS will inform DOE officials and the public of the potential environmental impacts associated with the proposed action, which is to demonstrate U.S. capability to safely recycle spent nuclear fuel using proliferation-resistant separation processes and the conversion of transuranics into shorter-lived radioisotopes.

The proposed action includes three key elements that would comprise a proliferation-resistant closed fuel cycle: (1) The demonstration of separation processes in which usable and waste materials that are found in spent nuclear fuel are separated; (2) the demonstration of the conversion of transuranics; and (3) the demonstration of an advanced fuel fabrication process.

The EIS will evaluate all reasonable alternative technologies and locations for the key elements of the proposed GNEP Technology Demonstration Program. New facilities and 
modifications to existing facilities might be required for the Technology Demonstration Program. The EIS will address siting, construction or modification, and operation of these facilities. DOE is issuing this ANOI, pursuant to its NEPA regulations at 10 CFR 1021.311(b), to inform and request early comments from Federal agencies, state and local governments, Native American tribes, industry, other organizations, and members of the public regarding the proposed action, the reasonable alternatives, and the potential environmental impacts.

DATES: DOE invites comments on this ANOI through May 8, 2006. DOE will consider comments received after May 8, 2006 to the extent practicable. DOE intends to issue a Notice of Intent (NOI) for the EIS later this year. After the NOI is issued, DOE will conduct public scoping meetings to assist in further defining the scope of the EIS and to identify significant issues to be addressed. The dates and locations of scoping meetings will be announced in the NOI, subsequent Federal Register notices (as needed), and in local media.

ADDRESSES: Please direct comments, suggestions, or relevant information on the planned EIS and questions concerning the proposed action to: Timothy A. Frazier, NEPA Document Manager, Office of Nuclear Energy, Science and Technology, U.S. Department of Energy, 1000 Independence Avenue, SW., Washington, DC 20585-0119, Telephone: 866-645-7803, Fax: 866645-7807, E-mail to:

GNEPTechDemo@nuclear.energy.gov.

FOR FURTHER INFORMATION CONTACT: TO request further information about the EIS or to be placed on the EIS distribution list, use any of the methods listed under ADDRESSES above. Supplementary information on GNEP and the proposed GNEP Technology Demonstration Program may be found at http://www.gnep.energy.gov.

For general information concerning the DOE NEPA process, contact: Carol Borgstrom, Director, Office of NEPA Policy and Compliance (EH-42), U.S. Department of Energy, 1000 Independence Avenue, SW., Washington, DC 20585-0119; telephone: 202-586-4600, or leave a message at 1800-472-2756; fax: 202-586-7031; or send an e-mail to askNEPA@eh.doe.gov.

This ANOI will be available on the Internet at http://www.eh.doe.gov/nepa and http://www.gnep.energy.gov.

SUPPLEMENTARY INFORMATION:

\section{Background}

As part of President Bush's Advanced Energy Initiative, DOE has launched a new initiative, the Global Nuclear Energy Partnership (GNEP). The broad goals of GNEP are to: (1) Reduce the United States' dependence on foreign sources of fossil fuels and encourage economic growth, while meeting increasing demand for electricity without emitting air pollution and greenhouse gases; (2) recycle nuclear fuel using new proliferation-resistant technologies to recover more energy and reduce the volume of waste; (3) encourage prosperity growth and clean development around the world; and (4) utilize the latest technologies to reduce the risk of nuclear proliferation worldwide.

The proposed GNEP Technology Demonstration Program would involve the development of technologies to promote GNEP's goals. The GNEP Technology Demonstration Program would demonstrate technologies needed to implement a closed fuel cycle that enables recycling and consumption of spent nuclear fuel in a proliferationresistant manner. While DOE has had some success at bench-scale testing of these technologies, it has not yet proven that these technologies will be feasible in demonstration-scale facilities.

The proposed GNEP Technology Demonstration Program includes three major projects that would be conducted in new or existing facilities. These projects would demonstrate: (1) Proliferation-resistant processes that would separate the usable elements in commercial spent nuclear fuel from its waste elements; (2) the conversion of transuranics into shorter-lived radioisotopes; and (3) operation of an advanced fuel fabrication facility. The GNEP Technology Demonstration Program EIS will address siting, construction or modification, and operation of these demonstration-scale facilities. (Decontamination and decommissioning of these facilities will be addressed in one or more future NEPA analyses.)

In addition, DOE anticipates preparing a separate NEPA analysis at a later date that would address the environmental impacts of potential future actions to encourage the commercial-scale adoption of these technologies for the management of spent nuclear fuel from commercial nuclear power reactors, as well as alternatives. At that time, DOE anticipates preparing a programmatic EIS that would address the potential environmental consequences of the widespread deployment of proliferation- resistant spent nuclear fuel separation technologies, technologies that consume transuranics while extracting their energy, and fuel fabrication technologies, including those technologies that are the subject of the Technology Demonstration Program.

As discussed above, the GNEP Technology Demonstration Program includes three major projects.

\section{Demonstration of an Advanced Separation Process}

Under the GNEP Technology Demonstration Program, DOE would demonstrate the capability to safely recycle spent nuclear fuel from commercial light-water nuclear power reactors using proliferation-resistant separation processes. In support of this effort, DOE would conduct

demonstration-scale testing of a process that would separate the usable elements in spent commercial nuclear fuel from its waste elements.

Spent nuclear fuel contains uranium, transuranics (plutonium and other longlived radioactive material), and fission products. The fission products are waste and make up less than five percent of the used fuel. The buildup of the fission products inhibits the nuclear fission reaction, so used fuel must be removed from a nuclear power plant. In order to consume transuranics and uranium, while recovering their energy content, the transuranics and uranium would be separated from the fission products and then fabricated into new fuel.

The GNEP Technology Demonstration Program would use advanced separation processes (such as, but not necessarily limited to, Uranium Extraction Plus, or UREX+). As discussed below, the products of these advanced separation processes can be used in a facility such as a fast reactor that would consume transuranics to produce energy.

\section{Demonstration of the Conversion of Transuranics}

DOE would demonstrate the destruction of transuranics separated from spent nuclear fuel from commercial nuclear power plants. To destroy the transuranics, DOE would take advantage of high-energy neutrons to fission, or split apart, long-lived transuranics and transmute, or convert, them into shorter-lived radioisotopes. DOE will consider a facility such as, but not necessarily limited to, a fast reactor as a source of high-energy neutrons. As transuranics are consumed, significant energy is released and can be converted into electricity, thereby producing useful energy from material that would otherwise be waste. 
3. Demonstration of a Proliferation-

Resistant Fuel Cycle and Advanced Fuel Fabrication

DOE would demonstrate the fabrication, testing, and qualification of advanced fuel forms in a multi-hot cell, multi-purpose research, development, and demonstration laboratory that can serve fuel cycle testing needs. The facility would use modular, flexible construction technologies with the nearterm objective to fabricate and qualify fuels to be used in the facility for the conversion of transuranics.

\section{Purpose and Need for Action}

The purpose of the GNEP Technology Demonstration Program is to demonstrate U.S. capability to safely recycle spent nuclear fuel using proliferation-resistant separation processes and the conversion of transuranics into shorter-lived radioisotopes. DOE needs to identify and demonstrate technologies and identify the locations where those technologies would be demonstrated.

\section{Potential Range of Alternatives}

As part of the NEPA process, DOE will consider and evaluate all reasonable alternatives, including those identified in response to the ANOI, NOI, and during the public scoping process. DOE will also evaluate a No Action alternative.

\section{Invitation To Comment}

DOE invites Federal agencies, state and local governments, Native American tribes, industry, other organizations, and members of the public to provide comments on the proposed scope, alternatives (both technology and siting), and environmental issues to be analyzed in the forthcoming EIS for the GNEP Technology Demonstration Program. DOE will consider all such comments and other relevant information in developing an NOI. Comments on this ANOI should be submitted as described under DATES and ADDRESSES above.

\section{Potential Environmental Issues for Analysis}

DOE has tentatively identified the following environmental issues for analysis in the GNEP Technology Demonstration Program EIS. The list is presented to facilitate early comment on the scope of the EIS; it is not intended to be comprehensive nor to predetermine the alternatives to be analyzed or their potential impacts.

- Potential impacts to the general population and workers from radiological and nonradiological releases.
- Potential impacts of emissions on air and water quality.

- Potential impacts on flora and fauna of a region.

- Potential transportation impacts from the shipment of radioactive materials and waste.

- Potential impacts from postulated accidents.

- Potential disproportionately high and adverse effects on low-income and minority populations (environmental justice).

- Potential Native American concerns.

- Short-term and long-term land use impacts.

- Compliance with applicable Federal and state regulations.

- Long-term health and environmental impacts.

- Long-term site suitability.

\section{NEPA Process}

DOE plans to publish the NOI for the proposed GNEP Technology

Demonstration Program EIS in the

Federal Register later this year. The NOI will identify the technologies and sites that DOE proposes to evaluate as reasonable alternatives in the EIS. Following the publication of the NOI, there will be a 60-day public scoping period. Subsequently, DOE will announce the availability of the Draft EIS in the Federal Register and other media outlets. Federal agencies, state and local governments, Native American tribes, industry, other organizations, and members of the public will have an opportunity to submit comments. These comments will be considered and addressed in the Final EIS. DOE will issue a Record of Decision(s) no sooner than 30 days after publication of the Environmental Protection Agency's Notice of Availability of the Final EIS. DOE might announce its decision to implement all three projects in a single Record of Decision or in separate Records of Decision.

Issued in Washington, DC, on March 16, 2006.

\section{Russell H. Shearer,}

Acting Assistant Secretary for Environment, Safety and Health.

[FR Doc. E6-4162 Filed 3-21-06; 8:45 am]

BILLING CODE 6450-01-P

\section{DEPARTMENT OF ENERGY}

\section{Federal Energy Regulatory Commission}

\section{Combined Notice of Filings \#1}

March 15, 2006.

Take notice that the Commission received the following electric rate filings.

Docket Numbers: ER96-1551-014; ER01-615-010; EL05-2-000.

Applicants: Public Service Company of New Mexico.

Description: Public Service Co of New Mexico submits an amendment to its July 15, 2005 compliance filing and requests FERC to consider the information submitted as further evidence that PNM lacks generation market power etc.

Filed Date: March 10, 2006.

Accession Number: 20060314-0015.

Comment Date: 5 p.m. Eastern Time on Friday, March 31, 2006.

Docket Numbers: ER03-447-004.

Applicants: Black Oak Energy, LLC.

Description: Black Oak Energy LLC submits an amendment to its triennial updated market analysis filed on February 13, 2006.

Filed Date: March 9, 2006.

Accession Number: 20060310-0182.

Comment Date: 5 p.m. Eastern Time on Thursday, March 30, 2006.

Docket Numbers: ER06-464-001.

Applicants: Highlands Energy Group LLC.

Description: Highlands Energy Group LLC submits a petition for acceptance of initial rate schedule, waivers and blanket authority. Highland also amended its filing on March 10, 2006, including a revised tariff per the Commission's request.

Filed Date: March 8, 2006.

Accession Number: 20060313-0130.

Comment Date: 5 p.m. Eastern Time on Wednesday, March 29, 2006.

Docket Numbers: ER06-710-000.

Applicants: New York Independent System Operator, Inc.

Description: New York Independent System Operator, Inc submits revisions to its open access transmission tariff \& market administration and control area services tariff to allow three additional forms of credit support etc.

Filed Date: March 8, 2006.

Accession Number: 20060315-0019.

Comment Date: 5 p.m. Eastern Time on Wednesday, March 29, 2006.

Docket Numbers: ER06-711-000. Applicants: Hunlock Creek Energy Ventures.

Description: Hunlock Creek Energy Ventures submits a Notice of 


\section{R--EOI - GNEP Technology Demonstration Program \\ Solicitation Number: DE-RP07-06ID14760 \\ Agency: Department of Energy \\ Office: Federal Locations \\ Location: All DOE Federal Contracting Offices}

Notice Type:

Modification/Amendment

Original Posted Date:

March 17, 2006

Posted Date:

May 16, 2006

Response Date:

Original Response Date:

March 31, 2006

Archiving Policy:

Automatic, on specified date

Archive Date:

September 30, 2006

Original Set Aside:

N/A

Set Aside:

N/A

Classification Code:

$\mathrm{R}$-- Professional, administrative, and management support services

\section{Synopsis:}

Added: March 17, 2006 Modified: May 16, 2006 Track Changes

The U.S. Department of Energy (DOE) Office of Nuclear Energy is providing additional information relating to its March 17, 2006, Request for Expressions of Interest to perform Site Evaluation Studies in support of the Global Nuclear Energy Partnership (GNEP) Technology Demonstration Program. DOE is providing clarifying information regarding the scope of the GNEP Technology Demonstration Program and notification of the revised approach for awarding funding necessary to complete the site studies. DOE will make final decisions on the siting of GNEP Technology Demonstration Program projects after completion of the Environmental Impact Statement (EIS) for the GNEP Technology Demonstration Program. (Advance Notice of Intent, 71 FR 14505, March 22, 2006). The EIS will evaluate the reasonable siting alternatives, including the location(s) of technology demonstration projects at 
DOE and potentially non-DOE sites. DOE desires to have a broad range of sites be considered for the technology demonstration projects, including non-DOE sites. The eligibility for award to conduct Site Evaluation Studies will be limited to domestic non-DOE sites. The restriction to non-DOE sites applies regardless of the entity that would intend to propose to conduct a project on a DOE site. The decision to limit awards to non-DOE sites does not affect the ultimate eligibility of DOE sites for the siting of projects under GNEP Technology Demonstration Program. DOE decided to restrict eligibility to non-DOE sites because DOE sites are generally well-characterized, and additional information required to support the development of the EIS can be obtained by tasking DOE contractors directly through their existing contracts. The anticipated requirements and deliverables for the site evaluation studies remain unchanged from the Request for Expressions of Interest. It is important for entities who are interested in being considered for hosting a technology demonstration project to be aware that the technology demonstration project(s) will require the storage of nuclear materials to support the demonstration facility activities. In particular, the demonstration of a spent nuclear fuel recycling facility will require the hosting site to accept and store spent nuclear fuel as feed into the separations process.

\section{Contracting Office Address:}

850 Energy Drive (MS-1221) Idaho Falls, ID

\section{Point of Contact(s):}

Wade Hillebrant, Contracting Officer, 208-526-0547, hillebtw@id.doe.gov;Janet Surrusco, Contract Specialist, 208-526-5477, surrusjk@id.doe.gov Janet Surrusco, Contract Specialist

\section{Opportunity History}

- Original Synopsis

Presolicitation

Mar 17, 2006

7:00 pm

\section{- Changed}

May 16, 2006

12:00 am 


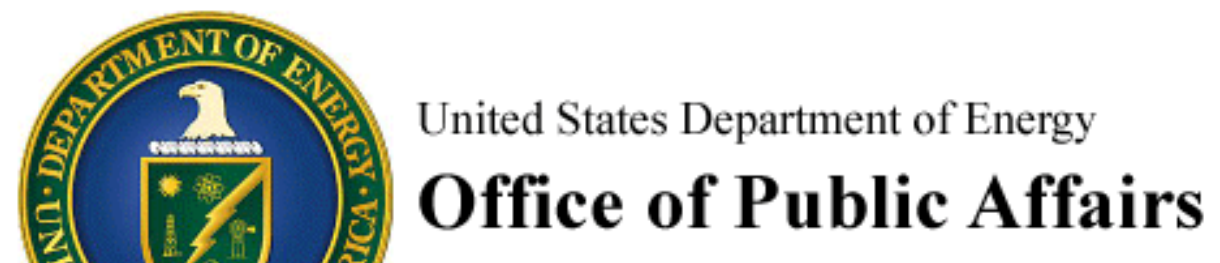

Washington, D.C. 20585

News Media Contact(s):

Craig Stevens, (202) 586-4940

For I mmediate Release

August 3, 2006

\section{DOE Continues Path Forward on Global Nuclear Energy Partnership}

Department Announces $\$ 20$ Million for GNEP Siting Studies and Seeks Further Coordination with Industry

WASHINGTON, DC - The U.S. Department of Energy (DOE) today announced \$20 million to conduct detailed siting studies for public or commercial entities interested in hosting DOE's Global Nuclear Energy Partnership (GNEP) facilities. Entities could qualify to receive up to \$5 million per site. DOE also announced that it is seeking expressions of interest to obtain input from U.S. and international nuclear industry on the feasibility of accelerating development and deployment of advanced recycling technologies by proceeding with commercial scale demonstration facilities, specifically a Consolidated Fuel Treatment Facility and an Advanced Burner Reactor.

"The siting studies and expressions of interest enable public and commercial entities to provide useful input to the Department's decision-making process for siting and building GNEP facilities in the U.S.," DOE Assistant Secretary for Nuclear Energy Dennis Spurgeon said. "These are important steps forward for the GNEP initiative."

GNEP, launched earlier this year as part of the President's Advanced Energy Initiative, aims to expand the use of nuclear energy to address the growing demand for energy. GNEP proposes private-publicinternational partnerships to develop advanced technologies to recycle used nuclear fuel, reduce wastes, and avoid misuse of nuclear materials.

Based on international and private sector response to GNEP, the Energy Department believes there are advanced technologies available to recycle used nuclear fuel that may be ready for deployment in conjunction with those currently under development by DOE. In light of this information, DOE is investigating the feasibility of accelerating development and deployment of advanced recycling technologies by proceeding with commercial demonstrations of the technologies.

The Department is considering a two-track approach to demonstrate technologies under GNEP. The first track involves deployment of commercial scale facilities for which advanced technologies are available now or in the near future. The second track would focus on further research and development on transmutation fuels (containing plutonium and minor actinides) technologies.

Under the first track, DOE is currently considering two commercial scale facilities: a Consolidated Fuel Treatment Center, capable of separating used fuel into its usable and waste components; and an Advanced Burner Reactor which would convert transuranics into shorter-lived radioisotopes while producing electricity. 
Under the second track, an Advanced Fuel Cycle Facility announced earlier this year to support development of technologies to separate and fabricate the transmutation fuels for the Advanced Burner Reactor would be designed and directed through DOE's national laboratories and therefore, is not part of the siting studies or the industry-requested expressions of interest.

Congress allocated \$20 million in FY 2006 to DOE for siting studies of integrated recycling facilities, with a maximum of $\$ 5$ million available per site. To be eligible for funding for siting studies, the proposed site must meet minimum criteria related to size, hydrology, electricity capacity, population density, zoning, water availability, road access, and seismic stability.

Preference for award of funds for the siting studies may be given to sites where the applicant has demonstrated community and state support for the use of the site for GNEP facilities. Preference may also be given if the proposed site has the potential for supporting both facilities.

Applications for financial assistance grants must be received by September 7, 2006. DOE anticipates announcing applications it will fund by the end of October 2006. Winning applicants will have 90 days to complete the site studies and submit required information to DOE.

Information generated from the detailed siting studies may be used in an environmental impact statement (EIS) that will evaluate the potential environmental impacts from each proposed GNEP facility. At the conclusion of the EIS, DOE will make decisions about whether to move forward with the facilities, and if so, where to locate them. Both the Consolidated Fuel Treatment Center and the Advanced Burner Reactor could be located together.

Industry-submitted expressions of interest on the recycling technologies are due to the Energy Department by September 8, 2006. The Department believes that industry's input is valuable in considering the configuration of GNEP's closed fuel cycle. Information gained from the expressions of interest will be used to create Requests for Proposals for the proposed Consolidated Fuel Treatment Facility and the Advanced Burner Reactor.

A briefing to describe DOE's baseline plan and answer expression of interest-related questions will be held August 14, 2006, from 8:00 AM - 12:00 PM in the Washington, D.C. metropolitan area. DOE requests that interested parties who wish to attend the briefing send an email to GNEP_EOI_RSVP@nuclear.energy.gov.

The Financial Assistance Funding Opportunity Announcement for the siting studies and the Expressions of Interest may be found at: http://gnep.gov/. The specific location for the briefing on the request for expressions of interest also will be announced on the GNEP website, http://gnep.gov/. The Financial Assistance Funding Opportunity Announcement is also available at http://www.grants.gov/. The request for expressions of interest issued today will be published in the Federal Register on August 7, 2006.

Additional information on DOE’s nuclear energy programs may be found at: http://www.nuclear.gov/.

\section{U.S. Department of Energy, Office of Public Affairs, Washington, D.C.}




\section{. \\ GRANTS.GOV:}

For Applicants About Grants

Contact

\section{APPLICANTS}

About Federal Grants

Get Registered

Find Grant Opportunities

Search Opportunities

Basic Search

Browse by Category

Browse by Agency

Advanced Search

Email Subscription

Apply for Grants

Track My Application

Applicant Help

ABOUT GRANTS.GOV

FOR AGENCIES

RESOURCES

HELP

CONTACT US

SITE MAP

Home > Find Grant Opportunities > Search Grant Ppportunities > Search Results > Synopsis

\section{Global Nuclear Energy Partnership (GNEP) Siting Studies}

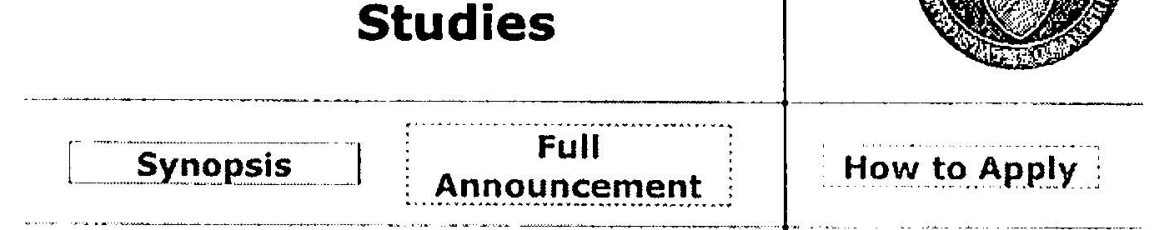

The synopsis for this grant opportunity is detailed below, following this paragraph. This synopsis has been modified and is not considered current. Please click on the Synopsis link above to display the current synopsis.

If you would like to receive notifications of changes to the grant opportunity click send me change notification emails. The only thing you need to provide for this service is your email address. No other information is requested.

Changed sections from the previous version of the synopsis are highlighted with a light grey background.

Any inconsistency between the original printed document and the disk or electronic document shall be resolved by giving precedence to the printed document.

Document Type:

Funding Opportunity Number:

Opportunity Category:

Posted Date:

Creation Date:

Current Closing Date for Applications:

Archive Date:

Funding Instrument Type:

Category of Funding Activity:

Category Explanation:

Expected Number of Awards:

Estimated Total Program Funding:

Award Ceiling:

Award Floor:

CFDA Number:
Grants Notice

DE-PS07-

06ID14760

Discretionary

Aug 03, 2006

Aug 03, 2006

Sep 07, 2006

Dec 03, 2006

Grant

Energy

$\$ 5,000,000$

$\$ 0$

81.121 -- Nuclear 


\section{Eligible Applicants}

Others (see text field entitled "Addit onal Information on Eligibility" for clarification)

\section{Additional Information on Eligibility:}

All types of applicants are eligible to apply, except other Federal agencies, Federally Funded Research and Development Center (FFRDC) Contractors, and nonprofit organizations described in section $501(c)(4)$ of the Internal Revenue Code of 1986 that engaged in lobbying activities after December 31, 1995. Other elig bility requirements are provided in Part III, Section C, of this Financial Opportunity Announcement.

\section{Agency Name}

Idaho Field Office

\section{Description}

The U.S. Department of Energy (DOE), Idaho Operations Office (DOE-ID), is seeking applications from eligible entities to perform detailed siting studies. These studies will describe prospective locations to host one or both anticipated Global Nuclear Energy Pattnership (GNEP) facilities. Information obtained from these studies, along with other relevant information, will be used to support the preparation of an Environmental Impact Statement (EIS) that will evaluate reasonable siting a ternatives for the anticipated GNEP facilities. Selection of an application for award does not guarantee that the site will be evaluated in detail in the EIS, only that it will be considered for further evaluation. In addition, there may be other sites considered besides those for which applications are being submitted under this announcement. In the EIS, DOE intends to evaluate certain DOE sites as potential locations for the anticipated GNEP facilities. Selection for award under this announcement in no way guarantees that a proposed site will host a GNEP facility.

\section{Link to Full Announcement}

Click_here to view the Opportunity.

\section{If you have difficulty accessing the full announcement electronically, please contact:}


using this

link

iips_helpdesk@e-center.doe.gov

Wade Hillebrant

hillebtw@id.doe.gov

If you have any problems linking to the funding

opportunity please contact the IIPS HelpDesk

\section{Latest Revision}


Program Authority: 20 U.S.C. 1221e-3; 20 U.S.C. 6301 et. seq.

Dated: August 1, 2006.

Margaret Spellings,

Secretary of Education.

[FR Doc. E6-12780 Filed 8-4-06; 8:45 am] BILLING CODE 4000-01-P

\section{DEPARTMENT OF EDUCATION}

\section{Safe and Drug-Free Schools and Communities Advisory Committee}

AGENCY: Office of Safe and Drug-Free Schools, Department of Education. ACTION: Notice of open meeting.

SUMmARY: This notice sets forth the schedule and proposed agenda of an upcoming open meeting of the Safe and Drug-Free Schools and Communities Advisory Committee. The notice also describes the functions of the Committee. Notice of this meeting is required by section 10(a)(2) of the Federal Advisory Committee Act and is intended to notify the public of their opportunity to attend.

DATES: Monday, August 21, 2006, and Tuesday, August 22, 2006.

Time: August 21, 2006: 8:30 a.m. to 5 p.m.; August 22, 2006: 8 a.m. to 11:30 a.m.

ADDRESSES: The Committee will meet at the U.S. Department of Education, 400 Maryland Avenue, SW., Barnard Auditorium, Washington, DC.

FOR FURTHER INFORMATION CONTACT: Catherine Davis, Executive Director, Safe and Drug Free Schools and Communities Advisory Committee, U.S. Department of Education, 400 Maryland Avenue, SW., Room 1E110, Washington, DC 20202-3510; telephone: (202) 2054169, or e-mail at OSDFS@ed.gov.

SUPPLEMENTARY INFORMATION: The Committee was established to provide advice to the Secretary on Federal, State and local programs designated to create safe and drug-free schools, and on issues related to crisis planning. The focus for this meeting is the Safe and Drug Free Schools and Communities State Grants Programs, a formula grant program. The agenda will include panel presentations by invited speakers offering an overview of the program and looking at opportunities to strengthen and improve it in order to ensure that schools and communities are implementing the most effective programs and interventions, and are prepared to meet current and future needs of students. Further, the Committee will address strategies for accomplishing their mission as stated in the committee charter.
Individuals who will need accommodations for a disability in order to attend the meeting (e.g., interpreting services, assistive listening devices, or materials in alternative format) should notify Catherine Davis at OSDFSC@ed.gov or 202-205-4169 no later than August 7, 2006. We will attempt to meet requests for accommodations after this date but cannot guarantee their availability. The meeting site is accessible to individuals with disabilities.

Individuals interested in attending the meeting must register in advance because limited space is available at the meeting site. Please notify Catherine Davis at OSDFSC@ed.gov or 202-2054169 of your intention to attend the meeting.

Opportunities for public comment are available on August 22 from 8:40-9:15 a.m. on a first come, first served basis. Comments presented at the meeting must be limited to 5 minutes in length. Written comments that accompany oral remarks are optional. Five copies are recommended and should be submitted to the committee Chairman.

Request for Written Comments: We invite the public to submit written comments relevant to the focus of the Advisory Committee. We would like to receive written comments from members of the public no later than April 30, 2007.

ADDRESSES: Submit all comments to the Advisory Committee using one of the following methods: 1 . Internet. We encourage the public to submit comments through the Internet to the following address: OSDFSC@ed.gov. 2. Mail. The public may also submit your comments via mail to Catherine Davis, Office of Safe and Drug Free Schools, U.S. Department of Education, 400 Maryland Avenue, SW., Room 1E110, Washington, DC 20202. Due to delays in mail delivery caused by heightened security, please allow adequate time for the mail to be received.

Records are kept of all Committee proceedings and are available for public inspection at the Office of Safe and Drug Free Schools, U.S. Department of Education, 400 Maryland Avenue, SW., Room 1E110, Washington, DC 20202, from the hours of 9 a.m. to 5 p.m. Eastern Standard Time.

\section{Ray Simon,}

Deputy Secretary.

[FR Doc. 06-6710 Filed 8-4-06; 8:45 am]

BILLING CODE 4000-01-M

\section{DEPARTMENT OF ENERGY}

\section{Notice of Request for Expressions of Interest in an Advanced Burner Reactor To Support the Global Nuclear Energy Partnership}

AGENCY: Office of Nuclear Energy, Department of Energy.

ACTION: Notice of request for expressions of interest.

SUMmARY: Based upon feedback since the President of the United States announced the Global Nuclear Energy Partnership (GNEP) in February 2006, the U.S. Department of Energy (DOE) is seeking Expressions of Interest (EOI) from domestic and international industry in building an Advanced Burner Reactor (ABR). An ABR in the United States would establish a fast reactor capability to be used to transmute fuel and consume transuranic elements within the fuel, generate electricity, and support implementation of GNEP. DOE is also seeking to define the interest of industry to build upon their proven capabilities and participate in demonstrating spent nuclear fuel (SNF) recycling technologies that meet GNEP goals. This EOI will help inform DOE's GNEP Program as to those issues that industry and potential host sites consider important to the construction of sustainable, commercial-scale SNF recycling technologies that meet GNEP objectives. The information gained from this EOI will be used to create Requests for Proposals (RFP) for the proposed ABR.

DATES: Interested parties wishing to submit an EOI should do so in writing by September 8, 2006, to ensure their input is considered. A briefing for respondents to learn about DOE's baseline plan and answer EOI-related questions will be held on August 14, 2006, 8 am-12 pm, in the Washington, DC metropolitan area. The specific meeting location will be announced on the GNEP Web site, http:// www.gnep.energy.gov. Please indicate your interest in attending the briefing by sending an e-mail indicating your intent to attend to

GNEP_EOI_RSVP@nuclear.energy.gov. It is recognized that GNEP is moving forward on an aggressive schedule that will task all of the responders' abilities to provide quality information in a short period of time. DOE believes that GNEP can help to revitalize the U.S. nuclear industry and improve its global competitive position. Early participation by industry in this effort will greatly maximize GNEP's success.

FOR FURTHER INFORMATION CONTACT: By postal mail, Mr. John F. Gross, Mail 
Stop: NE-2.4/Germantown, 1000

Independence Avenue, SW.,

Washington DC 20585-0119; by phone

on 301-903-3918; by e-mail at

GNEP_EOI_RSVP@nuclear.energy.gov.

ADDRESSES: Please send all hardcopy Expressions of Interest to Mr. John F. Gross, Mail Stop: NE-2.4/Germantown, U.S. Department of Energy, 1000

Independence Avenue, SW.,

Washington, DC 20585-0119. Electronic versions of the Expressions of Interest may be submitted in pdf (portable document format) format by e-mail to GNEP_EOI_RSVP@nuclear.energy.gov.

\section{SUPPLEMENTARY INFORMATION:}

\section{Background}

As part of President Bush's Advanced Energy Initiative, DOE has launched the Global Nuclear Energy Partnership (GNEP). The broad goals of GNEP are described in the Report to CongressSpent Nuclear Fuel Recycling Program Plan issued May 2006, http:// www.gnep.energy.gov/pdfs/ snfRecyclingProgframPanMay2006.pdf.

A major element of GNEP is the development and deployment of advanced nuclear fuel recycling technologies. In general, advanced recycling technologies focus on three operations:

(1) Separate commercial LWR SNF into its usable and waste components.

Spent nuclear fuel contains uranium, transuranics (plutonium and other longlived radioactive elements), and fission products. The fission products are waste and make up less than five percent of the used fuel. Buildup of fission products within the fuel inhibits nuclear fission reactions so the spent fuel must be replaced with fresh fuel for continued operation of a nuclear reactor. The transuranics and uranium in SNF would be separated from the fission products and then fabricated into new fuel for a fast reactor to consume the transuranics and uranium while simultaneously recovering their energy content. The SNF recycling program would use advanced separation processes (e.g., Uranium Extraction Plus or other comparable processes).

(2) Fabricate and recycle fast reactor fuel containing transuranic elements.

Fabricating, testing, and qualifying fast reactor fuel containing transuranic and actinide elements (i.e., transmutation fuel), obtained from recycled spent fast reactor fuel, is required to provide fresh fuel for the reactor. After the qualification of transmutation fuel, the GNEP facilities would demonstrate recycle of fast reactor transmutation fuel and eventually could include the construction of a separate transmutation fuel separations and fabrication facility.

(3) Convert transuranics into shorterlived radioisotopes while producing electricity.

Fast reactors produce high-energy neutrons that can fission long-lived transuranics, thus converting the transuranics into shorter-lived radioisotopes. As the transuranics are consumed, significant energy is released that can be used to produce electricity from material that would otherwise be considered waste and potentially require disposal in a geologic repository.

The Department initially announced an approach that would demonstrate technologies from the laboratory at engineering scale, prior to a second phase of commercialization. This approach is described in the Report to Congress-Spent Nuclear Fuel

Recycling Program Plan issued May 2006, http://www.gnep.energy.gov/pdfs/ snfRecyclingProgframPanMay2006.pdf.

Following the announcement of the GNEP Program by the President, a number of foreign governments and private companies expressed interest in cooperating in the near-term with the Department in the development and deployment of advanced recycling technologies. Some of these entities indicated they are pursuing similar technologies and, in some cases, these technologies may be ready for deployment prior to those currently under development by the Department. In light of this information, DOE seeks to determine the feasibility of accelerating the development and deployment of advanced recycling technologies that would enable commercial scale demonstrations that meet GNEP objectives. These demonstrations would utilize industry expertise to build the well-understood stages of advanced technology for the separation of LWR SNF, and the construction and operation of a fast reactor, while designing in the modules for incorporating group separation of actinides, transmutation fuel production, burning, and recycling operations.

This approach would involve two simultaneous tracks: (1) Deployment of commercial scale facilities for which advanced technologies are available now or in the near future and (2) further research and development on transmutation fuels technologies. This two-track approach could result in two commercial scale facilities, one of which is the subject of this EOI. These facilities are:

- Consolidated Fuel Treatment Center (CFTC) - a facility to separate the usable uranium and transuranics from spent light-water reactor fuel for use in fabricating fast reactor fuel. During the second track the CFTC would be augmented or a separate transmutation fuel separations and fabrication facility would be constructed to separate and fabricate fast reactor transmutation fuel.

- Advanced Burner Reactor (ABR; subject of this EOI)-fast reactor to use transmutation fuel and consume transuranic elements within the fuel and generate electricity. The ABR is expected to be qualified with conventional fast reactor fuel. Subsequently, the ABR would be used to demonstrate the feasibility of recycling fast reactor transmutation fuel.

A third facility, the Advanced Fuel Cycle Facility (AFCF), will be designed and directed through DOE's national laboratories and will support development of the technologies required to separate and fabricate fast reactor transmutation fuel. The AFCF is not currently a subject of a Request for Expressions of Interest.

\section{ABR Characteristics}

DOE prefers to constrain as little as possible this EOI on the fuel cycle pathway to meet GNEP goals. Industry's input is valuable in considering the ultimate technical and pragmatic configuration of GNEP's closed fuel cycle. Some rough parameters for considering the ultimate characteristics of an ABR for the GNEP Technology Demonstration Program are set out below. They simply illustrate the type of information DOE is requesting in this EOI and respondents should not interpret the following information as a final decision from DOE on the ABR's characteristics or the overall demonstration program. The responses to this EOI may significantly influence subsequent RFPs.

\section{Desired ABR General Characteristics}

The ABR is essential to perform key functions in support of GNEP technology development objectives, including:

- Providing a fast neutron reactor necessary to consume the transuranic and actinide elements contained in transmutation fuel, i.e., fuel that is fabricated from uranium, plutonium, and other transuranics found in light water reactor (LWR) spent fuel.

- Generating and providing electricity to a power grid and contribute to commercial sustainability. Thus, the ABR would consume transuranic elements in fuel made possible by other key elements of the technology program: separation of LWR and fast reactor SNF into their usable components and the 
fabrication of transmutation fuel from those components.

- Consuming transuranic elements separated from LWR SNF. See the Consolidated Fuel Treatment Center (CFTC) EOI for a discussion of that element.

- Ensuring that facility designs meet U.S. standards for safeguards and security.

Developing this complete system to support GNEP remains the central objective, drawing upon the expertise and capabilities of industry and international partners to achieve it. Further,

The ABR shall safely and reliably perform its power generation and transmutation functions. The ABR shall be capable of being licensed by the U.S. Nuclear Regulatory Commission (NRC) and operated in accordance with NRC regulations. The ABR shall incorporate design features and technologies to promote reliable system performance during normal operations and in response to postulated accident scenarios.

- The ABR shall be designed such that the future cost of electrical power generation using ABRs can be shown to be economical, with a goal of being competitive with Advanced Light Water Reactors, reasonably accounting for any externalities.

- ABRs shall be capable of generating power through the net destruction of transuranic material.

- The strategy for potential development of ABRs shall be made to be as affordable as possible without introducing undue risk into the development effort so as to place in serious jeopardy the potential to successfully achieve the ABR mission.

- To support timely implementation supportive of GNEP goals, the ABR system shall be capable of commercial deployment as early as possible.

Example Technical Characteristics of the $A B R$

- Reactor neutron energy spectrum: Fast.

- Reactor technology: Pool-type sodium cooled.

- Power conversion technology: Steam-Rankine or Super-critical $\mathrm{CO}_{2}$ Brayton Cycle.

- Reactor fuel type: Oxide or metal based.

- Reactor unit thermal power: 500 MWt-2000 MWt.

- Electrical power from reactor unit: $200 \mathrm{MWe}-800 \mathrm{MWe}$, generated electricity can be provided to a commercial power grid.

- For modular approach, technology for reactor unit should be scalable to higher power levels up to at least 1 GWe.

- The ABR would have the capability of being started on conventional fast reactor driver fuel, transitioned to full core operation on transmutation fuel, and provide a capability for transmuting minor actinide targets prior to this transition.

- Process storage capacity: Sufficient process storage capacity should be included to support full-scale plant operations, including storage of spent fuel prior to recycling.

Geographic

- The reactor may be collocated with the SNF processing and fuel fabrication operations. This is not a requirement but rather a possibility.

\section{Regulatory}

- Must comply with all environmental protection laws and regulations.

- Must be capable of being licensed under NRC regulations applicable to demonstration operations on privately owned land regardless of where the demonstration is sited.

\section{Content of EOI}

The following items identify the information that DOE is requesting in this EOI. All respondents are encouraged to provide information beyond that requested if it is believed to be beneficial to their responses.

\section{Level of Interest and Proposed Scope of Interest}

Please describe how you believe DOE could accelerate successful demonstration of SNF integrated recycling technologies to advance the goals of GNEP. Describe the approach that you believe should be taken to accomplish this goal, including its benefits and risks, and describe your level of interest or potential participation. Also, provide a description of what you believe your approach does to advance the broad goals of GNEP (as described, for example, in the Background section). In particular, for the ABR, DOE is interested in:

a. What reactor unit size (MWt) would be proposed by industry to achieve the ABR mission, and what reactor size would be proposed for the

demonstration program (e.g., sub-scale, full-size module)?

b. What set of reactor system technologies (e.g., basic type of fuel, reactor and power conversion technologies) is proposed to achieve the ABR mission? c. What would the general fuel qualification approach and schedule be for initial driver fuel and transmutation fuel? Identify the basic in-reactor tests and facilities that would be used to support fuel qualification.

d. In addition to advanced reactor systems, what research and development (R\&D) on near-term watercooled reactor approaches could be pursued to support transmutation of transuranics consistent with the goals of GNEP?

\section{Proposed Roles of Parties Involved}

Please identify who you believe the parties to such a venture should include and the role of each party. Parties could include U.S. Government and foreign government agencies, state and local government agencies, nongovernmental organizations, domestic and foreign commercial firms (e.g., Architect \& Engineering (A\&E) firms, component manufacturers, electric utility companies, etc.) or any other entity you may identify that fits into your proposed solution. Your statement should clearly identify the role each party would play in ensuring the success of your proposition, whether direct or indirect. Examples of roles include, but are not limited to, providing financing, guaranteeing financing, A\&E services, construction, facility operations, program or project management, regulatory compliance support, and hardware vendor. Provide an assessment of the benefit to the U.S. Government and GNEP of your proposed parties and their roles. Also, provide a description of the benefits that would accrue to each of the parties in this venture. Benefits could include, but are not limited to, financial gain, intellectual property, market position, facilities, education, and advancing policy goals.

\section{Resources}

For each entity you have identified in Item 2 above, provide specifics describing the resources each party could provide to ensure the program's success. These resources may include, but are not limited to, financial, existing or new facilities, personnel (include a description of the type of personnel, e.g., technical, management, regulatory, financial, etc.), intellectual property, and leased equipment.

\section{Proposed Contractual Vehicle}

Please provide a description of the contractual vehicle(s) you feel should be employed in furtherance of your approach. Examples may include, but are not limited to, contracts, financial assistance, Cooperative Research and 
Development Agreements, loan guarantees, other transactional arrangements. Please limit your suggestions to those contractual authorities already granted to DOE or other government agencies you identify.

\section{Areas of Technology Development Required for Potential \\ Commercialization}

Please identify what technical areas associated with your approach would benefit from additional research, development or demonstration (RD\&D) activities, how and to what extent this RD\&D would mitigate technical or technology risk, estimated timeframes to accomplish this RD\&D, parties performing the activities, and other technical issues that need to be addressed.

\section{Government Furnished Data/ Technology/Equipment}

Describe what, if any, government furnished data, technology, or equipment you would require to accomplish your defined approach. State whether you have any existing rights or license for the use of the data or technology, and if not, how you would pursue acquiring such rights.

\section{Confidentiality}

Confidential or business sensitive information contained in the submission must be identified and marked accordingly. DOE will protect this information from public disclosure to the extent permitted by law.

This EOI is not a formal solicitation requesting proposals and does not represent a commitment by the Government to award a contract. The Government does not intend to formally respond to information submitted in response to this EOI. The Government is not responsible for costs incurred to submit a response to this EOI, conducting other activities associated with pre-solicitation planning, or submitting a proposal in response to a solicitation, if issued.

Issued in Washington, DC, on July 31 , 2006

Dennis R. Spurgeon,

Assistant Secretary for Nuclear Energy, Office of Nuclear Energy.

[FR Doc. E6-12747 Filed 8-4-06; 8:45 am] BILLING CODE 6450-01-P

\section{DEPARTMENT OF ENERGY}

\section{Notice of Request for Expressions of Interest in a Consolidated Fuel Treatment Center To Support the Global Nuclear Energy Partnership}

AGENCY: Office of Nuclear Energy, Department of Energy.

ACTION: Notice of request for expressions of interest.

SUMmARY: Based upon feedback since the President of the United States announced the Global Nuclear Energy Partnership (GNEP) in February 2006, the U.S. Department of Energy (DOE) is seeking Expressions of Interest (EOI) from domestic and international industry in building spent nuclear fuel recycling and transmutation fuel fabrication capabilities. DOE contemplates locating these capabilities together in a Consolidated Fuel Treatment Center (CFTC) and seeks expressions of interest from potential domestic host sites. DOE is also seeking to define the interest of industry to build upon their proven capabilities and participate in demonstrating spent nuclear fuel (SNF) recycling technologies that meet GNEP goals. This EOI will help inform DOE's GNEP Program as to those issues that industry and potential host sites consider important to the ultimate construction of sustainable, commercial-scale SNF recycling technologies that meet GNEP objectives. The information gained from this EOI will be used to create Requests for Proposals (RFP) for the proposed CFTC.

DATES: Interested parties wishing to submit an EOI should do so in writing by September 8, 2006, to ensure their input is considered. A briefing for respondents to learn about DOE's baseline plan and answer EOI-related questions will be held on August 14, 2006, 8 a.m.-12 p.m., in the Washington, DC metropolitan area. The specific meeting location will be announced on the GNEP Web site, http://www.gnep.energy.gov. Please indicate your interest in attending the briefing by sending an e-mail indicating your intent to attend to

GNEP_EOI_RSVP@nuclear.energy.gov. It is recognized that GNEP is moving forward on an aggressive schedule that will task all of the responders' abilities to provide quality information in a short period of time. DOE believes that GNEP can help to revitalize the U.S. nuclear industry and improve its global competitive position. Early participation by industry in this effort will greatly maximize GNEP's success.
FOR FURTHER INFORMATION CONTACT: BY postal mail, Mr. John F. Gross, Mail Stop: NE-2.4/Germantown, 1000 Independence Avenue, SW., Washington, DC 20585-0119; by phone on 301-903-3918; by e-mail at GNEP_EOI_RSVP@nuclear.energy.gov.

ADDRESSES: Please send all hardcopy Expressions of Interest to Mr. John F. Gross, Mail Stop: NE-2.4/Germantown, U.S. Department of Energy, 1000 Independence Avenue, SW., Washington, DC 20585-0119. Electronic versions of the Expressions of Interest may be submitted in pdf (portable document format) format by e-mail to GNEP_EOI_RSVP@nuclear.energy.gov.

\section{SUPPLEMENTARY INFORMATION:}

\section{Background}

As part of President Bush's Advanced Energy Initiative, DOE has launched the Global Nuclear Energy Partnership (GNEP). The broad goals of GNEP are described in the Report to CongressSpent Nuclear Fuel Recycling Program Plan issued May 2006, http:// www.gnep.energy.gov/pdfs/ snfRecyclingProgframPanMay2006.pdf.

A major element of GNEP is the development and deployment of advanced nuclear fuel recycling technologies. In general, advanced recycling technologies focus on three operations:

(1) Separate commercial LWR SNF into its usable and waste components.

Spent nuclear fuel contains uranium, transuranics (plutonium and other longlived radioactive elements), and fission products. The fission products are waste and make up less than five percent of the used fuel. Buildup of fission products within the fuel inhibits nuclear fission reactions so the spent fuel must be replaced with fresh fuel for continued operation of a nuclear reactor. The transuranics and uranium in SNF would be separated from the fission products and then fabricated into new fuel for a fast reactor to consume the transuranics and uranium while simultaneously recovering their energy content. The SNF recycling program would use advanced separation processes (e.g., Uranium Extraction Plus or other comparable processes).

(2) Fabricate and recycle fast reactor fuel containing transuranic elements.

Fabricating, testing, and qualifying fast reactor fuel containing transuranic and actinide elements (i.e., transmutation fuel), obtained from recycled spent fast reactor fuel, is required to provide fresh fuel for the reactor. After the qualification of transmutation fuel, the GNEP facilities would demonstrate recycle of fast 
reactor transmutation fuel and eventually could include the construction of a separate transmutation fuel separations and fabrication facility.

(3) Convert transuranics into shorterlived radioisotopes while producing electricity

Fast reactors produce high-energy neutrons that can fission long-lived transuranics, thus converting the transuranics into shorter-lived radioisotopes. As the transuranics are consumed, significant energy is released that can be used to produce electricity from material that would otherwise be considered waste and potentially require disposal in a geologic repository.

The Department initially announced an approach that would demonstrate technologies from the laboratory at engineering scale, prior to a second phase of commercialization. This initial approach is described in the Report to Congress-Spent Nuclear Fuel Recycling Program Plan issued May 2006, http://www.gnep.energy.gov/pdfs/ snfRecyclingProgframPanMay2006.pdf.

Following the announcement of the GNEP Program by the President, a number of foreign governments and private companies expressed interest in cooperating in the near-term with the Department in the development and deployment of advanced recycling technologies. Some of these entities indicated they are pursuing similar technologies and, in some cases, these technologies may be ready for deployment prior to those currently under development by the Department. In light of this information, DOE seeks to determine the feasibility of accelerating the development and deployment of advanced recycling technologies that would enable commercial scale demonstrations that meet GNEP objectives. These demonstrations would utilize industry expertise to build the well-understood stages of advanced technology for the separation of LWR SNF, and the construction and operation of a fast reactor, while designing in the modules for incorporating group separation of actinides, transmutation fuel production, burning, and recycling operations.

This approach would involve two simultaneous tracks: (1) Deployment of commercial scale facilities for which advanced technologies are available now or in the near future and (2) further research and development on transmutation fuels technologies. This two-track approach could result in two commercial scale facilities, one of which is the subject of this EOI. These facilities are:
- Consolidated Fuel Treatment Center (CFTC; subject of this EOI) - a facility to separate the usable uranium and transuranics from spent light-water reactor fuel for use in fabricating fast reactor fuel. During the second track the CFTC would be augmented or a separate transmutation fuel separations and fabrication facility would be constructed to separate and fabricate fast reactor transmutation fuel.

- Advanced Burner Reactor (ABR)fast reactor to use transmutation fuel and consume transuranic elements within the fuel and generate electricity. The ABR is expected to be qualified with conventional fast reactor fuel. Subsequently, the ABR would be used to demonstrate the feasibility of recycling fast reactor transmutation fuel.

A third facility, the Advanced Fuel Cycle Facility (AFCF), will be designed and directed through DOE's national laboratories and will support development of the technologies required to separate and fabricate fast reactor transmutation fuel. The AFCF is not currently a subject of a Request for Expressions of Interest.

\section{CFTC Characteristics}

DOE prefers to constrain as little as possible this EOI on the fuel cycle pathway to meet GNEP goals. Industry's input is valuable in considering the ultimate technical and pragmatic configuration of GNEP's closed fuel cycle. Some rough parameters for considering the ultimate characteristics of a CFTC facility for the GNEP Technology Demonstration Program are set out below. They simply illustrate the type of information DOE is requesting in this EOI and respondents should not interpret the following information as a final decision from DOE on the CFTC's characteristics or the overall demonstration program. The responses to this EOI may significantly influence subsequent RFPs.

\section{Desired CFTC General Characteristics}

The complete CFTC would be designed to perform several key functions in support of GNEP technology development objectives, including:

- Separating reusable uranium and transuranics from spent light water reactor (LWR) fuel for use in fabricating fast reactor driver fuel. (An additional facility designed and directed through a DOE national laboratory will support development of the technologies required to separate and fabricate fast reactor transmutation fuel, i.e., fuel that is fabricated from uranium, plutonium, and other transuranics found in LWR spent fuel.)
- Demonstrating the separation of LWR and fast reactor SNF into their usable components and the fabrication of transmutation fuel from those components.

- Consuming transuranic elements in a fast reactor. See the Advanced Burner Reactor (ABR) EOI for a discussion of that element.

- Ensuring that facility designs meet U.S. standards for safeguards and security.

Developing this complete system to support GNEP remains the central objective, drawing upon the expertise and capabilities of industry and international partners to achieve it. Further,

- The CFTC shall safely and reliably perform its LWR spent fuel process storage and separations functions as well as providing safe and reliable ABR driver fuel fabrication capabilities. The CFTC shall be capable of being licensed by the U.S. Nuclear Regulatory Commission (NRC) and operated in accordance with NRC regulations. The CFTC shall incorporate design features and technologies to promote reliable system performance during normal operations and in response to postulated accident scenarios.

- The CFTC shall demonstrate improved spent fuel separations technologies. This shall be accomplished in a process whose end products are not pure plutonium or other weapons-grade fissile material. The spent fuel separations technology will be further enhanced by advanced safeguards and security monitoring technology.

- The CFTC will produce, through spent fuel separations, high-purity uranium for reuse as reactor fuel or disposal as low-level waste, transuranic fuel feed material for transmutation in a fast reactor, and fission products with reduced heat generation and radiotoxicity for long-term geologic disposal.

- The CFTC shall be designed such that the future cost of spent fuel receipt, separations process, product management, and fuel fabrication capabilities can be shown as an efficient component of an economical fuel cycle. It is desirable that the material remain throughout in as low a category as possible for attractiveness for use in a nuclear weapon and for safeguarding purposes.

- The CFTC shall fabricate the driver fuel (i.e., fuel for the initial startup core and subsequent refueling of the core in advance of the availability of transmutation fuel) for the ABR to initially generate power. 
- CFTC technologies shall be capable of commercial deployment.

\section{Example of Technical Characteristics of the CFTC}

- Process storage capacity: Sufficient storage capacity should be included to support full-scale plant operation, including storage of spent fuel prior to separations as well as storage of the resulting separated material.

- Spent fuel separations throughput: Able to be increased to approximately 2,000 to 3,000 metric tons per year to support commercial operation.

- Separations technology: UREX+1a where major products include highpurity uranium, cesium and strontium, transuranics, spent fuel cladding hulls, and fission products. Alternative separation technologies with different product streams (e.g., different actinide separation efficiencies or distributions) may be proposed.

- Waste disposition strategies: Waste minimization is a priority and should focus on reducing radiotoxicity, halflife, heat generation, and minimize criticality concerns.

- Fast reactor driver fuel type: Oxide or metal based (depends on fuel type selected in related GNEP ABR EOI).

\section{Geographic}

- The SNF processing and fuel fabrication operations may be collocated with ABR.

- Existing DOE or commercial facilities or new facilities may be addressed in the response.

\section{Regulatory}

- Must comply with all environmental protection laws and regulations.

- Must be capable of being licensed under NRC regulations applicable to demonstration operations on privately owned land regardless of where the demonstration is sited.

\section{Content of EOI}

The following items identify the information that DOE is requesting in this EOI. All respondents are encouraged to provide information beyond that requested if it is believed to be beneficial to their responses.

\section{Level of Interest and Proposed Scope of Interest}

Please describe how you believe DOE could accelerate successful demonstration of SNF integrated recycling technologies to advance the goals of GNEP. Describe the approach that you believe should be taken to accomplish this goal, including its benefits and risks, and describe your level of interest or potential participation. Also, provide a description of what you believe your approach does to advance the broad goals of GNEP (as described, for example, in the Background section). In particular, for the CFTC, DOE is interested in:

a. What LWR spent fuel process storage capabilities, separations technology and throughput (initial and final), and fast sodium reactor driver fuel fabrication system characteristics would be proposed to achieve the CFTC mission?

b. What set of separations process technologies are sufficiently mature to implement immediately and what proposed technologies or components require additional developmental work (e.g., advanced centrifugal contactors, advanced monitoring instrumentation) to achieve the CFTC mission?

c. What are the key elements of the proposal's product and waste management strategies? Are there nearterm strategies using existing technology as well as long-term strategies for improved waste minimization and product form as well as storage and disposition technologies envisioned? If so, specify the key elements of future improvements, their relative costs and their benefits.

d. In addition to advanced separation processes, what technology development could be pursued to support spent fuel recycling consistent with the goals of GNEP?

\section{Proposed Roles of Parties Involved}

Please identify who you believe the parties to such a venture should include and the role of each party. Parties could include U.S. Government and foreign government agencies, state and local government agencies, nongovernmental organizations, domestic and foreign commercial firms (e.g., Architect \& Engineering (A\&E) firms, component manufacturers, electric utility companies, etc.) or any other entity you may identify that fits into your proposed solution. Your statement should clearly identify the role each party would play in ensuring the success of your proposition, whether direct or indirect. Examples of roles include, but are not limited to, providing financing, guaranteeing financing, A\&E services, construction, facility operations, program or project management, regulatory compliance support, and hardware vendor. Provide an assessment of the benefit to the U.S. Government and GNEP of your proposed parties and their roles. Also, provide a description of the benefits that would accrue to each of the parties in this venture. Benefits could include, but are not limited to, financial gain, intellectual property, market position, facilities, education, and advancing policy goals.

\section{Resources}

For each entity you have identified in Item 2 above, provide specifics describing the resources each party could provide to ensure the program's success. These resources may include, but are not limited to, financial, existing or new facilities, personnel (include a description of the type of personnel, e.g., technical, management, regulatory, financial, etc.), intellectual property, and leased equipment.

\section{Proposed Contractual Vehicle}

Please provide a description of the contractual vehicle(s) you feel should be employed in furtherance of your approach. Examples may include, but are not limited to, contracts, financial assistance, Cooperative Research and Development Agreements, loan guarantees, other transactional arrangements. Please limit your suggestions to those contractual authorities already granted to DOE or other government agencies you identify.

\section{Areas of Technology Development Required for Potential}

\section{Commercialization}

Please identify what technical areas associated with your approach would benefit from additional research, development or demonstration activities, how and to what extent this research and development (R\&D) would mitigate technical or technology risk, estimated timeframes to accomplish this R\&D, parties performing the activities, and other technical issues that need to be addressed.

\section{Government Furnished Data/ Technology/Equipment}

Describe what, if any, government furnished data, technology, or equipment you would require to accomplish your defined approach. State whether you have any existing rights or license for the use of the data or technology, and if not, how you would pursue acquiring such rights.

\section{Confidentiality}

Confidential or business sensitive information contained in the submission must be identified and marked accordingly. DOE will protect this information from public disclosure to the extent permitted by law.

This EOI is not a formal solicitation requesting proposals and does not represent a commitment by the 
Government to award a contract. The Government does not intend to formally respond to information submitted in response to this EOI. The Government is not responsible for costs incurred to submit a response to this EOI, conducting other activities associated with pre-solicitation planning, or submitting a proposal in response to a solicitation, if issued.

Issued in Washington, DC, on July 31, 2006

Dennis R. Spurgeon,

Assistant Secretary for Nuclear Energy, Office of Nuclear Energy.

[FR Doc. E6-12646 Filed 8-4-06; 8:45 am] BILLING CODE 6450-01-P

\section{DEPARTMENT OF ENERGY}

\section{Biological and Environmental Research (BER); Federal Interagency Steering Committee on Multimedia Environmental Modeling}

AGENCY: Office of Science; Biological and Environmental Research (BER), Department of Energy, (DOE).

ACTION: Notice of open meeting.

SUMMARY: The annual public meeting of the Federal Interagency Steering Committee on Multimedia Environmental Modeling (ISCMEM) will convene to discuss new operational initiatives for FY 2007 as a result of the revised Memorandum of Understanding (MOU) among the participating agencies.

DATES: August 24, 2006. Time: 9:30 a.m. to 5 p.m.

ADDRESSES: The American Geophysical Union (AGU) headquarters building, 2000 Florida Avenue, NW., Washington, DC 20009.

\section{FOR FURTHER INFORMATION CONTACT:} Inquiries and notice of intent to attend the meeting may be faxed or E-mailed to: Dr. Robert T. Anderson, ISCMEM Chair, Office of Biological and Environmental Research SC-23.4 / Germantown Building, U.S. Department of Energy, 1000 Independence Avenue, SW., Washington, DC 20585-1290. Tel: 301-903-5549. Fax: 301-903-4154.

Todd.Anderson@science.doe.gov.

\section{SUPPLEMENTARY INFORMATION:}

Background: Nine Federal agencies have been cooperating under a MOU on the research and development of multimedia environmental models for the last 5 years. The MOU establishes a framework for facilitating cooperation and coordination among the following agencies (the specific research organization within the agency is in parenthesis): U.S. Army Corps of
Engineers (Engineer Research and Development Center): U.S. Department of Agriculture (Agricultural Research Service); U.S. Department of Agriculture (Natural Resources Conservation Service); U.S. Department of Energy (Office of Biological and Environmental Research); U.S. Environmental Protection Agency; U.S. Geological Survey; U.S. National Oceanographic and Atmosphere Administration; and U.S. Nuclear Regulatory Commission (Office of Nuclear Regulatory Research); U.S. Bureau of Reclamation. These agencies are cooperating and coordinating in the research and development (R\&D) of multimedia environmental models, software and related databases, including development, enhancements, applications and assessments of site specific, generic, and process-oriented multimedia environmental models as they pertain to human and environmental health risk assessment. Multimedia model development and simulation supports interagency interests in risk assessment, uncertainty analyses, water supply issues and contaminant transport. This MOU was just renewed by member agencies ensuring another 5 years of continuing collaboration and cooperation among the participating agencies in these areas.

Purpose of the Public Meeting: The annual public meeting provides an opportunity for the scientific community, other Federal and State agencies, and the public to be briefed on ISCMEM activities and their initiatives for the upcoming year, and to discuss technological advancements in multimedia environmental modeling.

Proposed Agenda: The ISCMEM Chair will open the meeting with a brief overview of the goals of the MOU, the activities of ISCMEM and changes in organizational operations as a result of the revised and renewed ISCMEM MOU. This introduction will be followed by series of invited presentations throughout the morning session focusing on topics of mutual interest to ISCMEM participants. The afternoon session will be largely devoted to discussing future goals and projects that will set the stage for collaborative interactions among ISCMEM participating agencies for the next 5 years. A detailed agenda with presentation titles and speakers will be posted on the MOU public Web site: http://www.ISCMEM.org.

Meeting Access: The headquarters of the American Geophysical Union (AGU) is located at 2000 Florida Avenue, NW. Washington, DC 20009. The most convenient transportation to the meeting venue is via Metro. Please take
Metro to the Dupont Circle Metro stop on the Red Line. Take the "Q” Street exit of the Dupont Circle station. Upon exiting the Metro station proceed North on Connecticut Avenue for about 3 blocks. Turn right onto Florida Avenue for about one-half block. AGU building is on the right. Please inform the security personnel upon entering the building that you are attending the public meeting on multimedia environmental modeling. The meeting room is on the ground floor to your left as you enter the building.

Robert T. Anderson,

Chair, Federal Interagency Steering Committee on Multimedia Environmental Modeling.

[FR Doc. E6-12748 Filed 8-4-06; 8:45 am] BILLING CODE 6450-01-P

\section{DEPARTMENT OF ENERGY}

\section{Energy Information Administration}

Continuation of Forms EIA-182, "Domestic Crude Oil First Purchase Report," and EIA-856, “Monthly Foreign Crude Oil Acquisition Report"

AGENCY: Energy Information Administration, Department of Energy. ACTION: Notice of Continuation of Forms EIA-182, "Domestic Crude Oil First Purchase Report," and EIA-856, "Monthly Foreign Crude Oil Acquisition Report."

SUMMARY: The Energy Information Administration (EIA) will continue the monthly collection of data on the Forms EIA-182, "Domestic Crude Oil First Purchase Report,” and EIA-856, "Monthly Foreign Crude Oil Acquisition Report," through the reporting of October 2006 data that is due to EIA by November 30, 2006.

DATES: Data collection on Forms EIA182 and EIA-856 will continue though November 30, 2006.

ADDRESSES: Inquiries about the continuation of Forms EIA-182 and EIA-856 should be directed to Susan Harris at the Energy Information Administration, EI-42, Forrestal Building, Mail Stop: 2E-050, U.S. Department of Energy, Washington, DC 20585, telephone: (202) 586-8384, Email address: susan.harris@eia.doe.gov or fax number: (202) 586-1076.

FOR FURTHER INFORMATION CONTACT:

Requests for additional information should be directed to Susan Harris at the address listed above.

\section{SUPPLEMENTARY INFORMATION:}

I. Background

II. Current Actions 


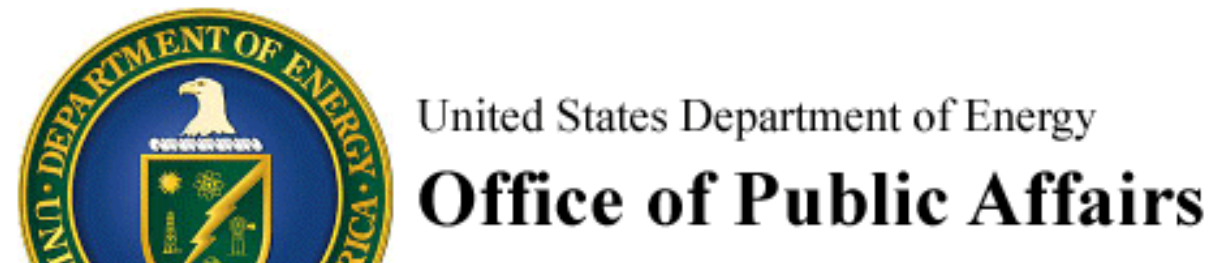

Washington, D.C. 20585

News Media Contact(s):

Craig Stevens, (202) 586-4940

For I mmediate Release

November 29, 2006

\section{Department of Energy Selects Recipients of GNEP Siting Grants}

Eleven sites to be analyzed for potential nuclear recycling facilities

WASHINGTON, DC - The U.S. Department of Energy (DOE) today announced that 11 commercial and public consortia have been selected to receive up to \$16 million in grants, subject to negotiation, to conduct detailed siting studies for integrated spent fuel recycling facilities under the Global Nuclear Energy Partnership (GNEP) initiative. DOE will award the grants early next year after negotiations are completed with prospective awardees.

"As our economy grows so will the need for reliable, emissions-free energy generation. Nuclear energy can help meet that need and GNEP can do it in a way that maximizes the benefit of nuclear fuel while minimizing the risk of nuclear proliferation,” DOE Assistant Secretary for Nuclear Energy Dennis Spurgeon said. "That is why we are pleased that so many communities across the country are interested in hosting the initial facilities necessary to support this exciting project. These selections are an important initial step in proceeding to evaluate and select locations to host GNEP facilities.”

Of the 11 sites located throughout the country, six are currently owned and operated by DOE. The study sites and sponsors are:

1. Atomic City, ID EnergySolutions, LLC

2. Barnwell, SC EnergySolutions, LLC

3. Hanford Site, WA Tri-City Industrial Development

Council/Columbia Basin Consulting

Group

4. Hobbs, NM

Eddy Lea Energy Alliance

5. Idaho National

Regional Development Alliance, Inc. Laboratory, ID

6. Morris, IL

General Electric Company

7. Oak Ridge National Laboratory, TN

Community Reuse Organization of East

Tennessee 

8. Paducah Gaseous Paducah Uranium Plant Asset
Diffusion Plant, KY Utilization, Inc.
9. Portsmouth Gaseous Piketon Initiative for Nuclear
Diffusion Plant, $\mathrm{OH}$ Independence, LLC
10. Roswell, NM EnergySolutions, LLC
11. Savannah River Economic Development Partnership of
National Laboratory, Aiken and Edgefield Counties
SC

The grantees will perform detailed siting studies related to hosting one or both of the Consolidated Fuel Treatment Center and the Advanced Burner Reactor. The subsequent awards will be for a 90-day period of performance to complete a detailed site characterization study of each sponsored site. Congress provided up to \$20 million in FY 2006 for integrated spent fuel recycling facilities siting studies. The remaining funds will be held in reserve to potentially fund supplemental activities if required.

Information generated from the detailed siting studies of non-DOE sites is expected to address a variety of site-related matters, including site and nearby land uses;

demographics; aquatic and riparian ecological communities; terrestrial plant and animal habitat; threatened or endangered species; historical, archaeological and cultural resources; geology and seismology; weather and climate; and regulatory and permitting requirements. Information requirements for the DOE sites are more limited due to the availability of previous studies.

The information may also be used in the environmental impact statement (EIS) that will evaluate the potential environmental impacts from each proposed GNEP facility. At the conclusion of the EIS, DOE will make decisions about whether to move forward with the facilities, and if so, where to locate them.

Fourteen applications were originally submitted, and twelve were selected to receive a comprehensive merit review under the criteria listed in the Financial Assistance Funding Opportunity Announcement (FOA) issued in August 2006. Two of the twelve recently decided to collaborate and team, as they proposed the same site for study.

An advanced nuclear fuel recycling center contains facilities where usable uranium and transuranics are separated from spent light water reactor fuel for use in producing new fuel that can be reused in a power reactor. An advanced recycling reactor is a fast reactor that would demonstrate the ability to reuse and consume materials recovered from spent nuclear fuel, including long-lived elements that would otherwise have to be disposed of in a geologic repository. Both facilities could be located at the same site.

The development and deployment of advanced nuclear fuel recycling facilities is a major element of GNEP, part of President Bush's Advanced Energy Initiative. In general, these technologies focus on separating commercial light water reactor Spent Nuclear Fuel (SNF) into its usable and waste components, fabricating and recycling fast reactor fuel containing transuranic elements from the usable components of SNF, and converting 
those transuranics into shorter-lived radioisotopes while producing electricity in an advanced recycling reactor.

For more information on GNEP, visit: http://www.gnep.gov/. Additional information on DOE’s nuclear energy program may be found on http://www.nuclear.energy.gov/.

U.S. Department of Energy, Office of Public Affairs, Washington, D.C. 
Bde, 25th ID(L) to an SBCT and home station it in Hawaii.

The 2nd Bde, 25th ID(L) began its transformation to the 5th SBCT shortly after completion of the 2004 FEIS and ROD. As of November 2006, the Brigade has completed about $60 \%$ of the training required to achieve combat efficiency and has received about $70 \%$ of its equipment. The Brigade is scheduled to complete its training and equipment fielding in late 2007. The Brigade must be available for deployment to meet joint force and on-going operational requirements in November of 2007.

The National Environmental Policy Act (NEPA) of 1969 (42 U.S.C. \& et seq.) and the Army NEPA procedures, Environmental Analysis of Army Action (32 CFR Part 651) require the Army to consider the environmental impacts of their actions and alternatives, and to solicit the views of the public, so they can make an informed final decision regarding how to proceed. In particular, the Court concluded the Army had a duty under the National Environmental Policy Act (NEPA) to consider locations other than Hawaii for the 5th SBCT.

The proposed action would result in the permanent home stationing of the 5th SBCT. Evaluations will include strategic military and National defense and security considerations. Evaluations will include strategy military and National defense and security consideration, to include which locations, if selected, are capable of supporting the National Security Strategy (2006), the Quadrennial Defense Review (QDR, 2006), National Military Strategy, and the Army Campaign Plan (ACP). These strategic guidance documents have been incorporated into the Army's decision making process. All of these individual components will be considered in the 5th SBCT stationing SEIS to ensure a range of reasonable alternatives are carried forward which support the National Security Strategy (2006). Based on public scoping and factors discussed above, the Army will refine its range of reasonable alternatives to the extent possible to accommodate both mission requirements and Soldier and family quality of life. In reaching this decision the Army will assess and consider public concerns. Analysis will focus on the Purpose of and Need for the Proposed Action. The analysis will evaluate each installation's capability to support the stationing and training of the 5th SBCT in conjunction with meeting the requirements set forth in the National Security Strategy (2006) and its supporting Army initiatives and plans.
The SEIS will assess, consider, and compare the direct, indirect, and cumulative environmental effects from the permanent stationing of the 5 th SBCT in Hawaii and reasonable alternate locations. These locations could include permanent stationing of the 5th SBCT in Hawaii, at Fort Richardson and Donnelly Training Area in Alaska, Fort Lewis and Yakima Training Center in Washington, Fort Carson and Piñon Canyon Maneuver site in Colorado, or Fort Knox in Kentucky. The no action alternative is to return the 2-25th $\mathrm{BDE}(\mathrm{L})$ to its original structure as it existed prior to its transformation. Under established Army Force Structure the no-action alternative is not feasible, as the ACP directed that all Brigades be transformed to expeditionary modular standardized configurations. Only three types of expeditionary modular BCTs exist; Heavy, Infantry and Stryker.

The primary environmental issues to be analyzed will include those identified as the result of the scoping process and installation-specific considerations. These issues may include impacts to soil, water and air quality, airspace conflicts, natural and cultural resources, land use compatibility, noise, socio-economics, environmental justice, energy use, human health and safety considerations, and infrastructure and range/training requirements.

Scoping and Public Comment: All interested members of the public, including native communities and Federally Recognized Indian Tribes (to include Alaska Native Tribes), Native Hawaiian groups, and Federal, State, and local agencies are invited to participate in the scoping process for the preparation of this SEIS. Written comments identifying environmental issues, concerns and opportunities to be analyzed in the SEIS will be accepted following publication of the Notice of Intent in the Federal Register. There will be a 45-day public comment period following publication of the Notice of Intent in the Federal Register. Scoping meetings will be held at the installations identified as potentially reasonable alternative home stationing sites. Notification of the times and locations for the scoping meetings will be published in local newspapers. The scoping process will help identify environmental issues, concerns and opportunities to be analyzed in the SEIS.
Dated: December 28, 2006.

Addison D. Davis, IV,

Deputy Assistant Secretary of the Army, (Environment, Safety, and Occupational Health).

[FR Doc. 06-9966 Filed 1-3-07; 8:45 am] BILLING CODE 3710-08-M

\section{DEPARTMENT OF ENERGY}

\section{Notice of Intent To Prepare a Programmatic Environmental Impact Statement for the Global Nuclear Energy Partnership}

AGENCY: Department of Energy. ACTION: Notice of Intent.

SUMMARY: The Department of Energy (DOE) intends to prepare a

Programmatic Environmental Impact Statement for the Global Nuclear Energy Partnership initiative (GNEP PEIS) pursuant to the National Environmental Policy Act (NEPA) of 1969, as amended (42 U.S.C. 4321 et seq.), and the Council on Environmental Quality's (CEQ's) and DOE's regulations implementing NEPA (40 CFR Parts 1500-1508 and 10 CFR Part 1021, respectively). GNEP would encourage expansion of domestic and international nuclear energy production while reducing nuclear proliferation risks, and reduce the volume, thermal output, and radiotoxicity of spent nuclear fuel (spent fuel or SNF) before disposal in a geologic repository.

Domestically, GNEP involves a programmatic proposal as well as project-specific proposals. The programmatic proposal is to begin to recycle spent fuel and destroy the longlived radioactive components of that spent fuel. Toward this end, GNEP includes project-specific proposals to construct and operate three facilities. The proposed nuclear fuel recycling center would separate the SNF into its reusable components and waste components and manufacture new nuclear fuel using reusable components that still have the potential for use in nuclear power generation. The proposed advanced recycling reactor would destroy long-lived radioactive elements in the fuel while generating electricity. The advanced fuel cycle research facility would perform research into SNF recycling processes and other aspects of advanced nuclear fuel cycles. The GNEP PEIS will consider 13 sites as possible locations for one or more of these facilities, as well as alternative technologies to be used in these facilities. Internationally, GNEP involves two programmatic initiatives. First, the United States would cooperate with countries that have advanced 
nuclear programs to supply nuclear fuel services to countries that refrain from pursuing enrichment or recycling facilities to make their own nuclear fuel. Such countries would have no need to develop the technology and infrastructure to enrich uranium or separate plutonium, both of which have application in the production of nuclear weapons. Second, the United States would promote proliferation-resistant nuclear power reactors suitable for use in developing economies.

The GNEP PEIS will analyze the potential environmental impacts of these programmatic and project-specific proposals, as well as reasonable alternatives. The GNEP PEIS also will evaluate at a programmatic level the potential environmental impacts associated with the international aspects of GNEP, including alternatives. The SUPPLEMENTARY INFORMATION section of this Notice of Intent (NOI) describes the alternatives that DOE proposes to evaluate in the GNEP PEIS. This NOI also identifies dates, times, and locations for public scoping meetings on the GNEP PEIS.

DATES: DOE invites Federal, state, and local governments, Native American Tribes, industry, other organizations, and members of the public to provide comments on the proposed scope, alternatives, and environmental issues to be analyzed in the GNEP PEIS. The public scoping period starts with the publication of this NOI in the Federal Register and will continue through April 4, 2007. All comments received during the public scoping period will be considered in preparing the GNEP PEIS. Late comments will be considered to the extent practicable. Public scoping meetings are discussed below in the SUPPLEMENTARY INFORMATION section. Federal or state agencies, local governments, or Native American Tribes that want to be considered as a cooperating agency in preparation of this PEIS should contact Mr. Timothy A. Frazier at the address listed below.

ADDRESSES: Please direct comments, suggestions, or relevant information on the GNEP PEIS to: Mr. Timothy A. Frazier, GNEP PEIS Document Manager, Office of Nuclear Energy, U.S. Department of Energy, 1000 Independence Avenue, SW., Washington, DC 20585-0119, Telephone: 866-645-7803, Fax: 866645-7807, e-mail to: GNEPPEIS@nuclear.energy.gov. Please mark envelopes, faxes, and e-mail: "GNEP PEIS Comments.” Additional information on GNEP may be found at http://www.gnep.energy.gov.
For general information on the DOE NEPA process, please contact: Ms. Carol M. Borgstrom, Director, Office of NEPA Policy and Compliance, GC-20, U.S. Department of Energy, 1000 Independence Avenue, SW., Washington, DC 20585-0103, 202-5864600 , or by leaving a message at 1-800472-2756. Additional information regarding DOE's NEPA activities is available on the DOE NEPA Web site at http://www.eh.doe.gov/nepa. This NOI is available at http://www.eh.doe.gov/ nepa and http://www.gnep.energy.gov. SUPPLEMENTARY INFORMATION:

\section{Terminology}

To aid in understanding the information that follows, a brief explanation of key terms and the three proposed facilities that support GNEP is provided below:

- Advanced Fuel Cycle InitiativeThe Advanced Fuel Cycle Initiative (AFCI) is an ongoing DOE initiative to develop proliferation-resistant spent nuclear fuel treatment and transmutation technologies to enable a transition from the current once-through nuclear fuel cycle to a future sustainable, closed nuclear fuel cycle where valuable material is separated from spent fuel and recycled, thereby extracting energy and reducing waste.

- Enriched uranium-Uranium in which the proportion of uranium-235 to uranium-238 has been increased above the naturally occurring 0.7 percent uranium-235. Reactor-grade uranium is uranium that has been enriched to about three to five percent uranium-235 for use in reactors to produce electricity. The same process can be used to further enrich uranium for weapons use.

- Fission-The splitting of an atom into at least two other atoms and the release of a relatively large amount of energy. Two or three neutrons are usually released during the transformation. Fission is the scientific principle by which nuclear power reactors work.

- Fission product-The atoms (fission fragments) formed by the fission of heavy elements such as uranium. Fission products build up in nuclear fuel as a normal part of reactor operations.

- Light-water reactor-A nuclear power reactor that uses water to cool the reactor and to moderate (slow down) neutrons. It belongs to the class of nuclear power plants called "thermal reactors.” Most nuclear power reactors in the world are light-water reactors.

- Recycling-The separation of used nuclear fuel into: Uranium; waste (fission products and fuel element structural materials); and transuranics.
Uranium and transuranics would be incorporated into new fuel to be consumed in reactors to generate electricity.

- Spent nuclear fuel (used nuclear fuel)-The fuel that has been used in a nuclear reactor. As a typical nuclear reactor operates, the fission process creates energy to generate electricity. During this process, the uranium is being "used" and fission products accumulate and interfere with efficiency until the fuel can no longer effectively produce energy. At this point, the used fuel is said to be "spent" and is replaced.

- Transmutation-The conversion of one element to another by changing its atomic structure. There are two primary transmutation processes: Fission, which splits atoms, releasing energy; and neutron capture, which adds one neutron to an atom. Transmutation can be used to destroy radioactive elements with very long half-lives, such as transuranic elements, by converting them to stable elements or elements with shorter half-lives, while producing energy.

- Transuranics (transuranic elements)_Elements with atomic numbers greater than uranium (atomic number 92), including neptunium (93), plutonium (94), americium (95), and curium (96). Transuranic elements are created in nuclear power reactors when uranium absorbs or captures neutrons.

- Uranium enrichment-The physical process of increasing the proportion (or ratio) of uranium-235 to uranium-238 to make the uranium more usable as nuclear fuel.

The three proposed GNEP facilities that DOE will evaluate in the GNEP PEIS are:

- A nuclear fuel recycling center-A nuclear fuel recycling center would support two of the three key components of an SNF recycling program: (1) It would separate lightwater reactor SNF and fast reactor SNF into their reusable and non-reusable constituents, and (2) after completion of transmutation fuel development at the advanced fuel cycle research facility, it would fabricate such fuel for use in the destruction of transuranic elements in a fast reactor (the advanced recycling reactor). A nuclear fuel recycling center could be privately owned and operated, potentially with government-supplied incentives or other involvement yet to be determined.

- An advanced recycling reactor-A fast neutron spectrum reactor that would be capable of converting longlived radioactive elements (e.g., plutonium and other transuranics) into shorter-lived radioactive elements while 
producing electricity. The advanced recycling reactor could be privately owned and operated, potentially with government-supplied incentives or other involvement yet to be determined.

- An advanced fuel cycle research facility - A research facility that DOE would design, build, and operate at a DOE site. Among other activities, the advanced fuel cycle research facility would support research and development (R\&D) relating to separation and fabrication of fast reactor transmutation fuel to enable the destruction of transuranic elements separated from SNF.

\section{Background}

The United States faces significant energy challenges including increasing energy supplies in ways that protect and improve the environment. Meeting each of these challenges is critical to expanding the United States economy and protecting energy and national security.

The President's Advanced Energy Initiative has identified three ways to meet the challenge of generating more electricity: Clean coal technology, advanced emission-free nuclear power, and renewable resources such as solar and wind. The GNEP PEIS will evaluate the potential environmental impacts of alternative ways to recycle spent nuclear fuel using technologies that increase its usefulness while reducing the threat of proliferation.

Nuclear power provides approximately one-fifth of the electricity that the United States uses to power factories, office buildings, homes, and schools. Over 100 operating nuclear power plants, located at 65 sites in 31 states, constitute the second-largest source of electricity generation in the United States. The plants are, on average, approximately 25 years old and are licensed to operate for 40 years with an option to renew for an additional 20 years. Nuclear reactors do not emit the air pollutants and greenhouse gases that result from coal-fired, oil-fired, and natural gas-fired generation. Nuclear power contributes to United States energy security.

Historically, the United States has used a "once through" or "open" fuel cycle in which nuclear fuel is used a single time by a nuclear power reactor, and then the spent fuel is stored at that plant pending disposal. The Federal government has responsibility for the disposal of SNF, and plans to dispose of it in the geologic repository located at Yucca Mountain, Nevada.

GNEP would establish a "closed" fuel cycle by recycling spent nuclear fuel rather than disposing of it after one use.
Recycling spent fuel rather than disposing of it potentially would extend the stock of nuclear fuel available to meet growing electricity demand and reduce waste from the generation of nuclear power. DOE has been researching and developing recycling technologies in its laboratories for many years and has identified processes that would be needed for GNEP to accomplish its objectives. However, additional R\&D is necessary to implement the proposed GNEP recycling associated with the transmutation fuel.

GNEP also offers the potential for more efficient nuclear waste disposal. Technological advancements through GNEP could reduce the volume, thermal output, and radiotoxicity of waste requiring permanent disposal at the Yucca Mountain geologic repository. It is important to emphasize, however, that GNEP does not diminish in any way the need for, or the urgency of, the nuclear waste disposal program at Yucca Mountain. Yucca Mountain is still required under any fuel cycle scenario.

The Energy Information Administration projects that the world's electricity consumption will double from 2003 to 2030. GNEP as envisioned would promote the expanded use of carbon-free nuclear energy to meet growing electricity demand throughout the world, while reducing nuclear proliferation risks. GNEP would achieve this goal by having nations with secure, advanced nuclear capabilities provide fuel services-fresh fuel and recovery of used fuel-to other nations that refrain from pursuing uranium enrichment or recycling activities. The closed fuel cycle model envisioned by this partnership requires development and deployment of technologies that enable recycling and reduction of long-lived radioactive waste.

As these technologies are developed, the United States would work with partners to provide developing countries with reactors that would be secure, cost-effective, and able to meet their energy needs, as well as related nuclear services that would ensure that they have a reliable fuel supply. In exchange, these countries would agree to use nuclear power only for electricity and refrain from pursuing uranium enrichment and reprocessing activities that can be used to develop nuclear weapons. By working with other nations under the GNEP, the United States could provide safe and reliable energy that growing economies need, while reducing the risk of nuclear proliferation.
The commercial marketplace will ultimately determine how to meet future increased demand for electricity. By recycling SNF, GNEP is designed to provide an alternative to the oncethrough fuel cycle. DOE is not proposing in this PEIS that DOE would construct and operate any facilities for the primary purpose of generating electricity. The proposed advanced recycling reactor would demonstrate the feasibility of consuming transuranics in transmutation fuel in a reactor, while also generating electricity.

\section{The Purpose and Need for Agency Action}

DOE's underlying purpose and need in proposing this action is to encourage expansion of domestic and international nuclear energy production while reducing the risks associated with nuclear proliferation, and to reduce the volume, thermal output, and radiotoxicity of SNF before disposal in a geologic repository. To meet its nonproliferation goals with regard to SNF recycling, DOE will only assess as reasonable alternatives those technologies that do not separate pure plutonium.

\section{Advance Notice of Intent; Funding Opportunity Announcement; Requests for Expressions of Interest}

On March 22, 2006, DOE published in the Federal Register (71 FR 14505) an Advance NOI (ANOI) related to the then-proposed GNEP Technology Demonstration Program EIS. That ANOI explained the goals of GNEP as it was then conceived and identified the three major project-specific elements (the demonstration of advanced separations processes, conversion of transuranics, and advanced fuel fabrication) of a GNEP Technology Demonstration Program, which was intended to demonstrate closed fuel cycle technologies at an engineering scale. The ANOI also invited comments on the proposed scope, alternatives, and environmental issues to be analyzed in that EIS. DOE received over 800 comment documents, more than 750 of which contained similar substantive comments.

DOE considered all comments received. One of the main comments received was that DOE should do a programmatic NEPA review instead of limiting its review to the three facilities. Comments received on the ANOI also included the following:

- The proposed technologies are not sufficiently advanced to proceed with engineering-scale demonstrations;

- DOE should pursue and analyze alternatives to nuclear power in a PEIS; 
- DOE is proceeding with Federal action related to GNEP before conducting the required NEPA analysis.

These issues will be addressed in the GNEP PEIS

In addition, a number of foreign governments and private companies have expressed interest in cooperating with DOE to develop and deploy advanced nuclear fuel recycling technologies. Some of these entities indicated they are pursuing technologies that may be ready for deployment faster, and at a larger, commercial scale, than those currently under development by DOE.

In response to the comments and the interest expressed, DOE has made two fundamental changes to its GNEP NEPA strategy: (1) DOE will prepare a PEIS to assess the programmatic elements of GNEP, as well as the three proposed projects; and (2) DOE is now proposing to analyze engineering-scale and commercial-scale demonstrations of GNEP technologies at two of the three proposed facilities, rather than only at the smaller engineering scale.

Since publication of the ANOI, DOE has taken several steps to determine the level of interest in GNEP and obtain useful information. First, DOE has sought input regarding potential hosting sites in the United States for a nuclear fuel recycling center and an advanced recycling reactor. On August 3, 2006, DOE issued a Financial Assistance Funding Opportunity Announcement (FOA) for public or commercial entities interested in hosting GNEP facilities to conduct detailed siting studies. These siting studies will be used by DOE to help evaluate potential locations for a nuclear fuel recycling center and an advanced recycling reactor.

Applications for these financial assistance grants were due to DOE by September 7, 2006. On November 29, 2006, DOE announced that 11 commercial and public consortia had been selected to receive grants under this FOA. The study sites and sponsors are:

Atomic City, Idaho-EnergySolutions, LLC,

Barnwell, South Carolina-

EnergySolutions, LLC,

Hanford Site, Washington-Tri-City

Industrial Development Council/

Columbia Basin Consulting Group,

Hobbs, New Mexico-Eddy Lea

Energy Alliance,

Idaho National Laboratory, Idaho-

Regional Development Alliance, Inc., Morris, Illinois-General Electric

Company,

Oak Ridge National Laboratory, Tennessee-Community Reuse Organization of East Tennessee,
Paducah Gaseous Diffusion Plant, Kentucky-Paducah Uranium Plant Asset Utilization, Inc.,

Portsmouth Gaseous Diffusion Plant, Ohio-Piketon Initiative for Nuclear Independence, LLC,

Roswell, New Mexico-

EnergySolutions, LLC,

Savannah River National Laboratory, South Carolina-Economic

Development,

Partnership of Aiken and Edgefield

Counties.

Second, on August 7, 2006, DOE issued two requests for Expressions of Interest (EOIs) related to GNEP (see 44 FR 44673 and 44 FR 44676). The purpose of the EOIs was to obtain information from the domestic and international nuclear industry on the potential development of a commercialscale nuclear fuel recycling center and an advanced recycling reactor using advanced technologies available now or in the near future. DOE is using the industry responses to the EOIs to help identify available technologies, alternative facility sizes, potential financial arrangements, and other factors related to the development of a nuclear fuel recycling center and an advanced recycling reactor. This information will contribute to the development of reasonable alternatives for evaluation in the GNEP PEIS.

DOE also would pursue an R\&D program using an advanced fuel cycle research facility to develop additional technologies (not yet available) to separate and fabricate transmutation fuel for a fast reactor. DOE did not include an advanced fuel cycle research facility in the FOA or EOI processes because an advanced fuel cycle research facility is intended to be an R\&D facility on a DOE site. Like a nuclear fuel recycling center and an advanced recycling reactor, an advanced fuel cycle research facility will be evaluated in the GNEP PEIS.

\section{Description of GNEP Recycling}

In general terms, GNEP recycling would work as follows. Spent fuel would be received from commercial nuclear reactors and would be processed in a nuclear fuel recycling center to separate the potentially reusable constituents (uranium and transuranic elements) from the nonreusable constituents (e.g., fuel element structural materials and fission products). The reusable constituents would be used to make transmutation fuel for an advanced recycling reactor and, possibly, other reactor fuels (e.g., uranium could be re-enriched and made into light-water reactor fuel). The transmutation fuel would be consumed in an advanced recycling reactor, and the advanced recycling reactor would also produce electricity during these operations. The spent transmutation fuel would then be separated and the remaining transuranics used to make new transmutation fuel to be further destroyed in the advanced recycling reactor while producing electricity. Non-reusable constituents would be converted to waste forms for eventual disposal in a geologic repository or for other long-term storage or disposal, as appropriate. This fuel cycle has the potential to reduce the volume, thermal output, and radiotoxicity of waste that would need to be placed in a geologic repository, thereby increasing the geologic repository's effective capacity and lessening the need for additional repository capacity.

\section{Current Research and Development Activities}

DOE has been conducting R\&D related to the nuclear fuel cycle and nuclear reactor programs for many decades. Current R\&D efforts are focused on exploring new, innovative concepts for advanced nuclear energy technologies that can address the key issues facing the long-term viability and expansion of nuclear power, including: The need to reduce and deal satisfactorily with nuclear wastes; improving economic performance; further advancing the safety of nuclear power generation; and addressing issues associated with the proliferation of fissile materials and sensitive nuclear technologies. GNEP would build upon these activities. While these activities share a common purpose with GNEP, they are outside the scope of the GNEP PEIS.

\section{Proposed Alternatives}

The GNEP PEIS will analyze the potential environmental impacts of programmatic and project-specific proposals, as well as reasonable alternatives.

\section{A. International Programmatic Alternatives}

The GNEP PEIS will evaluate the potential environmental impacts of two proposed international initiatives and, for each, a No Action Alternative. The No Action Alternative would reflect the continuation of the status quo.

The two initiatives are the reliable fuel services program and the reactor program. Under the reliable fuel services program, the United States would work with partner nations to provide assurances of fuel availability for operators of nuclear power reactors in nations that refrain from pursuing uranium enrichment and reprocessing 
programs. DOE is not proposing any specific action with regard to the reliable fuel services program, and the GNEP PEIS will include only a general, qualitative analysis of the potential impacts on the United States or the global commons that might be involved with such activities.

Under the reactor program, the United States would explore promoting proliferation-resistant reactors designed to meet the needs of developing economies. Because the designs for these reactors are not yet determined and DOE is not proposing any specific action to make the reactors available, the GNEP PEIS will include only a general, qualitative analysis of the potential impacts on the United States or the global commons that might be involved with such activities.

\section{B. Domestic Programmatic Alternatives}

The domestic programmatic alternatives currently envisioned are:

Programmatic Alternative 1, No Action Alternative: Continue the status quo by relying upon a "once through" or "open" fuel cycle in which commercial reactors generate and store SNF until DOE can dispose of it in a geologic repository, while continuing the ongoing nuclear fuel cycle R\&D activities, including those activities associated with DOE's Advanced Fuel Cycle Initiative (AFCI).

Programmatic Alternative 2, Proposed Action: Pursue the GNEP closed fuel cycle and recycle SNF in a system that includes one or more nuclear fuel recycling centers and one or more advanced recycling reactors to process SNF generated after their deployment. The PEIS analysis would be based upon alternative assumptions regarding the amount of SNF processed and the corresponding potential cumulative impacts of reasonably foreseeable actions as a result of this alternative.

The closed fuel cycle programmatic alternative will include an analysis of the potential environmental impacts associated with broad implementation of a closed fuel cycle. In addition, DOE is now proposing to site, construct, and operate a single set of closed fuel cycle facilities.

\section{Domestic Project-Specific Alternatives}

The project-specific alternatives are:

Project Alternative 1, No Action Alternative: Continue relying upon a "once through" or “open” fuel cycle in which commercial reactors generate and store SNF until DOE can dispose of it in a geologic repository, while continuing the ongoing nuclear fuel cycle R\&D activities, including those activities associated with DOE's AFCI. A nuclear fuel recycling center, an advanced recycling reactor, and an advanced fuel cycle research facility would not be built.

Project Alternative 2, Proposed Action: Select site(s) and construct and operate the following GNEP facilities: (1) A nuclear fuel recycling center, (2) an advanced recycling reactor, and (3) an advanced fuel cycle research facility. The GNEP PEIS will assess alternative technologies and implementation approaches (e.g., engineering or commercial facility scale) that are deemed reasonable, based in part on the EOIs discussed in the BACKGROUND section above. With respect to a nuclear fuel recycling center, DOE plans to evaluate alternative separations technologies for SNF from commercial light-water reactors and the advanced recycling reactor. For each technology, DOE would evaluate potential waste streams and alternative waste forms (e.g., borosilicate glass, ceramic).

For a nuclear fuel recycling center, DOE will analyze several alternative SNF throughputs from approximately 100 metric tons of heavy metal (MTHM) annually, up to 3,000 MTHM annually. At the low range of throughputs, the analyses would correspond to engineering-scale capacities consistent with the ANOI. At the high range of throughput, the Department expects that a nuclear fuel recycling center would have the capacity to recycle up to 2,000-3,000 MTHM annually, which would enable a nuclear fuel recycling center to recycle commercial SNF inventories at approximately the same rate that such inventories are now generated. DOE also will assess appropriate storage alternatives for the recycling facilities. DOE will evaluate storage of spent fuel prior to recycling, as well as storage of waste generated from recycling, at a level related to the projected throughput for a nuclear fuel recycling center.

For an advanced recycling reactor, the baseline technology that will be assessed is a sodium-cooled fast reactor. DOE plans to evaluate alternative fuel types (e.g., oxide, metal) and power ratings $\left(250-2,000 \mathrm{MW}_{\text {thermal }}\right)$ for an advanced recycling reactor. DOE also will assess appropriate storage alternatives for spent fuel generated by an advanced recycling reactor prior to recycling, at a level related to the projected size of an advanced recycling reactor.

DOE envisions that a nuclear fuel recycling center and an advanced recycling reactor could begin operation before DOE has fully completed its research and development of the transmutation fuel recycling at an advanced fuel cycle research facility. During this interim period, DOE may use a nuclear fuel recycling center to separate light-water reactor SNF and support the fabrication of fast reactor driver fuel which would be consumed in the advanced recycling reactor. This fuel could be made of uranium and plutonium, but would likely not contain other transuranics. Once DOE completes the $\mathrm{R} \& \mathrm{D}$ required to fabricate fuel containing other transuranic elements, it would use a nuclear fuel recycling center to fabricate fast reactor fuels containing other transuranics, and demonstrate the consumption of transuranic elements in an advanced recycling reactor. DOE would then separate the resulting spent transmutation fuel and fabricate new transmutation fuel in a nuclear fuel recycling center.

At this time, the following DOE sites are under consideration for the location of a nuclear fuel recycling center and/ or an advanced recycling reactor: Idaho National Laboratory (Idaho Falls, Idaho); Paducah Gaseous Diffusion Plant (Paducah, Kentucky); Portsmouth Gaseous Diffusion Plant (Piketon, Ohio); Savannah River Site (Aiken, South Carolina); Oak Ridge National Laboratory (Oak Ridge, Tennessee); and Hanford Site (Richland, Washington). In addition, non-DOE sites in the following locations also are under consideration for the location of a nuclear fuel recycling center and/or an advanced recycling reactor: Atomic City, Idaho; Morris, Illinois; Hobbs, New Mexico; Roswell, New Mexico; and Barnwell, South Carolina.

DOE is proposing that the advanced fuel cycle research facility be located at a DOE site. The DOE sites under consideration include: Idaho National Laboratory (Idaho Falls, Idaho); Argonne National Laboratory (DuPage County, Illinois); Los Alamos National Laboratory (Los Alamos, New Mexico); Savannah River Site (Aiken, South Carolina); Oak Ridge National Laboratory (Oak Ridge, Tennessee); and Hanford Site (Richland, Washington).

To determine reasonable site alternatives for an advanced fuel cycle research facility, DOE is conducting a site screening process that is considering criteria specific to an advanced fuel cycle research facility. Similarly, for a nuclear fuel recycling center and an advanced recycling reactor, DOE will use the information received through the FOA process, as well as other information, to develop the reasonable site alternatives. As a result of these site screening processes, some sites may be eliminated from 
consideration as reasonable site alternatives. DOE will document the results of the site screening processes in the GNEP PEIS Site Alternative

Screening Report.

DOE intends that the alternatives and analyses in the GNEP PEIS will provide the maximum amount of flexibility in making decisions related to GNEP. In any event, however, in order for a site to be selected as the preferred site for a facility, DOE will require adequate assurances that there are no legal impediments to the siting and operation of that facility in that State.

The GNEP PEIS analysis will address the potential environmental impacts of proceeding with a nuclear fuel recycling center, an advanced recycling reactor, and an advanced fuel cycle facility, either individually or in any combination. In addition, the PEIS will analyze the environmental impacts of not developing transmutation fuel in a timely manner.

\section{Potential Environmental Issues for Analysis}

DOE has identified the following potential environmental issues for analysis in the GNEP PEIS. The list is presented to facilitate comment on the scope of the PEIS; it is not intended to be comprehensive or to predetermine the alternatives to be analyzed or their potential impacts. Additional issues may be identified as a result of the public scoping process. The current list includes the following issues:

- Potential impacts to the general population and workers from radiological and nonradiological releases

- Potential impacts of emissions on air and water quality

- Potential impacts on flora and fauna of a region

- Potential impacts from transportation-in the United States and across the global commons

- Potential impacts from treatment, storage, and disposal of radioactive materials and waste

- Potential impacts from postulated accidents, as well as potential impacts from acts of terrorism or sabotage

- Potential disproportionately high and adverse effects on low-income and minority populations (environmental justice)

- Potential Native American concerns (cultural and archaeological)

- Short-term and long-term land use impacts

- Compliance with applicable Federal and state regulations

- Long-term health and environmental impacts

- Long-term site suitability
- Consumption of natural resources and energy

- Socioeconomic impacts to potentially affected communities

- Potential impacts to cultural resources

- Cumulative impacts

- Pollution prevention and waste management practices

- Potential impacts from

decontamination and decommissioning (D\&D) of facilities

\section{Public Scoping Meetings}

Public scoping meetings will be held to provide the public with an opportunity to present comments, ask questions, and discuss the scope of the GNEP PEIS with DOE officials. DOE selected the following scoping meeting locations based on the responses received to the Financial Assistance Funding Opportunity Announcement and a preliminary identification of DOE sites that could support the proposed DOE-directed R\&D facility.

As discussed in this NOI, inclusion on the list below does not necessarily mean that a particular location will be considered as a reasonable site alternative for any GNEP facilities.

Oak Ridge, Tennessee: DoubleTree Hotel (Salons A and B) 215 South Illinois Avenue Oak Ridge, Tennessee 37830 Tuesday, February 13, 2007, 6 p.m.-9:30 p.m.

North Augusta, South Carolina: North Augusta Community Center 495 Brookside Avenue North Augusta, South Carolina 29841 Thursday, February 15, 2007, 6 p.m.-9:30 p.m. Joliet, Illinois: Barber \&

Oberwortmann Horticultural Center 227

North Gougar Road Joliet, Illinois 60435

Thursday, February 22, 2007, 6 p.m.9:30 p.m.

Hobbs, New Mexico: Lea County Event Center 5101 N Lovington-Hobbs

Hwy Hobbs, New Mexico 88240

Monday, February 26, 2007, 6 p.m.-9:30 p.m.

Roswell, New Mexico: Best Western Sally Port Inn \& Suites (Ballroom) 2000 N Main Street Roswell, New Mexico 88201-6450 Tuesday, February 27, 2007, 6 p.m.-9:30 p.m.

Los Alamos, New Mexico: Hilltop House Best Western (La Vista Room) 400 Trinity Drive (at Central) Los Alamos, New Mexico 87544 Thursday, March 1, 2007, 6 p.m.-9:30 p.m.

Paducah, Kentucky: Executive Inn Riverfront (Meeting Room International D) One Executive Blvd. Paducah, Kentucky 42001 Tuesday, March 6, 2007, 6 p.m.-9:30 p.m.

Piketon, Ohio: Ohio State University Endeavor Center, Room 1601862 Shyville Road Piketon, Ohio 45661
Thursday, March 8, 2007, 6 p.m.-9:30 p.m.

Pasco, Washington: Red Lion Hotel (Gold Room) 2525 N. 20th Avenue Pasco, Washington 99301 Tuesday, March 13, 2007, 6 p.m.-9:30 p.m.

Idaho Falls, Idaho: Red Lion Hotel on the Falls (Yellowstone/Teton Rooms) 475 River Parkway Idaho Falls, Idaho 83402 Thursday, March 15, 2007, 6 p.m.-9:30 p.m.

Washington, DC: Hotel Washington (Washington Room) 15th and Pennsylvania Ave, NW Washington, DC 20004 Monday, March 19, 2007, 1 p.m.5 p.m.

DOE also will publish notices in local media in advance of the scheduled public scoping meetings with the dates, times, and locations.

\section{NEPA Process}

DOE plans to publish the GNEP Draft PEIS in 2007 and the GNEP Final PEIS in 2008. Following the 90-day public scoping period that commences with publication of this NOI, DOE will prepare the GNEP Draft PEIS. Once approved, DOE will announce the availability of the GNEP Draft PEIS in the Federal Register and hold public hearings to solicit comments on the GNEP Draft PEIS from Federal, state, and local governments, Native American Tribes, industry, other organizations, and members of the public. These comments will be considered and addressed in the GNEP Final PEIS. DOE will issue one or more Records of Decision no sooner than 30 days after publication of the Environmental Protection Agency's Notice of Availability of the GNEP Final PEIS.

Issued in Washington, DC, on December 27, 2006 .

David R. Hill,

General Counsel.

[FR Doc. E6-22548 Filed 1-3-07; 8:45 am] BILLING CODE 6450-01-P

\section{DEPARTMENT OF ENERGY}

\section{Privacy Act of 1974; Notice to Amend an Existing System of Records}

AGENCY: U.S. Department of Energy. ACTION: Notice.

SUMmARY: As required by the Privacy Act of 1974, 5 U.S.C. 552a, and the Office of Management and Budget (OMB) Circular A-130, the Department of Energy (DOE) is publishing a notice of a proposed amendment to an existing system of records. DOE proposes to amend and change the name of DOE-21 “Emergency Defense Mobilization 


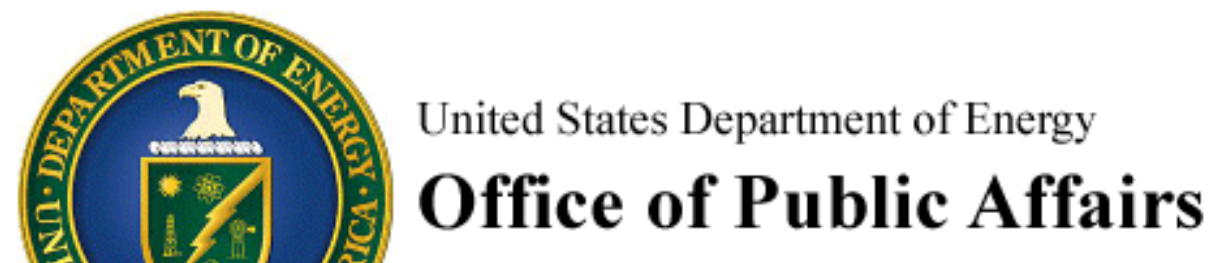

Washington, D.C. 20585

News Media Contact(s):

Craig Stevens, (202) 586-4940

For I mmediate Release

January 10, 2007

\section{Department of Energy Releases Global Nuclear Energy Partnership Strategic Plan}

WASHINGTON, DC - The U.S. Department of Energy (DOE) Assistant Secretary for Nuclear Energy Dennis Spurgeon today released the Global Nuclear Energy Partnership (GNEP) Strategic Plan, which details the Initiative's purpose, principles and implementation strategy. The Plan outlines a path forward to enable worldwide increase in the use of safe, emissions-free nuclear energy without contributing to the spread of nuclear weapons capabilities in a manner that responsibly addresses the waste produced.

"For the United States, GNEP is good policy; for industry, it could be very good business,” Assistant Secretary Spurgeon said. “Releasing GNEP's Strategic Plan demonstrates the seriousness DOE places on this Initiative as well as the seriousness of our nation's need to incorporate safe, emissions-free nuclear power into our nation's energy mix. While DOE labs and research facilities host some of the best scientists, the GNEP Strategic Plan gives researchers, experts and industry the opportunity to examine and understand our vision.”

The Strategic Plan is a guiding document, one that can be modified if the U.S. Government, our international partners and industry deem it appropriate. It lays out DOE's plan to prepare for construction and operation of a nuclear fuel recycling center and an advanced recycling reactor, and for continuing an aggressive research and development program focused on advanced fuel cycle technology. The Plan also specifies criteria necessary to consider in order to safely and successfully implement the goals of GNEP.

The Strategic Plan provides a framework for the U.S. to:

1. Expand nuclear power to meet growing energy demand;

2. Develop, demonstrate, and deploy advanced technologies for recycling spent nuclear fuel without separating plutonium;

3. Develop, demonstrate, and deploy advance reactors that consume transuranics;

4. Establish reliable fuel services worldwide;

5. Develop, demonstrate, and deploy proliferation resistant reactors appropriate to power grids and;

6. Develop enhanced safeguards to ensure nuclear energy systems are used for peaceful purposes.

This Plan identifies the technology, economic and environmental information necessary to present a convincing case to the Secretary of Energy for his decision on a path forward regarding the design and construction of recycling facilities in support of GNEP. 
GNEP is a part of President Bush's Advanced Energy Initiative, which seeks to reduce our reliance in imported oil by changing the way we power our cars, homes and business. For more information on GNEP, visit: http://www.gnep.gov/.

GNEP Strategic Plan Jan 2007

U.S. Department of Energy, Office of Public Affairs, Washington, D.C. 


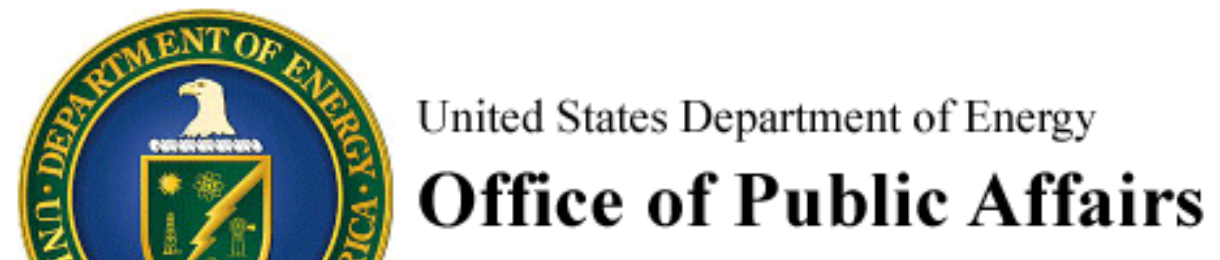

Washington, D.C. 20585

News Media Contact(s):

Craig Stevens, (202) 586-4940

For I mmediate Release

January 30, 2007

\section{Department of Energy Awards Over \$10 Million for GNEP Siting Grants}

WASHINGTON, DC - The U.S. Department of Energy (DOE) today announced that over \$10 million will be used for 11 commercial and public consortia selected to conduct detailed siting studies for integrated spent fuel recycling facilities under President Bush's Global Nuclear Energy Partnership (GNEP).

“These facilities will enable us to effectively recycle spent nuclear fuel in a safe and proliferation-resistant manner. They will set the technological standard and allow us to influence energy policy abroad while increasing energy security here at home,” DOE Assistant Secretary for Nuclear Energy Dennis Spurgeon said. "With the negotiations complete, we are ready to proceed from an initial phase to one where actual studies can explore sites for GNEP-related facilities.”

Award recipients, announced in November 2006, will carry out siting studies to determine the possibility of hosting an advanced nuclear fuel recycling center and/or an advanced recycling reactor. Beginning today, recipients will conduct detailed site characterization studies of the sites which were proposed in their Funding Opportunity Announcement (FOA) responses. Recipients will have 90-days to complete these studies and submit a Site Characterization Report to DOE on May 1, 2007.

Of the 11 sites, six are currently owned and operated by DOE. Sites, lead award recipients, and award amounts are as follows:

$\begin{array}{lll}\begin{array}{l}\text { Proposed Site } \\ \text { Location }\end{array} & \text { Teaming Consortia } & \begin{array}{l}\text { Award } \\ \text { Amounts }\end{array} \\ \begin{array}{ll}\text { 1. Atomic City, ID EnergySolutions, LLC } \\ \text { 2. Barnwell, SC }\end{array} & \begin{array}{l}\$ 915,448 \\ \text { EnergySolutions, LLC }\end{array} & \$ 936,151 \\ \text { 3. Hanford Site, } & \text { Tri-City Industrial } & \$ 1,027,715 \\ \text { WA } & \begin{array}{l}\text { Development } \\ \text { Council/Columbia Basin }\end{array} & \\ & \text { Consulting Group } & \end{array}$




\begin{tabular}{|c|c|c|}
\hline 4. Hobbs, NM & Eddy Lea Energy Alliance & $\$ 1,590,016$ \\
\hline $\begin{array}{l}\text { 5. Idaho National } \\
\text { Laboratory, ID }\end{array}$ & $\begin{array}{l}\text { Regional Development } \\
\text { Alliance, Inc }\end{array}$ & $\$ 648,745$ \\
\hline 6. Morris, IL & General Electric Company & $\$ 1,484,875$ \\
\hline $\begin{array}{l}\text { 7. Oak Ridge } \\
\text { National } \\
\text { Laboratory, TN }\end{array}$ & $\begin{array}{l}\text { Community Reuse Organization } \\
\text { of East Tennessee }\end{array}$ & 4,704 \\
\hline $\begin{array}{l}\text { 8. Paducah } \\
\text { Gaseous Diffusion } \\
\text { Plant, KY }\end{array}$ & $\begin{array}{l}\text { Paducah Uranium Plant Asset } \\
\text { Utilization, Inc. }\end{array}$ & $\$ 664,600$ \\
\hline $\begin{array}{l}\text { 9. Portsmouth } \\
\text { Gaseous Diffusion } \\
\text { Plant, OH }\end{array}$ & $\begin{array}{l}\text { Piketon Initiative for Nuclear } \\
\text { Independence, LLC }\end{array}$ & $\$ 673,761$ \\
\hline 10. Roswell, NM & EnergySolutions, LLC & $\$ 1,134,522$ \\
\hline 11. Savannah River & Economic Developmen & $\$ 468,420$ \\
\hline $\begin{array}{l}\text { National } \\
\text { Laboratory, SC }\end{array}$ & $\begin{array}{l}\text { Partnership of Aiken and } \\
\text { Edgefield Counties }\end{array}$ & \\
\hline
\end{tabular}

TOTAL:

$\$ 10,458,242$

Information generated from the detailed siting studies of non-DOE sites is expected to address a variety of site-related matters, including site and nearby land uses; demographics; ecological and habitat assessment; threatened or endangered species; historical, archaeological and cultural resources; geology and seismology; weather and climate; and regulatory and permitting requirements. Information requirements for the DOE sites are more limited due to the availability of previous studies.

Such information may also be used in preparing the draft programmatic environmental impact statement (PEIS) - a process that began in early January (http://www.energy.gov/news/4560.htm) - which will evaluate the potential environmental impacts from each proposed GNEP facility.

An advanced nuclear fuel recycling center contains facilities where usable uranium and transuranics are separated from spent light water reactor fuel then produced into new fuel (or "transmutation fuel") which then could be reused in an advanced recycling reactor. This advanced recycling reactor is a fast reactor that would demonstrate the ability to reuse and consume materials recovered from spent nuclear fuel, including long-lived elements that would otherwise be disposed of in a geologic repository.

GNEP is a part of President Bush's Advanced Energy Initiative, which seeks to reduce our reliance in imported oil by changing the way we power our cars, homes and business. For more information on GNEP, visit: http://www.gnep.gov/. Additional information on the DOE's nuclear energy program may be found on http://www.nuclear.energy.gov/.

\section{U.S. Department of Energy, Office of Public Affairs, Washington, D.C.}


support document for the PEIS investigated the feasibility of depleted uranium disposal at six low-level waste disposal facilities based on waste acceptance criteria, available capacity, and disposal cost (Depleted Uranium Storage and Disposal Trade Study: Summary Report, ORNL/TM-2000/10). This document and subsequent followup studies have verified that the only currently operating dry-environment, low-level waste disposal facilities that are feasible for disposal of the depleted uranium oxide conversion product are the NTS and EnergySolutions facilities.

Like the PEIS, site-specific EISs for each conversion facility assumed that depleted uranium oxide would be classified as low-level waste. This assumption is consistent with a recent ruling by the U.S. Nuclear Regulatory Commission (NRC) in the licensing proceeding for a commercial uranium enrichment facility (NRC 2005a,b,c,d and 2006a,b). The site-specific EISs stated that the disposal facility (or facilities) would be (1) selected in a manner consistent with DOE policies and orders, and (2) authorized or licensed to receive the conversion products by DOE (in conformance with DOE orders), the NRC (in conformance with NRC regulations), or an NRC agreement state agency (in conformance with state laws and regulations determined to be equivalent to NRC regulations).

DOE is now proposing to amend the site-specific RODs to decide that the depleted uranium oxide conversion product may be disposed of at either the NTS or the EnergySolutions low-level waste disposal facilities. Accordingly, DOE has prepared the draft SA that is the subject of this Notice. All other aspects of the depleted $\mathrm{DUF}_{6}$ conversion program remain as previously described in the site-specific EISs and RODs.

The draft SA identifies no significant new circumstances or information relevant to environmental concerns that bear on DOE's decisions on disposal locations or the impacts of those decisions. Since issuance of the two site-specific $\mathrm{DUF}_{6}$ conversion facility final EISs, the following circumstances have changed. In May 2006, a contract was signed with Solvay Fluorides, a commercial vendor, for purchase of the HF co-product. On June 2, 2006, the NRC issued an order that determined that the Envirocare (now EnergySolutions) site near Clive, Utah, appears to be suitable for near-term disposal of depleted uranium. The transportation campaign has been slightly modified to include more cylinders per railcar with fewer shipments per year. Impacts from the modified campaign for both operations and accident scenarios are projected to be about the same as those presented in the site-specific EISs.

DOE believes, based on the analysis in the draft SA, that disposal at either NTS or EnergySolutions low-level waste disposal facilities are reasonable alternatives. Regarding the alternative of disposal at the EnergySolutions facility, DOE believes that adequate NEPA documentation exists to support disposal of any unused depleted uranium oxide conversion product as well as for emptied DUF $_{6}$ cylinders that would be used for disposal containers and the small quantity of $\mathrm{CaF}_{2}$ that would be generated during the conversion process. With respect to NTS low-level waste facility, the draft SA analyses show that there is adequate NEPA coverage for all actions leading up to delivery at the NTS and that sitespecific NEPA coverage at the NTS is adequate for disposal of up to $60,000 \mathrm{~m}^{3}$ of unused depleted uranium oxide conversion product. Furthermore, upcoming reviews of the NTS site-wide EIS will evaluate disposal of additional uranium oxide conversion product volumes at NTS. Accordingly, DOE believes that a supplemental EIS (or an environmental assessment) is not needed to support amending the sitespecific RODs to address disposal of the depleted uranium oxide conversion product.

DOE plans to issue amended RODs under the conversion facility EISs no sooner than 30 days after issuance of the final SA. DOE will consider all public comments on the draft SA submitted by May 18, 2007.

Issued in Washington, DC, March 27, 2007. Mark W. Frei,

Deputy Assistant Secretary for Program Planning and Budget.

[FR Doc. E7-6039 Filed 4-2-07; 8:45 am] BILLING CODE 6450-01-P

\section{DEPARTMENT OF ENERGY}

\section{Notice of Extension of Time to Submit Scoping Comments on the Programmatic Environmental Impact Statement for the Global Nuclear Energy Partnership}

AGENCY: Office of Nuclear Energy, U.S. Department of Energy.

ACTION: Notice of extension of time to submit scoping comments.

SUMMARY: In response to public requests, the Department of Energy (DOE) announces an extension of time to submit comments on the proposed scope, alternatives, and environmental issues to be analyzed in the

Programmatic Environmental Impact Statement for the Global Nuclear Energy Partnership (GNEP PEIS). This date has been extended to June 4, 2007, thereby giving an additional 61 days to provide comments.

ADDRESSES: Please direct comments, suggestions, or relevant information on the GNEP PEIS to: Mr. Timothy A.

Frazier, GNEP PEIS Document Manager, Office of Nuclear Energy, U.S.

Department of Energy, 1000

Independence Avenue, SW.,

Washington, DC 20585-0119;

Telephone: 866-645-7803, Fax: 866645-7807, e-mail to: GNEP-

PEIS@nuclear.energy.gov. Please mark envelopes, faxes, and e-mails: "GNEP PEIS Comments.” Additional information on GNEP may be found at http://www.gnep.energy.gov.

FOR FURTHER INFORMATION CONTACT: For general information on DOE's National Environmental Policy Act (NEPA) process, please contact: Ms. Carol M. Borgstrom, Director, Office of NEPA Policy and Compliance, GC-20, U.S. Department of Energy, 1000

Independence Avenue, SW., Washington, DC 20585-0103, 202-5864600 , or by leaving a message at $1-800-$ 472-2756. Additional information regarding DOE's NEPA activities is available on the DOE NEPA Web site at http://www.eh.doe.gov/nepa. This notice is available at http:// www.eh.doe.gov/nepa and http:// www.gnep.energy.gov.

\section{SUPPLEMENTARY INFORMATION: On}

January 4, 2007, DOE published a Notice of Intent (NOI) (72 FR 331) to prepare the GNEP PEIS pursuant to the National Environmental Policy Act of 1969, as amended, 42 U.S.C. 4321 et seq., and the Council on Environmental Quality's (CEQ's) and DOE's regulations implementing NEPA, 40 CFR parts 1500-1508 and 10 CFR part 1021, respectively. With the publication of the NOI, DOE began the PEIS scoping period and invited Federal, state, and local governments, Native American Tribes, industry, other organizations, and the public to provide comments on the proposed scope, alternatives, and environmental issues to be analyzed in the GNEP PEIS. In response to public requests, $\mathrm{DOE}$ is now extending the time for submittal of scoping comments an additional 61 days from April 4, 2007, to June 4, 2007. DOE will consider all comments received during the scoping period in preparing the GNEP PEIS. Late comments will be considered to the extent practicable. 
Issued in Washington, DC, on March 29, 2007.

Dennis R. Spurgeon,

Assistant Secretary for Nuclear Energy. [FR Doc. E7-6175 Filed 4-2-07; 8:45 am] BILLING CODE 6450-01-P

\section{DEPARTMENT OF ENERGY}

\section{Energy Information Administration}

Agency Information Collection Activities: Proposed Collection; Comment Request

AGENCY: Energy Information Administration (EIA), Department of Energy (DOE).

ACTION: Agency Information Collection Activities: Proposed Collection; Comment Request.

SUMMARY: The EIA is soliciting comments on the proposed revision and three-year extension to the following EIA Forms:

- EIA-63A, "Annual Solar Thermal Collector Manufacturers Survey."

- EIA-63B, "Annual Photovoltaic Module/Cell Manufacturers Survey."

- EIA-902, "Annual Geothermal Heat Pump Manufacturers Survey."

DATES: Comments must be filed by June 4 , 2007. If you anticipate difficulty in submitting comments within that period, contact the person listed below as soon as possible.

ADDRESS: Send comments to Fred Mayes. To ensure receipt of the comments by the due date, submission by FAX (202-287-1964) or e-mail fred.mayes@eia.doe.gov is recommended. The mailing address is Energy Information Administration, EI52, Forrestal Building, U.S. Department of Energy, Washington, DC 20585. Alternatively, Fred Mayes may be contacted by telephone at 202-2871750.

\section{FOR FURTHER INFORMATION CONTACT:}

Requests for additional information or copies of any forms and instructions should be directed to Fred Mayes at the address listed above.

\section{SUPPLEMENTARY INFORMATION:}

I. Background

II. Current Actions

III. Request for Comments

\section{Background}

The Federal Energy Administration Act of 1974 (Pub. L. 93-275, 15 U.S.C. 761 et seq.) and the DOE Organization Act (Pub. L. 95-91, 42 U.S.C. 7101 et seq.) require the EIA to carry out a centralized, comprehensive, and unified energy information program. This program collects, evaluates, assembles, analyzes, and disseminates information on energy resource reserves, production, demand, technology, and related economic and statistical information. This information is used to assess the adequacy of energy resources to meet near and longer term domestic demands.

The EIA, as part of its effort to comply with the Paperwork Reduction Act of 1995 (Pub. L. 104-13, 44 U.S.C. 3501, et seq.), provides the general public and other Federal agencies with

opportunities to comment on collections of energy information conducted by or in conjunction with the EIA. Any comments received help the EIA to prepare data requests that maximize the utility of the information collected, and to assess the impact of collection requirements on the public. Also, the EIA will later seek approval by the Office of Management and Budget (OMB) under Section 3507(a) of the Paperwork Reduction Act of 1995.

Form EIA-63A, "Annual Solar Thermal Collector Manufacturers Survey," collects information on the distribution of solar thermal panels by manufacturers; Form EIA-63B, “Annual Photovoltaic Module/Cell Manufacturers Survey," collects information on the distribution by manufacturers of photovoltaic (PV) cells/modules; and Form EIA-902,

"Annual Geothermal Heat Pump Manufacturers Survey," collects information on distribution of geothermal heat pumps by manufacturers. Specifically, all forms collect information on manufacturing, imports, exports, and shipments. The EIA has been collecting the above information annually and proposes to continue the surveys. The data collected will be disseminated in electronic products and electronic data files for use by government and private sector analysts. For details on EIA's

renewables information program, please visit the renewable and alternative fuels page of EIA's Web site at http:// www.eia.doe.gov/fuelrenewable.html.

\section{Current Actions}

EIA proposes to collect information on Forms EIA-63A, EIA-63B, and EIA902 using EIA's Internet Data Collection (IDC) system as the primary mode for reporting information. Survey respondents must provide an e-mail address to EIA to receive instructions on the procedures for submitting information electronically. The IDC system utilizes secure socket layer software to encrypt and protect the information transmitted between a respondent and EIA. All software that is necessary to report electronically is provided by EIA at no cost to the respondents. Respondents need to register one time with EIA and receive a mailing identification and code prior to reporting electronically.

The EIA has completed an extensive review and update of the renewable survey collection instruments. The objective of the review is to provide a standardized survey instrument and unified data collection approach for all three renewable forms. All three forms collect information from manufacturers of renewable energy equipment. The proposed forms revision is the result of efforts, which includes input from the renewable energy industry, other industry users of the data, government agencies, consumer groups, and private sector analysts. EIA will be requesting approval for its revisions and a threeyear extension for its renewable surveys with the following proposed survey changes.

Form EIA-63A, "Annual Solar Thermal Collector Manufacturers Survey."

The EIA proposes the following revisions, additions, and deletions to harmonize the data requested across the three surveys.

(1) Addition: Item 3.1 (a) Collector Manufacturing.

(2) Addition: Item 4.3 Average Thermal Performance Rating of Collector.

(3) Revision: Item 4.3 Market Sector becomes Item 4.4 Domestic Shipments by Sector.

- Collect domestic shipments by sector instead of total shipments by sector.

- Change the sector headings from Residential, Commercial, Industrial, Utility, and Other to Residential, Commercial, Industrial, Electric Power, and Transportation.

(4) Revision/Deletion: Item 4.4 End Use becomes Item 4.5 Domestic Shipments by End Use.

- Collect only domestic shipments by end use instead of domestic and foreign shipments by end use as the total number of shipments.

- Delete "other" end use type category under Item 4.4.8 Other (describe).

(5) Revision/Deletion: Item 4.9 becomes Item 4.10. Delete the seller type category Item 4.9 (f) Other (describe).

Form EIA-63B, "Annual Photovoltaic Modules/Cells Manufacturers Survey."

The EIA proposes the following revisions, additions, and deletions to harmonize the data requested across the three surveys.

(1) Addition: Item 3.4 What percentage of your company's total sales 


\section{IIPS Financial Assistance Opportunity}

\section{Sensitive I nformation}

This web site (not necessarily this web page or every document on this site) may contain information that is procurement sensitive and may be privileged or confidential and is therefore exempt from disclosure under applicable law. Pages containing Sensitive Information will be clearly identified. Access to Sensitive Information on this web site is limited to individuals and/or entities authorized by a formal registration process. Authorized individuals must log in and be authenticated to access this sensitive information. If you have inadvertently gained access to Sensitive Information without having been authenticated, you are hereby notified that any downloading, printing, copying, dissemination, or distribution of this information is strictly prohibited. If you have received access inappropriately, you should disregard the contents of that Sensitive Information and immediately notify the IIPS Help Desk by e-mail at mailto:\%20IIPS_HelpDesk@e-center.doe.gov. Thank you.

\section{Agency Information}

Agency Name: $\quad$ U.S. Department of Energy

Requiring Activity: $\quad$ NE - Office of Nuclear Energy, Science and Technology (NE)

\section{Opportunity Information}

Funding Opportunity Title: Global Nuclear Energy Partnership Deployment Studies

Attach XML files from Yes

Grants.gov?

Funding Opportunity Number: DE-PS01-07NE24448

CFDA Code: 81.121

CFDA Title: Nuclear Energy Research I nitiative

Time Zone for Due Date Eastern Time

Times:

Application Due Date: 06/21/2007

Application Due Time: 11:59 PM

Application Due Date Application Due Date is June 21, 2007 Explanation:

Grant Officer Name: Lynnette Desorcie

Grant Officer Phone: 202-287-1435

Grant Officer E-mail: Lynnette.Desorcie@hq.doe.gov

Grant Specialist Name: Jacqueline Kniskern

Grant Specialist Phone: 202-287-1476

Grant Specialist E-mail: Lacqueline.Kniskern@hq.doe.gov 
I nstrument Type: Grant, Other

\title{
Solicitation Description:
}

The U.S. Department of Energy (DOE) is seeking applications from industry on endeavors to explore the technical and business parameters that would support the Global Nuclear Energy Partnership (GNEP) program. Information is being sought in the areas of business planning, technology development roadmaps, conceptual design studies for GNEP facilities, and a communications plan for disseminating scientific, technical and practical information relating to clsing the fuel cycle. The conceptual design studies for GNEP facilities will focus on providing scope, cost and schedule information for the initial nuclear fuel recycling center and advanced recycling reactor, with capabilities of: 1 ) separating light water reactor spent nuclear fuel into its reusable components and waste components, 2 ) reducing the volume, heat load and radio-toxicity of waste requiring geologic repository disposal, and 3) generating electricity with an advanced reactor that consumes transuranic elements as part of its fuel. The business plan, technology development roadmap and communications plan will address approaches to achieve the overall long-term GNEP goals and will be used to inform the public and key stakeholders regarding proposed options for successful GNEP implementation. Applicants with expertise to design, build, and operate GNEP facilities are encouraged to resopnd to this Funding Opportunity Announcement and share their recommendations for GNEP deployment.

\author{
Category of Funding EN - Energy \\ Activity: \\ Explanation of "Other" \\ Category of Funding \\ Activity:
}

Eligible Applicants: 99 - Unrestricted (i.e. open to any type of entity below) - subject to any clarification in the text field "Additional Information on Eligibility"

\section{Additional I nformation on}

Eligibility:

All types of entities are eligible to apply, except other Federal agencies, Federally Funded Research and Development Center (FFRDC) Contractors, and nonprofit organizations described in section 501(c)(4) of the Internal Revenue Code of 1986 that engaged in lobbying activities after December 31, 1995.

As a result of its unique status in the commercial energy market, for the purposes of this funding opportunity, the restriction on funding a Federal Agency is waived with respect to TVA only.

\section{Cost Sharing or Matching No Requirement:}

Type of Action: Competitive

Estimated Total Funding $\$ 15,000,000$ Available: 


\section{Expected Number of 3 \\ Awards:}

Anticipated Award Size: \$5 - \$10 million

Award Ceiling: None

Award Floor: None

Period of Performance: 6 months

Anticipated Start Date: 09/26/2007

\section{Additional Information}

Status: 1. Announcement Issued

Date Posted: 05/09/2007

Archive Date: 09/09/2007

\section{URL Links}

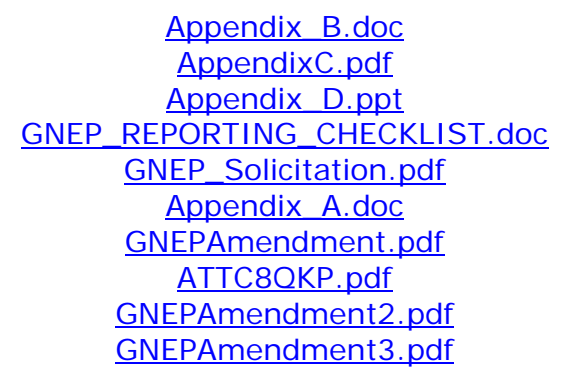

Appendix_B.doc

AppendixC.pdf

EPORTING CHECKLIST.doc

Apposicitation.pd

NEPAmendment.pd

GNEPAmendment2.pdf

GNEPAmendment3.pdf
$29 \mathrm{~KB}$

$2057 \mathrm{~KB}$

$144 \mathrm{~KB}$

$98 \mathrm{~KB}$

2265 KB

$61 \mathrm{~KB}$

$119 \mathrm{~KB}$

$119 \mathrm{~KB}$

$98 \mathrm{~KB}$

$101 \mathrm{~KB}$

Total:5.1 MB

Messages; Questions and Answers; 05/17/2007

Document; Questions and Answers Number 2; 05/22/2007

Document; Questions and Answers; 05/24/2007 


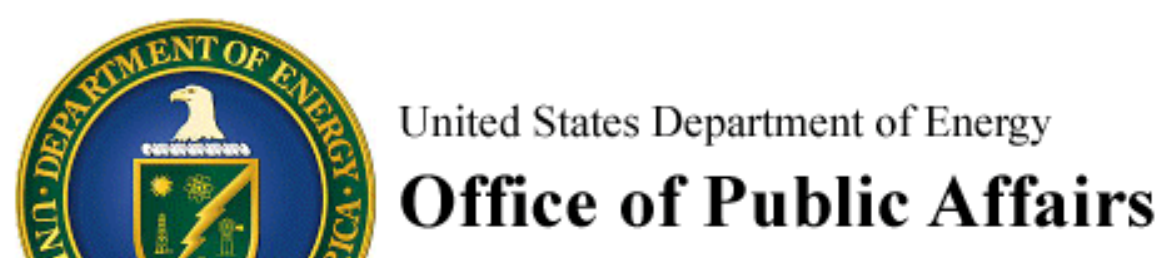

Washington, D.C. 20585

News Media Contact(s):

For I mmediate Release

Angela Hill, (202) 586-4940

July 17, 2007

\section{Department of Energy and Nuclear Regulatory Commission I ncrease Cooperation to Advance Global Nuclear Energy Partnership}

WASHINGTON, DC - The U.S. Department of Energy (DOE) and Nuclear Regulatory Commission (NRC) expanded cooperation for President Bush's Global Nuclear Energy Partnership (GNEP) through a Memorandum of Understanding (MOU) that was signed on Friday by DOE's GNEP Deputy Program Manager Paul Lisowski and NRC Executive Director for Operations Luis Reyes. The MOU establishes the foundation for increased cooperation between DOE and NRC on technological research and engineering studies and marks another important milestone towards closing the nuclear fuel cycle in the United States.

"This MOU represents a significant step in the development of nuclear fuel recycling technologies as envisioned by President Bush's Global Nuclear Energy Partnership,” DOE's Assistant Secretary for Nuclear Energy Dennis Spurgeon said. "Working with the NRC, DOE is expanding federal involvement in preparation for advanced nuclear power technologies that will increase our nation's energy security.”

Through this cooperation memorialized in the MOU, DOE will share the latest information on advanced recycling technologies with the NRC, enabling them to develop license criteria for GNEP facilities. The NRC will also participate in and observe DOE tests, simulations, and demonstrations. NRC will review and provide feedback to DOE on GNEP reports and engineering studies, review literature and take facility tours, and provide annual reports to DOE on work performed under this MOU. DOE and NRC officials agreed to continue to regularly meet and exchange the latest GNEP information.

As part of President Bush's Advanced Energy Initiative, GNEP seeks to expand the use of clean, affordable nuclear energy to meet the growing worldwide demand for energy in ways that manage nuclear waste safely, advance non-proliferation objectives, and improve the environment. This MOU builds on over two years of the Department's nuclear fuel cycle research, environmental studies, GNEP facility planning, and international discussion and cooperation. DOE has also engaged international partners through bilateral nuclear agreements to advance research in proliferation-resistant technologies. And in May, the United States hosted a GNEP Ministerial in Washington, DC, where leaders from China, France, Japan, Russia and the United States agreed to work together to bring the benefits of nuclear energy to the world safely and securely. The United Kingdom and the International Atomic Energy Agency also participated as observers in this Ministerial.

Read this MOU and find additional information on GNEP.

\section{U.S. Department of Energy, Office of Public Affairs, Washington, D.C.}




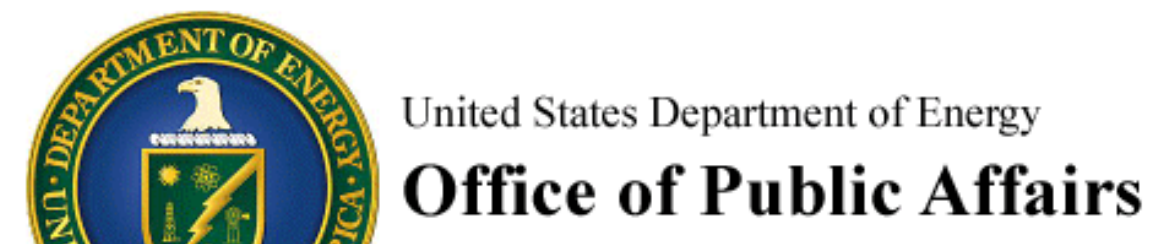

Washington, D.C. 20585

News Media Contact(s):

For I mmediate Release

Angela Hill, (202) 586-4940

July 30, 2007

\section{Department of Energy to Award \$16 Million for GNEP Studies}

Teams to Provide Analysis on Technology Development

WASHINGTON, DC - The U.S. Department of Energy (DOE) today announced that four consortia have been selected to receive up to \$16 million for technical and supporting studies to support President Bush's Global Nuclear Energy Partnership (GNEP). AREVA Federal Services, LLC; EnergySolutions, LLC; GEHitachi Nuclear Americas, LLC; and General Atomics will each lead teams in developing the cost, scope and schedule for conceptual design studies for an initial fuel recycling center and advanced recycling reactor for GNEP. DOE will negotiate the final terms, under cooperative agreements, with the selected applicants and awards are expected to be finalized by the end of September 2007.

"These studies will contribute to the analysis and inform the research that DOE is conducting to further President Bush’s Global Nuclear Energy Partnership”, Assistant Secretary of Nuclear Energy Dennis R. Spurgeon said. "GNEP seeks to increase the use of safe and clean nuclear energy worldwide in ways that reduces both the proliferation risks as well as nuclear waste.”

DOE will use the information and recommendations provided by the teams, as well as other data and analyses, to evaluate the development and deployment of GNEP activities and to inform decision making on the path forward for GNEP. Today's announcement is part of $\$ 60$ million in funding opportunities announced by Deputy Secretary of Energy Clay Sell in May to engage industry experts in conceptual design of proposed GNEP facilities. The $\$ 60$ million in funding opportunities will be made available through September 2009, subject to Congressional appropriations.

The FOA sought applications from commercial entities interested in providing technology development roadmaps, business plans, and a communications strategy supporting the GNEP conceptual design studies for the nuclear fuel recycling center and advanced recycling reactor. The technology development roadmaps will describe the state of the current technology, perform a technology "gap" analysis, and define the methods and plans to acquire technology needed to achieve the GNEP goals. The business plans will address how the market may facilitate DOE plans to develop and commercialize the advanced fuel cycle technologies and facilities. The communications plans will focus on the dissemination of scientific, technical, and practical information relating to nuclear energy and closing the nuclear fuel cycle.

GNEP is part of President Bush's Advanced Energy Initiative and seeks to enable the expanded use of economical, carbon-free nuclear energy worldwide to meet growing electricity demand. GNEP seeks to close the nuclear fuel cycle in ways that reduce proliferation risks, reduce waste and further increase global energy security.

Read more information on GNEP or view the FOA at Grants.gov.

U.S. Department of Energy, Office of Public Affairs, Washington, D.C. 


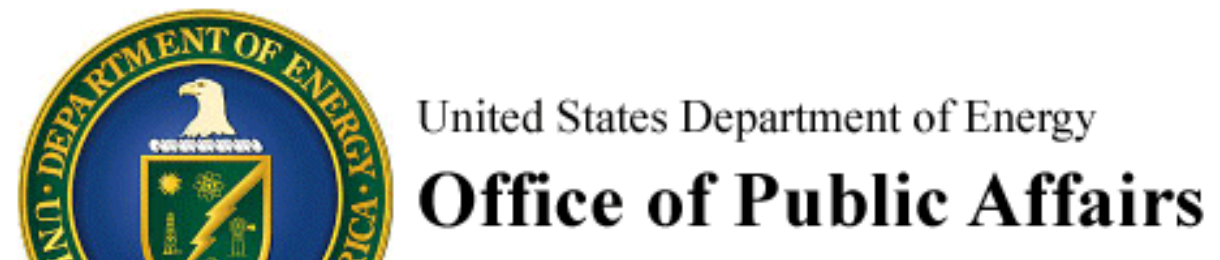

Washington, D.C. 20585

News Media Contact(s):

Angela Hill, (202) 586-4940
For I mmediate Release

October 1, 2007

\section{Department of Energy Awards More Than \$16 Million for GNEP Technology Development Plans}

Areva, EnergySolutions, GE-Hitachi Nuclear Americas, and General Atomics to Develop Conceptual Design

WASHINGTON, DC - The U.S. Department of Energy (DOE) completed cooperative agreements on Friday with four industry consortia to receive \$16.3 million for technical and conceptual design studies to further the Global Nuclear Energy Partnership (GNEP). Today's announcement follows the selections for negotiation of terms under a Funding Opportunity Announcement in July to AREVA; Energy Solutions; GE-Hitachi Nuclear Americas, LLC; and General Atomics to develop studies for a GNEP nuclear fuel recycling center and advanced recycling reactor. Funding under the cooperative agreements awarded last week is as follows: \$5.6 million to AREVA; \$4.3 million to EnergySolutions, LLC; \$4.8 million to GE-Hitachi Nuclear Americas, LLC; and \$1.6 million to General Atomics. DOE will evaluate the information and recommendations provided by the teams, as well as other data and analyses, to explore the technical and business parameters that could support the development and deployment of GNEP technology.

"These studies will contribute to the analysis and inform the research that DOE is conducting to further the Global Nuclear Energy Partnership,” Assistant Secretary of Nuclear Energy Dennis R. Spurgeon said. "These awards enable DOE to benefit from the vast technological and business experience of the private sector as we move towards the goal of closing the nuclear fuel cycle."

In July, DOE announced that four consortia led by AREVA and Mitsubishi Heavy Industries, Ltd.; EnergySolutions, LLC; GE-Hitachi Nuclear Americas, LLC; and General Atomics were selected to receive up to \$16 million. DOE has since negotiated the final terms of the cooperative agreements with the selected applicants and awards have been made for the consortia to provide conceptual design studies, technology development roadmaps, business plans, and a communications strategy in 2008 supporting decisions regarding the GNEP proposal for a nuclear fuel recycling center and advanced recycling reactor. 
The following outlines the funding negotiated for each applicant.

AREVA AND MITSUBISHI HEAVY INDUSTRIES, LTD. (\$5.6 MILLION) Principal Team Members: Japan Nuclear Fuel Limited; Battelle Memorial Institute; BWX Technologies, Inc.; and Washington Group International

\section{ENERGY SOLUTIONS, LLC (ENERGY SOLUTIONS) (\$4.3 Million)}

Principal Team Members: The Shaw Group and Westinghouse Electric Company. Additional members: Atomic Energy of Canada Limited (AECL); Booz Allen Hamilton; Nexia Solutions; Nuclear Fuel Services; and Toshiba.

\section{GE-HITACHI NUCLEAR AMERICAS, LLC (GE-HITACHI) (\$4.8 Million)}

Team Members: Burns and Roe; Ernst \& Young; Fluor Corporation; International Business Machines (IBM); and Lockheed Martin.

\section{GENERAL ATOMICS (GENERAL ATOMICS) (\$1.6 Million)}

Team Members: CH2M Hill; United Technologies Corporation - Hamilton Sundstrand Rocketdyne Division (UTC); a Russian consortium led by OKB Mechanical Engineering (OKBM); Potomac Communications Group; LISTO; and KAERI.

Today's announcement is part of $\$ 60$ million in funding opportunities announced by the Deputy Secretary of Energy Clay Sell in May to engage industry experts in the conceptual designs for proposed GNEP facilities. The $\$ 60$ million in funding opportunities includes the current funding announced today of $\$ 16.3$ million and planned future funding of $\$ 44$ million that is expected to be made available through September 2009, subject to congressional appropriations and other considerations.

GNEP is part of President Bush's Advanced Energy Initiative and seeks to enable the expanded use of nuclear energy worldwide to meet growing electricity demand. GNEP seeks to close the nuclear fuel cycle in ways that reduce proliferation risks, reduce waste and increase global energy security.

Read more information on the Global Nuclear Energy Partnership (GNEP).

U.S. Department of Energy, Office of Public Affairs, Washington, D.C. 


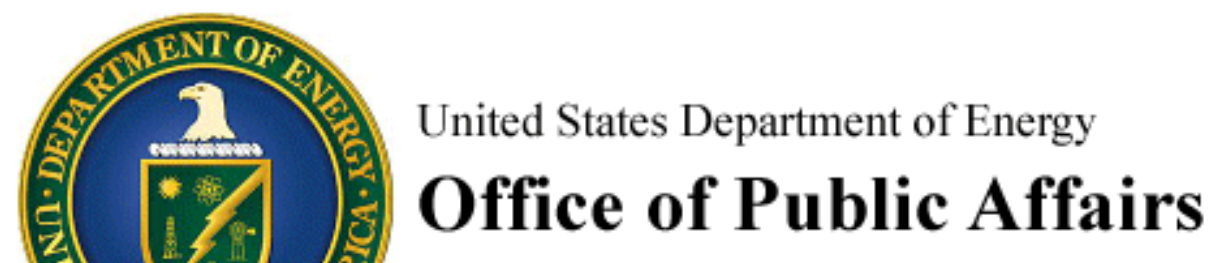

Washington, D.C. 20585

New s Media Contact(s):

Angela Hill, (202) 586-4940
For I mmediate Release

February 1, 2008

\section{United States, France and J apan I ncrease Cooperation on Sodium-Cooled Fast Reactor Prototypes}

WASHINGTON, DC -The U.S Department of Energy (DOE), the French Atomic Energy Commission (CEA) and Japan Atomic Energy Agency (JAEA) today expanded cooperation to coordinate SodiumCooled Fast Reactor Prototype development through a Memorandum of Understanding (MOU) signed by DOE Assistant Secretary for Nuclear Energy Dennis R. Spurgeon, CEA Chairman Alain Bugat and JAEA President Toshio Okazaki. The MOU establishes a collaborative framework with the ultimate goal of deploying sodium-cooled fast reactor prototypes. A sodium-cooled fast reactor uses liquid sodium to transfer heat, burning the plutonium and other transuranic elements in the process producing clean, safe nuclear power, less waste and increasing non-proliferation goals.

The U.S., France and Japan currently cooperate within the framework of the Global Nuclear Energy Partnership (GNEP) which seeks to expand the use of clean and affordable nuclear energy, as well as in the Generation IV International Forum (GIF) which furthers the research and development of future nuclear energy systems. The sodium-cooled fast reactor technology is one of the most advanced nuclear technologies being researched to date and could potentially be used as an advanced recycling reactor, one of the key components of GNEP. A prototype reactor is the first step to demonstrate the feasibility of the sodium-cooled fast reactor technology to accomplish GNEP objectives and to test advanced technologies that would allow these reactors to be built and operated by private industry on a large scale.

“This MOU supports the nuclear expansion and non-proliferation goals of the Global Nuclear Energy Partnership by expanding the signatory parties' cooperation on a technology that has shown great promise for the next generation of nuclear reactors”, said Assistant Secretary Dennis Spurgeon. “This agreement highlights the continued cooperation between the United States, France and Japan in expanding civilian nuclear energy in a safe, secure and environmentally sustainable manner.”

The three countries will work together to establish design goals and high-level requirements for sodiumcooled fast reactor prototypes; identify common safety principles and key technical innovations to reduce capital, operating and maintenance costs. This cooperation will enable important discussion on power levels, reactor types, fuel types and an appropriate timetable for the potential deployment of prototype facilities.

In addition, the participants plan to pursue joint infrastructure development activities to leverage existing, refurbished and new facilities to support development of the prototype reactors. This could include facilities used for component or safety testing, fuel development, or irradiation and evaluation of materials. There also exists the potential for additional countries to participate in this cooperation. 
In signing the MOU, each of the parties affirms its intent to develop advanced fast reactor prototypes according to its respective national program's objectives, and recognizes that each country's individual development of sodium-cooled fast reactor technology should not be duplicative. This cooperation will utilize the technical expertise and resources required to deploy sodium-cooled fast reactor prototypes.

DOE has engaged with several international partners through bilateral agreements to advance research in proliferation-resistant technologies. In September 2007 China, France, Japan, Russia and the United States hosted the second GNEP Ministerial in Vienna, Austria where 35 countries and three intergovernmental organizations attended the meeting and 16 nations signed the Statement of Principles to become GNEP partner countries. Since the ministerial, Italy, Canada and the Republic of Korea, have become official partners by signing the GNEP Statement of Principles, which serves as the framework for the Partnership.

As part of President Bush's Advanced Energy Initiative, GNEP seeks to expand the use of clean, affordable nuclear energy to meet the growing worldwide demand for energy in ways that manage nuclear waste safely, advance non-proliferation objectives, and improve the environment. Gen IV explores advances in nuclear energy system design and has engaged governments, industry, and the research community worldwide to broaden the opportunities for the use of nuclear energy.

For more information on DOE's international nuclear cooperation and to read the MOU, visit the Office of Nuclear Energy.

U.S. Department of Energy, Office of Public Affairs, Washington, D.C. 


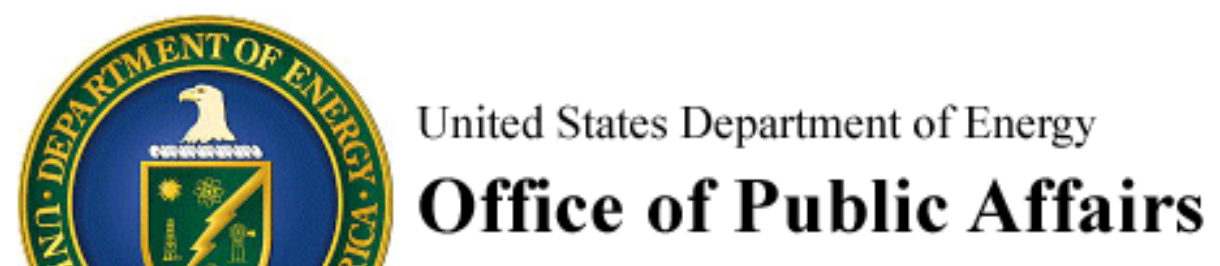

Washington, D.C. 20585

New s Media Contact:

Angela Hill, (202) 586-4940

For I mmediate Release

Friday, March 28, 2008

\section{DOE Awards \$18.3 Million to Nuclear Industry Consortia for GNEP Studies \\ Today's announcement follows DOE's award of \$16 million last September}

WASHINGTON, DC - The U.S. Department of Energy (DOE) this week awarded \$18.3 million to four industry teams to further develop plans for an initial nuclear fuel recycling center and advanced recycling reactor as part of the Global Nuclear Energy Partnership (GNEP). Today's awards include \$5.9 million to EnergySolutions; \$5.7 million to the International Nuclear Recycling Alliance, led by AREVA and Mitsubishi Heavy Industries; \$5.5 million to General Electric-Hitachi; and \$1.3 million to General Atomics. These firms will further develop detailed studies that build on conceptual design studies, technology development roadmaps, business plans submitted earlier this year by these four industry consortia.

“The expertise that these industry teams bring to the table provides an important perspective as DOE evaluates technology options and business approaches to close the nuclear fuel cycle,” Assistant Secretary for Nuclear Energy Dennis R. Spurgeon said. “This industry analysis and technical planning will inform GNEP decision making and support international cooperation as nations seek to safely expand the benefits of clean, reliable, and affordable nuclear power worldwide.”

DOE will use the information and recommendations provided by these studies, as well as other information and analyses, to determine the cost, feasibility and technical aspects of proposed GNEP activities. In January 2008, the four consortia presented their analysis to DOE, which helped determine where additional studies were needed and provided the basis for today's awards. DOE may make another round of awards for additional GNEP studies later this year.

GNEP is part of President Bush's Advanced Energy Initiative and seeks to enable the expanded use of economical, carbon-free nuclear energy worldwide to meet growing electricity demand. GNEP seeks to close the nuclear fuel cycle in ways that reduce proliferation risks, reduce waste and further increase global energy security. For further information on DOE's GNEP and other nuclear energy programs, visit: www.ne.doe.gov.

\section{U.S. Department of Energy, Office of Public Affairs, Washington, D.C.}




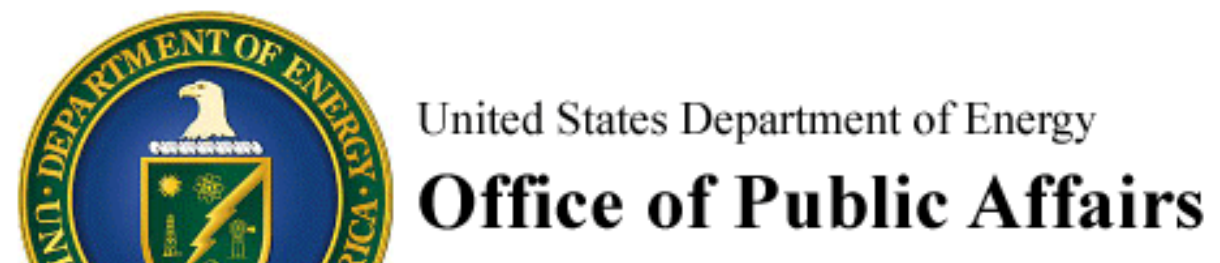

Washington, D.C. 20585

News Media Contact(s):

Angela Hill, (202) 586-4940

For I mmediate Release

April 17, 2008

\section{DOE Seeks to I nvest up to $\$ 15$ Million in Funding for Nuclear Fuel Cycle Technology Research and Development}

WASHINGTON, DC - The U.S. Department of Energy (DOE) today issued a Funding Opportunity Announcement (FOA) inviting universities, national laboratories, and industry to compete for up to \$15 million to advance nuclear technologies closing the nuclear fuel cycle. These projects will provide necessary data and analyses to further U.S. nuclear fuel cycle technology development, as part of the Department's Advanced Fuel Cycle Initiative (AFCI), the domestic technology R\&D component of the Global Nuclear Energy Partnership (GNEP). Studies resulting from this FOA will include computing and simulation of spent fuel technology, advanced fuel systems analyses and properties of future waste forms. This announcement builds on over \$328 million that DOE has provided to universities, national labs and industry since GNEP was announced in February 2006.

"To ensure that we have enough energy to meet growing demands, DOE is partnering with experts across the board to develop the necessary technology to advance the current state of nuclear energy and close the nuclear fuel cycle,” said Assistant Secretary for Nuclear Energy Dennis Spurgeon.

"Harnessing the power of technology will bring about the solutions to decrease the quantity and radiotoxicity of spent fuel, reduce the proliferation risk and lower greenhouse gas emissions while enhancing our nation’s energy security.”

In the FOA issued today, DOE is seeking applicants from industry, universities and national laboratories to conduct R\&D in the following areas: Used Fuel Separations Technology, Advanced Nuclear Fuel Development, Fast Burner Reactors and Advanced Transmutation Systems, Advanced Fuel Cycle Systems Analysis, Advanced Computing and Simulation, Safeguards and Advanced Waste Forms. Responses are due by May 8, 2008.

As part of President Bush's Advanced Energy Initiative, GNEP aims to accelerate development and deployment of advanced fuel cycle technologies to encourage clean energy development worldwide, responsibly manage nuclear waste, and reduce the risk of nuclear proliferation. In March 2008, DOE announced the next stage of awards to four industry consortia, AREVA Federal Services, LLC; EnergySolutions, LLC; GE-Hitachi Nuclear Americas, LLC; and General Atomics, which included \$18 million for additional studies on GNEP conceptual design, technology development roadmaps, and business plans. Over the past two years, DOE has also awarded universities approximately \$39 million for research grants and fellowships, to upgrade laboratories and reactor facilities and purchase state-ofthe-art equipment for researching advanced nuclear fuel cycle technology. DOE's national labs received approximately \$182 million to advance domestic nuclear technology development through AFCI. 
View the full contents of the Funding Opportunity Announcement on Grants.gov under number: DEPS07-08ID14906.

Learn more about GNEP and DOE’s other nuclear energy programs at the Office of Nuclear Energy.

U.S. Department of Energy, Office of Public Affairs, Washington, D.C. 


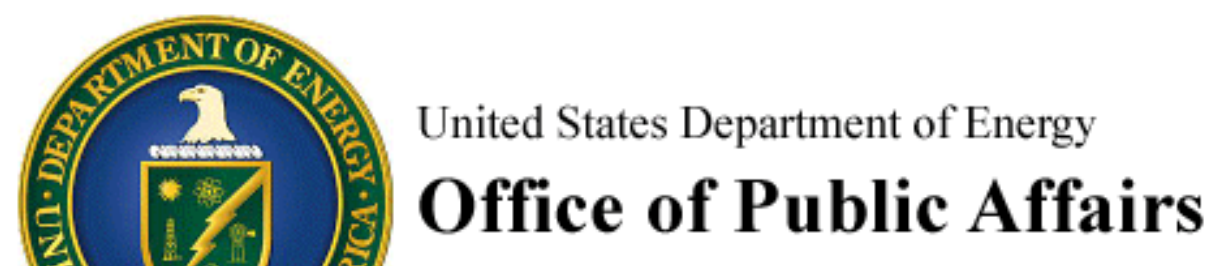

Washington, D.C. 20585

News Media Contact(s):

Angela Hill, (202) 586-4940

For I mmediate Release

April 24, 2008

\section{U.S. Department of Energy and Tennessee Valley Authority I ncrease Cooperation on Nuclear Fuel Cycle Data}

WASHINGTON, DC - The U.S. Department of Energy (DOE) and the Tennessee Valley Authority (TVA) this week agreed to collaborate on developing and exchanging information on advanced fuel cycle technologies through a Memorandum of Understanding (MOU) signed by DOE Assistant Secretary for Nuclear Energy Dennis Spurgeon and TVA Chief Operating Officer William McCollum. This joint effort furthers DOE's ongoing nuclear research and development activities and along with other analyses and studies from nuclear industry, universities and DOE's national laboratories will help to determine the best path forward for the Global Nuclear Energy Partnership (GNEP).

"We look forward to gaining valuable knowledge and experience in working with TVA to advance the goals of GNEP and expand clean, safe nuclear power,” Dennis Spurgeon, DOE’s Assistant Secretary for Nuclear Energy said. "The information provided and utility perspective offered from this partnership will be vital in departmental decisions on GNEP and closing the nuclear fuel cycle in the United States.”

This MOU establishes the overall framework for the exchange of information and conduct of activities between the two organizations. Future work associated with this MOU, which would be detailed in an Interagency Agreement to be developed subsequent to the MOU, would be focused on providing supporting data and information to help inform DOE on advanced fuel cycle technology development concepts and include conceptual plans, utility perspectives, suitable business models and additional research and development needed for the advancement of nuclear technology.

"TVA is in a unique position to look for ways to improve how used nuclear fuel could be managed," said TVA Chief Operating Officer William McCollum. "We look forward to working with DOE to determine the best path forward.”

TVA currently operates six nuclear reactors as part of its power system, which serves approximately 8.8 million consumers in seven southeastern states. TVA recently restarted a nuclear unit at its Browns Ferry plant, has submitted a Combined License application to the Nuclear Regulatory Commission for two advanced reactor design nuclear units at its Bellefonte site and has resumed efforts to complete a second nuclear unit at its Watts Bar plant. TVA is the nation's largest public power provider and is completely self-financing. TVA also manages the Tennessee River and its tributaries to provide multiple benefits, including flood damage reduction, navigation, water quality and recreation.

GNEP was announced by President Bush in February 2006 and includes key nuclear research and technology development programs as well as international policy collaboration. Currently, 21 partner 
nations have joined the effort to globally expand nuclear power and help meet growing energy demand in a safe and secure manner, while at the same time reducing the risk of nuclear proliferation and responsibly managing spent nuclear fuel.

For more information on this MOU, GNEP and other nuclear energy programs visit the Office of Nuclear Energy.

U.S. Department of Energy, Office of Public Affairs, Washington, D.C. 


\section{APPENDIX H}

\section{SUMMARY OF SCOPING COMMENTS}





\section{APPENDIX H SUMMARY OF SCOPING COMMENTS}

This appendix summarizes major scoping comments received by the U.S. Department of Energy (DOE) in response to an Advance Notice of Intent (ANOI) (71 FR 14505; March 22, 2006) and the Notice of Intent (NOI) to prepare this Global Nuclear Energy Partnership (GNEP) Programmatic Environmental Impact Statement (PEIS) (72 FR 331; January 4, 2007), as well as DOE's response to those comments. This appendix also describes the scoping process. A copy of the ANOI and the NOI are contained in Appendix G, Project Notices.

\section{H.1 Advance Notice OF InTent Scoping Summary}

The ANOI for the GNEP Technology Demonstration Program Environmental Impact Statement (EIS) explained the goals of the GNEP Program, described three major elements of the as-thenproposed GNEP Technology Demonstration Program, stated the purpose and need for agency action, and included a list of potential environmental issues for analysis. The ANOI also invited comments through May 8, 2006, on the proposed scope, alternatives, and environmental issues to be analyzed in the GNEP Technology Demonstration Program EIS.

As explained in the ANOI, the purpose of the GNEP Technology Demonstration Program was to demonstrate certain technologies that could change the way spent nuclear fuel (SNF) from commercial light water nuclear power reactors is managed. The GNEP Technology Demonstration Program EIS was intended to inform DOE officials and the public of the potential environmental impacts associated with the proposed action and the reasonable alternatives. The proposed action was to demonstrate, at an engineering scale, the United States capability to safely recycle SNF using proliferation-resistant separation processes and to convert transuranics into shorter-lived radioisotopes. The as-then-proposed action included projects for three key elements that would comprise a proliferation-resistant closed fuel cycle: 1) the demonstration of separation processes in which usable and waste materials that are found in SNF are separated; 2) the demonstration of the conversion of transuranics into shorter-lived isotopes; and 3) the demonstration of an advanced fuel fabrication process.

In response to the ANOI, DOE received more than 800 comment documents. More than 750 of these were part of a campaign letter (i.e., multiple submissions of the same comment document). DOE considered the comments received on the ANOI in developing the GNEP PEIS NOI and in preparing this Draft GNEP PEIS.

\section{H.1.1 Advance Notice of Intent Major Scoping Comments}

All comments received in response to the ANOI are included in the draft Advance Notice of Intent (ANOI) Scoping Summary Report (Tetra Tech 2006), which is part of the record of this review. The following paragraphs summarize major comments received on the ANOI and include DOE's responses: 
1) DOE should prepare a PEIS for the entire GNEP Program proposal, not just the GNEP Technology Demonstration Program. Commentors stated that DOE should withdraw the ANOI for the GNEP Technology Demonstration Program.

DOE response: DOE agrees and has decided to prepare a PEIS that assesses programmatic alternatives associated with the GNEP Program. There was no need to withdraw the ANOI to implement this change in scope and National Environmental Policy Act (NEPA) strategy.

2) DOE should pursue alternatives to nuclear power and GNEP. Commentors stated that renewable energy technologies - such as wind, solar, advanced hydroelectric, and some types of biomass and geothermal energy-are cleaner and safer technologies and can completely meet U.S. energy needs over the coming decades.

DOE response: The Purpose and Need for agency action is focused on activities related to the nuclear fuel cycle. Other DOE programs address alternative electricity generation technologies.

3) The proposed technologies are not sufficiently advanced to proceed with engineeringscale demonstrations. Commentors stated that the technologies involved in the GNEP Technology Demonstration Program have not reached a level of maturity to perform a realistic or sensible analysis.

DOE response: DOE believes that it has sufficient information to analyze the programmatic alternatives. DOE's Advanced Fuel Cycle Initiative (AFCI) and other related DOE programs were established to develop the technologies needed to: reduce the environmental consequences associated with SNF management, reduce proliferation risk from the use of nuclear power, and extend uranium resources. The initiative relies on utilization of existing facilities, located mostly within United States national laboratories. See Chapter 2 and Appendix A, Section A.9 for a discussion of the major tasks and facilities associated with the AFCI. A description of additional research and development needs for the programmatic alternatives is included in Chapter 4, Section 4.8.1 of this PEIS.

4) DOE is proceeding with federal actions related to GNEP before conducting the required NEPA analyses. Commentors stated that DOE has taken specific steps that demonstrate a clear commitment to an expenditure of resources on the GNEP Program before any programmatic analysis has been undertaken. Commentors cited the initiation of preconceptual design activities for then-proposed engineering-scale demonstrations.

DOE response: Expending resources prior to preparing NEPA documentation is not prohibited by any law or regulation. Such actions are allowable prior to a record of decision so long as the action would not "have an adverse environmental impact" or "limit the choice of reasonable alternatives" (see 40 CFR 1506.1). In addition, DOE Order 413.3A, Program and Project Management for the Acquisition of Capital Assets, requires that NEPA compliance be completed prior to the beginning of final design. A 
prime example of the allowable expenditure of resources prior to a record of decision involves the development of information to support the NEPA review. Some of these comments addressed the use of specific facilities such as the F-Canyon facility at SRS. There is no longer a project-specific proposal being considered for any GNEP alternative.

After considering these comments, DOE modified its NEPA compliance strategy for the GNEP Program. Most significantly, DOE decided to prepare an EIS that assesses programmatic elements of the GNEP Program now rather than after demonstration activities occur.

\section{H.2}

NOTICE OF INTENT SCOPING SUMMARY

On January 4, 2007, DOE published the NOI for the GNEP PEIS in the Federal Register (72 FR 331). The public scoping comment period initially was scheduled to end on April 4, 2007; however, in response to public requests, the public scoping comment period was extended until June 4, 2007 (72 FR 15871). DOE invited the public to submit comments during the scoping period by postal mail, electronic mail, fax, and through written and oral comments submitted at the public scoping meetings.

DOE held 13 public scoping meetings around the country between February 13 and March 26, 2007. The NOI listed 11 meetings; in response to public requests, 2 additional meetings were added: Carlsbad, NM, and Hood River, OR. The meeting dates and locations are illustrated on Figure H.2-1.

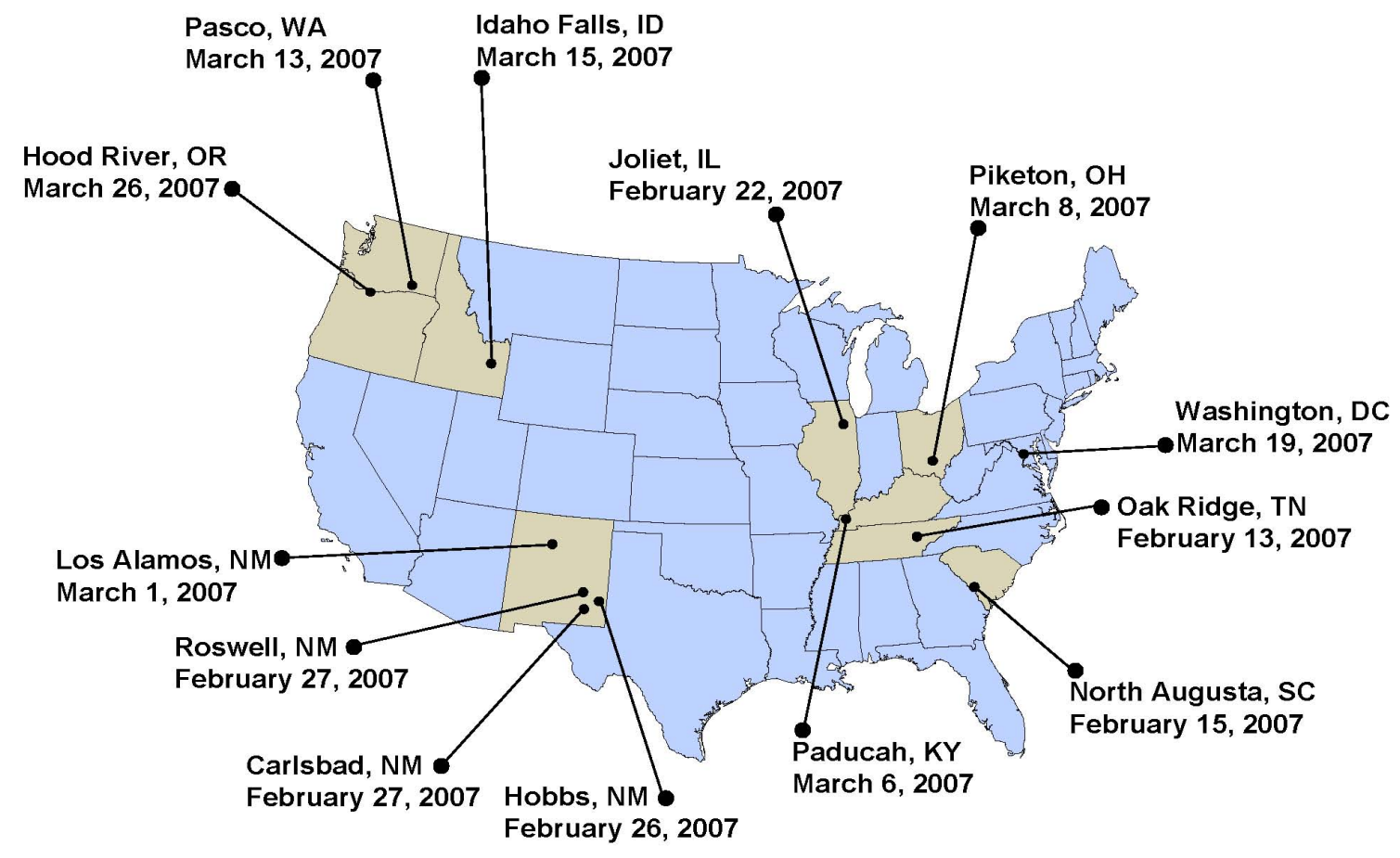

FIGURE H.2-1—Location of Global Nuclear Energy Partnership Programmatic Environmental Impact Statement Scoping Meetings 
DOE received more than 14,000 scoping comment documents from members of the public, interested groups, and Federal, state, tribal, and local officials. These include comments received at the 13 public scoping meetings. Transcripts of these scoping meetings are available for public review at http://www.gnep.energy.gov/PEIS/gnepPEISmeetingTranscripts.html. Approximately 12,400 of the documents were part of 28 letter, postcard or e-mail campaigns (i.e., multiple people sending the same comment document). Additionally, 12 petitions were received with a total of approximately 7,500 signatures; each petition is recorded as 1 comment document. DOE has given each comment document a unique document number, and electronically scanned, reviewed, and analyzed the comments. Each comment was assigned to an appropriate issue category (see Table H.2-1). Similar comments were grouped and summarized.

\section{TABLE H.2-1—Scoping Comment Categories}

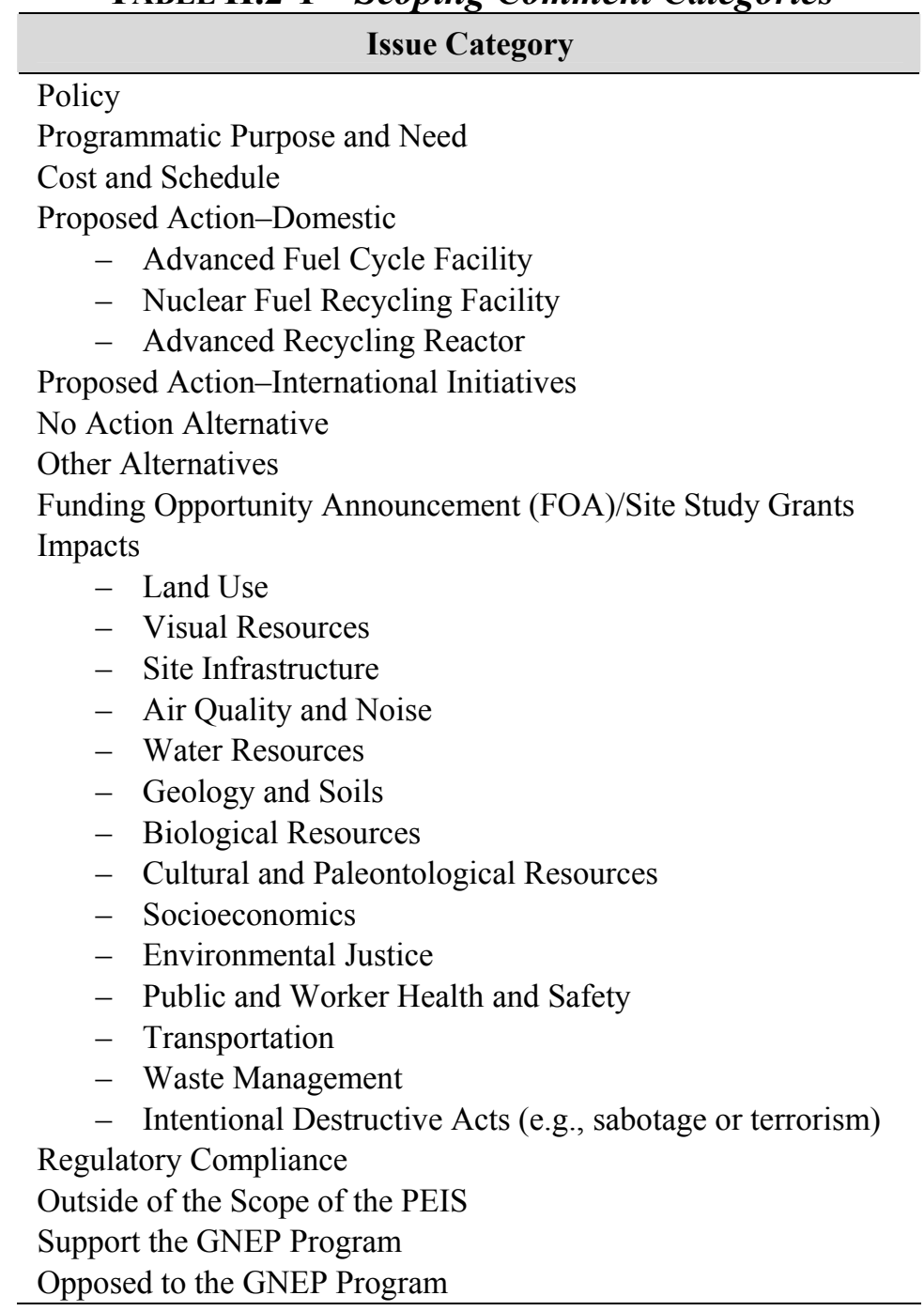

\section{H.2.1 Major Scoping Comments}

DOE has considered all scoping comments in preparing the GNEP Draft PEIS. Major issues identified during scoping are summarized below, along with information about where the comments are addressed in the Draft PEIS. In addition, Chapter 2, Section 2.8 of the Draft PEIS 
addresses several alternatives that were proposed during the scoping period but that DOE determined do not require detailed analysis.

1) Commentors stated that the Purpose and Need was excessively narrow and limited reasonable alternatives to only DOE's proposal to reprocess SNF. Commentors added that combining the programmatic analysis with project-specific proposed actions prejudiced the PEIS and presumed a certain programmatic outcome. Commentors identified a broad range of possible alternatives for evaluation in the PEIS. These included different reactor and fuel types (e.g., reactor technologies, coolants [gas, sodium], mixed-oxide [MOX] recycle in thermal reactors, and thorium fuel).

DOE response: DOE has modified its statement of Purpose and Need to clarify that DOE did not intend to unduly limit the range of reasonable alternatives. DOE reviewed the scoping comments and other available information carefully and, as a result, added both closed and open fuel cycle technologies to the range of reasonable programmatic alternatives. Chapter 1 of the PEIS provides a discussion of the Purpose and Need. Chapter 2 provides a description of the additional programmatic alternatives that have been added for consideration. The alternatives now considered in the GNEP PEIS are No Action Alternative-Continue Existing Once-Through Fuel Cycle, Fast Reactor Recycle Alternative, Thermal/Fast Reactor Recycle Alternative, Thermal Reactor Recycle Alternative, Once-Through Fuel Cycle Alternative using Thorium, and Once-Through Fuel Cycle using the Heavy Water Reactor/High Temperature Gas-Cooled Reactor. Some of these alternatives include sub-options that involve different technology combinations.

2) Commentors recommended a demonstration program to ensure both that the fuel recycling technology is feasible and that it will not cause more waste than current technologies. Commentors stated that the PEIS should assess timing issues such as building fast reactors before a reprocessing plant and, conversely, assess impacts of reprocessing without fast reactors.

DOE response: The GNEP PEIS identifies the major research and development needs associated with each programmatic alternative (Chapter 4, Section 4.8.1) and discusses how these needs could affect implementation of the technologies analyzed and associated environmental impacts (Chapter 4, Section 4.8.2). Any specific research and development needs would be the subject of future proposals by DOE or other entities. This section (Chapter 4, Section 4.8.2) also provides qualitative information on the constraints which may impact actual transition timing.

3) Commentors stated that the PEIS should analyze a wide range of potential environmental impacts associated with each alternative, and they provided specific comments regarding public and worker health and safety, accidents and intentional destructive acts, transportation, land use, cultural impacts, waste management issues, water quality/water availability issues, air quality, socioeconomics, environmental justice, and other potential impacts. For example, commentors requested that DOE estimate the quantity of SNF that would be reprocessed from existing reactors, forecast a range of new reactors in the 
decades ahead, and estimate the quantity and radiological characteristics of any waste that would go to a geologic repository. In regard to using reprocessing to separate usable materials from waste in SNF, commentors stated that storing the hottest fission products, strontium and cesium, would involve about the same amount of storage capacity as storing the SNF in the first place. Additionally, there would be the problem of dealing with the rest of the waste and process residues. Commentors asked how reprocessing wastes would be classified (as high-level waste [HLW], transuranic waste, or low-level waste); what form, composition, and quantity of wastes would result from nuclear fuel reprocessing, operation of fast reactors, and operation of the proposed Advanced Fuel Cycle Facility (AFCF); and how and where wastes would be stored, treated, and disposed.

DOE response: The GNEP PEIS discusses each of these types of impacts based on the best available information. For example, the PEIS discusses alternatives for disposition of separated cesium and strontium; under one disposition alternative, storage would be needed for about 300 years to allow for radioactive decay, compared to thousands of years required for SNF. The potential environmental impacts of programmatic alternatives are discussed in Chapters 4 and 5. For the programmatic alternatives, the PEIS acknowledges that additional information would become available as future proposals are considered and designs advance. Types, forms, and quantities of waste would vary with technology and other implementation decisions yet to be made. Information on these and other topics would be considered in more detail in future NEPA analyses. Because the GNEP PEIS only addresses programmatic alternatives, the AFCF is no longer being considered in the PEIS.

4) Commentors stated that the PEIS should assess nonproliferation issues. Commentors stated that GNEP involves a major departure from U.S. policy on SNF and may affect agreements and treaties with other nations. Commentors asserted that reprocessing increases nuclear weapons proliferation threats. Commentors suggested that DOE assess a nuclear fuel leasing and SNF take-back program with the current open fuel cycle.

DOE response: Separate from the GNEP PEIS, the National Nuclear Security Administration (NNSA), a semiautonomous agency within DOE, is preparing a Nonproliferation Impact Assessment (NPIA) that will analyze the nonproliferation aspects of the programmatic alternatives evaluated in this GNEP PEIS. The NPIA will assess the programmatic alternatives and technologies against major U.S. nonproliferation policy objectives. The NPIA will also identify the nonproliferation issues associated with potential future technology choices under each of these programmatic alternatives. The assessment framework is based on a qualitative evaluation of U.S. Government policy factors and on internationally accepted Proliferation Resistance and Physical Protection methodology (GIF 2006). NNSA intends to make a draft of the NPIA publicly available in 2008. The final NPIA will be publicly available prior to the Record of Decision for the GNEP PEIS and will be considered by DOE in its decisions regarding the GNEP Program. 
5) Commentors would like all technology information to be presented and include a history and evaluation of past performance of reactors and reprocessing facilities. Commentors stated that the reprocessing of irradiated fuel has not solved the nuclear waste problem in any country and actually exacerbates it by creating numerous additional waste streams that must be managed.

DOE response: Chapter 2 and Appendix A include a discussion of reactor technologies being considered in the PEIS, and Chapter 1 includes a history of reprocessing. Waste streams associated with programmatic alternatives are discussed in Chapter 4.

6) Commentors stated that the PEIS should propose and assess specific international aspects of the GNEP Program and include reasonably foreseeable scales of global action. Commentors stated that the Draft PEIS should also disclose how much SNF from abroad would be imported for reprocessing under GNEP.

DOE response: Chapter 7 of the PEIS describes the international implications of the domestic programmatic alternatives, as well as the types of environmental impacts that could occur from international activities. The information in that chapter provides an overview of the types of actions and impacts that could occur if international activities are pursued. At this time, DOE has no specific proposal involving receipt of SNF from abroad.

7) Commentors stated that GNEP is fundamentally inconsistent with DOE's objective of disposing of SNF deep underground where it would be as inaccessible as possible. If DOE is permitted to go forward with the Yucca Mountain project, much of the nation's SNF and HLW effectively would be made unavailable for reprocessing and reuse well before GNEP facilities could begin operations.

DOE response: As explained in Chapter 4, Section 4.1.5, a geologic repository would be needed under any programmatic alternative. Each fuel cycle technology generates some quantity of SNF and/or HLW, although the forms and quantities differ among alternatives. DOE assumes that the particular SNF and HLW currently proposed for disposal at Yucca Mountain would still be disposed of there regardless of any decision made subsequent to completion of the GNEP PEIS. The PEIS assumes that any reprocessing, for example, would only involve $S N F$ generated in the future. 


\section{H.3 REFERENCES}

40 CFR 1506.1

71 FR 14505

72 FR 331

72 FR 15871

DOE O 413.3A

GIF 2006

Tetra Tech 2006
Council on Environmental Quality (CEQ), "Limitations on Actions During NEPA Process," Code of Federal Regulations, Office of the Federal Register, National Archives and Records Administration, Washington, DC, Revised July 1, 2007.

U.S. Department of Energy (DOE), "Advance Notice of Intent (ANOI) to Prepare an Environmental Impact Statement for the Global Nuclear Energy Partnership Technology Demonstration Program," Office of the Federal Register, National Archives and Records Administration, Washington, DC, March 22, 2006.

DOE, "Notice of Intent To Prepare an Environmental Impact Statement for the Global Nuclear Energy Partnership," Office of the Federal Register, National Archives and Records Administration, Washington, DC, January 4, 2007.

DOE, "Notice of Extension of Time to Submit Scoping Comments on the Programmatic Environmental Impact Statement for the Global Nuclear Energy Partnership," Office of the Federal Register, National Archives and Records Administration, Washington, DC, April 3, 2007.

DOE Order 413.3A, "Program and Project Management for the Acquisition of Capital Assets," U.S. Department of Energy, Washington, DC, July 28, 2006.

Generation IV International Forum (GIF), "Evaluation Methodology for Proliferation Resistance and Physical Protection of Generation IV Nuclear Energy Systems," Revision 5, The Proliferation Resistance and Physical Protection Evaluation Methodology Expert Group Of the Generation IV International Forum, November 30, 2006.

Tetra Tech, Inc., "Scoping Summary Report for the Global Nuclear Energy Partnership Technology Demonstration Program Environmental Impact Statement Advance Notice of Intent," Tetra Tech, 2006. 


\section{APPENDIX I}

NEPA DISCLOSURE STATEMENT FOR PREPARATION OF THE GLOBAL NUCLEAR ENERGY PARTNERSHIP PROGRAMMATIC ENVIRONMENTAL IMPACT STATEMENT 



\section{NEPA DISCLOSURE STATEMENT FOR PREPARATION OF THE GLOBAL NUCLEAR ENERGY PARTNERSHIP PROGRAMMATIC ENVIRONMENTAL IMPACT STATEMENT}

CEQ Regulations at 40 CFR 1506.5(c), which have been adopted by the DOE (10 CFR 1021), require contractors who will prepare an EIS to execute a disclosure specifying that they have no financial or other interest in the outcome of the project. The term "financial interest or other interest in the outcome of the project" for purposes of this disclosure is defined in the March 23, 1981 guidance "Forty Most Asked Questions Concerning CEQ's National Environmental Policy Act Regulations," 46 FR 8026-18038 at Question 17a and b.

"Financial or other interest in the outcome of the project" includes "any financial benefit such as a promise of future construction or design work in the project, as well as indirect benefits the contractor is aware of (e.g., if the project would aid proposals sponsored by the firm's other clients)." 46 FR 18026-18038 at 18031.

In accordance with these requirements, the offeror and any proposed subcontractors hereby certify as follows: (check either (a) or (b) to assure consideration of your proposal).

(a) $\mathrm{X}$ Offeror and any proposed subcontractor have no financial or other interest in the outcome of the project.

(b) Offeror and any proposed subcontractor have the following financial or other interest in the outcome of the project and hereby agree to divest themselves of such interest prior to award of this contract.

\section{Financial or Other Interests}

1.

2.

3.

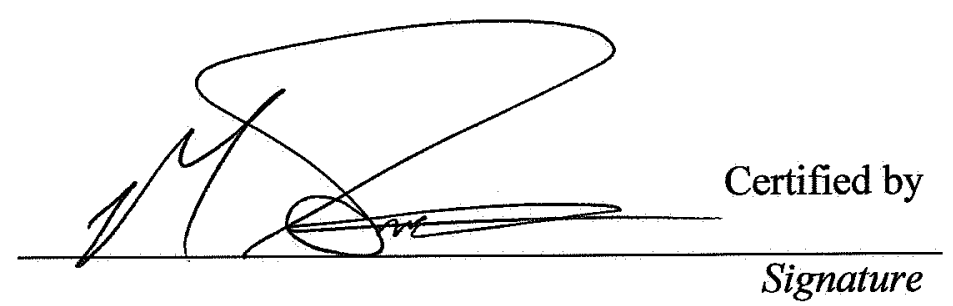

Mark E. Smith, Vice President

Printed Name and Title

Tetra Tech, Inc.

Company

September 20,2006 


\section{NEPA DISCLOSURE STATEMENT FOR PREPARATION OF THE GLOBAL NUCLEAR ENERGY PARTNERSHIP PROGRAMMATIC ENVIRONMENTAL IMPACT STATEMENT}

CEQ Regulations at 40 CFR 1506.5(c), which have been adopted by the DOE (10 CFR 1021). require contractors who will prepare an EIS to execute a disclosure specifying that they have no financial or other interest in the outcome of the project. The term "financial interest or other interest in the outcome of the project" for purposes of this disclosure is defined in the March 23. 1981 guidance "Forty Most Asked Questions Concerning CEQ's National Environmental Policy Act Regulations," 46 FR 8026-18038 at Question 17a and b.

"Financial or other interest in the outcome of the project" includes "any financial benefit such as a promise of future construction or design work in the project, as well as indirect benefits the contractor is aware of (e.g., if the project would aid proposals sponsored by the firm's other clients)." 46 FR 18026-18038 at 18031.

In accordance with these requirements, the offeror and any proposed subcontractors hereby certify as follows: (check either (a) or (b) to assure consideration of your proposal).

(a) $\mathrm{X}$ Offeror and any proposed subcontractor have no financial or other interest in the outcome of the project.

(b) __ Offeror and any proposed subcontractor have the following financial or other interest in the outcome of the project and hereby agree to divest themselves of such interest prior to award of this contract.

Financial or Other Interests

1.

2.

3.

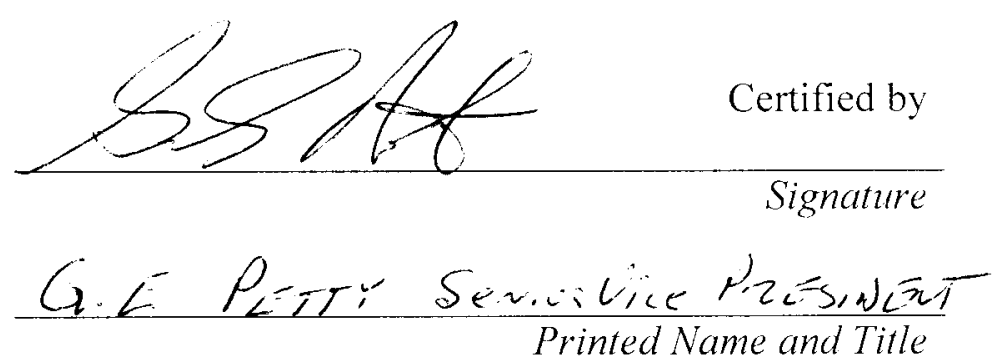

Epsilon Systems Solutions, Inc.

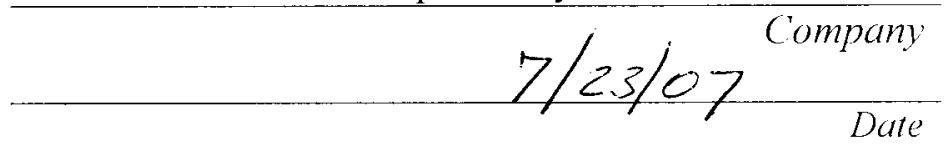




\section{NEPA DISCLOSURE STATEMENT FOR PREPARATION OF THE GLOBAL NUCLEAR ENERGY PARTNERSHIP PROGRAMMATIC ENVIRONMENTAL IMPACT STATEMENT}

CEQ Regulations at 40 CFR 1506.5(c), which have been adopted by the DOE (10 CFR 1021), require contractors who will prepare an EIS to execute a disclosure specifying that they have no financial or other interest in the outcome of the project. The term "financial interest or other interest in the outcome of the project" for purposes of this disclosure is defined in the March 23, 1981 guidance "Forty Most Asked Questions Concerning CEQ’s National Environmental Policy Act Regulations,” 46 FR 8026-18038 at Question 17a and b.

"Financial or other interest in the outcome of the project" includes "any financial benefit such as a promise of future construction or design work in the project, as well as indirect benefits the contractor is aware of (e.g., if the project would aid proposals sponsored by the firm's other clients).” 46 FR 18026-18038 at 18031.

In accordance with these requirements, the offeror and any proposed subcontractors hereby certify as follows: (check either (a) or (b) to assure consideration of your proposal).

(a) $\mathrm{X}$ Offeror and any proposed subcontractor have no financial or other interest in the outcome of the project.

(b) _ Offeror and any proposed subcontractor have the following financial or other interest in the outcome of the project and hereby agree to divest themselves of such interest prior to award of this contract.

$\underline{\text { Financial or Other Interests }}$

1.

2.

3.

Certified by

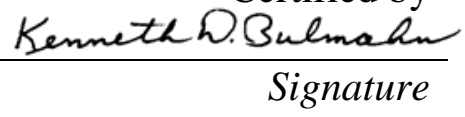

Kenneth D. Bulmahn, Sole Proprietor

Printed Name and Title 



\section{APPENDIX J}

\section{FUNDING OPPORTUNITY ANNOUNCEMENT SITE SUMMARIES}





\section{APPENDIX J FUNDING OPPORTUNITY ANNOUNCEMENT SITE SUMMARIES}

\section{J.1 INTRODUCTION}

Following the comment period on the Advance Notice of Intent (ANOI) (71 FR 14505), the U.S. Department of Energy (DOE) sought additional input from industry, both international and domestic, and potential hosting sites to obtain more information from which to determine the feasibility of the Global Nuclear Energy Partnership (GNEP) Program. On August 3, 2006, DOE announced a Funding Opportunity Announcement (FOA) of \$20 million available for public or commercial entities to conduct detailed siting studies of potential sites for GNEP facilities (DOE 2006n). Applications for these financial assistance grants were received by DOE by September 7, 2006. DOE reviewed these applications and on January 30, 2007, issued financial assistance grants to 11 public and commercial entities to conduct detailed siting studies for hosting a nuclear fuel recycling center and/or an advanced recycling reactor (DOE 2007a). The consortia locations are: Atomic City (ID), Barnwell (SC), Morris (IL), Hanford (WA), Idaho National Laboratory (ID), Hobbs (NM), Oak Ridge Reservation (TN), Paducah (KY), Portsmouth (OH), Roswell (NM), and Savannah River Site (SC). Recipients completed these siting studies and submitted Site Characterization Reports (SCR 2007 a,b,c,d,e,f,g,h,i) to DOE by May 1, 2007 (DOE 2007b). The results of these site studies were reviewed by DOE and are included in the administrative record for this programmatic environmental impact statement (PEIS) to respond to public comment requesting information on the FOA responses. A summary of the information from those site studies is included here.

During public scoping, several additional sites were suggested by the public as suitable for locating a nuclear fuel recycling center and/or an advanced recycling reactor. No determination has been made regarding the sites suggested through the FOA and public scoping processes as potential locations for a nuclear fuel recycling center and/or an advanced recycling reactor. Because site selection will not be completed at this time, no sites have been eliminated from consideration for these two facilities. 



\section{J.2 Atomic City Site}

This section presents a summary of the affected environment for Atomic City Site. The information was summarized from the Site Characterization Report prepared by the Funding Opportunity Announcement (FOA) grant recipient (SCR 2007a).

\section{J.2.1 Land Use}

The Atomic City Site covers approximately 3,310 acres (1,340 ha) and is located in the arid, high desert rangeland of east-central Idaho in Bingham County. The entire Atomic City Site is currently zoned A-Agricultural, but could potentially be rezoned for heavy manufacturing according to the Bingham County Planning and Zoning Board. The Atomic City Site is bounded by undeveloped ranch land to the east, west, north and south, some of which is Bureau of Land Management (BLM) land. The U.S. Department of Energy (DOE)-managed Idaho National Laboratory (INL) is located north of the Atomic City Site.

\section{J.2.2 Visual Resources}

Currently there are no existing structures or facilities within the boundaries of the Atomic City Site. INL borders the site to north. Volcanic buttes near the northern boundary of the site can be seen from most locations on the site. The area surrounding the site consists of open desert land predominantly covered by big sagebrush and grasslands. Pasture and farmland border much of the site.

\section{J.2.3 Site Infrastructure}

Currently, there are no structures or facilities within the Atomic City Site and therefore no existing infrastructure within site boundaries.

U.S. Highway 26 is the closest highway and joins U.S. 20 seven miles (mi) (11.3 kilometers $[\mathrm{km}]$ ) northwest from the Atomic City exit. The Union Pacific Railroad provides rail service near the site and crosses the southern boundary of the site.

\section{J.2.4 Air Quality and Noise}

The climate at the Atomic City Site and the surrounding region is characterized as that of a steppe (a vast semiarid grass-covered plain). The average annual precipitation is 8.7 in $(22.1 \mathrm{~cm})$, and prevailing winds are generally southwest or northeast. The average annual temperature at the Atomic City Site is about $42^{\circ} \mathrm{F}\left(20^{\circ} \mathrm{C}\right)$, and average monthly temperatures range from around negative $16^{\circ} \mathrm{F}\left(-8^{\circ} \mathrm{C}\right)$ in January to $68^{\circ} \mathrm{F}\left(20^{\circ} \mathrm{C}\right)$ in July. The annual average wind speed is $7.5 \mathrm{mph}(12.1 \mathrm{~km} / \mathrm{hr})$.

Ambient air pollutant concentrations in the Atomic City Site region are monitored by DOE, the Idaho DEQ, and the National Park Service. None of the ambient air pollutant concentrations measured by the monitors cited in this section exceeded the state or national standards. 
There are no current or existing facilities at the Atomic City Site to contribute to nonradiological or radiological pollutant emissions. There are no existing facilities or activities at the Atomic City Site, which result in elevated noise levels.

\section{J.2.5 Water Resources}

The nearest water course to the Atomic City Site is the Big Lost River. The Atomic City Site is located $9.5 \mathrm{mi}(15.3 \mathrm{~km})$ from the Big Lost River as it flows east of Arco and onto the INL. The USGS gaging station located near Arco has registered no flow in 12 of the past 22 years. The Atomic City Site is not connected to the Big Lost River by any developed drainage system. Based on this information, the Big Lost River would not be a reliable source of water for the Atomic City Site.

No drainage system connects the site to the Snake River, located $25 \mathrm{mi}(40 \mathrm{~km})$ to the southeast. A source of water supply for the Atomic City Site from the Snake River would require construction of a pipeline at least $25 \mathrm{mi}(40 \mathrm{~km})$ in length.

Existing contamination at the Atomic City Site, if present, would have no potential to impact the current quality of surface water in the area. The Atomic City Site is above the flood plain, with no water bodies within the $6 \mathrm{mi}(10 \mathrm{~km})$ radius.

Water is available from wells in the Snake River Plain Aquifer beneath the site. This aquifer has been designated a Sole Source Aquifer by EPA. Water storage in the aquifer is estimated at some 2 billion acre $\mathrm{ft}\left(2\right.$ trillion $\left.\mathrm{m}^{3}\right)$, and irrigation wells can yield 7,000 gal $/ \mathrm{min}(26,498(\mathrm{~L} / \mathrm{min})$. The aquifer is composed of numerous relatively thin basalt flows with interbedded sediments extending to depths in excess of 3,500 ft $(1,067 \mathrm{~m})$ below land surface.

The two most likely sources of potential groundwater contamination at the Atomic City Site are agricultural contamination and groundwater contamination associated with facilities at the INL. No industrial facilities, fuel filling stations, or other commercial enterprises that are common sources of groundwater contamination exist within $5 \mathrm{mi}(8 \mathrm{~km})$ upgradient of the Atomic City Site.

As part of a 1984 settlement of a dispute between Idaho Power Company and the State of Idaho over Idaho Power Company's water rights for hydroelectric power, the entire Snake River Basin, which includes the Snake River and its tributaries, is undergoing water rights adjudication for both ground and surface water. The adjudication commenced in 1987 and is ongoing. The water right allows a diversion rate of 1.89 cubic feet per second (cfs) or volume of 483 acre $\mathrm{ft} / \mathrm{yr}$ $\left(595,775 \mathrm{~m}^{3} / \mathrm{yr}\right)$. This is the only water right that has been identified for the Atomic City Site. There are no known future rights, including Native American tribal rights that would be claimed or would impact the existing water right for the property.

\section{J.2.6 Geology and Soils}

The Atomic City Site occupies a relatively flat area on the northwestern edge of the Eastern Snake River Plain, part of the Eastern Snake River Plain Physiographic Province. The area 
consists of a broad plain that has been built up from the eruptions of multiple flows of basaltic lava over the past 4 million years.

The upper 0.6 to $1.2 \mathrm{mi}(1.0$ to $1.9 \mathrm{~km})$ of the crust beneath INL is composed of a sequence of Quaternary age (recent to 2 million years old) basalt lava flows and poorly consolidated sedimentary interbeds collectively called the Snake River Group. The lava flows at the surface range from 2,100 to 2 million years old. The sediments are composed of fine-grained silts that were deposited by wind; silts, sands, and gravels deposited by streams; and clays, silts, and sands deposited in lakes such as Mud Lake and its much larger ice-age predecessor, Lake Terreton. The accumulation of these materials in the Eastern Snake River Plain has resulted in the observed sequence of interlayered basalt lava flows and sedimentary interbeds (DOE 2005a).

The Arco Segment of the Lost River Fault is thought to terminate about $4.3 \mathrm{mi}(6.9 \mathrm{~km})$ from the Atomic City Site boundary. The Howe Segment of the Lemhi Fault terminates near the northwest boundary of INL (DOE 2005a). Both segments are considered capable or potentially active. A capable fault is one that has had movement at or near the ground surface at least once within the past 35,000 years, or recurrent movement within the past 500,000 years (10 CFR Part 100).

Based on the maximum considered earthquake ground motions, Atomic City is located in a broadly defined region of low and moderate to high seismicity. Ground motions in these regions are controlled by earthquake sources that are not well defined, with estimated maximum earthquake magnitudes having relatively long return periods.

Basaltic volcanic activity occurred from about 2,100 to 4 million years ago in the Atomic City Site area. Although no eruptions have occurred on the Eastern Snake River Plain during recorded history, lava flows of the Hell's Half Acre lava field erupted near the northern Atomic City boundary as recently as 5,400 years ago. The most recent eruptions within the area occurred about 2,100 years ago, $19 \mathrm{mi}(31 \mathrm{~km})$ southwest of the site at the Craters of the Moon Wilderness Area. The estimated recurrence interval for volcanism associated with the five identified volcanic zones ranges from 16,000 to 100,000 years (DOE 2005a).

\section{J.2.7 Biological Resources}

The project area occurs on nearly level flats or benchlands to rolling or broken foothills between outcrops of lava or as lava flows that are highly fractured and have vegetation growing where soil material has accumulated. Small lava outcrops may be scattered throughout the area and range from nearly level to about 30 percent slopes.

There are no riparian, wetlands, or aquatic habitats present within or directly adjacent to the Atomic City Site. Therefore, species associated with these habitat types are not anticipated to be found within the project area. None of the species identified for this area are critical to the structure and function of the ecosystem or provide a broader ecological perspective of the area primarily due to the small amount of native vegetation that remains on the site. 
No aquatic, riparian, wetland areas or source water bodies capable of supporting fish or shellfish communities are present within the boundaries of the Atomic City Site, due to the dry climate and lack of perennial surface water.

The following are the special concern species:

- $\quad$ Sage grouse. The sagebrush habitat on the project area is limited to the southwest corner and the northern and western edges. Sage grouse were seen during the field survey, but the sagebrush is very fragmented and limited.

- Ferruginous hawk, Prairie falcon, and Townsend's big-eared bat. These species may use the area for foraging, but nesting and roosting habitat is not available on site. Ferruginous hawks were seen during the field survey hunting in the vicinity of the Atomic City Site.

\section{J.2.8 Cultural and Paleontological Resources}

A branch of the Oregon Trail, Goodale's Cutoff, is located within the current Atomic City Site. The route diverts from the main trail at Fort Hall and continues west past Big Southern Butte to Camas Prairie where it reconnects with the main Oregon Trail at Ditto Creek. The first Oregonbound emigrants followed Goodale's Cutoff in 1852. The INL is located within the aboriginal territory of the Shoshone and Bannock people.

\section{J.2.9 Socioeconomics}

According to the U.S. Census Bureau, an estimated 26 people lived in Atomic City in 2005, and 27 are estimated to reside in the town in 2007 (SCR 2007a).

This area is sparsely populated and primarily relies on agriculture, food processing, and services to support its economy. The population density within a $50 \mathrm{mi}(80 \mathrm{~km})$ radius of the Atomic City Site is approximately 30 persons per square mile, with a population density of less than one person per square mile within $20 \mathrm{mi}(32 \mathrm{~km})$ of the Atomic City Site. The most populated areas are along the Interstate 15 corridor (SCR 2007a).

The county's growth rate is primarily the result of natural change, or the net change in population as the result of births and deaths in the region. Between 2000 and 2005, Bingham County population grew by 4.8 percent $(2,004$ persons) due to natural change, compared to a growth rate of 10.4 percent for the State of Idaho as a whole (SCR 2007a).

\section{J.2.10 Environmental Justice}

U.S. Census Bureau data were analyzed on the block group level to identify minority and lowincome communities within the $50 \mathrm{mi}(80 \mathrm{~km})$ region of influence. In 2000 , there were a total of 192 census block groups fully or partially within 50 miles of the Atomic City site. Block groups with a population of minority or low income residents that are 10 percent or more above the state average are considered minority or low income communities (SCR 2007a). In 2000, the average minority population in Idaho was 12 percent; therefore, block groups with a minority population of 22 percent or greater were considered minority areas. A total of 25 block groups within the 50 -mile radius of the site are classified as minority communities based on 2000 census data. 
Approximately 40,322 (or almost 19 percent) of residents within the $50 \mathrm{mi}(80 \mathrm{~km})$ radius classified themselves as belonging to a minority group or being one or more other race in the 2000 Census (SCR 2007a). The low-income population in Idaho based on the 2000 census was 11.8 percent; therefore, block groups with a low-income population of 21.8 percent or greater were considered low-income areas. The 2000 Census identified 28 low-income block groups within the $50 \mathrm{mi}(80 \mathrm{~km})$ radius $(\mathrm{SCR} 2007 \mathrm{a})$.

\section{J.2.11 Public and Worker Health and Safety}

There are currently no existing facilities or structures on the Atomic City Site to contribute radiological or hazardous chemical contaminants to the environment. However, because the Atomic City Site is contiguous with the INL, major sources and levels of background radiation exposure to individuals in the vicinity of Atomic City would be similar to INL. These doses fall within the radiological limits given in DOE Order 5400.5, Radiation Protection of the Public and the Environment, and are much lower than those from background radiation (DOE O 5400.5).

Health impacts to the public may occur during normal operations at Atomic City via inhalation of air containing hazardous chemicals released to the atmosphere by operations in the area, predominantly from INL. Risks to public health from ingestion of contaminated drinking water or direct exposure are also potential pathways.

\section{J.2.12 Transportation}

Two interstate highways serve the Atomic City regional area. Interstate 15 is a north-south route that connects several cities along the Snake River. Interstate 86 intersects Interstate 15 south of the Atomic City Site and provides a primary linkage from Interstate 15 to points west. U.S. Highways 20 and 26 are the main access routes to the southern portion of the site. Rail transportation to the Atomic City Site is provided by the Union Pacific Railroad line at the southwest corner of the property. Since there are no existing facilities, a transportation network within the site would need to be developed.

\section{J.2.13 Waste Management}

INL is one potential provider of waste management services for the Atomic City Site. INL is located to the north of the Atomic City Site and generates various waste streams during ongoing activities including routine operations and cleanup action, and stores wastes generated by past activities. INL manages the following types of waste: high-level, low-level radioactive, mixed low-level radioactive, transuranic, hazardous, sanitary solid, wastewater, and sanitary sewage. The waste is managed using appropriate treatment, storage, and disposal technologies, and in compliance with all applicable Federal and state statutes and DOE orders.

EPA placed INL on the National Priorities List on December 21, 1989. In accordance with Comprehensive Environmental Response, Compensation, and Liability Act (CERCLA), DOE entered into a consent order with EPA and the state of Idaho to coordinate cleanup activities at INL under one comprehensive strategy (42 U.S.C 9610). This agreement integrates DOE's 
CERCLA response obligations with Resource Conservation and Recovery Act (RCRA) corrective action obligations (40 CFR Parts 239-299).

There are currently no existing facilities or structures on the Atomic City Site; therefore, no waste is produced and no waste management services are provided. 


\section{J.3 BARNWELl Site}

This section presents a summary of the affected environment for the Barnwell Site. The information was summarized from the Site Characterization Report prepared by the Funding Opportunity Announcement (FOA) grant recipient (SCR 2007b).

\section{J.3.1 Land Use}

The Barnwell Site is located within Barnwell County, in the southwestern portion of South Carolina, close to the state border with Georgia. The proposed Barnwell Site is 970 acres (393 ha) of land within a 1,631 acre (660 ha) industrial park consisting of developed and undeveloped land.

The Barnwell Site is situated between two industrial parks and is partially located on one of these industrial parks, the South Carolina Advanced Technology Park (ATP). This site is located to the east of the Par Pond of the United States (U.S.) Department of Energy (DOE) Savannah River Site (SRS).

\section{J.3.2 Visual Resources}

The terrain surrounding the Barnwell Site is gently rolling, sloping upwards towards the northwest. There is a forest buffer along the north, west, and south of the site providing limited views from these directions. Par Pond located approximately $2 \mathrm{mi}(3.2 \mathrm{~km})$ to the west of the site, further obscures views of the Barnwell Site and its facilities.

\section{J.3.3 Site Infrastructure}

The Barnwell Site is surrounded by a system of well established transportation infrastructure. Major highways service the main entrance to ATP with several roads providing access to the proposed site.

Rail transportation is provided to the ATP by CSX Corporation.

South Carolina Electric and Gas (SCE\&G) provides electrical and gas service to the ATP with an electrical substation located approximately $6 \mathrm{mi}(10 \mathrm{~km})$ from the ATP in the City of Barnwell.

SCE\&G operates a 6 to 9 in $(15$ to $24 \mathrm{~cm})$ natural gas pipeline at 45 psi of pressure along SC Highway 64.

\section{J.3.4 Air Quality and Noise}

The climate in the area is temperate. The proximity of the Appalachian Mountain chain to the northwest, and the Atlantic Ocean to the southeast, both provide a moderating influence on the climate. The site has a long-term annual average precipitation of 48.96 in $(124.36 \mathrm{~cm})$. Thunderstorms, tornadoes, and hurricanes provide occasional severe weather to South Carolina. The only hurricane-force winds measured at the SRS, bordering the Barnwell Site, were 
associated with Hurricane Gracie on September 29, 1959, when wind speeds of $75 \mathrm{mi} / \mathrm{hr}$ $(120 \mathrm{~km} / \mathrm{hr})$ were measured.

The area in vicinity of Barnwell is considered within attainment. The Barnwell Site does not have any significant sources of regulated air pollutants, although the SRS site does. The SRS significant sources of regulated air pollutants include coal-fired boilers for steam production, diesel generators, chemical storage tanks, the Defense Waste Processing Facility (DWPF), groundwater air strippers, and various other process facilities.

The U.S. Environmental Protection Agency (EPA) annual effective dose equivalent limit of 10 millirem per year $(\mathrm{mrem} / \mathrm{yr})$ to members of the public for the atmospheric pathway is incorporated in DOE Order 5400.5, Radiation Protection of the Public and the Environment (DOE O 5400.5). Process area stacks that release, or have the potential to release, radioactive materials are monitored continuously by applicable online monitoring and/or sampling systems. Tritium in elemental and oxide forms accounted for more than 99 percent of the total radioactivity released to the atmosphere from SRS operations. During 2005, about 40,800 curies (Ci) of tritium were released from SRS, compared to about 61,300 Ci in 2004. Most of the SRS radiological facilities release small quantities of radionuclides at concentrations below the DOE limits derived concentration guides (DCGs). The offsite dose from all atmospheric releases remained well below the DOE and EPA annual atmospheric pathway dose standard of 10 mrem.

Major noise sources at the Barnwell Site are primarily located in developed or active areas and include various industrial facilities, equipment, machines, and vehicles operating at the nearby industrial park or at the SRS. Most industrial facilities at SRS are at a sufficient distance from the Barnwell Site boundary that noise levels at the boundary from these sources would not be distinguishable from ambient background noise levels. Traffic from the Barnwell Site (SRS operations) is the primary contributor to noise levels emanating from the Barnwell Site.

\section{J.3.5 Water Resources}

The Barnwell Site is located almost entirely within the Lower Three Runs Creek watershed, with surface drainage primarily southward to Lower Three Runs Creek. The Site has very low relief, with drainage from the northwestern portion going directly to Par Pond. Some drainage from the extreme northeast corner of the Barnwell Site may flow eastward to a tributary of the Salkehatchie River. Surface waters on the Site include several minor natural and manmade drainage swales and one named pond, Beacon Pond. Highland Pond is another named feature on the Site near Beacon Pond and is associated with an isolated wetland complex. Due to its having received water from R-Reactor incidents, Par Pond's sediments are contaminated by the radionuclides cesium-137 (the largest component of the radioisotope inventory), cobalt-60, plutonium-238, and plutonium-239.

Floodplains within the $6 \mathrm{mi}(9.7 \mathrm{~km})$ radius of the Barnwell Site are primarily associated with Par Pond and Lower Three Runs Creek, located west of the Barnwell Site within SRS property. The Barnwell Site is not located within a floodplain. 
Abundant groundwater resources exist at the Barnwell Site in over 1,000 $\mathrm{ft}(304.8 \mathrm{~m})$ of four distinct aquifers. The confined aquifers are capable of sustained yields of over 2,000 gal/min $(757.08 \mathrm{~L} / \mathrm{min})$ to production wells and provide more than adequate capacity for the end use of the nuclear fuel recycling center and the advanced recycling reactor. Water withdrawals in the Barnwell area are significantly below the capacity of the extensive aquifer system that underlies the area.

\section{J.3.6 Geology and Soils}

In general, the geology of the Barnwell Site and immediate vicinity is comprised of Coastal Plain clastics, clays, calcareous sediments, and conglomerates, that are approximately $1200 \mathrm{ft}(400 \mathrm{~m})$ thick beneath the ATP and overlie Paleozoic igneous and metamorphic rocks of the Appalachian orogen and Triassic sediments of the Dunbarton basin. The Site area is also characterized by geomorphic features known as Carolina Bays; shallow elliptical depressions with associated sand rims found on the surface of the coastal plain sediments. Within the SRS area the carbonate rich Tinker/Santee/Utley facies contain zones that offer lower resistance to drilling or Cone Penetration Tests (CPTs). These zones, depending on location, occur between approximately 100 to $180 \mathrm{ft}$ ( 30 to $55 \mathrm{~m}$ ) below ground surface.

Earthquakes located within $25 \mathrm{mi}(40 \mathrm{~km})$ of the Barnwell Site include approximately 24 from 1897 to 2002 with only 3 above MAG 3.0. Results of seismic studies show a peak horizontal ground acceleration of $0.28 \mathrm{~g}$ (at $100 \mathrm{~Hz}$ ) and peak spectral acceleration of about $0.8 \mathrm{~g}(\mathrm{at} 10 \mathrm{~Hz})$. Faulting is present within the region of the Site. In addition, available literature, both deterministic and probabilistic studies, indicate that none of the faults in the vicinity of the Site are "capable" as defined by 10 CFR Part 100, or have been active within the past 35,000 years.

\section{J.3.7 Biological Resources}

The 970 acre (393 ha) Barnwell Site is dominated by five of the eight habitat types known to occur in the coastal plain ecoregion with the most prominent ones being pine woodlands and upland forest. The Barnwell Site also contains grassland and early successional habitats, stream bottomland (bottomland hardwood), ponds and depressions, and developed land. These habitats cover approximately 840 acres (340 ha) (87 percent) of the Barnwell Site. The U.S. Fish and Wildlife Service (USFWS) confirmed that there are no federally designated or proposed critical habitats, as defined in 50 CFR 17.95 (fish and wildlife) and 50 CFR 17.96 (plants) (50 CFR Part 17), in Barnwell County.

The Barnwell Site contains approximately 15 wetland areas, including Beacon Pond and Highland Pond. The United States Army Corps of Engineers (USACE) determined previously that the one bottomland hardwood wetland, which drains to Lower Three Runs Creek, is jurisdictional pursuant to the Clean Water Act (33 U.S.C. 1251 et seq.). The other wetlands on the Barnwell Site are isolated and not regulated by the USACE.

The American alligator is the only federally- or state-listed Threatened and Endangered (T \& E) species known to occur at the Barnwell Site. A field reconnaissance conducted at the Barnwell Site in February 2007 confirmed that the Barnwell Site does not contain suitable habitat, other 
than occasional foraging or stopover habitat, for any federally- or state-listed T \& E species other than the American Alligator, the Smooth Coneflower, and Harperella.

\section{J.3.8 Cultural and Paleontological Resources}

Previous investigations assessed the potential of the Barnwell Site to contain cultural resources and intensively surveyed approximately 300 acres $(121 \mathrm{ha})$ for cultural resources. Four archaeological sites were identified within the Barnwell Site, of which none have been determined eligible for the National Register of Historic Places (NRHP). No aboveground historic sites have been identified within or near the Barnwell Site. There are no known historic properties within or near the Barnwell Site that may be affected by any future development or use.

\section{J.3.9 Socioeconomics}

The Barnwell Site is located in Barnwell County, in the southwestern portion of South Carolina. The area within a $5 \mathrm{mi}(8 \mathrm{~km})$ radius of the proposed Barnwell Site is a rural, agrarian setting. Within the $5 \mathrm{mi}(8 \mathrm{~km})$ radius, 100 percent of the population of 1,827 persons is classified as rural. This area had a year 2000 population density of 7.9 persons per square mile. The largest city in the county is Barnwell with a population of 23,478 persons.

Barnwell County's chronic high unemployment is linked to the decline in manufacturing, lack of growth in service jobs, low educational attainment of county residents, and lack of employment opportunities. Agriculture is a significant, but declining presence in the community. The average farm is 230 acres (93 ha) and generates about $\$ 19,102$ in products. In excess of 92 percent of the farms are operated by a family or individuals. Irrigated croplands, vegetables and orchards, the products most likely to need seasonal help in harvesting, account for about 1,200 acres (485.6 ha) under cultivation.

\section{J.3.10 Environmental Justice}

The last U.S. census reported that the Barnwell County per capita income was $\$ 15,870$. Approximately 20.9 percent of the Barnwell County's residents, 18.2 percent of families, were determined to be living in poverty. Approximately 27 percent of families with children were living in poverty. The per capita income in South Carolina was \$18,795 in 2000 and 14.1 percent of South Carolina residents were living in poverty. In 2004, approximately 3,238 households out of a total of 9,021 in Barnwell County were receiving food stamps.

One-hundred-ninety-four block groups have a significant Black or African American minority population and 207 block groups have significant aggregate minority percentages. One census block group within the $50 \mathrm{mi}(80 \mathrm{~km})$ radius has a significant Hispanic ethnicity population.

Based on the "more than 20 percent" or the "exceeded 50 percent" criteria, no American Indian or Alaskan Native, Asian, Native Hawaiian or Other Pacific Islander, Some other race, or Multiracial minority block groups exist in the geographic area 


\section{J.3.11 Public and Worker Health and Safety}

An individual's radiation exposure in the vicinity of the Barnwell Site amounts to approximately 357 mrem, and is comprised of natural background radiation from cosmic, terrestrial, and internal body sources; radiation from medical diagnostic and therapeutic practices; weapons test fallout; consumer and industrial products, and nuclear facilities. Annual background radiation doses to individuals are expected to remain constant over time. Releases of radionuclides to the environment from SRS operations provide another source of radiation exposure to individuals in the vicinity of the Barnwell Site. These doses fall well below the $100 \mathrm{mrem} / \mathrm{yr}$ (10 mrem from air) radiological limits given in DOE Order 5400.5, Radiation Protection of the Public and the Environment, and are much lower than those from background radiation (DOE Order 5400.5), (WSRC 2005). The average radiation dose recorded for workers at SRS in 2005 is 51 mrem (WSRC 2005).

The South Carolina Department of Health and Environmental Control (SCDHEC) regulate both radioactive and non-radioactive criteria and toxic air pollutant emissions from the Barnwell Site sources. Major non-radiological emissions of concern from stacks at SRS facilities include sulfur dioxide, carbon monoxide, oxides of nitrogen, $\mathrm{PM}_{10}$, volatile organic compounds (VOCs), and toxic air pollutants. All SRS permitted sources were found to be in compliance with their respective permit conditions and limits.

\section{J.3.12 Transportation}

The Barnwell Site is surrounded by a system of interstate highways, U.S. highways, state highways, and railroads. I-20 serves the northern region, providing the primary east-west corridor. I-520 provides a loop around Augusta, Georgia. Truck shipments to (or from) the Barnwell Site in the west normally enter the region from the west on I-20. In Augusta, Georgia, the trucks typically take I-520 to the Georgia/South Carolina border where U.S. 278 takes them into Barnwell. From the south, Barnwell is accessed by way of U.S. Route 301. From the north, Barnwell is accessed by way of either U.S. Route 301 or U.S. Route 321. From the east, Barnwell is accessed by way of U.S. Route 78.

The Barnwell Site does not have direct rail access. The closest line passes $30 \mathrm{mi}(48 \mathrm{~km})$ to the south through the town of Allendale and $15 \mathrm{mi}(24 \mathrm{~km})$ to the east going through the town of Denmark.

\section{J.3.13 Waste Management}

The Barnwell Site has existing waste storage facilities, previously existing waste facilities that have been dismantled, and land area that is available for development of additional waste storage capacity. For dry fuel storage, a large, concrete paved area is located within the fuel storage building. The currently developed area could provide storage for an estimated 5,000 metric ton unit (MTU) dry fuel. The AGNS facility had established infrastructure for liquid waste. The facility had three 500,000 gal $(1,892,700 \mathrm{~L})$ double-walled stainless steel tanks for storage of high level waste. The final component is storage appropriate for low-level waste. Low-level 
waste storage requirements for operating nuclear facilities is typically in the range of several thousand cubic feet per year and the Barnwell Site has ample space for construction of a facility of this size. 


\section{J.4 MORRIS SITE}

This section presents a summary of the affected environment for the Morris Site, which is owned by General Electric. The information was summarized from the Site Characterization Report prepared by the Funding Opportunity Announcement (FOA) grant recipient (SCR 2007c).

\section{J.4.1 Land Use}

The Morris Site encompasses 889 acres (360 ha) of land located in northeast Illinois, approximately $50 \mathrm{mi}(80 \mathrm{~km})$ southwest of Chicago, in Goose Lake Township, Grundy County. The Dresden Power Station is adjacent to the Morris Site.

The Morris operations are comprised of facilities to support the storage of spent nuclear fuel. The site uses approximately 15 acres (6 ha) of the 889 acres (360 ha) proposed by Morris. Historically, much of the area surrounding the Morris Site was mined for coal, clay, and building stone. The area surrounding the Morris Site is crossed by three major rivers: the Des Plaines, Kankakee, and Illinois Rivers. The site is located $1 \mathrm{mi}(2 \mathrm{~km})$ to the southwest of the convergence of these three rivers. Immediately to the northeast of the Morris Site is the Dresden Power Station. This station has been in operation since the 1970s, and has a peak generating capacity of 1,824 megawatts. To the northwest is the Reichhold Chemical Facility, which is a polyester resin manufacturing facility.

\section{J.4.2 Visual Resources}

The area surrounding the site is generally flat with sparse vegetation and tree cover. The Illinois River is to the north and north-west. The Des Plaines River, to the north-east, and the Kankakee River, to the east merge to form the Illinois River to the north and north-west of the site. The Morris facility and the Dresden Power Plant are highly visible from the site.

\section{J.4.3 Site Infrastructure}

The Morris Site has ready access to electrical power from the adjoining Dresden Power Station. The Morris Site is currently supplied with water from a ground water production well. There is no discharge of wastewater from the site, and sanitary sewage is treated in two onsite lagoons. Extensive rail lines exist throughout the area, with the closest spur approximately one mile to the west of the site.

\section{J.4.4 Air Quality and Noise}

Illinois is located in the Midwestern United States and experiences a wide range of weather patterns in both temperature and precipitation. In general, summers in northern Illinois are hot and humid and winters are cold and snowy. Southeasterly and easterly winds from the Atlantic Ocean and Gulf of Mexico usually bring mild and wet weather. Winds from the northwest and north out of Canada are usually cooler and drier. Winds in northern Illinois blow predominantly out of the northwest during the colder months followed by south wind directions during the 
warmer months. The annual average windspeed for Moline, Illinois is $8 \mathrm{mi} / \mathrm{hr}(13 \mathrm{~km} / \mathrm{hr})$ and for the same period and location, the maximum recorded peak wind gust was $81 \mathrm{mi} / \mathrm{hr}(130 \mathrm{~km} / \mathrm{hr})$.

The Great Lakes affect local climates by enhancing precipitation, particularly with the formation of lake-effect snows. The Morris Site has averaged 28 to 32 in $(71$ to $81 \mathrm{~cm})$ from 1971 through 2000. The average rainfall in the vicinity of the Morris Site from 1971 through 2000 (most recent comprehensive data set available) was 33 to $34 \mathrm{in} / \mathrm{yr}$ ( 84 to $86 \mathrm{~cm} / \mathrm{yr}$ ). Annual high and low temperatures are on average $60^{\circ} \mathrm{F}\left(15.6^{\circ} \mathrm{C}\right)$ and $39^{\circ} \mathrm{F}\left(3.9^{\circ} \mathrm{C}\right)$. Seasonal variations in temperature at the Morris Site are typical for a location in the Midwest.

High velocity wind speeds in the vicinity of the Morris Site can result from either straight-line winds or tornadoes. Grundy County has had an annual average of three days per year with wind speeds at or above $45 \mathrm{mi} / \mathrm{hr}(72 \mathrm{~km} / \mathrm{hr})$. Winds at this speed or above can result in some degree of damage. The recorded annual maximum for Grundy County is 20 days with windspeed above $45 \mathrm{mi} / \mathrm{hr}(72 \mathrm{~km} / \mathrm{hr})$. From 1950 to 2006, there were ten tornadoes in Grundy County. The closest tornado to the Morris Site was an F2 magnitude tornado $8.3 \mathrm{mi}(13.4 \mathrm{~km})$ to the southwest on April 19, 1973. Tropical storms affecting Illinois weather are rare. Over the past 20 years, the only storm of tropical origin that affected the weather near the Morris Site was Hurricane Gilbert in 1998.

The Morris Site is located in the Metropolitan Chicago Interstate Air Quality Control Region (AQCR). The AQCR is currently an attainment area for all criteria pollutants except ozone, and in some areas for $\mathrm{PM}_{10}$ as well.

\section{J.4.5 Water Resources}

The proposed site is located on the east bank of the Kankakee River, just on the confluence of the Kankakee River and the Des Plains River. Local hydrology is dominated by the flat topography of the proposed site which is amenable to development of wetlands, ponds and small intermittent streams. These waterbodies can be found on the southern and northwestern portions of the proposed site.

Much of the Kankakee River and the Illinois River are classified as impaired waters and included on the Illinois 303(d) list. The Illinois River is impaired for human fish consumption due to mercury and polychlorinated biphenyls (PCBs) contamination. The Kankakee River near the proposed site is impaired for fish consumption due to mercury contamination, and for primary contact recreation due to fecal coliform contamination. These impairments are not anticipated to inhibit use of either waterway as a source of water for the proposed facilities. The right to withdraw surface water for the proposed GNEP facility would be within the confines of environmental regulations which limit total water removal to no more than 5 percent of the annual mean flow (e.g., 40 CFR Part 125 Subpart I) and IEPA/IDNR water withdrawal reduction requirements near 7Q10 flow conditions. The water that could be withdrawn from the Kankakee River is 145 million gallons per day (mgd) and $320 \mathrm{mgd}$ from the Illinois River under normal flow conditions. 
The elevation for the proposed site is about $0.29 \mathrm{ft}(0.09 \mathrm{~m})$ less than msl elevation levels presented in U.S. Geological Survey (USGS) topographic maps. The eastern edge of the Morris Site is between $509.5 \mathrm{ft}$ and $510.0 \mathrm{ft}(155.3 \mathrm{~m}$ and $155.4 \mathrm{~m})$ National Geodetic Vertical Datum (NGVD 29). The 500-year flood is between $511.5 \mathrm{ft}$ and $512.0 \mathrm{ft}(155.9 \mathrm{~m}$ and $156.1 \mathrm{~m})$ NGVD. Therefore, the eastern edge of the proposed site borders the 100- and 500-year flood zones, but the northern portion of the proposed site is approximately 10 to $22 \mathrm{ft}$ ( 3 to $7 \mathrm{~m}$ ) above the 100 year floodplain and 8.5 to $20.5 \mathrm{ft}$ (2.6 to $6.3 \mathrm{~m}$ ) above the 500 -year floodplain.

The areal extent of aquifers and confining units vary in northeastern Illinois because of glacial erosion, depositional extent, and the presence of certain geologic structures (i.e., regional inactive faults). Overall, groundwater from the aquifers in the upper Illinois River basin is generally suitable for most uses. Although not considered a health issue, total dissolved solids (TDS), and chlorides can be high and cause difficulties with water distribution systems. In addition, naturally occurring constituents, such as arsenic, barium, and isotopes of radium, have been problematic enough to cause groundwater users (e.g., both domestic and community well systems) to abandon their wells in favor of surface water supplies. The available groundwater resources in northeastern Illinois are adequate to supply the needs of the region in the near future. With planning and careful management, large volumes of water could be safely withdrawn from the deep bedrock aquifer system. Illinois groundwater quantity use law is based principally on the doctrine of reasonable use. The Illinois General Assembly passed the Water Use Act in 1983, abolishing the English common law of absolute ownership (previously allowing capture of all groundwater beneath a parcel, regardless of the impact on neighboring wells). Currently, there are no groundwater use restrictions or mandatory reporting of water withdrawals in Illinois. Different types of groundwater users have been identified within $6 \mathrm{mi}$ $(10 \mathrm{~km})$ of the proposed site. These groundwater users may withdraw groundwater from wells in the sand and gravel aquifers, the shallow bedrock aquifer, the deep bedrock aquifer system, or potentially in a few cases, the Mt. Simon aquifer.

\section{J.4.6 Geology and Soils}

The Morris Site is located in Grundy County, in northeastern Illinois at the western end of the Kankakee Plain subprovince of the Till Plains Section of the Central Lowland Physiographic Province. Based on an age of faulting of more than 280 million years, a prior analysis concluded that the "faulting is not capable" (as defined by the USNRC in 10 CFR Part 100), meaning that no movement on the fault has taken place at or near the ground surface at least once within the past 35,000 years, or movement of a recurring nature has occurred within the past 500,000 years. The Morris Site is located adjacent to the Dresden Power Station, which underwent thorough seismic evaluations as part of its licensing process to operate as a nuclear generating station, and was found to be suitable by the Atomic Energy Commission when the Construction Permit for Dresden Unit I was issued.

The Morris Site is overlaid by approximately 1 to $2 \mathrm{ft}(0.3$ to $0.6 \mathrm{~m})$ of an undulating, erosional, bedrock surface soil. This soil generally consists of about 3 to 8 in $(8$ to $20 \mathrm{~cm})$ of dark brown to black clayey silt topsoil with some occasional inclusions of extremely weathered limestone, sandstone, and glacial erratics. The Channahon Series is the soil series that is the most 
prevalent ( $>35$ percent) on the Morris Site. This series consists of shallow, well-drained, moderately permeable soils that formed in loamy material over dolomitic limestone terraces.

\section{J.4.7 Biological Resources}

The animals observed within the 889 acre (360 ha) parcel during the winter field observations included: whitetail deer, gray squirrel, deer mouse, meadow vole, red-tailed hawk, rough-legged hawk, Swainson's hawk, northern harrier, American kestrel, rock dove, mourning dove, northern flicker, American goldfinch, song sparrow, house sparrow, tree sparrow, and dark-eyed junco.

There are some areas with wetland vegetation and soil located to the south and, to a lesser extent, west of the Morris Site. There is a small (0.6 acre [0.24 ha]) bluejoint and river bulrush dominated wetland area to the west of the Morris Site. There are apparent wetlands just to the south of the existing Morris Site that are primarily common reed and common cattail areas associated with a low swale.

\section{J.4.8 Cultural and Paleontological Resources}

No archaeological surveys were identified that have been conducted within the Morris Site. Additionally, no documentation of previously recorded archaeological sites within the site was identified. Upon evaluation of the historic maps, atlases, and plat maps, a number of potentially sensitive areas were identified within the Morris property. The most extensive of these areas is located in the southeastern corner of the site.

\section{J.4.9 Socioeconomics}

The population density near the site is 91.48 people per square mile within the first $5 \mathrm{mi}(8 \mathrm{~km})$ radius from the site. The population density slowly increases, reaching a cumulative 485.49 people per square mile at the $35 \mathrm{mi}(56 \mathrm{~km})$ radius. The population density then climbs quickly as the radii include portions of Cook County and Chicago. Between the $35 \mathrm{mi}(56 \mathrm{~km})$ radius and the $50 \mathrm{mi}(80 \mathrm{~km})$ radius, the cumulative population density increases to 842.78 people per square mile, even though the counties to the south and west of the site have relatively low population levels. The region's labor force was approximately 4.2 million in 2000 . In $2000,6.5$ percent of this labor force $(273,000)$ was unemployed. That year, the majority of the labor force (2.6 million) resided in Cook County.

\section{J.4.10 Environmental Justice}

Minority in this analysis is defined as any ethnic group other than white, non-Hispanic. Overall, more than 30 percent of the region's residents are members of minority groups. Minority residents are of special concern because their behaviors may cause higher exposures to environmental contaminants; they may do more subsistence fishing, for example, and thus be more affected by water pollution. Of the populations in the region for which the U.S. Census was able to determine the poverty status, more than 11 percent has income below the poverty line. Poverty status is determined for an individual, household, or family by comparing their reported income to officially determined income thresholds. Residents of the region who are both a 
minority and have incomes below the poverty line are of particular concern from an environmental justice perspective.

\section{J.4.11 Public and Worker Health and Safety}

There are small radiological air emissions associated with the storage of spent nuclear fuel. To assure compliance with regulatory standards, effluent air is continuously sampled for particulates. Samples are analyzed weekly for gross beta activity. With respect to surrounding population doses, the Dresden Power Plant is a more predominant source of radiological emissions than Morris. The review revealed that the doses to maximally exposed individuals (MEIs) in the vicinity of Dresden Site were a small fraction of the Environmental Protection Agency (EPA) limits. The impact to the environment from radioactive releases from Dresden Units 2 and 3 is small. For comparison, the average American living in the United States is typically exposed to 360 millirem (mrem) annually from natural and other sources of radiation.

\section{J.4.12 Transportation}

Grundy and Will Counties are crossed by I-55, I-57, I-80, and I-355, a network of interstates connecting them to the Chicago area. The Kankakee River and the Des Plains River come together near the Grundy-Will County line to form the Illinois River, providing a connection for barge traffic to the Chicago area and down the Mississippi River through a system of canals and locks. A total of nine airports or heliports were identified within $10 \mathrm{mi}(16 \mathrm{~km})$ of the Morris Site. Only two, the Morris Municipal Airport and the Joliet Regional Airport, are public airports. There are extensive rail lines in the area, and the Morris Site has a spur that connects it to the nearest rail line, which is located approximately 1 mile to the west.

\section{J.4.13 Waste Management}

Currently the Morris Site is classified as a conditionally exempt small quantity generator (CESQG) of hazardous waste. CESGQ facilities are those that generate less than $220 \mathrm{lbs}$ $(100 \mathrm{~kg})$ of hazardous waste per month. Solid wastes generated by the Morris Site include spent resin filter materials that are disposed of as radioactive waste and sanitary wastes that are disposed of as solid, non-hazardous wastes. 



\section{J.5 HANFORD SITE}

This section presents a summary of the affected environments for the Hanford Site (Hanford).

\section{J.5.1 Land Use}

Hanford, established in 1943 as one of the three original Manhattan Project sites, is located on approximately 375,000 acres (148,000 hectares [ha]) in Washington State, just north of Richland. It extends over parts of Adams, Benton, Grant, and Franklin counties (DOE 2006b).

Hanford is owned and used primarily by the U.S. Department of Energy (DOE), but portions of it are owned, leased, or administered by other Government agencies. Only about 6 percent of the land area has been disturbed and is actively used, leaving mostly vacant land with widely scattered facilities. On June 9, 2000, the President issued a proclamation that established the 195,000 acre (78,900 ha) Hanford Reach National Monument (65 FR 37253). Industrially and agriculturally developed land lies to the southwest (all zoned industrial by the City of Richland). The Columbia River is located due east. There is also a barge-docking facility, located to the southeast that is used for transferring reactor components and other materials destined for the Hanford Site. A haul road connecting the barge facility to Stevens Drive traverses the buffer area from southeast to northwest. The Washington State University (WSU)-Tri-Cities branch campus, Hanford High School, and Richland residential area are located to the south-southeast (DOE 2000g).

\section{J.5.2 Visual Resources}

The topography of land in the vicinity of Hanford ranges from generally flat to gently rolling. Rattlesnake Mountain, rising to 3,480 feet (ft) (1,061 meters [m]) above mean sea level, forms the southwestern boundary of the site. Gable Mountain and Gable Butte are the highest land forms within the site, rising approximately $200 \mathrm{ft}(61 \mathrm{~m})$ and $590 \mathrm{ft}(180 \mathrm{~m})$, respectively. The Columbia River flows through the northern part of the site and, turning south, forms part of the eastern site boundary. Typical of the regional shrub-steppe desert, the site is dominated by widely spaced, low-brush grasslands (DOE 2000g, DOE 2007h).

Hanford is characterized by mostly undeveloped land, with widely spaced clusters of industrial buildings along the southern and western banks of the Columbia River and at several interior locations. The adjacent visual landscape consists primarily of rural rangeland and farms. Viewpoints affected by DOE facilities are primarily associated with the public access roadways. The Energy Northwest (formerly known as the Washington Public Power Supply System) nuclear reactor and DOE facilities are brightly lit at night and are highly visible from many areas. The tallest structures within the 300 area vicinity are the water towers, with a height of $130 \mathrm{ft}(40 \mathrm{~m})$ and the meteorological tower with a height of $200 \mathrm{ft}(61 \mathrm{~m})$ in height. The 300 Area is visible from Route 4. The Fuels and Materials Examination Facility, the tallest building in the 400 Area, is $100 \mathrm{ft}(30 \mathrm{~m})$ tall and can be seen from State Route 240 (DOE 2000g). 


\section{J.5.3 Site Infrastructure}

The DOE road network at the Hanford Site includes about 122 lane miles (mi) (196 kilometers $[\mathrm{km}])$ of primary roads and 377 lane mi $(607 \mathrm{~km})$ of secondary roads that provide access to the various work centers (DOE 2007h).

The Hanford Site rail system now includes about $110 \mathrm{mi}(177 \mathrm{~km})$ of active track and an estimated $275 \mathrm{mi}(443 \mathrm{~km})$ of inactive track (DOE 1999a).

Electricity for the Hanford Site is purchased from Bonneville Power Administration (BPA), a federal power agency within the DOE, which provided 90 percent of the electricity consumed on the Hanford Site in 2005 (Slocum 2006).

The coal-fired steam plants at the Hanford Site are no longer in operation. Building heat is now provided by natural gas and fuel oil (Slocum 2006).

Propane and gasoline fuels are also used to support site operations. Fuels used onsite are delivered by truck. The Columbia River is the principal source of water for the Hanford Site. Based on current demand for water and water treatment, the systems now in place have plenty of excess capacity to accommodate additional water and treatment needs (Slocum 2006).

\section{J.5.4 Air Quality and Noise}

The Environmental Protection Agency (EPA) has issued regulations (40 CFR Part 50) setting National Ambient Air Quality Standards (NAAQS). Individual states have the primary responsibility for assuring that air quality within the state meets the NAAQS through state implementation plans (SIP) that are approved by EPA. Areas that meet ambient air quality standards are said to be in attainment. Areas that do not meet one or more ambient air quality standards are designated as nonattainment areas.

None of the areas within Hanford and its surrounding counties are designated as nonattainment areas with respect to NAAQS for criteria air pollutants (40 CFR Part 81). The primary sources of air pollutants at Hanford include emissions from power generation and chemical processing (DOE 2000g). Other sources include vehicles, construction, environmental remediation, and waste management activities (DOE 2000j). Hanford sources are limited and background concentrations of criteria pollutants are well below ambient standards. Carbon monoxide, sulfur dioxide, and nitrogen dioxide have been monitored periodically in communities and commercial areas southeast of Hanford (DOE 2006b).

Small quantities of tritium (i.e., hydrogen-3), strontium-90, iodine-129, cesium-137, plutonium238, plutonium-239/240, plutonium-241, americium-241, and several other longer lived isotopes are released to the environment through state and federally permitted emission points. Distinguishing Hanford-produced radionuclides in the environment is extremely challenging because concentrations in emissions from the Hanford Site stacks are comparable to background concentrations of radionuclides that originated from historical atmospheric nuclear weapons testing (DOE 2000g). 
Studies of the propagation of noise at Hanford have been concerned primarily with occupational noise at work sites. Environmental noise levels have not been extensively evaluated because of the remoteness of most Hanford activities and isolation from receptors that are covered by federal or state statutes. Most industrial facilities on the Hanford Site are located far enough away from the Site boundary that noise levels at the boundary are not measurable or are barely distinguishable from background noise levels.

\section{J.5.5 Water Resources}

Major surface water features at and surrounding the Hanford Site include the Columbia River, Columbia riverbank seepage, springs, and ponds. In addition, the Yakima River flows along a short section of the southern boundary of the site. The Columbia River is the second largest river in the contiguous United States in terms of total flow and is the dominant surface water feature on the site. Several communities use the Columbia River as their source of drinking water, and various facilities at the Hanford Site use water from the Columbia River (DOE 2006b).

About one-third of the Hanford Site drains into the Yakima River. Water is expected to flow from the Yakima River into the aquifer underlying the Hanford Site rather than from the aquifer into the river, due to the higher elevation of the river surface compared to the elevation of the adjacent water table (DOE 2006b). Groundwater contaminants from the Hanford Site do not reach the Yakima River (DOE 2006b).

No floodplains are found in the 400 Areas. Flooding on the Hanford Site has occurred along the Columbia River, but chances of recurrence have been greatly reduced by the construction of dams to regulate river flow. Major floods are typically due to the melting of the winter snowpacks combined with above normal precipitation (DOE 2006b). Discharges from the Hanford Site enter the Columbia River along the Hanford Reach, which is routinely monitored and regulated for radioactive and chemical pollutants in accordance with the Clean Water Act (CWA) (33 U.S.C. 1251 et seq.). According to the general water use and water quality criteria established by Washington State for the Columbia River, the stretch of the River from Grand Coulee Dam to the Washington-Oregon border, which includes the Hanford Reach is classified as Class A, Excellent (WAC 2006) Class A waters are suitable for essentially all uses, including raw drinking water, recreation, and wildlife habitat (DOE 2006b).

Groundwater under Hanford occurs in confined and unconfined aquifer systems. The unconfined aquifer system lies within the glacioalluvial sands and gravels of the Hanford Formation and, to a greater degree, the fluvial and lacustrine sediments of the Ringold Formation. Groundwater generally flows eastward across the site from recharge areas in the higher elevations on the western site boundary, with discharge primarily to the Columbia River (DOE 1999a, DOE 2000g).

The area of contaminant plumes on the Hanford Site with concentrations exceeding drinking water standards was estimated to be $80.3 \mathrm{mi}^{2}\left(207.9 \mathrm{~km}^{2}\right)$ in fiscal year 2001 . This estimate is 1 percent smaller than that for fiscal year 2000. The decrease is primarily due to shrinkage of the 
known tritium plume, which was caused primarily by radioactive decay (DOE 2004i). By 2006 the total combined plume area is $71.8 \mathrm{mi}^{2}\left(185.9 \mathrm{~km}^{2}\right)$ (Poston et al. 2007).

The groundwater usage in the Pasco Basin can be characterized by a large proportion (50 percent) of domestic use followed by agricultural uses ( 24 percent) and industrial ( 3 percent) (DOE 1999a). Most of Hanford Site's water supply is withdrawn from the Columbia River and it is distributed to the 100-B, 100-D, 200, and 300 Areas at Energy Northwest (DOE 1999a). The 400 Area and other low-use facilities at remote locations use groundwater from wells located at those locations. The 700 and 1100 Areas are supplied with water by the City of Richland (DOE 1999a).

\section{J.5.6 Geology and Soils}

The Hanford Site is located within the Pasco Basin, a topographic, structural depression in the southwest corner of the Columbia Basin physiographic subprovince. This subprovince is characterized by generally low-relief hills with deeply carved river drainage. Relief in the Pasco Basin area ranges from $390 \mathrm{ft}(120 \mathrm{~m})$ above mean sea level at the Columbia River level, to $750 \mathrm{ft}(230 \mathrm{~m})$ above mean sea level (DOE 2004i).

The stratigraphy of the Hanford Site consists of Miocene-age and younger rocks. Older Cenozoic sedimentary and volcaniclastic rocks underlying the Miocene rocks are not exposed at the surface. Over 100 basalt flows of the Columbia River Basalt Group, with a total thickness exceeding 10,000 ft (3000 m), lie beneath the Hanford Site. Interbedded between many of these basalt flows are sedimentary rocks of the Ellensburg Formation, a series of sand, gravel, or silt layers that were deposited by the ancestral Columbia River system. The sedimentary deposits of the Ringold Formation, Hanford Formation, and surficial deposits overlie the Columbia River Basalt Group and are up to $750 \mathrm{ft}(230 \mathrm{~m})$ thick. The 400 Area stratigraphy consists of sanddominated sediments of the Hanford Formation which attain a thickness of about $164 \mathrm{ft}(50 \mathrm{~m})$ beneath the site (DOE 2004i).

The Hanford Site lies in an area of relatively low seismic activity. The nearest capable fault to the 400 Area (Central Gable Mountain fault) is $12 \mathrm{mi}(19.3 \mathrm{~km})$ away. The most recent Hanford Site-specific hazard analysis (DOE 2004i) estimated that $0.10 \mathrm{~g}$ ( $1 \mathrm{~g}$ is the acceleration of gravity) horizontal acceleration would be experienced on average every 500 years (yr) (or with a 10 percent chance every $50 \mathrm{yr})$. This study also estimated that $0.2 \mathrm{~g}$ would be experienced on average every 2,500 years (or with a 2 percent chance in $50 \mathrm{yr}$ ) (DOE 2004i).

Several major volcanoes are located in the Cascade Range west of the Hanford Site. The nearest volcano, Mount Adams, is about $102 \mathrm{mi}(165 \mathrm{~km})$ from the Hanford Site. The most active volcano, Mount St. Helens, is located approximately $136 \mathrm{mi}(220 \mathrm{~km})$ west-southwest of the Hanford Site (DOE 2004i).

No economically viable mineral resources exist at the Hanford Site. Fifteen different soil types have been identified on the Hanford Site, varying from sand to silty and sandy loam (DOE 2004i). The predominant soil type in the 400 Area is the Quincy (Rupert) sand, and the soils and surface sediments are not subject to liquefaction or other instabilities. 


\section{J.5.7 Biological Resources}

Plants at the Hanford Site are adapted to low annual precipitation, low water-holding capacity of the rooting substrate (sand), dry summers, and cold winters. Range fires that burn through the area during dry summers have reduced species that are less resistant to fire (for example, big sagebrush) and have allowed more opportunistic and fire-resistant species a chance to become established. Perennial shrubs and bunchgrasses generally dominate native plant communities on the site. However, Euro-American settlement and development have resulted in the proliferation of non-native species. Of the 727 plant species recorded on the Hanford Site, approximately 25 percent of the species are considered non-native (DOE 2007h) (DOE 2006b). The Nature Conservancy of Washington also conducted rare plant surveys. The Conservancy found 112 populations/occurrences of 28 rare plant taxa on the Hanford Site. When combined with observations preceding the 1994-1999 inventories, a total of 127 populations of 30 rare plant taxa have been documented on the Hanford Site (DOE 2004i).

The shrub and grassland habitat of the Hanford Site supports many groups of terrestrial wildlife. Species include large game animals like Rocky Mountain elk and mule deer; predators such as coyote, bobcat, and badger; and herbivores like deer mice, harvest mice, ground squirrels, voles, and blacktailed jackrabbits. The most abundant mammal on the Hanford Site is the Great Basin pocket mouse (DOE 2006b).

Shrubland and grassland provide nesting and foraging habitat for many passerine bird species. Surveys conducted during 1993 (DOE 2007h) reported the occurrence of western meadowlarks and horned larks more frequently in shrubland habitats than in other habitats on the site. Longbilled curlews and vesper sparrows were also noted as commonly occurring species in shrubland habitat. Common upland game bird species that occur in shrub and grassland habitat include chukar partridge, California quail, and Chinese ring-necked pheasant. Among the raptor species that use shrubland and grassland habitats are American kestrel, red-tailed hawk, Swainson's hawk, and ferruginous hawks. Northern harriers, sharp-shinned hawks, rough-legged hawks, and golden eagles also occur in these habitats but are not sighted as frequently. Many species of insects occur throughout all habitats on the Hanford Site. Butterflies, grasshoppers, and darkling beetles are among the most conspicuous of the approximately 1,500 species of insects that have been identified from specimens collected on the Hanford Site (DOE 2007h). The high diversity of insect species on the Hanford Site is believed to reflect the size, complexity, and quality of the shrub-steppe habitat (DOE 2006b).

Two types of natural aquatic habitats are found on the Hanford Site: the Columbia River that flows along the northern and eastern edges of the site, and the small spring-streams and seeps located mainly on Arid Lands Ecology reserve (ALE) in the Rattlesnake Hills (DOE 2004i).

The Columbia River is the dominant aquatic ecosystem on the Hanford Site and supports a large and diverse community of plankton, benthic invertebrates, fish, and other communities. Steelhead and salmon are regulated as evolutionary significant units (ESUs) by the National Marine Fisheries Service based on their historic geographic spawning areas. The Upper Columbia River steelhead ESU is listed as threatened (USFWS 2007b). Conditions in the Hanford Reach promote spawning success for salmonids, sturgeon and bass. Three species of 
fish (bull trout, spring-run Chinook and steelhead) that are currently found on the federal list of threatened and endangered species are found at the Hanford Site.

Washington State considers shrub-steppe habitat as a priority habitat because of its relative scarcity in the state and because of its requirement as nesting/breeding habitat by several state and federal species of concern.

Primary wetland areas at Hanford are found in the riparian zone along the Columbia River. The extent of this zone varies, but includes large stands of willows, grasses, and other plants. There are no natural wetlands in the 400 Area, although a small cooling and wastewater pond does contain some wetland vegetation.

\section{J.5.8 Cultural and Paleontological Resources}

Twenty-four percent of the Hanford Site has been surveyed for archaeological resources (DOE 2005f). Archaeological surveys have focused on islands and a 1,312 ft (400 m) corridor on each side of the Columbia River. Approximately 1,447 cultural resource sites and isolated finds have been documented, and 127 of these have been evaluated for eligibility to the National Registry of Historic Places (NRHP). Documentation and evaluation have occurred on 531 buildings and structures at the Hanford Site.

Prehistoric resources at the Hanford Site include pithouse villages, open campsites, graves, spirit quest sites, hunting camps, game drive complexes, quarries, and temporary camps (DOE 2000g). Approximately 720 archaeological sites and isolated finds associated with the pre-contact period have been recorded on the Hanford Site; of these, 80 contain historic components as well (DOE 2005f). Forty-nine prehistoric archaeological sites have been listed on the NRHP, with 3 listed individually and 46 contained within 6 listed archaeological districts. Five prehistoric archaeological sites have been determined eligible for individual listing on the NRHP. Most of the 400 Area has been so disturbed by construction activities, that an archaeological survey in 1978 found that only 30 acres (12 ha) were undisturbed. Survey of the undisturbed acreage identified no archaeological resources. No archaeological sites are known to be located within 0.6 miles $(1 \mathrm{~km})$ of the 400 Area (DOE 2005f).

Historic resources at the Hanford Site that pre-date the Hanford era include homesteads, ranches, trash scatters, gold mines, roads, and townsites. More recent historic resources include reactors and materials processing facilities that played important roles in the Manhattan Project and Cold War era (DOE 2000g). The 400 Area does contain six Cold War-era buildings/structures that have been determined eligible for the NRHP as contributing properties within this historic district (DOE 2005f).

Native American tribes who retain secular and religious ties to the Hanford Site region include the Yakama, Cayuse, Nez Perce, Wanapum, Chamnapum, Palus, Walla Walla, and Umatilla Peoples. These groups have knowledge of the traditional and historical ceremonies and lifeways of their cultures, and resources that are found on the Hanford Site are used by tribal members for ceremonies and other traditional uses. 
Remains from the Pliocene and Pleistocene Ages have been identified at the Hanford Site. The Upper Ringold Formation dates to the Late Pliocene Age and contains fish, reptile, amphibian, and mammal fossil remains. Late Pleistocene Touchet beds have yielded mammoth bones. These beds are composed of fluvial sediments deposited along ridge slopes that surround the Hanford Site. No paleontological resources have been discovered in the 400 Area at Hanford.

\section{J.5.9 Socioeconomics}

Socioeconomic characteristics addressed at Hanford include employment, income, population, housing, and community services. These characteristics are analyzed for a two-county ROI consisting of Benton and Franklin Counties in Washington.

The state and local government, professional and technical services, retail trade, and administrative and waste services sectors employ the greatest number of workers in the ROI (BEA 2006a, TtNUS 2006a). The state and local government sector provides 12.4 percent of all employment, while the professional and technical services sector provides 11.1 percent, the retail trade sector provides 11.1 percent, and the administrative and waste services sector provides 9.2 percent of the jobs in the ROI. Another important sector of employment is healthcare and social assistance (8.7 percent) (BEA 2006a, TtNUS 2006e).

The labor force in the ROI increased 43.8 percent from 1990 to 2005 (BLS 2005b, TtNUS 2006a). In comparison, for the same period, the state-wide labor force in Washington increased 29.8 percent. Between 1990 and 2005, the ROI population grew from 150,033 to 220,961, an increase of 47.3 percent (USCB 1990, USCB 2007c, and TtNUS 2006e). This was a higher rate of growth than for the state of Washington, which grew at a rate of 29.2 percent, during the same time period.

\section{J.5.10 Environmental Justice}

Census data from the year 2000 was used to determine minority and low-income characteristics by block group within $50 \mathrm{mi}(80 \mathrm{~km})$ of the Hanford Site. Eleven census block groups (3 percent) have a significant American Indian or Alaskan Native minority population, 94 census block groups (26 percent) have significant "some other race" populations, 87 census block groups (24 percent) have significant aggregate minority percentages, and 147 census block groups (41 percent) have significant Hispanic Ethnicity populations (TtNUS 2006e).

Thirty-seven census block groups within the $50 \mathrm{mi}(80 \mathrm{~km})$ radius have a significant percentage of low-income households (TtNUS 2006e).

\section{J.5.11 Public and Worker Health and Safety}

An individual's radiation exposure in the vicinity of the Hanford Site amounts to approximately 365 millirem (mrem), and is comprised of natural background radiation from cosmic, terrestrial, and internal body sources; radiation from medical diagnostic and therapeutic practices; weapons test fallout; consumer and industrial products, and nuclear facilities. 
Releases of radionuclides to the environment from Hanford operations provide another source of radiation exposure to individuals in the vicinity of Hanford. Types and quantities of radionuclides released from Hanford operations in 2005 are listed in Hanford Site Environmental Report for Calendar Year 2005 (DOE 2006b). The potential sources of radionuclide contamination included gaseous emissions from stacks and ventilation exhausts, liquid effluent from operating wastewater treatment facilities, contaminated groundwater seeping into the Columbia River, and fugitive emissions from contaminated soil areas and facilities. The doses from these emissions and effluents fall within the radiological limits given in DOE Order 5400.5, Radiation Protection of the Public and the Environment, and are much lower than those from background radiation (DOE Order 5400.5), (DOE 2006b).

Hanford worker doses have typically been well below DOE worker exposure limits. DOE set administrative exposure guidelines at a fraction of the exposure limits to help enforce doses that are as low as reasonably achievable (ALARA). Every year DOE evaluates the Hanford Sites' ALARA administrative control levels and adjusts them as needed.

Liquid effluent and airborne emissions that may contain hazardous constituents are continually monitored at the Hanford Site (DOE 2006b).

\section{J.5.12 Transportation}

Vehicle access to Hanford is provided by State Routes 240, 243, and 24. State Route 240 connects to the Richland bypass highway, which interconnects with I-182. State Route 243 exits the site's northwestern boundary and serves as a primary link between the site and I-90. State Routes 24 and 240 are both two-lane roads that traverse the Hanford Site. These roads are maintained by Washington State (DOE 1999a). State Route 24 enters the site from the west and continues eastward across the northernmost portion of the site and intersects State Route 26 about $10 \mathrm{mi}(16 \mathrm{~km})$ east of the site boundary. State Route 240 is a north-south highway that skirts the western edge of the Site.

A DOE-maintained road network within the Hanford Site, mostly paved and two lanes wide provides access to the various work centers. There is presently no rail service at Hanford, except for a spur to Energy Northwest.

The ports of Benton, Kennewick, and Pasco use the commercial waterways of the Snake and Columbia Rivers to provide access to the deep-water ports of Portland, Oregon and Vancouver, Washington. The Port of Benton provides a barge slip where shipments arriving at Hanford may be off-loaded (DOE 2000g).

\section{J.5.13 Waste Management}

Currently, Hanford's mission is focused on cleanup of wastes associated with past nuclear research, development, and weapons production activities, and decommissioning and demolition projects. The following waste types are managed at Hanford: high-level, transuranic, mixed transuranic, low-level, mixed low-level and hazardous waste. In addition to these radioactive and hazardous wastes, Hanford generates and manages sanitary solid waste, uncontaminated 
demolition debris, and sanitary sewage. A major focus of DOE's environmental management mission at Hanford is cleanup and management of the site's legacy waste from more than 45 years of nuclear materials production. However, beginning in 1999, non-dangerous waste has been disposed of at an offsite landfill. In addition to newly generated waste, significant quantities of legacy waste remain from years of nuclear material production and waste management activities. Most legacy waste from past operations at the Hanford Site resides in Resource Conservation and Recovery Act (RCRA) compliant waste sites or is stored in places awaiting cleanup and ultimate safe storage or disposal (40 CFR Parts 239-299), (DOE 2004i). 



\section{J.6 IDAHO NATIONAL LABORATORY}

The Idaho National Laboratory (INL) is located on approximately 570,000 acres $(230,671 \mathrm{ha})$ in southeastern Idaho, and is 45 miles (mi) (72 kilometers [km]) west of Idaho Falls, $38 \mathrm{mi}(61 \mathrm{~km})$ northwest of Blackfoot, and $22 \mathrm{mi}(35 \mathrm{~km})$ east of Arco. It is primarily located within Butte County, but portions of the site are also in Bingham, Jefferson, Bonneville, and Clark Counties. The site is roughly equidistant from Salt Lake City, Utah, and Boise, Idaho (INL 2006).

This section presents a summary of the affected environments for the Idaho National Laboratory site.

\section{J.6.1 Land Use}

The Federal Government, the state of Idaho, and various private parties own lands immediately surrounding INL. Regional land uses include grazing, wildlife management, mineral and energy production, recreation, and crop production. Two national natural landmarks border INL: Big Southern Butte (1.5 mi [2.4 km] south) and Hell's Half Acre (1.6 mi [2.6 km] southeast). Land is also used for recreation and environmental research associated with the designation of INL as a National Environmental Research Park. Much of INL is open space that has not been designated for specific use. Because INL is remote from most developed areas, its lands and adjacent areas are not likely to experience residential and commercial development, and no new development is planned near the site. Recreational and agricultural uses, however, are expected to increase in the surrounding area in response to greater demand for recreational areas and the conversion of rangeland to cropland (DOE 2005b).

\section{J.6.2 Visual Resources}

The Bitterroot, Lemhi, and Lost River Mountain ranges border INL on the north and west. Volcanic buttes near the southern boundary of INL can be seen from most locations on the site. INL generally consists of open desert land predominantly covered by big sagebrush and grasslands. Pasture and farmland border much of the site. INL facilities have the appearance of low-density commercial/industrial complexes clustered and widely dispersed throughout the site. Structure heights generally range from 10 to 100 feet (ft) (3 to 30 meters [m]); a few stacks and towers reach $250 \mathrm{ft}(76 \mathrm{~m})$. Although many INL facilities are visible from highways, most are more than $0.5 \mathrm{mi}(0.8 \mathrm{~km})$ from public roads. The operational areas are well defined at night by security lights (DOE 2005b).

\section{J.6.3 Site Infrastructure}

The road network at INL provides for onsite ground transportation. There are about $90 \mathrm{mi}$ $(145 \mathrm{~km})$ of paved public roads at the INL site. In addition, there are $87 \mathrm{mi}(140 \mathrm{~km})$ of non-public paved roads and $100 \mathrm{mi}(161 \mathrm{~km})$ of unpaved non-public roads at the INL site (INL 2006).

The Union Pacific Railroad's Blackfoot-to-Arco Branch crosses the southern portion of INL and provides rail service to the site. There are $30 \mathrm{mi}(48 \mathrm{~km})$ of railroad track at INL (DOE 2005b). 
DOE presently contracts with the Idaho Power Company and Rocky Mountain Power and Light to supply electric power to INL. The contract allows for power demand of up to 45,000 kilowatts (45 megawatts [MW]) (DOE 2005b).

Fuel consumed at INL includes natural gas, fuel oil (heating fuel), diesel fuel, gasoline, and propane. All fuels are transported to the site for use and storage (INL 2006).

The Snake River Plain Aquifer is the source of all water used at INL. The water is provided by a system of about 30 wells, together with pumps and storage tanks (DOE 2005b).

\section{J.6.4 Air Quality and Noise}

The climate at INL and the surrounding region is characterized as that of a steppe (a vast semiarid grass-covered plain). The average annual precipitation is 8.7 in $(221.0 \mathrm{~mm})$, and prevailing winds are generally southwest or northeast. The average annual temperature at INL is about $42^{\circ} \mathrm{F}\left(6^{\circ} \mathrm{C}\right)$ and average monthly temperatures range from a minimum of around $16^{\circ} \mathrm{F}\left(-9^{\circ} \mathrm{C}\right)$ in January to a maximum of $68^{\circ} \mathrm{F}\left(20^{\circ} \mathrm{C}\right)$ in July. The annual average wind speed is $7.5 \mathrm{mi} / \mathrm{hr}(12.1 \mathrm{~km} / \mathrm{hr})(\mathrm{DOE} 2005 \mathrm{~b})$.

None of the ambient air pollutant concentrations measured by the monitors exceeded the state or national standards (DOE 2005b).

The primary source of air pollutants at INL are from combustion of fuel oil for heating. Other emission sources include combustion of waste materials, industrial processes, stationary diesel engines, vehicle engines, and fugitive dust from waste burial and construction activities (IDEQ 2004a).

Radiological air pollutants are routinely monitored at locations within, around, and at longer distances from INL. In 2005, an estimated 6,614 curies of radioactivity were released to the atmosphere from all INL sources (DOE 2005b). The impacts to human health from radiological releases are summarized in Section J.6.11.

Noise emission sources within INL include various industrial facilities, equipment, and machines (e.g., coolant systems, transformers, engines, pumps, boilers, steam vents, pager systems, construction equipment and materials-handlers, and vehicles). Most INL industrial facilities are far enough from the site boundary that noise levels from these sources are not measurable or are barely distinguishable from background levels at the boundary (DOE 2005b).

\section{J.6.5 Water Resources}

INL is in the Mud Lake-Lost River Basin (also known as the Pioneer Basin). This closed drainage basin includes three main streams, the Big and Little Lost Rivers and Birch Creek. These three streams are essentially intermittent and drain the mountain areas to the north and west of INL, although most flow is diverted for irrigation in the summer months before it reaches the site boundaries. Flow that reaches INL infiltrates into the ground surface along the length of the streambeds in the spreading areas at the southern end of INL and, if the streamflow is 
sufficient in the ponding areas (playas or sinks), in the northern portion of INL. During dry years, there is little or no surface water flow on the INL site.

The Snake River Plain Aquifer, which lies below INL, extends from near the western boundary of Yellowstone National Park in eastern Idaho to the Idaho-Oregon border where the Snake River enters Hells Canyon. The Snake River Plain Aquifer is the most widely used source of water for drinking and agriculture in southern Idaho (Roback et al. 2001). This aquifer has been designated a Sole Source Aquifer by Environmental Protection Agency (EPA). Water storage in the aquifer is estimated at some 2 billion acre $\mathrm{ft}\left(2.47 \times 10^{12} \mathrm{~m}^{3}\right)$, and irrigation wells can yield $7,000 \mathrm{gal} / \mathrm{min}(26,498 \mathrm{~L} / \mathrm{min})(\mathrm{DOE} 2002 \mathrm{e})$. The aquifer is composed of numerous relatively thin basalt flows with interbedded sediments extending to depths in excess of 3,500 ft (1,067 m) below land surface (DOE 2005b).

The U.S. Geological Survey has estimated that the thickness of the active portion of the Snake River Plain Aquifer at INL ranges between 250 to $820 \mathrm{ft}$ (76 to $250 \mathrm{~m}$ ). Depth to the water table ranges from about $200 \mathrm{ft}(61 \mathrm{~m})$ below land surface in the northern part of the site to more than $900 \mathrm{ft}(274 \mathrm{~m})$ in the southern part (Ackerman et al. 2006). Depth to water at the proposed site is $475 \mathrm{ft}(145 \mathrm{~m})($ DOE 1989a).

Average groundwater consumption during 2004 was 1.6 billion gal/yr (6.1 billion L/yr). This amount of water represents less than 1 percent of the groundwater that flows underneath INL (ATSDR 2004). Since 1950, DOE has held a Federal Reserved Water Right for the INL site that permits a pumping capacity of approximately $80 \mathrm{ft}^{3} / \mathrm{sec}$. Total groundwater withdrawal at INL historically averages between 15 and 20 percent of that permitted amount (DOE 2002e).

\section{J.6.6 Geology and Soils}

INL occupies a relatively flat area on the northwestern edge of the Eastern Snake River Plain, part of the Eastern Snake River Plain Physiographic Province. The area consists of a broad plain that has been built up from the eruptions of multiple flows of basaltic lava over the past 4 million years. The proposed site is fairly level to gently sloping, with some areas of moderate slope due to basalt rock outcroppings. Elevations on the proposed site range from 4,900 to 5,000 ft (1,493 to $1524 \mathrm{~m})$. Generally, the terrain slopes toward the Big Lost River.

The upper 0.6 to $1.2 \mathrm{mi}$ ( 1.0 to $1.9 \mathrm{~km}$ ) of the crust beneath INL is composed of a sequence of Quaternary age (recent to 2 million years old) basalt lava flows and poorly consolidated sedimentary interbeds collectively called the Snake River Group. The lava flows at the surface range from 2,100 to 2 million years old. The sediments are composed of fine-grained silts that were deposited by wind; silts, sands, and gravels deposited by streams; and clays, silts, and sands deposited in lakes such as Mud Lake and its much larger ice-age predecessor, Lake Terreton. The accumulation of these materials in the Eastern Snake River Plain has resulted in the observed sequence of interlayered basalt lava flows and sedimentary interbeds (DOE 2005b).

The Arco Segment of the Lost River Fault is thought to terminate about $4.3 \mathrm{mi}(6.9 \mathrm{~km})$ from the INL boundary, and approximately $22 \mathrm{mi}(35 \mathrm{~km})$ west of the proposed site. The Howe Segment of the Lemhi Fault terminates near the northwest boundary of INL, and approximately $17 \mathrm{mi}$ $(27 \mathrm{~km})$ northwest of the proposed site (DOE 2005b). Both segments are considered capable or 
potentially active. A capable fault is one that has had movement at or near the ground surface at least once within the past 35,000 years, or recurrent movement within the past 500,000 years (10 CFR Part 100).

Based on the maximum considered earthquake ground motions, INL is located in a broadly defined region of low and moderate to high seismicity. Ground motions in these regions are controlled by earthquake sources that are not well defined, with estimated maximum earthquake magnitudes having relatively long return periods.

Basaltic volcanic activity occurred from about 2,100 to 4 million years ago in the INL site area. Although no eruptions have occurred on the Eastern Snake River Plain during recorded history, lava flows of the Hell's Half Acre lava field erupted near the southern INL boundary as recently as 5,400 years ago. The most recent eruptions within the area occurred about 2,100 years ago, $19 \mathrm{mi}(31 \mathrm{~km})$ southwest of the site at the Craters of the Moon Wilderness Area. The estimated recurrence interval for volcanism associated with the five identified volcanic zones ranges from 16,000 to 100,000 years (DOE 2005b).

Within INL, mineral resources include sand, gravel, pumice, silt, clay, and aggregate (e.g., sand, gravel, and crushed stone). These resources are extracted at several quarries or pits at INL and used for road construction and maintenance, new facility construction and maintenance, waste burial activities, and ornamental landscaping. The geologic history of the Eastern Snake River Plain makes the potential for petroleum production at INL very low. The potential for geothermal energy exists at INL and in parts of the Eastern Snake River Plain; however, a study conducted in 1979 identified no economic geothermal resources (DOE 2005b).

Four basic soilscapes exist at INL: river-transported sediments deposited on alluvial plains, finegrained sediments deposited into lake or playa basins, colluvial sediments originating from bordering mountains, and wind-blown sediments over lava flows. The surface soils at the proposed site are shallow with numerous basalt outcrops. Malm sandy loam, Matheson sandy loam, bondfarm sandy loam, Matheson loamy sand, and Malm loamy sand comprise most of the soils at the proposed site. Basalt bedrock was typically encountered at depths ranging from 1.5 to $4 \mathrm{ft}(0.5$ to $1 \mathrm{~m})$ (DOE 2005b).

\section{J.6.7 Biological Resources}

INL lies in a cool desert ecosystem dominated by shrub-steppe communities. Most land within the site is relatively undisturbed and provides important habitat for species native to the region. Facilities and operating areas occupy 2 percent of INL; approximately 60 percent of the area around the periphery of the site is grazed by sheep and cattle. Although sagebrush communities occupy about 80 percent of INL, a total of 20 plant communities have been identified. These communities may be grouped into six basic types: juniper woodland, grassland, shrub-steppe (which consists of sagebrush-steppe and salt desert shrubs), lava, bareground-disturbed, and wetland vegetation (DOE 2005b). Similar to most of INL, vegetation at the proposed site is dominated by big sagebrush vegetation associations (DOE 1989a). 
The interspersion of low sagebrush (Artemisia arbuscula) and big sagebrush (Artemisia tridentate) communities in the northern portion of INL and juniper communities in the northwestern and southeastern portions of the site are considered sensitive habitats.

Large wildfires in 1994, 1995, 1996, 1999, 2000, and 2007 played an important role in the ecology of INL. The most recent fires burned about 36,000 acres (14,568 ha) in the summer and early fall of 2000 (DOE 2005b). Of particular concern is the loss of sagebrush. This plant is slow to regenerate since it must grow from seed, whereas many other plant species regenerate from underground root systems. The slow recovery of sagebrush is likely to have a detrimental impact on greater sage grouse (DOE 2005b).

INL supports numerous animal species, including two amphibian, 11 reptile, 225 bird, and 44 mammal species. Common animals on the site include short-horned lizards (Phrynosoma douglassi), gopher snakes (Pituophis melanoleucus), sage sparrows (Amphispiza belli), Townsend's ground squirrels (Spermophilus townsendii), and black-tailed jackrabbits (Lepus californicus). Important game animals include the greater sage grouse, mule deer (Odocoileus hemionus), elk (Cervus elaphus), and pronghorn (DOE 2005b).

Aquatic habitat on INL is limited to the Big Lost River, Little Lost River, Birch Creek, and a number of liquid waste disposal ponds. All three streams are intermittent and drain into four sinks in the north-central part of the site. Six species of fish have been observed within water bodies located onsite. Species observed in the Big Lost River include brook trout (Salvelinus fontinalis), rainbow trout (Salmo gaidneri), mountain whitefish (Prosopium williamsoni), speckled dace (Rhinichthys osculus), shorthead sculpin (Cottus confuses), and kokanee salmon (Oncorhynchus nerka) (DOE 2005b).

Twenty Federal- and state-listed threatened, endangered, and other special status species occur, or possibly occur on INL. Federally-listed plants and animals include 2 threatened, one candidate, and ten species of concern. No critical habitat for threatened or endangered species, as defined in the Endangered Species Act, exists on INL.

National Wetland Inventory maps prepared by the U.S. Fish and Wildlife Service (USFWS) have been completed for most of INL. These maps indicate that the primary wetland areas are associated with the Big Lost River, the Big Lost River spreading areas, and the Big Lost River sinks, although smaller (less than about 1 acre) isolated wetlands also occur intermittently. Wetlands associated with the Big Lost River are classified as riverine/intermittent, indicating a defined stream channel with flowing water during only part of the year (DOE 2006r).

\section{J.6.8 Cultural and Paleontological Resources}

Archaeological investigations conducted in southeastern Idaho have provided evidence of human use of the Eastern Snake River Plain for at least 15,000 years (INL 2006). Prehistoric resources identified at INL are generally reflective of Native American hunting and gathering activities. At least 688 prehistoric sites and 753 prehistoric isolates have been located, and known resources are concentrated along the Big Lost River and Birch Creek, atop buttes, and within craters and caves (DOE 2005a). Resources include residential bases, campsites, caves, hunting blinds, rock 
alignments, and limited activity locales such as lithic and ceramic scatters, isolated hearths, and concentrations of fire-cracked rock. Most known sites at INL have not been formally evaluated for nomination to the National Register of Historic Places (NRHP), but are considered to be potentially eligible. Given the rather high density of prehistoric sites at INL, additional sites are likely to be identified as more surveys are conducted (DOE 2005a).

Historic resources found at INL are representative of European-American activities, including fur trapping and trading, immigration, transportation, mining, agriculture, and homesteading, as well as more recent military and scientific/engineering research and development activities (DOE 2005b).

The INL is located within the aboriginal territory of the Shoshone and Bannock peoples. These two groups of nomadic hunters and gatherers used the region at the time of European-American contact for harvesting plant and animal resources and collecting obsidian from Big Southern Butte and Howe Point (DOE 2005a), among other uses. Because the INL site is considered part of the Shoshone-Bannock Tribes' ancestral homeland, it contains many localities that are important for traditional, cultural, educational, and religious reasons (DOE 2005b).

Surveys for paleontological remains outside of and within INL boundaries have identified several fossils that suggest the region contains abundant and varied paleontological resources, including vertebrate and invertebrate animals, plants, and pollen. No paleontological localities have been identified within the proposed project area. The north and northwest margins of the proposed project area level out across the Big Lost River floodplain, where Pleistocene vertebrate fossils have been discovered near the surface and in deeply buried sand and gravel deposits. The potential for encountering surface or buried paleontological remains in the project area is characterized as low to moderate (DOE 2005b).

\section{J.6.9 Socioeconomics}

Approximately 8,000 people work at the INL Site. The state and local government, retail trade, and healthcare and social assistance sectors employed the greatest number of workers in the region of influence (ROI) during 2004 (BEA 2006a, TtNUS 2006a). The labor force in the ROI increased 27.2 percent from 1990 to 2005 (BLS 2005b, TtNUS 2006a). In comparison, for the same period, the state-wide labor force in Idaho increased 49.5 percent. Between 1990 and 2005, the ROI population grew from 192,359 to 235,330, an increase of 22.3 percent (USCB 1990, USCB 2007a, TtNUS 2006a). This was a slower rate of growth than for the state of Idaho, which grew at a rate of 42 percent during the same time period.

\section{J.6.10 Environmental Justice}

Census data for Idaho characterizes 0.4 percent of the population as Black or African American; 1.4 percent American Indian or Alaskan Native; 0.9 percent Asian; 0.1 percent Native Hawaiian or other Pacific Islander; 4.2 percent some other race; 2.0 percent multi-racial (two or more races); 9.0 percent aggregate of minority races; and 7.9 percent Hispanic ethnicity (USCB 2007a). 
Based on the "more than 20 percent" or the "exceeded 50 percent" criteria, no Black or African American, Native Hawaiian or Other Pacific Islander, Asian, or Multi-racial minority block groups exist in the geographic area (TtNUS 2006a). Five American Indian or Alaskan Native block groups, three Some Other Race, six Aggregate, and five Hispanic block groups are found within the $50 \mathrm{mi}(80 \mathrm{~km})$ radius. Also within this area, two block groups have a significant percentage of low-income households (TtNUS 2006a).

\section{J.6.11 Public and Worker Health and Safety}

Releases of radionuclides to the environment from INL operations provide a source of radiation exposure to individuals in the vicinity of INL. These doses fall within the radiological limits given in DOE Order 5400.5 (DOE O 5400.5), Radiation Protection of the Public and the Environment, and are much lower than those of background radiation.

INL workers receive the same dose as the general public from background radiation, but they also receive an additional dose from working in facilities with nuclear materials. These doses fall within the radiological regulatory limits of 10 CFR Part 835.

The background chemical environment important to human health consists of the atmosphere, which may contain hazardous chemicals that can be inhaled; drinking water, which may contain hazardous chemicals that can be ingested; and other environmental media with which people may come in contact (e.g., soil through direct contact or via the food pathway). Adverse health impacts to the public are minimized through administrative and design controls to decrease hazardous chemical releases to the environment and to achieve compliance with permit requirements. The effectiveness of these controls is verified through the use of monitoring information and inspection of mitigation measures. Health impacts to the public may occur during normal operations at INL via inhalation of air containing hazardous chemicals released to the atmosphere by INL operations. Risks to public health from ingestion of contaminated drinking water or direct exposure are also potential pathways. Workers are protected from hazards specific to the workplace through appropriate training, protective equipment, monitoring, and management controls. INL workers are also protected by adherence to Occupational Safety and Health Administration and EPA occupational standards that limit atmospheric and drinking water concentrations of potentially hazardous chemicals.

\section{J.6.12 Transportation}

Two interstate highways serve the INL regional area. Interstate 15, a north-south route that connects several cities along the Snake River, is approximately $25 \mathrm{mi}(40 \mathrm{~km})$ east of INL. Interstate 86 intersects Interstate 15 approximately $40 \mathrm{mi}(64 \mathrm{~km})$ south of INL and provides a primary linkage from Interstate 15 to points west. U.S. Highways 20 and 26 are the main access routes to the southern portion of INL and the Materials and Fuels Complex. Idaho State Routes 22, 28, and 33 all pass through the northern portion of INL, with State Routes 22 and 33 providing access to the northern INL facilities.

The Union Pacific Railroad's Blackfoot-to-Arco Branch crosses the southern portion of INL and provides rail service to the site. There are $30 \mathrm{mi}(48 \mathrm{~km})$ of railroad track at INL (DOE 2002e). 


\section{J.6.13 Waste Management}

INL generates various waste streams during ongoing activities including routine operations and cleanup action, and stores wastes generated by past activities. INL manages the following types of waste: high-level, low-level radioactive, mixed low-level radioactive, transuranic, hazardous, sanitary solid, wastewater, and sanitary sewage. The waste is managed using appropriate treatment, storage, and disposal technologies, and in compliance with all applicable Federal and State statutes and DOE Orders (DOE 2005a).

EPA placed INL on the National Priorities List on December 21, 1989. In accordance with the Comprehensive Environmental Response, Compensation, and Liability Act (CERCLA), DOE entered into a consent order with EPA and the state of Idaho to coordinate cleanup activities at INL under the 1995 Settlement Agreement (42 U.S.C. 9610).

Under the 1995 Settlement Agreement, the state of Idaho, U.S. Navy, and DOE reached agreement settling a lawsuit filed by the state to prevent shipment of spent nuclear fuel to the INL for storage. This agreement integrates DOE's CERCLA response obligations with Resource Conservation and Recovery Act (RCRA) corrective action obligations (40 CFR Parts 239-299). Clean up activities at INL are under the oversight of EPA Region 10 and the Idaho Department of Environmental Quality. 


\section{J.7 LeA County Site}

This section presents a summary of the affected environment for the Lea County site. The information was summarized from the Site Characterization Report prepared by the Funding Opportunity Announcement (FOA) grant recipient (SCR 2007d).

\section{J.7.1 Land Use}

The site is located in southeastern New Mexico in Lea County, 32 miles (mi) (51 kilometers $[\mathrm{km}])$ east of Carlsbad, New Mexico, and $34 \mathrm{mi}(55 \mathrm{~km})$ west of Hobbs, New Mexico. The site is comprised of 1,040 acres (421 hectares [ha]) of patented land spread across three section of land running west to east. The area surrounding the site is Bureau of Land Management (BLM) land and two small parcels of state land. The surface estate is privately owned, and the subsurface minerals are owned by the state of New Mexico. The nearest residents to the site are located at the Salt Lake Ranch, $1.5 \mathrm{mi}(2.4 \mathrm{~km})$ north of the site. There are several existing right-of-ways (ROW) in the site. These existing ROW include pipelines, roads, well pads, power lines, telephone lines, and a communications tower.

Intrepid Mining, LLC owns both mines located within $6 \mathrm{mi}(10 \mathrm{~km})$ of the site. Mineral extraction in the area consists of underground potash mining and oil/gas extraction. Both industries support major facilities on the surface, although mining surface facilities are confined to a fairly small area. The Intrepid North mine, located to the west, is no longer actively mining potash underground. However, the surface facilities are still being used in the manufacture of potash products. The Intrepid East facility is still mining its underground potash ore.

\section{J.7.2 Visual Resources}

The following are situated at the site

- A communications tower in the southwest corner of the site;

- A producing gas and distillate well with associated tank battery is located near the communications tower;

- A small water drinker (livestock) is located along the aqueduct in the northern half of the property;

- $\quad$ Oil recovery facility (abandoned) that still has tanks and associated hardware left in place in the northeast corner; and

- An oil recovery facility with tanks and associated hardware still in place in the far southeast corner.

\section{J.7.3 Site Infrastructure}

Oil and gas extraction provides most of the activity in the vicinity. Roads are built and maintained to provide access to the various wells. Pipelines are installed to move the product efficiently from one area to the next. Where pipelines are not used, access for heavy trucks to haul the oil and produce water is required. Compressor stations are needed to pump the product through the pipelines. Electric power is required at the individual well pads to provide the 
electricity necessary to operate the pumps, compressors, and other equipment as needed. There are two major facilities related to oil/gas activity in the area. The Zia Gas Plant is located northwest of the site, while Controlled Recovery Incorporated is southwest of the site.

\section{J.7.4 Air Quality and Noise}

The climate at the site and the surrounding region is characterized as that of semi arid region with generally mild temperatures, low precipitation and humidity, and a high evaporation rate. The average precipitation in Hobbs is 18.5 inches (in) (47.0 centimeters [cm]) annually. The average temperature is $62.2^{\circ} \mathrm{F}\left(16.7^{\circ} \mathrm{C}\right)$. The annual mean wind speed was 11.0 miles per hour $(\mathrm{mi} / \mathrm{hr})(17.6$ kilometers per hour $[\mathrm{km} / \mathrm{hr}])$ and the prevailing wind direction was wind from 180 degrees with respect to True North.

One exceedance of the national ambient air quality standards (NAAQS) maximum 24-hour limit was reported in Hobbs, New Mexico, for particulate matter in 2003 due to a natural event-a dust storm. Corrective actions were taken by the state of New Mexico. According to NAAQS, one exceedance of this limit is allowed per year. Based on U.S. Environmental Protection Agency (EPA) information (EPA 2007a), the entire region within $50 \mathrm{mi}(80 \mathrm{~km})$ of the site is in an attainment area for all of the criteria pollutants.

There are no existing facilities at the Lea County site resulting in increased noise levels.

\section{J.7.5 Water Resources}

There are no potable surface water resources within the vicinity of the site. Surface drainage at the site is contained within two local playa lakes that have no external drainage. The only major natural lakes or ponds within $6 \mathrm{mi}(10 \mathrm{~km})$ of the site include Laguna Gatuna, Laguna Tonto, Laguna Plata, and Laguna Toston which are ephemeral playas. Surface runoff from the site flows into Laguna Gatuna to the east and Laguna Plata to the northwest (SCR 2007d). The site lies within the Pecos River Basin, which has a maximum basin width of $130 \mathrm{mi}(209 \mathrm{~km})$, and a drainage area of 44,535 square miles $\left(\mathrm{mi}^{2}\right)\left(71,672\right.$ square kilometers $\left.\left[\mathrm{km}^{2}\right]\right)$. The Pecos River generally flows year-round. Seventy-five percent of the total annual precipitation and 60 percent of the annual flow result from intense local thunderstorms between April and September. Water quality in the Pecos River basin is affected by mineral dissolution from natural sources and from irrigation return flows. The site is not located in any 100 year or 500 year floodplain.

The site is located in the Lea County Underground Water Basin (UWB). Evapo-transpiration at the site is five times the precipitation rate, indicating that there is little infiltration of precipitation into the subsurface. Groundwater encountered on the east side of the site is brackish, exceeding 10,000 parts per million in total dissolved solids which is the New Mexico regulatory threshold (NM Water Quality Control Commission Regulations, 20.6.2.3101A) for protected water. Regional data indicates that groundwater is on the order of 300 to 400 feet (ft) (91 to 122 meters [m]) deep (WQCC 2002).

Potable water for the area is generally obtained from potash company pipelines that convey water to area potash refineries from the Ogallala High Plains aquifer on the caprock area of 
eastern Lea County. Much of the shallow groundwater near the site has been directly or indirectly influenced by brine discharges from potash refining or oil and gas production. The High Plains Aquifer in the Ogallala Formation contains 3.270 billion acre-feet (4.03 trillion $\mathrm{m}^{3}$ ) of water and underlies $174,050 \mathrm{mi}^{2}\left(450,787 \mathrm{~km}^{2}\right)$ in parts of eight states. The volume of recoverable water in the New Mexico portion of the aquifer is on the order of 50 million acre feet $\left(61.67\right.$ billion $\left.\mathrm{m}^{3}\right)$. It is estimated that the Lea County portion of the High Plains Aquifer contains $14,000,000$ acre feet of recoverable water.

The City of Carlsbad owns and operates Double Eagle Water System, located near Maljamar in northwestern Lea County. The Double Eagle Water System is supplied by groundwater pumped from 11 wells completed in the Ogallala Formation. The first $16 \mathrm{mi}(26 \mathrm{~km})$ segment of the pipeline carrying water from these wells to the Waste Isolation Pilot Plant (WIPP) facility has a 24 in $(61 \mathrm{~cm})$ diameter and runs to Highway 62/180.

The Double Eagle Water Resource System is $3 \mathrm{mi}(5 \mathrm{~km})$ west of the site. The City of Carlsbad has indicated that the Double Eagle water line near the site is capable of delivering 6,000 gallons per minute $(22,712$ liters per minute). This equates to over $8,000,000$ gallons of water per day (30,283,290 liters per day). The City of Carlsbad is in the process of modeling the Double Eagle system to determine what upgrades are needed for future users.

\section{J.7.6 Geology and Soils}

The entire site is underlain by Triassic bedrock consisting of shale, siltstone, and minor, finegrained, poorly sorted sandstone. Most of the proposed operational area is relatively flat and the shale bedrock is covered by a laterally extensive veneer of $25 \mathrm{ft}(8 \mathrm{~m})$ of Quaternary sediment deposits consisting of well sorted eolian sand and sandy-gravelly materials near the bedrock interface.

The site is located in the northern portion of the Delaware Basin, a northerly-trending, southward plunging asymmetrical trough with structural relief of greater than $20,000 \mathrm{ft}(6,096 \mathrm{~m})$ on top of the Precambrian. The Basin was formed by early Pennsylvanian time, followed by major structural adjustment from Late Pennsylvanian to Early Permian time. Regional eastward tilting of the Basin occurred much later in the Cenozoic era.

Tectonic activity in the Basin is characterized by slow uplift relative to surrounding areas which has resulted in erosion and dissolution of rocks in the Basin. Faulting has not occurred in the northern Delaware Basin in the area of the site. The regional geology suggests that there have been no recent, dramatic changes in geologic processes and rates in the vicinity of the site.

The USGS shows that the Guadalupe fault is located $80 \mathrm{mi}(129 \mathrm{~km})$ west of the site. Little is known about this fault except that it is a normal fault, $3.6 \mathrm{mi}(5.8 \mathrm{~km})$ in length, and has a slip rate of less than $0.01 \mathrm{in} / \mathrm{yr}$. The Guadalupe fault forms a scarp on unconsolidated Quaternary deposits at the western base of the Guadalupe Mountains in the Basin and Range physiographic province. 


\section{J.7.7 Biological Resources}

The site does not support any vegetation of significance. The site is located primarily (roughly 98 percent) in an environment of Simona-Tonuca soils and includes varying combinations of sand, fine sands, loam, and gravel. The soil type affects the depth to which roots can grow and thus, the vegetative species in the area. The vegetation community for the site is Desert Grassland which contains both prairie grasses and shrubs and provides food and cover for specific types of wildlife.

There are three species considered "Species of Concern" within the habitat near the site. These include the Lesser Prairie Chicken (Tympanuchus pallidicinctus), the Sand Dune Lizard (Sceloporus aerinicolus), and Gypsum wild-buckwheat (Eriogonum gypsophilum). These species have not been located within the site and regulatory reviews and field inspections do not support the belief that they are present within the site.

There are no wetlands or unique habitats for threatened or endangered plant or animal species on the site.

\section{J.7.8 Cultural and Paleontological Resources}

Only three archaeological sites (LA 22116, 89675, and 89676) have been recorded within or immediately adjacent to the site. LA 22116, a non-structural site measuring 7.4 acres (2.9 ha) was identified in 1979 by New Mexico State University (NMSU). It contains fire-cracked rock and lithic debitage (the waste from tool manufacture), but is of unknown cultural and temporal affiliation. LA 89675 is a 7.4 acre (2.9 ha) non-structural Mogollon site dated at A.D. 750-1175. LA 89676 is of unknown cultural and temporal affiliation, measures 7.4 acres (2.9 ha), and contains fire-cracked rock and lithic debitage. These sites were identified in 1992.

The $6 \mathrm{mi}(10 \mathrm{~km})$ zone around the site contains 211 previously recorded archaeological sites.

\section{J.7.9 Socioeconomics}

Statistics for population, housing, and local transportation are presented for the region of influence, a three-county area in New Mexico, consisting of Chaves, Eddy and Lea Counties. The number of people that are covered within the $50 \mathrm{mi}(80 \mathrm{~km})$ radius indicates that approximately 20,000 people reside within $30 \mathrm{mi}(48 \mathrm{~km})$ of the site. Extending the radius another three miles captures an additional 30,000 people. More than 100,000 people reside just over $40 \mathrm{mi}(64 \mathrm{~km})$ from the site. The areas within the $30 \mathrm{mi}(48 \mathrm{~km})$ radius of the project are sparsely populated. The cities and urban areas in the study area are more than $30 \mathrm{mi}(48 \mathrm{~km})$ away. Altogether, approximately 115,000 people reside in the study area.

From 1990 to 2000, the study area population increased by almost four percent or approximately 4,200 people. The assumption is that the compound annual average growth rate experienced during the period July 1, 2001 to July 1, 2005 continues into the future. For the very near future the population projections should be useful. However, projections need to be updated every 3 to 
5 years, especially for places like southeastern New Mexico that are undergoing rapid economic and demographic change.

\section{J.7.10 Environmental Justice}

The preliminary conclusion is that although there are census tracts within the $50 \mathrm{mi}(80 \mathrm{~km})$ radius that have minority percentages exceeding 64 percent, they are confined to the urban areas which are at least $30 \mathrm{mi}(48 \mathrm{~km})$ from the site.

From 1990 to 2000, the Hispanic population in the study area increased by 26 percent. In comparison, the overall study area population increased by only four percent. The younger age groups are represented by minority and Hispanic individuals while the older age groups are primarily Anglos or White Not Hispanic. The minority population comprised approximately 60 percent of the population who were younger than 10 years old and greater than 50 percent among the 10-19 years old.

\section{J.7.11 Public and Worker Health and Safety}

There are currently no existing facilities or structures on the site to contribute radiological or hazardous chemical contaminants to the environment. The closest facilities with the potential to contribute radiological or hazardous chemical contaminants are the Waste Isolation Pilot Plant (WIPP) and the National Enrichment Facility (NEF). The WIPP is located approximately $37 \mathrm{mi}$ $(60 \mathrm{~km})$ southwest of the proposed GNEP sites, while the NEF is approximately $40 \mathrm{mi}(64 \mathrm{~km})$ southeast.

\section{J.7.12 Transportation}

The nearest transportation route to the site is U.S. Highway $62 / 180(0.5 \mathrm{mi}$ to the south $[0.8 \mathrm{~km}]$ ), which is the major route between Carlsbad and Hobbs, New Mexico. The nearest Interstate Highway is Interstate 20, $95 \mathrm{mi}(153 \mathrm{~km})$ to the southeast in Odessa, Texas.

Two railroads service the area. One railroad company operates to the west of the site and the other to the east. Southwestern Railroad operates the Burlington Northern-Santa Fe (BNSF) Carlsbad Subdivision (Carlsbad to Clovis, New Mexico, plus industrial spurs serving potash mines east of Carlsbad and east of Loving, New Mexico) under a lease agreement.

\section{J.7.13 Waste Management}

There are currently no existing facilities or structures on the Lea County site; therefore, no waste is produced and no waste management services provided. 

This section presents a summary of the affected environments for the Oak Ridge Reservation (ORR) and Oak Ridge National Laboratory (ORNL).

\section{J.8.1 Land Use}

ORR was established in 1943 as one of the three original Manhattan Project sites. It is located on 33,718 acres $(13,645$ hectares [ha]) in Oak Ridge, Tennessee, and includes ORNL, the Y-12 National Security Complex (Y-12), and the East Tennessee Technology Park (ETTP).

Land use at the ORR site includes industrial, mixed industrial, institutional/research, institutional/environmental laboratory, Black Oak Ridge Conservation Easement, and mixed research/future initiatives. Land within the mixed research/future initiative category includes land that is used or available for use in field research and land reserved for future U.S. Department of Energy (DOE) initiatives. Most mixed research and future initiatives areas are forested. Undeveloped forested lands on ORR are managed for multiple uses. Although soils that would be identified as prime farmland occur on the site, that designation is waived because they are within the city of Oak Ridge (DOE 2000g). Only a small fraction of ORR has been disturbed by Federal activities, including the construction and operation of facilities, roadways, or other structures (DOE 2005b).

The largest mixed use is biological and ecological research in the Oak Ridge National Environmental Research Park (ORNERP), which is on 20,000 acres (8,094 ha). The National Environmental Research Park, established in 1980, is used by the Nation's scientific community as an outdoor laboratory for environmental science research on the impact of human activities on the eastern deciduous forest ecosystem (DOE 2000g, DOE 2005b).

ORNL is primarily located within Bethel Valley between Haw and Chestnut Ridges, and covers 4,250 acres (1,720 ha) of land. The site is classified as an industrial area that encompasses a number of facilities dedicated to energy research. Lands bordering ORNL and ORR are predominantly rural and are used primarily for residences, small farms, forest land, and pasture land. The city of Oak Ridge, Tennessee, has a typical urban mix of residential, public, commercial, and industrial land uses. It also includes almost all of ORR (DOE 2000g, DOE 2005b).

The landscape at ORR is characterized by a series of ridges and valleys that trend in a northeastto-southwest direction. The vegetation is dominated by deciduous forest mixed with some coniferous forest.

\section{J.8.2 Visual Resources}

The surrounding area consists mainly of rural land. Sensitive viewpoints affected by DOE facilities are primarily associated with Interstate 40, State Highways 58, 62, and 95, and Bethel Valley and Bear Creek Roads. The Clinch River/Melton Hill Lake, and the bluffs on the opposite side of the Clinch River also have views of ORR, but views of most of the existing DOE 
facilities are blocked by terrain and/or vegetation. Although only a small portion of State Highway 62 crosses ORR, it is a major route for traffic to and from Knoxville and other communities. The hilly terrain, heavy vegetation, and generally hazy atmospheric conditions limit views (DOE 2005b).

While a large part of ORNL is visible from Bethel Valley Road, it is not visible to persons in offsite locations because of the presence of the Haw and Chestnut Ridges.

\section{J.8.3 Site Infrastructure}

ORNL contains $217 \mathrm{mi}(349 \mathrm{~km})$ of improved roadways, including $37 \mathrm{mi}(59.5 \mathrm{~km})$ of paved roads. Two main branches provide rail service to the ORR (DOE 2005b).

Electrical power is supplied to ORNL and ORR by the Tennessee Valley Authority. Two transmission lines supply ORNL and vicinity. Total electrical energy availability to ORR from the Tennessee Valley Authority grid is 13,880,000 megawatt-hours per year. Total electrical energy consumption across ORR is about 726,000 megawatt-hours annually (DOE 2005b).

The Duke Energy Company supplies natural gas to ORNL. This company owns, operates, and maintains the main line and the three pressure-reduction stations that comprise the supply system to ORR. The system is designed with more capacity than is now demanded. However, contractual agreements do limit the amount of gas ORNL can demand (DOE 2005b).

Water for ORNL is taken from the Clinch River south of the eastern end of the Y-12 National Security Complex and pumped to the water treatment plant located on the ridge northeast of the Y-12 Plant. The treatment plant is owned and operated by the City of Oak Ridge and can supply water at a potential rate of 24 million gallons (gal)/day (991.8 million liters ([L]/day) to two storage reservoirs with a combined capacity of 7 million gal (26.5 million L). Water from the two reservoirs is distributed to the Y-12 Plant, ORNL, and the City of Oak Ridge (ORNL 2002).

\section{J.8.4 Air Quality and Noise}

ORNL is located entirely within Anderson County. The Environmental Protection Agency (EPA) has designated Anderson County as a basic non-attainment area for the 8-hour ozone standard, as part of the larger Knoxville basic 8-hour ozone non-attainment area that encompasses several counties, and for $\mathrm{PM}_{2.5}$. For all other criteria pollutants for which EPA has made attainment designations, existing air quality in the greater Knoxville and Oak Ridge areas is in attainment with the National Ambient Air Quality Standards (NAAQS) (DOE 2006e).

Average radionuclide concentrations measured for the ORNL network were less than 1 percent of the applicable derived concentration guides (DCGs) in all cases (DOE 2006e).

ORNL holds a Title V permit that covers ten emission sources and a separate Title V permit for Environmental Management (EM) activities. No permit limits were exceeded in 2005. Cumulative actual criteria pollutant emissions from ORNL in 2004 were roughly one-thirtieth of the actual emissions from the Y-12 site. Current ORNL emissions would therefore have only a minor affect on regional criteria pollutant concentrations (DOE 2006e). 
Radioactive airborne discharges at ORNL consist primarily of ventilation air from radioactively contaminated areas, vents from tanks and processes, and ventilation for hot cell operations and reactor facilities. These airborne emissions are treated and then filtered with high-efficiency particulate air filters or charcoal filters before discharge (DOE 2006e).

Radiological airborne emissions from ORNL include solid particulates, absorbable gases (e.g., iodine), tritium, and nonadsorbable gases (e.g., noble gases). The major radiological emission point sources for ORNL include five stacks located in Bethel and Melton Valleys (DOE 2006e).

Noise emission sources within ORNL include various industrial facilities, equipment, and machines (e.g., coolant systems, transformers, engines, pumps, boilers, steam vents, pager systems, construction equipment and materials-handlers, and vehicles). Most ORNL industrial facilities are far enough from the residential or commercial areas that noise levels from these sources are not measurable or are barely distinguishable from background levels. The most significant noise to nearby off-site receptors is due to traffic noise along State Highway 95 generated by personal vehicles and trucks that travel to and from ORNL (DOE 2005b).

Existing ORNL-related noises of public significance result from the transportation of people and materials to and from the site and in-town facilities primarily via private vehicles and trucks. A site-specific survey has not been conducted, but ambient noise levels in a rural environment such as the ORNL site boundary are typically in the $35-45 \mathrm{~dB}$ range (DOE 2005b).

\section{J.8.5 Water Resources}

The major surface water feature in the immediate vicinity of ORNL is the Clinch River, which borders ORR to the south and west. There are four major subdrainage basins on ORR that flow into the Clinch River and are affected by site operations: Poplar Creek, East Fork Poplar Creek, Bear Creek, and White Oak Creek.

The Clinch River and connected waterways supply raw water for ORNL. The ORR water supply system, which includes the city of Oak Ridge treatment facility (formerly the DOE treatment facility) and the East Tennessee Technology Park (ETTP) treatment facility, has a capacity of 24 to 32.1 million gal/day (90.8 to 121.5 million L/day) (DOE 2000g).

The Tennessee Valley Authority has conducted flood studies along the Clinch River, Bear Creek, and East Fork Poplar Creek, and has also performed probable maximum flood studies along the Clinch River. Based on the studies, most of ORNL is above the probable maximum flood elevation along the Clinch River (DOE 2000g).

The Clinch River is the only surface water body near ORNL classified for domestic water supply. In addition, the Clinch River and a short segment of Poplar Creek from its confluence with the Clinch River are also classified for industrial water supply use.

White Oak Creek and Melton Branch are the only streams not classified for irrigation. East Fork Poplar Creek is posted by the state of Tennessee with warnings against fishing and contact recreation (DOE 2000g). Wastewater treatment facilities are located throughout ORR, including 
six treatment facilities at $\mathrm{Y}-12$ that discharge to East Fork Poplar Creek, and three treatment facilities at ORNL that discharge into White Oak Creek Basin.

These discharge points are included in existing National Pollutant Discharge Elimination System (NPDES) permits (DOE 2000b, Hughes et al. 2004). At ORNL, water samples are collected and analyzed from 18 locations around the reservation to assess the impact of past and current DOE operations on the quality of local surface water. Sampling locations include streams, both upstream and downstream of ORNL waste sources, and public water intakes.

Two broad hydrologic units have been identified on the ORR: 1) the Knox Aquifer, which includes the Maynardville Limestone and is highly permeable, and 2) the ORR Aquitards, which consist of the less permeable Rome Formation, Conasauga Group, excluding the Maynardville Limestone, and the Chickamauga Group. Active groundwater flow can occur at substantial depths in the Knox Aquifer (300 to 400 feet (ft) [91.4 to 121.9 meters $\{\mathrm{m}\}]$ deep). The Knox Aquifer is the primary source of groundwater to many streams (base flow), and most large springs on ORR receive discharge from the Knox Aquifer. Because of the abundance of surface water and its proximity to the points of use, very little groundwater is used at ORNL. Industrial and drinking water supplies are primarily taken from surface water sources. However, singlefamily wells are common in adjacent rural areas not served by the public water supply system (DOE 2000g).

Groundwater monitoring at ORNL consists of two components: the DOE Environmental Management and Enrichment Facilities (EMEF) groundwater monitoring program and the DOE Office of Science (OS) groundwater monitoring surveillance program (DOE 2006e). In the current ORNL program, groundwater quality wells are sampled on an annual basis (Hughes et al. 2004).

\section{J.8.6 Geology and Soils}

ORNL is in the southwestern portion of the Valley and Ridge physiographic province in eastcentral Tennessee. The topography consists of alternating valleys and ridges that have a southwest-northeast trend, with most facilities occupying the valleys. The topography reflects the underlying geology, which consists of a sequence of sedimentary rocks deformed by a series of major southeast-dipping thrust faults. The ridges are underlain by relatively erosion-resistant rocks, while weaker rock strata underlie the valleys (DOE 2005b).

Bedrock in the ORNL vicinity is of Early Cambrian (about 570 million years ago) to Ordovician Age (505 to 540 million years ago). The bedrock units encompass a wide variety of lithologies ranging from pure limestone to dolostone to fine sandstone. The total thickness of the stratigraphic section is about 1.6 miles (mi) (2.6 kilometers $[\mathrm{km}])$. Four primary geologic units occur in the area. These include (from oldest to youngest) the Rome Formation, Conasauga Group, Knox Group, and Chickamauga Group (DOE 2005b).

There is no evidence of active capable faults in the Valley and Ridge physiographic province or within the rocks comprising the Appalachian Basin structural feature where ORNL is located. A capable fault is one that has had movement at or near the ground surface at least once within the 
past 35,000 years, or recurrent movement within the past 500,000 years (10 CFR Part 100). The nearest capable faults are approximately $298 \mathrm{mi}(479.6 \mathrm{~km})$ northwest in the New Madrid (Reelfoot Rift) Fault Zone. Historical earthquakes occurring in the Valley and Ridge are not attributable to fault structures in underlying sedimentary rocks, but rather occur at depth in basement rock (DOE 2005b). Numerous studies have been conducted as part of establishing the design-basis earthquake for evaluating and designing new ORR facilities. For this purpose, an earthquake producing an effective peak-ground acceleration of $0.15 \mathrm{~g}$ has been established and calculated to have an annual probability of occurrence of about 1 in 1,000. For comparison, an earthquake with a peak acceleration of $0.32 \mathrm{~g}$ has an annual probability of occurrence of 1 in 5,000 (DOE 2005b).

There is no volcanic hazard at ORNL. The area has not experienced volcanic activity within the last 230 million years (DOE 2005b).

Soils of ORNL are highly disturbed and would be classified as Urban Land. Urban Land includes areas where more than 80 percent of the surface is covered with industrial plants, paved parking lots, and other impervious surfaces (DOE 2005b). While there are soils that would be classified as prime farmland on ORR, that designation is waived within the ORR site boundary (DOE 2005b).

The ORNL main site is underlain primarily by calcareous siltstones and silty-to-clean limestone of the Chickamauga Group. No mineral resources have been identified at the site.

\section{J.8.7 Biological Resources}

Plant communities at ORNL are characteristic of the intermountain regions of central and southern Appalachia; only a small fraction of ORR has been disturbed by Federal activities. A portion of land was set aside for the Black Oak Ridge Conservation Easement, which is managed by the State of Tennessee.

The vegetation of ORR has been categorized into seven plant communities. Although outbreaks of southern pine beetles (Dendroctonus frontalis) killed over 1,100 acres (445 ha) of pine forests in 1994 and 1999 to 2000, pine and pine-hardwood forest is the most extensive plant community on the site. Another abundant community is the oak-hickory forest, which is commonly found on ridges. Northern hardwood forest and hemlock-white pine-hardwood forest are the least common forest community types on the site. Over 1,100 vascular plants species are found on ORR (DOE 2005b, ORNL 2002). ORNL in Melton Valley contains a variety of ecosystems that range from those that are greatly disturbed to some that are relatively undisturbed. Where the valley has been heavily disturbed, the current vegetation cover is primarily grass and weeds. Vegetation of the rest of the valley is typical of forests found throughout ORR. Relatively undisturbed second-growth forests of mixed oak-hickory occur on the ridges and dry slopes, while pine and pine-hardwood on the lower slopes and valleys are typical of abandoned, eroded farmland (DOE 1996a).

According to the ORNERP animal species found on the ORR include 64 amphibians and reptiles, 205 birds, and 34 mammals (USFWS 2007b). Fauna of Melton Valley are typical of 
ORR and include the rat snake (Elaphe obsolete), black racer (Coluber constrictor), red-eyed vireo (Vireo olivaceus), scarlet tanager (Piranga olivacea), red-tailed hawk, red-shouldered hawk (Buteo lineatus), yellow-billed cuckoo (Coccyzus americanus), coyote, deer mouse, eastern gray squirrel (Sciurus carolinensis), southern flying squirrel (Glaucomys volans), and whitetail deer (DOE 2005b).

Aquatic habitat on or adjacent to ORNL and ORR ranges from small, free-flowing streams in undisturbed watersheds to larger streams with altered flow patterns due to dam construction. These aquatic habitats include tailwaters, impoundments, reservoir embayments, and large and small perennial streams. Aquatic areas in ORR also include seasonal and intermittent streams and old farm ponds (DOE 2005b). The minnow family has the largest number of species and is numerically dominant in most streams. Fish species representative of the Clinch River in the vicinity of ORR are shad, herring, common carp (Cyprinus carpio), catfish, bluegill (Lepomis macrochirus), crappie (Pomoxis spp.), and freshwater drum (Aplodinouts grunniens). The most important fish species taken commercially in the ORR area are common carp and catfish. Commercial fishing is permitted on the Clinch River downstream from Melton Hill Dam.

Thirty Federal- and state-listed threatened, endangered, and other special status species have been recently identified on the ORR (ORNERP). Among these are 26 birds, two mammals, one fish, and one amphibian and reptile. The spotfin chub (Cyprinella monnacha), both a Federal and state threatened species, has been sighted and collected in the city of Oak Ridge and is potentially present on the ORR (USFWS 2007b). Approximately 580 acres (235 ha) of wetlands occur on ORR, ranging in size from several square yards to about 25 acres (10 ha) (ORNL 2002). There are six wetlands at ORNL in the vicinity of the Radiochemical Engineering Development Center and the High Flux Isotope Reactor, including one small unclassified wetland; however, none are within the developed area.

\section{J.8.8 Cultural and Paleontological Resources}

At least ten major archaeological reconnaissance surveys have been conducted on the ORR. In 1993, an archaeological field review of the ORNL installation was conducted. In 1994, an intensive architectural and historic survey was conducted for the ORNL complex.

The project area has been assessed as having very low archaeological potential due to moderate to steep terrain, and drainages with low banks and wide floodplains. No historic archaeological resources are located within the ORNL complex, and the likelihood for intact historic archaeological resources is extremely low (Thomason and Associates 2004).

The majority of the geological units with surface exposures at ORR contain paleontological materials consisting primarily of invertebrate remains (DOE 2005b). These types of remains are relatively widespread and common, and as such, have relatively low research potential. Paleontological resources at ORNL would not be expected to differ from those found elsewhere on ORR. 


\section{J.8.9 Socioeconomics}

Socioeconomic characteristics addressed at ORNL include employment, income, population, housing, and community services. These characteristics are analyzed for a four-county region of influence (ROI) consisting of Anderson, Knox, Loudon, and Roane Counties in Tennessee, in which 87.7 percent of all ORNL employees reside.

In 2003, ORNL employed 12,856 persons. The retail trade, state and local government, manufacturing, and healthcare and social assistance, sectors employ the greatest number of workers in the ROI (BEA 2006a and TtNUS 2006c). The retail trade sector provides more than 12 percent of all employment in the ROI, while the state and local government, healthcare and social assistance, and manufacturing sectors provide 11.5, 9.9, and 8.9 percent, respectively. Other important sectors of employment include professional and technical services (7.9 percent), accommodation and food services (7.6 percent), and administrative and waste services (7.1 percent) (BEA 2006a).

The labor force in the ROI increased 21.3 percent from 1990 to 2005 (BLS 2005b, TtNUS 2006c). In comparison, for the same period, the state-wide labor force in Tennessee increased 21.2 percent. Total employment in the ROI increased at a similar rate to the labor force, at 21.9 percent. The unemployment rate in the ROI decreased from 4.9 percent in 1990 to 4.4 percent in 2005. In comparison, the state-wide unemployment rate increased in Tennessee from 5.5 percent in 1990 to 5.6 percent in 2005 (BLS 2005b, TtNUS 2006c).

In 2004, per capita income in the ROI ranged from a high of $\$ 32,040$ in Knox County to a low of $\$ 26,051$ in Roane County (BEA 2006b). In 2004, per capita income in the ROI was $\$ 30,838$, compared to the Tennessee per capita income of $\$ 29,844$ (TtNUS 2006c). Per capita income increased in the ROI by 70.8 percent between 1990 and 2004, compared to a state-wide increase of 78.8 percent in Tennessee (BEA 2006b, TtNUS 2006c).

Between 1990 and 2005, the ROI population grew from 482,481 to 573,678, an increase of 18.9 percent (USCB 1990, USCB 2007f, TtNUS 2006c). This was a slower rate of growth than for Tennessee, which grew at a rate of 22.3 percent, during the same time period.

\section{J.8.10 Environmental Justice}

Census data from the year 2000 was used to determine minority and low-income characteristics by block group within $50 \mathrm{mi}(80 \mathrm{~km})$ of ORNL. Twenty-nine block groups have a significant Black or African American minority population, one census block group has a significant Asian population, and 29 block groups have significant aggregate minority percentages (TtNUS 2006c).

Based on the "more than 20 percent" or the "exceeded 50 percent" criteria, no American Indian or Alaskan Native, Native Hawaiian or Other Pacific Islander, some other race, multi-racial, or Hispanic ethnicity minority block groups exist in the geographic area (TtNUS 2006c). 
Fifty-six census block groups within the $50 \mathrm{mi}(80 \mathrm{~km})$ radius have a significant percentage of low-income households (TtNUS 2006c).

\section{J.8.11 Public and Worker Health and Safety}

An individual's radiation exposure in the vicinity of ORNL amounts to approximately 390 mrem, and is comprised of natural background radiation from cosmic, terrestrial, and internal body sources; radiation from medical diagnostic and therapeutic practices; weapons test fallout; consumer and industrial products; and nuclear facilities. Annual background radiation doses to individuals are expected to remain constant over time. The total dose to the population, in terms of person-rem, changes as the population size changes. Background radiation doses are unrelated to ORNL operations (DOE 2000g).

Releases of radionuclides to the environment from ORNL operations provide another source of radiation exposure to individuals in the vicinity of ORNL. ORNL worker doses have typically been well below DOE worker exposure limits (ORNL 2004a).

The average radiation dose recorded for workers at ORNL with a measurable dose in 2005 was 71 mrem (DOE 2005b). ORNL workers receive the same dose as the general public from background radiation, but they also may receive an additional dose from working in facilities with nuclear materials. These doses fall within the radiological regulatory limits of 10 CFR Part 835. The number of projected latent cancer fatalities (LCFs) among ORR workers from normal operations in 2003 is 0.02 . For the population living within $50 \mathrm{mi}(80 \mathrm{~km})$ of ORNL 0.002 excess fatal cancers are projected from normal ORNL operations.

\section{J.8.12 Transportation}

Vehicles access to ORNL is via three State Routes: State Route 95 forms an interchange with Interstate 40 and enters the reservation from the south approximately $1 \mathrm{mi}(2 \mathrm{~km})$ to the west of ORNL's main complex; State Route 58 enters ORR from the west and passes just south of the East Tennessee Technology Park; and State Route 62 provides access from the east.

The Norfolk Southern main line from Blair provides easy access to the East Tennessee Technology Park. No tracks run to the ORNL (DOE 2005b). ORNL is bordered by the Clinch River on the south, but no barge facility has been developed.

\section{J.8.13 Waste Management}

ORNL generates waste from its ongoing operations and from cleanup and decommissioning and demolition projects. ORNL has 344 sites that are contaminated to the extent that they require monitoring and remediation and the waste quantities from these activities are expected to increase (ORNL 2002). The following types of waste are generated from operations: transuranic (TRU); low-level radioactive; mixed low-level radioactive; hazardous; and nonhazardous including sanitary solid waste, industrial waste and construction debris, sanitary sewage, and process wastewater. In addition, TRU waste mixed with Resource Conservation and Recovery Act (RCRA) hazardous waste, and waste mixed with PCBs which are regulated under the Toxic 
Substances Control Act (TSCA), are generated by cleanup and decommissioning and demolition activities (40 CFR Parts 239-299), (15 U.S.C. 2601 et seq.).

Waste management responsibilities at ORNL are shared between the generator (i.e., ORNL) and the waste management contractor. The generator is responsible for collecting, characterizing, and certifying the waste prior to receipt by the waste management contractor. The waste management contractor is then responsible for storage, transport, treatment, and disposal operations (ORNL 2002). 



\section{J.9 PADUCAH SiTe}

This section presents a summary of the affected environments for the Paducah Site. The information was summarized from the Site Characterization Report prepared by the Funding Opportunity Announcement (FOA) grant recipient (SCR 2007e).

\section{J.9.1 Land Use}

The Paducah Site covers an estimated 3,556 acres (1,439 hectares [ha]) currently held by U.S. Department of Energy (DOE) in rural McCracken County of western Kentucky. The city of Paducah is located approximately 10 miles (mi) (16 [km]) east of the site, and the Ohio River runs $3.6 \mathrm{mi}(5.8 \mathrm{~km})$ north of the Paducah Site.

The Paducah Gaseous Diffusion Plant occupies a 750 acre (303.5 ha) complex within the Paducah Site. The Paducah Site is heavily developed and includes approximately 115 buildings with a combined floor space of an estimated 8.2 million square feet $\left(\mathrm{ft}^{2}\right)(0.76$ million square meters $\left[\mathrm{m}^{2}\right]$ ). In 1994, the Paducah Site was placed on the Environmental Protection Agency (EPA) National Priorities List (NPL), a list of hazardous waste sites across the nation that the EPA has designated as high priority for site remediation. The NPL designation was assigned primarily because of groundwater contamination with trichloroethylene (TCE) and Technetium99 (Tc-99), which were first detected in 1988. As a site on the NPL, the Paducah Site would undergo remediation efforts that met the requirements set forth by Comprehensive Environmental Response, Compensation, and Liability Act (CERCLA) (42 U.S.C. 9610). The City of Paducah is the largest urban area in the six counties surrounding the Paducah Site. The six-county area in which the site is located is primarily rural, with industrial uses accounting for less than 5 percent of the land use.

\section{J.9.2 Visual Resources}

The Paducah Site is characterized by a flat, rural landscape. Over 90 percent of the land surrounding the site is either undeveloped or serves as agricultural lands. The Ohio River flows $3.6 \mathrm{mi}(5.8 \mathrm{~km})$ north of the site. SR 358 (Ogden Landing Road) provides public access through the northern section of the Paducah Site.

\section{J.9.3 Site Infrastructure}

The Paducah Site has the infrastructure to functions as a standalone operation, with the exception of imported electrical power and telecommunications. The site is served by two interstate highways, several U.S. and state highways, several rail lines, barge service, and a regional airport (DOE 2004d). There are $9 \mathrm{mi}(14 \mathrm{~km})$ of railroad and $19 \mathrm{mi}(31 \mathrm{~km})$ of road on site.

Eighteen 161 kilovolt $(\mathrm{kV})$ transmission lines deliver power to the site from three separate providers (Tennessee Valley Authority, Electric Energy, Inc., and Kentucky Utilities). Peak electrical demand is about 2,000 megawatts (MW) with a site capacity of 3,040 MW. 
The Paducah Site has waste management systems in place for treatment and disposal of hazardous, non-hazardous, and radioactive waste. The Paducah Site steam plant burns coal to generate steam used primarily to heat non-production facilities. Annual coal consumption is nearly 33,100 tons (30,000 metric tons [MT]). All water (potable, process, fire) used by the site is obtained from the Ohio River through an intake at the steam plant near the Shawnee Power Plant north of the site.

\section{J.9.4 Air Quality and Noise}

The Paducah Site is located in the humid continental zone, characterized by warm summers and moderately cold winters. Tornadoes are rare in the area surrounding the Paducah Site.

The Paducah Site is located in the Paducah-Cairo Interstate Air Quality Control Region (AQCR), which covers the westernmost parts of Kentucky. McCracken County currently is designated as being in attainment for all criteria pollutants (40 CFR 81.318). Major air pollution sources around the Paducah Site in Kentucky include United States Enrichment Corporation (USEC) and the Tennessee Valley Authority's (TVA) coal-fired Shawnee Power Plant, about $3 \mathrm{mi}(5 \mathrm{~km})$ northeast of the Paducah Site. Potential radionuclide sources from the Paducah Site in 2000 were the Drum Mountain Removal Project, Northwest Plume Groundwater System, and fugitive emission sources. Ambient air monitoring stations in and around the site mainly collect data on radionuclides released from the site. Monitoring results showed that all airborne radionuclide concentrations in the surrounding area were at or below background levels.

The noise-producing activities within the Paducah Site are associated with processing and construction activities and local traffic, similar to those at any other industrial site. During site operations, noise levels near the cooling towers are relatively high, but most noise sources are enclosed in the buildings. Another noise source is associated with rail traffic in and out of the Paducah Site. In particular, train whistle noise, at a typical noise level of 95 to $115 \mathrm{~dB}$ (A), is high at public grade crossings. Currently, rail traffic noise is not a factor in the local noise environment because of infrequent traffic (one train per week).

\section{J.9.5 Water Resources}

The Paducah Site existing water supply plant obtains water from the Ohio River through an intake near the TVA Shawnee Fossil Plant. The Paducah Site water supply plant's capacity is about 30 million gallons per day (gal/day) (113.6 million liters per day [L/day]), which is approximately double the current requirement for the Paducah Site. The State of Kentucky has created a permitting system to allocate groundwater resources. Any person, business, industry, city, county, water district or other political subdivision desiring to withdraw, divert, or transfer public water must register with the Cabinet and submit an application for a permit if not exempted by the law. The regional gravel aquifer and sections of the McNairy Flow System are contaminated with volatile organic compounds (VOCs) and radiological components. Plumes emanating from the Paducah Site are located to the southwest, northwest, and northeast and generally flow north toward the Ohio River. Big Bayou Creek and its main tributary receive discharges of treated process water and sanitary wastewater through KPDES-permitted outfalls. 
Flooding is associated with the Ohio River, Big Bayou Creek, and Little Bayou Creek. The majority of overland flooding is associated with the Ohio River floodplain.

Floodplains outside the DOE property have been mapped by the Federal Emergency Management Agency but no floodplain determination has been made within the DOE property. The minimum elevation of the proposed site is approximately 380 feet (ft) (116 meters [m]), which is above both the 100-year floodplain level $(333 \mathrm{ft}[101 \mathrm{~m}]$ elevation) and the historical high water level (1937 flood level of $342 \mathrm{ft}$ [104 m]) for the Ohio River.

\section{J.9.6 Geology and Soils}

The topography of the Paducah Site is relatively flat. The Paducah Site is located near the northern end of the Mississippian Embayment, which is characterized by unconsolidated Cretaceous, Tertiary, and Quaternary sediments that dip gently to the south and overlie indurated Paleozoic limestone and shale bedrock. Several zones of faulting occur in the vicinity of the site. These zones include the New Madrid, St. Genevieve, Rough Creek, Cottage Grove, Wabash Valley, and Shawneetown fault zones. In addition, there is a northeast-trending rift zone. The area near the site has been the location of some of the largest earthquakes that have occurred in North America. The largest recorded earthquakes that occurred in the vicinity of the site happened between 1811 and 1812. Four of the earthquakes had Modified Mercalli intensities (MMI) that ranged from IX to XI. The largest earthquakes that have occurred since then were on January 4, 1843, and October 31, 1895, with body wave magnitude estimates of 6.0 and 6.2, respectively. In addition to these events, seven events of magnitude greater than 5.0 have occurred in the area. Since 1895, more than 4,000 earthquakes have been located in the zone. For the Paducah Site, the evaluation basis earthquake (EBE) was designated by DOE to have a return period of 250 years. A detailed analysis indicated that the peak ground motion for the EBE was 0.15 times the acceleration of gravity. An earthquake of this size would have an equal probability of occurring any time during a 250-year period, which approximately correlates to an MMI of VII.

\section{J.9.7 Biological Resources}

The DOE property between the Paducah Site and the surrounding West Kentucky Wildlife Management Area consists primarily of open, frequently mowed grassy areas. The DOE property also includes several small upland areas of mature forest, old-field, and transitional habitats. The habitats at the Paducah Site support a relatively high diversity of wildlife species.

Common species of the surrounding West Kentucky Wildlife Management Area and undeveloped areas of the Paducah Site outside the Paducah Site fence line include white-tailed deer, red fox, raccoon, opossum, coyote, turkey, and bobwhite quail. Ground-nesting species include the white-footed mouse, bobwhite, and eastern box turtle. Bayou Creek, upstream of the Paducah Site, supports aquatic fauna indicative of oxygen-rich, clean water, including 14 fish species. Aquatic species just downstream of the Paducah Site discharge points include 11 fish species. 
Although no occurrence of federally listed plant or animal species on the Paducah Site itself have been documented, the Indiana Bat (Federal- and state-listed as endangered) has been found near the confluence of Bayou Creek and the Ohio River $3 \mathrm{mi}(5 \mathrm{~km})$ north of the Paducah Site.

Although no wetlands are identified on the Paducah Site by the National Wetlands Inventory, approximately 5 acres ( $2 \mathrm{ha}$ ) of jurisdictional wetlands have been identified in drainage ditches scattered throughout the Paducah Site. Several wetland areas occur on the Paducah Site and total approximately 7.2 acres (2.9 ha). The open area in the northern portion of this location is crossed by several drainage ditches and swales that contain wetlands. The northernmost of these drainages conveys storm water from the cylinder storage yard to KPDES Outfall 017, located west of the Paducah Site entrance road.

\section{J.9.8 Cultural and Paleontological Resources}

In 1994, the United States Department of the Army (USDOA) completed a cultural resources survey (CRS) of 1,653 acres (669 ha) surrounding the Paducah Site. Besides presenting the results of the 1994 survey, it also included data from a survey conducted in 1932 by the University of Kentucky. In 2004, forty-one sample survey units were examined. Three of the 41 survey units were located within the proposed site. No pre-historic or historic sites were discovered within those three aforementioned survey units. No determinations of eligibility for listing in the National Register of Historic Places (NRHP) were made at that time.

\section{J.9.9}

Socioeconomics

Socioeconomic data for the Paducah Site focus on a region of influence (ROI) surrounding the site consisting of six counties: Ballard, Carlisle, Graves, Marshall, and McCracken Counties in Kentucky, and Massac County in Illinois. More than 92 percent of Paducah workers currently reside in these counties.

The population of the ROI in 2000 was 161,465 people and 65,514 people (41 percent of the ROI total) resided in McCracken County, with 26,307 of them residing in the City of Paducah.

In 2000 , total employment in the ROI was 67,866 . The economy of the ROI is dominated by the trade and service industries, with employment in these activities currently contributing 60 percent of all employment in the ROI.

In the ROI, total personal income grew at an annual rate of 2.1 percent over the period 1990 through 2000.

\section{J.9.10 Environmental Justice}

Based on data from the 2000 census, of the 173 census tracts within $50 \mathrm{mi}$ of the proposed site, 42 had minority populations in excess of state percent minority (SCR 2007e). As recommended by the Council on Environmental Quality (CEQ) guidelines, the environmental justice analysis identifies low-income populations as those falling below the statistical poverty level identified annually by the U.S. Bureau of the Census in its Series P-60 documents on income and poverty. Based on data from 2000, of the 173 census tracts within $50 \mathrm{mi}(80 \mathrm{~km})$ of the then-proposed 
conversion facility at Paducah, 109 had low-income populations in excess of state-specific thresholds - a total of 118,029 low-income persons in all. In McCracken County in 1999, 15.1 percent of the individuals for whom poverty status was known were low-income (SCR 2007e, DOE 2004d).

\section{J.9.11 Public and Worker Health and Safety}

Operations at the Paducah Site result in radiation exposure of both on-site workers and off-site members of the general public. Exposures of onsite workers generally are associated with the handling of radioactive materials used in the on-site facilities and with the inhalation of radionuclides released from processes conducted on site. Offsite members of the public are exposed to radionuclides discharged from onsite facilities with airborne and/or waterborne emissions and, in some cases, to radiation emanated from radioactive materials handled in the on-site facilities. The total radiation dose to a maximally exposed individual (MEI) of the general public is estimated to be $1.9 \mathrm{mrem} / \mathrm{year}$ (yr), which is much lower than the maximum radiation dose limit set for the general public of $100 \mathrm{mrem} / \mathrm{yr}$.

Permissible exposure limits (PELs) for uranium compounds and hydrogen fluoride in the workplace (29 CFR Part 1910) are as follows: $0.05 \mathrm{mg} / \mathrm{m}^{3}$ for soluble uranium compounds, $0.25 \mathrm{mg} / \mathrm{m}^{3}$ for insoluble uranium compounds, and $2.5 \mathrm{mg} / \mathrm{m}^{3}$ for HF. Paducah worker exposures are kept below these limits.

\section{J.9.12 Transportation}

The Paducah Site is located in an area with an established highway network. The area is served by an interstate highway, several U.S. and state highways, and local roads and freeways. The Site is surrounded by the West Kentucky Wildlife Management Area, which in turn is bordered on the west by Route 1132 and on the west by State Highway 996. These two roadways do not access the Site. Two roads provide access to Paducah Site. Along the northern border is the east-west rural major collector State Highway 358. Along the southern border lies State Highway 725; this interchanges with an access road, Route 1154. Route 1154 is a freeway connecting the Site with US Highway 60 , which is approximately $3 \mathrm{mi}(4.8 \mathrm{~km})$ to the south.

The onsite network of roadways is approximately $19 \mathrm{mi}(30.6 \mathrm{~km})$ in distance. State Highway 358 links the Site with the greater area through an interchange with Interstate 24 to the east between the Site and the City of Paducah, which lies approximately $10 \mathrm{mi}(16 \mathrm{~km})$ to the east. US Highway 60 travels east-west linking the City of Paducah with Missouri to the west and Louisville to the east. US Highway 60 also has an interchange with Interstate 24 . The US Highway in the area that traverses north-south is US Highway 45. It travels from the Tennessee border to the south through Paducah and into Illinois.

DOE owns an onsite railway system, a spur from the Paducah and Louisville rail line. The Paducah and Louisville rail lines also serve the Paducah-McCracken Riverport for transferring shipments to and from Ohio River barges. The onsite system is composed of approximately $9 \mathrm{mi}$ $(14 \mathrm{~km})$ of track). Rail traffic is approximately one train per week. The Paducah Site can be served by barge transportation via the Ohio River. 


\section{J.9.13 Waste Management}

The Paducah Site generates wastewater, solid low level waste (LLW), solid and liquid mixed low level waste (MLLW), nonradioactive hazardous waste, and nonradioactive nonhazardous solid waste. Wastes generated from site operations and environmental restoration is managed by DOE. DOE also manages the disposal of waste generated from ongoing management of the DOE-generated DUF $_{6}$ cylinders currently in storage. Wastewater at the Paducah Site consists of nonradioactive sanitary and process-related wastewater streams, cooling water blowdown, and radioactive process-related liquid effluents. Wastewater is processed at on-site treatment facilities and is discharged to Bayou Creek or Little Bayou Creek through eight permitted outfalls. The total capacity of the site wastewater control facilities is approximately 1.75 million gal/day (6.6 million L/day). Solid waste - including sanitary refuse, cafeteria waste, industrial waste, and construction and demolition waste - is collected and disposed of at the on-site landfill, which consists of three cells. The landfill is permitted for 1 million cubic yards $\left(\mathrm{yd}^{3}\right)$ (764,600 cubic meters $\left.\left[\mathrm{m}^{3}\right]\right)$ per Permit KY073-00045.

The site has a permit that authorizes it to treat and store hazardous waste in 10 treatment units, 16 tanks, and 4 container storage areas at the site. Several additional 90-day storage areas for temporary storage of hazardous waste are located on the site. LLW generated at the Paducah Site is stored on site pending shipment to a commercial facility in Tennessee for volume reduction. 


\section{J.10 PORTSMOUTH SITE}

This section presents a summary of the affected environments for the Portsmouth Site (Portsmouth). The information was summarized from the Site Characterization Report prepared by the Funding Opportunity Announcement (FOA) grant recipient (SCR 2007f).

\section{J.10.1 Land Use}

The Portsmouth Site is located on the U.S. Department of Energy (DOE) Reservation in Piketon, Ohio. It covers an estimated 3,714 acres (1,500 hectares [ha]) located in Pike County, approximately 22 miles (mi) (35 kilometers [km]) north of the Kentucky/Ohio state line and $3 \mathrm{mi}$ $(5 \mathrm{~km})$ southeast of the town of Piketon in south-central Ohio. The Portsmouth Gaseous Diffusion Plant (PGDP) was previously operated by DOE and then by the United States Enrichment Corporation (USEC). Uranium enrichment operations were discontinued in May 2001, and the plant has been placed in cold standby, a non-operational condition in which the plant retains the ability to resume operations within 18 to 24 months. Currently, NRC has given USEC a license to locate the American Centrifuge Program at the Portsmouth Site. The facility will be located on approximately 200 acres ( $81 \mathrm{ha}$ ) of the southwest quadrant of the controlled access area.

Of the 3,714 acre (1,500 ha) Portsmouth Site, 800 acres ( 320 ha) comprise the fenced core area which contains the former uranium enrichment operation facilities. The 2,914 acres (1,180 ha) outside the core area include restricted buffers, waste management areas, plant management and administrative facilities, gaseous diffusion plant support facilities, and vacant land. The site is heavily developed and includes approximately 150 buildings, trailers, and sheds.

\section{J.10.2 Visual Resources}

The Portsmouth Site is characterized by a primarily flat, rural landscape. Over 90 percent of the land surrounding the site is either undeveloped or serves as grazing or agricultural lands. SR 23 runs parallel to the western border of the Portsmouth Site less than $1 \mathrm{mi}(2 \mathrm{~km})$ away. It provides limited public views to the site due to the forested portions of the surrounding site area, which partially obscure the view of the facilities at the Portsmouth Site.

\section{J.10.3 Site Infrastructure}

The PGDP was constructed in the mid-1950s. The Portsmouth Site has an on-site steam plant, water treatment plant, wastewater treatment plant, and storm water management system. The DOE Reservation is the largest industrial user of water in the vicinity and obtains its water supply from an on-site X-611 Water Treatment Facility that draws water from three well fields located along the Scioto River. The maximum potential production associated with the well fields is 13 million gallons per day (gal/day) (49 million liters per day [L/day]). The current production is approximately 5 million gal/day ( 19 million $\mathrm{L} /$ day).

The Portsmouth Site is supplied electricity by the Ohio Valley Electric Corporation. Sewage treatment at the site is provided by the X-6619 Sewage Treatment Facility. The system is 
activated sludge using plug flow processes, aerobic digestion, secondary clarification, and granular-media filtration for effluent polishing. Post-chlorination is used to produce a bacteriologically safe effluent, and the final product is dechlorinated with sulfur dioxide before discharge to the Scioto River at National Pollutant Discharge Elimination System (NPDES) Permit Outfall 003. The X-6619 Sewage Treatment Plant has a design capacity of $700,000 \mathrm{gal} /$ day $(2,649,780 \mathrm{~L} /$ day $)$ and currently has 400,000 gal/day $(1,514,160 \mathrm{~L} /$ day $)$ excess capacities available. The proposed site has a developed and functioning storm water system consisting of open ditch and some very limited storm drains adjacent to the existing buildings that discharge to open ditches.

\section{J.10.4 Air Quality and Noise}

The Portsmouth Site is located in the humid continental climatic zone and has weather conditions that vary greatly throughout the year. Tornadoes are rare in the area surrounding the Portsmouth Site, and those that do occur are less destructive in this region than those occurring in other parts of the Midwest. For the period from 1950 through 1995, 656 tornadoes were reported in Ohio, with an average of 14 tornadoes per year. For the same period, 3 tornadoes were reported in Pike County, but most of those were relatively weak, at most, F2 of the Fujita tornado scale.

The Portsmouth Site is located in the Wilmington-Chillicothe-Logan Intrastate Air Quality Control Region (AQCR), which covers the south-central part of Ohio. Currently, Pike County is designated as being in attainment for all criteria pollutants. Ambient concentration data for criteria pollutants around the site are not available. On the basis of 2003 monitoring data, the highest concentration levels for $\mathrm{SO}_{2}, \mathrm{NO}_{2}, \mathrm{CO}, \mathrm{PM}_{10}$, and $\mathrm{Pb}$ representative of the region near the Portsmouth Site are less than 44 percent of their respective National Ambient Air Quality Standards (NAAQS). However, the highest $\mathrm{O}_{3}$ and $\mathrm{PM}_{2.5}$ concentrations are approaching or are somewhat higher than the applicable NAAQS. These high ozone concentrations of regional concern are associated with high precursor emissions from the Ohio Valley region and longrange transport from southern states.

Nonradiological air emissions from the USEC are predominant sources in Pike County. Currently, USEC has three Ohio Environmental Protection Agency (OEPA) operating permits. These emissions are associated with the boilers at the X-600 steam plant (which provides steam for the Portsmouth reservation), a boiler at the X-611 water treatment plant, an emergency generator, and a trash pump (DOE 2004b). DOE operates numerous small sources that release criteria pollutants and volatile organic compounds (VOCs). Other emission sources at DOE, which include two landfill venting systems, two glove boxes (not used in 2001), two aboveground storage tanks in the X-6002A fuel oil storage facility, and two groundwater treatment facilities, emit less than 1.0 ton (0.9 metric tons [MT]) per year of conventional air pollutants (on an individual basis).

\section{J.10.5 Water Resources}

The Portsmouth reservation is within the Lower Scioto River watershed. Surface waters drain from the Portsmouth Site via a network of tributaries to the Scioto River located approximately $2 \mathrm{mi}(3.2 \mathrm{~km})$ to the west. The average flow in the Scioto River is $2.1 \times 10^{6}$ gallons per minute 
( $7.9 \times 10^{6}$ liters per minute). The Scioto River discharges into the Ohio River approximately 25 $\mathrm{mi}(40 \mathrm{~km})$ south and downstream of the reservation. There are no known public- or privatewater supplies drawn from this section of the Scioto River. Storm water at the Portsmouth Site is collected by a series of storm water sewers and open culverts. The reservation has eight specific storm water collection areas, which transmit the storm water flow to one of the onsite streams or ditches. The largest stream on the Portsmouth Site is Little Beaver Creek, which discharges into Big Beaver Creek, which then discharges into the Scioto River.

The surface water features that drain the Portsmouth reservation as well as the Scioto River and their designated uses are as follows:

- $\quad$ Little Beaver Creek: State Resource Water; Warm Water Habitat; Agricultural Water Supply; Industrial Water Supply; and Primary Contact Recreation.

- Big Run Creek: Warm Water Habitat; Agricultural Water Supply; Industrial Water Supply; and Primary Contact Recreation.

- $\quad$ DOE Piketon Tributary: Limited Resource Water; Agricultural Water Supply; Industrial Water Supply; and Secondary Contact Recreation.

- West Ditch: Warm Water Habitat; Agricultural Water Supply; Industrial Water Supply; and Secondary Contact Recreation.

- Scioto River: Warm Water Habitat; Public Water Supply; Agricultural Water Supply; Industrial Water Supply; and Primary Contact Recreation.

The domestic wastewater generated by the offices and change houses is treated on the reservation at the sewage treatment plant. The design capacity of the sewage treatment plant is 601,000 gallons per day (gal/day) (2.3 million liters per day [L/day]), and in 2003, the facility operated at 27 percent of that capacity. The discharge from the sewage treatment plant is within its National Pollutant Discharge Elimination System permit criteria.

The Portsmouth reservation has not been affected by flooding of the Scioto River. The highest recorded flood elevation of the Scioto River in the vicinity of the site was 570 feet (ft) (174 meters $[\mathrm{m}]$ ) above mean sea level in January 1913. The reservation occupies an upland area at an elevation of $670 \mathrm{ft}(204 \mathrm{~m})$ above mean sea level.

Groundwater quality has been studied extensively as part of DOE's environmental restoration activities. Groundwater quality is monitored for radioactive and nonradioactive constituents in 11 areas at and near the facility using more than 400 wells. On site, five areas of groundwater contamination have been identified that contain contaminants. The main contaminants are VOCs (mostly trichloroethylene) and radionuclides (e.g., uranium, technetium-99). Data from the 2000 annual groundwater monitoring showed that five contaminants exceeded primary drinking water standards at the Portsmouth Site: beryllium, chloroethane, americium, trichloroethylene, and uranium. Alpha and beta activity also exceeded the standards. The concentration of contaminants and the lateral extent of the plume did not significantly increase in 2001.

\section{J.10.6 Geology and Soils}

The topography of the Portsmouth Site area consists of steep hills and narrow valleys, except where major rivers have formed broad floodplains. The site is underlain by bedrock composed of 
shale and sandstone. Surface and near-surface geology at the site have been heavily influenced by glaciation and the resultant ice damming and drainage reversals.

The Portsmouth Site is within $60 \mathrm{mi}(96 \mathrm{~km})$ of the Bryand Station-Hickman Creek Fault (DOE 2004b). The largest recorded seismic event in this zone was the Sharpsburg, Kentucky, earthquake of July 1980. That earthquake registered a magnitude of 5.3 and a Modified Mercalli intensity of VII. For this site, the evaluation-basis earthquake (EBE) was designated by DOE to have a return period of 250 years. The USGS earthquake database shows that 9 earthquakes have occurred within $62 \mathrm{mi}(100 \mathrm{~km})$ of the site since 1973. The magnitudes of the earthquakes ranged from 1.60 to 4.40 . The closest earthquake was a distance of $21 \mathrm{mi}(34 \mathrm{~km})$, had a magnitude of 3.5 and occurred at a depth of $7 \mathrm{mi}(11 \mathrm{~km})$. This earthquake occurred August 17, 1983.

\section{J.10.7 Biological Resources}

The vegetative cover in surrounding Pike County consists mostly of hardwood forests and field crops. The most common type of vegetation on the Portsmouth Site is managed grassland, which makes up about 1,100 acres (445 ha). Grasses are the dominant species in these communities.

The other types of habitat on the site include oak-hickory forest which covers 17 percent of the site and occurs on well-drained upland areas; old-field communities, approximately 11 percent of the site, consisting of tall weeds, shade-intolerant trees and shrubs that occur in previously disturbed areas; upland mixed hardwood forest which also covers 11 percent of the site and consists of black walnut, black locust, honey locust, black cherry, and persimmon in these mesic to dry upland communities; and riparian forest which occurs in low, periodically flooded areas near streams, makes up four percent of the site, and for which the dominant species are cottonwood, sycamore, willows, silver maple, and black walnut.

Within the area surrounded by Perimeter Road, the Portsmouth Site consists primarily of open grassland (including areas maintained as lawns) and developed areas consisting of buildings, paved areas, and storage yards. Wetlands are also located around one of the Cylinder Storage Yards and are associated with the tributaries of Little Beaver Creek. The flora associated with the wetlands includes emergent vegetation including sedges, rushes, cat-tails, and various woody species (trees and shrubs) tolerant of the saturated conditions of wetlands.

A wetland survey of the Portsmouth Site was conducted in 1995 . Approximately 34 acres (84 ha) of wetlands occur on the site, excluding retention ponds. Forty-one wetlands meet the criteria for jurisdictional wetlands, while four wetlands are non-jurisdictional. Wetlands on the site primarily support emergent vegetation that includes cattail, great bulrush, and rush. Palustrine forested wetlands occur on the site along Little Beaver Creek.

No occurrence of federally listed plant or animal species has been documented on the Portsmouth Site. 


\section{J.10.8 Cultural and Paleontological Resources}

An archaeological reconnaissance was performed in September 1996, April 1997, and May 1997 on the entire Portsmouth Site, with the exception of areas occupied by plant-related buildings or structures, sanitary landfills, or lagoons. The surveys resulted in the identification of 36 previously undocumented archaeological sites within the boundary of the Portsmouth Site. The 36 sites included 13 remnants of historic farmsteads, seven historic scatters or open refuse dumps, two historic isolated finds, four Portsmouth Site plant related structural remnants, one historic cemetery, five prehistoric isolated finds, two prehistoric lithic scatters, and two sites that contained both prehistoric and historic temporal components, an historic cemetery with a prehistoric isolated find, and a prehistoric lithic scatter on a historic farmstead.

\section{J.10.9 Socioeconomics}

Currently, approximately 92 percent of workers reside in the four selected counties. Geographically, Ross, Jackson, and Scioto counties bound Pike County to the North, East and South, respectively.

The major population centers in the four county region of influence are as follows:

- Piketon is the nearest residential center to the Portsmouth Site. Located in Pike County, this town is approximately $4 \mathrm{mi}(6.4 \mathrm{~km})$ north of the Portsmouth Site on U.S. Route 23. In 2000, the population of Piketon was 1,907.

- Waverly is the largest town in Pike County. Located $8 \mathrm{mi}(13 \mathrm{~km})$ north of the Portsmouth Site, the population of Waverly was 4,433 in 2000.

- Chillicothe, which is located in Ross County, is the largest population center in the region of influence. Chillicothe is $27 \mathrm{mi}(43 \mathrm{~km})$ north of the Portsmouth Site, and had a population of 21,796 in 2000.

- Portsmouth is in Scioto County and is $27 \mathrm{mi}(43 \mathrm{~km})$ south of the Portsmouth Site. The population of Portsmouth was 20,909 in 2000.

- Jackson is located in Jackson County and is $26 \mathrm{mi}(42 \mathrm{~km})$ east of the Portsmouth Site. In 2000, Jackson's population was 6,184.

The population of the region of influence was 212,876 people in 2000 , having grown 4.3 percent since 1990. This growth was marginally lower than the Ohio population growth rate of 4.7 percent in the same decade.

\section{J.10.10 Environmental Justice}

In 2000 , of the 206 census tracts within $50 \mathrm{mi}(80 \mathrm{~km})$ of the proposed conversion facility at Portsmouth, 12 had minority populations in excess of state-specified thresholds, a total of 7,735 minority persons in all. Within the region of influence, as well as in Pike County, 3.7 percent of the population is minority. There are two census tracts in which minority populations either exceed 50 percent and/or are significantly greater than the State or county percentage. 
In 1999 , of the 206 census tracts within $50 \mathrm{mi}(80 \mathrm{~km})$ of the proposed facilities at Portsmouth, 142 had low-income populations in excess of state-specified thresholds, a total of 133,303 low-income persons in all. In Pike County, 18.6 percent of the individuals for whom poverty status was known in 1999 were low-income. There are 18 census tracts in which low-income populations either exceed 50 percent and/or are significantly greater than the State or county percentage.

\section{J.10.11 Public and Worker Health and Safety}

The maximum radiation dose to an off-site member of the public as a result of on-site facility operations is estimated to be $2.0 \mathrm{millirem} / \mathrm{year}(\mathrm{mrem} / \mathrm{yr})$, which is significantly less than the NRC or DOE dose limit for the general public and the 40 CFR Part 190 regulatory limits of $25 \mathrm{mrem} / \mathrm{yr}$ for uranium fuel-cycle facilities. According to USEC, the Portsmouth Site reservation worker average whole body dose is less $10 \mathrm{mrem} / \mathrm{yr}$. Radiation exposures of the cylinder yard workers include exposures from activities performed outside the cylinder yards. The average dose in 2001 was $64 \mathrm{mrem} / \mathrm{yr}$. That dose is considerably below the maximum dose limit of 5,000 mrem/yr set for radiation workers (10 CFR Part 835). The average dose in 2001 for all monitored DOE/Portsmouth employees and subcontractors was $1.85 \mathrm{mrem} / \mathrm{yr}$.

Two of the key chemicals of concern-soluble and insoluble uranium compounds and hydrogen fluoride-are historically below permissible exposure limits. Other chemicals have been measured over the years at various levels at the Portsmouth Site. Some of these levels have approached or exceeded occupational health benchmarks. For example, arsenic levels ranged up to 2.1 milligrams per cubic meter $\left(\mathrm{mg} / \mathrm{m}^{3}\right)$, which is higher than the permissible exposure limit of $0.01 \mathrm{mg} / \mathrm{m}^{3}$, and lead levels ranged up to $19.5 \mathrm{mg} / \mathrm{m}^{3}$, which is higher than the permissible exposure limit of $0.050 \mathrm{mg} / \mathrm{m}^{3}$. Several other such examples exist. The measured levels were at the upper ends of the relevant ranges and the permissible exposure limits for eight-hour time weighted averages.

\section{J.10.12 Transportation}

The Portsmouth Site is served directly by road and rail. The site is $3.5 \mathrm{mi}(5.6 \mathrm{~km})$ south of the intersection of the U.S. Route 23 and Ohio SR 32 interchange. Two rail carriers, CSX and Norfolk Southern, service Pike County. The Norfolk Southern rail line is connected to the CSX Transportation Inc. rail line via a rail spur entering the northern portion of the site. The onsite system is used infrequently.

The site can be served by barge transportation via the Ohio River at the ports of Wheelersburg, Portsmouth, and New Boston. The Portsmouth barge terminal bulk-materials-handling facility is available for bulk materials and heavy unit loads. Nearby barge terminals on the Ohio River can be accessed by public road.

The nearest airport is the Greater Portsmouth Regional Airport located approximately $15 \mathrm{mi}$ $(24 \mathrm{~km})$ south of the site. Three international airports are within a two-hour drive of the site: Cincinnati/Northern Kentucky International Airport, Dayton International Airport, and Port Columbus International Airport. 


\section{J.10.13 Waste Management}

Waste is generated at the Portsmouth Site from DOE cleanup activities and its monitoring activities for stored waste including depleted uranium hexafluoride $\left(\mathrm{UF}_{6}\right)$ cylinders, hazardous waste, and classified/sensitive waste. DOE waste types are low-level radioactive waste, mixed (radioactive and Resource Conservation and Recovery Act [RCRA] hazardous) waste, RCRA hazardous waste, Toxic Substances Control Act (TSCA) waste, and mixed TSCA waste (radioactive and TSCA hazardous) (40 CFR Parts 239-299), (15 U.S.C. 2601 et seq.). Portsmouth does not generate or store high-level radioactive waste or store transuranic (TRU) waste. Solid low level waste generated by DOE activities include refuse, sludge, and debris contaminated with radionuclides, primarily uranium and Technetium-99 (DOE 2004b). 



\section{J.11 Roswell SITE}

This section presents a summary of the affected environments for the Roswell Site. The information was summarized from the Site Characterization Report prepared by the Funding Opportunity Announcement (FOA) grant recipient (SCR 2007g).

\section{J.11.1 Land Use}

The Roswell Site is approximately 920 acres (372 hectares [ha]) and is located in the arid high desert ranchland of east-central New Mexico's Chaves County, 40 miles (mi) (64 kilometers $[\mathrm{km}]$ ) east of Roswell. Currently, there are no existing structures or facilities within the boundaries of the site. Within the Roswell Site, the western 480 acres (194 ha) is zoned industrial for use as a Resource Conservation and Recovery Act (RCRA) hazardous waste disposal facility owned by Grandy Marley and permitted by the New Mexico Oil Conservation Division (40 CFR Parts 239-299). The remaining 440 acres (178 ha) are zoned for agricultural use.

\section{J.11.2 Visual Resources}

There are currently no existing facilities or structures within the boundaries of the Roswell Site that could affect the aesthetic resources of the area.

\section{J.11.3 Site Infrastructure}

There is an existing section of railroad track owned and operated by Burlington Northern and Santa Fe and/or Union Pacific Rail Roads that runs through Roswell and northwest through Elida, approximately $30 \mathrm{mi}(48 \mathrm{~km})$ from the site. One electrical power distribution line $(>13.5 \mathrm{kv})$ is located several miles to the east. One existing water well, owned by Robert W. Marley (a principle in Gandy Marley, Inc.), is present within $3 \mathrm{mi}(4.8 \mathrm{~km})$ of the site property and two additional wells are permitted for construction. The western 480 acres (194 ha) of the Roswell Site are zoned for use as a RCRA hazardous waste disposal facility.

\section{J.11.4 Air Quality and Noise}

The site is located in an arid to semiarid continental climate. The normal average daily temperature ranges from $38^{\circ} \mathrm{F}\left(3.3^{\circ} \mathrm{C}\right)$ in January to $80.8^{\circ} \mathrm{F}\left(27^{\circ} \mathrm{C}\right)$ in July.

There are no non-attainment, maintenance, or near non-attainment areas within the $50 \mathrm{mi}$ $(80 \mathrm{~km})$ buffer radius of the Roswell Site. There are no current or existing facilities at the Roswell Site to contribute to radiological air emissions. There are no existing facilities at the Roswell Site resulting in elevated noise levels.

One exceedance of the $\mathrm{PM}_{10}$ concentration of 150 micrograms occurred in Chavez County due to strong prevailing winds. The strong winds resulted in the lifting and blowing of dust. Since this was caused by natural events, the Environmental Protection Agency (EPA) allows States to describe alternative steps and measures to take to avoid nonattainment status by developing a Natural Events Action Plan (NEAP) to protect public health. In October 2004, the NMED submitted to EPA a NEAP for Chaves County to avoid non-attainment. 
Average rainfall in New Mexico ranges from less than 10 inches (in) (25 centimeters [cm]) over much of the south desert and the Rio Grande and San Juan Valleys to more than 20 in $(51 \mathrm{~cm})$ in the higher elevations in the state. Rainfall at the Roswell Site falls within these averages.

\section{J.11.5 Water Resources}

There are no perennial surface water bodies present at or near the site. The only surface water present in the vicinity of the site is runoff from precipitation or snowmelt. The site is located in the arid eastern ranchland of New Mexico where annual potential evaporation of up to 110 inches so greatly exceeds average annual precipitation of 13 to 16 in $(33$ to $41 \mathrm{~cm})$ that perennial surface water simply does not exist. There are no natural perennial surface water features in the vicinity of the site for which a water quality assessment can be determined. The site is not in or near a 10, 100, or 500 year floodplain delineated by Federal Emergency Management Act (42 U.S.C. 5121-5170).

The Roswell Site is situated in the Roswell Artesian Underground Water Basin (UWB), near its boundary with the Lea County UWB. The Roswell UWB is an administrative unit that includes several aquifers, including an alluvial aquifer about $35 \mathrm{mi}(56 \mathrm{~km})$ west of the site along the Pecos River, the Roswell Artesian Aquifer, local perched groundwater bodies near the site, and groundwater in formations beneath the site. Formations beneath the site yield little groundwater and water quality is considered poor. The western boundary of the Ogallala Aquifer coincides with Mescalero Ridge about $1 \mathrm{mi}(2 \mathrm{~km})$ east of the site. The Ogallala is the only aquifer within $10 \mathrm{mi}(16 \mathrm{~km})$ that is known to yield large amounts of groundwater. The closest major body of perennial surface water is the Pecos River, located approximately $35 \mathrm{mi}(56 \mathrm{~km})$ west of the site at its nearest point. Ephemeral surface water at the site is derived exclusively from local precipitation and snowmelt.

The saturated thickness in the aquifer near Mescalero Point is approximately 60 to 70 feet $(\mathrm{ft})$ (18 to 21 meters [m]) and transmissivity is reported to be 10,000 to $30,000 \mathrm{gal} /$ day per $\mathrm{ft}$ or 1,300 to $4,000 \mathrm{ft}^{2}$ per day. Storativity of the aquifer is approximately 0.2 . The expected yield from wells completed in the Ogallala Aquifer is in excess of $100 \mathrm{gpm}$ near the site. No groundwater wells have been completed at the Roswell Site. There are no known future groundwater rights appurtenant to the site. There are no known Native American Tribal water rights that would be affected. There are no known existing permits that will expire, providing available water rights.

\section{J.11.6 Geology and Soils}

The Roswell Site is located approximately $40 \mathrm{mi}(64 \mathrm{~km})$ east of Roswell, New Mexico in the Pecos River Valley Section of the Great Plains Physiographic Province. Terrain within this province ranges from low-lying plains to rugged canyons. In the area near the Roswell Site, the terrain consists of hummocky eolian deposits, sand ridges and dunes. The site encompasses 920 acres (372 ha) and slopes moderately from east to west from an elevation of 4,260 $\mathrm{ft}$ $(1,298 \mathrm{~m})$ above sea level to 4,120 ft $(1,256 \mathrm{~m})$ above sea level. No faults or folds that have been active in Quaternary time are near the site. The closest capable fault is the Rio Grande Rift approximately $100 \mathrm{mi}(161 \mathrm{~km})$ west of the site. 


\section{J.11.7 Biological Resources}

There are four ecological habitats known to occur within the boundaries of the Roswell Site. These include the loamy, sandhills, deep sand, and sandy plains ecosystems. The most important vegetation communities on the Roswell Site are those that provide habitat for the lesser prairiechicken and sand dune lizard. These are both federal candidate species.

The privately owned 980 acre (396 ha) Roswell Site is located within the Caprock Wildlife Habitat Management Area (WMA), which encompasses approximately 561,300 acres (227,150 ha) of public, state, and private lands in eastern Chaves County, southwestern Roosevelt County, and northern Eddy County, New Mexico. The WMA was established to protect the Mescalero Sands habitat area that is located primarily to the west of the Roswell Site; protection of this habitat is primarily focused on the lesser prairie-chicken. There are no riparian, wetlands, or aquatic habitats present within or directly adjacent to the Roswell Site. There are no wetlands under jurisdiction of the U.S. Army Corps of Engineers (USACE) at or near the site. The only 2 species that have been documented within or adjacent to the Roswell Site are the sand dune lizard and lesser prairie-chicken.

\section{J.11.8 Cultural and Paleontological Resources}

Twelve previously recorded sites were noted in the NMCRIS review for lying near but not within the Roswell Site.

\section{J.11.9 Socioeconomics}

The Roswell Site is located in the sparsely populated ranchland of eastern Chaves County, approximately $40 \mathrm{mi}(64 \mathrm{~km})$ east of Roswell. Based on the 2000 Census block group data, it is estimated that 91,713 people live within $50 \mathrm{mi}(80 \mathrm{~km})$ of the Roswell Site. The construction, mining, and accommodation and food sectors employ the greatest number of workers in the ROI.

At a radial distance up to $50 \mathrm{mi}(80 \mathrm{~km})$ of the Roswell Site, the great majority of the area has a population density of less than 10 people per square mile. In some areas of Roswell, Artesia, and Lovington, however, the population density is greater than 1,000 people per square mile. Based on the 2000 Census the average population density within $50 \mathrm{mi}(80 \mathrm{~km})$ from the Roswell Site is estimated to be less than 12 people per square mile.

The unemployment level in the ROI for 2006 was 3.9 percent. This level was below the New Mexico average of 4.3 percent and the national unemployment average of 4.6 percent for 2006 .

The New Mexico economy is expected to generate about 158,000 new jobs from 2002 to 2012. This represents growth of about 20 percent (an average of approximately 2 percent per year), faster than the projected national increase of 14.8 percent over the same 10-year period. Employment growth for the ROI from 2003 to 2006 has averaged 1.6 to 4.6 percent per year. 


\section{J.11.10 Environmental Justice}

The average minority population in New Mexico as of the 2000 Census was 55.3 percent. Therefore, block groups with a minority population of 65.3 percent or greater were considered minority areas. During the 2000 Census, there were a total of 83 New Mexico census block groups fully or partially within $50 \mathrm{mi}(80 \mathrm{~km})$ of the Roswell Site. A total of 15 block groups within $50 \mathrm{mi}(80 \mathrm{~km})$ of the Roswell Site had minority populations that were at least 10 percent greater than the state average.

The low-income population (households below the poverty line) in New Mexico as of the 2000 Census was 18.4 percent. Therefore, New Mexico block groups with a low-income population of 28.4 percent or greater were considered low-income areas. A total of 18 block groups had low-income populations that were at least 10 percent greater than the state average. The low-income census block groups were located in Roswell and Hagerman (in Chaves County).

Two census block groups within $50 \mathrm{mi}(80 \mathrm{~km})$ of the Roswell Site were located in Texas. The average minority population in Texas as of the 2000 Census was 47.6 percent. Block groups in Texas with a minority population of at least 57.6 percent were considered minority areas in Texas. The low-income population in Texas as of the 2000 Census was 15.4 percent. Therefore, block groups with a low income population of at least 25.4 percent were considered low-income areas in Texas. Neither of the Texas census block groups within $50 \mathrm{mi}(80 \mathrm{~km})$ of the Roswell Site was considered minority or low-income areas.

\section{J.11.11 Public and Worker Health and Safety}

There are currently no existing facilities or structures on the Roswell Site to contribute radiological or hazardous chemical contaminants to the environment.

\section{J.11.12 Transportation}

Major U.S. Highway 380 is located within $3 \mathrm{mi}(5 \mathrm{~km})$ of the site. The nearest rail access is located $30 \mathrm{mi}(48 \mathrm{~km})$ northwest of the site. There are currently no forms of transportation on the Roswell Site.

\section{J.11.13 Waste Management}

The western 480 acres $(194 \mathrm{~km})$ of the Roswell Site are zoned for use as a RCRA hazardous waste disposal facility. The surface waste management facility is permitted to use lined landfill-type cells for the disposal of oilfield waste classified as non-hazardous by RCRA subtitle $\mathrm{C}$ exemption or by characteristic testing. 


\section{J.12 SAVANNAH River Site}

This section provides a summary of the affected environments for the Savannah River Site (SRS).

\section{J.12.1 Land Use}

SRS is located in south-central South Carolina and occupies an area of approximately 198,420 acres (80,300 hectares [ha]) in Aiken, Barnwell, and Allendale Counties (DOE 2005b). The site is approximately 15 miles (mi) (9.5 kilometers [km]) southeast of Augusta, Georgia and $12 \mathrm{mi}(7.5 \mathrm{~km})$ south of Aiken, South Carolina (DOE 2003a).

Currently, production and support facilities, infrastructure, research and development (R\&D), and waste management facilities account for approximately 10 percent (approximately 19,000 acres [8,000 ha]) of land on the SRS (DOE 2000b; DOE 2003a). Of the remaining 90 percent (approximately 191,000 acres [77,300 ha]), approximately 80 percent is planted pine forest managed by the U.S. Forest Service (USFS) (under an interagency agreement with U.S. Department of Energy [DOE]), with the remainder consisting of aquatic habitats and developed landscapes (DOE 1995d, SRS 2006, Wike et al. 2006). The 19,000 acres (8,000 ha) of developed SRS land includes five non-operational nuclear production reactors, two chemical separations facilities (one is being deactivated), waste treatment, storage and disposal facilities, and various supporting facilities. The site was designed with a buffer zone that provides security and prevents accidental exposure to the general public (DOE 2003a, SRS 2006).

\section{J.12.2 Visual Resources}

The industrial areas, including the reactors and large facilities, are primarily located in the interior of the site away from public access (DOE 2003a). SRS facilities are not generally visible from public access roads due to the distance to the boundary from the industrialized areas, the gently rolling terrain, and heavy vegetation (DOE 2003a). The limited public areas that have views of some SRS structures (other than the administrative areas) are approximately $5 \mathrm{mi}$ $(8 \mathrm{~km})$ or more away from viewable structures (DOE 2003a).

The facilities are scattered across SRS and are brightly lit at night (DOE 1995d). Typically, the reactors and principal processing facilities are large concrete structures as much as $100 \mathrm{ft}(30 \mathrm{~m})$ tall adjacent to shorter administrative and support buildings and parking lots (DOE 1995d). These facilities are visible in the direct line-of-sight when approaching them on SRS access roads. Heavily wooded areas that border the SRS road system and public highways crossing SRS limit views of the facilities (DOE 1995d).

\section{J.12.3 Site Infrastructure}

The SRS site has over 1,400 $\mathrm{mi}(2,250 \mathrm{~km})$ of roads total. About $143 \mathrm{mi}(230 \mathrm{~km})$ of these roads are paved, and $34.2 \mathrm{mi}(55 \mathrm{~km})$ of onsite roads are public roads. Most of the roads are adequate for the current level of normal transportation activity and could handle increased traffic volume. In addition, there are $64 \mathrm{mi}(103 \mathrm{~km})$ of railroad track at SRS. 
SRS uses a 115-kilovolt $(\mathrm{kV})$ power line system to supply electricity to the operations areas. Power is supplied by three transmission lines from the South Carolina Electric and Gas Company. The total SRS usage of electrical power is 370,000 megawatt-hours per year (MWh/yr) out of a site capacity of 4,400,000 MWh/yr.

Coal and oil are used at SRS to power steam plants located in A-, D-, H- and K-Areas. Coal is delivered by rail and is stored at coal piles in A-, D-, and H-Areas. Number 2 grade fuel oil is delivered by truck and is used in the K-Area. Natural gas is not used at SRS.

Domestic water supplies at SRS come from a system composed of several wells and water treatment plants.

\section{J.12.4 Air Quality and Noise}

The SRS is located in the Augusta-Aiken Interstate Air Quality Control Regions (AQCR). All areas within this region are classified as achieving attainment with the National Ambient Air Quality Standards (NAAQS) (40 CFR Part 50). Ambient air is defined as that portion of the atmosphere, external to buildings, to which the general public has access. The NAAQS define ambient concentration criteria or limits for sulfur dioxide $\left(\mathrm{SO}_{2}\right)$, particulate matter equal to or less than 10 microns in aerodynamic diameter $\left(\mathrm{PM}_{10}\right)$, carbon monoxide $(\mathrm{CO})$, nitrogen dioxide $\left(\mathrm{NO}_{2}\right)$, ozone $\left(\mathrm{O}_{3}\right)$, and lead $(\mathrm{Pb})$. These pollutants are generally referred to as "criteria pollutants."

Significant sources of regulated air pollutants at SRS include coal-fired boilers for steam production, diesel generators, chemical storage tanks, the Defense Waste Processing Facility (DWPF), groundwater air strippers, and various other process facilities. Another source of criteria pollutant emissions at SRS is the prescribed burning of forested areas across the Site by the USFS.

Atmospheric emissions of radionuclides from DOE facilities are limited under the U.S. Environmental Protection Agency (EPA) regulation "National Emission Standards for Hazardous Air Pollutants (NESHAP)," 40 CFR Part 61, Subpart H. A network of sampling stations in and around SRS monitors the concentrations of tritium and radioactive particulate materials in the air. Except for tritium, specific radionuclides are not routinely detectable at the site perimeter.

Most industrial facilities at SRS are at a sufficient distance from the site boundary that noise levels at the boundary from these sources would not be distinguishable from ambient background noise levels. Major noise sources in active areas at the SRS include industrial facilities and equipment such as cooling systems, transformers, engines, vents, paging systems, construction and materials handling equipment, and vehicles. Outside of active operational areas, vehicles and trains generate noise. 


\section{J.12.5 Water Resources}

The regional drainage is dominated by the north to south running Savannah River. This major river forms in Lake Hartwell with the confluence of the Seneca and the Tugaloo rivers. It drains a watershed of 10,577 square miles $\left(\mathrm{mi}^{2}\right)\left(27,394\right.$ square kilometers $\left.\left[\mathrm{km}^{2}\right]\right)$ in the mountains of North Carolina, South Carolina and Georgia. There are five main watersheds that originate on, or pass through the SRS before discharging into the Savannah River Swamp. Closer to SRS, the flood plain of the Savannah River turns into a swamp and begins to flood over a levee when river flows exceed 15,300 cubic feet $\left[\mathrm{ft}^{3}\right] / \mathrm{s}$ (433 cubic meters $\left.\left[\mathrm{m}^{3}\right] / \mathrm{s}\right)$ (DOE 2003a).

There are two major artificial bodies of water onsite, Par Pond and L-Lake. There are also approximately 200 Carolina bays, which are naturally occurring pond formations found in parts of the Southeastern United States, that are scattered throughout the site covering a total area of approximately 1,100 acres (445.5 ha). These bays serve as natural habitats for many species of wildlife on the site.

A series of five upstream reservoirs-Jocassee, Keowee, Hartwell, Richard B. Russell, and Strom Thurmond - were built along the river with the objectives to reduce the variability of flow downstream in the area of SRS, create hydroelectric power, and improve navigation and recreation among other things (DOE 2005d).

The Savannah River is classified as a freshwater source that is suitable for primary and secondary contact recreation, drinking after appropriate treatment, balanced native aquatic species development, and industrial and agricultural purposes.

Steel Creek received cooling water from L-Reactor and ash basins runoff, non-process cooling water, powerhouse wastewater, reactor process effluents, sanitary treatment plant effluents, and vehicle wash waters. Releases of radioactive materials to surface water were highest during the early and middle 1960s. Tritium, cesium-137, and strontium-90 were the main radioactive materials of concern for releases to surface streams at SRS. Meyer et al. (1999) estimated that, for all years of operation at SRS, the total tritium released to the Savannah River is 1.8 million curies $(\mathrm{Ci})$, the total cesium-137 released is about $250 \mathrm{Ci}$ and the total strontium-90 released to the river for all years is about $100 \mathrm{Ci}$ (DOE 1995d).

SRS monitors nonradioactive liquid discharges to surface waters through the NPDES, as mandated by the Clean Water Act (33 U.S.C. 1251 et seq.). As required by Environmental Protection Agency (EPA) and SCDHEC, SRS has NPDES permits in place for discharges to the waters of the United States and South Carolina. These permits establish the specific sites to be monitored, parameters to be tested, and monitoring frequency - as well as analytical, reporting, and collection methods (SRS 2006).

The hydrostratigraphic units of primary interest beneath SRS are part of the Southeastern Coastal Plain Hydrogeologic Province. Within this sequence of aquifers and confining units are two principal subcategories, the overlying Floridan Aquifer System and the underlying DublinMidville Aquifer System. These systems are separated from one another by the Meyers Branch 
Confining System. In turn, each of the systems is subdivided into two aquifers, which are separated by a confining unit (WSRC 2005).

In the central to southern portion of SRS, the Floridan Aquifer System is divided into the overlying Upper Three Runs Aquifer and the underlying Gordon Aquifer, which are separated by the Gordon Confining Unit. The water table surface can be as deep as $160 \mathrm{ft}$ (49 $\mathrm{m})$ below ground surface (bgs), but intersects the ground surface in seeps along site streams. The top of the Gordon Aquifer typically is encountered at depths of 150-250 ft (46-76 m) bgs (WSRC 2005).

The shallower groundwater aquifers underneath SRS are contaminated with a variety of elements that range from organic compounds to metals and radionuclides. The sources of the detected groundwater contamination included burial grounds, waste management facilities, canyon buildings, seepage basins, and saltstone disposal facilities (NRC 2005c). The shallower Upper Three Runs Aquifer is contaminated with solvents, metals, and low levels of radionuclides near several SRS areas and facilities, including the F-Area. Tritium has been reported in the Gordon Aquifer under the Separation Areas (F- and H-Areas). The deep Crouch Branch Aquifer is generally unaffected by site operations, except for a location near A-Area, where trichloroethylene (TCE) contamination has been found.

SRS derives its own drinking and production water supply from groundwater. The site ranks as South Carolina's largest self-supplied industrial consumer of groundwater, utilizing approximately 5.3 million gallons (gal)/day (20 million liters (L)/day). SRS domestic and process water systems are supplied from a network of approximately 40 wells in widely scattered locations across the site, of which eight supply the primary drinking water system for the site (WSRC 2005).

\section{J.12.6 Geology and Soils}

The Aiken Plateau, the subdivision of the Coastal Plain that includes SRS, is highly dissected and characterized by broad, flat areas between streams and narrow, steep-sided valleys. It slopes from an elevation of approximately 300 to $330 \mathrm{ft}(91$ to $100 \mathrm{~m}$ ) above mean sea level (msl) with an average slope of less than four percent (DOE 2002a).

The sediments of the Atlantic Coastal Plain dip gently seaward from the Fall Line thickening from essentially $0 \mathrm{ft}(0 \mathrm{~m})$ thick at the Fall Line to more than 4,000 $\mathrm{ft}(1,219 \mathrm{~m})$ at the coast. The topmost sediment layer (known as the Tinker/Santee Formation) consists of $60 \mathrm{ft}(18 \mathrm{~m})$ of Paleocene-age clayey and silty quartz sand and silt (NRC 2005c). Within this layer, there are occasional beds of clean sand, gravel, clay, or carbonate. Deposits of pebbly, clayey sand, conglomerate, and Miocene and Oligocene-age clay occur at higher elevations. This layer is noteworthy because it contains small, discontinuous, thin calcareous sand zones (i.e., sand containing calcium carbonate) that are potentially subject to dissolution by water. These "soft-zone" areas have the potential to subside, causing settling of the ground surface (NRC 2005c). The second layer of sediments overlies bedrock and consists of about $700 \mathrm{ft}$ $(210 \mathrm{~m})$ of Upper Cretaceous-age quartz sand, pebbly sand, and kaolinitic clay. The underlying bedrock consists of sandstones of Triassic age and older metamorphic and igneous rocks (DOE 2002a). 
The Atlantic Coastal Plain tectonic province in which SRS is located is characterized by generally low seismic activity that is expected to remain subdued (DOE 2005p). There are six subsurface faults at SRS: Pen Branch, Steel Creek, Advanced Tactical Training Area, Crackerneck, Ellenton, and Upper Three Runs. The actual faults do not reach the surface, but stop several hundred feet below grade. The most active seismic zones in the southeastern United States are all located over $100 \mathrm{mi}(160 \mathrm{~km})$ away from the site (DOE 2002a).

Seven soil associations are represented within SRS (Rogers 1990). Generally, sandy soils occupy the uplands and ridges and are less fertile than the loamy-clayey soils of the stream terraces and floodplains. The surface soils at the proposed GNEP site range from nearly level to sloping and well-drained, with a sandy surface and subsurface layer and a loamy subsoil. The Fuquay sand is the dominant soil mapping unit in the project area.

Some small gravel deposits were noted in the vicinity of the F-area. However, no other economically viable geologic resources occur (DOE 1995d).

Subsidence (lowering of the ground surface) and soil liquefaction are two geologic processes that are potentially problematic at SRS. Rock strata under some areas of SRS include layers of pockets of carbonate rock that are subject to dissolution, which would cause subsidence and could lead to soil liquefaction. Sites underlain by these "soft zones" are considered unsuitable for structural formations unless extensive soil stabilization is done (NRC 2005c).

\section{J.12.7 Biological Resources}

Currently, nearly 90 percent of the land (180,000 acres [72,000 ha]) at the SRS is forested with upland pine, hardwood, mixed (pine and hardwood), and bottomland hardwood forests. The loblolly-longleaf-slash pine community (Pinus taeda-P. palustris- $P$. elliottii) is the dominant community covering approximately 65 percent of the site. Swamp forests and bottomland hardwood forests are found along the Savannah River. Farming, fire, soil, and topography have influenced SRS vegetation patterns.

SRS supports numerous animal species, including 44 species of amphibians, 59 species of reptiles, 258 species of birds and 54 species of mammals (NRC 2005c). The SRS has among the highest biodiversity of herpetofauna (reptiles and amphibians) in the United States because of the area's warm, moist climate and its wide variety of habitats (NRC 2005c).

Approximately 25 percent of SRS's surface area is covered by water, including wetlands, bottomland hardwoods, cypress-tupelo swamp forests, two large cooling water reservoirs (i.e., Par Pond and L Lake), creeks, and streams. (Kilgo and Blake 2005, Lide et al. 1995, Wike et al. 2006). Six major streams and several associated tributaries flow through SRS, and the Savannah River bounds the southwestern border of SRS. More than 50 man-made ponds also occur at the SRS. The two largest are L Lake (1,000 acres [405 ha]), which discharges into Steel Creek, and Par Pond (2,640 acres [1,069 ha]), which discharges into Lower Three Runs Creek. Altogether, about 4,940 acres (2,000 ha) of open water occurs at the SRS (NRC 2005c). At least 81 fish species have been identified at SRS (NRC 2005c). 
Under the Endangered Species Act, the Federal Government provides protection to six species that are known to occur on the SRS: American alligator (Alligator mississippiensis); shortnose sturgeon (Acipenser brevirostrum); wood stork (Mycteria americana); red-cockaded woodpecker (Picoides borealis); smooth purple coneflower (Echinacea laevigata); and pondberry (Lindera melissifolia). SRS contains no designated critical habitat for any listed threatened or endangered species (Wike et al 2006).

Wetlands on SRS encompass approximately 49,030 acres (19,850 ha), or over 20 percent of the SRS area, and are extensively and widely distributed. These wetlands include bottomland hardwood forests, cypress-tupelo swamp forests, floodplains, creeks, impoundments, and over 300 isolated upland Carolina bays and wetland depressions (NRC 2005c).

\section{J.12.8 Cultural and Paleontological Resources}

Approximately 60 percent of the SRS site has been inventoried and over 850 archaeological (prehistoric and historic) sites have been identified (NRC 2005c). Sixty-seven of these sites are considered potentially eligible for listing on the National Register of Historic Places (NRHP); however, most of the sites have not been evaluated for eligibility.

Prehistoric resources at SRS consist of villages, base camps, limited-activity sites, quarries, and workshops. Evidence of prehistoric use of the area is present at approximately 800 of the recorded archaeological sites. Fewer than 8 percent of these sites have been evaluated for NRHP eligibility (DOE 2003a).

Historic resources at SRS consist of farmsteads, tenant dwellings, mills, plantations and slave quarters, rice farm dikes, dams, cattle pens, ferry locations, towns, churches, schools, cemeteries, commercial building locations, and roads. Evidence of historic use of the area has been found at approximately 400 of the recorded archaeological sites. About 10 percent of the historic sites have been evaluated for National Register eligibility (DOE 2003a). Systematic historic building surveys have not yet been conducted at SRS. Native American groups with traditional ties to the SRS area include the Apalachee, Cherokee, Chickasaw, Creek, Shawnee, Westo, and Yuchi.

Paleontological resources at SRS date from the Eocene Age (54 to 39 million years ago) and include fossil plants, numerous invertebrate fossils, and deposits of giant oysters, other mollusks, and bryozoa. All resources from SRS are marine invertebrate deposits and, with the exception of the giant oysters, are relatively widespread and common fossils. Therefore, the assemblages have relatively low research potential or scientific value (DOE 2003a).

\section{J.12.9 Socioeconomics}

Socioeconomic characteristics addressed at SRS include employment, income, population, housing, and community services. These characteristics are analyzed for a four-county region of influence (ROI) consisting of Aiken and Barnwell Counties in South Carolina, and Columbia and Richmond Counties in Georgia, where 88 percent of site employees reside.

SRS employs approximately 15,112 workers, including DOE employees and multiple contractors. This represents approximately 7.3 percent of area employment. The labor force of 
the Regional Economic Area grew by approximately 8 percent from 209,560 in 2000 to 226,087 in 2005. The overall ROI employment experienced a comparable growth rate of 6 percent with 195,162 in 2000 to 207,162 in 2005.

The ROI unemployment rate was 8.4 percent in 2005, which was higher than the unemployment rate of 6.9 percent in 2000. In 2005, unemployment rates within the regional economic area ranged from a low of 5.4 percent in Columbia County to a high of 10.9 percent in Richmond County. The unemployment rate in South Carolina was 6.7 percent in 2005, while the unemployment rate in Georgia was 5.2 percent (BLS 2005b, TtNUS 2006f).

Per capita income in the ROI was $\$ 26,621$ in 2004, a 54.9 percent increase from the 1990 level of $\$ 17,188$. Per capita income in 2004 in the ROI ranged from a low of $\$ 19,809$ in Barnwell County, South Carolina to a high of $\$ 33,523$ in Columbia County, Georgia. The 2004 per capita income in South Carolina was \$27,185 and \$29,782 in Georgia (BEA 2006a).

In 2000, approximately 563,501 people lived within census tracts, all or part of which are within a $50 \mathrm{mi}(80 \mathrm{~km})$ radius of SRS. The ROI population increased by 16 percent during the 15 year period, while the population in South Carolina and Georgia increased by 18 percent and 36 percent respectively.

\section{J.12.10 Environmental Justice}

Census data from 2000 was used to determine minority and low-income characteristics by block group within $50 \mathrm{mi}(80 \mathrm{~km})$ of SRS. A block group was included if any part of its area was within $50 \mathrm{mi}(80 \mathrm{~km})$ of the centroid of SRS. The $50 \mathrm{mi}(80 \mathrm{~km})$ radius includes 522 block groups (TtNUS 2006b). The geographic area was defined as Georgia and South Carolina, independently, for analysis of block groups in each state.

One-hundred-ninety-four block groups have a significant Black or African American minority population and 207 block groups have significant aggregate minority percentages. One census block group within the $50 \mathrm{mi}(80 \mathrm{~km})$ radius has a significant Hispanic ethnicity population (TtNUS 2006b).

Based on the "more than 20 percent" or the "exceeded 50 percent" criteria, no American Indian or Alaskan Native, Asian, Native Hawaiian or Other Pacific Islander, Some other race, or Multi-racial minority block groups exist in the geographic area (TtNUS 2006b).

Sixty seven census block groups within the $50 \mathrm{mi}(80 \mathrm{~km})$ radius have a significant percentage of low-income households (TtNUS 2006b).

\section{J.12.11 Public and Worker Health and Safety}

An individual's radiation exposure in the vicinity of SRS amounts to approximately 357 millirem (mrem), and is comprised of natural background radiation from cosmic, terrestrial, and internal body sources; radiation from medical diagnostic and therapeutic practices; weapons test fallout; consumer and industrial products, and nuclear facilities. 
Releases of radionuclides to the environment from SRS operations provide another source of radiation exposure to individuals in the vicinity of SRS. Types and quantities of radionuclides released from SRS operations in 2004 are listed in the Savannah River Site Environmental Report for 2004 (WSRC 2005). The radionuclide emissions contributing the majority of the dose to the offsite maximally exposed individual (MEI) from liquid releases were tritium and cesium137 (WSRC 2005). For atmospheric releases, the radionuclides contributing the majority of the dose to the offsite MEI were tritium, iodine-129, and unspecified alpha emissions (estimated to be from diffuse and fugitive sources). These doses fall within the radiological limits given in DOE Order 5400.5 (DOE O 5400.5), Radiation Protection of the Public and the Environment, and are much lower than those from background radiation (WSRC 2005).

The average radiation dose recorded for workers at SRS in 2005 was 51.4 mrem (SRS 2006). The cumulative dose to all workers at SRS from operations in 2001 was 121.3 person-rem. These doses fall within the radiological regulatory limits of 10 CFR Part 835.

Major non-radiological emissions of concern from stacks at SRS facilities include sulfur dioxide, carbon monoxide, oxides of nitrogen, $\mathrm{PM}_{10}$, volatile organic compounds (VOCs), and toxic air pollutants. Emissions from SRS sources are determined during an annual emissions inventory from calculations using source operating parameters such as fuel oil consumption rates, total hours of operation, and the emission factors provided in the EPA "Compilation of Air Pollution Emission Factors."

Air dispersion modeling was conducted during 2004 for new emission sources or modified sources as part of the sources' construction permitting process. The modeling analysis showed that SRS air emission sources were in compliance with applicable regulations (WSRC 2005).

\section{J.12.12 Transportation}

SRS is surrounded by a system of interstate highways, U.S. highways, state highways, and railroads. The regional transportation network services the four South Carolina counties (Aiken, Allendale, Bamberg, and Barnwell) and two Georgia counties (Columbia and Richmond) that generate nearly all of the SRS commuter traffic.

Railroads on the Site include both CSX Transportation tracks and $33 \mathrm{mi}(53 \mathrm{~km})$ of operational SRS track (DOE 2005d).

The Savannah River is navigable to the barge slip at SRS located at river mile 157 (SCR 2007b). The Savannah River barge dock is located approximately two miles northwest of the D Area on SRS and is surrounded by wooded areas (DOE 1992b). An on-site heavy-duty construction access road originates at the barge dock and extends approximately $2 \mathrm{mi}(3.2 \mathrm{~km})$ and connects with SC-125 (Atomic Road) (SCR 2007i). 


\section{J.12.13 Waste Management}

SRS manages spent nuclear fuel, high level waste (HLW), low level waste (LLW), mixed low level waste (MLLW), transuranic (TRU) waste, hazardous waste, sanitary solid waste, low-level wastewater, and sanitary sewage.

Each operation at SRS has the goal of identifying and implementing measures that minimize waste and prevent pollution. Pollution prevention is integral to the SRS Environmental Management System. SRS's Pollution Prevention Program establishes the preference of source reduction and recycling over treatment, storage, and disposal. Accomplishments during 2004 included completion of 51 pollution prevention projects, resulting in an annualized avoidance of $9,277 \mathrm{yd}^{3}\left(7,093 \mathrm{~m}^{3}\right)$ of waste, with an accompanying cost avoidance of $\$ 41.5$ million (WSRC 2005).

SRS is also engaged in cleanup and decommissioning and demolition projects. SRS is responsible for cleaning up more than 500 waste and groundwater units to reduce risk and protect human health and the environment. In 2004, SRS had completed more than 300 of the units. By 2025, all inactive SRS waste sites that pose a risk to human health or the environment will be remediated and controlled, and contaminated surface and groundwater will be remediated, in remediation, or closely monitored. By the end of 2006, more than 250 buildings were scheduled to be demolished. Across the site, there are about 6,000 buildings, encompassing about 10 million $\mathrm{ft}^{2}\left(929,030 \mathrm{~m}^{2}\right)$. Decommissioning and decontamination (D\&D) work is expected to continue until about 2025 (WSRC 2005). 



\section{J.13 REFERENCES}

10 CFR Part 100

10 CFR Part 835

29 CFR Part 1910

40 CFR Part 50

40 CFR Part 61

40 CFR Part 81

40 CFR 81.318

40 CFR Part 125

40 CFR Part 190
U.S. Nuclear Regulatory Commission (NRC), "Reactor Site Criteria," Code of Federal Regulations, Office of the Federal Register, National Archives and Records Administration,

Washington, DC, Revised January 1, 2008.

NRC, "Occupational Radiation Protection," Code of Federal Regulations, Office of the Federal Register, National Archives and Records Administration, Washington, DC, Revised January 1, 2008.

Occupational Safety and Health Administration (OSHA), "Occupational Safety and Health Standards," Code of Federal Regulations, Office of the Federal Register, National Archives and Records Administration, Washington, DC, Revised July 1, 2007.

U.S. Environmental Protection Agency (EPA), "National Primary and Secondary Ambient Air Quality Standards," Code of Federal Regulations, Office of the Federal Register, National Archives and Records Administration, Washington, DC, Revised July 1, 2007.

EPA, "National Emission Standards for Hazardous Air Pollutants (NESHAPs)," Code of Federal Regulations, Office of the Federal Register, National Archives and Records Administration, Washington, DC, Revised July 1, 2007.

EPA, "Designation of Areas for Air Quality Planning Purposes," Code of Federal Regulations, Office of the Federal Register, National Archives and Records Administration, Washington, DC, Revised July 1, 2007.

EPA, "Designation of Areas for Air Quality Planning Purposes, Kentucky," Code of Federal Regulations, Office of the Federal Register, National Archives and Records Administration,

Washington, DC, Revised July 1, 2007.

EPA, "Criteria and Standards for the National Pollutant Discharge Elimination System," Code of Federal Regulations, Office of the Federal Register, National Archives and Records Administration, Washington, DC, Revised July 1, 2007.

EPA, "Environmental Radiation Protection Standards for Nuclear Power Operations," Code of Federal Regulations, Office of the Federal Register, National Archives and Records Administration, Washington, DC, Revised July 1, 2007. 
40 CFR Parts 239-299

50 CFR Part 17

65 FR 37253

15 U.S.C. 2601 et seq.

33 U.S.C. 1251 et seq.

42 U.S.C. $5121-5170$

42 U.S.C. 9610

Ackerman et al. 2006

ATSDR 2004

BEA 2006a
EPA, "Resource Conservation and Recovery Act," Code of Federal Regulations, Office of the Federal Register, National Archives and Records Administration, Washington, DC, Revised July 1, 2007.

U.S. Fish and Wildlife Service (USFWS), "Endangered and Threatened Wildlife and Plants," Code of Federal Regulations, Office of the Federal Register, National Archives and Records Administration, Washington, DC, Revised October 1, 2007.

Presidential Documents, "Establishment of the Hanford Reach National Monument," Office of the Federal Register, National Archives and Records Administration, Washington, DC, June 13, 2000 .

"Toxic Substance Control Act," United States Code, Washington, DC, January 3, 2006.

"Clean Water Act (CWA)," United States Code, Washington, DC, 1972.

"Federal Emergency Management Act," United States Code, Washington, DC, 1974.

"Comprehensive Environmental Response, Compensation, and Liability Act (CERCLA)," United States Code, Washington, DC, December 11, 1980.

Ackerman, D.J., G.W. Rattray, J.P. Rousseau, L.C. Davis, and B.R. Orr, " A Conceptual Model of Ground-Water Flow in the Eastern Snake River Plain Aquifer at the Idaho National Laboratory and Vicinity with Implications for Contaminant Transport," Scientific Investigations Report 2006-5122, U.S. Geological Survey, 2006.

Agency for Toxic Substances and Disease Registry (ATSDR), "Public Health Assessment, Idaho National Engineering and Environmental Laboratory (U.S. Department of Energy), Idaho Falls, Butte, Clark, Jefferson and Bin Counties, Idaho," Department of Health and Human Services, March 29, 2004.

Bureau of Economic Analysis (BEA), "CA25N - Total Full-Time and Part-Time Employment by Industry," Bureau of Economic Analysis, U.S. Department of Commerce, Washington, DC, 2006. 
BEA 2006b

BLS 2005b

DOE 1989a

DOE 1992b

DOE 1995d

DOE 1996a

DOE 1999a

DOE 2000b
BEA, "CA30 - Regional Economic Profiles," Bureau of Economic Analysis, U.S. Department of Commerce, Washington, DC, 2006.

Bureau of Labor Statistics (BLS), "Local Area Unemployment Statistics," Bureau of Labor Statistics, U.S. Department of Labor, Washington, DC, 2006. Accessed at http://www.bls.gov/lau/ lastrk05.htm on August 28, 2008.

U.S. Department of Energy (DOE), "Site Selection Report for the New Production Reactor at the Idaho National Engineering Laboratory," EGG-NPR-8517, Revision1, U.S. Department of Energy, Idaho Operations Office, Idaho Falls, ID, July 1989.

DOE, "Environmental Assessment for DOE Permission for OffLoading Activities to Support the Movement of Millstone Unit 2 Steam Generator Sub-Assemblies Across the Savannah River Site," U.S. Department of Energy, Savannah River Field Office, Aiken, SC, October 1992.

DOE, "Savannah River Site (SRS) Waste Management Final Environmental Impact Statement,” DOE/EIS-0217, U.S.

Department of Energy, Savannah River Site Office, Aiken, SC, July 1995.

DOE, "Environmental Assessment and FONSI Management of Spent Nuclear Fuel on the Oak Ridge Reservation Oak Ridge, Tennessee," DOE/EA-1117, Oak Ridge National Laboratory, Oak Ridge, TN, U.S. Department of Energy, Washington, DC, February 1996.

DOE, "Final Hanford Comprehensive Land-Use Plan Environmental Impact Statements," DOE/EIS-0222F, U.S. Department of Energy, Richland Operations Office, Richland, WA, September 1999.

DOE, "Final Site-Wide Environmental Impact Statement for Oak Ridge Y-12 Plant," DOE/EIS-0309, Y-12 Site Office, National Nuclear Security Administration, U.S. Department of Energy, Washington, DC, November 2000. 
DOE 2000g

DOE 2000j

DOE 2002a

DOE 2002e

DOE 2003a

DOE 2004b

DOE 2004d

DOE 2004i
DOE, "Final Programmatic Environmental Impact Statement for Accomplishing Expanded Civilian Nuclear Energy Research and Development and Isotope Production Missions in the United States, Including the Role of the Fast Flux Test Facility," DOE/EIS-0310, Office of Nuclear Energy, Science and Technology, U.S. Department of Energy, Washington, DC, December 2000.

DOE, "Environmental Management Performance Report," DOE/RL-99-83, Revision 3, U.S. Department of Energy, Richland Operations Office, Richland, WA, April 2000.

DOE, "Savannah River Site High-Level Waste Tank Closure Final Environmental Impact Statement," DOE/EIS-0303, U.S. Department of Energy, Washington, DC, May 2002. Accessed at http://www.gc.energy.gov/NEPA/finalEIS-0303.htm on September $16,2008$.

DOE, "Idaho High-Level Waste \& Facilities Disposition, Final Environmental Impact Statement," DOE/EIS-0287, U.S. Department of Energy, Washington, DC, September 2002. Accessed at http://gc.energy.gov/NEPA/nepa documents/EIS/EIS0 287/0287TOC.html on September 16, 2008.

DOE, "Draft Supplemental Programmatic Environmental Impact Statement on Stockpile Stewardship and Management for a Modern Pit Facility," DOE/EIS-0236-S2, U.S. Department of Energy, Washington, DC, June 2003.

DOE, "Final Environmental Impact Statement for Construction and Operation of a Depleted Uranium Hexafluoride Conversion Facility at Portsmouth, Ohio Site," DOE/EIS-0360, U.S. Department of Energy, Oak Ridge Operations Office, Oak Ridge, TN, June 2004.

DOE, "Final Environmental Impact Statement for Construction and Operation of a Depleted Uranium Hexafluoride Conversion Facility at the Paducah, Kentucky, Site," DOE/EIS-0359, U.S. Department of Energy, Washington, DC, June 2004.

DOE, "Final Hanford Site Solid (Radioactive and Hazardous) Waste Program Environmental Impact Statement Richland, Washington," DOE/EIS-0286F, U.S. Department of Energy, Richland Operations Office, Richland, WA, January 2004. 
DOE 2005a

DOE 2005b

DOE 2005d

DOE $2005 f$

DOE 2005p

DOE 2006b

DOE 2006e

DOE 2006n

DOE 2006r
DOE, "Idaho National Engineering and Environmental Laboratory Site Environmental Report Calendar Year 2004," DOE/ID12082(04), Environmental Surveillance, Education and Research Program, U.S. Department of Energy, Idaho Falls, ID, October 2005.

DOE, "Draft Environmental Impact Statement for the Proposed Consolidation of Nuclear Operations Related to Production of Radioisotope Power Systems" DOE/EIS-0373D, U.S. Department of Energy, Washington, DC, June 2005.

DOE, "Savannah River Site Specific End State Vision," U.S. Department of Energy, Washington, DC, June 26, 2005. Accessed at http://www.srs.gov/sro/pubact1.htm on October 14, 2007.

DOE, "Hanford Site National Environmental Policy Act (NEPA) Characterization," PNNL-6415, Revision 17, Pacific Northwest National Laboratory, Richland, WA, September 2005.

DOE, "Environmental Assessment for the Storage of Tritium Producing Burnable Absorber Rods In K- Area Transfer Bay at the Savannah River Site," DOE/EA-1528, U.S. Department of Energy, Savannah River Operations Office, Savannah River Site, June 2005.

DOE, "Hanford Site Environmental Report for Calendar Year 2005," PNNL-15892, U.S. Department of Energy, Washington, DC, September 2006.

DOE, "The Oak Ridge Reservation Annual Site Environmental Report for 2005," DOE/ORO/2218, U.S. Department of Energy, Oak Ridge Operations Office, Oak Ridge, TN, 2006.

DOE, "Financial Assistance Funding Opportunity Announcement Global Nuclear Energy Partnership (GNEP) Siting Studies," Funding Opportunity Number: DE-PS07-06ID14760, U.S. Department of Energy, Washington, DC, 2006.

DOE, "Idaho National Laboratory Site Environmental Report Calendar Year 2005," DOE/ID-12082(05), Environmental Surveillance, Education and Research Program, U.S. Department of Energy, Idaho Operations Office, ID, October 2006. Accessed at http://www.stoller-eser.com/Annuals/2005/index.htm on January 15, 2008. 
DOE 2007a

DOE 2007b

DOE 2007h

DOE O 5400.5

EPA 2007a

Hughes et al. 2004

IDEQ 2004a

INL 2006

Kilgo and Blake 2005

Lide et al. 1995
DOE, "Financial Assistance Funding Opportunity Announcement, GNEP Deployment Studies," Funding Opportunity Number: DEPS01-07NE24448, U.S. Department of Energy, Washington, DC, 2007.

DOE, "GNEP Siting Studies Received," U.S. Department of Energy, Washington, DC, May 30, 2007.

DOE, "Hanford Site National Environmental Policy Act (NEPA) Characterization," PNNL-6415 Rev 18, U.S. Department of Energy, Pacific Northwest National Laboratory, Richland, WA, September, 2007.

DOE Order 5400.5, "Radiation Protection of the Public and the Environment," Office of Environment, Safety and Health, U.S. Department of Energy, Washington, DC, July 1, 1993.

EPA, "National Emissions Inventory (NEI) Air Pollutant Emissions Trends Data," U.S. Environmental Protection Agency, Washington, DC, April 2006. Accessed at http://www.epa.gov/ ttn/chief/trends/ on January 15, 2007.

Hughes, J., W. McMahon and M. Coffey, "Oak Ridge Reservation Annual Site Environmental Report for 2003," DOE/ORO/2185, Oak Ridge National Laboratory, Oak Ridge, TN, 2004.

Idaho Department of Environmental Quality (IDEQ), "Portneuf Valley $\mathrm{PM}_{10}$ Nonattainment Area State Implementation Plan, Maintenance Plan and Redesignation Request," Idaho Department of Environmental Quality, Pocatello, ID, May 2004.

Idaho National Laboratory (INL), "Idaho National Laboratory Comprehensive Land Use and Environmental Stewardship Report," INL/EXT-05-00726, Idaho National Laboratory, Infrastructure Optimization, Integration and Planning, Idaho Falls, Idaho, September 2006.

Kilgo, J.C., and J.I. Blake," Ecology and Management of a Forested Landscape: Fifty Years on the Savannah River Site," OSTI ID: 842217, USDA Forest Service, Savannah River, New Ellenton, SC, July 1, 2005

Lide, R.F., V.G. Meentenmeyer, J.E.III Pinder, and L.M. Beatty, "Hydrology of a Carolina Bay Located on the Upper Coastal Plain of Western South Carolina," Wetlands, Volume 15, No. 1, PP: 47-57, 1995. 
Meyer et al. 1999

NRC 2005c

ORNL 2002

ORNL 2004a

Poston et al. 2007

Rogers 1990

SCR 2007a

SCR 2007b

SCR 2007c
Meyer, K.R., J.E. Till, G.G. Killough, W.S. Sinclair, P.G. Voillequé, S.K. Rope, and M.J. Case, "Savannah River Site Environmental Dose Reconstruction Project," Phase II: Source Term Calculation and Ingestion Pathway Data Retrieval Evaluation of Materials Released from the Savannah River Site, RAC Report No. 1-CDC-SRS-1999-Final, Community Executive Summary, Risk Assessment Corporation, Neeses, South Carolina, 1999. Accessed at http://www.racteam.com/Experience/

Publications/Community_Summary.pdf on August 17, 2007.

NRC, "Environmental Impact Statement on the Construction and Operation of a Proposed Mixed Oxide Fuel Fabrication Facility at the Savannah River Site, South Carolina-Final Report," NUREG1767, U.S. Nuclear Regulatory Commission, Washington, DC, January 2005.

Oak Ridge National Laboratory (ORNL), "Oak Ridge National Laboratory Land and Facilities Plan," ORNL/TM-2002/1, Oak Ridge National Laboratory, Oak Ridge, TN, August 2002.

ORNL, "Oak Ridge Reservation Annual Site Environmental Report Summary 2003," DOE/ORO/2185, Oak Ridge Operations Office, Oak Ridge, TN, 2004.

Poston, T.M., R.W. Hanf, J.P. Duncan, and R.L.Dirkes, "Hanford Site Environmental Report for Calendar Year 2006," Pacific Northwest National Laboratory, Richland, WA, September 2007.

Rogers, V.A., "Soil Survey of Savannah River Plant Area, Parts of Aiken, Barnwell, and Allendale Counties, South Carolina," DOE/SR/10708-1, June 1, 1990.

Site Characterization Report (SCR), "Detailed Site Report for the Global Nuclear Energy Partnership, Atomic City, Idaho Site," DE-FG07-07ID14801, Energy Solutions, Laurel, MD, May 1, 2007.

SCR, "Global Nuclear Energy Partnership (GNEP) Detailed Site Report for Barnwell County, South Carolina," DE-FG0707ID14800, Energy Solutions, Laurel, MD, April 30, 2007.

SCR, "GNEP Siting Study Detailed Site Report for GE Morris Site, Illinois," General Electric, April 27, 2007. 
SCR 2007d

SCR 2007e

SCR 2007f

SCR $2007 \mathrm{~g}$

SCR 2007h

SCR 2007i

Slocum 2006

SRS 2006

Thomason and Associates 2004
SCR, "Final Detailed Siting Report for Lea County Site," EddyLea Siting Study, DE-FG07-07ID14799, Eddy Lea Energy Alliance, LLC, April 28, 2007.

SCR, "Detailed Site Report for a Global Nuclear Energy Partnership (GNEP) Siting Study of a Selected Geographical Location in McCracken County, Kentucky," DE-FG0707ID14796, Paducah Uranium Plant Asset Utilization, Inc. and CH2M Hill, Revision 2, April 30, 2007.

SCR, "GNEP Detailed Site Study Report for Portsmouth Reservation, Piketon, Ohio," DE-FG07-07ID14795, Piketon Initiative for Nuclear Independence (ePIFNI), May 1, 2007.

SCR, "Detailed Site Report for the Global Nuclear Energy Partnership, Roswell, New Mexico Site," DE-FG07-07ID14802, Energy Solutions, Roswell, New Mexico Site, May 1, 2007.

SCR, "Site Characterization Report for the Oak Ridge Reservation Melton Valley Site," DE-FG07-07ID14793, Community Reuse Organization of East Tennessee, Oakridge, Tennessee, May 1, 2007.

SCR, "Global Nuclear Energy Partnership Siting Study Final Report," Energy Park on the Savannah River Site, DE-FG0707ID14794, The Central Savannah River Area Community Team, April 30, 2007.

Telecom between Rich Slocum, Site Utilities Director, FluorHanford and Daniel Theisen, Tetra Tech, "Data Necessary to Populate the Hanford Site Infrastructure Summary Table of the EIS (road and rail miles, electrical usage, fuel usage, and water usage)," November 8, 2006.

Savannah River Site (SRS), "Facts About the Savannah River Site," Washington Savannah River Company, Savannah River Site, Aiken, SC, 2006.

Thomason and Associates Preservation Planners, "National Historic Preservation Act, Historic Preservation Plan," Oak Ridge National Laboratory, Oak Ridge, Tennessee, April 2004. 
TtNUS 2006a

TtNUS 2006b

TtNUS 2006c

TtNUS 2006e

TtNUS $2006 f$

USCB 1990

USCB 2007a

USCB 2007c

USCB 2007f

USFWS $2007 b$

Wike et al. 2006

WQCC 2002
Tetra Tech NUS Inc. (TtNUS), "Calculation Package for Data included in GNEP EIS Section 4.2.10 Idaho National Laboratory Environmental Justice," Emily H. McRee, Aiken, SC,

September 18, 2006.

TtNUS, "Calculation Package for Data included in GNEP EIS Section 4.3.10 Savannah River Site Environmental Justice," Emily H. McRee, Aiken, SC, September 18, 2006

TtNUS, "Calculation Package for Data included in GNEP EIS Section 4.5.10 Oak Ridge National Laboratory Environmental Justice," Emily H. McRee, Aiken, SC, October 17, 2006.

TtNUS, "Calculation Package for Data included in GNEP EIS Section 4.6.10 Hanford Environmental Justice," Emily H. McRee, November 16, 2006.

TtNUS, "Calculation Package for Socioeconomics Analyses included in the GNEP Advanced Fuel Cycle Facility Programmatic EIS," Aiken, South Carolina, September 5, 2006.

United States Census Bureau (USCB), "DP-1. General Population and Housing Characteristics: 1990,” U.S. Census Bureau, 1990.

USCB, "Idaho-2006 American Community Survey," Data Profile Highlights, U.S. Census Bureau, 2007.

USCB, "Washington-2006 American Community Survey," Data Profile Highlights, U.S. Census Bureau, 2007.

USCB, "Tennessee-2006 American Community Survey," Data Profile Highlights, U.S. Census Bureau, 2007.

USFWS, "Threatened and Endangered Species System, Species Profile: Steelhead (Oncorhynchus (=Salmo) mykiss)," U.S. Fish and Wildlife Service, 2007.

Wike, L., D. Martin, E. Nelson, N. Halverson, J.Mayer, M. Paller, R.Riley, and M. Serrato, "SRS Ecology Environmental Information Document, WSRC-TR-2005-00201, Washington Savannah River Company, Savannah River Site, Aiken, SC, March 1, 2006.

Water Quality Control Commission, " 20.6.2.3101A NMAC, Purpose," Title 20, Chapter 6, Part 2, Water Quality Control Commission, New Mexico, Revised 2002. 
WSRC 2005

Westinghouse Savannah River Company (WSRC), "Savannah River Site Environmental Report for 2004," WSRC-TR-200500005, Westinghouse Savannah River Company, 2005. Accessed at http://www.srs.gov/general/pubs/ERsum/er05/er2004.htm, on September 8, 2006. 


\section{Global Nuclear Energy Partnership Programmatic Environmental Impact Statement}

Draft 



\title{
COVER SHEET
}

RESPONSIBLE AGENCY: United States Department of Energy (DOE)

TITLE: Draft Global Nuclear Energy Partnership Programmatic Environmental Impact Statement (GNEP PEIS; DOE/EIS-0396)

\section{CONTACT:}

For further information on this PEIS, write or call:

For general information on the DOE National

Environmental Policy Act (NEPA) process, write or call:

Mr. Francis Schwartz

GNEP PEIS Document Manager

Carol Borgstrom, Director

Office of Nuclear Energy, NE-5

U.S. Department of Energy

1000 Independence Avenue, SW

Washington, DC 20585

(866) 645-7803

Office of NEPA Policy and Compliance, GC-20

U.S. Department of Energy

1000 Independence Avenue, SW

Washington, DC 20585

(202) 586-4600

or leave a message at 1-800-472-2756

\begin{abstract}
The proposed Global Nuclear Energy Partnership (GNEP) Program, which is part of the President's Advanced Energy Initiative, is intended to support a safe, secure, and sustainable expansion of nuclear energy, both domestically and internationally. Domestically, the GNEP Program would promote technologies that support economic, sustained production of nuclear-generated electricity, while reducing the impacts associated with spent nuclear fuel disposal and reducing proliferation risks. The Department of Energy (DOE) proposed action envisions changing the United States nuclear energy fuel cycle from an open (or once-through) fuel cycle-in which nuclear fuel is used in a power plant one time and the resulting spent nuclear fuel is stored for eventual disposal in a geologic repository - to a closed fuel cycle in which spent nuclear fuel would be recycled to recover energy-bearing components for use in new nuclear fuel. At this time, DOE has no specific proposed actions for the international component of the GNEP Program. Rather, the United States, through the GNEP Program, is considering various initiatives to work cooperatively with other nations. Such initiatives include the development of grid-appropriate reactors and the development of reliable fuel services (to provide an assured supply of fresh nuclear fuel and assist with the management of the used fuel) for nations who agree to employ nuclear energy only for peaceful purposes, such as electricity generation.
\end{abstract}

DOE's Office of Nuclear Energy is preparing this programmatic environmental impact statement (PEIS) to assess the potential environmental impacts of expanding nuclear power in the United States using either the existing fuel cycle or various alternative closed and open fuel cycles. Six programmatic alternatives are assessed: No Action Alternative; Fast Reactor Recycle Alternative; Thermal/Fast Reactor Recycle Alternative; Thermal Reactor Recycle Alternative; Thorium Alternative; and Heavy Water Reactor/High Temperature Gas-Cooled Reactor Alternative. DOE has not selected a specific preferred alternative in this Draft PEIS, but DOE's preference is to close the fuel cycle.

Public Comments: A 60-day comment period on this document begins with the publication of the Environmental Protection Agency's Notice of Availability in the Federal Register. DOE will consider comments received after the 60-day period to the extent practicable. DOE will hold public hearings to receive comments on this document at the times and locations announced in local media and the DOE Notice of Availability. Comments may also be submitted to Mr. Francis Schwartz by mail at the above address or electronically at http://www.regulations.gov/. This document and related information are available on the Internet at www.gnep.energy.gov. 

DOE/EIS-0396

Draft

Global Nuclear Energy Partnership Programmatic Environmental Impact Statement

Summary

October 2008

Prepared by:

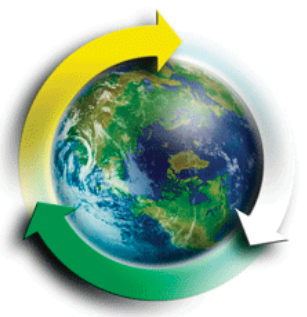





\section{SUMMARY}





\section{Table of Contents}

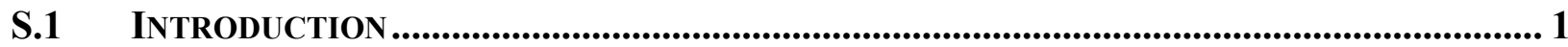

S.1.1 Purpose and Need for Agency Action ........................................................... 3

S.1.1.1 Energy/Electricity ............................................................................... 3

S.1.1.2 Spent Nuclear Fuel Disposal and Waste Reduction ...................................... 4

S.1.1.3 Proliferation Risk Reduction......................................................................... 5

S.1.2 Public Participation.................................................................................... 5

S.2 Domestic Programmatic Alternatives ............................................................. 7

S.2.1 No Action Alternative ........................................................................... 8

S.2.2 Fast Reactor Recycle Alternative.............................................................. 9

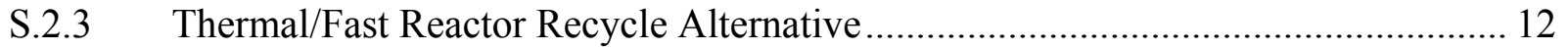

S.2.4 Thermal Reactor Recycle Alternative................................................................ 13

S.2.4.1 Option 1 - Thermal Reactor Recycle in Light Water Reactors .......................... 13

S.2.4.2 Option 2 - Thermal Reactor Recycle in Heavy Water Reactors ........................ 14

S.2.4.3 Option 3 - Thermal Reactor Recycle in High Temperature Gas-Cooled

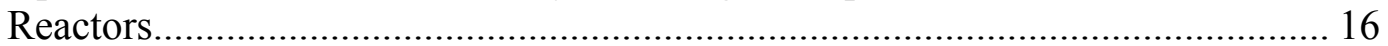

S.2.5 Thorium Alternative.................................................................................... 17

S.2.6 Heavy Water Reactor/High Temperature Gas-Cooled Reactor Alternative............ 18

S.2.6.1 Option 1 - Heavy Water Reactor.................................................................. 18

S.2.6.2 Option 2 - High Temperature Gas-Cooled Reactor ....................................... 19

S.2.7 Alternatives Considered but Eliminated from Detailed Study .............................. 20

S.2.7.1 Institute Interim Storage of Spent Nuclear Fuel ............................................ 20

S.2.7.2 Terminate the Advanced Fuel Cycle Initiative .............................................. 20

S.2.7.3 Fuel Cycle and Related Reactor and Technology Alternatives ........................ 21

S.2.7.4 Increase Burnup of Light Water Reactor Fuels ............................................. 21

S.2.7.5 Recycle Spent Nuclear Fuel Planned for the Yucca Mountain Repository .......... 21

S.2.7.6 Non-nuclear Electricity Production ............................................................. 22

S.3 IMPLEMENTATION OF DOMESTIC ALTERNATIVES.................................................. 22

S.3.1 Research and Development Needs.............................................................. 22

S.3.2 Transition and Implementation ........................................................................ 24

S.3.3 Design and Operation of a Future Geologic Repository...................................... 26

S.4 ENVIRONMENTAL IMPACTS OF DOMESTIC ALTERNATIVES ......................................... 31

S.4.1 Facility and Resource Requirements ............................................................ 36

S.4.2 Spent Nuclear Fuel and Radioactive Wastes .................................................. 36

S.4.3 Human Health ......................................................................................... 39

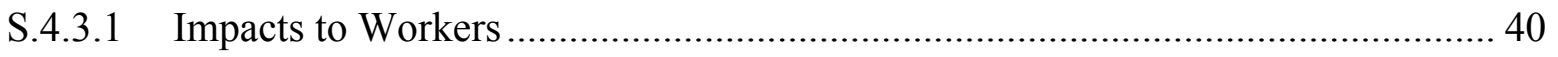

S.4.3.2 Impacts to the Public............................................................................... 41

S.4.4 Facility Accidents .................................................................................. 41

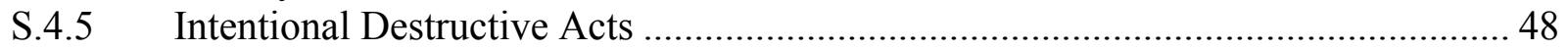

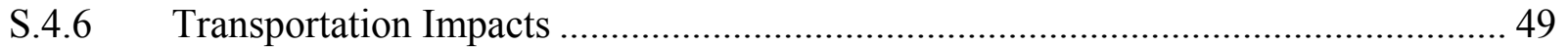

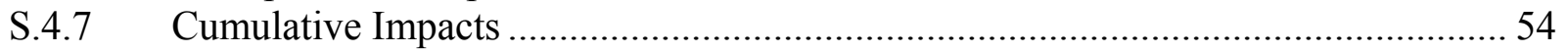

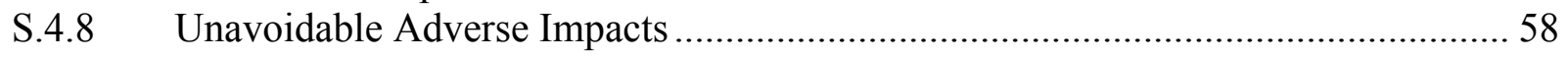

S.4.9 Irreversible and Irretrievable Resource Commitments ...................................... 58

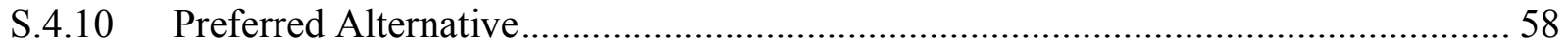

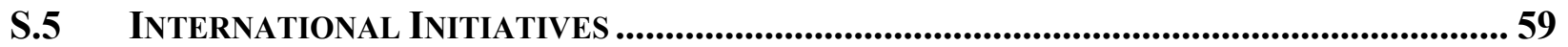




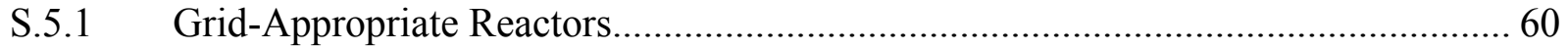

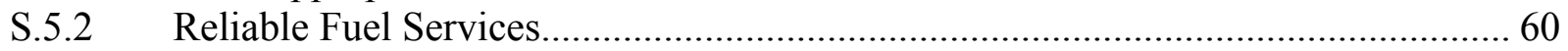

S.6 ENVIRONMENTAL IMPACTS OF INTERNATIONAL INITIATIVES .................................... 61

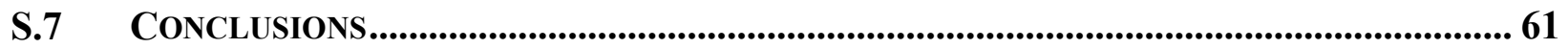

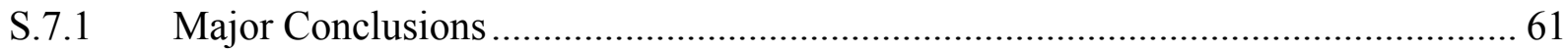

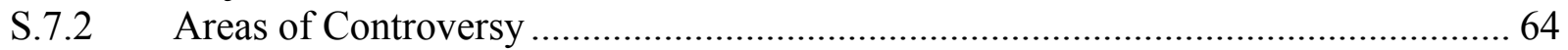

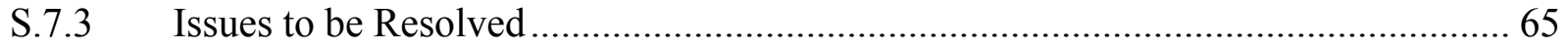

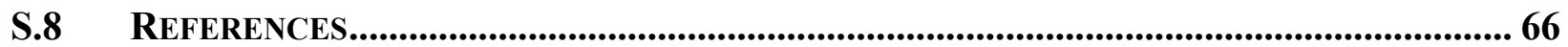

\section{List of Figures}

FIGURE S.2-1 - GNEP PEIS Scope and Alternatives ...................................................... 8

FIGURE S.2-2 - No Action Alternative Once-Through Uranium Fuel Cycle .............................. 9

FIGURE S.2-3 -Fast Reactor Recycle Alternative ........................................................... 11

FIGURE S.2-4-Thermal/Fast Reactor Recycle Alternative .................................................. 13

FIGURE S.2-5-Thermal Reactor Recycle Alternative: Option 1 (Thermal Reactor

Recycle in Light Water Reactors) ..................................................................... 14

FIGURE S.2-6-Thermal Reactor Recycle Alternative: Option 2 (Thermal Reactor

Recycle in Heavy Water Reactors) ....................................................................... 15

FIGURE S.2-7-Thermal Reactor Recycle Alternative: Option 3 (Thermal Reactor

Recycle in High Temperature Gas-Cooled Reactors).................................................... 17

FIGURE S.2-8 - Thorium Fuel Cycle Alternative................................................................. 18

FIGURE S.2-9-Heavy Water Reactor Open Fuel Cycle ....................................................... 19

FiguRE S.2-10 — High Temperature Gas-Cooled Open Fuel Cycle .......................................... 19

FIGURE S.3-1-Radiotoxicity of Spent Nuclear Fuel and/or High-Level Radioactive

Waste Over Time ......................................................................................... 27

\section{List of Tables}

TABLE S.3-1 - Comparative Summary of Programmatic Alternatives (Steady-State 200

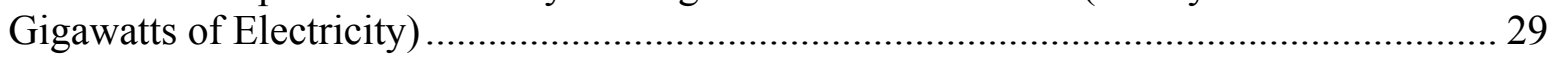

TABLE S.4-1 - Comparison of Domestic Programmatic Alternatives for $200 \mathrm{GWe}$

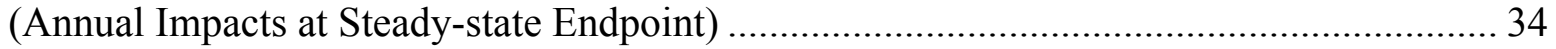

TABLE S.4-2 - Comparison of Programmatic Alternatives for 200 GWe (Cumulative

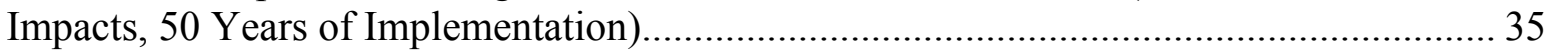

TABLE S.4-3 - Annual Impacts to Workers for Domestic Programmatic Alternatives............... 41

TABLE S.4-4 - Internally Initiated Accident with Highest Consequences to the

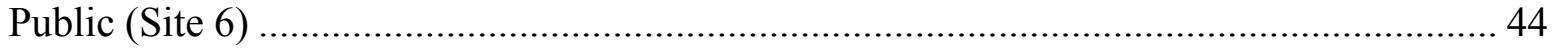

TABLE S.4-5-Internally Initiated Event with the Highest Accident Risks to the

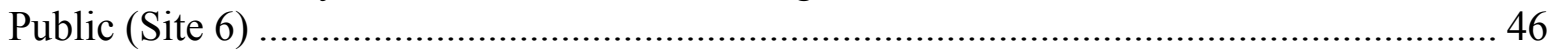

TABLE S.4-6 - Summary of Bounding Intentional Destructive Acts Scenario ......................... 48

TABLE S.4-7-Total Number of Shipments (50 years of implementation) ............................... 49

TABLE S.4-8 - Truck Handling Health and Safety Impacts (50 Years of

Implementation for 200 Gigawatts of Electricity) .................................................... 50 
TABLE S.4-9-Truck and Rail Handling Health and Safety Impacts (50 Years of

Implementation for 200 Gigawatts of Electricity)... 51

TABLE S.4-10 - Summary of In-Transit, Truck Transportation Impacts (50 Years of Implementation for 200 Gigawatts of Electricity)

TABLE S.4-11 - Summary of In-Transit, Truck and Rail Transportation Impacts

(50 Years of Implementation for 200 Gigawatts of Electricity)

TABLE S.4-12 - Potential Cumulative Transportation Impacts

\section{List of Acronyms and Abbreviations}

$\begin{array}{ll}\text { CFR } & \text { Code of Federal Regulations } \\ \text { DOE } & \text { U.S. Department of Energy } \\ \text { DUPIC } & \text { direct use of spent pressurized water reactor fuel in } \underline{\text { Canada Deuterium }} \\ \text { EIA } & \text { Uranium } \\ \text { Energy Information Administration } \\ \text { FR } & \text { Environmental Impact Statement } \\ \text { GNEP } & \text { Federal Register } \\ \text { GWe } & \text { Global Nuclear Energy Partnership } \\ \text { LCF } & \text { gigawatt-electric } \\ \text { MOX } & \text { Latent Cancer Fatality } \\ \text { MOX-TRU } & \text { Mixed-oxide } \\ \text { MOX-U-Pu } & \text { Mixed-oxide fuel made up of uranium and transuranics } \\ & \text { Mixed-oxide fuel in which pure plutonium is not separated out from the } \\ \text { MTHM } & \text { uranium } \\ \text { PEIS } & \text { Metric Tons Heavy Metal } \\ \text { PUREX } & \text { Programmatic Environmental Impact Statement } \\ \text { R\&D } & \text { Plutonium and Uranium Recovery by Extraction } \\ \text { U.S. } & \text { research and development } \\ & \text { United States }\end{array}$





\section{SUMMARY}

\section{S.1 INTRODUCTION}

The Global Nuclear Energy Partnership (GNEP) Program, a United States (U.S.) Department of Energy (DOE) program, is intended to support a safe, secure, and sustainable expansion of nuclear energy, both domestically and internationally. Domestically, the GNEP Program would promote technologies that support economic, sustained production of nuclear-generated electricity, while reducing the impacts associated with spent nuclear fuel disposal and reducing proliferation risks. DOE envisions changing the U.S. nuclear energy fuel cycle ${ }^{1}$ from an open (or once-through) fuel cycle-in which nuclear fuel is used in a power plant one time and the resulting

spent nuclear fuel is stored for eventual disposal in a geologic repository-to a closed fuel cycle, in which spent nuclear fuel would be recycled to recover energy-bearing components for use in new nuclear fuel.

\section{The National Environmental Policy Act (NEPA)} requires that an Environmental Impact Statement (EIS) be prepared in order to inform the public and the decision-makers of the potential environmental impacts of proposed Federal actions and the reasonable alternatives prior to making any such decisions. For a

Nuclear Energy Fuel Cycle
A nuclear energy fuel cycle is the series of
steps from mining to waste disposal
involved in the production of electricity
from nuclear fuel.

Spent Nuclear Fuel

Spent nuclear fuel consists of nuclear fuel that has been withdrawn from a nuclear reactor following irradiation. Typically, no more than five percent of the fuel has been used before the nuclear fuel is considered used, or "spent," and must be replaced with fresh fuel. broad program such as GNEP, which could involve many actions with far-reaching consequences over a long period of time, a program-level EIS (referred to as a Programmatic Environmental Impact Statement [PEIS]), is the appropriate document because it is relevant to policy-level decisions and is timed to coincide with meaningful points in agency planning and decision making (40 Code of Federal Regulations [CFR] Section 1502.4(b)).

This GNEP PEIS provides an analysis of the potential environmental impacts of expanding nuclear power in the U.S. using either the existing fuel cycle or various alternative closed and open fuel cycles. DOE's preference is to close the fuel cycle. The alternatives are described below in Section S.2.

In general, the analyses in this PEIS indicate that the closed fuel cycle alternatives offer a greater opportunity, relative to the open fuel cycle alternatives, to reduce the capacity requirements for a future geologic repository, and to reduce the hazards associated with the disposal of spent fuel or high-level radioactive waste. However, the closed fuel cycle alternatives require more disposal

\section{High-Level Radioactive Waste}

High-level radioactive waste is defined as: 1) the highly radioactive material resulting from the reprocessing of spent nuclear fuel, including liquid waste produced directly in reprocessing and any solid material derived from such liquid waste that contains fission products in sufficient concentrations; and 2) other highly radioactive material that the Nuclear Regulatory Commission, consistent with existing law, determines by rule requires permanent isolation.

\footnotetext{
${ }^{1}$ Text boxes provide additional information on words that are bold-faced.
} 
capacity for other radioactive wastes than is required under the open fuel cycle alternatives. Furthermore, transportation and associated health impacts from the closed fuel cycle alternatives would be generally higher during the operational period than those from the open fuel cycle alternatives (with one exception ${ }^{2}$ ). Potential environmental impacts are summarized in Section S.4.

The GNEP Program also has an international component (referred to as international initiatives) pursuant to which the U.S. would cooperate with other fuel cycle nations (i.e., those already recycling spent nuclear fuel) to develop and deploy advanced nuclear recycling and reactor technologies in those countries in order to move away from producing separated pure plutonium. Furthermore, the GNEP Program would work to put in place a framework for reliable nuclear fuel services in order to remove the need for a country to develop its own enrichment or reprocessing facilities. This PEIS identifies two international initiatives and discusses how these initiatives could produce environmental impacts within the U.S. and the global commons (defined as the environment outside the jurisdiction of any nation, such as the oceans or Antarctica). The

Enrichment-The process of increasing the proportion (or ratio) of uranium-235 atoms to uranium-238 atoms to make the mixture more usable as nuclear fuel.

Reprocessing-The process of separating the usable and unusable constituents of spent nuclear fuel. analyses in the PEIS indicate that, in particular, the radiological dose to the public from the international component would be low in general, and would be somewhat greater under the closed fuel cycle alternatives than under the open fuel cycle alternatives (additional details are provided in Section S.6).

Following completion of this PEIS, DOE will be in a position to decide whether to pursue a closed fuel cycle. This PEIS is a first, important step in deciding whether and how to recycle spent nuclear fuel. A decision to go forward with recycling could trigger additional proposals and research to achieve DOE's programmatic goal. Subsequent DOE policies and actions could also affect decisions by the U.S. commercial utility industry, which would ultimately determine whether and how to implement any changes in the domestic fuel cycle.

With regard to the international aspects of the GNEP Program, this PEIS does not evaluate any specific proposed actions or alternatives. Consequently, DOE would not make any decisions related to international initiatives and activities based on this PEIS.

At this time, DOE is not proposing project-specific or site-specific actions, such as the construction and operation of individual facilities to support the demonstration and deployment of any programmatic alternative. If such proposals were to be made after completion of this PEIS, DOE would conduct the appropriate level of review under the National Environmental Policy Act prior to making any decision on the proposals.

\footnotetext{
${ }^{2}$ As explained in Section S.4.6, the All-High Temperature Gas-Cooled Reactor Option, which is an open fuel cycle, would have the highest transportation impacts for truck transport due to the high number of spent fuel shipments associated with this alternative.
} 


\section{S.1.1 Purpose and Need for Agency Action}

DOE's underlying purpose and need is to support expansion of domestic and international nuclear energy production, while reducing the risks of nuclear proliferation and reducing the impacts associated with the disposal of spent nuclear fuel (e.g., by reducing the volume, thermal output, and/or radiotoxicity of waste requiring geologic disposal). To meet its nonproliferation goals with regard to spent nuclear fuel recycling, DOE will assess, as reasonable alternatives, only those technologies that do not separate or use pure plutonium.

\section{S.1.1.1 Energy/Electricity}

Electricity use in the United States is expected to continue to grow. In its most recent Energy Outlook Report, issued in June 2008, the Energy Information Administration (EIA), an independent organization within DOE, estimates that demand for electricity will increase by approximately 1.1 percent annually through 2030 (EIA 2008a). An early release of that report, issued in December 2007, estimated United States electricity growth at 1.3 percent annually through 2030 (EIA 2007a). This Draft PEIS utilizes the higher 1.3 percent growth rate; however, in the Final PEIS, DOE will consider whether any changes to the document are warranted to account for the 1.1 percent growth rate or other relevant information that becomes available. Based on an annual growth rate of

Radiotoxicity
Radiotoxicity is a measure of the hazard
posed by radioactive material.
Radiotoxicity is an inherent property of the
radioactive material, and represents the
source of the potential hazard associated
with exposure. It is a measure of the
adverse health effects caused by a
radionuclide due to its radioactivity.
Because different radionuclides give
different biological effects, the total
radiotoxicity from a group of radionuclides
is the sum of the radiotoxicity of each
radionuclide. Since the radionuclides are
decaying with time, the radiotoxicity also
changes with time.
1.3 percent, electricity use could increase by approximately 40 percent by 2030 , and if that annual rate were to continue, electricity use could double (relative to use in 2004) by approximately 2060 .

With respect to the generation of electricity by nuclear power, which currently supplies approximately 19 percent of United States electricity needs, the Energy Information Administration estimated an annual growth of 0.6 percent in the June 2008 Energy Outlook Report and 0.7 percent in the December 2007 report (EIA 2008a, EIA 2007a). This Draft PEIS utilizes the higher 0.7 percent growth rate. When compared to the 1.3 percent annual growth in overall electricity use, nuclear energy's contribution to U.S. needs (its market share) would decline. This PEIS analyzes four different growth rates for electricity generation from nuclear power ( 0 or no growth, 0.7 percent, 1.3 percent and 2.5 percent for a high growth rate case). Unless indicated otherwise, the environmental impact analysis in this Summary is presented for a 1.3 percent growth scenario (which would equate to approximately 200 gigawatts of electricity $(\mathrm{GWe})^{3}$ from nuclear power in the 2060-2070 time frame).

\footnotetext{
${ }^{3}$ One GWe is equal to 1,000 megawatts of electricity.
} 
Consistent with the President's 2006 Advanced Energy Initiative, DOE seeks to develop ways to support the expanded use of nuclear energy to meet growing electricity demand. DOE policies and actions resulting from decisions in response to this PEIS could affect subsequent decisions made by the U.S. commercial utility industry, which ultimately would determine how to meet the future increased demands for electricity.

\section{S.1.1.2 Spent Nuclear Fuel Disposal and Waste Reduction}

The Nuclear Waste Policy Act of 1982, as amended, provides for the disposal of spent nuclear fuel and highlevel radioactive waste in the Nation's first proposed geologic repository to be located at Yucca Mountain, Nevada. Yucca Mountain is located in a remote desert on Federal land on and adjacent to the secure boundaries of the Nevada Test Site in Nye County,

\section{Advanced Energy Initiative}

Includes, in part, a combination of initiatives intended to accelerate research and development in three areas of power generation:

- National and international nuclear energy activities, such as the GNEP Program

- Coal-based clean power and carbon sequestration

- Renewable resources such as solar, wind and geothermal power.

Nevada (DOE 2008f) ${ }^{4}$. Pursuant to the Nuclear Waste Policy Act of 1982 and by contract, the Federal government has responsibility for the disposal of commercial spent nuclear fuel currently being stored onsite at commercial reactor facilities.

Under the Nuclear Waste Policy Act of 1982, the statutory capacity limit for the Yucca Mountain repository is 70,000 metric tons of heavy metal $(\mathrm{MTHM})^{5}$ of spent nuclear fuel and high-level radioactive waste. DOE estimates that this statutory capacity limit will be reached by approximately 2010 . Regardless of any DOE decision related to the GNEP PEIS, the Nation requires a permanent geologic repository for the disposal of spent nuclear fuel and high-level radioactive waste. The GNEP Program has been proposed in addition to the Yucca Mountain

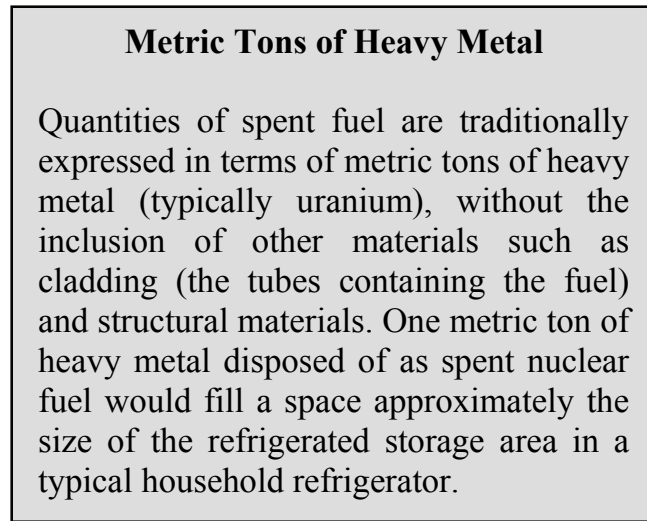

\footnotetext{
${ }^{4}$ The potential environmental impacts of the construction, operation, and closure of the Yucca Mountain repository are addressed in the Environmental Impact Statement for a Geologic Repository for the Disposal of Spent Nuclear Fuel and High-Level Radioactive Waste at Yucca Mountain, Nye County, Nevada (DOE/EIS-0250, February 2002) (DOE 2002i) and the Final Supplemental Environmental Impact Statement for a Geologic Repository for the Disposal of Spent Nuclear Fuel and High-Level Radioactive Waste at Yucca Mountain, Nye County, Nevada (DOE/EIS-0250-S1) (DOE 2008f).

${ }^{5}$ The Nuclear Waste Policy Act of 1982 (NWPA) limits the initial capacity of Yucca Mountain, the first proposed geologic repository, to 70,000 MTHM of spent nuclear fuel and high-level radioactive waste (DOE has allocated this capacity between 63,000 MTHM of commercial spent nuclear fuel and 7,000 MTHM of DOE spent nuclear fuel and high-level radioactive waste) until such time as a second repository is in operation. In its cumulative impacts analysis, the Yucca Mountain Supplemental Environmental Impact Statement, issued in July 2008, evaluated the disposal of up to approximately 130,000 MTHM of spent nuclear fuel, equivalent to the amount projected from all existing commercial power reactors during all of their projected lifetimes. Disposal of more than 70,000 MTHM of spent nuclear fuel and high-level radioactive waste at the Yucca Mountain site prior to completion of a second repository would require a legislative change. DOE believes that if the statutory capacity limit is eliminated, then the Yucca Mountain geologic repository would have sufficient capacity to receive at least all of the spent nuclear fuel that has been or will be generated by the current fleet of nuclear power reactors.

Also, the current 70,000 MTHM statutory limit as defined in the NWPA pertains to the heavy metal content of the original fuel. As a result, from the standpoint of the Yucca Mountain geologic repository statutory capacity limit, it does not matter if spent nuclear fuel is emplaced as the original spent fuel rods, or spent nuclear fuel is reprocessed and only the resulting high-level waste is emplaced. While recycling spent nuclear fuel could significantly reduce the volume, radiotoxicity, and/or heat load in a future repository, recycling would have no impact on the initial Yucca Mountain repository capacity, because under current law its statutory capacity limit is based on initial MTHM (not volume, radiotoxicity, or heat load).
} 
repository mandated by the Nuclear Waste Policy Act of 1982, and does not change the planning for the Yucca Mountain repository. Any decisions pursuant to the GNEP PEIS would not diminish in any way the need for the nuclear waste disposal program at a permanent geologic repository. Under all alternatives, spent nuclear fuel and/or high-level radioactive waste would continue to be produced and require disposal.

The GNEP PEIS assesses alternatives that would reduce the volume, thermal output, and/or radiotoxicity of spent fuel and wastes requiring geologic disposal for quantities in excess of the 70,000 MTHM that DOE has proposed for disposal in the repository at Yucca Mountain.

Reducing the volume, thermal output, and/or radiotoxicity could expand the number of acceptable sites for future geologic repositories, and could reduce both the cost and difficulty of siting and operating a geologic repository.

\section{S.1.1.3 Proliferation Risk Reduction}

It is a long-standing U.S. national security policy objective to reduce proliferation risks throughout the nuclear fuel cycle via systematic and comprehensive efforts to prevent the spread of nuclear weapon materials and sensitive technologies. Therefore, in order for the U.S. to support nuclear energy in an expanded role in the global energy market, the risk of proliferation needs to be addressed. Accordingly, DOE seeks to explore reliable nuclear fuel service programs to enable other nations to acquire nuclear energy

Proliferation risks relate to the potential use of the nuclear materials and/or technologies from the civil nuclear fuel cycle to make a nuclear weapon. Proliferation risks can result from the spread of sensitive nuclear materials and/or technologies. economically while limiting the spread of sensitive fuel cycle technologies, particularly enrichment and reprocessing technologies. In addition, DOE seeks to advance programs to design and deploy nuclear reactors having less proliferation potential that are both cost effective and suited to conditions in developing nations.

Separate from the GNEP PEIS, the National Nuclear Security Administration, a separately organized agency within DOE, is preparing an assessment of the nonproliferation aspects of the programmatic alternatives evaluated in this GNEP PEIS. The draft assessment is expected to be publicly available in the same time frame as this Draft GNEP PEIS. The final assessment will be publicly available prior to the Record of Decision for this GNEP PEIS, and will be considered by DOE in decisions regarding the GNEP Program.

\section{S.1.2 Public Participation}

Regulations of the Council on Environmental Quality require "an early and open process for determining the scope of issues related to a proposed action" as part of NEPA compliance (40 CFR 1501.7). This activity is known as the public scoping process. The purpose of this scoping process is to inform the public about a proposed action and the alternatives being evaluated, and to solicit public comments on the range of reasonable alternatives and potential environmental impacts. 
On March 22, 2006, DOE published an Advance Notice of Intent for the Global Nuclear Energy Partnership Technology Demonstration Program Environmental Impact Statement in the Federal Register (71 FR 14505). The Advance Notice of Intent explained the goals of the GNEP Program, three major elements of the then-proposed GNEP Technology Demonstration Program, and the purpose and need for action, and presented a list of potential environmental issues for analysis. In the notice, DOE also solicited comments on the proposed scope, alternatives, and environmental issues to be analyzed in the then-planned GNEP Technology Demonstration EIS. DOE received about 800 comment documents, including comments that DOE should prepare a PEIS of the entire GNEP Program, not just the GNEP Technology Demonstration Program.

On August 3, 2006, DOE announced that it would issue financial assistance grants to public or commercial entities interested in hosting GNEP facilities (DOE 2006n). DOE reviewed the resulting grant applications and on January 30, 2007, issued grants to 11 commercial and public consortia to conduct siting studies for hosting an advanced nuclear fuel recycling center and/or an advanced recycling reactor at the following sites: Atomic City, Idaho; Idaho National Laboratory, Idaho; Morris, Illinois; Paducah, Kentucky; Hobbs, New Mexico; Roswell, New Mexico; Portsmouth, Ohio; Barnwell, South Carolina; Savannah River Site, South Carolina; Oak Ridge Reservation, Tennessee; and Hanford, Washington.

On January 4, 2007, DOE published the Notice of Intent for the GNEP PEIS in the Federal Register (72 FR 331). That Notice of Intent explained the scope of the revised GNEP Program, identified the alternatives that were then proposed for evaluation, described the purpose and need for action, identified potential sites that could host GNEP Program facilities, and listed potential environmental issues for analysis. Subsequent to the Notice of Intent, DOE held public scoping meetings near the sites that were proposed and in Washington, DC.

DOE received approximately 14,000 comment letters/emails and oral comments related to the scope of the GNEP PEIS. The major scoping comments related to the purpose and need, the alternatives that were being considered, the various resource areas that should be addressed in the PEIS, and proliferation risk.

DOE considered all comments received in the preparation of this PEIS. Some of the key comments requested additional programmatic alternatives. In the Notice of Intent, DOE identified two programmatic alternatives for analysis - a No Action Alternative and the Proposed Action. Under the No Action Alternative, the U.S. would continue to rely upon a once-through fuel cycle in which commercial light water reactors, which are classified as thermal reactors, would use fuel one time and the resulting spent nuclear fuel would be stored for eventual disposal in a geologic

\section{Types of Reactors}

Light water reactor. A nuclear reactor using ordinary water to cool the reactor and to slow down (moderate) neutrons. Light water reactors belong to the class of nuclear reactors called thermal reactors (so called because they use slow, thermal neutrons to cause fission).

Advanced recycling reactor: A sodiumcooled fast reactor containing nuclear fuel comprising a blend of uranium and various transuranic elements (for example, plutonium) recovered from processed spent nuclear fuel. A fast reactor is a reactor in which the chain reaction is sustained by fast neutrons. These higher energy neutrons can fission all types of uranium and transuranic elements, rather than only the fissile isotopes split in thermal reactors. This allows the fast reactor to transmute (consume) the transuranics. Thus, fast reactors can extract energy from both uranium and transuranic elements. 
repository. Under the Proposed Action, the U.S. would pursue a closed fuel cycle in a system that would process light water reactor spent nuclear fuel in one or more nuclear fuel recycling centers and would reuse some of the recovered materials in one or more fast reactors (also referred to as advanced recycling reactors). In response to scoping comments, the Department added four domestic programmatic alternatives that are evaluated in detail in this PEIS.

In response to public comments and as the programmatic analysis developed, DOE determined that to make project-specific or site-specific decisions regarding any of the three originally proposed facilities would be premature. The programmatic decisions to be made would influence the size and type of facilities required for implementing an alternative fuel cycle (the originally proposed nuclear fuel recycling center and advanced recycling reactor) as well as the facility needed to support research, development, and deployment (an Advanced Fuel Cycle Facility). As a result, no project-specific or site-specific proposals are being made at this time. Based on the proposed programmatic decisions, the DOE might make future proposals for particular actions. Any such proposals would be subject to appropriate NEPA review.

\section{S.2 Domestic Programmatic Alternatives}

This PEIS evaluates six domestic programmatic alternatives, which include both closed and open fuel cycles - a No Action Alternative (open cycle), three action alternatives with recycling of spent nuclear fuel (closed cycle), and two action alternatives without recycling of spent nuclear fuel. Figure S.2-1 provides a representation of the six domestic alternatives and the scope of the analyses in this PEIS. Each alternative is described in greater detail in Sections S.2.1-S.2.6. 


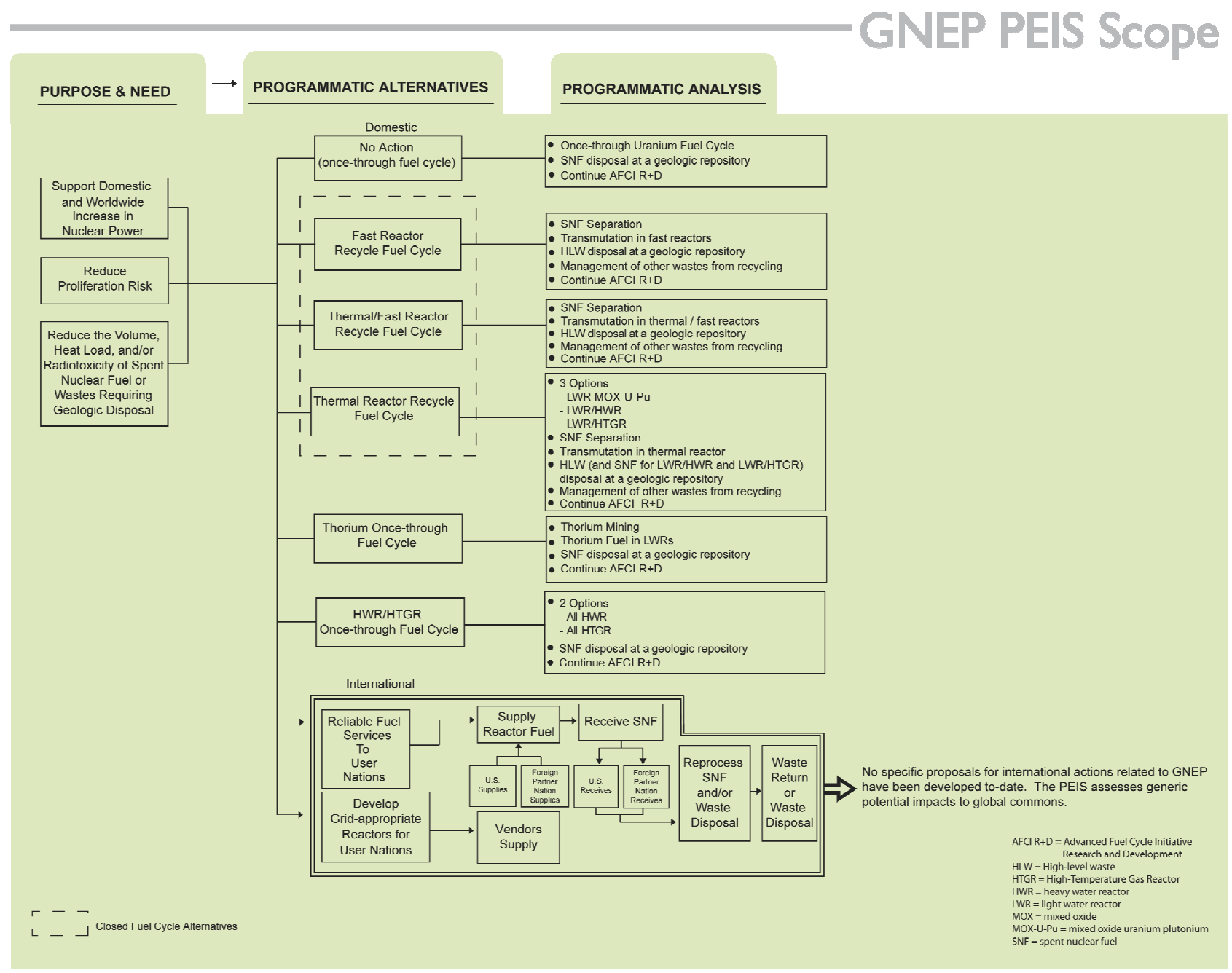

FIGURE S.2-1-GNEP PEIS Scope and Alternatives

\section{S.2.1 No Action Alternative}

The No Action Alternative, which is required in an EIS, provides a baseline from which to compare the environmental impacts of the action alternatives. Under the No Action Alternative, DOE would continue to support a once-through fuel cycle (Figure S.2-2) in which nuclear fuel would be used one time to generate electricity, and the resulting spent nuclear fuel would be stored for eventual disposal in a geologic repository. This alternative assumes that commercial reactors would be similar to those currently licensed by the Nuclear Regulatory Commission and those under consideration for licensing by the Nuclear Regulatory Commission (i.e., light water reactor and advanced light water reactor designs). In addition, this alternative assumes continued performance improvements in reactor operation (e.g., higher fuel burnup at discharge from the reactor).

Burnup refers to the amount of energy generated per unit mass of fuel. Higher burnup fuels can reduce the total amount of spent nuclear fuel generated by providing more energy per fuel assembly. Improved performance as a result of higher fuel burnup would be pursued under all domestic programmatic alternatives. 
Under the No Action Alternative, as well as under any of the action alternatives, DOE would continue activities associated with the Advanced Fuel Cycle Initiative and other related DOE programs, including programs that address safety, safeguards and security requirements for advanced fuel cycle technologies. The objective of the Advanced Fuel Cycle Initiative is to develop the technologies needed to: reduce the environmental consequences associated with spent nuclear fuel management, reduce the proliferation risk from the use of nuclear power, and extend uranium resources.

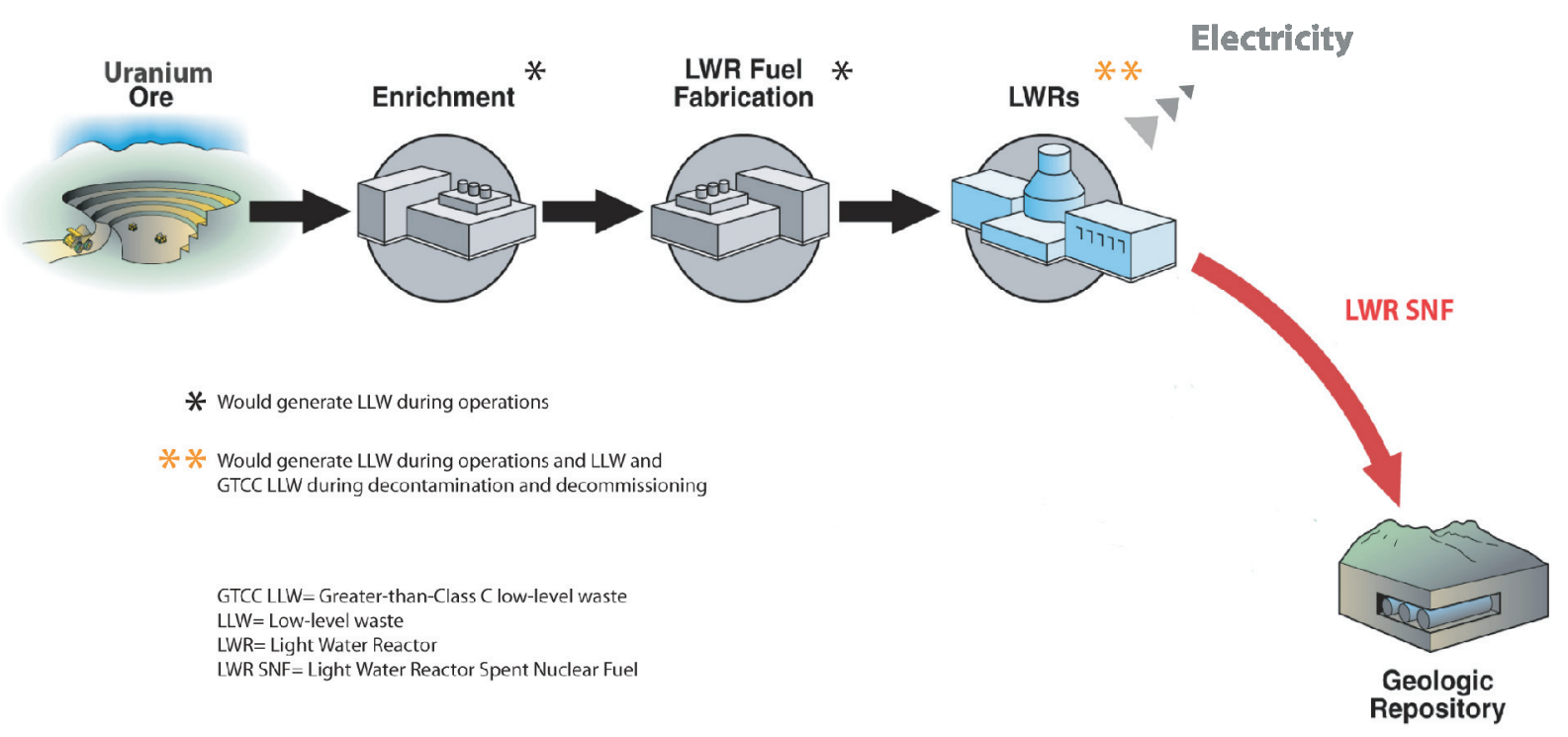

FIGURE S.2-2-No Action Alternative Once-Through Uranium Fuel Cycle

\section{S.2.2 Fast Reactor Recycle Alternative}

Under this alternative, DOE would support a domestic closed fuel cycle in a system that would process light water reactor spent fuel in a nuclear fuel recycling center and would recycle some of the recovered materials in advanced recycling reactors (i.e., fast reactors). The spent fuel from the fast reactors also would be processed to recover materials for repeated recycle in advanced recycling reactors.

Some uranium recovered during the recycling of light water reactor spent fuel would be used to fabricate new fuel for use in light water reactors and advanced recycling reactors. ${ }^{6}$ Transuranic elements also would be recovered to be fabricated into new fuel, along with uranium, for use in advanced recycling reactors. Transuranic elements from spent nuclear fuel from advanced recycling reactors would also be recovered for further recycling. A balanced system in which the

Transuranic Elements

These are man-made elements that are heavier (i.e., have a higher atomic number) than uranium, and include, for example, neptunium, plutonium, americium, and curium.

Transuranic elements are created in nuclear power plants when uranium absorbs or captures neutrons. Transuranic elements are generally long-lived and radiotoxic, and certain transuranic elements can be used in nuclear weapons.

\footnotetext{
${ }^{6}$ The uranium recovered could also be sold or stored for future use, or disposed of as low-level waste. This decision would likely be an economic issue and would be driven largely by the price of uranium.
} 
amount of transuranics produced in light water reactors approximates the amount consumed in the advanced recycling reactors could be achieved with approximately 60 percent light water reactors and 40 percent fast reactors (Wigeland 2008a). Such a balanced system would avoid the accumulation of separated transuranics.

Under the Fast Reactor Recycle Alternative (Figure S.2-3), uranium and transuranic elements would be separated from other elements when processing light water reactor spent fuel and advanced recycling reactor spent fuel. A number of advanced separations technologies have been developed as part of the Advanced Fuel Cycle Initiative and through other international programs. One of these technologies could be considered for implementation, or an alternative technology that meets the separations requirements could be used. For nonproliferation reasons, DOE is not considering separations processes that produce a pure plutonium stream.

\section{Advanced Separations}

This PEIS considers the use of technologies that could separate spent nuclear fuel into usable and non-usable constituents. The objective of advanced separations is to allow options for management of particular elements in the spent fuel and reduce the wastes requiring geologic disposal.

Advanced separations technologies could provide the capability to selectively remove certain fission products (e.g., technetium, cesium, and strontium) and minor actinides (e.g., neptunium, americium and curium) from the high-level radioactive waste stream. The minor actinides could be recycled in reactors, while the fission products could be managed and disposed appropriate to their hazard.

Variations to existing separations technologies that have been developed and could be implemented in the near term would target the co-extraction of uranium and plutonium (and possibly neptunium) but would leave the other minor actinides and fission products in the high-level radioactive waste. Existing separations technology with variations could be deployed at commercial scale with confidence in its readiness. However, advanced separations technologies require research, development and demonstration prior to deploying at commercial scale.

Separating out minor actinides (and destroying them in a reactor) and select fission products would allow tailored management of the wastes streams and could significantly reduce the heat load and radiotoxicity of wastes requiring disposal in a geologic repository. 


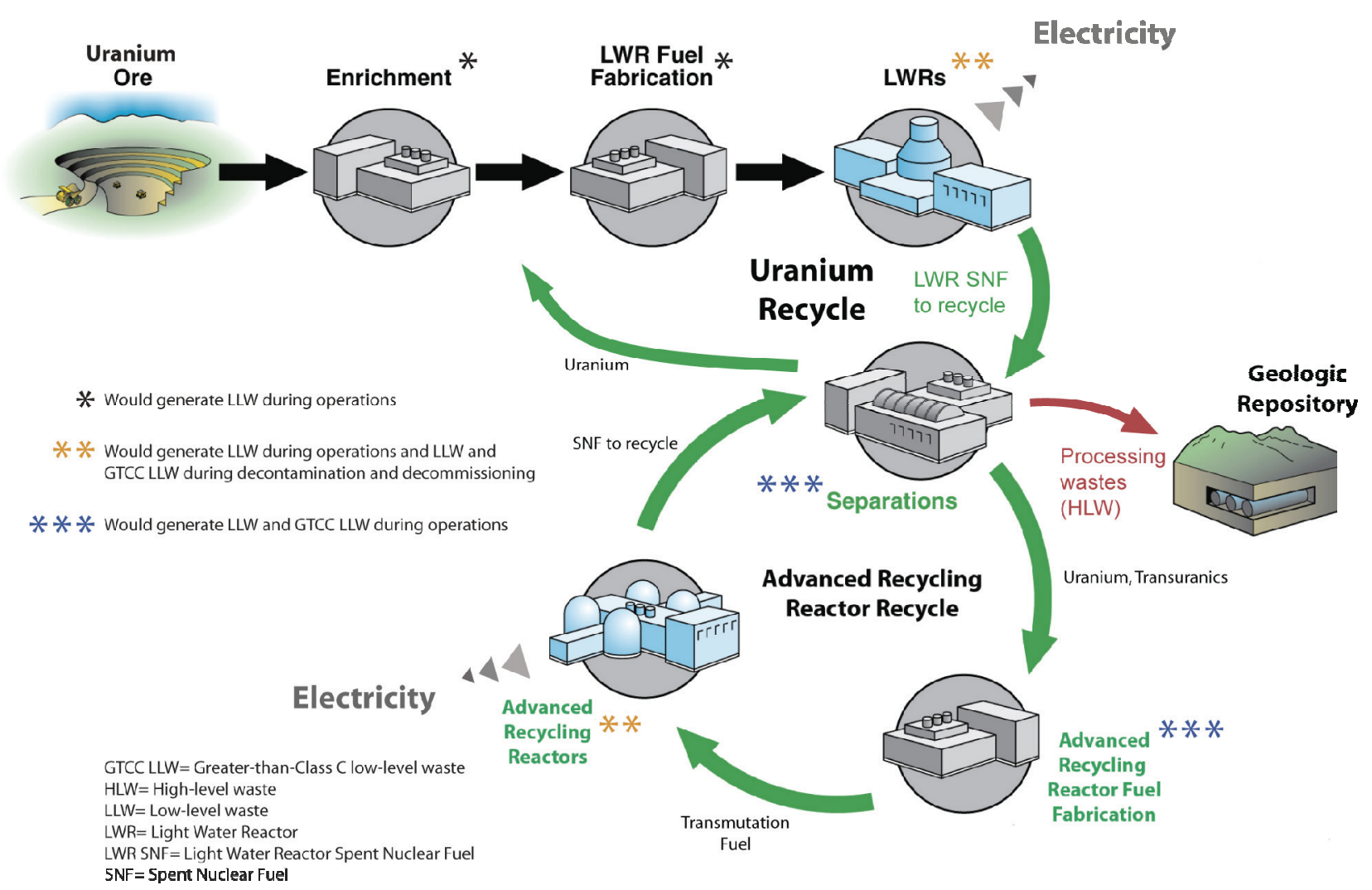

FIGURE S.2-3-Fast Reactor Recycle Alternative

The processing of spent nuclear fuel would result in high-level radioactive waste requiring eventual disposal in a geologic repository. The advanced separations technology could include the capability to separate cesium and strontium, which could be stored for about 300 years until they have become less radioactive, and then potentially disposed of as low-level radioactive waste. Alternatively, cesium and strontium could be disposed of as high-level radioactive waste in a geologic repository. In addition, implementation of this alternative would result in the generation of Greater-than-Class-C low-level radioactive waste, and low-level radioactive waste, both of which would require disposal. The Fast Reactor Recycle Alternative would require research and development $(\mathrm{R} \& \mathrm{D})$ primarily in the following areas: fast reactor fuel fabrication and fuel performance; increasing fast reactor capacity to commercial scale; and scaling up fuel recycling (see Section S.3.1). Because transition to this fuel cycle would involve both new reactors and fuels, and the new fuels would require separations to provide feedstock, transition is expected to be more complex than most other fuel cycle alternatives (see Section S.3.2).

\section{Greater-than-Class-C Low-Level Radioactive Waste}

As defined by the Nuclear Regulatory Commission in $10 \mathrm{CFR}$ 72.3, low-level radioactive waste that exceeds the concentration limits of radionuclides established for Class $\mathrm{C}$ waste in $10 \mathrm{CFR}$ 61.55 . 


\section{S.2.3 Thermal/Fast Reactor Recycle Alternative}

Under this alternative, DOE would support a domestic closed fuel cycle in a system that would process light water reactor spent fuel in a nuclear fuel recycling center, and would recycle some of the recovered materials in both thermal reactors, such as light water reactors, and fast reactors. Such an approach would lower the number of fast reactors required to consume the transuranics generated in the light water reactors and allow recycling to start sooner by using existing reactors. A balanced system could be achieved with approximately 70 percent light water reactors and 30 percent fast reactors.

The process would separate light water reactor spent fuel into a combined uranium and plutonium product stream that would be used to fabricate a mixed oxide-uranium-plutonium fuel (referred to hereafter as MOX-U-Pu fuel) for use in light water reactors. Following use, the MOX-U-Pu spent fuel would be recycled and the recovered materials would be fabricated into new fuel for additional recycle in thermal or advanced recycling reactors. There are many variations that could be proposed for this approach, including which transuranic elements would be recovered, which would be recycled in thermal reactors, and which would be disposed of as waste.

Spent nuclear fuel would be processed to create new nuclear fuel, but the process would result in the same waste types (i.e., high-level radioactive waste, Greater-than-Class-C low-level radioactive waste, and low-level radioactive waste) as the Fast Reactor Recycle Alternative, but in different quantities and with different characteristics. The Thermal/Fast Reactor Recycle Alternative would require $R \& D$ in the same areas as the Fast Recycle Alternative. However, because the initial recycling would be performed in thermal reactors, near-term deployment of the Thermal/Fast Recycle Alternative is possible with variations to existing separations technologies, fuel, and reactor technologies. For example, for the initial recycle in thermal reactors, a MOX-U-Pu fuel has already been developed and is in use in Europe. From an implementation standpoint, because the Thermal/Fast Reactor Recycle Alternative would require limited development, licensing of a new fuel type, and the development of facilities to provide feedstock for the fuel, this alternative could start transition relatively quickly, compared to some of the other action

Feedstock refers to the nuclear materials used to produce fuel for a reactor. alternatives (see Section S.3.2). This alternative differs from the Fast Reactor Recycle Alternative in that the Thermal/Fast Reactor Recycle Alternative could be implemented more quickly by use of existing thermal reactors and variations to existing separations technologies as the first step in this fuel cycle. The Thermal/Fast Reactor Recycle Alternative differs from the Thermal Reactor Recycle Alternative (Option 1) because in the longer term this alternative would transition to advanced separations technologies and fast reactors which would result in a greater reduction in the radiotoxicity and heat load of remaining spent nuclear fuel. Both the Thermal/Fast Reactor Recycle Alternative and the Fast Reactor Recycle Alternative have the potential for much greater reduction benefits in the radiotoxicity and heat load of remaining spent nuclear fuel than any other closed or open fuel cycles. 


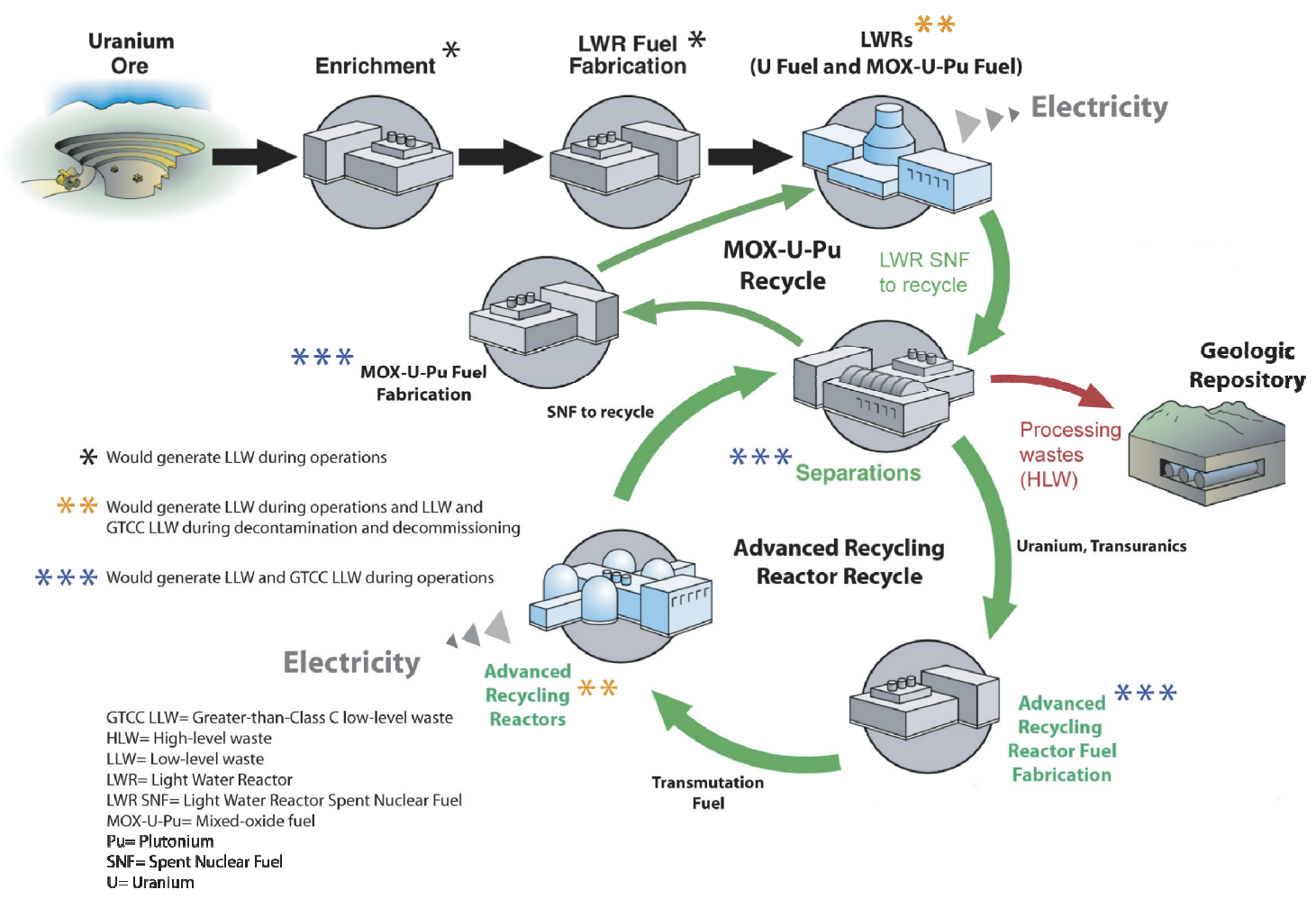

FIGURE S.2-4-Thermal/Fast Reactor Recycle Alternative

\section{S.2.4 Thermal Reactor Recycle Alternative}

Under this alternative, DOE would support a domestic fuel cycle that would process light water reactor spent nuclear fuel in a nuclear fuel recycling center, and would recycle some of the recovered materials to fabricate fuel for use in thermal reactors. The Thermal Reactor Recycle Alternative includes three options.

- Option 1: Recycle light water reactor spent fuel to produce a MOX-U-Pu fuel ${ }^{7}$ for use in light water reactors

- Option 2: Recycle light water reactor spent fuel to produce fuel for use in heavy water reactors, and

- Option 3: Recycle light water reactor spent fuel to produce a transuranic fuel for use in high-temperature gas-cooled reactors.

\section{S.2.4.1 Option 1-Thermal Reactor Recycle in Light Water Reactors}

Under Option 1, DOE would support a domestic closed fuel cycle in a system that would process light water reactor spent fuel at a nuclear fuel recycling center and recycle some of the recovered materials as new fuel for use in light water reactors. This option would involve the recycle of

\footnotetext{
${ }^{7}$ The use of a MOX-U-Pu fuel is analyzed as the baseline approach for this alternative. It would, however, be conceptually possible to use a mixed-oxide fuel with transuranics (referred to as MOX-TRU), particularly for the stabilization of the total transuranics, rather than disposing of the minor actinides in a repository. Chapter 4 discusses the major differences between the use of MOX-U-Pu fuel and MOX-TRU fuel.
} 
uranium and plutonium for reuse in light water reactors using a fuel assembly concept that combines traditional uranium dioxide with mixed-oxide fuels.

This option would require facilities to recycle light water reactor spent fuel (using variations to existing separations technologies), and to fabricate MOX-U-Pu fuel. The MOX-U-Pu spent fuel would be recycled to recover the uranium and plutonium. Multiple recycle of plutonium in light water reactors would reduce the rate at which plutonium accumulates in the high-level radioactive waste that would require disposal in a geologic repository. During spent fuel recycling, this option would generate the same waste types as the Fast Reactor Recycle Alternative, but in different quantities and with different characteristics.

The Thermal Reactor Recycle Alternative (Option 1) would require R\&D related to fuel development and fabrication, and large-scale recycling (see Section S.3.1). However, this alternative could start to transition sooner, and proceed through transition more quickly than many fuel cycle alternatives because it would only require development and licensing of a new fuel type and development of facilities to provide feedstock for the fuel (see Section S.3.2). Option 1 of the Thermal Reactor Recycle Alternative is shown in Figure S.2-5.

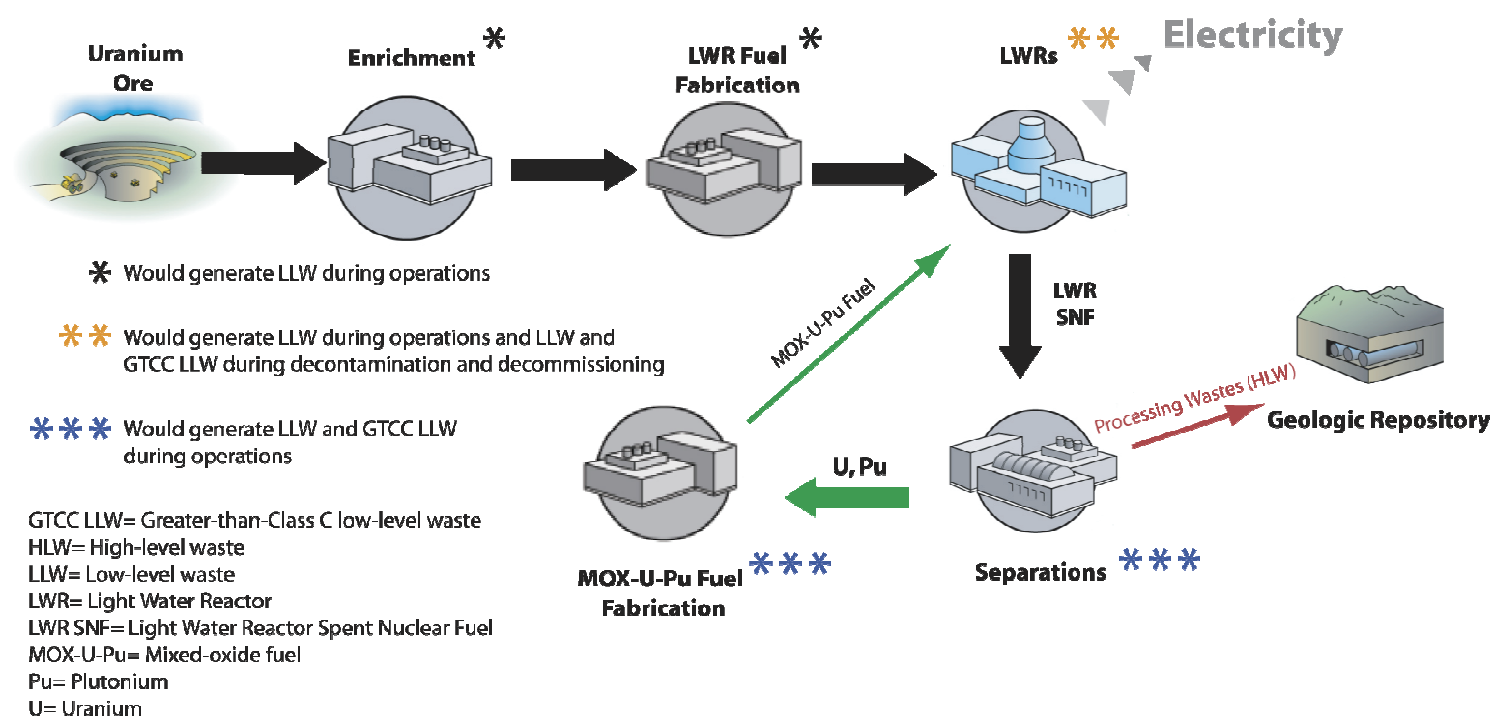

FIGURE S.2-5-Thermal Reactor Recycle Alternative: Option 1 (Thermal Reactor Recycle in Light Water Reactors)

\section{S.2.4.2 Option 2-Thermal Reactor Recycle in Heavy Water Reactors}

Under Option 2, DOE would support a domestic closed fuel cycle in a system in which light water reactor spent nuclear fuel would be used as a source of fissile material to fuel heavy water reactors. This option would be possible because heavy water reactors require no or low initial fuel enrichment, which can be provided by light water reactor spent nuclear fuel. This is referred to in this PEIS
Heavy water reactors are thermal reactors that use deuterium oxide (heavy water) as a moderator and coolant for the reactor core. Natural (non-enriched) uranium typically is used as fuel, although other fuels consisting of slightly enriched uranium, mixed oxides of plutonium and uranium, or mixed oxides of plutonium and thorium, can be used. 
as DUPIC - the Direct Use of Spent Pressurized Water Reactor (a type of light water reactor) Fuel in $\underline{\text { CANDU. }}{ }^{8}$

The basic concept of the DUPIC fuel cycle is to fabricate heavy water reactor nuclear fuel from light water reactor spent fuel, principally by use of dry thermal/mechanical processes. By utilizing light water reactor spent fuel as an energy source for heavy water reactors, approximately 50 percent more energy can be derived from the light water reactor fuel. A steadystate material balance for the DUPIC fuel cycle would require approximately 75 percent light water reactors and 25 percent heavy water reactors (Yang and Park 2006). Recycling the light water reactor spent fuel would generate the same waste types as the other recycle alternatives but in different quantities and with different characteristics. This option would also generate heavy water reactor spent fuel that would require disposal in a geologic repository.

The Thermal Reactor Recycle Alternative (Option 2) would require R\&D related to fuel development and fabrication, and large-scale recycling. Because both light water reactors and heavy water reactors are widely used commercially, most transition issues would be related to spent fuel treatment to provide feedstock for the heavy water reactors. Additionally, the development and deployment of heavy water production facilities would be required. Option 2 of the Thermal Reactor Recycle Alternative is shown in Figure S.2-6.

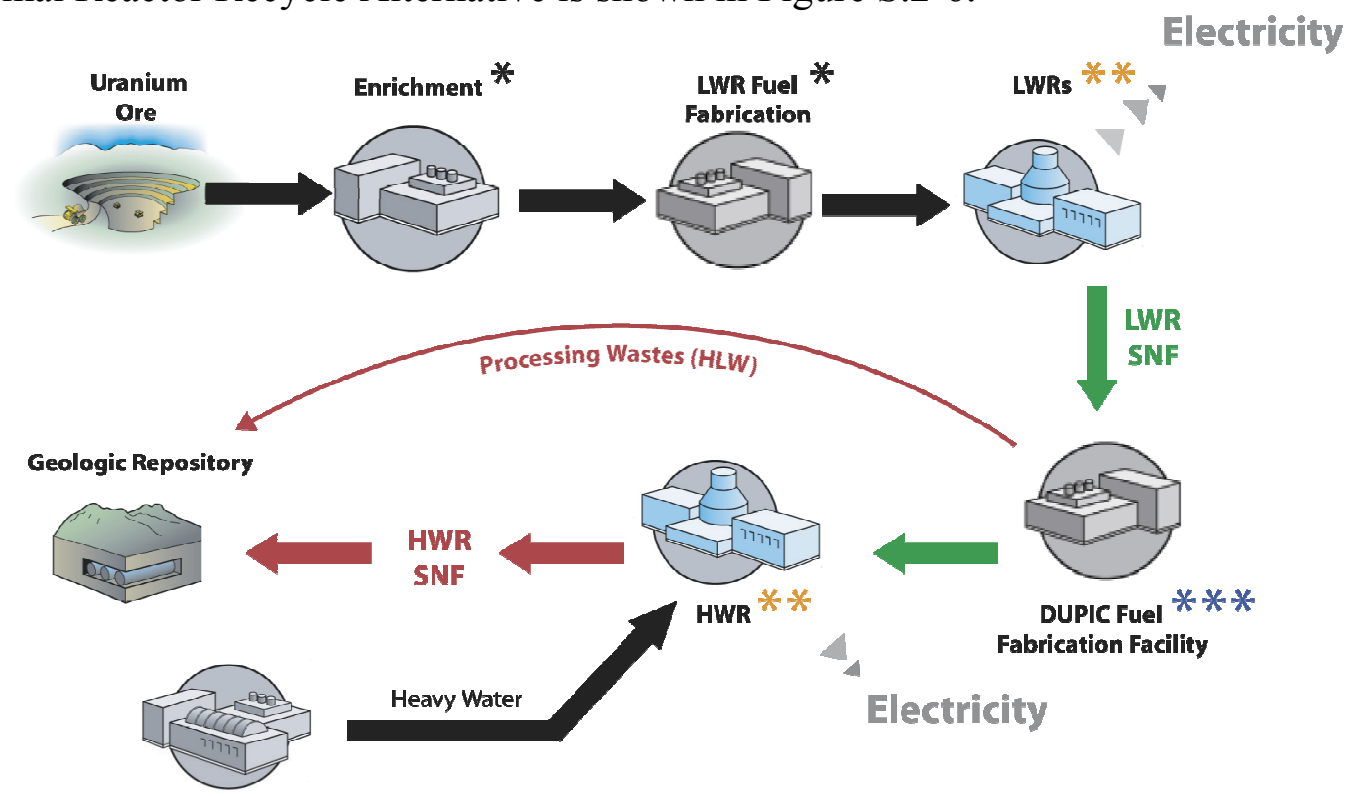

Heavy Water Production Plant

* Would generate LLW during operations

GTCC LLW= Greater-than-Class C low-level waste $H L W=$ High-level waste $\mathrm{HWR}=$ Heavy Water Reactor

HWR SNF= Heavy Water Reactor Spent Nuclear Fuel

* * Would generate LLW during operations and LLW and

GTCC LLW during decontamination and decommissioning

LLW= Low-level waste

LWR= Light Water Reactor

LWR SNF= Light Water Reactor Spent Nuclear Fuel

*** Would generate LLW and GTCC LLW during operations

FIGURE S.2-6-Thermal Reactor Recycle Alternative: Option 2 (Thermal Reactor Recycle in Heavy Water Reactors)

\footnotetext{
${ }^{8}$ The acronym "CANDU," a registered trademark of Atomic Energy of Canada Limited, stands for "CANada Deuterium Uranium." This is a reference to its deuterium-oxide (heavy water) moderator and its use of natural uranium fuel.
} 


\section{S.2.4.3 Option 3-Thermal Reactor Recycle in High Temperature Gas-Cooled Reactors}

Under Option 3, DOE would support a domestic closed fuel cycle in a system that would recycle light water reactor spent nuclear fuel using advanced separations and use the recovered transuranic materials in high temperature gas-cooled reactors to achieve deep-burn. Recycling the light water reactor spent fuel would generate the same waste types as other recycle alternatives, but likely in different quantities and with different characteristics. ${ }^{9}$ This option would also generate high temperature gas-cooled reactor spent fuel that would require disposal in a geologic repository. Based on a steady-state material balance for transuranic consumption, this alternative would require approximately 80 percent light water reactors and 20 percent high temperature gas-cooled reactors (Goldner and Versluis 2006).

The Thermal Reactor Recycle Alternative (Option 3Thermal Reactor Recycle in High Temperature GasCooled Reactors) is the least developed domestic programmatic alternative, with only limited data available. Many key data (such as the amount of light water reactor spent fuel that would be processed, the amount of transuranics to be recovered, and the deepburn fuel composition) have not been determined. Much of the data that has been quantified has been from one of the principal high temperature gas-cooled reactor vendors. Data from the vendor indicate that a 70 percent reduction in transuranic waste and a two- to three-fold reduction in thermal heat load are possible (Goldner and Versluis 2006). The use of these data would indicate an improvement in meeting the purpose and need objectives compared to the No Action Alternative. While DOE has reviewed the information available, there is currently insufficient research available to verify that these data are correct. However, DOE believes that these data represent an initial estimate that can be used to reach some general conclusions that are not sensitive to the potential inaccuracies associated with such estimates. Consequently, any quantifications presented in this section for this option are only preliminary estimates, and do not have the same level of confidence as the data for other alternatives. DOE has recently sponsored additional research through the Generation IV program, which will result in information that will increase DOE's knowledge base regarding this concept, but this research will not be available for use in this PEIS.

This alternative would require significant $R \& D$ related to: fuel development and fabrication; large scale high temperature gas-cooled reactors that utilize a non-uranium fuel; and large-scale recycling of light water reactor spent fuel. This alternative would also require one or more reactor-grade graphite production plants, which currently do not exist in the United States. Transition to this alternative is considered complex (see Section S.3.2). Option 3 of the Thermal Reactor Recycle Alternative is shown in Figure S.2-7.

\footnotetext{
${ }^{9}$ Because the Thermal Reactor Recycle Alternative (Option 3) is the least developed domestic programmatic alternative, with only limited data available, it is not possible to quantify the specific differences in quantities and characteristics of wastes.
} 


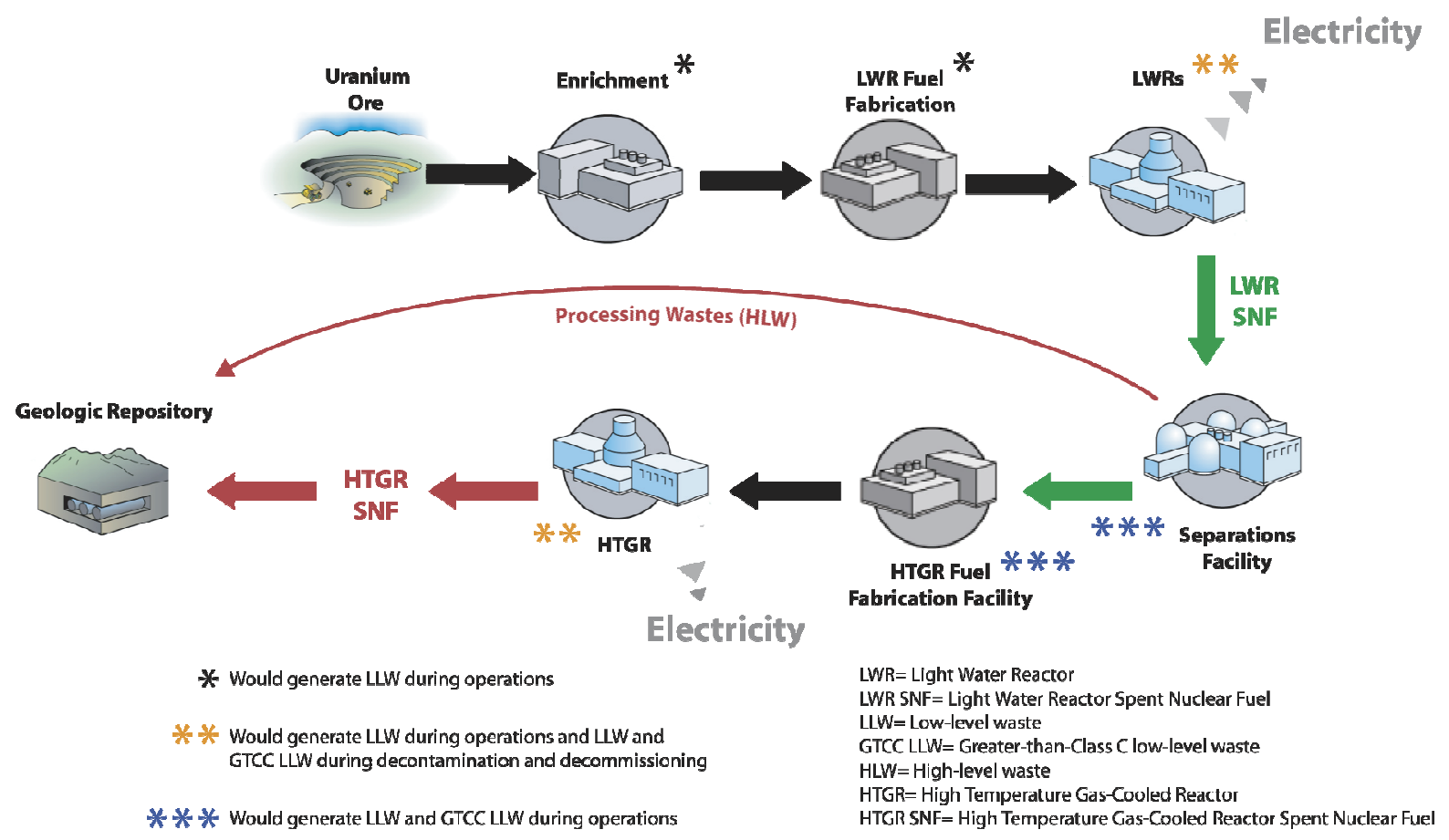

FIGURE S.2-7-Thermal Reactor Recycle Alternative: Option 3 (Thermal Reactor Recycle in High Temperature Gas-Cooled Reactors)

\section{S.2.5 Thorium Alternative}

Under this alternative, DOE would support a domestic open fuel cycle in a system that would use a thorium fuel in light water reactors. Thorium is a lighter element than either uranium or plutonium. As such, when thorium is used as a major component of reactor fuel, the production of transuranics (neptunium, plutonium, americium, and curium), which are the primary contributors to long-term waste radiotoxicity and heat load in geologic repositories, is reduced relative to conventional uranium-based fuels (IAEA 2002b).

The thorium once-through fuel cycle, while different in many aspects from the existing uranium once-through fuel cycle, can be characterized as a "new fuel design" rather than as a new reactor concept, because the thorium fuel cycle would be compatible with existing thermal reactors (e.g., light water reactors, heavy water reactors, high temperature gas-cooled reactors). The thorium fuel cycle would be feasible in most existing commercial nuclear power plants without major modifications to the engineered systems. Under this alternative, thorium-based spent nuclear fuel from the reactors would be stored for eventual disposal in a geologic repository.

The Thorium Alternative would require R\&D related to fuel development and fabrication, and increasing reactor capacity to commercial scale. Transition could proceed relatively quickly because development and licensing of a new fuel type would be less complex than issues related to many of the other fuel cycle alternatives. The Thorium Alternative is shown in Figure S.2-8. 


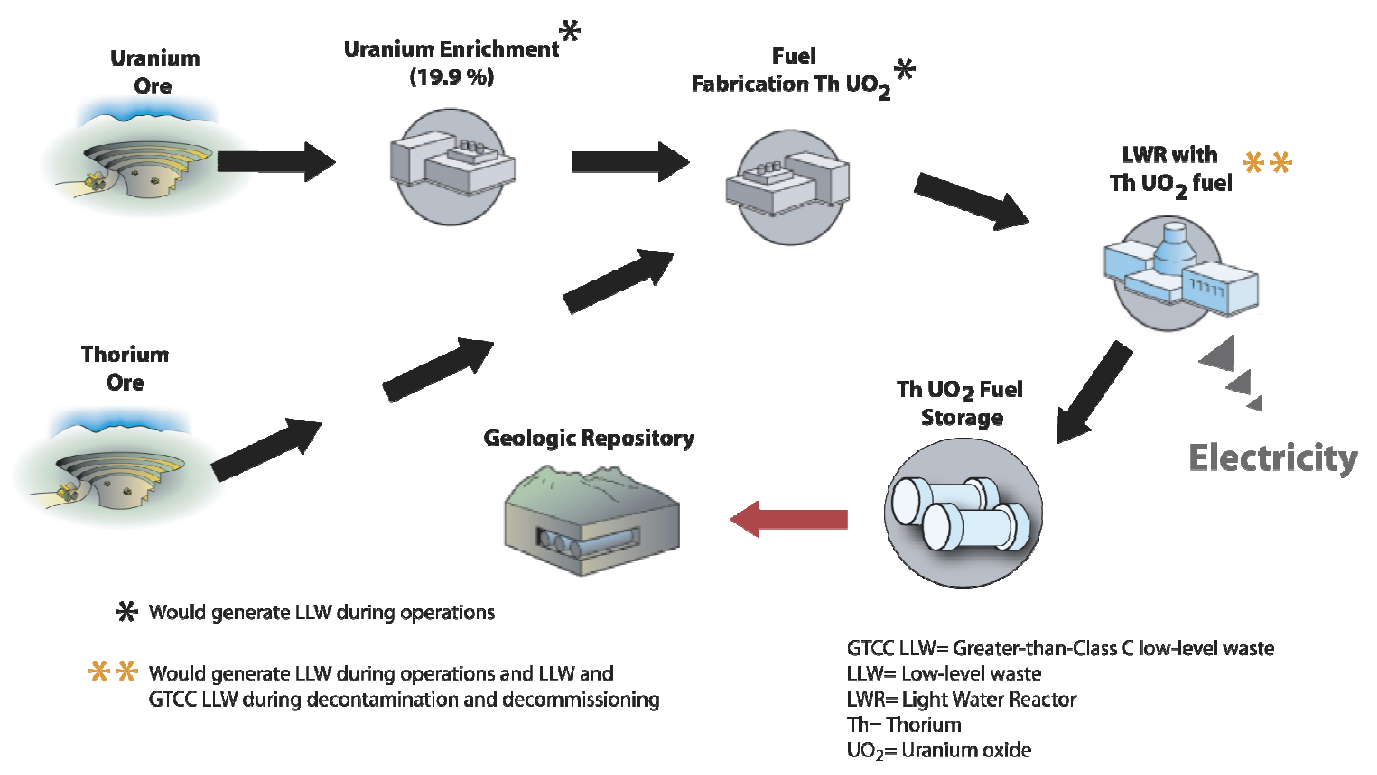

FIGURE S.2-8-Thorium Fuel Cycle Alternative

\section{S.2.6 Heavy Water Reactor/High Temperature Gas-Cooled Reactor Alternative}

This alternative would involve a once-through fuel cycle that would use either heavy water reactors or high temperature gas-cooled reactors. Two options are assessed: Option 1 - use heavy water reactors and Option 2-use high temperature gas-cooled reactors. In either option, the spent nuclear fuel would be stored until DOE could accept it for disposal in a geologic repository.

\section{S.2.6.1 Option $1-$ Heavy Water Reactor}

Under this option (referred to hereafter as All-Heavy Water Reactor Option), DOE would support a domestic open fuel cycle in a system that would involve phasing out light water reactors in favor of heavy water reactors. With fewer neutrons absorbed by heavy water (600 times fewer) than normal light water, more are available to fission the uranium atoms in the fuel. This enables natural, rather than enriched, uranium to be used for fuel in a heavy water reactor. However, by using slightly enriched uranium, fuel cycle costs can be reduced compared to the natural uranium fuel cycle. This PEIS assesses the use of slightly enriched uranium in heavy water reactors (Figure S.2-9). 


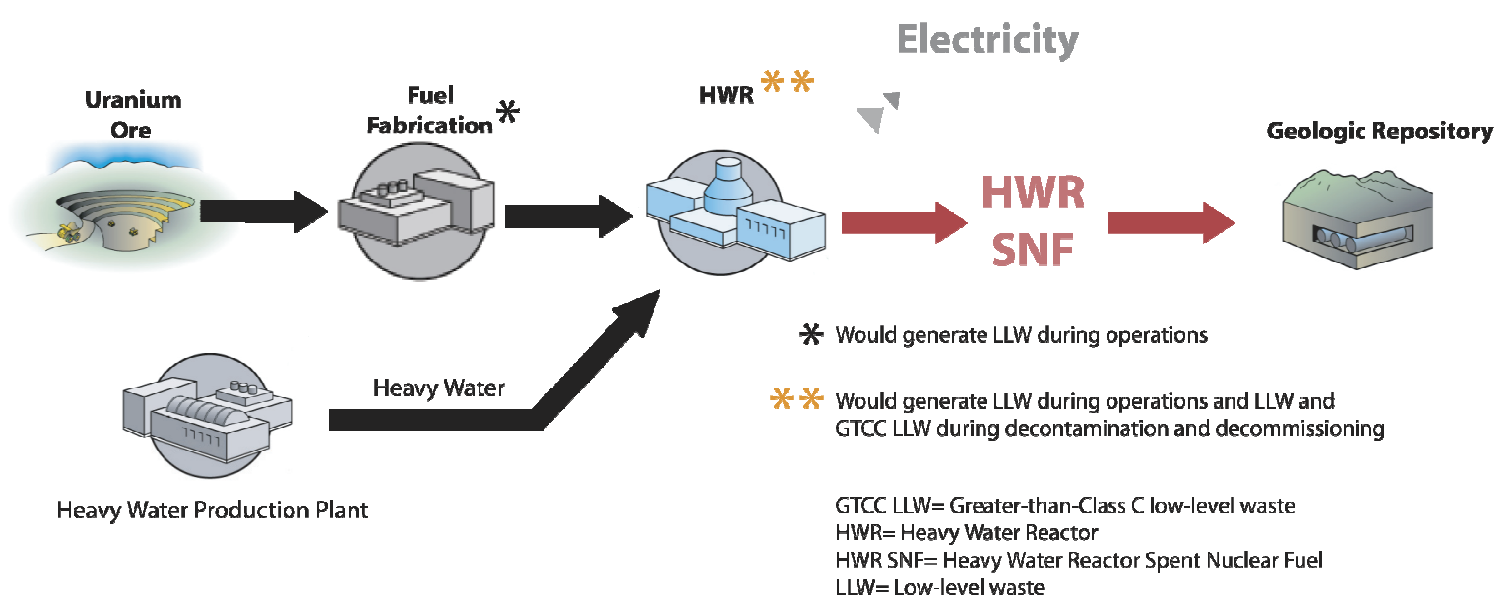

FIGURE S.2-9—Heavy Water Reactor Open Fuel Cycle

This alternative would require R\&D related to fuel development and fabrication (see Section S.3.1). Because heavy water reactors are widely used commercially in other countries, transition issues would be less complex than for some other fuel cycle alternatives (see Section S.3.2). However, because heavy water reactors are not used commercially in the United States and commercial scale heavy water production facilities do not exist domestically, the development and deployment of heavy water production facilities would be required.

\section{S.2.6.2 Option 2-High Temperature Gas-Cooled Reactor}

Under this option (referred to hereafter as the All-High Temperature Gas-Cooled Reactor Option), DOE would support a domestic open fuel cycle in a system that would involve phasing out light water reactors in favor of high temperature gas-cooled reactors. This option would use only uranium fuel and would not involve recycling. This option is shown in Figure S.2-10.

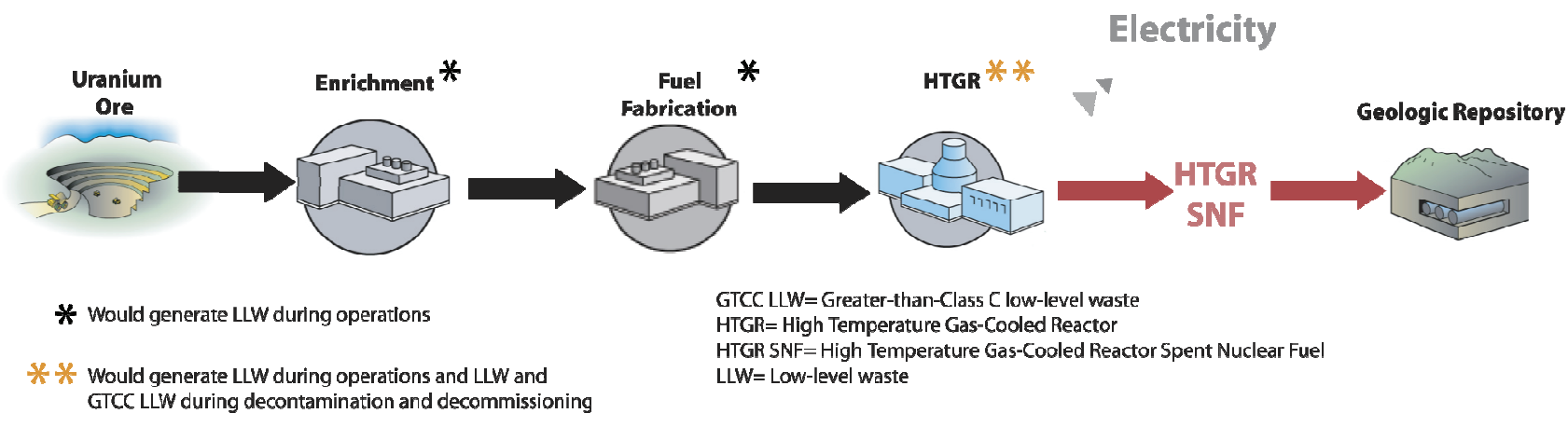

\section{Figure S.2-10—High Temperature Gas-Cooled Open Fuel Cycle}

This alternative would require R\&D related to fuel development and fabrication, and increasing the capacity of high temperature gas-cooled reactors to commercial scale. This alternative would also require one or more reactor-grade graphite production plants, which currently do not exist in the United States. Transition to this alternative could be deployed once a new reactor type is available (see Section S.3.2). 


\section{S.2.7 Alternatives Considered but Eliminated from Detailed Study}

In preparing this PEIS, DOE considered many alternatives for meeting the underlying purpose and need for agency action. DOE identified some of these alternatives through internal scoping, while the public identified others during the public scoping process. DOE reviewed each of these alternatives relative to their ability to meet the purpose and need to support the expansion of domestic and international nuclear energy production, while also reducing the impacts associated with disposal of spent nuclear fuel and the risks of nuclear proliferation. The alternatives considered but eliminated from detailed study are discussed below.

\section{S.2.7.1 Institute Interim Storage of Spent Nuclear Fuel}

DOE considered an alternative in which commercial spent fuel residing at each nuclear power plant site would be consolidated for centralized storage at one or more sites until ultimate disposal in a geologic repository. Proponents suggest that interim storage might support growth in nuclear electricity production by relieving the buildup of spent fuel at commercial reactor sites and reducing the amount of dry storage required at these sites. Interim storage would leave the spent fuel in a form that would make it difficult to steal or divert to other purposes, and centralized storage could also make the spent fuel easier to protect. ${ }^{10}$

DOE does not have the authority under law to accept commercial spent nuclear fuel for interim storage at this time. Furthermore, consolidating spent fuel would not reduce its volume and would have a limited effect on the use of space in a geologic repository from the standpoint of thermal output. In certain respects, interim storage would be analogous to the No Action Alternative but would defer a decision of what to do with spent nuclear fuel to the future. Even if current law were modified and interim storage was authorized and pursued, there would be additional costs and risks associated with handling and transport of the spent fuel from the utilities to the interim storage sites, and then again to a repository for disposal or to a recycling facility for processing. For these reasons, DOE has concluded that interim storage does not satisfy DOE's purpose and need to reduce impacts associated with the disposal of spent nuclear fuel and therefore, is not considered to be a reasonable alternative.

\section{S.2.7.2 Terminate the Advanced Fuel Cycle Initiative}

One of DOE's missions is to undertake R\&D activities in support of civilian nuclear energy programs. The objective of the Advanced Fuel Cycle Initiative is to develop the technologies needed to: reduce the environmental consequences associated with spent nuclear fuel management, reduce the proliferation risk from the use of nuclear power, and extend uranium resources. During the scoping period, some commentors suggested that DOE terminate the ongoing Advanced Fuel Cycle Initiative as an alternative. DOE has determined that this alternative is unreasonable in that it would not advance the purpose and need for DOE's action, and would inhibit the nation's ability to conduct research necessary for its energy future.

\footnotetext{
${ }^{10}$ For example, centralized storage could use hardened storage technology that would provide better protection against terrorist attacks.
} 


\section{S.2.7.3 Fuel Cycle and Related Reactor and Technology Alternatives}

As a result of scoping comments, DOE considered several alternatives associated with various fuel cycles and associated technologies, such as accelerators for transmutation, breeder reactors, different technologies to process spent fuel, fast reactor types other than sodium-cooled reactors, supercritical water-cooled reactors and molten salt reactors. DOE also considered the use of a thorium closed fuel cycle alternative, a high temperature gas-cooled reactor closed fuel cycle alternative and a MOX-U-Pu fuel open fuel cycle alternative.

DOE eliminated some of these alternatives from detailed consideration because certain reactors (e.g., breeder reactors) or separations methods (e.g., PUREX process) would produce weapons-usable materials, which would be inconsistent with DOE's objective to decrease the inventory of pure plutonium. The long-term sustainability of nuclear energy may require breeder reactors at some

PUREX
Plutonium and Uranium Recovery by
Extraction (PUREX) is an aqueous
separation process that has been used to
extract uranium and plutonium
independently from one another.
time in the future if uranium resources become scarce or uneconomical to extract. The long-term sustainability of nuclear energy is, however, a mission of another DOE program: the GenerationIV Initiative (DOE 2006t).

Some technologies are not sufficiently viable or mature to enable meaningful analysis relative to other technologies analyzed in detail. DOE considers, for example, supercritical water-cooled or molten salt reactors, certain elements of spent fuel processing and recycling in a thorium closed fuel cycle and the use of accelerators to convert transuranic radionuclides to more stable and less radiotoxic elements, to be reactor or processing technologies that are not as advanced as those considered in detail in this PEIS. Other closed fuel cycle technologies are even more immature and tend to be impractical or unfeasible, such as processing spent fuel from high temperature gas-cooled reactors. The alternative to use MOX-U-Pu fuel in an open fuel cycle would produce spent fuel not amenable to substantially reducing the impacts of disposal; that is, it would not substantially reduce volume, thermal output or radiotoxicity.

\section{S.2.7.4 Increase Burnup of Light Water Reactor Fuels}

DOE considered an alternative in which light water reactor operations would significantly increase the burnup of light water reactor fuels, which would reduce the total amount of spent fuel generated, by providing more energy per fuel assembly. Any benefit from this volume reduction would be off-set by a larger quantity of fission products in the spent fuel, which would increase radiotoxicity and thermal output of the fuel. As a result, increased burnup of light water reactor fuels was not analyzed as a discrete alternative.

\section{S.2.7.5 Recycle Spent Nuclear Fuel Planned for the Yucca Mountain Repository}

During the scoping period, some commentors suggested that DOE should recycle the spent nuclear fuel that is now planned for disposal at the Yucca Mountain repository. Some commentors stated that recycling this spent nuclear fuel could eliminate the need for the Yucca Mountain repository. Under all nuclear fuel cycles, however, the United States will need a 
permanent geologic repository to dispose of spent nuclear fuel and/or high-level radioactive waste from the operation of commercial nuclear power plants and defense-related activities. All programmatic alternatives analyzed in this PEIS, including the No Action Alternative, would require at least one geologic repository; the GNEP PEIS would have no effect on the ongoing planning for that initial repository. GNEP PEIS alternatives are at a stage of initial proposal, and DOE has not made any decisions to proceed with any specific alternative. Given the many uncertainties associated with the timing and the scope of the implementation of any action alternative that might be selected here, the present pressing need for disposal capacity that the Yucca Mountain repository is intended to address, and current statutory mandates, it is reasonable and necessary to go forward with the Yucca Mountain repository as planned. Consequently, the GNEP PEIS does not address the recycle of spent nuclear fuel currently planned for disposal at the Yucca Mountain geologic repository (i.e., up to the statutory capacity limit).

\section{S.2.7.6 Non-nuclear Electricity Production}

Some commentors suggested that the United States should meet future electricity demands through conservation and increased use of renewable energy sources, rather than through increased use of nuclear energy. While DOE agrees that conservation and increased use of renewable energy resources are needed, DOE seeks to support the expansion of nuclear energy as one element of a diverse portfolio of power-generation systems. Thus, DOE recognizes that the alternatives in this PEIS, which relate exclusively to nuclear fuel cycles, are not "either/or" alternatives with respect to the various options for meeting future electricity demands. Programs other than GNEP address renewable energy and energy conservation.

\section{S.3 IMPLEMENTATION OF DOMESTIC ALTERNATIVES}

The Department recognizes that deployment of any of the domestic programmatic alternatives would occur largely as a result of actions of private industry, which would be driven primarily by market forces. Other factors, such as future national policies and regulatory issues, might also influence the nature of, and degree to which any of the alternatives would be deployed. While it is not possible to predict with confidence how any of the alternatives would be implemented on a national scale, DOE assumes that these factors would not ultimately be barriers to the widespread implementation of any alternative. Nevertheless, DOE in this PEIS considers certain factors that are likely to have a bearing on the extent to which the alternatives could be implemented by private industry: the need for R\&D, the costs and timing of transition to and implementation of the alternatives, and the design and operation of a future geologic repository.

\section{S.3.1 Research and Development Needs}

Many of the alternatives require additional $R \& D$ before wide-scale deployment could be accomplished. Below, R\&D needs are grouped by technical area and compared among the alternatives.

- Fuel Development and Fabrication: The need for R\&D of fuel fabrication technologies is considered from two perspectives: first, whether a fabrication technology exists, and second, whether the existing technology has been developed sufficiently to allow an 
alternative to be implemented. Most of the alternatives have candidate processes for fabrication of fuel; however, all but the No Action Alternative and the All-Heavy Water Reactor Option would require additional R\&D to apply these technologies. The time frame to complete the necessary $R \& D$ would be similar among the alternatives and is estimated to require about 5 to 10 years.

- Fuel Performance: R\&D would be required to develop and demonstrate fuel performance in the reactor and in storage after discharge from the reactor (whether destined for processing or not) for each of the alternatives, except for the No Action Alternative and the All-Heavy Water Reactor Option, which utilize proven fuel technologies. For most alternatives, relevant fuel performance experience is available, although for some of the reactor types this experience may be limited to experimental or testing conditions only. Even for reactor types for which there may be prior commercial experience, it is likely that testing and verification of fuel performance would be required as one of the licensing conditions, regardless of the alternative, prior to widespread use (with the exceptions of light water reactors and heavy water reactors). In contrast, it is also likely that each reactor type, whether commercially available or not, could begin operations using nuclear fuel that is within the existing experience base, and then move toward the required fuel composition as new experience is gained.

Some of the alternatives would use reactor types that are not available in the United States, although either they have existed in the United States in the past as experimental or first-of-a-kind commercial plants, or they exist outside of the United States. For example, heavy water reactors are used extensively in Canada, which would likely facilitate licensing in the United States. For alternatives involving fast reactors and high temperature gas-cooled reactors, no facility exists in the United States where fuel performance experience sufficient for licensing can be acquired. Even for those alternatives where light water reactors would be used, it is likely that the licenses of existing light water reactors would need to be amended to allow fuel performance tests, and this may not be possible. The time frame for achieving the required fuel performance information would depend on the availability of the appropriate irradiation facilities, but such development could be done as part of the ongoing operation of the facility.

- Reactor Technology: Each of the reactor technologies associated with the domestic programmatic alternatives have different operating experience, which could affect the amount of R\&D needed to implement that technology. For example, light water reactors and heavy water reactors are used throughout the world and would not necessarily require any new $R \& D$. Other reactor technologies (thorium-fueled reactors, ${ }^{11}$ fast reactors and high temperature gas-cooled reactors) have been operated on much smaller scales than light water reactors and heavy water reactors: therefore, these reactor technologies would benefit the most from R\&D. The high temperature gas-cooled reactor, in particular, would require the most R\&D, as the operating experience with this reactor technology at industry-scale (greater than 250 megawatts) has been limited.

\footnotetext{
${ }^{11}$ Although the Thorium Alternative is characterized as a "new fuel design" rather than as a new reactor concept in this PEIS, the insertion of thorium fuel into a light water reactor would not be as simple as, for example, the substitution of MOX-U-Pu fuel assemblies for uranium fuel assemblies in a light water reactor. Consequently, the need for R\&D related to the use of thorium fuel is included under the "Reactor Technology" category in this section.
} 
- Spent Fuel Processing: Only the closed fuel cycle alternatives require processing of spent nuclear fuel. For these alternatives, processing technologies have been developed and tested that would meet separations requirements. Some of the new technologies are evolutions of technologies that have been operated at commercial scale, and for those, implementation would expedite the required scale-up. There are many subsidiary issues associated with each new technology that would require $R \& D$, especially with final treatment and consolidation of the wastes and with ensuring that the new technologies are capable of limiting releases of radioactive materials from the processing plant to allowable limits. The time frame for completing the required R\&D is estimated to be 5 to 10 years for each of the closed fuel cycle alternatives.

- Spent Fuel and High-Level Radioactive Waste Disposal: All fuel cycle alternatives would require disposal of spent nuclear fuel and/or high-level radioactive waste in a geologic repository. DOE has already conducted significant R\&D related to such disposal at the proposed Yucca Mountain repository and has submitted a license application for construction authorization with the Nuclear Regulatory Commission. The need for R\&D related to geologic disposal in any future geologic repository would depend on the characteristics of the future geologic repository as determined by a site-specific assessment of repository performance (i.e., how well the repository would contain radionuclides). Such a performance assessment would consider: the form of the materials to be disposed of, barriers to release (e.g., waste packages and engineered repository systems), characteristics of the geologic environment (e.g., presence of water, chemistry of water, temperature, rock stability) and exposure pathways. DOE estimates that it would take 5 to 10 years or longer to complete such a R\&D review. Testing of the waste forms under accelerated repository-relevant conditions could be accomplished more quickly. However, experimenting with changes to the formulation of proposed waste forms to enhance performance, if deemed necessary for a particular repository concept, could add years to such an effort.

\section{S.3.2 Transition and Implementation}

All alternatives, except the No Action Alternative, would involve an evolution from the current nuclear power generating system to one involving a new system. The environmental consequences during transitioning to the new system would be a mix of the No Action Alternative effects and the effects of the new system. The alternatives have been grouped where aspects of the transition analysis are similar:

Group 1: Alternatives that require new fuels with current reactor types. This includes the Thorium Alternative and the Thermal Reactor Recycle Alternative (Option 1).

Group 2: Alternatives that require transition from the current light water reactors to a single new reactor type. This includes the All-Heavy Water Reactor Option and the All-High Temperature Gas-Cooled Reactor Option.

Group 3: Alternatives that require transition to a system involving more than one reactor type in a balanced system. This includes the Fast Reactor Recycle Alternative, the Thermal/Fast Reactor 
Recycle Alternative, the Thermal Reactor Recycle Alternative (Option 2) and the Thermal Reactor Recycle Alternative (Option 3).

The first group of alternatives (the Thermal Reactor Recycle Alternative-Option 1 and the Thorium Alternative) could start the transition sooner than some of the other fuel cycle alternatives and complete the transition more quickly, because Group 1 would primarily require only development and licensing of new fuel types and development of facilities to provide materials for these fuels. For the Thermal Reactor Recycle Alternative (Option 1), MOX-U-Pu fuel has been fabricated and is in use in Europe. Thorium fuel has been used in the past, but may require some reactor $\mathrm{R} \& \mathrm{D}$ and new data to satisfy licensing requirements.

The Thermal Reactor Recycle Alternative (Option 1) would require separations of light water reactor spent fuel to provide material (feedstock) to develop and fabricate the new fuel. Existing technologies, with some modification, could then support the recycle of MOX-U-Pu spent fuel as it becomes available.

Thorium fuel would obtain its feedstock of uranium and thorium from mining and stockpiles; adequate uranium mining exists and reliable reserves of thorium are available both in the United States and around the world. The level of enrichment of the uranium for the thorium fuel would be much higher, and would require new enrichment facilities. Both Group 1 alternatives would require construction or modification of fuel fabrication facilities.

Because the necessary technologies and facilities are understood, transition from the current system could begin within approximately 10 to 15 years. During such a transition, the new fuel could be used as a replacement during refueling, and specific reactors could switch over to the new system during a period of 5 to 6 years. A balanced system under the Thermal Reactor Recycle Alternative (Option 1) would also require recycle of the MOX-U-Pu spent fuel, which could begin roughly 5 years after it is discharged from the reactors. Thus, transition from the current light water reactor uranium oxide system to a Group 1 alternatives system could be completed in about 20 to 25 years. Transition could take longer if the principal technology uncertainties of the Thermal Reactor Recycle Alternative (Option 1) (i.e., separations capacity) and the Thorium Alternative (i.e., fresh fuel infrastructure, including facilities to enrich uranium to 19.9 percent [Todosow $2007 \mathrm{~b}$ ]) require additional time to resolve.

The second group of alternatives (the All-Heavy Water Reactor Option and the All-High Temperature Gas-Cooled Reactor Option) could be deployed once these reactor types were developed and licensed by the Nuclear Regulatory Commission. Heavy water reactors are available commercially internationally and would only require U.S. licensing, while high temperature gas-cooled reactors would require development of both the reactor and the fuel, which could take 10 to 15 years or longer. Feedstock would not be a constraint, because both options would depend on the existing uranium fuel infrastructure. Complete transition would require early construction of production facilities, including heavy water production plants for heavy water reactors and reactor-grade graphite production plants for high temperature gascooled reactors. The completion of transition would occur once all current (legacy) reactors were retired. Based on licensing and license extension considerations, DOE expects that reactors in the existing light water reactor fleet would be operated for 60 years, with retirements beginning in 
2029 and completing in 2053. Construction of new light water reactors now under consideration could extend the transition period.

Transition for the final group of alternatives (the Fast Reactor Recycle Alternative, the Thermal/Fast Reactor Recycle Alternative, the Thermal Reactor Recycle Alternative (Option 2), and the Thermal Reactor Recycle Alternative (Option 3)) would be more complex relative to the Group 1 and Group 2 alternatives. The start of transition would involve new reactors and new nuclear fuels, and the new fuels would require separations to provide feedstock. Transition could begin in 15-20 years, but the rate of transition would be slower than the other groups of alternatives. This would be due to the feedstock required for startup of the new reactors, a full core of fuel would be needed to start each new reactor, while for the previous groups only a partial core would need to be replaced at a time. The feedstock would initially come from light water reactor spent fuel separations, and therefore would be tied to the separations capacity. While this would not affect deployment of heavy water reactors associated with the Thermal Reactor Recycle Alternative (Option 2), it could constrain the rate of fast reactor deployment, each of which would require a significant quantity of transuranics. The amount of transuranics needed to start up a new fast reactor would also depend on whether the fast reactor spent nuclear fuel would be recycled on-site or at a central facility. Centralized recycling would require longer storage of the fast reactor spent nuclear fuel so it could cool prior to transport. This could result in a greater delay before any of the residual transuranics from the fast reactor spent fuel could become available, so more transuranics would be required from separated uranium oxide before any would be available from the fast reactor spent fuel. The result would be that transition would not be completed for several decades.

\section{S.3.3 Design and Operation of a Future Geologic Repository}

The programmatic alternatives could impact, beneficially, the design and/or operation of a future geologic repository by reducing the radiotoxicity, heat load, or the volume of spent nuclear fuel and high-level radioactive waste. These reductions have the potential to decrease the uncertainty in predicting long-term performance of such a repository, or increase the public acceptability of geologic disposal, so that adequate disposal capacity can be found for future commercial nuclear waste inventories.

Potential Reduction in Radiotoxicity: Radiotoxicity, which is a measure of the hazard posed by radioactive material, is a function of time in part because the radiotoxicity from any isotope will be reduced to negligible levels as radioactive materials decay over time, although the decay process can require millions of years for some isotopes. One measure of the potential hazard of spent fuel and high-level radioactive waste is to compare the time required for the radiotoxicity of these radioactive materials to be reduced to that of the natural uranium ore used as the source material for the nuclear fuel. Although such a comparison is informative, it should be noted that radiotoxicity is not a regulatory standard relevant to the disposal of spent fuel and high-level radioactive waste. 
Figure S.3-1 shows the radiotoxicity of the various types of spent nuclear fuel and/or high-level radioactive waste relative to uranium ore as a function of time. Table S.3-1 includes the time required for the spent nuclear fuel and high-level radioactive waste to decay to the radiotoxicity of natural uranium ore. As shown, spent fuel from light water reactors remains more radiotoxic than uranium ore for about 240,000 years. Alternatives that do not recycle spent fuel and transmute the long-lived actinides (with either fast reactors or thermal reactors) would generate waste that would remain more radiotoxic than the original natural uranium ore for approximately 85,000 to 525,000 years (Wigeland 2008a).

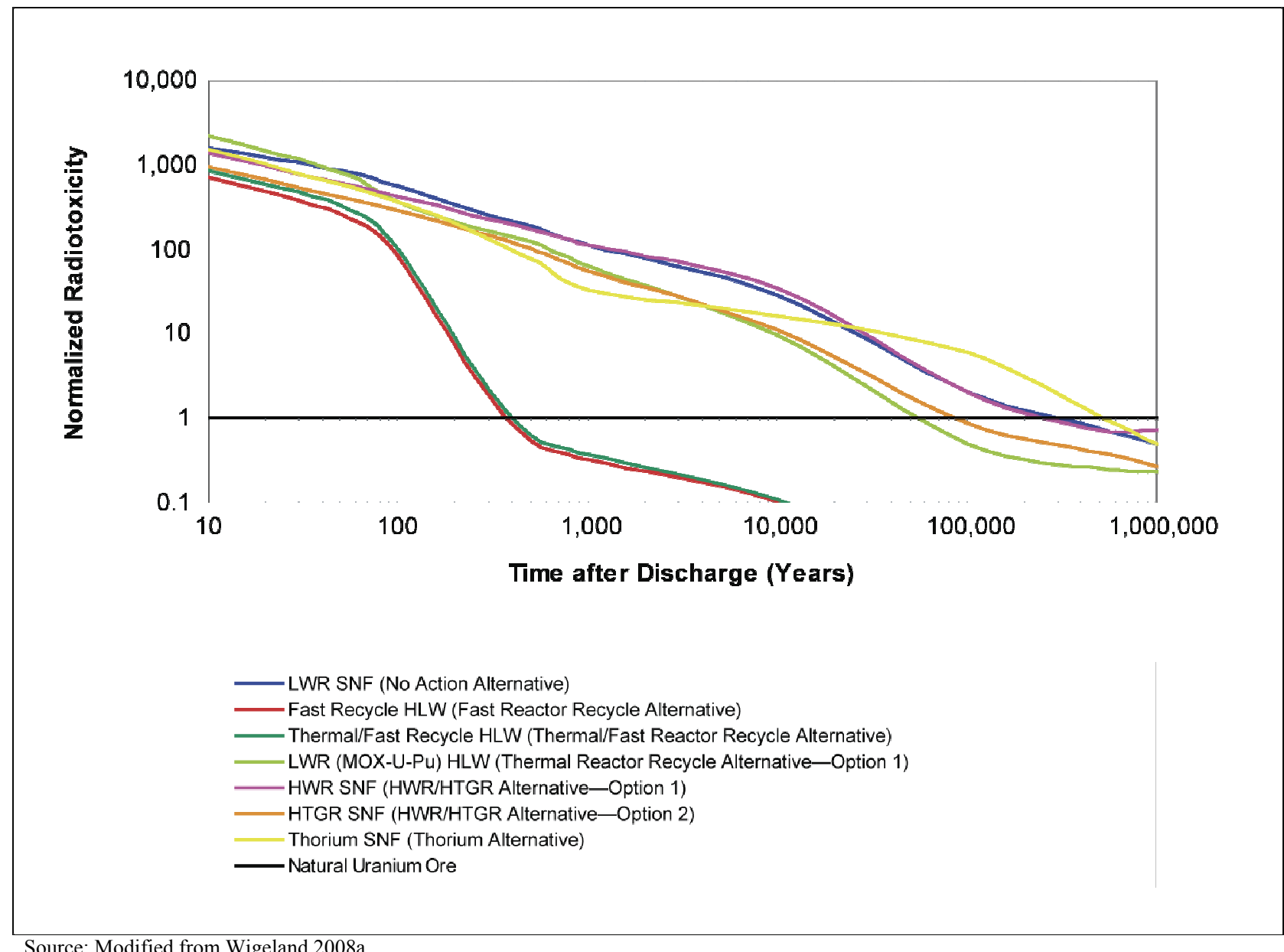

FIGURE S.3-1—Radiotoxicity of Spent Nuclear Fuel and/or High-Level Radioactive Waste Over Time

Implementation of the Thermal Reactor Recycle Alternative (Option 1) could reduce the time period for which the radiotoxicity of the radioactive materials exceeds that of uranium ore to approximately 55,000 years. Implementation of the Fast Reactor Recycle Alternative or the Thermal/Fast Reactor Recycle Alternative could further reduce the longer-lived transuranic isotopes remaining in the radioactive wastes. Removal of uranium and transuranic elements via recycling could reduce the time period for which the radiotoxicity of the waste exceeds that of uranium ore from between approximately 85,000 and 525,000 years to perhaps less than 1,000 years, depending on the amount of uranium and transuranic loss from all processes that eventually becomes part of the wastes destined for disposal. 
Potential Reduction in Thermal Load: Thermal load is a potentially relevant measure for geologic disposal because a repository would have thermal limits on both the engineered structures and the repository environment. For purposes of analysis in the PEIS, the thermal load reduction factor on a repository is 1.0 for the No Action Alternative, and the relative thermal load reduction of the action alternatives is compared to this value. For example, the high-level radioactive waste associated with the Fast Reactor Recycle Alternative and the Thermal/Fast Reactor Recycle Alternative would reduce the thermal loading on a repository by a factor of approximately 235 for the same total electricity generation (i.e., these alternatives could generate 235 times as much electricity as the No Action Alternative before producing the same thermal loading on a repository) (Table S.3-1). With respect to the other action alternatives, DOE estimates that thermal load reduction factors would range between 0.9 and 2.0. While most alternatives show an improvement compared to the No Action Alternative, recycling light water reactor and fast reactor spent fuel would achieve the most significant improvements in repository thermal loading.

Potential Reduction in Volume: The volume of radioactive materials requiring geologic disposal can be determined by the mass of material to be disposed multiplied by the concentration of waste in the final waste form, then adjusted to reflect the volume of surrounding waste packaging. For example, one potential waste form is borosilicate glass, for which there is a maximum radionuclide concentration that would dissolve into the glass, which in turn would determine the maximum waste loading. The glass would then be put into a waste package, the design of which is yet to be determined for a future geologic repository.

As shown in Table S.3-1, the annual volume of spent nuclear fuel generated by the open fuel cycle alternatives (e.g., No Action Alternative, Heavy Water Reactor/High Temperature GasCooled Reactor Alternative) is much greater than that of the closed fuel cycle alternatives (e.g., Fast Reactor Recycle Alternative, Thermal/Fast Reactor Recycle Alternative) in which the spent fuel is recycled. In contrast, the closed fuel cycle alternatives would generate high-level radioactive waste requiring geologic disposal, and Greater-than-Class-C low-level radioactive waste, neither of which is generated by operations related to the open fuel cycle alternatives. DOE recognizes that the volume of high-level radioactive waste could be reduced by employing advanced methods to separate long-lived fission products (such as technetium and iodine) from potentially useful products (such as uranium and transuranic elements) and potentially from cesium and strontium. 


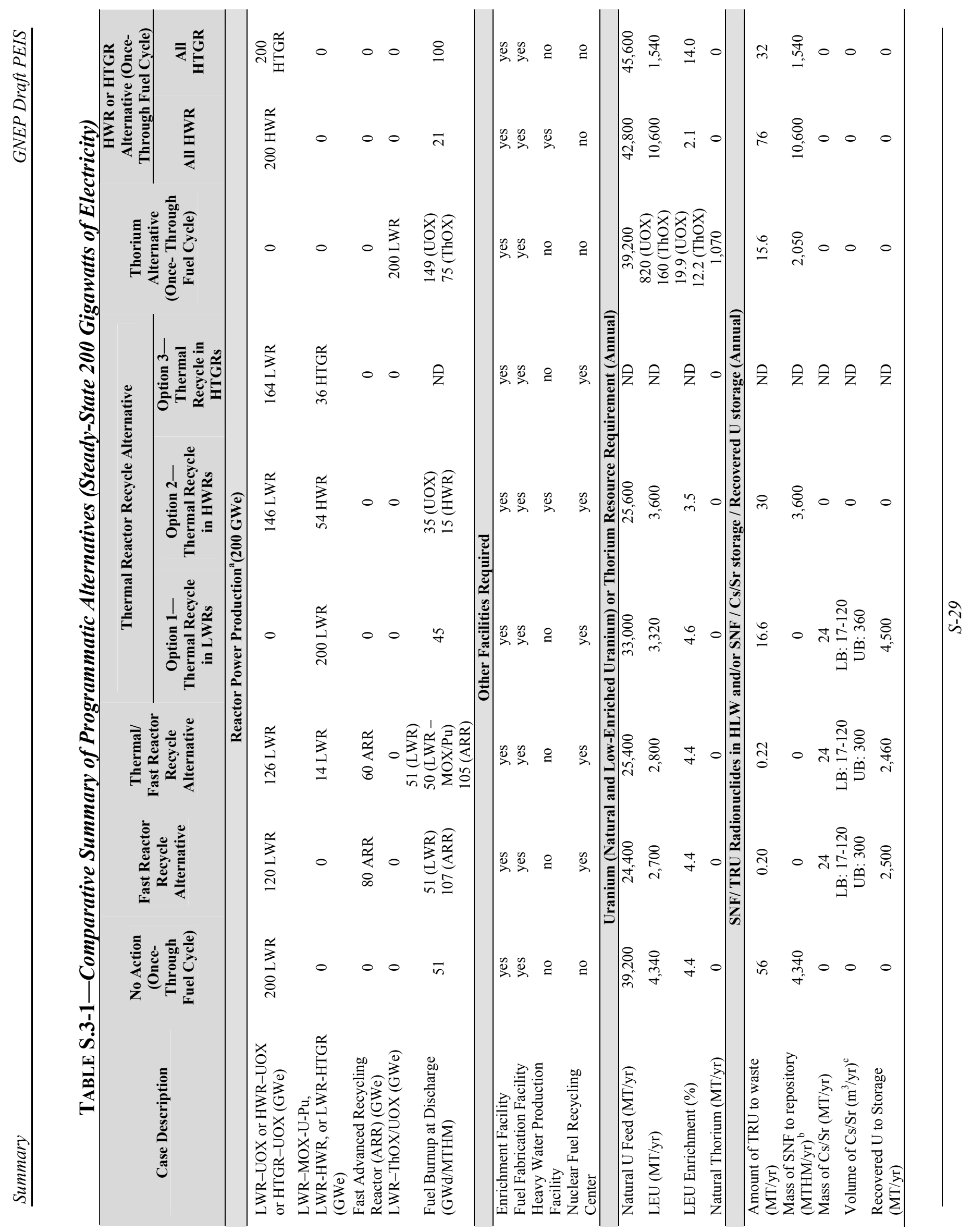




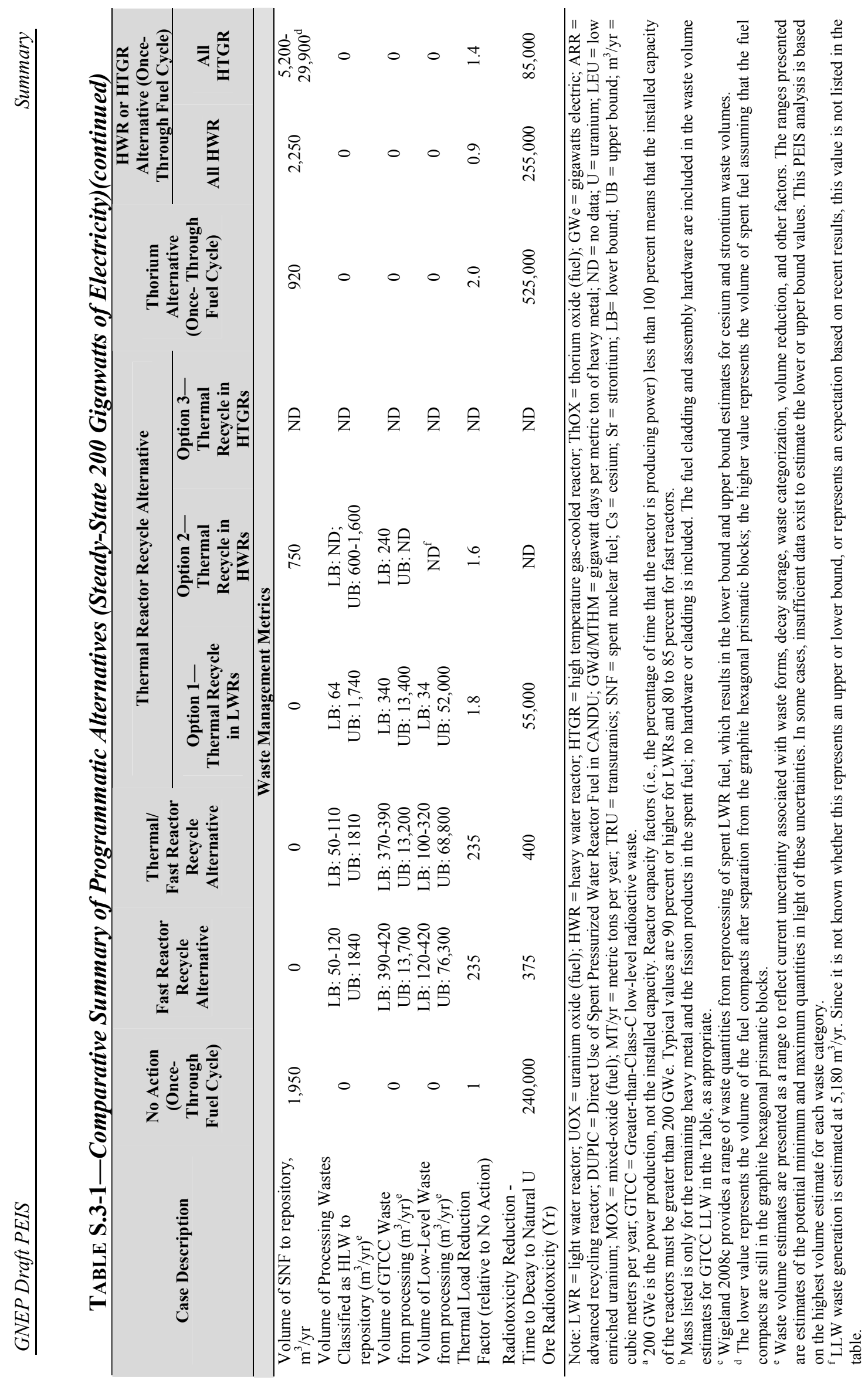




\section{S.4 ENVIRONMENTAL IMPACTS OF DOMESTIC ALTERNATIVES}

This GNEP PEIS analyzes and compares the potential environmental impacts associated with the current U.S. commercial nuclear fuel cycle and implementation of alternative nuclear fuel cycles. As a result, the analysis is necessarily long-term, focusing on the potential impacts that could result from implementing each of the programmatic alternatives over many decades. It is not possible to predict with confidence when any of the action alternatives would be implemented in their entirety, as many factors would affect the success of implementing any alternative, including market forces, public policy, the costs and timing for transition to and implementation of the alternatives, and regulatory issues. Based on cautious but reasonable assumptions, this PEIS considers that transition to, and complete implementation of any action alternative could be achieved in the 2060-2070 time frame.

This PEIS analyzes four different growth rates for electricity generation from nuclear power ( 0 or no growth, 0.7 percent, 1.3 percent and 2.5 percent for a high growth rate case). Unless indicated otherwise, the environmental impact analysis in this Summary is presented for a 1.3 percent growth scenario (which would equate to approximately 200 gigawatts of electricity) from nuclear power in the 2060-2070 time frame. While it is recognized that there are other potential combinations, the scenarios analyzed provide a reasonably foreseeable range of future conditions.

Many of the environmental consequences associated with the alternatives vary directly with the electricity production. For example, if the future electricity production by nuclear reactors at full implementation is 400 gigawatts instead of 200 gigawatts, the number of reactors associated with any alternative could double. Many other factors, such as the annual amount of spent nuclear fuel generated, the annual quantities of wastes generated and the annual radiological emissions from facilities, could be scaled in a similar manner.

For any programmatic alternative, there are a large number of reactor scenarios that could be used to represent a national nuclear power generating system, and thus to estimate environmental impacts for the four scenarios. For example, to achieve an electricity production of 200 gigawatts, an alternative could include 200 reactors, each producing 1,000 megawatts or 400 reactors each producing 500 megawatts. Instead, to simplify the analysis, environmental impacts are estimated based on achieving an electricity production level rather than the number of reactors.

DOE, in this PEIS, evaluates the environmental impacts from the construction and operation of various facilities, including reactors, spent fuel processing and fuel fabrication facilities through approximately 2060-2070. For all programmatic alternatives, the analysis of impacts relies on the following common approach: 
- $\quad$ Existing U.S. nuclear capacity is approximately 100 gigawatts of electric capacity.

- Nuclear electricity capacity would grow to approximately 200 gigawatts by the 2060-2070 time frame.

- $\quad$ The first new light water reactor would come on-line in approximately 2015.

- Conversion to new fuel types, if applicable, would begin in approximately 2020, and new reactors would operate using the new fuel. The 104 existing reactors would continue to operate on the typical uranium-dioxide fuel.

- Retirement of existing light water reactors would begin in 2029, and would be replaced by the same amount of nuclear generating capacity. By about the 2060-2070 time frame, all existing light water reactors would have retired or been replaced.

- New light water reactors, which are being pursued by the commercial nuclear power industry independently of DOE, could be constructed during the PEIS analysis time frame. Except for the Heavy Water Reactor/High Temperature Gas-Cooled Reactor Alternative, each of the domestic programmatic alternatives would continue to need and use light water reactors. As such, for these alternatives, it is likely that any newly constructed light water reactors would continue to operate in the 2060-2070 time frame. For the Heavy Water Reactor/High Temperature Gas-Cooled Reactor Alternative, this PEIS assumes that full implementation would occur by approximately 2060-2070, meaning that all light water reactors would be phased-out by that time. However, because it is possible that some light water reactors could continue to operate past 2060-2070 for the Heavy Water Reactor/High Temperature Gas-Cooled Reactor Alternative, the PEIS also discusses how impacts would change if that were to occur.

- Quantities of spent nuclear fuel and radioactive wastes are based on generation from approximately 2010 through approximately 2060-2070.

Sections S.4.1 through S.4.9, which follow, present a summary comparison of the domestic programmatic alternatives. The alternatives are compared in the following areas: facility and resource requirements, quantities of spent nuclear fuel and wastes generated, occupational and public health impacts, facility accidents, intentionally destructive acts, transportation impacts, cumulative impacts, unavoidable impacts and irreversible and irretrievable impacts. Tables S.4-1 and S.4-2 present a comparative summary of the impacts of the domestic fuel cycle alternatives. Table S.4-1 presents the annual impacts once implementation is achieved in approximately 2060-2070. Table S.4-2 presents the cumulative impacts over the entire implementation period (2010 to approximately 2060-2070).

In general, given the broad, programmatic nature of the analyses, the PEIS presents impacts to certain resources such as land use, socioeconomics, air quality and visual resources which do not discriminate significantly among the alternatives. Water usage varies, but only at the fuel cycle level; that is, water usage among the open or closed fuel cycle alternatives does not vary, but usage is higher under the closed fuel cycle alternatives. In addition, the PEIS (Chapter 4, Section 4.1) examines impacts that would be common to each of the domestic programmatic 
alternatives, with a focus on the impacts from uranium mining, uranium enrichment, uranium fuel fabrication, low-level radioactive waste disposal and continuation of the Advanced Fuel Cycle Initiative - none of which vary significantly among the alternatives. Given the above, this Summary presents the potential impacts to those resources that tend to offer a means to discriminate among the alternatives. 


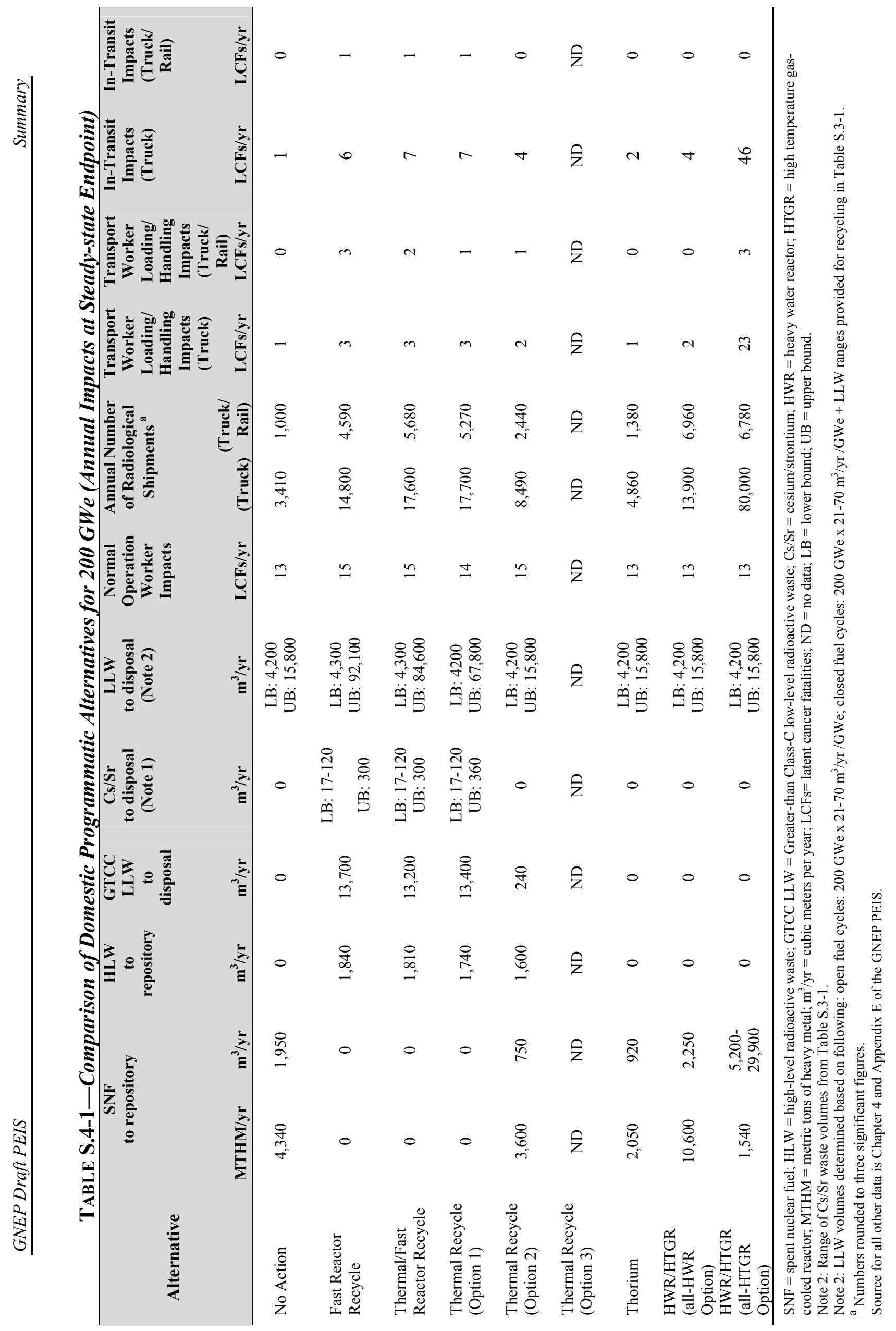




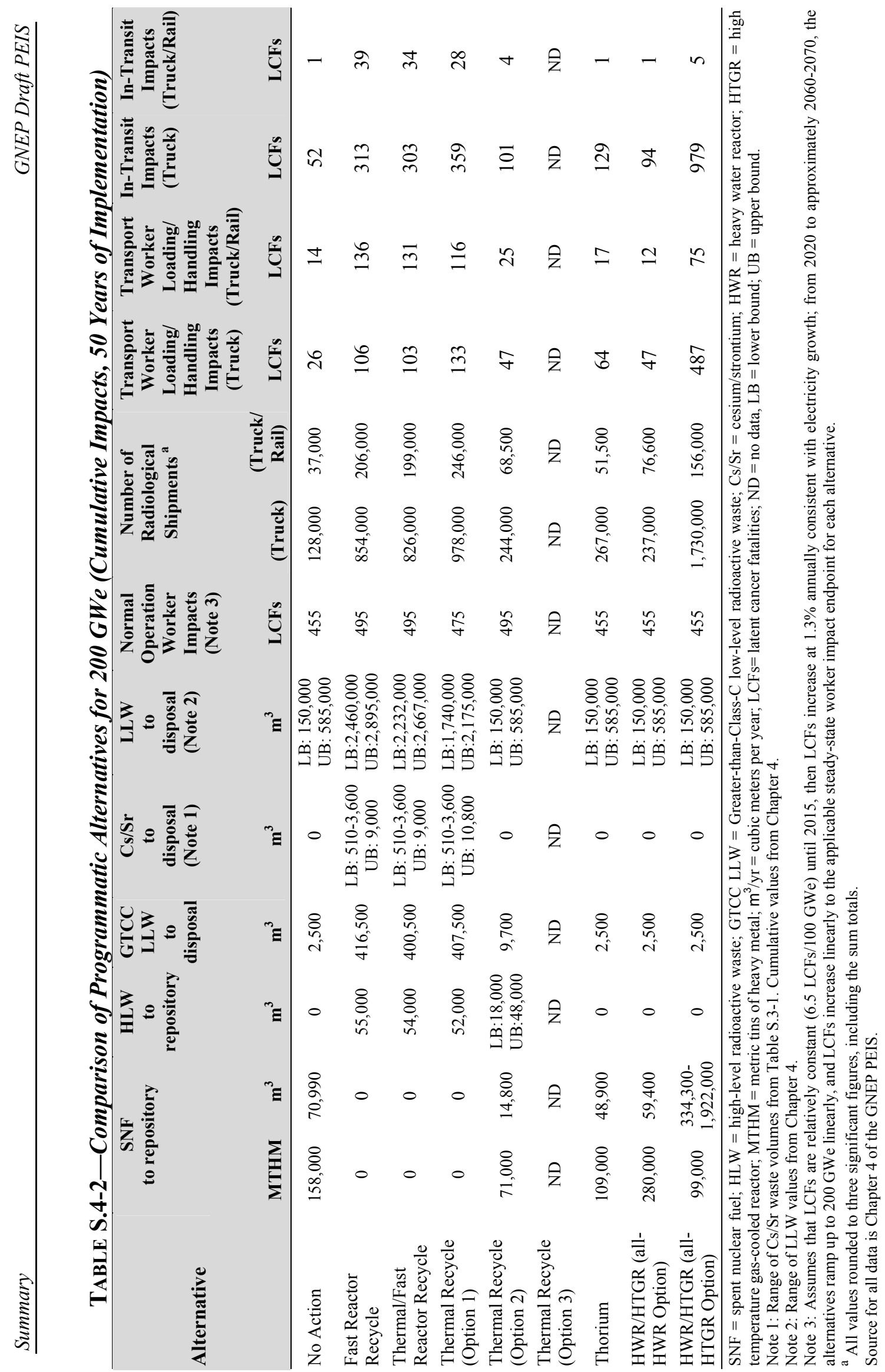




\section{S.4.1 Facility and Resource Requirements}

All fuel cycle alternatives would require significant quantities of natural uranium feed. The open fuel cycle alternatives (No Action Alternative, Thorium Alternative and Heavy Water Reactor/High Temperature Gas-Cooled Reactor Alternative) would require the highest quantities of natural uranium feed. The All-High Temperature Gas-Cooled Reactor Option would require the highest natural uranium feed on an annual basis (about 45,600 metric tons). The closed fuel cycle alternatives would require much less natural uranium feed, the lowest of which is the Fast Reactor Recycle Alternative, which would require about 24,400 metric tons per year. The closed fuel cycle alternatives also would recover for future use approximately 2,460-4,500 metric tons of uranium yearly and about 26 to 56 metric tons of transuranics yearly, depending upon the closed fuel cycle alternative.

All alternatives would require various types of new facilities, including fuel enrichment and fuel fabrication facilities. The closed fuel cycle alternatives (Fast Reactor Recycle Alternative, Thermal/Fast Reactor Recycle Alternative and the Thermal Reactor Recycle Alternative [all options]) would require light water reactor spent fuel separation facilities/fuel fabrication facilities. Facilities to produce heavy water also would be required to implement the Thermal Reactor Recycle Alternative (Option 2) and the All-Heavy Water Reactor Option. Facilities to produce reactor-grade graphite also would be required to implement the Thermal Reactor Recycle Alternative (Option 3) and the All-High Temperature Gas-Cooled Reactor Option.

During operations, the facilities would use water for domestic needs, process support and to cool the reactor (primary and secondary cooling). Most of this water would not be consumed, but would be used for cooling and then discharged. Each light water reactor spent fuel separation facility would require approximately 330 million gallons per year (1.3 billion liters per year), and each reactor ( 1 gigawatt electric output) would use approximately 3 to 6 billion gallons per year (11 to 23 billion liters per year), mainly for heat dissipation. In arid environments, "dry" cooling towers could be utilized to reduce water requirements to approximately 195 million gallons per year (740 million liters per year).

\section{S.4.2 Spent Nuclear Fuel and Radioactive Wastes}

All programmatic alternatives would generate spent nuclear fuel and/or high-level radioactive waste that would require disposal in a geologic repository. The most radiotoxic contents of spent fuel and high-level radioactive waste are generally the actinide elements such as plutonium, and to a lesser extent, certain fission products (such as cesium and strontium). The amount of spent nuclear fuel and high-level radioactive waste created per year would vary from one alternative to another. In addition, each alternative would generate low-level radioactive waste during operations and Greater-than-Class-C low-level radioactive waste during decontamination and decommissioning following plant shutdown. The closed fuel cycle alternatives also would generate Greater-than-Class-C low-level radioactive waste during spent fuel recycling operations. Under the Fast Reactor Recycle Alternative, Thermal/Fast Reactor Recycle Alternative and Thermal Reactor Recycle Alternative (Options 1 and 3), it is also possible that cesium and strontium could be separated from other fission products, and then be stored for a period of time (300 years) and possibly disposed of as low-level radioactive waste. 
The following spent nuclear fuel and waste streams do not have a clear path to disposal at this point:

- Spent nuclear fuel in quantities greater than the limit established by law for the Yucca Mountain repository

- High-level radioactive waste (including separated cesium and strontium) in quantities greater than the limit established by law for the Yucca Mountain repository

- Greater-than-Class-C low-level radioactive waste for which no disposal facilities are available

- Low-level radioactive waste in quantities that would exceed capacities of existing disposal facilities

The impact on spent nuclear fuel and high-level radioactive waste management for each alternative is evaluated by assessing: the mass/volume of spent nuclear fuel and/or high-level radioactive waste that would be sent to geologic disposal, the amount of fission products and transuranic elements requiring consolidation in waste forms that would be sent to geologic disposal, the radiotoxicity of the emplaced spent nuclear fuel and/or high-level radioactive waste and the decay heat that would have to be accommodated by the repository design. Table S.3-1 provides this information for each alternative.

Spent Nuclear Fuel Requiring Repository Disposal: All alternatives would require a geologic repository. Under the No Action Alternative at the 1.3 percent growth rate, about 158,000 metric tons of heavy metal of spent nuclear fuel would be cumulatively created between 2010 and approximately 2060-2070, which is more than 2.2 times that of the Yucca Mountain statutory capacity limit.

Of the other alternatives, the Fast Reactor Recycle Alternative, Thermal/Fast Reactor Recycle Alternative and the Thermal Reactor Recycle Alternative (Option 1) would avoid direct disposal of spent nuclear fuel in a geologic repository. These alternatives, however, would produce high-level radioactive waste as part of the recycling of spent nuclear fuel.

On an annual basis at full implementation (approximately 2060-2070), the All-Heavy Water Reactor Option would generate the highest mass of spent fuel requiring geologic disposal (10,600 metric tons of heavy metal per year). For the once-through fuel cycles, the All-High Temperature Gas-Cooled Reactor Option could generate the least mass of spent fuel requiring geologic disposal (1,540 metric tons of heavy metal per year). ${ }^{12}$ This reflects the higher burnup of high temperature gas-cooled reactors compared to the lower burnup of heavy water reactors. The Thorium Alternative would generate approximately 2,050 metric tons of heavy metal per year of spent nuclear fuel. As a point of comparison, the No Action Alternative would generate

${ }^{12}$ While the mass of spent nuclear fuel can be relatively smaller with the HTGR, if the spent fuel compacts are not removed from the graphite blocks, the volume of spent nuclear fuel can be substantial (see Table S.3-1). 
approximately 4,340 metric tons of heavy metal per year. The total quantities generated between 2010 and approximately 2060-2070 for each alternative reflect the time-phased implementation of each alternative. For example, under the All-Heavy Water Reactor Option, no heavy water reactor spent fuel would be generated until after the initial facilities begin to operate in 2020 . From that time, the amount of heavy water reactor spent fuel generated would continue to increase annually to about 10,600 metric tons of heavy metal per year, until full implementation is reached in approximately $2060-2070$.

Processing Wastes Classified as High-Level Radioactive Waste Requiring Repository Disposal: The Fast Reactor Recycle Alternative, Thermal/Fast Reactor Recycle Alternative and the Thermal Reactor Recycle Alternatives (all options) would generate processing wastes that would be classified as high-level radioactive waste in the amount of about 50 to 1,840 cubic meters per year (65 to 2,400 cubic yards per year). The recycling of the spent fuel that would occur under these alternatives could generate approximately 50,000 cubic meters (71,500 cubic yards) of high-level radioactive waste between 2010 and approximately 2060-2070.

There are several options for encapsulating the waste in forms suitable for geologic disposal, such as in borosilicate glass, as is planned for some DOE defense-related wastes. The cladding and assembly hardware recovered at the processing plant have been included in the estimated quantity of Greater-than-Class-C low-level radioactive waste. The values listed in Table S.3-1 are estimates based on existing technologies and the best available information for encapsulating both transuranics and fission products.

As shown on Table S.3-1, the amount of transuranic radionuclides also varies among the alternatives. The Fast Reactor Recycle Alternative and Thermal/Fast Reactor Recycle Alternative would generate the lowest amount of transuranic radionuclides $(0.20$ to 0.22 metric tons per year) that would have to be sent to a repository for disposal. The Thorium Alternative (15.6 metric tons per year), Thermal Reactor Recycle Alternative (Option 1) (16.6 metric tons per year), Thermal Reactor Recycle Alternative (Option 2) (30 metric tons per year) and the AllHigh Temperature Gas-Cooled Reactor Option (32 metric tons per year) are the next lowest generators of transuranic radionuclides (either in high-level radioactive waste and/or in spent fuel that would have to be sent to a geologic repository). The No Action Alternative and the AllHeavy Water Reactor Option produce relatively large quantities of transuranic radionuclides (56 and 76 metric tons per year, respectively) in spent fuel that would have to be sent to a geologic repository.

Other Wastes: Compared to the open fuel cycle alternatives, recycling spent fuel generates much higher quantities of Greater-than-Class-C low-level radioactive waste and low-level radioactive waste, as well as potentially producing separated cesium and strontium waste (Table S.3-1). The Fast Reactor Recycle Alternative, Thermal/Fast Reactor Recycle Alternative, and Thermal Reactor Recycle Alternative (Option 1) would generate relatively large quantities of Greaterthan-Class-C low-level radioactive waste (more than 13,000 cubic meters per year in the peak year of operation) or about 400,000 cubic meters (520,000 cubic yards) from the spent fuel generated between 2010 and approximately 2060-2070. 
The Low-Level Radioactive Waste Policy Amendments Act of 1985 assigns the responsibility for the disposal of Greater-than-Class-C low-level radioactive waste that results from activities licensed by the Nuclear Regulatory Commission to the Federal government (DOE), and specifies that this waste must be disposed of in a facility licensed by the Nuclear Regulatory Commission. There are no facilities licensed by the Nuclear Regulatory Commission for the disposal of Greater-than-Class-C low-level radioactive waste, and therefore this waste would remain in storage until a disposal facility can be developed. ${ }^{13}$

If cesium and strontium wastes are stored for approximately 300 years, their radioactivity levels would have decayed sufficiently so that these wastes potentially could be disposed of as lowlevel radioactive waste. Another option would be to store these wastes for eventual disposal as high-level radioactive waste in a geologic repository. About 24 metric tons per year of cesium and strontium wastes could be generated for the Fast Reactor Recycle Alternative, Thermal/Fast Reactor Recycle Alternative and Thermal Reactor Recycle Alternative (Options 1 and 3).

The programmatic alternatives that recycle spent fuel also would generate relatively large quantities of low-level radioactive waste compared to the open fuel cycle alternatives. The Fast Reactor Recycle Alternative, Thermal/Fast Reactor Recycle Alternative, and Thermal Reactor Recycle Alternative (Option 1) would generate approximately 1.7 million to 2.9 million cubic meters (2.2 to 3.8 million cubic yards) from 2010 to approximately 2060-2070.

\section{S.4.3 Human Health}

In this PEIS, DOE estimates the health and safety impacts to workers and the public that could occur during construction and operation of facilities under each domestic alternative. These impacts include those that could occur 1) to workers from hazards common to similar industrial settings and excavation operations, such as falling or tripping (referred to as industrial hazards), 2) to workers as a result of radiation exposure during their work activities and 3) to the public from airborne releases of radionuclides. DOE concluded, based on analysis in the PEIS (see Appendix C), that adverse occupational impacts from industrial hazards would be expected to be low and would not vary among the alternatives.

To estimate potential radiological impacts, DOE used actual information from commercial nuclear plants and preliminary design information for other reactors and spent nuclear fuel recycling facilities. For impacts to workers, DOE used actual worker doses to estimate the collective dose (expressed as person-rem) to the workforce considered for each programmatic alternative. For impacts to the public, DOE used projected airborne radioactive releases from routine operations of facilities associated with each of the alternatives to estimate collective dose to the population, and the dose to the maximally exposed member of the public. Dose was then converted to latent cancer fatalities to the population, or to an increased risk of contracting a fatal cancer to the maximally exposed individual.

\section{Maximally Exposed Individual}

A hypothetical member of the public at a fixed location who, over an entire year, receives the maximum effective dose equivalent (summed over all pathways) from a given source of radionuclide releases to air.

\footnotetext{
${ }^{13}$ DOE is currently preparing an Environmental Impact Statement to evaluate a range of reasonable alternatives for disposal of Greater-thanClass-C low-level radioactive waste (see Chapter 1, Section 1.3.7).
} 
Because the location of any new commercial facility can not be known with certainty, DOE estimated impacts to the public at six hypothetical sites. DOE developed these sites using offsite population (50 mile [80 kilometer]) and meteorological information from existing commercial reactor facilities. A combination of population and meteorological data was chosen to develop a range of conditions from generally favorable (large atmospheric mixing and small population) to unfavorable (small atmospheric mixing and large population). For this reason, the six hypothetical sites represent the range of dose and health impacts to the population that would be found at most locations that might house either separations facilities or reactors. The health effects identified in this PEIS analysis are for the operational period (2010 through approximately 2060-2070) only. By reducing the volume, thermal output, and/or radiotoxicity of spent fuel and high-level radioactive wastes requiring geologic disposal, there is also a potential to reduce long-term health impacts from such disposal.

\section{S.4.3.1 Impacts to Workers}

All domestic programmatic alternatives could affect worker health through direct radiation exposure. Table S.4-3 presents annual impacts to the involved (radiation) workers for each of the domestic programmatic alternatives. As shown in that table, reactor operation doses were assumed to not vary among reactor technologies. ${ }^{14}$ As shown in Table S.4-3, there would be slightly higher impacts to workers for the closed fuel cycle alternatives than the open fuel cycle alternatives. These higher impacts are due to the additional worker doses associated with recycling. Additionally, the closed fuel cycle alternatives that recycle the highest quantities of spent fuel would result in the highest worker doses.

There also would be impacts to workers due to the storage of spent fuel and/or radioactive wastes. For the No Action Alternative, doses from storing the cumulative quantity of spent fuel that would be generated during the implementation period (approximately 158,000 MTHM of spent fuel) for 50 years at the reactor sites prior to geologic disposal was estimated at 140 person-rem, or less than 3 person-rem per year. Doses from the other open fuel cycle alternatives would be expected to vary according to the quantity of spent fuel in storage, and to range from approximately 90 person-rem to 250 person-rem. For the closed fuel cycle alternatives, the doses from the recycling facilities would include storage of radioactive wastes. Doses from such storage were not estimated for the cumulative quantities of wastes that would be generated, but these impacts are expected to be less than or similar to the spent fuel storage impacts, as these waste would generally produce smaller radiation doses. Therefore, worker doses due to storage are not expected to vary significantly among alternatives, and are expected to be much lower than doses due to reactor operations or recycling facility operations.

\footnotetext{
${ }^{14}$ In 2006, the average dose to a radiation worker at a Light Water Reactor in the United States was approximately 190 mrem (NRC 20071). This average dose to a radiation worker falls within the range of doses to radiation workers at Heavy Water Reactors in Canada (Health Canada 2008). This average dose represents the best estimate of the dose to a radiation worker for the other reactor technologies.
} 
TABLE S.4-3-Annual Impacts to Workers for Domestic Programmatic Alternatives

\begin{tabular}{lccc}
\hline \multicolumn{1}{c}{ Alternative } & $\begin{array}{c}\text { Annual Dose from Reactor } \\
\text { Operations (person-rem) }\end{array}$ & $\begin{array}{c}\text { Annual Dose from Recycling } \\
\text { Facility Operations a } \\
\text { (person-rem) }\end{array}$ & $\begin{array}{c}\text { Annual Latent } \\
\text { Cancer Fatalities } \\
\text { from All Facility } \\
\text { Operations }\end{array}$ \\
\hline $\begin{array}{l}\text { No Action } \\
\text { Fast Reactor Recycle }\end{array}$ & 20,900 & 0 & 13 \\
$\begin{array}{l}\text { Thermal/Fast Reactor } \\
\text { Recycle }\end{array}$ & 20,900 & 4,600 & 15 \\
$\begin{array}{l}\text { Thermal Reactor Recycle } \\
\text { Option 1) }\end{array}$ & 20,900 & 4,400 & 15 \\
$\begin{array}{l}\text { Thermal Reactor Recycle } \\
\text { (Option 2) }\end{array}$ & 20,900 & 3,300 & 14 \\
$\begin{array}{l}\text { Thermal Reactor Recycle } \\
\text { (Option 3) }\end{array}$ & 20,900 & 4,600 & 15 \\
$\begin{array}{l}\text { Thorium } \\
\text { All-Heavy Water }\end{array}$ & No Data & No Data & No Data \\
$\begin{array}{l}\text { Reactor Option } \\
\text { All-High Temperature }\end{array}$ & 20,900 & 0 & 13 \\
$\begin{array}{l}\text { Gas-Cooled Reactor } \\
\text { Option }\end{array}$ & 20,900 & 0 & 13 \\
\hline${ }^{a}$ Doses from recycling facility operations differ because of worker differences among the closed fuel cycle alternatives. &
\end{tabular}

\section{S.4.3.2 Impacts to the Public}

All domestic programmatic alternatives could affect public health through the release of radiological materials to the environment. The PEIS analyzes the impacts to both the maximally exposed individual, as well as the population within 50 miles ( 80 kilometers) of a facility. The analysis indicates that releases from spent nuclear fuel recycling facilities would generally cause the highest doses. As a result, the alternatives that involve spent nuclear fuel recycling would be expected to result in the highest doses to the public. However, DOE estimates that all alternatives would result in less than 1 latent cancer fatality per year to the populations surrounding the six hypothetical sites. Additional information may be found in Chapter 4 of the PEIS.

\section{S.4.4 Facility Accidents}

Each of the domestic programmatic alternatives could impact public and worker health in the event of an accident. An accident can be initiated by external events, internal events or natural phenomena. External initiators originate outside a facility and affect the facility's ability to confine radioactive material. External initiators include human-induced events, such as: aircraft crashes, external fires and explosions and natural phenomena, such as seismic disturbances and extreme weather conditions.

Accident

An unplanned event or sequence of events that results in undesirable consequences.

Internal initiators occur inside a facility and include human errors, equipment failures or combinations of the two. 
DOE considered a spectrum of accidents, including low consequence/high probability events and high consequence/low probability events. These accidents were chosen by defining a

\section{Internally, Externally, and Natural Phenomena Initiated Accidents}

This PEIS considers accidents that are internally, externally, and natural phenomena initiated. Internally initiated accidents are associated with a specific reactor design. These accidents could include events like failure of a reactor coolant pump, operator error, or loss of coolant. Externally initiated accidents are location-dependent and could be caused by an event such as an aircraft crash. Natural phenomena are typically location-dependent and include events such as earthquakes and tornadoes. Externally and natural phenomena initiated events are analyzed by the use of consistent release parameters regardless of the reactor design or generic location in order to provide a common basis for comparison.

Externally and natural phenomena initiated accidents, which are described and the results presented in Appendix $\mathrm{D}$, are generally the highest consequence accidents. Externally and natural phenomena accidents have the potential to mask any differences between reactor technologies and are most useful in providing a basis of comparison for core inventory (i.e., ultimate consequences).

bounding set of conditions such that any reasonably foreseeable accidents that could occur under the alternatives would be expected to have smaller consequences and/or risks. In this PEIS, DOE analyzed accident scenarios involving different types of reactors and nuclear fuels and those associated with nuclear fuel recycling facilities. Each scenario was analyzed using population and environmental characteristics from the six hypothetical sites. Results presented here are for the hypothetical site with the highest population and least favorable meteorological conditions (i.e., conditions that result in minimal dispersion of the radioactive material, thereby increasing the dose to individuals in the path of the plume). For each accident scenario, the PEIS includes the probability of that accident occurring during each year of reactor or facility operation, the potential consequences to the population and a maximally exposed individual if the accident were to occur (expressed as latent cancer fatalities) and the increased risk (probability multiplied by consequence) of those latent cancer fatalities. Accident analysis without a reactor design and specific site location gives results that could be misleading. The use of these results should be interpreted as providing a general range of impacts. Any reactor that would be proposed would be required to meet current Nuclear Regulatory Commission licensing and safety requirements regardless of the technology proposed. The Nuclear Regulatory Commission has approved four advanced reactor designs and is evaluating others.

Table S.4-4 presents the estimated frequencies, consequences and risks from those internally initiated accidents having the highest consequences to the public. Table S.4-5 also presents the estimated frequencies, consequences and risks, but for those internally initiated accidents having the highest risks to the public. Chapter 4 and Appendix D of the PEIS provide additional information regarding the accident scenarios and their analysis, as well as the impacts to workers. Differences in the results among the various reactors are primarily due to differences in the assumed fuel and reactor designs. Another factor is the difference in

\section{Probability and Frequency}

The probability of an accident occurring is expressed as a number between 0 (no chance of occurring) and 1 (certain to occur). Alternatively, instead of probability of occurrence, one can specify the frequency of occurrence (e.g., once in 200 years, which also can be expressed as 0.005 times per year) (DOE 2006p). 
assumed reactor electricity generation rates (reactor power level). For example, the light water reactor power level is nearly 10 times greater than the power level of the high temperature gascooled reactor.

The highest consequence, and highest risk, internally-initiated accident involving light water reactors using mixed oxide fuel (or, similarly, low enriched uranium fuel) is a scenario in which there is a direct loss of coolant because the primary coolant system overpressurizes other systems, and radionuclides are released to the atmosphere. DOE estimates that this accident, which has a probability of occurrence of about 7 in 100 million per year (i.e., frequency of about $7 \times 10^{-8} / \mathrm{yr}$ ), would result in an estimated 40,000 additional latent cancer fatalities to the surrounding population of 8.2 million. These consequences are consistent with the results of the NRC's Severe Accident Risks: An Assessment for Five U.S. Nuclear Power Plants, NUREG1150 (NRC 1990) and the Surplus Plutonium Disposition Final Environmental Impact Statement, DOE/EIS-0283 (DOE 1999d) when the high population and least favorable meteorological conditions used in this analysis are considered. The higher consequences for this accident are not the result of differences in the fuels relative to other reactors, but are instead the result of the use of high release parameters and an assumption that all containment and filter systems would fail. Therefore, although the consequences of such an accident could be large, to put such an accident into perspective, the probability of the accident should be considered. When probability is taken into account, the collective risk to the offsite population from this accident is about $2 \times 10^{-3}$ to $3 \times 10^{-3}$ latent cancer fatalities per year of operation. For the maximally exposed individual, this accident would result in an increased risk of contracting a fatal cancer of about $7 \times 10^{-8}$ per year of reactor operation.

The highest consequence, internally-initiated accident involving advanced light water (mixed oxide or low enriched uranium fueled) reactors is a scenario in which a relief value is opened inadvertently, thereby allowing the reactor to depressurize and the nuclear fuel rods to melt causing a release of radionuclides to the environment. DOE estimated that this accident would result in approximately 200 additional latent cancer fatalities in a population of about 8.2 million. The probability that such an accident would occur is about 1 in 100 million per year (i.e., frequency of $1.1 \times 10^{-8} / \mathrm{yr}$ ). Another useful metric is risk, which takes into account the probability of an accident, and is determined by multiplying the consequences of an accident by the probability of occurrence. The internally-initiated advanced light water reactor accident with the highest risk to the public is a small loss of coolant that would occur outside of the containment structure and would be released into the reactor building. The collective risk to the offsite population for this accident is $6 \times 10^{-6}$ latent cancer fatalities per year of operation. For the maximally exposed individual, this accident would result in an increased risk of contracting a fatal cancer of $1 \times 10^{-8}$ per year of reactor operation. 
TABle S.4-4-Internally Initiated Accident with Highest Consequences to the Public (Site 6)

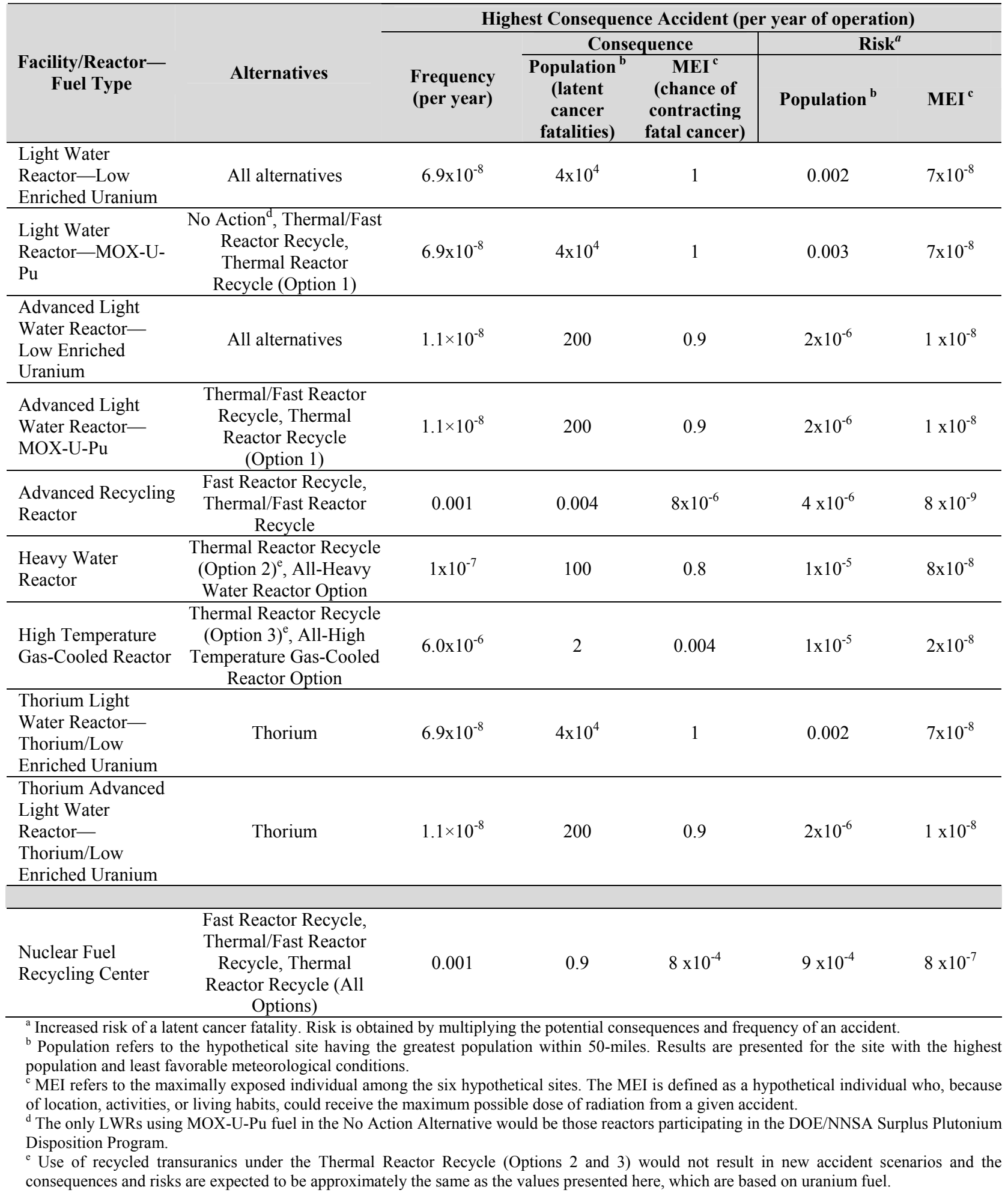


The highest consequence, and highest risk, internally initiated accident involving advanced recycling reactors is based on the published Clinch River Breeder Reactor analysis and is a scenario in which the system that extracts radioactive argon from the reactor cover gas ruptures, and radioactive gases are released to the atmosphere during reactor operation (PMC 1982). The Clinch River Breeder Reactor information assigned this accident to the unlikely frequency category with a probability of occurrence of about 1 in 1,000 per year $(0.001 / y r)$, and it would result in an estimated 0.004 additional latent cancer fatalities to the surrounding population. The collective risk to the offsite population is about $4 \times 10^{-6}$ latent cancer fatalities per year of operation. For the maximally exposed individual, this accident would result in an increased risk of contracting a fatal cancer of $8 \times 10^{-9}$ per year of reactor operation. 
TABLE S.4-5-Internally Initiated Event with the Highest Accident Risks to the Public (Site 6)

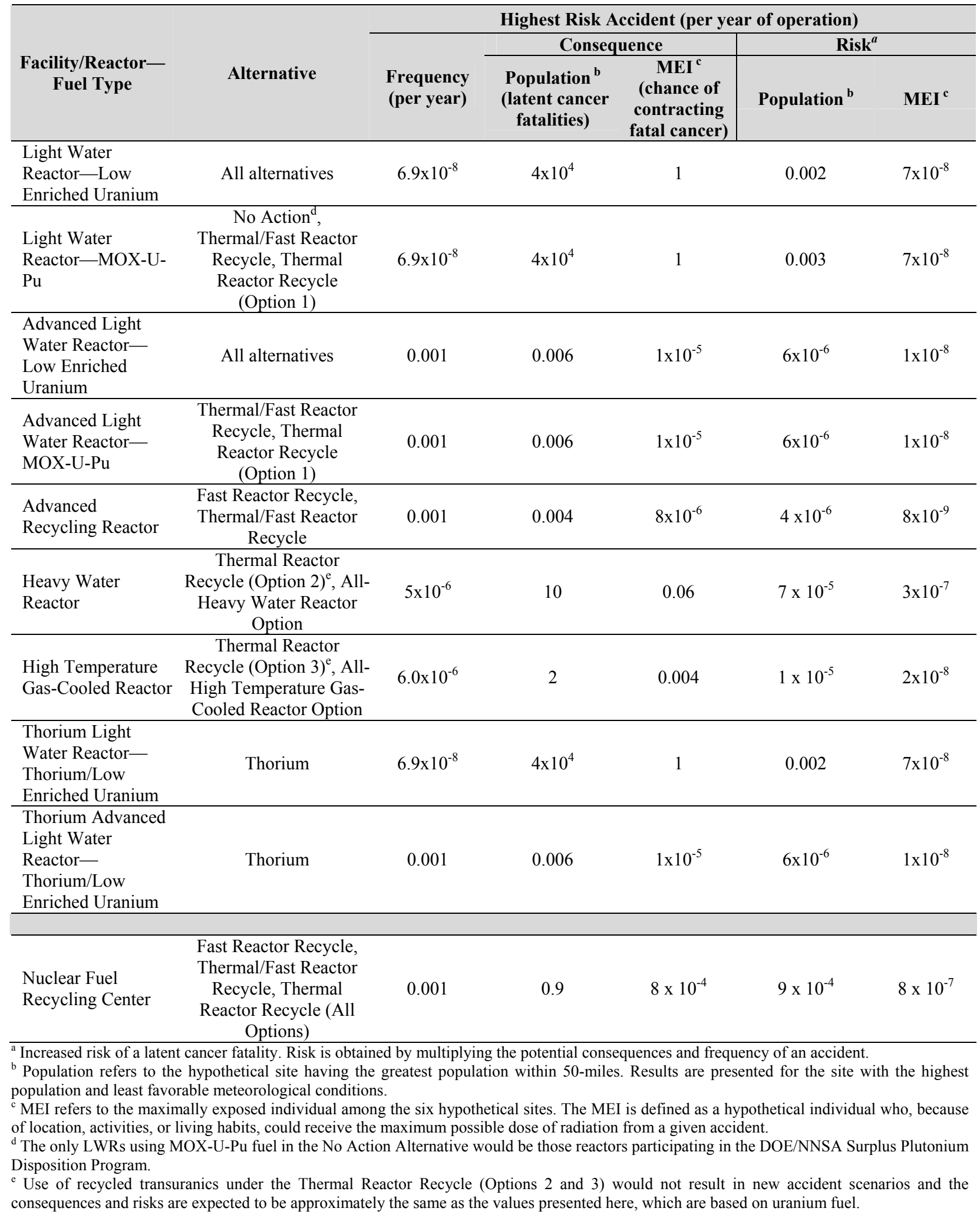


In analyzing potential heavy water reactor accidents, DOE found that the highest consequence internally initiated accident is one in which an internally initiated event causes the nuclear fuel core to melt and the containment spray system (an emergency water spray system that condenses steam in the containment and reduces radionuclide content of the vapor) fails, as do containment structures (structural barrier surrounding the reactor that contains radionuclides that may be released as a result of accidents). DOE estimates that this accident, which has a probability of occurrence of about 1 in 10 million per year (i.e., frequency of $1 \times 10^{-7} / \mathrm{yr}$ ), would result in an estimated 100 additional latent cancer fatalities to the surrounding population. In contrast, DOE found that the internally initiated heavy water reactor accident with the highest risk to the public is one in which the fuel core melts, but the containment spray system and structures remain intact and effective. The collective risk to the offsite population is about $7 \times 10^{-5}$ latent cancer fatalities per year of operation. For the maximally exposed individual, this accident would result in an increased risk of contracting a fatal cancer of $3 \times 10^{-7}$ per year of reactor operation.

In analyzing potential accidents involving high temperature gas-cooled reactors, DOE found that the highest consequence and highest risk internally initiated accident is one in which the reactor is depressurized by a loss of coolant (helium), and radionuclides are released to the atmosphere. DOE estimates that this accident, which has a probability of occurrence of about 6 in 1 million per year (i.e., frequency of $6 \times 10^{-6} / \mathrm{yr}$ ), would result in an estimated 2 additional latent cancer fatalities to the surrounding population. The collective risk to the offsite population is about $1 \times 10^{-5}$ latent cancer fatalities per year of operation. For the maximally exposed individual, this accident would result in an increased risk of contracting a fatal cancer of about $2 \times 10^{-8}$ per year of reactor operation.

The accident impacts for the thorium fueled LWR and ALWR are estimated to be the same as the low enriched uranium fueled LWR and ALWR, respectively.

In addition to reactor accident scenarios, DOE also evaluated potential accidents involving the nuclear fuel recycling center and found that the highest consequence, and highest risk, accident is one in which an explosion and fire release radionuclides to the environment. DOE estimates that this accident, which has a probability of occurrence of about 1 in 1,000 per year (i.e., frequency of $0.001 / \mathrm{yr}$ ), would result in less than 1 additional latent cancer fatality in the surrounding population. The collective risk to the offsite population is about $9 \times 10^{-4}$ latent cancer fatalities per year of operation. For the maximally exposed individual, this accident would result in an increased risk of contracting a fatal cancer of about $8 \times 10^{-7}$ per year of reactor operation.

DOE also evaluated accidents initiated by external phenomena and found that an aircraft crash into a reactor containment building that causes severe damage to the fuel core and results in loss of containment, and an earthquake that causes similar damage and containment loss would have the highest consequences of any externally-initiated accident. The consequences and collective risk of these accidents, however, are less than those of the light water reactors fueled by mixed oxide or low enriched uranium fuels in which there is a direct loss of coolant because the primary coolant system overpressurizes other systems and radionuclides are released. 


\section{S.4.5 Intentional Destructive Acts}

Whether acts of sabotage or terrorism would occur, and the exact nature and location of the events or the magnitude of the consequences of such acts if they were to occur, are inherently uncertain. Nevertheless, DOE estimated the consequences of intentional destructive acts, such as terrorism events. The analysis of intentional destructive acts differs from the accident analysis presented above in that this analysis is intended to provide an estimate of the consequences of such events, without attempting to determine a frequency associated with intentional destructive acts (DOE assumes an intentional destructive act would occur; i.e., with a probability of 1.0). Table S.4-6 summarizes the results of the analysis.

TABLE S.4-6-Summary of Bounding Intentional Destructive Acts Scenario

\begin{tabular}{|c|c|c|c|c|c|c|}
\hline \multirow[t]{2}{*}{ Facility } & \multicolumn{2}{|c|}{$\underline{\text { Offsite Population }}^{\text {a }}$} & \multicolumn{2}{|c|}{$\underline{\text { MEI }^{\mathbf{b}}}$} & \multicolumn{2}{|c|}{$\frac{\text { Noninvolved }}{\text { Worker }^{b}}$} \\
\hline & $\begin{array}{c}\text { Dose } \\
\text { (person-rem) }\end{array}$ & $\begin{array}{l}\text { Latent } \\
\text { Cancer } \\
\text { Fatality }\end{array}$ & $\begin{array}{l}\text { Dose } \\
\text { (rem) }\end{array}$ & $\begin{array}{l}\text { Latent } \\
\text { Cancer } \\
\text { Fatality }\end{array}$ & $\begin{array}{l}\text { Dose } \\
\text { (rem) }\end{array}$ & $\begin{array}{l}\text { Latent } \\
\text { Cancer } \\
\text { Fatality }\end{array}$ \\
\hline $\begin{array}{l}\text { Light Water Reactor- Low Enriched } \\
\text { Uranium, MOX-U-Pu, Thorium }\end{array}$ & $6 \times 10^{7}$ & $4 \times 10^{4}$ & $1 \times 10^{5}$ & 1 & $5 \times 10^{5}$ & 1 \\
\hline $\begin{array}{l}\text { Advanced Light Water Reactor- Low } \\
\text { Enriched Uranium, MOX-U-Pu, Thorium }\end{array}$ & $8 \times 10^{6}$ & 5,000 & $2 \times 10^{4}$ & 1 & $2 \times 10^{5}$ & 1 \\
\hline Advanced Recycling Reactor & $2 \times 10^{7}$ & $1 \times 10^{4}$ & $5 \times 10^{4}$ & 1 & $4 \times 10^{5}$ & 1 \\
\hline Heavy Water Reactor & $3 \times 10^{6}$ & 2,000 & 7,000 & 1 & $6 \times 10^{4}$ & 1 \\
\hline High Temperature Gas-Cooled Reactor & $1 \times 10^{6}$ & 800 & 3,000 & 1 & $3 \times 10^{4}$ & 1 \\
\hline Nuclear Fuel Recycling Center & $2 \times 10^{5}$ & 100 & 70 & 0.09 & 500 & 0.6 \\
\hline
\end{tabular}

The offsite population impacts in Table S.4-6 differ among the various reactors due in part to the differences in the amount of electricity produced (power levels) by the reactors. For example, the power level of a light water reactor is nearly 10 times greater than the power level of a high temperature gas-cooled reactor. When power level is considered, offsite population impacts are consistent among the reactors with the exception of the light water reactor.

Even after considering differences in power levels, the low enriched uranium and MOX-U-Pu fueled light water reactor offsite population impacts are still greater than the offsite population impacts for the other reactors. This is because the light water reactor results are based on an internally-initiated intentional event in which coolant is lost and higher release fractions are assumed, whereas the impacts for all other reactors are based on an aircraft crash event. The advanced light water reactor design includes safety features that make the probability of internal events (such as a catastrophic loss of coolant) remote, but the light water reactor analyzed does not include these safety features. As a result of the different events and higher release parameters, the light water reactor offsite population impacts are greater than the impacts for the advanced light water reactor. All future reactors are expected to have advanced designs that would make scenarios, such as the catastrophic loss of coolant, remote. 


\section{S.4.6 Transportation Impacts}

Transportation of spent fuel, high-level radioactive waste and/or other radiological materials would be required for all alternatives. Once generated at a commercial reactor, spent nuclear fuel would be transported to a repository (for open fuel cycle alternatives) or to a recycling facility (for closed fuel cycle alternatives). Reusable materials from recycling would be fabricated into new reactor fuel, which would then be transported to the reactors, and non-reusable materials would be transported for disposal. In this PEIS, DOE evaluates the health and safety impacts to workers and the public from 1) loading and inspecting (handling) the shipping casks, 2) routine (in transit, incident-free) transportation and 3) transportation accidents (both radiological impacts and fatalities due to traffic accidents). Both all-truck transport and a combination of truck and rail transport are analyzed.

Based on a 50-year shipping campaign, the number of shipments (assuming all truck) would range from 128,000 (No Action Alternative) to 1,730,000 (All-High Temperature Gas-Cooled Reactor Option) for the open fuel cycle alternatives, and from 244,000 (Thermal Reactor Recycle Alternative (Option 2)) to 978,000 (Thermal Reactor Recycle Alternative (Option 1)) for the closed fuel cycle alternatives (Table S.4-7). The number of shipments (assuming a combination of truck and rail) would range from 37,000 (No Action Alternative) to 156,000 (AllHigh Temperature Gas-Cooled Reactor Option) for the open fuel cycle alternatives, and from 68,500 (Thermal Reactor Recycle Alternative (Option 2)) to 246,000 (Thermal Reactor Recycle Alternative (Option 1)) for the closed cycle alternatives (Table S.4-7).

TABLE S.4-7-Total Number of Shipments (50 years of implementation)

\begin{tabular}{|c|c|c|c|c|c|c|c|c|}
\hline \multirow[b]{2}{*}{$\begin{array}{c}\text { Transportation } \\
\text { Mode }\end{array}$} & \multirow{2}{*}{$\begin{array}{c}\text { No } \\
\text { Action }\end{array}$} & \multirow{2}{*}{$\begin{array}{c}\text { Fast } \\
\text { Reactor } \\
\text { Recycle }\end{array}$} & \multirow{2}{*}{$\begin{array}{c}\text { Thermal/Fast } \\
\text { Reactor } \\
\text { Recycle }\end{array}$} & \multirow{2}{*}{$\begin{array}{l}\text { Thermal } \\
\text { Reactor } \\
\text { Recycle- } \\
\text { Option } 1\end{array}$} & \multirow{2}{*}{$\begin{array}{c}\text { Thermal } \\
\text { Reactor } \\
\text { Recycle- } \\
\text { Option } 2\end{array}$} & \multirow[b]{2}{*}{ Thorium } & \multicolumn{2}{|c|}{$\begin{array}{c}\text { Heavy Water } \\
\text { Reactor/High } \\
\text { Temperature Gas-Cooled } \\
\text { Reactor }\end{array}$} \\
\hline & & & & & & & $\begin{array}{c}\text { All- } \\
\text { Heavy } \\
\text { Water } \\
\text { Reactor } \\
\text { Option } \\
\end{array}$ & $\begin{array}{c}\text { All-High } \\
\text { Temperature } \\
\text { Gas-Cooled } \\
\text { Reactor } \\
\text { Option } \\
\end{array}$ \\
\hline Truck & 128,000 & 854,000 & 826,000 & 978,000 & 244,000 & 267,000 & 237,000 & $1,730,000$ \\
\hline Truck and Rail $^{\mathrm{a}}$ & 37,000 & 206,000 & 199,000 & 246,000 & 68,500 & 51,500 & 76,600 & 156,000 \\
\hline
\end{tabular}

${ }^{a}$ All shipment of fresh nuclear fuel is assumed to be via truck transport. See Table 4.8-10 for detailed breakdown of material shipments.

Note 1: All numbers rounded to three significant figures.

Note 2: Thermal Reactor Recycle Alternative (Option 3) not included due to unavailability of data.

The handling of spent fuel and other radiological materials at the various facilities could result in health and safety impacts to workers. The estimated latent cancer fatalities from the handling of truck casks (under the open fuel cycle alternatives) would range from about 26 (No Action Alternative) to 487 (All-High Temperature Gas-Cooled Reactor Option); under the closed fuel cycle alternatives from about 47 (Thermal Reactor Recycle (Option 2)) to about 133 (Thermal Reactor Recycle (Option 1)) (Table S.4-8). The estimated latent cancer fatalities from the handling of casks for truck and rail transport under the open fuel cycle alternatives would range from about 12 (All-Heavy Water Reactor Option) to 75 (All-High Temperature Gas-Cooled Reactor Option), and under the closed fuel cycle alternatives would range from about 25 (Thermal Reactor Recycle (Option 2)) to 136 (Fast Reactor Recycle Alternative) (Table S.4-9). 
The estimated number of latent cancer fatalities would occur in a worker population of several hundred thousand who would be involved in these operations every year.

TABLE S.4-8-Truck Handling Health and Safety Impacts (50 Years of Implementation for 200 Gigawatts of Electricity)

\begin{tabular}{|c|c|c|c|c|c|c|}
\hline \multirow{3}{*}{ Alternative } & \multicolumn{6}{|c|}{ Handling Impacts } \\
\hline & \multicolumn{2}{|c|}{ Loading } & \multicolumn{2}{|c|}{ Inspection } & \multicolumn{2}{|l|}{ Total } \\
\hline & person-rem & LCFs & person-rem & LCFs & person-rem & LCFs \\
\hline No Action & 36,700 & 22 & 6,430 & 4 & 43,200 & 26 \\
\hline Fast Reactor Recycle & 160,000 & 96 & 17,900 & 11 & 177,000 & 106 \\
\hline Thermal/Fast Reactor Recycle & 155,000 & 93 & 17,200 & 10 & 172,000 & 103 \\
\hline Thermal Reactor Recycle-- Option 1 & 198,000 & 119 & 23,800 & 14 & 222,000 & 133 \\
\hline Thermal Reactor Recycle-- Option 2 & 67,100 & 40 & 11,100 & 7 & 78,100 & 47 \\
\hline Thorium & 91,700 & 55 & 15,800 & 9 & 107,000 & 64 \\
\hline All-Heavy Water Reactor Option & 67,500 & 40 & 11,700 & 7 & 79,100 & 47 \\
\hline All-High Temperature Gas-Cooled Reactor Option & 693,000 & 416 & 119,000 & 71 & 812,000 & 487 \\
\hline
\end{tabular}

Source: Appendix E

Note 1: All latent cancer fatalities (LCFs) rounded to nearest whole number.

Note 2: Thermal Reactor Recycle Alternative (Option 3) not included due to unavailability of data. 
TABLE S.4-9—Truck and Rail Handling Health and Safety Impacts (50 Years of Implementation for 200 Gigawatts of Electricity)

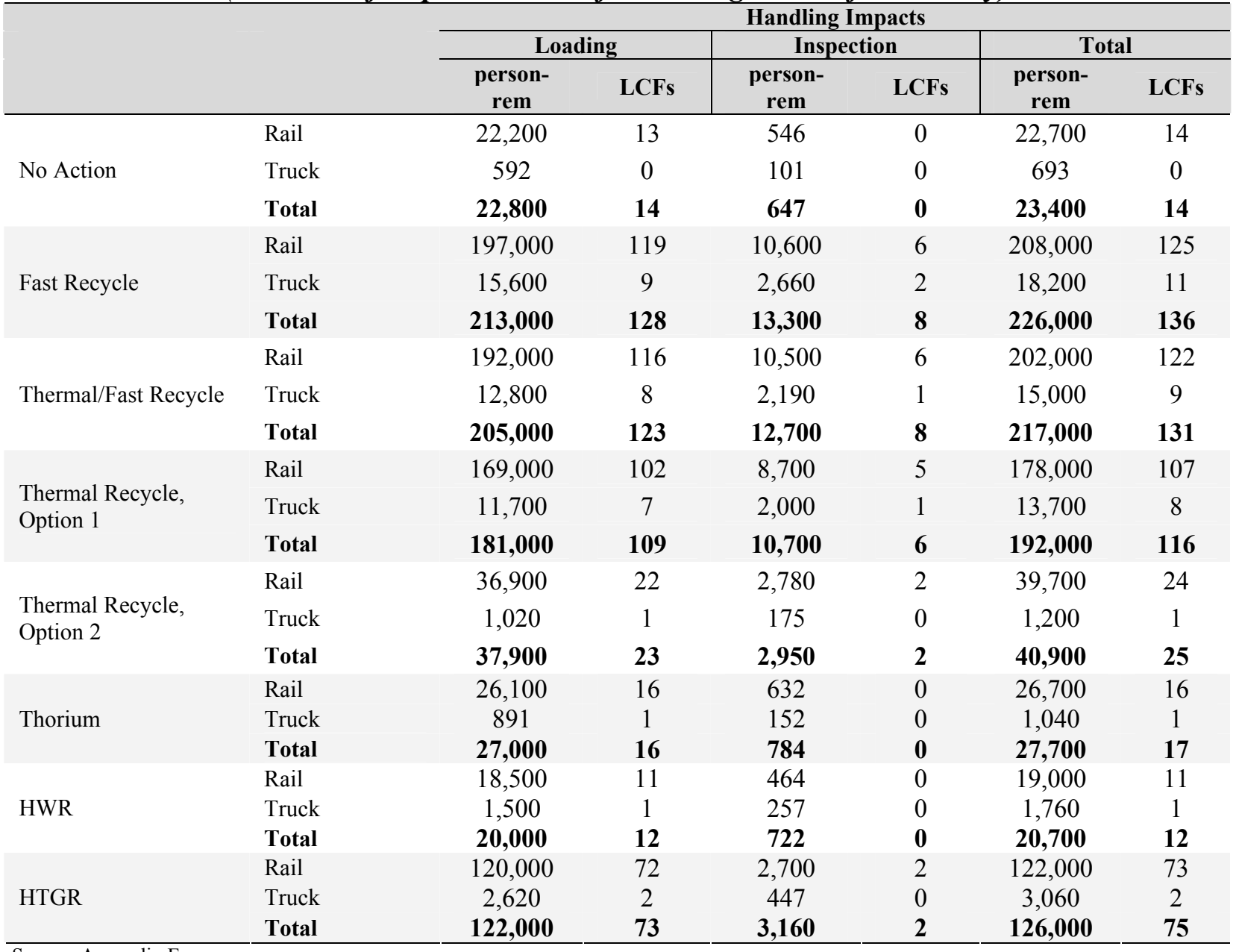

Source: Appendix E

Note 1: All latent cancer fatalities (LCFs) rounded to nearest whole number.

Note 2: Thermal Reactor Recycle Alternative (Option 3) not included due to unavailability of data.

The in-transit, incident-free impacts are shown in Tables S.4-10 (truck transit) and S.4-11 (truck/rail transit) for the programmatic domestic fuel cycle alternatives. Unlike handling impacts, the in-transit impacts are dependent on the distance that material would be transported, the specific routes that would be utilized and the population densities along those routes. Of these factors, the transport distance is the most significant factor, and for this PEIS, DOE based this distance on the average distance used in previous DOE National Environmental Policy Act documents involving the disposal of spent nuclear fuel and high-level radioactive waste (about $2,100 \mathrm{mi}[3,380 \mathrm{~km}])$. 
TABLE S.4-10 - Summary of In-Transit, Truck Transportation Impacts (50 Years of Implementation for 200 Gigawatts of Electricity)

\begin{tabular}{|c|c|c|c|c|c|c|c|c|}
\hline \multirow{3}{*}{ Alternative } & \multicolumn{4}{|c|}{ In-Transit Impacts } & \multirow{3}{*}{$\begin{array}{l}\text { Incident-Free } \\
\text { LCFs }\end{array}$} & \multicolumn{3}{|c|}{ Accident Impacts } \\
\hline & \multicolumn{2}{|c|}{ Crew } & \multicolumn{2}{|c|}{ Public } & & & & \\
\hline & $\begin{array}{c}\text { person- } \\
\text { rem }\end{array}$ & LCFs & $\begin{array}{c}\text { person- } \\
\text { rem }\end{array}$ & LCFs & & $\begin{array}{c}\text { person- } \\
\text { rem }\end{array}$ & LCFs & Fatalities \\
\hline No Action & 14,900 & 9 & 71,300 & 42 & 52 & 1.37 & 0 & 11 \\
\hline Fast Recycle & 151,000 & 90 & 371,000 & 222 & 313 & 51.6 & 0 & 73 \\
\hline $\begin{array}{l}\text { Thermal/Fast } \\
\text { Recycle }\end{array}$ & 146,000 & 87 & 360,000 & 216 & 303 & 41.0 & 0 & 71 \\
\hline $\begin{array}{l}\text { Thermal } \\
\text { Recycle-- } \\
\text { Option } 1\end{array}$ & 157,000 & 94 & 441,000 & 265 & 359 & 2.97 & 0 & 84 \\
\hline $\begin{array}{l}\text { Thermal } \\
\text { Recycle- } \\
\text { Option } 2\end{array}$ & 31,000 & 19 & 137,000 & 82 & 101 & 1.23 & 0 & 21 \\
\hline Thorium & 36,300 & 22 & 179,000 & 107 & 129 & 0.881 & 0 & 23 \\
\hline HWR & 26,600 & 16 & 130,000 & 78 & 94 & 0.597 & 0 & 20 \\
\hline HTGR & 271,000 & 162 & $1,360,000$ & 816 & 979 & 0.592 & 0 & 149 \\
\hline
\end{tabular}

Source: Appendix E

Note 1: All latent cancer fatalities (LCFs) rounded to nearest whole number.

Note 2: Thermal Reactor Recycle Alternative (Option 3) not included due to unavailability of data. 
TABLE S.4-11-Summary of In-Transit, Truck and Rail Transportation Impacts (50 Years of Implementation for 200 Gigawatts of Electricity)

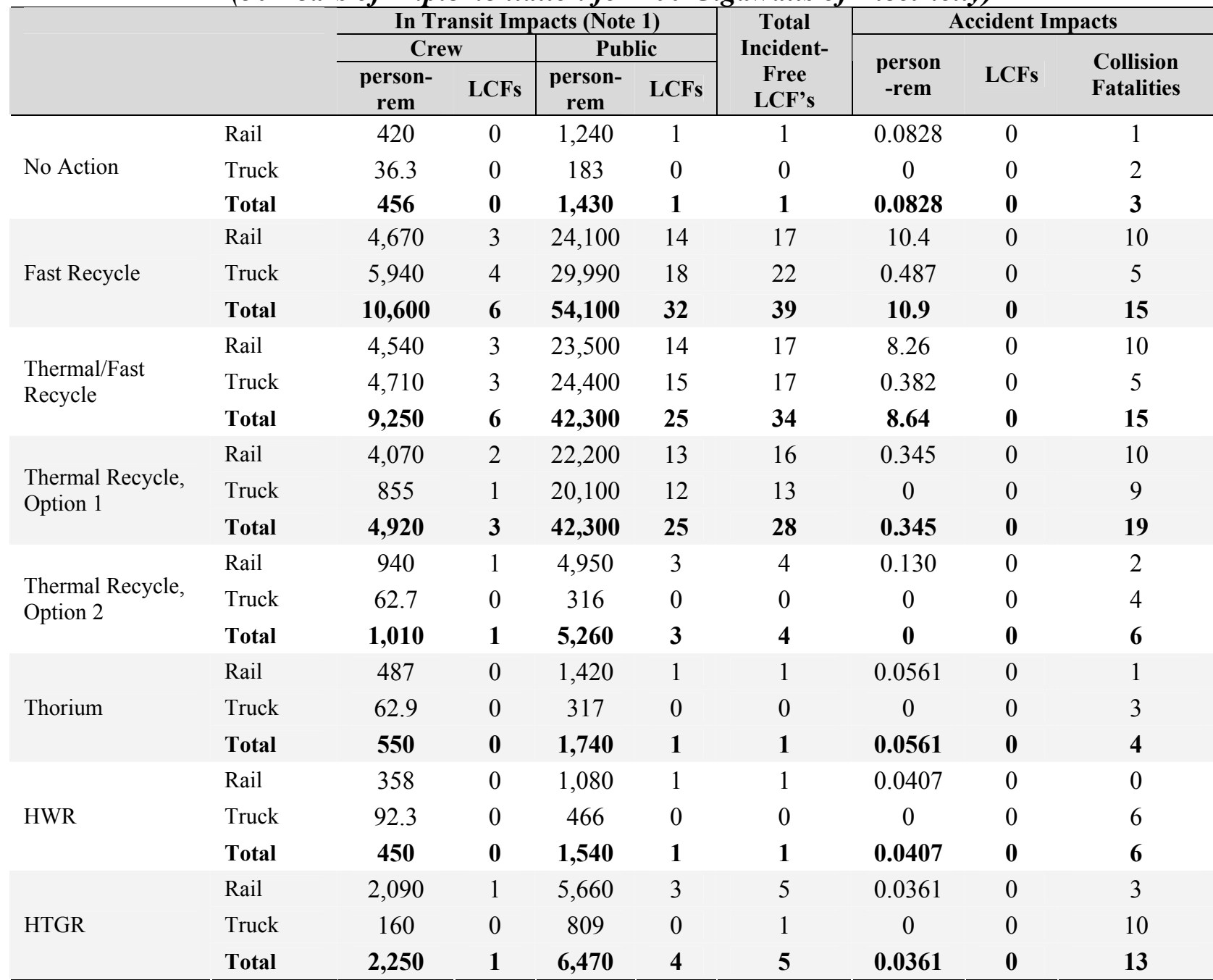

Source: Appendix E.

Note 1: All latent cancer fatalities (LCFs) rounded to nearest whole number.

Note 2: Thermal Reactor Recycle Alternative (Option 3) not included due to unavailability of data.

As shown on Tables S.4-10 and S.4-11, truck and rail transport would result in smaller impacts than truck transport because there are fewer total shipments, which results in fewer total miles, which in turn results in lower exposures to workers (referred to as 'crew') and the public. Additionally, and for the same reasons, the number of fatalities (collisions) due to traffic accidents would be lower for the combination truck and rail transport.

For truck transport, the All-High Temperature Gas-Cooled Reactor Option would have the highest transportation impacts (incident-free and traffic fatalities), primarily due to the large number of shipments of spent fuel (more than 1.7 million shipments, as shown in Table S.4-7). This relatively large number of shipments is caused primarily by the large volume of spent fuel associated with the graphite blocks in high temperature gas-cooled reactors. The Fast Reactor Recycle Alternative, Thermal/Fast Reactor Recycle Alternative and Thermal Reactor Recycle Alternative (Option 1) would have the next highest impacts. 
As shown on Table S.4-11, for truck and rail transport, the Fast Reactor Recycle Alternative, Thermal/Fast Reactor Recycle Alternative and Thermal Reactor Recycle Alternative (Option 1) would have the highest expected transportation impacts. For truck and rail transport, these closed fuel cycle alternatives would have the most shipments, the highest handling impacts, and the highest in-transit impacts.

The reason why the All-High Temperature Gas-Cooled Reactor Option would not have the highest transportation impacts for truck and rail transport is because the packaging of spent nuclear fuel potentially could allow for a reduction in the number of spent fuel shipments by a factor of approximately 45 (from 1,560,000 truck shipments of spent fuel to 33,000 rail shipments of spent fuel). By contrast, the transportation impacts of the closed fuel cycle alternatives (with the exception of the Thermal Reactor Recycle Alternative (Option 2)) are dominated by Greater-than-Class-C low-level radioactive waste shipments. When packaged for rail transportation, these waste shipments, while reduced compared to truck transport, would remain large.

Transportation accidents, some of which could potentially breach the shipping container, are represented by a spectrum of accident severities and releases of radioactive material. Two types of analyses were performed. The first analysis takes into account the probabilities and consequences of a spectrum of potential accident severities. For the spectrum of accidents considered in the analysis, accident consequences in terms of collective dose to the population within $50 \mathrm{mi}(80 \mathrm{~km})$ were multiplied by the accident probabilities to yield collective dose risk to the population (person-rem), which were converted to latent cancer fatalities (see Tables S.4-10 and S.4-11). From a risk perspective, the truck or combination of truck and rail shipping campaigns would not be expected to result in a latent cancer fatality in the affected population.

DOE also analyzed the maximum reasonably foreseeable accident, which is a long-duration, high-temperature fire event that engulfs the entire cask, and whose probability of occurrence is about 1 in 10 million. This accident scenario would involve spent nuclear fuel from high temperature gas-cooled reactors or light water reactors, or MOX-U-Pu spent fuel. DOE found there would be approximately 1 latent cancer fatality in an urban area.

\section{S.4.7 Cumulative Impacts}

As defined by the Council of Environmental Quality regulations implementing the procedural provisions of NEPA, cumulative impacts are "the impact on the environment which results from the incremental impact of the action when added to other past, present, and reasonably foreseeable future actions regardless of what agency (Federal or non-Federal) or person undertakes such actions." The regulations further explain that "cumulative impacts can result from individually minor but collectively significant actions taking place over a period of time" (40 CFR 1508.7).

Implementation of any of the programmatic alternatives could result in the construction and operation of hundreds of new facilities that would be located throughout the U.S. These facilities would have short-term (50-60 years) environmental impacts, and much longer-term impacts (thousands of years) as additional, future geologic disposal capacity is developed. Accordingly, 
in this PEIS, DOE assesses the cumulative impacts of the programmatic alternatives on various resources, such as water and land use, and the demand for materials and electricity, and on public health from transportation of radiological shipments.

DOE estimates, based on current rates of water use, that water consumption would increase to about 460 billion gallons per day (1,800 billion liters per day) by 2060. Implementation of any of the domestic programmatic alternatives would require approximately 3.3 billion gallons per day (12.2 billion liters per day), based on the use of approximately 6 billion gallons per year (24 billion liters per year) for each gigawatt of energy produced, which is about 0.7 percent of the daily water use of the U.S. Most of the water used by the alternatives would be required for cooling purposes and as much as 99 percent of the water used for this purpose would be returned to its source.

The alternatives in this PEIS would contribute to cumulative amounts of spent nuclear fuel and radioactive wastes that would require management and disposal, including: 1) spent nuclear fuel and high-level radioactive waste; 2) Greater-than-Class-C low-level radioactive waste; and 3) low-level radioactive waste. The Nuclear Waste Policy Act of 1982, as amended, provides for the disposal of commercial spent nuclear fuel and DOE spent nuclear fuel and high-level radioactive waste in the Nation's first proposed geologic repository to be located at Yucca Mountain, Nevada. The Nuclear Waste Policy Act limits the initial capacity of Yucca Mountain to 70,000 MTHM of spent nuclear fuel and high-level radioactive waste until such time as a second repository is in operation (42 U.S.C. 10101 et seq.). DOE has allocated this capacity between 63,000 MTHM of commercial spent nuclear fuel and 7,000 MTHM of DOE spent nuclear fuel and high-level radioactive waste. Disposal of more than 70,000 MTHM of spent nuclear fuel and high-level radioactive waste at the Yucca Mountain site prior to completion of a second repository would require a legislative change.

In its cumulative impacts analysis, the Yucca Mountain Supplemental Environmental Impact Statement (SEIS) (DOE 2008f), issued in June 2008, evaluated the disposal of up to approximately 130,000 MTHM of commercial spent nuclear fuel, ${ }^{15}$ equivalent to the amount projected from all existing commercial power reactors during all of their projected lifetimes. The Yucca Mountain SEIS also evaluated an alternative disposal case in which DOE would dispose of 63,000 MTHM of commercial spent nuclear fuel as spent fuel, as in the Yucca Mountain SEIS proposed action, but the balance of this commercial spent nuclear fuel inventory (approximately 67,000 MTHM) would be recycled and the resultant high-level radioactive waste would be transported to and disposed of at the Yucca Mountain geologic repository. This amount of commercial spent nuclear fuel (i.e., approximately 67,000 MTHM) also is a part of the commercial spent nuclear fuel inventory evaluated in the GNEP programmatic alternatives.

For the 200 GWe scenario, the GNEP closed fuel cycle alternatives could generate between 18,000 and 55,000 cubic meters of high-level radioactive waste that would require disposal in a geologic repository. (In addition, the Thermal Reactor Recycle Alternative (Option 2), while considered a closed fuel cycle alternative, could generate approximately 71,000 MTHM spent

\footnotetext{
15 The Yucca Mountain SEIS cumulative impacts analysis also evaluated the disposal of all DOE spent nuclear fuel (approximately 2,500 MTHM) and all DOE high-level radioactive waste (approximately 36,000 canisters).
} 
nuclear fuel.) ${ }^{16}$ For the 200 GWe scenario, the GNEP open fuel cycle alternatives could generate between 99,000 and 280,000 MTHM spent nuclear fuel that would require disposal in a geologic repository.

Independent of the domestic programmatic alternatives, DOE is preparing an Environmental Impact Statement for the Disposal of Greater-than-Class-C Low-Level Radioactive Waste (DOE/EIS-0375) (72 FR 40135). DOE estimates that approximately 2,600 cubic meters of Greater-than-Class-C low-level radioactive waste will require management nationwide (72 FR 40135). In addition, DOE estimates that there will be certain wastes that will be generated from DOE activities which may not have an identified disposal path and will have characteristics similar to Greater-than-Class-C low-level radioactive waste. This DOE waste is estimated to be 3,000 cubic meters ( 72 FR 40135). Thus, the total Greater-than-Class-C low-level radioactive waste that will require management is projected to be 5,600 cubic meters. For the $200 \mathrm{GWe}$ scenario, the GNEP closed fuel cycle alternatives could generate 9,700 to 416,500 cubic meters of Greater-than-Class-C low-level radioactive waste, while the open fuel cycle alternatives (including the No Action Alternative) could generate approximately 2,500 cubic meters. (The estimates DOE has developed for the GTCC EIS, as well as the estimates developed for the GNEP programmatic alternatives, include the quantities of Greater-than-Class-C low-level radioactive waste that would be generated from the decontamination and decommissioning of existing light water reactors.) Consequently, the closed fuel cycle alternatives would account for approximately 64 to 99 percent of the total Greater-than-Class-C low-level radioactive waste, while the open fuel cycle alternatives would account for approximately 31 percent of the total Greater-than-Class-C low-level radioactive waste.

In 2005 and 2006, the total amount of low-level radioactive waste disposed of at the three commercial disposal facilities in the United States was approximately 113,000-115,000 cubic meters annually (NRC 2007g, MIMS 2008). Of this low-level radioactive waste, in 2006, approximately 52,500 cubic meters was related to nuclear-generated electricity and 62,000 cubic meters was unrelated to nuclear-generated electricity (MIMS 2008). Assuming that low-level radioactive wastes unrelated to nuclear-generated electricity would continue at this rate, over the next 50 years, approximately 3,100,000 cubic meters of low-level radioactive waste would require disposal. For the $200 \mathrm{GWe}$ scenario, the GNEP closed fuel cycle alternatives ${ }^{17}$ could generate approximately 1,740,000-2,895,000 cubic meters of low-level radioactive waste, or approximately 36-48 percent of the total low-level radioactive waste that would require disposal. The open fuel cycle alternatives would generate approximately 150,000-585,000 cubic meters of low-level radioactive waste, or approximately 5-16 percent of the total low-level radioactive waste that would require disposal. As a result of recycling spent fuel, the closed fuel cycle alternatives generate much higher quantities of low-level radioactive waste. All of the estimates of low-level radioactive waste quantities assume that future reactors would generate low-level radioactive waste in quantities similar to existing commercial reactors.

With respect to radiological transportation, the Yucca Mountain SEIS (DOE 2008f) includes a detailed analysis of the cumulative transportation impacts associated with past, present and future radiological shipments (including spent nuclear fuel associated with the Yucca Mountain

\footnotetext{
${ }^{16}$ Insufficient data exists to estimate the amount of spent nuclear fuel from the Thermal Reactor Recycle Alternative (Option 3 )

${ }^{17}$ Thermal Reactor Recycle Alternative (Option 2) not included due to lack of data for DUPIC fuel fabrication facility.
} 
repository). That analysis includes consideration of impacts from 1943 through 2073 (which falls within the approximate endpoint for implementation (2060-2070) in this GNEP PEIS). Based on the Yucca Mountain SEIS cumulative impact analysis, DOE estimated the cumulative impacts shown in Table S.4-12.

TABLE S.4-12-Potential Cumulative Transportation Impacts

\begin{tabular}{|c|c|c|c|c|c|}
\hline & \multicolumn{2}{|c|}{ Worker Dose } & \multicolumn{2}{|c|}{ General Population Dose } & \multirow[t]{2}{*}{$\begin{array}{c}\text { Traffic } \\
\text { Fatalities }^{\text {a }} \\
\end{array}$} \\
\hline & person-rem & LCF & person-rem & LCF & \\
\hline \multicolumn{6}{|c|}{ Collective dose and traffic fatalities of non-GNEP transportation } \\
\hline $\begin{array}{l}\text { Historical DOE shipments and } \\
\text { reasonably foreseeable actions }\end{array}$ & 28,000 & 17 & 49,000 & 29 & 94 \\
\hline $\begin{array}{l}\text { General radioactive material } \\
\text { transportation (1943 to 2073) }^{c}\end{array}$ & 350,000 & 210 & 300,000 & 180 & 28 \\
\hline $\begin{array}{l}\text { Yucca Mountain estimated } \\
\text { impacts }\end{array}$ & $5,600-5,900$ & 3 & $1,100-1,200$ & 1 & 3 \\
\hline $\begin{array}{l}\text { Subtotal of non-GNEP } \\
\text { transportation impacts }\end{array}$ & 380,000 & 230 & 350,000 & 210 & 130 \\
\hline 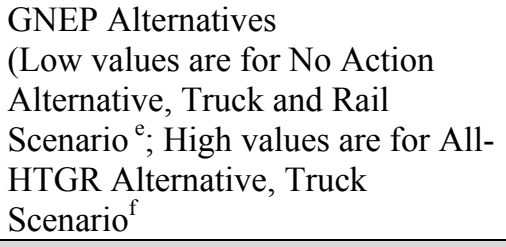 & $450-270,000$ & $0-160$ & $1,540-1,400,000$ & $1-820$ & $3-150$ \\
\hline $\begin{array}{l}\text { Total Collective Transportation } \\
\text { Impacts }\end{array}$ & $380,000-650,000$ & $230-390$ & $350,000-1,800,000$ & $210-1,000$ & $130-280$ \\
\hline
\end{tabular}

Note: Numbers are rounded to two significant figures; therefore, totals may differ from sums.

${ }^{a}$ The values provided in this column represent the number of expected vehicular accident fatalities. Additional fatalities due to release of radioactive materials are less than one percent of these impacts; therefore, these are not included. For comparison, there could be 28 expected fatalities over the 131-year period (1943-2073) based on the NRC traffic fatality rate of 0.213 traffic fatalities per year from radioactive material shipments (NRC 1977b).

b The values provided in this row represent all known historical DOE shipments, starting in 1943 (the year operations began at the Hanford Site and Oak Ridge Reservation) and all reasonably foreseeable actions involving transportation of radioactive materials through 2073 (the assumed end date for Yucca Mountain shipments) provided in other NEPA documents. The values are based on in-transit impacts only. Table 8-14 of DOE $2008 \mathrm{f}$ is the source of the data provided.

${ }^{\mathrm{c}}$ This row represents an estimated collective dose due to transport of eight categories of radioactive materials [1) industrial, 2) radiography, 3) medical, 4) fuel cycle, 5) research and development, 6) unknown, 7) waste, and 8) other]. The values are based on in-transit impacts only. Source: DOE 2008f, Table 8-14.

${ }^{\mathrm{d}}$ Values provided represent the Yucca Mountain Supplemental EIS proposed action. The values are based on in-transit impacts only. Source: DOE 2008f, Table 8-14.

${ }^{\mathrm{e}}$ The No Action Alternative, Truck and Rail Scenario represents the minimum estimated transportation impacts of the programmatic alternatives analyzed in the GNEP PEIS. The values are based on in-transit impacts only. Source: Table S.4-11

${ }^{\mathrm{f}}$ The All-High Temperature Gas-Cooled Option, Truck Scenario represents the maximum estimated transportation impacts of the programmatic alternatives analyzed in the GNEP PEIS. The values are based on in-transit impacts only. Source: Table S.4-10.

The programmatic alternatives, including the No Action Alternative, could result in land disturbances of approximately 600,000 acres $(243,000$ hectares) for the 1.3 percent growth rate. Future land use requirements associated with population growth are projected to result in the development of an additional 52 million acres (21 million hectares) by 2060. Consequently, the land use impacts from the alternatives would account for less than a 1.5 percent increase compared to the land use associated with population growth.

The alternatives in this PEIS could have a beneficial impact on air quality and greenhouse gas emissions as nuclear power generation of electricity could replace a similar amount of fossil fuel 
generation of electricity. For every gigawatt of electricity produced by nuclear power, approximately 2,000,000 metric tons of carbon dioxide (conventional coal plant) or $1,000,000$ metric tons of carbon dioxide (conventional natural gas plant) would not be emitted to the atmosphere.

The alternatives in this PEIS could result in the construction of more than 200 nuclear facilities over an approximate 50-year period for the 1.3 percent growth rate scenario. Based on the construction requirements of a typical 1,000 megawatt electric nuclear plant on an annual basis, these new nuclear facilities would use approximately 600,000 metric tons of steel and 3.4 million metric tons of concrete. Compared to the current usage of steel and concrete, these increases would amount to less than 1 percent (steel) and 2.8 percent (concrete). Of course, construction of fossil fuel burning plants or even alternative energy plants to produce a similar amount of electricity as a nuclear option would also use a substantial amount of construction resources.

\section{S.4.8 Unavoidable Adverse Impacts}

All of the domestic programmatic alternatives would result in unavoidable adverse impacts. For the 1.3 percent growth scenario, the construction and operation of nuclear facilities would disturb up to 600,000 acres (242,000 hectares) of land, use approximately 3 to 6 billion gallons (12 to 24 billion liters) of water annually per gigawatt of capacity, and expose workers and the general public to radiation from the nuclear facilities and from the transportation of radiological materials. Each alternative also would generate spent nuclear fuel and/or other radioactive wastes that would require transportation and management for long periods of time, which for some waste types would last for thousands of years and would require additional geologic repository capacity.

\section{S.4.9 Irreversible and Irretrievable Resource Commitments}

Under all alternatives, construction and operation of new facilities would cause a short-term commitment of resources (such as concrete, steel, and water), and would permanently commit certain other resources, such as land. Losses of terrestrial and aquatic habitats from natural productivity to accommodate new facilities and temporary disturbances required during construction would occur. Land clearing and construction activities would disperse wildlife and temporarily eliminate habitats. Although some destruction would be inevitable during and after construction, these losses would be minimized by selection of mitigation measures developed through environmental reviews at the site-specific level.

\section{S.4.10 Preferred Alternative}

The Council on Environmental Quality regulations require an agency to identify its preferred alternative or alternatives, if one or more exists, in a draft EIS (40 CFR 1502.14(e)). DOE's preference is to close the fuel cycle. DOE has not determined which of the specific closed fuel cycle alternatives is preferred, but will do so in the Final PEIS.

Recycling spent fuel could include the destruction and use of the transuranic materials in the spent fuel, thereby significantly reducing the thermal output and radiotoxicity of wastes requiring 
geologic disposal. The analysis shows that recycling spent fuel could reduce the time period required for the radiotoxicity of the wastes to fall to that of natural uranium ore from approximately 240,000 years (for the No Action Alternative) to 1,000 years or less (for the Fast Reactor Recycle and Thermal/Fast Reactor Recycle Alternatives) or to 55,000 years (for the Thermal Reactor Recycle Alternative (Option 1)). Moreover, recycling has the potential to significantly reduce the thermal loading on any geologic repository (in the best case, up to a factor of 235 relative to the No Action Alternative). This could be a substantial reduction in heat load. Finally, the reprocessing of the spent fuel would be designed to meet nonproliferation objectives and would avoid separation of pure plutonium.

The closed fuel cycle offers the potential for near-term deployment with variations to existing separations, fuel and reactor technologies. Commercial spent fuel reprocessing is presently being done in other countries, while the recovered material is recycled in mixed-oxide fuel for existing light water reactors. Consequently, the near-term deployment (by approximately 2020) could allow the recycle of spent nuclear fuel generated in amounts beyond the Yucca Mountain geologic repository statutory capacity, rather than storing it pending development of the additional geologic disposal capacity required if spent fuel were to be directly disposed. Recycling spent nuclear fuel could also delay the need for, and decrease the magnitude of, additional geologic repository capacity compared to direct disposal of spent nuclear fuel. A longer-term strategy could include the use of advanced separations and reactor technologies. The potential to use variations to existing separations technology in the near-term could allow time, where necessary, to complete additional research, development and demonstration on advanced separations and reactor technologies, if pursued. The closed fuel cycle also supports expansion of nuclear energy by making better use of uranium resources.

\section{S.5 INTERNATIONAL INITIATIVES}

The Energy Information Administration (EIA) projects that worldwide generation of electricity will nearly double by 2030 . The EIA also projects that electricity generated by nuclear power will increase by about 40 percent in that time, as increasing fossil fuel prices, energy security concerns, improved reactor designs and environmental considerations are expected to improve prospects for new nuclear power plants in many countries (EIA 2008b). Accordingly, the U.S., through the GNEP Program, is considering various initiatives to work cooperatively with other nations to expand nuclear power to help meet growing energy demand, develop and deploy advanced nuclear recycling and reactor technologies, establish international frameworks to provide nuclear fuel supplies, and promote the development of nuclear safeguards and of more proliferation-resistant nuclear power reactors.

At this time, DOE has no specific proposals for the international component of the GNEP Program. Rather, as a preliminary step in this PEIS, DOE addresses two potential international initiatives that could affect the global commons and the environment in the U.S.-GridAppropriate Reactors and Reliable Fuel Services.

Grid-Appropriate Reactors are nuclear power reactors designed and sized to achieve high standards of safety and security, and satisfy the power grid requirements of the receiving country.

Reliable Fuel Services is an initiative under which nuclear suppliers would provide an assured supply of new nuclear fuel to countries pursuing nuclear power programs, and would assist such countries with management of the resulting spent fuel. 


\section{S.5.1 Grid-Appropriate Reactors}

Under this initiative, DOE would support the development of grid-appropriate reactors to meet the capabilities and electricity demand needs of developing countries. These reactors would be designed and sized to suit those countries' smaller and less developed power grids. Smaller nuclear power plants (less than 500 megawatts electric) would be well suited for use in these countries as they are more able to meet grid capacities, offer simplified operations with greater margins of safety, require less capital outlay to develop and allow countries to add capacity in smaller increments to match electricity demand.

The successful deployment of these reactors, coupled with reliable fuel services, would provide an attractive energy solution to many countries. Although it is the responsibility of private industry to develop and market commercial nuclear power plants, DOE could support the development of grid-appropriate reactors by assisting U.S. industry efforts to standardize reactor designs and to obtain licensing of these reactors for export to developing countries.

\section{S.5.2 Reliable Fuel Services}

Under this initiative, DOE, working with other international nuclear fuel supplier nations, would develop mechanisms to provide an assured supply of fresh nuclear fuel to countries pursuing nuclear power programs. This initiative would build on complementary ongoing programs, including the Reliable Access to Nuclear Fuel program of the International Atomic Energy Agency (an organization within the United Nations) and a National Nuclear Security Administration (a separately organized agency within DOE) program to blend down excess highly enriched uranium to create new (low enriched) fuel to support a reliable fuel supply. In addition, a Reliable Fuel Services Program could help other countries manage the resulting spent nuclear fuel.

The objective of a Reliable Fuel Services initiative is to limit the spread of enrichment and reprocessing by offering countries an alternative to developing such facilities indigenously. Countries using such services would receive the benefit of having reliable access to nuclear fuel services without having to make the significant infrastructure investments required for enrichment and reprocessing.

Under this initiative, spent nuclear fuel could be returned to the country that supplied it or to a third party supplier nation. If the country taking the spent fuel had a closed fuel cycle, it could process that fuel, and the uranium and other usable transuranics could be separated and used to fabricate new fuel for recycle. Alternatively, if the country accepting the spent nuclear fuel had a once-through fuel cycle, it would store the spent fuel pending disposal. The radioactive waste from recycling would be stored or disposed of either by the supplier nation (the nation that provided the fresh fuel), returned to the user nation (the nation that generated the spent fuel), or sent to a third-party nation (a nation that neither supplied the fresh fuel nor generated the spent nuclear fuel). 


\section{S.6 ENVIRONMENTAL IMPACTS OF INTERNATIONAL INITIATIVES}

The Grid Appropriate Reactor and Reliable Fuel Services initiatives could produce environmental impacts within the U.S. and the global commons. To determine these impacts, DOE focused on the transportation impacts based on a scenario involving 1 gigawatt electric of foreign light water reactor production. This reactor production would require sufficient fresh fuel for initial start-up and steady-state operations. ${ }^{18}$ Under this scenario, fresh fuel would be manufactured in the U.S. or a foreign partner nation, and the fresh fuel assemblies would be shipped to the user nation for use in the reactor. Following use, the spent fuel resulting from operation would be returned to the U.S. or a foreign partner nation.

For open fuel cycle alternatives, the spent fuel would be transported to and disposed of in a geologic repository. For closed fuel cycle alternatives, the spent fuel would be recycled in a nuclear fuel recycling center. The useful constituents would be fabricated into fuel assemblies to provide fuel for U.S. or partner nation reactors (not for reuse in a foreign user nation's reactor in this scenario). Any waste materials from recycling would be stabilized, appropriately packaged for shipment and potentially could be disposed of or returned to the user nation.

Based on the analysis of impacts associated with handling, shipping, and receiving all radiological materials associated with international initiatives, DOE estimates that the fuel cycle alternatives would result in a total dose to the public of less than 100 person-rem; resulting in much less than 1 latent cancer fatality, for activities to support every gigawatt of foreign reactor production.

\section{S.7 CONCLUSIONS}

\section{S.7.1 Major Conclusions}

1. Geologic Disposal Capacity:

- The closed fuel cycle alternatives offer the greatest opportunity to reduce the impacts associated with disposal of future spent fuel (e.g., by reducing the volume, thermal output and/or radiotoxicity of waste requiring geologic disposal).

- All domestic programmatic alternatives would require the development of additional geologic repository capacity, in excess of the statutory capacity limit for the proposed Yucca Mountain repository, for disposal of spent fuel and/or high-level radioactive waste.

- Compared to the No Action Alternative, the Fast Reactor Recycle Alternative and the Thermal/Fast Reactor Recycle Alternative have the potential for the largest reduction in the volume, radiotoxicity, and thermal output with respect to material that would require disposal in a geologic repository.

${ }^{18} \mathrm{DOE}$ analyzed the steady-state impacts associated with annual operations; the initial start-up of a foreign reactor would require approximately

3-4 times as much start-up fuel as were analyzed for steady-state annual operations. 
- The Thermal Reactor Recycle Alternative (Option 1) also provides the potential for a relative reduction in volume, radiotoxicity and thermal output of material requiring geologic disposal, though not as great of a reduction as that provided under the Fast Reactor Recycle and Thermal/Fast Reactor Recycle Alternatives.

- The open fuel cycle alternatives (Heavy Water Reactor/High Temperature Gas-Cooled Reactor Alternative and Thorium Alternative) and the Thermal Reactor Recycle Alternative (Option 2) provide the least potential net repository capacity benefit when compared to the No Action Alternative.

- The All-Heavy Water Reactor Option would result in slightly higher radiotoxicity, higher spent fuel volume and higher thermal output of spent fuel requiring geologic disposal than the No Action Alternative.

- The All-High Temperature Gas-Cooled Reactor Option would result in lower radiotoxicity and thermal load, but also would result in a larger volume of spent fuel requiring geologic disposal than the No Action Alternative.

- The Thorium Alternative would result in a lower spent fuel volume and thermal output, but would result in a higher radiotoxicity than the No Action Alternative.

- The Thermal Reactor Recycle Alternative (Option 2) would result in a slightly lower spent fuel volume, lower thermal output and the potential for some reduction in radiotoxicity.

- For the HWR and HTGR open fuel cycle alternatives and the Thermal Reactor Recycle Alternative (Option 2), it is not clear that any reduction in future geologic capacity would be realized when compared to the No Action Alternative.

2. Implementability and Transition:

- Research and Development. The timing of implementation of alternatives would be influenced by the R\&D needs as well as other factors.

- Fuels Fabrication and Fuel Performance: Most of the alternatives have candidate processes for fabrication of fuel; however, all but the No Action Alternative and the All-Heavy Water Reactor Option would require additional R\&D to apply these technologies. The time frame to complete the necessary R\&D would be similar among the alternatives, an estimated 5 to 10 years.

- Spent Nuclear Fuel Reprocessing: For closed fuel cycle alternatives, there are many subsidiary issues associated with each new technology that would require $\mathrm{R} \& \mathrm{D}$, especially with final treatment and consolidation of the wastes, and with ensuring the availability of technologies that are capable of maintaining any releases of radioactive materials from the processing plant to within allowable limits as specified in licensing.

- Transition: Transition would be the least complicated for the alternatives that require new fuels with current reactor types. This includes the Thorium Alternative and the 
Thermal Reactor Recycle Alternative (Option 1). Alternatives that would transition from the current light water reactors to a system involving more than one reactor type in a balanced system (this includes the Fast Reactor Recycle Alternative, the Thermal/Fast Reactor Recycle Alternative and the Thermal Reactor Recycle Alternative [Options 2 and 3]) could have the most complex transition. However, under the Thermal/Fast Reactor Recycle Alternative, the potential exists to begin implementation using existing reactor and variations to existing separations technologies and later transition to advanced reactor and separations technologies. The start of transition for the Fast Reactor Recycle Alternative, Thermal/Fast Reactor Recycle Alternative and Thermal Reactor Recycle Alternative (Options 2 and 3) would involve both new reactors and nuclear fuels, and the new fuels could require separations to provide a sustained feedstock.

- Facility and Resource Requirements: All alternatives would require uranium enrichment and fuel fabrication facilities. The closed fuel cycle alternatives (Fast Reactor Recycle Alternative, Thermal/Fast Reactor Recycle Alternative and the Thermal Reactor Recycle Alternative [all options]) would require light water reactor spent fuel separation facilities/fuel fabrication facilities. Facilities to produce heavy water also would be required to implement the Thermal Reactor Recycle Alternative (Option 2) and the All-Heavy Water Reactor Option. All fuel cycle alternatives would require significant quantities of natural uranium feed. The open fuel cycle alternatives (No Action Alternative, Thorium Alternative and Heavy Water Reactor/High Temperature Gas-Cooled Reactor Alternative) would require the highest quantities of natural uranium feed. The Thermal Reactor Recycle Alternative (Option 3) and the AllHigh Temperature Gas-Cooled Reactor Option could also require construction of a facility to provide the required amount of reactor-grade graphite.

3. Environmental Impacts:

- Human Health: Radiation exposures to the public from reactors under any alternative would be very low and well within regulatory limits. Alternatives with recycling would result in a greater dose to the public and workers than the open fuel cycle alternatives; however, those doses would also be within established regulatory limits.

- Transportation: The All-High Temperature Gas-Cooled Reactor Option would have the highest transportation impacts for truck transport. The Fast Reactor Recycle Alternative, Thermal/Fast Reactor Recycle Alternative and the Thermal Recycle Alternative (Option 1) would have the highest transportation impacts for the combination truck and rail transport.

- Radioactive Waste: The closed fuel cycle alternatives would require less geologic disposal capacity for high-level radioactive waste volumes compared to the volumes of spent fuel from open fuel cycle alternatives. However, the closed fuel cycle alternatives require significantly more disposal capacity for low-level radioactive waste and Greater-than-Class-C low-level radioactive waste than is required under the open fuel cycle alternatives. 
- Facility Accidents: Each of the domestic programmatic alternatives could impact public and worker health in the event of an accident. For all alternatives considered, the annual risk of a latent cancer fatality from an accident would be less than one.

- Other Resource Areas: For other resource areas, the differences between alternatives are not significant enough on a programmatic scale to provide a discriminator between alternatives. This includes required uranium enrichment facilities, Land Resources, Visual Resources, Air Resources, Water Resources, and Socioeconomic Resources.

4. Other Benefits:

- Nuclear reactors emit no greenhouse gases

- Recycle of spent fuel makes better use of uranium natural resources

During the scoping process, concerns were raised relative to nuclear power in general and the alternatives specifically. DOE believes that several of these areas remain of concern and reflect differing points of view or irreducible uncertainties.

1. Nuclear power is and will likely remain controversial. Although nuclear power is perhaps becoming less controversial because of its expanded use throughout the world and the environmental benefits it offers for addressing greenhouse gas emissions, there continue to be concerns about safe disposition of spent fuel. DOE is making significant progress in developing a geologic repository at Yucca Mountain for the disposal of high-level radioactive waste and spent fuel; however, there is currently no licensed geologic repository for the disposal of these materials, and the siting and development of additional future repository capacity will likely remain controversial.

2. Recycling of spent fuel is and will likely remain controversial. In the past, the processing of spent fuel and other materials associated with the defense nuclear weapons complex has produced significant environmental impacts, including the creation of millions of gallons of liquid high-level radioactive waste at several DOE sites requiring many billions of dollars to prepare that waste for geological disposal. These activities have resulted in radioactive and hazardous material contamination of land and groundwater at these sites. Additionally, recycling is perceived by some as creating a high risk of nuclear proliferation.

3. Transportation of radiological materials, particularly spent nuclear fuel and high-level radioactive waste, is and likely will remain controversial.

4. Sodium-cooled fast reactors, high temperature gas-cooled reactors and thorium-fueled reactors have not yet proven to be economically competitive with light water reactors. 
5. The safety and environmental record of commercial nuclear power generating facilities is well established; nevertheless, the safety of nuclear power facilities is and will likely remain controversial.

\section{S.7.3 Issues to be Resolved}

The implementation of any programmatic alternative would require these primary issues to be resolved:

1. Utilities, public utility regulatory bodies, and the financial markets would need to be convinced that an alternative would provide an adequate return on capital. This would require that the alternative be demonstrated to be cost-effective and economical compared to other means of generating electricity.

2. Any new commercial nuclear facility (spent fuel recycling center, enrichment facility, fuel fabrication facility and reactor) would be subject to permitting or licensing decisions by a number of different government agencies. Changes to the regulatory framework may be needed to enable the licensing of these nuclear facilities, some of which would be first-of-a-kind facilities.

3. For the programmatic alternatives that involve recycle of spent fuel, a regulatory system that provides for appropriate protection to the public health, safety and the environment may need to be modified or developed to address potential new waste categories. An example of this need would be to determine the appropriate disposition path for cesium and strontium wastes from a spent fuel recycling center if segregated as a separate waste stream.

4. The nature and extent of Government involvement or encouragement in the implementation of any alternative, including providing financial and other incentives, continuing $\mathrm{R} \& \mathrm{D}$ and conducting demonstrations of technologies would need to be determined. 


\section{S.8 REFERENCES}

10 CFR 61.55

10 CFR 72.3

40 CFR 1501.7

40 CFR 1502

40 CFR 1508.7

71 FR 14505

72 FR 331

72 FR 40135

42 U.S.C. 10101 et seq.
U.S. Nuclear Regulatory Commission (NRC), "Waste Classification," Code of Federal Regulations, Office of the Federal Register, National Archives and Records Administration, Washington, DC, Revised January 1, 2008.

NRC, "Definitions," Code of Federal Regulations, Office of the Federal Register, National Archives and Records Administration, Washington, DC, Revised January 1, 2008.

Council on Environmental Quality (CEQ), "Scoping," Code of Federal Regulations, Office of the Federal Register, National Archives and Records Administration, Washington, DC, Revised July 1, 2007.

CEQ, "Environmental Impact Statement," Code of Federal Regulations, Office of the Federal Register, National Archives and Records Administration, Washington, DC, Revised July 1, 2007.

CEQ, "Cumulative Impacts," Code of Federal Regulations, Office of the Federal Register, National Archives and Records Administration, Washington, DC, Revised July 1, 2007.

U.S. Department of Energy (DOE), “Advance Notice of Intent To Prepare an Environmental Impact Statement for the Global Nuclear Energy Partnership Technology Demonstration Program," Office of the Federal Register, National Archives and Records Administration, Washington, DC, March 22, 2006.

DOE, "Notice of Intent To Prepare a Programmatic Environmental Impact Statement for the Global Nuclear Energy Partnership," Office of the Federal Register, National Archives and Records Administration, Washington, DC, January 4, 2007.

DOE, "Notice of Intent to Prepare an Environmental Impact Statement for the Disposal of Greater-Than-Class-C Low-Level Radioactive Waste," Office of the Federal Register, National Archives and Records Administration, Washington, DC, July 23, 2007.

"Nuclear Waste Policy Act of 1982," NWPA, United States Code, Washington, DC, January 7, 1983. 
DOE 1999d

DOE $2002 \mathrm{i}$

DOE 2006n

DOE 2006p

DOE 2006t

DOE $2008 f$

EIA 2007a

EIA 2008a
DOE, "Surplus Plutonium Disposition Final Environmental Impact Statement," DOE/EIS-0283, Office of Fissile Materials Disposition, U.S. Department of Energy, Washington, DC, November 1999.

DOE, "Final Environmental Impact Statement for a Geologic Repository for the Disposal of Spent Nuclear Fuel and High-Level Radioactive Waste at Yucca Mountain, Nye County, Nevada," DOE/EIS-0250, U.S. Department of Energy, Washington, DC, February 1, 2002.

DOE, "Financial Assistance Funding Opportunity Announcement Global Nuclear Energy Partnership (GNEP) Siting Studies," Funding Opportunity Number: DE-PS07-06ID14760, U.S. Department of Energy, Washington, DC, 2006.

DOE, "Preparation Guide for U.S. Department of Energy Nonreactor Nuclear Facility Safety Analysis Reports," DOE-STD3009-94, U.S. Department of Energy, Washington, DC, July 1994, Change Notice No.1, January, 2002, Change Notice No.2, April 2002, Change Notice No.3, March 2006.

DOE, "The U.S. Generation IV Fast Reactor Strategy," DOE/NE0130, Office of Nuclear Energy, U.S. Department of Energy, Washington, DC, December 2006.

DOE, "Final Supplemental Environmental Impact Statement for a Geologic Repository for the Disposal of Spent Nuclear Fuel and High-Level Radioactive Waste at Yucca Mountain, Nye County, Nevada," DOE/EIS-0250F-S1, Office of Civilian Radioactive Waste Management, U.S. Department of Energy, Washington, DC, June 2008.

Energy Information Administration (EIA), "AEO2008, Annual Energy Outlook 2008 (Early Release)," DOE/EIA-0383, Energy Information Administration, U.S. Department of Energy, Washington, DC, December 2007. Accessed at http://www.eia.doe.gov/oiaf/aeo/pdf/earlyrelease.pdf on January 22, 2008.

EIA, "Annual Energy Outlook 2008 With Projections to 2030," DOE/EIA-0383 (2008), Energy Information Administration, U.S. Department of Energy, Washington, DC, June 2008. Accessed at http://www.eia.doe.gov/oiaf/aeo/pdf/0383(2008).pdf on July 3, 2008. 
EIA 2008b

Goldner and Versluis 2006

Health Canada 2008

IAEA $2002 b$

MIMS 2008

NRC $1977 b$

NRC 1990

NRC 2007g

NRC 20071

PMC 1982
EIA, “International Energy Outlook 2008: Highlights," DOE/EIA0484(2008), Energy Information Administration, U.S. Department of Energy, Washington, DC, June 2008. Accessed at http://www.eia.doe.gov/oiaf/ieo/world.html on July 3, 2008.

Goldner, F. and R. Versluis, "Transmutation Capabilities of GENIV Reactors," Global Nuclear Energy Partnership Program, U.S. Department of Energy, Washington, DC, September 28, 2006.

Health Canada, "2007 Report on Occupational Radiation Exposures in Canada," Minister of Health, Canada, 2008.

International Atomic Energy Agency (IAEA), "Thorium Fuel Utilization: Options and Trends," IAEA-TECDOC-1319, Proceedings of Three IAEA Meetings held in Vienna in 1997, 1998, and 1999, November 1, 2002.

Manifest Information Management System (MIMS), "Volume and Activity Summary," U.S. Department of Energy, Washington, DC, 2008. Accessed at http://mims.apps.em.doe.gov/mims.asp\# on August 15, 2008.

NRC, "Final Environmental Statement on the Transportation of Radioactive Material by Air and Other Modes," NUREG-0170, Office of Standards Development, U.S. Nuclear Regulatory Commission, Washington, DC, December 1977.

NRC, "Severe Accident Risks: An Assessment for Five U.S. Nuclear Power Plants," NUREG-1150, U.S. Nuclear Regulatory Commission, Washington, DC, December 1990. Accessed at http://www.nrc.gov/reading-rm/doc-collections/nuregs/staff/ sr1150/ on September 08, 2008.

NRC, "Year 2005 Low-Level Waste Disposal Statistics," U.S. Nuclear Regulatory Commission, Washington, DC, March 21, 2007.

NRC, "Occupational Radiation Exposure at Nuclear Power Reactors and Other Facilities 2006," Thirty-Ninth Annual Report, NUREG-0713, U.S. Nuclear Regulatory Commission, Washington, DC, December 2007.

PMC, "Clinch River Breeder Reactor Project-Preliminary Safety Analysis Report," Volume 1-Volume 14, Project Management Corporation, May 1982. 
Todosow $2007 \mathrm{~b}$

Wigeland 2008a

Wigeland 2008c

Yang and Park 2006
Email from Michael Todosow, Brookhaven National Laboratory to Jay Rose, Tetra Tech "PEIS Thorium," October 17, 2007.

Wigeland, R.A., "Performance Summary of Advanced Nuclear Fuel Cycles," GNEP-TIO-AI-AI-RT-2008-000268, Revision 1, Idaho National Laboratory, Nuclear Science \& Technology, June 10, 2008.

Wigeland, R.A., "Cs/Sr Waste Volume Estimates," Addendum to the "Performance Summary of Advanced Nuclear Fuel Cycles" GNEP-TIO-AI-AI-RT-2008-000268, Revision 1, Idaho National Laboratory, Nuclear Science \& Technology, August 18, 2008.

Yang, M.S., and J.H. Park, "Korean Assessment of the Proliferation Resistance on the Whole Fuel Cycle of DUPIC," Korean Atomic Energy Research Institute, 2006. 